

\section{ANAIS DO I}

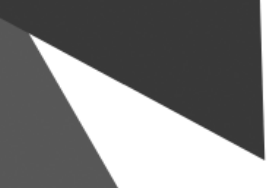

\section{CONGRESSO}

NACIONAL DE RESIDÊNCIAS

\section{EM SAÜDE}

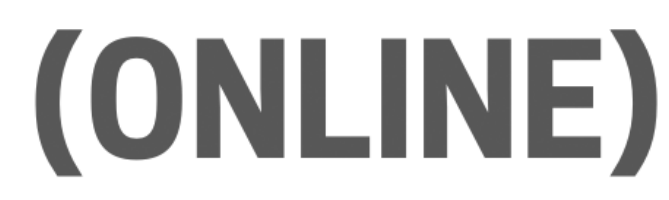

EDITORA

OMNIS SCIENTIA

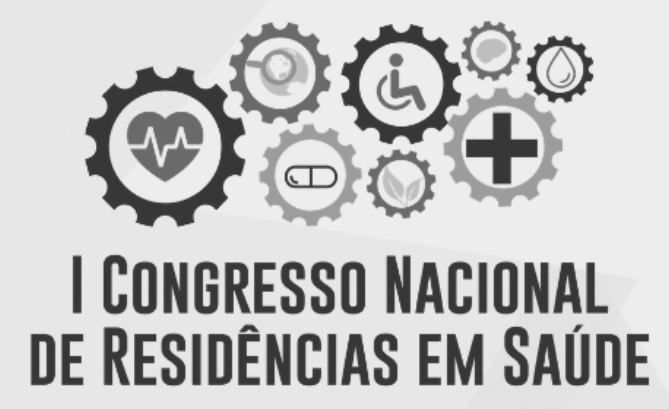

$\circ \cap<$ i $\cap$ e 
Editora Omnis Scientia

ANAIS DO I CONGRESSO NACIONAL DE RESIDÊNCIAS EM SAÚDE (ONLINE)

Volume 1

$1^{\mathrm{a}}$ Edição

TRIUNFO - PE 


\section{COORDENADOR CIENTÍFICO}

Luiz Henrique Alexandre dos Santos

COORDENADOR DE PUBLICAÇÃO

Daniel Luís Viana Cruz

\section{COORDENADORA DO EVENTO}

Andréa Telino Gomes

\section{ORGANIZADORES}

Academics - Eventos acadêmicos online

Andréa Telino Gomes

Bianca de Deus Verolla

Daniel Luís Viana Cruz

Editora Omnis Scientia

Luiz Henrique Alexandre dos Santos

Thialla Larangeira Amorim

\section{PALESTRANTES}

Allan Martins

Amanda Rose Alves Jorge

Antonio Henrique Alves Resende

Éricka Cecília Resende de Souza Alves

Ewerton Handerson Figueiredo de Medeiros

Gustavo Rego Muller de Campos Dantas

Isabelle Cristina de Oliveira Vieira

Karolina de Cássia Lima da Silva Duarte

Diego Francisco Lima da Silva

Túlio Paulo Alves da Silva

Thiago Emanuel Véras Lemos 


\section{AVALIADORES}

Ana Mikaele da Silva Melo

Eliane Oliveira da Silva

Lucas Lopes Antunes

Luis Roberto Gomes da Silva

Mylena Rafhaele Gomes de Oliveira Alexandre

Sergialyson Brasil Farias

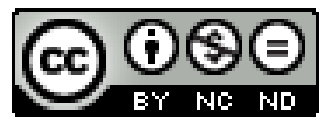

Este trabalho está licenciado com uma Licença Creative Commons - AtribuiçãoNãoComercial-SemDerivações 4.0 Internacional.

O conteúdo abordado nos artigos, seus dados em sua forma, correção e confiabilidade são de responsabilidade exclusiva dos autores. 


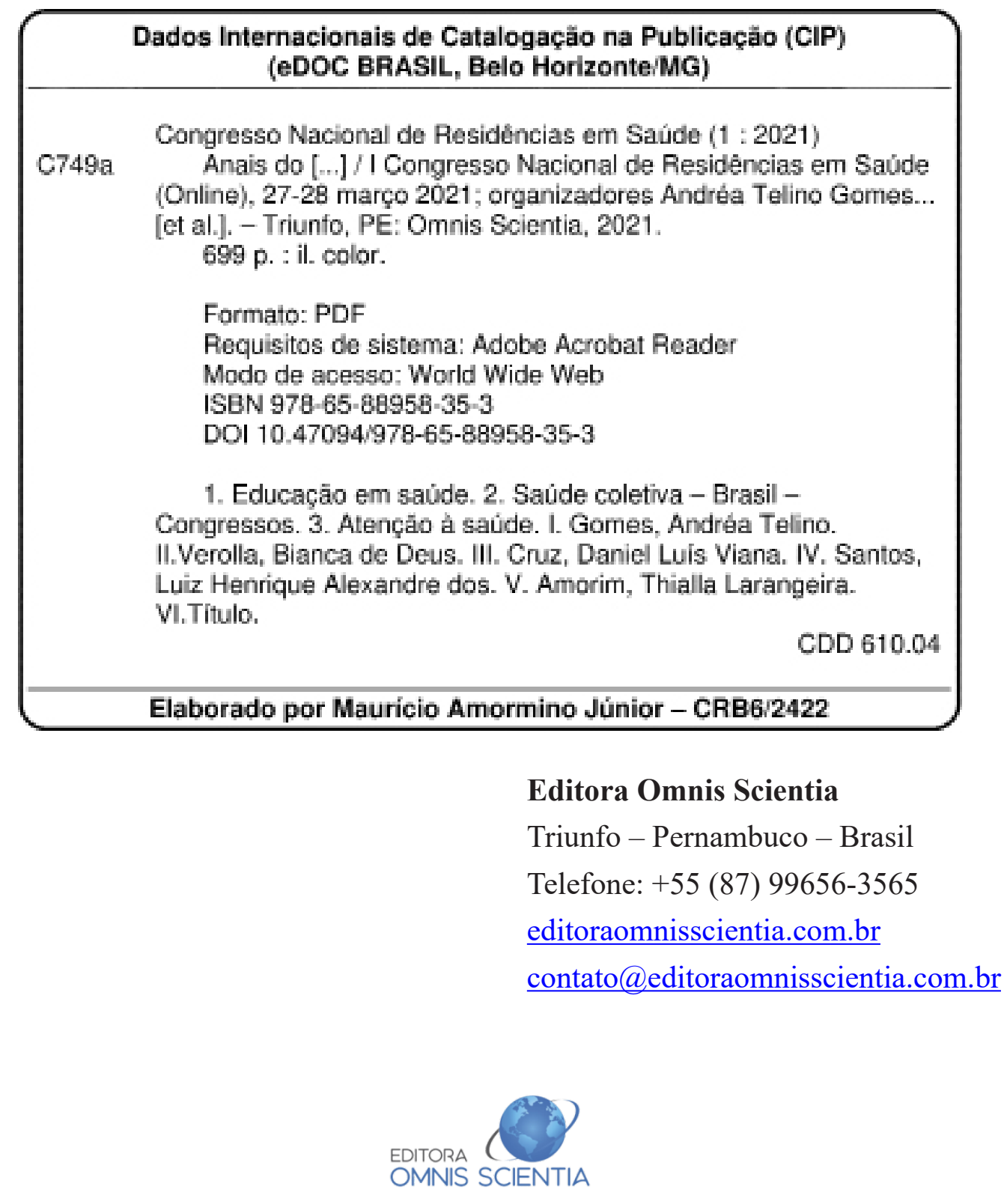




\section{EDITORIAL}

O I Congresso Nacional de Residências em Saúde (online) - I CONRES surgiu da necessidade de ser ofertado um evento focado exclusivamente nas áreas de atuações de residentes de saúde do Brasil, com diversas palestras de docentes de IES, profissionais de saúde e até ex-residentes, no intuito de atualizar estudantes de graduação, residentes e demais profissionais da área da saúde sobre o tema.

O congresso contou com 599 inscritos, de todas as regiões do Brasil. Além disso, 298 trabalhos foram submetidos e aprovados, sendo 194 na modalidade resumos simples e 104 na modalidade resumos expandidos, divididos nas seguintes áreas temáticas: Atenção à saúde; Clínico - Hospitalar; Educação em Saúde; Medicina Veterinária; Saúde Coletiva e Áreas Afins.

Dessa forma, alguns resumos simples e expandidos receberam menção honrosa a critério da Comissão Avaliadora:

\section{Resumos simples:}

- A atuação do fisioterapeuta no cuidado do paciente oncológico, de autoria de Elídia Keila Oliveira Portela;

- Esquizofrenia e a eficácia da eletroconvulsoterapia, de autoria de Thialle Roberta da Silva Cruz, Ilana De Souza Cavalcanti e Maria Clara Cavalcanti;

- Tratamento de fraturas nasais isoladas por meio de redução fechada uma revisão integrativa, de autoria de Gabriel Luiz Linn Valeria Juliana Jandrey e Natasha Magro Érnica;

- Territorializar em saúde fortalecendo a formação de profissionais residentes, de autoria de João Caio Silva Castro Ferreira, Maria Karolayne de Araújo Pereira, Amanda de Oliveira Lima, Maycon Guimarães Santos e Nanielle Silva Barbosa;

\section{Resumos expandidos:}

- A tempestade de citocinas no desenvolvimento da covid 19, de autoria de Gustavo Henrique Dias da Silva, Sheila Oliveira Falcão, Aslanny Ferreira Siqueira Freitas, Bianca Barbosa Martins, Layene Ariely de Oliveira Barros, Edson de Jesus Sá, Cesar Augusto Da Silva;

- Saúde da população masculina e suas principais demandas na unidade básica revisão integrativa, de autoria de Larissa Artimos Ribeiro e Pâmela Ramos Januário;

- Atuação de médicos veterinários residentes em uma unidade de triagem de pacientes suspeitos de covid 19 no município de Jaboticabal/SP, de autoria de Rafael Bezerra Mamede, Beatriz Estevez de Oliveira, Pedro Zangrando Maria Soban Martins Gaspar, Thaynara Pavaneli Lira, Talita Turmina Nívea, Maria Gomes Misson Carneiro e Karina Paes Bürger; 
Luiz Henrique Alexandre dos Santos

Coordenador do I CONRES 


\section{SUMÁRIO}

\section{RESUMO SIMPLES}

ATENÇÃO À SAÚDE

A IMPORTÂNCIA DA HUMANIZAÇÃO NA PRÁTICA PROFISSIONAL DO ASSISTENTE SOCIALNASÁUDE.

A IMAGINOLOGIA VINCULADA COM O DIAGNOSTICO DO PROECESSO PATOLÓGICO DA ATEROSCLEROSE. BRASIL EUROPA

O AUTOCUIDADO RELACIONADO À HIGIENE DE CRIANÇAS EM VULNERABILIDADE SOCIAL EM UM ABRIGO DE MANAUS.

DESAFIOS NO ATENDIMENTO DE ENFERMAGEM A PACIENTES DO SEXO FEMININO..33 ASPECTOSCLINICORRADIOLOGICOSDADOENÇATROFOBLÁSTICAGESTACIONAL.....34 SAÚDE SEXUAL E REPRODUTIVA EM TEMPOS DE PANDEMIA: UMA ANÁLISE DA ADESÃO DE ADOLESCENTES NAATENÇÃO PRIMÁRIA À SAÚDE.

SÍNDROME METABÓLICA: A DOENÇA DA CIVILIZAÇÃO MODERNA, SUAS COMORBIDADES E A RELAÇÃO COM OS TRANSTORNOS MENTAIS.

CONTRIBUIÇÕES DAS PRÁTICAS INTEGRATIVAS E COMPLEMENTARES NO CUIDADO NO CONTEXTO DAPANDEMIADACOVID-19.

A IMPORTÂNCIA DA PROMOÇÃO DA SAÚDE MENTAL DO IDOSO NA ATENÇÃO BÁSICA

A INTEGRALIDADE DO CUIDADO À SAÚDE DA CRIANÇA NAATENÇÃO BÁSICA. 39

A ATUAÇÃO DO FISIOTERAPEUTA NO CUIDADO DO PACIENTE ONCOLÓGICO. .40

A IMPORTÂNCIA DO EXERCÍCIO FÍSICO COMO PARTE INTEGRANTE DO TRATAMENTO DE PACIENTES COM DOENÇAS CRÔNICAS.

ABORDAGEM DE SISTEMAS COMPLEXOS NA SAÚDE E NA DOENÇA .42

IMPACTO DO DIAGNÓSTICO DE LEUCEMIA LINFOIDE AGUDA NA VIDA DO INDIVÍDUO E DOS CUIDADORES. 
GESTÃO DE ENFERMAGEM NO CENTRO CIRÚRGICO EM TEMPOS DE PANDEMIA POR COVID-19: UMA REVISÃO INTEGRATIVA.

O PAPEL SOCIAL DA RESIDÊNCIA MULTIPROFISSIONAL EM SAÚDE DO ADULTO E IDOSO: UMA REVISÃO INTEGRATIVA.

FATORES RELACIONADOS AO DÉFICIT DE COMUNICAÇÃO SETORIAL ENTRE RESIDENTES MULTIPROFISSIONAIS: UMA REVISÃO INTEGRATIVA...............................47

MEDIDAS DE CONFORTOA PACIENTES CRÍTICOS: UMAREVISÃO INTEGRATIVA............48

MORBIDADE HOSPITALAR POR ANEMIA FERROPÊNICA NO ESTADO DO ACRE...........49

PERFIL DA MORTALIDADE NEONATAL NO ESTADO DO ACRE.......................................50

ATUAÇÃO DO NUTRICIONISTA NA ONCOLOGIA - UMA REVISÃO DE LITERATURA.....51

AROMATERAPIA: UTILIZAÇÃO E BENEFÍCIOS NA SAÚDE DO IDOSO...............................52

PESSOA FERIDA: UMA VISÃO INTEGRAL AO PORTADOR DE LESÃO...............................53

CONTRIBUIÇÕES DOS RESIDENTES NOS SERVIÇOS DE SAÚDE: UMA RESVISÃO

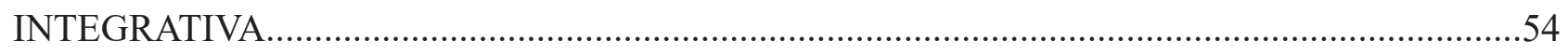

COMPORTAMENTO SUICIDA NO TRANSTORNO DE PERSONALIDADE BORDERLINE...55 CONHECIMENTOS DE HOMENS SOBRE A SÍFILIS PRIMÁRIA........................................56

MANUSEIODO CATETER TOTALMENTE IMPLANTADO:RELATODEEXPERIÊNCIAEMUM

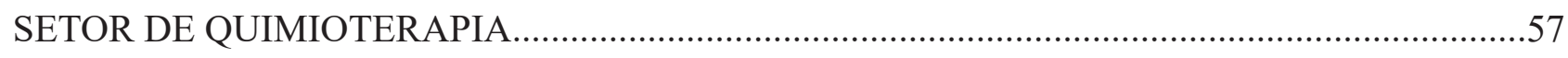

A RESIDÊNCIA MULTIPROFISSIONAL NAS AÇÕES DE VIGILÂNCIA EM SAÚDE NO

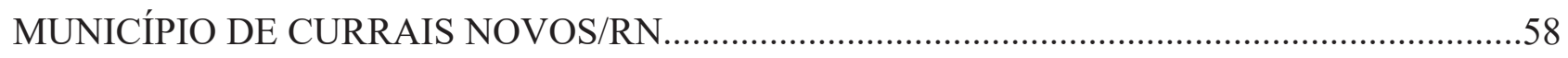

SALA DE SITUAÇÃO EM SAÚDE VOLTADA PARA A COVID-19 NUM MUNICÍPIO DO

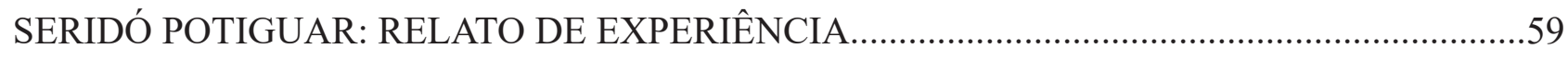

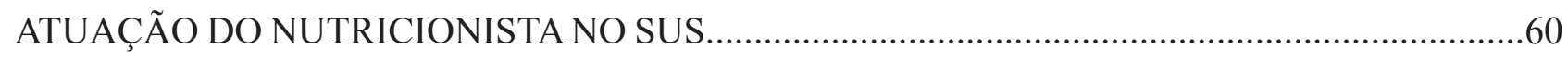

A CONTRIBUIÇÃO DOS ALIMENTOS FUNCIONAIS PARA O TRATAMENTO DO DIABETES

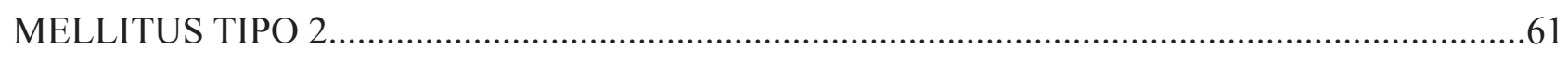

GRUPO ANTITABAGISMO: VIVÊNCIA EM UMA UNIDADE DE SAÚDE DA FAMÍLIA NA PRÁTICADARESIDÊNCIAMÉDICA

O ACOLHIMENTO DOS PACIENTES DE SAÚDE MENTAL PELO SERVIÇO SOCIAL DURANTE A PANDEMIA NA USF PARQUE VERDE. 
INSERÇÃO DE DIU: VIVÊNCIA NA UNIDADE DE SAÚDE DA FAMÍLIA NA PRÁTICA DA RESIDÊNCIAMÉDICA.

APRÁTICADEATIVIDADE FÍSICA E OAUMENTO DO VÍNCULO NO CONTEXTO DA SAÚDE MENTAL

VIVÊNCIA EM UMA UNIDADE DE SAÚDE DA FAMÍLIA: CUIDADO, FARMACOLOGIA E PLANTAS MEDICINAIS.

OS IMPACTOS DA PANDEMIA DO SARS-COV-2 NA POPULAÇÃO EM SITUAÇÃO DE RUA...

O CUIDADO DOS PACIENTES DE SAÚDE MENTAL NA ATENÇÃO PRIMÁRIA DURANTE A PANDEMIA DE COVID-19.

A SISTEMATIZAÇÃO DA ASSISTÊNCIA DE ENFERMAGEM EM SERVIÇOS DE URGÊNCIA E EMERGÊNCIA: UMA REVISÃO INTEGRATIVA.

PERFIL EPIDEMIOLÓGICO DOS PACIENTES ATENDIDOS NA EMERGÊNCIAONCOLÓGICA EM UMA CAPITAL NORDESTINA.

A RELAÇÃO ENTRE A TOXOPLASMOSE E OS PROFISSIONAIS DE SAÚDE QUEATUAM NO PRÉ-NATAL.

O CONHECIMENTO DA POPULAÇÃO ACERCA DA PREVENÇÃO E CONTROLE DA DOENÇA DE CHAGAS.

PROGRAMA PREVINE BRASIL SUBSTITUI O NASF-AB. .73

COVID-19 E PUÉRPERAS: A POTENCIAL TRASMISSÃO VERTICAL E AS PRECAUÇÕES DE CONTATO DURANTE O ALEITAMENTO MATERNO.

ADAPTAÇÃO DO TRABALHO DA ENFERMAGEM EM SAÚDE DA FAMÍLIA DURANTE A PANDEMIACOVID-19.

RELATO DE EXPERIÊNCIA: INSERÇÃO DE RESIDENTES DE ENFERMAGEM EM UM PROGRAMA DE ATENDIMENTO RESIDENCIAL DE CASCAVEL .76

POTENCIALIDADES DO ENSINO EM SERVIÇO MULTIPROFISSIONAL EM SAÚDE DA FAMÍLIA: RELATO DE EXPERIÊNCIA.

O ABUSO SEXUAL INFANTIL COMO FATOR DE RISCO PARA TRANSTORNOS ALIMENTARES: UMA REVISÃO DA LITERATURA.

PREDIÇÃO DO PARTO PREMATURO POR PARÂMETROS ULTRASSONOGRÁFICOS: UMA REVISÃO SISTEMATIZADA. 
OS IMPACTOS DAS REDES SOCIAIS NA SAÚDE MENTAL DO ADOLESCENTE: UMA REVISÃO INTEGRATIVA

A VISITA DOMICILIAR ODONTOLÓGICA NA RESIDÊNCIA MULTIPROFISSIONAL COMO POTENCIALIDADE NO DIAGNÓSTICO PRECOCE DE CÂNCER BUCAL.

ABORDAGEM INTERPROFISSIONAL ENTRE ATENÇÃO PRIMÁRIA E O CAPSII NA

PREVENÇÃO E PROMOÇÃO DA SAÚDE DO IDOSO: RELATO DE EXPERIENCIA. .82

A PREVALÊNCIA DA DISSEMINAÇÃO DO COVID-19 NO BRASIL .83

\section{CLÍNICO - HOSPITALAR}

HOSPITALIZAÇÃO DE PACIENTES ADULTOS POR COMPLICAÇÕES DE DOENÇAS CRÔNICAS NÃO TRANSMISSÍVEIS. 85

CANSAÇO, ALTERAÇÃO DO SONO E PREOCUPAÇÃO COM O CORPO: INDICADORES DE DEPRESSÃO MATERNA. .86

OBSERVAÇÃO DA INTERAÇÃO MÃE-BEBÊ E O COMPORTAMETO EXPLORATÓRIO DO BEBÊ NO CONTEXTO DA DEPRESSÃO MATERNA.

ASPECTOS OBJETIVOS E SUBJETIVOS DA INTERAÇÃO MÃE-BEBÊ NO CONTEXTO DA DEPRESSÃO MATERNA. .88

CUIDADOS PALIATIVOS INTEGRADOS PARAO TRATAMENTOS DE IDOSOS INTERNADOS EM UTI'S. .89

TUBERCULOSE EXTRAPULMONAR E PACIENTES IMUNOCOMPROMETIDOS, UMA ATUALIZAÇÃO BIBLIOGRÁFICA. . .90

LEUCEMIA MIELÓIDE AGUDA: CARACTERISTICAS CLÍNICA E DIAGNÓSTICO, UMA REVISÃO BIBLIOGRÁFICA.

A IMPORTÂNCIA E O PAPEL DO PSICÓlOGO INSERIDO NO AMBIENTE HOSPITALAR. .92

PRINCIPAIS COMPLICAÇÕES ASSOCIADAS À QUADROS GRAVES DA COVID-19, UMA REVISÃO INTREGATIVA DE LITERATURA..... . .93

PRINCIPAIS MANIFESTAÇÕES CLÍNICAS ASSOCIADAS À SÍFILIS CONGÊNITA PRECOCE: UMA REVISÃO DE LITERATURA. 
A COMUNICAÇÃO NOS CUIDADOS PALIATIVOS E A ATUAÇÃO DA EQUIPE MULTIPROFISSIONAL NO ATENDIMENTO AO PACIENTE TRAQUEOSTOMIZADO..........95

TROMBOSE VENOSA EM PACIENTES DE UNIDADES DE TERAPIA INTENSIVA COM INFECÇÕES POR COVID-19.....

DERMATITE ASSOCIADA À INCONTINÊNCIA EM PACIENTES COM COVID 19: RELATO DE EXPERIÊNCIA.

ESQUIZOFRENIA E A EFICÁCIA DA ELETROCONVULSOTERAPIA . .98

MANEJO DA VENTILAÇÃO MECÂNICA INVASIVA EM PACIENTES CARDIOPATAS COM COVID 19.

AVALIAÇÃO E TERAPIA NUTRICIONAIS EM PACIENTE COM LINFOMA HODGKIN REFRATÁRIO: ESTUDO DE CASO. 100

AVALIAÇÃO NUTRICIONAL DO PACIENTE HEPATOPATA - UMA REVISÃO DE LITERATURA. 101

VISITAS VOLUNTÁRIAS REALIZADAS PELO INSTITUTO TCHIBUM PARA CRIANÇAS HOSPITALIZADAS EM MANAUS, RELATO DE EXPERIÊNCIA.

SÍNDROME DE BURNOUT NOS PROFISSIONAIS DA ENFERMAGEM DURANTE O ENFRENTAMENTODACOVID-19.

CONTRIBUIÇÕES DA RESIDÊNCIA EM GESTÃO DOS SERVIÇOS DE SAÚDE PARA O DESENVOLVIMENTO DA VISÃO SISTÊMICA NO CONTEXTO HOSPITALAR. 104

ALTERAÇÃO DA FORMA FARMACÊUTICA SÓLIDA PARA LÍQUIDA DE MEDICAMENTOS EM HOSPITAL PEDIÁTRICO. .105

PARCERIA SERVIÇO-ESCOLA NA FORMAÇÃO TEÓRICA DE RESIDENTES DE ENFERMAGEM: RELATO DE EXPERIÊNCIA. 106

A INTERVENÇÃO FISIOTERAPÊUTICA NO PRÉ E PÓS CONTÁGIO POR COVID-19, UMA REVISÃO INTEGRATIVA DE LITERATURA. 107

A FISIOTERAPIA RESPIRATÓRIA NA REABILITAÇÃO PULMONAR DE PACIENTES PÓS COVID-19, UMA REVISÃO INTEGRATIVA DE LITERATURA.. 108

PRECEPTORIA DE RESIDÊNCIA HOSPITALAR NO CONTEXTO DA PANDEMIA DE COVID-19: RELATO DE EXPERIÊNCIA. 109

CONTRIBUIÇÕES DA RESIDÊNCIA MULTIPROFISSIONAL EM FONOAUDIOLOGIA PARA O HOSPITAL REFERÊNCIA EM CARDIOPNEUMOLOGIA. 
A NECESSIDADE DE DESENVOLVER HABILIDADES EM NEFROLOGIA DO ENFERMEIRO GENERALISTA PARA ASSISTÊNCIA INTEGRAL EM SAÚDE.

PRÁTICA DE RESSUSCITAÇÃO CARDIOPULMONAR EM PACIENTES COM PARADA CARDIORRESPIRATÓRIA DECORRENTE DA COVID-19

TRANSTORNO DE ESTRESSE PÓS-TRAUMÁTICO APÓS INFECÇÃO POR COVID-19: UMA REVISÃO DA LITERATURA.

ASSOCIAÇÃO ENTRE A DEFICIÊNCIA DE VITAMINA D E A TUBERCULOSE. 114

AGRAVAMENTO DE DOENÇAS DERMATOLÓGICAS ASSOCIADAS A ALTERAÇÕES EMOCIONAIS

ESTUDO SOBRE O COMPROMETIMENTO RENAL NA ANEMIA FALCIFORME. 116 ATUALIZAÇÃO DO TRATAMENTO CIRÚRGICO DA NEFROLITÍASE 117

ABORDAGEM CIRÚRGICA PARA FRATURAS DO COMPLEXO ZIGOMÁTICO- REVISÃO INTEGRATIVA DE LITERATURA.

TRATAMENTO DE FRATURAS NASAIS ISOLADAS POR MEIO DE REDUÇÃO FECHADA: UMA REVISÃO INTEGRATIVA. 119

\section{EDUCAÇÃO EM SAÚDE}

ESTRATÉGIAS DE UM GRUPO DE EXTENSÃO NA PROMOÇÃO DA AMAMENTAÇÃO EXCLUSIVA PARA PRIMIGESTAS NA PANDEMIA.

PROGRAMA DE INTEGRAÇÃO SAÚDE COMUNIDADE EM UMA ESCOLA PÚBLICA DE MANAUS: RELATO DE EXPERIÊNCIA.

AÇÃO EDUCATIVA EM SAÚDE PARA A PREVENÇÃO DE HIV/AIDS EM IDOSOS. 123

DOENÇAS CARDIOVASCULARES: EFEITOS DAS AÇÕES PREVENTIVAS NA INFÂNCIA.

ATUAÇÃO DE ACADÊMICOS DE MEDICINA NO PROJETO DE EXTENSÃO SOBRE PLANEJAMENTO REPRODUTIVO NO ACRE.

O POTENCIAL PEDAGÓGICO DO CINEMA NOS ESTUDOS SOBRE O TRANSTORNO DE PERSONALIDAEANTISSOCIAL

NOVEMBRO AZUL COMO FERRAMENTA DE CONSCIENTIZAÇÃO E PREVENÇÃO AO CÂNCER DE PRÓSTATA $\square$ RELATO DE EXPERIÊNCIA. 
DESAFIOS NA ESCOLARIZAÇÃO DO INDIVÍDUO COM TRANSTORNO DO ESPECTRO AUTISTA.

A REPERCUSSÃO DOS EVENTOS CIENTÍFICOS EM SAÚDE NAFORMAÇÃO ACADÊMICA: UMRELATODEEXPERIÊNCIA.

O IMPACTO NAATUAÇÃO DO ASSISTENTE SOCIALDURANTEAPANDEMIADO COVID-19: RELATODEEXPERIÊNCIA.

BRINQUEDOTERAPÊUTICO:ESTIMULANDOAUTISTASAODESENVOLVIMENTO. 131

EDUCAÇÃO EM SAÚdE E SUA RELAÇÃO NO ÂMBITO ESCOLAR PARA ADOLESCENTES.

AÇÃO SOCIAL DEZEMBRO VERMELHO: UM MEIO DE PROMOVER ESTRATÉGIAS DE EDUCAÇÃO EM SAÚDE E PREVENÇÃO DAS IST'S NO AMAZONAS.

AUTISMO E SUAS FERRAMENTAS DIAGNÓSTICAS: REVISÃO DE LITERATURA. .134 ASSISTÊNCIA FARMACÊUTICA: USO RACIONAL DOS MEDICAMENTOS, NA PANDEMIA DA COVID 19.

A IMPORTÂNCIA DA ENFERMAGEM E DA EQUIPE MULTIDISCIPLINAR NO APRIMORAMENTO DO MANEJO A SAÚDE MENTAL.

EDUCAÇÃO EM SAÚDE: RELATOS DA EXPERIÊNCIA DE RESIDENTES MULTIPROFISSIONAIS.

EDUCAÇÃO EM SAÚDE: UMA ALTERNATIVA PARA PROMOVER A QUALIDADE DE VIDA DO IDOSO.

REFLEXÕES EM TORNO DO ENVELHECER: O IDOSO, A FAMILIA E O ALZHEIMER.....139 ATUAÇÃO DO NUTRICIONISTA NO PNAE. .140

UTILIZAÇÃO DE METODOLOGIAS ATIVAS NO PROCESSO DE ENSINO-APRENDIZAGEM DURANTE A RESIDÊNCIA: UM RELATO DE EXPERIÊNCIA.

A IMPORTÂNCIA DA INFLUÊNCIA PATERNA NO PRÉ-NATAL.

SEDENTÁRISMO EM PRÉ-PUBERES E PUBERES E O LETRAMENTO EM SAÚDE PARA UM ENVELHECER SAUDAVEL

BIOMECÂNICA E MICROBIOLOGIA EM CADAVERES DE GATOS QUIMICAMENTE PREPARADOS E EMBALADOS À VÁCUO.

CONSUMO DE ALIMENTOS NÃO SAUDÁVEIS RELACIONADOS A DOENÇAS CRÔNICAS NÃO TRANSMISSÍVEIS 
TREINAMENTOS DE PARAMENTAÇÃO E DESPARAMENTAÇÃO DE EQUIPAMENTOS DE PROTEÇÃO INDIVIDUAL DURANTE A PANDEMIA.

SER MULTI É + SAÚDE E QUALIDADE NAS AÇÕES DE PROMOÇÃO E PREVENÇÃO À SAÚDE DO MUNICÍPIO DE CASCAVEL - PARANÁ

BRINQUEDO TERAPÊUTICO: NA ATENÇÃO À CRIANÇA AUTISTA HOSPITALIZADA...149 COMO O SUICÍDIO TEM SIDO ABORDADO NOS CURSOS DE SAÚDE NO BRASIL?.......150

DESAFIOS DE ENFERMEIROS GESTORES DE UMA UNIDADE DE URGENCIA E EMERGÊNCIA REFERÊNCIA EM CARDIOLOGIA.

O PLANEJAMENTO DE UMA AÇÃO EDUCATIVA SOBRE O BRINCAR PARA CRIANÇAS INSTITUCIONALIZADAS E A INTEGRAÇÃO ENTRE RESIDENTES MULTIPROFISSIONAIS.

152

\section{MEDICINA VETERINÁRIA}

MENINGIOMA CEREBRAL EM GATO: RELATO DE CASO.

INSPEÇÃO NOS CASOS DE AGRESSIVIDADE POR CÃES DOMÉSTICOS.

DESENVOLVIMENTO DE MODELO ANATÔMICO PARA O ENSINO E TREINAMENTO CIRÚRGICO EM CADÁVERES DE PEQUENOS RUMINANTES - ESTUDO PILOTO.

BENEFÍCIOS DA TÉCNICA DE TUMESCÊNCIA EM CADELAS SUBMETIDAS A MASTECTOMIA

CADÁVERES DE CÃES PREPARADOS E EMBALADOS À VÁCUO VISANDO AO ENSINO DA CIRURGIA VETERINÁRIA - EFEITO NA BIOMECÂNICA DA PELE.

EFEITO NA BIOMECÂNICA DO JEJUNO DE CADÁVERES CANINOS PREPARADOS QUIMICAMENTE E EMBALADOS À VÁCUO VISANDO O ENSINO CIRÚRGICO.

CADÁVERES DE CÃES PREPARADOS QUIMICAMENTE E EMBALADOS À VÁCUO EFEITO CRÔNICO NA BIOMECÂNICA DA PELE E ANÁLISE MICROBIOLÓGICA.

CADÁVERES DE CÃES PREPARADOS QUIMICAMENTE E EMBALADOS À VÁCUO EFEITO CRÔNICO NA BIOMECÂNICA DO JEJUNO.

FREQUÊNCIA DE PLATINOSSOMÍASE FELINA NA CIDADE DE SÃO JOSÉ DOS CAMPOSSP 
MÉTODOS DE CONSERVAÇÃO DE TÚNICA ALBUGÍNEA TESTICULAR BOVINA PARA USO EM ENXERTOS E IMPLANTES.

BLOQUEIO DO QUADRADO LOMBAR EM CÃES E GATOS. 164

DIAGNÓSTICO DE ESPOROTRICOSE (Sporothrix Schenckii) EM GATOS NA VIGILÂNCIA EM SAÚDE AMBIENTAL, CAMARAGIBE-PE. .165

CARACTERIZAÇÃO DE CASOS CONFIRMADOS PARA INFECÇÕES POR SARS-CoV-2 ACOLHIDOS NO CENTRO DE ATENDIMENTO AO CORONAVIRUS DE JABOTICABALSP. 166

\section{SAÚDE COLETIVA}

ANÁLISE DO LAZER COMO UM FATOR DETERMINANTE DE SAÚDE EM UMA DETERMINADA POPULAÇÃO.

POLÍTICAS DE SAÚDE: A UTILIZAÇÃO DA VARIÁVEL RAÇA/COR EM SAÚDE PÚBLICA: LIMITES E POSSIBILIDADES

ESTRATÉGIA SAÚDE DA FAMÍLIA E PROGRAMA SAÚDE NA ESCOLA: A IMPORTÂNCIA DAS AÇÕES DE PROMOÇÃO DA SAÚDE.

SAÚDE MENTAL DA POPULAÇÃO INDÍGENA: FATORES DE RISCO PARA O SUICÍDIO...171 USO TERAPÊUTICO DA FITOTERAPIA NO SISTEMA ÚNICO DE SAÚDE 172

OCORRÊNCIA DE PARASITAS SANGUÍNEOS COM POTENCIAL ZOONÓTICO EMANIMAIS DE COMPANHIA NO MUNICÍPIO DE BOA VISTA, RORAIMA, BRASIL

ATENDIMENTO MÉDICO DA POPULAÇÃO MASCULINAEM UNIDADE BÁSICA DE SAÚDE DO INTERIOR DO AMAZONAS.

EDUCAÇÃO EM SAÚDE COM PROFISSIONAIS DE UNIDADE BÁSICA DE SAÚDE NO INTERIOR DO AMAZONAS.

PRÉ-NATAL EM COMUNIDADES RURAIS NO INTERIOR DO AMAZONAS- UM RELATO DE EXPERIÊNCIA.

QUALIDADE DE VIDA E PERCEPÇÕES DAS PESSOAS COM HIV/AIDS.

ASSISTÊNCIA DE ENFERMAGEM NA ATENÇÃO PRIMÁRIA À PORTADORES COM HIPERTENSÃO ARTERIAL. 
A PROMOÇÃO DA SAÚDE COM ENFOQUE NOS DETERMINANTES SOCIAIS PARA A QUALIDADE DE VIDA DA POPULAÇÃO........................................................................ 180

A IMPORTÂNCIA DO ENFERMEIRO FRENTE AO TRATAMENTO DO HIV........................181

DESAFIOS E COMPETÊNCIAS DA ATENÇÃO PRIMÁRIA À SAÚDE NO ENFRENTAMENTO Á COVID-19: RELATO DE EXPERIÊNCIA......................................................................... 182

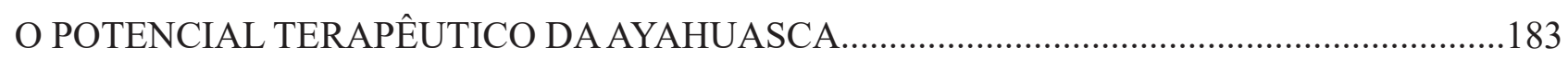

INSERÇÃO DE RESIDENTES MULTIPROFISSIONAIS NO SERVIÇO DE TELE-ORIENTAÇÃO COVID-19: PERFIL DOS USUÁRIOS E RESULTADOS...................................................... 184

OS RESIDENTES EM SAÚDE COLETIVA NO ACOLHIMENTO DE NOVOS SERVIDORES PÚBLICOS NA VII GERÊNCIA REGIONAL DE SAÚDE DE PERNAMBUCO........................185

SALA DE ESPERA COMO FERRAMENTA EDUCATIVA EM TEMPOS DE PANDEMIA: RELATO DE EXPERIÊNCIA EM DUAS UNIDADES DE SAÚDE EM SALGUEIRO-PE........186

RELATO DE EXPERIÊNCIADAS RESIDENTES EM SAÚDE COLETIVA SOBRE OS DESAFIOS NA TERRITORIALIZAÇÃO EM SAÚDE DURANTE A PANDEMIA DO COVID-19...............187

A INFLUÊNCIA DA FAMÍLIA NA ADESÃO AO TRATAMENTO DE PACIENTES DIABÉTICOS:

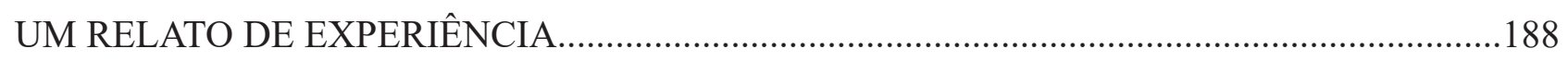

REPERCUSSÕES DO ENVELHECER NA AUTOESTIMA DE IDOSOS: UM RELATO DE

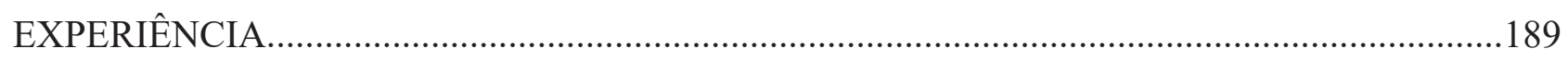

FATORES DE ESTRESSE EM PROFISSIONAIS DE SAÚDE DURANTE A PANDEMIA DO

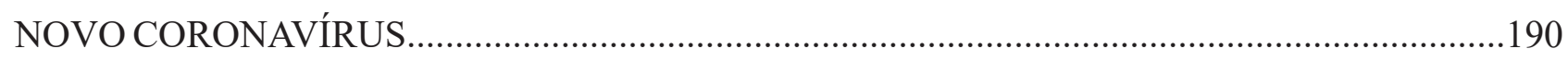

NARRATIVAS DAS MULHERES SOBRE O VÍNCULO DOULA-MÃE COMO ESTRATEGIA

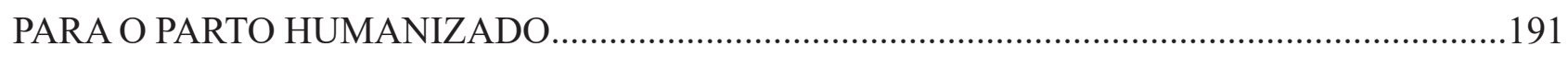

TERRITORIALIZAR EM SAÚDE: FORTALECENDO A FORMAÇÃO DE PROFISSIONAIS

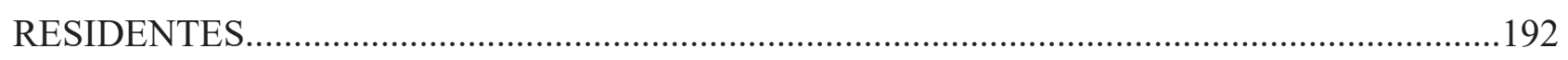

O USO DO CHÁ DE CAMOMILA COMO FITOTERÁPICO PARA A INSÔNIA.......................193

A EXPERIÊNCIA DE UMA RESIDÊNCIA MULTIPROFISSIONAL DESCENTRALIZADA EM SAÚDE COLETIVA NA X GERES EM PERNAMBUCO.....................................................194

PERFIL EPIDEMIOLÓGICO DO MUNICÍPIO DE AFOGADOS DA INGAZEIRA EM

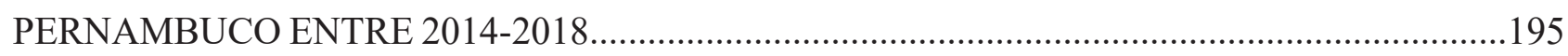

O ESTÁGIO RURAL EM SAÚDE COLETIVA E SUAS CONTRIBUIÇÕES PARAA FORMAÇÃO DO ENFERMEIRO: RELATO DE EXPERIÊNCIA. 
ANÁLISE COMPARATIVA DE OCORRÊNCIA DAS ARBOVIROSES E DADOS DO LIRAS EM RECIFE- PE

A TRAJETÓRIA E A MODULAÇÃO DO APOIO INSTITUCIONAL NA ATENÇÃO PRIMÁRIA DE PORTO ALEGRE/RS.

TELESSAÚDE NA ATENÇÃO PRIMÁRIA À SAÚDE: UM RELATO DE EXPERIÊNCIA NO NORDESTE BRASILEIRO.

AVALIAÇÃO DAEFICÁCIA DO DISTANCIAMENTO SOCIALNACONTENÇÃO DACOVID-19 - UMA REVISÃO DE LITERATURA.

O HETEROCONTROLE DO FLUORETO NA ÁGUA DE ABASTECIMENTO E A SAÚdE DENTAL.

CONTRIBUIÇÕES DOS RESIDENTES EM SAÚDE NO ENFRENTAMENTO DAS FAKE NEWS DA COVID 19 .

POTENCIALIDADES DO SANITARISTA DE GRADUAÇÃO NAATENÇÃO BÁSICA: RELATO DA PRAXIS DE UMA RESIDENTE.

A PRECEPTORIA NA FORMAÇÃO DO RESIDENTE MULTIPROFISSIONAL EM SAÚDE COLETIVA NO ESTADO DA PARAÍBA. .204

\section{ÁREAS AFINS}

COMPLICAÇÕES DECORRENTES DA LIPOASPIRAÇÃO DE ALTA DEFINIÇÃO EM PACIENTES COM GRANDE PERCENTUAL DE GORDURA CORPÓREA.

PREVALÊNCIADEDOENÇASCRÔNICASEMIDOSOSCOMTRAUMACRANIOENCEFÁLICO APÓS QUEDA DA PRÓPRIA ALTURA.

BENEFÍCIOS DO EXCERCÍCIO FÍSICO DURANTE A GESTAÇÃO: UMA REVISÃO DE LITERATURA.

A RELEVÂNCIA DA TERRITORIALIZAÇÃO PARA ORGANIZAÇÃO DOS SERVIÇOS DE SAÚDE: RELATO DE EXPERIÊNCIA DE RESIDENTES EM SAÚDE.

USO DAS REDES SOCIAIS PARA INFORMAÇÃO E CONSCIENTIZAÇÃO SOBRE OS CUIDADOS PREVENTIVOS CONTRA A COVID-19.

GOOGLE EARTH E SW MAPS: GEOTECNOLOGIAS COMO RECURSO DE TRABALHO EM VIGILÂNCIA EM SAÚDE. 
RESIDÊNCIA MULTIPROFISSIONAL EM SAÚDE COLETIVA E PET-SAÚDE: INTERPROFISSIONALIDADE NA VIGILÂNCIA EM SAÚDE.

FATORES QUE FAVORECEM A INCIDÊNCIA DE QUEDAS EM IDOSOS: UMA REVISÃO DE LITERATURA.

A FISIOTERAPIA PEDIÁTRICA COM ÊNFASE NA ABORDAGEM LÚDICA: UMA REVISÃO DE LITERATURA.

O PAPEL DA ESPIRITUALIDADE NAS DOENÇAS CRÔNICAS NÃO TRANSMISSÍVEIS...215 A EFICÁCIA DO MÉTODO BAD RAGAZ NO TRATAMENTO DA FIBROMIALGIA - UMA REVISÃO SISTEMÁTICA DA LITERATURA.

CONTRIBUIÇÃO DA EQUOTERAPIA ENQUANTO INTERVENÇÃO TERAPÊUTICA EM PACIENTES COM SÍNDROME DE DOWN: UMA REVISÃO DE LITERATURA.....

A ATUAÇÃO DO PSICÓLOGO NAS POLÍTICAS PÚBLICAS DE ÁLCOOL E OUTRAS DROGAS.

A IMPORTÂNCIA DO PROFISSIONAL DE ENFERMAGEM NO ACOLHIMENTO HUMANIZADO ÀS VÍTIMAS DE VIOLÊNCIA SEXUAL.

O LUTO VIVENCIADO POR ADOLESCENTES DE PERIFERIA NO CONTEXTO PANDÊMICO DE COVID-19.

A INSERÇÃO DE MEDIDAS PREVENTIVAS EM TEMPO DE PANDEMIA.

O IMPACTO DA INICIAÇÃO CIENTÍFICA E SUA CONTRIBUIÇÃO PARA O GRADUANDO EM ENFERMAGEM: RELATO DE EXPERIÊNCIA.

A INFLUÊNCIA DA ESPIRITUALIDADE NO ENFRENTAMENTO DE TRATAMENTOS ONCOLÓGICOS.

MISTANÁSIA X CRISE DE OXIGÊNIO EM MANAUS: UMA REVISÃO DE LITERATURA...224 ASPECTOS FISIOPATOLÓGICOS DA SÍNDROME DO INTESTINO IRRITÁVELE OS FATORES PSICOSSOCIAIS NA FORMAÇÃO DA DOENÇA.

UTILIZAÇÃO DA METODOLOGIA SALA DE AULA INVERTIDA NO ENSINO REMOTO EM ENFERMAGEM.

A IMPORTÂNCIA DA ASSISTÊNCIA ODONTOLÓGICA PARA PACIENTES A SEREM TRATADOS COM BISFOSFONATOS. 


\section{RESUMOS EXPANDIDOS}

\section{ATENÇÃO À SAÚDE}

DISPOSITIVO INTRAUTERINO (DIU): FATORES QUE DIFICULTAM A INSERÇÃO E DISPONIBILIZAÇÃO NA REDE DE ATENÇÃO À SAÚDE DA MULHER 230

A ENFERMAGEM NO MANEJO DA DOR E AS REPERCUSSÕES NA SAÚDE DAS PESSOAS. .234

A IMPORTÂNCIA DOS PROBIÓTICOS E PREBIÓTICOS NA PROMOÇÃO DA SAÚDE

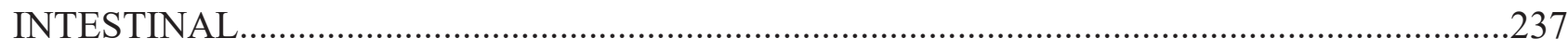

ATIVIDADE FÍSICA ORIENTADA PARA ADOLESCENTES GRÁVIDAS: RELATO DE EXPERIÊNCIA PELO OLHAR DA BIOÉTICA DA PROTEÇÃO.

PREVENÇÃOAOHIV/AIDSENTREADOLESCENTES:UMAREVISÃODELITERATURA...245 AÇÕES VOlTADAS AO CONTROLE DA DiABETES GESTACIONAL NA ATENÇÃO BÁSICA.

COVID-19 E A INFLUÊNCIA NA SAÚDE MENTAL DOS TRABALHADORES DA ÁREA DA SAÚDE: UMA REVISÃO DE LITERATURA. .255

COVID-19 E A VULNERABILIDADE DE PACIENTES PORTADORES DE DIABETES MELITTUS: UMA REVISÃO DE LITERATURA. .260

INTERAÇÃO MEDICAMENTOSA NO ÂMBITO HOSPITALAR: UMA REVISÃO

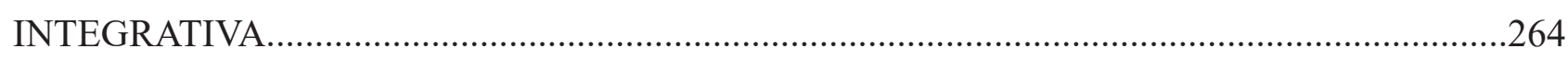

LEVANTAMENTO ETNOBOTÂNICO DE ESPÉCIES VEGETAIS UTILIZADAS NA MEDICINA POPULAR PARA O TRATAMENTO DE DISTÚRBIOS GASTROINTESTINAIS. .268

FATORES RELACIONADOS À PRÁTICA DA POLIFARMÁCIA EM IDOSOS: REVISÃO BIBLIOGRÁFICA

O COMPROMISSO BIOÉTICO DA ENFERMAGEM, FRENTE À VACINAÇÃO CONTRA COVID-19 NO ESTADO DO AMAPÁ.

PROMOÇÃO EM SAÚDE COM CUIDADORES DE CRIANÇAS E ADOLESCENTES COM DEFICIÊNCIA

UMA ENFERMIDADE NEGLIGENCIADA: DOENÇA DA ARRANHADURA DO GATO........286 ASPECTOS GERAIS SOBRE A MENINGOENCEFALITE AMEBIANA PRIMÁRIA CAUSADA PELA NAEGLERIA FOWLERI. 
REFLEXÕES E AVALIAÇÕES SOBRE A EUTANÁSIA DE CÃES INFECTADOS COM LEISHMANIOSE.

BIOÉTICA COTIDIANA NA INICIAÇÃO CIENTÍFICA: RELATO DE EXPERIÊNCIA...........301 BIOÉTICA À LUZ DA EDUCAÇÃO POPULAR COMO DISPOSITIVO DE TRANSFORMAÇÃO: RELATO DE EXPERIÊNCIA

IMPORTÂNCIA DA HUMANIZAÇÃO NA ASSISTÊNCIA POR PROFISSIONAIS DE ENFERMAGEM: REVISÃO INTEGRATIVA DA LITERATURA

CONHECIMENTO DO ENFERMEIRO FRENTE O CÂNCER DE MAMA NA ATENÇÃO PRIMÁRIA EM SAÚDE

A INSERÇÃO DA SAÚdE MENTAL NA ESTRATÉGIA DE SAÚDE DA FAMÍLIA: UMA COMPREENSÃO NECESSÁRIA.

ASSISTÊNCIA DE ENFERMAGEM EM SERVIÇO DE ONCOLOGIA: RELATO DE EXPERIÊNCIA.

RESISTÊNCIA MASCULINAAOS SERVIÇOS DE SAÚDE: DESAFIOS PARAASUA INCLUSÃO NA ATENÇÃO PRIMÁRIA. .326

SABERES ETNOFARMACOBOTÂNICOS À LUZ DA TEORIA DA COMPLEXIDADE: UMA CONTRIBUIÇÃO À ATENÇÃO PRIMÁRIA EM SAÚDE

\section{CLÍNICO - HOSPITALAR}

A IMPORTÂNCIA DA HUMANIZAÇÃO NA PRÁTICA DO PSICÓLOGO HOSPITALAR......335 CONSTRUÇÃO DE UM INSTRUMENTO DE AVALIAÇÃO FISIOTERAPÊUTICA PRÉ E PÓS CIRÚRGICO NO AMBIENTE HOSPITALAR

OS DESAFIOS DA ASSISTÊNCIA HUMANIZADADA EVIDENCIADOS NO SERVIÇO HOSPITALAR POR ENFERMEIROS: REVISÃO INTEGRATIVA DA LITERATURA. .343

INTERVENÇÕES DE ENFERMAGEM PARA PACIENTES NA UTI COM INCONTINÊNCIA INTESTINAL: REVISÃO INTEGRATIVA

ATUAÇÃO INTERPROFISSIONAL FRENTE À HIPERSENSIBILIDADE DENTINÁRIA CERVICAL 


\section{EDUCAÇÃO EM SAÚDE}

A FREQUÊNCIA DE ESTUDO DOS DISCENTES MÉDICOS DURANTE A PANDEMIA DO

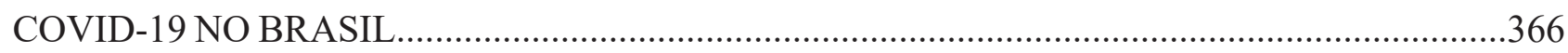

PROJETO DE EXTENSÃO NA ÁREA DE CIRURGIA E TRAUMATOLOGIA BUCO-MAXILOFACIAL NO HOSPITAL DE URGÊNCIA DE TERESINA - RELATO DE EXPERIÊNCIA............371

ABORDAGEM DA FITOTERAPIA NOS CURSOS DE SAÚDE DOS MUNICÍPIOS DE

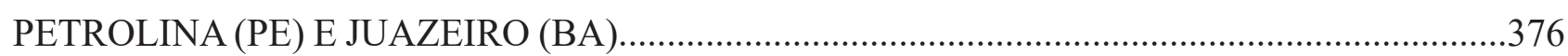

CAPACITAÇÃO REMOTA DE PROFISSIONAIS DURANTE A PANDEMIA DO SARS-CoV-2:

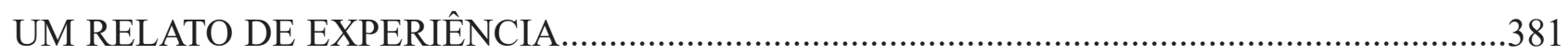

PALHAÇOTERAPIA COMO FERRAMENTA DE EDUCAÇÃO EM SAÚDE ACERCA DA

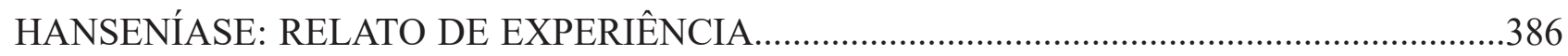

USO DO 'SOCRATIVE’ COMO FERRAMENTA DE ENSINO NA ÁREA DA SAÚDE: REVISÃO DE INTEGRATIVA. 391

PERFIL DE AUTOMEDICAÇÃO EM UMA UNIDADE BÁSICA DE SAÚDE NO INTERIOR DO CEARÁ 396

ESTÁGIO SUPERVISIONADO EM ENFERMAGEM NO CONTEXTO DA PANDEMIA DE COVID-19: EXPERIÊNCIA NA ATENÇÃO TERCIÁRIA..... 401

IMPORTÂNCIA DA EDUCAÇÃO EM SAÚDE NOS CASOS DE ACIDENTES PROVOCADOS POR ANIMAIS MARINHOS. 406

EDUCAÇÃO EM SAÚDE COMO ESTRATÉGIA DE PREVENÇÃO PARA O CÂNCER DE COLO DE ÚTERO... 409

BIOSSEGURANÇA E COVID-19: DESAFIOS DA ATENÇÃO PRIMÁRIA À SAÚDE.. 413

ENVELHECER BEM: PROMOVENDO O AUTOCUIDADO EM SAÚDE MENTAL NA TERCEIRA IDADE DURANTE A PANDEMIA. 416

PREVENÇÃO AO SUICÍDIO NA ATENÇÃO PRIMÁRIA DE SAÚDE NO MUNICÍPIO DE CASCAVEL - PR.

EDUCAÇÃO EM SAÚDE SOBRE INFECÇÕES SEXUALMENTE TRANSMISSÍVEIS COM PROFISSIONAIS DA SEGURANÇA PÚBLICA. .425

CAMPANHA OUTUBRO ROSA: EDUCAÇÃO EM SAÚDE COMO FERRAMENTA DE CONSCIENTIZAÇÃO PARA O CÂNCER DE MAMA. 


\section{MEDICINA VETERINÁRIA}

SÍNDROME DE BURNOUT NA MEDICINA VETERINÁRIA. .433

LEPTOSPIROSE CANINA: RELATO DE CASO 437

LEISHMANIOSE TEGUMENTAR EM CADELA: RELATO DE CASO 442

ABORTO CANINO POR TOXOPLASMA GONDII: RELATO DE CASO. .447

LEISHMANIOSE VISCERAL CANINA - RELATO DE CASO. 452

A TOXOPLASMOSE E SUA RELAÇÃO COM A SAÚDE PÚBLICA E A SAÚDE ANIMAL....457

O PAPEL DO MÉDICO VETERINÁRIO NA SAÚDE PÚBLICA 462

LEPTOSPIROSE BOVINA: UMA ZOONOSE EMERGENTE 467

CERATITE PIGMENTAR: REVISÃO DE LITERATURA. 471

PROSPECÇÃO DE ESTUDOS SOBRE A TOXICIDADE DE OPIOIDES EM QUADROS DE DOR PÓS-OPERATÓRIA EM CANINOS.

USO DE SOLUÇÃO ALCOÓLICA E DE SAIS DE CURA NO PREPARO QUÍMICO DE CADÁVERES DE PEQUENOS RUMINANTES, VISANDO AO TREINAMENTO CIRÚRGICO. 479

DOENÇADAARRANHADURADO GATO: ZOONOSE SUBDIAGNOSTICADA 482

ATUAÇÃO DE MÉDICOS VETERINÁRIOS RESIDENTES EM UMA UNIDADE DE TRIAGEM DE PACIENTES SUSPEITOS DE COVID-19 NO MUNICÍPIO DE JABOTICABAL/SP. 486

\section{SAÚDE COLETIVA}

EFEITO DA PANDEMIA DE COVID-19 SOBRE A INCIDÊNCIA DE TRAUMA DE TRÂNSITO NO ESTADO DO AMAZONAS.

CAPACITAÇÃO EM BIOSSEGURANÇA PARA EQUIPE DE VIGILÂNCIA EM SAÚDE DO TRABALHADOR: RELATO DE EXPERIÊNCIA. .496

IMPACTOS DA PANDEMIA DA COVID-19 NA SAÚDE MENTAL DOS TRABALHADORES DA SAÚDE: REVISÃO INTEGRATIVA. 
CARACTERÍSTICAS DOS ACIDENTES POR ESCORPIÃO EM SERRA TALHADA, SERTÃO DE PERNAMBUCO (2010-2019).

TESTAGEM RÁPIDA PARA COVID-19 EM TRABALHADORES DE UMA CENTRAL DE ABASTECIMENTO: EXPERIÊNCIA DE UM CEREST ESTADUAL.....

RESIDÊNCIA MULTIPROFISSIONAL EM SAÚDE DA FAMÍLIA: A TERRITORIALIZAÇÃO PARA ELABORAÇÃO DE ESTRATÉGIAS DE ATUAÇÃO.

A PARTICIPAÇÃO SOCIAL COMO LEGITIMAÇÃO DA DEMOCRACIA E A CONSOLIDAÇÃO DO SISTEMA ÚNICO DE SAÚDE.

ASPECTOS EPIDEMIOLÓGICOS DA FEBRE MACULOSA NO BRASIL NOS ÚLTIMOS CINCO ANOS DE NOTIFICAÇÃO.....

SAÚDE DA POPULAÇÃO MASCULINA E SUAS PRINCIPAIS DEMANDAS NA UNIDADE BÁSICA:REVISÃOINTEGRATIVA.

ACIDENTES PROVENIENTES DO CONTATO HUMANO COM ANIMAIS MARINHOS: UMA REVISAO DE LITERATURA.

SAÚDE MENTAL NO BRASIL DIANTE DO CENÁRIO DA PANDEMIA DE COVID-19: DESAFIOS PARA A REDE DE ATENÇÃO PSICOSSOCIAL .................................................538

RELAÇÃO DA ESPOROTRICOSE COM A SAÚDE PÚBLICA................................................543

PREVENÇÃO DE INFECÇÃO DO ZIKA VÍRUS EM MULHERES GESTANTES

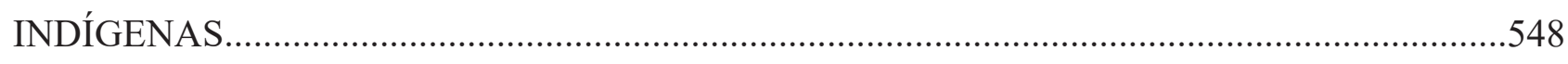

DESAFIOS NO ENFRENTAMENTO DA COVID-19: A MEDICINA VETERINÁRIA E SUA ÁREA DE ATUAÇÃO - REVISÃO.

CONTAMINAÇÃO DE AREIAS EM ÁREAS DE RECREÇÃO INFANTIL POR OVOS DE TOXOCARA E LARVAS DE ANCYLOSTOMA NO MUNICÍPIO DE SÃO JOSÉ DOS CAMPOS - SP. .556

PERCEPÇÕES DA EQUIPE DE ENFERMAGEM ACERCA DA VIOLÊNCIA DOMÉSTICA CONTRA A MULHER

EXPOSIÇÃO À DISRUPTORES ENDÓCRINOS AMBIENTAIS E HIPOTIREOIDISMO: UMA BREVE REVISÃO NA PERSPECTIVA DA SAÚDE COLETIVA...............................................567

HANSENÍASE EM UM MUNICÍPIO HIPERENDÊMICO: UM ESTUDO DESCRITIVO.........572 ATENÇÃO À SAÚDE MENTAL: DOS MANICÔMIOS AOS PARÂMETROS ATUAIS.............576 PERSPECTIVAS DE ATUAÇÃO DOS RESIDENTES EM SAÚDE DA FAMÍLIA DURANTE A PANDEMIA DE COVID-19. 
ATUAÇÃO DO PRAPS-MVS DA FCAV/UNESP/JABOTICABAL/SP NA VIGILÂNCIA DE EPIZOOTIAS DE PRIMATAS NÃO HUMANOS.................................................................586

RELAÇÃO ENTRE DIABETES MELLITUS E A SAÚDE PERIODONTAL..............................590 AÇÕES DO ENFERMEIRO PARA À PROMOÇÃO DA SAÚDE DA POPULAÇÃO LGBT......595 ASSISTÊCIA DE ENFERMAGEM À POPULAÇÃO EM SITUAÇÃO DE RUA: REVISÃO INTEGRATIVA. .600

RELEVÂNCIADAATUAÇÃODEMÉDICOS VETERINÁRIOS RESIDENTES EMCAMPANHAS DE VACINAÇÃO CONTRA RAIVA ANIMAL. .605

VARIÁVEIS ANTROPOMÉTRICAS EM ADULTOS E IDOSOS COM DIABETES MELLITUS.. 609

NOTIFICAÇÃO DE ZOONOSES EM CÃES E GATOS EM VIÇOSA, MG: PRIMEIROS PASSOS. .614

PERFIL DE PACIENTES ATENDIDOS POR TENTATIVA DE SUICÍDIO EM UM SERVIÇO DE ATENDIMENTO MÓVEL DE URGÊNCIAS..... .618

ESTRATÉGIASAÚDE DAFAMÍLIAE O ENFRENTAMENTO DA RESISTÊNCIABACTERIANA EM VIÇOSA, MG.

MEDICINA VETERINÁRA NO COMBATE A PANDEMIA DE COVID-19 EM VIÇOSA, MG...626

\section{ÁREAS AFINS}

MANIFESTAÇÕES ORAIS DECORRENTES DO TRATAMENTO QUIMIOTERÁPICO REVISÃO DE LITERATURA.

ASPECTOS FISIOLÓGICOS DA HIPERTROFIA CARDÍACA ESQUERDA EM ATLETAS: UMA REVISÃO DE LITERATURA. .636

TRATAMENTO COM ÁCIDO HIALURÔNICO PARA DISFUNÇÃO TEMPOROMANDIBULAR - REVISÃO DE LITERATURA. .641

A TEMPESTADE DE CITOCINAS NO DESENVOLVIMENTO DA COVID-19 .645

UMA ANÁLISE HISTÓRICO-CULTURAL ACERCA DO ADOECIMENTO MENTAL DE PROFISSIONAIS DA ÁREA DA ENFERMAGEM .650

DOSE CLÍNICA DE 5-FLUOROURACIL PROMOVE ALTERAÇÕES MORFOLÓGICAS E BIOQUÍMICAS NO FÍGADO DE RATOS. 
EXERCÍCIO AERÓBICO NO TRATAMENTO DA FIBROMIALGIA E MELHORA DA

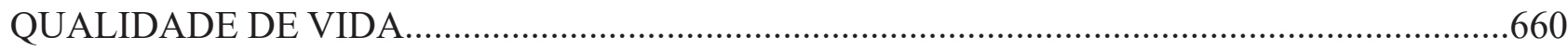

A DOR FALCIFORME RETRATADA NOS DESENHOS: SIGNIFICADOS PESSOAIS............663 FATORES DE RISCOS PARA INCONTINÊNCIA URINÁRIA NO CICLO GRAVÍDICO

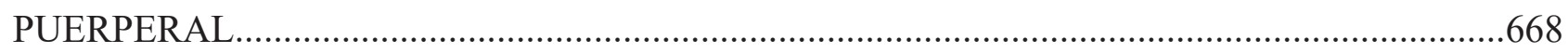

QUALIDADE DE VIDA SEXUAL DE MULHERES NO CLIMATÉRIO.................................672

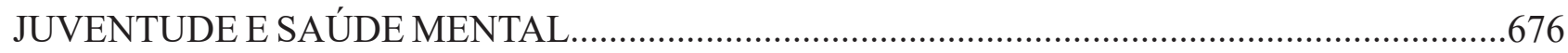

RELATO DE EXPERIÊNCIA DE MESTRANDOS EM ENFERMAGEM NAS ATIVIDADES

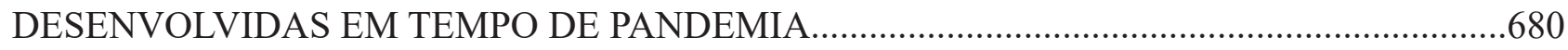

ESTRESSE OCUPACIONAL EM ENFERMEIROS NO AMBIENTE HOSPITALAR................685 ATIVIDADE EDUCATIVA VIRTUAL SOBRE GRAVIDEZ NA ADOLESCÊNCIA: RELATO DE EXPERIÊNCIA. .689

REVISÃO DE LITERATURA SOBRE SITEMATIZAÇÃO DA ASSISTÊNCIA EM ENFERMAGEM. .693 


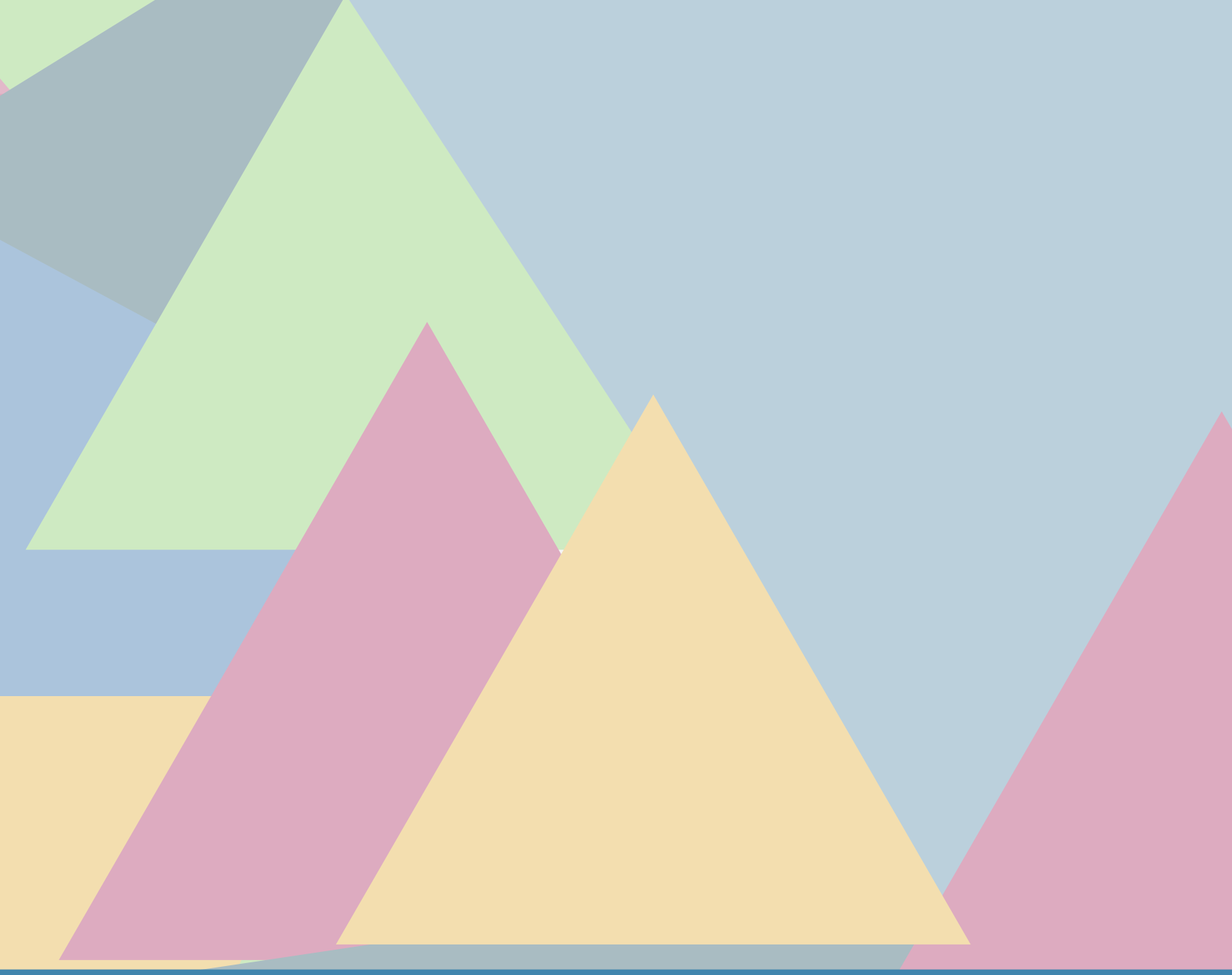

Atenção à Saúde 


\section{A IMPORTÂNCIA DA HUMANIZAÇÃO NA PRÁTICA PROFISSIONAL DO ASSISTENTE SOCIAL NA SÁUDE}

\section{Clara dos Santos Silva Linhares ${ }^{1}$ Francisca Viviane Matos Soares ${ }^{2}$}

${ }^{1}$ Escola de Saúde Pública do Ceará ${ }^{2}$ Escola de Saúde Pública do Ceará

Introdução: No campo das políticas de saúde, humanização diz respeito à transformação dos modelos de atenção e de gestão nos serviços e sistemas de saúde, indicando a necessidade da construção de novas relações entre usuários e trabalhadores. Orientada pelos princípios da transversalidade e da indissociabilidade entre atenção e gestão, a "humanização" se expressa a partir de 2003 com Política Nacional de Humanização (PNH). Objetivo: Refletir acerca da importância da humanização na prática do assistente social na saúde. Metodologia: É um estudo bibliográfico de natureza qualitativa. Resultados: A humanização na saúde é uma construção coletiva que envolve o trabalho em equipes multiprofissionais, dentre estes profissionais, destaca-se o assistente social. Considerando a postura ético-política que faz parte do exercício da profissão, o assistente social se coloca a frente aos desafios de construir um processo reflexivo acerca das ações, princípios, valores, direitos e deveres que norteiam a prática social, no desenvolvimento de relações humanizadas na política de saúde. Considerações Finais: Em seu cotidiano o assistente social atua com usuários em processo de fragilização causados pelo adoecimento, desse modo, torna-se fundamental uma prática humanizada, pautada no respeito, cuidado, diálogo, na construção de relações empáticas e solidárias. O profissional atua na perspectiva de viabilizar o acesso aos direitos sociais que muitas vezes podem estar sendo violados, neste sentido, sua intervenção humanizada faz toda diferença para os sujeitos, viabilizando o cuidado necessário diante da situação de vulnerabilidade em que se encontra o público atendido.

Palavras-chave: Humanização. Diálogo. Assistente Social.

Área Temática: Saúde Coletiva 


\section{A IMAGINOLOGIA VINCULADA COM O DIAGNOSTICO DO PROECESSO PATOLÓGICO DA ATEROSCLEROSE. BRASIL EUROPA.}

\section{Josué Brito Gondim¹, Francisco Augusto Santana Pires², Larissa da Silva Leite Muniz.}

Tecnólogo em Radiologia-UNIFIP ${ }^{1}$, Acadêmicos no curso de Medicina-Unipê $\hat{e}^{2,3}$

Introdução: A artéria carótida localizada no pescoço humano apresenta um forte grau de importância Carotídea. A mesma, é responsável por $90 \%$ das doenças cerebrovascular extracraniana e Acidente vascular cerebral (AVC), forte causador de mortes e mobilidade na Europa. Também, adentra a segunda colocação de índice de desenvolvimento de demência pelos pacientes que sobrevivem ao avc, além de ser um forte fator de depressão nos idosos, proporcionando a mesma, uma desenvoltura de duas novas patologias, como demência e depressão, além de alterações fisiológicas. Devido a mesma apresentar-se em um local de difícil acesso e imperceptível ao olho nu, submete-se a dois exames: Tomografia e ressonância magnética. Objetivo: Abordar tal patologia e conscientizar a população do índice de pacientes no Brasil, usando a comparativa com a Europa, explanar o grau de periculosidade da mesma. Metodologia: Teve-se o uso de revisão literária de artigos correspondentes da área e afins. Resultados: Durante a pesquisa, teve-se a observação das estáticas da devida patologia no Brasil e países da Europa. Na Europa, a partir dos 45 anos, $90 \%$ da população são propensos a ter a patologia e no Brasil, 70\%. Com 35 anos na Europa tem- se $60 \%$ de desenvolvimento da patologia e no Brasil 40\%. Com 20 anos na Europa, 40\% da população são propensos a desenvolver a patologia e no Brasil,30\%. Conclusões: Os pesquisadores demostraram interesse em devido tema, pelo o fato do mesmo ser uma patologia de grau elevado e periculosidade tão abrangente na sociedade Europeia e sua perspectiva no país ser tão elevada comparada a outras doenças no país, não ter o nível de explanação devida.

Palavras-Chaves: Avc. Tomografia. População.

Área Temática: Atenção a saúde. 


\title{
O AUTOCUIDADO RELACIONADO À HIGIENE DE CRIANÇAS EM VULNERABILIDADE SOCIAL EM UM ABRIGO DE MANAUS
}

\author{
Leandro Guimarães Ribeiro ${ }^{1}$
}

${ }^{1}$ Centro Universitário do Norte (UNINORTE)

DOI: $10.47094 /$ ICONRES.2021/15

Introdução: A higiene pessoal afeta o conforto, a segurança e o bem-estar de uma pessoa e pode ser evidenciada pelo autocuidado, o qual é influenciado por fatores como práticas sociais (ex: costumes familiares), imagem corporal e condição socioeconômica. A forma que esses fatores influenciam uma pessoa resulta em um bom ou ruim autocuidado relacionado à higiene, sendo este último responsável por acarretar patologias bucais como cárie, dermatológicas como a pediculose. Objetivo: relatar a experiência de um acadêmico de Enfermagem, ressaltar a importância do autocuidado relacionado à higiene para crianças em estado de vulnerabilidade em um abrigo e avaliar o conhecimento dos cuidadores acerca deste tema. Metodologia: estudo exploratório-descritivo que usou como coleta de dados uma entrevista semiestruturada com cinco cuidadores onde foram levantadas questões como "você sabe o que é o autocuidado na higiene?" e "você sabe a importância de ministrar isso para as crianças?”, e avaliação física em doze crianças em estado de vulnerabilidade, com idade entre zero a dez anos, dentro de um abrigo localizado no município de Manaus-AM. Resultados: Através das entrevistas, notou-se que uma parcela dos cuidadores não sabiam a importância do autocuidado da higiene enquanto a outra porção não achava relevante, um cuidador relata não haver treinamento ou orientação para isso, apenas cumprimento de regras nos horários reservados para higiene. Por meio do exame físico, foi evidenciado uma grande carência na higiene pessoal observado por cáries, halitose, tártaro, pele com sujidades excessivas, dermatite e caspa. Conclusões: $O$ tema autocuidado relacionado à higiene é negligenciado pelos cuidadores, em grande parte por falta de capacitação e motivação oriunda da gerência. Perceber a importância de aprender e ensinar esse cuidado às crianças acarretaria em melhorias na saúde, autoestima, vivência e relações interpessoais das mesmas. Nesse sentido é importante a instrução e acompanhamento por parte dos profissionais da saúde.

Palavras-chave: Saúde da Criança. Bem-estar. Condições Sociais.

Área Temática: Atenção à saúde 


\title{
DESAFIOS NO ATENDIMENTO DE ENFERMAGEM A PACIENTES DO SEXO FEMININO
}

\author{
Leandro Guimarães Ribeiro ${ }^{1}$, Antonio Mateus Araujo Teixeira ${ }^{2}$ \\ ${ }^{1,2}$ Centro Universitário do Norte (UNINORTE)
}

DOI: $10.47094 /$ ICONRES.2021/16

Introdução: De acordo com Marinelli (2012), o sexo masculino apresenta maior dificuldade em trabalhar com saúde da mulher devido questões culturais intrínsecas da população e o Enfermeiro, não está excluído desse tópico, principalmente em virtude da necessidade de realização de procedimentos que envolve a intimidade da paciente. Desta forma, a timidez da paciente pode gerar constrangimento e isso dificulta a interação no atendimento. Objetivo: Relatar a experiência de um acadêmico de enfermagem em uma clínica dermatológica consultando pacientes do sexo feminino. Metodologia: Trata-se de um relato de experiência de um acadêmico de enfermagem ao participar de um estágio extracurricular em uma clínica particular em Manaus. A atividade ocorreu no período de fevereiro a junho de 2019, sendo realizada aos finais de semana, período em que existia um maior fluxo de pessoas. Os serviços eram voltados a consultas dermatológicas com público do sexo feminino e masculino. Resultados: Durante o período de atividades, percebeu-se que havia uma certa resistência por parte do público feminino. A nível de protocolo, era necessário que o paciente ficasse somente de roupa íntima, foi percebido que tal atividade gerava maior desconforto em pacientes do sexo feminino. A existência de recusa pode estar atrelada ao estigma de que o sexo masculino em algum momento pode agir desrespeitosamente, desconsiderando o lado profissional. Grande parte dessas mulheres sentiam-se assediadas somente pelo olhar do profissional. Conclusões: É comum que a mulher não se sinta confortável em uma consulta com um homem devido a realidade da sociedade. O medo, assédio, trauma dificultam a realização de um bom atendimento. É um direito da mulher não querer ser atendida por um homem, seja qual for o motivo, e é necessário que o futuro profissional saiba solucionar esses conflitos.

Palavras-chave: Constrangimento. Relações Enfermeiro-Paciente. Saúde da Mulher.

Área Temática: Atenção à saúde 


\title{
ASPECTOS CLINICORRADIOLOGICOS DA DOENÇA TROFOBLÁSTICA GESTACIONAL
}

\author{
Mariana Isaura Cordeiro Araújo ${ }^{1}$, Josué Brito Gondim².
}

Tecnólogo em Radiologia-UNIFIP., ${ }^{1,2}$

Introdução: A Doença Trofoblástica Gestacional (DTG), é o termo amplo utilizado para designar patologias que acometem o tecido placentário que cresce de forma anômala. A DTG apresenta derivações benignas como nos casos de Mola Hidatiforme (MH), dividindo-se em Mola Hidatiforme Parcial (MHP) e Mola Hidatiforme Completa (MHC); e manifestações malignas ocorrem na forma de Neoplasias Trofoblásticas Gestacionais, segmentando-se em coriocarcinoma, tumor trofoblástico epitelioide (TTE), mola invasora (MI) e tumor trofoblástico do sítio placentário (TTSP). Objetivo: Demonstrar a utilização da imaginologia aplicada ao diagnóstico da doença trofoblástica gestacional e as formas de manifestação da patologia através da imagem. Metodologia: Esse estudo foi uma revisão integrativa da literatura tomando como base o seguinte banco de dados como BVS, LILACS, google acadêmico. Levando como critérios de inclusão os cinco últimos anos e estudos em português, inglês e espanhol. Resultados: De acordo com o estudo, o exame de estadiamento da doença trofoblástica gestacional é a ultrassonografia. Níveis alterados da fração beta da gonadotrofina coriônica humana gera indícios de alteração no Trofoblástos e no sitio placentário da paciente.; no exame feito por meio vaginal a visualização das estruturas anatômicas, lesões e suas dimensões são melhor vistas devido a resolução espacial proporcionada pela proximidade da estrutura de estudo. As formas malignas da doença trofoblástica gestacional conhecidas também como neoplasias trofoblásticas gestacionais são tumores raros que representam menos de $1 \%$ das doenças ginecológicas. Conclusões: A ultrassonografia é a principal ferramenta para o diagnóstico das DTG's. Porém com o quadro evolutivo da doença para NTG exames de imagem adicionais se fazem necessário.

Palavras-chave: Ultrassonografia. Radiologia. Gonadotrofina.

Área Temática: Atenção à Saúde. 


\title{
SAÚDE SEXUAL E REPRODUTIVA EM TEMPOS DE PANDEMIA: UMA ANÁLISE DA ADESÃO DE ADOLESCENTES NA ATENÇÃo PRIMÁRIÀ̀ SAÚDE
}

\author{
Sarah Bianca Trindade ${ }^{1}$, Vanessa Gomes de $\mathrm{Souza}^{2}$, Alana Corrêa Santos ${ }^{3}$, Márcia Eduarda \\ Dias Conceição ${ }^{4}$, Tatiana do Socorro dos Santos Calandrini ${ }^{5}$, Marlucilena Pinheiro da Silva ${ }^{6}$, \\ Luzilena de Sousa Prudêncio ${ }^{7}$, Nely Dayse Santos da Mata ${ }^{8}$
}

1,2,3,4,5,6,7,8 Universidade Federal do Amapá

Introdução: A pandemia pelo covid-19 impôs regras sanitárias que objetivam controlar seu impacto, restringiu o acesso a bens e serviços, com finalidade de reduzir aglomerações, em especial nas consultas subsequentes de saúde sexual e reprodutiva de adolescentes, grupo populacional foco deste relato. Objetivo: analisar a adesão às consultas de saúde sexual e reprodutiva de adolescentes em tempos da pandemia do Covid-19. Métodos: dados coletados do ano de 2020, do livro de registro de usuárias, do serviço de saúde sexual e reprodutiva desenvolvido Policlínica da Universidade Federal, no município de Macapá/Amapá. Resultados: Analisou-se 57 registros entre a faixas etária dos 14 aos 19 anos, assim como a escolha do método anticoncepcional, e constatou-se que a idade de maior índice que procurou pelo método com $28,1 \%$ foram adolescentes de 18 anos e o anticoncepcional predominante com $41,1 \%$ foi o trimestral (Demedrox), seguido pelo ciclo21 com 17,9\%. Os dados são relevantes, pois a escolha do método contraceptivo está voltado para o tipo hormonal, o qual deve ser uma preocupação a considerar a idade das usuárias. Outro fator de inquietação é o longo tempo entre as consultas, onde 25 usuárias fizeram apenas primeira consulta, e 18 fizeram apenas uma consulta subsequente, no mês seguinte. A considerar a pandemia, a busca de faltosos está sendo restringida, o que interfere na continuidade da assistência a ser prestada, por não haver continuidade de consultas subsequentes. Conclusão: Evidenciou-se que a pandemia do covid-19 está interferindo no acesso às diferentes áreas da saúde, a citar a saúde sexual e reprodutiva de adolescentes, preocupantes, pelo elevado o risco de uma gravidez indesejada em função da ruptura nas consultas subsequentes que envolve orientações, exames, diagnóstico, tratamento de agravos e continuidade ao uso do contraceptivo de escolha.

Palavras-chave: Planejamento. Prevenção. Reprodução.

Área Temática: Atenção à Saúde. 


\title{
SÍNDROME METABÓLICA: A DOENÇA DA CIVILIZAÇÃO MODERNA, SUAS COMORBIDADES E A RELAÇÃO COM OS TRANSTORNOS MENTAIS.
}

\author{
Raphaela Moury Fernandes Melloㅁ, Maria Fernanda Durando Gomes ${ }^{1}$, Mariana Vasconcelos \\ de Melo Lima ${ }^{1}$ Isabela Gomes de Oliveira ${ }^{1}$ \\ ${ }^{1}$ Centro Universitário Maurício de Nassau
}

Introdução: A síndrome metabólica (SM) é uma doença em que a obesidade visceral é um fator obrigatório ao seu diagnóstico. É uma epidemia global que no Brasil estima-se a prevalência da SM em 8,9\% ${ }^{1}$, já nos EUA chega a $23.7 \%^{2}$. Existem diversos fatores envolvidos nessa doença, como a vida cotidiana que leva indivíduos a recorrência de fastfoods, também pode estar associada a transtornos psicológicos, podendo a obesidade ser a causa, como a consequência de transtornos de depressão, ansiedade, bipolaridade, esquizofrenia. Objetivo: O objetivo desse estudo é analisar como as comorbidades sofridas na SM impacta negativamente na vida dos portadores e sua relação com transtornos psiquiátricos. Metodologia: Estudo realizado a partir de uma revisão de literatura, com a base de dados colhidos na ScieLo. Resultados: Existem comorbidades da SM que impactam qualidade de vida do ser humano, muito relacionada a problemas cardiovasculares, um dos principais obstáculos da saúde pública atual ${ }^{3}$. Há também a limitação devido as condições físicas da obesidade, impossibilitando muitos de trabalhar e precisando de auxílio para simples atividades habituais, pois muitos tem doenças artríticas devido ao excesso de peso nas articulações. O fator psicológico também limita pessoas obesas, as populações psiquiátricas têm uma causalidade multifatorial, em que se incluem fatores ligados ao estilo de vida desses pacientes, fatores genéticos, perinatais, neuroquímicos e hormonais, além do uso de psicofármacos. Sabe-se que alimentação inadequada e estilo de vida sedentário desempenham papéis importantes na gênese da SM. Indivíduos com esquizofrenia ou transtorno bipolar realizam pouca atividade física e consomem dieta pouco saudável ${ }^{4}$. Conclusão: Os estudos sugerem que a SM é significativamente associada à piora da qualidade de vida, devido a todas as comorbidades relacionada a essa doença, assim como os transtornos psiquiátricos que podem cursar junto ou após a SM, diminuindo assim a qualidade de vida dos portadores dessa síndrome.

Palavras-chave: Obesidade; Distúrbio metabólico; Disfunção mental.

Área Temática: Atenção à Saúde. 


\title{
CONTRIBUIÇÕES DAS PRÁTICAS INTEGRATIVAS E COMPLEMENTARES NO CUIDADO NO CONTEXTO DA PANDEMIA DA COVID-19
}

\author{
Maria Margarida Gonçalves Diniz ${ }^{1}$, Adrícia Gonçalves Diniz ${ }^{2}$ \\ ${ }^{1}$ Escola de Governo em Saúde Pública de Pernambuco (ESPPE) ${ }^{2}$ Faculdade de Integração do \\ Sertão (FIS)
}

Introdução: As Práticas Integrativas e Complementares (PICs) podem ser descritas como recursos que atuam nos distintos aspectos da saúde, no que concerne a recuperação da saúde e a prevenção de doenças e outros agravos ao proporcionar importantes contribuições para lidar com os desafios impostos pela pandemia da Covi-19, pois, além de ressignificarem o processo saúde-doença, estimulam o empoderamento do sujeito, com atendimentos como: acupuntura, aromaterapia, auriculoterapia, fitoterapia, terapia floral, yoga, entre outros. Objetivo: Realizar uma revisão bibliográfica acerca das contribuições das Práticas Integrativas e Complementares no cuidado integral no contexto da pandemia da Covid-19, através das publicações em revistas científicas brasileiras. Metodologia: Trata-se de uma pesquisa bibliográfica com o viés qualitativo, onde foram selecionadas pesquisas no banco de dados da Scientific Electronic Library Online (Scielo). Na análise emergiram 18 artigos, porém apenas 9 foram selecionados. Os critérios para seleção, incluíram o período de tempo do material, datados a partir de 2016 a 2020, e publicados nos bancos de dados citados, com o idioma em língua portuguesa, que retratassem a temática tratada. Resultados: Os estudos revelam o empoderamento dos usuários ao buscarem o autocuidado, assim como a redução da medicalização e dos sintomas psicossomáticos, tendo em vista que, algumas PICs são incorporadas na prática pelos profissionais que enxergam a potencialidade dessas práticas para melhorar os serviços de saúde. Conclusões: As PICs possibilitam um cuidado holístico e uma assistência humanizada, efetivando o princípio do Sistema Único de Saúde (SUS) da integralidade. Dessa forma, é necessário mais investimentos no aperfeiçoamento profissional, especialmente para os trabalhadores da atenção básica, para que haja sucesso na implantação, acesso e uso dessas práticas no SUS, que mais do que nunca, carece de ferramentas potentes para o enfrentamento da pandemia da Covi-19.

Palavras-chave: PICS. SUS. Coronavírus.

Área Temática: Atenção à Saúde. 


\section{A IMPORTÂNCIA DA PROMOÇÃO DA SAÚDE MENTAL DO IDOSO NA ATENÇÃO BÁSICA}

\section{Maria Margarida Gonçalves Diniz ${ }^{1}$, Adrícia Gonçalves Diniz ${ }^{2}$}

${ }^{1}$ Escola de Governo em Saúde Pública de Pernambuco (ESPPE) ${ }^{2}$ Faculdade de Integração do Sertão (FIS)

Introdução: O envelhecimento é uma etapa da vida caracterizada pelo surgimento de prejuízos nas capacidades físicas e cognitivas, porém, as implicações sociais e psicológicas nem sempre são evidenciadas. O Pacto em Defesa da Vida possui três prioridades voltadas para a saúde da população idosa, são elas: a promoção da saúde e maior efetividade na Atenção Básica (AB), que deve desenvolver ações que promovam a saúde mental e o bem estar do idoso. Objetivo: Realizar uma revisão bibliográfica analisando os estudos acerca da importância de se promover a saúde mental da terceira idade na atenção básica. Por vezes, o cuidado em Saúde Mental do idoso na Atenção Básica tem como principal oferta a prescrição de psicofármacos, não havendo uma visão holística do sujeito. Metodologia: Trata-se de uma pesquisa bibliográfica com o viés qualitativo, onde foram selecionadas pesquisas no banco de dados da Scientific Electronic Library Online (Scielo). Na análise emergiram 18 artigos, todavia apenas 9 foram selecionados. Os critérios para seleção, incluíram o período de tempo do material, datados a partir de 2015 a 2020, com o idioma em língua portuguesa, que retratassem a temática tratada. Resultados: Na Atenção Básica é indispensável à inserção de um cuidado que enxergue o idoso como um ser biopsicossocial, com profissionais que considerem não apenas aspectos físicos, mas também tenham um olhar para a saúde mental, fatores cognitivos e de humor, ampliando assim a atuação para além das doenças crônicas. Conclusões: A efetivação do cuidado à saúde da população idosa de modo integral exige como tarefa urgente do Sistema Único de Saúde, um melhor preparo dos trabalhadores e uma mudança nas compreensões que hoje orientam a forma de pensar e fazer o cuidado em saúde, essecialmente na Atenção Básica, com isso, destaca-se além de reformas curriculares, a oferta de educação permanente e educação continuada.

Palavras-chave: Saúde emocional. Idoso. Atenção Primária.

Área Temática: Atenção à Saúde. 


\title{
A INTEGRALIDADE DO CUIDADO À SAÚdE DA CRIANÇA NA ATENÇÃO BÁSICA
}

\author{
Maria Margarida Gonçalves Diniz ${ }^{1}$, Adrícia Gonçalves Diniz ${ }^{2}$ \\ ${ }^{1}$ Escola de Governo em Saúde Pública de Pernambuco (ESPPE) ${ }^{2}$ Faculdade de Integração do \\ Sertão (FIS)
}

Introdução: O cuidado na Atenção Integral à Saúde da Criança constitui-se primordialmente na atenção ao parto e ao puerpério, além de cuidados com o recém-nascido, o que compreende: prestar assistência ao longo do crescimento, triagem neonatal, aleitamento materno, doenças predominantes na infância e saúde coletiva em organizações de educação infantil. Objetivo: Realizar uma revisão bibliográfica analisando os estudos acerca da integralidade do cuidado à Saúde da Criança no nível da Atenção Básica. Tendo em vista que, as dificuldades da AB em efetivar a integralidade corrobora para a não resolutividade dos problemas de saúde durante a infância. Metodologia: Pesquisa bibliográfica com o viés qualitativo, onde foram selecionadas pesquisas no banco de dados da Scientific Electronic Library Online (Scielo). Na análise emergiram 18 artigos, todavia apenas 9 foram selecionados. Os critérios para seleção, incluíram o período de tempo do material, datados a partir de 2015 a 2020, com o idioma em língua portuguesa, que retratassem a temática tratada. Resultados: A integralidade do cuidado implica em uma assistência qualificada, que considera a criança como um ser biopsicossocial. Todavia, ainda existem fatores a serem superados, como: a infraestrutura inapropriada das unidades básicas de saúde, dificuldades de comunicação na atenção à saúde da criança, insuficiência de recursos humanos, ausência de qualificações direcionadas para o cuidado à criança, dentre outros. Conclusões: O cuidado integral é realizado ao enxergar a criança de forma multidimensional, contemplando suas relações com a família e seu contexto de vida. Ademais, é necessária uma rede de cuidados com trabalhadores e serviços da atenção básica e dos outros níveis de atenção restante, bem como a articulação entre o serviço de referência e contrarreferência, para que haja a continuidade da assistência de forma exitosa. Outro ponto essencial é a oferta da educação permanente e da educação continuada.

Palavras-chave: Cuidado Integral. Infância. Atenção Primária.

Área Temática: Atenção à Saúde. 


\title{
A ATUAÇÃO DO FISIOTERAPEUTA NO CUIDADO DO PACIENTE ONCOLÓGICO
}

\section{Elídia Keila Oliveira Portela ${ }^{1}$}

\author{
${ }^{1}$ Universidade Federal do Delta do Parnaíba - UFDPAR
}

Introdução: o profissional fisioterapeuta possui um vasto campo de atuação, estando habilitado a empreender em todos os setores de atenção à saúde. A fisioterapia em oncologia surge como uma importante área de tratamento, objetivando a prevenção e reabilitação de disfunções e complicações comuns decorrentes de pré e pós-operatórios, dentre as quais, está a mastectomia, sendo configurada como um processo cirúrgico de retirada total da mama em conseqüência do câncer. Tais objetivos podem ser alcançados através de um programa fisioterapêutico apropriado e preventivo. Objetivo: buscar nas obras literárias as principais atuações do fisioterapeuta ao paciente com câncer de mama no pré e pós-operatório. Metodologia: o presente estudo é uma revisão da literatura desenvolvida em fevereiro de 2021 e embasada em 8 trabalhos científicos extraídos das bases de dados Scielo e PubMed, na qual obedeceram os critérios de inclusão, estando na íntegra para leitura e publicados entre 2010 e 2020. Resultados: diante da análise dos referenciais foi possível constatar que um programa fisioterápico precoce é fundamental, tendo em vista a necessidade de se evitar possíveis complicações. No pré-operatório o fisioterapeuta atuará principalmente na preparação do paciente para o procedimento cirúrgico. Já no pós-operatório, o profissional abordará técnicas visando identificar alguma alteração neurológica, em conseguinte, intervenções fisioterapêuticas com o objetivo da reabilitação musculoesquelética, buscando a plenitude das funções cinético-funcionais do paciente. Atuará ainda na prevenção do linfedema através de técnicas consagradas como a cinesioterapia e a drenagem linfática manual. Conclusões: diante do exposto, faz-se necessário retificar a importância da intervenção fisioterapêutica no cuidado do paciente em todas as fases do câncer de mama, tendo em vista que a abordagem precoce e contínua repercutirá na melhora da sua qualidade de vida e, consequentemente, lhe proporcionará maior independência.

Palavras-chave: Câncer de Mama. Mastectomia. Fisioterapia.

Área Temática: Atenção à Saúde. 


\title{
A IMPORTÂNCIA DO EXERCÍCIO FÍSICO COMO PARTE INTEGRANTE DO TRATAMENTO DE PACIENTES COM DOENÇAS CRÔNICAS
}

\author{
Rhuan Pinheiro Marquezini ${ }^{1}$, Marcio Luis de Lacio ${ }^{1,2}$, Derick Francisco Santana ${ }^{1}$, Jonathan \\ Dias Teixeira ${ }^{1}$, Victor de Souza Rodrigues ${ }^{1}$, Carlos Eduardo da Costa Schultz ${ }^{1}$, Emerson \\ Rodrigues Duarte ${ }^{1}$
}

${ }^{1}$ Faculdade Metodista Granbery (FMG), ${ }^{2}$ Universidade Federal de Juiz de Fora (UFJF)

Introdução: O sedentarismo é uma das principais causas de mortalidade e, aliado à má alimentação ao longo da vida, é determinante para o surgimento de doenças crônicas como Diabetes Mellitus, Hipertensão e Dislipidemias. Pacientes portadores de doenças crônicas estão sujeitos a sofrerem eventos cardiovasculares como infarto agudo do miocárdio e acidente vascular encefálico, portanto, correm grande risco de óbito. Estes pacientes comumente convivem com mais de uma morbidade e muitas das vezes, previamente sedentários, tornam-se cada vez menos funcionais e passam a viver com menos qualidade de vida; Objetivo: Elucidar como a prática do exercício físico pode contribuir para a qualidade de vida e o tratamento de pacientes portadores de doenças crônicas; Metodologia: Revisão não sistematizada de literatura desenvolvida com base em artigos relacionados à temática e publicados entre os anos de 2015 a 2020 na base de dados PubMed; Resultados: O quadro comum dos pacientes crônicos é uma condição de estresse oxidativo e inflamação de etiologia dependente de sua doença, podendo ser provenientes da resistência à insulina, resistência vascular periférica e deposição de partículas de colesterol como as LDL; podendo estas três condições estarem presentes simultaneamente. O exercício físico, através do aumento do débito cardíaco e do estresse de cisalhamento na parede dos vasos sanguíneos, promove o aumento de um potente vasodilatador, o óxido nítrico endotelial, diminuindo dessa forma, a resistência vascular periférica. Promove também o controle da glicemia, reduzindo a hemoglobina glicosilada dos pacientes e intensifica o transporte reverso do colesterol, diminuindo a deposição das LDL nos vasos sanguíneos; Considerações Finais: Os inúmeros benefícios obtidos com a prática de exercícios físicos, verificados através da melhora dos parâmetros laboratoriais, proporcionam aos pacientes com doenças crônicas uma melhora em sua saúde e qualidade de vida. Assim, a prática do exercício físico é uma estratégia indispensável para o tratamento destes pacientes.

Palavras-chave: Sedentarismo. Morbidade. Saúde.

Área Temática: Atenção à saúde. 


\section{ABORDAGEM DE SISTEMAS COMPLEXOS NA SAÚDE E NA DOENÇA}

\section{Derick Francisco Santana1, Marcio Luis de Lacio², Rhuan Pinheiro Marquezini', Victor de Souza Rodrigues ${ }^{1}$, Jonathan Dias Teixeira ${ }^{1}$, Carlos Eduardo da Costa Schultz ${ }^{1}$, Emerson Rodrigues Duarte ${ }^{1}$}

${ }^{1}$ Faculdade Metodista Granbery (FMG), ${ }^{2}$ Universidade Federal de Juiz de Fora (UFJF)

Introdução: A abordagem dos sistemas complexos foi empregada em diversas áreas de pesquisa como, saúde, lesões esportivas, fisiologia do exercício, psicoterapia, biologia molecular e na visualização do organismo humano como uma rede integrada. Apesar disso, o pensamento vigente na área da saúde ainda é de teor reducionista e, diante de suas limitações, é insuficiente quando aplicado à saúde para o real entendimento do corpo humano; Objetivo: Revisar a literatura atual a cerca do comportamento de sistemas complexos e fazer uma interface aplicada à saúde e à doença; Metodologia: Trata-se de uma revisão narrativa, realizada a partir da busca artigos científicos publicados entre os anos de 2001 e 2020 nas bases de dados PubMed, Web of Science e Scopus. Para a constituição da revisão foram utilizados 9 artigos científicos; Resultados: O reducionismo adota uma relação linear para a explicação de um fenômeno e na maioria dos casos um único fator é atribuído para tal fenômeno. Porém, contrapondo esse pensamento limitado aplicado à saúde, surge uma abordagem de sistemas complexos. Sistemas complexos são altamente compostos, construídos a partir de inúmeras subunidades integradas cujas interações repetidas resultam em um comportamento emergente, rico e coletivo, alimentando dessa forma o comportamento das partes individuais. Esses sistemas são não lineares e se auto-organizam. A abordagem de sistemas complexos entende a saúde como subjetiva e a doença como sendo composta por estados emergentes das interações entre os contextos ambientais, sócioculturais e econômico-políticos, juntamente com as interações fisiológicas e psicológicas recursivas de células e redes de funções orgânicas; Considerações finais: $O$ entendimento de saúde passa por uma mudança de paradigma do reducionismo para a complexidade, onde a saúde é visualizada sobre a ótica de sistemas complexos, sendo entendida como não linear e subjetiva, e a doença entendida como fenômeno emergente de interações entre diferentes contextos.

Palavras-chave: Complexidade. Reducionismo. Emergência.

Área Temática: Atenção à saúde. 


\title{
IMPACTO DO DIAGNÓSTICO DE LEUCEMIA LINFOIDE AGUDA NA VIDA DO INDIVÍDUO E DOS CUIDADORES
}

\author{
Ane Maryne Rodrigues Fiuza ${ }^{1}$ \\ ${ }^{1}$ UniFG - Centro Universitário FG
}

Introdução: Designa-se como Leucemia Linfoblástica Aguda (LLA), a patologia caracterizada pelo acúmulo de linfoblastos na medula óssea. Trata-se de uma doença maligna, cuja incidência é mais comum na infância, mas atinge, em menor proporção, outras faixas etárias. Em pacientes pediátricos apresenta curabilidade global de $85 \%$, de modo que o prognóstico relaciona-se com o subtipo. Objetivo: Avaliar as principais problemáticas associadas ao diagnóstico de Leucemia Linfoide Aguda nos pacientes e em seus respectivos cuidadores. Metodologia: Trata-se de uma revisão bibliográfica realizada a partir da análise sistemática de publicações disponíveis na Biblioteca Virtual de Saúde (BVS), nos anos compreendidos entre 2016 e 2021. Os descritores utilizados foram Leucemia Linfoide Aguda, família, psicologia e qualidade de vida. Com isso, foram encontrados 5 artigos internacionais, dos quais um foi excluído por não se relacionar diretamente ao tema. Por fim, a amostra restringiu-se a 4 artigos. Resultados: Nota-se que o decorrer dos diferentes estágios da doença impacta e altera as dificuldades e os desafios enfrentados pelos indivíduos com LLA e suas famílias. Constatou-se que a aproximação do Transplante de Células-tronco Hematopoiéticas provoca picos de depressão e ansiedade nos envolvidos. Ademais, destacam-se fatores de sobrecarrega nesse processo, os quais se referem às inúmeras decisões a serem tomadas durante o tratamento e que abrangem benefícios e riscos múltiplos, e às questões geradas pela necessidade de informação, socialização, bem estar físico, mental, econômico e espiritual. Considerações finais: O diagnóstico de leucemia provoca incertezas que ultrapassam as demandas clínico-hospitalares. Assim, o desenvolvimento de ferramentas pelos profissionais de saúde que amparem as necessidades psicossociais é primordial, cabendo uma investigação aprofundada dessa temática.

Palavras-chave: Câncer. Qualidade de vida. Apoio psicossocial.

Área temática: Atenção à Saúde. 


\title{
LEISHMANIOSE TEGUMENTAR: O PAPEL DO VÍRUS DE RNA DE LEISHMANIA 1
}

\author{
Edmilson Pereira Barroso ${ }^{1}$; Ylêdo Fernandes de Menezes Júnior ${ }^{2}$ \\ Universidade Federal do Acre - UFAC ${ }^{1}$, Centro Universitário Uninorte ${ }^{2}$
}

Introdução: A Leishmaniose é uma doença infecciosa que engloba as formas tegumentar, difusa, visceral e mucocutânea. Esta fenotipologia diversa reflete uma relação complexa entre hospedeiro, parasita, fatores ambientais incluindo fatores genéticos, não genéticos e fatores vetoriais. $\mathrm{O}$ exemplo mais proeminente é o Leishmania RNA Virus 1 (LRV1) envolvido na patogênese dos parasitas de Leishmania e detectado até agora em espécies de parasitas do subgênero Leishmania Viannia. Objetivo: Descrever o papel do vírus de RNA de Leishmania (LRV1) no agravamento da Leishmaniose. Metodologia: Realizou-se uma revisão de literatura sistemática por meio de buscas na base Pubmed utilizando "Leishmania RNA vírus 1" na qual foram selecionados 13 artigos em língua inglesa e publicados no período de 2010 a 2020. Resultados: Diante dos estudos, foi demonstrado que o LRV1 presente no citoplasma do parasita Leishmania afeta o agravamento de lesões mucosas e o curso geral da doença, sendo um componente simbiótico, principalmente dos parasitas de Leishamnia da América do Sul. Isso porque, a presença de vírus LRV1 em Leishmania spp. pode levar a diversas complicações, a saber: à hiperinflamação destrutiva, resultando na gravidade da doença, onde o LRV1 em Leishmania spp. pode exacerbar o prognóstico clínico de leishmaniose cutânea e induzir a mucocutânea, bem como, mostraram padrões de resistência à quimioterapia em isolados de Leishmania e provável metástase do parasita. Além disso, estudos recentes demonstram que o principal tipo celular em que os parasitos se replicam é o macrófago, onde modulam diversas vias de sinalização, incluindo aquelas envolvidas na ativação da imunidade inata. Conclusões: De acordo com os resultados encontrados, o Leishmania RNA vírus 1 (LRV1) demonstrou ser um componente simbiótico dos parasitas de Leishmania ssp. e um fator contundente para gravidade da doença.

Palavras-chave: Leishmania. LRV1. Leishmaniose tegumentar.

Área Temática: Atenção à Saúde 


\title{
GESTÃO DE ENFERMAGEM NO CENTRO CIRÚRGICO EM TEMPOS DE PANDEMIA POR COVID-19: UMA REVISÃO INTEGRATIVA
}

\author{
Wanmar de Souza Oliveira ${ }^{1}$, Graciela da Silva Migueis ${ }^{2}$ \\ Universidade Federal de Rondonópolis ${ }^{1}$, Universidade Federal de Rondonópolis ${ }^{2}$
}

Introdução: Diante das adversidades em decorrência da nova pandemia por Covid-19 a gestão de enfermagem dos setores "Centro Cirúrgico" tiveram que adaptar e implementar novos protocolos e diretrizes na prática assistencial aos pacientes suspeitos ou portadores da Covid-19, já que por intermédio dessas condutas pretende-se reduzir o contágio dos profissionais e dos próprios pacientes no pré, trans e pós-cirúrgico. Objetivo: identificar as modificações na gestão de enfermagem ocasionadas pela pandemia da Covid-19 no setor centro cirúrgico. Metodologia: trata-se de uma revisão integrativa realizada entre dezembro de 2020 à janeiro de 2021 em bases eletrônicas Medline, Scopus e Web of Science, tendo como critérios de elegibilidade artigos de pesquisa publicados entre 2019 e 2020, nos idiomas português, inglês e espanhol, disponíveis na íntegra e que respondessem a questão norteadora "Quais as modificações existentes na gestão de enfermagem do centro cirúrgico em tempos de pandemia por Covid-19?". Resultados: foram encontrados 10 estudos, e em sua maioria os artigos expressam que a gestão de enfermagem na pandemia priorizou a organização do ambiente e equipamentos com exclusividade de salas cirúrgicas para o atendimento de pacientes acometidos por Covid-19. Semelhantemente os textos discursam que em decorrência da pandemia, horários prédeterminados foram protocolados para o atendimento desses pacientes, sendo as cirurgias realizadas ao final do dia ou em horários de menor fluxo cirúrgico. Outra modificação citada nos artigos foi à inclusão da sala de triagem e testes rápidos para atendimentos dos pacientes pré-cirúrgicos para identificação de resultados positivos ou negativos para Covid-19. Conclusões: O advento da pandemia pelo novo Covid-19 acarretou no setor de centro cirúrgico inúmeras modificações no que se refere à estruturação, a organização e a reconfiguração da gestão da assistência. Nota-se que agestão da enfermagem em centro cirúrgico foi fundamental com adoção de protocolos e demais ações para prevenção da contaminação por Covid-19.

Palavras-Chave: Centro cirúrgico. Covid-19. Gestão de enfermagem.

Área Temática: Atenção à saúde. 


\section{O PAPEL SOCIAL DA RESIDÊNCIA MULTIPROFISSIONAL EM SAÚDE DO ADULTO E IDOSO: UMA REVISÃO INTEGRATIVA}

\section{Wanmar de Souza Oliveira ${ }^{1}$, Graciela da Silva Migueis ${ }^{2}$}

Universidade Federal de Rondonópolis ${ }^{1}$, Universidade Federal de Rondonópolis ${ }^{2}$

Introdução: Entende-se que as residências multiprofissionais centradas na "Saúde do Adulto e do Idoso" são grandes vivências e oportunidades para a integração das atividades de ensino e pesquisa da pós-graduação, uma vez que incentiva a junção de conhecimentos e experiências multiprofissionais. A residência em saúde do adulto e idoso oportuniza a dualidade da teoria e da prática multiprofissional para lidar com os aspectos biopsicossocioespirituais do processo de adoecimento, favorecendo assim a reestruturação e inovação do cuidado. Objetivo: identificar as atribuições sociais da residência multiprofissional em saúde do adulto e idoso. Metodologia: trata-se de uma revisão integrativa realizada no mês de janeiro de 2021 nas bases de dados eletrônicas Medline, Scopus e Web of Science, tendo como critérios de elegibilidade artigos de pesquisa publicados entre janeiro de 2017 e janeiro de 2021, nos idiomas português, inglês e espanhol, disponíveis na íntegra e que respondessem a questão norteadora: "Qual o papel social da residência multiprofissional em saúde do adulto e idoso?”. A amostra final da revisão integrativa foi composta de 05 estudos. Resultados: os artigos explicitam que a residência multiprofissional em saúde do adulto e idoso amplia o acesso a serviços de saúde para essa biocenose adulta e idosa, aprimora os indicadores de saúde das populações atendidas pelos residentes e, além disso, possibilita reestruturar a atenção ao paciente, de maneira que dinamiza uma assistência mais assertiva, humanizada e holística, se distanciando do modelo biomédico. Conclusões: é possível concluir que a residência multiprofissional em saúde do adulto e idoso exerce papel social de potencializar a promoção de um cuidado humanizado, holístico e especifico para a população destinada, de maneira igual à mesma visa à assistência de cuidado para alcançar a excelência com interação mais efetiva entre residentes e sociedade.

Palavras-Chave: Enfermagem. Equipe multiprofissional. Saúde do adulto e idoso.

Área Temática: Atenção à saúde. 


\title{
FATORES RELACIONADOS AO DÉFICIT DE COMUNICAÇÃO SETORIAL ENTRE RESIDENTES MULTIPROFISSIONAIS: UMA REVISÃO INTEGRATIVA
}

\author{
Wanmar de Souza Oliveira ${ }^{1}$, Graciela da Silva Migueis ${ }^{2}$
}

Universidade Federal de Rondonópolis ${ }^{1}$, Universidade Federal de Rondonópolis ${ }^{2}$

Introdução: Comunicar é algo natural e cotidiano para todos, seja através da linguagem verbal expressa pela fala, escrita e pela não-verbal por meio de gestos, desenhos e outras maneiras. O ato de comunicar junto à equipe multiprofissional torna-se um importante pilar para um cuidado humanizado e de qualidade, entretanto muitas vezes não ocorre de maneira eficaz e assertiva, prejudicando a garantia do cuidado centrado ao paciente. Objetivo: identificar os fatores que influenciam na comunicação setorial efetiva de residentes multiprofissionais. Metodologia: trata-se de uma revisão integrativa realizada entre janeiro e fevereiro de 2021, nas bases de dados Medline, Scopus e Web of Science, tendo como critérios de elegibilidade artigos de pesquisa publicados entre 2017 até janeiro de 2021, nos idiomas português, inglês e espanhol, disponíveis na íntegra e compatíveis ao objetivo geral da pesquisa. A amostra final da revisão integrativa foi de 10 artigos após diversas leituras. Resultados: os textos explicitam que os principais fatores que influenciam na comunicação setorial entre residentes multiprofissionais são: diferenças hierárquicas, em que o poder e conflitos afetam diretamente na qualidade da assistência, fazendo com que as categorias profissionais atuem em paralelo em detrimento do trabalho em equipe; a diversidade na formação dos profissionais, na qual a habilidade de comunicação não é desempenhada da mesma maneira, a tendência de uma mesma categoria profissional se comunicar mais uns com os outros e a própria fragmentação do cuidado em saúde que ainda pode ser observada pela hegemonia do modelo biomédico. Conclusões: São inúmeros os fatores que afetam direta ou indiretamente a comunicação assertiva intersetorial de multiprofissionais residentes, o que dificultam o compartilhamento de informações, decisões e consequentemente a qualidade do cuidado. Nesse sentido, é imperativo favorecer a efetividade da comunicação e melhorar vínculos entre os profissionais de saúde/residentes para uma adequada qualidade na assistência de cuidado.

Palavras-Chave: Comunicação. Residência. Intersetorial.

Área Temática: Atenção à saúde. 


\title{
MEDIDAS DE CONFORTO A PACIENTES CRÍTICOS: UMA REVISÃO INTEGRATIVA
}

\author{
Washington Júnio Oliveira ${ }^{1}$, Meg Caroline do Couto ${ }^{2}$, Michele Salles da Silva ${ }^{3}$ \\ ${ }^{1,2}$ Residente do Programa de Residência Multiprofissional em Saúde do Idoso/Universidade \\ Federal de Rondonópolis, ${ }^{3}$ Docente do Curso de Enfermagem e do Programa de Residência \\ Multiprofissional em Saúde do Idoso/Universidade Federal de Rondonópolis
}

Introdução: A internação em Unidades de Terapia Intensiva (UTI) predispõe a ideia de gravidade associada com a morte. Sentimentos negativos e agravos físicos são comuns aos pacientes críticos submetidos ao tratamento intensivo, dificultando sua recuperação e prorrogando a reabilitação e alta. Assim, a equipe de saúde precisa estar preparada para promover o conforto e alívio, reduzindo agravos associados a permanência nas UTI. Objetivo: Compreender a importância da aplicação de 'medidas de conforto e identificar as principais formas de promoção utilizadas em pacientes internados em Unidades de Terapia Intensiva. Metodologia: Trata-se de uma revisão integrativa fundamentada na questão norteadora: "Qual a importância e as formas de ofertar conforto aos pacientes críticos?". Realizada por meio de artigos publicados entre 2016 e 2021, em português, nos bancos de dados Bireme e Scielo pautado nos descritores: "Segurança do paciente" e "Cuidados de enfermagem". Resultados: Os estudos evidenciam a oferta do conforto como uma ação essencial para a saúde, ao promover a melhora do prognóstico dos pacientes. Destacando que os sujeitos do cuidado podem ser influenciados a desenvolverem hábitos que promova a saúde. Diversos autores evidenciam formas de conforto por meio da promoção do alívio, da calma e trabalhando aspectos psicossociais e espirituais. Dentre as formas de execução mais citadas estão as orientações aos pacientes acerca de sua condição de saúde e dos cuidados necessários; fortalecimento do vínculo com a equipe e familiares; ambientação adequada diante dos ruídos e distração; atenção voltada as necessidades físicas; arrumação do leito; troca de roupas; posicionamento adequado no leito e alívio da dor. Conclusões: A promoção e aplicação de medidas de conforto em UTI fortalece processo de recuperação dos pacientes críticos. Trata-se de uma ação da equipe de enfermagem que se fundamenta nos princípios da segurança do paciente, proporcionando a melhoria da qualidade da assistência à saúde.

Palavras-chave: Segurança do Paciente. Cuidados de enfermagem. Conforto do Paciente.

Área Temática: Atenção à saúde. 


\title{
MORBIDADE HOSPITALAR POR ANEMIA FERROPÊNICA NO ESTADO DO ACRE
}

\author{
Antonia Tasmyn Mesquita de Melo ${ }^{1}$, Carlos Eduardo Rocha da Costa ${ }^{2}$, Debora da Silva Fraga \\ ${ }^{3}$, Eder Ferreira de Arruda ${ }^{4}$
}

${ }^{1}$ Centro Universitário UNINORTE

Introdução: A anemia ferropênica ou ferropriva decorre da baixa biodisponibilidade de ferro $\left(\mathrm{Fe}^{+}\right)$ no organismo ocasionando uma redução na produção, dimensão e composição das moléculas de hemoglobina nos eritrócitos, sendo considerada uma importante deficiência nutricional e um problema de saúde pública persistente em todo o mundo. Objetivo: Descrever o perfil das internações por anemia ferropriva no estado do Acre durante o ano de 2019. Metodologia: Foi realizado um estudo descritivo, do tipo transversal, com abordagem quantitativa a partir de dados do Sistema de Informações Hospitalares (SIH) que se encontravam disponíveis no site do Departamento de Informática do Sistema Único de Saúde (DATASUS) durante o mês de março do ano de 2021. Os dados foram analisados por meio do programa Microsoft ${ }^{\circledR}$ Office Excel 2016, no qual foram calculadas as frequências absolutas e relativas das variáveis de interesse. Resultados: No estado do Acre, no ano de 2019, foram registrados 174 casos de hospitalizações por anemia ferropriva, sendo que $62,6 \%$ dessas internações ocorreram na cidade de Rio Branco e a maior taxa de morbidade hospitalar foi evidenciada no município de Xapuri com 5,69 casos a cada 10.000 habitantes. A maioria das internações ocorreu entre homens (60,1\%), indivíduos na faixa etária de 30 a 49 anos $(24,1 \%)$ e da cor/raça parda (29,9\%). Considerações Finais: É necessário estabelecer ações e medidas de educação em saúde, estimular a suplementação de ferro e a capacitar as equipe de atenção básica em saúde para a identificação precoce dos indivíduos em situação de insegurança alimentar e risco nutricional.

Palavras-chave: Deficiências Nutricionais. Ferro. Hospitalização.

Área Temática: Atenção à saúde. 


\section{PERFIL DA MORTALIDADE NEONATAL NO ESTADO DO ACRE}

\section{Antonia Tasmyn Mesquita de Melo ${ }^{1}$, Carlos Eduardo Rocha da Costa ${ }^{2}$, Debora da Silva Fraga ${ }^{3}$, Eder Ferreira de Arruda ${ }^{4}$}

${ }^{1}$ Centro Universitário UNINORTE

Introdução: A mortalidade neonatal corresponde ao óbito ocorrido nos primeiros 28 (vinte oito) dias de vida, pode ser precoce ou tardia e se constitui como um indicador da qualidade da assistência em saúde materno-infantil da população. Objetivo: Descrever o perfil da mortalidade neonatal no estado de Acre no ano de 2018. Metodologia: Trata-se de um estudo transversal que foi realizado a partir de dados disponíveis no Sistema de Informação sobre Mortalidade (SIM) e no Sistema de Informações sobre Nascidos Vivos (SINASC) no site do Departamento de Informática do Sistema Único de Saúde (DATASUS) durante o mês de março de 2021. Os dados foram analisados no programa Microsoft ${ }^{\circledR}$ Office Excel 2016, no qual foram calculadas as taxas de mortalidade neonatal (TMN) e as frequências das variáveis estudadas. Resultados: No Acre, em 2018, foi observado um total de 177 óbitos neonatais, sendo que a maior proporção das mortes ocorreu na cidade de Rio Branco (34,5\%). A taxa de mortalidade neonatal geral no estado foi de 10,7 a cada 1.000 nascidos vivos, tendo Feijó apresentado a maior taxa por município (20,4/1.000 nascidos vivos). Dentre os óbitos, $75,7 \%$ ocorreram na fase precoce e $24,3 \%$ na fase tardia, principalmente, entre neonatos do sexo masculino (58,0\%), pardos (54,2\%), em ambiente hospitalar (92,1\%) e por causas reduzíveis pela adequada atenção ao recém-nascido (27,8\%). Considerações Finais: A taxa de mortalidade neonatal no Acre foi elevada, assim necessitando de ações e medidas que promovam expressivas reduções desse indicador por meio ao aumento do acesso das mulheres aos serviços de saúde materno-infantil.

Palavras-chave: Óbito. Recém-Nascido. Saúde Materno-Infantil.

Área Temática: Atenção à saúde. 


\section{ATUAÇÃO DO NUTRICIONISTA NA ONCOLOGIA - UMA REVISÃO DE \\ LITERATURA}

\section{Marcos Rodrigo Guimarães Cruz ${ }^{1}$}

${ }^{1}$ Faculdade Única;

Introdução: Atualmente, câncer é o nome geral dado a um conjunto de mais de 100 doenças, que têm em comum o crescimento desordenado de células que tendem a invadir tecidos e órgãos vizinhos. A nutrição tem papel de destaque tanto na prevenção quanto no tratamento do câncer. É atribuição privativa do nutricionista prestar assistência nutricional e dietoterápica. Metodologia: $\mathrm{O}$ presente artigo tem como objetivo realizar um levantamento bibliográfico sobre a atuação do nutricionista na oncologia. O artigo constitui-se de uma revisão de literatura especializada, publicada nos anos de 2005 até 2016. As bases de dados consultadas foram Biblioteca Eletrônica Científica Online (SCIELO), Sistema Online de Busca e Análise de Literatura Médica (MEDLINE), Literatura Latino-Americana e do Caribe em Ciências da Saúde (LILACS), livros e publicações legislativas da profissão. Tendo como critérios de inclusão os artigos científicos com as palavras-chave "Oncologia", "Câncer", "Terapia nutricional”, "Assistência nutricional na Oncologia”. Resultado: A análise dos artigos selecionados demonstrou a importância do profissional nutricionista na área de oncologia. As atividades encontradas vão desde admissão hospitalar, terapia nutricional individualizada, preparação da alta ao seguimento ambulatorial. Considerações finais: Sendo assim, observa-se que o profissional nutricionista está qualificado para ajudar a minimizar os impactos nutricionais, durante as fases da doença e tratamento. O acompanhamento clínico-nutricional permite que o paciente tenha um organismo tão saudável quanto possível através de uma dieta equilibrada e personalizada, seja ela via oral ou não, diminuindo desconfortos que podem surgir na realização da alimentação devido aos efeitos colaterais e atrelados à assistência médica, aumentando-se assim consideravelmente as chances de eficácia dos tratamentos instituído.

Palavras-chave: Assistência. Saúde coletiva. Terapia nutricional.

Área Temática: Atenção à Saúde. 


\section{AROMATERAPIA: UTILIZAÇÃO E BENEFÍCIOS NA SAÚDE DO IDOSO}

\section{Rubens Barbosa Rezende}

Faculdade Santa Rita (FASAR), Conselheiro Lafaiete, Minas Gerais

Introdução: A aromaterapia é uma técnica caracterizada pelo uso intencional de óleos essenciais no intuito de proporcionar o bem-estar do indivíduo. No Brasil, essa técnica está inserida nas Práticas Integrativas e Complementares em Saúde e possui uma ampla utilização coletiva e/ou individual. Objetivo: Compreender e discutir o uso e benefícios oriundos da aromaterapia na saúde do idoso. Metodologia: Trata-se de uma revisão integrativa da literatura nas bases de dados SciELO e PubMed, utilizando como questão norteadora: "Quais são os benefícios do uso da aromaterapia na saúde do idoso?" A busca foi feita utilizando os descritores: "aromaterapia", "idoso" e "atenção à saúde", cadastrados no DeCS/MeSH e empregando o operador booleano AND. Os critérios de inclusão foram: artigos completos, disponibilizados de forma gratuita, publicados em inglês, espanhol e português, entre janeiro de 2010 a fevereiro de 2021. Resultados: Foram encontrados 15 artigos, sendo seis na base de dados SciELO e nove na PubMed, e selecionados 10 para compor essa revisão. A literatura reporta que a utilização de óleos essenciais auxilia na obtenção do bem-estar do paciente, eleva os níveis do sistema imune, restaura o equilíbrio, auxilia no tratamento da depressão e da cicatrização, como também na minimização de manchas corporais, estresse e sensação de dor. Além disso, o uso da técnica para alívio da dor em idosos, teve como resultado a eficácia na sua diminuição, melhora da autoestima e da qualidade de vida deles, bem como a redução dos sintomas comportamentais e neuropsiquiátricos. Considerações finais: Portanto, a aromaterapia se demonstrou eficaz e foi um meio utilizado para o alívio da dor e a melhora na autoestima, bem como está associada na manutenção e preservação da saúde. Porém, são necessários mais estudos voltados a utilização desta técnica em especial na população idosa, uma vez que se tem uma limitação de exemplares publicados.

Palavras-chave: Atenção à Saúde. Serviços de Saúde para Idosos. Terapias Complementares.

Área Temática: Atenção à Saúde. 


\section{PESSOA FERIDA: UMA VISÃO INTEGRAL AO PORTADOR DE LESÃO}

\section{Fernanda dos Santos Almeida ${ }^{1}$}

${ }^{1}$ Enfermeira da comissão de cuidados com a pele e curativos da clínica médica do Hospital Evangélico

Introdução: O paciente no ambiente hospitalar é assistido por uma equipe multidisciplinar, onde cada profissional contribui através de sua área de atuação para a recuperação do paciente assistido. $\mathrm{O}$ paciente portador de lesão requer atenção específica à lesão, nutrição, mobilidade, acompanhamento clínico e exames laboratoriais. Objetivo: Descrever a assistência de enfermagem ao paciente portador de lesão em uma clínica médica. Metodologia: Trata-se de um trabalho descritivo, do tipo relato de experiência em uma clínica médica ao paciente portador de lesão durante o ano de 2021. Resultados: A comissão de cuidados com a pele e curativo traça conduta para o tratamento de lesões de pacientes internados na clínica médica e interage com todos os profissionais envolvidos no cuidado ao paciente. Destacamos o caso do acompanhamento a uma paciente idosa, portadora de lesão por pressão categoria 3 em região sacra com presença de tecido de granulação em fundo de lesão e pouca quantidade de tecido desvitalizado em bordo, sem presença de secreção e odor característico. Durante sua internação em 24 horas a lesão evoluiu com isquemia e regiões de necrose. Conferido a nutrição, mobilidade, mudança de decúbito e conduta do curativo. Checado os exames laboratoriais no qual foi evidenciado quadro de anemia severa. Sinalizado o achado clínico a equipe multidisciplinar. Paciente recebeu um concentrado de hemácias e em 48 horas foi possível visualizar melhora das regiões de isquemia. Conclusões: Esse relato de experiência contribui para a discussão da importância da visão integral ao paciente portador de lesão. Sendo a clínica do paciente de suma importância na evolução da lesão. Buscando constantemente a discussão de casos com a equipe multidisciplinar e o acesso a resultados de exames, caso um profissional não consiga identificar uma alteração outro possa realizalo. Pois cuidamos de uma pessoa ferida e não somente de uma lesão.

Palavras-chave: Assistência. Enfermagem. Lesões.

Área Temática: Atenção à saúde 


\title{
CONTRIBUIÇÕES DOS RESIDENTES NOS SERVIÇOS DE SAÚDE: UMA RESVISÃO INTEGRATIVA
}

\section{Washington Júnio Oliveira ${ }^{1}$, Meg Caroline do Couto ${ }^{2}$, Michele Salles da Silva ${ }^{3}$}

\author{
${ }^{1,2}$ Residente do Programa de Residência Multiprofissional em Saúde do Idoso/Universidade \\ Federal de Rondonópolis, ${ }^{3}$ Docente do Curso de Enfermagem e do Programa de Residência \\ Multiprofissional em Saúde do Idoso/Universidade Federal de Rondonópolis
}

Introdução: O Programa de Residência Multiprofissional em Saúde (PRMS) é um espaço de formação profissional realizado através do trabalho em saúde na perspectiva do Sistema Único de Saúde (SUS) visando o fortalecimento da multiprofissionalidade. Trata-se de uma iniciativa que concretiza a cooperação intersetorial aproximando as instituições de ensino e os serviços de saúde, estimulando competências que integram a assistência, a gestão e a pesquisa, em prol da melhoria da qualidade do serviço. Objetivo: Descrever as contribuições da Residência Multiprofissional em Saúde para os serviços de saúde no contexto hospitalar. Metodologia: Revisão integrativa realizada a partir da questão norteadora: "Quais as contribuições da residência multiprofissional para a melhoria assistencial?". Possuindo como critério de inclusão: estudos publicados entre 2016 e 2021, disponíveis na integra, com títulos que tenham referência ao cruzamento das palavras-chaves disponíveis no DeCS/MeSH, nos bancos de dados da Pub Med, Bireme e Scielo. Resultados: A partir da atuação dos residentes nos serviços de saúde e possível evidenciar que diversos estudos destacam contribuições capazes de influenciar melhorias no cuidado. Dentre elas, a possibilidade de troca de saberes por meio do trabalho colaborativo, a ampliação do cuidado prestado aos usuários por meio do trabalho multiprofissional possibilitando uma assistência ampliada através de olhares holísticos, uma maior rotina de educações permanentes e continuadas, a criação e atualização de protocolos e melhor dimensionamento do serviço. Considerações finais: Desta forma, durante seu processo de formação os profissionais vinculados aos PRMS aprimoram sua forma de observar e de conhecer as práticas assistenciais e consequentemente contribuem para a melhoria dos serviços de saúde e das práticas de cuidado, com a perspectiva do trabalho multiprofissional. Neste sentido é possível construir estratégias que fortaleçam o sistema de saúde de acordo com a realidade local para a resolução dos problemas de saúde da população.

Palavras-chave: Residência hospitalar. Equipe multiprofissional. Formação Profissional em Saúde. Área Temática: Atenção à saúde. 


\title{
COMPORTAMENTO SUICIDA NO TRANSTORNO DE PERSONALIDADE BORDERLINE
}

\section{Ilana de Souza Cavalcanti ${ }^{1}$, Maria Clara Lima Cavalcanti ${ }^{1}$, Thialle Roberta da Silva Cruz $^{1}$}

\author{
${ }^{1}$ Centro Universitário Maurício de Nassau, Recife
}

Introdução: Segundo o DSM-5 o Transtorno de personalidade Borderline (TB) é caracterizado por um padrão de instabilidade das relações interpessoais, da autoimagem, dos afetos e de impulsividade acentuada que surge no início da vida adulta, estando presente em vários contextos. Um desses contextos usados como critério diagnóstico dá-se pela reincidência de comportamentos ou ameaças suicidas. A maneira pela qual esses fatores interagem para causar suicídio ou comportamento suicida em sentido amplo é complexa e frequentemente mal compreendida. Porém, a população afetada por TB sempre precisa ser considerada em sua maior vulnerabilidade por se tratar de indivíduos com índices de comportamentos suicidas acima da média. Objetivo: Compilar achados presentes na literatura cientifica sobre o comportamento suicida no TB. Metodologia: O trabalho foi elaborado no segundo semestre de 2020 em formato de revisão de literatura. Os dados foram retirados da base de dados Scielo. Resultado: O comportamento suicida é frequente em pacientes com Borderline; pelo menos três quartos desses casos apresentam história de tentativa de suicídio e aproximadamente 8 a $10 \%$ conseguem o êxito, ainda vivenciando ameaças e tentativas de suicídio, as quais passam a ser muito comuns os atos de automutilação e a ideação suicida recorrente por vezes funcionam como a razão de base para que essas pessoas busquem ajuda profissional. Pacientes com maior risco de comportamento suicida incluem aqueles com tentativas anteriores, transtorno depressivo comórbido ou transtorno por uso de substâncias. Conclusão: Conclui-se, que baseado na literatura cientifica atual faz-se necessário considerar e estudar o elevado índice de vulnerabilidade de indivíduos que possuem o Transtorno de Personalidade Borderline em relação ao suicídio, visando um maior cuidado e prevenção.

Palavras-chave: Comportamento Autodestrutivo. Tentativa de suicídio. Prevalência.

Área temática: Atenção à Saúde 


\title{
CONHECIMENTOS DE HOMENS SOBRE A SÍFILIS PRIMÁRIA
}

\author{
Antonia Tasmyn Mesquita de Melo ${ }^{1}$, Carlos Eduardo Rocha da Costa $^{1}$, Debora da Silva \\ Fraga $^{1}$, Daniel Brito de Souza ${ }^{1}$, Eder Ferreira de Arruda ${ }^{1}$ \\ ${ }^{1}$ Centro Universitário UNINORTE, Rio Branco - Acre.
}

Introdução: A sífilis é uma infecção sexualmente transmissível que possui diferentes estágios (sífilis primária, secundária, latente e terciária) e se configura como um importante e persistente problema de saúde pública. Objetivo: Identificar o nível de conhecimento de homens sobre a sífilis primária. Metodologia: Trata-se de um estudo transversal envolvendo 55 homens atendidos em uma unidade básica de saúde da cidade de Rio Branco, Acre e foi realizado por meio da aplicação de um questionário sobre as características sociodemográficas e referente aos conhecimentos dos participantes acerca de aspectos relacionados à sífilis primária. Os dados foram digitados e revisados no programa Microsoft ${ }^{\circledR}$ Office Excel 2016 e analisados no programa estatístico Statistical Package for the Social Sciences (SPSS), versão 20.0, no qual foram calculadas as frequências absolutas e relativas de acordo com variáveis de interesse. Resultados: Observou-se que 38,2\% dos homens estavam na faixa etária de 18 a 24 anos, 61,9\% tinham cursado ou cursavam o ensino médio, 65,5\% eram da cor parda, $63,6 \%$ possuíam trabalho remunerado e $63,3 \%$ detinham renda familiar de até um salário mínimo mensal, sendo que 51,0\% conheciam as formas de transmissão da infecção, 60,0\% não tinham informações adequadas acerca da sintomatologia, 72,8\% desconheciam sobre as formas de tratamento e $63,6 \%$ tiveram dificuldades em reconhecer as principais medidas preventivas frente à sífilis primária. Considerações finais: De modo geral, os homens apresentaram um conhecimento inadequado, sobretudo aspectos relacionados à sintomatologia, tratamento e medidas de prevenção da sífilis primária. Portanto, são necessárias ações direcionadas para prevenção e controle da doença, sendo fundamental que o público masculino receba informações adequadas para que compreendam sobre a importância da prática sexual segura, do autocuidado, do diagnóstico precoce e tratamento eficaz da sífilis no intuito de reduzir a ocorrência de novos casos.

Palavras-chave: Acesso à Informação; Infecções por Treponema; Saúde do Homem.

Área Temática: Atenção à saúde. 


\section{MANUSEIO DO CATETER TOTALMENTE IMPLANTADO: \\ RELATO DE EXPERIÊNCIA EM UM SETOR DE QUIMIOTERAPIA}

\section{Fernanda dos Santos Almeida}

Enfermeira. Residente de enfermagem clínica e cirúrgica da Universidade Federal do Estado do Rio de Janeiro (2019)

Introdução: $O$ cateter venoso central totalmente implantado é uma alternativa na oncologia para o tratamento dos pacientes, garantindo segurança na administração de medicamentos endovenosos em longo prazo. O residente de enfermagem no setor de quimioterapia tem a oportunidade de realizar o manuseio do cateter e realizar orientações de cuidados ao paciente. Objetivo: Descrever a experiência durante a residência de enfermagem na assistência ao paciente com cateter venoso central totalmente implantado no setor de quimioterapia de um hospital federal do Rio de Janeiro. Metodologia: Trata-se de um estudo descritivo, do tipo relato de experiência, mediante assistência ao paciente oncológicos. Resultados: Na sala de quimioterapia, o enfermeiro residente desenvolve competências práticas com o paciente oncológico. Dentre estas, se destaca o manuseio do cateter venoso central totalmente implantado que é realizado por meio da punção do epicentro do catéter, utilizando a agulha (tipo huber). Assim como, administração de quimioterápicos, colocação e retirada de bomba de infusão contínua, coleta de amostras de sangue para exames laboratoriais e a manutenção programada do cateter. $\mathrm{O}$ dispositivo é considerado seguro e de longa permanência. Por isso, o profissional deve executar corretamente a técnica de manuseio, proporcionando diminuição da possibilidade de ocorrência de infecções e obstruções. Conclusões: A atuação do enfermeiro residente no setor de quimioterapia proporciona o conhecimento teórico prático com o paciente oncológico em uso de cateter totalmente implantado. Assim como, identificar, prevenir e tratar as possíveis complicações decorrentes do manuseio. Tais práticas que contribuem para a qualidade de vida do paciente e do tempo útil do dispositivo.

Palavras-chave: Enfermagem. Assistência. Oncologia.

Área Temática: Atenção à saúde 


\title{
A RESIDÊNCIA MULTIPROFISSIONAL NAS AÇÕES DE VIGILÂNCIA EM SAÚDE NO MUNICÍPIO DE CURRAIS NOVOS/RN
}

\author{
Maria Rita Garcia de Medeiros ${ }^{1}$, Taysa Rayane Lucas de Paiva², Johny da Silva Diniz ${ }^{3}$ \\ ${ }^{123}$ Escola Multicampi de Ciências Médicas/Universidade Federal do Rio Grande do Norte
}

Introdução: Em virtude do aumento de casos da covid-19 a nível mundial, a Organização Mundial da Saúde (OMS) declarou estado de pandemia na data 11 de março de 2020. A chegada do coronavírus no Brasil levou as autoridades sanitárias, de esfera federal, estadual e municipal, mobilizar ações e medidas preventivas a fim de evitar a propagação do vírus. A Secretaria Municipal de Saúde de Currais Novos, interior do Rio Grande do Norte $(\mathrm{RN})$, em conjunto com a Residência Multiprofissional em Atenção Básica realizaram ações preventivas em pontos estratégicos do município. Objetivo: Relatar a experiência dos residentes multiprofissionais nas ações vigilância em saúde para a prevenção da covid-19. Metodologia: Trata-se de um relato de experiência acerca da atuação dos residentes multiprofissionais no ano de 2020 nas ações de vigilância em saúde, voltadas para o contexto de pandemia no município de Currais Novos/RN. Resultados: No início da pandemia houve a suspensão de ações multiprofissionais em grupos e atendimentos eletivos nas Unidades Básicas de Saúde (UBS's). Logo, os residentes alocados nas UBS's, em 2020, foram redirecionados para atuarem em outros dispositivos, como a Vigilância em Saúde, que precisava de recursos humanos para as ações no município. Foram estruturadas equipes com residentes e profissionais da rede de saúde para fiscalizarem estabelecimentos, como bancos, lotéricas, supermercados e comércios no intuito de dispersar as aglomerações de pessoas, orientá-las quanto ao uso correto de máscaras, álcool 70\% e a importância do distanciamento social. Além disso, máscaras de tecidos foram distribuídas à população. Conclusões: Pode-se dizer, portanto, que as ações de prevenção da covid-19 proporcionaram diálogo e reflexão uma vez que a maioria das pessoas abordadas se mostrava interessadas às informações repassadas. Apesar de haver resistência por parte de alguns comerciantes, os cuidados sanitários logo foram intensificados. Ademais, a experiência demonstrou a relevância do trabalho colaborativo e interprofissional.

Palavras-chave: Covid-19. Prevenção. Equipes de Saúde.

Área Temática: Atenção à Saúde. 


\title{
SALA DE SITUAÇÃO EM SAÚDE VOLTADA PARA A COVID-19 NUM MUNICÍPIO DO SERIDÓ POTIGUAR: RELATO DE EXPERIÊNCIA
}

\author{
Taysa Rayane Lucas de Paiva ${ }^{1}$, Johny da Silva Diniz ${ }^{2}$, Maria Rita Garcia de Medeiros ${ }^{3}$ \\ ${ }^{123}$ Escola Multicampi de Ciências Médicas/Universidade Federal do Rio Grande do Norte
}

Introdução: Devido à alta taxa de transmissão do coronavírus, no dia 11 de março de 2020 a Organização Mundial de Saúde (OMS) decretou a COVID-19 como uma pandemia e desde então, o país necessitou buscar estratégias para seu enfrentamento. Nesse sentido, a Vigilância Epidemiológica (VE) assume um papel fundamental, pois busca detectar mudanças nos fatores determinantes e condicionantes da saúde individual e coletiva, com a finalidade de adotar medidas de prevenção e controle das doenças. Assim, a Sala de Situação em Saúde (SDSS), que tem como objetivo reunir dados e analisá-las para subsidiar tomadas de decisão, torna-se uma ferramenta importante ao fornecer informações oportunas e qualificadas aos gestores. No caso deste relato, foi implantada pelos profissionais da Residência Multiprofissional e a VE especificamente para o acompanhamento de informações acerca do comportamento do coronavírus num município do Seridó potiguar. Objetivo: Relatar a experiência de implantação de uma Sala de Situação em Saúde voltada para a COVID-19, no município de Currais Novos - RN. Metodologia: A SDSS foi implantada num espaço físico na Secretaria Municipal de Saúde, no setor de Vigilância Epidemiológica. Foi criada uma planilha online, alimentada diariamente com notificações dos casos positivos, acessados por meio do sistema nacional de notificações e-SUS VE, com dados pessoais, data de início de sintomas, etc. Resultados: Através dessa sistematização, foi possível acompanhar o perfil epidemiológico do coronavírus em Currais Novos-RN e partir disso direcionar a execução de ações como por exemplo, a realização de educação em saúde em lugares estratégicos, fiscalização e a produção de boletins epidemiológicos expandidos, visando a efetiva transparência das informações para a população. Conclusões: A SDSS se mostrou uma ferramenta de suma importância ao subsidiar um melhor planejamento e orientação para medidas de prevenção e controle e dessa forma conter a desenfreada propagação do vírus.

Palavras-chave: Pandemia. Vigilância Epidemiológica. Prevenção.

Área Temática: Atenção à Saúde 


\title{
ATUAÇÃO DO NUTRICIONISTA NO SUS
}

\section{Andressa Almeida Barbosa'; Lauany Maria dos Santos Barreto ${ }^{2}$}

\author{
Universidade Federal de Campina Grande, Cuité, Paraíba ${ }^{1 ; 2}$
}

Introdução: O SUS é uma união de serviços e ações de saúde prestados de forma gratuita e pública, por órgãos e instituições. Alusivo a essa união, o nutricionista desempenha cuidados com relação a alimentação, promovendo proteção, prevenção e tratamento, associados as ações de atenção à saúde do SUS, para toda a população. Proporcionando uma rede integrada e humanizada de cuidados. Objetivo: Entender as formas de atuação e a importância do nutricionista, no Sistema Único de Saúde. Metodologia: Essa revisão de literatura foi composta por artigos científicos encontrados nas bases de dados Pubmed, Lilacs, Scielo e no Ministério da Saúde, publicados entre 2013 a 2019. Resultados: Segundo a PNAN (Política Nacional de Alimentação e Nutrição), a participação efetiva do nutricionista no SUS é fundamental para garantir atenção básica resolutiva para prevenção e cuidado de patologias e implementação da linha de cuidado dessa afecção, para assim organizar e fortalecer a atenção nutricional na média e alta complexidade, ajudando na prevenção e controle das carências nutricionais e desnutrição em povos e comunidades tradicionais e por fim, disseminar e inserir o componente de nutrição nas diversas políticas do Ministério da Saúde, entretanto a realidade econômica brasileira dificulta essa ação. Conclusões: Portanto, é de suma importância e necessária a atuação do nutricionista para uma melhor promoção da saúde, com base em políticas públicas relacionadas com alimentação e nutrição. Além disso, uma relação interdisciplinar e multiprofissional com outros profissionais da saúde para uma adequada atenção nutricional, que possibilita o nutricionista desempenhar o papel de protagonista, indutor e qualificador de práticas a incorporação da alimentação como um direito social.

Palavras-chave: Promoção da Saúde; Prevenção; Desnutrição.

Área Temática: Atenção à Saúde. 


\section{A CONTRIBUIÇÃO DOS ALIMENTOS FUNCIONAIS PARA O TRATAMENTO DO DIABETES MELLITUS TIPO 2}

\section{Gleidison Andrade Costa ${ }^{1}$}

${ }^{1}$ Secretraria de Estado da Saúde do Maranhão (SES-MA);

Introdução: o diabetes mellitus tem sido colocada como epidemia do século XXI, sendo umas das principais causas de óbito nas sociedades desenvolvidas. Os alimentos funcionais despontam como importantes "ferramentas" no seu gerenciamento. Entende-se que para um alimento ser considerado funcional, ele deve além de possuir as funções nutritivas básicas; consumidos como parte de uma dieta frequente, cause efeitos tanto metabólicos quanto fisiológicos e até mesmo benefícios para a saúde, sendo seguro para o consumo sem acompanhamento médico. Objetivo: demonstrar a contribuição dos alimentos funcionais para o tratamento do diabetes mellitus tipo 2 (DM2). Metodologia: abordagem qualitativa, com natureza básica, de objetivo descritivo e com procedimento bibliográfico. Foram consultados livros, teses, dissertações, notícias, vídeos, artigos. $\mathrm{Na}$ buscar online, consultou-se fontes confiáveis de pesquisa, como: Biblioteca Virtual de Saúde (BVS), Scientific Electronic Library Online, Literatura Latino-Americana e do Caribe em Ciências da Saúde expressos por textos completos e diretrizes publicadas pelo Ministério da Saúde (MS). Resultados: percebeu-se que os alimentos funcionais contêm ingredientes biologicamente ativos associados a benefícios fisiológicos à saúde para prevenir e gerenciar doenças crônicas, como a DM 2. Um consumo regular de alimentos funcionais está associado a funções antioxidantes, antiinflamatórias, sensíveis à insulina e anticolesterol, que são consideradas essenciais para prevenir e modular a doença já citada. Considerações finais: para subsidiar o valor dos alimentos funcionais no tratamento do DM II, pontuou-se sobre os seus aspectos conceituais, epidemiológicos e bioquímicos; descreveu-se os alimentos funcionais e os seus benefícios; evidenciou-se a importância do apoio profissional prestado ao consumo de alimentos funcionais e ações direcionadas à gestão do DM2. Cabe ressaltar que, os componentes biotativos presentes nos alimentos funcionais fazem parte da terapia nutricional no DM II e podem ser efetivamente adotados como parte de um modelo integrado, individualizado e localizado, inserindo no contexto de estratégias comportamentais, bioquímicas, nutricionais e fisiológicas.

Palavras-chave: Nutrição; Saúde; Modulação glicêmica.

Área Temática: Atenção à Saúde. 


\section{GRUPO ANTITABAGISMO: VIVÊNCIA EM UMA UNIDADE DE SAÚDE DA FAMÍLIA NA PRÁTICA DA RESIDÊNCIA MÉDICA}

\section{Pollyana Leite ${ }^{1}$, Ailma de Sousa Barbosa ${ }^{2}$, Carolina Carvalho Nogueira ${ }^{3}$, Fabíola Moreira Casimiro de Oliveira ${ }^{4}$, Joyce Lane Braz Virgolino ${ }^{5}$, Veronica Ebrahim Queiroga ${ }^{6}$}

1;2;3;4;5;6 Secretaria Municipal de Saúde de João Pessoa - Paraíba (SMS - PB)

Introdução: O tabagismo é um mal hábito comum, especialmente entre os homens que geral e historicamente tem baixa adesão ao serviço de saúde, por isso o trabalho em grupo pode promover a saúde da população masculina. Objetivo: Trata-se de relato de vivência dos autores no processo de construção do grupo para oferta do antitabagismo aos homens na Atenção Primária à Saúde. Metodologia: A partir da iniciativa da residência médica, adesão dos profissionais e gerente da unidade, planejamento da formação do grupo, solicitação de medicamentos, adesivos e goma de mascar específicos para o tratamento para fumantes, bem como acesso a solicitação de alguns exames necessários e a partir das rodas de conversa com os homens sobre a temática. Assim, constatou-se o interesse e empoderamento dos mesmos pelo método de controle do tabagismo sendo formados três grupos com encontros semanais, quinzenais e mensal na sala de reunião da própria unidade de saúde, o que contribuiu de forma significativa atuando na melhoria da assistência à saúde da população masculina. Outra relevante contribuição foi a participação do NASF Educação Física dando sua contribuição, com atividades físicas e práticas alternativas e complementares, a exemplo da auriculoterapia para os participantes do grupo. Conclusão: Dessa forma, concluiu-se que o grupo é uma importante ferramenta de promoção a saúde das pessoas, sendo capaz de gerar benefícios diretos aos usuários, tendo nove participantes deixado o uso de cigarros e quinze diminuíram o consumo do fumo, garantindo mais qualidade no cuidado à saúde masculina ampliando a oferta do tratamento no serviço mais próximo da população a um custo baixo.

Palavras-chave: Grupo. Antitabagismo. Residência.

Área Temática: Educação em Saúde. 


\title{
O ACOLHIMENTO DOS PACIENTES DE SAÚDE MENTAL PELO SERVIÇO SOCIAL DURANTE A PANDEMIA NA USF PARQUE VERDE
}

\author{
Eli Fátima Monauer¹, Maria José Alves Boa Sorte Rodrigues², Matheus Henrique Rossatto ${ }^{3}$ \\ ${ }^{1}$ Residente Multiprofissional em Saúde da Família - Serviço Social, Escola de Saúde Pública, \\ Cascavel, PR.
}

${ }^{2}$ Preceptora Multiprofissional em Saúde da Família - Serviço Social, Escola de Saúde Pública, Cascavel, PR.

${ }^{3}$ Residente Multiprofissional em Saúde da Família - Serviço Social, Escola de Saúde Pública, Cascavel, PR.

Introdução: Um ano após o início da pandemia do novo coronavírus, vivenciamos o momento mais crítico do Sistema Único de Saúde (SUS). No âmbito da Atenção Primária em Saúde foi necessário a reorganização dos serviços de saúde, para o atendimento prioritário de pacientes com suspeita de Covid-19 nas Unidades de Saúde da Família (USF). No presente estudo focaremos nos atendimentos realizados por Assistentes Sociais aos pacientes de saúde mental na Unidade de Saúde da Família Parque Verde, no Município de Cascavel/PR no período de março de 2020 a março de 2021. Objetivo: Descrever a experiência de atendimento dos pacientes de saúde mental pelo Assistente Social e Residentes em Saúde da Família na USF Parque Verde. Metodologia: O presente estudo é um relato de experiência da prática profissional a partir da metodologia descritiva e reflexiva das principais dificuldades e possibilidades das demandas apresentadas em saúde mental. Desenvolvimento: Visualizamos como um fator agravante da Covid-19, os problemas provenientes do isolamento social, principalmente relacionados aos transtornos mentais, dependência química e violência doméstica. Cabe também ao Assistente Social, adaptar-se a essa nova realidade e realizar o acolhimento desses casos, enfrentando o desafio de prestar uma assistência humanizada. Dentre outras demandas, os pacientes vêm em busca de renovações de receitas de medicamentos psiquiátricos, informações sobre encaminhamentos para psicologia, psiquiatria e demais especialidades. Dado a grande quantidade de casos em acompanhamento pela unidade, somada as demandas espontâneas, estas se tornam um agravante a assistência, transformando o ambiente de trabalho exaustivo e desgastante. Considerações Finais: Devido à dificuldade do acompanhamento continuado dos pacientes de saúde mental, o Serviço Social busca alternativas para desenvolver o seu trabalho profissional na USF, garantindo ao usuário o acesso à saúde integral, que compreende uma série de necessidades e serviços que completam o sentido amplo do conceito de saúde humanizada.

Palavras-chave: Atenção primária em saúde; Humanização dos Serviços.; Assistente Social;

Área Temática: Atenção à Saúde. 


\title{
INSERÇÃO DE DIU: VIVÊNCIA NA UNIDADE DE SAÚDE DA FAMÍLIA NA PRÁTICA DA RESIDÊNCIA MÉDICA
}

\author{
Fabíola Moreira Casimiro de Oliveira ${ }^{1}$, Ailma de Souza Barbosa ${ }^{2}$, Carolina Carvalho \\ Nogueira $^{3}$, Joyce Lane Braz Virgolino ${ }^{4}$, Renata Teixeira Martins ${ }^{5}$, Pollyana Leite ${ }^{6}$ \\ Verônica Ebrahim Queiroga ${ }^{7}$.
} 1;2;3;4;5;6;. Secretaria Municipal de Saúde de João Pessoa - Paraíba (SMS - PB).

Introdução: O acesso aos métodos contraceptivos têm efeitos positivos nos níveis de saúde sexual e reprodutiva de mulheres e homens, atua na prevenção de gestações não planejadas e na redução de morbimortalidade materna e abortos inseguros. O Sistema Único de Saúde disponibiliza diversos tipos de métodos contraceptivos, incluindo aqueles reversíveis de longa duração, como o dispositivo intrauterino (DIU) de cobre. Objetivo: O presente trabalho objetivou relatar sobre os mutirões de inserção de DIU em uma Unidade Saúde da Família (USF), município João Pessoa/PB. Metodologia: A ação foi desenvolvida a partir de 2018 como uma estratégia do Outubro Rosa, aos sábados pela manhã na sala de citologia da USF. O planejamento coletivo envolveu médicos residentes, enfermeira, farmacêutica, NASF e gerencia distrital. Devido uma grande procura, os médicos residentes se dispuseram realizar uma capacitação com a colaboração dos demais profissionais que planejaram esses mutirões. Os recursos materiais foram disponibilizados pela gestão e seguidos os protocolos exigidos pelo Ministério da Saúde. Após seleção prévia por profissional treinado, foram realizadas rodas de conversa com às mulheres, esclarecendo dúvidas e trocando experiências e posteriormente a consulta individual para a adesão e continuidade do uso. Resultados: Constatou-se o interesse e empoderamento das mulheres pelo método para controle da procriação e gravidez indesejada, assim como, redução da prescrição de anticoncepcionais orais e injetáveis, gravidez precoce e indicação do DIU para o planejamento familiar. Importante destacar a relevante contribuição de outros médicos residentes e preceptor médico na inserção e reavaliação do DIU. Conclusão: Reduziram as desigualdades por meio do acesso aos serviços de saúde, destacando que essa é uma das premissas da Atenção Primária, além da oferta universal de métodos para planejamento reprodutivo ser um dos modos de garantir os direitos sexuais e reprodutivos da mulher, sendo o DIU um método contraceptivo de alta eficácia e baixo custo.

Palavras-chave: Dispositivos Intrauterinos. Planejamento Familiar. Atenção Primária à Saúde.

Área Temática: Atenção à Saúde. 


\title{
A PRÁTICA DE ATIVIDADE FÍSICA E O AUMENTO DO VÍNCULO NO CONTEXTO DA SAÚDE MENTAL
}

\author{
Johny da Silva Diniz ${ }^{1}$, Maria Rita Garcia de Medeiros² ${ }^{2}$ Taysa Rayane Lucas de Paiva ${ }^{3}$ \\ ${ }^{123}$ Escola Multicampi de Ciências Médicas/Universidade Federal do Rio Grande do Norte
}

Introdução: A Residência Multiprofissional em Saúde é uma pós-graduação lato sensu e tratase de um programa de cooperação intersetorial. Entre as categorias existentes na residência, está o Profissional de Educação Física, que tem, entre outras competências, a promoção de atividade física, a qual estende-se para as demais profissões devido ao caráter multiprofissional do programa. O exercício físico promove socialização e compartilhamento de valores e quando realizado em grupo, possui grande capacidade de criar e fortalecer vínculos. Sendo esta uma estratégia de cuidado em saúde, que também pode ser inserido no contexto da saúde mental. Objetivo: Relatar como a promoção da prática de atividade física no Centro de Atenção Psicossial (CAPS) pode fortalecer o vínculo entre usuários e profissionais de saúde. Metodologia: Trata-se de um estudo de caráter descritivo, do tipo relato de experiência e versa sobre como ocorre as práticas corporais com os usuários do CAPS. O cenário de prática sucede no município de Currais Novos-RN em praça pública ou em quadra espotiva. A atividade é realizada através do esporte Futsal e tem duração de uma hora e meia durante o período matutino. Resultados: Participam do exercício cerca de quinze pessoas mescladas entre usuários do CAPS, residentes e profisssionais do serviço. A proposta obteve êxito e considerável adesão dos participantes. A iniciativa é considerada promotora de saúde, gerando interação entre os participantes, lazer e construção de valores. É perceptível o aumento do vínculo dos profissionais residentes para com os usuários, proporcionando assim uma melhor assistência à saúde. Conclusões: Ainda é presente a verticalidade das relações entre os profissionais de saúde e os usuários do Sistema Único de Saúde (SUS) em diversos cenários no Brasil. Portanto, faz-se necessário a criação de estratégias que estimulem o fortalecimento de vínculo entre estes públicos para um maior êxito na assistência e cuidado a saúde.

Palavras-chave: Atividade Física. Centro de Atenção Psicossocial. SUS.

Área Temática: Atenção à Saúde. 


\title{
VIVÊNCIA EM UMA UNIDADE DE SAÚDE DA FAMÍLIA: CUIDADO, FARMACOLOGIA E PLANTAS MEDICINAIS
}

\author{
Carolina Nogueira Carvalho', Fabíola Moreira ${ }^{2}$, Ailma de Souza Barbosa ${ }^{3}$, Joyce Lane Braz \\ Virgolino $^{4}$, Lindemberg Medeiros de Araújo ${ }^{5}$, Pollyana Leite ${ }^{6}$, Verônica Ebrahim Quieroga ${ }^{7}$
}

1;2;;;4;5;6; Secretaria Municipal de Saúde de João Pessoa - Paraíba (SMS - PB).

Introdução: A inserção de hortas terapêuticas no Sistema Único de Saúde fomenta o cuidado compartilhado, incentiva novas abordagens no cuidado em saúde, promove a articulação entre os saberes socioculturais e as práticas de cuidado. Considera-se ainda a alternativa para modelos de atenção pautados na promoção de saúde e políticas comprometidas com horizontalidade da atenção e a construção democrática do trabalho em saúde. Objetivo: Relatar a construção e implantação de uma horta medicinal numa Unidade de Saúde da Família do município de João Pessoa-PB. Metodologia: Desenvolvida de março a agosto de 2020, o percurso metodológico envolveu a observação em campo, o registro em diário de experiências, a participação de profissionais da equipe, NASF, médicos residentes e usuários em reuniões de equipe e capacitações para a construção da horta na área externa da USF. Resultados: A inserção do trabalho interprofissional contribuiu de forma significativa para a melhoria da assistência farmacêutica básica, substituindo-se a prescrição alopática por plantas medicinais como tratamento dos usuários em determinadas situações de saúde. Conclusão: A horta é importante ferramenta para a saúde dos usuários, capaz de gerar benefícios diretos como: o desmame de benzodiazepínicos e drogas psicoativas, a melhoria da qualidade do cuidado à população e o vínculo serviço-profissionais-comunidade. Ressalte-se a importância do diálogo e da troca de saberes entre as equipes de saúde e populações de referência, a divulgação de práticas geradoras de autonomia (profissionais e população) e a reinvenção de cuidados humanizados, compartilhados e integrais.

Palavras-chave: Atenção Primária à Saúde. Residência médica. Preceptoria.

Área Temática: Atenção à Saúde. 


\section{OS IMPACTOS DA PANDEMIA DO SARS-COV-2 NA POPULAÇÃO EM SITUAÇÃO DE RUA}

\section{Ana Clara Freitas Galvão Soares da Costa ${ }^{1}$, Laura Helena Sousa de Medeiros ${ }^{2}$, Indira Aragão França $^{3}$, Yara Letícia Santos Nogueira ${ }^{4}$, Lidianne Torres Barbosa ${ }^{5}$, Vitor Caiaffo ${ }^{6}$.}

${ }^{1}$ Centro Universitário Maurício de Nassau (Uninassau); ${ }^{2,3,4}$ Faculdade Pernambucana de Saúde (FPS); ${ }^{5,6}$ Universidade Federal de Pernambuco - Centro Acadêmico do Agreste (UFPE-CAA);

Introdução: A Pandemia do Covid-19 afetou o mundo de forma totalitária, entretanto, seus impactos não se distribuíram de maneira equânime. Entre os exemplos de grupos mais vulneráveis do que a população geral, estão as pessoas em situação de rua. Diversos fatores de risco associados os tornam mais suscetíveis à infecção, visto que não podem atender as orientações de segurança. Objetivos: Realizar uma revisão integrativa compreendendo os impactos da pandemia do COVID-19 na vida de pessoas em situação de rua. Métodos: O resumo é uma revisão integrativa de levantamento bibliográfico com caráter exploratório. $\mathrm{O}$ trabalho resultou da busca nas bases de dados Biblioteca Virtual de Saúde e PubMed, utilizando os descritores: "SARS-CoV-2", "homeless persons" e "risks", no período de 2016 a 2020. Da pesquisa surgiram 30 artigos, porém, apenas 12 se alinharam aos critérios de inclusão. Foram selecionadas pesquisas que versavam como tema central as vulnerabilidades das pessoas em situação de rua à Covid-19. Resultados: Os artigos abordam fatores de susceptibilidade da população em situação de rua frente à Covid-19. É consenso que o acesso limitado aos utensílios de higiene pessoal, a falta de uso de máscaras faciais e a inevitabilidade de exposição em espaços públicos aglomerados, culminam em aumento de vulnerabilidade e maior quantitativo de casos de Covid-19 na população-alvo. Ademais, testagens positivas, internação hospitalar, terapia intensiva e taxas de mortalidade relacionados à doença são substancialmente mais elevados neste grupo. Outrossim, existem dificuldades em identificar os sintomas desta infecção, devido à prevalência de outros problemas respiratórios. Conclusão: Assim, são perceptíveis as consequências da Covid-19 nas pessoas em situação de rua, pois, para cumprir as medidas recomendadas é imprescindível acessibilidade aos recursos adequados. Das medidas aplicadas notaram-se repercussões positivas do diagnóstico precoce e da realocação desse público para abrigos temporários, pois a efetividade do serviço proporciona melhora no controle da infecção.

Palavras-chave: COVID-19. Grupos vulneráveis. Sem-teto.

Área temática: Atenção à Saúde ou Saúde Coletiva. 


\title{
O CUIDADO DOS PACIENTES DE SAÚdE MENTAL NA ATENÇÃO PRIMÁRIA DURANTE A PANDEMIA DE COVID-19.
}

\section{Anderson Henrique Carboni', Yasmin Luisa Dengo Lombardo ${ }^{2}$, Andréia Santina Seubert Dalfhert $^{3}$, Crislaine de Moura Castilhos ${ }^{4}$}

\begin{abstract}
${ }^{1}$ Secretaria Municipal de Saúde e Cascavel - PR/Escola de Saúde Pública Municipal, ${ }^{2}$ Secretaria Municipal de Saúde e Cascavel - PR/Escola de Saúde Pública Municipal, ${ }^{3}$ Secretaria Municipal de Saúde e Cascavel - PR/Escola de Saúde Pública Municipal, ${ }^{4}$ Secretaria Municipal de Saúde e Cascavel - PR/Escola de Saúde Pública Municipal.
\end{abstract}

DOI: $10.47094 /$ ICONRES.2021/14

Introdução: Frente aos desafios impostos para o enfrentamento da pandemia causada pelo SARS COV2 pelas equipes multiprofissionais em saúde da família, um deles foi lidar com o agravamento das demandas de saúde mental nos territórios adscritos, haja vista o fechamento dos serviços especializados e o isolamento forçado desta população, sobrecarregando, assim, os serviços da Atenção Primária. Sendo assim, as equipes precisaram se adaptar à nova realidade, buscando construir estratégias para o acolhimento deste segmento. Objetivo: Destacar as estratégias utilizadas por uma equipe de Unidade de Saúde da Família do Município de Cascavel - PR no acolhimento das demandas de saúde mental do seu território. Metodologia: O estudo é baseado em pesquisa quanti-qualitativa, baseado nas listas de espera das especialidades de psiquiatria e psicologia do ano de 2020 de uma USF do Município de Cascavel - PR. Resultados: No período de 01 de dezembro de 2020 até o momento, foram atendidos 171 pacientes com demanda de saúde mental. Destes, 15 pacientes são acompanhados com afinco pelas equipes de serviço social e enfermagem, compostas por preceptores e residentes, incluindo a prática da auriculoterapia, além de serem acolhidos por psicólogo voluntário que vem desenvolvendo sua prática na USF. Ademais, 5 pacientes foram encaminhados com priorização para psiquiatria. Considerações finais: A estratégia intensificou as escutas qualificadas dos pacientes com adoecimento mental, fortalecendo o vínculo com a população e ofertando um espaço de acolhimento humanizado no âmbito da USF. Para os casos mais urgentes, buscou-se fazer o manejo na própria USF, haja vista a delonga nas filas de espera para as especialidades, evitando assim, que os quadros de saúde mental se agravassem. Por fim, destacamos a importância do programa de residência multiprofissional em saúde da família, responsável por criar mecanismos que vão de encontro com as necessidades dos territórios, auxiliando assim, na longitudinalidade do cuidado.

Palavras-chaves: Saúde Mental, Atenção Primária, Cuidado.

Área temática: Atenção à Saúde. 


\title{
A SISTEMATIZAÇÃO DA ASSISTÊNCIA DE ENFERMAGEM EM SERVIÇOS DE URGÊNCIA E EMERGÊNCIA: UMA REVISÃO INTEGRATIVA
}

\section{Meg Caroline do Couto ${ }^{1}$, Washington Júnio Oliveira ${ }^{2}$, Michele Salles da Silva ${ }^{3}$}

\author{
${ }^{1,2}$ Residente do Programa de Residência Multiprofissional em Saúde do Idoso/Universidade \\ Federal de Rondonópolis, ${ }^{3}$ Docente do Curso de Enfermagem e do Programa de Residência \\ Multiprofissional em Saúde do Idoso/Universidade Federal de Rondonópolis
}

Introdução: A equipe de Enfermagem deve ser ágil e resolutiva, pautando suas ações na sistematização da assistência de enfermagem (SAE), instrumento que orienta e organiza o trabalho profissional, aplicado em todos os serviços de saúde onde há assistência de Enfermagem. Contudo, nos serviços de urgência e emergência, por apresentar uma dinâmica de trabalho que difere dos demais serviços de saúde ao impor ações complexas nas quais há a constância da finitude da vida, pode haver a dificuldade no desenvolvimento completo e de qualidade desta ferramenta. Objetivos: Compreender a importância da Sistematização da Assistência de Enfermagem e identificar as limitações para sua aplicação nos serviços de urgência e emergência. Metodologia: Trata-se de uma revisão integrativa que tem como questão norteadora "Qual é a importância da SAE e suas limitações nos serviços de urgência e emergência?”, realizada nos bancos de dados LILACS, BDENF e Medline, utilizando os descritores 'emergência', 'enfermagem baseada em evidências'. Foram selecionados somente os artigos entre os anos de 2016 a 2020, na língua portuguesa e encontrado o total de 16 artigos, destes, 5 foram utilizados na revisão. Resultados: Os estudos analisados apontaram que a SAE adequada proporciona um melhor desempenho durante os cuidados prestados aos pacientes, traz autonomia ao enfermeiro, promove a visibilidade do profissional e valoriza o seu conhecimento científico. As dificuldades para implementação estão associadas a diversos fatores como demanda e dinâmica de trabalho, estrutura da instituição, ausência de apoio no desenvolvimento adequado do instrumento, insatisfação e desmotivação dos profissionais. Conclusão: A partir das buscas, ficou evidente que existem diversas limitações que da SAE nos serviços de urgência e emergência, apesar sua importância para a qualidade do trabalho seja reconhecida pelos profissionais. Nesse caso, esforços institucionais precisam fomentar a aplicação correta da SAE, bem como o empenho dos profissionais na busca pela melhoria dos seus serviços. Palavras-chave: Serviço hospitalar de emergência. Processo de enfermagem. Enfermagem em emergência.

Área Temática: Atenção à saúde 


\title{
PERFIL EPIDEMIOLÓGICO DOS PACIENTES ATENDIDOS NA EMERGÊNCIA ONCOLÓGICA EM UMA CAPITAL NORDESTINA
}

\author{
Ana Flávia Silva Lima ${ }^{1}$, Verônica Bezerra Monteiro² ${ }^{2}$ Gabriela Ferreira da Silva ${ }^{3}$, Mário

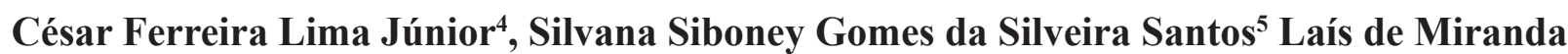 \\ Crispim Costa ${ }^{6}$
}

\begin{abstract}
${ }^{1}$ Santa Casa Rodrigo Ramalho/ Universidade Federal de Alagoas, ${ }^{2}$ Santa Casa Rodrigo Ramalho/ Centro Universitário Tiradentes, ${ }^{3}$ Santa Casa Rodrigo Ramalho/ Universidade de Ciências da Saúde de Alagoas, ${ }^{4,6}$ Programa de Pós-Graduação da Escola de Enfermagem/Universidade Federal de Alagoas, ${ }^{5}$ Centro de Ensino e Pesquisa em Ciências Médicas/ Universidade Federal de Alagoas
\end{abstract}

Introdução: No Brasil, segundo dados do Observatório Global de Câncer (OMS), no ano de 2020 houve 75.999 casos de câncer de mama (78 casos por 100.000 hab), 72.635 casos de câncer de próstata (61.9 casos por 100.000 hab), 38.907 casos de câncer de cólon e reto, 29279 casos de câncer de tireóide, 28.327 casos de câncer de pulmão e 15.672 de casos de câncer de colo uterino, sendo o câncer uma das doenças que mais matam no país (BRASIL, 2020). Objetivos: Traçar o perfil epidemiológico dos pacientes atendidos em uma emergência oncológica. Metodologia: Estudo epidemiológico retrospectivo sobre o perfil dos pacientes atendidos na emergência oncológica do hospital filantrópico Santa Casa Rodrigo Ramalho no estado de Alagoas no ano de 2020. Resultados: $\mathrm{Na}$ emergência oncológica - SUS do referido hospital desta capital nordestina, a incidência dos atendimentos para observação da emergência foi de 2.707, e de internações chegou a 584 atendimentos. Destes, 39\% foram do sexo masculino e $61 \%$ do sexo feminino, cuja faixa etária $38 \%$ possuíam 60 anos ou mais, $26 \%$ entre 50 e 59 anos, $18 \%$ entre 40 a 49 anos e mais $17 \%$ entre 20 a 39 anos). Os tipos mais prevalentes foram os de câncer de colo uterino (C 53) com 21\%; câncer de mama (C 50) com 17\%, câncer de próstata (C 61) com 9\%, e de cólon (C 18) com 8\%. Conclusões: Observou-se uma discrepância quando comparado ao perfil epidemiológico brasileiro com relação a maior prevalência do câncer de colo uterino, o que pode ser justificado devido a longevidade dos pacientes com esta patologia, recorrência de atendimentos costumeiramente necessários e fatores socioeconômicos. A partir do perfil epidemiológico traçado, pode-se estimular mais estudos para melhor compreensão da realidade e servir de subsídio para adoção de medidas que permitam uma melhor assistência à população atendida.

Palavras-chave: Epidemiologia. Oncologia. Perfil de Saúde.

Área Temática: Saúde Coletiva. 


\title{
A RELAÇÃO ENTRE A TOXOPLASMOSE E OS PROFISSIONAIS DE SAÚDE QUE ATUAM NO PRÉ-NATAL.
}

\section{José Victor Machado Coracira ${ }^{1}$, Gian Wellington William Ribeiro dos Santos ${ }^{2}$, Thalyta Roberta da Silva ${ }^{3}$}

\author{
Centro Universitário do Vale do Ipojuca - (UNIFAVIP | Wyden)
}

Introdução: A toxoplasmose é uma infecção causada pelo Toxoplasma gondii, que possui o humano como hospedeiro intermediário e os felinos como hospedeiros definitivos. A contaminação dos humanos ocorre através do contato com fezes de gatos, água e alimentos contaminados pelo protozoário. Também pode ocorrer uma contaminação vertical, onde o protozoário atravessa a barreira transplacentária e causa infecção do feto, podendo gerar alterações fetais ou resultar no aborto. Objetivo: O presente trabalho visa conscientizar profissionais atuantes no pré-natal sobre a importância do conhecimento acerca da toxoplasmose durante a gravidez e de seus riscos durante a gestação. Metodologia: Consiste em uma revisão da literatura, com pesquisa nas bases de dados: SciELO e Ministério da Saúde. Foram utilizados 4 artigos, publicados no período entre 2012 e 2020, nos idiomas português e espanhol. Resultados: A infecção do feto geralmente ocorre na fase aguda da doença na gestante, onde o parasita infecta e se multiplica na placenta, chegando a circulação fetal, podendo gerar sequelas como: microcefalia, cegueira e surdez. O diagnóstico ocorre por meio da identificação sorológica durante o pré-natal, geralmente através do teste imunoenzimático (ELISA), que busca a presença das imunoglobulinas igM e igG contra a toxoplasmose, podem-se ser solicitados: o IFI, teste imunofluorescência indireta, teste de avidez de igG e para a confirmação de infecção do feto é feito a amniocentese. A utilização de Espiramicina em casos de grávidas na fase aguda tem demonstrado uma diminuição de até 50\% dos casos de comprometimento fetal. Conclusão: Portanto, é de suma importância para a diminuição dos agravos durante a gestação o conhecimento dos malês advindos da infecção por Toxoplasma gondii pelos profissionais responsáveis por o acompanhamento de gestantes e também da utilização da profilaxia com o Espiramicina em casos da forma aguda.

Palavras-chave: Toxoplasma gondii, Complicação infecciosa na gravidez e Doenças endêmicas.

Área Temática: Atenção à saúde. 


\title{
O CONHECIMENTO DA POPULAÇÃO ACERCA DA PREVENÇÃO E CONTROLE DA DOENÇA DE CHAGAS
}

\author{
Gian Wellington William Ribeiro dos Santos ${ }^{1}$, Thalyta Roberta da Silva², José Victor \\ Machado Coraciara ${ }^{3}$, Jucineide Maria da Silva ${ }^{4}$
}

Centro Universitário do Vale do Ipojuca - (UNIFAVIP | Wyden)

Introdução: A Doença de Chagas (DC) acomete uma expressiva parte da população de regiões tropicais da América Latina. Atualmente ela participa das doenças negligenciadas, mas sua incidência expressa a necessidade do endurecimento de medidas de saúde para o enfrentamento desse problema. A DC é uma zoonose, acometida pelo protozoário Trypanosoma cruzi, presente nas fezes do inseto vetor Triatomíneo (Barbeiro). Esses insetos são hematófagos e contaminam os humanos durante o repasto sanguíneo. Após se alimentar defeca próximo a lesão de entrada o indivíduo coça a lesão e assim favorece a entrada do protozoário na corrente sanguínea. O diagnóstico ocorre pelos testes sorológicos: ELISA, e Imunofluorescência. $O$ tratamento consiste em medicamentos como: (Benzoidazol e Nifurtimox) antiparasitários. A prevenção consiste em técnicas sanitárias de aconselhamento da população, e informações de como impedir a multiplicação do vetor etc. Objetivo: O estudo planeja avaliar como a população reconhece o processo saúde-doença relacionado a DC. Analisando as condutas de prevenção adotadas pela comunidade. Metodologia: Consiste em uma revisão de literatura, usando artigos disponíveis nas bases de dados: Google Acadêmico e SciElo. Foi utilizado 8 artigos. Foram filtrados e utilizados os artigos do idioma português. Resultados: As comunidades de áreas endêmicas apresentam um certo nível de conhecimento acerca do inseto vetor e da DC. Contudo indivíduos mais jovens não conhecem o inseto nem os problemas de saúde acarretados a ele. E com o surgimento de novas doenças durante os anos, medidas de prevenção e controle da DC se tornaram cada vez menos implementadas. Conclusões: É necessário implementar novas medidas de saúde para controle e prevenção da transmissão da DC. Com os agentes de saúde promovendo a vigilância entomológica. Além do ensino continuado da população para identificação do vetor e acionamento do serviço de saúde.

Palavras-chave: Doenças Endêmicas, Trypanosoma cruzi, e Triatoma.

Área Temática: Atenção à Saúde. 


\section{PROGRAMA PREVINE BRASIL SUBSTITUI O NASF-AB}

\section{Thalyta Roberta da Silva ${ }^{1}$, Gian Wellington William Ribeiro dos Santos², José Victor Machado Coraciara ${ }^{3}$}

Centro Universitário do Vale do Ipojuca - (UNIFAVIP | Wyden)

Introdução: Os custeios relacionados ao financiamento da atenção básica obtiveram uma nova atualização de acordo com a publicação técnica $n^{\circ} 3 / 2020$ da Portaria $n^{\circ} 2.979$, o núcleo de ampliação a saúde da família (Nasf-AB) foi substituído pelo Programa Previne Brasil, As equipes de atenção primária (eAP) passaram a receber repasses federais .Isso se deu pela necessidade de uma maior resolutividade da qual o Nasf-AB não estava alcançando, ficara a disposição do gestor municipal analisar a necessidade da implantação se necessário da unidade de Nasf-AB, não estando em sua obrigatoriedade implementar unidades complementares de equipe multiprofissional. Objetivo: Este estudo objetiva estabelecer um sistema que faça a integração entre as diretrizes do SUS, traga vivencias com uma ampla resolutividade, não deixando de lado a equidade e a universalidade que com toda via eram o foco do Nasf-AB, Organizar ações estratégicas que possam assistir a populações como um todo incluindo a mais vulnerável. Metodologia: Consiste em uma revisão de literatura, utilizando artigos e revisões disponíveis nas bases de dados: Google Acadêmico e SciElo. Se utilizou de 7 artigos, publicados nas plataformas digitais. Foram filtrados e utilizados os artigos do idioma português. Resultados: A ampliação de recursos para aumentar o número de equipes de Saúde da Família (eSF), já que nem todos os municípios necessitam implantar o Nasf-AB, Profissionais receberam de acordo com as normas de incentivo e produtividade, tornando assim o sistema mais resolutivo. Considerações Finais: As atualizações da PNAB trazem consigo a necessidade de mudança tanto orçamentaria quanto normativa visto que estamos em meio a uma crise que decorre por anos e não possibilita a universalidade de uma assistência digna.

Palavras-chave: Pnab. Sus. Atenção Básica.

Área Temática: Atenção à Saúde. 


\title{
COVID-19 E PUÉRPERAS: A POTENCIAL TRASMISSÃO VERTICAL E AS PRECAUÇÕES DE CONTATO DURANTE O ALEITAMENTO MATERNO.
}

\author{
${ }^{1}$ Stephanie Karoline de Oliveira Oliveira
}

${ }^{1}$ Graduanda em Enfermagem pelo Centro Universitário Mauricio de Nassau - UNINASSAU, Parnaíba, Piauí

INTRODUÇÃO: O leite materno pode ser uma fonte de contaminação, provocada por equipamentos durante seu manuseio, por transmissão vertical ou direta, durante a amamentação. Quando contaminado, implicará na veiculação de patógenos, sendo fator de risco microbiológico para o lactente, tendo em vista a reconhecida imaturidade do sistema imunológico, o que sugere sua maior susceptibilidade as infecções. OBJETIVO: Referir a possibilidade da transmissão vertical e descrever as principais precauções para mães suspeitas ou diagnosticadas com COVID-19 ao entrar em contato com o lactente durante a amamentação. MÉTODOLOGIA: Revisão literária, tendo como fontes de coleta de dados SciELO Brasil, repositório científico IPVC e Biblioteca Virtual em Saúde. Foram incluídos dezesseis artigos em língua portuguesa entre 2019 a 2021, os quais abordavam o objetivo deste estudo. RESULTADOS: A partir das fontes compiladas, realizou-se uma análise dividida em dois aspectos: Meios de contaminação e Precauções. Dentre os meios de contaminação, até o momento inexistem evidências científicas robustas que comprovem a transmissão vertical, não sendo identificada a presença do vírus nas amostras do leite de mães infectadas, mas sim anticorpos antiSARScov2, entretanto, as gotículas expelidas através da fala, espirro e tosse constituem um meio de contaminação para o lactente. Das precauções, têm-se cuidados de higiene respiratória, individual e de objetos e superfícies: o uso da máscara durante as mamadas e ordenha, retirar acessórios, prender os cabelos, higienização das mãos e braços até os cotovelos com água e sabão ou álcool 70\%, manter as unhas limpas e curtas, realizar a limpeza das bombas de extração de leite após a utilização e desinfetar periodicamente superfícies as quais contactam com Hipoclorito de sódio 0,5\%. CONCLUSÕES: Mães com COVID-19 podem amamentar, se desejarem e se as condições clínicas permitirem, caso contrário, o leite pode ser ordenhado e oferecido ao lactente por um cuidador saudável, seguindo similarmente as precauções necessárias.

Palavras-chave: COVID-19. Amamentação. Transmissão.

Área temática: Atenção à saúde 


\title{
ADAPTAÇÃO DO TRABALHO DA ENFERMAGEM EM SAÚDE DA FAMÍLIA DURANTE A PANDEMIA COVID-19
}

\author{
Danieli Cristina Scalco ${ }^{1}$, Estefany Bahnert ${ }^{2}$, Luana Lunardi Alban ${ }^{3}$ \\ ${ }^{1,2,3}$ Escola Municipal de Saúde Pública, Cascavel-Paraná
}

Introdução: A pandemia provocada pela Covid-19, demandou reajustes no atendimento das Unidades de Saúde da Família (USF). Com as determinações de distanciamento social e a suspensão de consultas eletivas não prioritárias, muitos pacientes permanecem sem passar por atendimento. Ao mesmo tempo em que se adaptam para receber os pacientes com quadros suspeitos e confirmados de Covid-19, as equipes da USFs precisam de estratégias que permitam o menor dano possível aos outros pacientes da unidade, principalmente aqueles em cuidados crônicos; Objetivo: descrever as atividades da equipe de Enfermagem na Atenção Primária à Saúde (APS) durante a pandemia da covid-19; Metodologia: trata-se de relato de experiência, vivenciado em Março de 2021 por preceptora e residentes de Enfermagem em uma USF; Resultados: nesse momento, a enfermagem vem superando desafios para dar continuidade ao tratamento de pacientes crônicos, realização de curativos, visitas domiciliares, e atendimentos de urgência/emergência. Assim, realiza-se diariamente avaliação dos pacientes, para estabelecer os atendimentos prioritários e que não são possíveis de adiamento, além de realizar as notificações e monitoramentos de casos suspeitos e confirmados para Covid-19. O cuidado aos pacientes acamados também tem ganhado atenção prioritária, inclusive com a solicitação e aplicação da vacina contra a Covid-19 à domicílio. Considerações Finais: para manter o potencial resolutivo da APS, adequamos nosso atendimento buscando meios de manter nossos pacientes assistidos e enfrentamos os desafios de prestar uma assistência humanizada, pela necessidade de acompanhamento via teleatendimento. A Enfermagem tem um papel fundamental na detecção e avaliação dos casos suspeitos através de cuidados específicos e da sistematização da assistência de enfermagem.

Palavras-chave: Atenção Básica à Saúde. Saúde Coletiva. Treinamento em Serviço.

Área Temática: Atenção à Saúde. 


\section{RELATO DE EXPERIÊNCIA: INSERÇÃO DE RESIDENTES DE ENFERMAGEM EM UM PROGRAMA DE ATENDIMENTO RESIDENCIAL DE CASCAVEL}

\section{Estefany Bahnert ${ }^{1}$, Terezinha da Aparecida de Campos², Beatriz Talluly Bespalhok ${ }^{3}$}

${ }^{1}$ Programa de Residência Multiprofissional em Saúde da Família, Secretaria Municipal de Saúde

- Cascavel (PR), Brasil, ${ }^{2}$ Programa de Atendimento Residencial/PAR, Secretaria Municipal de Saúde de Cascavel (SESAU) - Cascavel (PR), Brasil. Programa de Residência Multiprofissional em Saúde da Família, Secretaria Municipal de Saúde - Cascavel (PR), Brasil, ${ }^{3}$ Programa de Residência

Multiprofissional em Saúde da Família, Secretaria Municipal de Saúde - Cascavel (PR), Brasil.

Introdução: O Programa de Atendimento Residencial (PAR) é uma política de governo municipal criada em 2018 para prestar suporte técnico e pedagógico aos profissionais da Atenção Primária à Saúde (APS). O serviço é acionado pelas Unidades de Saúde e tem por objetivo auxiliar/matriciar as equipes nas demandas de maior complexidade técnica com ênfase na capacitação das equipes multiprofissionais. Objetivo: Relatar a experiência vivenciada enquanto residente de enfermagem e as contribuições do programa para a formação do profissional enfermeiro. Metodologia: Trata-se de um relato de experiência que se deu no Programa de Atendimento Residencial no município de Cascavel/ PR, com atividades gerenciais e administrativas desenvolvidas no período de fevereiro a março de 2021. Resultados: Diante da necessidade constante de formação e qualificação dos profissionais que atuam e/ou atuarão no Sistema Único de Saúde (SUS) em especial na APS, as experiências vivenciadas no decorrer da residência possibilitam explorar novas tecnologias no cuidado e incorporar novas práticas para atuação na rede de atenção à saúde. Durante o período, no referido cenário de prática foi possível realizar alguns procedimentos que não são frequentes no cotidiano da APS e atividades além das executadas nas USF. Alguns desses procedimentos realizados foram, troca de sonda de gastrostomia e de cânula de traqueostomia, avaliação de lesões complexas e condutas de curativos especiais. Uma oportunidade no qual proporcionou refletir sobre a assistência de enfermagem direta ao paciente de uma forma diversa, bem como o trabalho em equipe. Considerações finais: Após este período no PAR foi possível empoderar-se para prestar uma assistência mais assertiva e proveitosa aos pacientes, tal experiência agregou conhecimento e auxiliou no desenvolvimento do perfil profissional, possibilitando olhar o ser humano na sua singularidade. Bem como, complementar a formação do residente para a continuidade dos cuidados dentro das unidades de Saúde da Família de forma mais qualificada. Palavras-chave: Residência. Atenção Primária à Saúde. Equipe de Saúde.

Área Temática: Atenção à Saúde. 


\title{
POTENCIALIDADES DO ENSINO EM SERVIÇO MULTIPROFISSIONAL EM SAÚDE DA FAMÍLIA: RELATO DE EXPERIÊNCIA
}

\section{Terezinha da Aparecida Campos'; Beatriz Talluly Bespalhok² Estefany Bahnert $^{3}$}

\begin{abstract}
${ }^{1}$ Programa de Atendimento Residencial/PAR, Secretaria Municipal de Saúde de Cascavel (SESAU) - Cascavel (PR), Brasil. Programa de Residência Multiprofissional em Saúde da Família, Secretaria Municipal de Saúde - Cascavel (PR), Brasil, ${ }^{2}$ Programa de Residência Multiprofissional em Saúde da Família, Secretaria Municipal de Saúde - Cascavel (PR), Brasil, ${ }^{3}$ Programa de Residência Multiprofissional em Saúde da Família, Secretaria Municipal de Saúde - Cascavel (PR), Brasil.
\end{abstract}

Introdução: Os Programas de Residências em Saúde são frutos de uma cooperação entre o Ministério da Saúde (MS) e o Ministério da Educação (ME), concebida para favorecer a inserção qualificada de profissionais da saúde no Sistema Único de Saúde (SUS) e, particularmente, em áreas prioritárias. Nessa perspectiva, a Residência Multiprofissional em Saúde da Família torna-se um fator de mudança de paradigmas na qualificação do profissional atrelado ao ensino e pesquisa. Objetivo: Relatar as potencialidades dessa modalidade de ensino vivenciadas no Programa de Atendimento Residencial (PAR). Metodologia: Trata-se de um relato de experiência. A fim de contextualizar, a Atenção à Saúde no município de Cascavel/PR está dividida em 3 (três) distritos sanitários e possui 29 (vinte e nove) Unidades de Saúde da Família (USF); 50 (cinquenta) equipes de saúde da família; 13 (treze) Unidades Básicas de Saúde (UBS). É neste contexto que os residentes têm a oportunidade de atuarem, bem como em alguns serviços especializados, dentre eles o PAR. Resultados: Dentre às atividades técnicas desenvolvidas no referido serviço estão: troca de sonda de gastrostomia e cânula de traqueostomia, avaliação de lesões complexas e conduta de curativos especiais, como Bota de Unna. Concomitante a isso, o residente é incentivado à realizar pesquisas e publicar trabalhos, uma vez que, não há como se distanciar da relação ensino e aprendizagem, já que a perspectiva da prática faz parte desse processo, que é norteador do programa - ensino em serviço e para o serviço. Considerações finais: Diante do exposto, evidencia-se, neste processo, que o residente e preceptor aprendem juntos, infere-se que esse processo se faz nas relações estabelecidas entre si e com o mundo. Entende-se que o preceptor é um mediador neste processo, pois, consegue integrar ensino, serviço e aprendizado, possibilitando ao residente desenvolver e aperfeiçoar competências e habilidades que se complementam na prática profissional.

Palavras-chave: Residência. Enfermagem. Preceptoria.

Área Temática: Atenção à Saúde. 


\title{
O ABUSO SEXUAL INFANTIL COMO FATOR DE RISCO PARA TRANSTORNOS ALIMENTARES: UMA REVISÃO DA LITERATURA
}

\author{
Iara Oliveira Costa ${ }^{1}$, Bruna Sampaio Lopes Costa ${ }^{2}$
}

${ }^{1}$ Centro Universitário Christus, ${ }^{2}$ Centro Universitário de João Pessoa

Introdução: O abuso sexual infantil (ASI) constitui um grave problema de saúde pública, visto que, pelo menos, cerca de $10 \%$ dos homens e $20 \%$ das mulheres relataram terem sido vítimas deste crime. Tal agravo é responsável por diversas repercussões negativas no aparelho psíquico de crianças e adolescentes, sendo o comportamento alimentar um dos campos em que se observam diversas alterações oriundas dos mecanismos de defesa. Sendo assim, tem crescido o número de debates acerca dos impactos dos traumas psicológicos provocados pelo ASI e a possibilidade deste de influenciar no desenvolvimento de transtornos alimentares (TA). Objetivo: Realizar uma revisão narrativa acerca do ASI como fator de risco para TA. Metodologia: Realizou-se uma revisão narrativa no PubMed utilizando as palavras-chave "children", "sexual abuse" e "eating disorders". Incluiu-se artigos originais e revisões bibliográficas publicados nos últimos cinco anos no idioma inglês ou português disponíveis na íntegra. Excluiu-se cartas aos editores, artigos de opinião e resenhas. Resultados: Algumas crianças que sofreram ASI associavam comida a um mecanismo de escape para lidar com situações emocionalmente perturbadoras, podendo haver um consumo de grandes quantidades de comidas em situações minimamente estressantes, mesmo na ausência de fome. Teorias apontam que algumas vítimas de ASI adotam dietas hipercalóricas a fim de ganhar peso, a fim de se tornarem menos atraentes para seus abusadores. Certos indivíduos adotam os comportamentos alimentares típicos da anorexia nervosa para tornarem-se extremamente magros e, assim, conseguirem negar sua própria sexualidade. Um estudo relatou como moderada a forte a correlação entre exposição ao ASI e desenvolvimento de TA. Outro estudo relatou não existir associações suficientes para sustentar tal correlação. Conclusões: A ocorrência do ASI provoca alterações no comportamento alimentar, predispondo o surgimento de hábitos típicos de TA, como anorexia nervosa. Entretanto, faz-se necessário realizar mais estudos sobre a associação de ambos os agravos.

Palavras-chave: Comportamento Alimentar. Mecanismos de Defesa. Saúde Pública.

Área Temática: Atenção à saúde. 


\title{
PREDIÇÃO DO PARTO PREMATURO POR PARÂMETROS ULTRASSONOGRÁFICOS: UMA REVISÃO SISTEMATIZADA
}

\author{
Nathália Siriano Costa ${ }^{1}$, Hellen Kristina Magalhães Brito ${ }^{2}$, Rubenrhaone Alberto Paulino ${ }^{3}$, \\ Isabella Siriano de Castro ${ }^{4}$, Lucas Carvalho da Silva ${ }^{5}$, Otávio Gomes Barreto Araújo ${ }^{6}$
}

\begin{abstract}
${ }^{1,2,3}$ Centro Universitário Atenas, ${ }^{4}$ Universidade de Rio Verde - Campus Aparecida de Goiânia, ${ }^{5}$ Universidade Cesumar- Campus Maringá-PR, ${ }^{6}$ Instituto Tocantinense Presidente Antônio Carlos Campus Palmas
\end{abstract}

INTRODUÇÃO: O parto pré-termo (PPT), definido como parto com idade gestacional (IG) menor que 37 semanas, não evidenciou declínio nas últimas décadas, permanecendo como causa principal de mortalidade perinatal. O método eficiente para identificar fatores que apontam para o diagnóstico precoce da prematuridade é a ultrassonografia transvaginal. Por meio dele identificase características como: o encurtamento do colo uterino e a presença do "sludge". OBJETIVO: Evidenciar a importância dos achados ultrassonográficos no diagnóstico precoce de prematuridade. Impactando na redução da mortalidade perinatal. MÉTODOS: Trata-se de uma revisão sistemática realizada nas bases PubMed, Lilacs e Scielo, utilizando-se os termos "prematuridade", "sludge" e “ultrassonografia transvaginal". Foram incluídos artigos de revisão, estudos clínicos randomizados e estudos observacionais, em língua portuguesa e inglesa com acesso aberto. Foram excluídos artigos incompletos, que não tratassem do tema estudado. RESULTADOS: Os principais parâmetros ultrassonográficos analisados foram o comprimento do colo uterino (CCU) e o "sludge". Sendo este a presença de partículas hiperecogênicas dentro da cavidade amniótica, agrupadas próximas ao colo uterino. Quanto ao CCU, 70\% das pacientes avaliadas que estavam entre a $20^{\mathrm{a}}$ e a $25^{\mathrm{a}}$ semana de gestação, apresentaram como fator preditor para PPT o comprimento menor que $25 \mathrm{~mm}$. Já o "sludge" representou fator de risco iminente para o PPT extremo (menor que 28 semanas) em 37,5\% dos casos, e $87,5 \%$ em menores que 35 semanas. Evidenciando uma variável independente para o PPT, sendo uma característica que eleva o valor preditivo positivo do seu rastreamento ao associa-lo com o CCU menor que 25mm em gestantes com IG menor que 25 semanas. CONCLUSÃO: A análise isolada do colo uterino é um importante indicador de parto prematuro, porém altamente subjetivo. Desta forma, ao alinhar a avaliação deste ao "sludge" haverá um aumento substancial do diagnóstico precoce de prematuridade. Permitindo em tempo hábil intervir deliberativamente para redução da mortalidade perinatal.

Palavras-chave: Prematuridade. Ultrassom. Gestante.

Área temática: Atenção à saúde 


\title{
OS IMPACTOS DAS REDES SOCIAIS NA SAÚDE MENTAL DO ADOLESCENTE: UMA REVISÃO INTEGRATIVA
}

\author{
${ }^{1}$ Kamila Fernanda dos Santos Sousa, ${ }^{2}$ Clara Liz Macêdo Isidoro, ${ }^{3}$ Rosely Leyliane dos Santos.
}

1,2,3 Universidade Regional do Cariri- URCA

Introdução: A adolescência é caracterizada como a transição da infância para a vida adulta com mudanças, físicas, psíquicas e sociais. Contudo, alguns fatores podem acarretar o desenvolvimento de problemas mentais, como o uso excessivo das redes sociais que são tecnologias que promovem a interação social, podendo causar a dependência à internet. Objetivo: Descrever os impactos das redes sociais na saúde mental do adolescente. Metodologia: Trata-se de uma revisão integrativa da literatura. As buscas sucederam-se nos bancos de dados: BVS, MEDLINE via PubMed e LILACS, com os descritores: "Impacts And Social Networking and Mental Health and (adolescents and not child)", a partir da pergunta norteadora: Quais impactos das redes sociais na saúde mental do adolescente? Os critérios de inclusão: trabalho completo, em português, inglês e espanhol, entre 2017 e 2020 . E, exclusão: editoriais e trabalhos que não responderam à pergunta norteadora. Foram encontrados 59 artigos, selecionados para leitura 11 e incluídos 4. Resultados: Um estudo com 440 adolescentes estudantes, mostrou que a prevalência da dependência de Internet foi de 80,7\%, ocasionando impactos negativos, tornando os adolescentes mais deprimidos, estressados e ansiosos. Ainda nesse estudo foi possível observar a associação significativa entre dependência de internet e depressão, ansiedade e estresse. Em concordância, outro estudo mostra que há relação entre a internet e depressão, estresse, intenção suicida, agressão e comportamentos antissociais. A literatura ainda identificou que as redes sociais acentuam a falta de interação entre os adolescentes com os familiares e amigos. Conclusões: Portanto, os impactos das redes sociais na saúde mental dos adolescentes foram a dependência à internet, problemas nas relações familiares ocasionando falta de diálogo com os familiares, além do aumento do estresse, deixando-os propícios aos quadros de depressão e ansiedade.

Palavras-chave: Depressão. Ansiedade. Internet.

Área Temática: Atenção à saúde. 


\title{
A VISITA DOMICILIAR ODONTOLÓGICA NA RESIDÊNCIA MULTIPROFISSIONAL COMO POTENCIALIDADE NO DIAGNÓSTICO PRECOCE DE CÂNCER BUCAL
}

\author{
Amanda Cadoso Bonna ${ }^{1}$, Fabiana de Freitas Bombarda Nunes ${ }^{2}$ \\ ${ }^{1}$ Instituto Capixaba de Ensino, Pesquisa e Inovação em Saúde, ${ }^{2}$ Faculdade Espírito Santense - \\ FAESA
}

Introdução: A assistência domiciliar se qualifica como uma ação adaptada ao domicílio e se mostra complementar às modalidades de atenção à saúde já existentes, assegurando a continuidade do cuidado àqueles restritos à moradia. A inserção de um profissional de saúde bucal nesse contexto promove a prevenção e diagnóstico precoce de doenças significativas da cavidade oral como o câncer de boca, além de propiciar pequenos procedimentos, orientações e criação de vínculos; Objetivo: O objetivo do presente relato de experiência é apresentar o fluxo do diagnóstico precoce do câncer bucal em uma visita domiciliar durante a atuação de uma cirurgiã-dentista vinculada a um programa de residência, salientando a importância dessa categoria profissional como parte integrante da equipe; Metodologia: Com a inserção da primeira turma de residência multiprofissional em saúde da família na unidade básica de saúde (UBS) de um estado da região sudeste do país, houve a participação da residente em espaços de atuação multiprofissional e interprofissional. A visita domiciliar ocorreu em um dos bairros do território abrangido pela UBS onde participaram, além desta, uma enfermeira e uma agente comunitária. Após a avaliação da enfermagem ao paciente restrito à moradia acometido por doença crônica, foi avaliada a cavidade bucal pela residente de odontologia; Resultados: Detectou-se uma lesão em bordo lateral posterior de língua e o paciente foi encaminhado à especialidade odontológica para avaliação e biópsia. O paciente foi diagnosticado com carcinoma epidermóide e conduzido ao hospital referência para tratamento do câncer; Considerações Finais: A assistência à saúde bucal no domicílio permite a equidade do atendimento de pacientes distantes da odontologia tradicional, entretanto, ainda não está completamente incluída às equipes na estratégia de saúde da família. $\mathrm{O}$ papel do cirurgião-dentista nesse cenário é de extrema importância, pois facilita o diagnóstico e elaboração de um fluxo adequado ao paciente, impedindo o agravamento de doenças bucais.

Palavras-chave: Assistência domiciliar. Saúde bucal. Atenção Primária à saúde.

Área Temática: Atenção à saúde 


\title{
ABORDAGEM INTERPROFISSIONAL ENTRE ATENÇÃO PRIMÁRIA E O CAPSII NA PREVENÇÃO E PROMOÇÃO DA SAÚDE DO IDOSO: RELATO DE EXPERIENCIA
}

\author{
Lidyane Kelly Lima Torres ${ }^{1}$; Maria de Lourdes Lima Ferreira ${ }^{2}$ \\ Universidade Estadual do Ceará - UECE
}

Introdução: Na última década, houve um aumento de $50 \%$ de idosos no país, sendo que hoje, 11\% da população são maiores de 60 anos e a projeção é de que a expectativa média de vida, alcance 82 anos em 2050. Em favorecimento ao envelhecimento ativo e saudável faz-se necessário um olhar ampliado para a saúde do idoso exigindo uma abordagem além de multiprofissional e sim com práticas colaborativas e interprofissionais. Objetivo: Relatar a experiência do cuidado interprofissional entre os profissionais da atenção primária e do CAPS II do município de Aracati no Ceará junto a um grupo de idosos. Metodologia: A proposta dessa ação em equipe era o cuidado integral à saúde de 32 idosos assistidos pela UBSF Abengruta I, de forma interprofissional objetivando ser instrumento facilitador do envelhecimento saudável e contribuir com ações efetivas para a evolução das condições de saúde do idoso, e consequentemente, torna-las funcionalmente independentes. Era realizada uma consulta com cada idoso, planejamento e discussões entre os profissionais traçando o perfil do grupo e as atividades a serem trabalhada discutidos assuntos referentes ao envelhecimento saudável, por meio de palestras, rodas de conversa e filmes. As práticas da atividade física eram realizadas três vezes por semana. Previamente as consultas, eram realizadas dinâmicas visando à interação e afetividade entre os envolvidos. Resultados: O relato dos participantes, nos levam a afirmar que as ações implementadas, cooperaram para a aquisição de novos conhecimentos por parte dos envolvidos, além de despertálos para o autocuidado com a saúde física, mental, além de favorecer a socialização e intercâmbio de experiências contribuindo para o envelhecimento saudável. Considerações finais: $\mathrm{O}$ incentivo ao envelhecimento ativo pode contribuir para a saúde do idoso, sendo as práticas interprofissionais e colaborativas entre os profissionais da saúde, uma importante estratégia para melhor responder as necessidades do idoso.

Palavras-chave: Envelhecimento saudável. Grupo de Idosos; Interprofissionalidade.

Área temática: Atenção à Saúde 


\title{
A PREVALÊNCIA DA DISSEMINAÇÃO DO COVID-19 NO BRASIL.
}

\section{Clara Liz Macêdo Isidoroํㅜ, Kamila Fernanda dos Santos Sousa ${ }^{2}$, Rosely Leyliane dos Santos ${ }^{3}$}

\author{
1,2,3 Universidade Regional do Cariri
}

Introdução: O vírus causador da doença COVID-19 tem alta taxa de transmissibilidade. Por ser um vírus respiratório, ele facilmente disseminou-se no mundo. No Brasil, o primeiro caso foi notificado foi em fevereiro de 2020, na cidade de São Paulo. Contudo, os dados epidemiológicos revelam o crescente número de casos, inclusive com óbitos nas diversas cidades brasileiras, mesmo após recomendações para conter a transmissão da doença. Assim, é importante compreender quais os fatores que contribuíram para a disseminação da COVID-19. Objetivo: Analisar a prevalência da disseminação do covid-19 no Brasil. Metodologia: Trata-se de uma revisão narrativa da literatura realizada com dados da Biblioteca Virtual em Saúde (BVS) em maio de 2020. Foi executado um cruzamento com o operador booleano AND para associação dos descritores Promoção, Saúde e Covid-19. Foram submetidos a filtragem em três etapas: texto completo disponível, idioma português e inglês, tipo de documento artigo. Onde, seis artigos atenderam o objetivo da pesquisa. Resultado: A literatura revela que o número de infecção por COVID-19 tem maior potencial de disseminação e capacidade de provocar mortes em populações vulneráveis. No Brasil, devido a desigualdade social, com populações vivendo em condições precárias, em situação de aglomeração como um exemplo as periferias. Mesmo que a pandemia já esteja estabelecida, o primeiro passo seria reduzir os picos, assim, reduziria os números nos serviços de saúde e permitiria um tratamento adequado a população infectada pelo vírus. Conclusão: É necessário que os Governos tomem medidas de combate e controle à COVID-19, pois apresenta uma grande ameaça para a população. Onde, além de conscientizar a população sobre cuidados para prevenir contágio do vírus, disponibilizar e orientar a forma correta do uso de máscaras, utilização do álcool à 70\% e lavagem das mãos. Ademais, ofertar treinamento aos profissionais de saúde para identificar e tratar os infectados pelo vírus.

Palavras-chave: Enfermagem. Infecção por coronavírus. Promoção da Saúde.

Área Temática: Atenção à saúde. 


\title{
HOSPITALIZAÇÃO DE PACIENTES ADULTOS POR COMPLICAÇÕES DE DOENÇAS CRÔNICAS NÃO TRANSMISSÍVEIS
}

\author{
Amanda Assis Andrade', Ivonete Sousa Freitas², Matheus Sobral Silveira ${ }^{3}$ \\ ${ }^{1}$ Centro Universitário Estácio da Bahia ${ }^{2}$ Centro Universitário Estácio da Bahia \\ ${ }^{3}$ Centro Universitário Estácio da Bahia
}

Introdução: Com o crescimento expressivo do sobrepeso e obesidade as Doenças Crônicas Não Transmissíveis (DCNT) são responsáveis por grandes despesas, elevadas taxas de hospitalizações e perda da qualidade de vida, cujos fatores como tabagismo, alimentação inadequada e sedentarismo têm contribuído para o aumento destas. Além da forte carga de morbidades, as DCNT estão entre as principais causas de amputações e de perdas de mobilidade e de outras funções neurológicas. Objetivo: Descrever a prevalência de hospitalização em pacientes adultos secundários as complicações por DCNT. Métodos: O estudo constitui-se de uma revisão da literatura do tipo narrativa, decorrente da análise de artigos obtidos nas bases de dados Google Acadêmico, SciELO, LILACS e Periódicos CAPES, foram selecionados trinta e sete artigos, após a análise dos critérios de exclusão e inclusão, resultaram em um total de vinte artigos. Resultados: Indicadores recentes descrevem que o número de portadores de DCNT que requerem atendimento hospitalar tende a aumentar, sendo estas as principais causas de morte e incapacidade na população mundial e responsáveis por altos encargos econômicos no sistema de saúde. Dentre as DCNT mais prevalentes, a Hipertensão Arterial (HA) e o Diabetes Mellitus (DM) destacam-se como importantes causas de internações hospitalares e mortalidade no Brasil. Além de constituírem grandes problemas de saúde pública, as duas condições associam-se as complicações como doenças cerebrovasculares, doença arterial coronariana, insuficiência cardíaca e renal e doenças vasculares periféricas. Conclusão: Considera-se que a HA e DM são responsáveis por diversas complicações e internação hospitalar. Aponta-se que a assistência à saúde realizada através dos serviços básicos e profissionais multidisciplinares possui o papel importante na redução e manutenção das internações hospitalares.

Palavras-chave: Internação. Hipertensão arterial. Diabetes mellitus.

Área Temática: Clínico - Hospitalar; 


\section{CANSAÇO, ALTERAÇÃO DO SONO E PREOCUPAÇÃO COM O CORPO: INDICADORES DE DEPRESSÃO MATERNA}

\section{Cristiane Ajnamei dos Santos Alfaya}

Universidade Federal do Recôncavo da Bahia

A transição para a maternidade, principalmente quando se trata do primeiro filho, está associada a importantes mudanças individuais (físicas e psíquicas) e sociais, as quais podem ser observadas em diferentes contextos. Destacando os aspectos psicológicos, autores como Winnicott têm sugerido que com a maternidade a mulher entra numa condição psíquica especial que a coloca num estado de grande disponibilidade emocional para o bebê, promovendo um ambiente suficientemente bom e o desenvolvimento saudável da criança. O presente estudo investigou a presença de indicadores de depressão em mães com bebês aos seis meses de vida. Participaram do estudo 17 mães com idade entre 16 e 38 anos, de diferentes níveis socioeconômicos que coabitavam com o pai do bebê e participavam do Programa de Saúde da Família na cidade de Santo Antônio de Jesus (Bahia Brasil). O Inventário Beck de Depressão (BDI) e uma Entrevista Diagnóstica detectaram 08 mães apresentando indicadores de depressão, atingindo o nível moderado de depressão (grupo I), e 09 mães não apresentando indicadores de depressão (grupo II). A Entrevista Diagnóstica foi utilizada com todas as mães, para complementar os resultados obtidos através do BDI. Para análise das entrevistas foi utilizada a análise de conteúdo. As respostas das mães foram categorizadas com base em três eixos temáticos de indicadores de depressão conforme a BDI, como sentimentos de cansaço, percepção de alteração no sono, e sentimentos de preocupação com o corpo. Os resultados encontrados chamaram a atenção para a similaridade entre os grupos em relação às categorias analisadas não havendo diferença entre as mães. Através da BDI, as mães de ambos os grupos apresentaram indicadores de depressão como cansaço; alteração do sono; e preocupação com o corpo. Os resultados foram discutidos com base na teoria de Winnicott sobre a maternidade e o valor da depressão.

Palavras-Chave: Depressão, Maternidade, Indicadores.

Área Temática: Clínico - Hospitalar 


\section{OBSERVAÇÃO DA INTERAÇÃO MÃE-BEBÊ E O COMPORTAMETO EXPLORATÓRIO DO BEBÊ NO CONTEXTO DA DEPRESSÃO MATERNA}

\section{Cristiane Ajnamei dos Santos Alfaya}

Universidade Federal do Recôncavo da Bahia

Estudos empíricos apontam relações entre a depressão materna e o desenvolvimento emocional do bebê. O presente estudo teve como objetivo examinar o comportamento de mães com depressão e o comportamento exploratório dos bebês, aos 12 meses de vida, na situação de observação da interação mãe-bebê. Participaram do estudo cindo díades mãe-bebê. Através de visitas domiciliares realizou-se uma filmagem da interação mãe-bebê em situação estruturada de jogo livre durante quinze minutos. A análise apoiou-se no Protocolo de Observação da Interação Mãe-bebê. A depressão materna foi examinada pelo Inventário Back de Depressão. O comportamento materno foi categorizado em comportamentos de sensibilidade e intrusivo. O comportamento exploratório do bebê foi analisado pelas respostas da criança aos estímulos comunicativos da mãe, e de tentativas da criança para estabelecer contato verbal elou fisico. Os resultados indicaram que as mães com depressão mostraramse moderadamente sensíveis aos sinais do bebê, enquanto as mães sem depressão se apresentaram sempre sensíveis durante a observação. O comportamento intrusivo também foi observado entre as mães com e sem depressão. Com relação aos comportamentos da criança em responder aos estímulos comunicativos da mãe, tanto àquelas de mães com depressão, como as de mães sem depressão demonstraram responder moderadamente os estímulos comunicativos. No tocante ao comportamento de tentativas da criança para estabelecer contato verbal e/ou físico com a mãe, as crianças de mães com e sem depressão apresentaram nível moderado. Este estudo chama a atenção para a necessidade de novas pesquisas, e critica a relação entre depressão e sensibilidade materna sem considerar a qualidade da interação. A discussão é baseada na teoria da separação-individuação, constatando que as crianças de mães com depressão apresentam comportamento exploratório, o que indica autonomia em termos do desenvolvimento emocional.

Palavras-chave: Interação, Depressão, Comportamento exploratório.

Área Temática: Clínico- Hospitalar 


\section{ASPECTOS OBJETIVOS E SUBJETIVOS DA INTERAÇÃO MÃE-BEBÊ NO CONTEXTO DA DEPRESSÃO MATERNA}

\section{Cristiane Ajnamei dos Santos Alfaya}

Universidade Federal do Recôncavo da Bahia

Com a maternidade, a mulher experimenta mudanças físicas, psíquicas, sociais, as quais irão repercutir nas trocas interativas mãe-bebê durante os cuidados com a criança, especialmente no contexto da depressão materna. O presente estudo examinou o comportamento exploratório dos bebês, e o comportamento das mães com indicadores de depressão, frente ao comportamento exploratório dos bebês, durante a psicoterapia breve mãe-bebê, no primeiro ano de vida dos bebês. Participaram do estudo 05 díades mãe-bebê. As mães com idade entre 16 e 38 anos, de diferentes níveis socioeconômicos que coabitavam com o pai do bebê e participavam do Programa de Saúde da Família na cidade de Santo Antônio de Jesus (Bahia - Brasil). O Inventário Beck de Depressão (BDI) e uma Entrevista Diagnóstica detectaram indicadores de depressão. Foram considerados os aspectos objetivos e subjetivos da interação, envolvidos no comportamento exploratório do bebê. O comportamento do bebê foi descrito e analisado conforme as categorias manipulação exploratória fina e ampla, e de locomoção exploratória em direção ao ambiente e ao brinquedo. O comportamento materno foi descrito e analisado conforme as categorias direto e indireto, construídas a partir da descrição da observação durante as sessões de psicoterapia. Apoiando-se na teoria psicanalítica da separaçãoindividuação, os resultados mostraram que os bebês apresentaram comportamentos de manipulação exploratória fina, ampla, locomoção exploratória em direção ao ambiente, e aos brinquedos. Esses achados indicam o desenvolvimento da autonomia dos bebês na perspectiva do desenvolvimento emocional. Através do discurso das mães nas sessões de psicoterapia, os resultados apoiam as evidências de que a mãe, ao interagir com o bebê, relaciona-se não apenas com o comportamento observado de maneira objetiva, mas também com imagens (modelos), os quais pertencem à mãe e aparecem na interação com o bebê por meio da identificação projetiva.

Palavras-chave: Observação, Interação, Depressão.

Área temática: Clínico - Hospitalar 


\title{
CUIDADOS PALIATIVOS INTEGRADOS PARA O TRATAMENTOS DE IDOSOS INTERNADOS EM UTI'S.
}

\section{Josué Brito Gondim¹, Francisco Augusto Santana Pires², Larissa da Silva Leite Muniz.}

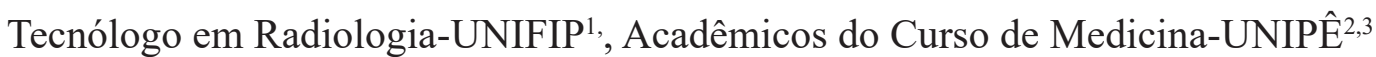

Introdução: Nos últimos anos, o índice de idosos no Brasil aumentou exponencialmente. Segundo o IBGE (2019), o número de idosos no país orçou a 32,9 milhões. Tais alterações proporcionou maior cuidado quando retratado aos cuidados paliativos em pacientes internados. Segundo Fonseca (2012), o impacto do envelhecimento da população só passou a ser valorizada no final da década de 1980 e, derivado da importância da terceira idade, diversas práticas clínicas especializadas para idosos foram criadas. Fratezi (2009) afirma que, a em termo dos sentimentos negativos existentes nesse momento da vida, o despertar das frustações e alterações emocionais. Fatores que interferem na didática social. Observando tais alterações, os cuidados paliativos como a música e a religião virou um forte apoiador nos tratamentos terminais dos idosos internados, devido a música está presente no tópico da "expressão não verbal". (SEKI; GALHEIRGO, 2019) e a religião ser um dos fatores impar para o conforto na situação do paciente. (BARBOSA; FREITAS, 2010). Objetivo: Observar a eficácia de tratamentos paliativos nos idosos em UTI's e quais alterações tais cuidados proporcionam no processo de cura em UTI's. Metodologia: Revisão literária baseado no scielo onde teve-se a filtragem :Idosos, tratamento, paliativo. Resultados: Percebe-se que, não importa o tratamento selecionado como cuidado paliativo, mas sim, a interação social e importancia que tem com os pacientes que ocasionam o melhoramento e eficacia no tratamento. Conclusões: Dadas as evidencias, a cura com o tratamento paliativo proporciona, na maioria dos casos, o conforto final para que o paciente descanse em paz.

Palavras-Chaves: Terceira Idade. Tratamento paliativo. Cura.

Área Temática: Clínico Hospitalar. 


\title{
TUBERCULOSE EXTRAPULMONAR E PACIENTES IMUNOCOMPROMETIDOS, UMA ATUALIZAÇÃO BIBLIOGRÁFICA
}

\section{Amanda dos Santos AMORIM'; Ana Maria Fernandes MENEZES²; Cássia Milene Ribeiro LOPES $^{3}$}

\author{
Centro Universitário Faculdade Guanambi ${ }^{1,2,3}$
}

Introdução: A tuberculose (TB) é uma doença antiga, infectocontagiosa causada pela micobactéria chamada Mycobacterium tuberculosis ou Bacilo de Koch (BK). Sua transmissão é direta, sendo através do contato de pessoa a pessoa pelas vias aéreas. É importante ressaltar que ao longo da vida as pessoas podem entrar em contato com o BK e não desenvolver a doença, devido a competência do sistema imunológico. Existem alguns tipos de TB, dentre esses a forma extrapulmonar está presente em 20\% dos casos, sendo 50\% dos contaminados imunocomprometidos. Objetivo: O objetivo desse estudo é analisar a relação que existe entre os pacientes com tuberculose extrapulmonar e paciente imunocomprometidos, principalmente portadores do HIV/AIDS. Material e Métodos: Esse estudo refere-se a uma exploração bibliográfica, em que utilizou-se as bases de dados google acadêmico, PubMed, Scielo, tese publicada pela FioCruz. Foram selecionados 8 artigos, sendo 7 nacionais e 1 internacional. Resultados: As manifestações clínicas ocasionadas pela tuberculose extrapulmonar são inespecíficas, pois está relacionada diretamente ao sistema acometido, podendo afetar pleura, nódulos linfáticos, abdome, sistema geniturinário, articulações, ossos, meninges, laringe e partes moles. O HIV/AIDS foi descoberto em 1981, nesse mesmo período houve um aumento considerável dos casos de TB extrapulmonar, vindo, principalmente desses pacientes, sendo assim a infecção pelo HIV é considerada fator de risco para o desenvolvimento de TB extrapulmonar, independente do grau de imunodepressão ou do uso de drogas anti-retrovirais. A TB extrapulmonar é a principal causa de morte por doença infecciosa em pessoas que vivem com HIV. Conclusão: É fato a relação entre tuberculose extrapulmonar e HIV/AIDS devido a fragilidade do sistema imunológico, já que muitas pessoas entram em contato com o BK e não desenvolvem a doença, concluindo que, pessoas que vivem com HIV têm mais chances de contrair tuberculose, portanto recomenda-se o teste anti-HIV a todo indivíduo com diagnóstico estabelecido de tuberculose.

Palavras-chave: Bacilo de Koch. Doença infectocontagiosa. Imunodepressão.

Área temática: Clínico-hospitalar. 


\title{
LEUCEMIA MIELÓIDE AGUDA: CARACTERISTICAS CLÍNICA E DIAGNÓSTICO, UMA REVISÃO BIBLIOGRÁFICA
}

\author{
Amanda dos Santos AMORIM1; Ana Maria Fernandes MENEZES ${ }^{2}$
}

Centro Universitário Faculdade Guanambi ${ }^{1,2}$

Introdução: A leucemia é um tipo de câncer derivada de células hematopoiéticas que inicia-se na medula óssea e posteriormente invade o sangue periférico, atingindo vários órgãos. De acordo com a célula de origem ela pode ser dividida em mielóide ou linfóide. Com base na velocidade do surgimento da doença pode ser classificada como aguda (LA), ocorre de forma rápida e agrava-se num curto intervalo de tempo, e crônica, uma forma mais lenta e progressiva. Tratando da epidemiologia, a leucemia mielóide aguda (LMA) está presente em 90\% das LA em adultos e 15 a 20\% em menores de 10 anos. Objetivo: O objetivo desse estudo é explanar as principais manifestações clínica e o diagnóstico da LMA. Material e Métodos: Esse estudo trata-se de uma revisão bibliográfica, em que se utilizou para sua construção as bases de dados google acadêmico, PubMed, Scielo. Foram selecionados 9 artigos, sendo 5 nacionais e 4 internacionais. Resultados: As principais manifestações clínica desse tipo de câncer são anemia, cefaleia, alteração visual, dispneia, infecções constantes, febre que podem ocasionar quadros de coagulação intravascular disseminada, além de sintomas como hepatoesplenomegalia e dor óssea. O diagnóstico da LMAé realizado através de exames laboratoriais, como o hemograma, exames de coagulação e observar a morfologia das células alteradas, é importante identificar os bastonetes de Auer, que são mieloblastos patognômigo da doença, além do auxílio dos exames de imagem, como a tomografia. Conclusão: Como a LMA é um câncer frequente de progressão rápida que gera diversas manifestações clínicas graves a sua detecção precoce é uma estratégia para encontrar o tumor em fase inicial e, assim, possibilitar maior chance de tratamento, para isso é necessário se atentar nos sinais clínicos e realizar uma investigação com exames clínicos, laboratoriais e radiológicos, de pessoas com manifestações sugestivas da doença e assim realizar o tratamento corretamente.

Palavras-chave: Câncer. Células mielóide. Patogenia.

Área temática: Clínico-hospitalar. 


\title{
A IMPORTÂNCIA E O PAPEL DO PSICÓLOGO INSERIDO NO AMBIENTE HOSPITALAR
}

\author{
Juliana Soares Laudelino Santos ${ }^{1}$ \\ ${ }^{1}$ Universidade Federal de Alagoas
}

Introdução: A Psicologia Hospitalar pode ser compreendida como a prática do psicólogo inserido no hospital, a qual objetiva entender os aspectos psicológicos em torno do adoecimento. Conforme Angerami-Camon (2009), após a inclusão do psicólogo no ambiente hospitalar, a Psicologia passou a rever suas premissas, alcançando novos questionamentos e concepções que a fizeram procurar uma nova compreensão da existência humana. Objetivo: A presente pesquisa teve como objetivo discutir sobre a importância e o papel da Psicologia inserida no ambiente hospitalar. Metodologia: Trata-se de uma pesquisa bibliográfica e qualitativa a qual teve como embasamento a posição de alguns autores, selecionados como referencial teórico por possuírem uma quantidade significativa de trabalhos enfatizando a discussão sobre a temática. Entre esses autores, destacamos Angerami-Camon, Simonetti e Chiattone. Resultados: Angerami-Camon(1995, p.23) ressalta que a Psicologia Hospitalar possui como principal objetivo a minimização do sofrimento provocado pela hospitalização. Diante disso, o Psicólogo Hospitalar é um agente especializado do ponto de vista técnico para identificar as necessidades dos pacientes, familiares e equipe de saúde em relação ao momento vivenciado. Por se tratar de um campo de atuação que trabalha com questões emocionais e simbólicas em torno do adoecimento, o psicólogo possui um valor inestimável no decorrer do processo de hospitalização, pois, conforme Simonetti (2011) esta é a única profissão da área da saúde que é dedicada à escuta e ao trabalho do corpo simbólico do paciente em seu leito, por isso, defendemos que o psicólogo apto a atuar na área da saúde e hospitalar deve ter consciência de que seus conhecimentos lhe servirão de base para a sua prática. Considerações Finais: Portanto, a atuação do psicólogo é importante e necessária no contexto hospitalar, pois esse profissional privilegia o corpo simbólico do paciente, proporcionando-lhe abertura para a reelaboração de suas questões existenciais diante do adoecimento.

Palavras-chave: Psicologia Hospitalar; Hospitalização; Atuação Profissional.

Área Temática: Clínica - Hospitalar 


\title{
PRINCIPAIS COMPLICAÇÕES ASSOCIADAS À QUADROS GRAVES DA COVID-19, UMA REVISÃO INTREGATIVA DE LITERATURA
}

\section{Cássia Milene Ribeiro Lopes, Ana Maria Fernandes Menezes²}

\author{
Centro Universitário Faculdade Guanambi ${ }^{1,2}$
}

Introdução: A COVID-19 é uma doença causada pelo vírus SARS-CoV-2, conhecido popularmente como novo Coronavírus, o qual, veio a ocasionar uma pandemia que já atinge mais de 200 países desde dezembro de 2019. Os principais sintomas incluem, tosse, febre, alterações respiratórias, anosmia, ageusia, náuseas, diarréia, vômitos, hiporexia, astenia, dispnéia, dores de garganta e coriza. Objetivo: Este estudo tem por finalidade analisar as principais complicações associadas a quadros graves da Covid-19. Material e Métodos: Trata-se de uma exploração bibliográfica, utilizando as bases de dados google acadêmico, PubMed, Scielo e LILACS. Foram selecionados doze artigos, sendo nove internacionais e três nacionais, baseados em complicações da COVID-19. Resultados: Os quadros mais graves da doença estão associados à pacientes idosos ou portadores de comorbidades como, diabetes, doenças pulmonares, cerebrais, cardiovasculares, neoplasias e indivíduos imunossuprimidos nos quais, a taxa de mortalidade é descrita como nove vezes maior do que em pacientes sem patologias prévias. Sendo assim, os principais agravos descritos até o momento incluem: Pneumonia grave, síndrome do desconforto respiratório agudo, tromboembolismo, danos alveolares, choque séptico e fibrose pulmonar. A nível de sistema cardiovascular podem ocorrer, lesões agudas, insuficiência cardíaca, miocardite e arritmias. O sistema nervoso pode sofrer danos celulares, além de, meningite, encefalite, encefalomielite, acidente vascular cerebral, convulsões, encefalopatia, síndrome de Guillain-Barré, danos musculares e neuro-oftalmológicos, distúrbios de ansiedade e depressão. Alterações hematológicas são também observadas e relacionadas à eventos como coagulação intravascular disseminada. Ademais, foram descritos casos de insuficiência sistêmica com acometimento de órgãos, como rins e fígado, associados a tempestade de citocinas ocasionada pelo sistema imunológico. Conclusão: A COVID-19 é uma patologia recente, com questões ainda não esclarecidas, por isso é de suma importância a adoção de medidas preventivas principalmente por pessoas que possuem comorbidades, evitando assim o aumento de casos graves, internações, óbitos e do colapso dos sistemas de saúde.

Palavras-chave: Novo coronavírus. Comorbidades. Agravos.

Área temática: Clínico-Hospitalar. 


\title{
PRINCIPAIS MANIFESTAÇÕES CLÍNICAS ASSOCIADAS À SÍFILIS CONGÊNITA PRECOCE: UMA REVISÃO DE LITERATURA
}

\section{Cássia Milene Ribeiro Lopes ${ }^{1}$, Amanda dos Santos de Amorim²}

\author{
Centro Universitário Faculdade Guanambi ${ }^{1,2}$
}

Introdução: A Sífilis Congênita é uma patologia transmitida da mãe infectada pela bactéria Treponema pallidum para o concepto durante a gestação ou parto. Esta doença apresenta-se de forma precoce, quando o diagnóstico ocorre até dois anos de vida e pode ocasionar inúmeras alterações fisiológicas ao bebê, além da possibilidade da ocorrência de abortos espontâneos e morte neonatal. Objetivo: A finalidade deste estudo é analisar as principais manifestações clínicas associadas a Sífilis Congênita Precoce. Metodologia: Trata-se de um estudo exploratório, realizado através de revisões bibliográficas, utilizando para isso as bases de dados google acadêmico, Scielo e PubMed. Foram selecionados doze artigos, sendo seis internacionais e seis nacionais. Resultados: Os principais sinais e sintomas ocasionados pela Sífilis Congênita Precoce (SCP), estão diretamente relacionadas à idade gestacional, à resposta imunológica do feto, estágio da sífilis materna e acompanhamento pré-natal. Sendo assim, as pesquisas denotam como principais manifestações clínicas da SCP, Hepatoesplenomegalia e rash mucocutêneo com lesões principalmente nas faces, palmar, plantar, oral e fissuras radiadas periofacias, bem como, condilomas anogenitais ocorrendo em cerca de $70 \%$ dos casos. As alterações oculares incluem, lesões nas pálpebras, uveíte, glaucoma e corriorenite; já as neurológicas compreendem, pleocitose, alterações no líquido cefalorraquidiano, meningite, Leptomeningite Sifilítica Aguda, e Neurossífilis. Acometimento musculoesquelético, com periostite, osteocondrite e pseudoparalisia de Parrot. Vale ressaltar, as lesões ao aparelho respiratório ocasionando pneumonia e rinite sanguinolenta, além dos sinais e sintomas inespecíficos como febre, púrpuras, irritabilidade, prematuridade e baixo peso ao nascer. Conclusões: Visto que a sífilis congênita é uma infecção evitável, pode-se concluir que o aumento da propagação de informações à cerca da educação sexual, maior disponibilização de preservativos, melhoria dos programas de acompanhamento pré-natal e de tratamento da Sífilis são de extrema importância para haver a diminuição dos casos dessa doença e consequentemente de sua forma congênita.

Palavras-chave: Treponema pallidum. Concepto. Sintomatologia.

Área Temática: Clínico-Hospitalar 


\title{
A COMUNICAÇÃO NOS CUIDADOS PALIATIVOS E A ATUAÇÃO DA EQUIPE MULTIPROFISSIONAL NO ATENDIMENTO AO PACIENTE TRAQUEOSTOMIZADO
}

\author{
Larissa da Silva Leite Muniz ${ }^{1,2}$ Francisco Augusto Pires Santana ${ }^{1.2},{ }^{1}$ Fabiana Ramos de \\ Oliveira,
}

${ }^{1}$ Instituto Michelle Sales, ${ }^{2}$ Graduando em Medicina no Centro Universitário de João Pessoa (UNIPÊ)

INTRODUÇÃO: A transversalidade das práticas humanizadas, inclusive no Paliativismo, pode ser aplicada por meio de diversos mecanismos e faz da comunicação uma ferramenta essencial para a funcionalidade de uma terapêutica, possibilitando que o idoso exteriorize sentimentos e necessidades. Isso permite aos agentes da saúde respeitar a autonomia da população idosa que, em sua maioria, constituem-se como os pacientes internados mais submetidos à traqueostomia, por isso que a interação com eles deve ser estabelecida a fim de facilitar a identificação de sinais e sintomas ou possíveis problemas e desconfortos físicos. OBJETIVOS: Descrever a atuação da equipe multidisciplinar envolvida com o atendimento e vínculo mantidos entre os profissionais da saúde e o paciente com traqueostomia, dentro dos cuidados paliativos. METODOLOGIA: Revisão por levantamento exploratório em bases de dados da SciELO e Lilacs. RESULTADOS: A traqueostomia é um procedimento cirúrgico que consiste na abertura de um estoma na traquéia e a inserção de uma cânula para passagem de ar. Embora comum em Unidade de Terapia Intensiva (UTI), é limitante e provoca alterações anatomofisiológicas que dificultam a verbalização, afetando o tratamento individualizado, além disso a idade configura fator de risco para complicações clínicas e a incapacidade de comunicação aliada à rotina nas unidades de internação tornam a experiência do idoso traqueostomizado mais negativa. A interação pode ser otimizada por dispositivos e medidas como válvula fonatória, PEEP, (pressão expiratória final positiva) associada a válvula de Passy-Muir, linguagem gestual e escrita, considerando a história clínica e particularidades de cada paciente. CONCLUSÃO: Conclui-se que é preciso definir e realizar estratégias para que a comunicação seja possível e eficiente, frente a uma conduta comumente praticada em pacientes debilitados e pertencentes a uma estrutura etária avançada, afim de prestar o cuidado integral previsto ao hospitalizado, amenizar sua ansiedade e aprimorar a recuperação.

Palavras-chave: Idoso. Internação. Interação.

Área Temática: Clínico-Hospitalar. 


\title{
TROMBOSE VENOSA EM PACIENTES DE UNIDADES DE TERAPIA INTENSIVA COM INFECÇÕES POR COVID-19
}

\author{
Ane Maryne Rodrigues Fiuza ${ }^{1}$, Kaic Trindade Almeida ${ }^{2}$ \\ ${ }^{1}$ UniFG - Centro Universitário FG ${ }^{2}$ Biomédico - Esp. Docência no Ensino Superior
}

Introdução: A infecção pelo novo coronavírus tem sido descrita como uma pandemia pela Organização Mundial da Saúde (OMS). Trata-se de uma doença ainda pouco conhecida, cuja elevada taxa de transmissibilidade é responsável pelo rápido alastramento. Somada às demais complicações dessa patologia, estudos têm identificado a ativação da coagulação sistêmica marcante em pacientes com quadro grave de covid-19. Objetivo: Avaliar a ocorrência e os fatores de risco associados à Trombose Venosa em pacientes de Unidades de Terapia Intensiva com covid-19. Metodologia: Revisão bibliográfica realizada a partir da análise sistemática de publicações disponíveis nas bases de dados PubMed, Scielo e Biblioteca Virtual de Saúde (BVS). Os descritores utilizados foram coronavírus, trombose e unidade de terapia intensiva. Foram encontrados 10 artigos, sendo 9 internacionais e 1 nacional. Resultados: Verificou-se uma prevalência de tromboembolismo venoso, (TEV), em cerca de um terço dos pacientes infectados. A covid-19 pode estar vinculada a uma intensa liberação de citocinas inflamatórias que propiciam eventos tromboembólicos. Constatou-se que a elevação de dímeros D é um marcador útil na identificação de pacientes que necessitem de terapia anticoagulante completa. As complicações foram observadas intensamente em pacientes de UTI, chegando a 40\%. Além disso, observou-se que a admissão dos pacientes na UTI, sem a realização de profilaxia anticoagulante, é um fator de risco associado à ocorrência de Trombose Venosa Profunda (TVP), juntamente à necessidade do uso de ventilação mecânica e imobilização. Considerações finais: Notase que a trombose venosa ocorreu predominantemente em indivíduos cuja enfermidade apresentou-se mais grave. Em vista disso, a realização de procedimentos de triagem antitrombótica é primordial e requer ações estratégicas dos profissionais envolvidos, a fim de se evitar desfechos ruins nesses pacientes. Para tanto, é essencial a realização de estudos mais aprofundados acerca dessa temática.

Palavras-chave: Tromboembolismo. Coronavírus. UTI.

Área temática: Clínico-Hospitalar. 


\section{DERMATITE ASSOCIADA À INCONTINÊNCIA EM PACIENTES COM COVID 19: RELATO DE EXPERIÊNCIA}

\section{Fernanda dos Santos Almeida ${ }^{1}$}

${ }^{1}$ Enfermeira da comissão de cuidados com a pele e curativos da clínica médica do Hospital Evangélico

Introdução: A clínica médica covid é reservada para o isolamento dos pacientes infectados com o coronavírus da síndrome respiratória aguda grave 2 (SARS-CoV-2) até o final do tratamento proposto. $\mathrm{Na}$ clínica foi identificado pela comissão de cuidados com a pele e curativos, o aumento de casos de Dermatite Associada à Incontinência (DAI) em região perianal e glútea dos pacientes. Segundo o Ministério da Saúde, os distúrbios gastrintestinais como a diarreia é um sintoma da covid 19. Sendo observada a dermatite tanto em pacientes que deambulam como nos pacientes acamados. Objetivo: Descrever a assistência de enfermagem aos pacientes com dermatite associada à incontinência fecal. Metodologia: Trata-se de um relato de experiência da assistência de enfermagem em uma clínica médica covid durante o ano de 2020. Resultados: Depois de detectado o aumento dos casos de DAI na clínica, foi realizado um levantamento de dados para identificar qual o tipo de incontinência envolvida na dermatite e quais os pacientes acometidos. Foram identificados mais casos de dermatite associada à incontinência fecal e em pacientes idosos acamados. A equipe de enfermagem foi orientada a intensificar a higiene íntima destes pacientes e utilizar emulsão com óleo de andiroba a cada troca de fralda. Alguns pacientes apresentaram perda da epiderme devido à dermatite. Nestes pacientes, além dos cuidados citados foi adotada a prática do uso de toalha higiênica, a fim de formar uma barreira de contato da pele com o conteúdo fecal. Conclusões: Todos os pacientes apresentaram resolução da dermatite com as condutas traçadas pela comissão de cuidados com a pele e executada pela equipe de enfermagem. Sendo uma conduta de baixo custo. Através desta experiência, foi possível criar um fluxo de assistência de enfermagem ao paciente com dermatite associada à incontinência na clínica médica covid.

Palavras-chave: Enfermagem. Assistência. Dermatite.

Área Temática: Clínico - Hospitalar. 


\title{
ESQUIZOFRENIA E A EFICÁCIA DA ELETROCONVULSOTERAPIA
}

\section{Thialle Roberta da Silva Cruz ${ }^{1}$, Ilana de Souza Cavalcanti ${ }^{1}$, Maria Clara Lima Cavalcanti ${ }^{1}$}

\author{
${ }^{1}$ Centro Universitário Maurício de Nassau
}

Introdução: A esquizofrenia é definida como um transtorno psiquiátrico grave, que acaba por gerar disfunções cognitivas, comportamentais e emocionais. Estima-se ter uma prevalência de 1\% na população mundial, tendo seu início por volta dos 18 anos ou mais e afetando, em sua maioria, homens. De acordo com DSM V o indivíduo deve possuir, por um período significativo de um mês, dois ou mais critérios estabelecidos e entre os sintomas, devem constar obrigatoriamente delírios, alucinações ou discurso desorganizado. Há diversos tipos de tratamentos para esquizofrenia e dentre eles, a eletroconvulsoterapia (ECT), logo é válido analisar a sua eficácia em pacientes com transtorno esquizofrênico. Objetivo: Compilar achados presentes na literatura a respeito da ECT e sua eficácia em pacientes com esquizofrenia. Metodologia: O trabalho foi elaborado no primeiro semestre de 2020 em formato de revisão de literatura. Os dados foram retirados das bases de dados LILACS, MEDLINE, PUBMED e Scielo. Resultado: É relevante pontuar que devido ao uso abusivo e inadequado, por muitos anos, profissionais ficaram com certo preconceito acerca da utilização da ECT, entretanto, há estudos de ensaios clínicos randomizados que concluem a eficácia da prática, principalmente em quadros de depressão e esquizofrenia. Encontra-se evidências que a ECT chega a ser, quando associada aos antipsicóticos, superior ao tratamento farmacológico sozinho e com isso consegue diminuir as taxas de recidiva e de permanência hospitalar. Estudos também indicam eficácia em casos de pacientes senis que não responderam bem ou tiveram resistência ao tratamento farmacológico e indivíduos que apresentaram agitação, catatonia e entre outros sintomas. Conclusão: Conclui-se, portanto, que na maior parte dos estudos houve de fato eficácia na utilização da ECT em pacientes psiquiátricos. É de extrema relevância que haja uma maior disseminação dos benefícios da eletroconvulsoterapia e com isso uma tentativa de retirar o preconceito enraizado entre profissionais de saúde.

Palavras-chave: Transtornos Esquizofênicos. Terapia Eletroconvulsiva. Estigma Social

Área Temática: Clínico - Hospitalar 


\title{
MANEJO DA VENTILAÇÃO MECÂNICA INVASIVA EM PACIENTES CARDIOPATAS COM COVID 19
}

\section{Ana Carolina Alves de Oliveira ${ }^{1}$, Samila Sousa Vasconcelos ${ }^{2}$.}

\author{
Centro universitário INTA - UNINTA ${ }^{1,2}$.
}

Introdução: Nos dias atuais a pandemia do vírus Covid 19 ganhou destaque, principalmente por meio da gravidade que a doença pode atingir gerando casos de intubação precoce, principalmente em pacientes com comorbidades crônicas sendo respiratória, cardíacas ou de natureza multifatorial. Estudos demonstram que são estes os pacientes que apresentam maior mortalidade. Objetivo: Investigar o manejo e a correta aplicação da ventilação mecânica invasiva em pacientes cardiopatas com na Covid 19. Metodologia: Trata-se de uma pesquisa bibliográfica de abordagem qualitativa, onde foi realizado um levantamento de literatura no período compreendido entre agosto e setembro de 2020 utilizando-se as bases de dados centíficas LILACS (Literatura Latino-Americana e do Caribe em Ciências da Saúde), SciELO (Scientific Electronic Library Online) e BVS (Biblioteca Virtual em Saúde). Como critério de inclusão selecionaram-se artigos publicados nas línguas portuguesa e inglesa disponibilizados na íntegra e de exclusão os artigos que não estiveram concernentes com o tema proposto. Resultados e discussão: Nos 3 estudos incluídos, observou-se que cerca de 6 a $42 \%$ dos infectados pelo Sars-Cov-19 precisam de suporte de ventilação mecânica invasiva. Dependendo da população estudada, tais números podem crescer. A pneumonia causada pelo novo coronavírus gera lesão grave do parênquima pulmonar com hipoxemia acentuada em 10-20\% dos casos. Percebese a busca por evitar a piora dos sintomas dos pacientes infectados pelo vírus, como forma de reduzir a necessidade de internação em UTI e do uso de ventilação mecânica invasiva. Os erros nos ajustes dos paramêntros do ventilador mecânico podem ocasionar graves iatrogenias e risco de óbito. Conclusão: São escassas as literaturas que discorrem sobre manejo da ventilação mecânica invasiva em pacientes cardiopatas com Covid 19 no tratamento direto, no entanto, é possível perceber as potencialidades desta, quando usada corretamente, no aumento da sobrevida dos pacientes.

Palavras-chave: Infecções por coronavirus. Pneumonia. Assistência à saúde.

Área Temática: Clínico - Hospitalar; 


\title{
AVALIAÇÃO E TERAPIA NUTRICIONAIS EM PACIENTE COM LINFOMA HODGKIN REFRATÁRIO: ESTUDO DE CASO
}

\author{
Gleidison Andrade Costa ${ }^{1}$, Camila Araújo Pereira ${ }^{2}$, Gabriela Sander de Sousa Nunes Costa ${ }^{3}$, \\ Marcos Rodrigo Guimarães Cruz ${ }^{4}$ \\ 1;2;3 Secretraria de Estado da Saúde do Maranhão (SES-MA);
}

Introdução: o Linfoma de Hodgkin (LH) é um tipo neoplasia linfoproliferativa concebida histopatologicamente pelo comparecimento de células cancerosas de morfologia diversa, designadas Reed-Sternberg (células grandes, multinucleada). Relato de caso: mulher cisgênero, 40 anos, sob diagnóstico clínico-oncológico de Linfoma Hodgkin Refratário com presença de massa retroperitoneal em ilíaco à esquerda. Incialmente, a paciente foi atendida pelo Serviço de Pronto Atendimento do Hospital de Câncer do Maranhão devido a quadro de neutropenia febril, edema e algia em membro inferior esquerdo, em seguida foi transferida para a Clínica Oncológica I de Hematologia. Na avaliação nutricional de admissão, o peso identificado foi de 52,0 kg, altura: 1,50 cm, IMC: $23 \mathrm{~kg} / \mathrm{m}^{2}$ (eutrofia). A paciente relatou peso há um mês de $55 \mathrm{~kg}$, evidenciando uma perda intensa $(>5 \%)$. No exame físico, observou-se déficit moderado das reservas musculares e de gordura, presença de edema em membro inferior, boa capacidade funcional, mastigação e deglutição adequadas; redução do consumo alimentar; apetite presente, porém sensação de plenitude gástrica precoce, abdômen globoso; presença de náuseas, vômitos, com função intestinal irregular, ausência de alergias e intolerâncias alimentares. Triagem nutricional: ASG-PPP: B - 13 (desnutrição suspeita ou moderada). Diagnóstico nutricional: desnutrição proteico-energético. Durante a internação, observou-se diminuição da ingesta alimentar por baixa adesão à dieta hospitalar, porém com relato de apetite preservado. A conduta nutricional foi dieta por via oral de consistência normal com característica adaptada à neutropênia e laxante, 6x/dia e sob o aporte nutricional de $2.200 \mathrm{kcal}$ e $90 \mathrm{~g}$ de proteínas, objetivando a não progressão do quadro de desnutrição hospitalar. Conclusão: Foi realizado acompanhamento da tolerância da dieta, manejo dos sintomas. Apesar das intervenções nutricionais com vistas à reversão do quadro de desnutrição, não foi possível atingir os objetivos propostos, podendo estar relacionado à progressão da doença $\mathrm{e}$ ao uso de múltiplas medicações para o controle de dor.

Palavras-chave: Linfoma de Hodgkin. Avaliação Nutricional. Terapia Nutricional.

Área Temática: Clínico - Hospitalar. 


\title{
AVALIAÇÃO NUTRICIONAL DO PACIENTE HEPATOPATA - UMA REVISÃO DE LITERATURA
}

\section{Marcos Rodrigo Guimarães Cruz ${ }^{1}$, Gleidison Andrade Costa ${ }^{2}$}

\author{
1;2Faculdade Estácio de São Luís
}

Introdução: a doença hepática avançada é responsável por alterações metabólicas acompanhadas de perda da massa e função muscular, com consequente deficiência motora global e inatividade física, as quais interferem negativamente na qualidade de vida dos pacientes. Portanto, a detecção precoce da desnutrição em pacientes com doença hepática é fundamental para prevenir a progressão da doença. Objetivo: nesta revisão serão abordados aspectos gerais da doença hepática, alguns mecanismos básicos da desnutrição nesses pacientes, métodos de avaliação antropométrica. Resultados: o uso da avaliação nutricional multicompartimental implica em alto custo financeiro destinado à saúde, o que limita drasticamente sua aplicação na prática clínica rotineira. Não existe, até o momento, um método considerado como padrão-ouro nesta situação clínica. Especificamente em pacientes cirróticos a prevalência de desnutrição é alta, independente da causa da doença. Considerações finais: o diagnóstico da desnutrição nesse grupo e a intervenção nutricional precoce são essenciais para o acompanhamento destes pacientes. As observações apontam a urgência em se obter um método adequado para a avaliação da composição corporal de pacientes com doença hepática na prática clínica.

Palavras-chave: Saúde. Doença hepática. Manejo nutricional.

Área Temática: Clínico - Hospitalar. 


\title{
VISITAS VOLUNTÁRIAS REALIZADAS PELO INSTITUTO TCHIBUM PARA CRIANÇAS HOSPITALIZADAS EM MANAUS, RELATO DE EXPERIÊNCIA
}

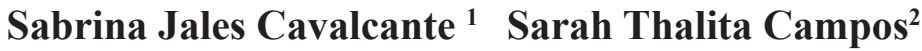

1 Centro Universitário do Norte - UNINORTE ${ }^{1}$ Centro Universitário do Norte - UNINORTE ${ }^{2}$ Centro Universitário do Norte - UNINORTE

Introdução: Um período prolongado de internação pode gerar ansiedade, estresse e depressão em crianças, conforme aponta especialistas, pois a criança tem a necessidade nata de expressar seus sentimentos no entanto a sua condição de hospitalizada a limita bastante o que pode prejudicar seu bem estar mental e social, é dever da equipe multiprofissional buscar meios de trabalhar os aspectos biopsicossocial destas crianças, as promovendo meios de expressarem e cuidarem dos seus impulsos emocionais. Objetivo: Relatar as vivências hospitalares por meio de visitas voluntárias em hospitais infantis da cidade de Manaus-Am, em parceria com o instituto tchibum no ano de 2019. Metodologia: trata-se de um relato de experiência de visitas voluntárias em hospitais infantis em parceria com um grupo de voluntários de distintas áreas de atuação tais como; engenharia, direito, enfermagem, pedagogia, psicologia, medicina, dentre outras. Com o objetivo de desenvolver, agir e potencializar ações sociais para contribuição do desenvolvimento humano. Resultados: em cada visita eram elaboradas as dinâmicas que poderiam ser aplicadas nas visitas voluntárias, seguindo principalmente os protocolos da instituição. As principais dinâmicas eram rodas de conversa, historias, músicas, piadas e danças e também os voluntários levavam consigo materiais para pintura e brinquedos. Conclusões: No decorrer de cada visita era possível a caracterização física de cada um dos voluntário, sendo assim cada voluntário assumia um personagem tal como palhaços, fadas, princesas, super-heróis. Proporcionando à interação dos voluntários com as crianças internadas junto aos seus respectivos acompanhantes e a equipe de enfermagem de cada setor, proporcionando conversas, brincadeiras e dinâmicas à fim de naquele momento ofertar alegria aos pacientes presentes ali.

Palavras-chaves: Dinâmicas. Hospitalização infantil. Ação social

Áreas temática: clínico- hospitalar 


\title{
SÍNDROME DE BURNOUT NOS PROFISSIONAIS DA ENFERMAGEM DURANTE O ENFRENTAMENTO DA COVID-19
}

\author{
Hanna Karina Melo Guimarães ${ }^{1}$, Rayana Gonçalves de Brito ${ }^{2}$, Loren Rebeca Anselmo do \\ Nascimento $^{3}$, Silvana Nunes Figueiredo ${ }^{4}$, Maria Leila Fabar dos Santos ${ }^{5}$, Leslie Bezerra \\ Monteiro $^{6}$
}

1,2,3,4,5,6Universidade Paulista

Introdução: a síndrome de Burnout afeta quase todas as facetas de vida de um indivíduo, é o resultado direto de tensão emocional, tensão no trabalho e o acúmulo excessivo de estresse, comum em profissionais que trabalham sob constante pressão. Este sofrimento foi perceptível na equipe de enfermagem que atuam na linha de frente durante apandemia da COVID-19 vivida nos últimos meses no Brasil, que além de lidar muitas vezes com a falta de equipamento de proteção individual, afastamento da família e pressões de pacientes, acompanhantes e gestores acarretou também prejuízos psicoemocionais na vida deste trabalhador. Objetivo: descrever fatores psicoemocionais que favorecem o aparecimento de sinais e sintomas da síndrome de Burnout em profissionais da enfermagem durante a pandemia da COVID-19 no município de Parintins-AM. Metodologia: tratase de um projeto de pesquisa de caráter exploratório descritivo de natureza qualitativa. A pesquisa envolverá a equipe de enfermagem do Hospital Regional Dr. Jofre Matos Cohen do município de Parintins-AM. Os dados serão coletados por meio de um questionário online indexado na plataforma Google Forms. Resultados esperados: dentre as mazelas sentidas pela equipe de enfermagem como as longas jornadas de trabalho, falta de reconhecimento profissional, sensação de exaustão, esgotamento físico, contato constante com o sofrimento e dificuldades de relacionamento levam a este trabalhador desenvolver a síndrome de Burnout. Considerações Finais: A síndrome está descrita como um problema de saúde laboral e tem consequências em nível individual e organizacional. Neste sentido, se faz necessário reconhecer as manifestações psíquicas e emocionais para identificar os agentes à ocorrência da síndrome de Burnout em profissionais da enfermagem.

Palavras-Chave: Saúde Mental. Exaustão Profissional. Enfermagem do Trabalho.

Área Temática: Clínico - Hospitalar. 


\title{
CONTRIBUIÇÕES DA RESIDÊNCIA EM GESTÃO DOS SERVIÇOS DE SAÚDE PARA O DESENVOLVIMENTO DA VISÃO SISTÊMICA NO CONTEXTO HOSPITALAR
}

\section{Elice Maria da Silva ${ }^{1}$, Stephanie Ramos de Almeida ${ }^{1}$, Aline Nazaré Carvalho de Almeida, Flavia Nishimura Bueno ${ }^{1}$, Natália Paranhos de Araújo ${ }^{1}$}

\author{
${ }^{1}$ Hospital Sírio Libanês
}

Introdução: O desenvolvimento da visão sistêmica é uma competência valorizada pelas diversas organizações do seguimento da saúde, pois auxilia a compreensão do todo com uma visão integrada de suas ações. A oportunidade de aprimorar essa competência na prática é potencializada pela residência, pois possibilita aos profissionais a vivência e reflexões sobre os princípios e diretrizes do sistema de saúde e o funcionamento da rede de serviços. Objetivo: Compartilhar a experiência da inserção em múltiplos cenários de atividades relacionadas à saúde e a contribuição da residência para o desenvolvimento da visão sistêmica. Metodologia: O estudo se desenvolve através do relato de experiência com a estratégia de incorporar cenários de prática com amplos contextos da área hospitalar adotada pelo programa de residência de Gestão dos Serviços de Saúde e Redes de Atenção à Saúde em 2020. Resultados: Durante as atividades práticas do programa, proporcionou-se o acompanhamento de rotinas hospitalares assistenciais e não assistenciais. Destacando o contexto não assistencial, observaram-se as atividades de diversos setores envolvendo atendimento, infraestrutura, financeiro, sustentabilidade e tecnologia, ampliando os conhecimentos para além dos cuidados prestados diretamente ao paciente, auxiliando o pensamento crítico-reflexivo e prático sobre conexão das áreas assistenciais e não assistenciais formando um sistema de atividades interdependentes. Considerando o contexto da gestão em saúde, essa percepção na prática favorece a investigação ampliada de problemas, construção de processos integrados, monitoramento de oportunidades de melhorias para a organização como um todo e desenvolvimento de estratégias alinhadas com o cenário interno e externo da saúde no Brasil. Conclusões: A residência em Gestão dos Serviços de Saúde proporcionou o desenvolvimento da visão sistêmica do contexto hospitalar através da estratégia do cronograma prático contribuindo positivamente para aperfeiçoamento profissional dinâmico, participativo e inteirado com o sistema interno da instituição resultando no despertar para reflexões da visão sistêmica da saúde como um todo.

Palavras-chave: Aprimoramento de competências. Departamentos hospitalares. Educação baseada em evidências.

Área Temática: Clínico - Hospitalar 


\section{ALTERAÇÃO DA FORMA FARMACÊUTICA SÓLIDA PARA LÍQUIDA DE MEDICAMENTOS EM HOSPITAL PEDIÁTRICO}

\section{Autores: Júlia Kath Pereira da Silva, Karoline Flach e Francieli Zanella Lazaretto.}

Introdução: A carência de medicamentos apropriados para a pediatria gera a necessidade de modificações de formas farmacêuticas. Estratégias como a trituração de comprimidos e abertura de cápsulas para dispersão, são empregadas, trazendo riscos como a inexatidão da dose, assim como exposição de profissionais a substâncias que requerem cuidados específicos. Formulações líquidas são preferíveis, facilitando a administração e reduzindo perdas e custos. Assim, um grupo de farmacêuticas clínicas desenvolveu um projeto a fim de propiciar a troca da apresentação sólida para a líquida de medicamentos prescritos em um hospital pediátrico. Objetivos: Realizar intervenções farmacêuticas para a alteração da apresentação sólida para a líquida de medicamentos prescritos para pacientes pediátricos, visando maior segurança. Metodologia: Busca ativa diária nas prescrições do Hospital da Criança Santo Antônio da Santa Casa de Porto Alegre, no período de 01 a 02/2021, que continham os medicamentos sólidos os quais possuem formulação líquida disponível na instituição: cloreto de potássio $600 \mathrm{mg}$, omeprazol $20 \mathrm{mg}$, captopril $25 \mathrm{mg}$ e $12,5 \mathrm{mg}$, espironolactona $25 \mathrm{mg}$, furosemida $40 \mathrm{mg}$, hidroclorotiazida $50 \mathrm{mg}$, propranolol $40 \mathrm{mg}$ e $10 \mathrm{mg}$ e sulfametozaxol $400 \mathrm{mg} /$ trimetoprima $80 \mathrm{mg}$. Foram excluídas as prescrições de pacientes com idade $\geq$ que 10 anos e com dose prescrita correspondente a concentração da forma sólida ou a de seus múltiplos, não necessitando modificação por trituração ou dispersão. Resultados: Os dados foram compilados em planilha Excel ${ }^{\circledR}$. O medicamento mais prescrito foi o omeprazol (35,8\%), seguido de sulfametoxazol/trimetoprima $(28,3 \%)$ e hidroclorotiazida $(8,4 \%)$. Foram avaliadas 106 prescrições, realizadas 29 intervenções farmacêuticas e 9 prescrições (31\%) tiveram a alteração da apresentação do medicamento para a forma líquida. Conclusões: Evidenciamos que, mesmo possuindo apresentações líquidas disponíveis, ainda prescrevem medicamentos sólidos em pediatria. O curto período de trabalho e a carência de cultura para alteração de prescrições pode ter impactado nos resultados. Como perspectiva, pretendemos continuar realizando as intervenções, a fim de promover maior segurança ao paciente.

Palavras-chave: Pediatria. Suspensões. Comprimidos

Área temática: Clínico - Hospitalar 


\section{PARCERIA SERVIÇO-ESCOLA NA FORMAÇÃO TEÓRICA DE RESIDENTES DE ENFERMAGEM: RELATO DE EXPERIÊNCIA}

\section{Angélica de Godoy Torres Lima ${ }^{1}$, Raianne Monteiro Soares ${ }^{2}$}

${ }^{1}$ Instituto Federal de Educação Ciência e Tecnologia de Pernambuco - IFPE campus Belo Jardim,

${ }^{2}$ Hospital Regional do Agreste - HRA/ Caruaru-PE

Introdução: A residência em enfermagem é uma pós-graduação Lato Sensu, pautada na metodologia de ensino-serviço, com duração de dois anos e carga horária de 60 horas semanais, com total de 5.760 horas de curso de dedicação exclusiva. Essa modalidade tem maior foco na aprendizagem in loco, em que o residente é acompanhado por profissional da área em cada rodízio e um tutor responsável pelas atividades teóricas. Objetivo: Discutir a importância da colaboração interprofissional entre escola de enfermagem e serviço hospitalar na capacitação teórica de residentes de enfermagem na área hospitalar para integralidade do cuidado ao paciente. Metodologia: Trata-se de um relato de experiência, de abordagem qualitativa, com o recurso metodológico auto narrativo que tem a finalidade de discutir a colaboração de uma instituição de ensino com um programa de residência em enfermagem na área hospitalar. Resultados: As atividades envolveram aulas teóricas por videoconferência para a capacitação dos 10 residentes de enfermagem das áreas de emergência, cirúrgica e unidade de terapia intensiva, do primeiro e segundo ano. As aulas tiveram como fundamento a discussão de casos, esclarecimento de dúvidas e a interação entre professor e residentes, dentro da temática do processo de enfermagem para pacientes com comprometimento renal agudo e crônico em âmbito hospitalar, em terapia renal substitutiva ou não. A docente ministrante do conteúdo apresentava expertise em nefrologia e segundo feedback dos residentes atendeu a expectativa da assistência desse perfil de paciente dentro de suas respectivas especialidades. Considerações Finais: A participação de convidados externos ao hospital-escola na formação teórica dos residentes promove o enriquecimento do conteúdo teórico desenvolvido durante o curso, fortalece relações entre escola-serviço, pois ambas se auxiliam mutuamente, o hospital como campo de estágio para a escola e em troca há capacitação e atualização de conteúdos aos residentes, promovendo o atendimento integral aos pacientes através de embasamento técnico-científico.

Palavras-chave: Instituições acadêmicas. Educação de pós-graduação. Assistência hospitalar.

Área Temática: Clínico - Hospitalar. 


\title{
A INTERVENÇÃO FISIOTERAPÊUTICA NO PRÉ E PÓS CONTÁGIO POR COVID-19, UMA REVISÃO INTEGRATIVA DE LITERATURA
}

\author{
Paula Thays Silva Souza ${ }^{1}$
}

${ }^{1}$ Centro Universitário Faculdade Guanambi

Introdução: O SARS-CoV-2, causador da COVID-19, provoca síndromes respiratórias agudas e promove sintomas leves a complexos, que acarretam em complicações sistêmicas, que necessitam de internação. A fisioterapia, no âmbito hospitalar, vem ganhando espaço ao auxiliar no tratamento dessa patologia. Embora fisioterapeutas dessa área, utilizem bases cientificas para intensificar a intervenção, o cenário proposto, se difere. Assim, estudos de outras afecções respiratórias, são utilizados para conter os agravos do coronavírus. Objetivo: Este estudo tem a finalidade de avaliar a intervenção fisioterapêutica no pré e pós contágio pela COVID-19. Material e Métodos: Trata-se de um estudo exploratório, realizado através de revisões bibliográficas, utilizando as bases de dados, SciELO, PubMed e LILACS. Foram selecionados cinco artigos nacionais e quatro internacionais. Resultados: Dados mostram que, $20 \%$ das pessoas que contraem o vírus, necessitam de internação hospitalar e de cuidados específicos. Os estudos apontam que além de complicações respiratórias, os pacientes podem apresentar disfunções gastrointestinais, musculoesqueléticas e descompensação do sistema cardiovascular, principalmente por indivíduos acometidos previamente por cardiopatias. A contaminação traz sequelas importantes, provenientes da própria ação viral, bem como do estado hospitalar, em que se encontra o paciente. A intervenção precoce do fisioterapeuta, pode auxiliar numa melhor ventilação/perfusão, através de suportes ventilatórios, como a oxigenoterapia e ventilação mecânica. Além disso, visa diminuir quadros de síndrome da imobilidade prolongada, que trazem fraqueza muscular, contraturas, tromboembolismo venoso, instabilidade postural e ulceras de pressão. Ainda sugerem que após a finalização da doença, para melhora da capacidade cardiorrespiratória e funcional, haja a intervenção fisioterápica, com intuito de promover melhor qualidade de vida. Conclusão: Assim, verifica-se que a intervenção fisioterapêutica é essencial para melhora do quadro clinico do paciente e que, a avaliação individualizada, o monitoramento e a escolha da melhor terapêutica para o paciente acometido pela COVID-19, são primordiais para reabilitação das funções perdidas e diminuição do contágio.

Palavras-chave: Síndromes respiratórias. Coronavírus. Ação fisioterápica

Área Temática: Clínico - Hospitalar 


\title{
A FISIOTERAPIA RESPIRATÓRIA NA REABILITAÇÃO PULMONAR DE PACIENTES PÓS COVID-19, UMA REVISÃO INTEGRATIVA DE LITERATURA
}

\author{
Paula Thays Silva Souza ${ }^{1}$, Damilly da Silva Souza ${ }^{2}$
}

Centro Universitário Faculdade Guanambi ${ }^{1,2}$

Introdução: O vírus SARS-CoV-2, conhecido popularmente como coronavírus, é responsável por causar a COVID-19. O surto de uma forma de pneumonia, causada por esse vírus, foi observado em Wuhan, na China, em 2019, e logo se espalhou mundialmente. A contaminação viral provoca inúmeras afecções, entre elas, alterações pulmonares que trazem consideráveis sequelas. Objetivo: Este estudo tem a finalidade de identificar as ações fisioterapêuticas que favoreçam a reabilitação pulmonar do paciente que contraiu a COVID-19. Metodologia: Trata-se de uma exploração de bibliografias, utilizando para isso, as bases de dados PubMed, SciELO e LILACS. Foram selecionados doze artigos, sendo cinco internacionais e sete nacionais, baseados na reabilitação fisioterapêutica respiratória. Resultados: Há evidências que a infecção provoca efeitos deletérios em vários sistemas, como a descompensação do sistema pulmonar. Dados trazem que 15\% dos pacientes, apresentam dispneia, fadiga e sintomas torácicos relacionados com a pneumonia grave. Outra preocupação em casos graves, é a formação de coágulos sanguíneos no pulmão, que obstruem vasos e prejudicam as trocas gasosas. Além disso, é observada indícios de fibrose pulmonar. Com a evolução e alta do paciente, é necessária uma avaliação fisioterapêutica para saber quais técnicas serão executadas para melhorar a condição pulmonar. Pode ser aplicada a espirometria para intervir na funcionalidade, condutas de expansão torácica, manobras de desobstrução das vias aéreas, fortalecimento dos músculos respiratórios, incluindo exercícios aeróbios e treinos que diminuam a dispneia. É importante, que o paciente esteja estabilizado e que não apresente sintomas como, pirexia, taquicardia, quedas na saturação de oxigênio, dispneia, tosse grave, palpitações, fadiga ou agravo do sistema respiratório. Conclusão: Assim, a fisioterapia respiratória em pacientes recuperados, traz a melhorara do prognóstico, promove a reabilitação de funções perdidas, assim como, preserva a funcionalidade e a qualidade de vida. Demonstrando que a avaliação e o plano individualizado, são cruciais para eficácia da intervenção.

Palavras-chave: Coronavírus. Intervenção fisioterapêutica. Alterações respiratórias.

Área Temática: Clínico - Hospitalar 


\section{PRECEPTORIA DE RESIDÊNCIA HOSPITALAR NO CONTEXTO DA PANDEMIA DE}

\section{COVID-19: RELATO DE EXPERIÊNCIA}

\section{Joana Angélica Marques Pinheiro', Antonia Amanda Araújo², Mariana Rodrigues De Araújo Ivna De Moura Brasil Ramos ${ }^{4}$, Ana Virgínia Sales Monte Costa ${ }^{5}$ Vera Lúcia Mendes de Paula $\operatorname{Pessoa}^{6}$ Thereza Maria Magalhães Moreira $^{7}$}

1,2,3,4,5 Hospital Dr Carlos Alberto Studart Gomes, ${ }^{6,7}$ Universidade Estadual do Ceará

DOI: $10.47094 /$ ICONRES.2021/22

Introdução: A necessidade de uma saúde ampliada que priorize assistência especializada e integral à população foi evidenciada com as residências integradas em saúde, modalidade de ensino aprendizagem em serviço, envolvendo diferentes categorias profissionais. No contexto hospitalar a residência possibilita relações transversais e complementares, tendo o preceptor um papel fundamental no direcionamento e aperfeiçoamento do aprendizado ao cuidado integral ao paciente. Com a pandemia de Covid-19, de rápida disseminação, os hospitais se viram obrigados a realizar mudanças estruturais e comportamentais de seus profissionais, incluindo preceptores e residentes. Objetivo: Relatar experiência de preceptoria de residência integrada em saúde, a nível hospitalar, no contexto da pandemia de Covid-19. Metodologia: Relato de experiência de preceptoria, em hospital referência em cardiopneumologia, no contexto da pandemia, com suas restrições e cuidados. Resultados: A pandemia provocou elevada demanda de atendimento hospitalar à pacientes com complicações por Covid-19, com necessidade de suportes tecnológicos e profissionais capacitados, exigindo cuidados rígidos com paramentação, uso de EPIs, normas de convívio e recursos técnicos para promover conforto e benefício a profissionais e pacientes. Preceptores e residentes precisaram se adaptar a essa nova realidade de assistência à beira leito, exigindo habilidade, comprometimento e agilidade na prestação do serviço, atuando próximo aos demais integrantes da equipe, na busca por rapidez e eficiência de cada caso, para favorecer alta precoce e minimizar seqüelas advindas da doença. Conclusão: A atuação de preceptor e residente, no contexto Covid em ambiente hospitalar, precisa ser pautada na parceria, suporte técnico e emocional, interprofissionalidade, celeridade e resolutividade dos casos, possibilitando aprendizado ampliado, cuidado integral e efetivo ao paciente.

Palavras-chave: Residência multiprofissional. Covid-19. Hospital.

Área Temática: Clínico - Hospitalar 


\title{
CONTRIBUIÇÕES DA RESIDÊNCIA MULTIPROFISSIONAL EM FONOAUDIOLOGIA PARA O HOSPITAL REFERENCIA EM CARDIOPNEUMOLOGIA
}

\author{
Antonia Amanda Araújo', Mariana Rodrigues De Araújo², Ivna De Moura Brasil Ramoª Ana \\ Virgínia Sales Monte Costa ${ }^{4}$, Joana Angélica Marques Pinheiro 5 , Vera Lúcia Mendes de Paula \\ Pessoa $^{6}$
}

\section{1,2,3,4,5 Hospital Dr Carlos Alberto StudartGomes, ${ }^{6}$ Universidade Estadual do Ceará}

Introdução: Atualmente tornou-se emergente a competência profissional além da teoria vista nas faculdades, evidenciando assim, as residências multiprofissionais em saúde que têm o intuito de preparar e qualificar o residente, para o cuidado assistencial integral e ao mesmo tempo especializado na prática. $\mathrm{O}$ residente em Fonoaudiologia hospitalar atua com o paciente a beira leito de forma precoce, preventiva, intensiva, pré e pós-cirúrgica, independentemente da idade, reabilitando e minimizando sequelas advindas da patologia de base ou dos procedimentos ocorridos. Objetivo: Compreender o entendimento que médicos possuem sobre a atuação e tempo ideal para solicitar avaliação fonoaudiológica pelo residente no contexto da pneumologia. Metodologia: Trata-se de estudo descritivo, qualitativo, desenvolvido para conclusão da residência integrada em saúde, com ênfase em cardiopneumologia, aprovado com número de parecer 4.005.183. Realizado em um hospital de referência, nas unidades da pneumologia, por meio de uma entrevista semi-estruturada, gravada sob autorização, com dez médicos que fazem parte da escala e rotina locais. Utilizou-se a análise de conteúdo de Minayo com transcrição das falas, organização e categorização em 5 eixos temáticos, sendo o eixo "Contribuições da Residência Multiprofissional para o serviço" abordado nesse trabalho. Resultado: A relevância da atuação do fonoaudiólogo nas alterações pulmonares foi destacado pelo reconhecimento da alteração na coordenação respiração e deglutição, riscos de aspiração e pneumonia de repetição, comuns nos pacientes pneumopatas. As falas dos médicos participantes enfatizaram a importância da presença do residente em Fonoaudiologia inserido no serviço, junto à equipe, como vantagem pela oportunidade de trocas, contribuições e compreensão do papel do outro, além de promover um olhar ampliado e integral em benefício ao paciente. Conclusão: A atuação do residente junto à equipe de saúde da unidade, oportuniza melhor assistência em termos de qualidade nos atendimentos dos pacientes, presta cuidado especializado e individualizado.

Palavras-chave: Práticas Interdisciplinares. Residência Multiprofissional. Pneumologia

Área Temática: Clínico - Hospitalar 


\title{
A NECESSIDADE DE DESENVOLVER HABILIDADES EM NEFROLOGIA DO ENFERMEIRO GENERALISTA PARA ASSISTÊNCIA INTEGRAL EM SAÚDE
}

\author{
Angélica de Godoy Torres Lima ${ }^{1}$
}

${ }^{1}$ Instituto Federal de Educação Ciência e Tecnologia de Pernambuco - IFPE campus Belo Jardim,

Introdução: As doenças renais nos últimos 20 anos passaram a ser consideradas como um importante e crescente problema de saúde pública a nível global, devido às suas elevadas e crescentes taxas de complicações e morbimortalidade, bem como suas repercussões sobre a qualidade de vida de seus portadores. Objetivo: Discutir a importância da nefrologia na formação de enfermeiros desde a graduação para a promoção do cuidado integral de pacientes com comprometimento renal nos diversos níveis de assistência. Metodologia: Estudo de relato de experiência que descreve a percepção de uma enfermeira nefrologista sobre o atendimento de enfermeiros generalistas e ou de outras especialidades para com o paciente renal desde a atenção primária até a terciária em setores não especializados em nefrologia. Resultados: As doenças renais apresentam desenvolvimento lento, que quando não diagnosticadas em tempo hábil exibem a inexorável evolução para a terapia de substituição renal e cabe ao sistema de saúde capacitar os profissionais de saúde com recursos que permitam a prevenção e o diagnóstico precoce da mesma. Observa-se que muitos pacientes renais descobrem a doença tardiamente, necessitando de terapia dialítica de urgência. A descoberta da doença e/ou início da hemodiálise, gera uma série de incertezas e mudanças na vida dos pacientes, com alterações abruptas de rotina. Infelizmente, pela formação deficiente em conceitos gerais de nefrologia na formação do enfermeiro generalista e de outras especialidades, como emergência e terapia intensiva, que lidam com este perfil de paciente, os mesmos se sentem desassistidos pela enfermagem que frequentemente relata temer atender esse paciente devido à complexidade. Considerações Finais: A atuação profissional, em especial da enfermagem que está mais presente durante o período de internação, torna-se de extrema relevância, desde os cuidados básicos até as orientações acerca das transformações ocorridas, além de ser o profissional que faz a conexão entre outros membros da equipe multiprofissional.

Palavras-chave: Insuficiência renal crônica. Lesão renal aguda. Cuidados de enfermagem

Área Temática: Clínico - Hospitalar. 


\title{
PRÁTICA DE RESSUSCITAÇÃO CARDIOPULMONAR EM PACIENTES COM PARADA CARDIORRESPIRATÓRIA DECORRENTE DA COVID-19
}

\author{
Dâmilly da Silva Souza', Paula Thais Silva Souza²
}

Centro Universidade Faculdade de Guanambi ${ }^{1,2}$

Introdução: A COVID 19 é uma infecção causada pelo novo Coronavírus SARSCoV-2, sendo um vírus identificado como a causa de um surto de doença respiratória, detectado pela primeira vez em Wuhan - China, em dezembro de 2019. Este vírus possui uma alta transmissibilidade e dispõe uma disseminação rápida, acarretando aos portadores complicações sistêmicas, entre elas, paradas cardiorrespiratórias (PCR). Objetivo: Este estudo teve como proposito, abordar sobre a ressuscitação cardiopulmonar em pacientes com COVID-19, em parada cardiorrespiratória Material e métodos: Trata- se de uma exploração bibliográfica, utilizando para isso bases de dados SciELO e LILACS. Foram selecionados seis bibliografias, sendo cinco artigos e um livro, todos nacionais. Resultados: Há indícios que a gravidade da infecção pode provocar ao indivíduo PCR. No contexto de seriedade desta infecção, a PCR torna-se comum em virtude de insuficiência respiratória, lesão miocárdica e arritmias ventriculares. A rápida identificação do fator desencadeante e a aplicação imediata e adequada das manobras de reanimação cardiopulmonar (RCP) em conjunto ao desfibrilador externo automático (DEA), garantem uma melhor sobrevida. No momento da ocorrência, a manobra de RCP deve-se manter uma frequência de 30 compressões torácicas, permitindo o retorno do tórax, minimizando as compressões para assegurar a oxigenação tecidual e com pausa no máximo de 10 segundos para 2 ventilações. A realização de ventilações com bolsa-válvula-máscara (BMV), deve ser evitada pelo elevado risco de aerolização e contaminação da equipe. Contudo, no caso de absoluta necessidade, o selamento da máscara deve feito corretamente e utilizando uma cânula orofaríngea. Caso haja precisão do desfibrilador, o profissional se afasta da vítima durante a descarga. Após o choque, é necessário retomar as manobras de compressão torácica e ventilação. Conclusão: Dessa maneira, as manobras de reanimação cardiopulmonar, podem intervir na melhora do quadro clínico, assim como, preservando as funcionalidades vitais e garantindo a sobrevida ao paciente.

Palavras-chave: Intervenção; Insuficiência Respiratória; Coronavírus.

Área Temática: Clínico - Hospitalar 


\title{
TRANSTORNO DE ESTRESSE PÓS-TRAUMÁTICO APÓS INFECÇÃO POR COVID-19: UMA REVISÃO DA LITERATURA
}

\author{
Iara Oliveira Costa ${ }^{1}$, Bruna Sampaio Lopes Costa ${ }^{2}$ \\ ${ }^{1}$ Centro Universitário Christus, ${ }^{2}$ Centro Universitário de João Pessoa
}

Introdução: O comprometimento funcional provocado pela COVID-19 também compreende repercussões neuropsiquiátricas adversas. Dentre elas, destaca-se o transtorno de estresse póstraumático (TEPT), o qual vem sendo discutido em estudos como uma das sequelas psiquiátricas mais frequentes e desgastantes da COVID-19 e como uma das principais causas de busca aos serviços psiquiátricos por indivíduos após a infecção. Objetivo: Revisar acerca dos casos de TEPT após infecção por COVID-19. Metodologia: Realizou-se uma revisão narrativa utilizando a base de dados Biblioteca Virtual em Saúde (BVS) com as palavras-chave "post-traumatic stress disorder", "covid-19" e "infection". Incluiu-se artigos originais e estudos bibliográficos publicados a partir de 2020 no idioma inglês ou português e que estivessem disponíveis na íntegra. Excluiu-se cartas aos editores, artigos de opinião e resenhas. Resultados: Um estudo apontou que, dentre 730 pacientes diagnosticados com COVID-19,96,2\% preencheram os critérios diagnósticos para TEPT. Outro estudo, por sua vez, relatou que, dos 238 pacientes internados pela infecção, apenas 41 (17,2\%) desenvolveram TEPT quatro meses após a alta hospitalar. Neste estudo, o sexo masculino foi considerado fator de risco independente para sintomas moderados a graves de TEPT. O desenvolvimento do transtorno foi associado ao trauma psicológico ao testemunhar infecção grave e morte em parentes e ao tratamento da COVID-19, que envolve diversos estressores: temor à morte; dor devido às intervenções médicas, como a intubação endotraqueal e sua longa duração; delirium. Pacientes internados em UTIs por COVID-19 grave podem ter taxas de TEPT mais altas após o tratamento do que os pacientes internados em UTIs gerais ou por cirurgia cardíaca. Conclusões: A COVID-19, desde seu surgimento em 2019, tem sido um importante desencadeador do transtorno. As causas mais associadas ao desenvolvimento do TEPT nos pacientes infectados estão relacionadas ao tratamento da infecção e aos sentimentos de angústia e de incerteza.

Palavras-chave: Dor. Medo. Sinais e Sintomas.

Área Temática: Clínico-Hospitalar. 


\title{
ASSOCIAÇÃO ENTRE A DEFICIÊNCIA DE VITAMINA D E A TUBERCULOSE
}

\author{
Bruna Sampaio Lopes Costa ${ }^{1}$, Iara Oliveira Costa ${ }^{2}$ \\ ${ }^{1}$ Centro Universitário de João Pessoa, ${ }^{2}$ Centro Universitário Christus
}

Introdução: A tuberculose atinge cerca de um quarto a um terço da população mundial. Concomitantemente, a deficiência de vitamina $\mathrm{D}$ é um problema que acomete cerca de 1 bilhão de pessoas mundialmente. Essa vitamina é um importante regulador imunológico, e estudos clínicos recentes demonstram a sua influência na patogênese da TB. Objetivo: Identificar a associação entre a deficiência de vitamina D e a tuberculose. Metodologia: Realizou-se uma revisão narrativa utilizando a base de dados PubMed. As palavras-chave utilizadas foram "Tuberculosis", "D Vitamin" e "Vitamin D Deficiency" combinadas com o operador booleano "AND". Incluiu-se artigos originais e revisões bibliográficas publicados nos últimos cinco anos, no idioma inglês e que estivessem disponíveis na íntegra de forma gratuita. Excluiu-se cartas aos editores, artigos de opinião e resenhas. Resultados: A ingestão adequada de vitamina D é essencial para evitar infecções graves por tuberculose, pois ela controla a sinalização do receptor de antígeno dos linfócitos $\mathrm{T}$, suprime a resposta imune adaptativa e diminui os níveis plasmáticos de interleucina - 1ß. Estudos demonstram que a deficiência de vitamina $\mathrm{D}$ aumentou o risco de TB e vice e versa. Devido à maioria destes estudos serem transversais, não houve avaliação dos níveis dessa vitamina antes da infecção, o que não permitiu inferir se existe um limite de concentração mínima que faça com que os indivíduos fiquem mais susceptíveis. A tuberculose pode levar à redução da ingestão alimentar e deficiências de micronutrientes, problemas estes resolvidos após tratamento adequado. A associação de baixos níveis de vitamina $\mathrm{D}$ com aumento do risco de tuberculose foi mais pronunciada entre pacientes HIV positivos. Conclusões: Concluímos que pode existir uma relação mútua entre deficiência de vitamina $\mathrm{D}$ e tuberculose. Estudos com evidências científicas precisam ser realizados para determinar a relação e a necessidade de suplementação profilática e terapêutica.

Palavras-chave: Mycobacterium tuberculosis. Suplementação nutricional. Hipovitaminose.

Área Temática: Clínico-Hospitalar. 


\title{
AGRAVAMENTO DE DOENÇAS DERMATOLÓGICAS ASSOCIADAS A ALTERAÇÕES EMOCIONAIS
}

\author{
Nathália Siriano Costa ${ }^{1}$, Hellen Kristina Magalhães Brito ${ }^{2}$, Isabella Siriano de Castro ${ }^{3}$, Lucas \\ Carvalho da Silva ${ }^{4}$, Otávio Gomes Barreto Araújo ${ }^{5}$
}

\begin{abstract}
${ }^{1,2}$ Centro Universitário Atenas, ${ }^{3}$ Universidade de Rio Verde - Campus Aparecida de Goiânia, ${ }^{4}$ Universidade Cesumar- Campus Maringá-PR, ${ }^{4}$ Instituto Tocantinense Presidente Antônio Carlos Campus Palmas
\end{abstract}

INTRODUÇÃO: A pele é um órgão capaz de transparecer diversas alterações emocionais, tornandose a principal via de acesso entre as emoções e reações psíquicas. Os transtornos emocionais podem tanto apresentarem-se como causas, quanto como consequências de afecções físicas. Dentre as doenças dermatológicas associadas ao psicológico, pode-se destacar a psoríase. OBJETIVOS: Enfatizar a relevância do tratamento multidisciplinar na qualidade de vida para pacientes dermatológicos. MÉTODOS: Os dados foram coletados nas bases SciELO, PUBmed e LILACS, através dos descritores "psicodermatologia", "estresse" e "dermatopatias", em língua portuguesa e inglesa. Foram incluídos ensaios clínicos randomizados, estudos observacionais e revisões sistemáticas. Foram excluídos carta ao editor, artigos sem acesso aberto, e que não tratassem do tema em questão. RESULTADOS: Em pacientes psoriáticos foi observado associação a altos níveis de estresse, depressão clínica, ansiedade crônica e pensamentos suicidas. Viu-se que esses pacientes cursavam com agravamento das feridas dermatológicas, e que os sintomas depressivos estavam altamente relacionados à diminuição da produção de melatonina. Esta é responsável pela inibição de processos inflamatórios, a partir da redução de TNF- $\alpha$, IL-6 e IL-8, sendo que a sua baixa implica na exacerbação dos efeitos da cascata inflamatória. Além disso, prologam o processo cicatricial das lesões cutâneas, tornando-as mais suscetíveis a infecções, agravando a manifestação da doença. Portanto, o tratamento associado ao acompanhamento psicológico é indispensável para o melhor prognóstico do paciente com doenças dermatológicas. CONCLUSÃO: Desta forma, a correlação entre transtornos depressíveis e a psoríase está intimamente ligado ao nível decrescente da produção de melatonina. Este evento, por sua vez, exacerba os sinais clínicos inflamatórios da doença. Sendo assim, faz-se estritamente necessário o acompanhamento multidisciplinar para o melhor prognóstico desses pacientes.

Palavras-chave: Psoríase. Dermatopatia. Depressão.

Área temática: Clinico-Hospitalar 


\title{
ESTUDO SOBRE O COMPROMETIMENTO RENAL NA ANEMIA FALCIFORME
}

\author{
Ester Rocha Lopes ${ }^{1}$, Mariana Coutinho Martins Ferreira ${ }^{1}$ \\ ${ }^{1}$ Centro Universitário Tocantinense Presidente Antônio Carlos - UNITPAC
}

Introdução: anemia falciforme é definida como uma doença genética em que há uma substituição de ácido glutâmico por valina na sexta cadeia beta da hemoglobina, originando uma molécula anormal com duas cadeias betas com defeitos e duas cadeias alfas normais. As alterações renais são comuns nessa patologia, podendo ser expressas em muitas formas que variam desde distúrbios da concentração urinária até síndrome nefrótica. Objetivo: o presente estudo tem o objetivo de identificar as principais alterações renais em pacientes portadores de anemia falciforme. Metodologia: tratase de uma revisão de literatura realizada com base em artigos científicas encontradas nos bancos de dados SciELO e Google Acadêmico, não havendo restrição de período. Foram incluídos apenas trabalhos completos em língua portuguesa, espanhola e inglesa sobre as alterações renais em paciente com doença falciforme, tendo a sua amostra final constituída por 12 artigos. Resultados: conforme as literaturas analisadas, a doença falciforme compromete em primeira circunstância a microvasculatura renal, gerando como consequência uma disfunção isquêmica tubular, sucedida de diversos infartos medulares e corticais. As desordens renais são classificadas em alterações estruturais e funcionais. As estruturais, podem ainda ser subdividas em glomerulares e medulares, sendo que as glomerulares são representadas principalmente por dilatação dos glomérulos com lobulação dos tufus glomerulares e hipercelularidade, enquanto que na medulares destaca-se oclusão da artéria vasa recta e lesões dos túbulos renais, junto com dilatação ou atrofia, deposição de ferro e cilindros proteicos. As alterações funcionais mais frequentes são proteinúria, disfunções hemodinâmicas e alterações da síntese dos hormônios renais. Conclusões: dessa forma, conclui-se que a anemia falciforme é associada a relevantes alterações renais, sendo crucial o conhecimento das suas principais manifestações patológicas a fim de proporcionar o desenvolvimento de melhores planos terapêuticos para os pacientes acometidos.

Palavras-chave: Doença Falciforme. Alterações Renais. Doença Genética.

Área Temática: Clínico-Hospitalar. 


\title{
ATUALIZAÇÃO DO TRATAMENTO CIRÚRGICO DA NEFROLITÍASE
}

\section{Mariana Coutinho Martins Ferreira ${ }^{1}$, Ester Rocha Lopes ${ }^{1}$}

\author{
${ }^{1}$ Centro Universitário Tocantinense Presidente Antônio Carlos - UNITPAC
}

Introdução: A nefrolitíase é caracterizada pela formação de cálculos, de diferentes composições, no trato urinário. Sua prevalência varia conforme a idade, o sexo, a raça e a geografia. Estima-se que no Brasil, o cálculo renal atinge cerca de $12 \%$ da população. Objetivo: Esse trabalho tem como objetivo evidenciar os principais métodos cirúrgicos, minimamente invasivos, na terapia dos cálculos do trato urinário. Metodologia: Trata-se de uma revisão bibliográfica, descritiva e qualitativa dos principais métodos cirúrgicos utilizados no tratamento da nefrolitíase. A fonte de pesquisa utilizada foi através dos seguintes sites de busca: Google Acadêmico, SCIELO e UpToDate. Foram empregados os seguintes descritores: nefrolitíase, litíase renal e urolitíase. O critério de inclusão atribuído foi artigos publicados entre os anos de 2015 a 2021, totalizando uma amostra de 11 artigos. Resultados: Os resultados demostram que o método de escolha para a terapêutica dos cálculos do trato urinário é determinado conforme o quadro clínico do paciente, o tamanho e a localização do cálculo, assim como o grau de obstrução. Sendo que $20 \%$ de todas as pedras nos rins requerem remoção cirúrgica. Atualmente, destacam-se a litotripsia extracorpórea por ondas de choque (LECO), a nefrolitotripsia percutânea (PCN), a ureterolitotripsia transureteroscópica (UL) e a ureterolitotomia laparoscópica (ULL) como opções de tratamento cirúrgico, minimamente invasivos, para os cálculos do sistema urinário. Já a cirurgia convencional - aberta - é realizada em menos de 1\% dos pacientes, reservada apenas nos casos de cálculos renais e uretrais complexos que não são removidos com os procedimentos menos invasivos. Conclusão: Dada a prevalência da formação de pedras no trato urinário, especialmente as que necessitam de intervenção cirúrgica, é imprescindível o conhecimento dos métodos menos invasivos em comparação com os métodos conservadores, levando em conta as mínimas complicações e a rápida recuperação pós-cirúrgica.

Palavras-Chave: Nefrologia. Recurso Terapêutico. Urolitíase.

Área Temática: Clínico - Hospitalar. 


\title{
ABORDAGEM CIRÚRGICA PARA FRATURAS DO COMPLEXO ZIGOMÁTICO- REVISÃO INTEGRATIVA DE LITERATURA
}

\author{
Valeria Juliana Jandrey ${ }^{1}$, Gabriel Luiz Linn ${ }^{1,}$ Natasha Magro Érnica $^{1}$
}

${ }^{1}$ Universidade Estadual do Oeste do Paraná - UNIOESTE.

Introdução: Por sua proeminência, o osso zigomático é a segunda fratura de face mais frequente, ficando atrás apenas dos traumas em ossos nasais. Devido a sua forma anatômica e seus pilares de resistência, ele é extremamente resistente a impactos. Suas fraturas ocorrem geralmente nas suas suturas, onde são os locais de menor resistência, separando o complexo zigomático dos ossos aos quais ele faz união, resultando em uma fratura completa do complexo zigomático-maxilar, complexo zigomático ou fratura órbito-zigomática. Objetivo: Realizar uma revisão integrativa da literatura, analisando as várias maneiras de tratamento, metodologia e resultados nos últimos dez anos do complexo zigomático. Materiais e método: revisão integrativa de literatura, utilizando os portais de dados PubMed (National Library of Medicine - PubMed) e Biblioteca Virtual em Saúde - BVS por meio das bases de dados da LILACS, MEDLINE e BBO com as terminologias DeSC/MeSH com três descritores "trauma", "zigomático" e "tratamento" do período entre 2010 à 2020. Resultados: por meio dos buscadores foram selecionados nas bases de dados 745 artigos. Após aplicado os critérios de inclusão e exclusão foram selecionados 12 artigos para fazer parte da amostra do estudo. Conclusões: diante do estudo realizado, chegou-se à conclusão de que existem várias técnicas eletivas eficazes no tratamento de fraturas do complexo zigomático, embora a redução aberta e a fixação interna tenham sido o tratamento padrão ouro. Como tal osso é aporte para o musculo masséter, um dos músculos responsáveis pela carga mastigatória, por vezes sua força acaba rotacionando o fragmento sendo então necessário uma fixação. Porém, independente de qual, o que determina o sucesso para o tratamento em fratura da face é o domínio da técnica elencada pelo cirurgião.

Palavras-chave: Trauma; Zigomático; Tratamento

Área Temática: Cliníco- Hospitalar. 


\title{
TRATAMENTO DE FRATURAS NASAIS ISOLADAS POR MEIO DE REDUÇÃO FECHADA: UMA REVISÃO INTEGRATIVA
}

\author{
Gabriel Luiz Linn', Valeria Juliana Jandrey', Natasha Magro Érnica1 \\ ${ }^{1}$ Universidade Estadual do Oeste do Paraná - UNIOESTE
}

Introdução: Os ossos nasais, devido a sua delgacidade e localização proeminente na face, estão mais susceptíveis a fraturas e, por esse motivo, são os ossos da face mais frequentemente fraturados em adultos. A manobra mais comumente utilizada para o tratamento do trauma nasal, especialmente em casos de fratura isolada, é a redução fechada. Essa intervenção pode ser realizada sob anestesia local ou anestesia geral. Objetivo: Analisar as evidências científicas publicadas que abordam o tratamento incruento de fraturas nasais isoladas em adultos, pertinentes à área de Cirurgia e Traumatologia BucoMaxilo-Facial, de forma a apresentar informações que possam melhorar a prática clínica e a obtenção de resultados satisfatórios. Metodologia: Realizou-se um levantamento bibliográfico de artigos publicados em português inglês ou espanhol, nas bases de dados MEDLINE (Medical Literature Analysis and Retrieval System Online), LILACS (Literatura Latino-Americana e do Caribe em Ciências da Saúde) e BBO (Biblioteca Brasileira de Odontologia), no período de janeiro de 2015 a setembro de 2020. Resultados: Após realização da busca nas bases indicadas e aplicação dos critérios de exclusão e inclusão, obteve-se uma amostra de doze trabalhos, cujas informações foram discutidas em três categorias: 1) Anestesia e analgesia em reduções fechadas de fraturas nasais; 2) Tratamento de fraturas nasais por redução fechada; e 3) Complicações e deformidades nasais secundárias decorrentes do tratamento de fraturas nasais por redução fechada. Conclusões: Diante da realização desse trabalho, pôde-se observar que diversas pesquisas vêm sendo realizadas sobre a temática em questão, procurando proporcionar melhores resultados em reduções fechadas de fraturas nasais. Além de discorrer sobre diminuição da dor trans e pós-operatória, os estudos também abordam aspectos como a satisfação do paciente, complicações pós-operatórias e deformidades nasais secundárias. Dessa forma, cabe ao Cirurgião Buco-Maxilo-Facial fazer uso das informações presentes na literatura, objetivando conhecer o melhor modo para tratar cada tipo de lesão.

Palavras-chave: Trauma nasal. Osso nasal. Redução incruenta.

Área Temática: Clínico - Hospitalar 


\section{Educação em Saúde}




\title{
ESTRATÉGIAS DE UM GRUPO DE EXTENSÃO NA PROMOÇÃO DA AMAMENTAÇÃO EXCLUSIVA PARA PRIMIGESTAS NA PANDEMIA
}

\author{
Alana Corrêa Santos ${ }^{1}$, Sarah Bianca Trindade ${ }^{2}$, Dheise Ellen Corrêa Pedroso ${ }^{3}$, Luiza Soares \\ Pinheiro $^{4}$, Marlucilena Pinheiro da Silva ${ }^{5}$, Tatiana do Socorro dos Santos Calandrini ${ }^{6}$, Nely \\ Dayse Santos da Mata ${ }^{7}$
}

1,2,3,4,5,6,7 Universidade Federal do Amapá

Introdução: O vírus da Covid-19 provocou a maior pandemia do século XXI. Desestruturou o mundo. As universidades interromperam suas atividades, afetando a tríade de ensino, pesquisa e extensão, resultando em novos desafios para a continuidade dos seus trabalhos presenciais durante a pandemia. O Grupo de Extensão de Apoio às Grávidas Adolescentes (GEAGA) do curso de Enfermagem da Universidade Federal do Amapá-UNIFAP, tem como público-alvo adolescentes primigestas e seus familiares, antes da pandemia realizava oficinas quinzenais promovendo a educação em saúde na gestação, parto e puerpério, fortalecendo a amamentação exclusiva. Com o distanciamento social, as oficinas do grupo foram suspensas e os desafios tornaram-se maiores. Objetivo: Relatar a experiência de um grupo de extensão da região norte, de enfrentar os desafios ao atuar no fortalecimento da amamentação exclusiva. Metodologia: Estudo descritivo, de caráter qualitativo, no formato de relato de experiência, elaborado a partir de vivencias de acadêmicos de Enfermagem do $5^{\circ}$ semestre, participantes do GEAGA. Resultados: Para dar continuidade ao trabalho produzido, o Grupo de Apoio às Grávidas Adolescentes com suporte da UNIFAP, conduz consultas de enfermagem no prénatal das adolescentes com escuta qualificada, e destacando a técnica e os benefícios da amamentação exclusiva. Criou-se também um grupo na rede social Whatsapp com as participantes atendidas no pré-natal, como ferramenta de promoção à saúde. Além da criação de mídias digitais educativas e produção de cadernos interativos de fácil compreensão sobre amamentação que serão utilizados até o final do pré-natal. Conclusão: Ainda que não seja possível encontros em grupo presenciais, os trabalhos continuam de forma individual durante as consultas na policlínica da universidade e por meios remotos, onde as participantes conseguem interagir entre si. Por meio dessas estratégias, é possível amenizar os desafios e continuar com a pesquisa e a extensão no período pandêmico, mantendo as participantes na prática da amamentação saudável.

Palavras-chave: Desafios. Aleitamento. Saúde.

Área Temática: Educação em saúde. 


\title{
PROGRAMA DE INTEGRAÇÃO SAÚDE COMUNIDADE EM UMA ESCOLA PÚBLICA DE MANAUS: RELATO DE EXPERIÊNCIA.
}

\author{
Francimar Oliveira de Jesus
}

Centro Universitário do Norte (UNINORTE)

DOI: $10.47094 /$ ICONRES.2021/12

Introdução: O Programa de Integração Saúde Comunidade (PISC), é uma disciplina do curso de enfermagem que visa proporcionar ao aluno uma integração à comunidade por meio de ações multiprofissionais, reunindo vários cursos da saúde para a prestação de serviços que gerem resultados positivos ao público assistido. Objetivo: Relatar a experiência de uma acadêmica de enfermagem ao participar de uma ação voltada para adolescentes do ensino médio em uma escola publica de Manaus. Métodos: Foram realizadas entrevistas semiestruturadas, com alunos do $1^{\circ}$ ao $3^{\circ}$ ano do ensino médio, com a finalidade de levantar as principais deficiências da instituição, como: falta de professores, merenda escolar e estrutura. Em seguida foram aplicados questionários a respeito da deficiência por parte dos alunos em relação a saúde do adolescente, como por exemplo, gravidez na adolescência, uso de preservativos e IST's. Resultados: Após análise das entrevistas ficou constatado que o maior problema em relação a Instituição era a falta de professores e da matéria Educação Física. Em relação aos alunos a maior deficiência de informação foi sobre a falta de educação sexual na escola. Diante disto, separou-se um dia da semana para a realização de atividades que suprissem essas necessidades, os alunos do curso de Enfermagem realizaram uma palestra sobre educação sexual abordando os temas gravidez na adolescência, uso de preservativos e infecções sexualmente transmissíveis. Os alunos de Educação Física e Nutrição criaram uma gincana na quadra poliesportiva da escola com premiação aos ganhadores. Conclusões: A partir destas ações tornou-se possível observar a necessidade de atividades voltadas ao público adolescente nas escolas e principalmente sobre a necessidade de ouvilos, dando assim o primeiro passo para a realização da educação em saúde.

Palavras-chave: Educação em Saúde. Multiprofissional. Enfermagem.

Área Temática: Educação em Saúde. 


\section{AÇÃO EDUCATIVA EM SAÚDE PARA A PREVENÇÃo DE HIV/AIDS EM IDOSOS}

\section{Joice de Souza Ribeiro ${ }^{1}$, Camila Carlos Bezerra ${ }^{2}$}

${ }^{1}$ Universidade Nilton Lins, ${ }^{2}$ Universidade Federal do Amazonas (UFAM)

Introdução: Educação e promoção em saúde são atividades que podem ser elaboradas pelo enfermeiro como parte de suas competências, essas estratégias objetivam a melhoria da qualidade de vida da população. As estratégias para a realização dessas atividades são inúmeras e devem ser escolhidas conforme público alvo e com base em suas necessidades. Objetivo: Relatar a experiência de uma ação educativa em saúde para a prevenção de HIV/AIDS em idosos de uma comunidade. Metodologia: Em Dezembro de 2019 foi realizada ação educativa em saúde em uma comunidade de Manaus, intitulada Dezembro Vermelho: idosos na luta contra a AIDS. A fim de reforçar que a campanha sobre combate à AIDS não se refere apenas aos jovens e adultos e sim a todos que possuem vida sexual ativa. A equipe formada por alunos e coordenadores do programa foi dividida e distribuída de acordo com a quantidade de ruas da comunidade, para contemplar a maior quantidade possível de idosos e pessoas. Resultados: Os grupos realizaram atividades de educação em saúde e distribuíram panfletos sobre a prevenção da AIDS. Além disso, foram ofertados testes rápidos de HIV, sífilis e glicemia em parceria com a Unidade Básica de Saúde da comunidade e seus profissionais (técnico de enfermagem, enfermeiro e médico) que tomaram todas as providências para que os testes fossem realizados de acordo com os protocolos do Ministério da Saúde. Através da campanha foi possível observar a necessidade do contato com a comunidade na realização de campanhas que alertem sobre riscos e prevenção de doenças como a AIDS que cresce na população idosa. Conclusão: A ação realizada foi fundamental para o processo de aprendizagem e experiência dos alunos na comunidade e também para estimular a percepção de que apesar dos diversos meios de comunicação existentes, ainda há necessidade de campanhas em saúde nas comunidades.

Palavras-chave: Saúde. Enfermagem. Educação.

Área Temática: Educação em Saúde. 


\title{
DOENÇAS CARDIOVASCULARES: EFEITOS DAS AÇÕES PREVENTIVAS NA INFÂNCIA
}

\author{
${ }^{1}$ Marta Bezerra dos Santos, ${ }^{2}$ Lucas Reis Angst, ${ }^{3}$ Sara Mille Souza Silva, ${ }^{4}$ Adriana Marinho \\ Pereira Dapont, ${ }^{5}$ Siglia Souza de França.
}

${ }^{12345}$ Universidade Federal do Acre

Introdução: Organização Mundial da Saúde (OMS) estabelece que as doenças cardiovasculares (DCV) têm sido a principal causa de mortes. Sabe-se que sedentarismo, excesso de sódio, sal e açúcar na alimentação contribuem para obesidade, diabetes e hipertensão arterial. Tais fatores de risco, desenvolvem-se nas fases iniciais da vida, dessa maneira, ações de prevenção primária desde a infância são uma das principais medidas para combater as doenças cardiovasculares. Objetivo: Enfatizar a importância das ações preventivas sobre hábitos saudáveis na infância a fim de prevenir doenças cardiovasculares. Metodologia: Foi realizada uma revisão literária, na qual foi efetuada a busca de artigos nas bases Scielo e Biblioteca Virtual em Saúde, sendo pré-selecionados 60 artigos e excluídos 36 não estarem relacionados ao tema. Resultados: Os estudos realizaram comparação entre grupos de crianças que participaram de ações preventivas e grupos que não tiveram acompanhamento. O estudo conduzido por REINEHR et al (2006), 240 crianças obesas de 6 a 14 anos, com índice de massa corporal $(\mathrm{IMC})>97^{\circ}$ percentil foram acompanhadas e destas 203 participaram do programa de intervenção durante 1 ano, o qual possibilitou educação nutricional, práticas de exercícios físicos e terapia comportamental. Avaliou-se as mudanças de peso e fatores de risco para DCV, após um ano de finalização da intervenção, juntamente houve a comparação com outras 37 crianças que não foram submetidas a intervenção e 12 crianças com peso normal. As crianças que diminuíram IMC após a intervenção tiveram diminuição da PA, lipídeos e aumento do HDL. Conclusão: Dessa maneira, é notória a importância de ações preventivas destinadas ao público infantil, como o incentivo a prática de atividades físicas, hábitos alimentares saúdaveis e mudanças no estilo de vida, visto que contribuem para diminuição dos fatores de risco de doenças cardiovasculares, permitindo o controle e a redução da morbimortalidade.

Palavras-chaves: Alimentação. Prevenção. Crianças.

Área Temática: Educação em Saúde. 


\title{
ATUAÇÃO DE ACADÊMICOS DE MEDICINA NO PROJETO DE EXTENSÃO SOBRE PLANEJAMENTO REPRODUTIVO NO ACRE
}

\author{
Marta Bezerra dos Santos', Lucas Reis Angst², Sara Mille Souza Silva ${ }^{3}$, Adriana Marinho \\ Pereira Dapont ${ }^{4}$, Siglia Souza de França ${ }^{5}$
}

${ }^{12345}$ Universidade Federal do Acre

Introdução: De acordo com a Pesquisa Nacional de Demografia e Saúde da Criança e da Mulher a prevalência de gravidez não planejada no país é de 45,8\%. Dessa forma, muitas mulheres desconhecem os métodos contraceptivos, assim como também a disponibilidade destes no Sistema Único de Saúde. Objetivo: Relatar os resultados da experiência de um projeto de extensão sobre planejamento reprodutivo especificamente sobre o dispositivo intrauterino (DIU). Metodologia: O projeto foi executado por acadêmicos de medicina da Universidade Federal do Acre (UFAC) e do Centro Universitário UNINORTE, na Maternidade Bárbara Heliodora em Rio Branco-Acre. Os acadêmicos foram capacitados e, posteriormente, realizaram palestras e rodas de conversas com temáticas relacionadas ao planejamento reprodutivo, abordando os principais métodos contraceptivos existentes, com elucidação de dúvidas e disponibilização de panfletos informativos sobre o tema. Resultados: Foram alcançadas 400 clientes pelas intervenções, oportunidade em que se percebeu um grande interesse na obtenção de maiores conhecimentos sobre o DIU, uma vez que a maior parte dessas mulheres apresentou desconhecimento acerca da eficácia e dos efeitos que o dispositivo poderia provocar no organismo. Por conseguinte, abordou-se a disponibilidade do DIU no SUS, revelando o desejo de uma grande quantidade de clientes em utilizá-lo. Conclusão: Diante dos resultados observados, evidenciou-se que as clientes usuárias da Maternidade Bárbara Heliodora carecem de informações sobre planejamento reprodutivo e métodos contraceptivos, sendo fator que influencia diretamente para que elas optem por métodos mais invasivos. Dessa forma, reforça-se a importância e necessidade das instituições e profissionais de saúde realizarem ações a fim de levar mais informação e conhecimento à população sobre planejamento reprodutivo.

Palavras-chaves: Planejamento familiar. Métodos contraceptivos. Dispositivo intrauterino.

Área Temática: Educação em Saúde. 


\title{
O POTENCIAL PEDAGÓGICO DO CINEMA NOS ESTUDOS SOBRE O TRANSTORNO DE PERSONALIDAE ANTISSOCIAL
}

\author{
Mariana Vasconcelos de Melo Lima ${ }^{1}$, Maria Fernanda Durando Gomes ${ }^{1}$, \\ Raphaela Moury Fernandes Mello ${ }^{1}$, Isabela Gomes de Oliveira ${ }^{1}$
}

${ }^{1}$ Centro Universitário Maurício de Nassau

Introdução: O cinema possibilita a construção de novos conhecimentos e vivências sem que o telespectador precise sair do conforto de sua casa. Tal fato contribui para que cada vez mais esse veículo de comunicação seja utilizado como fonte de aprendizado no meio acadêmico. $\mathrm{O}$ tema psicopatia desperta muita curiosidade na população e por isso sempre foi abordado nas produções cinematográficas. Objetivo: Sumarizar os achados que correlacionam o cinema e a sua importância nos estudos sobre o transtorno de personalidade antissocial (TPAS). Metodologia: Estudo realizado a partir de uma revisão de literatura, incluindo artigos disponíveis nas bases de dados Pubmed e Scielo. Resultado: Filmes brasileiros foram analisados a partir dos diferentes perfis de personagens com características antissociais. O estudo concluiu que há viabilidade na utilização do cinema no ensino de alunos e na preparação dos indivíduos para a prática clínica, uma vez que, muitas cenas foram capazes de ilustrar o diagnóstico do transtorno com clareza. Filmes com personagens diagnosticados com TPAS foram visualizados e analisados por psiquiatras forenses. O resultado do estudo foi que os filmes que abordam a psicopatia são importantes para as futuras gerações de psicólogos forenses e psiquiatras como materiais pedagógicos. Porém, é importante que os personagens sejam explorados além de seu arquétipo de vilão. Uma discursão sobre o retrato da psicopatia no cinema Apontou que os filmes que retratam o TPAS precisam ir além do "monstro" e relatar outras questões relacionadas a psicopatia, como problemas emocionais e de relacionamento, para que sejam usados na prática pedagógica. Conclusão: O cinema tem boa contribuição nos estudos sobre o TPAS, porém os benefícios seriam maiores se os filmes abrangessem os personagens psicopatas para além de suas características de vilão.

Palavras-chave: Cinematografia. Ensino. Psicopatia.

Área Temática: Educação em Saúde. 


\title{
NOVEMBRO AZUL COMO FERRAMENTA DE CONSCIENTIZAÇÃO E PREVENÇÃO AO CÂNCER DE PRÓSTATA - RELATO DE EXPERIÊNCIA
}

\author{
Sorlei de Souza Beltrão ${ }^{1}$, Chrystianne da Silva Oliveira ${ }^{2}$, Francisca Magda de Sousa Pinto \\ Silva Xavier ${ }^{3}$
}

\author{
${ }^{1}$ Centro Universitário do Norte - Uninorte / ${ }^{2}$ Centro Universitário do Norte - Uninorte \\ / ${ }^{3}$ Centro Universitário do Norte - Uninorte
}

Introdução: O câncer de próstata é uma das doenças mais frequentes entre homens, segundo a Organização Mundial da Saúde (OMS) 2017, apontam que o câncer de próstata é o segundo mais prevalente no mundo. No Brasil é o câncer mais prevalente entre essa população, o papel da enfermagem busca acolher, orientar e promover a prevenção através de palestras e campanhas educativas. Objetivo: Relatar a experiência dos alunos na realização da atividade de orientação e estimular o homem sobre a importância de refletir sobre o autocuidado e da realização de exames. Metodologia: trata-se de um trabalho descritivo, tipo relato de experiência vivenciado por acadêmicos do curso de bacharelado de enfermagem, visando a importância e a dimensão do assunto, a atividade intitulada Novembro Azul abordou como tema Câncer de Próstata, no qual foi aplicada nas unidades de ensino do Centro Universitário do Norte - UNINORTE, na cidade de Manaus no ano de 2019, através de panfletagens e explanar o assunto abordado em salas de aulas com alunos homens da instituição, buscando orientar, promover e sanar dúvidas sobre os sintomas, autocuidado e os temores sobre o exame de rastreamento (TR mais especificamente). Resultados: Sobre as abordagens utilizadas, foi notável a importância da atividade, sendo observada pela participação voluntária e interrogativa acerca das dúvidas sobre o assunto, identificando através dela o medo na realização do exame do TR, cujo o preconceito é o principal motivo pelo qual os homens se limitam buscar ajuda profissional e a realização do exame do toque. Considerações Finais: Diante das ações desenvolvidas, percebeu- se que as informações repassadas sobre medidas preventivas ao câncer de próstata, importância dos exames preventivos e um estilo de vida saudável, contribuem para combate deste Câncer, nesse contexto vale ressaltar que esse assunto é estigmatizado entre homens.

Palavras-chave: Autocuidado. Homem. Medo.

Área Temática: Educação em Saúde 


\title{
DESAFIOS NA ESCOLARIZAÇÃO DO INDIVÍDUO COM TRANSTORNO DO ESPECTRO AUTISTA
}

\author{
Maria Fernanda Durando Gomes ${ }^{1}$, Mariana Vasconcelos de Melo Lima ${ }^{1}$, \\ Raphaela Moury Fernandes Mello ${ }^{1}$, Isabela Gomes de Oliveira, Geovanna Oliveira de Mello \\ Cabral $^{1}$, Paulo José Tavares de Lima ${ }^{1}$.
}

${ }^{1}$ Centro Universitário Maurício de Nassau

Introdução: Indivíduos com Transtorno do Espectro Autista (TEA) apresentam sintomas como: dificuldade de comunicação, alterações na linguagem e coordenação motora, padrões de comportamento restritos e repetitivos. ${ }^{1}$ Portanto, existe um desafio na inclusão desses sujeitos no ambiente de aprendizagem, bem como sua permanência nas escolas e universidades, devido às presentes dificuldades. Objetivo: Compreender as dificuldades na inclusão de indivíduos com TEA no ambiente educacional. Metodologia: Foi realizada uma revisão de literatura na base de dados SciELO. Resultados: Estudos apontam que a maioria dos professores não são preparados para atender às demandas do aluno com TEA. ${ }^{2}$ Assim, uma pesquisa indicou as principais dificuldades desses educadores, dentre elas: pouco domínio sobre o TEA, pouco conhecimento sobre práticas de ensino voltadas para o indivíduo atípico, além da falta de recursos. ${ }^{2}$ Outros estudos evidenciaram a importância da análise individual desses indivíduos, para maior entendimento de suas particularidades e aplicação de mediações verbais e não verbais adequadas ao espectro de cada sujeito, para maior inclusão, principalmente nos primeiros anos de ensino. ${ }^{3}$ Além disso, pesquisas também citaram que o processo de inserção e desenvolvimento durante o ensino básico tem consequência direta no manejo desses indivíduos no ensino superior, influenciando no processo de escolarização e profissionalização. ${ }^{4}$ Vale ressaltar também que a maioria dos indivíduos atípicos matriculados em universidades se concentra no Nordeste, levando em consideração que indicadores sociais, étnicos e culturais relacionam-se com o desenvolvimento desses indivíduos. ${ }^{5}$ Conclusão: Destaca-se que o processo de educação e inclusão do indivíduo com TEA encara muitos desafios. Logo, é necessário maior disseminação de conhecimento sobre o transtorno e suas dificuldades entre os docentes, bem como ampliar a oferta de recursos, para aumentar o desenvolvimento do sujeito atípico no contexto educacional, inserindo-o na sociedade e aumentando a oferta de trabalho.

Palavras-chave: Autismo. Educação. Inclusão.

Área temática: Educação em saúde. 


\section{A REPERCUSSÃO DOS EVENTOS CIENTÍFICOS EM SAÚDE NA FORMAÇÃO ACADÊMICA: UM RELATO DE EXPERIÊNCIA}

\section{Larissa Artimos Ribeiro'; Pâmela Ramos Januárioº}

${ }^{1}$ Escola de Enfermagem Alfredo Pinto/Universidade Federal do Estado do Rio de Janeiro

Introdução: Os eventos científicos caracterizam-se pela busca e captação em novos conteúdos, tendo como intuito reunir a comunidade acadêmica com discentes, profissionais e pesquisadores para absorção e difusão de conhecimentos. Na área da saúde, os eventos são compostos de pesquisas, inovações, apresentações de conteúdos e trabalhos, com foco na linguagem acessível, assim como na partilha e amadurecimento de informações. Objetivo: Compreender a relevância dos eventos científicos para acadêmicas de Enfermagem. Metodologia: Trata-se de um relato de experiência de acadêmicas de Enfermagem da Universidade Federal do Estado do Rio de Janeiro (UNIRIO), durante o ano de 2020. Resultados: As discentes participaram, na modalidade virtual, como ouvintes de 12 eventos, sendo 2 Congressos, 2 seminários, 2 simpósios e 6 palestras. Na categoria de apresentação de trabalho oral contaram com 2 participações no ano de 2020, assim como a atuação na Comissão Organizadora de 2 eventos, dentre estes um curso, e na monitoria de 2 palestras. Em relação aos eixos temáticos, os mais abordados foram saúde da criança e coletiva, com enfoque em assuntos como o coronavírus, Sistema Único de Saúde, resiliência, imunização, saúde mental e amamentação. Tais conteúdos são vivenciados na prática pelos profissionais de enfermagem e amplamente debatidos no contexto atual de pandemia, o que enfatiza a relevância desses eventos científicos como agregadores na formação e atualização acadêmica. Conclusão: Através da experiência, as acadêmicas refletiram sobre a importância dos eventos científicos para o crescimento pessoal, visto que, contribuem para o desenvolvimento do senso crítico e da performance em apresentações públicas. Além disso, favorecem o desenvolvimento acadêmico e profissional, pois atuam como complemento da graduação, contribuindo para a valorização do profissional, na construção de conhecimentos científicos, na melhora da assistência prestada ao paciente e suprindo também a demanda de atividades num contexto em que diversos cursos se encontram limitados.

Palavras-chave: Educação. Aprendizagem. Acesso à informação.

Área temática: Educação em Saúde. 


\section{O IMPACTO NA ATUAÇÃO DO ASSISTENTE SOCIAL DURANTE A PANDEMIA DO COVID-19: RELATO DE EXPERIÊNCIA}

\section{Dyeme Alves Barbosa ${ }^{1}$}

${ }^{1}$ Escola de Saúde Pública do Estado do Ceará

Introdução: Durante a pandemia causada pelo vírus da Covid-19, as categorias multiprofissionais de saúde tiverem que desenvolver novas habilidades para desempenhar suas ações e serviços dentro de uma nova realidade de trabalho. Objetivo: O objetivo deste estudo foi refletir sobre a atuação do assistente social residente enquanto membro de uma equipe multiprofissional frente ao processo de enfrentamento ao novo coronavírus junto a familiares de pacientes acometidos pelo vírus Sars-Cov 2. Metodologia: Trata-se de um relato de experiência que descreve a vivência do setor de Serviço Social durante a pandemia, na realização de suas funções em um hospital terciário do Sistema Único de Saúde (SUS). Durante a experiência vivenciada entre março a julho de 2020, a equipe de Serviço Social teve que se aprofundar em um arsenal teórico/metodológico e operacional para atender as famílias diante das mudanças na rotina de trabalho com a suspensão dos acompanhantes e de visitas familiares. Resultados: Em março de 2020, o cenário hospitalar se modificou e gradativamente toda a instituição foi se constituindo por unidades de atendimento a pessoas com Covid-19. Nesse sentido, o Setor de Serviço Social experimentou diversas alterações nas unidades, rotinas e fluxos de atendimento à população. $\mathrm{O}$ serviço instituiu o teletrabalho, onde o acolhimento familiar e o preenchimento da Ficha Social passaram a ser realizados de forma remota, através de ligações telefônicas. Além disso, diariamente os assistentes sociais elaboravam listas com os contatos telefônicos de familiares dos pacientes internados para serem realizados os boletins médicos. Considerações Finais: O teleatendimento foi uma das principais estratégias para avançar e melhorar o atendimento do Serviço Social naquele momento. Observou-se no diálogo com os familiares a dimensão e a importância desse contato, com ações socioeducativas e uma escuta qualificada que proporcionou uma abordagem que valorizou e acolheu os sujeitos a partir de suas histórias de vida.

Palavras-chave: Serviço Social. Teleatendimento. SUS.

Área Temática: Educação em Saúde. 


\title{
BRINQUEDO TERAPÊUTICO:
}

\section{ESTIMULANDO AUTISTAS AO DESENVOLVIMENTO}

\author{
Valdete Pantoja Ribeiro Brito ${ }^{1}$ Linniky Lima Sanches ${ }^{1}$ Francisca Magda de Sousa Pinto Silva \\ Xavier $^{1}$
}

Centro Universitário do Norte/ UniNorte ${ }^{1}$

Introdução: No que tange à comunicação com crianças, um dos métodos empregados é a aplicação do brinquedo terapêutico (BT), na qual tem sido utilizado pelos profissionais para auxiliar crianças com autismo a manifestar seus sentimentos em relação a situações desconhecidas e desconfortáveis, sendo tal abordagem sempre interdisciplinar. As evidências científicas tem mostrado que os recursos terapêuticos envolvem estratégias psicossociais para modulação de comportamentos inadequados e intervenções desenvolvimentistas para corrigir atrasos e estimular habilidades ainda não adquiridas. Objetivo: Relatar a experiência sobre a confecção e exposição do Brinquedo Terapêutico voltado para crianças com Transtorno do Espectro do Autista (TEA). Metodologia: Trata-se de um estudo descritivo de relato de experiência, sobre a confecção e exposição do brinquedo terapêutico, realizada no dia 6 (seis) de Dezembro de 2020 na Feira da Eduardo Ribeiro em Manaus Amazonas sendo supervisionado pela Docente da disciplina de Saúde da Criança e do Adolescente do Centro Universitário do Norte - UNINORTE, na qual foi apresentado o brinquedo à população de maneira lúdica. Resultados: Tendo sido confeccionado manualmente, com produtos recicláveis de fácil higienização, o BT de nome "Chico" foi diferenciado para atender as peculiaridades autistas. Em sua exposição, presenciou-se que foi positivamente recebido pela população, além disso verificouse a importância da aplicabilidade do mesmo em alguma unidade hospitalar. Conclusão: De acordo com os dados, o uso do BT, de fato, contribui significativamente para maior crescimento psicomotor e social, com o uso lúdico, para intervir diariamente na criança com autismo, ajudando a melhorar seu nível de atenção para novas experiências e na área da comunicação, visando o melhor bem-estar relacional e comportamental.

Palavras-chaves: Autonomia. Crescimento. Cuidado.

Área Temática: Educação em Saúde 


\section{EDUCAÇÃO EM SAÚDE E SUA RELAÇÃO NO ÂMBITO ESCOLAR PARA ADOLESCENTES}

\section{Rubens Barbosa Rezende}

Faculdade Santa Rita (FASAR), Conselheiro Lafaiete, Minas Gerais

Introdução: A adolescência é caracterizada pela transição da infância para a vida adulta. De início, a metodologia de educação sexual acontece, de modo informal, com base nas relações com o ambiente, sendo a família sua referência, e de modo formal, os meios pedagógicos, no âmbito escolar e nas instituições sociais. Objetivo: Discutir e enfatizar a necessidade da educação em saúde no âmbito escolar para adolescentes. Metodologia: Trata-se de uma revisão integrativa da literatura nas bases de dados SciELO e PubMed, utilizando como questão norteadora: "Qual a necessidade da educação em saúde no âmbito escolar para adolescentes?" A busca foi feita utilizando os descritores: "educação em saúde", "sexualidade" e "adolescente", e empregando o operador booleano AND. Os critérios de inclusão foram: artigos completos, disponibilizados de forma gratuita, publicados em inglês e português, entre janeiro de 2018 a fevereiro de 2021. Resultados: Foram encontrados 1574 artigos, sendo 262 na base de dados SciELO e 1.312 na PubMed e selecionados 12 para compor essa revisão. A literatura reporta que a educação em saúde precisa assegurar uma aquisição de conteúdos significantes sobre a sexualidade e instigar os adolescentes a se perguntarem sobre as suas decisões e atitudes que atuem na minimização de riscos. Uma vez que, a sexualidade na adolescência é dada como um problema de saúde pública, tendo a escola como um local de execução de políticas públicas que propicia a saúde do adolescente, auxiliando no esclarecimento à educação sexual. Considerações finais: Portanto, fica claro a necessidade de discussão de temas que englobam preconceitos e estigmas, progredindo assim na promoção à saúde do adolescente. E este conhecimento ganho, impacta na autoproteção do adolescente, porém não condiz a mudança imediata em seu comportamento, uma vez que eles possuem fatores socioculturais que demandam uma atuação frequente.

Palavras-chave: Adolescente. Saúde. Sexualidade.

Área Temática: Educação em Saúde. 


\title{
AÇÃO SOCIAL DEZEMBRO VERMELHO: UM MEIO DE PROMOVER ESTRATÉGIAS DE EDUCAÇÃO EM SAÚDE E PREVENÇÃO DAS IST'S NO AMAZONAS
}

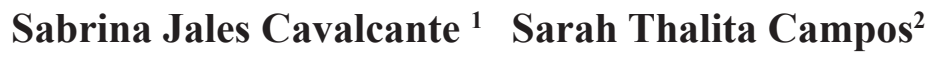 \\ 1 Centro Universitário do Norte - UNINORTE ${ }^{1}$ Centro Universitário do Norte - UNINORTE \\ ${ }^{2}$ Centro Universitário do Norte - UNINORTE
}

Introdução: O controle e prevenção das infecções sexualmente transmissíveis (IST's) no amazonas tem se tornado um desafio eminente nas esferas da saúde pública, visto que houve um evidente crescimento dos casos e HIV na região e a equipe de enfermagem da atenção primária, possui um papel de fundamental importância na promoção da saúde e prevenção dessas enfermidade na comunidade, promovendo ações educativas e métodos que estimulem e incentive a população ao autocuidado. Objetivo: relatar as vivências de discentes de enfermagem do centro universitário do norte, na ação social promovida pelos alunos e professores na escola municipal governador Danilo de Matos Areosa, localizada na comunidade grande Vitória, na cidade de Manaus. Metodologia: trata-se de um relato de experiência da acadêmica de enfermagem do quarto período na ação social voltada para educação em saúde pública no dia 08 de dezembro de 2019. Resultados: além de palestras e workshops dedicados a educação sexual e em saúde da população dessa comunidade, também forma ofertados serviços como; consultas médicas e de enfermagem, consultas de puericultura e vacinação para todas as idades, o evento contou com mais de 300 alunos do curso envolvidos e um público de 800 pessoas assistidas. Conclusões: essa ação possibilitou efetivamente a promoção de estratégias de educação sexual eficazes nessa comunidade e os serviços ofertados por professores e alunos do curso de enfermagem tiveram um impacto positivo, amplo e abrangente na comunidade grande Vitória.

Palavras-chaves: saúde coletiva. Prevenção. Conscientização

Áreas temática: educação em saúde 


\title{
AUTISMO E SUAS FERRAMENTAS \\ DIAGNÓSTICAS : REVISÃO DE LITERATURA
}

\author{
Ilana de Souza Cavalcanti ${ }^{1}$, Maria Clara Lima Cavalcanti ${ }^{1}$, Thialle Roberta da Silva Cruz ${ }^{1}$ \\ Centro Universitário Maurício de Nassau, Recife
}

INTRODUÇÃO: Comportamento estereotipado, repetitivo e restrição na comunicação são aspectos que caracterizam o Transtorno do Espectro Autista (TEA). Cerca de uma em cada 160 crianças no mundo possui autismo, doença que ocupa o terceiro lugar entre os distúrbios do neurodesenvolvimento. Privado de um marcador biológico, seu diagnóstico continua clínico. Dessa forma, critérios específicos e com alto grau de sensibilidade são empregados, todos esses contidos no DSM-V. Ainda assim, outros instrumentos são necessários com a finalidade de uma melhor avaliação dos sintomas e reconhecimento dos diagnósticos diferenciais. OBJETIVO: Reunir achados presentes na literatura que abordem sobre ferramentas diagnósticas do Transtorno do Espectro Autista. METODOLOGIA: O trabalho foi elaborado no primeiro semestre de 2021 em formato de revisão de literatura. Os dados foram retirados da base de dados Scielo. RESULTADOS: A utilização de instrumentos que esboçam detalhadamente características do desenvolvimento da criança ou critérios presentes nos sistemas de classificação podem ser utilizados para fazer diagnóstico. O (ADI-R) e o (ADOS-G), são destaques internacionais . Dados sobre o paciente e família fazem parte das seções constituintes do primeiro instrumento, tendo foco nos marcos do desenvolvimento. O ADOS-G, composto por quatro módulos, se baseia na verificação de algumas habilidades de acordo com os níveis linguísticos. Os instrumentos requerem treino internacional para serem aplicados e, se validados, o vasto uso só é permitido se o profissional comprar os direitos autorais da editora .

Conclusão: O elevado custo, necessidade de treinamento e a dependência de dados por parte dos cuidadores constituem entraves para a utilização dos instrumentos, ainda que tenham se mostrado efetivos. Assim, é vital deixar claro que, mesmo com o uso dos facilitadores, é preciso associar outras medidas de observação para chegar a um diagnóstico mais preciso.

Palavras-chave: Espectro. Diagnóstico. Critérios.

Área temática: Educação em Saúde 


\title{
ASSISTÊNCIA FARMACÊUTICA: USO RACIONAL DOS MEDICAMENTOS, NA PANDEMIA DA COVID 19
}

\author{
Francisco Daniel Ferreira Tavares de Lavôr ${ }^{1}$
}

Escola Multicampi de ciências médicas (EMCM/UFRN) ${ }^{2}$

Introdução: A assistência farmacêutica é um conceito que engloba o conjunto de práticas voltadas à saúde individual e coletiva, tendo o ciclo do medicamento e o seu uso racional como foco. Objetivos: Contribuir com estratégias de ação da atenção farmacêutica na assistência básica de saúde, na Unidade de Saúde dr. Ferreirinha Currais Novos - RN, frente ao desafio da automedicação na pandemia da COVID 19; Intensificar a farmacovigilância para garantir a continuidade dos tratamentos das doenças crônicas em pacientes com COVID 19, investigar a ocorrência da automedicação e suas motivações; incentivar o uso racional dos medicamentos. Metodologia: O público alvo foram as pacientes do sexo feminino entre 55 e 65 anos de idade, hipertensas, e portadores de diabetes mellitus; buscouse a elaboração de cartilhas explicativas avaliando todas as vantagens e as desvantagens sobre a automedicação; a mobilização de equipes sobre o tratamento adequado, conforme orientação do Ministério da Saúde. Discussão e resultados: A cartilha mostrou ser adequada para o publico escolhido, visto que nas próximas consultas a prescrição de medicamento não se mostrou como componente obrigatório; A equipe se sentiu mais preparada para conscientizar, orientar e identificar pessoas que se automedicam e encaminhar para avaliação prévia de um profissional de saúde Conclusão: Foi observado que, a promoção do uso racional de medicamentos, pode contribuir para a diminuição de agravos à saúde, e consequentemente, atuar mais em níveis de prevenção e promoção da saúde.

Palavras-chave: Atenção Primária à Saúde. COVID 19. Promoção da Saúde.

Área temática: Educação em Saúde 


\title{
A IMPORTÂNCIA DA ENFERMAGEM E DA EQUIPE MULTIDISCIPLINAR NO APRIMORAMENTO DO MANEJO A SAÚDE MENTAL
}

\author{
Sarah Thalita Campos ${ }^{1}$ Sabrina Jales Cavalcante ${ }^{2}$ \\ 1 Centro Universitário do Norte - UNINORTE ${ }^{1}$ Centro Universitário do Norte - UNINORTE \\ ${ }^{2}$ Centro Universitário do Norte - UNINORTE
}

Introdução: É notável as dificuldades relacionadas ao manejo da assistência à pacientes portadores de algum tipo de sofrimento psíquico, muitas vezes pelas dificuldades em intervir de forma eficiente no cuidado desse grupo populacional. Visto que raramente exista apenas uma conduta correta a ser tomada diante de tal diagnóstico clínico, levando em consideração a diversidade dos sujeitos, suas limitações e os recursos disponíveis para definir as medidas a serem tomadas. A Enfermagem possui um papel de fundamental importância na atenção biopsicossocial desses pacientes com algum diagnóstico de transtorno mental. Visto que é competência do enfermeiro atuar na supervisão do cuidado, ter conhecimento sobre as principais prescrições de psicotrópicos, prevenção e reabilitação psicossocial em situações clínicas, dentre outros aspectos que fazem parte do arcabouço de conhecimento e intervenções dos mesmos na busca de promover bem estar e qualidade de vida aos seus pacientes. Objetivo: Relatar as vivências e estudos sobre Neuropsicopatologia em pareceria com o grupo NEP, no centro psiquiátrico Eduardo Ribeiro, Manaus- Am. Metodologia: Trata-se de um relato de experiência da docente de enfermagem, do quinto período da graduação, no hospital de referência em transtornos mentais, Eduardo Ribeiro. Resultados: No transcorrer dos estudos referentes a Neuropsicopatologia, foi possível a troca de conhecimentos entre as categorias multiprofissionais de enfermagem, psicologia, pedagogia e direito. Baseando-se em livros de referência como o DSM-V, e em casos clínicos de internação do próprio hospital. Conclusões: A vivência do grupo no hospital trouxe um impacto positivo aos estudantes e a equipe multidisciplinar ali presentes, proporcionando valiosas oportunidades de interação com os pacientes internados, e um instante de autoconhecimento profissional.

Palavras-chaves: Neuropsicopatologia. Saúde mental. Grupo de estudos

Áreas temática: Educação em saúde 


\title{
EDUCAÇÃO EM SAÚDE: RELATOS DA EXPERIÊNCIA DE RESIDENTES MULTIPROFISSIONAIS
}

\author{
Amanda Patrícia da Silva1, Aline Vanessa da Silva² \\ 1Centro Universitário da Vitória de Santo Antão, 2Universidade Federal de Pernambuco
}

Introdução: O estudo em questão discorre sobre a prática da Educação Permanente em Saúde (EPS) na atenção primária em saúde, focando na importância da inserção desta ferramenta na atuação dos residentes multiprofissionais em saúde. Objetivo: Dessa forma, objetivou-se compartilhar as vivências dos Residentes Multiprofissionais em Saúde numa perspectiva prática da educação em saúde na atenção primária. Material e Métodos: Trata-se de um estudo de caráter qualitativo, exploratório de revisão bibliográfica, através do levantamento bibliográfico e documental, em legislação específica, livros, artigos, dissertações e teses em portais acadêmicos e de produção científica, a exemplo da SciELO, CNPq. Resultados e Discussão: Sabe-se que a EPS é uma política de saúde que foi criada pelo Ministério da Saúde, através das Portarias nº 198/2004 e n 1.996/2007, visando nortear a formação e qualificação dos profissionais adentrados nos serviços públicos de saúde, tencionando transformar as práticas profissionais e a organização do trabalho, fundamentando-se nas urgências e dificuldades do sistema, viabilizando uma interação entre a promoção de saúde e a propagação de conhecimentos. Conclusão: Frente à pesquisa realizada, conclui-se que a Política Nacional de Educação Permanente em Saúde compreende que para transformar os serviços, a educação e a direção dos sistemas de saúde não é simplesmente técnica, e envolve mudanças nos relacionamentos, nos procedimentos, na gestão de saúde e, especialmente nas pessoas. Consiste no trabalho estruturado dos sistemas de saúde, das esferas administrativas e instituições formadoras, visando à constituição de uma saúde que respeite seus usuários e valorize os agentes sociais desse trabalho.

Palavras-chave: Políticas de Saúde. Atenção Primária. Residentes.

Área Temática: Educação em Saúde 


\title{
EDUCAÇÃO EM SAÚDE: UMA ALTERNATIVA PARA PROMOVER A QUALIDADE DE VIDA DO IDOSO
}

\section{Jackeline Polyanna dos Santos Bezerra ${ }^{1}$, Tatiana de Paula Santana da Silva ${ }^{2}$}

\author{
${ }^{1}$ Aluno do Curso de Bacharelado em Fonoaudiologia da UNISÃOMIGUEL - Recife/PE, Brasil, \\ ${ }^{2}$ Docente do Curso de Fonoaudiologia da UNISÃOMIGUEL - Recife/PE, Brasil.
}

Introdução: $\mathrm{O}$ envelhecimento populacional é uma realidade presente nas últimas décadas, sendo visto como um fenômeno ocorrido de uma forma de escala global. No Brasil, observa-se que a pirâmide etária dessa transição demográfica vem sendo alterada, trazendo também uma proporção de números maior de idosos nesses últimos anos. Entretanto, esse processo envolve alterações biopsicossociais importantes, sendo necessário muitas vezes, ampliar o conhecimento sobre os aspectos envolvidos nessa transição, no qual as práticas de educação em saúde podem contribuir na promoção das ações de cuidados nesse ciclo etário. Objetivo: Investigar na literatura corrente as contribuições da Educação em Saúde como uma alternativa para promoção da qualidade de vida do idoso. Metodologia: Tratase de uma revisão integrativa de literatura. Foram utilizados os seguintes descritores: Promoção a saúde, Autocuidado, Saúde do idoso. Os critérios de inclusão adotados foram artigos em português, conduzido com amostras brasileiras que destacam alguma contribuição da educação em saúde para promoção da qualidade de vida na população idosa. As buscas foram conduzidas nas seguintes bases de dados: Biblioteca Virtual em Saúde, Scielo, Lilac, entre o período de 2010 a 2021. Resultados: O envelhecimento é um processo gradativo e progressivo que ocasiona em decorrer do tempo, levando a fragilidade e gerando vulnerabilidade ao indivíduo. Sobre as contribuições das ações de educação em saúde verificou-se que esta é indispensável como meio alternativo para o apoio dos profissionais de saúde da atenção primária, tendo como funções, promover programas de atividades, acolhimento e identificação da necessidade médica, sendo elas integradas ao autocuidado, que oferece o suporte preciso para a saúde do idoso. Conclusão: Portanto, a Educação em Saúde se torna um método importante para a promoção da saúde, levando como intuito de proporcionar autocuidado e autoimagem na saúde do idoso, buscando manter assim um processo de envelhecimento promovendo uma boa qualidade de vida.

Palavras-chave: Promoção da saúde. Autocuidado. Saúde do idoso.

Área Temática: Educação em Saúde 


\section{REFLEXÕES EM TORNO DO ENVELHECER: O IDOSO, A FAMILIA E O ALZHEIMER}

\section{Maycon Guimarães Santos ${ }^{1}$, Amanda de Oliveira Lima², Nanielle Silva Barbosa ${ }^{3}$, João Caio Silva Castro Ferreira ${ }^{4}$}

1,2,3,4 Universidade Estadual do Piauí,

Introdução: A Doença de Alzheimer (DA) é uma doença neurodegenerativa progressiva que se apresenta como a deterioração cognitiva e da memória, além de uma variedade de sintomas neuropsiquiátricos e de alterações comportamentais que se agravam ao longo do tempo. Objetivo: Relatar a experiência de profissionais residentes em ações de saúde sobre a Doença de Alzheimer. Metodologia: Trata-se de um estudo descritivo, qualitativo do tipo relato de experiência, construído a partir de vivências em uma roda de conversa entre profissionais residentes do Programa de Residência Multiprofissional em Saúde da Família e Comunidade, da Universidade Estadual do Piauí e, idosos pertencentes a um serviço de convivência, localizado na cidade de Teresina, Piauí. O encontro ocorreu virtualmente via plataforma zoom, em março de 2021. Resultados: Iniciou-se o encontro com acolhimento feito pelo coordenador do serviço, foi dado as boas-vindas e apresentado os profissionais residentes de enfermagem e psicologia. Utilizou-se como metodologia slides, fotos e um momento de tira-dúvidas. Os idosos participantes do grupo se mostraram conscientes e preocupados com os cuidados necessários. Alguns casos de Alzheimer em colegas, familiares e vizinhos contribuíram para a discussão, uma vez que as vivências relatadas demostram as mudanças sociais, de rotina, a perca da autonomia do idoso, os efeitos psicológicos e emocionais, como ansiedades, medos, angústia, a necessidade do cuidado multiprofissional, o impacto financeiro, causando estressores tanto no idoso como na família e ou cuidador. É necessário portanto, auxílio psicológico ao idoso, principalmente no início dos sintomas, assim como, à família. Finalizou-se o encontro apresentando algumas dicas de atividades de estimulação cognitiva, como a música, leitura, jogos e outros. Considerações finais: É pertinente a promoção de saúde para população idosa usando-se de espaços virtuais que possam oferecer, através da informação, meios de acolher e orientar quanto aos cuidados no processo de envelhecimento e seus possíveis adoecimentos.

Palavras-chave: Sistema Único de Saúde. Envelhecimento. Doença de Alzheimer. Área Temática: Educação em Saúde. 


\title{
ATUAÇÃO DO NUTRICIONISTA NO PNAE
}

\section{Andressa Almeida Barbosa ${ }^{1}$; Lauany Maria dos Santos Barreto ${ }^{2}$}

\author{
Universidade Federal de Campina Grande, Cuité, Paraíba ${ }^{1 ; 2}$
}

Introdução: A alimentação é um direito constitucional de todos. No âmbito escolar, essa constituição é respaldada pelo PNAE (Programa Nacional de Alimentação Escolar), que garante uma alimentação saudável, como também, proporciona ações de educação alimentar e nutricional para os estudantes de escolas públicas. Para isso, o papel do nutricionista é de grande relevância para a execução do programa. Objetivo: Entender as formas de atuação e a importância do nutricionista, no PNAE. Metodologia: Essa revisão de literatura foi composta por artigos científicos encontrados nas bases de dados Pubmed, Lilacs, Scielo e no Ministério da Saúde, publicados entre 2015 a 2021. Resultados: Dentre as funções dos nutricionistas para assegurar o bom funcionamento do PNAE, são: atuação no treinamento de diretores, cozinheiras, da equipe logística, com a aquisição de géneros alimentícios diretamente da agricultura familiar com produtos orgânicos, acompanhando os processos de compra até a distribuição aos discentes, produção e avaliação de cardápios e fichas técnicas, para o controle e evitar assim, desperdícios, elaboração de plano anual e relatórios de gestão. Conferem também, visitas técnicas aos fornecedores, agricultores e escolas promovendo oficinas, palestras, contribuindo assim, no crescimento biopsicossocial, desenvolvimento, rendimento escolar e na formação de bons hábitos alimentares dos discentes, como também, no fortalecimento do vínculo com a sociedade local. Vale salientar que em função da pandemia de covid-19, foram distribuídos kits de alimentos básicos adquiridos com os recursos do PNAE, a qual, foram distribuídos nas escolas e sucessivamente as famílias dos alunos. Conclusões: Portanto, o nutricionista é importante para a execução do PNAE, pois a sua missão é garantir que o programa funcione de acordo com as diretrizes da alimentação escolar.

Palavras-chave: Estudantes; Agricultura; Crescimento.

Área Temática: Educação em Saúde 


\title{
UTILIZAÇÃO DE METODOLOGIAS ATIVAS NO PROCESSO DE ENSINO- APRENDIZAGEM DURANTE A RESIDÊNCIA: UM RELATO DE EXPERIÊNCIA
}

\section{Elice Maria da Silva ${ }^{1}$, Stephanie Ramos de Almeida ${ }^{1}$, Aline Nazaré Carvalho de Almeida ${ }^{1}$, Flavia Nishimura Bueno', Natália Paranhos de Araújo ${ }^{1}$}

\author{
${ }^{1}$ Hospital Sírio Libanês
}

Introdução: A reorientação nos processos educacionais dos profissionais de saúde para estimular o pensamento crítico-reflexivo na construção do conhecimento, buscando atender as necessidades sociais, tem sido bastante abordada em sistemas e serviços de saúde. Neste ínterim, o uso de metodologias ativas, como a Aprendizagem Baseada em Problemas (ABP) e simulação realística, ganham destaque. As metodologias ativas buscam a participação do sujeito na construção do seu aprendizado e replicação de maneira dinâmica. Objetivo: Compartilhar a experiência com a utilização de métodos ativos no processo de ensino-aprendizagem durante a residência. Metodologia: $\mathrm{O}$ estudo se desenvolve através do relato de experiência com a incorporação das metodologias ABP e simulação realística realizadas nas atividades teóricas do programa de residência multiprofissional de Gestão dos Serviços de Saúde e Redes de Atenção à Saúde no ano de 2020. Resultados: Durante a atividade foi apresentado como problema à implantação de procedimentos para o avanço do Sistema Único de Saúde (SUS) a partir do diagnóstico de sistemas de saúde internacionais. Foram elencados quatro países e a partir da avaliação dos seus sistemas, que incluíram aspectos positivos e de atenção (melhorias), elaborou-se uma breve apresentação com percepção e análise crítica sobre qual destes atuaria como melhor como modelo para o SUS. A atividade resultou em uma simulação realística em cenário de consultoria, no qual a equipe apresentou para os presentes na dinâmica (clientes) o consolidado do estudo com a contextualização, justificativa, benefícios e riscos do sistema de saúde modelo e principais processos e ferramentas para implantação dos avanços no SUS. Conclusões: A utilização dos métodos da aprendizagem ativa possibilitou o estímulo da curiosidade, autonomia na construção do conhecimento, avaliação crítico-reflexiva de conteúdo, desenvolvimento de raciocínio lógico, resolutividade e oportunidade de alinhar o aprendizado teórico com o prático. Portanto, a aplicação destas metodologias foi relevante para o aperfeiçoamento profissional.

Palavras-chave: Aprendizado ativo. Educação em saúde. Treinamento por simulação.

Área Temática: Educação em Saúde 


\title{
A IMPORTÂNCIA DA INFLUÊNCIA PATERNA NO PRÉ-NATAL
}

\section{Maria Gizely Ferreira de Sena ${ }^{1}$, Stefany Augusto Pinto ${ }^{2}$}

\author{
Centro Universitário Faculdades Integradas de Patos $^{1}{ }^{2}$
}

Introdução; Uma gravidez é um momento delicado e de muita emoção para o casal, mas principalmente para a mulher que se vê necessitada de apoio físico e emocional. Diante disso, se faz a seguinte pergunta; como o apoio paterno influência durante o pré-natal?. Na atualidade é visto ainda mais a participação do pai no processo gestacional em comparação com o século passado pela quebra de paradigmas, mas ainda assim é um fato novo incluir a presença paterna nas consultas de prénatal pelo seguinte motivo: falta de orientação. Muitos dos profissionais não sabem que é assegurado pela lei a presença do pai em todas as fases da gestação, incluindo consultas, resultando na falta de orientação para os casais. O pré-natal é um forma de identificar possíveis patologias e até evita-las, além de observar o desenvolvimento do feto. Incluir o parceiro e orienta-lo nesse processo permite que ele transmita apoio e segurança para a mulher, e aprenda sobre todas as alterações que a gestante e o filho irão passar, para saber quando algo é normal ou não. Objetivo; O presente trabalho tem como objetivo influenciar os pais a participarem das consultas. Metodologia; Foi feito uma revisão bibliográfica sobre a questão da necessidade da presença dos pais. Resultados; Como resultados, observamos a contribuição que traz a presença paterna nessa fase da gravidez, o que resulta em um desenvolvimento saudável da gestação, pois favorece tanto a mãe quanto o bebê, trazendo apoio emocional e um puerpério tranquilo, além de fortalecer o vínculo entra pai a mãe e o filho. Conclusões; Diante do que foi exposto, o papel do pai nessas consultas é um fator importante para construção de um ambiente acolhedor para o filho, e ajudar a mulher a passar por essa fase para evitar fatores como depressão pós-parto e entre outras comorbidades.

Palavras-chave: Gestação. Paternidade. Humanização.

Área temática: Educação em Saúde. 


\section{SEDENTÁRISMO EM PRÉ-PUBERES E PUBERES E O LETRAMENTO EM SAÚDE PARA UM ENVELHECER SAUDAVEL}

\section{Rhuan Pinheiro Marquezini ${ }^{1}$, Derick Francisco Santana ${ }^{1}$, Marcio Luis de Lacio ${ }^{1,2}$, Jonathan \\ Dias Teixeira ${ }^{1}$, Victor de Souza Rodrigues ${ }^{1}$, Carlos Eduardo da Costa Schultz ${ }^{1}$, Emerson Rodrigues Duarte ${ }^{1}$, Moacyr dos Santos Oliveira ${ }^{1}$}
${ }^{1}$ Faculdade Metodista Granbery (FMG), ${ }^{2}$ Universidade Federal de Juiz de Fora (UFJF) - Juiz de Fora - MG

Introdução: Com o advento da revolução tecnológica e a crescente urbanização, crianças e adolescentes têm se tornado paulatinamente mais sedentários devido ao dispêndio de tempo diário em frente às telas. Tal condição de vida se torna preocupante quando considerada a correlação entre sedentarismo, o desenvolvimento de obesidade e diversas outras doenças que são fatores contribuintes para maiores índices de mortalidade. Nesse aspecto, o letramento em saúde, ou seja, a capacidade cognitiva de discernir informações relativas à saúde e ao entendimento da importância de medidas preventivas para uma vida saudável, como o exercício físico, torna-se imprescindível; Objetivo: Destacar a importância do letramento em saúde e sua relação com um estilo de vida sedentário; Metodologia: Trata-se de uma revisão narrativa de literatura estruturada com base em artigos publicados entre os anos de 2015 e 2020, disponíveis nas bases de dados PubMed e Scielo; Resultados: Hábitos saudáveis adquiridos na infância e adolescência tendem a ser mantidos na vida adulta. Diversas pesquisas quando analisam marcadores clássicos de saúde como composição corporal, pressão arterial e índices glicêmicos em pré-púberes e púberes fisicamente ativos, observam considerável melhora do estado de saúde comparando-os a seus congêneres sedentários. Apesar desta constatação, pesquisadores verificaram índices de um estilo de vida sedentário em $68,3 \%$ dessa faixa etária, e os motivos mais prevalentes para a manutenção do mesmo, se relacionaram a um desconhecimento de suas consequências e dos benefícios da prática de exercícios físicos; Considerações Finais: Diante das evidências que relacionam o comportamento sedentário a um aumento da mortalidade, e dos motivos que tornam esse estilo de vida presente na vida das crianças e adolescentes, é imperativo que os profissionais da saúde busquem informar e educar a população desta faixa etária sobre os riscos de tal condição e encorajem uma vida fisicamente ativa, contribuindo para um envelhecimento mais saudável.

Palavras-chave: Tecnologia. Senescência. Hábitos.

Área Temática: Educação em Saúde. 


\title{
BIOMECÂNICA E MICROBIOLOGIA EM CADAVERES DE GATOS QUIMICAMENTE PREPARADOS E EMBALADOS À VÁCUO
}

\author{
Andréa Barros Piazzon de Souza Queiroz ${ }^{\text {, Giovana Carvalho Vieira }}{ }^{2}$, Natália Teresina \\ Brandão Costa ${ }^{3}$, Fabrício Singaretti de Oliveira ${ }^{4}$ \\ $1,2,3,4$ Unesp FCAV
}

Introdução: Visando-se substituir animais vivos no ensino da cirurgia veterinária, métodos alternativos vêm sendo empregados para não haja prejuízo acadêmico nem estresse emocional nesse aprendizado. Objetivo: Avaliar a conservação por meio de análises biomecânicas e microbiológicas de cadáveres de gatos quimicamente preparados, visando a prática de cirurgia veterinária. Metodologia: Foram utilizados 8 cadáveres de gatos injetados com $120 \mathrm{~mL} / \mathrm{kg}$ de solução de cloreto de sódio a 20\%, nitrito a $1 \%$ e nitrato de sódio a $1 \%$ e $150 \mathrm{~mL} / \mathrm{kg}$ de álcool com glicerina a $5 \%$ e mantidos em embalagens a vácuo entre 0 e $4^{\circ} \mathrm{C}$. Amostras de pele e jejuno foram coletadas no dia 0 (amostras frescas) e nos dias D30, D60, D90, D120 e o fluido das embalagens plásticas foi analisado microbiologicamente. Resultados: A força de ruptura máxima e o alongamento de ruptura das amostras controle da pele e jejuno foram 294,14N, 9,84 mm, 28,05N, 4,84 mm e durante a conservação, 215,10N, 7,93 mm, 24,94N, 5,62 mm (D30), 268,41N, 7,70 mm, 25,71 N, 4,42 mm (D60), 197,75 N, 7,80 mm, 25,46 $\mathrm{N}, 5,50 \mathrm{~mm}(\mathrm{D} 90), 209,14 \mathrm{~N}, 7,81 \mathrm{~mm}, 25,18 \mathrm{~N}, 5,20 \mathrm{~mm}$ (D120), respectivamente. O teste de Tukey para a força máxima de ruptura da pele foi diferente do controle em todos os momentos, exceto no D60. E também, o mesmo aconteceu com o alongamento da ruptura. Não houve diferença entre os momentos de controle e conservação do jejuno na força máxima de ruptura; o alongamento da ruptura foi diferente do controle apenas no D60. A população microbiana não excedeu 4,0x10² UFC/mL em aeróbicos totais e $8,8 \times 10^{2} \mathrm{UFC} / \mathrm{mL}$ em anaeróbios totais. Conclusões: A biomecânica não foi significativamente afetada durante a conservação e a contagem microbiológica foi baixa, demonstrando a eficácia desta técnica para o ensino e treinamento cirúrgico.

Palavras-chave: Anatomia. Conservação. Ensino Cirúrgico.

Área Temática: Educação em Saúde 


\title{
CONSUMO DE ALIMENTOS NÃO SAUDÁVEIS RELACIONADOS A DOENÇAS CRÔNICASNÃO TRANSMISSÍVEIS.
}

\author{
Paloma Fonseca Silva ${ }^{1}$, Ana Carolina Alves de Oliveira ${ }^{2}$, Maria do Carmo Viana Andrade \\ Gomes ${ }^{3}$.
}

Centro universitário-UNINTA ${ }^{1,2,3}$

DOI: $10.47094 /$ ICONRES.2021/5

INTRODUÇÃO: A industrialização e a urbanização trouxeram o acréscimo da ingestão de calorias e redução da atividade física, constituindo o princípio do sobrepeso, ou seja, aumento da ingestão calórica e o déficit do gasto energético, com consequente acúmulo de gordura. Com a mudança nos padrões alimentarese estilo de vida da população, tornam-se as dietas com alta densidade enérgica. Devido alto consumo da população de alimentos não saudáveis, o excesso de peso se tornou algo notório. OBJETIVO: $O$ trabalho tem por objetivo descrever o consumo de alimentos não saudáveis considerados fatores de risco para DCNT na sociedade. METODOLOGIA: Trata-se de uma revisão bibliográfica, exploratória, de aspecto qualitativo, relacionada ao desenvolvimento de doença crônicas não transmissíveis causado pelo consumode alimentos. A coleta e dados foi realizada em consulta de artigos científicos selecionados através da buscano banco de dados do SCIELO, BIBLIOTECA VIRTUAL DA SAÚDE (BVS) e da BIREME, a partir da fonte LILACS. Como critério de inclusão e seleção dos artigos considerou-se, a partir das palavras chaves descritas, e artigos atualizados de 2015 a 2020. RESULTADOS E DISCUSSÃO: Diversas modificações nohábito de vida da população, em particular do padrão alimentar, causa efeitos sobre a composição corporal e a saúde, visto que as descrições das práticas alimentares adotadas pelos consumidores caracterizam-se pelo baixo consumo de frutas e hortaliças e preferência por dietas ricas em gorduras, açúcares e sódio, cujo excesso relaciona-se com o aumento da ocorrência de obesidade e de suas principais comorbidades. Portanto, investir em ações para prevenir as DCNT é altamente necessário, pois preconiza o controle dos principais fatores de risco. CONCLUSÃO: Foi possível observar com o presente trabalho, que alimentos semi-prontos, que são utilizados no cotidiano das pessoas possuem grandes quantidades de gorduras, e são parâmetros que causas a problematização de diversas patologias atualmente.

Palavras-chave: Doenças crônicas. Alimentação. Saudável.

Área temática: Educação em saúde 


\title{
USO DE FERRAMENTA DIGITAL COMO ALIADO DOS PROFISSIONAIS DE SAÚDE
}

\section{Suzanna Cavalcante Lins}

\author{
Centro Universitário de Patos - UNIFIP.
}

Introdução: Autoridades mundiais de saúde anunciaram em 2020 a pandemia pelo novo coronavírus, havendo a necessidade dos países adotarem medidas de controle para evitar maior propagação da COVID-19. No Brasil, criaram protocolos para nortear os profissionais de saúde e proteger a população. Alguns profissionais precisaram mudar sua forma de trabalho, e os Agentes Comunitários de Saúde (ACS) e Agentes de Combate às Endemias (ACE) foram orientados a não adentrar às casas dos territórios adscritos. No entanto, a população continuava necessitando de informações destes profissionais. Objetivo: Objetivou-se realizar uma capacitação com os ACS de Unidades Básicas de Saúde (UBS) sobre utilização de mídias digitais para que as informações fossem repassadas à população de forma segura e rápida. Metodologia: Este trabalho é do tipo relato de caso onde Residentes do Programa de Residência Multiprofissional em Atenção Primária à Saúde de Patos, Paraíba realizaram capacitação com equipes de UBS afim de auxiliá-los no repasse de informações à população. Resultados: Foi realizada capacitação sobre a rede social WhatsApp, orientando-os sobre o envio de mensagens em forma de "Lista de Transmissão" para a população. Nos meses de Maio e Junho de 2020 foram capacitados oito ACS e duas enfermeiras de duas UBS do município de Patos (UBS João Soares e UBS Aderban Martins). A capacitação reforçou a importância do trabalho dos ACS assim como ajudou-os a difundir as informações sobre atendimentos de saúde, exames solicitados, cuidados sobre a pandemia, vacinação e diversos assuntos referentes ao serviço de saúde com maior segurança, fazendo com que fosse cumprida as medidas de distanciamento social para os profissionais e para a população. Considerações Finais: Assim, conclui-se que com a pandemia, os profissionais precisaram se reinventar para realizar suas ações nos territórios e o uso das mídias digitais foi utilizado como aliado na período de pandemia e distanciamento social.

Palavras-chaves: Atenção primária à saúde; Pandemia; Relato de caso.

Área Temática: Educação em Saúde 


\title{
TREINAMENTOS DE PARAMENTAÇÃO E DESPARAMENTAÇÃO DE EQUIPAMENTOS DE PROTEÇÃO INDIVIDUAL DURANTE A PANDEMIA
}

\author{
Fernanda Evelyn Silva ${ }^{1}$
}

${ }^{1}$ Instituto de Medicina Integral Professor Fernando Figueira

Introdução: A pandemia causada pelo novo coronavírus SARS-CoV-2 foi e é um desafio para pesquisadores e gestores, que com urgência precisaram elaborar estratégias e tomar decisões para enfrentarem o vírus (AQUINO et al., 2020). Objetivo: O objetivo do presente trabalho é descrever os treinamentos ofertados aos profissionais de saúde quanto ao uso de equipamentos de proteção individual durante a pandemia da COVID-19. Metodologia: Trata-se de um relato de experiência vivenciada por residentes de saúde coletiva em um hospital de ensino, localizado na cidade capital de Recife, no período de março a maio de 2020. Resultados: No enfrentamento da pandemia, foram realizados treinamentos voltados aos profissionais que iriam lidar diretamente com os pacientes suspeitos ou confirmados de COVID-19 para a utilização adequada das barreiras de exposição. Foram realizados 39 treinamentos, de cerca 1 hora cada, e foram treinados 576 profissionais, entre esses estavam enfermeiros, fisioterapeutas, médicos, nutricionistas e técnicos. Os encontros aconteceram na unidade hospitalar, respeitando sempre as medidas de segurança estipuladas durante a pandemia. Durante os momentos foram demonstradas as técnicas ideais de paramentação e desparamentação, baseadas em Procedimento Operacional Padrão (POP), previamente estabelecido por residentes de saúde coletiva e a Comissão de Controle de Infecção Hospitalar (CCIH), que tem como base as determinações da ANVISA. Considerações Finais: Os treinamentos apresentaram-se como um desafio, tendo em vista ser uma realidade nunca antes vivenciada e o medo dos profissionais quanto à nova realidade. Contudo, considera-se um ponto positivo, o interesse de todos os profissionais participantes para a prestação de uma melhor e mais segura assistência à saúde.

PALAVRAS-CHAVE: Residentes; Saúde Coletiva; COVID-19.

ÁREA TEMÁTICA: Educação em Saúde 


\section{SER MULTI É + SAÚDE E QUALIDADE NAS AÇÕES DE PROMOÇÃO E PREVENÇÃO À SAÚDE DO MUNICÍPIO DE CASCAVEL - PARANÁ}

\section{Rafaela Zulmira de Oliveira Moraes ${ }^{1}$, Danieli Cristina Scalco²}

${ }^{12}$ Programa de Residência Multiprofissional em Saúde da Família/Secretaria Municipal de Saúde de Cascavel.

Introdução: ligadas as demandas da população e suas relações intrapessoais e interpessoais, sendo necessário considerar as questões psicossocioeconômicas do território ao desenvolver as ações. Durante a práxis dos residentes de serviço social, enfermagem e odontologia do Programa de Residência Multiprofissional em Saúde da Família de Cascavel/PR, observou a necessidade de efetivar a articulação entre as categorias profissionais de residentes e trabalhadores do SUS, para ações de educação permanente, educação em saúde e promover inovações nas práticas profissionais, melhorando as respostas dos serviços na promoção e prevenção de saúde. Neste contexto, criou-se o projeto de extensão: Ser Multi é + Saúde e Qualidade, para o desenvolvimento de práticas educativas, oportunizando o aprendizado multiprofissional e melhor assistência aos usuários do SUS. Objetivo: Relatar o desenvolvimento de ações multiprofissionais de educação em saúde. Metodologia: As ações foram desenvolvidas por residentes da turma 2019-2021, com atividades multiprofissional e intersetorial, desenvolvendo a Planilha de Sistematização do Cuidado, instrumento para tabulação de dados, com estratificação de risco dos grupos de comorbidades e covid-19; oficina de Planejamento Familiar Jogo da Vida, atividades lúdico-pedagógicas com temáticas sobre: sexualidade, ISTs e bullying; elaboração de gibis de educação popular - SUS na Boca do Povo. Resultados: O projeto realizou 7 ações multiprofissionais de educação em saúde em 2 colégios e 4 serviços da assistência social (CMEI, CRAS, Eureca e Centro da Juventude) e criou a planilha de monitoramento covid-19, com 19.629 teleatendimentos. Considerações finais: O desenvolvimento do Projeto de Extensão contribuiu para a transformação do processo mecânico entre as profissões, promovendo a integração dos saberes multiprofissional e da práxis no cotidiano das equipes, fomentando a educação permanente e em saúde para uma atuação eficaz na promoção e prevenção da saúde atendendo aos princípios de diretrizes do SUS.

Palavras-chave: Multiprofissional; intersetorialidade; educação em saúde.

Área Temática: Educação em saúde. 


\title{
BRINQUEDO TERAPÊUTICO: NA ATENÇÃO À CRIANÇA AUTISTA HOSPITALIZADA
}

\section{Jonathan Battanoli ${ }^{1}$ Raquel Sampaio Amazonas dos $\operatorname{Santos}^{1}$ Vinícius Jacquiminuth Vizzoni $^{1}$}

\author{
Centro Universitário do Norte/ UNINORTE ${ }^{1}$
}

Introdução: Atualmente existe um acervo escasso de publicações sobre a abordagem a criança portadora de Transtorno do Espectro Autista (TEA) onde requer atenção para o desenvolvimento social infantil. O brinquedo terapêutico (BT) é um instrumento assistencial que viabiliza uma comunicação lúdica e holística, a fim de melhorar a aceitação da criança à terapia, um desafio ainda maior quando se trata de portadores de TEA, considerando a apresentação de déficits na área social e comunicativa. Objetivo: Relatar a experiência sobre a confecção do brinquedo terapêutico voltado para crianças com TEA que estão hospitalizadas. Metodologia: Trata- se de um estudo descritivo de relato de experiência, sobre a confecção do brinquedo terapêutico voltado para criança com TEA que estão hospitalizadas, na qual foi solicitado como critério de avaliação da disciplina Saúde da criança e do adolescente. Resultados: Foi criado um boneco de baixo custo utilizando balões coloridos, enchimento em fibras de poliéster e fitilho para simbolizar cabelo. Além disso são personalizáveis com expressões na qual a criança busque se identificar, mostraram-se bastante resistentes e podem ser descartáveis pelo seu baixo custo. Com a criação desta ferramenta é esperado que o índice de aceitação das terapias propostas aumente e forneça novas maneiras de trabalhar com esse público, de forma a estimular a melhora da qualidade e eficiência na prestação de cuidados. Conclusão: A criança com TEA requer uma atenção maior da equipe de enfermagem, por sua dificuldade comunicativa, dessa forma a aplicabilidade do BT é mais uma ferramenta que possibilita um aumento na qualidade e no processo de cuidar, diminuindo o estresse do ambiente hospitalar.

Palavras-chaves: Cuidado. Desenvolvimento. Ferramentas

Área Temática: Educação em Saúde 


\section{COMO O SUICÍDIO TEM SIDO ABORDADO NOS CURSOS DE SAÚDE NO BRASIL?}

\section{Karina Macedo Gomes ${ }^{1}$}

Universidade do Estado do Amazonas ${ }^{1}$

Introdução: O suicídio é considerado um grave problema de saúde pública pela Organização Mundial de Saúde. Estudos apontam que mais de $40 \%$ dos suicidas receberam algum atendimento de saúde no ano em que ocorreu o fato, em grande parte, na atenção primária. Nesse sentido, é importante saber como o tema tem sido abordado em cursos de saúde para averiguar se profissionais se formam capacitados para identificar possíveis comportamentos suicidas. Objetivo: Apresentar uma revisão de literatura integrativa sobre como tem sido feita a abordagem sobre suicídio em cursos de saúde no Brasil. Metodologia: Foi feita uma revisão integrativa de literatura com base em 4 artigos principais. A coleta de dados deu-se a partir da busca dos termos "Suicídio", "Cursos de Saúde" e "Suicídio no Meio Acadêmico" na base de dados LILACS - Literatura Latino-Americana e do Caribe em Ciências da Saúde. Foram incluídos somente artigos publicados em português relacionados ao tema nos últimos cinco anos. Resultados: Conforme o crescimento dos casos nos últimos anos, a temática do suicídio ganhou espaço nas discussões no meio acadêmico. Ainda assim, esse espaço ainda é muito aquém do necessário e as discussões precisam ser constantemente aprimoradas. Isso porque da mesma forma que o acadêmico precisa saber a hora de procurar ajuda, ele necessita de conhecimento técnico fornecido durante a graduação para identificar comportamentos suicidas e orientar de forma adequada seu paciente. Considerações Finais: A abordagem sobre suicídio em cursos da saúde no Brasil é, em grande parte, voltada para o acadêmico em saúde, principalmente por contas dos índices de suicídio entre os acadêmicos. No entanto, observa-se que é preciso aumentar também a abordagem em relação ao paciente, uma vez que muitos estudantes, sejam de medicina ou de enfermagem, não se sentem prontos para identificar situações de risco de suicídio durante um atendimento.

Palavras-Chave: Medicina. Enfermagem. Educação em Saúde.

Área Temática: Educação em Saúde. 


\title{
DESAFIOS DE ENFERMEIROS GESTORES DE UMA UNIDADE DE URGÊNCIA E EMERGÊNCIA REFERÊNCIA EM CARDIOLOGIA.
}

\section{Hana Leticia Ferreira Araújo ${ }^{1}$; ${ }^{2}$ Késia Marques Moraes.}

\author{
${ }^{1}$ Centro Universitário Inta-UNINTA/ ${ }^{2}$ Centro Universitário Inta-UNINTA.
}

Introdução: O trabalho de enfermagem é composto por três ações básicas: educação em saúde, cuidado assistencial e gerência. O processo de gerenciamento tem a finalidade de organizar o espaço terapêutico, distribuir e controlar o trabalho da equipe de enfermagem, a fim de proporcionar condições para a realização do cuidado ${ }^{1}$. No entanto, para isto, o entrelaçamento entre cuidar e gerenciar sempre se mostrou como um desafio. Nas unidades de urgência e emergência essa realidade se mostra ainda mais preocupante, diante de situações de superlotação, exaustão da equipe, conflitos interpessoais e institucionais. Objetivo: Descrever os principais desafios dos profissionais enfermeiros no gerenciamento em uma Unidade de Urgência e Emergência de um hospital referenciado. Metodologia: Trata-se de um relato de experiência, onde se utilizou a observação sistemática, a partir da atuação de enfermagem na unidade de Pronto Atendimento de um hospital de referência em Cardiologia no interior do estado do Ceará. No período de Janeiro do ano de 2020. Resultados: Observou-se no período descrito que o enfermeiro coordenador do setor em questão, atua tanto na parte gerencial que envolve burocracia, como na área assistencial. Sendo este um dos maiores desafios enfrentado. A unidade em questão é referência para o município, é necessário estar atuando também na regulação destes pacientes, via sistema de regulação e envolve ainda assumir plantões extras. Estar na classificação de risco, atuar na educação continuada da equipe, estar à frente da resolução de conflitos internos e dinamizar os serviços são desafios em pauta que foram observados. Conclusão: A gerência ainda é uma prática colocada em segundo plano, diante das necessidades assistenciais. Não basta conhecer a administração de organizações e pessoas, é preciso estar preparado para essa função, cada vez mais cobrada do enfermeiro. É preciso ter habilidades gerenciais que identifiquem os comportamentos ou habilidade indispensáveis ao cargo gerencial³

Palavras-chave: Gerenciamento. Gestão em Saúde. Assistência de Enfermagem.

Área Temática: Educação em Saúde. 


\title{
O PLANEJAMENTO DE UMA AÇÃO EDUCATIVA SOBRE O BRINCAR PARA CRIANÇAS INSTITUCIONALIZADAS E A INTEGRAÇÃO ENTRE RESIDENTES MULTIPROFISSIONAIS
}

\author{
Amanda Cardoso Bonna ${ }^{1}$, Lícia Vieira Barbosa ${ }^{2}$, Fernanda de Oliveira Ferreira Roza Victor ${ }^{3}$
}

${ }^{123}$ Instituto Capixaba de Ensino, Pesquisa e Inovação em Saúde - ICEPI

Introdução: Durante o desenvolvimento infantil em seus aspectos cognitivos, físicos, sociais e afetivos, a brincadeira tem um importante papel pois partindo dessa atividade são estimulados a autoestima, criatividade e formação da personalidade. Baseado nas vivências práticas diárias de uma residência multiprofissional em saúde da família percebeu-se que existem, no território abrangido pela unidade de saúde, equipamentos voltados para crianças em que podem ser aplicadas ações relacionadas a essa temática; Objetivo: Relatar a experiência dos residentes na elaboração de uma de ação educativa com intuito direcionar o olhar de cuidadores de abrigos infantis de como a brincadeira e os brinquedos não precisam ser um material somente de terapia; Metodologia: A ação foi construída pelos residentes de terapia ocupacional, fonoaudiologia, odontologia, fisioterapia e enfermagem, após uma análise territorial, para ser aplicada em um centro de vivência para crianças de 0 a 6 anos. No primeiro momento a proposta é uma roda de conversa abordando sobre o que é o brincar, a importância disso na vida da criança e o papel das cuidadoras. Após isso será feita uma busca dos brinquedos existentes no abrigo, observando como e em quais momentos do dia eles são usados, e os materiais existentes no local que podem ser adaptados para brincadeiras, praticando o que foi conversado e enfatizando as orientações passadas; Resultados: A construção dessa ação educativa mostrou-se como um importante instrumento no aprofundamento da temática pesquisada e gerou a reflexão de como esse conteúdo não é abordado em diversas categorias profissionais; Considerações Finais: $\mathrm{O}$ fomento da busca dos residentes sobre como as brincadeiras podem ser utilizadas no seu campo do saber para estimular a ressignificação do brincar nesses espaços proporcionou uma maior interação entre os residentes acerca de um tema, que era restrito a uma categoria profissional, fortalecendo a formação de novas competências.

Palavras-chave: Atenção primária à saúde. Saúde da família. Abrigo social.

Área Temática: Educação em saúde. 
Medicina Veterinária 


\title{
MENINGIOMA CEREBRAL EM GATO: RELATO DE CASO
}

\section{Isabella Junqueira Rodrigues', Larissa Rodrigues Marchini', Anneliese Baetz Buzatto²,}

\author{
${ }^{1}$ Universidade Estadual Paulista "Júlio de Mesquita Filho" (Unesp)/ Faculdade de Ciências Agrárias \\ e Veterinárias (FCAV), ${ }^{2}$ AMEVE (Assistência Médica Veterinária Especializada)
}

Introdução: O meningioma é o neoplasma intracraniano mais frequente em gatos. Seu crescimento é lento, no entanto, por alojar-se no crânio, seu desenvolvimento pode gerar efeitos catastróficos. Algumas alterações neurológicas são presuntivas de acometimento cerebral e devem ser investigadas a fundo quanto às suas causas. Objetivo: Este trabalho tem, por objetivo, relatar um caso de meningioma em felino. Metodologia: Atendimento clínico e realização de exames complementares de um felino, sem raça definida, do sexo feminino, com 7 anos de idade, apresentando apatia, anorexia e andar em círculos há uma semana. Resultados: Os exames hematológicos e ultrassom de abdômen realizados no paciente não mostraram alterações significativas. No exame neurológico, apresentava-se em estado deprimido, com andar em círculos e nistagmo, sem outras alterações. Pelos sinais clínicos, suspeitou-se de alterações cerebrais, sendo o animal encaminhado para tomografia computadorizada, no entanto, o mesmo veio à óbito antes que pudesse ser submetido ao exame. No exame necroscópico, foi constatada uma massa em região encefálica, de consistência firme, coloração apardaçada e medindo $2,0 \times 1,5 \times 1,5 \mathrm{~cm}$, com superfície de corte homogênea e esbranquiçada. No exame histopatológico foi constatada proliferação neoplásica compatível com meningioma. O tratamento de escolha consiste na excisão cirúrgica, a qual pode ser realizada se o tumor for superficial e bem definido, gerando um melhor prognóstico do que tratamento clínico, quimioterapia ou radioterapia. No entanto, são poucos os casos em que a excisão cirúrgica é realizada. Considerações Finais: As técnicas cirúrgicas de acesso intracraniano são bem definidas na medicina humana, no entanto, são pouco praticadas na medicina veterinária devido à dificuldade de acesso a exames avançados de imagem e a profissionais capacitados e experientes neste tipo de cirurgia. Dessa forma, na maioria dos casos, a presença do tumor só é detectada no exame necroscópico.

Palavras-chave: Neoplasma, tumor intracraniano, felinos

Área Temática: Medicina veterinária 


\title{
INSPEÇÃO NOS CASOS DE AGRESSIVIDADE POR CÃES DOMÉSTICOS
}

\section{Juliana da Silva Cândidoํㅜㄹ Wanessa Ingrid de Albuquerque Paiva ${ }^{1}$, Lorenn Costa de Oliveira ${ }^{1}$}

\author{
${ }^{1}$ Universidade Federal Rural de Pernambuco
}

Introdução: Situações de agressividade por cães domésticos têm sido comuns devido à proximidade com os humanos, à dominância do ambiente e aos maus tratos sofridos, sendo raramente por doenças neurológicas. Os cães podem desenvolver a agressividade ofensiva, por disputa do ambiente com o tutor, quando as alterações comportamentais não são bloqueadas da forma adequada, ou quando sofrem maus tratos, desenvolvendo a agressividade defensiva, pois o cão, ao sentir-se ameaçado, ataca, podendo causar graves acidentes. São raros os casos em que o cão possui alguma doença que altere seu padrão comportamental, como Raiva, distúrbio neurológico ou tumor encefálico. Objetivo: Este trabalho objetivou apresentar a inspeção das situações de agressividade por cães, realizada pela Vigilância Ambiental em Saúde de Camaragibe, Pernambuco no ano de 2020. Metodologia: Os tutores que sofreram agressão de seus cães procuraram a Vigilância Ambiental de Saúde (VAS) de Camaragibe, Pernambuco, e receberam atenção especial para descartar um possível caso de Raiva. Foi avaliado o tipo das agressões se era comportamental, ofensiva ou defensiva, ou se o cão possuía alguma doença neurológica. Resultados: Na maioria das vezes que os tutores acionaram a VAS, o ataque do cão estava relacionado à agressividade ofensiva por dominância de ambiente. O tutor, instintivamente, recuava ao primeiro sinal de insatisfação do cão, que se sentia dominante, reagindo com latidos, rosnados e mordendo o tutor quando algo the desagradava. Os animais agressivos foram acompanhados durante algumas semanas pela Vigilância Ambiental em Saúde para que retornassem à vida normal com seus tutores em suas residências. Considerações finais: Os animais foram avaliados quanto à sanidade e ao bem-estar e os tutores receberam orientações quanto ao reconhecimento do comportamento animal para que possam realizar as ações corretas, prevenindo acidentes.

Palavras-chave: Comportamento animal. Sanidade. Bem-estar.

Área temática: Medicina Veterinária 


\title{
DESENVOLVIMENTO DE MODELO ANATÔMICO PARA O ENSINO E TREINAMENTO CIRÚRGICO EM CADÁVERES DE PEQUENOS RUMINANTES - ESTUDO PILOTO
}

\author{
Raphael Chiarelo Zero' ${ }^{1}$ : Marcela Rosalem ${ }^{1}$; Isabella Cristina da Silva Cavalini ${ }^{1}$ \\ Universidade Brasil, Fernandópolis, São Paulo.
}

Introdução: O uso de animais vivos no ensino e pesquisa é cada vez mais regulamentado e restrito, criando-se desta maneira a demanda pelo desenvolvimento de modelos alternativos ao seu uso. Objetivo: Desenvolver um modelo bioético e alternativo ao uso de animais vivos no ensino e treinamento cirúrgico, com o uso de solução alcoólica e de sais de cura. Metodologia: Utilizou-se um cadáver de ovino, de $15 \mathrm{~kg}$, que veio a óbito por causa desconhecida. Via artéria carótida comum, injetou-se $150 \mathrm{~mL} / \mathrm{kg}$ de solução de álcool etílico puro com $5 \%$ de glicerina e $120 \mathrm{~mL} / \mathrm{kg}$ de solução contendo $20 \%$ de cloreto de sódio, $1 \%$ de nitrito de sódio e $1 \%$ de nitrato de sódio. Procedeu-se a tricotomia em todo o corpo. O cadáver foi acondicionado em saco plástico transparente e mantido sob refrigeração $\left(2\right.$ a $\left.6^{\circ} \mathrm{C}\right)$ por 120 dias. Em datas aleatórias, realizaram-se treinamento de diversas técnicas cirúrgicas, assim como avaliação das características morfológicas, quanto à conservação. Resultados: A técnica anatômica de preparo utilizando solução alcoólica e de sais de cura foi eficaz na conservação do cadáver de pequeno ruminante, não havendo indícios de putrefação e mal odor. Características como textura, maleabilidade, coloração, maciez e cheiro foram preservados. O modelo proporcionou condições para o treinamento cirúrgico de técnicas como traqueotomia, traqueostomia, enucleação, flebotomia da jugular, amputação de dígito, orquiectomia, técnicas de preparo cirúrgico de rufião, laparotomia, toracotomia, reparo de laceração de língua, dentre outras. Conclusões: De acordo com a execução do presente estudo piloto, conclui-se que a técnica anatômica proposta para o preparo de cadáveres de pequenos ruminantes visando ao treinamento cirúrgico é eficaz, não havendo indícios de contaminação aparente, odores fétidos e alteração das características morfológicas, proporcionando condições favoráveis para o treinamento cirúrgico, além de corroborar com os padrões bioéticos de ensino e pesquisa, e de respeito para com a vida animal.

Palavras-chave: Conservação. Técnica cirúrgica. Preparo.

Área Temática: Medicina Veterinária 


\section{BENEFÍCIOS DA TÉCNICA DE TUMESCÊNCIA EM CADELAS SUBMETIDAS A MASTECTOMIA}

\section{Pedro Alarcon Angelo, Bianca Desordi Lima², Mariana Silva Olimpio², Milena Friolani}

${ }^{1}$ Discente Universidade de Marília ${ }^{2}$ Aprimoranda de Cirurgia e Anestesiologia de Pequenos Animais Universidade de Marília ${ }^{3}$ Docente Universidade de Marília

Introdução às neoplasias mamárias ocorre com maior frequência nas fêmeas que não passaram pelo procedimento de ovariosalpingohisterectomia. O tratamento indicado é a cirurgia de mastectomia, sendo necessária a retirada da cadeia mamária completa. A anestesia por tumescência vem sendo muito empregada devido sua efetividade na segurança nos pacientes que apresentam algum fator de risco na anestesia geral, sua associação diminui de forma significativa o uso de anestésicos voláteis e gerais. Objetivo deste resumo é realizar uma revisão de literatura com as vantagens de utilizar a técnica de tumescência em cadelas submetidas a cirurgias de mastectomias. Metodologia foi realizado um levantamento de dados em artigos da literatura com finalidade de analisar os benefícios descritos da técnica de tumescência. Resultado a técnica de tumescência consiste em infiltrar adrenalina, anestésico local diluído em solução fisiológica antes da incisão, apresentando um menor desconforto e edema no pós-operatório, juntamente com a ausência de sinais neurotóxicos, cardiotóxicos e necrose local, reduz o risco de infecção no pós-operatório, apresenta menor trauma cirúrgico por utilizar a retirada do tecido por hidrodivulsão. Por ser uma analgesia multimodal é possível reduzir o uso de anestésicos gerais e opioides que deprimem o SNC, trazendo maior segurança. Conclusão com base nos levantamentos desses artigos, a tumescência não é substituída pela anestesia geral, porém ela é uma ótima coadjuvante, reduzindo a concentração alveolar mínima nos inalatórios ou reduzir as doses em infusões contínuas de fármacos intravenosos além de grande eficácia na redução de sangramento local, analgesia no pós operatório satisfatório devido aos anestésicos locais que são os únicos fármacos que permite o bloqueio total dos impulsos nociceptivos até o córtex cerebral e assim podendo optar por outras formas de analgesia além do uso de opióides. A tumescência traz estabilidade e minimiza os riscos do trans-operatório sendo recomendado para cirurgias de mastectomia em cadelas.

Palavra-Chave: Anestesia, Locorregional, Neoplasia.

Área Temática: Medicina Veterinária 


\title{
CADÁVERES DE CÃES PREPARADOS E EMBALADOS À VÁCUO VISANDO AO ENSINO DA CIRURGIA VETERINÁRIA - EFEITO NA BIOMECÂNICA DA PELE
}

\section{Isabela Del Ponti', Giovana Carvalho Vieira², Andréa Barros Piazzon de Souza Queiroz ${ }^{3}$, Fabrício Singaretti de Oliveira ${ }^{4}$}

\begin{abstract}
1,2,3,4,5,6Universidade Estadual Paulista (UNESP) “Júlio de Mesquita Filho" - Faculdade de Ciências Agrárias e Veterinárias - Câmpus de Jaboticabal
\end{abstract}

DOI: $10.47094 /$ ICONRES.2021/26

Introdução: Atualmente, vários são os métodos alternativos que buscam o bem-estar animal no ensino da cirurgia, os quais visam substituir o emprego de animais vivos. As peças anatômicas são fixadas e comparadas a tecidos frescos, buscando modelo alternativo para o treinamento cirúrgico. Objetivo: determinar a força máxima de ruptura da pele, e o deslocamento para a ruptura, em cadáveres de cães preparados, comparativamente a frescos, além da avaliação dos graduandos de Medicina Veterinária dos cadáveres preparados. Metodologia: Foram utilizados 8 cadáveres de cães, colhidos 3 fragmentos de pele a fresco cada (amostras-controle) para análise biomecânica imediata. Após, cada cadáver recebeu solução composta por $120 \mathrm{ml} / \mathrm{kg}$ de sal cura, contendo $200 \mathrm{~g} / \mathrm{L}$ de cloreto de sódio, $10 \mathrm{~g} / \mathrm{L}$ de nitrito de sódio, $10 \mathrm{~g} / \mathrm{L}$ de nitrato de sódio, álcool etílico puro com 5\% de glicerina em relação ao volume do álcool, na quantidade de $150 \mathrm{ml} / \mathrm{kg}$ de peso corporal, via artéria carótida comum e embalados à vácuo e mantidos refrigerados. Considerando-se "dia zero" a colheita das amostrascontrole, foram, também, realizadas análises biomecânicas 7 dias consecutivos. Ademais, 8 cadáveres foram preparados com a mesma técnica descrita e disponibilizados aos alunos, dando-lhes escores de 1 a 10 referentes a maleabilidade da pele e incisão/sutura para comparação entre preparados e frescos. Resultados: Observou-se que não houve diferença significativa entre os tratamentos de força máxima de ruptura, assim como na análise de deslocamento, exceto nos dias 2 e 6 de tratamento. Assim, o preparo químico manteve as características biomecânicas por até 7 dias sob refrigeração utilizando embalagem à vácuo. Os escores avaliados foram maiores que 7,95 (0-10) representando ótima qualidade do material preparado. Conclusões: A técnica de conservação com álcool etílico e sais de cura, associado as embalagens a vácuo, tem bom custo-benefício, sendo um método efetivo na conservação das características biomecânicas da pele para treinamento cirúrgico.

Palavras-chave: Anatomia. Cirurgia. Diérese.

Área Temática: Medicina Veterinária 


\title{
EFEITO NA BIOMECÂNICA DO JEJUNO DE CADÁVERES CANINOS PREPARADOS QUIMICAMENTE E EMBALADOS À VÁCUO VISANDO O ENSINO CIRÚRGICO
}

\author{
Giovana Carvalho Vieira ${ }^{1}$, Isabela Del Ponti², Geovana Coelho Ferreira ${ }^{3}$, e Fabrício \\ Singaretti de Oliveira ${ }^{4}$
}

1,2,3,4, Faculdade de Ciências Agrárias e Veterinárias, Universidade Estadual Paulista "Júlio de Mesquita Filho" (UNESP - Câmpus Jaboticabal)

DOI: $10.47094 /$ ICONRES.2021/25

Introdução: Com a expansão da ideologia que defende o bem-estar animal e sua não utilização em pesquisa e ensino, o emprego de cadáveres para o treinamento de cirurgia torna-se cada vez mais frequente. Assim, é necessário o uso de técnicas de conservação anatômica para evitar a deterioração e manter as propriedades físicas dos tecidos. Objetivo: Analisar, biomecanicamente, o jejuno de cadáveres de cães submetidos a tratamento químico, comparando com amostras de cadáveres frescos, sem qualquer tratamento. Metodologia: Foram selecionados oito animais (grupo 1), e foram colhidas três amostras de jejuno (amostras controle), que foram enviadas imediatamente para análise biomecânica. Foi então realizada a fixação, via artéria carótida comum, com solução contendo 120ml/ $\mathrm{kg}$ de sal cura, composta de $200 \mathrm{~g} / \mathrm{litro}$ de cloreto de sódio, $10 \mathrm{~g} / \mathrm{litro}$ de nitrito de sódio e $10 \mathrm{~g} / \mathrm{litro}$ de nitrato de sódio e em seguida, álcool etílico puro com 5\% de glicerina em relação ao volume do álcool, na quantidade de $150 \mathrm{ml} / \mathrm{kg}$ de peso corporal. Feito isso, cada cadáver foi colocado em saco plástico e embalado à vácuo por máquina profissional, sendo mantido refrigerado entre $0 \mathrm{e} 4^{\circ} \mathrm{C}$. Nos sete dias seguintes também se coletaram três segmentos jejunais para análise. Para o grupo 2, foram preparados mais oito cães e os graduandos avaliaram a qualidade dos cadáveres, utilizando-se escores ( 0 a 10) para maleabilidade, incisão e sutura do tecido. Resultados: Na estatística, apenas as amostras coletadas no dia 4 diferiram-se quanto a força máxima de ruptura. Quanto aos escores, houve diferença estatística na comparação com o cadáver fresco, mas os escores nunca foram inferiores a 7,35 $\pm 1,95$ e a aceitabilidade dos alunos foi de 100\%. Conclusões: A técnica anatômica foi efetiva para manter as características biomecânicas do jejuno por pelo menos 7 dias, o que é recomendado para o treinamento cirúrgico.

Palavras-chave: Anatomia. Cirurgia. Ensino.

Área temática: Medicina Veterinária 


\title{
CADÁVERES DE CÃES PREPARADOS QUIMICAMENTE E EMBALADOS À VÁCUO - EFEITO CRÔNICO NA BIOMECÂNICA DA PELE E ANÁLISE MICROBIOLÓGICA
}

\author{
Geovana Coelho Ferrreira ${ }^{1}$, Andrea de Barros Piazzon de Souza Queiroz ${ }^{2}$, Natália Teresina \\ Brandão Costa ${ }^{3}$, Fabrício Singaretti de Oliveira ${ }^{4}$
}
1,2,3,4UNESP - Faculdade de Ciências Agrárias e Veterinárias/Câmpus de Jaboticabal, Medicina Veterinária, Departamento de Morfologia e Fisiologia Animal

DOI: $10.47094 /$ ICONRES.2021/24

Introdução: Como forma de adaptação ao contexto de bem-estar e de direitos dos animais, as Universidades têm buscado métodos alternativos para o ensino de cirurgia veterinária que visam substituir o emprego de animais vivos, sem tornar o ensino deficitário. Objetivo: Determinar a força máxima (Newtons), e deformação (milímetros) de ruptura da pele, em cadáveres de cães preparados quimicamente e realizar identificação microbiológica durante o processo de conservação. Metodologia: Foram utilizados 8 cadáveres de cães e 24 fragmentos de pele a fresco (amostracontrole) para biomecânica imediata. Cada cadáver recebeu $120 \mathrm{ml} / \mathrm{Kg}$ de solução de sal de cura (contendo 200g/litro de $\mathrm{NaCl}, 10 \mathrm{~g} /$ litro de $\mathrm{NaNO}_{2}$ e $10 \mathrm{~g} /$ litro de $\mathrm{NaNO}_{3}$ ) e posteriormente $150 \mathrm{ml} /$ $\mathrm{Kg}$ de solução contendo álcool etílico puro com $5 \%$ de glicerina, depois foram embalados à vácuo e guardados refrigerados. Considerando "dia zero" o momento da coleta das amostras-controle, as outras análises foram realizadas nos dias 30-60-90-120, com a coleta de 3 fragmentos de pele por cadáver. Também foram realizadas coletas do líquido das embalagens de 2 cadáveres para análise microbiológica. Resultados: Os resultados do teste ANOVA da força máxima indicam que não houve diferença significativa $(p=0,5344)$ entre a média da força máxima do grupo controle e as médias dos diferentes momentos avaliados, comprovando que o método de conservação manteve as características biomecânicas da pele por até 120 dias sob refrigeração. As análises microbiológicas mostraram que a população microbiana não excedeu $8 \times 10^{2} \mathrm{UFC} / \mathrm{mL}$ nos aeróbios totais e $5 \times 10^{2} \mathrm{UFC} /$ $\mathrm{mL}$ nos anaeróbios totais, e $25 \%$ das amostras não apresentaram contaminação. Para causar um efeito negativo, a quantidade de UFC deve estar acima de $10^{8}$. Conclusões: A conservação com álcool etílico e sais de cura, associado às embalagens a vácuo, é uma forma efetiva de preservar e conservar as características da pele fresca por até 120 dias, o que é recomendado para o ensino da cirurgia veterinária.

Palavras-chave: Cirurgia. Anatomia. Ensino.

Área Temática: Medicina Veterinária. 


\section{CADÁVERES DE CÃES PREPARADOS QUIMICAMENTE E EMBALADOS À VÁCUO - EFEITO CRÔNICO NA BIOMECÂNICA DO JEJUNO}

\section{Natália Teresina Brandão Costa ${ }^{1}$, Geovana Coelho Ferreira ${ }^{2}$, Isabela Del Ponti ${ }^{3}$, Fabrício Singaretti de Oliveira ${ }^{4}$}

1,2,3,4 Universidade Estadual Paulista (UNESP) “Júlio de Mesquita Filho” - Faculdade de Ciências Agrárias e Veterinárias - Câmpus de Jaboticabal

DOI: $10.47094 /$ ICONRES.2021/21

Introdução: Pela busca ao bem estar animal métodos alternativos ao uso de animais vivos no ensino da cirurgia veterinária vêm sendo empregados, como o uso de cadáveres preparados quimicamente. Objetivo: Determinar a força máxima (em Newtons - N) de ruptura do jejuno, o deslocamento para a ruptura (em mm), além de realizar a avaliação microbiológica durante todo o processo e desenvolver um modelo anatômico para prática de cirurgia veterinária intestinal. Metodologia: Foram utilizados 8 cadáveres de cães, na amostra controle foram coletados 3 fragmentos de jejuno submetidos a análise biomecânica imediata. Seguida de solução contendo $120 \mathrm{ml} / \mathrm{kg}$ de solução com sal de cura, contendo $200 \mathrm{~g} /$ litro de cloreto de sódio, $10 \mathrm{~g} /$ litro de nitrito de sódio e $10 \mathrm{~g} /$ litro de nitrato de sódio, seguido da injeção de álcool etílico puro com 5\% de glicerina em relação ao volume do álcool, na quantidade de $150 \mathrm{ml} / \mathrm{kg}$ de peso corporal via artéria carótida comum. Cada cadáver foi colocado em embalagem plástica a vácuo e mantido refrigerado entre 0 e $4^{\circ} \mathrm{C}$. As análises biomecânicas foram realizadas nos dias 30, 60, 90 e 120. As análises microbiológicas foram feitas da embalagem de 2 cadáveres, escolhidos ao acaso, no líquido que extravasava. Resultados: Não houve diferença significativa entre os momentos, o teste ANOVA mostrou não haver diferença estatística significativa $(p=0,1339)$ entre a média das amostras controle e tratadas. A população microbiana não excedeu $8,4 \times 10^{2} \mathrm{UFC} / \mathrm{mL}$ nos

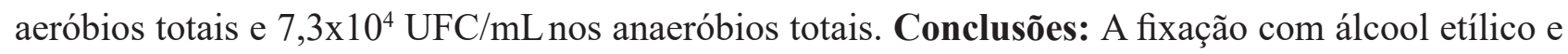
sais de cura, associado às embalagens a vácuo, é uma forma de baixo impacto ambiental e efetiva de conservar as características biomecânicas do jejuno fresco por pelo menos 120 dias, aliado à baixa contaminação microbiana, o que é recomendado para o ensino da cirurgia veterinária por mimetizar nos cadáveres fixados a resistência intestinal apresentada pelos cadáveres frescos.

Palavras-chave:Anatomia.Animal.Ensino.

Área Temática: Medicina Veterinária 


\title{
FREQUÊNCIA DE PLATINOSSOMÍASE FELINA NA CIDADE DE SÃO JOSÉ DOS CAMPOS-SP
}

\author{
Jéssica Pinheiro Augusto ${ }^{1}$, Eduarda Rodrigues Teixeira Cassiano ${ }^{1}$, Joelma Moura Alvarez ${ }^{1}$
}

${ }^{1}$ Universidade Paulista (UNIP), São José dos Campos, SP

Introdução: A Platinossomíase é uma doença que acomete o trato biliar de gatos domésticos. Apesar de nem sempre serem verificados sinais clínicos, o animal pode vir a óbito por conta de obstrução da vesícula biliar, devendo então ser considerada como diagnóstico diferencial de hepatopatias na clínica de pequenos animais. Adoença ocorre em regiões tropicais e subtropicais, pois estas oferecem condições ideais para o desenvolvimento dos seus hospedeiros intercalados e portanto, dos parasitas, que se trata de um trematódeo do gênero Platynossomum spp., o qual tem como hospedeiros intercalados caracóis terrestres, hospedeiro intermediário lagartixas, e como definitivo o gato, o qual se contamina ao ingerir a lagartixa com metacercárias. Objetivo: O estudo visou demonstrar a frequência do parasita, através do exame coproparasitológico de fezes de gatos da cidade de São Jose dos Campos pelo teste de Ritchie (centrifugo-sedimentação) e pelo Kato-katz (diagnóstico quantitativo). Metodologia: O número de amostras utilizadas no estudo foi um total de 50, provenientes de clínicas veterinárias da cidade de São José dos Campos- SP, cujos proprietários dos animais responderam um questionário a respeito dos hábitos dos mesmos. As amostras foram refrigeradas e armazenadas em prazo máximo de 1 dia, sendo realizados os testes de Ritchie e pelo Kato-katz. Resultados: Do total de 50 amostras, uma foi positiva para Platynossomum spp. pela técnica de Ritchie, representando um total de $2 \%$ de infectados. Foram ainda encontrados oocisto do protozoário Cystoisospora felis, representando 5\% das amostras, e Toxocara cati representando 9\% das amostras. Considerações Finais: Apesar da baixa prevalência da Platinossomíase observada no estudo, a mesma não deve ser descartada como diagnostico diferencial de hepatopatias, e o teste de Ritchie se mostrou mais eficiente para a confirmação da infecção.

Palavras-chave: Gato.Hepatopatias.Lagartixa.

Área Temática: Medicina Veterinária 


\title{
MÉTODOS DE CONSERVAÇÃO DE TÚNICAALBUGÍNEA TESTICULAR BOVINA PARA USOEM ENXERTOS E IMPLANTES
}

\author{
Afonso Rangel Ribeiro ${ }^{1}$, Gustavo Silva de Sousa ${ }^{2}$, Ítalo dos Santos Coutinho ${ }^{3}$, Tatiana Cruz \\ Siqueirade Carvalho ${ }^{4}$, Felipe Antunes Luz de Oliveira ${ }^{5}$, Victor Jordan Souto da Paixão ${ }^{6}$, \\ Ana Bárbara Freitas Rodrigues Godinho ${ }^{7}$
}

Universidade Estadual do Norte Fluminense 1234567

Introdução: A túnica albugínea testicular é bastante utilizada em reparações de vários tipos de lesões na medicina veterinária. Esta é composta por um tecido conjuntivo levemente modelado, rico em fibras colágenas dispostas de forma entrelaçada promovendo resistência a trações em todas direções alem de possuir baixa celularidade. A glicerina a 98\% mantida em temperatura ambiente é o principal meio de conservação utilizado e, atualmente, o etilenoglicol tambem tem ganhado espaço na medicina veterinária, sendo muito utilizado para criopreservação. Objetivo: determinar a viabilidade da utilização do etilenoglicol como conservante de túnica albugínea testicular em comparação com a glicerina, considerando a preservação das características morfológicas da membrana em questão. Metodologia: foram coletadas 20 túnicas albugíneas testiculares de animais provenientes de um frigorífico em Campos dos Goytacazes - RJ que foram divididas em dois grupos de 10 túnicas, onde um grupo ficou submerso em solução de glicerina $98 \%$ coberto com gaze para manter todo material submerso e o outro grupo ficou submerso na solução de etilenoglicol 98\%. Os dois grupos ficaram 30 dias submersos em suas soluções para após este período seremanalisadas histologicamente. Resultados: após as análises dos dados foi observado que tanto a túnica que foi conservada em solução de glicerina quanto em etilenoglicol mantiveram sua integridade histológica, com a arquitetura colágena bem semelhante tanto qualitativamente quanto quantitativamente, diante da avaliação através da coloração de Tricômico de Masson. Considerações finais: Através da análise histológica das membranas, nenhuma alteração tecidual foi evidenciada em relação aos diferentes tipos de soluções conservadoras. O aspecto histo arquitetônico do tecido se manteve inalterado, não sendo possível diferenciaruma melhor eficácia entre elas. Neste sentido, é possível afirmar que o uso da solução de glicerina, como conservante de membrana biológica, se justifica já que atende às propriedades de uma solução conservadora e com melhor custo benefício.

Palavras - chave: Glicerol. Etilenoglicol. Histológica.

Área temática: Medicina veterinária. 


\title{
BLOQUEIO DO QUADRADO LOMBAR EM CÃES E GATOS
}

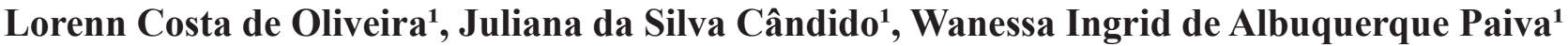

\author{
${ }^{1}$ Universidade Federal Rural de Pernambuco
}

Introdução: A Anestesia Locorregional (ALR) em protocolos balanceados promove melhores resultados perioperatórios e reduz o consumo de opióides em comparação com protocolos sem ALR. A ultrassonografia (US) é uma importante ferramenta para realização de bloqueios locorregionais. O bloqueio do quadrado lombar ecoguiado (QL-block) é a injeção de anestésico local (AL) na fáscia do músculo quadrado lombar (QL), promovendo o alívio da dor somática e visceral do abdômen, sendo uma excelente opção para analgesia nesta cavidade. O QL em cães e gatos é o músculo hipaxial lombar mais dorsal e por estar próximo aos corpos das vértebras e forames transversais, comunica-se com inervações viscerais, nociceptivas e somáticas. Objetivo: Este trabalho objetivou fazer uma breve revisão de literatura sobre o QL-block em cães e gatos. Metodologia: O transdutor linear é posicionado paralelo às últimas costelas, nos processos transversos das vértebras L1-L2. Em Veterinária há duas abordagens descritas, a primeira se dá através da injeção do AL entre as fáscias do músculo QL e o psoas, denominando QL-plane, e o agulhamento pode ser dorsoventral e ventrodorsal. A segunda, consiste na injeção superficial na face lateral do músculo QL e medial à fáscia toracolombar, definido como LQL-plane, o agulhamento pode ser longitudinal ou transversal à coluna espinhal. Após visibilização das estruturas, o AL é injetado, formando-se um círculo anecóico depositado na fáscia do músculo QL. Resultados: O Q1-block ao fornecer analgesia visceral e somática permite o menor consumo de analgésicos no transoperatório tornando o procedimento mais confortável para o paciente e anestesista e proporciona alívio da dor pós-operatória. Conclusões: É importante que os anestesiologistas conheçam a técnica do QL-block para oferecer aos seus pacientes um excelente bloqueio locorregional para cirurgias abdominais.

Palavras-chave: Dor. Ultrassonografia. Anestesiologia

Área temática: Medicina Veterinária 


\title{
DIAGNÓSTICO DE ESPOROTRICOSE (Sporothrix Schenckii) EM GATOS NA \\ VIGILÂNCIA EM SAÚDE AMBIENTAL, CAMARAGIBE-PE
}

\section{Wanessa Ingrid de Albuquerque Paiva ${ }^{1}$, Juliana da Silva Cândido ${ }^{1}$, Lorenn Costa de Oliveira ${ }^{1}$}

\author{
${ }^{1}$ Universidade Federal Rural de Pernambuco
}

Introdução: A esporotricose é uma infecção fúngica subcutânea provocada pelo fungo Sporothrix $s p$. que acomete mamíferos, sendo o felino doméstico e o homem os mais acometidos. Clinicamente, os gatos com esporotricose apresentam lesões ulceradas na pele, geralmente com pus, que evoluem rapidamente. A micose pode ser disseminada por meio de mordeduras e arranhaduras de gatos infectados, sendo essa a forma mais comum de disseminação da doença entre os gatos urbanos. As lesões comumente estão localizadas na face, pontas de orelha e membros superiores. Os casos suspeitos para esporotricose são encaminhados à Vigilância Ambiental em Saúde (VAS) de três formas: através dos Agentes de Combate à Endemias (ACE), por encaminhamento das Unidades Básicas de Saúde ou através de denúncias de moradores. Para o diagnóstico da doença, a cultura micológica é considerada padrão-ouro, isolando a espécie do gênero Sporothrix sp. Objetivo: Este trabalho objetivou descrever o diagnóstico dos casos de gatos domésticos com suspeita de esporotricose urbana, os quais foram examinados pela Vigilância Ambiental em Saúde do município de Camaragibe-PE, no período de 02 de março a 21 de outubro 2020. Metodologia: Mediante solicitação de suspeita da doença, a equipe técnica composta por médico-veterinário e ACE deslocou-se às residências e colheu as amostras das lesões de quatro gatos suspeitos de esporotricose e prestou orientações quanto à manipulação dos animais, bem como dos riscos de transmissão da doença aos humanos. No laboratório da VAS, realizouse exame citológico, porém foi necessária a realização de contraprova, por isso, as amostras coletadas foram enviadas ao Laboratório de Endemias (LABEND) - PE para realização de cultura micológica. Resultados: As amostras dos quatro gatos examinados foram positivas na cultura micológica para a espécie Sporothrix Schenckii. Conclusões: Após o resultado do diagnóstico padrão-ouro da cultura micológica, os tutores foram orientados sobre o tratamento nos animais.

Palavras-chave: Médico-Veterinário. Gato. Sporothrix sp.

Área temática: Medicina Veterinária 


\title{
CARACTERIZAÇÃO DE CASOS CONFIRMADOS PARA INFECÇÕES POR SARS- COV-2 ACOLHIDOS NO CENTRO DE ATENDIMENTO AO CORONAVIRUS DE JABOTICABAL-SP
}

\author{
Beatriz Estevez de Oliveira ${ }^{1}$, Paulo Aléscio Canola ${ }^{1}$
}

${ }^{1}$ Faculdade de ciências agrárias e Veterinárias da Universidade estadual paulista Júlio de mesquita filho (FCAV-UNESP) - câmpus de Jaboticabal

Introdução: O Coronavírus da Síndrome Respiratória Aguda Grave 2 (SARS-CoV-2), agente causador da COVID-19 é um patógeno de grande importância na saúde pública. Como estratégia para o combate à pandemia da COVID-19 o município de Jaboticabal - SP implementou o Centro de Atendimento ao Coronavírus (CAC), seguindo as normas de funcionamento dos Centros de Triagem COVID-19 (CT COVID-19). Objetivo: Caracterizar os casos confirmados para COVID-19 no CAC de Jaboticabal-SP e identificar correlações entre as informações presentes no prontuário médico e a necessidade de internação do paciente. Metodologia: Este estudo foi aprovado pelo Comitê de Ética em Pesquisa (CEP), número do parecer 4.479.246. Foram utilizados os dados obtidos através de prontuários de 352 pacientes com infecção por SARS-CoV-2 confirmada por critério laboratorial (PRC ou Imunocromatografia) no período de 27 março a 30 de setembro de 2020. Foi realizada análise descritiva dos dados epidemiológicos coletados e regressão logística entre as variáveis: idade, sexo, sintomas relatados, comorbidades, parâmetros clínicos e necessidade de internação. Resultados: A idade mediana dos pacientes neste estudo foi de 46 anos, sendo a maioria do sexo feminino (58\%). A mediana de atendimentos por paciente foi 2 e 32 (9\%) pacientes foram hospitalizados. Os fatores de risco para hospitalização encontrados neste estudo foram idade maior que 60 anos, presença de diarreia, dor abdominal, fadiga e/ou cansaço, febre e/ou calafrio, náusea e/ou vômito, tosse, hipertensão arterial sistêmica, saturação de $\mathrm{O}_{2}$ menor ou igual a $90 \%$ e temperatura corporal aferida durante o atendimento maior que $37,5^{\circ} \mathrm{C}$. Conclusões: Pacientes com hipertensão arterial sistêmica, pacientes idosos, aqueles que apresentem sintomas gastrointestinais, tose e febre devem ser receber maior atenção durante o atendimento inicial e o monitoramento na atenção básica para que seja possível a detecção precoce de sinais e sintomas de agravamento da doença e realizar, quando necessário, o encaminhamento para unidades hospitalares de referência.

Palavras-chave: Síndrome Respiratória Aguda Grave. Sistema Único de Saúde. COVID-19.

Área temática: Medicina Veterinária 


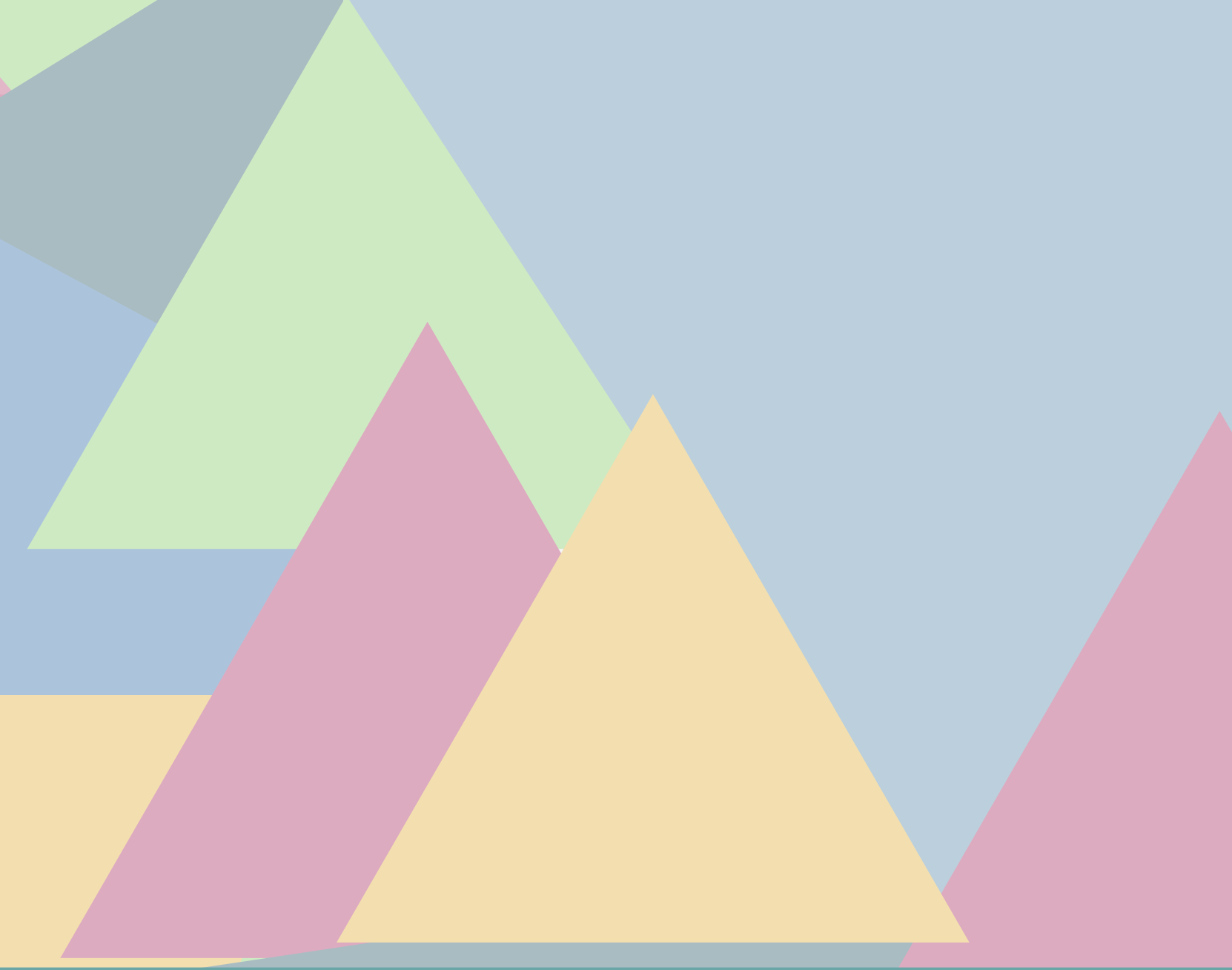

Saúde Coletiva 


\title{
ANÁLISE DO LAZER COMO UM FATOR DETERMINANTE DE SAÚDE EM UMA DETERMINADA POPULAÇÃO
}

\author{
Raul Emanoel Silva ${ }^{1}$ \\ ${ }^{1}$ Universidade do Extremo Sul Catarinense (UNESC) - Criciúma/SC
}

Introdução: Na literatura constata-se a relevância dos fatores determinantes da condição de saúde de um determinado grupo populacional. Entre eles, fazem parte de maneira importante as opções de lazer escolhidas pela população. Objetivo: Analisar a distribuição das opções de lazer dos integrantes das famílias do bairro São Defende (Criciúma/SC), e discutir se essa distribuição está adequada e equilibrada e se influencia positiva ou negativamente na vida dessas pessoas. Metodologia: Foi realizado um estudo transversal e descritivo através de questionários aplicados aos moradores do bairro São Defende durante o $1^{\circ}$ semestre de 2016. Realizou-se uma amostragem de conveniência considerando os que se dispuseram a responder, totalizando 118 famílias. Resultados: Das famílias questionadas, 71\% têm como atividade de lazer assistir à televisão, 58\% recebem visitas em casa, $54 \%$ reúnem-se com amigos, 28\% realizam viagens, 27\% praticam leitura, $22 \%$ praticam atividades físicas, 20\% participam de festas, 13\% divertem-se com jogos, 11\% vão ao cinema. Conclusões: Sendo o lazer uma parte indispensável no dia a dia, é de suma importância que a população pratique hábitos rotineiros saudáveis, visando seu próprio bem-estar. A análise sobre as atividades de lazer exercidas pelas famílias entrevistadas mostrou que o hábito mais praticado por essas pessoas é assistir à televisão, enquanto atividades como amigos, jogos, leitura e atividade física ficaram em segundo plano. Ter passatempos é uma atitude saudável e contribui positivamente para o organismo e bemestar da população, porém, quando a televisão assume um papel mais importante do que praticar atividades físicas, o lazer pode ter uma influência negativa sobre a saúde dessas pessoas.

Palavras-chave: Lazer. Determinante. Saúde.

Área Temática: Saúde Coletiva. 


\section{POLÍTICAS DE SAÚDE: A UTILIZAÇÃO DA VARIÁVEL RAÇA/COR EM SAÚDE PÚBLICA: LIMITES E POSSIBILIDADES.}

\section{Jacelino Batista da SILVA.}

Especialista em Gestão de Saúde Pública pela Faculdade de Tecnologia e Ciências do alto do Paranaíba - FATAP.

Introdução: O presente trabalho visa debater o emprego da simbologia etnia, classe ou cor como causa preponderante em termo de desigualdades sociais, expondo os indivíduos ao risco de adoecer e até mesmo morrer. O objetivo é refletir acerca da literatura nacional e internacional com relação à Saúde Pública. Constatou-se que as pesquisas internacionais dialogam e exploram o uso da variável raça e cor no campo da saúde. No Brasil, a questão de raça enquanto desigual na área da saúde é ainda introdutória, porém há evidências distintivas as quais sugestionam uma crescente busca nessa linha. Averiguações acerca do papel da etnia, classe ou cor como fatores de diferenciação na saúde tendem a fornecer dados eficientes e que desempenharão papel fundamental na elaboração de diretrizes destinadas a diminuir as desigualdades na área da saúde. A construção teórica deste estudo foi elaborada por meio da metodologia de revisão bibliográfica para levantar diferentes pesquisas, com o intuito de analisar, investigar e estudar os diferentes conhecimentos científicos sobre o assunto proposto, comum caráter pragmático, um processo formal e sistemático de desenvolvimento do método científico. Resultado, a metodologia deseja descobrir respostas para problemas mediante o emprego de procedimentos científicos. Conclusão: justifica-se o tema pela importância para a comunidade científica, pois até o ano de 2020, poucos trabalhos científicos foram publicados a respeito do assunto e poucas pesquisas foram realizadas, porém o tema possui grande importância das políticas de saúde, a utilização da variável raça/cor em saúde pública: limites e possibilidades.

Palavras Chaves: Contraste Social. Etnia, Raça e Cor. Saúde Pública.

Área Temática: Saúde Coletiva 


\title{
ESTRATÉGIA SAÚDE DA FAMÍLIA E PROGRAMA SAÚDE NA ESCOLA: A IMPORTÂNCIA DAS AÇÕES DE PROMOÇÃO DA SAÚDE
}

\author{
Francisca Viviane Matos Soares ${ }^{1}$ Clara dos Santos Silva Linhares ${ }^{2}$
}

${ }^{1}$ Escola de Saúde Pública do Ceará ${ }^{2}$ Escola de Saúde Pública do Ceará

Introdução: Propõe-se através da Estratégia Saúde da Família(ESF) à reorganização e o fortalecimento da Atenção Básica, de acordo com os preceitos do Sistema Único de Saúde. São desenvolvidas ações de promoção da saúde, prevenção, recuperação, reabilitação de doenças e agravos. Ações realizadas por equipes multiprofissionais. Dentre as ações têm-se o Programa Saúde na Escola (PSE), este visa à integração e articulação da educação e da saúde, através de ações de promoção, prevenção e atenção à saúde nas escolas públicas. Objetivo: Compreender a importância das ações de promoção da saúde realizadas pelo PSE. Metodologia: É um estudo bibliográfico de abordagem qualitativa. Resultados: As atividades de educação em saúde do PSE contribuem para a qualidade de vida de estudantes através de temas abordados como alimentação saudável, prática de atividade física, prevenção ao uso de álcool e outras drogas, prevenção de doenças sexualmente transmissíveis (DST/ AIDS), atualização da situação vacinal, promoção à cultura de paz, cidadania e Direitos Humanos, dentre outros. Considerações Finais: Torna-se de fundamental importância as ações de educação em saúde nas escolas, devido à troca de informações e conhecimento entre a equipe da ESF e alunos, proporcionando através da articulação de saberes impactos positivos na qualidade de vida de crianças, adolescentes e jovens. Ademais, o PSE colabora com a autonomia dos estudantes, contribuindo para o autocuidado a partir dos conhecimentos adquiridos.

Palavras-chave: Programa Saúde na Escola. Estratégia Saúde da Família. Educação em saúde.

\section{Área Temática: Saúde Coletiva}




\title{
SAÚDE MENTAL DA POPULAÇÃO INDÍGENA: FATORES DE RISCO PARA O SUICÍDIO.
}

\section{Francimar Oliveira de Jesus ${ }^{1}$}

\author{
${ }^{1}$ Centro Universitário do Norte (UNINORTE)
}

Introdução: Segundo a Organização Mundial da Saúde (OMS), o suicídio é a $16^{\circ}$ maior causa de mortes no planeta. Sendo a população indígena a detentora das piores estatísticas, com valores elevados e proporções quase epidêmicas. Objetivo: Identificar através de uma revisão integrativa de literatura, quais são os fatores de risco para o suicídio na população indígena. Metodologia: Para a construção desta pesquisa foram realizadas as seguintes etapas: identificação do tema, definição da questão norteadora, definição dos critérios de inclusão e exclusão e leitura minuciosa dos estudos encontrados para extração de dados. As bases de dados utilizados foram: MEDLINE e SciELO. Utilizou-se a estratégia PICO auxiliar na estratégia de busca por meio dos descritores, onde $\mathrm{P}=$ População Indígena, I= Fatores de Risco e $\mathrm{Co}=$ Saúde Mental. Resultados: Foram contemplados seis artigos como amostra desta revisão. Quanto ao idioma dos estudos, todos foram escritos na língua inglesa, no que se refere à faixa etária dos sujeitos dos estudos, três consideravam indivíduos a partir dos 11 anos, dois abordaram apenas adultos com idades a partir de 18 anos e, apenas um abordou indivíduos a partir dos 15 anos. Em relação aos fatores de riscos abordados, observou-se que, o fator cultural, assim como o fator histórico foram citados em apenas um estudo. Prevaleceu a abordagem dos fatores socioeconômicos, alcoolismo, uso indevido de substancias e traumas, nos demais estudos. Entretanto, apenas um abordou o método utilizado para cometer suicídio. Na maioria dos estudos, o suicídio foi apontado em maior número em adolescentes do sexo masculino. Conclusões: A partir dos dados analisados, é possível identificar que o suicídio indígena quase sempre esteve em níveis elevados. Portanto, propõe-se uma releitura das políticas de saúde mental voltadas para esta população, a fim de reduzir os riscos que os levam a causar danos próprios intencionais.

Palavras-chave: Aborígenes. Autocídio. Psicopatologia.

Área Temática: Saúde Coletiva 


\title{
USO TERAPÊUTICO DA FITOTERAPIA NO SISTEMA ÚNICO DE SAÚDE
}

\section{Beatriz Cunha da Paixãoํㅜ, Renata Maiana de Almeida Ferreira Oliveira ${ }^{2}$, Sthefani Sávia Dantas Guimarães ${ }^{3}$, Cristiane Queiroz Borges ${ }^{4}$ Matheus Sobral Silveira $^{5}$}

\author{
${ }^{1}$ Centro Universitário Estácio da Bahia ${ }^{2}$ Centro Universitário Estácio da Bahia \\ ${ }^{3}$ Centro Universitário Estácio da Bahia ${ }^{4}$ Centro Universitário Estácio da Bahia \\ ${ }^{5}$ Centro Universitário Estácio da Bahia
}

DOI: $10.47094 /$ ICONRES.2021/2

Introdução: Segundo o Ministério da Saúde (MS), a fitoterapia é a terapêutica caracterizada pelo uso de plantas medicinais em suas diferentes formas farmacêuticas, sem a utilização de substâncias ativas isoladas, ainda que de origem vegetal. Desta forma, considerando a biodiversidade do Brasil, e tendo o objetivo de melhorar a saúde da população, o MS vem investindo no uso da fitoterapia para o Sistema Único de Saúde (SUS). Objetivo: Verificar o uso terapêutico da fitoterapia no Sistema Único de Saúde no Brasil. Metodologia: Foi adotado revisão da literatura, consistindo na busca em banco de dados da Scientific Electronic Library Online- SCIELO, Medical Literature Analysis and Retrieval System Online - MEDLINE, Literatura Latino Americana e do Caribe em Ciências da Saúde - LILACS, Biblioteca Virtual em Saúde (BVS) e US National Library of Medicine- PUBMED, publicados no período de 2010 a 2020. A busca bibliográfica foi realizada entre os meses de setembro a dezembro de 2020 sendo utilizados 23 artigos originais. Resultados: A fitoterapia é reconhecida como um método eficaz de tratamento e cura. A evolução histórica do reconhecimento dessa prática conduziu à regulamentação de políticas de incentivo à pesquisa. Observa-se o crescimento do número de programas de fitoterapia no SUS, contudo, para a introdução desta prática como terapêutica se faz necessário planejar e executar atividades voltadas para a educação em saúde, valorizando também os aspectos culturais envolvidos no seu uso. Conclusão: De acordo com a revisão, foi perceptível que o conhecimento da fitoterapia necessita ser difundido entre os profissionais do sistema de saúde, que muitas vezes não se sentem seguros para sua prescrição. Aponta-se que a Política Nacional possibilitou o aumento expressivo do número de programas voltados para a expansão da fitoterapia, entretanto, é preciso a inserção de fomentos para aprimorar a aplicabilidade.

Palavras-chave: Brasil. Plantas medicinais. Programas.

Área Temática: Saúde Coletiva 


\section{OCORRÊNCIA DE PARASITAS SANGUÍNEOS COM POTENCIAL ZOONÓTICO EM ANIMAIS DE COMPANHIA NO MUNICÍPIO DE BOA VISTA, RORAIMA, BRASIL}

\section{Nailde de Paula Silva1, Denym Andrade de Queiroz², Cesar Amaro², Craudenilde Maracaipes Constantino $^{3}$, José Ricardo Soares Silva ${ }^{3}$, Fábio Silva de Souza ${ }^{1}$}
${ }^{1}$ Docente no curso de Medicina Veterinária..Centro Universitário Estácio da Amazônia. Boa Vista/ RR

${ }^{2}$ Discente no curso de Medicina Veterinária.Centro Universitário Estácio da Amazônia..Boa Vista/ RR

${ }^{3}$ Hospital Veterinário Hpet. Boa Vista/RR.

Introdução: Na periferia de áreas urbanas do Brasil é comum a presença de cães parasitados por carrapatos. Esses artrópodes ao fazer hematofagia podem transmitir microrganismos patogênicos tanto para animais domésticos quanto para o homem. Objetivo: Realizar levantamento da ocorrência de hemoparasitas de cães e gatos com potencial zoonótico em animais atendido s em um hospital veterinário no Estado de Roraima. Metodologia: Inicialmente, foram analisadas 323 amostras (294 cães e 29 gatos) de sangue de cães e gatos atendidos entre os meses de janeiro a agosto de 2020 provenientes de Hospital Veterinário localizado no município de Boa Vista/RR. A busca de hemoparasitas nas amostras sanguíneas foi realizada por meio de esfregaços de sangue coradas pelo método Panótipo Rápido. Resultados: Os gêneros observados incluíram Anaplasma $(\mathrm{n}=220 ; 68,11 \%)$, Erliquia $(\mathrm{n}=59 ; 18,27 \%)$, Babesia $(\mathrm{n}=12 ; 3,72 \%)$ e Hepatozoon $(\mathrm{n}=4 ; 1,24 \%)$. Alguns animais apresentaram infecção dupla em diferentes células sanguíneas, como por exemplo, Ehrlichia e Anaplasma ( $\mathrm{n}=28 ; 8,67 \%$ ). Cinquenta e um bairros de Boa Vista, de um total de 56, foram identificados como a residência desses 323 animais, o que demonstrou ampla distribuição desses parasitos no território estudado. O maior percentual da população humana de Boa Vista concentra-se nos bairros da Zona Oeste da cidade onde, por este levantamento, apontou 87,62\% dos animais parasitados conferindo-se, portanto, um maior risco de contato de pessoas com carrapatos possivelmente infectados ou contaminados com algum patógeno. Conclusões: Esses resultados alertam para a escassez de dados da ocorrência de hematozoários e hemobactérias em animais de companhia em Roraima e para a possibilidade de ocorrência de infecções zoonóticas transmitidas por carrapatos aos seres humanos. Ressalta-se a necessidade de investigação clínico-epidemiológica e identificação molecular para melhor caracterização dos vetores e espécies de parasitos envolvidos no ciclo de transmissão.

Palavras-chave: Hemoparasitas. Ixodídeos. Zoonose.

Área temática: Saúde Coletiva 


\title{
ATENDIMENTO MÉDICO DA POPULAÇÃO MASCULINA EM UNIDADE BÁSICA DE SAÚDE DO INTERIOR DO AMAZONAS.
}

\author{
Andréa Regina Martins de Carvalho
}

Introdução: A Unidade Básica de Saúde é o local ideal para educar e estimular a comunidade quanto à necessidade de se adotar hábitos preventivos. Homens na faixa etária produtiva pouco procuram a UBS. Sobre os motivos da pouca procura masculina pela UBS, encontram-se relatos de este ser um local destinado aos problemas da mulher e da criança e a crença de que os homens adoecem menos que as mulheres. Estudos mostraram que a maioria dos pacientes do sexo masculino vão raramente ou no máximo uma vez ao ano nas unidades básicas de saúde. O número dos que vão mais de uma vez é pequeno e sua ida está atrelada ao acompanhamento de familiares e não para busca de atendimento próprio. Objetivos: Apresentar dados referentes aos atendimentos médicos à população masculina durante o período de um ano em um município no interior do Amazonas. Metodologia: A pesquisa foi realizada em uma UBS no município de Itacoatiara, no interior do Amazonas. Foram contabilizados os atendimentos médicos através do Prontuário Eletrônico do Cidadão (PEC), ocorridos no período de um ano (entre janeiro de 2019 e dezembro de 2019), para homens com idade entre 25 e 59 anos. Resultados: Integraram essa amostra 282 atendimentos para homens contra 970 atendimentos em mulheres na mesma faixa etária. Conclusões: A pesquisa reforça a necessidade de discussão acerca do acesso dos homens ao serviço público de saúde. É necessária a adoção de políticas de saúde direcionadas ao sexo masculino. Os serviços devem construir as estratégias para incluir as necessidades deste público. É importante que os profissionais de saúde adotem uma atitude de acolhimento aos homens, se capacitem e juntamente com os gestores, viabilizem estratégias de inclusão para o público masculino.

Palavras-Chave: Atenção primária. Saúde do homem. Atenção básica.

Área temática: Saúde Coletiva. 


\section{EDUCAÇÃO EM SAÚDE COM PROFISSIONAIS DE UNIDADE BÁSICA DE SAÚDE NO INTERIOR DO AMAZONAS}

\section{Andréa Regina Martins de Carvalho}

Introdução: A Educação em Saúde é importante na medida em que facilita medidas de prevenção de agravos e patologias, promove a saúde e propaga meios de autocuidado. As Unidades Básicas de Saúde são portas de entrada para usuários do Sistema Único de Saúde (SUS), então são necessárias estratégias de disseminação de informações acerca de prevenção de doenças e manutenção da saúde.

Objetivos: Apresentar um relato de experiência acerca da implementação da estratégia de Educação em Saúde semanal realizada em Unidade Básica de Saúde no interior do Amazonas. Metodologia: Realizam-se semanalmente palestras, cursos, rodas de conversa e capacitações em UBS localizada em município do interior do Estado do Amazonas. Para tais atividades, são convidados profissionais de saúde das mais diversas áreas, como médica, enfermeira, técnica de enfermagem, microscopista, dentre outros. Os temas escolhidos variam de acordo com a realidade epidemiológica local ou levando em consideração as dúvidas e dificuldades dos profissionais que atuam na unidade. Resultados: A capacitação de trabalhadores da UBS tem sido satisfatória, importante e utilizada na propagação de informações aos pacientes do SUS, gestores e trabalhadores. Conclusões: Educação em saúde com usuários do SUS e profissionais de saúde é útil para disseminação de ações de autocuidado e aumento da qualidade de vida, bem como melhora dos índices de comorbidades.

Palavras-chave: Educação continuada. Atenção primária à saúde. Sistema único de saúde.

Área temática: Saúde Coletiva. 


\section{PRÉ-NATAL EM COMUNIDADES RURAIS NO INTERIOR DO AMAZONAS- \\ UM RELATO DE EXPERIÊNCIA.}

\section{Andréa Regina Martins de Carvalho}

Introdução: A realização do pré-natal é de suma importância para prevenção de agravos e promoção da saúde em gestantes. As comunidades rurais têm acesso diminuído aos serviços de saúde por motivo das barreiras geográficas, principalmente no Amazonas, em que muitos usuários do Sistema Único de Saúde habitam em locais que só é possível ter acesso através de embarcações pelos rios das florestas. Objetivos: Realizar o pré-natal adequado em comunidades rurais do interior do Amazonas. Relatar a experiência da equipe de saúde na assistência a gestantes e fetos em área rural. Metodologia: Trata-se de um relato de experiência acerca da realização da assistência pré-natal em zona rural do interior do Amazonas. Resultados: A equipe de saúde se desloca semanalmente até a zona rural para oferecimento de assistência em saúde aos mais diversos grupos etários de habitantes, inclusive com realização de pré-natal, coleta de testes rápidos, exame físico, ausculta dos batimentos cardíacos do feto. $\mathrm{O}$ deslocamento se dá através de barco ou lancha, kombi ou até mesmo os profissionais de saúde indo a pé pelos ramais de barro. Conclusões: O pré-natal pode evitar doenças maternas e fetais, garante um acompanhamento adequado do binômio mãe-filho e propicia a resolução de dúvidas acerca da gestação. É de fundamental importância a realização desta política pública mesmo em locais afastados da zona urbana.

Palavras-chave: Cuidado pré-natal. População rural. Saúde da população rural.

Área temática: Saúde Coletiva. 


\section{QUALIDADE DE VIDA E PERCEPÇÕES DAS PESSOAS COM HIV/AIDS.}

\section{Jacelino Batista da SILVA.}

Assistente Social e Professor Especialista em Gestão de Saúde Pública pela Faculdade de Tecnologia e Ciências do alto do Paranaíba - FATAP.

Introdução: O presente artigo estuda o impacto da infecção pelo HIV, bem como as diversas mudanças na vida das pessoas. Enfrentar este problema, associado as dificuldades que a condição sorológica impõe em relação à qualidade de vida, tem sido um dos desafios enfrentados pelas pessoas com HIV/AIDS, bem como os elementos que influenciam a percepção de qualidade de vida de pessoas que vivem com HIV/AIDS. Este estudo tem como Objetivo é analisar através de entrevistas semiestruturadas realizadas com 10 pessoas, a análise resultou em quatro categorias: Qualidade de vida: subjetividade e multidimensionalidade; viver com HIV/AIDS e a qualidade de vida; O cuidado para o viver com qualidade; e os serviços de saúde como potencializadores da qualidade de vida. A Metodologia utilizada como instrumento para coleta de dados foi um questionário padronizado, a fim de se obter uma melhor apreciação do conteúdo apresentado no trabalho. Portanto percebemos como Resultado que existem vários fatores que interferem na qualidade de vida dessas pessoas portadoras de HIV/AIDS, como: aspectos físicos decorrentes da doença, o seguimento do tratamento e o uso dos antirretrovirais. Como aspectos sociais, identificou-se a presença de discriminação e preconceito. Considerações finais, a aceitação do tratamento com medicamentos antirretrovirais melhora consideravelmente a qualidade de vida. A identificação dos fatores que interferem na qualidade de vida poderá contribuir para o atendimento mais humanizado às pessoas que vivem com HIV/Aids, direcionando o cuidado para além dos aspectos clínicos, instrumentalizando estas pessoas na busca por um viver com mais qualidade.

Palavras Chaves: Tratamento. Preconceito. Desafios.

Área Temática: Saúde Coletiva 


\title{
ASSISTÊNCIA DE ENFERMAGEM NA ATENÇÃO PRIMÁRIA À PORTADORES COM HIPERTENSÃO ARTERIAL
}

\author{
Victor Guilherme Pereira da Silva Marques ${ }^{1}$, Guilia Rivele Souza Fagundes²
}

${ }^{1}$ Centro Universitário do Piauí/ UNIFAPI, ${ }^{2}$ Universidade do Estado da Bahia/ UNEB

Introdução: A hipertensão arterial sistêmica (HAS) é uma doença multifatorial e crônica que não pode ser transmitida sendo sua principal característica seus altos índices de pressão arterial, sendo também um dos principais fatores de doenças cardiovasculares. Considerada um grande problema de saúde pública a HAS é frequentemente assintomática e silenciosa na maioria dos diagnósticos. Sendo assim o enfermeiro precisa utilizar de forma estratégica seus conhecimentos em educação e saúde para assim se obter resultados satisfatórios em relação a doença. Objetivo: Identificar o papel do enfermeiro a pacientes com hipertensão arterial na atenção primária. Metodologia: Tratase de uma revisão de literatura realizada na bases de dados LILACS e BDENF. Utilizou-se os seguintes descritores: "Doença Crônica", "Educação em Saúde" e "Unidade Básica de Saúde". Os artigos foram selecionados nos idiomas português, inglês e espanhol com recorte temporal de 2016 a 2021. Resultados: Para o início do tratamento os pacientes precisam estar informados sobre as orientações e medidas preventivas para o controle da HAS, sendo transmitidas através das consultas de enfermagem. Visando um resultado eficiente o enfermeiro busca realizar ações de forma que não haja o agravamento da doença entre elas está educação em saúde a todo esse público, consultas de enfermagem regularmente, busca ativa desses pacientes faltosos as consultas dentre outros. Tanto a equipe multidisciplinar quanto o enfermeiro são essenciais, para contribuir de forma eficaz na adesão e continuidade do tratamento. Conclusões: Conclui-se que a presença do enfermeiro na ESF é essencial para a transmissão de informação sobre a HAS e a execução de medidas realizadas na atenção primária, para assim se obter resultados eficientes e satisfatórios em combate a doença.

Palavras-chave: Doença crônica. Educação em saúde. Unidade básica de saúde.

Área Temática: Saúde Coletiva 


\title{
ASSISTÊNCIA DE ENFERMAGEM NO PUERPÉRIO
}

\section{Victor Guilherme Pereira da Silva Marques', Guilia Rivele Souza Fagundes²}

\author{
${ }^{1}$ Centro Universitário do Piauí/UNIFAPI, ${ }^{2}$ Universidade da Bahia/UNEB
}

Introdução: O puerpério é definido como a etapa inicial após o parto com a saída da placenta e o término é quando o corpo consegue retomar ao seu estado anterior a gestação. No puerpério a mulher passar por grandes transformações, tanto fisicamente quanto em sua rotina diária, pois necessita prestar cuidados ao bebê. Diante disso o profissional que realiza sua assistência precisa prestar apoio no processo de reorganização psíquica no contexto do bebê, mudanças no corpo, amamentação dentre outros. Objetivo: Realizar um levantamento bibliográfico acerca da assistência de enfermagem no puerpério. Metodologia: Trata-se de uma revisão de literatura realizada na bases de dados LILACS e BDENF. Utilizou-se os seguintes descritores: "Cuidados de Enfermagem", "Período Pós-Parto" e "Saúde da Mulher". Os artigos foram selecionados nos idiomas português, inglês e espanhol com recorte temporal de 2016 a 2021. Resultados: O período pós-parto é marcado por vários acontecimentos na mulher indo de modificações corporais a cuidados com o bebê no dia a dia, ocasionando inseguranças as mulheres e sentindo-se vulneráveis. O enfermeiro tem um grande papel nessa assistência, buscando sempre utilizar maneiras estratégicas para minimizar esses acontecimentos por meio do plano de alta que visa em informações prévias com ênfase na aprendizagem sobre o entendimento da avaliação da puérpera e da família, o profissional de enfermagem pode disponibilizar esse guia para a puérpera ou acompanhante afim de ser utilizado nas respectivas orientações para os cuidados do dia a dia da puérpera. Conclusões: Conclui-se que o enfermeiro busca por meio de ações estratégicas minimizar os acontecimentos que acontecem com a maioria das mulheres no período puerperal.

Palavras-chave: Cuidados de enfermagem. Período pós-parto. Saúde da mulher.

Área Temática: Saúde Coletiva 


\title{
A PROMOÇÃO DA SAÚDE COM ENFOQUE NOS DETERMINANTES SOCIAIS PARAA QUALIDADE DE VIDA DA POPULAÇÃO
}

\author{
Morgana Gomes Izidório', Francisco Natanael Lopes Ribeiro ${ }^{2}$, Maria Cassiana Rosa \\ Carneiro $^{3}$, Antônia Gescica Arcanjo ${ }^{4}$, Pedro Ítalo Alves de Carvalho ${ }^{5}$, Breno Carvalho de \\ Farias $^{6}$, Érika Aguiar Mouta ${ }^{7}$
}

\begin{abstract}
${ }^{1}$ Escola de Saúde Pública Visconde de Saboia (ESPVS), ${ }^{2}$ Escola de Saúde Pública Visconde de Saboia, ${ }^{3}$ Centro Universitário INTA (UNINTA), ${ }^{4}$ Centro Universitário INTA (UNINTA), ${ }^{5}$ Escola de Saúde Pública Visconde de Saboia, ${ }^{6}$ Escola de Saúde Pública Visconde de Saboia, ${ }^{7}$ Centro Universitário INTA (UNINTA)
\end{abstract}

Introdução: Não existe um conceito único sobre os determinantes sociais de saúde, para mais, existe uma multiplicidade quanto à concepção sobre os mecanismos que ocasionam em iniquidades de saúde. A compreensão das diferentes dimensões envolvidas no processo de saúde-doença potencializa e amplia o espaço profissional no enfretamento das suas determinações. Objetivo: Realizar uma reflexão crítica acerca da promoção da saúde com enfoque nos determinantes sociais para a qualidade de vida da população. Metodologia: Trata-se de um estudo bibliográfico, de abordagem qualitativa. Resultados: O processo saúde-doença não é tão somente biológico, mas também um processo social, imbricado na relação do homem com o meio ambiente, o espaço-território onde vive, o trabalho, as relações sociais, culturais, econômicas e políticas. Os determinantes sociais da saúde apontam este fenômeno, evidenciando que esse processo é pré-determinado socialmente. No que consiste à promoção da saúde, relaciona-se as ações estratégicas de enfrentamento aos condicionantes sociais da saúde, direcionadas a atingir positivamente a qualidade de vida da população. Conclusões: Embora seja muito importante que a promoção da saúde no Brasil seja voltada para a diminuição das iniquidades em saúde, objetivando atingir o fortalecimento da ação comunitária, necessária ao exercício da autonomia e valorização do conhecimento popular e da participação social, permanece um distanciamento das práticas em promoção da saúde e a implementação da Política Nacional de Promoção da Saúde.

Palavras-chave: Política de Saúde. Sistema Único de Saúde. Atenção Primária.

Área Temática: Saúde Coletiva. 


\section{A IMPORTÂNCIA DO ENFERMEIRO FRENTE AO TRATAMENTO DO HIV}

\section{Victor Guilherme Pereira da Silva Marques ${ }^{1}$, Guilia Rivele Souza Fagundes²}

${ }^{1}$ Centro Universitário do Piauí/ UNIFAPI, ${ }^{2}$ Universidade do Estado da Bahia/ UNEB

Introdução: O vírus da imunodeficiência humana (HIV) é conhecido como um retrovírus que ataca o sistema imune, sistema responsável por defender o organismo. Esse vírus infecta as células do sistema imunológico provocando principalmente uma queda dos linfócitos T CD4+, deixando o sistema vulnerável tantos á outras infecções quanto ao próprio HIV. Sendo necessário a comunicação entre profissional e paciente, pois assim o profissional capacitado irá orientar de forma correta para se ter uma assistência humanizada de enfermagem e conseguir controlar a doença. Objetivo: Realizar um levantamento bibliográfico acerca da importância do enfermeiro frente ao tratamento do HIV. Metodologia: Trata-se de uma revisão de literatura realizada na bases de dados LILACS e BDENF. Utilizou-se os seguintes descritores: "Assistência ao Paciente”, "Doenças Sexualmente Transmissíveis" e "Educação em Saúde". Os artigos foram selecionados nos idiomas português, inglês e espanhol com recorte temporal de 2016 a 2021. Resultados: Diante disso, o enfermeiro precisa ter uma postura de acolhimento, conscientização e criar um vínculo com esse paciente buscando resultados satisfatórios em sua assistência, sempre realizando buscas ativas para se identificar seus hábitos, comportamentos e estilo de vida. Se possível o enfermeiro precisa ter como aliado a família, pois a mesma influencia em diversos fatores no tratamento desse paciente possibilitando um maior vigor diante desse processo de reabilitação. Tratamento farmacológico também é essencial, sendo que essas condutas medicamentosas são principalmente inibidores das enzimas que atuam na replicação do HIV. Conclusões: Conclui-se que o enfermeiro sempre busca por meio de ações estratégicas de educação em saúde que o paciente com HIV tenham uma excelente qualidade de vida, dando orientações fidedignas e eficazes.

Palavras-chave: Assistência ao paciente. Doenças sexualmente transmissíveis. Educação em saúde.

Área Temática: Saúde Coletiva 


\title{
DESAFIOS E COMPETÊNCIAS DA ATENÇÃO PRIMÁRIA À SAÚDE NO ENFRENTAMENTO Á COVID-19: RELATO DE EXPERIÊNCIA
}

\author{
Pollyana Renata Nirelly da Silva e Silva ${ }^{1}$, Marcos Antônio Medeiros de Oliveira ${ }^{2}$ \\ ${ }^{1,2}$ Escola Multicampi de Ciências Médicas/UFRN
}

Introdução: A COVID 19 se apresenta como um dilema de grandes proporções no campo econômico, político e social. Alertada em dezembro de 2019 em Wuhan na China, acentua as desigualdades socioeconômicas históricas do Brasil frente aos direitos garantidos pela Constituição Federativa de 1988. Nesse contexto, a Atenção Primária à Saúde (APS) representa ferramenta marcante no fluxo de assistência uma vez que, como porta de entrada do Sistema Único de Saúde, possibilita o acesso e articulação do cuidado. Objetivos: Apresentar uma breve reflexão sobre a importância da APS diante da pandemia. Metodologia: Constitui-se de um relato de experiência desenvolvido por dois médicos residentes em medicina de família e comunidade sobre as vivências face à pandemia, entre março e junho de 2020, no interior do Rio Grande do Norte. Resultados: Diante da realidade exposta foi possível observar as potencialidades da APS, aliado à competência cultural e orientação familiar, como elo importante na longitudinalidade e coordenação do cuidado. Ademais, sinalizam-se os desafios ao teleatendimento que, apesar de suscitar papel facilitador e redutor de contágio, traz repercussões à relação médico-paciente e se limita à escassez de recursos humanos e materiais necessários. Entre os desafios, destacam-se também a capacidade do serviço de gerenciar os casos suspeitos de coronavírus acrescidos às demandas tradicionais, o dilema médico frente às orientações de distanciamento sociais para comunidades em situação de vulnerabilidade e o comprometimento psicológico dos profissionais de saúde e usuários. Conclusões: Por fim, se reforça o fortalecimento da APS para enfrentamento da doença e suas consequências em longo prazo.

Palavras-chave: Infecções por coronavírus. Modelos de Assistência à saúde. Pandemias.

Área Temática: Saúde Coletiva. 


\title{
O POTENCIAL TERAPÊUTICO DA AYAHUASCA
}

\section{Ylêdo Fernandes de Menezes Júnior ${ }^{1}$; Edmilson Pereira Barroso ${ }^{2}$}

\author{
${ }^{1}$ Centro Universitário Uninorte, ${ }^{2}$ Universidade Federal do Acre - UFAC
}

Introdução: Ayahuasca é um chá obtido da casca do caule da videira Banisteriopsis caapi (contendo alcaloides beta-carbolina) em combinação com as folhas do arbusto Psychotria viridis (fornecendo o alucinógeno N, N-dimetiltriptamina, DMT), sendo, inicialmente, utilizado em rituais religiosos por populações indígenas da Amazônia. Todavia, nas últimas duas décadas, seu uso se expandiu em todo o mundo e, atualmente, foi incorporado à medicina popular brasileira e a rituais de cura de diferentes religiões do Brasil, Europa e América do Norte, como também, vem sendo utilizado para o tratamento de doenças psicossomáticas. Objetivo: Descrever os efeitos e os benefícios da ayahuasca em indivíduos com doenças psicossomáticas. Metodologia: Realizou-se uma revisão de literatura sistemática por meio de buscas na base Pubmed utilizando "psychotropic"; "Banisteriopsis caapi" e "Psychotria viridis" na qual foram selecionados 12 artigos em língua inglesa e publicados no período de 2012 a 2019. Resultados: Verificou-se que a ayahuasca tem efeitos terapêuticos e possui propriedades antidepressivas de ação rápida. O consumo de ayahuasca, também foi relacionado à redução dos transtornos com álcool e drogas de abuso, depressão e ansiedade, além disso, foi verificado que o uso contínuo do chá não interfere negativamente nas funções neuropsicológicas. Os efeitos colaterais são relativamente leves e podem incluir náuseas, vômitos e diarreias. Com relação aos aspectos biopsicossociais, os indivíduos relataram redução do estresse, boa saúde mental, alegria na vida, alimentação mais saudável, melhora no humor, flexibilidade psicológica, autoaceitação, dentre outros. Conclusões: É notório o potencial terapêutico da ayahuasca no tratamento de distúrbios da saúde mental, como a depressão e ansiedade, além dos diversos benefícios biopsicossociais. Assim, com o crescente interesse e uso da ayahuasca, é importante entender a segurança, os efeitos comportamentais e a realização de possíveis ensaios clínicos mais abrangentes.

Palavras-chave: Psychotria viridis. Banisteriopsis caapi. Psicotrópicos

Área Temática: Saúde Coletiva 


\title{
INSERÇÃO DE RESIDENTES MULTIPROFISSIONAIS NO SERVIÇO DE TELE- ORIENTAÇÃO COVID-19: PERFIL DOS USUÁRIOS E RESULTADOS
}

\author{
Ana Paula de Castro Murussi e Júlia Kath Pereira da Silva
}

Introdução: O Sars-Cov-2 é altamente transmissível e requer um manejo especializado a fim de diminuir as taxas de transmissão. Diante desse cenário, a Irmandade Santa Casa de Misericórdia de Porto Alegre (ISCMPA) lançou a Tele Orientação Covid-19 (TO), onde profissionais residentes multiprofissionais orientam a população através de consultas por vídeo chamadas. Objetivo: Descrever o perfil de usuários que buscaram a TO, principais demandas e encaminhamentos. Metodologia: Levantamento dos dados dos usuários que buscaram a TO de 29/05/20 a 28/08/20, sendo as demandas classificadas em cinco categorias (sintomas leves e graves suspeitos da Covid-19, sintomas não relacionados e casos confirmados com sintomas leves e graves) e as condutas em quatro (manejo domiciliar, pronto atendimento, acolhimento de funcionários da ISCMPA e encaminhamento para consultas médicas específicas). Funcionamento em horário comercial com apoio de um repositório de perguntas e respostas, via plataforma on-line. Os dados serão apresentados através de estatísticas descritivas. Resultados: 637 indivíduos buscaram a TO, sendo finalizado o atendimento com 73,1\% dos pacientes (26,9\% inconclusivos por problemas de conexão). Dentre os 466 usuários atendidos, $80,7 \%$ eram mulheres variando entre 18 e 89 anos (média 38 anos). Dentre as principais demandas para a TO, 71,6\% relataram sintomas leves e 1,7\% sintomas graves suspeitos de Covid-19, 18,6\% apresentavam sintomas não relacionados, 6,8\% eram casos positivos leves e 1\% relatava sintomas graves. $14,2 \%$ dos usuários foram orientados ao manejo domiciliar ou atendimento na atenção básica, para 3,7\% para pronto atendimento, $65,6 \%$ encaminhados para atendimento médico do TeleCovid do Hospital e 16,5\% consultas médicas específicas. Conclusões: Mulheres adultas foram as principais usuárias da TO, por suspeita ou diagnóstico confirmado. O cenário atual ressalta a importância da orientação da população sobre medidas de prevenção e transmissão e o correto manejo dos sintomas, evitando aglomerações nos serviços de saúde.

Palavras-chave: Sars-Cov-2. Telemedicina. Vírus

Área temática: Saúde Coletiva 


\section{OS RESIDENTES EM SAÚDE COLETIVA NO ACOLHIMENTO DE NOVOS SERVIDORESPÚBLICOS NA VII GERÊNCIA REGIONAL DE SAÚDE DE PERNAMBUCO}

\section{Ana Carolina dos Santos Anjos ${ }^{1}$, Diana Loyce Monteiro' ${ }^{1}$, Rafaela de Oliveira Xavier ${ }^{1}$}

${ }^{1}$ Residente em Saúde Coletiva com ênfase em Gestão de Redes, Escola de Saúde Pública de Pernambuco(ESPPE), Salgueiro, Pernambuco.

Introdução: Devido à pandemia do coronavírus, houve aumento da demanda de atividades na maioria dos setores que compõe as Instituições de Saúde, em consonância, muitos servidores públicos se afastaram por estarem em grupo de risco da gravidade do COVID-19, dessa forma, foi necessária a contratação de mais colaboradores. Tendo em vista o número de funcionários novos na VII Gerência Regional em Saúde (GERES) em Salgueiro-PE, os residentes com apoio dos profissionais a frente do setor de Gestão de Pessoas, colocaram-se a disposição para criação de materiais que auxiliassem na recepção dos recém contratados. Objetivo: Descrever a participação dos residentes em saúde coletiva na elaboração de um instrumento de apoio ao acolhimento de novos servidores na VII GERES. Metodologia: Trata-se de um estudo descritivo do tipo relato de experiência das residentes multiprofissionais em Saúde Coletiva com Ênfase em Gestão de Redes de Saúde da Escola de Governo de Saúde Pública de Pernambuco - ESPPE,em consequência das práticas vivenciadas no período de dezembro de 2020, na VII GERES. Resultados: Os residentes criaram uma carta de acolhimento contendo informações básicas acerca da Instituição e sua ambiência bem como a apresentação de todos os setores do local com seus respectivos coordenadores. O setor de Gestão de Pessoas enxergou o material como uma genuína forma de boas-vindas e passou a constituir comoum dos documentos entregues no ato da entrada do colaborador. Os novos apoiadores sentiram o empenho dos servidores mais antigos da casa em recebê-los como parte de uma família. Conclusões: Tal processo contribuiu para a motivação e trabalho em equipe, refletindo em melhor desempenho das atividades realizadas diariamente. A experiência também evidenciou que o acolhimento é um processo dinâmico e permanente, portanto, é necessário que os gestores e equipe realizem ajustes constantes quanto à forma de receber os novos trabalhadores de saúde.

Palavras-chave: Gestão de Pessoas. Pandemia. SUS.

Área Temática: Saúde Coletiva. 


\title{
SALA DE ESPERA COMO FERRAMENTA EDUCATIVA EM TEMPOS DE PANDEMIA: RELATO DE EXPERIÊNCIA EM DUAS UNIDADES DE SAÚDE EM SALGUEIRO-PE.
}

\author{
Diana Loyce Monteiro', Ana Carolina dos Santos Anjos ${ }^{1}$, Rafaela de Oliveira Xavier ${ }^{1}$
}

${ }^{1}$ Residentes em Saúde Coletiva com Ênfase em Gestão de Redes, Escola de Governo em Saúde Pública dePernambuco (ESPPE).

Introdução: A pandemia do COVID-19 trouxe desafios para a saúde pública mostrando a dificuldade de se implantarem medidas de proteção contra a infecção pelo vírus. Ações de educação em saúde são importantes diante desse cenário facilitando a disseminação de conhecimento e contribuindo para o protagonismo do indivíduo para a promoção da saúde. Diante da resistência da população em manter bons hábitos de higiene eo isolamento social, as residentes elaboraram sala de espera em duas Unidades Básicas de Saúde do municípiode Salgueiro-PE, com o intuito de transmitir informações sobre os cuidados e formas de prevenção contra o COVID-19 para os usuários. Objetivo: Relatar a contribuição das residentes em saúde coletiva para a educação em saúde no contexto da pandemia do COVID-19. Metodologia: Trata-se de um relato deexperiência das residentes em Saúde Coletiva com Ênfase em Gestão de Redes, no município de Salgueiro - PE, acerca da realização de sala de espera em duas Unidades Básicas de Saúde, no período de agosto e setembro de 2020. As atividades desenvolvidas consistiram em perguntas relacionadas ao COVID-19 e eramdirecionadas aos usuários que se encontravam nas unidades. Os mesmos deveriam responder utilizando pequenas placas com os dizeres "SIM" ou "NÃO". Após cada pergunta as residentes e a equipe da unidade estimulavam a discussão sobre o tema e esclareciam todas as dúvidas que surgiam. Resultados: Em ambas as unidades a aceitação por meio dos usuários foi muito satisfatória, sendo observado que os principais erros cometidos por eles para prevenir a infecção pelo vírus foram corrigidos. Dentre eles estavam lavagem corretadas mãos, uso consciente da máscara e importância do isolamento social. Conclusões: A inserção das residentes nas estratégias de promoção e educação em saúde durante a pandemia possibilita maior aprendizadoe contribui de forma positiva para o serviço de saúde e seus usuários.

Palavras-chave: Atenção Primária. COVID-19. SUS.

Área Temática: Saúde Coletiva. 


\section{RELATO DE EXPERIÊNCIA DAS RESIDENTES EM SAÚDE COLETIVA SOBRE OS DESAFIOS NA TERRITORIALIZAÇÃO EM SAÚDE DURANTE A PANDEMIA DO COVID-19}

\section{Rafaela de Oliveira Xavier ${ }^{1}$, Ana Carolina dos Santos Anjos ${ }^{1}$, Diana Loyce Monteiro ${ }^{1}$}

${ }^{1}$ Residentes em Saúde Coletiva com Ênfase em Gestão de Redes, Escola de Governo em Saúde Pública de Pernambuco (ESPPE).

Introdução: A territorialização em saúde é uma ferramenta fundamental na Atenção Primária à Saúde para mapear e conhecer o perfil socioeconômico, demográfico, ambiental e cultural, como também as principais morbidades que acometem sua população coberta. Realizar esse processo requer um contato próximo da Equipe de Saúde da Família (ESF) com a população adscrita, o qual precisou ser adaptado pelas residentes em saúde coletiva, devido à pandemia do COVID-19. Objetivo: Relatar os desafios na construção da territorialização em saúde durante a pandemia do COVID-19. Metodologia: Trata-se de um estudo descritivo do tipo relato de experiência das residentes em Saúde Coletiva com Ênfase em Gestão de Redes, do processo de territorialização em saúde realizado em duas Unidades Básicas de Saúde no município de Salgueiro - PE, no período de agosto a outubro de 2020. O desenvolvimento da territorialização foi limitado pela pandemia o que necessitou de uma abordagem diferenciada, incluindo entrevistas com a população através de ligações e na porta das residências, respeitando o distanciamento necessário. O apoio dos Agentes Comunitários de Saúde foi essencial, e algumas informações foram colhidas no sistema e-SUS. Resultados: Ao final de coleta de dados foi construído um mapa falante de duas microáreas de cada unidade para que auxiliassem as equipes na melhor visualização da situação de saúde de sua área coberta. Conclusões: A Atenção Primária como principal porta de entrada do Sistema Único de Saúde, deve conhecer sua população adscrita para realizar ações na prevenção e promoção da saúde. A pandemia do novo coronavírus trouxe inúmeros desafios para a saúde pública, mas mostrou a importância de adaptar a forma de trabalho para que os usuários não fiquem desassistidos. Com isso, a inserção das residentes nesse processo foi de suma importância para se obter um instrumento que irá beneficiar tanto a ESF como toda a população coberta.

Palavras-chave: Atenção Primária à Saúde. Saúde Pública. COVID-19.

Área temática: Saúde Coletiva 


\title{
A INFLUÊNCIA DA FAMÍLIA NA ADESÃO AO TRATAMENTO DE PACIENTES DIABÉTICOS: UM RELATO DE EXPERIÊNCIA
}

\author{
Mônica Sena Barbosa ${ }^{1}$, Mariane Pimentel Ramos²
}

\begin{abstract}
${ }^{1,2}$ Universidade Federal do Amapá- UNIFAP/ Programa de Residência Multiprofissional em Saúde Coletiva na área de concentração em Saúde do Adulto e do Idoso
\end{abstract}

Introdução: A Diabetes Mellitus (DM) é uma doença crônica que transforma o cotidiano dos pacientes e, por conseguinte, dos familiares, tendo em vista as mais variadas mudanças tanto ao aspecto físico como na utilização de medicações, como no aspecto emocional de ter que lidar com as emoções decorrentes de uma nova fase de vida. Neste entendimento, diversos estudos apontam a relevância do papel e da influência da família para o auxílio de tais pacientes seja no aspecto físico ou emocional. Objetivo: Descrever a partir das vivências das psicólogas, a influência que os familiares possuem para a aderência ao tratamento de pacientes diabéticos da Universidade Federal do Amapá. Metodologia: O relato de experiência visa descrever as percepções das psicólogas sobre a influência dos familiares na adesão ao tratamento de pacientes diabéticos a partir dos acompanhamentos individuais e dos familiares realizados na Unidade Básica de Saúde da UNIFAP. Resultados: Podese concluir que a Diabetes Mellitus acarreta inúmeras complicações em seus mais variados contextos e graus e que tais desdobramentos afetam diretamente toda uma dinâmica familiar uma vez que as reações ao diagnóstico por parte dos pacientes geram recusa, negação e dificuldades em ter que lidar com uma nova rotina que requer a todo momento, cuidados e monitoramento da saúde do paciente. $\mathrm{E}$ dentre tais rotinas encontram-se a de verificação do controle glicêmico, utilização de medicamentos e a prática de atividades físicas no qual a família tem um papel essencial como potencializador de tais práticas por parte do paciente. Conclusões: Conclui-se que uma família mais compreensiva e sensível aos cuidados e repercussões que a doença causa e gera no paciente, pode ser o ponto crucial para uma maior adesão ao tratamento dos pacientes. Isto porque, quanto maior a compreensão e ajuda, mais aceito, valorizado e cuidado o paciente se sente.

Palavras-chave: Doença crônica. Dinâmica Familiar. Mudança de Hábito.

Área Temática: Saúde Coletiva 


\title{
REPERCUSSÕES DO ENVELHECER NA AUTOESTIMA DE IDOSOS: UM RELATO DE EXPERIÊNCIA
}

\author{
Mariane Pimentel Ramos', Mônica Sena Barbosa²
}

${ }^{1,2}$ Universidade Federal do Amapá- UNIFAP/ Programa de Residência Multiprofissional em Saúde Coletiva na área de concentração em Saúde do Adulto e do Idoso

Introdução: $\mathrm{O}$ envelhecimento faz parte do desenvolvimento humano e o fato da população brasileira estar mais composta por idosos tem se fomentado diversas discussões. O processo do envelhecimento envolve múltiplas dimensões que dão ao fenômeno um caráter complexo, compreender este fator por uma única visão possibilita a um conhecimento fragmentado, pois o corpo que envelhece associa-se a estigmas, preconceitos, aparecimento de doenças, limitações físicas, necessidade de cuidado e apoio social, assim como interrupção dos relacionamentos sociais e restrição em papéis sociais. Objetivo: Discutir as repercussões do envelhecer na autoestima de idosos a partir de atendimentos individuais ao grupo de Hiperdia. Metodologia: Trata-se de um relato de experiência que objetiva descrever as observações e percepções das psicólogas acerca das repercussões do envelhecer na autoestima de idosos a partir dos acompanhamentos individuais realizados na Unidade Básica de Saúde da UNIFAP no período de Novembro de 2020 até o presente momento. Resultados: Os resultados constatam que muitos idosos rejeitam o próprio envelhecimento em decorrência da imagem que fazem de si mesmo, desenvolvendo sentimento de autodesvalorização e de baixa autoestima o que acarreta grande impacto na sua qualidade de vida. O corpo do idoso não possui a mesma estética do corpo jovem e com o envelhecimento o mesmo tende a não se aceitar o que torna o envelhecimento mais desafiador. Conclusões: Conclui-se que é imprescindível explorar novos significados do envelhecimento, visto que, em sua grande maioria, os indivíduos não se preparam para este momento. Sobretudo, há um desejo de existir por muitos anos, mas não há um querer ficar velho. A velhice compõe-se da circunstância de que ela não é uma condição, mas um contínuo e inacabado processo de subjetivação.

Palavras-chave: Envelhecimento. Corpo. Subjetividade.

Área Temática: Saúde Coletiva 


\title{
FATORES DE ESTRESSE EM PROFISSIONAIS DE SAÚDE DURANTE A PANDEMIA DO NOVO CORONAVÍRUS
}

\author{
Ane Maryne Rodrigues Fiuza ${ }^{1}$, Kaic Trindade Almeida ${ }^{2}$ \\ ${ }^{1}$ UniFG - Centro Universitário FG ${ }^{2}$ Biomédico - Esp. Docência no Ensino Superior
}

Introdução: O final do ano de 2019 foi marcado pelo início da pandemia de uma nova variante do coronavírus. Com a rápida proliferação da infecção causada pelo Sars-CoV-2, medidas de contenção da doença foram tomadas. No que tange a atuação dos profissionais de saúde, tal impacto se estabeleceu de modo ainda mais vigoroso, já que, por estarem em contato direto com os indivíduos infectados, desenvolveram sintomas de ansiedade e pânico, por receio de se infectarem e também a seus familiares. Objetivo: Identificar os principais fatores geradores de estresse psicológico e sofrimento psíquico nos profissionais de saúde que atuam no enfrentamento da pandemia da covid-19. Metodologia: Trata-se de uma revisão bibliográfica realizada a partir da análise sistemática de publicações disponíveis nas bases de dados PubMed, Scielo e Biblioteca Virtual de Saúde (BVS). Os descritores utilizados foram coronavírus, profissionais da saúde, estresse e saúde mental. Com isso, foram encontrados 9 artigos, dos quais quatro foram excluídos por não se relacionarem diretamente ao tema. Resultados: Os sintomas evidenciados foram ansiedade, insônia, angústia, estresse, fadiga física e mental e depressão. O surgimento desses decorre da sobrecarga dos locais de atendimento, a qual gera uma pressão sobre os profissionais envolvidos. Ademais, nesse cenário somam se outros fatores, como falta de recursos, pânico social, superlotação, jornadas de trabalho exaustivas, saturação dos serviços e o ambiente de incertezas gerado por uma patologia pouco conhecida. Considerações Finais: Os fatores supracitados favorecem o desenvolvimento de sintomatologia emocional e de desgaste nesses agentes primários de combate à pandemia. Em vista disso, faz-se necessário um enfoque sobre a saúde mental dos profissionais da linha de frente, a fim de que estratégias para minimizar esse sofrimento sejam colocadas em prática. Constata-se, portanto, a importância de que mais estudos sejam realizados, com o intuito de se elaborar ações que reduzam tais impactos.

PALAVRAS-CHAVES: Saúde mental. Pessoal da saúde. Covid-19.

ÁREA TEMÁTICA: Saúde coletiva. 


\section{NARRATIVAS DAS MULHERES SOBRE O VÍNCULO DOULA-MÃE COMO ESTRATEGIA PARA O PARTO HUMANIZADO}

\section{Maria Elaine Guimaraes dos Santos ${ }^{1}$, Maria Amanda Rodrigues Silva ${ }^{2}$, Mônica Cordeiro Ximenes de Oliveira ${ }^{3}$.}

${ }^{1}$ Centro Universitário Christus , ${ }^{2}$ Centro Universitário Christus ${ }^{3}$ Centro Universitário Christus.

Introdução: O parto humanizado consiste na ressignificação de atenção dada a mulher, visto que, é mais que um processo biológico. Para o Ministério da Saúde as "práticas e atitudes que visam à promoção do parto e do nascimento saudável, a participação da doula é mais um instrumento humanizador" no reconhecimento da paciente como sujeito da sua história. Objetivo: Conhecer as narrativas das mulheres sobre o vínculo doula-mãe como estratégia para o parto humanizado. Metodologia: Pesquisa de campo com abordagem qualitativa. Participaram do estudo quatro mães acompanhadas por doulas e quatro doulas com experiência no parto humanizado. Foram realizadas oito entrevistas semi-estruturada online, após a assinatura do Termo de Consentimento Livre e Esclarecido, nos meses de junho e julho de 2020, através da plataforma digital Google Meet. Utilizamos como instrumento de produção de dados a análise temática para a interpretação das entrevistas A pesquisa seguiu os aspectos éticos da Resolução 466/12 e da Resolução no 510/2016. Resultados: Evidenciamos com as narrativas que a escolha do parto e a presença da doula trazem um sentimento positivo para a hora do parto: “Eu acredito que a participação dela no parto humanizado é fundamental porque ela se vincula a você, como você quer um parto, como você quer ser respeitada, ao que você quer fazer, até onde você que ir." (Mãe 4). "Eu sempre quis ser mãe e eu sempre imaginava quando eu fosse mãe, eu ia querer um parto normal. [...] mas eu acho que o que fez total diferença para eu ficar segura, me sentir amparada, foi a presença da doula...”(Mãe 2). Conclusões: Com a pesquisa concluímos que as entrevistadas ressaltam a experiência positiva através da doula em seu parto, sendo notória a melhora da vivência dessa mulher com todo o processo pré e pós-parto.

Palavras-chave: Doulas. Mães. Parto Humanizado

Área Temática: Saúde Coletiva. 


\title{
TERRITORIALIZAR EM SAÚDE: FORTALECENDO A FORMAÇÃO DE PROFISSIONAIS RESIDENTES
}

\author{
João Caio Silva Castro Ferreira', Maria Karolayne de Araújo Pereira², Amanda de Oliveira \\ Lima $^{3}$, Maycon Guimarães Santos ${ }^{4}$, Nanielle Silva Barbosa ${ }^{5}$
}

1,3,4,5 Programa de Residência Multiprofissional em Saúde da Família e Comunidade/Universidade Estadual do Piauí, ${ }^{2}$ Universidade Federal do Piauí.

Introdução: A territorialização na Atenção Primária à Saúde é um processo sociopolítico fundamental para a execução dos princípios constitucionais do Sistema Único de Saúde no Brasil. A prática de territorializar é essencial para conhecer e acolher um território, levando em consideração suas singularidades. Objetivo: Relatar a experiência de profissionais residentes em Saúde da Família e Comunidade durante o processo de territorialização. Metodologia: Trata-se de um estudo descritivo do tipo relato de experiência, desenvolvido em Março de 2020. A territorialização ocorreu em um bairro da zona sul de Teresina. As visitas ao território foram previamente agendadas com os Agentes Comunitários de Saúde. Durante o momento de reconhecimento registrou-se as principais características socioambientais e culturais da comunidade, a fim de diagnosticar as principais necessidades e identificar pontos de apoio para a articulação de possíveis resoluções. Resultados: Por meio da territorialização foi traçado um perfil sociodemográfico do bairro. Constatou-se uma população majoritariamente idosa, famílias pequenas e com alto ou médio poder aquisitivo. Quanto à cultura, o bairro possuí algumas tradições culturais que costumam mobilizar seus moradores e promover a inclusão social, principalmente, entre o público jovem. Em relação aos equipamentos sociais da região, pode-se identificar igrejas, escolas, centros sociais, emissoras de rádio e praças públicas. Como necessidades de saúde, identificou-se a predominância de doenças crônicas, como hipertensão, diabetes e depressão, além da presença de problemáticas sociais como uso abusivo de substância ilícitas e alta criminalidade, associado a um ambiente com relevo de acentuadas elevações, que dificultam o deslocamento da população idosa e, áreas com saneamento básico precário. Considerações finais: Embora a pandemia da COVID-19 tenha impossibilitado a finalização desta territorialização, as informações coletadas permitiram a formação do vínculo comunidade-residentesserviço, sendo crucial para o desenvolvimento de ações de promoção à saúde dessa população, mesmo diante das dificuldades encontradas.

Palavras-chave: Sistema Único de Saúde. Atenção Básica. Estratégia Saúde da Família.

Área Temática: Saúde coletiva. 


\title{
O USO DO CHÁ DE CAMOMILA COMO FITOTERÁPICO PARAA INSÔNIA
}

\section{Andressa Almeida Barbosa ${ }^{1}$; Lauany Maria dos Santos Barreto ${ }^{2}$}

\author{
Universidade Federal de Campina Grande, Cuité, Paraíba ${ }^{1 ; 2}$
}

Introdução: Segundo dados disponibilizados pelo ministério da saúde, a insônia afeta cerca de $40 \%$ da população brasileira, com isso, o uso de plantas psicoativas é um fenômeno comum em humanos, já que seus efeitos psicológicos e comportamentais são amplamente conhecidos, pois ajudam na redução da insônia, em especial o chá de camomila. Objetivo: Entender como o chá de camomila ajuda na modulação do sono. Metodologia: Essa revisão de literatura foi composta por artigos científicos encontrados nas bases de dados Pubmed, Lilacs, Scielo e no Ministério da Saúde, publicados entre 2016 a 2021. Resultados: O nervosismo e dificuldade para dormir, provocam um aumento da demanda pelo uso de ervas, dentre as diferentes espécies utilizadas para distúrbios do sono, o extrato de camomila tem o efeito dos benzodiazepínicos, causando relaxamento do sistema nervoso, melhorando assim a qualidade do sono. Sendo também, utilizado como um calmante suave no tratamento da ansiedade e da insônia de fundo nervoso, pois atua regulando o sono, que é um mecanismo fisiológico de recuperação e regeneração celular. E quando se dorme bem, o corpo produz várias substâncias e hormônios no processo de síntese, incluindo hormônios de crescimento importantes a proteína e a melatonina, principal antioxidante natural, as quais, protegem o DNA central dos danos oxidativos. Conclusão: Portanto, além da prescrição de fitoterápicos, como o chá de camomila, para regulação do sono, recomenda-se a utilização de outras estratégias em conjunto, tais como: higiene do sono, terapia cognitivo-comportamental, terapia de controle de estímulos, terapia de restrição de sono, terapia de relaxamento e de biofeedbac.

Palavras-chave: Camomila; Chá; Sono.

Área Temática: Saúde Coletiva. 


\section{A EXPERIÊNCIA DE UMA RESIDÊNCIA MULTIPROFISSIONAL DESCENTRALIZADA EM SAÚDE COLETIVA NA X GERES EM PERNAMBUCO}

\section{Creuza Laíze Barboza de Souza Bezerra ${ }^{1}$, Bruna Diniz Oliveira ${ }^{2}$, Danielly Soares Magalhães ${ }^{3}$, Valdete Pereira Melo ${ }^{4}$, Thatiana Maria Cabral Ferreira da Silva ${ }^{4}$, Wedson Ferreira dos Santos $^{6}$, Thaís Morgana Bequiman Silva ${ }^{7}$}

\section{1, 2, 3, 4, 5, 6 e 7 Escola de Governo em Saúde Pública de Pernambuco - ESPPE}

Introdução: Com a consolidação da saúde como um direito constitucional e dever do Estado, o Sistema Único de Saúde passou, entre outras atribuições, a ordenar as ações de formação dos recursos humanos na saúde. Desse modo, as residências em saúde se apresentam como uma importante estratégia para consolidar essas ações em todo o território brasileiro. Objetivo: Descrever a experiência da vivência de uma residência em Saúde Coletiva com ênfase em gestão de redes de saúde e sua contribuição para a formação em saúde. Metodologia: Relato de experiência do tipo descritivo elaborado a partir da vivência de uma residência multiprofissional em saúde coletiva na $\mathrm{X}$ Gerência Regional de Saúde de Pernambuco. A proposta dessa residência surge a partir de discussões sobre a necessidade de implementação das ações de educação permanente em saúde, principalmente no que tange a descentralização das mesmas para regiões mais interiorizadas e que apresentam uma carência representativa nesse sentido. A vivência dessa residência nesse contexto possibilita uma visão ampliada acerca da gestão das redes de atenção à saúde, pelo fato da inserção durante 2 anos em diversos pontos dessa rede, como por exemplo: Atenção Básica, Atenção Psicossocial, Atenção Hospitalar, Gerência Regional, entre outros, o que permeia uma formação enquanto sanitarista mais crítica e atuante no Sistema Único de Saúde. Resultados: A residência em saúde coletiva com ênfase em gestão de redes propicia uma atuação em diversos pontos estratégicos da mesma, trazendo para o residente uma análise critica acerca da atuação enquanto sanitarista nesse complexo sistema de saúde. Conclusões: Pelo fato de ser uma residência que funciona de maneira descentralizada em várias regiões do estado, a mesma apresenta um diferencial de proporcionar variadas vivências e ao mesmo tempo, representa um constante desafio para se manter a organização do programa, visto que a mesma acontece em cenários territoriais diversificados.

Palavras-chave: Educação Permanente. Gestão em Saúde. Capacitação Profissional.

Área Temática: Saúde Coletiva 


\title{
PERFIL EPIDEMIOLÓGICO DO MUNICÍPIO DE AFOGADOS DA INGAZEIRA EM PERNAMBUCO ENTRE 2014-2018
}

\author{
Valdete Pereira Meloํㅜ, Creuza Laíze Barboza de Souza Bezerra², Danielly Soares Magalhães ${ }^{3}$, \\ Thatiana Maria Cabral Ferreira da Silva ${ }^{4}$, Wedson Ferreira dos Santos ${ }^{5}$, Bruna Diniz \\ Oliveira $^{6}$, Thais Morgana Bequiman Silva ${ }^{7}$
}

1,2,3,4,5,6 e 7 Escola de Governo em Saúde Pública de Pernambuco (ESPPE)

Introdução: A partir das informações de saúde, obtidas em diferentes sistemas, é possível identificar problemas do contexto sanitário de uma população, fornecendo subsídios para análise e avaliação da situação encontrada, orientando a tomada de decisões baseadas em evidências. Esses estudos epidemiológicos são essenciais para identificar problemas prioritários, de modo a orientar decisões relativas de prioridades para intervenção, proporcionando maior resolubilidade ao serviço. Objetivo: Traçar o perfil epidemiológico do município de Afogados da Ingazeira - PE no período de janeiro de 2014 a dezembro de 2018. Metodologia: Trata-se de uma pesquisa descritiva quantitativa, exploratória, realizada a partir de dados secundários presentes no Sistema de Informação de Agravos de notificação (SINAN), Sistema de Informação de Mortalidade (SIM) e do Sistema de Informação de Nascidos Vivos (SINASC), esses dois últimos através do TABNET. O local de estudo foi o município de Afogados da Ingazeira-PE, o qual faz parte da X Gerência Regional de Saúde, esta que referencia 12 municípios do Alto Pajeú do Estado. Resultados: A partir desse estudo foi possível observar os principais agravos notificados, podendo destacar a hanseníase, a tuberculose, dengue, chagas, meningite, sífilis congênita e em gestantes, violência interpessoal e autoprovocada como os principais agravos notificados e de prevalências significativas, também se atenta para a Leishmaniose que nos últimos anos vem mostrando uma incidência relevante. No que diz respeitos aos indicadores de mortalidade natalidade observa-se que a mortalidade é mais prevalente no sexo masculino, seguindo uma tendência nacional, ressaltando também um declínio na mortalidade materno-infantil, que pode ter relação com a qualificação da assistência a esse público. Conclusão: A importância de evidenciar esse perfil constitui-se em realizar uma análise situacional do contexto de saúde, objetivando uma melhora significativa na estruturação da rede de saúde, identificando necessidades e propondo soluções, direcionando assim, as ações de saúde para as dificuldades evidenciadas.

Palavras-chave: Vigilância em Saúde. Informações de Saúde. Análise Situacional.

Área Temática: Saúde Coletiva 


\title{
O ESTÁGIO RURAL EM SAÚDE COLETIVA E SUAS CONTRIBUIÇÕES PARA A FORMAÇÃO DO ENFERMEIRO: RELATO DE EXPERIÊNCIA
}

\author{
Aline Francisca Gomes de Brito ${ }^{1}$ \\ ${ }^{1}$ Universidade do Estado do Amazonas
}

Introdução: Amparado pela lei $\mathrm{n}^{\circ}$. 11.788/2008, de 25 de setembro de 2008, o objetivo do estágio é preparar os estudantes para a rotina de trabalho. Tal preparação faz parte do projeto pedagógico de diversos cursos promovidos por instituições de nível superior. O Estágio Curricular Rural em Saúde Coletiva está incluído como disciplina obrigatória do curso de Bacharelado em Enfermagem da Universidade do Estado do Amazonas (UEA) e proporciona aprendizagem aos estudantes através da atuação no serviço de atenção básica à saúde. Objetivo: Retratar a experiência de uma discente do curso de enfermagem durante a vivência do Estágio Rural em Saúde Coletiva de uma universidade pública estadual, destacando as contribuições do mesmo para a formação do enfermeiro. Metodologia: Estudo descritivo, do tipo relato de experiência. As atividades do estágio rural perduraram pelo período de 30 dias, sendo realizadas em uma Unidade Básica de Saúde da Família (UBSF) do município de Tabatinga, localizado no interior do Amazonas, sob supervisão de preceptores locais. Resultados: A trajetória vivenciada resultou na aplicação de conhecimentos técnico-científicos na área de saúde coletiva. O atendimento realizado na UBSF propiciou a realização de consultas de prénatal, planejamento familiar, Hiperdia, crescimento e desenvolvimento, entre outros atendimentos assistenciais. As orientações de enfermagem aos pacientes foram imprescindíveis em todos os atendimentos realizados, comprovando a relevância do papel do enfermeiro da atenção básica como educador. Considerações finais: A vivência preparou a discente para a rotina de trabalho característica dos enfermeiros atuantes da atenção básica e agregou conhecimentos acerca do funcionamento do SUS. As práticas demandaram maleabilidade, pois o município faz fronteira com Colômbia e Peru, de onde muitos pacientes se deslocavam para procurar atendimento.

Palavras-chave: Educação em Saúde. Sistema Único de Saúde. Ensino Superior.

Área temática: Saúde coletiva 


\section{ANÁLISE COMPARATIVA DE OCORRÊNCIA DAS ARBOVIROSES E DADOS DO LIRAS EM RECIFE- PE.}

\section{Luiz Henrique Alexandre dos Santos, Plínio Pereira Gomes Júnior², Mylena Rafhaele Gomes de Oliveira ${ }^{3}$}

\footnotetext{
${ }^{1}$ Programa de Residência Multiprofissional em Saúde Coletiva (COREMU-IMIP/ SESAU-Recife) -

${ }^{2}$ Universidade Federal Rural de Pernambuco (UFRPE) ${ }^{3}$ Universidade de Pernambuco (UPE)
}

Introdução: Nos últimos anos, as arboviroses (dengue, chikungunya, vírus zika), tornaram-se um grave problema de saúde pública no Brasil. No estado de Pernambuco, não é diferente, observa-se um importante aumento de casos notificados dessas arboviroses, sendo considerada uma tríplice epidemia, o que preocupa gestores e a população. O diagnóstico de possíveis riscos de epidemias e identificação precoce dos casos de agravos é de vital importância para que sejam tomadas decisões, visando principalmente evitar a ocorrência de óbitos. Com um bom nível de conhecimento e informações se obtêm uma boa qualidade de serviços de saúde, tanto na área de vigilância em saúde quanto na prestação de assistência médica, permitindo conhecer a real situação das doenças em cada região. Objetivo: Analisar comparativamente os casos confirmados das arboviroses em destaque atualmente e os Índices do LIRAa no município de Recife, no período de 2014 a 2017. Metodologia: Estudo descritivo através da análise comparativa de dados referente aos índices de infestação obtidos do LIRAa, e de casos notificados no Sistema de Informação de Agravos de Notificação (SINAN), ambos disponibilizados pela Secretaria de Saúde do Recife. Resultados(concluídos): Foram registrados um total de 48606 casos notificados e confirmados de arboviroses no SINAN entre 2014 e 2017. Os anos de 2015 e 2016 tiveram maior número de casos confirmados. Quanto aos índices de infestação, o ano de 2015 se destaca com maior média. Conclusões: A análise comparativa possibilitou a percepção e conhecimento no que diz respeito aos dados de infestação vetorial e ocorrência de arboviroses. Uma vez que permite comparar variáveis de tempo e localidade de diferentes fontes, para sinalização de maiores riscos de infestação e epidemias desses agravos.

Palavras-Chave: Saúde Pública, Vigilância em Saúde, Epidemiologia.

Área Temática: Saúde Coletiva 


\section{A TRAJETÓRIA E A MODULAÇÃO DO APOIO INSTITUCIONAL NA ATENÇÃO PRIMÁRIA DE PORTO ALEGRE/RS}

\section{Clarissa Einsfeldt de Lima ${ }^{1}$}

${ }^{1}$ Escola de Saúde Pública do RS

Introdução: O apoio institucional surge como uma nova tecnologia de gestão para auxiliar as equipes de saúde a lidarem com seus problemas e conflitos cotidianos, através da problematização e análise dos processos de trabalho, na perspectiva de reconstruí-los. Assim como em vários municípios do Brasil, Porto Alegre adota esta ferramenta de gestão, tendo uma trajetória marcada por vários momentos de reformulação das práticas dos apoiadores institucionais. Objetivo: Esta pesquisa se propôs a verificar como se deu a trajetória desta ferramenta em POA e nesse percurso como foram moduladas as práticas destes profissionais, buscando identificar, através do arcabouço teórico proposto por Gastão Campos, principais marcos que influenciaram nas práticas dos apoiadores, métodos utilizados e dispositivos empregados, bem como os frutos e aprendizados deixados para a rede de atenção primária do município. Metodologia: Pesquisa de abordagem qualitativa, do tipo exploratória-descritiva, sendo utilizado como instrumento de coleta de dados entrevistas semi-estruturadas, norteadas a partir de um roteiro de perguntas. Fizeram parte da pesquisa apoiadores institucionais e coordenadores da ferramenta no município. A pesquisa foi aprovada pelos CEPs da UFRGS (parecer $n^{\circ}$ 3.260.098), e da SMS de Porto Alegre (parecer n ${ }^{\circ}$ 3.294.489). Resultados: Observou-se que o fazer apoio institucional não foi exercido de forma homogênea na medida em que se modelou conforme o entendimento e perfil de cada profissional. Os apoiadores relataram haver desvalorização do cargo e falta de reposição de profissionais. Considerações Finais: O trabalho do apoio institucional foi importante para a atenção primária, sendo fundamental na implantação do acolhimento nas unidades de saúde, no processo de informatização, na avaliação do PMAQ e no auxílio às equipes na resolução de seus conflitos. Os apoiadores institucionais não conseguiram se desvincular totalmente da lógica da supervisão, e isso repercutiu na forma como se posicionaram nas equipes.

Palavras-chave: Cogestão. Democracia institucional. Trabalho em saúde.

Área Temática: Saúde Coletiva. 


\section{TELESSAÚDE NA ATENÇÃO PRIMÁRIA À SAÚDE: UM RELATO DE EXPERIÊNCIA NO NORDESTE BRASILEIRO}

\section{Izabel Viviane de Oliveira Fagundes ${ }^{1}$, César Luis Porpino Santos da Silva Júnior'}

${ }^{1}$ Residência Multiprofissional em Atenção Básica/Escola Multicampi de Ciências Médicas EMCM/UFRN

Introdução: a telessaúde apresenta-se como um artificio tecnológico que permite o desenvolvimento de atividades à distância voltadas à saúde em seus diversos níveis de atenção. Além disso, contribui para melhorar tanto os cuidados relacionados à assistência, como o acesso a informações de qualidade técnica. No cenário pandêmico atrelado à Covid-19, a telessaúde possibilitou a continuidade das atividades e das ações em saúde, o que trouxe benefícios ao longo do último ano. Objetivo: relatar as experiências vivenciadas por residentes em saúde, com o serviço de teleatendimento na Atenção Primária à Saúde (APS), no contexto da pandemia do novo coronavírus. Metodologia: trata-se de um relato de experiência realizado a partir de reflexões acerca da atuação de residentes multiprofissionais em Atenção Básica no teleatendimento criado em uma Unidade Básica de Saúde (UBS) no interior do Rio Grande do Norte. Resultados: ao vivenciar a pandemia pela Covid-19, os serviços de atenção à saúde, incluindo as UBS, necessitaram se reinventar para conseguir dar continuidade aos cuidados em saúde frente às necessidades do território, diante das medidas de isolamento social. Dessa maneira, os atendimentos via Telessaúde possibilitaram comunicação direta com os usuários que já eram assistidos pela unidade, ao passo em que trouxeram uma maior aproximação e acolhimento para pessoas que anteriormente não procuravam o serviço. Essa implantação também serviu como apoio para monitoramento, avaliação e intervenção de diversos serviços oferecidos pela UBS, implicando na mudança dos processos de trabalho do serviço, como também possibilitou a discussão de estratégias para o atendimento dos usuários de forma imediata. Considerações finais: consoante ao dito, foi possível observar a flexibilidade proporcionada pelas tecnologias digitais, que tornaram possível ajustar-se às necessidades de saúde demandadas pelo território, funcionando como uma alternativa inovadora para continuidade da prestação de serviços e ações em saúde na APS, sobretudo no enfrentamento à pandemia.

Palavras-chave: Telemedicina. Sistema único de saúde. COVID-19.

Área Temática: Saúde Coletiva 


\title{
AVALIAÇÃO DA EFICÁCIA DO DISTANCIAMENTO SOCIAL NA CONTENÇÃO DA COVID-19 - UMA REVISÃO DE LITERATURA
}

\author{
Valdília Ribeiro de Alencar Ulisses ${ }^{1}$, Maria Anelice de Lima² \\ ${ }^{1,2}$ Universidade Regional do Cariri - URCA
}

Introdução: No Brasil, o surto do vírus COVID-19 levou a óbito quase 300.000 pessoas até o momento. Os governantes das três esferas administrativas tiveram que adotar várias medidas de controle e prevenção quando os primeiros casos da COVID-19 começaram a surgir. Uso de máscaras, isolamento social, quarentena e lockdaw foram as medidas utilizadas para minimizar o contagio dessa doença. Foram emitidos vários decretos para possibilitar a análise objetiva da pandemia, contendo restrições a cada atividade econômica, fazendo um mapeamento e classificação em categorias, de acordo com o resultado pretendido: comércio essencial e não essencial. Objetivo: Avaliar a eficácia do distanciamento social na contenção da COVID-19. Metodologia: Trata-se de uma pesquisa exploratória descritiva, realizada a partir da revisão de literatura com base em análise bibliográfica de artigos encontrados na SciELO - (Scientific Electronic Library Online) e Revista de Saúde Pública. Resultados: Como as doenças transmitidas por gotículas respiratórias requerem certa proximidade física para ocorrer o contágio, o distanciamento social permite reduzir a transmissão. O fechamento de bares, estágios de futebol, lojas de roupas e assessórios, entre outros vistos como não essenciais; escolas e a proibição de eventos foram algumas medidas adotadas para evitar aglomeração de pessoas. O comércio não essencial teve que se reinventar utilizando os meios virtuais para driblar a situação das vendas. O distanciamento social adotado pela população é efetivo, especialmente quando combinado ao isolamento de casos e à quarentena dos contatos. Conclusões: Os trabalhos científicos utilizados na presente revisão sugerem que a junção de isolamento dos casos, quarentena de contatos e medidas amplas de distanciamento social, têm grandes chances de diminuir a transmissão da doença viral COVID-19.

Palavras-chave: Isolamento. Transmissão. Doença.

Área Temática: Saúde Pública 


\section{O HETEROCONTROLE DO FLUORETO NA ÁGUA DE ABASTECIMENTO E A SAÚDE DENTAL}

\section{Lorena Rodrigues Souza ${ }^{1}$.}

${ }^{1}$ Universidade Estadual de Feira de Santana.

Introdução: A presença de fluoreto nas águas pode se dar de modo natural, estando muitas vezes acima ou abaixo do recomendado. Quando abaixo da quantidade ideal, o flúor não possui efeito contra a doença cárie, e quando em altas concentrações, pode causar a fluorose dentária. Com isso, é necessário o controle do fluoreto para evitar danos à saúde dental. Uma das medidas de monitoramento dessa concentração é pelo programa de heterocontrole. Objetivo: Revisar na literatura o papel do heterocontrole do fluoreto da água de abastecimento na saúde dental. Método: A pesquisa dos artigos ocorreu nos portais PubMed e Biblioteca Virtual de Saúde utilizando os termos "Water" AND "Fluoride", "Dental Caries" AND "Water", "Fluorosis, Dental" AND "Water" e os respectivos termos em português. Foram incluídos trabalhos publicados entre 2015 e 2020 sem restrição de idiomas. Resultados: O heterocontrole apresenta uma estratégia eficaz no controle e vigilância dos níveis de fluoreto e é realizado pela coleta periódica de amostras de água para posteriores análises em laboratórios. O programa é capaz de identificar lugares onde a concentração de fluoreto nas águas de abastecimento está acima ou abaixo do recomendado, como acontece frequentemente nas regiões abastecidas por mananciais subterrâneos, rios e outras fontes de águas naturais. Com o rastreamento dessas localidades, o programa ajuda no planejamento da adequação dos valores ideais de flúor nas comunidades. Porém tal medida pode ser inviável em municípios de pequeno e médio porte por questão da falta de recursos, dependência de outros setores, disponibilidade dos aparelhos e treinamentos para a coleta correta das amostras. Conclusão: O heterocontrole é significativo para o oferecimento de água potável de qualidade à população, o tratamento da cárie dentária e controle do aparecimento da fluorose dental. Porém pode ser limitado em municípios pequenos por falta de estrutura na localidade.

Palavras-chave: Flúor. Saúde Bucal. Saúde Pública.

Área Temática: Saúde Coletiva. 


\title{
CONTRIBUIÇÕES DOS RESIDENTES EM SAÚDE NO ENFRENTAMENTO DAS FAKE NEWS DA COVID 19
}

\author{
${ }^{1}$ Maria Anelice de Lima, ${ }^{2}$ Valdília Ribeiro de Alencar Ulisses
}

${ }^{1,2}$ Universidade Regional do Cariri - URCA

Introdução: $\mathrm{Na}$ área da saúde, a veiculação de notícias falsas, são notórias como ameaça à saúde pública, no contexto à pandemia da COVID-19, corroborando para apropriações inadequadas dos que buscam informações sobre saúde na internet. Várias Fake News, como terapêuticas farmacológicas, sugestivos tratamentos e cura, e ataques as vacinas são disseminadas nas redes sociais. Notícias falsas em torno da pandemia refletem intenção duvidosa de confundir as pessoas, sendo importante o papel dos residentes em saúde em combater tais notícias, contribuindo para informação adequada à população. Objetivo: Identificar as Fake News sobre as vacinas para COVID-19 propagadas no Brasil. Metodologia: Foram realizadas pesquisas de buscas na mídia nacional, sites e páginas oficiais do Ministério da Saúde e bibliográficas, sendo selecionados quatro artigos nacionais publicados entre 2019 e 2020 nas bases de dados da Literatura Latino Americana e do Caribe de Informações em Ciências da Saúde (LILACS), realizada em março de 2021. O estudo obedeceu aos preceitos preconizados pela Resolução $n^{\circ}$ 466/2012 do Conselho Nacional de Saúde. Resultados: Constatouse que diversas notícias falsas disseminadas à população corroboram para credibilidade no que é veiculado, oportunizando práticas prejudiciais à saúde, como automedicação e o uso de misturas falsamente apontadas como eficazes para o combate da COVID-19. No aspecto da propagação de Fake News sobre as vacinas, referem como produzidas pelas células de fetos abortados, causadoras de autismo e não seguras. Conclusão: Evidenciou-se ser imprescindível que os meios de comunicação sejam mecanismos de identificação e combate às Fake News, sendo importante que os residentes em saúde procurem atuar combatendo essas notícias infundadas, esclarecendo matérias verdadeiras, divulgando pesquisas científicas para que leitores, motivados pela segurança da informação, desenvolvam a capacidade crítica para benefício da população.

Palavras-Chave: Vacinas. Brasil. Pandemia.

Área Temática: Saúde Coletiva 


\title{
POTENCIALIDADES DO SANITARISTA DE GRADUAÇÃO NA ATENÇÃO BÁSICA: RELATO DA PRAXIS DE UMA RESIDENTE
}

\author{
Aline Vanessa da Silva ${ }^{1}$; Amanda Patrícia da Silva ${ }^{2}$; \\ ${ }^{1}$ Universidade Federal de Pernambuco - UFPE/CAV, ${ }^{2}$ Centro Universitário da Vitória de Santo \\ Antão
}

Introdução: Os primeiros cursos de graduação em saúde coletiva iniciaram em 2008, voltados a formação do bacharel em saúde coletiva. Tal profissional atua em vários eixos da gestão em saúde pública e privada. $\mathrm{O}$ sanitarista tem se inserido também na atenção básica através das residências multiprofissionais, carregando consigo uma visão ampliada, de atributos e potenciais, que visam desbravar esse novo campo de atuação. Objetivo: Relatar a experiência de uma residente bacharel em saúde coletiva na atenção básica. Métodos: Estudo qualitativo e descritivo realizado através do processo de trabalho de uma profissional de saúde residente e atuante na atenção básica. Resultados: A atenção básica é a principal porta de entrada do Sistema Único de Saúde - SUS e também o nível de atenção a saúde mais próximo da população e de seu processo saúde-doença. O Núcleo Ampliado de Saúde da Família e Atenção Básica (NASF-AB) é uma equipe multiprofissional de apoio a Estratégia de Saúde da família (ESF), sendo no NASF-AB a inserção da residente. Apesar das dificuldades encontradas, o sanitarista bacharel por meio da sua formação consegue ampliar o olhar da equipe, a análise dos casos, e a robustez do apoio matricial e das ferramentas de trabalho, bem como trazer eixos de sua formação como planejamento, promoção da saúde, educação permanente, articulação de rede, vigilância em saúde e demais habilidades para as reuniões de equipe, atividades coletivas, compartilhadas e de maneira especial no processo de trabalho. Conclusão: O sanitarista graduado é um profissional de atuação múltipla, de grande potência e é um diferencial nos serviços de saúde. Espera-se com esse relato contribuir para o conhecimento acerca deste profissional, suas habilidades e seus campos de atuação.

Palavras-chave: Saúde Pública. Atenção Primária. Sistema Único de Saúde.

Área Temática: Saúde Coletiva 


\section{A PRECEPTORIA NA FORMAÇÃO DO RESIDENTE MULTIPROFISSIONAL EM SAÚDE COLETIVA NO ESTADO DA PARAÍBA}

\section{Fernanda Prudêncio da Silva ${ }^{1}$; Joanne Days de Sousa Nóbrega ${ }^{2}$; Jovelina Fernandes dos Santos $^{3}$; Juciara Noara Santana de Araújo Costa ${ }^{4}$; Kelly Clennia Ribeiro Costa ${ }^{5}$}

${ }^{1}$ Escola de Saúde Pública da Paraíba, ${ }^{2}$ UNIFIP, ${ }^{3}$ Escola de Saúde Pública da Paraíba, ${ }^{4}$ UNIFIP, ${ }^{5}$ Escola de Saúde Pública da Paraíba

Introdução: Considerando as lacunas da formação universitária, torna-se importante que exista um espaço que prepare o profissional para trabalhar na realidade do Sistema Único de Saúde. A estrutura da Residência Multiprofissional em Saúde Coletiva proporciona que o residente tenha contato com diversas vertentes do SUS: gestão, organização do sistema e serviços, vigilâncias em saúde, redes de atenção à saúde, assistência, planejamento, etc. Possibilitando, assim, enxergar as potencialidades e fragilidades dos processos de trabalho e de formação dos profissionais de saúde, utilizando como ferramenta a Educação Permanente em Saúde, a práxis e a defesa do SUS consolidado a partir de seus princípios e diretrizes. Objetivo: Apontar a importância do preceptor na formação crítica-reflexiva do residente multiprofissional em Saúde Coletiva. Metodologia: Relato baseado na experiência de preceptoria de uma Residência Multiprofissional em Saúde Coletiva, no Estado da Paraíba, que tem como campo de prática a $8^{\mathrm{a}}$ Região de Saúde. Resultados: Pôde-se observar a potencialidade do diálogo preceptor-residente, a partir da construção de vínculos, o que impulsionou o processo de formação tornando a aprendizagem mais significativa. O papel do preceptor trouxe a importância de desconstruir as modalidades engessadas de educação, atuando como agente facilitador na construção do Ser Residente. Outros elementos que se destacaram na relação preceptor-residente, foram: o estímulo à criticidade, o embasamento e direcionamento teórico-prático, o acompanhamento aos residentes, o apoio emocional e o estímulo motivacional. Considerações Finais: Foi possível perceber que o vínculo preceptor-residente favoreceu um processo de ensino-aprendizagem mais significativa. Um dos desafios foi manter um estímulo constante no acompanhamento dos residentes, considerando as diversas personalidades e histórias de vida que fazem parte desse espaço. Este trabalho abre margem para afirmar que uma atuação de preceptoria que parte do real, trabalhando a amorosidade, o pertencimento e a construção de identidade tem potencial transformador na formação dos residentes em saúde.

Palavras-chave: Sus. Práxis. Dialogicidade.

Área Temática: Saúde Coletiva 

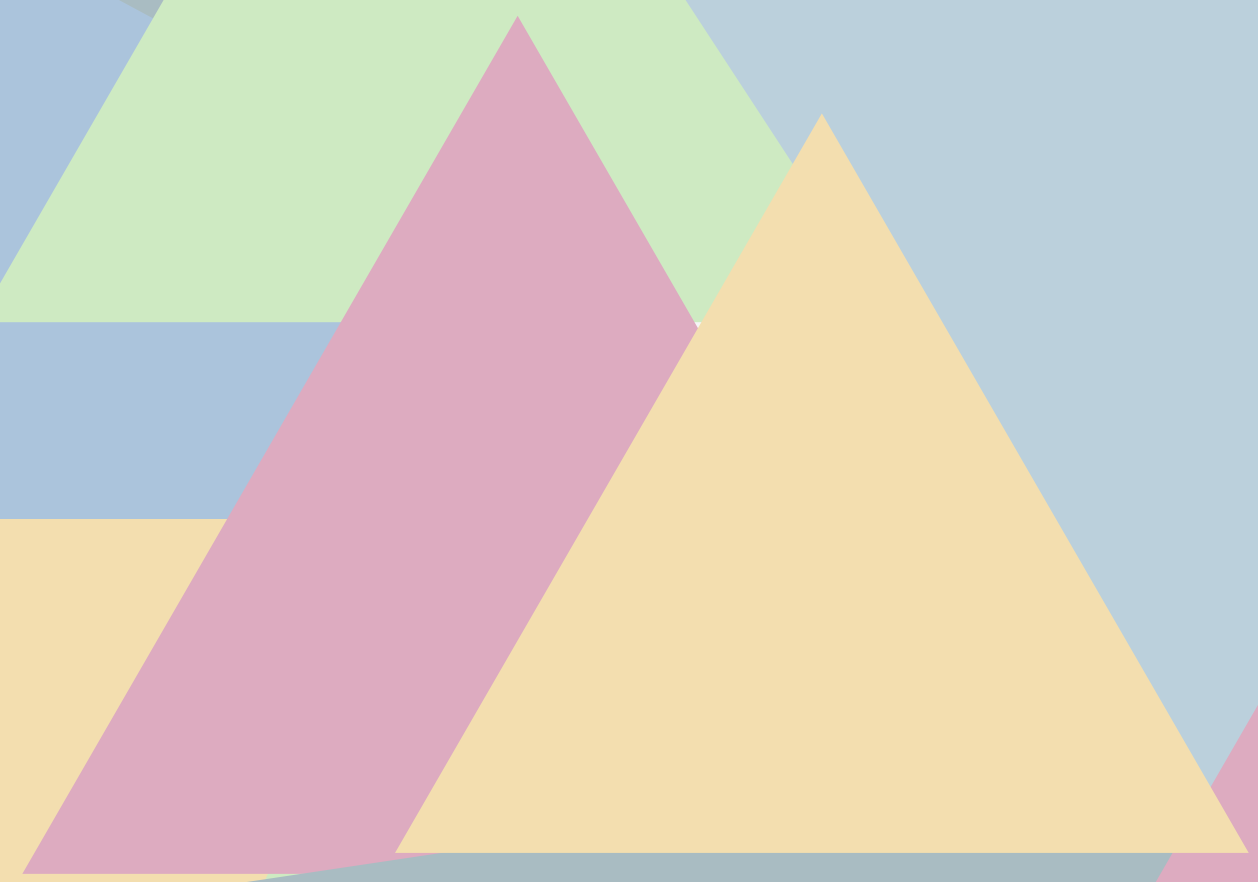

\section{Áreas afins}




\section{COMPLICAÇÕES DECORRENTES DA LIPOASPIRAÇÃO DE ALTA DEFINIÇÃO EM PACIENTES COM GRANDE PERCENTUAL DE GORDURA CORPÓREA.}

\section{Fernando Fernandes Rodrigues ${ }^{1}$, Érica Paulinne Pereira Brandão ${ }^{2}$, Lorrana Xavier do Nascimento $^{3}$, Max Walber Lima Freitas ${ }^{4}$, Raphaella Viana Guimarães ${ }^{5}$}

${ }^{12}$ Centro Universitário Metropolitano de Manaus (Fametro) $/ 3$ Universidade do Estado do Amazonas (UEA)

\footnotetext{
${ }^{4}$ Universidade Federal do Amazonas (UFAM) ${ }^{5}$ Universidade Nilton Lins (UNL)
}

Introdução: A lipoaspiração de alta definição, popularmente conhecida como Lipo LAD é um procedimento realizado com o intuito de proporcionar um aspecto desenhado do músculo reto abdominal, sendo a princípio indicada para ressaltamentos de contornos em pacientes com pouca gordura localizada, ${ }^{1}$ as quais não foram eliminadas ou reduzidas por meio de prática de exercícios físicos e hábitos saudáveis, não sendo indicada para pacientes sobrepeso, obesos ou com obesidade mórbida por conta de suas complicações. ${ }^{2}$ Objetivo: Identificar a presença de complicações decorrentes da realização de lipoaspiração de alta definição em pacientes com grande percentual de gordura corpórea. Metodologia: Trata-se de Pesquisa Bibliográfica, por meio de fontes de pesquisas secundárias, com a análise pormenorizada de manuais e artigos de revisão ,embasados em resultados qualitativos e com ênfase no cruzamento de dados documentais. Resultados(Concluídos): Fora constatada que a lipoaspiração não deve ser feita como uma terapêutica alternativa para a obesidade e não substitui a realização regular de exercício físico e de hábitos saudáveis. ${ }^{1}$ Corroborou-se que Indivíduos com poucas áreas de gordura no corpo e que se exercitam regularmente são os melhores candidatos a esse procedimento, sobretudo para que as expectativas após a cirurgia sejam atendidas. ${ }^{2}$ Entre os resultados negativos em pacientes obesos foram apresentadas uma série de consequências , entre elas: imperfeições na superfície lipoaspirada; necrose de pele, e falha no ressaltamento de contornos, a presença de embolia pulmonar gordurosa e grande flacidez de pele na região lipoaspirada. ${ }^{2}$ Conclusão: Portanto, conclui-se que a Lipoaspiração de Alta Definição não deve ser realizada em pacientes com doenças crônicas pré existentes, sobretudo sobrepeso e obesidade, para que não sofram com consequências pós operatórias, sendo elas de acontecimentos independentes do trabalho médico ter sido feito corretamente, consolidando o procedimento como altamente recomendável para aqueles que desejam realçar contornos, mas que já possuam hábitos de vida saudáveis.

Palavras-Chave: Lipo LAD. Consequências. Sobrepeso.

Área Temática: Áreas Afins. 


\section{PREVALÊNCIA DE DOENÇAS CRÔNICAS EM IDOSOS COM TRAUMA CRANIOENCEFÁLICO APÓS QUEDA DA PRÓPRIA ALTURA.}

\section{Fernando Fernandes Rodrigues ${ }^{1}$, Érica Paulinne Pereira Brandão², Lorrana Xavier do Nascimento $^{3}$, Max Walber Lima Freitas ${ }^{4}$, Raphaella Viana Guimarães $^{5}$}

${ }^{12}$ Centro Universitário Metropolitano de Manaus (Fametro) $/{ }^{3}$ Universidade do Estado do Amazonas (UEA)

${ }^{4}$ Universidade Federal do Amazonas (UFAM) ${ }^{5}$ Universidade Nilton Lins (UNL)

Introdução: A queda consiste em um deslocamento não intencional do corpo para o nível inferior à posição inicial, podendo ser ocasionada por diversos fatores intrínsecos que prejudicam a estabilidade do indivíduo. Em idosos, quedas da própria altura com sangramento intracraniano traumático é relatada na literatura com alta prevalência. Em casos mais graves, a queda pode ocasionar o trauma cranioencefálico (TCE) nos pacientes, originando quadros de déficits temporários ou permanentes, sendo uma lesão, hematomas subdural, contusional e intracerebral no tecido cerebral. Objetivo: Analisar a prevalência de doenças crônicas em idosos com trauma cranioencefálico após queda da própria altura, com base na literatura especializada. Metodologia: Trata-se de Pesquisa Bibliográfica, por meio de fontes de pesquisas secundárias, com a análise pormenorizada de manuais e artigos de revisão literárias, embasados em resultados qualitativos e com ênfase no cruzamento de dados documentais. Resultados(concluídos): Corroborou-se que muitos são os fatores associados a essa problemática, como alterações de equilíbrio, dificuldade de caminhar, deficiências visuais, cognitivas e perda da rigidez do corpo. Fora observado aumento do espaço subdural decorrente do envelhecimento e atrofia cerebral presente em grande número de idosos, induzindo quedas que podem lesionar grandemente o tecido cerebral. Essas alterações frequentemente estão relacionadas a patologias crônicas de saúde, uma vez que é retratado que a prevalência de quedas é maior em idosos que possuem Doença de Parkinson, osteoartrite no joelho e dor crônica no sistema musculoesquelético. Conclusão: Evidenciou-se que há grande prevalência de doenças crônicas em pessoas da $3^{\circ}$ Idade com TCE após queda de própria altura. Portanto, pesquisas e politicas preventivas devem ser criadas e praticadas, com o intuito de prevenir e proporcionar melhor qualidade de vida para esses pacientes, impactando até mesmo no número de atendimentos no serviço público.

Palavras-Chave: TCE. $3^{\circ}$ Idade. Patologias.

Área Temática: Áreas Afins. 


\section{BENEFÍCIOS DO EXCERCÍCIO FÍSICO DURANTE A GESTAÇÃO: UMA REVISÃO DE LITERATURA}

\section{Danielton Castro de França ${ }^{1}$, Lenilson Ricardo Oliveira Campos ${ }^{2}$, Valquiria de Oliveira Silva e Silva ${ }^{3}$, Evelane Almeida de Jesus ${ }^{4}$.}

\footnotetext{
${ }^{1.2}$ Faculdade de Ensino Superior do Piauí - FAESPI, ${ }^{3}$ Centro Universitário de Ciências e Tecnologia do Maranhão - UNIFACEMA, ${ }^{4}$ Fisioterapeuta pelo Centro Universitário UniFacid Wyden -
}

UNIFACID.

Introdução: O exercício, definido como atividade física consiste em movimentos corporais planejados, estruturados e repetitivos para melhorar um ou mais componentes da aptidão física, é um elemento essencial de estilo de vida saudável, e os obstetras, ginecologistas e outros prestadores de cuidados obstétricos devem incentivar seus pacientes a continuar ou iniciar o exercício como um componente importante de saúde ideal. Objetivo: Identificar, na literatura cientifica, os benefícios do exercício físico durante a gestação. Metodologia: Este estudo é uma revisão de literatura em que se realizou uma busca de publicações disponíveis nas bases de dados PubMed, LILACS e SciELO entre os anos de 2014 a 2020. Os descritores utilizados foram Atividade Física, Gestante e Qualidade de vida. Resultados: Com a aquisição da prática de exercício físico, a gestante mantém seus níveis glicêmicos através do aumento da sensibilização dos receptores de insulina, evitando aumento da glicose sanguínea, prevenindo assim à Diabetes Mellitus. No sistema respiratório, ocorre uma melhor captação, utilização e transporte de oxigênio além de melhorar o processo de oxigenação do feto e a irrigação da placenta. Pesquisas mostraram um risco significativamente reduzido de distúrbios hipertensivos gestacionais, e cesariana em mulheres que realizaram exercícios aeróbicos 30 a 60 minutos, por 2 a 7 vezes por semana, em comparação com as mulheres que estavam sedentárias. Os exercícios podem ajudar em controle de algias posturais na gravidez e também no trabalho de parto. A dor lombo-pélvica é um problema para a uma grande parcela das gestantes e a Yoga é um dos métodos alternativos mais utilizados para aliviar essa dor. Considerações Finais: Conclui-se que o exercício físico influencia positivamente a qualidade de vida das gestantes, antes e depois do parto.

Palavras-chave: Atividade Física. Gestante. Qualidade de Vida.

Área Temática: Áreas afins. 


\title{
A RELEVÂNCIA DA TERRITORIALIZAÇÃO PARA ORGANIZAÇÃO DOS SERVIÇOS DE SAÚDE: RELATO DE EXPERIÊNCIA DE RESIDENTES EM SAÚDE
}

\author{
Francisca Viviane Matos Soares ${ }^{1}$ Clara dos Santos Silva Linhares ${ }^{2}$
}

${ }^{1}$ Escola de Saúde Pública do Ceará ${ }^{2}$ Escola de Saúde Pública do Ceará

Introdução: O propósito da realização da territorialização é apreender o modo de vida da comunidade e seu processo saúde-doença, identificando espaços e práticas de promoção da saúde no território, assim como seus problemas e possíveis intervenções. Considerando que para intervir nas redes de atenção à saúde, é necessário compreender a dinâmica social, assim como, conhecer o território e possuir vínculos com a população local. Objetivo: Relatar a experiência na territorialização de residentes integrantes da ênfase Saúde da Família e Comunidade da Escola de saúde Pública do Ceará. Metodologia: Trata-se de um estudo bibliográfico e descritivo, do tipo relato de experiência de residentes de Serviço Social. Resultados: A territorialização possibilitou um amplo conhecimento da comunidade, auxiliando na identificação de prioridades a serem inicialmente trabalhadas, frente às necessidades encontradas. Foram identificadas potencialidades e vulnerabilidades no território, vulnerabilidades como situações de violência doméstica, negligência contra idosos e crianças, situação de extrema pobreza, dentre outras. Potencialidades como a presença de líderes comunitários ativos e participativos, equipes da Estratégia Saúde da Família, rede intersetorial, conselho tutelar etc. Considerações Finais: O processo de territorialização promoveu o encontro entre residentes e usuários, propiciou o conhecimento dos espaços e das práticas populares do cuidado, possibilitou o entendimento de como se manifesta a saúde e/ou sua ausência na comunidade. Dessa forma, tornouse possível uma melhor organização dos serviços de saúde, entendendo que estes devem se adaptar as necessidades da população.

Palavras-chave: Encontro. Residência. Comunidade.

\section{Área Temática: Áreas afins}




\title{
USO DAS REDES SOCIAIS PARA INFORMAÇÃO E CONSCIENTIZAÇÃO SOBRE OS CUIDADOS PREVENTIVOS CONTRAA COVID-19
}

\author{
Pedro Carlos Silva de Aquino ${ }^{1}$
}

Universidade Regional do Cariri ${ }^{1}$

Introdução: Ao novo cenário desencadeado pela pandemia da Covid-19, a preocupação com a saúde e os cuidados preventivos da população foram importantes para evitar a transmissão, e o aumento dos números de casos da doença. Com isso, a informação em saúde com base científica nas redes sociais foi um recurso que apresentou fundamental importância para propiciar a educação em saúde e a conscientização para os cuidados com a doença. Objetivo: Descrever as atividades desenvolvidas com o uso do Instagram ${ }^{\circledR}$ para conscientização da população do Crato/CE sobre os cuidados preventivos contra a Covid-19. Metodologia: Trata-se de um estudo descritivo do tipo relato de experiência com abordagem qualitativa. As atividades foram desenvolvidas entre abril a novembro de 2020, que consistiu na produção de conteúdo informativo para publicação no Instagram ${ }^{\circledR}$ da Residência Multiprofissional em Saúde Coletiva e do Programa de Educação para o Trabalho em Saúde da Universidade Regional do Cariri. Os conteúdos publicados abordavam temas selecionados previamente, consultados em documentos com base científica, aliados com aplicativos de criação e edição de pôsteres e vídeos. Resultados: No tocante aos conteúdos produzidos e publicados, as informações foram adaptadas em formato de pôsteres e vídeos didáticos para facilitar o entendimento da população em geral acerca dos temas. Consistiram, em explicação geral sobre a doença; cuidados preventivos contra o vírus; combate as notícias falsas; higienização dos alimentos; importância da prática de exercício físico em casa; cuidados com a saúde mental; orientações para prevenção da Covid-19 no uso de serviços e comércio; violência contra a mulher e cuidados com a dengue durante a pandemia. Considerações Finais: Diante do cenário pandêmico, as redes sociais dos Programas foram um importante veículo de comunicação e informação para conscientizar e empoderar a população acerca dos cuidados preventivos a serem tomados contra a Covid-19.

Palavras-chave: Tecnologias. Educação em Saúde. Pandemia.

Área Temática: Áreas afins. 


\title{
GOOGLE EARTH E SW MAPS: GEOTECNOLOGIAS COMO
}

\section{RECURSO DE TRABALHO EM VIGILÂNCIA EM SAÚDE}

\author{
Pedro Carlos Silva de Aquino ${ }^{1}$
}

Universidade Regional do Cariri ${ }^{1}$

Introdução: O uso de geotecnologias na Atenção Primária à Saúde (APS) para o georreferenciamento e mapeamento, possibilita a territorialização da população usuária do serviço de saúde. Assim, é possível compreender as necessidades de saúde, bem como o planejamento do processo de trabalho. Objetivo: Descrever o uso de ferramentas para georreferenciamento e geoprocessamento de informações em saúde como recurso de trabalho em vigilância em saúde na (APS). Metodologia: Trata-se de um estudo descritivo do tipo relato de experiência com abordagem qualitativa. Foi desenvolvido um trabalho de vigilância em saúde para a produção de informações em saúde de um território em 2019 na cidade do Crato/CE. Realizado por um grupo de profissionais da Residência Multiprofissional em Saúde Coletiva e integrantes do Programa de Educação para o Trabalho em Saúde da Universidade Regional do Cariri, e uma equipe da Unidade Básica de Saúde. O Google Earth e o SW Maps são softwares gratuitos para computador e celular que permitem por coordenadas geográficas a localização e demarcação do território para criação de mapas e armazenamento de dados. Resultados: O trabalho consistiu em visitas em grupo aos territórios para georreferenciar com o uso do SW Maps, através de pontos de localização enumerados dos imóveis; ruas; pontos de riscos e vulnerabilidades; e equipamentos sociais da localidade. Com as informações salvas, foram transferidas no Google Earth para uma visualização tridimensional no globo terrestre. A partir disso, realizou-se o geoprocessamento dos dados coletados para registro e armazenamento de informações de ordem socioeconômica e ambiental do território, e dos usuários do serviço disponibilizado pela equipe de saúde. Considerações finais: Neste contexto, a utilização das ferramentas possibilitou a criação de mapas com informações de indicadores de saúde, para formulação de planejamentos e estratégias em cuidados em saúde da população do território.

Palavras-Chave: Tecnologias. Georreferenciamento. Atenção Primária.

Área Temática: Áreas afins 


\title{
RESIDÊNCIA MULTIPROFISSIONAL EM SAÚDE COLETIVA E PET-SAÚDE: INTERPROFISSIONALIDADE NA VIGILÂNCIA EM SAÚDE
}

\author{
Pedro Carlos Silva de Aquino ${ }^{1}$
}

Universidade Regional do Cariri ${ }^{1}$

Introdução: As ações de vigilância em saúde desenvolvidas pelos profissionais na Atenção Primária à Saúde (APS) na perspectiva da interprofissionalidade, promovem melhores resultados nas ações de planejamento e implementação de medidas para a proteção, e prevenção contra doenças e a promoção da saúde da população do território. Objetivo: Relatar a prática do trabalho interprofissional da Residência Multiprofissional em Saúde Coletiva e do Programa de Educação para o Trabalho em Saúde. Metodologia: Trata-se de um estudo descritivo do tipo relato de experiência com abordagem qualitativa. O trabalho desenvolvido consistiu em ações de territorialização, georreferenciamento e estratificação de risco como tecnologias de vigilância em saúde. Realizado entre 2019-2020 por um grupo formado de profissionais da Residência Multiprofissional em Saúde Coletiva e bolsistas do PET-Saúde/interprofissionalidade da Universidade Regional do Cariri numa Estratégia Saúde da Família (ESF) em Crato/CE. Resultados: As atividades desenvolvidas pelo o grupo permearam na realização de oficinas para o conhecimento do processo de trabalho na APS; oficinas para manusear aplicativos de georreferenciamento; visitas para o conhecimento da equipe da Unidade de Saúde da Família (USF); visitas com os Agentes Comunitários de Saúde para o conhecimento do território adstrito à ESF; práticas de territorialização e georreferenciamento com o uso de geotecnologias para o mapeamento do território; análises de dados dos usuários do serviço de saúde; geoprocessamento de informações para estratificação de risco familiar; criação de sala de situação com indicadores de saúde na USF; confecção de mapas do território; reuniões para o planejamento de ações em vigilância em saúde; e execução de atividades para educação em saúde aos usuários. Considerações Finais: Diante do trabalho desenvolvido, a interprofissionalidade entre o grupo promoveu o ensino-aprendizagem de competências para a prática colaborativa e a resolução dos problemas com eficiência nas atividades de vigilância em saúde do território.

Palavras-Chave: Trabalho Interprofissional. Práticas Colaborativas. Atenção Primária à Saúde.

Área Temática: Áreas afins 


\section{FATORES QUE FAVORECEM A INCIDÊNCIA DE QUEDAS EM IDOSOS: UMA REVISÃO DE LITERATURA}

\section{Elídia Keila Oliveira Portela ${ }^{1}$}

${ }^{1}$ Universidade Federal do Delta do Parnaíba - UFDPAR

Introdução: o transcurso do envelhecer humano acarreta muitas transfigurações nos sistemas funcionais dos indivíduos. Tais mudanças estão retratadas, principalmente, no sistema musculoesquelético, no estado mental e nas relações sociais, diante disso a população idosa se torna frágil e vulnerável a uma série de situações comuns do dia a dia. A ocorrência de quedas se configura como uma preocupante problemática, tendo em vista que pode ocasionar lesões graves e fraturas permanentes, dessa forma refletindo de forma negativa na qualidade de vida do idoso. Objetivo: descrever de acordo com a literatura as principais condições que favorecem a ocorrência de quedas em idosos. Metodologia: o estudo em questão é uma revisão da literatura executada em janeiro de 2021, a partir das bases de dados Scielo e Pubmed. Foram eleitos 8 artigos para constituir esse trabalho, publicados entre 2015 e 2020. Resultados: os trabalhos analisados apontaram que idosos com menor escolaridade, hipertensos, portados de doenças crônicas, e que fazem uso de medicamentos estão propensos a sofrer quedas, tendo em vista que podem apresentar comprometimento funcional e cognitivo, acarretando em alteração do equilíbrio. Também são fatores preditivos à quedas a fraqueza muscular, vertigem, déficit visual e o próprio medo de cair. Considerações finais: diante desse contexto, é fundamental destacar que a ocorrência de quedas em idosos é uma problemática de saúde pública, dessa forma fazendo-se necessário que haja o comprometimento de todos os envolvidos no processo de promoção de saúde, objetivando o cuidado integral e apropriados.

Palavras-chave: Envelhecimento. Qualidade de Vida. Promoção de Saúde.

Área Temática: Áreas afins 


\section{A FISIOTERAPIA PEDIÁTRICA COM ÊNFASE NA ABORDAGEM LÚDICA: UMA REVISÃO DE LITERATURA}

\section{Elídia Keila Oliveira Portela ${ }^{1}$}

${ }^{1}$ Universidade Federal do Delta do Parnaíba - UFDPAR

Introdução: a fisioterapia pediátrica é uma importante área da saúde voltada para o tratamento e reabilitação de crianças acometidas por alguma disfunção, sendo fundamental no processo de humanização da saúde, na qual deve considerar o paciente como ser distinto e pessoal. Tendo em vista as particularidades e as necessidades do público alvo, é imprescindível que o fisioterapeuta lance mão de uma abordagem lúdica no transcurso da intervenção terapêutica, uma vez que a ludicidade, por meio da brincadeira, faz com que os atendimentos sejam mais aceitáveis por parte da criança. Objetivo: descrever os benefícios proporcionados à criança através da fisioterapia com uso de atividades lúdicas. Metodologia: trata-se de uma revisão da literatura desenvolvida em fevereiro de 2021, a partir das bases de dados Scielo, Lilacs e Pubmed. Para o desenvolvimento desse trabalho foram selecionadas 10 publicações, publicadas entre 2010 e 2020, disponíveis para leitura na íntegra e que condiziam com a temática proposta. Resultados: a partir da análise dos artigos, foi possível concluir que a abordagem lúdica do profissional fisioterapeuta trás benefícios nas esperas físicas, psicológicas e sociais, dessa forma agregando na melhora da qualidade de vida da criança. Dentre os benefícios está a melhora do equilíbrio, do desempenho físico, e da coordenação motora, e ainda o ganho de amplitude articular. Contribui também para a diminuição dos sintomas de ansiedade e desânimo, proporcionando assim, otimismo e vontade de progredir com a terapia, além disso, estimula o senso crítico e favorece a interação social. Conclusão: diante do contexto, vale destacar a importância do lúdico em todas as fases do desenvolvimento da criança, tendo em vista que o ato de brincar faz parte da infância e é a partir dele que o indivíduo irá desenvolver suas características comportamentais, cognitivas e motoras.

Palavras-chave: Ludicidade. Criança. Brincar.

Área Temática: Áreas afins 


\section{O PAPEL DA ESPIRITUALIDADE NAS DOENÇAS CRÔNICAS NÃO TRANSMISSÍVEIS}

\section{Tercília Maria Sousa Soares ${ }^{1}$, Cristina Setenta Andrade ${ }^{2}$ (Orientador)}

O aumento de pessoas com DCNT requer do trabalhador de saúde um olhar humanizado centrado na real necessidade do usuário do serviço, para isso, dispõe da espiritualidade como auxiliar á terapêutica das DCNT. Trata-se de uma revisão integrativa, realizada na base de dados do Google Acadêmico, a partir dos seguintes descritores em português: espiritualidade, doenças crônicas não transmissíveis e atenção básica, utilizando o operador booleano "and", identificando 193 artigos, selecionando 6 artigos, entre o período de 2018 e 2020, excluindo-se artigos que não estavam completos, fora do idioma selecionado, patentes ou citações. A espiritualidade permite ao trabalhador resgatar no indivíduo a esperança e o otimismo diante de situações estressoras, minimizando os danos, sendo que há uma ressignificação da vida e melhoria da sua qualidade, gerando assim, ações de promoção à saúde baseadas na realidade e necessidade da pessoa.

Palavras-chave: hipertensão; diabetes; espiritualidade. 


\title{
A EFICÁCIA DO MÉTODO BAD RAGAZ NO TRATAMENTO DA FIBROMIALGIA - UMA REVISÃO SISTEMÁTICA DA LITERATURA
}

\author{
Pedro Jonathan Sousa Araujo', Bruna Maiara de Brito Tavares². \\ ${ }^{1,2}$ Graduação em Fisioterapia pela Universidade Federal do Delta do Parnaíba - UFDPar
}

Introdução: a fibromialgia pode ser caracterizada como um distúrbio crônico com presença de algia do músculo, associado a algia em pontos específicos, cefaleia, rigidez articular, fadiga muscular, depressão, sintomas estes que estão ligados diretamente na qualidade de vida do paciente. Sua causa ainda é desconhecida, predominante no sexo feminino. Não existe tratamento específico para a doença, gerando desafio para melhoria da condição de vida do paciente. A hidroterapia tem sido uma grande aliada no tratamento da patologia, o Método Bad Ragaz utiliza exercícios de flutuação sustentada, promovendo a estabilidade do corpo, redução do tônus, sendo utilizado de forma passiva ou ativa e é indicado no tratamento da doença, principalmente para o alívio da dor. Objetivo: analisar os benefícios da utilização do Método Bad Ragaz no tratamento de pacientes acometidos pela fibromialgia. Metodologia: o estudo trata-se de uma revisão de literatura, executado a partir de bases de dados Google Acadêmico, Scielo e Pubmed. Os critérios de inclusão dos materiais foram publicações entre 2007 a 2020, estando em língua portuguesa e inglesa na íntegra. A pergunta norteadora foi: Qual a eficácia do Método Bad Ragaz no tratamento de pacientes com fibromialgia? Resultados: um total de 8 artigos foram incluídos nesse estudo, o Bad Ragaz possibilita uma maior estabilidade da articulação pois permite trabalhar todo o corpo de uma só vez e com várias possibilidades, dessa forma, causando relaxamento muscular e analgesia na maioria dos casos nos quais o método é aplicado, expondo que o uso do mesmo foi eficaz no tratamento da sintomatologia da fibromialgia, inclusive colaborando para a melhoria de quadros de dor e depressão Conclusão: com esse estudo foi possível concluir que a técnica fisioterapêutica foi capaz de gerar redução da dor na maioria dos casos analisados, consequentemente agindo de forma eficiente na melhoria da qualidade de vida dos pacientes.

Palavras-chave: Fisioterapia. Hidroterapia. Dor.

Área Temática: Áreas afins. 


\title{
CONTRIBUIÇÃO DA EQUOTERAPIA ENQUANTO INTERVENÇÃO TERAPÊUTICA EM PACIENTES COM SÍNDROME DE DOWN: UMA REVISÃO DE LITERATURA.
}

\author{
Bruna Maiara de Brito Tavares ${ }^{1}$, Pedro Jonathan Sousa Araujo². \\ ${ }^{1,2}$ Graduação em Fisioterapia pela Universidade Federal do Delta do Parnaíba - UFDPar
}

Introdução: a Síndrome de Down (SD) é uma das alterações cromossômicas mais conhecidas, caracterizada como trissomia do cromossomo 21, podendo ser detectada durante a gravidez. É uma anomalia identificada por vários déficits, tanto físicos quanto mentais. Entre os tratamentos que podem ser desenvolvidos em busca de uma evolução no quadro dos pacientes está a equoterapia, que utiliza cavalo como forma de ganhos físicos, psicológicos ou emocionais, pois os estímulos provocados pelos movimentos do animal vão envolver coordenação motora, flexibilidade, respiração, equilíbrio, autoconfiança e outros. Objetivo: analisar a contribuição da equoterapia em pacientes com Síndrome de Down. Metodologia: o estudo trata-se de uma revisão de literatura, executado a partir de bases de dados Google Scholar, Scielo e LILACS. Foram selecionados 10 artigos com publicações entre 2006 a 2021, estando em língua portuguesa e inglesa na íntegra. Resultados: observou -se que houve contribuição por parte da equoterapia tanto para o alinhamento biomecânico, equilíbrio estático, lateralidade, força, velocidade e fortalecimento muscular. O padrão da marcha de indivíduos com SD que praticam equoterapia se aproxima do normal, uma vez que proporciona alterações consideráveis nas variáveis angulares do tornozelo e joelho. Foi possível perceber, que os resultados com a equoterapia foram mais rápidos do que com a fisioterapia convencional. Em um estudo observacional longitudinal, que tinha objetivo analisar postura antes e após o uso da equoterapia, mostrou através da fotogrametria mudanças satisfatórias no comportamento motor, sugerindo melhora nos ajustes posturais de pacientes com SD. O movimento tridimensional do cavalo, junto aos pés afastados do estribo e cobertor, gerou incitamentos que promoveram ativação muscular de membros inferiores. Conclusão: diante do exposto, a equoterapia participa da reabilitação trazendo crescimento, desenvolvimento e melhora das alterações neurofisiológicas e motoras, afinal de contas é um agente terapêutico capaz de transformar uma atividade de montaria em benefícios.

Palavras-chave: Estimulação. Desenvolvimento Motor. Reabilitação.

Área Temática: Áreas afins. 


\title{
A ATUAÇÃO DO PSICÓlOGO NAS POLÍTICAS PÚBLICAS DE ÁLCOOL E OUTRAS DROGAS
}

\section{Hanna Helena Gadelha de Souza Othon' ${ }^{1}$, Fernanda Emanuely Oliveira Alves da Silva ${ }^{2}$}

\author{
${ }^{1,2}$ Universidade Estadual do Ceará
}

Introdução: o presente trabalho se baseará na cartilha "Referências Técnicas para Atuação de Psicólogas(os) em Políticas Públicas de Álcool e outras drogas”. Objetivo: suscitar a reflexão para questões sociais, éticas e políticas que envolvem a atuação do psicólogo na área das políticas públicas de álcool e outras drogas. Metodologia: o presente artigo possui caráter qualitativo, visto que irá analisar aspectos difíceis de serem mensurados e quantificados. Resultados: Apesar de o psicólogo, em sua maioria, durante a graduação ser preparado para utilizar-se do modelo clássico da clínica, nesse contexto de atuação torna-se necessário o profissional ter uma visão mais abrangente, considerando as diversidades sociais, econômicas e culturais do público que ele irá atender e se comprometendo a realizar práticas diversificadas e humanizadas que vão para além de um diagnóstico. a cartilha aborda ainda os desafios para os psicólogos em manterem práticas que visem a emancipação do sujeito. Dentro disso, duas grandes problemáticas se relacionam: a sociedade atribuir ao sujeito e à família as causas e as responsabilidades por situações históricas e coletivas, gerando uma dupla penalização e uma intensificação do sofrimento psíquico e a dificuldade em se delimitar o que é normal e patológico. Esses pontos se relacionam, uma vez que, o profissional da psicologia deve buscar não classificar ou simplesmente reduzir a uma condição patológica o indivíduo. Isso é bastante importante, visto que o usuário de drogas, principalmente ilícitas, no Brasil é estigmatizado, marginalizado e criminalizado. Conclusão: foi percebida a importância do olhar crítico dos psicólogos atuantes nas políticas públicas de álcool e outras drogas para que seja possível atenuar os reflexos advindos do rompimento do sujeito com os seus direitos, e criticar duramente a falta de apoio governamental, em que muitas vezes mais atrapalham por insistirem em discursos higienizadores.

Palavras-chave: Psicologia. Sofrimento psíquico. Atuação.

Área Temática: Saúde coletiva. 


\title{
A IMPORTÂNCIA DO PROFISSIONAL DE ENFERMAGEM NO ACOLHIMENTO HUMANIZADO ÀS VÍTIMAS DE VIOLÊNCIA SEXUAL
}

\section{Jose Marloanne Marlon de Oliveira Costa ${ }^{1}$, Larissa Linhares Nogueira ${ }^{2}$, Salyne Olga Abreu $\operatorname{Reis}^{2}$}

\author{
${ }^{1}$ Universidade Nilton Lins, ${ }^{2}$ Centro Universitário Fametro
}

DOI: $10.47094 /$ ICONRES.2021/6

Introdução: A temática da violência sexual repercute em toda a sociedade. Destaca-se a importância das ações de prevenção e combate ao crime, que se constitui em uma das principais transgressões dos direitos humanos. Trata-se de uma ofensa direta a integridade física, psicológica, moral e sexual. Ademais, a violência sexual é um crime que atinge vítimas de diferentes faixas etárias, classes sociais e etnias. Nesse sentido, a intervenção dos profissionais de enfermagem é imprescindível para o acompanhamento, tratamento e reabilitação dos danos à saúde, compreendendo a complexidade do problema com respeito e confidencialidade, preservando a dignidade da vítima, ouvindo-a com atenção para fortalecer a confiança no atendimento profissional. Objetivo: Descrever a importância do profissional de enfermagem na assistência às vítimas de violência sexual. Metodologia: Tratase de uma revisão de literatura,e o levantamento de dados foi realizado nas bases de periódicos da SCIELO (Scientific Eletronic Library Online) e o BIREME (Centro Latino-Americano e do Caribe de Informação em ciências da Saúde). Resultados: Aponta-se a necessidade de qualificação do profissional de enfermagem no que tange ao acolhimento humanizado às vítimas de violência sexual. Baseando-se em técnicas de diálogos para obtenção de confiança para promover um atendimento adequado, a fim de reduzir os efeitos ocasionados pela violência. Observando os devidos protocolos para que a vítima sinta-se segura no atendimento prestado. Conclusão: Tendo em vista o exposto, compreende-se que o acolhimento realizado pelo profissional de enfermagem transcende as habilidades técnicas ao humanizar o atendimento. Dessa forma, entende-se que o "cuidar" abrange um contexto emocional, humanitário e solidário.

Palavras-chave: Violência Sexual. Enfermagem. Humanização.

Área Temática: Áreas afins. 


\title{
O LUTO VIVENCIADO POR ADOLESCENTES DE PERIFERIA NO CONTEXTO PANDÊMICO DE COVID-19
}

\section{Hanna Helena Gadelha de Souza Othon ${ }^{1}$, Fernanda Emanuely Oliveira Alves da Silva²}

\author{
${ }^{1,2}$ Universidade Estadual do Ceará
}

Introdução: Puberdade, ações inconsequentes e rebeldia são algumas das características que costumam ser associadas aos adolescentes. No entanto, para que um indivíduo se identifique como criança, adolescente, adulto ou idoso, existem diversos aspectos e características que precisam ser avaliadas. Algumas delas são independência financeira, grupos aos quais a pessoa se identifica, e a maturidade emocional. E isso tudo está englobado nos parâmetros biopsicossociais que devem ser analisados para que haja uma compreensão acerca do que é a adolescência e como ela pode ser vivenciada. Até mesmo a puberdade, que é um período relacionado intrinsecamente a aspectos biológicos da fase da adolescência, e não é exclusivo dela, podendo ocorrer precoce ou tardiamente. Sendo assim, percebe-se que cada adolescente vivencia essa etapa da vida de modo diferente. Objetivo: compreender as implicações da pandemia na saúde mental de adolescentes. Metodologia: o presente artigo possui caráter qualitativo, visto que irá analisar aspectos difíceis de serem mensurados e quantificados. Resultados: em relação ao luto no período da adolescência, entende-se que, apesar do adolescente compreender o que é a morte, que ela é irreversível e inevitavelmente estará presente em sua vida, ele prefere ignorar essas questões. Ele possui dificuldade para pensar na possibilidade de perder pessoas próximas, chegando a não perceber sua morte como possível, provavelmente pelos sentimentos de imortalidade e onipotência geralmente presentes nessa fase. Por esse motivo, frustração, raiva e sofrimento podem surgir de modo mais intenso quando situações de morte e luto se mostram presentes em sua vida. E com a pandemia do coronavírus, é inevitável que essas sensações não perpassem a maior parte dos indivíduos, inclusive adolescentes. Conclusão: Assim, o sentimento de invulnerabilidade que o adolescente possui e a dificuldade que ele tem em pensar na morte são características que agravam as reações de desespero, desorientação e dor diante de uma perda.

Palavras-chave: Adolescência. Morte. Saúde mental.

Área Temática: Áreas afins. 


\section{A INSERÇÃO DE MEDIDAS PREVENTIVAS EM TEMPO DE PANDEMIA}

\section{Kallyne dos Santos ${ }^{1}$, Débora Pintro Bueno ${ }^{1}$}

${ }^{1}$ Estudantes de Enfermagem, CIES, Campo Mourão, Paraná.

INTRODUÇÃO: O mundo está lutando contra a doença COVID-19, causada pelo coronavírus, denominado SARS-CoV-2. Esse vírus teve surgimento na China, rapidamente se alastrou pelo mundo inteiro, onde em março de 2020, a Organização Mundial de Saúde (OMS), anunciou o coronavírus como uma pandemia global. Mudanças e adequações foram necessárias frente a essa nova realidade para controle e disseminação do vírus. OBJETIVO: Esclarecer a importância de adotar as medidas preventivas. METODOLOGIA:Trata-se de uma revisão integrativa a base de dados utilizada foi a Biblioteca Mundial de Saúde (BVS). Utilizando os descritores "Prevenção de Doenças" and "Coronavírus", foram exibidos 80 artigos, sendo que 6 desses artigos, foram selecionados para a construção deste resumo. RESULTADOS: Rapidamente os meios tecnológicos foram auxiliando para a passagem das informações, boletins epidemiológicos, entrevistas coletivas, contam com informações atualizadas todos os dias para transparência, agilidade de comunicação da situação epidemiológica. A utilização de máscaras, higienização das mãos com água e sabão e/ou álcool 70\%, isolamento social, o não compartilhamento de objetos pessoais têm sido informações claras para a população. A reabertura e funcionamento dos comércios, contam com apoio e assistência efetiva da saúde de cada município, como educação em saúde e fiscalização presente, além de ajudar os comerciantes a passar as informações para a população, para que entendam a importância das medidas preventivas. CONSIDERAÇÕES FINAIS: O presente estudo mostrou a importância do cumprimento dos decretos municipais, recomendações da OMS, orientações das autoridades sanitárias, isolamento social, medidas preventivas, etc. A conscientização parte de um princípio de toda uma coletividade e não apenas individual, o bom senso e a solidariedade que determinará qual será o impacto que o COVID-19 terá sobre a saúde e a economia brasileira.

Palavras-chave: Contaminação. Conscientização. Prevenção.

Área Temática: Saúde Pública. 


\title{
O IMPACTO DA INICIAÇÃO CIENTÍFICA E SUA CONTRIBUIÇÃO PARA O GRADUANDO EM ENFERMAGEM: RELATO DE EXPERIÊNCIA
}

\author{
Aline Francisca Gomes de Brito ${ }^{1}$ \\ ${ }^{1}$ Universidade do Estado do Amazonas
}

Introdução: Criado em 1951, o Conselho Nacional de Desenvolvimento Científico e Tecnológico $(\mathrm{CNPq})$, institucionalizou as ações de incentivo e apoio à pesquisa, reconhecendo a importância estratégica da ciência. A Iniciação Científica (IC), instrumento presente em diversas instituições de ensino superior, permite incluir acadêmicos no ambiente de pesquisa, incentivando o interesse pela produção científica. Através da participação nos programas de IC, o discente do curso de Enfermagem é estimulado a desenvolver projetos com criatividade, a fim de contribuir com a produção científica com responsabilidade e senso crítico, sendo acompanhado nesse universo por professores-orientadores. Objetivo: Relatar a experiência de uma acadêmica do curso de enfermagem durante sua participação em um projeto de iniciação científica desenvolvido em uma universidade pública estadual, enfatizando as contribuições da vivência para a formação do enfermeiro. Metodologia: Estudo descritivo, do tipo relato de experiência. O desenvolvimento do projeto e a vivência na iniciação científica perduraram pelo período de 1 ano, sendo realizadas coleta de dados em Unidades Básicas de Saúde (UBS) do município de Manaus, no Amazonas, e as demais etapas na própria universidade. Resultados: A IC oportunizou a aplicação de conhecimentos técnico-científicos no campo da ética, da metodologia do trabalho científico e da pesquisa em saúde. Através da participação no programa houve o contato direto com a atividade científica pela primeira vez, sendo, portanto, um divisor de águas, proporcionando a formação de uma nova mentalidade. Considerações finais: A experiência adquirida despertou o interesse pela pesquisa e trouxe reflexões acerca do papel do enfermeiro para além da assistência, docência ou gestão e a relevância do seu papel como pesquisador, contribuindo para a comunidade científica.

Palavras-chave: Atividades Científicas e Tecnológicas. Pesquisa. Ensino Superior.

Área temática: Áreas afins 


\title{
A INFLUÊNCIA DA ESPIRITUALIDADE NO ENFRENTAMENTO DE TRATAMENTOS ONCOLÓGICOS
}

\section{Larissa Linhares Nogueira}

\author{
Centro Universitário Fametro
}

Introdução: Espiritualidade pode ser definida de várias formas, sendo uma delas a busca pessoal de respostas sobre o significado da vida, que pode ou não levar ao desenvolvimento de práticas religiosas. O tratamento de neoplasias malignas (câncer) pode ser desafiador, visto que o paciente enfrenta muitas fases e estigmas relacionados ao tratamento e à doença, o que pode suscitar questionamentos acerca da importância da espiritualidade durante o tratamento oncológico. Objetivo: Descrever a influência da espiritualidade no tratamento oncológico. Metodologia: Revisão Integrativa da Literatura, através de busca de artigos na base de dados PubMed, publicados entre os anos de 2016 e 2021, com as palavras-chave "spirituality", "palliative cancer", "therapies", "cancer treatment" e o conectivo “AND”, na língua portuguesa. Resultados: Após inserção de palavras-chave e seleção de artigos, a pesquisa apontou vinte artigos, e destes quatro respondiam ao objetivo da pesquisa. Observa-se que a espiritualidade torna-se ainda mais forte em momentos difíceis, o que permite ao paciente manter-se firme e buscar conforto em suas crenças. Estudos apontam que a espiritualidade é uma forte aliada no que concerne à qualidade de vida do paciente oncológico, que deve ser compreendido em sua totalidade. As análises evidenciam que os pacientes que praticam sua espiritualidade demonstramse mais seguros, maduros, confiantes e otimistas em relação ao tratamento oncológico. Ainda segundo as pesquisas, indicam que a espiritualidade melhora a imunidade e a resposta ao tratamento. Conclusões: Levando-se em consideração esses aspectos, percebe-se que independente dos pacientes serem praticantes ou não de alguma religião, veem a espiritualidade como algo positivo no tratamento, visto que ela faz parte da integralidade do ser humano. Avalia-se que a espiritualidade possui grande influência na recuperação, reestruturação no estilo de vida e, até mesmo, no processo de luto dos familiares no caso de morte do paciente.

Palavras-chave: Câncer. Crença. Religião.

Área temática: Áreas afins. 


\title{
MISTANÁSIA X CRISE DE OXIGÊNIO EM MANAUS: UMA REVISÃO DE LITERATURA
}

\author{
Karina Macedo Gomes ${ }^{1}$
}

Universidade do Estado do Amazonas ${ }^{1}$

Introdução: Em 1989 foi proposto o termo "mistanásia", que se refere a uma morte evitável. No contexto da saúde, entende-se que estas mortes ocorrem principalmente em decorrência da má gestão de recursos. Nos dias 14 e 15 do mês de janeiro de 2021, cerca de 30 pessoas morreram em decorrência da falta de oxigênio hospitalar na cidade de Manaus, Amazonas segundo dados do Ministério Público. Por conta disso, este trabalho buscou responder se há relação entre o conceito de mistanásia e a situação ocorrida na capital amazonense. Objetivo: Apresentar uma revisão de literatura integrativa expondo a relação entre a crise de oxigênio no Amazonas aos conceitos relacionados à mistanásia. Metodologia: Foi feita uma revisão integrativa de literatura com base em 3 artigos principais. A coleta de dados deu-se a partir da busca dos termos "Mistanásia", "Covid-19" e "Amazonas" nas bases de dados LILACS e MEDLINE. Foram incluídos somente artigos publicados em português relacionados ao tema nos últimos seis anos. Resultados: A literatura nos mostra que a mistanásia é a morte em decorrência das falhas nos três níveis de governo, principalmente na falta de infraestrutura. Assim, as mortes são proporcionais à precarização do financiamento da saúde por meio da má gestão de orçamento, serviços e unidades de saúde. Apesar disso, as equipes de saúde prestam atendimento mesmo expostas às doenças e carentes de estrutura adequada. Com base nisso, as mortes ocorridas no Amazonas durante a segunda onda de Covid-19 em meio à crise de abastecimento de oxigênio se adequam ao conceito de mistanásia. Considerações Finais: A falta de oxigênio hospitalar em Manaus se originou na falta de planejamento por parte dos governantes. Logo, as mortes ocorridas na crise poderiam ter sido evitadas se houvesse uma melhor gestão prévia de recursos. Portanto, enquadram-se como mistanásia.

Palavras-Chave: Covid-19. Saúde Pública. Gestão em Saúde.

Área Temática: Áreas Afins 


\title{
ASPECTOS FISIOPATOLÓGICOS DA SÍNDROME DO INTESTINO IRRITÁVEL E OS FATORES PSICOSSOCIAIS NA FORMAÇÃO DA DOENÇA
}

\author{
${ }^{1}$ Aylce Lima Soares (FACESF), Gabriela Cristina da Silva Pereira Lopes (FACESF), Lara \\ Karoline da Silva Lopes (FACESF), Maíra Cristina de Souza (FACESF) e ${ }^{2}$ Raul Sousa \\ Andreza (Docente - FACESF)
}

Faculdade de Ciências Humanas e Exatas do Sertão do São Francisco (FACESF)

Introdução: A Síndrome do Intestino Irritável (SII) é um distúrbio funcional comum do trato gastrointestinal, apesar dos aspectos fisiopatológicos e fatores psicossociais que interferem na formação da doença serem pouco compreendidos. Objetivo: Descrever estudos teóricos sobre este distúrbio, com enfoque na fisiopatologia e na análise de como os fatores psicossociais intervêm no desenvolvimento desta. Metodologia: Trata-se de uma revisão da literatura de artigos científicos publicados no Scientific Electronic Library Online (Scielo) e na Revista Eletrônica Acervo Saúde. Fez-se a pesquisa comparando os pontos em comuns levantados nos artigos estudados, sendo esta desenvolvida durante os seminários da disciplina de Fisiologia Humana, do curso de Fisioterapia. Resultados parciais: Certificou-se de que entre os artigos estudados todos relatam a dificuldade que existe em compreender os aspectos fisiopatológicos da doença, acreditando-se que é de causa multifatorial, relacionada principalmente com alterações no padrão de motilidade gastrointestinal e hipersensibilidade visceral. Quanto a interferência dos fatores psicossociais, os estudos existentes são mais escassos, no entanto, os artigos usados como referência mostram fortemente que os fatores psicossociais (como a ansiedade e certas razões sociais aos quais estamos expostos - dificuldades no trabalho, na vida pessoal e entre outros), podem interferir na formação da síndrome ou no mínimo, ser um agravante para esta. Os artigos explanam as alterações que tais fatores podem desencadear no trato gastrointestinal, mostrando que o sistema nervoso central coordena nossas atividades corporais, bem como as atividades motoras, sensoriais e autonômicas do trato gastrointestinal. A conexão estabelecida entre ambos permite que a motilidade deste sistema aconteça, assim como permite perceber a sua sensibilidade. Considerações finais: Para melhor compreensão da SII, devese conhecer as abordagens multifatoriais desta, que incluem os distúrbios motores, hipersensibilidade visceral e os fatores psicossociais, pois estes são os responsáveis por modular os sintomas da doença, devendo serem considerados no diagnóstico e tratamento do paciente.

Palavras-chave: Trato gastrointestinal. Hipersensibilidade visceral. Sistema nervoso.

Área Temática: Áreas afins. 


\title{
UTILIZAÇÃO DA METODOLOGIA SALA DE AULA INVERTIDA NO ENSINO REMOTO EM ENFERMAGEM
}

\author{
Amanda Maria Silva da Cunha ${ }^{1}$ \\ ${ }^{1}$ Universidade Federal de Alagoas (UFAL)
}

Introdução: $\mathrm{O}$ advento do ensino remoto como adequação às mudanças decorrentes da pandemia por Covid-19 ocasionou mudanças na forma de desenvolver o ensino em escolas e universidades. A adoção de metodologias ativas apresenta-se como uma estratégia válida para o desenvolvimento da aprendizagem significativa especialmente nesse período. A sala de aula invertida, metodologia ativa também conhecida com flipped classroom, deriva do ensino híbrido, que propõe o desenvolvimento de atividades educacionais síncronas e assíncronas conjuntamente, culminando em uma aprendizagem invertida. Objetivo: relatar a experiência da autora no desenvolvimento da sala de aula invertida como metodologia ativa no ensino remoto em um curso técnico de enfermagem. Metodologia: tratase de um relato de experiência acerca do desenvolvimento da sala de aula invertida no ensino remoto de uma disciplina em um curso técnico de enfermagem de um estado do nordeste brasileiro entre os meses de setembro e dezembro de 2020. Resultados: seguindo-se o desenvolvimento proposto pela metodologia, a facilitadora preparava os materiais antecipadamente na forma de sínteses, fichamentos e mapas mentais disponibilizando-os aos estudantes por meio eletrônico, estes dispunham de um período mínimo de três dias para a leitura dos mesmos, sendo estimulada ainda a busca individual de materiais que estendessem o entendimento sobre os temas. Os encontros síncronos, desenvolvidos semanalmente na plataforma Google Meet, eram marcados pela apresentação pelos estudantes do conteúdo aprendido, dúvidas e materiais adicionais encontrados. Realizava-se a consolidação do aprendizado através da participação em jogos eletrônicos construídos na plataforma Kahoot!, o que estimulava ainda a revisão dos conteúdos pelos estudantes. Considerações finais: a metodologia apresentou-se de fácil desenvolvimento, tendo proporcionado uma aprendizagem prazerosa. Os resultados das avaliações formativas demonstraram que os estudantes conseguiram apreender os conteúdos trabalhados.

Palavras-chave: Educação em Enfermagem. Metodologia. Educação a Distância.

Área Temática: Áreas afins 


\title{
A IMPORTÂNCIA DA ASSISTÊNCIA ODONTOLÓGICA PARA PACIENTES A SEREM TRATADOS COM BISFOSFONATOS
}

\author{
Gabriel Luiz Linn', Valeria Juliana Jandrey¹, Natasha Magro Érnica1
}

${ }^{1}$ Universidade Estadual do Oeste do Paraná - UNIOESTE

Introdução: Os bisfosfonatos são fármacos amplamente utilizados no tratamento de neoplasias malignas metastáticas, osteoporose e diversas outras doenças, podendo ser administrados tanto por via oral quanto intravenosa. Esses medicamentos, quando usados por um longo período, podem promover o desenvolvimento da osteonecrose medicamentosa dos maxilares (OMM), cuja faixa etária de maior acometimento é a sétima década de vida. A discussão multiprofissional sobre o uso dos bisfosfonatos é de extrema importância, visto que a chance do desenvolvimento de OMM em pacientes que fazem o uso dessa droga por via intravenosa, quando submetidos à cirurgia dentoalveolar, aumenta no mínimo sete vezes. Objetivo: Salientar a importância do manejo multiprofissional de pacientes a serem tratados com bisfosfonatos. Metodologia: O presente levantamento bibliográfico foi realizado por meio da coleta de dados em artigos científicos relevantes encontrados na BIREME, publicados entre os anos de 2010 e 2020, que abordavam OMM causada por bisfosfonatos. Resultados: De acordo com a revisão de literatura realizada, a execução de procedimentos odontológicos invasivos em pacientes que fazem o uso dos bisfosfonatos é tida como fator de risco para o desenvolvimento da OMM. A prevenção dessa doença se dá por meio de condutas multiprofissionais, onde o cirurgiãodentista executa procedimentos preventivos e curativos antes do emprego da medicação, como também realiza o acompanhamento do paciente durante a terapêutica, de forma a proporcionar um meio bucal saudável que evite a necessidade futura de procedimentos invasivos. Conclusões: Diante do exposto, torna-se evidente a importância da atuação Cirurgião-Dentista no manejo de pacientes que fazem ou farão o uso de bisfosfonatos, procurando evitar o desenvolvimento da OMM e, consequentemente, possibilitar uma melhor qualidade de vida a esses indivíduos.

Palavras-chave: Osteonecrose medicamentosa dos maxilares. Prevenção. Cirurgião-Dentista.

Área Temática: Áreas afins 


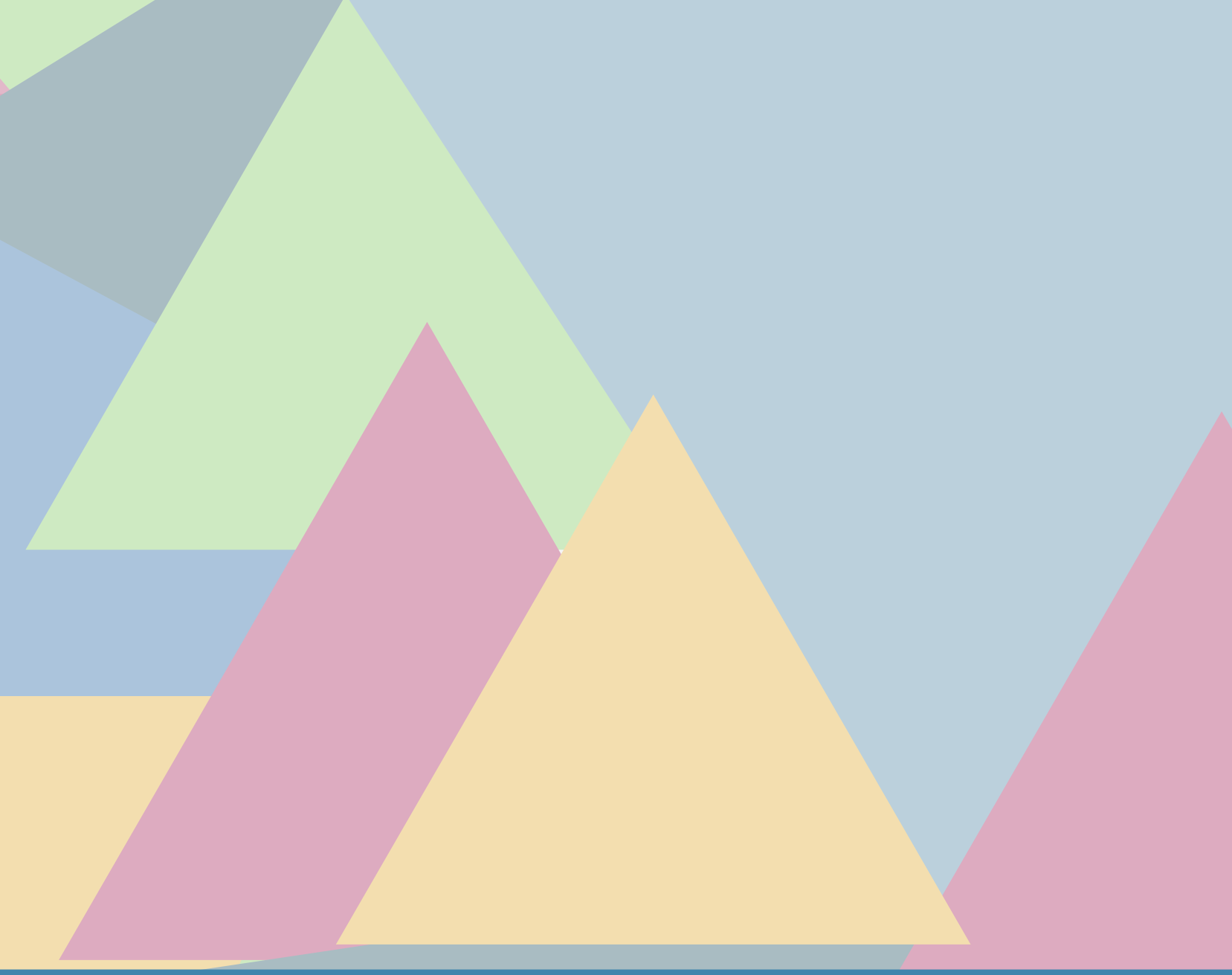

Atenção à Saúde 


\title{
DISPOSITIVO INTRAUTERINO (DIU): FATORES QUE DIFICULTAM A INSERÇÃO E DISPONIBILIZAÇÃO NA REDE DE ATENÇÃ̃ À SAÚDE DA MULHER
}

\author{
Sara Mille Souza Silva ${ }^{1}$, Marta Bezerra dos Santos ${ }^{2}$, Lucas Reis Angst ${ }^{3}$, Adriana Marinho \\ Pereira Dapont ${ }^{4}$, Siglia Sousa de França ${ }^{5}$ \\ ${ }^{1}$ Acadêmica de Medicina, Universidade Federal do Acre (UFAC), Rio Branco, Acre. \\ ${ }^{2}$ Acadêmica de Medicina, Universidade Federal do Acre (UFAC), Rio Branco, Acre. \\ ${ }^{3}$ Acadêmico de Medicina, Universidade Federal do Acre (UFAC), Rio Branco, Acre. \\ ${ }^{4}$ Especialista, docente da Universidade Federal do Acre (UFAC), Rio Branco, Acre. \\ ${ }^{5}$ Mestre, docente da Universidade Federal do Acre (UFAC), Rio Branco, Acre.
}

\section{RESUMO}

Esse estudo teve como objetivo realizar uma revisão da literatura sobre fatores que dificultam a inserção do dispositivo intrauterino em mulheres assistidas pelos serviços saúde. A coleta dos dados desta revisão foi realizada nos meses de novembro e dezembro de 2020 e os descritores aplicados foram "dispositivo intrauterino" e "métodos contraceptivos". Para as pesquisas, utilizouse as seguintes bases de dados: LILACS, SCIELO e PUBMED. Após o levantamento, obteve-se 78 artigos, deste total apenas 31 obedeciam aos critérios da pesquisa. Os estudos indicam que a falta de informação ou atualização acerca do DIU por parte das pacientes e dos profissionais de saúde é um dos fatores que dificultam e se mostram como barreiras à disponibilização do método. Além disso, questões envolvendo a organização do atendimento e uso de critérios dispensáveis para a inserção do método se tornam obstáculo para o acesso ao DIU, levando muitas pacientes a optarem por outros contraceptivos.

PALAVRAS-CHAVES: Métodos contraceptivos; Planejamento familiar; Liberdade reprodutiva. ÁREA TEMÁTICA: Atenção à Saúde.

\section{INTRODUÇÃO}

Na Pesquisa Nacional de Demografia e Saúde da Criança e da Mulher (PNDS), realizada no ano de 2006, 65,2\% da população de mulheres em idade fértil indicou que utilizavam métodos contraceptivos modernos à época (uso atual). Sobressaíram-se, às respostas, as seguintes prevalências: 22,1\% em relação aos contraceptivos orais, $21,8 \%$ da esterilização feminina, o preservativo masculino indicou $12,9 \%$, a injeção contraceptiva teve $3,5 \%$ e percentual de 3,3 em relação à esterilização masculina ao passo que o dispositivo intrauterino teve prevalência de apenas $1,5 \%$ no ano em questão. 
Conforme Kaneshiro (2010), apesar da subutilização do DIU no panorama brasileiro, tratase do anticoncepcional reversível mais utilizado globalmente. De acordo com Lubianca (2016) e Bahamondes (2014), se trata de um método seguro, devido à alta eficácia - próxima de 99\% -, que não contém hormônios e não prejudicial à fertilidade futura da usuária, além de apresentar reconhecidos benefícios à saúde reprodutiva, uma vez que atua na diminuição da morbidade materna, da mortalidade materna e infantil.

As inúmeras vantagens envolvendo o método, como alta eficácia, grande aceitação por parte das usuárias e taxas elevadas de continuidade no uso, vão de encontro com o cenário de subutilização do DIU entre as mulheres brasileiras, embora ser um método disponível junto ao Sistema Único de Saúde. Segundo Borges (2020), esse panorama é um reflexo de desafios que envolvem a efetiva disponibilização e inserção do método contraceptivo. Assim, traduz-se, enquanto objetivo da pesquisa, identificar fatores que dificultam a inserção e disponibilização do dispositivo intrauterino em mulheres assistidas pelos serviços de saúde.

\section{METODOLOGIA}

A presente pesquisa se trata de uma revisão da literatura, de caráter analítico, acerca dos fatores que dificultam a inserção e disponibilização do dispositivo intrauterino em mulheres assistidas pelos serviços de saúde. No que diz respeito à coleta de dados, foi realizada nos meses de novembro e dezembro de 2020, e os descritores aplicados foram "dispositivo intrauterino" e "métodos contraceptivos". Para as pesquisas, utilizou-se as seguintes bases de dados: Literatura Latino-Americana e do Caribe em Ciências da Saúde (LILACS), Scientific Eletrônic Library Online (SCIELO) e National Library of Medicine (PUBMED).

Para tanto, adotou-se, como critérios de inclusão, a publicações no período de 2009 a 2020, com textos disponíveis de forma integral nas bases de dados pesquisadas. Após o levantamento, obteve-se 78 artigos, deste total apenas 31 obedeciam aos critérios e tinha proximidade com a temática.

Foram definidos de forma prévia os critérios de inclusão, pelos quais se promoveu a seleção dos artigos. Assim, passada a seleção, procedeu-se às etapas, em ordem: leitura de exploração; leitura seletiva com a consequente escolha de materiais que correspondessem ao objetivo e temática deste estudo; leitura analítica exame dos textos para proceder com a realização de leitura interpretativa e, ao final, proceder com a redação.

\section{FUNDAMENTAÇÃO TEÓRICA}

Em primeiro plano, quanto à escolha do método, White (2013) e Michie (2014) indicam que o ideário das mulheres e dos casais é permeado por diversos estigmas e achismos que não correspondem à realidade. De acordo com Potter (2014) e Silva-Filho (2016), destacam-se as crenças de que: o DIU é cancerígeno, causa infertilidade permanente; não é adequado para mulheres jovens e nulíparas ou 
mesmo que o procedimento de inserção é demasiadamente complicado. O que representa falta de intervenções educativas por parte do serviço de saúde e orientação adequada das mulheres, por parte próprios profissionais.

De forma análoga e preocupante, Daniele (2017) afirma que tais concepções também abrangem os profissionais de saúde, enfatizado nos países em desenvolvimento, tal qual o Brasil, onde a falta de informação e conhecimento ou atualização acerca do DIU por parte dos profissionais afeta diretamente a escolha do método pelas pacientes.

Ainda que ultrapassem estas dificuldades e optem pelo método, há questões envolvendo a organização do atendimento, nas palavras de Gonzaga (2016), como a demora nos resultados de exames, o agendamento de consulta com apenas um dia da semana para inserção do dispositivo intrauterino, a falta de profissionais habilitados a inserir o DIU e a oferta inconstante e insuficiente do dispositivo nas unidades de saúde. Dessa maneira, esses fatores organizacionais dificultam sobremaneira o acesso, levando a muitas pacientes desistirem do método e optarem pela pílula ou esterilização.

No mesmo sentido, relata-se o uso de critérios dispensáveis para a disponibilização desta contracepção. A título de exemplo, segundo Heilborn (2009), em Minas Gerais se observou a exigência de exames complementares, como hemograma e ultrassonografia, para inserção do dispositivo, apesar da medida não ser estabelecida nos protocolos propostos pelo Ministério da Saúde.

\section{CONSIDERAÇÕES FINAIS}

Assim, torna-se necessário a constante capacitação dos profissionais de saúde acerca do DIU, visto que uma orientação adequada reflete diretamente na escolha do método por parte das pacientes. Além disso, os serviços de saúde devem investir intervenções educativas destinadas a população, a fim de sanar achismos e estigmas existentes no ideário das mulheres sobre o dispositivo.

Além disso, é fundamental o investimento em políticas públicas que visem cessar o uso de critérios dispensáveis para a inserção do dispositivo intrauterino e as barreiras existentes no atendimento, pois se tornam obstáculo para o acesso ao DIU, levando muitas pacientes a optarem por outros contraceptivos. Dessa maneira, será possível ampliação do acesso ao DIU, com os avanços necessários na área de atenção à saúde da mulher, concretizados com a garantia da liberdade reprodutiva.

\section{PRINCIPAIS REFERÊNCIAS}

DANIELE, Marina AS et al. Provider and lay perspectives on intra-uterine contraception: a global review. Reproductive health, v. 14, n. 1, p. 1-11, 2017.

GONZAGA, Vanderlea Aparecida Silva. Barreiras organizacionais para disponibilização do dispositivo intrauterino nos serviços de Atenção Básica à Saúde (macrorregião Sul de Minas Gerais). 2016. Tese de Mestrado. Universidade de São Paulo.

MINISTÉRIO DA SAÚDE. Pesquisa Nacional de Demografia e Saúde da Criança e da Mulher- 
PNDS 2006: dimensões do processo reprodutivo e da saúde da criança. 2009. 


\title{
A ENFERMAGEM NO MANEJO DA DOR E AS REPERCUSSÕES NA \\ SAÚDE DAS PESSOAS
}

\author{
Fernanda Pimentel de Oliveira ${ }^{1}$; Maria Raquel da Silva Lima² \\ ${ }^{1}$ Mestre em Saúde Coletiva, Universidade de Fortaleza (UNIFOR), Fortaleza, Ceará. \\ ${ }^{2}$ Mestre em Saúde Coletiva, Universidade de Fortaleza (UNIFOR), Fortaleza, Ceará.
}

\begin{abstract}
RESUMO
Introdução: A dor desempenha o papel de alerta, informando ao indivíduo alguma alteração biológica. Objetivo: Compreender a enfermagem no manejo da dor e as repercussões na saúde das pessoas. Metodologia: Revisão integrativa realizada na Biblioteca Virtual de Saúde (BVS), Literatura LatinoAmericana e do Caribe em Ciências da Saúde (LILACS) e Base de Dados em Enfermagem (BDENF). A busca do material realizou-se com o agrupamento dos Descritores em Ciências da Saúde (DeCS) “dor" "avaliação da dor" e "enfermagem". Resultados: Os achados foram agrupados em dois grandes eixos que compilam as evidências de forma a facilitar a sua discussão, os quais são: A avaliação da dor pela equipe de enfermagem; As intervenções e monitoramento para alívio da dor. Considerações finais: O profissional de enfermagem deve identificar as intervenções adequadas para alivio da dor e seus efeitos, contribuindo assim para uma melhor evolução do paciente e humanização da assistência prestada.
\end{abstract}

PALAVRAS-CHAVES: Enfermagem; Dor.

ÁREA TEMÁTICA: Atenção à Saúde

\section{INTRODUÇÃO}

A dor desempenha o papel de alerta, informando ao indivíduo alguma alteração biológica. É um fenômeno multifatorial, onde lesão tecidual, aspectos emocionais, sócioculturais e ambientais a unificam. Manifesta-se em cada indivíduo de forma diferente e única, pois cada um possui uma percepção individual sobre a dor e está associada a fatores físicos e psíquicos . O profissional de enfermagem frente ao manejo de dor deve utilizar-se de métodos de avaliação que orientam o tratamento que colaboram no reconhecimento e intervenção durante o processo de dor ofertando conforto e bem-estar ao paciente assistido. A atuação desse profissional, de modo independente e colaborativo, compreende a identificação de queixa álgica, a caracterização da experiência dolorosa em todos os seus domínios, a aferição das suas repercussões no funcionamento biológico, emocional 
e comportamental do indivíduo (RUVIARO; FILIPPIN et al., 2012). Desta forma, Este estudo teve como objetivo compreender a enfermagem no manejo da dor e as repercussões na saúde das pessoas.

\section{METODOLOGIA}

Para alcançar o objetivo proposto, optou-se pela revisão integrativa. O estudo foi realizado nos meses de dezembro de 2019 à abril de 2020 .O levantamento bibliográfico foi realizado na Biblioteca Virtual de Saúde (BVS) nas bases de dados Literatura Latino-Americana e do Caribe em Ciências da Saúde (LILACS) e Base de Dados em Enfermagem (BDENF). A busca do material realizouse com o agrupamento dos Descritores em Ciências da Saúde (DeCS) "dor" "avaliação da dor" e "enfermagem". Os critérios de inclusão foram artigos disponíveis na integra, em português e inglês, teses, dissertações. Os de exclusão foram artigos repetidos e capítulos de livros. A organização dos dados foi feita por meio da Análise de Conteúdo, que é um conjunto de técnicas de análise que verifica proposições e está relacionada com o tipo de interpretação que se pretende como objetivo, e que será o ponto de partida para a identificação do conteúdo (BARDIN, 2009). A amostra contou com 10 artigos selecionados para discussão organizados em duas categorias para a discussão dos resultados.

\section{FUNDAMENTAÇÃO TEÓRICA}

Para análise, os achados foram agrupados em dois eixos que compilam as evidências de forma a facilitar a sua discussão:

\section{A avaliação da dor pela equipe de enfermagem}

A avaliação é uma etapa essencial para que ocorra o alívio adequado da dor. A avaliação é realizada no início e regularmente ao longo de toda a trajetória do tratamento ou da enfermidade (KAZANOWSKI; LACCETTI 2005). As pesquisas revelam que o enfermeiro ao buscar a avaliação da dor está colocando em prática o princípio da assistência de enfermagem, pois, com isso, possibilitará selecionar as medidas que possam aliviar de maneira adequada o sofrimento do doente, em consequência constatar a eficácia do tratamento (CHAVES, 2004). Na avaliação da dor podem ser usadas escalas unidimensionais ou multidimensionais, porém antes de aplicá-las deve-se analisar se ela está adequada à população em questão. As escalas unidimensionais são aquelas que medem apenas a intensidade da dor, sendo as mais utilizadas a escala numérica verbal de dor (ENV), na qual 0 é a ausência de dor e 10 a dor mais forte imaginável, e a escala visual analógica (EVA). São muitas as escalas multidimensionais que já foram traduzidas e validadas para o português, elas medem e avaliam o efeito da dor no humor e na vida do indivíduo (SBED, 2011). 


\section{As intervenções e monitoramento para alívio da dor}

A dor como $5^{\circ}$ sinal vital gera mudanças em toda equipe multidisciplinar, bem como na própria organização de saúde, exigindo a elaboração de protocolos de avaliação e manejo da dor crônica e aguda, como também na educação e treinamento contínuo para modificar comportamentos e práticas arraigadas dos profissionais (DICCINI,2004; MENDONÇA; LEÃO,2007). O uso sistematizado de instrumento de mensuração e registro da dor promove a consciência no profissional que presta cuidados ao paciente com dor, além de contribuir para o aperfeiçoamento da assistência de enfermagem (DAVIS; WALSH, 2004).

\section{CONSIDERAÇÕES FINAIS}

É essencial o conhecimento da dor como $5^{\circ}$ sinal vital no manejo do atendimento de profissionais de enfermagem a pacientes acometidos por algum agravo, dano ou doença, em decorrência de inúmeros fatores a ele associados, predispondo aos mais diversos quadros de alterações, sejam elas psicológicas, biológicas, emocionais entre outras. O profissional de enfermagem deve identificar as intervenções adequadas para alivio da dor e seus efeitos, contribuindo assim para uma melhor evolução do paciente e humanização da assistência prestada.

\section{PRINCIPAIS REFERÊNCIAS}

CHAVES, L. D. O enfermeiro no manejo da dor do câncer. Prát Hosp, v. 6, n. 35, 2004.

DAVIS, M.P.; WALSH, D. Cancer pain: how to measure the fifth vital sign. Cleveland Clinic journal of medicine, v. 71, n. 8, p. 625-632, 2004.

DICCINI S. Dor como o 5º sinal vital. Acta Paul Enferm. v. 17, n.1, 2004.

KAZANOWSKI, M.K.; LACCETTI, M.S. Intervenções para alívio da dor. In: Dor:

Fundamentos, abordagem clínica e tratamento. Rio de Janeiro: Guanabara Koogan, 2005.

RIBEIRO, M.A.S.; LOPES, M.H.B.M. Development, implementation and evaluation of a distance course about wound treatment. Revista latino-americana de enfermagem, v. 14, n. 1, p. 77-84, 2006.

RUVIARO, L. F.; FILIPPIN, L. I. Prevalência de dor crônica em uma Unidade Básica de Saúde de cidade de médio porte. Revista Dor, v. 13, n. 2, p. 128-131, 2012.

SOCIEDADE BRASILEIRA PARA O ESTUDO DA DOR (SBED). II Consenso Nacional de Dor Oncológica. São Paulo: Grupo Editorial Moreira Jr.; 2011. 


\title{
A IMPORTÂNCIA DOS PROBIÓTICOS E PREBIÓTICOS NA PROMOÇÃO DA SAÚDE INTESTINAL
}

\author{
Fernanda Pimentel de Oliveira ${ }^{1}$; Maria Raquel da Silva Lima ${ }^{2}$ \\ ${ }^{1}$ Mestre em Saúde Coletiva, Universidade de Fortaleza (UNIFOR), Fortaleza, Ceará. \\ ${ }^{2}$ Mestre em Saúde Coletiva, Universidade de Fortaleza (UNIFOR), Fortaleza, Ceará.
}

\begin{abstract}
RESUMO
Introdução: Para um bom funcionamento intestinal, os alimentos funcionais exercem papéis fundamentais na regulação da microbiota. Objetivo: Relatar a importância dos probióticos e prebioóticos na promoção da saúde in testinal. Metodologia: Revisão integrativa realizada nos meses de setembro à dezembro. O levantamento bibliográfico foi realizado na Scielo (Scientific Electronic Library on line) e Medline (Medical Literature Analysis and Retrieval System Online). A busca do material realizou-se com o agrupamento dos Descritores em Ciências da Saúde (DeCS) "disbiose"; "probióticos"; "prebióticos" "alimento funcional". Resultados: Os achados foram agrupados em dois eixos que compilam as evidências, de forma a facilitar a sua discussão: Benefícios; Probióticos e Prebióticos como agentes promotores de saúde. Considerações finais: Os prebióticos e os probióticos podem ser incorporados tanto na alimentação infantil quanto na adulta com diversos benefícios à saúde, promovendo a modulação e reestruturação da função intestinal.
\end{abstract}

PALAVRAS-CHAVES: Probiótico; Prebiótico; Intestino.

ÁREA TEMÁTICA: Atenção à saúde.

\section{INTRODUÇÃO}

Para um bom funcionamento intestinal, os alimentos funcionais exercem papéis fundamentais na regulação da microbiota. Alimentos funcionais são aqueles que trazem benefícios fisiológicos, com funções nutricionais e redução de risco em alguns tipos de doenças crônicas (NEUZA; CARLA, 2016). Entre eles estão os probióticos e prebióticos. Os probióticos auxiliam no restabelecimento do equilíbrio da microbiota intestinal e reforçam a estabilidade da barreira intestinal, prevenindo agravos (VARANKOVICH et al., 2015). Os prebióticos são ingredientes alimentares que são capazes de inibir a multiplicação de patógenos, atuando no intestino grosso em sua maioria, após fermentação, promove mudanças na composição e/ou atividade de bactérias gastrointestinais, alterando a microbiota, conferindo benefícios à saúde do hospedeiro. Alguns exemplos de prébioticos são: galacto- 
oligossacarídeos, xilo-oligossacarídeos, fruto-oligossacarídeo, inulina, fosfo-oligossacarídeos, isomalto-oligossacarídeos, lactulose e pectina (RAMIREZ, 2017).

\section{METODOLOGIA}

Estudo de revisão integrativa, realizada nos meses de Setembro à Dezembro de 2020. O banco de dados consultados para busca ativa de publicações de 2006 e 2019, foram as bibliotecas eletrônicas Scielo (Scientific Electronic Library on line) e Medline (Medical Literature Analysis and Retrieval System Online), utilizando os seguintes descritores: "disbiose "; "probióticos"; "alimento funcional". Os critérios de inclusão foram artigos disponíveis na integra em português, inglês e espanhol, monografias, dissertações, editoriais, guidelines e capítulos de livros. Os de exclusão foram artigos repetidos e incompletos na plataforma online. Foram selecionados 25 artigos nas bases, porém a amostra para desenvolvimento da temática contou com 15 artigos para discussão e apresentação dos resultados em duas categorias de análise. Os artigos selecionados foram apresentados em um quadro construído pelos autores constando de título, autor(es), ano, metodologia e objetivo.

\section{FUNDAMENTAÇÃO TEÓRICA}

Foram desenvolvidas duas categorias de análise, no intuito de abordar eixos mais importantes contemplados na literatura e melhor compreensão do estudo: Beneffícios; Probióticos e prebióticos como agentes promotores de saúde.

\section{Benefícios}

Os probióticos são caracterizados e indicados para preservar e reestabelecer a homeostase do intestino. A ação dos probióticos sobre o trato gastrointestinal (TGI) inclui fatores como efeitos antagônicos, competição e efeitos imunológicos. São utilizadas em sua maioria bactérias ácidoláticas e bifidobactérias, podendo ser úteis também certos fungos e leveduras, principalmente a Saccharomyces boulardii (SAAD, 2006; CARLET, 2012). Uma fórmula adicionada de probióticos representa a estratégia principal para reduzir a incidência de diarreia em lactentes, esta informação é baseada no fato de que no aleitamento materno, especialmente o aleitamento materno exclusivo e de longa duração, demonstrou-se muito eficiente para a proteção de doenças infecciosas como a gastroenterite (VANDENPLAS et al., 2013, apud, CHASSARD, et al., 2014). Os prébioticos podem ser consumidos em fibras dietéticas, outros açucares não absorvíveis, álcoois do açúcar e oligossacarídeos, que são encontrados em vários alimentos como frutas, vegetais, leite e mel (SANTOS; RICCI, 2016). Prebióticos como galactooligossacarídeos e fibras de milho solúveis têm sido utilizados para a fermentação seletiva pela microbiota intestinal humana, aumentando notavelmente Bifidobacterium e diminuindo C. histolyticum, com um benefício global positivo para a saúde humana (Foo et al., 2017). 


\section{Probióticos e prebióticos como agentes promotores de saúde}

A promoção da saúde pode ser influenciada pela utilização de alimentos funcionais. A nutrição otimizada, por possuir o objetivo de maximizar as funções fisiológicas, representa uma das ações preventivas e terapêuticas contra esses agravos, uma vez que, a adoção de uma dieta rica em alimentos funcionais pode promover benefícios à saúde, já comprovados cientificamente (HENRIQUE et al., 2018). A utilização dos probióticos na saúde humana surge a partir da necessidade de alternativa a terapêuticas, que neste momento apresentem resultados que vão além do desejado. Tem crescido exponencialmente o interesse nos produtos naturais e dos microrganismos, tanto na saúde humana como no nosso planeta. Isto se deve a evidências encontradas nas propriedades genéticas e metabólicas da eficácia de estirpes probióticas demonstradas em estudos realizados (PUEBLA-BARRAGAN; REID, 2019).

\section{CONSIDERAÇÕES FINAIS}

O intestino humano possui inúmeras bactérias em sua microbiota que podem ser benéficas ou maléficas ao seu funcionamento, a depender de fatores como idade, alterações dietéticas, resposta imunitária entre outras. Os prebióticos e os probióticos podem ser incorporados tanto na alimentação infantil quanto na adulta com diversos benefícios à saúde, promovendo a modulação e reestruturação da função intestinal. Entendemos que o consumo de probióticos auxiliam na função intestinal, protegendo o organismo das bactérias maléficas e que os prebióticos consideradas fibras não digeríveis, fermentam o intestino e estimulam o crescimento das bactérias probióticas, corroborando na promoção do funcionamento do intestino.

\section{PRINCIPAIS REFERÊNCIAS}

CARLET, J. The gut is the epicenter of antibiotic resistance. Journal Antimicrobial Resistance \& Infection Control, Paris, v. 1, n. 1, p. 1-7, nov. 2012.

CHASSARD, C. et al. Probiotics tailored to the infant: a window of opportunity. Current Opinion In Biotechnology, v. 26, p.141-147, abr. 2014.

FOO, J.L. et al. Microbiome engineering: Current applications and its future. Biotechnology journal, v. 12, n. 3, 2017.

HENRIQUE, V. A. et al. Alimentos Funcionais aspectos nutricionais na qualidade de vida. 1 ed. Aracaju: Instituto Federal de Educação, Ciência e Tecnologia de Sergipe; 2018.

NEUZA, MBC; CARLA, OBR. Livro- Alimentos funcionais, componentes bioativos e efeito fisiológico. 2.ed. Rio de Janeiro: Rubio; 2016 
PUEBLA-BARRAGAN, S.; REID, G. Forty-five-year evolution of probiotic therapy. Microbial Cell, v.6, n.4, p.184-196, 2019.

RAMIREZ, A.V.G. A importância da microbiota no organismo humano e sua relação com a obesidade. International Journal Of Nutrology, v. 10, n. 4, p.153-160, 2017.

SAAD, S. Probióticos e prebióticos: o estado da arte. Revista Brasileira de Ciências

Farmacêuticas, Tocantins, v. 42, n. 1, p. 1-16, jan./mar. 2006.

SANTOS, K.E.R; RICCI, G.C.L. Microbiota intestinal e a obesidade. Revista Uningá Review, v. 26, n. 1, p.74-82. Maringá, 2016.

VANDENPLAS, Y.; HUYS G.; DAUBE, Georges. Probiotics: an update. Jornal de Pediatria, v. 91, n. 1, p. 6-21, 2015. 


\title{
ATIVIDADE FÍSICA ORIENTADA PARA ADOLESCENTES GRÁVIDAS: RELATO DE EXPERIÊNCIA PELO OLHAR DA BIOÉTICA DA PROTEÇÃO
}

\author{
Samily Batista da Silva ${ }^{1}$; Camila Rodrigues Barbosa Nemer²; Tatiana do Socorro dos Santos \\ Calandrini $^{3}$, Luzilena de Sousa Prudêncio ${ }^{4}$
}

\author{
1. Profissional de Educação Física, Residente no Programa de Residência Multiprofissional em \\ Saúde Coletiva, Universidade Federal do Amapá (UNIFAP), Macapá, Amapá. \\ 2 Mestre, Universidade Federal do Amapá (UNIFAP), Macapá, Amapá. \\ 3 Mestre, Universidade Federal do Amapá (UNIFAP), Macapá, Amapá. \\ ${ }_{4}$ Doutorado, Universidade Federal do Amapá (UNIFAP), Macapá, Amapá.
}

\begin{abstract}
RESUMO
Objetivo: Descrever a experiência de profissional de Educação Física, residente em Saúde Coletiva na atenção à saúde de grávidas adolescentes sob a ótica da bioética da proteção. Método: Estudo descritivo, qualitativo, na modalidade relato de experiência. Resultados: Foram realizadas orientações quanto a intensidade, duração e frequência adequadas ao período gestacional de cada adolescente, estímulo a adesão à prática de exercícios àquelas que possuíam comportamento sedentário e incentivo àquelas que já se exercitavam antes de descobrir a gravidez. Conclusão: Com base na bioética da proteção, sendo uma ética de responsabilidade social, em que o Estado deve assumir suas obrigações sanitárias para com as populações humanas, considerando seus contextos reais, que são, ao mesmo tempo, culturais, sociais, entre outros deve-se haver uma assistência integral a grupos vulneráveis tais como as adolescentes grávidas. A inserção do profissional de educação física nas Unidades Básicas de Saúde possibilita integralidade no atendimento e acompanhamento do pré-natal.
\end{abstract}

PALAVRAS-CHAVES: Gravidez na Adolescência; Pré-natal.

ÁREA TEMÁTICA: Atenção à Saúde.

\section{INTRODUÇÃO}

O índice de gravidez na adolescência no Brasil está acima da média mundial, sendo que em 2020 o país registrou que a cada mil brasileiras entre 15 e 19 anos, 53 tornam-se mães. No mundo, são 41, de acordo com o relatório lançado pelo Fundo de População das Nações Unidas (UNFPA, 2021). No Brasil os índices ainda são altos, com uma tendência ascendente de gravidez entre adolescentes 
com menos de 15 anos, de acordo com o UNFPA. Estima-se que, a cada ano, 15\% de todas as gestações ocorrem entre meninas menores de 20 anos.

Em relação ao desenvolvimento de patologias, a gravidez na adolescência é agente determinante de vulnerabilidade quando associada ao sedentarismo, portanto na ausência de contraindicações clínicas ou obstétricas para a prática de atividade física, todas as gestantes devem ser estimuladas a manter ou adotar um estilo de vida ativo e saudável durante todo o período gestacional (FIGUEIREDO, 2020). A atividade física é considerada prática segura tanto para a mãe quanto para o feto e dentre seus inúmeros benefícios físicos e psicológicos está o efeito protetor contra o desenvolvimento da diabetes gestacional e pré-eclâmpsia. Outro benefício associado a essa prática é a redução da incidência de sintomas indesejáveis durante a gravidez, como câimbras, edema e fadiga.

A Organização Mundial de Saúde (OMS, 2020) define atividade física como qualquer movimento corporal produzido pelos músculos esqueléticos que resulte em gasto energético maior que os níveis de repouso, incluindo não apenas o exercício físico (atividade física planejada acompanhada e realizada de forma sistemática, com o objetivo de melhorar ou manter a aptidão física), como também as atividades cotidianas, laborais e de lazer. A inserção do PEF no Sistema Único de Saúde (SUS) ocorreu somente em 2008, com a criação do Núcleo de Apoio à Saúde da Família e Atenção Básica (NASF-AB), pela portaria 154, de 24 de janeiro de 2008, consolidando-se com a criação das Academias da Saúde em 2011. Somente a partir de 2013 que a atividade física passa a constar na Lei Orgânica da Saúde (lei n. 8080/90) como fator determinante e condicionante de saúde (LOTTI e NAKAMURA, 2020).

Contrapondo o estabelecido pelo Ministério da Saúde (MS), em 2019 foi publicado uma segunda a portaria $\mathrm{n}^{\circ} 2.979$, de 12 de novembro de 2019, que exime o MS de efetuar repasses financeiros para contratação de PEF, responsabilizando os municípios que tiverem interesse em manter o educador físico em suas equipes de NASF. O exposto parece ser incongruente, a citar que é uma máxima afirmar sobre as necessidades de orientações para atividade física como estratégia de manutenção, prevenção e controle de doenças, assim como reabilitação de usuários dos serviços de saúde.

Neste contexto, trazemos para o palco das discussões as adolescentes grávidas, foco deste estudo, sobre o modo como um profissional capacitado poderá acompanhar e orientar as atividades físicas de acordo com suas necessidades individuais. A temática da gravidez na adolescência, bem como as necessidades de atividade física nessa idade e condição, nos faz refletir sobre as implicações bioéticas que a omissão deste serviço pode ocasionar a esse grupo populacional em estudo. Assim, entendemos que é importante relacionarmos a bioética nesta discussão, mais especificamente a bioética da proteção, portanto este trabalho tem como objetivo: Descrever a experiência de profissional de Educação Física, residente em Saúde Coletiva na atenção à saúde de grávidas adolescentes sob a ótica da bioética da proteção. 


\section{METODOLOGIA}

Trata-se de um estudo descritivo de natureza qualitativa na modalidade de relato de experiência, a partir da vivência com o grupo de gestantes que participam de um projeto denominado Grupo de Extensão de Apoio às Grávidas Adolescentes (GEAGA) na Policlínica da Universidade Federal do Amapá (UNIFAP). Participaram do estudo 5 grávidas adolescentes. O projeto é composto por enfermeiros, acadêmicos, residentes e profissional de educação física. Os atendimentos são realizados duas vez na semana, todas as terças e quintas feiras na Policlínica da UNIFAP, no horário das $13 \mathrm{~h} 00 \mathrm{~min}$ às $16 \mathrm{~h} 30 \mathrm{~min}$.

O projeto tem por objetivo o acompanhamento de adolescentes em estado gestacional. Entre as atividades desenvolvidas no grupo estão a educação para o parto, exercícios e práticas integrativas e complementares. Os assuntos abordados nas consultas de pré-natal foram baseadas no que o Ministério da Saúde preconiza: a importância do pré-natal; gestação na adolescência; dificuldades sociais e familiares; atividade física específica para gestantes; alimentação saudável; desenvolvimento da gestação; atividade sexual; prevenção de DST/AIDS e aconselhamento para teste anti-HIV; sinais comuns na gestação e orientações nas queixas mais frequentes; sinais de alerta; preparo para o parto; incentivo e orientações para o parto normal; orientações e incentivo para o aleitamento materno; sinais e sintomas de parto; lei do acompanhante; importância da participação paterna durante a gestação e parto e estímulo o retorno aos serviços de saúde.

\section{RESULTADOS E DISCUSSÕES}

Foi analisado durante a consulta de pré-natal se a adolescente apresentava alguma intercorrência como sangramento vaginal, dispneia após o esforço, tonturas, cefaleias, dor torácica, fraqueza muscular, dor ou edema dos tornozelos, contrações uterinas, diminuição dos movimentos fetais ou perda de líquido amniótico. Em caso negativo para essas intercorrências, as atividades físicas foram prescritas seguindo orientações quanto a intensidade, duração e frequência apropriadas ao período gestacional que a adolescente se encontrava.

Houve orientações sobre a prática de atividades físicas, estímulo a adesão à prática de exercícios àquelas que possuíam comportamento sedentário e incentivo àquelas que já se exercitavam antes de descobrir a gravidez.

A experiência possibilitou vislumbrar a importância da inserção do profissional de educação física nos serviços de saúde, no sentido de potencializar o cuidado e a atenção à saúde, promovendo orientações e atividades físicas, respeitando as singularidades durante o período gestacional, garantindo a saúde e o bem-estar do binômio mãe e filho. 


\section{CONCLUSÃO}

Observou-se que a vivência profissional possibilitou conhecer, compreender e identificar a importância quanto a bioética da proteção. Esta pode ser interpretada como o resguardo ou cobertura de necessidades básicas, ou seja, a proteção deve garantir que as demandas sejam acolhidas, de modo que toda pessoa necessitada possa estar em condições de conseguir outros bens, ou satisfazer outros interesses contidos em seus projetos de vida e que dependem da satisfação das necessidades essenciais.

O grupo de adolescentes grávidas é considerado vulnerável, sendo assim é necessário que o Estado promova a saúde e isso significa abrir um leque de possibilidades de intervenção, com enfoque na saúde como qualidade de vida na área da atenção básica, possibilitando a atuação do profissional de educação física nas Unidades Básicas de Saúde, por meio do Núcleo de Apoio à Saúde da Família e Atenção Básica.

\section{REFERÊNCIAS}

BRASIL. Ministério da Saúde. Gabinete do Ministro. Portaria n 2.979, de 12 de novembro de 2019. Institui o Programa Previne Brasil, que estabelece novo modelo de financiamento de custeio da Atenção Primária à Saúde no âmbito do Sistema Único de Saúde, por meio da alteração da Portaria de Consolidação no 6/GM/MS, de 28 de setembro de 2017, Seção 1, p. 97. Disponível em: $<$ https://www.in.gov.br/en/web/dou/-/portaria-n-2.979-de-12-de-novembro-de-2019-227652180>. Acesso em: 15 fev. 2021.

FIGUEIREDO, Verónica. Contributos do enfermeiro especialista em enfermagem de saúde materna e obstétrica na capacitação da mulher grávida para a atividade física. Orientadora: Hélias Dias, 2020,144 f. Dissertação (Mestrado). Curso de Mestrado em enfermagem de saúde materna e obstétrica, 2020. Disponível em: <https://repositorio.ipsantarem.pt/ handle/10400.15/3090>. Acesso em: 06 fev. 2021.

LOTTI, Alessandro Demel; NAKAMURA, Eunice. Significados da prática profissional em educação física na área da saúde. Revista Pensar a Prática. São Paulo, 2020, v.23. Disponível em: $<$ https://www.revistas.ufg.br/fef/article/view/54518>. Acesso em: 04 fev. 2021.

OMS. Organização Mundial de Saúde. Diretrizes sobre atividade física e comportamento sedentário. Brasília, DF, 2020. Disponível em: <https:/www.paho.org/pt/noticias/26-11-2020oms-lanca-novas-diretrizes-sobreatividade-fisica-e-comportamento-sedentario $>$. Acesso em: 04 fev. 2021.

UNFPA. Fundo de População das Nações Unidas. Gravidez na Adolescência no Brasil: Projeto Fala, Adolescente! 2021. Disponível em: $<$ https://brazil.unfpa.org/ptbr/news/fala-adolescente $>$. Acesso em: 10 fev. 2021. 


\section{PREVENÇÃO AO HIV/AIDS ENTRE ADOLESCENTES: UMA REVISÃO DE LITERATURA}

Edylany Almeida de Oliveira ${ }^{1}$; Samily Batista da Silva ${ }^{2}$; Luzilena de Sousa Prudêncio ${ }^{3}$; Rosana Oliveira do Nascimento ${ }^{4}$; Anneli Mercedes Celis de Cárdenas ${ }^{3}$; Maria Virgínia Filgueiras de Assis Mello $^{3}$; Camila Rodrigues Barbosa Nemer ${ }^{4}$

${ }^{1}$ Enfermeira, Residente no Programa de Residência Multiprofissional em Saúde Coletiva, Universidade Federal do Amapá (UNIFAP), Macapá, Amapá, Brasil.

${ }^{2}$ Profissional de Educação Física, Residente no Programa de Residência Multiprofissional em Saúde Coletiva, Universidade Federal do Amapá (UNIFAP), Macapá, Amapá, Brasil.

${ }^{3}$ Doutorado, Universidade Federal do Amapá (UNIFAP), Macapá, Amapá, Brasil.

${ }^{4}$ Mestre, Universidade Federal do Amapá (UNIFAP), Macapá, Amapá, Brasil.

\section{RESUMO}

Objetivo: Analisar as evidências científicas publicadas nos últimos cinco anos sobre estratégias e práticas de prevenção ao HIV/aids para adolescentes. Método: Foi realizada uma revisão da literatura. As buscas foram realizadas no mês de fevereiro de 2021 na Biblioteca Virtual em Saúde (BVS), nas bases de dados: Medical Literature Analysis and Retrieval System Online (MEDLINE), Literatura Latino-Americana e do Caribe em Ciências da Saúde (LILACS) e Base de Dados em Enfermagem (BDENF). A amostra final foi composta de 21 artigos. Resultados: A partir da leitura crítica e sistematizada dos artigos, emergiram seis categorias de análise: Estratégias de educação utilizadas na prevenção; Da informação ao conhecimento e prática; Influências da religião/igreja; Iniquidades de gênero; O uso de preservativo; O destaque para o papel do(a) enfermeiro(a). Conclusão: O estudo revela as potencialidades e fragilidades para promover a prevenção. Instiga o engajamento de outros profissionais nessas estratégias e práticas que abordem a prevenção.

PALAVRAS-CHAVES: Vulnerabilidade em Saúde; Educação em Saúde; Saúde Pública.

ÁREA TEMÁTICA: Atenção à saúde

\section{INTRODUÇÃO}

No âmbito mundial a epidemia do Vírus da Imunodeficiência Humana (HIV) continua a ser um grande desafio de saúde. Segundo o último relatório mundial das Nações Unidas (UNAIDS, 
2020) revelam que atualmente há, no mundo, aproximadamente 38 milhões de pessoas vivendo com o HIV, e que todas as semanas, cerca de 5.500 jovens entre 15 e 24 anos são infectados pelo HIV.

A adolescência é uma fase que marca a transição entre a infância e a idade adulta. Segundo o Estatuto da Criança e do Adolescente (ECA), a adolescência vai dos 12 aos 18 anos. O Ministério da Saúde segue a Organização Mundial da Saúde que demarca o período entre 10 e 19 anos de idade como adolescência e o situado entre 15 e 24 anos como juventude (MOREIRA et al., 2019). No período da adolescência que o jovem passa por inúmeras mudanças, indecisões e dúvidas, é nesta fase da vida que o exercício da sexualidade começa a ocupar espaço de grande destaque e muitos iniciam sua a vida sexual, o que torna muitos adolescentes vulneráveis a sofrerem problemas de saúde, sendo a infecção pelo HIV uma importante forma de expressar essa vulnerabilidade, principalmente por se tratar de uma doença infecciosa e incurável.

Ações educativas voltadas para os adolescentes devem contemplar a saúde sexual e reprodutiva, esclarecendo dúvidas e medos em relação à temática abordada, identificando o contexto cultural no qual está inserido, pois as estratégias devem condizer com a realidade, de modo a serem efetivas (ROUBERTE et al., 2017), portanto este trabalho tem como objetivo analisar as evidências científicas publicadas nos últimos 5 anos sobre estratégias e práticas de prevenção ao HIV/aids para adolescentes.

\section{METODOLOGIA}

Foi realizada uma revisão da literatura utilizando a seguinte questão de investigação: como se caracteriza as evidências científicas sobre as estratégias e práticas de prevenção ao HIV/aids para adolescentes? As buscas foram realizadas no mês de fevereiro de 2021, na Biblioteca Virtual em Saúde (BVS), nas bases de dados: Medical Literature Analysis and Retrieval System Online (MEDLINE), Literatura Latino-Americana e do Caribe em Ciências da Saúde (LILACS) e Base de Dados em Enfermagem (BDENF). Os descritores selecionados para busca, bem como os operadores boleanos foram: Adolescente AND HIV OR Aids. Os critérios de inclusão adotados foram: artigos completos, no idioma português, publicados entre 2016 e 2021. Os critérios de exclusão foram: artigos repetidos (considerando apenas uma versão), artigos não correspondentes à temática, outras revisões. A aplicação de filtros, a partir dos critérios de inclusão descritos acima possibilitou a captura de 199 artigos. Após leitura dos títulos e resumos, foram excluídos 175 por não se relacionarem com o tema desta revisão e 03 por serem repetidos. Ao fim, restaram 21 artigos para leitura na íntegra e posterior seleção de estudos para incluir nos resultados finais desta revisão. Os 21 artigos entraram na amostra final. 


\begin{tabular}{|c|c|c|}
\hline $\begin{array}{l}\text { Código } \\
\text { do Artigo }\end{array}$ & Título & Autores e ano \\
\hline A1 & $\begin{array}{l}\text { Estratégia de educação por pares na prevenção de HIV/aids } \\
\text { entre adolescentes }\end{array}$ & BARRETO et al., 2020 \\
\hline $\mathrm{A} 2$ & $\begin{array}{l}\text { Website sobre sexualidade e prevenção de infecções } \\
\text { sexualmente transmissíveis para adolescentes católicos }\end{array}$ & FERREIRA et al., 2020 \\
\hline A3 & $\begin{array}{l}\text { O direito à prevenção da aids em tempos de retrocesso: } \\
\text { religiosidade e sexualidade na escola }\end{array}$ & $\begin{array}{l}\text { PAIVA; ANTUNES; } \\
\text { SANCHEZ, } 2020\end{array}$ \\
\hline A4 & $\begin{array}{l}\text { Iniquidades de gênero e vulnerabilidade às IST/HIV/aids em } \\
\text { adolescentes de assentamento urbano: um estudo exploratório }\end{array}$ & SOUZA et al., 2020 \\
\hline A5 & $\begin{array}{c}\text { Vulnerabilidade ao HIV/aids em adolescentes de uma escola } \\
\text { pública no interior de Sergipe }\end{array}$ & MOREIRA et al., 2019 \\
\hline A6 & $\begin{array}{c}\text { Fatores associados ao uso de preservativo em jovens - } \\
\text { inquérito de base populacional }\end{array}$ & GUTIERREZ et al., 2019 \\
\hline A7 & $\begin{array}{l}\text { Sistemas bioecológicos e elementos que vulnerabilizam } \\
\text { adolescentes frente às infecções sexualmente transmissíveis }\end{array}$ & $\begin{array}{l}\text { BRUM; MOTTA; } \\
\text { ZANATTA, } 2019\end{array}$ \\
\hline A8 & Análise de vídeos sobre HIV/aids e adolescência & SILVA et al., 2018 \\
\hline A9 & $\begin{array}{c}\text { Dilemas e desafios da prevenção ao HIV nas representações de } \\
\text { jovens católicos }\end{array}$ & COUTO et al., 2018 \\
\hline A10 & $\begin{array}{l}\text { Adolescentes em conflito com a lei e a vulnerabilidade para } \\
\text { IST/HIV/aids: conhecimentos e vivências }\end{array}$ & SILVA et al., 2018 \\
\hline A11 & $\begin{array}{l}\text { Práticas de enfermeiros para a prevenção do HIV/aids na } \\
\text { adolescência: análise representacional }\end{array}$ & $\begin{array}{l}\text { CONCEIÇÃO; COSTA, } \\
2017\end{array}$ \\
\hline A12 & $\begin{array}{l}\text { Conhecimento de adolescentes relacionados às doenças } \\
\text { sexualmente transmissíveis e gravidez }\end{array}$ & ALMEIDA et al., 2017 \\
\hline A13 & $\begin{array}{l}\text { A prevenção do vírus da imunodeficiência humana pela equipe } \\
\text { de atenção primária voltada aos adolescentes }\end{array}$ & SANTOD et al., 2017 \\
\hline A14 & $\begin{array}{l}\text { Adolescentes escolares acerca das DST/aids: quando o } \\
\text { conhecimento não acompanha as práticas seguras }\end{array}$ & CORDEIRO et al., 2017 \\
\hline A15 & Jovens universitários da área da saúde são vulneráveis ao HIV & PEREIRA et al., 2017 \\
\hline A16 & $\begin{array}{l}\text { Fatores de risco e de proteção entre adolescentes em relação às } \\
\text { DST/HIV/aids }\end{array}$ & MESQUITA et al., 2017 \\
\hline A17 & $\begin{array}{c}\text { Significados a respeito da prevenção ao HIV/aids e da } \\
\text { sexualidade para jovens católicos }\end{array}$ & COUTO et al., 2017 \\
\hline A18 & $\begin{array}{l}\text { Conhecimento e acesso aos programas de educação sexual e } \\
\text { prevenção da aids: um estudo com adolescentes escolares }\end{array}$ & ROLIM et al., 2016 \\
\hline A19 & $\begin{array}{l}\text { Conhecimento de estudantes adolescentes sobre transmissão, } \\
\text { prevenção e comportamentos de risco em relação às DST/HIV/ } \\
\text { aids }\end{array}$ & SILVA et al., 2016 \\
\hline A20 & $\begin{array}{l}\text { Fatores contribuintes da vulnerabilidade individual dos jovens } \\
\text { ao HIV }\end{array}$ & RODRIGUES et al., 2016 \\
\hline A21 & $\begin{array}{l}\text { Prática educativa com jovens usuários de crack visando a } \\
\text { prevenção do HIV/aids* }\end{array}$ & SOUZA et al., 2016 \\
\hline
\end{tabular}

Quadro 1: Distribuição dos estudos selecionados, de acordo código do artigo, título, autores e ano

Fonte: Elaboração própria. 
Foram extraídas as informações dos estudos, conforme instrumento de coleta de dados proposto pelos autores. Realizou-se a análise dos artigos de forma crítica. Os temas centrais e resultados dos estudos foram sintetizados, momento este em que se detectaram as categorias emergentes.

\section{RESULTADOS E DISCUSSÕES:}

Foram identificadas seis categorias emergentes capazes de sinalizar nas evidências científicas disponíveis na literatura as estratégias e práticas de prevenção ao HIV/aids para adolescentes. Alguns artigos foram incluídos em mais de uma categoria.

Categoria 1 - Estratégias de educação utilizadas na prevenção (A1, A2, A8, A13): os artigos dessa categoria relatam diferentes formas de abordagem aos adolescentes para realização de educação em saúde e de promoção da prevenção. Foi utilizada educação por pares, websites, mídias virtuais (vídeos), facebook, grupo de conversa, ações educativas na Estratégia saúde da Família na abordagem.

Categoria 2 - Da informação ao conhecimento e prática (A1, A5, A7, A10, A12, A14, A15, A18, A19): os artigos relatam a necessidade de intensificar as informações de prevenção aos adolescentes principalmente nas escolas. Evidenciaram ausência de conhecimento ou conhecimento inadequado, ressaltando a falta de diálogo com a família sobre o assunto, o que torna esses adolescentes mais suscetíveis às infecções sexualmente transmissíveis, em específico o HIV. Ressaltam também que ter acesso ao conhecimento, às informações, não significa colocar em prática, sugerindo que esse grupo não percepção de vulnerabilidade.

Categoria 3 - Influências da religião/igreja (A3, A9, A17): evidenciam que a religiosidade, nos estudos em específico na igreja católica, trazem dilemas enfrentados sobre a prática sexual segura e tem efeitos tanto positivo como negativo na prevenção, a exemplo do não incentivo do uso da camisinha.

Categoria 4 - Iniquidades de gênero (A4, A20): as desigualdades entre os sexos implicam na vulnerabilidade das meninas adolescentes, apontando para as tendências de feminização e pauperização da infecção pelo HIV.

Categoria 5 - O uso de preservativo (A6, A16, A21): nessa categoria os artigos evidenciam os fatores que contribuem (primeira relação, casualidade da relação) ou dificultam o uso de preservativo (indisponibilidade, crenças). Ressaltam a importância de oferta gratuita de preservativo (dispensadores de preservativos em locais oportunos).

Categoria 6-O destaque para o papel do(a) enfermeiro(a) (A11, A13): os artigos dessa categoria abordam sobre a relevância de ações educativas de Enfermagem na ESF quanto à prevenção ao HIV/aids, tanto nas unidades básicas de saúde, como nas escolas, apontam a potencialidade da inserção do(a) enfermeiro(a) na comunidade. 


\section{CONCLUSÃO}

$\mathrm{O}$ estudo revela as potencialidades e fragilidades para promover a prevenção. Instiga o engajamento de outros profissionais nessas estratégias e práticas que abordem a prevenção, não só os profissionais de enfermagem que tiveram seu destaque nos artigos, mas de todos os profissionais que trabalham principalmente na assistência na atenção primária à saúde. E abre caminhos para novos estudos, visto que é um tema que necessita de mais abordagem.

\section{REFERÊNCIAS}

ROUBERTE, E. S. C. et al. Adolescentes: Maior Vulnerabilidade Às IST/AIDS?. Rev. Tendên. da Enferm, 2017; 9(4): 2289-2295. Disponível em: < http:/www.coren-ce.org.br/wp-content/ uploads/2019/02/ADOLESCENTES-MAIOR VULNERABILIDADE-\%C3\%80S-ISTAIDS.pdf $>$. Acesso em: 15 fev. 2021.

MOREIRA, P.A. et al. Vulnerabilidade ao HIV/AIDS em adolescentes de uma escola pública no interior de Sergipe. Rev.: fundam. care. Online, 2019 jul/set 11(4): 868-872. Disponível em: < https://ciberindex.com/index.php/ps/article/view/P868872 Acesso em: 15 fev. 2021.

UNAIDS. Estatísticas. Disponível em: <https://unaids.org.br/estatisticas/> Acesso em: 21 fev. 2021. 


\title{
AÇÕES VOLTADAS AO CONTROLE DA DIABETES GESTACIONAL NA ATENÇÃO BÁSICA.
}

\author{
Nágila Silva Alves ${ }^{1}$; Kaliny Vieira dos Santos Alves Pereiraª ${ }^{2}$ Adrielle Martins da Conceição ${ }^{3}$ \\ ${ }^{1}$ Fisioterapeuta Residente em Saúde da Família e Comunidade, Universidade Estadual do Piauí - \\ UESPI, Teresina, Piauí. \\ ${ }^{2}$ Graduanda em Enfermagem, Universidade Estadual do Piauí - UESPI, Picos, Piauí. \\ ${ }^{3}$ Bacharel de Fisioterapia, Centro Universitário do Piauí - UNIFAPI, Teresina, Piauí.
}

\section{RESUMO}

A Diabetes Mellitus Gestacional é a intolerância a carboidratos em qualquer nível, com gravidade variável na hiperglicemia, com diagnóstico ou início na gestação. Objetiva-se buscar na literatura evidências para analisar as ações realizadas na atenção básica quanto a assistência e controle da diabetes gestacional. Estudo de revisão da literatura por meio de levantamento bibliográfico, baseados em estudos descritivo, com abordagem qualitativa., realizada na BVS. Diante critérios de inclusão e exclusão, elegeu-se 6 artigos para análise e discussão. Os resultados encontrados, segundo a perspectiva conceitual analisada foram que a terapia nutricional é a primeira opção de tratamento aconselhada na atenção básica, além da pratica de atividades fisicas leve a moderada, sendo indicada na ausencia de contraindicações obstétricas, além do tratamento medicamentoso. Conclui-se que a atenção básica é indispensável no controle da patologia, cooperando para uma gestação sem intercorrências, contribuindo para o nascimento saudável do bebê sem maiores complicações.

PALAVRAS- CHAVE: Saúde do mulher; Diabetes mellitus; Promoção da saúde.

ÁREA TEMÁTICA: Atenção à saúde.

\section{INTRODUÇÃO}

O diabetes mellitus (DM), se enquadra no grupo de doeças metabólicas, que apresenta uma etiologia múltipla, e que pode acabar acontecendo em gestantes durante o seu período gestacional. Normalmente é classificada em duas formas, a Diabetes Mellitus tipo I ou tipo II, mais também se apresenta em outras formas específicas como Diabetes Mellitus Gestacional (DMG), sendo o foco do presente trabalho esta última classificação a DMG. (ZIMMET, et al., 2016)

Mulheres que durante avaliação é reconhecido alguma intolerância à glicose ou no inicio ou durante a gravidez se enquadra no termo Diabetes Gestacional. Essa patologia é definida como intolerância a carboidratos em qualquer nível, com gravidade variável em relação a hiperglicemia, 
com diagnóstico podendo ser feito ou no início ou durante a gestação. Sua fisiopatologia é esclarecida a partir do aumento de hormônios contrarreguladores da insulina, mais também pelo aparecimento de estresse fisiológico atribuído pela gravidez e por fatores pré-determinantes como ambientais ou genéticos. Logo o hormônio que mais se relaciona a resistência a insulina quando gravida é o lactogênico placentário, porém não é o único, com o avanço da ciência hoje sabe-se que outros hormônios como prolactina, estrógeno, progesterona e cortisol que são considerados hiperglicemiantes também se envolvem a essa alteração. (TAVARES, et al., 2017)

Quando se fala de DMG, múltiplos são os fatores de risco relacionados ao seu desevolvimento, podendo variar de riscos pré-gestacionais e gestacionais, que devem ser bem esclarecidos e observados pois são grande contribuintes para se usar como guia para se prestar a assistência e atenção individualizada a cada paciente a partir do seu quadro e necessidade. Diante disto, a relevância de se oferecer e realizar corretamente o pré-natal e a busca ativa para a diabetes gestacional em qualquer nível de assistência, pois são as formas mais eficaz de se evitar complicações para o neonato e para as gestantes. Assim os riscos adversos para as mães, feto e/ou neonato a partir da elevação da glicemia materna só vem aumento de forma contínua. (ZIMMET, et al., 2016)

Portanto, com o elevado número de casos nos últimos anos de gestantes com esta patologia, e que a maioria está relacionada a seus hábitos de vida diária e a falta de assitência adequada pelo sistema de saúde. Seguindo esta perspectiva, buscamos respostas para a seguinte questão de pesquisa: como a atenção basica tem contribuído para a assitência e controle da diabetes gestacional ? Objetivase com o estudo descrever e analisar as ações e colaborações da equipe da Atenção Básica na Diabetes Mellitus Gestacional.

\section{METODOLOGIA}

É um estudo de revisão da literatura por meio de levantamento bibliográfico, baseados em estudos descritivos, com abordagem qualitativa. A busca dos dados se deu no banco de dados da Biblioteca Virtual em Saúde (BVS). Quanto aos descritores da pesquisa foram empregadas as palavras Saúde do Mulher, Diabetes Gestacional e Atenção Básica em combinação com operador booleano and.

Isto posto, os critérios de inclusão foram baseado na busca de artigos completos, em português, publicados entre 2013 e 2020, assunto principal diabete gestacional e atenção básica e com relevância para o estudo. Já como critérios de exclusão optou-se por eliminar textos incompletos e duplicados, em outros idiomas e trabalhos publicados antes de 2013. Na busca bibliográfica na base de dados da BVS foram elencados 23 artigos, e ao filtrar pelos critérios de inclusão e exclusão, além da leitura e averiguação dos trabalhos, selecionaram-se 6 artigos para análise e discussão. 


\section{FUNDAMENTAÇÃO TEÓRICA}

As mulheres gestantes diagnosticadas com diabetes mellitus recebem total atenção e assistência prestada pelas equipes da atenção básica, e esse acompanhamento varia mediante várias terapêuticas voltada para os seus hábitos de vida desde uma dieta, a utilização de tratamento farmacológico, a prática regular de exercícios, além de todo um suporte para ser ralizada as etapas do acompanhamento do pré-natal, sendo realizado por uma equipe multiprofissional capacitada para esse público e situação. E através de toda uma averiguação a Organização Mundial de Saúde (OMS) indica a insulina como a melhor forma para o controle da diabetes no metabolismo da mulher gestante. (CARVALHO, NOGUEIRA \& MEDINA, 2014)

No cotidiano de trabalho da equipe de atenção básica é importante que os profissionais além da assitência se preocupem em realizar a educação em saúde, para incentivar as mulheres com DMG a exercer o autocuidado. Pois com a estimulação do cuidado consigo, auxilia na efetivação e sucesso do tratamento além de deixar mais leve a sua vivência no período de gravidez, apesar dos riscos impostos pelo diabetes gestacional tanto para o bebê quanto para si. Posto isto, é importante a equipe ser qualificada para trabalhar com esse grupo, sempre orientando e deixado a mulher ciente sobre os cuidados que deve tomar, e das consequências que podem vim a surgir caso haja negligência no tratamento. (SANTOS, 2015)

Por meio da litetura foi notado que a prática de exercícios fisicos diários aliado com a dieta, constitui a etapa inicial na maioria dos casos, colocando metas glicêmicas para duas semanas a serem acalcançadas pelas gestantes, caso não funcionando é indicado o início do tratamento medicamentoso, que o padrão é a insulinoterapia subcutânea. Todavia, o uso desta droga é complexo, pois tem pouca aceitação pelas gestantes pelo ganho de peso através do seu uso, além do alto custo. E como solução medicações orais vem sendo inserido como alternativa terapêutica, o que vem mostrando efetividade se comparada com a insulina para o tratamento da DMG, além da maior aceitação.(SANTOS, 2015)

Como citado acima a prática de exercícios fisicos regular aliado com a dieta é a primeira opção de tratamento a ser indicada para mulheres com diabetes gestacional. Essa deve ser a terapia mais incentivada pela equipe de saúde a ser aceita pela gestante pois evita o aumento de massa corporal pelas mesmas, e diminui consideravelmente a taxa de macrossomia fetal e de maiores complicações perinatais.

A prática regular de exercícios trás uma série de vantagens, dentre elas a diminuição da glicemia, abatimento do peso corporal por conta da gestação, e ainda redução da macrossomia fetal diminuindo a incidência de casos. Logo é uma terapêutica excelente para ser prestada e orientada para as gestantes, de fácil execução podendo ser feita em pouco tempo entre 15 a 30 minutos, sendo indicada caminhadas ou cicloergômetro. É importante que a prática seja feita com supervisão de um profissional até para que durante ou após a prática seja realizada a monitorização da atividade fetal e da glicemia capilar. (SCHMALUSS, et al., 2016) 
Diante de duas semanas com medidas de mudança dos hábitos e estilo de vida, e mesmo assim um ou mais valores da glicemia capilar continuar elevado, ou quando a avaliação ecográfica revelar sinais de crescimento fetal exagerado, é indicado começar o tratamento farmacológico. Devido comprovada segurança e eficácia científica a insulinoterapia é o tratamento padrão do diabetes gestacional, porém só deve ser iniciado nas mulheres que não alcançam as metas de controle glicêmico com exercício e dieta ou exibem falha do tratamento com medicação via oral. (CARVALHO, NOGUEIRA \& MEDINA, 2014)

Após a equipe indicar e iniciar o tratamento a base de dieta e exercícios fisicos diariamente, além do início da terapia medicamentosa, é imprecidível a constância de monitorização da glicemia para observar se o tratamento estar evoluindo da forma adequada e apresentando os resultados esperados. Além da realização da medida da circuferência abdominal fetal por meio de ultrassonografias seriadas, que devem ser feitas a partir de 28 semanas de gestação, repetindo a análise a cada duas a quatro semanas. (SCHMALUSS, et al., 2016)

Ademais é de suma importância que a grupo da atenção básica acompanhe a fase do parto e pós parto, pois é essencial o prosseguimento puerperal dessas gestantes. Logo para as que realizam tratamento farmacológico e que apresentam o nível de controle glicêmico bom, além de ausência de indicações obstétricas, devem ser avaliadas até a $36^{\mathrm{a}}$ semana de gestação com a frequencia a cada duas semanas, após isso o controle obstétrico deve ser semanal. O mesmo deve ser feito para as gestantes que usam antidiabéticos orais ou insulina com aconpanhamento até a $32^{\mathrm{a}}$ semana a cada duas semanais e após isso semanal até o momento do parto. Já no pós parto a atenção deve ser redobrada com frequência de avaliação, observando a involução uterina, além de cuidados com a ferida e cicatrização cirúrgica e com as orientações voltada as mamas. Além de ser importante ressaltar que por ter apresentado diabetes gestacional em uma gestação, põe a mulher em alto nível de risco para o aparecimento de diabetes em gestações futuras, portanto é necessário uma orientação correta sobre sempre buscar uma investigação periódica nos serviços de saúde. (ARAUJO, et al., 2018)

\section{CONSIDERAÇÕES FINAIS}

Como visto, a atenção básica desempenha um papel fundamental no cuidado a esse grupo, colaborando no controle da patologia, desfecho gestacional sem intercorrências e de maneira satisfatória, para que o bebê tenha um nascimento saudável, além do cuidado para que não haja complicações nem para a mãe e nem para o neonato.

A atenção básica se preocupa em promover um cuidado a partir da necessidade e da realidade que cada gestante se encontra, procurando olhar de perto para as suas dificuldades, prestando e oferecendo suporte sobre o controle glicêmico, os sinais e sintomas, a utilização da insulina de forma correta, sobre a monitorização frequente do feto, a educação sobre o plano alimentar e a realização de exercícios físicos, entre outros cuidados. 
O restrito número de artigos encontrados sobre a temática abordada nesta revisão de literatura demonstra que existem lacunas e falta de estudos voltados na atenção prestada as mulheres com diabetes gestacional. Além disso, os altos índices de mulheres acometidas por essa patologia reforçam a necessidade de realizar trabalhos envolvendo esse grupo populacional.

\section{REFERÊNCIAS BIBLIOGRÁFICAS}

ZIMMET P, ALBERTI GK, MAGLIANO DJ, ET AL. Diabetes mellitus statistics on prevalence and mortality: facts and fallacies. Nat. rev. endocrinol. v.12, n.10, p.616-22, Jul/Set. 2016.

TAVARES VSA, VIDAL SA, GUSMÃO-FILHO FAR, ET AL. Avaliação da atenção ao diabetes mellitus em Unidades de Saúde da Família de Petrolina, Pernambuco. Epidemiol. serv. saúde. v.23, p.527-36, Abr/Jun. 2017.

CARVALHO FILHA FSS, NOGUEIRA LT, MEDINA MG. Avaliação do controle de hipertensão e diabetes na Atenção Básica: perspectiva de profissionais e usuários. Saúde debate. V.38, n.26578, Jan/Mar. 2014.

SANTOS, ALINY DE LIMA ET AL. Diabetes Pré-Gestacional: Experiência de Grávidas com o controle da doença. Cogitare Enfermagem., v. 19, n. 3, p. 561-8, Jul./Set. 2015.

SCHMALUSS, JOICE MOREIRA ET AL. Implicações das restrições alimentares na vida diária de mulheres com diabete melito gestacional. Rev enferm UERJ, Rio de Janeiro, 2016.

ARAÚJO, MÁRCIO FLÁVIO MOURA ET AL. Diabetes gestacional na perspectiva de mulheres grávidas hospitalizadas. Rev bras enferm., Brasília, v. 66, n. 2, Mar./Apr. 2018. 


\title{
COVID-19 E A INFLUÊNCIA NA SAÚDE MENTAL DOS TRABALHADORES DA ÁREA DA SAÚDE: UMA REVISÃO DE LITERATURA
}

\author{
Nágila Silva Alves'; Kaliny Vieira dos Santos Alves Pereira²; Adrielle Martins da Conceição ${ }^{3}$ \\ ${ }^{1}$ Fisioterapeuta Residente em Saúde da Família e Comunidade, Universidade Estadual do Piauí - \\ UESPI, Teresina, Piauí. \\ ${ }^{2}$ Graduanda em Enfermagem, Universidade Estadual do Piauí - UESPI, Picos, Piauí. \\ ${ }^{3}$ Bacharel de Fisioterapia, Centro Universitário do Piauí - UNIFAPI, Teresina, Piauí.
}

\section{RESUMO}

A partir da declaração de estado pandêmico pela Covid-19, os profissionais voltados a saúde passaram por mudanças pessoais e laborais visando combater a doença, passando por constante estresse psicológico. Seguindo esta perspectiva o estudo tem por objetivo analisar a literatura existente sobre as implicações e efeitos da pandemia do coronavírus na saúde mental dos profissionais da área da saúde, em virtude a investigar os possíveis impactos trazidos pela pandemia ao cotidiano desses. Trata-se de um estudo de revisão de literatura, realizado nas bases de dados BVS e Scielo, que objetiva sintetizar os resultados de pesquisas de maneira ordenada, auxiliando no aprofundamento do tema. Os sintomas psicológicos mais constatados incluíram insônia, ansiedade, depressão, ideação suicida, obsessivos-compulsivos, burnout e Transtorno de Estresse Pós-traumático. Portanto, verifica-se a importância do cuidado a esses trabalhadores, principalmente incentivo ao cuidado da saúde mental e física, disponibilizando atenção de profissionais da saúde mental capacitados.

PALAVRAS-CHAVE: Pandemia; Atenção à Saúde; Doenças do Trabalho.

ÁREA TEMÁTICA: Atenção à saúde

\section{INTRODUÇÃO}

Após declaração de estado de pandemia em todo o planeta, pela doença provocada por uma nova variação do coronavírus, a Covid-19, em questão de semanas, milhares de pessoas e governos tiveram que se readaptar para melhor enfrentamento dessa crise, assim foram necessárias revisões e reformulações de algumas normas e regimes internos dos serviços, para assim, conseguir diminuir a transmissão (SILVA et al., 2020). Na vanguarda dessas medidas encontram-se os profissionais de saúde, que apesar de se tornarem grupo emblemático do combate ao coronavírus, também se tornaram grupo com maior contato direto com a doença, e consequentemente, alto risco de contágio. Profissionais 
da área desconstruíram a rotina que tinham, passando a adotar medidas de distanciamento dos seus familiares, sofreram pressões acerca das exigências diárias enfrentadas, e tornaram-se, dessa forma, peças chaves no combate a pandemia, mas, ao mesmo tempo, muito vulneráveis às suas expectativas e influências (MINISTÉRIO DA SAÚDE, 2020).

No dia a dia os profissionais de saúde enfrentam condições de trabalho instáveis, onde o ambiente de trabalho passa insegurança, desde riscos ocupacionais até infraestrutura inadequada. Logo, são motivos que acarretam em alto nível de desgaste, adoecimento físico e psicológico, má qualidade de vida o que influi na qualidade da assistência prestada a população assistida. Diante desta perspectiva, o estresse é considerado um dos maiores males a saúde mental dos profissionais, fazendo com que agrave o nível de ansiedade, depressão, transtorno de estresse pós-traumático e comportamentos sociais negativos afetando o rendimento dos profissionais (REGO, PALÁCIOS, 2020).

Tendo em vista a alta demanda de trabalho desses profissionais, estes passaram a ser vítimas de um constante estresse psicológico diante perspectivas, cobranças e exigências acerca dos cuidados com a comunidade ao redor, e com a forma com a qual poderiam ser vias de transmissão. Nesse contexto, adentrou-se a um debate sobre os efeitos específicos desse momento trágico e histórico da humanidade para essa população.

Portanto, o presente trabalho tem por objetivo analisar a literatura existente sobre as implicações e efeitos da pandemia do coronavírus na saúde mental dos profissionais da área da saúde, em virtude a investigar os possíveis impactos trazidos pela pandemia ao cotidiano desses.

\section{METODOLOGIA}

Trata-se de um estudo de revisão de literatura que objetiva sintetizar resultados de pesquisas sobre o tema em questão de maneira ordenada, amparando no aprofundamento de informação e conhecimento do assunto averiguado (HOHENDORFF, 2014). Logo, foi feita caracterização do tema e preferência da hipótese de pesquisa para a elaboração da revisão. Foram então, estabelecidos os descritores da pesquisa onde optou por utilizar as palavras Covid-19, Saúde Mental e Trabalhadores da Saúde em combinação com operador booleano and e or para busca bibliográfica nas bases de dados Biblioteca Virtual em Saúde (BVS) e Scielo.

Os critérios de inclusão abrangeram artigos entre os anos de 2019 a 2020, que abordaram o tema saúde mental de trabalhadores da área da saúde durante a pandemia da Covid-19 e artigos na língua portuguesa. Os critérios de exclusão foram artigos publicados antes de 2019 e que abordaram profissionais de outras áreas que não da saúde, artigos que enfocavam a saúde mental de pacientes, crianças, adultos ou idosos da população geral, e textos que não fossem artigos em português.

Desta maneira, após a busca de publicações sobre o tema proposto, foram encontrados 07 artigos na Scielo e 14 na BVS. Após a leitura do título e resumos, e filtrar através dos critérios de 
inclusão e exclusão, desses 21 trabalhos, restaram 09. Logo, foram selecionados para análise na íntegra e inclusão nesta revisão 09 artigos.

\section{FUNDAMENTAÇÃO TEÓRICA}

Dos artigos analisados envolvendo a temática, todos foram publicados no ano de 2020. Entre as categorias profissionais investigadas estão médicos, enfermeiros, fisioterapeutas, psicólogos, auxiliares, farmacêuticos, técnicos e estagiários. Os resultados revelaram que o perfil epidemiológico dos profissionais da saúde que tiveram acometimento da saúde mental inclui, principalmente, mulheres jovens e que essa prevalência diminui com a idade. Os principais acometimentos psicológicos identificados nesta população incluíram sintomas de insônia ou distúrbios do sono, ansiedade, depressão, pensamentos suicidas, obsessivos-compulsivos, bem como de burnout e Transtorno de Estresse Pós-traumático.

O estresse e sofrimento que são expostos e que são em altos níveis muitas das vezes pode exceder as habilidades individuais de enfrentamento dos trabalhadores da área da saúde, podendo levar a uma sobrecarga emocional a longo prazo. Esta sobrecarga pode ser ainda aumentada pelo crescimento ou surgimento de sintomas de ansiedade, depressão, estresse pós-traumático e insônia. A literatura aponta que os acometimentos de saúde mental podem agravar fatores de risco, ou constituírem-se como fatores, para doenças virais e crônicas (BARROS et al., 2020; TEIXEIRA et al., 2020).

De acordo com ZHANG et al. (2020), o surgimento desses sintomas pode estar associado à incerteza que o vírus traz no ambiente de trabalho, como a falta de segurança, a falta de conhecimento sobre o coronavírus, sobre como se dá a sua prevenção e controle, a falta de equipamentos de segurança, a sobrecarga de trabalho, a falta de descanso e a exposição frequente à morte, somando-se ao medo dos riscos de contaminação de familiares, ou então a necessidade de afastamento destes.

Uma das principais demandas apontadas pelos trabalhos analisados foi a falta de preparação técnica desses profissionais para enfrentarem as dificuldades de se trabalhar em um contexto pandêmico. A carência de EPIs (equipamentos de proteção individual) e o inexorável risco de contaminação a que estão expostos mostraram-se contribuir significativamente para o sofrimento mental no trabalho dessas categorias profissionais, bem como medo, desgaste e até mesmo desvinculação com a atividade (TEIXEIRA et al., 2020).

Ressalta-se, portanto, a necessidade iminente e reparatória de preparação técnica em relação às demandas específicas de um contexto de pandemia para os profissionais da saúde, de autocuidado e minimização de contágios dentro, principalmente, dos ambientes hospitalares. Isso se traduz de forma que esses profissionais, além de todas as demandas que têm em lidar com a própria saúde mental, têm uma função social de suporte às queixas, medos e angústias dos pacientes e familiares, necessitando, portanto, de um espaço seguro para que possam sair de suas responsabilidades trabalhistas e sejam apenas um ser humano compartilhando suas angústias e sofrimentos a outro ser humano. (SAIDEL et 
al., 2020).

\section{CONSIDERAÇÕES FINAIS}

Os efeitos psicológicos sobre os profissionais que enfrentam diretamente a pandemia da Covid-19, são apresentados amplamente na literatura. A partir disso, verifica-se a importância do esforço conjunto para prevenção e cuidado desses trabalhadores, fazendo corriqueiramente um mapeamento dos trabalhadores que estão em processo de sofrimento durante a pandemia, assim como capacitação dos profissionais na identificação de sintomas psicopatológicos precoces em si e em pessoas próximas.

Os impactos trazidos pela problemática incluem alterações psicológicas como depressão, ansiedade, síndrome de burnout, além de outros distúrbios de saúde mental que diminuem expectativas e autossatisfação profissional, culminando em intensas consequências para os profissionais. Viu-se ainda que esse embate extrapola o viés psicológico e alcança um cenário de impacto para o sistema de saúde.

Ademais, é importante que a gestão da equipe de saúde articule estratégias que mobilizem esses profissionais a uma adesão considerável aos serviços de saúde mental, visto que a falta de tempo e a sobrecarga do trabalho podem gerar baixa anuência ao cuidado psíquico. O estabelecimento de ambientes de trabalho adequados, o incentivo ao cuidado da saúde mental e física (por meio de exercícios físicos e psicoterapia), assim como oferecendo atendimento e atenção de profissionais capacitados, podem auxiliar na sensibilização à procura por um serviço da área da saúde mental (MELO et al., 2020).

Em vista disso, tão urgente quanto o atendimento às vítimas da Covid-19, é o cuidado e assistência com a saúde mental dos seres humanos que tão prontamente colocaram-se à linha de frente para zelar por outros seres humanos.

\section{REFERÊNCIAS BILIOGRÁFICAS (ABNT)}

BARROS, M. B. et al. Relato de tristeza/depressão, nervosismo/ansiedade e problemas de sono na população adulta brasileira durante a pandemia de COVID-19. Epidemiologia e Serviços de Saúde:

Revista Do Sistema Único de Saúde Do Brasil, v. 29, n. 4, 2020.

BRASIL. MINISTÉRIO DA SAÚDE. Portaria MS/GM nº 188, de 3 de fevereiro de 2020. Declara Emergência em Saúde Pública de importância Nacional (ESPIN) em decorrência da Infecção Humana pelo novo Coronavírus (2019-nCoV) [Internet]. Diário Oficial da União, Brasília (DF), 2020 fev 4 [citado 2020 abr 7]; Seção Extra:1.

HOHENDORFF, J. V. Como escrever um artigo de revisão de literatura. IN: KOLLER, S. H.; COUTO, 
M. C. P. de P.; HOHENDORFF, J. V. (orgs.). Manual de Produção Científica. Porto Alegre: Penso, 2014, p. 39-54.

MELO, B. D. et al. Saúde mental e atenção psicossocial na pandemia COVID-19: recomendações para gestores. Fiocruz/CEPEDES, p. 1-13, 2020.

REGO S, PALÁCIOS M. Saúde mental dos trabalhadores de saúde em tempos de coronavírus. 2020 [acesso em: 28 de fevereiro de 2021].

SAIDEL, M. G. B. et al. Mental health interventions for health professionals in the context of the coronavirus pandemic. Revista Enfermagem, v. 28, p. 1-6, 2020.

SILVA MR, SILVA PC, RABELO HD, VINHAS BCV. A Terapia Ocupacional pediátrica brasileira diante da pandemia da COVID-19: reformulando a prática profissional. Rev. Interinst. Bras. Ter. Ocup. Rio de Janeiro. v.4, n. 3, p.422-437, 2020.

TEIXEIRA, C. F. S. et al. A saúde dos profissionais de saúde no enfrentamento da pandemia de Covid-19. Ciência \& Saúde Coletiva, v. 25, n. 9, 2020.

ZHANG, W. et al. Mental Health and Psychosocial Problems of Medical Health Workers during the COVID-19 Epidemic in China. Psychotherapy and Psychosomatics, v. 89, n. 4, p. 242-250, 2020. 


\section{COVID-19 E A VULNERABILIDADE DE PACIENTES PORTADORES DE DIABETES MELITTUS: UMA REVISÃO DE LITERATURA}

\section{Adrielle Martins da Conceição ${ }^{1}$; Nágila Silva Alves²; Kaliny Vieira dos Santos Alves Pereira ${ }^{3}$}

${ }^{1}$ Bacharel de Fisioterapia, Centro Universitário do Piauí - UNIFAPI, Teresina, Piauí.

${ }^{2}$ Fisioterapeuta Residente em Saúde da Família e Comunidade, Universidade Estadual do Piauí UESPI, Teresina, Piauí.

${ }^{3}$ Graduanda em Enfermagem, Universidade Estadual do Piauí - UESPI, Picos, Piauí.

\section{RESUMO}

A COVID-19 é uma doença causada pelo novo coronavírus SARS-CoV-2 (Severe Acute Síndrome Respiratória Coronavírus-2). A principal característica do SARS-CoV-2 que o distingue de outros vírus é a velocidade de transmissão combinada com maior risco de morte por síndrome do desconforto respiratório agudo (SDRA). Pessoas com diabetes mellitus (DM), são mais suscetíveis a serem infectadas além de possuírem maior risco de mortalidade por COVID-19. Um possível fator que pode desempenhar esse aumento do risco em pessoas diabéticas é o comprometimento inato e resposta imune adaptativa, caracterizado por um estado crônico e de baixo grau de inflamação que pode levar a alteração metabólica sistêmica repentina. Configura-se como um estudo de revisão de literatura, elaborado através das bases de dados BVS, Scielo e PubMed, que tem por objetivo reunir os resultados de pesquisas de maneira clara e sucinta destacando assim a vulnerabilidade desses pacientes.

PALAVRAS-CHAVE: Diabetes; Coronavírus; Comorbidade.

ÁREA TEMÁTICA: Atenção à saúde

\section{INTRODUÇÃO}

A Organização Mundial de Saúde (OMS) decretou condição de pandemia pela Covid-19, no dia 11 de março de 2020. Um surto de doença provocada por uma nova variação do coronavírus, o SarsCov-2. Com esse anúncio em pouquíssimos dias países em todo o mundo junto de potências mundiais tiveram que se reformular junto aos governos com medidas públicas para melhor enfrentamento dessa pandemia (FANG et al., 2020).

A principal característica do SARS-CoV-2 que o distingue de outros vírus é a velocidade de transmissão combinada com maior risco de óbito ocasionado pela síndrome do desconforto 
respiratório agudo (SDRA). Pessoas com comorbidades já pré existentes como Diabetes Mellitus (DM), obesidade grave, doença cardiovascular e hipertensão são mais prováveis infectados e com maior risco de mortalidade por Covid-19 (BLOOMGARDEN, 2020).

Isso porque esses pacientes já apresentam um quadro de saúde crítico quando comparado com pessoas sem nenhuma comorbidade. Em vista que a Diabete Mellitus tipo 2 é um grande fator de risco a vida por se tratar de uma patologia que leva consigo fatores deletérios sobre a imunidade do hospedeiro aumentando assim a susceptibilidade infecciosa e também piorando o prognóstico de infecção (ZHOU et al., 2019).

Desse forma, o presente estudo tem por finalidade analisar a literatura existente sobre a vulnerabilidade de pessoas portadoras de Diabetes Mellitus diante a pandemia da Covid-19, de forma a investigar as complicações como um fator de risco maior para esse grupo de pessoas. (WU et al., 2020)

\section{METODOLOGIA}

Esse trabalho trata-se de um estudo de revisão de literatura que tem por objetivo analisar resultados de pesquisas sobre o tema em questão de forma sucinta, explanando de forma clara e objetiva o assunto abordado (GONÇALVES, 2020).

Logo após serem estabelecidos os descritores da pesquisa optou-se por utilizar os descritores: Covid-19, Diabetes e Comorbidade, que foram encontrados na plataforma DECS (Descritores em Ciências da Saúde). Os quais foram combinados com descritores booleanos (and e or), para busca bibliográfica nas bases de dados Biblioteca Virtual em Saúde (BVS), Scielo e PubMed.

Os critérios de inclusão abrangeram artigos entre os anos de 2019 a 2021, que abordaram o tema Diabetes Mellitus tipo 2 e Covid-19, artigos na língua portuguesa e inglesa. Para os critérios de exclusão foi ultilizado filtro para artigos publicados antes de 2019 e que não abordavam o assunto do tema diabetes e Covid-19, revisões sistemáticas, e artigos que não fossem na língua portuguesa ou inglesa.

Desse modo, após a busca de publicações sobre o tema proposto, foram encontrados 27 artigos na Scielo e 254 na BVS e 3796 na PubMed. Após a leitura do título e resumos, e utilizar os critérios para inclusão e exclusão, o total de trabalhos selecionados foram 08 para análise na íntegra da presente pesquisa.

\section{FUNDAMENTAÇÃO TEÓRICA}

Sabe-se que os indivíduos com diabetes correm maior risco de várias infecções agudas e crônicas em comparação com indivíduos não diabéticos. Durante as pandemias de SARS, a taxa de 
admissão a unidade de terapia intensiva (UTI), junto a necessidade do uso da ventilação mecânica e mortalidade de pacientes diabéticos foi 3,1 vezes maior do que de pacientes não diabéticos (BLOOMGARDEN, 2020).

Diante disso, foi publicado o primeiro estudo no qual foi analisado as características bioquímicas, de pacientes diabéticos e infectados por Covid-19 e pacientes não diabéticos também infectados por Covid-19. O estudo indicou que a contagem absoluta de linfócitos em pacientes diabéticos é significativamente menor do que aqueles sem diabetes, enquanto a contagem de neutrófilos é notavelmente maior. Fatores de alto risco que indicam que pacientes com diabetes são suscetíveis a desenvolver uma avalanche inflamatória mais rápido, assim predispondo a rápida deterioração da Covid-19 (ZHOU et al., 2019).

Corroborando com isso WAN et al. (2020) disse que a hiperglicemia descontrolada está associada com aumento da gravidade de COVID-19 e aos números de óbitos, isso porque a hiperglicemia induz o aumento de ACE2 (angiotensin-converting enzyme) Como a entrada do SARSCoV-2 dar-se principalmente através da ligação dada por meio da proteína spike existente no vírus com o receptor da mólecula $\mathrm{ACE} 2$, com o aumento da quantidade dessa molécula sobre as células de pacientes diabéticos, torna-se mais suscetíveis as chances de infecções e influenciando também no agravo da patologia, Covid-19.

É válido considerar que pacientes portadores de Diabetes Melittus não estão mais suscetíveis e propensos a desenvolver apenas a Covid-19, mas todo e qualquer tipo de doença que seja de classe viral e/ou ameace o seu sistema imune. Assim, trazendo mais um alerta do quanto esse grupo de pessoas apresenta uma decadência e necessidade de atenção redobrada enquanto estamos diante de um cenário de pandemia a nível global. Além disso, a infecção por Covid-19 pode desenvolver resistência à insulina assim piorando a pré-existência do diabetes ou também induzir a evolução do pré-diabetes, desenvolvendo assim um ciclo vicioso (BODE et al., 2020)

\section{CONSIDERAÇÕES FINAIS}

Com o avanço do tempo podemos reconsiderar diversos fatores e formas de como tratar pacientes que foram acometidos pela Covid-19, no entanto quando se trata de pacientes diabéticos a suscetibilidade para um prognóstico e evolução ruim da doença ainda é consideravelmente maior. Os efeitos da pandemia da Covid-19 sobre esse grupo de pessoas em muitas situações tem sido irreparável.

Em vista disso, é aconselhável e extremamente necessário que pessoas com Diabetes Mellitus, tomem precauções em demasia para não contrair o vírus. Distanciamento social, higienização das mãos e uso de máscara são cuidados necessários para o momento. Além também, de buscarem garantir um bom controle da glicose, alimentação adequada e atividade física, como resposta fisiológica a melhora na glicemia aumentando dessa forma a resposta imune desse grupo de pessoas. 


\section{REFERÊNCIAS BILIOGRÁFICAS (ABNT)}

BLOOMGARDEN, ZT. Diabetes e COVID-19. Journal of Diabetes, 12 (4), 347-348, 2020.

BODE B, Garrett V, Messler J, et al. Glycemic characteristics and clinical outcomes of COVID-19 patients hospitalized in the United States. J Diabetes Sci Technol ;14:813-821, 2020.

FANG, L., Karakiulakis, G., \& Roth, M. Os pacientes com hipertensão e diabetes mellitus apresentam risco aumentado de infecção por COVID-19? The Lancet Respiratory Medicine, 2020.

GONÇALVES, Jonas Rodrigo. Como escrever um Artigo de Revisão de Literatura. Revista JRG de Estudos Acadêmicos, v. 2, n. 5, p. 29-55, 2019.

HUSSAIN, A., Bhowmik, B., \& Cristina do Vale Moreira, N. COVID-19 e Diabetes: Conhecimento em andamento. Diabetes Research and Clinical Practice, 108142, 2020.

Li X, Geng M, Peng Y, Meng L, Lu S. Molecular immune pathogenesis and diagnosis of COVID-19. J Pharm Anal;10:102-108, 2020.

MUNIYAPPA R, Gubbi S. COVID-19 pandemic, coronaviruses, and diabetes mellitus. Am J Physiol Endocrinol Metab. ; 318:E736-e41, 2020

PAL, R. e BHANSALI, A. COVID-19, diabetes mellitus e ACE2: O enigma. Diabetes Research and Clinical Practice, 162, 108132, 2020.

WAN Y, Shang J, Graham R, Baric RS, Li F. Receptor recognition by the novel coronavirus from Wuhan: an analysis based on decade-long structural studies of SARS coronavirus. J Virol ;94:e00127-e00120, 2020.

WU, Z., Tang, Y., \& Cheng, Q. (2020). Diabetes aumenta a mortalidade de pacientes com COVID-19: uma meta-análise. Acta Diabetologica, 2020.

ZHOU, Y., Chi, J., Lv, W., \& Wang, Y. Obesidade e diabetes como fatores de alto risco para doença coronavírus grave 2019 (COVID -19). Pesquisa e análises sobre diabetes / metabolismo, 2020. 


\section{INTERAÇÃO MEDICAMENTOSA NO ÂMBITO HOSPITALAR: UMA REVISÃO INTEGRATIVA}

\section{Thays Lima Araújoㅜㅜ Naiane Nadylla Nobre Sombra²; Lana Karine Vasconcelos Barroso ${ }^{3}$}

${ }^{1}$ Farmacêutica clínica e hospitalar do Hospital Municipal de Quixeré, Faculdade Vale do Jaguaribe (FVJ), Aracati, Ceará.

${ }^{2}$ Acadêmicas do curso de farmácia, Centro Universitário Maurício de Nassau (UNINASSAU), Fortaleza, Ceará.

${ }^{3}$ Professora da Faculdade Vale do Jaguaribe, Faculdade Vale do Jaguaribe (FVJ), Fortaleza, Ceará.

\section{RESUMO}

Introdução: Interação Medicamentosa (IM) é o fenômeno que ocorre quando a farmacodinâmica ou farmacocinética de um fármaco é alterada pela ingestão anterior ou concomitante de outro fármaco ou até mesmo alimento, benéficas ou danosas. Alguns fatores contribuem para seu surgimento, como idade, sexo, estado nutricional e polifarmácia. Objetivo: Analisar as interações medicamentosas que ocorrem no âmbito hospitalar, com ênfase nas principais classes de medicamentos envolvidas com interações medicamentosas. Metodologia: Revisão de literatura integrativa, analisados 12 artigos que seguiam o tema e objetivo do estudo. Fundamentação Teórica: É comum na prática clínica uso concomitante de vários medicamentos, contribuindo para o risco de interações medicamentosas. Considerações Finais: Ressaltar-se que a identificação de interações medicamentosas permite um tratamento seguro, eficaz e redução dos custos para o setor de saúde. Principais Referências: BALEN, E. et al. Interações medicamentosas potenciais entre medicamentos psicotrópicos dispensados. Jornal Brasileiro Psiquiatria, Niterói, Rio de Janeiro, v.66, n.3, p.172-177, 2017.

PALAVRAS-CHAVES: Segurança do paciente; Sinergismo farmacológico; Polifarmacoterapia. ÁREA TEMÁTICA: Atenção à Saúde

\section{INTRODUÇÃO}

Uma interação medicamentosa é definida como o fenômeno que ocorre quando os efeitos ou a farmacocinética de um fármaco são alterados pela administração prévia ou coadministração de um segundo fármaco. (TATRO, 2011). As interações medicamentosas podem ser sinérgicas, quando leva a uma melhora da terapêutica do paciente ou antagônica, quando surgem efeitos adversos ou diminuição do efeito do medicamento. (BALEN et al., 2017). Quanto à classificação, as interações 
medicamentosas podem ser do tipo farmacêutico, farmacocinético ou farmacodinâmico, este último podendo ser de efeito ou ação. (RANG et al., 2007).

Alguns fatores contribuem para o surgimento de interações medicamentosas; entre os quais, idade do paciente, condição clínica, patologia apresentada, frequência em que o medicamento é administrado, bem como o uso concomitante de vários medicamentos. Esta última sendo conhecida como Polifarmácia. (OKUNO et al., 2013). Que é o uso simultâneo de cinco medicamentos ou mais. (SECOLI, 2010). A incidência de interações medicamentosas é maior no ambiente hospitalar. (HAMMES et al., 2008). Esse resultado contribui de forma significativa no aumento de custos das instituições hospitalares. O aumento de interações medicamentosas contribui para o surgimento de reações adversas, levando em um maior tempo de internação do paciente no hospital, aumentando de forma direta os custos com medicamentos e afins. (RODRIGUES; OLIVEIRA, 2016). Conforme Pilau, Hegele e Heineck (2014) sabendo-se que no âmbito hospitalar o índice de interações medicamentosas é relevante, a atuação de uma equipe multidisciplinar é fundamental para reduzir erros de prescrições e dessa forma, aumentando a segurança do paciente.

A atuação do farmacêutico na equipe multidisciplinar é indispensável na identificação de interações medicamentosas, visto que ele possui correlação direta com prescritores e pacientes. Esse profissional atua na análise de prescrições, evitando desta forma 2 medicamentos desnecessários, na elaboração de guias terapêuticos, na dispensação do medicamento, na promoção do uso racional de medicamentos, sobretudo, na orientação quanto ao tratamento. (BERGSTEN-MENDES, 2008).

Este trabalho teve como objetivo analisar as interações medicamentosas que ocorrem no âmbito hospitalar, com ênfase nas principais classes de medicamentos envolvidas com interações medicamentosas

\section{METODOLOGIA}

Revisão de literatura integrativa, com pesquisa nas bases de dados, Scielo, Pubmed e Google Acadêmico. Foram considerados como critérios de inclusão artigos publicados no período de 2007 a 2018, bem como artigos que se referiam a interações medicamentosas no âmbito hospitalar incluindo Unidade de Terapia Intensiva. Foram encontrados 18 artigos relacionados ao tema, após uma leitura dos artigos foram excluídos 6 artigos. Desta forma, restaram-se 12 artigos para leitura. Os artigos foram lidos com cautela e serviram de base para elaboração do artigo.

\section{FUNDAMENTAÇÃO TEÓRICA}

Os artigos escolhidos e analisados foram dispostos em tabela, divididos por nome do(s) autor(es), título do artigo, ano de publicação, objetivo do artigo e o principal achado relacionado com o tema proposto. É comum na prática clínica o uso concomitante de vários medicamentos, contribuindo dessa forma para o risco de interações medicamentosas. Essa prática é conhecida como 
polifarmácia e tal situação são comuns e crítica em ambiente hospitalar, visto que os pacientes recebem uma quantidade variável de medicamentos durante o período de internação. (MOURA; RIBEIRO; MAGALHÃES, 2007; MOURA; TAVARES; ACURCIO, 2012).

Desta forma, o número de medicamentos prescritos está diretamente associado com o surgimento de interações medicamentosas. (FERREIRA SOBRINHO et al., 2006). Moura, Ribeiro e Magalhães (2007) em estudo realizado no Hospital das Clínicas da Universidade Federal de Minas Gerais observaram que a maioria das interações medicamentosas ocorreram quando foram prescritos cinco ou mais medicamentos, resultando em uma associação estatisticamente significativa. estima-se que a maioria dos pacientes no âmbito hospitalar utilize simultaneamente pelo menos seis medicamentos, justificando a prevalência de interações medicamentosas. (ALMEIDA; GAMA; AKAMINE, 2007). Esse risco é maior em pacientes de unidade de terapia intensiva (UTI), visto que o consumo de medicamentos nesse setor é elevado, podendo atingir 15 medicamentos prescritos por paciente. (ALVIM et al, 2015).

Como supõe Carvalho e colaboradores (2013) além do risco relacionado a polifarmácia, pacientes de unidades de terapia intensiva apresentam um risco relacionado a gravidade das doenças apresentadas, bem como falência de órgãos. Quanto à frequência de medicamentos prescritos, considerando o número de artigos avaliados, alguns medicamentos foram comumente observados com frequência nas prescrições de diferentes estudos realizados. Entre eles podemos citar a dipirona, furosemida, ranitidina, metoclopramida e omeprazol. Nos estudos as interações medicamentosas foram ainda avaliadas de acordo com sua gravidade. Elas podem ser do tipo grave, quando ocorre ameaça à vida devendo ter intervenção médica imediata, do tipo moderada, quando há piora do quadro clínico do paciente, nesse caso deve-se alterar a terapia medicamentosa ou ainda ser do tipo leve, onde o paciente apresenta mudança no quadro clínico, porém, não há necessidade de ocorrer mudança na terapia medicamentosa. (LIMA; CASSIANI, 2009).

Embora nem todas as interações medicamentosas possam ser evitadas, é importante que os profissionais de saúde tenham conhecimento quanto aos riscos e fatores associados das interações medicamentosas. Com isso os profissionais de saúde poderão optar por protocolos terapêuticos e horários de administração dos medicamentos de forma mais segura. (LIMA; CASSIANI, 2009).

Portanto ressalta-se a importância de uma equipe multidisciplinar, principalmente médicos, enfermeiros e farmacêuticos para uma avaliação sucinta dos medicamentos utilizados na terapêutica dos pacientes. Se houvesse uma análise criteriosa das prescrições, muitas interações medicamentosas poderiam ser evitadas. (MOURA; RIBEIRO; MAGALHÃES, 2007).

As interações medicamentosas estão diretamente relacionadas com a quantidade de medicamentos que são prescritos e utilizados por pacientes durante o dia, essa prática é denominada polifarmácia sendo mais frequente em pacientes hospitalizados e idosos. Sabe-se que a frequência de interação medicamentosa é maior em ambiente hospitalar, principalmente em pacientes submetidos à unidade de terapia intensiva, visto que são pacientes que apresentam condições saúde delicadas, muitas vezes associada a alterações fisiológicas, como problema renal ou hepático. 


\section{CONSIDERAÇÕES FINAIS}

De acordo com os resultados analisados, foi possível observar que a Dipirona foi o medicamento mais prescrito, além de apresentar o maior envolvimento com interações medicamentosas. Justificando a relação quanto à frequência de medicamentos prescritos e o surgimento de interações medicamentosas.

Diante do exposto, a ocorrência de interações medicamentosas no âmbito hospitalar interfere diretamente na eficácia do tratamento de pacientes internados, contribuindo para uma redução na qualidade de vida desses pacientes, além de elevar os custos do setor hospitalar.

O reconhecimento de interações medicamentosas por profissionais de saúde possibilita evitar situações de insucesso terapêutico, além de minimizar o aparecimento de interações medicamentosas.

\section{PRINCIPAIS REFERÊNCIAS}

BALEN, E. et al. Interações medicamentosas potenciais entre medicamentos psicotrópicos dispensados. Jornal Brasileiro Psiquiatria, Niterói, Rio de Janeiro, v.66, n.3, p.172-177, 2017. Disponível em: < http://www.scielo.br/pdf/jbpsiq/v66n3/0047-2085-jbpsiq-66-3- 0172.pdf>. Acesso em: 24 set. 2018. BERGSTEN-MENDES, G. Uso racional de medicamentos: o papel fundamental do farmacêutico. Revista Ciência \& Saúde Coletiva, v.13, n.(sup), p.569-577, 2008. Disponível em: $<$ http://www.scielo.br/pdf/csc/v13s0/a03v13s0.pdf >. Acesso em: 24 set. 2018.

CARVALHO, R.E.F..L de et al. Prevalência de interações medicamentosas em unidades de terapia intensiva no Brasil. Revista Acta Paulista Enfermagem, São Paulo, v.26, n.2, p.150- 157, 2013. Disponível em: < http://www.scielo.br/pdf/ape/v26n2/v26n2a08.pdf>. Acesso em: 25 set. 2018.

HAMMES, J. A. et al. Prevalência de potenciais interações medicamentosas droga-droga em unidades de terapia intensiva. Revista Brasileira de Terapia Intensiva, São Paulo, v.20, n.4, p.349354, 2008. Disponível em: < http://www.scielo.br/pdf/rbti/v20n4/v20n4a06.pdf>. Acesso em: 08 ago. 2018.

PASSOS, M. M. B de et al. Interações medicamentosas em pacientes internados na clínica médica de um hospital de ensino e fatores Associados. Revista Brasileira de Farmácia, Rio de Janeiro, v.93, n.4, p.450-456, 2012. Disponível em: < http://rbfarma.org.br/files/rbf-2012- 93-4-9. pdf>. Acesso em: 03 nov. 2018. 


\title{
LEVANTAMENTO ETNOBOTÂNICO DE ESPÉCIES VEGETAIS UTILIZADAS NA MEDICINA POPULAR PARA O TRATAMENTO DE DISTÚRBIOS GASTROINTESTINAIS
}

\author{
Rubens Barbosa Rezende ${ }^{1}$ \\ ${ }^{1}$ Graduando em Biomedicina, Faculdade Santa Rita (FASAR), Conselheiro Lafaiete, Minas Gerais.
}

\section{RESUMO}

Em todo o mundo, espécies vegetais com propriedades curativas, são utilizadas como a principal via para o tratamento de enfermidades em comunidades. E dessa forma, objetivou-se discutir e analisar os acervos etnobotânicos de plantas medicinais utilizados na medicina popular para tratamento de distúrbios gastrointestinais. Por meio de uma revisão integrativa da literatura nas bases de dados SciELO, MEDLINE e LILACS, utilizando os critérios de inclusão: artigos completos, disponibilizados de forma gratuita, publicados em inglês, espanhol e português, entre janeiro de 2010 a fevereiro de 2021. Foi observado que dentre as espécies vegetais encontradas, a janaúba, demonstrou um amplo espectro de aplicações como a terapia de gastrite, inflamações uterinas, uso veterinário, complemento alimentar, fortificante, e tratamento de cânceres.

Portanto, as plantas medicinais estão bem difundidas na medicina popular e possuem uma significante importância na terapia de distúrbios gastrointestinais.

PALAVRAS-CHAVES: Etnobotânica; Gastrite; Plantas Medicinais.

ÁREA TEMÁTICA: Atenção à Saúde

\section{INTRODUÇÃO}

Em todo o mundo, espécies vegetais com propriedades curativas, são utilizadas como a principal via para o tratamento de enfermidades em comunidades. E no Brasil, mesmo com muitas contribuições científicas relacionadas as atividades biológicas e aos aspectos fitoquímicos, ainda se tem uma carência em resultados para as descobertas de novos medicamentos, uma vez que, muitas plantas identificadas com potenciais farmacológicos a partir da medicina popular ainda não foram estudadas quanto à sua eficácia do ponto de vista terapêutico (GOIS, et al., 2016). E desde muitos anos, as plantas medicinais têm desenvolvido uma significante fonte de meios terapêticos, na qual diversas fontes de substâncias naturais vêm sendo muito empregadas como meio de obtenção de compostos bioativos. E mesmo com esta gama de utilizações, o interesse medicinal frequente é para 
a terapia de úlceras duodenais e gástricas, além das gastrites (HOLNIK, et al., 2015).

Holnik e colaboradores (2015) enfatizam que o trato gastrointestinal é um potente somatizador dos quadros emocionais vividos pelo ser humano, sendo evidente o seu impacto nas últimas décadas, dessa forma, distúrbios gastrointestinais com a gastrite, doenças inflamatórias intestinais, úlceras pépticas, constipação intestinal e refluxo gastroesofágico têm agravado os índices de enfermidades na sociedade, trazendo assim destaque para investigação clínica e experimental para a identificação de novas terapias. Dessa forma, objetivou-se discutir e analisar os acervos etnobotânicos de plantas medicinais utilizados na medicina popular para tratamento de distúrbios gastrointestinais.

\section{METODOLOGIA}

Trata-se de uma revisão integrativa da literatura nas bases de dados SciELO, MEDLINE e LILACS, utilizando como questão norteadora: “Quais plantas medicinais já descritas na literatura possuem indicação para tratamento de distúrbios gastrointestinais?" A busca foi feita utilizando os descritores: "gastrite" e "plantas medicinais", cadastrados no DeCS/MeSH e empregando o operador booleano AND. Foram encontrados 163 artigos nas três bases de dados, e selecionados 15 para compor essa revisão. Os critérios de inclusão foram: artigos completos, disponibilizados de forma gratuita, publicados em inglês, espanhol e português, entre janeiro de 2010 a fevereiro de 2021. Bem como os critérios de exclusão foram: resumos, artigos nos demais idiomas, não disponibilizados de forma gratuita e nos quais não abordavam o uso das plantas medicinais pela medicina popular para o tratamento de doenças gastrointestinais.

\section{FUNDAMENTAÇÃO TEÓRICA}

As plantas utilizadas como tratamento pela medicina popular demonstram uma relevante importância quando referidas a enfermidades menos graves e que estão inclusas na atenção primária à saúde, como por exemplo, feridas, gastrite, úlceras, gripes, enjoos, dores e inflamações (ALBERTASSE; THOMAZ e ANDRADE, 2010). De acordo com Liporacci e Simão (2013), o sistema digestório obteve o recorde de citações de enfermidades e sintomas associados a ele, e dentre estas patologias, estão azia, males do estômago, gastrite e úlcera.

Dentre as espécies vegetais encontradas, a janaúba demonstrou um amplo espectro de aplicações como a terapia de gastrite, inflamações uterinas, uso veterinário, complemento alimentar, fortificante, e tratamento de cânceres (LINHARES, 2010). Ainda Linhares (2010) em seu estudo, ressalta que a espécie Vernonia condensata conhecida popularmente como boldo, é utilizada na terapia para a gastrite, diarreia e dores estomacais, como também é considerada a mais prevalente nos levantamentos etnobotânicos medicinais brasileiros. E em relação ao seu perfil fitoquímico, o boldo demonstrou a presença de esteroides, triterpenoides, cariocal e barbatusina.

Já Gois e colaboradores (2016) em seu estudo realizado no Rio Urubueua de Fátima, 
Abaetetuba - PA, demonstrou também que o boldo ( $V$. condensata), obteve muitas indicações para os quadros associados ao sistema gastrointestinal. A terapia de doenças gastrointestinais com a utilização de espécies vegetais como a erva-cidreira (Lippia thymoides Mart. \& Schauer) possuem atuação nas perturbações hepáticas, digestivas, disentéricas e diarreicas, como demonstrado no quadro 1.

Quadro 1. Espécies vegetais indicadas no tratamento de distúrbios gastrointestinais.

\begin{tabular}{|c|c|c|c|}
\hline Família/Espécie & Nome popular & Indicações & $\begin{array}{c}\text { Parte } \\
\text { utilizada }\end{array}$ \\
\hline \multicolumn{4}{|c|}{ AMARANTHACEAE } \\
\hline Chenopodium ambrosioides L. & Mastruz & Enjoo e diarreia & Folhas \\
\hline \multicolumn{4}{|c|}{ APIACEAE } \\
\hline Eryngium foetidum $\mathrm{L}$. & Sucuuba & Gastrite & Casca. Látex \\
\hline \multicolumn{4}{|c|}{ ANACARDIACEAE } \\
\hline Anacardium occidentale L. & Cajú & Diarreia & Casca. Grelo* \\
\hline \multicolumn{4}{|c|}{ ASTERACEAE } \\
\hline $\begin{array}{l}\text { Pluchea sagittalis (Lam.) } \\
\text { Cabrera }\end{array}$ & Boldo & $\begin{array}{l}\text { Gastrite e dor de } \\
\text { estômago }\end{array}$ & Folhas \\
\hline Vernonia condensata Baker & Boldo & $\begin{array}{l}\text { Dor de estômago e } \\
\text { diarreia }\end{array}$ & Folhas \\
\hline Mikania lindleyana DC. & Sucuriju & Dor de estômago & Folhas \\
\hline \multicolumn{4}{|c|}{ CHRYSOBALANACEAE } \\
\hline Licania laxiflora Fritsch & Anoerá & Gastrite & Casca \\
\hline \multicolumn{4}{|c|}{ COSTACEAE } \\
\hline Costus lasius Loes. & Canaficha & Gastrite & Folhas \\
\hline \multicolumn{4}{|c|}{ EUPHORBIACEAE } \\
\hline Croton cajucara Benth. & Sacaca & Dor de estômago & Folhas \\
\hline \multicolumn{4}{|c|}{ FABACEAE } \\
\hline $\begin{array}{c}\text { Libidibia ferrea (Mart. ex. } \\
\text { Tul.) }\end{array}$ & Escada-de-jabuti & Gastrite & Fruto \\
\hline Dalbergia monetaria L. f & Verônica & Diarreia & Casca \\
\hline \multicolumn{4}{|c|}{ LAMIACEAE } \\
\hline $\begin{array}{l}\text { Aeollanthus suaveolens Mart. } \\
\text { Ex Spreng. }\end{array}$ & $\begin{array}{l}\text { Catinga-de- } \\
\text { mulata }\end{array}$ & Dor de estômago & Folhas \\
\hline Coleus sp. & Sete-dores & Dor de estômago & Folhas \\
\hline \multicolumn{4}{|c|}{ RUTACEAE } \\
\hline Ruta graveolens L. & Arruda & Dor de estômago & Folhas \\
\hline Citrus $\times$ limonia $(\mathrm{L}$.$) Osbeck$ & Limão & $\begin{array}{c}\text { Dor de estômago } \\
\text { Enjoo }\end{array}$ & $\begin{array}{l}\text { Folhas } \\
\text { Casca }\end{array}$ \\
\hline \multicolumn{4}{|c|}{ VERBENACEAE } \\
\hline Lippia alba (Mill) N.E. Brown & Manjerona-salva & Dor de estômago & Folhas \\
\hline $\begin{array}{c}\text { Lippia thymoides Mart. \& } \\
\text { Schauer }\end{array}$ & Erva-cidreira & Dor de estômago & Folhas \\
\hline \multicolumn{4}{|c|}{ XANTHORRHOEACEAE } \\
\hline Aloe vera $\mathrm{L}$. & Babosa & Dor de estômago & Folhas \\
\hline
\end{tabular}

Nota: *Grelo: pontas dos ramos da árvore. Fonte: adaptado de Gois, et al. 2016, p. 550-551. 


\section{CONSIDERAÇÕES FINAIS}

Portanto, ficou evidente que as plantas medicinais estão bem difundidas na medicina popular e possuem uma significante importância na terapia de distúrbios gastrointestinais. E dentre as muitas espécies vegetais encontradas, a janaúba e o boldo apresentaram uma gama de aplicações, sendo utilizadas na terapia de diversas enfermidades. E dentre as famílias avaliadas, a Asteraceae foi a que possuiu maior número de espécies utilizadas pela população, tendo inclusas, duas espécies de boldo com dupla indicação na medicina popular, além de possuir um perfil fitoquímico rico em esteroides, triterpenoides, cariocal e barbatusina.

E mesmo com esta riqueza de espécies vegetais utilizadas, mais estudos são necessários para comprovarem a eficácia de seus usos na terapia das demais doenças ligadas ao sistema gastrointestinal, além da avaliação da toxicidade vegetal, identificação e posologia correta, nas quais se ocorrerem erros, podem comprometer de forma negativa na vida da população.

\section{PRINCIPAIS REFERÊNCIAS}

ALBERTASSE, P.D.; THOMAZ, L.D.; ANDRADE, M.A. Plantas medicinais e seus usos na comunidade da Barra do Jucu, Vila Velha, ES. Rev. bras. plantas med., Botucatu, v. 12, n. 3, p. 250260, Sept. 2010. https://doi.org/10.1590/S1516-05722010000300002.

FEIJÓ, E.V.R.S.; et al., Levantamento preliminar sobre plantas medicinais utilizadas no bairro Salobrinho no município de Ilhéus, Bahia. Revista Brasileira de Plantas Medicinais, v.15, n.4, p.595$604,2013$.

GOIS, MAF et al. Etnobotânica de espécies vegetais medicinais no tratamento de transtornos do sistema gastrointestinal. Rev. bras. plantas med., Botucatu, v. 18, n. 2, pág. 547-557, junho de 2016. https://doi.org/10.1590/1983-084X/15_170.

HOLNIK, P.R. et al. Comparação do teor de taninos entre duas espécies de espinheira-santa (Maytenus aquifolium Mart.e Maytenus ilicifolia Mart. ex Reissek) cultivadas no Horto Medicinal do Refúgio Biológico Bela Vista - RBBV da Itaipu Binacional - Foz do Iguaçu, PR - Brasil. Rev. bras. plantas med., Botucatu, v. 17, n. 3, p. 385-391, Sept. 2015. http://dx.doi.org/10.1590/1983-084X/12_160.

LINHARES, J. F. P. L. Sustentabilidade sócio-ambiental da extração de janaúba (Himatanthus Willd. Ex Schult.) no município de Alcântara, MA, Brasil. São Luís, UFMA. 116f. 2010. Dissertação (Sustentabilidade de Ecossistemas). Programa de Pós-graduação em Sustentabilidade de Ecossistemas. Departamento de Oceanografia e limnologia. Universidade Federal do Maranhão. São Luís. 2010

LIPORACCI, HSN; SIMAO, DG. Levantamento etnobotânico de plantas medicinais nos quintais do Bairro Novo Horizonte, Ituiutaba, MG. Rev. bras. plantas med., Botucatu, v. 15, n. 4, pág. 529-540, 2013. https://doi.org/10.1590/S1516-05722013000400009. 
SIMAO, DG. Levantamento etnobotânico de plantas medicinais nos quintais do Bairro Novo Horizonte, Ituiutaba, MG. Rev. bras. plantas med., Botucatu, v. 15, n. 4, pág. 529-540, 2013. https:// doi.org/10.1590/S1516-05722013000400009. 


\title{
FATORES RELACIONADOS À PRÁTICA DA POLIFARMÁCIA EM IDOSOS: REVISÃO BIBLIOGRÁFICA
}

\author{
Daniela Vieira Cardoso ${ }^{1}$; Izadora Zucolotto Zampiroli \\ ${ }^{1}$ Graduanda em Medicina, Centro Universitário UNIFACIG, Manhuaçu, Minas Gerais. \\ ${ }^{2}$ Graduanda em Medicina, Centro Universitário UNIFACIG, Manhuaçu, Minas Gerais.
}

\begin{abstract}
RESUMO
Introdução: $\mathrm{O}$ aumento da expectativa de vida elevou o número de idosos e portadores de doenças crônicas, que estão sujeitos a polifarmácia, definida pelo uso de cinco ou mais medicamentos. $\mathrm{O}$ termo foi associado ao aumento do risco de reações adversas medicamentosas, toxicidade cumulativa, morbimortalidade, má adesão ao tratamento e iatrogenia, resultando em gastos dispensáveis ao SUS. Metodologia: Trata-se de uma pesquisa qualitativa, de revisão literária de caráter descritivo e bibliográfico. Objetivo: Elucidar os fatores associados a polifarmácia em idosos. Fundamentação teórica: Relacionou-se a comunicação médico-paciente ineficiente a sobreutilização de fármacos, bem como o atendimento por muitos profissionais num curto período de tempo. Também, a polifarmácia foi associada ao sexo feminino, analfabetismo, a automedicação e ao acesso a planos de saúde privados, que facilitam a obtenção de prescrições. Conclusão: Deve-se desenvolver programas que envolvam a educação dos idosos e da equipe de saúde quanto a automedicação, polifarmácia e prescrições racionais.
\end{abstract}

PALAVRAS-CHAVES: Efeitos Adversos; Medicamentos; Farmacoterapia.

ÁREA TEMÁTICA: Atenção à Saúde

\section{INTRODUÇÃO}

Durante o século XX houveram alterações nos perfis demográficos e de morbimortalidade que evidenciaram redução da fecundidade e elevação da expectativa de vida (PEREIRA et al., 2017). Desse modo, observou-se o aumento de manifestações clínicas decorrentes do envelhecimento e pacientes com doenças crônicas, os quais estão sujeitos ao uso de mais medicamentos do que a média.

O uso racional de medicamentos é definido como aquele realizado com o medicamento correto, doses adequadas e por um período apropriado (ALMEIDA, 2017). Em contrapartida, a polifarmácia pode ser definida pelo uso de mais medicamentos do que está clinicamente proposto ou o consumo de cinco ou mais medicamentos (SALES; SALES; CASOTTI, 2014). 
Nesse sentido, erros entre o diagnóstico e o tratamento prescrito, o uso inadequado de medicamentos e a comunicação médico-paciente deficiente, são correlacionados a causas de eventos adversos (NASCIMENTO et al., 2017), que podem aumentar o risco de iatrogenia, hospitalização e óbito (PEREIRA et al., 2017). Em harmonia, o aumento do risco e gravidade das Reações Adversas a Medicamentos (RAM), a toxicidade cumulativa, os erros de prescrição, bem como a redução da adesão ao tratamento e a elevação da morbimortalidade foram associadas a polifarmácia (SECOLI, 2010). Logo, tal prática deve ser relacionada aos excessivos custos assistenciais dos medicamentos e das consequências do seu uso indevido (ALMEIDA, 2017).

Assim, tendo em vista os referidos riscos relativos a polifarmácia, o presente estudo tem como objetivo incentivar o uso racional de medicamentos e reduzir gastos dispensáveis ao SUS através da elucidação dos fatores associados ocorrência da polifarmácia em idosos.

\section{METODOLOGIA}

Desenvolveu-se esse estudo utilizando abordagem de pesquisa qualitativa a partir de uma revisão literária de caráter descritivo e bibliográfico. As principais fontes de consulta para este trabalho foram as bases de dados eletrônicos: Scielo e Google acadêmico, onde os artigos foram localizados por meio dos seguintes descritores: Idosos; Polifarmácia; Atenção Primária. Os artigos foram integralmente lidos para a realização da obra.

\section{FUNDAMENTAÇÃO TEÓRICA}

A senescência por si só, mesmo se tratando de um envelhecimento natural, traz consigo alterações fisiológicas, farmacocinéticas e farmacodinâmicas que interferem na farmacoterapia dos pacientes, principalmente se esses forem acometidos pelo fenômeno da senilidade. Desse modo, os idosos, além de serem propensos ao uso elevado de medicamentos, têm maior vulnerabilidade a eventos adversos e interações medicamentosas, o que, consequentemente, os submete a mais fármacos (CARVALHO, 2012).

Nesse seguimento, o diálogo ineficaz corrobora com a sobreutilização de medicamentos quando o médico não informa ao paciente sobre a duração do tratamento e não o questiona sobre os medicamentos em uso, principalmente quando esse é atendido por diferentes profissionais em momentos próximos (CARVALHO, 2012). Assim, as receitas são repetidas continuamente, devido a facilidade de obtenção dos medicamentos pelo SUS (PEREIRA et al., 2017).

Além disso, estudos indicam que há predomínio de polifarmacias entre idosos analfabetos, por haver dificuldade em compreender o plano terapêutico proposto e, logo, acarretar o uso incorreto do medicamento. O mesmo estudo sugeriu relação entre a automedicação e menor grau de escolaridade (CARNEIRO et al., 2018). 
Também, mulheres foram associadas ao cenário de polifarmácias em razão da maior consciência a respeito da própria saúde, prevalência de doenças não fatais e maior familiaridade com os medicamentos (SALES; SALES, CASSOTTI, 2014), além de conviverem mais tempo com processos crônicos, dada a maior expectativa de vida (PEREIRA, et al., 2017).

Finalmente, houve conexão entre a polifarmácia e indivíduos com plano de saúde privado, pelo acesso facilitado a consultas e prescrições diversas, enquanto os médicos de instituições públicas costumam prescrever medicamentos disponíveis no SUS (NASCIMENTO et al., 2017).

\section{CONCLUSÃO}

Compreende-se que é necessário o envolvimento de toda a equipe de saúde nos cuidados com os idosos através de programas integrados que envolvam a educação dos idosos quanto a automedicação e implementação de protocolos que os auxiliem no seguimento da terapia medicamentosa, favorecendo a racionalidade nas prescrições e, portanto, menor possibilidade de polifarmácia. Nesse cenário, temse como imprescindível a inclusão do profissional farmacêutico corresponsável no monitoramento dos resultados terapêuticos e efeitos adversos. Por fim, há que fomentar prescrições claras e de fácil compreensão no que tange aos horários de tomada dos medicamentos, com relação benefício-risco muito bem classificada.

\section{PRINCIPAIS REFERÊNCIAS}

DE ALMEIDA, N. A. et al. Prevalência e fatores associados à polifarmácia entre os idosos residentes na comunidade: Revista Brasileira de Geriatria e Gerontologia. 1. ed. Rio de Janeiro: [s. n.], 2017. 143-153 p. v. 20. DOI https://doi.org/10.1590/1981-22562017020.160086. Disponível em: https://www.redalyc.org/pdf/4038/403850707015.pdf. Acesso em: 1 mar. 2021.

CARNEIRO, J. et al. Prevalência e fatores associados à polifarmácia em idosos comunitários. Medicina (Ribeirão Preto), v. 51, n. 4, p. 254-264, 27 dez. 2018. Disponível em: https://core.ac.uk/download/pdf/268328257.pdf. Acesso em: 16 fev. 2021.

CARVAlHO, M. F. C. Polifarmácia entre idosos do Município de São Paulo - Estudo SABE. Revista Brasileira de Epidemiologia, São Paulo, SP, Brasil, 17 jan. 2012. Disponível em: https://www.scielosp.org/article/rbepid/2012.v15n4/817-827/pt/\#ModalArticles. Acesso em: 18 fev. 2020.

MONTEIRO, O. R. B. et al. Polifarmácia entre idosos assistidos pela Estratégia Saúde da Família. Revista de Enfermagem da UFPI, Teresina- PI, Brasil., 2014. Disponível em: https:// revistas.ufpi.br/index.php/reufpi/article/view/1419/pdf. Acesso em: 25 fev. 2020.

NASCIMENTO, R. C. R. M. et al. Polypharmacy: a challenge for the primary health care of 
the Brazilian Unified Health System. Revista de Saúde Pública [online]. 2017, v. 51, suppl 2. Disponível em: <https://doi.org/10.11606/S1518-8787.2017051007136>. Epub 13 Nov 2017. ISSN 1518-8787. https://doi.org/10.11606/S1518-8787.2017051007136. Acesso em: 25 fev. 2020.

PEREIRA, K. G. et al. Polifarmácia em idosos: um estudo de base populacional. Revista Brasileira de Epidemiologia [online]. 2017, v. 20, n. 02, pp. 335-344. Disponível em: <https:// doi.org/10.1590/1980-5497201700020013>. ISSN 1980-5497. https://doi.org/10.1590/19805497201700020013. Acesso em: 22 fev. 2020.

SALES, A. S.; SALES, M. G. S.; CASOTTI, C. A.. Perfil farmacoterapêutico e fatores associados à polifarmácia entre idosos de Aiquara, Bahia, em 2014. Epidemiologia e Serviços de Saúde, Campus de Jequié-BA, v. 26, ed. 1, p. 121-132, 2014. Disponível em: https:/www.scielosp.org/ article/ress/2017.v26n1/121-132/pt/\#ModalArticles. Acesso em: 23 fev. 2020.

SECOLI, Silvia Regina. Polifarmácia: interações e reações adversas no uso de medicamentos por idosos. Rev. bras. enferm., Brasília, v. 63, n. 1, p. 136-140, Feb. 2010. Disponível em: http:// www.scielo.br/scielo.php?script=sci_arttext\&pid=S0034-71672010000100023\&lng=en\&nrm=iso. Acesso em: 24 Feb. 2020. 


\title{
O COMPROMISSO BIOÉTICO DA ENFERMAGEM, FRENTE À VACINAÇÃO CONTRA COVID-19 NO ESTADO DO AMAPÁ
}

\author{
Alana Corrêa Santos ${ }^{1}$; Sarah Bianca Trindade²; Luiza Soares Pinheiro ${ }^{3}$; Marcia Eduarda \\ Dias Conceição ${ }^{4}$; Vanessa Gomes de Souza ${ }^{5}$; Camila Rodrigues Barbosa Nemer ${ }^{6}$; Nely Dayse \\ Santos da Mata $^{7}$ \\ ${ }^{1}$ Graduanda em enfermagem, Universidade Federal do Amapá (UNIFAP), Santana, Amapá. \\ ${ }^{2}$ Graduanda em enfermagem, Universidade Federal do Amapá (UNIFAP), Macapá, Amapá. \\ ${ }^{3}$ Graduanda em enfermagem, Universidade Federal do Amapá (UNIFAP), Macapá, Amapá. \\ ${ }^{4}$ Graduanda em enfermagem, Universidade Federal do Amapá (UNIFAP), Macapá, Amapá. \\ ${ }^{5}$ Residente em saúde da criança e do adolescente, Universidade Federal do Amapá (UNIFAP), \\ Macapá, Amapá \\ ${ }^{6}$ Doutoranda, Fundação Oswaldo Cruz, Macapá, Amapá. \\ ${ }^{7}$ Doutorado, Universidade Federal do Amapá (UNIFAP), Macapá, Amapá.
}

\begin{abstract}
RESUMO
Descrever a experiência de acadêmicos de enfermagem na campanha de vacinação contra covid-19 no estado do Amapá, abordando princípios éticos e bioéticos no manejo da vacina. Método: trata-se de um relato de experiência a partir da vivência de acadêmicos de enfermagem na vacinação dos profissionais de saúde. Resultados: Observou-se tentativas de profissionais que buscavam prevalecer a sua posição funcional, na tentativa de vacinar seus familiares. Mesmo diante das determinações da equipe, a qual estava à frente da vacinação, alguns profissionais, mostraram-se incompreensíveis, quanto ao cumprimento da fila de prioridade. Conclusão: A experiência de participar da vacinação contra covid-19 evidenciou implicações bioéticas quanto ao princípio da Justiça. Observou-se a imposição de profissionais de saúde, no sentido de tentar garantir um direito, que naquele momento não estava estabelecido. Neste sentido, vivenciamos o empoderamento da equipe de enfermagem, que diante do conflito seguiu os princípios bioéticos que envolviam a imunização contra covid-19.
\end{abstract}

PALAVRAS-CHAVES: Saúde pública; Ética; Responsabilidade.

ÁREA TEMÁTICA: Atenção à Saúde. 


\section{INTRODUÇÃO}

No ano de 2020, o Brasil e o mundo passaram a enfrentar um vírus novo, conhecido como SARS-CoV-2, que até fevereiro de 2021 acumulou 9.548.079 milhões de casos confirmados da doença, ceifando vidas, sobrecarregando os hospitais e evidenciando as fragilidades no sistema de saúde (BRASIL, 2021).

Tratando-se de um vírus recente, a ciência não possuía conhecimentos e técnicas adequadas para o combate à doença, dando início aos esforços científicos para desenvolver uma vacina capaz de combater os índices de infecção e morte, causados pela COVID-19. Na região Norte, o estado do Amapá acumulava, até janeiro de 2021, com mais de 76 mil casos da doença. A vacina trouxe a discussão acerca da ética e bioética dos profissionais da saúde, uma vez que, o respeito para com as prioridades do plano de vacinação é primordial, colocando os profissionais que atuam na linha de frente contra o vírus como público-alvo. Com isso, Sanches (2020) analisa que em situações de emergência e de um possível dano, deve-se levar em consideração a justiça e o respeito, diminuindo a busca incessante por vantagens. Nesse momento o conhecimento técnico-científico deve ser utilizado para influenciar o certo e o errado, para que haja bioética em qualquer decisão de saúde.

A equipe de enfermagem, que está à frente da imunização no estado do Amapá, necessita levar consigo o Código de Ética dos Profissionais de Enfermagem ao exercer seu trabalho, com justiça, responsabilidade e honestidade, com o objetivo de evitar possíveis comportamentos corruptos durante a vacinação, e garantir que o público-alvo seja contemplado em sua totalidade. Portanto, este trabalho tem como objetivo: descrever a experiência de acadêmicos de enfermagem na campanha de vacinação contra covid-19 no estado do Amapá, abordando princípios éticos e bioéticos no manejo da vacina.

\section{METODOLOGIA}

Estudo descritivo de caráter qualitativo, no formato de relato de experiência, vivenciado por acadêmicos do quinto semestre do Curso de Bacharelado em Enfermagem da Universidade Federal do Amapá- UNIFAP, participantes da campanha de vacinação contra covid-19 do estado do Amapá, no desenvolvimento das vacinações dos profissionais atuantes na linha de frente do combate à pandemia, no período de 20 a 22 de janeiro de 2021, nos centros de covid-19 na capital do estado, Macapá. As observações foram desenvolvidas nas salas de vacinas constituídas para a primeira etapa da imunização dos profissionais da saúde.

\section{RESULTADOS E DISCUSSÕES}

As equipes de vacinação dos profissionais dos Centros de Covid-19 em Macapá- Amapá eram formadas por uma enfermeira, responsável pela equipe, duas acadêmicas de enfermagem e uma técnica de enfermagem. O processo para vacinação contra covid-19, segue um protocolo rígido de 
identificação, por ser uma vacina nova e muito aguardada, os cuidados para evitar fraudes nas filas de imunização são intensos, assim como todas as informações referentes à vacinação precisam ser devidamente registradas e enviadas ao ministério da saúde, para que haja o maior controle possível na distribuição das doses no Brasil.

Os diretores de cada unidade que receberam os primeiros lotes da vacina Sinovac, estavam cientes de todo o processo da vacinação que ocorrera nos dias 20, 21 e 22 de janeiro de 2021, os profissionais elegíveis para vacinação deveriam estar presentes na lista dos funcionários enviada pelo diretor da unidade, além de apresentar, no ato da vacinação, documento válido com foto, CPF ou cartão do SUS. Seguindo os informes técnicos, não poderiam ser vacinados aqueles que apresentassem sequelas pós-covid não controladas, como hipertensão e diabetes, profissionais com sintomas da doença, ou que estiveram acometidos recentemente pelo vírus, e aqueles que receberam alguma outra vacina há menos de 15 dias.

Na manhã do primeiro dia de vacinação contra covid-19 no Amapá, recebemos a visita da Secretária Municipal de Saúde de Macapá, para ratificar a responsabilidade da equipe na campanha de imunização, alertando contra as possíveis tentativas de fraude na fila da vacina. Adicionalmente, a Secretária reforçou a importância do correto preenchimento de todos os documentos a serem enviados para o Ministério da Saúde. Também recebemos a visita de um representante da Superintendência de Vigilância em Saúde - SVS/AP, cumprindo a fiscalização e orientação das equipes, garantindo a transparência nesse momento histórico e tão aguardado.

Dessa forma, a equipe estava perfeitamente ciente e bem orientada quanto ao processo de vacinação, tentando seguir precisamente todos os informes já repassados. Com isso, alguns profissionais não puderam obter a primeira dose da vacina naquele momento, porque apresentavam hipertensão pós-covid que não estava controlada, esses compreenderam a impossibilidade de vacinarse, houve também profissionais que apresentaram covid-19 recente e/ou que estavam doentes, porém assintomáticos e não entenderam a princípio, o motivo de não serem vacinados, alegando que não apresentavam sintomas, por mais que tenham demonstrado insatisfação, após garanti-los de que teriam direito à primeira dose, após resultado negativo para covid, mostraram aceitação das determinações.

As tentativas de fraudes na fila de vacinação foram frustradas, visto que, mesmo com o posicionamento da equipe responsável pela imunização, de impedir tais ações, ao final do primeiro dia, um dos funcionários solicitou à enfermeira, que vacinasse um familiar em seu lugar, a enfermeira prontamente explicou ao profissional que esses pedidos não poderiam ser atendidos, pois as determinações do Ministério da Saúde eram que naquele momento fossem atendidos apenas o público alvo, profissionais de saúde, não havendo quaisquer exceções. O profissional mostrou-se incompreensível quanto às determinações do protocolo, causando conflitos na sala de vacinação na tentativa de mudar o posicionamento da equipe, o mesmo insatisfeito, procurou a diretora da unidade para persuadir a decisão. A experiencia causou desconforto na equipe de enfermagem, pela tentativa de imposição de um direito que não estava garantido, infringindo o princípio Bioético de Justiça, o qual estabelece como condição fundamental a equidade como obrigação ética de tratar cada indivíduo 
conforme o que é moralmente correto e adequado, de dar a cada um o que lhe é devido.

\section{CONCLUSÃO}

A experiência na vacinação contra covid-19 no Amapá evidenciou a pressão que os profissionais de saúde recebem de outros profissionais, quando esses não são beneficiados, ao assumir uma postura ética e bioética no exercício de sua função, o profissional está sujeito a situações de represálias ou pressão psicológica principalmente por parte de funcionários de outras categorias, como ocorreu com a equipe desse relato. Por estar a frente de inúmeras ações, como vacinação a enfermagem possui a responsabilidade de seguir os princípios éticos e bioéticos na imunização contra covid-19.

\section{PRINCIPAIS REFERÊNCIAS}

BARRAVIERA, BENEDITO. Vacinas: guia de referência. Petrópolis, RJ: EPUB, 2007.

BRASIL, Ministério da Saúde. COVID-19 no Brasil, 2021. Disponível em:https://susanalitico. saude.gov.br/extensions/covid-19_html/covid-19_html.html. Acesso em:09/02/2021

SANCHES, Mário. Perspectivas bioéticas sobre tomada de decisão em tempos de pandemia. Revista Bioética. Brasília, vol.28, n 3,p.(410-417), Jul./Set. 2020. Disponível em: http://dx.doi. org/10.1590/1983-80422020283401. Acesso em 24/02/2021 


\title{
PROMOÇÃO EM SAÚDE COM CUIDADORES DE CRIANÇAS E ADOLESCENTES COM DEFICIÊNCIA
}

\section{Ana Carolina Alves de Oliveiraª ; Cláudia Patrícia da Silva Ribeiro Menezes²; Samila Sousa Vasconcelos $^{3}$}
${ }^{1}$ Residente em Urgência e Emergência, Centro Universitário INTA/Santa Casa de Misericórdia de Sobral (UNINTA/SCMS), Sobral, Ceará.
${ }^{2}$ Doutoranda em Saúde Coletiva, UECE.

${ }^{3}$ Fisioterapeuta, Mestre em Saúde da Criança e do Adolescente pela Universidade Estadual do Ceará, UECE.

\begin{abstract}
RESUMO
O nascimento de uma criança com deficiência é motivo de mudanças na organização e na rotina familiar. Na maioria das famílias, um único cuidador, em geral a mãe, se torna responsável por atender as demandas desta criança causando, por vezes, redução de qualidade de vida e intenso sofrimento físico e psíquico. Este estudo teve como objetivo a promoção em saúde de cuidadores de crianças e adolescentes com deficiência. Foi realizado um estudo transversal e intervencionista, realizado no período de janeiro e fevereiro de 2020. Participaram da pesquisa 21 cuidadores, todos do gênero feminino. O procedimento consistiu em um encontro em que foi realizado um protocolo de exercício físico e a avaliação do impacto deste na dor e no estado físico desses cuidadores. Obteve-se como resultado a redução da dor, o aumento da satisfação e o interesse em programas desse tipo por parte dos cuidadores.
\end{abstract}

PALAVRAS-CHAVE: Assistência Integral à Saúde; Pessoas com Deficiência; Atenção à Saúde.

ÁREA TEMÁTICA: Atenção à Saúde

\section{INTRODUÇÃO}

Entende-se como cuidador, um indivíduo que possui a responsabilidade de dar total suporte e cuidados a um paciente, responsável por cuidar das necessidades e auxiliar nas atividades de vida diária, dedicando a maior parte do seu tempo em função do sujeito. Cuidar é uma atitude, pois inclui um momento de atenção e zelo e constitui uma atividade de ocupação, responsabilidade e um cuidar mais dedicado. O cuidador passa a observar as necessidades do indivíduo na sua totalidade, proporcionando um envolvimento afetivo com o outro (FALLER et al., 2012). 
Entretanto, assumir essas responsabilidades podem na maioria vezes trazer consequências negativas, já que a rotina cansativa e a grande demanda de cuidados prestados causa sobrecarga física e emocional. Essa sobrecarga, causa prejuízos esses que afetam a saúde física e mental dos cuidadores, que podem passar a apresentar alto grau de estresse, insônia, impaciência, insatisfação, tendo como consequência, um declínio na qualidade vida (SILVA; GOMES; FRANZOLIN, 2013).

Em relação ao cuidado de uma criança com deficiência, a literatura demonstra que o diagnóstico de uma deficiência, além da frustração dos pais, provoca a destruição de sonhos e idealizações. Estudos comprovam que a família não reage de uma forma positiva no primeiro momento, alternado entre sentimentos de negação e estranhamento. A família busca adaptar-se à nova realidade e reorganizarse para enfrentar a experiência, situação essa que envolve sentimento de vulnerabilidade e também um reajuste emocional que requer tempo (ROCHA et al, 2018). Geralmente, esse cuidado passa a ser feito de maneira informal, por um ou mais membros da família, geralmente, a mãe.

Sabendo-se da sobrecarga que esses cuidadores são expostos e do impacto que se observa na saúde física e mental, surgiu o interesse na realização da pesquisa. O objetivo deste trabalho foi promover um momento de educação e promoção de saúde com os cuidadores de crianças e adolescentes atendidos num serviço de atenção secundária em Sobral-Ce.

\section{METODOLOGIA}

Foi realizado um estudo transversal e intervencionista, de abordagem qualitativa/quantitativa. O estudo foi realizado no período de janeiro e fevereiro de 2020, num serviço de atenção secundária à criança e ao adolescente em Sobral-CE.

Foi feito, primeiramente, um estudo prévio no local onde foi possível avaliar o grau de sobrecarga física e emocional dos cuidadores, tendo tido como resultado a sobrecarga grave na maioria dos participantes.

Foram incluídos no estudo cuidadores de pacientes atendidos no serviço, independentes do sexo, sem discriminação de idade e que aceitassem participar do momento de promoção de saúde. Foram excluídos cuidadores que não demonstraram interesse em participar da pesquisa e que apresentassem distúrbios cognitivos, neurológicos, cardiológicos, vasculares e gestantes.

O estudo seguiu a Resolução 466/12 do Conselho Nacional de saúde e foi submetido ao comitê de Ética em Pesquisa do Centro Universitário INTA (BRASIL, 2012), obtendo aprovação (parecer número 3.571.711). Após aprovação do CEP, organizou-se através de reunião com a coordenação, direção e profissionais do serviço, os dias em que a coleta do estudo aconteceria, sendo exposto no momento da reunião, os objetivos do estudo, e a viabilidade do mesmo.

No primeiro momento, foi feito a caracterização dos participantes por meio de uma ficha de avaliação elaborada pelos autores da pesquisa. Em seguida, os participantes quantificaram a dor

por meio da EVA e responderam o Questionário Nórdico. O segundo momento do procedimento foi 
composto pelos exercícios de aquecimento, alongamento e relaxamento. O protocolo de exercícios foi aplicado em um único encontro 20 a 30 minutos. Foram priorizados exercícios ativos - livre. Os alongamentos foram realizados de forma ativa livre, ou seja, feitos pelo próprio paciente, em três séries de dez a 15 repetições.

Os dados qualitativos foram analisados pelo método de Análise de Conteúdo (BARDIN, 2011), compreendendo as fases de pró-análise, exploração do material ou codificação, tratamento dos resultados, inferência e interpretação. E os dados quantitativos foram analisados através do Excel, por meio de estatística descritiva e pelo SPSS (Versão 21.0), por meio de estatística descritiva, média, desvio padrão e distribuição de frequência.

\section{RESULTADOS E DISCUSSÃO}

Participaram da pesquisa 21 cuidadores, todos do gênero feminino e com média de idade de $34,95 \pm 5,15$ anos. A maioria (90,9\%) cuidava de crianças e tinha tempo médio de atuação de $86 \pm 41,13$ meses.

Solicitou-se que as participantes atribuíssem uma pontuação para o seu estado físico, variando de 1 a 4, sendo 1 ótimo e 4 ruim. As mesmas atribuíram tal pontuação antes e logo após o protocolo de atendimento. Calculou-se as médias destas variáveis, e, tendo apresentado distribuição normal, aplicou-se o teste t para amostras pareadas, obtendo-se diferenças estatisticamente significantes entre antes e após o protocolo $(\mathrm{p}=0,004)$. Esse é o importante dado, pois é possível identificar o efeito do protocolo de exercícios para o estado físico do paciente.

Quanto a avaliação da dor por meio da Eva, antes do protocolo a média foi 5,08, desvio padrão 2,57. E ao final do protocolo foi de 1,92, desvio padrão 1,93.

Por fim, perguntou-se o nível de satisfação das participantes com os exercícios realizados antes da jornada de trabalho, ao que $100 \%$ afirmou estar muito satisfeita.

Nos dados qualitativos, obtidos por meio do relato dos participantes, foi observado que desde o momento de triagem, até a realização da ginástica laboral e, posteriormente, da aplicação da parte final do instrumento de avaliação percebeu-se de forma unânime entre as participantes o interesse em que um programa de exercícios, fosse realizado de forma contínua.

Ao final do protocolo de exercício, foi entregue um panfleto com orientações de alongamentos a serem realizados em domicílio. Ao questionar qual o momento em que teriam disponibilidade para realiza-los, a maioria relatou que seria no início do dia, antes de iniciarem suas rotinas como cuidadores.

MISQUIATTI et al (2015) analisou o comprometimento na qualidade de vida de familiares de crianças com transtornos do espectro do autismo. E encontrou dados que estão em concordância com o estudo piloto dessa pesquisa. O que corrobora com a importância de promover momentos 
de cuidado, já que as consequências e limitações na vida pessoal do cuidador correspondem a um conjunto de situações, as quais podem provocar alterações e impacto na vida pessoal, como diminuição de tempo disponível, saúde física e mental afetada. Em um estudo realizado por Barros et al. (2017) em que foi avaliado a sobrecarga física e emocional de cuidadores de crianças e adolescentes com Síndrome de Down, foi constado semelhanças com o presente estudo.

\section{CONSIDERAÇÕES FINAIS}

Os resultados demonstraram que um programa de promoção de saúde voltado ao cuidador de crianças e adolescentes com deficiência física e metal poderá trazer benefício ao reduzir a sobrecarga física e emocional vivenciada na rotina de cuidado. Um único momento de promoção e educação em saúde, voltado para a realização de um programa de exercícios, foi bastante eficaz na diminuição da intensidade e frequência da dor dos cuidadores, proporcionado mais motivação e disposição as secretarias de cursos.

Os dados apresentados nesta pesquisa poderiam subsidiar propostas de promoção de saúde, para implantar novas estratégias para a melhoria da saúde dos cuidadores de crianças e adolescentes com deficiência, a partir dos relatos de que este programa seria bastante eficaz no âmbito se aplicado, no mínimo uma vez na semana.

\section{PRINCIPAIS REFERÊNCIAS}

BARDIN, L. Análise de conteúdo. São Paulo: ed 70, 2011.

BARROS, A. L. O; et al, Sobrecarga dos cuidadores de crianças e adolescentes com Síndrome de Down. Revista Ciência \& Saúde Coletiva. v. 22, n. 11, 2017.

BRASIL. Resolução 466/2012. Diretrizes e normas regulamentadoras de pesquisas envolvendo seres humanos. Ministério da Saúde/Conselho Nacional de Saúde, Brasília, 12 dez. 2012.

ESTEVES, Joyce Souza; SILVA, Liliane, Faria; Conceição Daniele Santos; Paiva Eny Dórea. Dúvidas de familiares sobre o cuidado de crianças com necessidades especiais de saúde dependentes de tecnologia. Invest Educ Enferm.; v. 33, n.3, p. 547-555, 2015.

FALLER, J. W et al; Sobrecarga e mudanças no cotidiano de cuidadores familiares de paciente com doença crônica. Ciência, Cuidado e Saúde, Paraná, v. 11, n. 1, p. 181-189, 2012.

MISQUIATTI, A.R.N. et al.; Sobrecarga familiar e crianças com transtornos do espectro do autismo: perspectiva dos cuidadores. Revista Cefac,v. 17, n.1, p. 192-200, 2015.

ROCHA, M. C. P. et al, Necessidades e dificuldades de famílias que vivenciam a experiência de ter uma criança com hidrocefalia. Saúde em revista, v. 15, n. 40, p. 49-66, 2015. 
SILVA, L. M.; GOMES, T.T.; FRANZOLIN, S. O. B. Qualidade de vida e sobrecarga de cuidadores familiares de pessoas com deficiência física e múltipla adquirida. Journal of Health Sciences Institute, São Paulo, v. 31, n. 4, p. 429-433, 2013. 


\title{
UMA ENFERMIDADE NEGLIGENCIADA: DOENÇA DA ARRANHADURA DO GATO
}

\author{
Isadora Conceição de Souza ${ }^{1}$; Delcivan Lima dos Santos ${ }^{2}$ \\ ${ }^{1}$ Graduada em Medicina Veterinária, Universidade Federal do Recôncavo da Bahia (UFRB), Cruz \\ das Almas, BA.
}

${ }^{2}$ Mestre em Ciência Animal, Universidade Federal do Recôncavo da Bahia (UFRB), Cruz das Almas, BA.

\begin{abstract}
RESUMO
Adoença da arranhadura do gato é causada por bactérias do gênero Bartonella spp. Afeta principalmente seres humanos e existem várias ocorrências de síndromes de doenças crônicas em profissionais de saúde como veterinários, pesquisadores e outras pessoas que estejam com o sistema imunológico deficiente. As doenças que já foram relatadas foram a angiomatose bacilar, peliose hepática (em pessoas imunocomprometidas) endocardite e outras síndromes graves em seres humanos e cães. A prevalência de infecção difere entre populações de gatos e região geográfica. Métodos para a identificação laboratorial de infecções por $B$. henselae incluem histologia, cultivo bacteriano, molecular (PCR) e sorológico (imunofluorescência indireta, Elisa). Os ensaios imunoenzimáticos (ELISAs) têm sido desenvolvidos como métodos alternativos de triagem soroepidemiológica. O tratamento é feito utilizando a eritromicina, claritromicina, azitromicina, rifampicina e cefalosporinas de terceira geração e tetraciclina. A bactéria tem sensibilidade intermediária ao sulfametoxasol/trimetropim, e aminoglicosídios, e é resistente às cefalosporinas de primeira geração e fluoroquinolonas.
\end{abstract}

PALAVRAS CHAVE: Bactéria; Felino; Zoonose.

ÁREA TEMÁTICA: Atenção a Saúde

\section{INTRODUÇÃO}

As espécies de Bartonella spp são bactérias intracelulares, gram-negativas, zoonóticas e com crescente importância na medicina veterinária e humana. A família Bartonellaceae inclui o único gênero Bartonella spp com mais de 22 espécies. As espécies se replicam intracelularmente nos eritrócitos e em células endoteliais, e geralmente são transmitidas por artrópodes.

Os gatos são os principais hospedeiros do reservatório de Bartonella henselae, Bartonella clarridgeiae e provavelmente de Bartonella koehlerae. B henselae e B clarridgeiae são transmitidos entre gatos ou de gatos para pessoas através de Ctenocephalides felis (pulga) ou através de suas fezes. 
Espécies de Ixodes spp também podem atuar como vetores.

Gatos infectados podem desenvolver bacteremia recorrente ou persistente com duração de vários meses. Nos hospedeiros e reservatórios, $B$ henselae e $B$ clarridgeiae raramente causam problemas clínicos. Infecções e sinais clínicos em gatos infectados geralmente permanecem sem serem detectadas. O objetivo deste estudo é reunir informações pertinentes sobre este agente zoonótico e os danos que ele pode causar ao organismo.

\section{FUNDAMENTAÇÃO TEÓRICA}

O gênero Bartonella spp é formado por bactérias pleomórficas, gram-negativas e intracelulares facultativas. São transmitidas por vetores artrópodes, como pulgas, que podem causar infecções persistentes em hospedeiros mamíferos. Contém pelo menos 30 espécies, das quais Bartonella henselae, B. clarridgeiae e B. koehlerae são os mais prevalentes no Gato. B. henselae está relacionada aos casos humanos mais graves da chamada doença da arranhadura do gato (DAG), já que geralmente é transmitido através de mordida e arranhões do gato infectado.

Os gatos estão envolvidos no ciclo de vida e manutenção de alguns agentes zoonóticos de origem vetorial, como Rickettsia spp. e Bartonella spp. Eles podem manter uma infecção sistêmica e ao mesmo tempo assintomática e infectar seus ectoparasitas (por exemplo, pulgas e carrapatos). Em relação à Bartonella spp a infecção também pode ocorrer em humanos através da arranhadura do gato. Assim, seu papel como reservatórios ou sentinelas é de importância médica. São patógenos onipresentes que apresentam alta prevalência, principalmente em condições ambientais, e os fatores comportamentais humanos são favoráveis pela sobrevivência de seus vetores.

As pulgas constituem o principal vetor, embora esse agente foi detectado em outros artrópodes hematófagos, como carrapatos. Em geral, os gatos podem manter a bacteremia por um longo tempo sem sinais clínicos. Alguns fatores como idade, animal, estado sanitário (ou seja, animal de estimação ou perdido), bem como condições geográficas e condições climáticas podem influenciar o risco de infecção por B. henselae.

A doença da arranhadura do gato (DAG) é causada por $B$. henselae e menos frequentemente por B. clarridgeiae, B. koehlerae, B. quintana e B. doshiae. Estes patógenos são transmitidos por mordidas ou arranhões de gatos infectados. A DAG é comumente diagnosticada em crianças, mas os adultos também podem apresentar a doença. Deve-se suspeitar da doença em pacientes com linfadenopatia unilateral, especialmente se houver histórico de exposição á gatos. A manifestação clínica da infecção por $B$. henselae depende do estado imunológico do paciente.

Os pacientes podem desenvolver nódulos no pescoço e no maxilar, podem apresentar sensibilidade com sinais de inflamação (eritema, calor) e supurar em 13\% a 48\% de casos. Os linfonodos infectados podem formar uma fístula de drenagem de pus através da pele. Pacientes imunocomprometidos que estejam com a DAG podem apresentar lesões multi-vasoproliferativas em 
fígado, baço ou na pele.

Os gatos são o reservatório natural de $B$. henselae e geralmente desenvolvem um quadro de bacteremia intra-eritrocítico assintomático, que pode persistir por meses ou anos. A pulga do gato é o vetor responsável pela disseminação da bactéria.

A presença de pulgas é essencial para manutenção da infecção pela bactéria dentro da população felina. A transmissão não ocorre quando gatos infectados vivem juntos com gatos não infectados em um ambiente livre de pulgas. A transmissão consequentemente não ocorre através de mordidas, arranhões (na ausência de pulgas), ou compartilhamento de caixas de areia, alimentos e pratos.

Gatos naturalmente infectados geralmente não mostram sinais clínicos. Tanto em estudo experimental, quanto em estudo de infecção natural, não foi comprovado uma associação entre sinais clínicos e a infecção. Gatos de rua apresentam prevalência maior do que gatos domiciliados. A infecção por $B$. henselae parece ser mais comum em gatos jovens e a infecção diminui com o aumento da idade do gato. A temperatura e a umidade relativa são os dois maiores fatores essenciais para a reprodução bem sucedida, o desenvolvimento e a sobrevivência de pulgas.

A soroprevalência é maior na população de gatos de estimação em climas quentes e úmidos do que em climas frios e secos, porque as pulgas de $C$. felis são mais comuns em climas mais quentes. Cães domésticos podem representar excelentes sentinelas epidemiológicos para a infecção de Bartonella spp em humanos. Isso é possível por vários fatores: exposição aos mesmos ambientes domésticos e recreativos com seres humanos, parasitismo pelos mesmos vetores, e pela grande diversidade de espécies identificadas de Bartonella spp.

Os testes laboratoriais são necessários para doadores de sangue e também á pessoas imunossuprimidas que tenham gatos. Quando a doença é diagnosticada, o gato que reside na casa também deve fazer o teste laboratorial.

Os métodos de laboratório para o diagnóstico de infecções por Bartonella spp incluem o isolamento dos agentes por cultura, ensaios sorológicos e detecção molecular do DNA. O diagnóstico também depende de fatores epidemiológicos e clínicos.

Alguns cientistas concluíram que na utilização correta do Elisa é possível obter $100 \%$ de sensibilidade e $93 \%$ de especificidade, que são os dados de desempenho mais conhecidos de $B$. henselae, através da comprovação pelo PCR das amostras de soro ou outras amostras, incluindo os antígenos produzidos a partir do cultivo da bactéria. A identificação rápida de agentes infecciosos é fundamental para iniciar prontamente o tratamento do paciente e impedir a propagação da doença. $\mathrm{O}$ uso do Elisa utilizando antígenos de proteínas bacterianas altamente purificadas sugere que seu uso proporciona uma alta sensibilidade e especificidade aprimoradas ao resultado.

A cultura primária requer longos períodos de incubação, já que as bactérias são exigentes e o crescimento é consideravelmente lento. Por outro lado, a identificação do agente por sequenciamento 
de DNA com amplificadores de PCR leva muito tempo e tem um custo considerável.

Alguns antibióticos são utilizados no tratamento da doença: doxiciclina, rifampicina, azitromicina, vancomicina, ceftriaxona, trimetoprim / sulfametoxazol, gentamicina, clindamicina, cloxacilina.

\section{CONCLUSÃO}

Diante da proximidade dos gatos com os seres humanos, é imprescindível manter uma adequada condição sanitária dos gatos. As pulgas e os carrapatos são os vetores responsáveis pela transmissão do agente.

A presença de pulgas é essencial para manutenção da infecção por $B$. henselae dentro da população felina. Em um ambiente livre de pulgas, a transmissão não ocorre entre gatos infectados juntos com gatos não infectados. A transmissão consequentemente não ocorre através de mordidas, arranhões (na ausência de pulgas), ou compartilhamento de caixas de areia, alimentos e pratos.

\section{PRINCIPAIS REFERÊNCIAS}

BOUHSIRA, E.; FRANC, M.; BOULOUIS, H. J.; JACQUIET, P.; RAYMOND-LETRON, I.; LIÉNARD, E. 2013. Assessment of Persistence of Bartonella henselae in Ctenocephalides felis. Appl. Environmental Microbiology. 79, 7439-7444.

BOUlOUIS, H. J.; CHANG, C. C.; HENN, J. B.; KASTEN, R. W.; CHOMEL, B. B. 2005. Factors associated with the rapid emergence of zoonotic Bartonella infections. Veterinary Research. 36: 383-410.

CARITHERS, H. A. 1985. Cat-scratch disease. An overview based on a study of 1,200 patients. The american Journal of Diseases of Children. 139: 1124-1133.

CHOMEL, B. B.; BOULOUIS, H. J.; MARUYAMA, S.; BREITSCHWERDT, E. B. 2006. Bartonella spp. in pets and effect on human health. Emerging Infectious Diseases. 12: 389-394.

GURFIELD, A. N.; BOULOUIS, H. J.; CHOMEL, B. B.; KASTEN, R. W.; HELLER, R.; BOUILLIN, C. 2001. Epidemiology of Bartonella infection in domestic cats in France. Veterinary Microbiology. 80: 185-198.

GUTIERREZ, R.; VAYSSIER-TAUSSAT, M.; BUFFET, J. P.; HARRUS, S. 2017. Guidelines for the isolation, molecular detection, and characterization of bartonella species. Vector Borne and Zoonotic Diseases. 17: 42-50.

IANNINO, F.; SALUCCI, S.; DI PROVVIDO, A.; PAOLINI, A.; RUGGIERI, E. 2018. Bartonella infections in humans dogs and cats. Veterinaria Italiana. 54: 63- 72. 
KAISER, P. O.; RIESS, T.; O’ROURKE, F.; LINKE, D.; KEMPF, V. A. 2011. Bartonella spp.: throwing light on uncommon human infections. Jornal Internacional de Microbiologia Médica. 301: 7-15.

SPADA, E.; CANZI, I.; BAGGIANI, L.; PEREGO, R.; VITALE, F.; MIGLIAZZO, A.; PROVERBIO, D. 2016. Prevalence of Leishmania infantum and co-infections in stray cats in northern Italy. Comparative Immunology, Microbiology \& Infectious Diseases. 45: 53-58.

VALTIERRA, M. A.; VALENCIA, C. S.; NEGRO, H. F.; GALARZA, A. U.;SOMARRIBA, B. F.; KASSAB, N. H. 2016. Epidemiología molecular de Bartonella henselae en gatos callejeros y de albergue en Zaragoza, España. Revista Española de Salud Pública. 90: 1-11. 


\title{
ASPECTOS GERAIS SOBRE A MENINGOENCEFALITE AMEBIANA PRIMÁRIA CAUSADA PELA Naegleria fowleri
}

\author{
Delcivan Lima dos Santos'; Isadora Conceição de Souza² \\ ${ }^{1}$ Mestre em Ciência Animal, Universidade Federal do Recôncavo da Bahia (UFRB), Cruz das \\ Almas, BA. \\ ${ }^{2}$ Graduada em Medicina Veterinária, Universidade Federal do Recôncavo da Bahia (UFRB), Cruz \\ das Almas, BA.
}

\section{RESUMO}

O gênero Naegleria spp é composto por um grupo de ameboflagelados de vida livre encontrados em diversos habitats em todo o mundo. Mais de 30 espécies foram isoladas no solo e em corpos de água doce, mas apenas Naegleria fowleri foi associada a humanos e causa à meningoencefalite amebiana primária (PAM), atinge o sistema nervoso central e quase sempre é fatal. A patogênese do PAM e o papel da imunidade do hospedeiro são mal compreendidos. Estratégias de combate infecção são limitados porque a progressão da doença é rápida e o agente tem desenvolvido estratégias para escapar do sistema imunológico. Essas espécies de ameba de vida livre não devem ser subestimados, não apenas porque podem ser agentes graves e fatais de doenças humanas, mas também porque podem servir como reservatórios de bactérias patogênicas, já que se alimentam de bactérias e leveduras presentes no solo.

PALAVRAS CHAVE: letalidade; ameba; sistema nervoso.

ÁREA TEMÁTICA: Atenção á Saúde

\section{INTRODUÇÃO}

O gênero Naegleria spp consiste em um grupo de ameboflagelados encontrados em diversos habitats ao longo do mundo. Naegleria spp foram isolados de lagos de água doce, lagoas, suprimentos de água doméstica, piscinas de natação, piscinas termais, solo e poeira. Embora mais de 30 espécies de Naegleria spp foram isoladas de fontes ambientais, apenas Naegleria fowleri foi isolado de humanos. Causa a meningoencefalite amebiana primária (PAM), uma doença rapidamente fatal do sistema nervoso central (SNC) que ocorre com mais frequência em crianças e jovens adultos com histórico de natação e mergulho em locais de água doce. 
Duas outras espécies de Naegleria spp, Naegleria australiensis e Naegleria italica podem causar infecção em animais experimentais, mas não foram associados com doença em humanos. Possui três estágios morfológicos do ciclo de vida: trofozoíta, flagelado e cisto. O trofozoíto é a alimentação, divisão e, presumivelmente, o estágio infeccioso para humanos. No entanto, é concebível que os cistos também possam entrar nas narinas, converter-se em trofozoítos e prossiga para invadir o cérebro. Estruturas de superfície nos trofozoítos, denominados "copos para comida", são usados para ingerir bactérias e leveduras no ambiente, bem como tecidos no hospedeiro infectado.

Até o momento, a droga de escolha para o tratamento de PAM foi a Anfotericina B em combinação com rifampicina e fluconazol. O obetivo desta revisão de literatura é reunir o máximo de informações mais pertinentes possíveis sobre este agente infeccioso, e alertar as pessoas sobre seus perigos e sua alta taxa de letalidade.

\section{FUNDAMENTAÇÃO TEÓRICA}

$N$. fowleri é uma ameba anfizóica, pois pode sobreviver em uma vida livre estando na água, solo ou no hospedeiro, que pode ser o sistema nervoso central humano. As infecções por $N$. fowleri foram documentadas em crianças e adultos saudáveis, através do contato com água de atividades recreativas, incluindo natação, mergulho e esqui aquático. Acredita-se que o agente infecte o corpo humano ao entrar no hospedeiro pelo nariz quando a água é espirrada ou forçada para a cavidade nasal.

A patologia ocorre com mais facilidade em indivíduos imunocompetentes e inicia um curso ainda mais rápido da doença. A infecção é iniciada pela introdução de organismos presentes na água dentro da cavidade nasal do hospedeiro. Existem diversos métodos diagnósticos. O exame direto no microscópico utiliza líquido cefalorraquidiano. O objetivo é identificar trofozoítos móveis. Também podem ser utilizados imunofluorescência direta, PCR e PCR em tempo real. A progressão da doença causada por N. Fowleri no SNC é rápida e a disponibilidade de técnicas de diagnóstico rápido oferece uma oportunidade para aplicar o tratamento imediato, que é essencial para o sucesso do resultado do paciente. Houve poucos sobreviventes do PAM, mas a sobrevivência ocorreu quando a doença foi reconhecida e tratada precocemente, até mesmo sem uso de métodos diagnósticos laboratoriais.

A infecciosidade ocorre primeiro por meio da ligação do agente ao tubo da mucosa nasal, seguida de locomoção ao longo do nervo olfatório e através da placa cribriforme (que é mais porosa em crianças e adultos jovens) para atingir os bulbos olfatórios dentro do SNC. Uma vez que $N$. fowleri atinge os bulbos olfatórios, ele provoca uma significativa resposta imunológica através da ativação do sistema imunológico inato, incluindo macrófagos e neutrófilos.

$N$. fowleri entra no corpo humano na forma trofozoíta. Estruturas no superfície dos trofozoítos conhecidos como "copos de comida" permitem que o organismo possa ingerir bactérias, fungos e tecido humano. Além de destruição de tecidos, a patogenicidade da ameba depende da liberação de moléculas citolíticas, incluindo hidrolases ácidas, fosfolipases, neuraminidases e 
enzimas fosfolipolíticas que desempenham um papel na destruição da célula hospedeira e do nervo. A combinação da patogenicidade e a intensa resposta imune resultante de sua presença, resulta em dano significativo do nervo e dano subsequente do tecido do SNC, que muitas vezes resultam em morte. $\mathrm{Na}$ América do Sul, houve o segundo relato de meningoencefalite associada à Naegleria fowleri em bovino, e o primeiro na região sul do Brasil.

Sintomas clínicos e sinais de infecção geralmente estão presentes dentro de 2 a 8 dias de infecciosidade, embora alguns casos tenham sido relatados em 24 horas. Apesar da ausência de sinais específicos e sintomas que indicam infecção por $N$. fowleri, o mais comum dos sintomas incluem forte dor de cabeça, febre, calafrios, sinal de Brudzinski positivo, sinal de Kernig positivo, fotofobia, confusão, convulsões, e possível coma. Além disso, anormalidades do ritmo cardíaco e necrose miocárdica foram observadas em alguns casos.

Possivelmente, os sinais mais importantes são o aumento na pressão intracraniana e cerebral A pressão do fluido espinhal (líquido cefalorraquidiano- LCR) foi diretamente associada com a morte em pacientes com infecção por $N$. fowleri. É possível visualizar a presença de trofozoítos no LCR. Em exames de imagem por ressonância magnética do cérebro, frequentemente mostra anormalidades em várias regiões do cérebro, incluindo o mesencéfalo e o espaço subaracnóide.

Devido à raridade de infecções por $N$. fowleri em humanos, não há ensaios clínicos até o momento que avaliam a eficácia de um regime de tratamento. A maioria das informações sobre medicamentos e eficácia é baseada em relatos de casos ou estudos in vitro. Possivelmente, o medicamento mais aceito para o tratamento da infecção é a anfotericina B, que foi estudada in vitro e também usada em vários relatos de casos. Outros relatos de anti-infecciosos que tem sido utilizados incluem fluconazol, miconazol, miltefosina, azitromicina e rifampicina. Existem outros agentes que foram estudados in vitro e / ou in vivo, incluindo higromicina, rokitamicina, claritromicina, eritromicina, roxitromicina e zeocina.

Até o momento, houve apenas sete sobreviventes em todo o mundo. Em todos esses relatos, os pacientes foram tratados utilizando alguns destes medicamentos: anfotericina B (medicamento de eleição contra o agente infeccioso), miconazol, rifampicina, dexametasona, fenitoína, fluconazol, miltefosina e azitromicina. É importante ressaltar que o sucesso obtido nestes casos só foram possíveis graças á rapidez com que o tratamento foi realizado.

Existe um consenso de que exista um número de casos subnotificados, e que também nunca tenham sido diagnosticados. Os sinais clínicos da infecção por $N$. fowleri não são patognômicos desta enfermidade. Sendo assim, seu diagnóstico só é possível quando se busca fazer uma verdadeira investigação. Porém, não existe tempo hábil para tal, uma vez que, os agravos da doença se dão em pouco tempo. Nota-se que em boa parte do mundo, este agente ainda seja pouco conhecido pela população e por boa parte dos médicos. 


\section{CONCLUSÃO}

Existem algumas precauções que podem ser tomadas por pessoas que participam de atividades esportivas ou que frequentam ambientes que podem conter o agente, em climas mais quentes. Evitar a exposição a corpos de água doce, como lagos, rios e lagoas, especialmente durante os meses de verão, quando a temperatura da água é mais elevada. Tanto á água clorada quanto a salgada diminuem significativamente o risco de infecção por $N$. fowleri devido à incapacidade dele sobreviver em tais ambientes.

Se as atividades de água doce não podem ser evitadas, é recomendado que os indivíduos evitem pular no corpo d'água, espirrando ou submergindo suas cabeças na água. Isso evita que $N$. fowleri entre nas vias nasais. Se tais atividades não podem ser evitadas, os indivíduos devem usar clipes de nariz para diminuir a chance de á água contaminada entrar pelo nariz.

Algumas pessoas enxaguam o nariz e as passagens nasais com água limpa após nadar em corpos d'água frescos; no entanto, a eficácia deste método é hipotético e desconhecido no momento. Se quiser enxáguar os seios nasais da face, é recomendado que se utilize água destilada ou purificada, disponíveis comercialmente.

\section{PRINCIPAIS REFERÊNCIAS}

BARNETT, N. D.; KAPLAN, A. M.; HOPKIN, R. J.; SAUBOLLE, M. A.; RUDINSKY, M. F. 1996. Primary amoebic meningoencephalitis with Naegleria fowleri: clinical review. Pediatric Neurology $15: 230-234$.

CENTERS FOR DISEASE CONTROL AND PREVENTION. 2014. N. fowleri treatment. Centers for Disease Control and Prevention, Atlanta, GA.

DE JONCKHEERE, J. F. 2011. Origin and evolution of the worldwide distributed pathogenic amoeboflagellate Naegleria fowleri. Molecular Epidemiology e Evolutionary Genetics of Infectious Diseases 11:1520-1528.

DEBNATH, A.; TUNAC, J. B.; GALINDO-GOMEZ, S.; SILVA-OLIVARES, A.; SHIBAYAMA, M.; MCKERROW, J. H. 2012. Corifungin, a new drug lead against Naegleria, identified from a highthroughput screen. Antimicrobial Agents and Chemotherapy 56:5450-5457.

DORLO, T. P.; BALASEGARAM, M.; BEIJNEN, J. H.; DE VRIES, P. J. 2012. Miltefosine: a review of its pharmacology and therapeutic efficacy in the treatment of leishmaniasis. Journal of Antimicrobial Chemotherapy 67:2576-2597.

EDDIE, GRACE.; SCOTT, ASBILL.; KRIS, VIRGA. 2015. Naegleria fowleri: Pathogenesis, Diagnosis, and Treatment Options. American Society for Microbiology. Vol. 59, no 11.

KIM, J. H.; JUNG, S. Y.; LEE, Y. J.; SONG, K. J.; KWON, D.; KIM, K.; PARK, S.; IM, K. I.; SHIN, 
H. J. 2008. Effect of therapeutic chemical agents in vitro and on experimental meningoencephalitis due to Naegleria fowleri. Antimicrobial Agents and Chemotherapy 52:4010-4016.

MARCIANO-CABRAL, F.; CABRAL, G. A. 2007. The immune response to Naegleria fowleri amebae and pathogenesis of infection. FEMS Immunology and Medical Microbiology 51:243-259.

MENEZ, C.; BUYSE, M.; FARINOTTI, R.; BARRATT, G. 2007. Inward translocation of the phospholipid analogue miltefosine across Caco-2 cell membranes exhibits characteristics of a carriermediated process. Lipids 42:229-240. 


\title{
REFLEXÕES E AVALIAÇÕES SOBRE A EUTANÁSIA DE CÃES INFECTADOS COM LEISHMANIOSE
}

\author{
Delcivan Lima dos Santos'; Isadora Conceição de Souza ${ }^{2}$ \\ ${ }^{1}$ Mestre em Ciência Animal, Universidade Federal do Recôncavo da Bahia (UFRB), Cruz das \\ Almas, BA. \\ ${ }^{2}$ Graduada em Medicina Veterinária, Universidade Federal do Recôncavo da Bahia (UFRB), Cruz \\ das Almas, BA.
}

\section{RESUMO}

A Leishmaniose visceral (LV), causada por Leishmania donovani na Ásia e África e por L. infantum na Bacia do Mediterrâneo, Oriente Médio, Ásia Central, América do Sul e América Central é uma zoonose que afeta cerca de 200.000 a 400.000 pessoas anualmente e causa cerca de 20.000 a 40.000 mortes por ano. Cães permanecem como fonte indireta fundamental em muitas situações onde ocorre o ciclo de transmissão de L. infantum. Ao longo dos anos, milhões de cães foram mortos como parte das políticas governamentais para controlar a LV humana causada por L. infantum. O abate de cães positivos ainda acontece. Na América Central e do Sul, o sacrifício de cães foi recomendado e praticado em vários países, incluindo Argentina, Brasil, Colômbia, Uruguai e Venezuela. No entanto, essa prática foi substituída por abordagens mais eficazes, mesmo em países como o Brasil, onde milhares de cães costumavam ser sacrificados todos os anos.

PALAVRAS CHAVE: Leishmania; Zoonose; Animais.

ÁREA TEMÁTICA: Saúde Coletiva

\section{INTRODUÇÃO}

As políticas nacionais de saúde pública dos países da Ásia Central, países Caucasianos e alguns Balcãs, ainda recomendam o abate de qualquer cão positivo para $L$. infantum. Nas áreas rurais da China, nos países do norte da África e em partes do Oriente Médio, o abate de cães continua a ser uma prática comum, embora a terapia médica seja geralmente permitida para os cães que pertencem a esses países.

No Brasil, a estratégia usada como controle da infecção do reservatório canino do Programa Nacional de Vigilância e Controle da Leishmaniose Visceral (PNVCLV) é a eutanásia de cães soropositivos. Mesmo com a utilização em massa dessa estratégia, existem muitos aspectos 
relacionados a sua utilização, no que diz respeito a infraestrutura inadequada dos municípios, financiamento insuficiente ou inexistente para seu desenvolvimento e, sobretudo, as questões éticas envolvidas. Essas questões levam a questionamentos quanto à sua eficiência.

Nos últimos 20 anos, acumulou-se uma massa de evidências científicas em todo o mundo e sob diferentes cenários ecológicos que demonstram o fracasso do abate de cães como estratégia de controle, particularmente no Brasil. Em áreas da Ásia (por exemplo, China), onde os regimes governamentais promoveram abate maciço de todos os cães (independentemente do status soropositivo), em associação com o uso generalizado de DDT para controle de vetores, a incidência da doença diminuiu por muitos anos. No entanto, é difícil dizer se esse foi um efeito de eliminação de cães, controle de vetores ou ambos.

A identificação de características no peridomicílio das áreas estudadas, que são importantes para manter o ciclo de vida do vetor, permite que sejam adotadas medidas de manejo ambiental para a redução do contato do mosquito flebotomíneo com o homem. A educação em saúde constitui um bom instrumento de prevenção do Poder Público, seja ele federal, estadual ou municipal, a fim de conscientizar a população e diminuir a ocorrência da leishmaniose humana.

\section{FUNDAMENTAÇÃO TEÓRICA}

Nas últimas quatro décadas, o desenvolvimento econômico do Brasil concorreu para alterar as interações entre o homem, o ambiente e os processos biológicos. O perfil epidemiológico do território nacional foi redesenhado pelo estabelecimento de um quadro endêmico de leishmaniose, sobretudo a visceral, uma zoonose transmitida por um vetor de importância mundial, que envolve os cães como reservatórios, e, espécies animais, dentre as quais, um parasito depende para sua sobrevivência.

A dispersão espaço-temporal dessa e de outras doenças infecto-parasitárias, como a malária, a dengue e a hantavirose, acompanha o rápido crescimento de megacidades com um alto fluxo populacional, o aumento da pobreza, as baixas condições sanitárias, o deslocamento do reservatório doméstico e a adaptação das espécies vetoras, entre outros fatores de risco. Tais características são propícias à expansão e à adaptação de um patógeno a um novo nicho, em diferentes escalas, desde a local, passando pela regional e nacional, até a global.

Uma estratégia de abate de cães não é suportável por vários motivos Nenhum corpo confiável de evidência científica apóia a eficácia do abate de cães como forma de reduzir a incidência de LV. Hospedeiros alternativos de reservatórios podem desempenhar um papel na manutenção do ciclo de vida do parasito, e devem ser levados em consideração quando uma estratégia de controle integrada é formulada. Os cães selecionados são rapidamente substituídos por cães jovens, muitas vezes mais suscetíveis à infecção primária.

As ferramentas de diagnóstico sorológico frequentemente usadas para rastrear cães como parte de um programa de abate têm limitações em termos de sensibilidade e especificidade (por 
exemplo, reatividade cruzada onde ocorrem outras Leishmania spp Ou tripanossomatídeos).

O abate de cães não é uma alternativa válida e econômica do ponto de vista socioeconômico (por exemplo, efeito da remoção do cão em seus donos e medicamentos para eutanásia) para instituições governamentais, particularmente em países em desenvolvimento, que promete um longo prazo solução para o problema. O controle efetivo da transmissão de L. infantum requer abordagens integradas com foco não apenas no cão como fonte indireta, mas também no parasita e, mais importante, no vetor flebotomíneo.

Assim, o uso do abate de cães como estratégia para reduzir a incidência de LV em humanos não pode ser justificado e não deve mais ser usado. Para o controle da LV, os dados científicos estão claramente alinhados com os sentimentos expressos pelos Médicos Veterinários, certos no conhecimento de que métodos preventivos devem ser usados, em vez da prática de abate de cães, que se acredita serem antiéticos e injustificáveis do ponto de vista científico.

A vacinação, o tratamento de cães infectados e o uso de coleiras impregnadas com deltametrina, têm sido utilizados como alternativas á eutanásia. O uso de coleiras com repelentes tem apresentado resultados promissores quanto à sua utilização como medida de saúde pública. A deltametrina é um composto lipofílico que pertence à classe química dos piretróides, e tem sido utilizada em cães na forma de coleira de policloreto de polivinila.

Estudos experimentais mostraram que o uso de inseticida tópico e coleiras impregnadas de deltametrina podem proteger os cães de picadas de flebotomíneo, reduzindo assim a infecção canina por L. infantum e prevenindo diretamente a doença humana. Essas medidas tem se mostrado bastante eficientes no impedimento das picadas de fêmeas de flebotomíneos durante o repasto sanguíneo, interrompendo o clico de transmissão da Leishmania spp.

O mecanismo de repelência é pouco estudado, mas supõe-se que o inseticida atua nos órgãos sensitivos do vetor juntamente com a combinação de gás carbônico e odores exalados pelo hospedeiro afetando a sua atração à picada.

O longo tempo de efeito que a coleira apresenta é explicado pela liberação da deltametrina induzida pelo atrito do colar com o pescoço do cão, o que provoca uma deposição contínua do inseticida na pele. Em função da deltametrina ser lipolítica, como todos os piretróides sintéticos, ela dissolve-se nos lipídeos presentes na pele do cão, espalhando-se por todo o corpo do animal e protegendo-o contra picadas.

Atualmente, as preparações à base de piretróides sintéticos são as mais utilizadas, devido a sua eficácia contra os flebotomíneos e baixa toxicidade para o hospedeiro canino. Algumas pesquisas demostraram que o efeito das coleiras (repelente e letal) sobre os flebotomíneos ocorre uma a duas semanas após sua colocação, que corresponde ao tempo necessário para que a deltametrina se espalhe pelo corpo do cão. Os piretróides, além do efeito tóxico, provocam, também, irritação e desorientação nos flebotomíneos, resultando na diminuição da taxa de alimentação, causando a morte. 
Diversas pesquisas realizadas no Brasil, atestaram a eficácia da implementação em larga escala de coleiras para cães impregnadas com deltametrina a 4\%, na redução da taxa de incidência de infecção canina por L. infantum em um áreas endêmicas de LV. Os Cientistas concluíram que os colares impregnados de deltametrina são eficazes de reduzir a infecção canina após um ano de acompanhamento e sugeriram uma implementação em larga escala dessas coleiras como estratégia de controle de LV que poderia produzir ótimos resultados a médio e longo prazo.

\section{CONCLUSÃO}

Diante das informações reunidas nesta revisão de literatura, é imprescindível que as ações voltadas ao controle, prevenção e ao tratamento, sejam sempre mantidas e melhoradas. Sabe-se que a leishmaniose é uma zoonose que causa impactos diretos nos seres humanos e nos animais.

Com o avanço da ciência, as mudanças nas formas de controle, sobretudo, com relação à eutanásia de cães, já estão sendo modificadas. Visto que, eles são mais uma vítima da leishmaniose, e existem relatos de tratamentos bem sucedidos. Neste sentido, é primordial que o poder público mude as políticas de controle e prevenção da leishmaniose visceral.

É de suma importância que continuem sendo desenvolvidos medicamentos que possam proporcionar a cura dos pacientes caninos, não apenas pelo fato da leishmaniose ser uma zoonose, mas também pela questão do bem estar animal e da preservação de sua vida.

A prática oficial extensiva de extermínio de animais de estimação não é condizente com as evidências científicas atuais, os valores das ciências e da sociedade brasileira do século XXI.

A eutanásia, que deveria servir como instrumento para diminuir a ocorrência de uma doença emergente no Brasil, como a leishmaniose visceral, parece influenciar mais na estrutura da população canina do que no seu tamanho; as implicações epidemiológicas resultantes de uma população canina mais jovem podem ser graves.

Programas de posse responsável de cães, com enfoque na qualidade de vida dos animais, métodos de controle ambiental do mosquito e programas de educação em saúde, configuram-se como os meios mais adequados e eficientes de controle e prevenção da LV, do que a técnica de controle populacional em áreas endêmicas para leishmaniose visceral.

\section{PRINCIPAIS REFERÊNCIAS}

ALVAR J, VÉLEZ ID, BERN C, HERRERO M, DESJEUX P, CANO J. Who Leishmaniasis Control Team. Leishmaniasis worldwide and global estimates of its incidence. Plos One. 2012;7:e35671.

COSTA, C. H. 2011. How effective is dog culling in controlling zoonotic visceral leishmaniasis? A critical evaluation of the science, politics and ethics behind this public health policy. Revista da 
Sociedade Brasileira de Medicina Tropical. 44:232-42.

DANTAS-TORRES, F.; MIRÓ, G.; BOWMAN, D. D.; GRADONI, L.; OTRANTO, D. 2019. Culling dogs for zoonotic visceral leishmaniasis control: the wind of change. Trends in Parasitology.35:97-101.

DORLO, T. P. C., BALASEGARAM, M., BEIJNEN, J. H.; VRIES, P. 2012. Miltefosine: a review of its pharmacology and therapeutic efficacy in the treatment of leishmaniosis. Journal of Antimicrobial Chemotherapy. 67, 2576-2597.

DOS SANTOS NOGUEIRA, F.; AVINO, V. C.; GALVIS-OVALLOS, F.; PEREIRA-CHIOCCOLA, V L.; MOREIRA, M. A. B.; ROMARIZ, A. P. P. L. 2019. Use of miltefosine to treat canine visceral leishmaniasis caused by Leishmania infantumin Brazil. Parasites \& Vectors. 12:79.

FILIPE DANTAS-TORRES. 2020. Canine Leishmaniasis Control in the Context of One Health. Emerging Infectious Diseases. Vol. 25, No. 12.

GÁlVEZ, R.; MONTOYA, A.; FONTAL, F.; MARTÍNEZ DE MURGUÍA, L.; MIRÓ, G. 2018. Controlling phlebotomine sand flies to prevent canine Leishmania infantum infection: a case of knowing your enemy. Research in Veterinary Science. 121:94-103. 


\section{BIOÉTICA COTIDIANA NA INICIAÇÃO CIENTÍFICA: RELATO DE EXPERIÊNCIA}

\section{Max Amaral Balieiro'; Samily Batista da Silva ${ }^{2}$; Luiz Victor da Silva Moreira ${ }^{3}$; Juliana Ramos}

Motta de Oliveira $^{4}$; Edylany Almeida de Oliveira ${ }^{5}$; Marlucilena Pinheiro da Silva ${ }^{6}$; Maria Virgínia Filgueiras de Assis Melo7; Rosana Oliveira do Nascimento ${ }^{8}$

${ }_{5}$ Aluno, Curso de Bacharelado em Enfermagem, Bolsista de iniciação Científica; Núcleo de Pesquisa em Bioética e Saúde Coletiva, Universidade Federal do Amapá (UNIFAP), Macapá, Amapá.

6 Profissional de Educação Física, Residente no Programa de Residência Multiprofissional em Saúde Coletiva, Universidade Federal do Amapá (UNIFAP), Macapá, Amapá.

7 Aluno, Curso de Bacharelado em Enfermagem, Bolsista de Extensão; Núcleo de Pesquisa em Bioética e Saúde Coletiva, Universidade Federal do Amapá (UNIFAP), Macapá, Amapá.

s Aluna, Curso de Bacharelado em Enfermagem, Bolsista de Extensão; Núcleo de Pesquisa em Bioética e Saúde Coletiva, Universidade Federal do Amapá (UNIFAP), Macapá, Amapá.

๑ Enfermeira, Residente no Programa de Residência Multiprofissional em Saúde Coletiva, Universidade Federal do Amapá (UNIFAP), Macapá, Amapá.

${ }_{10}$ Doutorado, Universidade Federal do Amapá (UNIFAP), Macapá, Amapá.

${ }_{11}$ Doutorado, Universidade Federal do Amapá (UNIFAP), Macapá, Amapá. ${ }_{12}$ Mestre, Universidade Federal do Amapá (UNIFAP), Macapá, Amapá.

\section{RESUMO}

Objetivo: Descrever a experiência de bolsistas de iniciação científica e Residentes em Saúde Coletiva, na construção de conhecimentos sobre Bioética Cotidiana, tendo como palco um Núcleo de Pesquisa em Bioética e Saúde Coletiva. Método: Estudo descritivo, qualitativo, na modalidade relato de experiência. Resultados: Foram realizados estudos das produções relevantes sobre a temática bioética cotidiana, bem como a atuação de seu precursor, Giovanni Berlinguer. Adicionalmente foi organizado uma oficina envolvendo discentes e docentes, na qual foi discutido os conceitos de deontologia, diceologia, moral, ética, bioética e bioética cotidiana. Foi utilizado como instrumento de reflexão, um vídeo com o título "Ética e Indiferença" da série Ser ou não Ser produzido pela filósofa Viviane Mosé. Conclusão: A bioética Cotidiana constitui-se um referencial de análise e reflexão sobre como as questões da vida cotidiana são tratadas. Assim, faz-se imperativo a construção de espaços de diálogo sobre os problemas que permeiam o cotidiano da vida. 
PALAVRAS-CHAVES: Ética; Pesquisa; Extensão comunitária.

ÁREA TEMÁTICA: Atenção à Saúde

\section{INTRODUÇÃO}

A Ética é tradicionalmente entendida como o estudo ou reflexão sobre os costumes dos seres humanos na sociedade, mas também podemos chamar de ética a própria vida daqueles que seguem as regras consideradas corretas. A ética pode ser o estudo de ações e costumes e considerar a realização de um comportamento (VALLS, 2013). Enquanto isso, a Bioética é o estudo sistemático da conduta humana que pode examinar os princípios dos valores morais identificados nas ciências da vida e da atenção à saúde, podendo ser considerada um estudo sistemático das dimensões na decisão de condutas e normas (MOTTA, 2012).

Já a Bioética Cotidiana está estritamente relacionada com as ciências biológicas e da saúde, com as ciências humanas, políticas e sociais; enfim, com a ética da qualidade da vida (SILVA et al., 2017). Ela analisa criticamente conflitos e dilemas que acontecem no dia a dia e em todos os lugares, como por exemplo a fome, a exclusão social, a pobreza, o abandono, o racismo, a violência doméstica, entre outros. Estes temas, geralmente, são pouco discutidos no mundo da ciência e reduzidos a uma categoria de "menor valor" em comparação com as questões emergentes como por exemplo a reprodução assistida, o coronavírus, entre outros. Seu precursor o italiano Giovanni Berlinguer, médico, sanitarista, bioeticista e uma importante referência na história da saúde pública italiana e brasileira, foi quem conceituou o novo ramo da bioética designado de Bioética Cotidiana, desde sua vida acadêmica esteve voltado para as questões ligadas ao direito à saúde, especialmente para a relação entre saúde e desigualdades sociais, tema de sua monografia de conclusão do curso de medicina (FLEURY, 2015).

O Projeto de pesquisa Bioética Pelas Lentes Do Cinema, tal qual a participação no grupo de pesquisa e extensão comunitária atua como fator de inserção acadêmica, uma vez que os dois possibilitam que o acadêmico amplie seus conhecimentos voltados para a temática Bioética bem como seu envolvimento na produção de estudos que favoreçam a apresentação de resultados na forma de monografias, artigos, capítulos de livro ou ainda trabalhos de conclusão de curso.

Para entender a relevância na ampliação diante do tema Bioética e seus preceitos no campo da formação acadêmica na área da saúde, foi criado no ano de 2019 o Núcleo de Pesquisa em Bioética e Saúde Coletiva - NUPEBISC-AP, onde a proposta deste projeto de extensão foi construir um espaço de diálogo sobre Bioética, problematizando a realidade cotidiana do processo de trabalho das equipes de saúde, envolvendo professores, estudantes, trabalhadores da saúde e outras áreas. O projeto destinase a docentes e discentes de cursos do ensino médio, graduação, pós-graduação da UNIFAP e outras instituições de ensino; usuários e grupos de profissionais de saúde de instituições públicas e privadas conveniadas ao SUS. A inserção de acadêmicos na pesquisa por meio do NUPEBISC-AP possibilita e oportuniza abertura a vivências e implicações bioéticas que permeiam o cotidiano das práticas do 
docente e dos trabalhadores da saúde.

Assim, entende-se que é importante relacionar a bioética nesta discussão, mais especificamente a bioética cotidiana, portanto este relato de experiência tem como objetivo descrever a experiência de discentes de graduação e Residentes em Saúde Coletiva na construção de conhecimentos sobre Bioética Cotidiana, tendo como palco o Núcleo de Pesquisa em Bioética e Saúde Coletiva.

\section{METODOLOGIA}

Trata-se de um estudo descritivo de natureza qualitativa na modalidade de relato de experiência, a partir da vivência em um Núcleo de Pesquisa em Bioética e Saúde Coletiva (NUPEBISC-AP) na Universidade Federal do Amapá (UNIFAP). O NUPEBISC-AP é composto por docentes, acadêmicos e Residentes. As reuniões ocorrem duas vezes por mês, todas as quartas feiras nas dependências do Prédio do Curso de Bacharelado em Enfermagem/UNIFAP, com início às 18h00min, com duração média de $2 \mathrm{~h}$. Sendo que no momento devido a pandemia os encontros estão ocorrendo de forma remota por meio de plataformas on-line como o Meet, Skype, entre outras.

As atividades desenvolvidas no NUPEBISC-AP utilizam como instrumentos metodológicos estudos no formato de artigos, capítulos de livros, obras cinematográficas, vídeos, músicas dentre outros. Os assuntos abordados são pactuados entre os membros do núcleo no início de cada semestre, sendo que, no ano de 2020 devido a interrupção do calendário acadêmico, em função da Pandemia do Corona Vírus, o plano de estudos teve prosseguimento de forma virtual, sendo que foram debatidas as seguintes temáticas: ética em pesquisa, racismo, vulnerabilidade social, duplo standart, conflito de interesses, indústria farmacêutica, aborto, modelo de atenção à saúde, relações interpessoais, sistema de saúde, Sistema Único de Saúde - SUS e humanização, o nascimento da bioética, a consolidação acadêmica da bioética, a teoria principialista, os limites da teoria principialista, bioética cotidiana e bioética da proteção.

Adicionalmente foi organizado uma oficina envolvendo discentes e docentes, na qual foi discutido os conceitos de deontologia, diceologia, moral, eticidade ética, bioética e por fim bioética cotidiana. Objetivando a reflexão sobre a temática Bioética Cotidiana foi utilizado como estratégia metodológica um vídeo com o título "Ética e Indiferença" da série Ser ou não Ser produzido pela filósofa Viviane Mosé. Posteriormente ao vídeo foi apresentado alguns conceitos que envolvem a Bioética, quais sejam: ética, moral, eticidade, deontologia, diceologia e Bioética Cotidiana. Ao final, a equipe responsável elaborou alguns questionamentos que foram publicados no chat da plataforma Skype, o que estimulou a fala dos participantes. 


\section{RESULTADOS E DISCUSSÕES}

A experiência possibilitou após as primeiras oficinas de estudos teóricos, perceber um maior entendimento sobre o que é a bioética, uma vez que até então, uma grande parte dos participantes do grupo nunca sequer teve conhecimento sobre o termo. No decorrer dos estudos teóricos dúvidas a seu respeito foram esclarecidas e familiaridades com a temática foram criadas, isso se deu de acordo com a construção de um ambiente de diálogo fluido e a partir da troca de experiências dos participantes do NUPEBISC-AP. Por conseguinte, foi apresentado numa destas oficinas teóricas o conceito de bioética cotidiana, em comparação, nesta foi possível analisar uma afinidade maior dos participantes com a temática do que as primeiras, isso se torna evidente devido ao tema ser uma vertente que trata de questões do cotidiano. Adicionalmente, o uso do vídeo se mostrou como um melhor instrumento metodológico para a análise crítica no que diz respeito a marginalização de problemáticas que ocorrem no cotidiano de nossas vivências, seja no mundo do trabalho, acadêmico, pessoal ou das coletividades.

\section{CONCLUSÃO}

Portanto, conclui-se que a temática bioética cotidiana envolve muitas nuances e nos permite abertura para debates e observações relevantes sobre as implicações do cotidiano no ambiente dos serviços de saúde. O NUPEBISC-AP pontuou essas vivências em um ambiente neutro onde foi possível discutir e questionar experiências de modo que os participantes esclarecessem dúvidas, ampliassem conhecimentos e compartilhassem ideias, em um núcleo onde seus indivíduos estão em estágios diferentes da academia e da profissão, edificando um espaço para o aprendizado da prática, da observação, do exercício da profissão e da sapiência.

\section{REFERÊNCIAS}

FLEURY, Sonia. Giovanni Berlinguer: socialista, sanitarista, humanista! Ciência \& Saúde Coletiva, v. 20, n. 11, p. 3555-3559, 2015. ISSN 1678-4561. Disponível em: http://www.scielo.br/scielo. php?script=sci_arttext\&pid=S1413-81232015001103553. Acesso em: 17 mar. 2021.

MOTTA, LUÍS; et al. Bioética: afinal, o que é isto? Revista Brasileira Clínica Médica. São Paulo, 2012.

SILVA, Ana Luísa Remor da; et al. A Bioética Cotidiana como instrumento de reflexão sobre a atenção à saúde da população LGBT. Revista Brasileira de Bioética, v. 133, n. 3, p. 1-10, 2017. Disponível em: http://www.bioetica.org.br/library/modulos/varias_bioeticas/arquivos/Bioetica_ cotidiana_lgbt.pdf. Acesso em: 17 mar. 2021.

VALLS, Álvaro Luiz Montenegro. O que é ética? 13 Edição. São Paulo: Editora Hedra, 2013. 


\title{
BIOÉTICA À LUZ DA EDUCAÇÃO POPULAR COMO DISPOSITIVO DE TRANSFORMAÇÃO: RELATO DE EXPERIÊNCIA
}

\section{Luiz Victor da Silva Moreira ${ }^{1}$; Max Amaral Balieiro ${ }^{2}$; Juliana Ramos Motta de Oliveira ${ }^{3}$; Edylany Almeida de Oliveira ${ }^{4}$; Aneli Mercedes Celis de Cárdenas; ${ }^{5}$ Rosana Oliveira do Nascimento ${ }^{6}$}

${ }_{13}$ Aluno, Curso de Bacharelado em Enfermagem, Bolsista de Extensão; Núcleo de Pesquisa em Bioética e Saúde Coletiva, Universidade Federal do Amapá (UNIFAP), Macapá, Amapá. ${ }_{14}$ Aluno, Curso de Bacharelado em Enfermagem, Bolsista de iniciação Científica; Núcleo de Pesquisa em Bioética e Saúde Coletiva, Universidade Federal do Amapá (UNIFAP), Macapá, Amapá.

${ }_{15}$ Aluna, Curso de Bacharelado em Enfermagem, Bolsista de Extensão; Núcleo de Pesquisa em Bioética e Saúde Coletiva, Universidade Federal do Amapá (UNIFAP), Macapá, Amapá.

${ }_{16}$ Enfermeira, Residente no Programa de Residência Multiprofissional em Saúde Coletiva, Universidade Federal do Amapá (UNIFAP), Macapá, Amapá ${ }_{17}$ Doutorado, Universidade Federal do Amapá (UNIFAP), Macapá, Amapá. ${ }_{18}$ Mestre, Universidade Federal do Amapá (UNIFAP), Macapá, Amapá.

\begin{abstract}
RESUMO
Objetivo: descrever a compreensão dos docentes e discentes sobre Bioética Cotidiana a partir das práticas da educação popular como ferramenta de ensino- aprendizagem. Tal prática ocorreu por meio de oficina e contou com auxílio de metodologias ativas, no caso foi utilizado letra de música conhecida dos participantes da oficina, além do diálogo entre os sujeitos. Métodos: as técnicas metodológicas utilizadas foram auxiliadas por metodologias ativas e ancoradas nas letras da música "Rita" que expressa em seu conteúdo violência, paixões emoções sentimentos, vivenciados por muitos sujeitos. Resultados e Discussão: constatou-se, atenção e reflexão por parte dos participantes da oficina, em relação a temática apresentada. Além disso, observou-se o entendimento em relação aos temas abordados a partir da manifestação por meio da interação e discursos. Também ficou explicito impacto diante da metodologia utilizada, que suscitou o discurso e reflexão sobre a temática, correlacionando à violência familiar, enquanto implicação da bioética cotidiana.
\end{abstract}

PALAVRAS-CHAVES: Ética; Ensino aprendizagem; Extensão comunitária;

ÁREA TEMÁTICA: Atenção à Saúde 


\section{INTRODUÇÃO}

A ética, como ciência, é um conjunto de conhecimentos derivados da investigação do comportamento humano na tentativa de explicar as regras morais de forma racional, fundamentada teórica e cientificamente. No entanto, a ética é mais reflexiva quando questiona porque alguns comportamentos são considerados válidos e outros não, ou seja, busca e analisa o fundamento de cada comportamento (PERÉZ e LIMA, 2015).

Atribui-se à bioética a função de estabelecer políticas públicas voltadas à saúde, definindo normas para instituições, profissionais, procedimentos de cuidado e tomada de decisão. A principal característica da bioética é o estudo das barreiras que afetam a saúde das pessoas, buscando possibilidades para resolvê-las. Para discorrer acerca dos dilemas éticos e morais, a bioética se firma em quatro princípios, estes devem guiar discussões, decisões, procedimentos e ações na esfera dos cuidados da saúde. São eles: beneficência, não maleficência, autonomia e justiça (BARCHIFONTAINE e TRINDADE, 2019).

Baseado nesses importantes princípios da bioética os discentes buscaram nas práticas da educação popular uma estratégia de ensino - aprendizagem visando construir conhecimentos sobre a bioética cotidiana de forma dialógica e humanizada e por meio de comunicação simplificada que em conformidade com Maciazeki-Gomes et al., (2016) esta prática tende aproximar as relações dos afetos estabelecidos associando-se ao diálogo e à práticas de amorosidade junto com o outro. Nessa perspectiva Souza et al., (2015) informam que o movimento da educação popular surgido no século XX, despontou no Brasil durante a década de 70, por meio da luta dos movimentos sociais com o intuito de melhorar a relação com a população, rompendo com a tradição do autoritarismo predominante e o desprezo pelo saber popular.

Esse movimento fortaleceu a relação entre intelectuais e classes populares que foi sistematizada por Paulo Freire, surgiu a partir de construção da participação popular, privilegiando as questões sociais e práticas educativas que possibilitem a autonomia dos sujeitos. Além disso, está centrada no diálogo com o sujeito. Esse diálogo não torna os sujeitos iguais, mas sinaliza a posição democrática existente entre eles e possui significado relevante crescendo um com o outro. Neste cenário infere-se que o aprendizado entre os participantes da oficina sobre bioética cotidiana foi eficaz, por meio do uso de instrumento de metodologia ativa que motivou o diálogo e reflexão sobre a temática (COSTA, 2016).

\section{METODOLOGIA}

Trata-se de um relato de experiência do tipo descritivo, as pesquisas descritivas visam primordialmente a descrição das características de uma determinada população, fenômenos ou até mesmo a relação entre as variáveis. Quanto à abordagem, optou-se pela qualitativa em virtude deste campo se relacionar ao universo de aspirações, significados, compreensões, crenças e valores (BARBOSA, 2020). 
O presente estudo relata experiência vivenciada por graduandos do Curso de Bacharelado em Enfermagem e Residentes de Saúde Coletiva da Universidade Federal do Amapá (UNIFAP) no período de fevereiro de 2021, sobre Bioética Cotidiana a partir das práticas da educação popular como ferramenta de ensino aprendizagem. Tal prática ocorreu por meio de oficina e contou com auxílio de metodologias ativas, no caso foi utilizado letra de música conhecida dos participantes da oficina, "Rita”, além do diálogo entre os participantes. Nesse cenário o grupo citado buscou compreender qual seria o entendimento desses sujeitos sobre Bioética Cotidiana à luz da educação popular, considerando saberes e o cotidiano dos atores. Os participantes do estudo foram docentes e discentes da UNIFAP e integrantes do NUPEBISC-AP.

\section{RESULTADOS E DISCUSSÕES}

Constatou-se, atenção e reflexão por parte dos participantes da oficina, em relação a temática apresentada. Além disso, observou-se o entendimento em relação aos temas abordados a partir da manifestação por meio da interação e discursos. Também ficou explicito impacto dos participantes diante da metodologia utilizada, que suscitou o discurso e reflexão sobre a temática, correlacionando a violência familiar, enquanto implicação da bioética cotidiana.

A experiência possibilitou um novo olhar por parte dos participantes da oficina em relação ao ensino aprendizado utilizando metodologias ativas que proporcionou troca de conhecimento e muito aprendizado sobre bioética cotidiana. Ressalta-se que a explanação dos temas, em consonância com a música proporcionaram um momento dinâmico com maior interação dos participantes, Xavier e Flôr (2015) afirmam que essas abordagens levam os sujeitos a reflexão, compreensão da sua realidade ressignificando o cotidiano e provocando mudanças na visão de mundo.

O entendimento do grupo sobre bioética cotidiana a partir das práticas da educação popular tornou-se explicito diante do discurso de participantes, quando relacionaram o trecho da música com a violência inserida no cotidiano, a qual é retratada pela mídia diariamente e compartilhada entre os grupos sociais "volta, Rita, que eu perdoo a facada" (...) sendo assim, afirmaram sobre o ressignificado da palavra "facada" que poderia estar presente no sentido figurado e expressar a traição pelo (a) parceiro (a) e foi perdoada. Enfim, a música revela as brigas corriqueiras entre casais. Afonso et al., (2015) explicam que o ser humano na sua essência é social e por meio da interação com outros, constroem opiniões e comportamentos favorecendo a capacidade de entendimento e aprendizagem.

Quanto ao impacto dos participantes da oficina, em relação à letra da música se deu por considerarem a linguagem coloquial inviável para o momento, no entanto, foram surpreendidos com a relevância e o significado da melodia culminado com a temática apresentada pelos graduandos e residentes proporcionando assim, o empoderamento e autonomia do grupo em questão. Nesse sentido vale dizer que essa forma, de linguagem usando expressões do cotidiano, em alguns momentos se faz necessário para facilitar a compreensão dos sujeitos. A esse respeito Afonso et al., (2018) afirmam que a prática educativa baseada na premissa da educação popular deve partir da realidade dos sujeitos 
que compõem determinados grupos.

\section{CONCLUSÃO}

Diante do exposto, conclui-se que a bioética cotidiana como referencial de análise para educação popular, possibilita diversas trocas de saberes por meio de debates, onde os sujeitos possuem autonomia e liberdade de expressão para construção de conhecimentos e aprendizagem sobre a temática abordada, não existindo um saber acabado ou imudável. A oficina propiciou uma reflexão profunda acerca da banalização da violência doméstica e de como nós nos posicionamos frente a essa implicação bioética.

\section{REFERÊNCIAS}

AFONSO, A.Q. et al. Educação popular em saúde: relato de experiências da prática de residentes de universidades públicas paraenses, Revista Baiana Saúde Pública, v. 42, n. 4, p. 763-774, 2018. Disponível em: https://rbsp.sesab.ba.gov.br/index.php/rbsp/article/view/2537/2590. Acesso em: 17 mar. 2021.

BARBOSA, S. R. M. A enfermagem e o gerenciamento do cuidado integral 3. Ponta Grossa: Atena, 2020.

BARCHIFONTAIRE, C. P. TRINDADE, M. A. Bioética, saúde e realidade brasileira. Revista Bioética, Brasília, v. 27, n. 3, p. 439-445,2019. ISSN 1983-8034. Disponível em: https://www.scielo. br/scielo.php?script=sci_arttext\&pid=S198380422019000300439. Acesso em: 15 mar. 2021.

COSTA, B. B. Paulo Freire: educador-pensador da libertação. Pro-Posições, v. 27, n. 1, n. 79, p. 93-110, ISSN 1980-6248, 2016. Disponível em: https://www.scielo.br/pdf/pp/v27n1/1980-6248pp-27-01-00093.pdf. Acesso em: 16 mar. 2021.

MACIAZEKI-GOMES, R. C. et al. O trabalho do agente comunitário de saúde na perspectiva da educação popular em saúde: possibilidades e desafios. Ciência \& Saúde Coletiva [online]. v. 21, n. 5, p. 1637-1646, 2016. ISSN 1678-4561. Disponível em: https://doi.org/10.1590/141381232015215.17112015. Acesso em: 15 mar. 2021.

PÉREZ, H.; LIMA, R. Moral, ética e bioética. Um ponto de vista prático (traduzido). Medicina e Investigação. México, Toluca, v. 3, n.1, p.79-84, 2015. ISSN 2214-3106. Disponível em: https:// www.elsevier.es/es-revista-revista-medicina-e-investigacion-353-articulo-moral-etica-bioetica-unpunto-S2214310615000084. Acesso em: 15 mar. 2021.

SOUZA, K. M. et al. Práticas pedagógicas de Educação Popular em Saúde e a formação técnica de Agentes Comunitários de Saúde no município do Rio de Janeiro, Brasil. Interface - Comunicação, Saúde, Educação [online]. v. 18, suppl 2, p. 1513-1522, 2015. ISSN 1807-5762. Disponível em: 
https://www.scielosp.org/article/icse/2014.v18supp12/1513-1522/. Acesso em: 15 mar. 2021.

XAVIER, P. M. A.; FLÔR, C. C. C. Saberes populares e educação científica: um olhar a partir da literatura na área de ensino de ciências. Ensaio, v. 17, n. 2, p. 308-328, 2015. Disponível em: https:// www.scielo.br/pdf/epec/v17n2/1983-2117-epec-17-02-00308.pdf. Acesso em: 17 mar. 2021. 


\title{
IMPORTÂNCIA DA HUMANIZAÇÃO NA ASSISTÊNCIA POR PROFISSIONAIS DE ENFERMAGEM: REVISÃO INTEGRATIVA DA LITERATURA
}

\author{
Maíra de Lima Silva ${ }^{1}$ \\ ${ }^{1}$ Graduanda de bacharelado de Enfermagem, Universidade Federal de Pernambuco (UFPE), Vitória \\ De Santo Antão, Pernambuco.
}

\begin{abstract}
RESUMO
Introdução: A humanização éa transformação dos modelos assistenciais da atenção à saúde objetivandose a prestação de cuidados holísticos. Essa atuação prestada por profissionais de enfermagem traz benefícios nos níveis de atenção para todos envolvidos nas ações de saúde. Objetivo: identificar a importância da humanização na assistência por profissionais de enfermagem presentes nas publicações científicas e literárias. Metodologia: trata-se de uma revisão integrativa da literatura, realizada na base de dados LILACS e SCIELO, com descritores: Cuidados de enfermagem; Enfermagem centrada no paciente; Humanização da assistência hospitalar. Foram realizadas seleções resultando uma amostra final de 12 artigos. Resultados: Em 25\% dos artigos houve redução de sintomas sentimentais que poderiam repercutir em sintomatologias e 59\% dos artigos identificaram-se melhorias em diversas relações que qualificam a assistência de saúde. Considerações finais: Portanto, a humanização é muito importante na assistência de enfermagem, trazendo benefícios para o desenvolvimento e melhoria das ações em saúde.
\end{abstract}

PALAVRAS-CHAVES: Cuidados de enfermagem; Enfermagem centrada no paciente; Humanização da assistência hospitalar.

ÁREA TEMÁTICA: Atenção à Saúde

\section{INTRODUÇÃO}

A assistência humanizada é um método de cuidado que vem sendo adotado por todas as classes profissionais, principalmente a da enfermagem. Essa humanização visa o cuidado integral do paciente de maneira holística, individual e humanizada obedecendo os princípios naturais e humanos, vistos também como adoção dos direitos do paciente. A enfermagem atua de maneira holística em diversos serviços de saúde, sendo no perfil hospitalar ou assistencial, essas ações entram em contradição com o método biomédico da assistência, logo a atuação da humanização por profissionais de enfermagem assim como outros profissões são respaldadas pela Política Nacional de Humanização (PNH), criada em 2003, e estabelece alguns princípios a serem seguidos, como: acolhimento, gestão 
democrática, clínica ampliada, valorização do trabalho e garantia aos direitos dos usuários. Assim, o profissional de saúde adotando todas essas diretrizes no seu atendimento irá haver a ampliação do olhar de cuidado com o paciente.

A humanização no atendimento favorece o vínculo profissional-paciente, pois, com as atitudes respeitosas e humanas o paciente desenvolve a confiança nas ações desenvolvidas pelo profissional e seus cuidados prestados, valorizando os serviços prestados e desenvolvidos, assim, o profissional desenvolve suas ações em saúde de maneira qualificada, oferecendo um bom serviço tanto para o paciente que está sendo atendimento como para a população no qual aquele serviço é prestado. Assim, cria-se uma satisfação mutua, tanto para o paciente quanto para o profissional de enfermagem. Os cuidados de enfermagem, sejam eles, anamnese, exame físico, educação em saúde, prevenção, promoção e proteção, serviços de intervenções e de atuação em procedimentos prestados de maneira holística é muito mais aceitada pela sociedade que está recebendo esses serviços.

Logo, a enfermagem pode utilizar diversas formas para implantar uma saúde humanizada nos mais diversos cenários de atuação, como serviços com metodologias ativas e até mesmo situações em que as tecnologias que auxiliem nessa adequação. Todas essas alternativas são válidas quando o objetivo é manter uma boa relação com o paciente e realizar uma assistência visando um olhar complexo com um eixo bio-psíquico-social-espiritual e outros meios que se associem a esses vínculos.

Contudo, a assistência deve ser prestada de maneira natural, com interação entre o profissional e o paciente a ser assistido, logo, o profissional deve ter sentimentos de empatia, gentileza e cuidado com o outro de maneira virtuosa. Assim, objetivou-se identificar a importância da humanização na assistência por profissionais de enfermagem.

\section{METODOLOGIA}

Trata-se de uma revisão integrativa da literatura, partindo da seguinte questão norteadora: qual a importância da humanização na assistência evidenciado por profissionais de enfermagem?, a partir desse questionamento buscamos por produções cientificas contidas na base de dados LILACS e na Biblioteca Virtual SCIELO referentes a assistência humanizada nos serviços de saúde por profissionais de enfermagem, com os descritores disponíveis no DeCs: Cuidados de enfermagem; Enfermagem centrada no paciente; Humanização da assistência hospitalar, foram feitos cruzamentos deles para ampliar a captação dos artigos a serem avaliados, logo os pesquisadores foram: Cuidados de enfermagem and Humanização da assistência hospitalar e Enfermagem centrada no paciente and Humanização da assistência hospitalar. Após o levantamento bibliográfico, foram realizadas as seleções devidos aos critérios de inclusão: artigos disponíveis na integra, publicados nos últimos 5 anos (2016-2021), em idiomas: português, inglês e espanhol, e critérios de exclusão: artigos que não se enquadravam no eixo temático da pesquisa e que não se enquadravam com o tema. Logo, foram selecionados inicialmente 349 artigos e após a realização das leituras e adoção dos critérios de exclusão e inclusão, foram selecionados 12 artigos científicos para compor a amostra final. 


\section{FUNDAMENTAÇÃO TEÓRICA}

Resultando da leitura e avaliação dos artigos científicos $25 \%$ deles, equivalentes a 3 artigos, mostraram que o papel primordial na realização dos cuidados é a humanização, pois, em muitos casos minimizam sinais e sintomas, como: ansiedade, medo, receio, angústias, e outros sentimentos que podem repercutir em achados sintomatológicos, assim, com a atuação da escuta qualificada, receptividade do paciente com um acolhimento adequado e o desmembramento da mecanização e engessamento da prática da enfermagem, uma vez que o serviço de enfermagem busca a harmonização do bem-estar físico, psíquico e espiritual que está relacionado a todos esses eixos complexos, abrangendo todas essas dimensões para uma prestação de um cuidado de qualidade, para isso, é necessário que tenha o empenho e dedicação dos profissionais. Já em aproximadamente 59\% dos artigos, equivalentes a 7 artigos, mostraram que a humanização traz consigo benefícios para assistência aos serviços de saúde prestados e assistidos pelos profissionais de enfermagem, uma vez que, tem como consequência a melhoria das relações interpessoais entre os profissionais quanto entre profissionais e pacientes, relações respeitosas, relações de confiança, relações de cuidado, relações de afinidade, relação de apoio e relação harmoniosa.

Além de facilitar a assistência esse contato pessoal irá gerar melhorias e qualidade na assistência prestada, satisfazendo o usuário e o prestador do serviço com essas ações integradas situadas no atendimento humanizado.

Essas atitudes profissionais são efetivas e trazem uma compreensão e incorporação da humanização na prática do serviço de saúde, principalmente o serviço público que possui suas precariedades geracionais e podem ser melhoradas com a atuação de boas atitudes profissionais, no qual assistem e atendem pessoas com um alcance do cuidado integral, logo, esse cuidado profissional englobam estratégias desenvolvidas pelos profissionais de enfermagem que fortalecem o cuidado com os usuários dos serviços de saúde.

Assim, os profissionais se disponibilizam para que estejam presentes em cursos e capacitações para aprender e captar informações sobre o tratamento dos pacientes com técnicas humanizadas, assim essa assistência torna-se uma ação de valorização de sentimentos e emoções do usuário, resultando no empoderamento profissional da enfermagem.

\section{CONSIDERAÇÕES FINAIS}

Portanto, a humanização é um assunto muito discutido e comentado atualmente e a assistência de enfermagem de modo humanístico traz consigo suas importâncias para o desenvolvimento dos serviços de saúde e para a melhoria das ações realizadas por esses profissionais de enfermagem, com técnicas e modos de cuidados holísticos. Assim, os usuários irão possuir um serviço de saúde de qualidade e essas ações humanizadas podem auxiliar na melhoria do paciente em relação ao modo assistencial e redução de críticas devido má assistência advinda do sistema de saúde. Além de ser um modo assistencial que descontrói o modo biomédico centrado apenas nas patologias presentes, 
com ausência de atenção de sentimentos e sem a visão de individuo como um todo, de maneira integral. Logo, o profissional de enfermagem pode mudar a construção do sistema de saúde, trazendo melhorias, qualidades e satisfações, tornando um alicerce de cuidados.

\section{PRINCIPAIS REFERÊNCIAS}

BREZOLIN, C. A.; et al. A importância da humanização do cuidado em centro cirúrgico. Saúde em Redes. 2020; 6(2):289295

CARVALHO, S. S.; et al. Percepção da equipe de enfermagem sobre a implantação do setor de acolhimento com classificação de risco às gestantes. Rev. Bras. Saúde Mater. Infant., Recife, 18 (2): 309-315 abr-jun., 2018

CASTRO, M. R.; et al. Humanization in the work of nursing faculty. Rev. Bras. Enferm. vol.73 no.1 2020 Epub 10-Fev-2020

GIANTAGLIA, F. N.; et al. O cuidado de enfermeiras de um programa de residência obstétrica sob o olhar da humanização. Rev enferm UFPE on line., Recife, 11(5):1882-90, maio., 2017

RIVEROS, C. C. A natureza do cuidado humanizado. Enfermagem (Montevidéu) vol.9 no.1 Montevidéu 2020 Epub 01-Jun-2020

VELOSO, A. C. E.; et al. Atuação dos profissionais de saúde e o processo de humanização no centro obstétrico. Revista Nursing, 2020; 23(268): 4570-4574 


\title{
CONHECIMENTO DO ENFERMEIRO FRENTE O CÂNCER DE MAMA NA ATENÇÃO PRIMÁRIA EM SAÚDE
}

\author{
Débora Pintro Bueno; Kallyne dos Santos ${ }^{2}$ \\ ${ }^{1}$ Estudante de Enfermagem, CIES, Campo Mourão, Paraná. \\ ${ }^{2}$ Estudante de Enfermagem, CIES, Campo Mourão, Paraná.
}

\begin{abstract}
RESUMO
Introdução: A atenção primária em saúde tem papel fundamental no rastreamento do câncer de mama, integrado pelo Sistema Único de Saúde. Isto posto, o enfermeiro deve dispor de conhecimento especializado para um atendimento de qualidade aos pacientes portadores. Objetivou-se avaliar o conhecimento do enfermeiro frente o câncer de mama para atuação na atenção primária à saúde Metodologia: Trata-se de uma revisão integrativa de literatura. Os descritores utilizados foram: "Atenção primária à saúde", "Cuidados de enfermagem" e "Câncer de mama", obtendo assim, um total de 6 artigos. Fundamentação Teórica: As pesquisas revelam que 100\% (6) dos artigos selecionados para o estudo eram pesquisa de campo/estudo transversal. Desses, 66,6\% dos estudos foram feitos com base em entrevistas com enfermeiros. Considerações finais: Porém, vê-se a necessidade de uma educação permanente com relação a detecção precoce do câncer de mama
\end{abstract}

PALAVRAS-CHAVES: Assistência; Rastreamento; Exame.

ÁREA TEMÁTICA: Atenção à Saúde

\section{INTRODUÇÃO}

No Brasil, em 2017, 16,724 mulheres morreram por câncer de mama, o que equivale a 16,16 mulheres a cada 100 mil. Os gestores da saúde se viram na necessidade da criação de campanhas com o intuito de diagnosticar precocemente este tipo de câncer, para assim reduzir o número de mortalidades e prevenir o desenvolvimento tardio da doença. A atenção primária em saúde tem papel fundamental no rastreamento, tendo em vista as solicitações de mamografias integradas pelo Sistema Único de Saúde. Isto posto, o enfermeiro responsável pela Estratégia de Saúde da Família deve dispor de um conhecimento especializado para um atendimento de qualidade aos pacientes portadores. Este estudo teve como objetivo avaliar o conhecimento do enfermeiro frente o câncer de mama para atuação na atenção primária à saúde. 


\section{METODOLOGIA}

Trata-se de uma revisão integrativa de literatura de índole exploratória e descritiva. Para a seleção dos artigos, foi realizada uma busca eletrônica no site da Biblioteca Virtual em Saúde (BVS), utilizando as bases de dados MEDLINE, LILACS e BDENF. Os descritores utilizados foram: "Atenção Primária à Saúde", "Cuidados de Enfermagem" e "Câncer de Mama". Na junção dos descritores citados, foram encontrados 116 artigos. Em seguida, foram estabelecidos os seguintes critérios de inclusão: artigos publicados nos últimos cinco anos (2016 - 2021), escrito em língua portuguesa ou inglesa e que apresentasse o texto na íntegra, obtendo um total de 24 artigos. Logo após foram estabelecidos os critérios de exclusão, sendo eles relacionados à títulos e/ou resumos que não estavam de acordo com o tema principal, obtendo assim, um total de 6 artigos.

\section{FUNDAMENTAÇÃO TEÓRICA}

As pesquisas revelam que $100 \%$ (6) dos artigos selecionados para o estudo eram pesquisa de campo/estudo transversal. Desses, 66,6\% dos estudos foram feitos com base em entrevistas com enfermeiros, 16,6\% mulheres de 20 a 64 anos e 16,6\% gestores com conhecimento prévio. Nos anos de 2018 e 2021 não foram publicados artigos correspondentes a temática, 2016 e 2020 publicaram 16,6\% dos trabalhos selecionados e 2017 e 2019 foram os anos com mais publicações, sendo 33,3\% dos trabalhos selecionados.

Um dos artigos selecionado expõe que, dos entrevistados, no que se refere a Exame Clínico de Mama (ECM), 41,6\% alegaram não haver dificuldades na realização, 16,6\% disseram que a falta de rotina dificulta tal prática e a maioria $92,3 \%$ realizavam o exame, 33,3\% em conjunto com a citologia oncótica, 58,5\% sem seguir indicação de faixa etária e 66,7\% realizavam anualmente ${ }^{1}$. Outro artigo relatou que $100 \%$ dos entrevistados gostariam de uma educação permanente, 95,8\% se sentiam preparados para realização do ECM; foi questionado a conduta, onde 77,1\% solicitariam mamografia, 54,2\% realizariam ECM e 18,8\% encaminhariam para o mastologista; com relação a orientações, $79,2 \%$ forneceriam informações sobre CA de mama e investigação familiar e 68,8\% reforçariam a importância das consultas periódicas ${ }^{2}$. Em outro artigo destaca-se a opinião dos enfermeiros frente os fatores de risco, onde 83,8\% relataram o histórico familiar, 50\% tabagismo e 22,5\% idades; já com relação as manifestações clínicas, 83,8\% falaram de nódulos mamários, 40,35 secreções mamárias e 25,8\% alterações na pele; também é importante destacar que 29,1\% dos entrevistados não se sentem motivados pelos gestores a realizarem consulta de enfermagem de qualidade na detecção precoce do câncer de mama ${ }^{3}$. 


\section{CONSIDERAÇÕES FINAIS}

Os enfermeiros terem respondido corretamente, em sua maioria, a questões de condutas, fatores de risco e manifestações clínicas. Porém, vê-se a necessidade de uma educação permanente com relação a detecção precoce do câncer de mama para habilitação dos profissionais para um atendimento e assistência qualificados e, para promoção e educação em saúde para a população motivando o autocuidado e fortificando o diagnóstico precoce, para que assim, possa se reduzir os níveis de mortalidade e também o desenvolvimento da doença.

\section{REFERÊNCIAS}

${ }^{1}$ MARQUES, C.A.V., et al. Ações do enfermeiro na detecção precoce do câncer mamário. Rev enferm UERJ. V.25. 2017. Acesso em: 17/03/2021. Disponível em: http://dx.doi.org/10.12957/ reuerj.2017.22639

2 SANTOS, C.S., et al. Conhecimento sobre câncer de mama entre enfermeiros da atenção primária de Divinópolis/MG. Revista Nursing. V.23. 2020. Acesso em 17/03/2021. Disponível em: https://doi.org/10.36489/nursing.2020v23i267p4452-4465.

${ }^{3}$ FERREIRA, D.S., et al. Conhecimento, atitude e prática de enfermeiros na detecção do câncer de mama. Escola Anna Nery. V.24. 2020. Acesso em: 17/03/2021. Disponível em: DOI: 10.1590/21779465-EAN-2019-0054

4 ROSS, J.R., et al. Rastreamento do câncer de colo de útero e mama. Rev enferm UFPE on line. V.11. 2017. Acesso em: 17/03/2021. Disponível em: https://doi.org/10.5205/1981-8963$\underline{\mathrm{v} 11 \mathrm{i} 12 \mathrm{a} 231284 \mathrm{p} 5312-5320-2017}$

5 MORAES, D.C., et al. Rastreamento oportunístico do câncer de mama desenvolvido por enfermeiros da Atenção Primária à Saúde. Rev Esc Enferm USP. V.50. 2016. Acesso em: 17/03/2021. Disponível em: DOI: http://dx.doi.org/10.1590/S0080-623420160000100002

${ }_{6}$ GOLDMAN, R.E., et al. Rede de Atenção ao Câncer de Mama: perspectiva de gestores da saúde. Rev Bras Enferm. V.72. 2019. Acesso em: 17/03/2021. Disponível em: https://doi.org/10.1590/00347167-2017-0479 


\title{
A INSERÇÃO DA SAÚDE MENTAL NA ESTRATÉGIA DE SAÚDE DA FAMÍLIA: UMA COMPREENSÃO NECESSÁRIA
}

\author{
Creuza Laíze Barboza de Souza Bezerraㅜ; Danielly Soares Magalhães²; Valdete Pereira \\ Melo; ; Thatiana Maria Cabral Ferreira da Silva ${ }^{4}$; Wedson Ferreira dos Santos ${ }^{5}$; Bruna Diniz \\ Oliveira $^{6 ;}$ Thais Morgana Bequiman Silva ${ }^{7}$
}

1,2,3,4,5,6,7 Residente em Saúde Coletiva com Ênfase em Gestão de Redes, Escola de Governo em Saúde Pública de Pernambuco (ESPPE), Afogados da Ingazeira, Pernambuco.

\section{RESUMO}

Introdução: Os transtornos mentais são um problema de saúde pública de grande relevância, sendo demanda cotidiana para as equipes que atuam nas Unidades Básicas de Saúde (UBS). Objetivo: Analisar o contexto da Atenção psicossocial na Atenção Primária à Saúde. Metodologia: Trata-se de uma revisão narrativa de literatura acerca da saúde mental na Atenção Primária à Saúde, analisando 14 (quatorze) artigos sobre este tema. Fundamentação Teórica: Pontuou-se como a saúde mental está inserida no contexto da Estratégia de Saúde da Família, bem como os impasses que refletem na qualidade da rede de saúde mental. Considerações finais: Observa-se que os serviços oferecidos em saúde mental evoluíram bastante, porém falta articulação entre a rede, devendo apontar para profundas metamorfoses nos modos de conceber o sujeito da clínica de saúde mental, para além de práticas institucionalizadas. Principais Referências: BOSI, 2011; BARIONI, 2014; DANTAS, 2014.

PAlaVRAS-CHAVES: Atenção Primária em Saúde; Rede de Saúde; Atenção Psicossocial.

ÁREA TEMÁTICA: Atenção à Saúde

\section{INTRODUÇÃO}

Na contemporaneidade os transtornos mentais são um problema de saúde pública de grande relevância. De acordo com os dados da Organização Mundial de Saúde (OMS), estima-se que aproximadamente 300 milhões de pessoas em todo o mundo sofram de depressão e que 1 em cada 4 indivíduos será afetado por uma doença psiquiátrica em alguma fase de sua vida (WHO, 2017). A Prevalência dos transtornos mentais na atenção primária em saúde é alta. Cerca de $50 \%$ dos usuários atendidos em Atenção Primária de Saúde (APS) apresentam algum tipo de sofrimento psíquico, e $35 \%$ destes preenchem critérios para transtornos mentais específicos de intensidade grave. Contudo, 20 a 30\% apresentam remissão espontânea dos sintomas e melhora do quadro (FORTES; VILLANO; LOPES, 2008). 
Dessa forma, os transtornos mentais constituem-se demanda cotidiana para as equipes multiprofissionais que atuam na Estratégia de Saúde da Família (ESF), causando grande impacto na saúde pública, dada a alta prevalência destas patologias neste serviço, e também o nível de complexidade dos casos. A Atenção Básica (AB) desempenha imprescindível papel no diagnóstico precoce, no início rápido do tratamento, na manutenção do tratamento farmacológico dos quadros estáveis e na reabilitação psicossocial.

Ademais, vale frisar que a integração de saúde mental e atenção primária assegura que a população usuária tenha acesso aos cuidados de saúde mental. O cuidado em saúde mental na Atenção Básica é bastante estratégico devido à facilidade de acesso das equipes aos usuários (CADERNOS DE ATENÇÃO BÁSICA - SAÚDE MENTAL, 2013). À vista dessa realidade, esta revisão de literatura narrativa objetiva debater a saúde mental e assim contribuir para o exercício profissional dos trabalhadores que encontram-se atuando na ESF.

\section{METODOLOGIA}

O presente trabalho se caracteriza como uma revisão de literatura, onde foi realizada uma pesquisa na Biblioteca Virtual em Saúde (BVS) disponível na internet e que inclui os seguintes índices bibliográficos: SCIELO, LILACS, MEDLINE, IBECS e Biblioteca Cochrane. Os critérios de inclusão foram os seguintes: artigos nacionais em português, inglês e espanhol; artigos sobre o tema compreendidos no período de 2010 a 2020. Buscamos através dos seguintes descritores: "saúde mental", "atenção primária", "ações em saúde mental" e "políticas de saúde". Também foi pesquisado sobre o assunto nos Documentos oficiais do Ministério da Saúde (MS) e em relatórios da OMS. Foram utilizados 14 artigos para construção do estudo, numa leitura minuciosa e criteriosa acerca da temática.

\section{FUNDAMENTAÇÃO TEÓRICA}

No Brasil a saúde mental pública transformou-se e vem sendo cotidianamente construída respaldada nos preceitos do movimento de Reforma Sanitária e da Reforma Psiquiátrica (RP) que aparecem para tentar atender às necessidades dos profissionais de saúde, dos usuários e dos familiares. Para Bosi et al., (2011): "é fulcral romper com os paradigmas que permeiam as relações na saúde mental, como as nomenclaturas "louco", "loucura", que nada dizem sobre o homem, sua formação social e histórica, o seu modo de viver e ser.

Diante disso, torna-se urgente uma nova atitude, uma maior capacidade de pactuar e acolher essas pessoas, para produção do cuidado em saúde mental poder vislumbrar o combate à exclusão e preconceito (BOSI et al., 2011). Um trabalho direcionado ao acolhimento, a construção de Projetos Terapêuticos Singulares (PTS), o matriciamento, as reuniões de equipe e supervisões promovem transformações positivas nos processos de trabalho, as quais funcionam como instrumentos que 
potencializam as ações terapêuticas, o trabalho de forma coletiva e o dialógico democrático, e se aproximam das diretrizes estabelecidas tanto pelo Sistema Único de Saúde (BALLARIN, 2011).

O apoio matricial pode efetivar a (re)organização dos serviços para acolher a demanda por uma saúde mental de qualidade. A clínica ampliada também é um ponto exitoso no SUS e principalmente na saúde mental. Trata-se de uma intervenção que se baseia na construção do trabalho clínico segundo certo traço artesanal por meio do qual a divisão do processo de trabalho é acompanhada da responsabilização dos profissionais de um modo mais integrado.

O objeto de trabalho é ampliado para além dos transtornos mentais apresentados pelos indivíduos, inclui questões mais amplas do meio social (GARCIA; MORENO; PRATES, 2013). Outra questão importante para a construção/efetivação da saúde mental é o apoio institucional, que é um instrumento que se constitui de estar junto com os diferentes sujeitos discutindo e analisando os processos de trabalho e intervindo nas formas como os serviços estão organizados.

O apoio institucional constrói espaços coletivos e de democracia, maior comunicação entre os sujeitos envolvidos, cogestão, sujeitos comprometidos com a reforma psiquiátrica, etc. (ACIOLE; ALMEIDA, 2014). Para garantir maior efetividade dos direitos das pessoas que sofrem algum tipo de transtorno mental, o MS criou a Rede de Atenção Psicossocial (RAPS), com o objetivo de prestar assistência integrada, articulada e efetiva nos diferentes pontos de atenção às pessoas em sofrimento e/ou com demandas decorrentes de transtornos mentais e/ou do consumo de crack, álcool e outras drogas. A RAPS possibilitou o fortalecimento da Atenção Básica, aproximando e integrando as ações.

Em um estudo, feito a partir da análise de relatos, ficou claro para os autores que a escassez de recursos materiais, o espaço físico inadequado, os diferentes tipos de vínculo empregatício e o desconhecimento do papel do CAPS por parte de alguns profissionais estavam entre as dificuldades ao oferecimento do cuidado integral (BALLARIN et al., 2011 ).

No tocante ao financiamento em Saúde Mental, há um baixo investimento, alertando sobre a lógica racionalizadora do financiamento, baseado na oferta e em contraste com a demanda e os cuidados necessários (BARIONI; IBANHES, 2014). Outro ponto relevante é que as limitações encontradas nos serviços de saúde é que não há um diálogo sobre o cuidado/cotidiano com os usuários atendidos em saúde mental, fazendo com que a intervenção seja voltada apenas para a medicalização dos sujeitos (SILVA, 2016).

Mesmo diante de toda discussão da RP, as intervenções em saúde mental são centradas no profissional médico e na medicalização, preterindo ações interdisciplinares ou de trabalho em equipe (SILVEIRA, 2012). Nesta perspectiva, há prevalência do modelo assistencial psiquiátrico, baseado em uma racionalidade tecnológica, em detrimento de abordagens complementares e substitutivas, agravados por uma demanda excessiva e despreparo dos profissionais da ESF para abordar os problemas de saúde mental (BORSARI; ROSA, 2014).

Outra dificuldade apresentada é a articulação em rede, tanto em relação ao sofrimento psíquico, quanto ao sofrimento na relação de abuso de substâncias psicoativas, no sentido de 
composição do cuidado em saúde mental na APS com os outros pontos da rede setorial e intersetorial (PAULON, PROTAZIO, TSCHIEDEL, 2018). As autoras ainda evidenciam outra situação bastante preocupante, é que: “as práticas de cuidado em saúde mental tendem a se tornar invisíveis, porque são dificilmente protocoláveis, não existindo procedimentos antecipáveis, claros e padronizados, que sirvam para todos os casos." (idem, p. 16). Em outro estudo, sobre pesquisas avaliativas nos serviços de saúde mental no Brasil observou que as pesquisas não têm a diversidade e a completude para fornecer indicadores de saúde mental considerados básicos (DANTAS; ODA, 2014).

\section{CONSIDERAÇÕES FINAIS}

A partir da discussão desse tema, constata-se que é necessário um maior esforço, em conjunto, dos gestores, autoridades responsáveis, profissionais de saúde e população em um continuum de evolução, com o objetivo de melhorar a estrutura da rede psicossocial a fim de se melhorar a saúde mental dos usuários.

\section{PRINCIPAIS REFERÊNCIAS}

BOSI, Maria Lúcia Magalhães; et al. Inovação em Saúde Mental: subsídios à construção de práticas inovadoras e modelos avaliativos multidimensionais. Revista de Saúde Coletiva. v.21, n.4, p.1231-1252. São Paulo, 2011.

BARIONI, Paula Montanheiro; IBANHES, Lauro César. Políticas Públicas e Saúde Mental: notas sobre demandas atuais. Boletim Institucional de Saúde (BIS). v.15, p.104-115. São Paulo, 2014.

DANTAS, Clarissa de Rosalmeida; ODA, Ana Maria Gladini Raimundo. Cartografia das pesquisas avaliativas de serviço de saúde mental no Brasil (2004-2013). Revista de Saúde Coletiva. v.24, n.4, p.1127-1179. Rio de Janeiro, 2014. 


\title{
ASSISTÊNCIA DE ENFERMAGEM EM SERVIÇO DE ONCOLOGIA: RELATO DE EXPERIÊNCIA
}

\author{
Ana Flávia Silva Lima1; Verônica Bezerra Monteiro²; Mário César Ferreira Lima Júnior; \\ Amanda Maria Silva da Cunha ${ }^{4}$; Gabriela Ferreira ${ }^{5}$; Laís de Miranda Crispim Costa ${ }^{6}$ \\ ${ }^{1}$ Enfermeira, Santa Casa Rodrigo Ramalho (SCRR), Maceió, Alagoas. \\ ${ }^{2}$ Enfermeira, Santa Casa Rodrigo Ramalho (SCRR), Maceió, Alagoas. \\ ${ }^{3}$ Mestrando, Universidade Federal de Alagoas (UFAL), Maceió, Alagoas. \\ ${ }^{4}$ Mestranda, Universidade Federal de Alagoas (UFAL), Maceió, Alagoas. \\ ${ }^{5}$ Enfermeira, Santa Casa Rodrigo Ramalho (SCRR), Maceió, Alagoas. \\ ${ }^{6}$ Doutora em Enfermagem, Universidade Federal de Alagoa (UFAL), Maceió, Alagoas.
}

\section{RESUMO}

Os cuidados paliativos (CP) afirmam a vida, entendendo a morte como integrante do ciclo vital. A enfermagem na assistência a pacientes oncológicos em CP pode utilizar práticas integrativas para melhor atender os usuários. O estudo objetiva relatar experiência de enfermeiros na assistência a pacientes oncológicos em CP com utilização de práticas integrativas. Trata-se de relato de experiência sobre a assistência de enfermagem a pacientes oncológicos com utilização de práticas integrativas à luz da teoria do final de vida pacífico, em um Hospital filantrópico de Alagoas, durante dezembro de 2020 a março 2021. Adotaram-se práticas de shantala e musicoterapia e os resultados tiveram relação com conceitos de não estar com dor, experiência de conforto, experiência de respeito/dignidade e proximidade de pessoas que se preocupam. A experiência oportunizou utilizar práticas integrativas como ferramenta para cuidado humanizado. Nota-se que a teoria pode ser aplicada na assistência de enfermagem a pacientes oncológicos em CP.

PALAVRAS-CHAVES: Cuidados de Enfermagem; Cuidados Paliativos; Oncologia.

ÁREA TEMÁTICA: Atenção à Saúde 


\section{INTRODUÇÃO}

Os Cuidados paliativos devem ser compreendidos além da definição limitada de terminalidade de vida e não possibilidade de tratamento convencional, de modo amplo são cuidados integrais e ativos que visam promoção de qualidade de vida para paciente e família por meio da prevenção e alívio do sofrimento, tendo como princípio não acelerar ou adiar o processo de morte, compreender o ser humano de maneira holística, oferecer suporte a família durante e após a doença e oferecer uma abordagem interprofissional. Busca assim uma política de afirmar a vida e perceber a morte como parte do processo vital (GOMES, OTHERO, 2016).

Para tanto, não abre mão da biotecnologia e seus avanços para manejo da dor, nem do humanismo para alcance integral das necessidades do indivíduo e família. A enfermagem por ser uma ciência humanística pode se valer das práticas integrativas e descobrir novas formas de melhor atender os usuários/família, rompendo com o paradigma biomédico e mecanicista, ao prestar uma assistência individual, humanizada e holística (MENDES et al, 2019).

Por ser uma profissão que permanece mais tempo com o paciente e presta grande parte dos cuidados, tem papel relevante na equipe de cuidados paliativos. Durante a sistematização da assistência de enfermagem faz-se imprescindível que o cuidado seja norteado por uma teoria de enfermagem (BRANDÃO et al, 2019), neste ínterim a teoria do final de vida pacífico mostra-se como referencial coerente com os princípios dos Cuidados Paliativos, visto que o foco do cuidado de enfermagem está em proporcionar alívio de medos e ansiedades, bem como promover conforto, dignidade e um final de vida tranquilo (ZACCARA et al, 2020). Pelo exposto, este trabalho objetiva relatar experiência de enfermeiros na assistência a pacientes em cuidados paliativos com a utilização de práticas integrativas à luz da teoria do final de vida pacífico.

\section{METODOLOGIA}

Trata-se de uma pesquisa qualitativa, descritiva do tipo relato de experiência de enfermeiros sobre a assistência de enfermagem a pacientes oncológicos com utilização de práticas integrativas, examinada à luz da teoria do final de vida pacífico. A experiência dos enfermeiros se dá em um Hospital filantrópico de um município alagoano, local onde os enfermeiros exercem suas atividades laborais. As práticas integrativas aconteceram quinzenalmente uma vez por semana, durante o período de dezembro de 2020 a março 2021. O estudo cumpre adequada citação dos autores e obedece aos pressupostos éticos e critérios de confiabilidade conforme a Lei n ${ }^{0} 9.610$ de fevereiro de 1998, a Lei dos Direitos Autorais (BRASIL, 1998). 


\section{RESULTADOS E DISCUSSÕES}

A assistência e processo de enfermagem tem como elemento base as teorias de enfermagem, as quais servem como subsídio importante para sistematização da assistência, pois permitem a geração de explicações da multiplicidade e complexidade dos fenômenos trazidos pelos pacientes nos diversos serviços de saúde (BRANDÃO et al, 2019). Neste contexto, a teoria do final de vida pacífico mostra-se pertinente e um referencial importante, pois seus conceitos e pressupostos se aproximam dos princípios dos Cuidados Paliativos. É uma teoria que aborda o cuidado de enfermagem como contribuição para um viver pacífico, propondo o alívio do medo e ansiedade real ou percebida pelo paciente e família. Assim, o enfermeiro guiado por esta teoria rompe o paradigma mecanicista, de simplesmente cumprir tarefas e pode promover um final de vida mais tranquilo para o paciente (ZACCARA et al, 2017).

Com o intuito de proporcionar um cuidado individual e humanizado foi implementado na prática assistencial de enfermeiros em um serviço de oncologia a utilização de práticas integrativas, e foi possível notar a aproximação da assistência de enfermagem executada com a teoria do final de vida pacífico, visto que é notório que seus conceitos segundo Zaccara e colaboradores (2020) (não estar com dor, experiência de conforto, experiência de dignidade e respeito, estar em paz e experiência com pessoas importantes/pessoas que se preocupam) permeiam esta assistência de enfermagem que faz uso de múltiplos métodos terapêuticos para proporcionar qualidade de vida ao paciente.

Uma das práticas integrativas adotadas pelos enfermeiros deste serviço foi a "shantala", um método de massagem indiano, tendo como alguns de seus benefícios o manejo não farmacológico da dor, alongamento dos membros e ativação da circulação (SILVA et al, 2020). A prática da "shantala" é aplicada nos pacientes acamados durante o banho associado com um fundo musical, com objetivo de reduzir o sofrimento e repercussões negativas da doença, proporcionar conforto e qualidade de vida. É um procedimento simples que oportuniza o toque terapêutico e o cuidado individual e humanizado (SILVA et al, 2020). Nesta prática, é possível ver a aplicação de intervenção de enfermagem com base nos conceitos da teoria do final de vida pacífico, no que diz respeito ao conceito de não estar com dor, visto que a shantala é uma medida que busca evitar a dor no paciente, além de favorecer a experiência do conforto por meio do relaxamento e dar condições para a experiência de estar em paz (MENEZES, SILVA, SILVA, 2020).

Outra técnica adotada na prática é a de musicoterapia, que conta com as habilidades musicais e instrumentais da própria equipe de enfermagem e multidisciplinar e em conjunto com os pacientes é realizado este momento de musicoterapia nas enfermarias, onde foi possível notar a participação e reação positiva dos pacientes e familiares com sentimentos de alegria e emoção. Além disso, foi possível perceber que os elementos da música (som, ritmo, melodia e harmonia) permite a distração, e assim desvio de foco da dor e sofrimento para um momento prazeroso (LIMA, CARVALHO, SILVA, 2019). Ao conceder a participação para os pacientes e familiares na escolha da música e o protagonismo em cantá-las, é perceptível que essa assistência dialoga com a teoria em estudo e além dos conceitos de conforto, estar em paz e não estar com dor, também é visto o conceito de respeito à 
dignidade, bem como de proximidade de pessoas que se preocupam (ZACCARA et al, 2020).

\section{CONSIDERAÇÕES FINAIS OU CONCLUSÃO}

A experiência de enfermeiros na assistência de pacientes oncológicos por meio da utilização de práticas integrativas oportunizou a prestação de um cuidado humanizado e individual e permitiu fazer reflexões da assistência a partir da teoria do final de vida pacífico. A oferta de métodos terapêuticos como a shantala e a musicoterapia permitiu que o cuidado de enfermagem baseado nos conceitos desta teoria contribuiu para o não estar com dor, a experiência de conforto, a experiência de respeito/ dignidade e proximidade de pessoas que se preocupam.

Contudo, foi possível perceber que a teoria contempla o contexto de pacientes em cuidados paliativos e pode ser aplicada na assistência de enfermagem a pacientes oncológicos em cuidados paliativos. Além disso, o estudo desperta para a importância de adoção de práticas integrativas como ferramenta para um cuidado humanizado, o que serve de estímulo para utilização destas na prática assistencial.

\section{PRINCIPAIS REFERÊNCIAS}

BRANDÃO, M.A.G. et al. Teorias de enfermagem na ampliação conceitual de boas práticas de enfermagem. Rev Bras Enferm [Internet]. 2019; 72(2):604-8. Disponível em: https://www.scielo.br/ pdf/reben/v72n2/pt_0034-7167-reben-72-02-0577.pdf. Acesso em 18 mar. 2021.

BRASIL. Lei no 9.610, de 19 de fevereiro de 1998. Disponível em: <http://www.planalto.gov.br/ ccivil 03/leis/19610.htm $>$.

GOMES, A.L.Z.; OTHERO, M.B. Cuidados paliativos. Estud. av. São Paulo, v. 30, n. 88, p. 155-166, Dec. 2016. Disponível em: scielo.br/scielo.php?script=sci_arttext\&pid=S0103-40142016000300155. Acesso em 19 mar. 2021.

LIMA, C.L.; CARVALHO, M.J.; SILVA, E.R. Musicoterapia para pacientes oncológicos e/ou em cuidados paliativos: revisão integrativa da literatura. São Paulo: Revista Recien. 2019; 9(28):162175. Disponível em: https://recien.com.br/index.php/Recien/article/view/329/pdf_1. Acesso em 19 mar. 2021.

MENEZES, T.M.O.; SILVA, V.M.; SILVA, D.E.S. Cuidados Paliativos em Instituição de Longa Permanência frente a pandemia do COVID-19: reflexões a partir da teoria do final de vida pacífico. Enfermagem gerontológica no cuidado ao idoso em tempos da COVID-19. Brasília, DF : ABen/ DCEG, 2020. Disponível em: http://www.abennacional.org.br/site/wp-content/uploads/2020/05/EBOOK-GERONTO.pdf. Acesso em 18 mar. 2021. 
SILVA, F.L. et al. Shantala as non-pharmacological therapy for pain relief in hospitalized children. Research, Society and Development, v (9), n. 10, e3259108610, 2020. Disponível em: https://rsdjournal.org/index.php/rsd/article/view/8610. Acess on 19 Mar. 2021.

ZACCARA, A.A.L. et al. Análise e avaliação da teoria final de vida pacífico segundo critérios de fawcett. Texto Contexto Enferm, 2017; 26(4):e2920017. Disponível em: http:/www.scielo.br/ scielo.php?script=sci_arttext\&pid=S0104-07072017000400615\&lng=pt\&nrm=iso. Acesso em 18 mar. 2021.

ZACCARA, A.A.L.; BATISTA, P.S.S.; VASCONCELOS, M.F. et al. Contribuições da Teoria Final de Vida Pacífico para Assistência de Enfermagem ao Paciente Em Cuidados Paliativos. Rev Fun Care Online.2020. jan./dez.; 12:1247- 1252. DOI: http://dx.doi.org/10.9789/2175-5361.rpcfo. v12.9558 


\section{RESISTÊNCIA MASCULINAAOS SERVIÇOS DE SAÚDE: DESAFIOS PARAA SUA INCLUSÃO NA ATENÇÃO PRIMÁRIA}

\section{Caroline Natielle Rocha da Silva ${ }^{1}$; Linielce Portela Nina ${ }^{2}$; Joana Maria Machado Mendes ${ }^{3}$; Hemerson Felipe Fernandes Abreu ${ }^{4}$ Antonia Katia Lopes Araújo ${ }^{5}$; Sudário Vítor de Aguiar}

\section{$\operatorname{Lima}^{6}$}

${ }^{1}$ Especialista em Estratégia Saúde da Família pela Sociedade de Ensino Superior Estácio de Ribeirão Preto LTDA - UNISEB. Graduada em Enfermagem pela Faculdade de Educação São Francisco (FAESF), Pedreiras, Maranhão.

2,3,4,5 Graduados em Enfermagem Bacharelado, Universidade Estadual do Maranhão (UEMA), Coroatá, Maranhão.

${ }^{6}$ Especialista em Urgência e Emergência pelo Instituto de Ensino Superior Multiplo (IESM), Timon, Maranhão. Graduado em Enfermagem pelo Centro Universitário UNINOVAFAPI, Teresina, Piauí.

\section{RESUMO}

A inserção dos homens de forma preventiva em ações de saúde é um grande desafio, especialmente devido a questões como o autocuidado e valorização do corpo em relação à saúde, que não são observados como práticas comuns na socialização deste sujeito. Os homens têm dificuldade em reconhecer suas necessidades, cultivando o pensamento mágico que rejeita a possibilidade de adoecer. Tratou-se de um estudo de revisão bibliográfica, de caráter exploratório, do tipo descritivo e de natureza qualitativa que busca identificar fatores determinantes que contribuem para as grandes taxas epidemiológicas de morbimortalidade masculina e sua resistência na busca aos serviços de saúde com o intuito de conscientizar essa população sobre a importância da sua assiduidade na atenção primária. Conclui-se que a baixa procura pelos serviços de atenção à saúde pelo gênero masculino ocorre devido à falta de sinais e sintomas característicos de alguma doença e limita-se a ações de cunho curativo.

PALAVRAS-CHAVES: Promoção da Saúde; Qualidade de Vida; Saúde do Homem.

AREA TEMÁTICA: Atenção à Saúde 


\section{INTRODUÇÃO}

Nos últimos anos tem se percebido um crescente interesse voltado especificamente à saúde da população masculina, como fator precursor desse novo foco da saúde pública têm-se os resultados de vários estudos, os quais demonstram que, em geral, os homens vivem menos que as mulheres.

O homem brasileiro morre prematuramente, e conforme estatísticas, seu risco de morte é $40 \%$ maior que o das mulheres. O homem busca tardiamente os serviços de saúde, pois culturalmente não tem o hábito de se prevenir contra enfermidades e isto faz com que na maioria das vezes, a doença seja descoberta em fase avançada, iniciando o tratamento em tempo inoportuno, dificultando a recuperação e aumentando a probabilidade de óbito (BRASIL, 2008).

A procura pela atenção básica pode impedir muitos agravos à saúde, pois permite a participação em programas de prevenção e a detecção precoce de doenças. Deste modo, com o propósito de desvelar as ações de atenção integral à saúde dos indivíduos do sexo masculino, com idade entre 20 e 59 anos, o Ministério da Saúde, em 2008, apresentou como uma das prioridades do governo a Política Nacional de Atenção Integral à Saúde do Homem, cujos objetivos principais são: qualificar a assistência à saúde masculina na perspectiva de linhas de cuidado que conserve a integralidade da atenção primária para que ela não se limite apenas à recuperação, garantindo, sobretudo, a promoção da saúde e a prevenção de agravos evitáveis.

Por esse angulo, considerou-se relevante desenvolver o presente estudo, que teve como objeto de identificar fatores determinantes na ausência de integralidade por parte da atenção primária destinada a esse público.

\section{METODOLOGIA}

Tratou-se de um estudo de revisão bibliográfica, de caráter exploratório, do tipo descritivo e de natureza qualitativa que busca identificar fatores determinantes que contribuem para as grandes taxas epidemiológicas de morbimortalidade masculina e sua alta resistência na busca por qualidade de vida e aos serviços de saúde com o intuito de conscientizar essa população sobre a importância da sua assiduidade na atenção primária.

\section{FUNDAMENTAÇÃO TEÓRICA}

Segundo Gomes (2007), vários estudos constatam que os homens, em geral, padecem mais de condições severas e crônicas de saúde do que as mulheres e também morrem mais do que elas pelas principais causas de morte. Entretanto, apesar de as taxas masculinas assumirem um peso significativo nos perfis de morbimortalidade, observa-se que a presença de homens nos serviços de atenção primária à saúde é menor do que a das mulheres. 
Santana (2011) continua dizendo que, com base na observação dos indicadores de saúde existentes em diferentes partes do mundo, observa-se uma situação de saúde desfavorável para os homens que precisa ser considerada e enfrentada pelos serviços de saúde.

Segundo Silva, et. al (2012), os homens têm dificuldades em reconhecer suas necessidades, cultivando o pensamento mágico de que não adoecem. A doença é considerada como um sinal de fragilidade que os homens não compreendem como inerente à sua própria condição social, psíquica e biológica.

Nesse sentido, a prevenção se volta para a uma ação orientada para que o indivíduo não adoeça e possa desfrutar de melhor qualidade de vida e, para tal, é necessário envolvê-lo com informações relevantes inserindo-os ativamente e assiduamente no contexto do processo saúde-doença com o objetivo de incorporar novos hábitos preventivos e assisti-los holisticamente.

A relação entre Enfermagem e a saúde do homem merece ser destacada neste trabalho, pois, durante o levantamento do estado da arte, pôde-se perceber a pouca produção científica - mesmo com a PNAISH - construída pelo coletivo profissional e, assim, atentar-se para importância de se ampliar esse campo de estudo.

Vale ressaltar que a categoria sofre uma persistente feminização, o que dificulta o aprofundamento das reflexões sobre o processo saúde-doença da população masculina e, por conseguinte, o não acompanhamento da evolução da sociedade por parte dos sistemas de saúde (FILGUEIREDO, 2005 E GOMES, 2007).

Em pesquisa feita por Ferraz L, Trindade LL, Bevilaqua E, Santer J. (2013), observou-se que, depois da implantação da PNAISH, aumentaram as discussões sobre o tema, contudo, ainda são escassos os estudos sobre a saúde do homem na atenção primária em saúde. Os aspectos estabelecidos nessa política revelam, por um lado, os desafios a serem enfrentados por gestores e profissionais da saúde, especialmente e, por outro, a urgência de ser viabilizada em todo território nacional, por representar uma necessidade da referida população e pelo reconhecimento dos agravos à saúde desta que se constitui em um magno problema de saúde pública.

À medida que os serviços de saúde oferecidos correspondem à variedade das necessidades de saúde dos homens, eles se vinculam mais a esses serviços. Isto é evidenciado quando eles relatam que preferem ser atendidos pelo profissional em quem já confiam e com quem já existe um vínculo. Não se pode afirmar que o vínculo por si só garanta um atendimento que almeje a integralidade. Entretanto, sem o reconhecimento entre profissionais e pacientes não é possível pensar em integralidade. Desse modo, para haver integralidade, é preciso que as necessidades do sujeito sejam percebidas em suas diversidades e, para que isso ocorra, é fundamental a comunhão possibilitada pelo vínculo.

O enfermeiro, como educador, necessita de formação teórica e de práticas que desenvolvam sua visão crítica e inovadora para que possa aplicar da melhor forma os conhecimentos adquiridos de acordo com as necessidades da comunidade. 


\section{CONCLUSÃO}

O enfrentamento do quadro epidemiológico dos problemas de saúde pública que acometem o contingente masculino requer do enfermeiro que atua na atenção básica um fazer ousado e inovador na valorização do saber popular e na descoberta de potencialidades condutoras da evolução humana e profissional.

Nessa trajetória, é preciso considerar a necessidade de estratégias de ações integradas para envolver os homens no contexto da saúde. Para tanto, é essencial o estabelecimento de uma relação de parceria entre os profissionais que integram as equipes de saúde da família e os usuários do sexo masculino para propiciar ações que promovam saúde para o homem e para sua comunidade.

\section{REFERENCIAS}

BRASIL. Ministério da Saúde. Política Nacional de Atenção Integral à Saúde do Homem. 2008.

FERRAZ L, TRINDADE LL, BEVILAQUA E, SANTER J. As demandas do homem rural: informações para a assistência nos serviços de saúde da atenção básica. REME rev min enferm [Internet]. 2013.

FIGUEIREDO, Wagner. S. Masculinidades e cuidado: diversidade e necessidades de saúde dos homens na atenção primária. São Paulo, 2008.

GOMES, Romeu et. al. Por que os homens buscam menos os serviços de saúde do que as mulheres? As explicações de homens com baixa escolaridade e homens com ensino superior.

SANTANA, Elizangela Nunes et.al. A atenção à saúde do homem: ações e perspectivas dos enfermeiros. Recife; 2011.

SILVA, NA et. Al. Promoção da saúde do homem nos serviços de atenção primária à saúde. Em Extensão, Uberlândia, v. 13, n. 1, p. 82-88, jan. / jun. 2014. 


\title{
SABERES ETNOFARMACOBOTÂNICOS À LUZ DA TEORIA DA COMPLEXIDADE: UMA CONTRIBUIÇÃO À ATENÇÃO PRIMÁRIA EM SAÚDE
}

\author{
Paulo Ricardo Batista ${ }^{1}$ \\ ${ }^{1}$ Graduação em Ciências Biológicas, Universidade Regional do Cariri (URCA), Crato, Ceará.
}

\begin{abstract}
RESUMO
O uso de plantas medicinais é prática recorrente no Sistema Único de Saúde e atenção primária a saúde. Considerando o despreparo e desconhecimento de profissionais da saúde frente ao campo da Etnofarmacobotância, o presente trabalho tem por objetivo tecer uma discussão dessa área do conhecimento à luz da ciência da Complexidade, a fim de fomentar melhorias na promoção à saúde. Trata-se de uma revisão narrativa da literatura que propõe a visualização da Etnofarmacobotânica como um sistema adaptativo complexo, posto os $n$ elementos envolvidos na sua elaboração e transmissão de saberes. Este insight pretende-se contribuir lançando luzes para os profissionais da atenção primária à saúde, posto que orientações são necessárias em razão da toxicidade das plantas medicinais e interações medicamentosas, possibilitando um tratamento holístico. Em adição alçar essa visão por meio da Teoria da Complexidade pode melhorar o entendimento do funcionamento desse sistema e quem sabe permitir técnicas de modelagem.
\end{abstract}

PALAVRAS-CHAVE: Sistemas adaptativos complexos; Atenção à saúde; Fitoterapia.

ÁREA TEMÁTICA: Atenção à saúde

\section{INTRODUÇÃO}

A Etnofarmacobotânica estuda os remédios simples e compostos elaborados com partes de vegetais e que são empregados para tratar afecções físicas, mentais e/ou espirituais (CAMARGO, 2008). As plantas medicinais e seus derivados, por sua vez, compreendem um dos principais recursos terapêuticos da Medicina Tradicional Complementar, cuja denominação recente do Ministério da Saúde corresponde às Práticas Integrativas e Complementares. Aquelas junto à fitoterapia são as mais recorrentes no Sistema Único de Saúde e a maioria das vivências ocorrem na atenção primária à saúde (GONÇALVES et al., 2017).

Destarte, apontando para a interdisciplinaridade dos saberes etnofarmacobotânicos das comunidades tradicionais e locais e suas contribuições para os profissionais da saúde da atenção primária no manejo e orientações das plantas medicinais para a promoção da saúde que ainda 
permanece um desafio, o presente trabalho tem por objetivo tecer uma discussão dessa área do conhecimento à luz da ciência da Complexidade, a fim de fomentar melhorias à saúde.

\section{METODOLOGIA}

Este estudo descritivo-qualitativo compõe uma revisão narrativa da literatura. Conforme Rother (2007), revisões desse tipo são estudos amplos e convenientes para descrever e discutir o desenvolvimento ou o estado da arte de um determinado tema, sob o posto de vista teórico e/ ou contextual. Consistindo na análise da literatura publicada e interpretação e análise crítica do pesquisador. Ainda, possui uma metodologia mais flexível e variável para prospecção das fontes de informação.

O banco de pesquisa selecionado foi o Google Scholar, devido sua ampla cobertura, expressa pela indexação de diferentes e variados tipos de documentos, não se limitando apenas aos trabalhos publicados em periódicos científicos (TORRES-SALINAS; RUIZ-PÉREZ; DELGADO-LÓPEZCÓZAR, 2009).

\section{FUNDAMENTAÇÃO TEÓRICA}

Dados da Organização Mundial da Saúde reportam que mais da metade da população mundial se utilizam de plantas medicinais para tratamento de saúde, além disso, nos países em desenvolvimento, boa parte da população depende da medicina tradicional para sua atenção primária (GONÇALVES et al., 2017). Cabe ressaltar que a atenção primária em saúde trata-se de uma estratégia de organização voltada para responder de forma regionalizada, contínua e sistematizada à maior parte das necessidades de saúde de uma população, englobando ações preventivas e curativas à indivíduos e comunidades (MATTA; MOROSINI, 2009).

Face, a Teoria da Complexidade vem ganhando popularidade entre acadêmicos e praticantes, com aplicações em diversas áreas, possibilitando novas perspectivas, encontrar soluções e inovar abordagens. Ao passo que estuda os sistemas complexos constituídos por vários agentes que se integram para produzir estratégias adaptativas de sobrevivência para os componentes do sistema e para este como um todo (LUKOSEVICIUS; MARCHISOTTI; SOARES, 2016).

Aliteraturajáindica estudos querelacionam/integramosconhecimentosecológicostradicionais (um dos objetos de estudo da Etnoecologia) sob a abordagem da Teoria da Complexidade, uma vez que há uma grande necessidade da articulação do conhecimento ecológico científico e tradicional (BARENHO; COPERTINO; CALLONI, 2008). Em adição, sabe-se que a Etnofarmacobotânica deriva da Etnoecologia por meio da Etnobotânica (CAMARGO, 2008). Corroborando com a proposta desta revisão, Dong-Tao (2010) concebe a medicina tradicional chinesa como pertencente ao sistema científico da Complexidade, e de acordo com os diferentes campos e níveis daquela, pode-se adotar o modelo de sistema adaptativo complexo. 
Conforme destaca Hammond (2009), um sistema composto por um conjunto variável de atores, em muitos níveis distintos de escala, com diferentes motivações e prioridades individuais, cujas partes interatuam (sutil ou não linearmente) para produzir uma gama de resultados (multiplicidade de mecanismos) que não podem ser limitados a um único mecanismo. No qual tais propriedades figuram um paradigma de um Sistema Adaptativo Complexo (SAC), uma abordagem que inclui entre suas características: (i) a individualidade, na qual cada nível é composto por atores autônomos; (ii) heterogeneidade, em que os autores de cada nível detém objetivos, regras, repertório adaptativo e restrições próprias; (iii) interdependência, nos diferentes níveis; (iv) emergência, padrões de comportamento coletivo de difícil predição mediante compreensão fragmentada dos elementos; (v) inclinação, em razão da não linearidade.

Partindo desses pressupostos, evidencia-se inúmeros elementos e atributos presentes no campo da medicina caseira com base nas plantas medicinais, entre eles: sociais, culturais, ambientais, econômicos, políticos e biológicos, além de envolver inúmeros agentes (a exemplo, moradores de comunidades tradicionais e profissionais da saúde) e níveis de escalas (da atuação concreta bioquímica terapêutica à crença abstrata, e até mesmo divulgação digital) e multiplicidades de mecanismos, estes são os fundamentos para proposição e desfecho dessa revisão.

\section{CONSIDERAÇÕES FINAIS}

Este insight ainda requer um longo caminho para sua validação na literatura não obstante pretende-se contribuir para a integração dos saberes etnofarmacobotânicos (empíricos) e biomédicos (científicos), lançando luzes para os profissionais da atenção primária à saúde, posto que orientações/intervenções são necessárias em razão da toxicidade das plantas medicinais e interações medicamentosas, por exemplo, e por vezes, àqueles profissionais não detêm o preparo e conhecimento destas práticas, assim possibilitando um tratamento holístico. Em adição alçar essa visão por meio da Teoria da Complexidade pode melhorar o entendimento do funcionamento desse sistema e quem sabe permitir processos científicos de técnicas de modelagem.

\section{PRINCIPAIS REFERÊNCIAS}

BARENHO, C. P.; COPERTINO, M.; CALLONI, H. Traçando relações entre o conhecimento ecológico tradicional e a Teoria da Complexicidade. Revista Eletrônica do Mestrado em Educação Ambiental, v. 20, p. 477-487, 2008.

CAMARGO, M. T. L. A. Etnofarmacobotânica: metodologia de pesquisa. Dominguezia, v. 24, n. 2, p. 71-75, 2008.

DONG-TAO, L. Inspiration of complexity science on research of traditional Chinese medicine. Journal of Shandong University of Traditional Chinese Medicine, p. 04, 2010.

GONÇALVES, R. N.; GONÇALVES, J. R. S. N.; BUFFON, M. C. M.; NEGRELLE, R. R. B. Plantas 
medicinais: relacionando conhecimento popular e científico na atenção primária à saúde. Visão Acadêmica, v. 18, n. 4, p. 25-65, 2017.

HAMMOND, R. A. Complex systems modeling for obesity research. Preventing Chronic Disease, v. 6, n. 3, p. 1-10, 2009.

LUKOSEVICIUS, A. P.; MARCHISOTTI, G. G.; SOARES, C. A. P. Panorama da complexidade: principais correntes, definições e constructos. Revista Eletrônica Sistemas \& Gestão, v. 11, n. 4, p. 455-465, 2016.

MATTA, G. C.; MOROSINI, M. V. G. Atenção primária à saúde. In: PEREIRA, I. B.; LIMA, J. C. F. Dicionário da Educação Profissional em Saúde. Rio de Janeiro: Fiocruz; Escola Politécnica de Saúde Joaquim Venâncio, 2009, p. 23- 28.

ROTHER, E. T. Revisión sistemática X Revisión narrativa. Acta Paulista de Enfermagem, v. 20, n. 2, p. ix-x, 2007.

TORRES-SALINAS, D.; RUIZ-PÉREZ, R.; DELGADO-LÓPEZ-CÓZAR, E. Google Scholar como herramienta para la evaluación científica. El Profesional de la Información, v. 18, n. 5, p. 501-510, 2009. 


\title{
A IMPORTÂNCIA DA HUMANIZAÇÃO NA PRÁTICA DO PSICÓLOGO HOSPITALAR
}

\author{
Juliana Soares Laudelino Santos ${ }^{1}$ \\ ${ }^{1}$ Graduada em Psicologia Bacharelado, Universidade Federal de Alagoas (UFAL), Residente \\ Multiprofissional em Saúde do Adulto e do Idoso, Hospital Universitário Professor Alberto Antunes \\ HUPAA/UFAL, Maceió, Alagoas.
}

\begin{abstract}
RESUMO
Esta pesquisa teve como objetivo discutir sobre a importância da Humanização na prática do Psicólogo hospitalar. Para isso, tratamos sobre a importância da humanização, evidenciando o seu surgimento, bem como refletindo sobre o que a Política Nacional de Humanização propõe, considerando seus objetivos e instrumentos. A discussão se deu através de leituras de referenciais teóricos que se destacam em suas pesquisas relacionadas ao tema. Desse modo, para chegar ao objetivo proposto, foram selecionados alguns artigos científicos através de uma pesquisa virtual na base de dados Google Acadêmico, que serviram de fundamento para a análise desse estudo. Chegamos à conclusão que o trabalho humanizado no hospital possui importância significativa e deve ser realizado em um trabalho multidisciplinar, que envolva todos os profissionais que compõem a equipe, pois essa busca não deve ser realizada apenas pelo psicólogo.
\end{abstract}

PALAVRAS-CHAVES: Psicologia; Hospital; Trabalho Humanizado.

ÁREA TEMÁTICA: Clínico - Hospitalar

\section{INTRODUÇÃO}

Humanizaré “tornar humano, dar condição humana”. Étambém definido como “tornarbenévolo, afável, tratável" e ainda "fazer adquirir hábitos sociais polidos, civilizar". Já o termo "humano" vem da natureza humana, significando também "bondoso, humanitário" (BORGES; WALDOW, 2011, p. 415). Assim, a atuação psicólogo hospitalar diz respeito à humanização neste espaço, uma vez que, pode acontecer, conforme pontua Angerami-Camon (1995), de a pessoa hospitalizada passar por um processo de despersonalização, isto é, ter o seu nome esquecido e passar a ser identificada por um número, um leito ou até mesmo pelo nome da sua doença. Logo, adquire um estigma de doente, de paciente, até mesmo no sentido de sua passividade perante aos novos fatos e perspectivas existenciais. Deste modo, a presente pesquisa teve como objetivo discutir sobre a importância do trabalho humanizado realizado pelo psicólogo hospitalar, destacando suas possibilidades de atuação, bem como as dificuldades encontradas por esse profissional no contexto hospitalar. 


\section{METODOLOGIA}

Sobre os aspectos metodológicos, realizamos este trabalho com base na pesquisa qualitativa e bibliográfica, com o intuito de levantar as produções já existentes sobre o nosso tema de interesse. A pesquisa bibliográfica é uma modalidade de estudo que se fundamenta em fontes de pesquisa e pela discussão de vários autores. Com isso, temos que esse tipo de pesquisa "[...] implica em um conjunto ordenado de procedimentos de busca por soluções, atento ao objeto de estudo, e que, por isso, não pode ser aleatório" (LIMA; MIOTO, 2007, p. 38). Desse modo, a pesquisa qualitativa permite que haja uma aproximação da realidade da temática seguida para a investigação, porque esta modalidade também promove a aquisição de novos sentidos para o entendimento do fato estudado, admitindo a compreensão das particularidades que envolvem o objeto de estudo. A pesquisa bibliográfica foca na análise literária de algum tema, pois realiza um levantamento acerca das produções existentes do tema de interesse. Esse procedimento admite investigarmos, de forma pormenorizada e crítica, o objeto de estudo em busca de princípios, fatos ou dados que corroborem com o tema em análise, pondo o pesquisador em contato direto com o que já foi produzido através da escrita, fala ou filmagem, as quais serão suas fontes bibliográficas (MARCONI; LAKATOS, 2008). Portanto, as análises realizadas nesta pesquisa foram acessadas por meio de uma revisão bibliográfica de artigos científicos de autores bem conceituados e que possuem destaque sobretudo no contexto da Humanização. Nesse sentido, a discussão do tema se deu também por meio de leituras de referenciais teóricos que se destacam em suas produções relacionadas ao assunto.

\section{FUNDAMENTAÇÃO TEÓRICA}

A Política Nacional de Humanização (PNH) (BRASIL, 2004) é de grande valia para que exista um bom funcionamento e prestação de serviços no sentido de ocasionar melhorias para todos aqueles que fazem parte da rotina hospitalar: usuários do serviço, profissionais de saúde e gestores.

Segundo o posicionamento de Campos (1995), a humanização em saúde sugere uma mudança nos indivíduos, na maneira de trabalhar e nas estruturas, fazendo-se necessária uma reparação da tradição clínica e epidemiológica, onde deve estar presente a combinação da objetivação científica do processo saúde-doença-intervenção com novas formas de trabalhar, incorporando a pessoa e sua história do momento do diagnóstico ao momento da intervenção. Para a autora, o trabalho em saúde se humaniza quando há uma combinação na defesa de uma vida mais longa com novos padrões de qualidade para sujeitos concretos, porém essa integração só será efetivada com a participação ativa do usuário e com a contribuição do saber tecnológico.

O Programa Nacional de Humanização da Atenção Hospitalar (PNHAH) deu início em 2000 as atividades nos hospitais para a invenção de Comitês de Humanização que objetivavam uma melhor qualidade da atenção prestada aos usuários. Com o desenvolvimento desse programa este recebeu uma nova nomenclatura, passou a ser denominado de Política Nacional de Humanização da Atenção e da Gestão na Saúde (PNH). Portanto, a humanização é abarcada a partir da PNH, a qual 
apoia atividades que venham a qualificar o Sistema Único de Saúde (SUS), assim como defende uma melhoria nas relações entre os profissionais, usuários e gestores dos sistemas de saúde, e ainda busca estimular o exercício do controle social participativo e democrático.

A partir dessa proposta, espera-se que o trabalho seja realizado com qualidade e acolhimento, levando em conta também as possíveis melhorias nas condições de trabalho para que exista o desenvolvimento dessa política pelos trabalhadores. Todavia, salientamos que, às vezes, pode ser desafiador efetivar, na prática, os princípios da humanização propostos pelo SUS, considerando todas as questões estruturais envolvidas: investimento na estrutura física, recursos humanos etc.

No entanto, há hospitais, instituições e profissionais de saúde que declaram possuírem uma prática humanizada, mas, no cotidiano dessas instituições isso pouco se percebe, pois, frequentemente, as regras e normas são feitas pensando, sobretudo, no planejamento do trabalho do que na humanização do atendimento que é ofertado ao paciente. Sendo assim, o atendimento psicológico precisa considerar as variáveis e os aspectos encontrados no processo de hospitalização, como os limites de atuação e os princípios institucionais.

Consideramos também a importância de o profissional ter seu trabalho baseado nos princípios da humanização do ambiente hospitalar. Considerando isso, Angerami-Camon (1995) pontua que o psicólogo hospitalar atua no sentido de tentar diminuir os processos de despersonalização nesse ambiente e auxiliar na humanização desse espaço, que é um dos maiores aniquiladores da dignidade existencial da pessoa hospitalizada. Com isso, esse profissional deve exercer um trabalho de reflexão que possibilite envolver a equipe de saúde, sendo uma necessidade presente no hospital, fazendo com que este perca seu caráter meramente curativo e venha a ser uma instituição que trabalhe não só com a reabilitação orgânica, mas também com o reestabelecimento da dignidade humana.

Diante disso, para que exista uma diminuição dos processos de despersonalização e auxilio na humanização do ambiente hospitalar, convém que se realize um trabalho multidisciplinar, que envolva todos os profissionais que compõem a equipe de saúde, pois essa busca não deve ser realizada somente pelo psicólogo. Esse processo de humanização do atendimento é importante, estende-se desde a indicação de internação, à orientação médica e também à assistência global que o paciente recebe, incluindo o atendimento que também deverá ser prestado à sua família.

Assim, o trabalho da Psicologia no âmbito hospitalar, além de privilegiar o ser em sua existência, contribui para que esse movimento de humanização possa se proliferar em ações direcionadas aos outros profissionais que compõem a equipe de saúde. 


\section{CONSIDERAÇÕES FINAIS}

Diante do exposto defendemos que o psicólogo no contexto hospitalar começou a ser melhor visualizado a partir do momento em que sua atenção se voltou para a humanização, bem como foi melhor compreendida a relação dos profissionais da saúde com a pessoa hospitalizada e com os acompanhantes/familiares. Nesse sentido, o trabalho desse profissional é focal, voltado para a diminuição do sofrimento e nas repercussões decorrentes da hospitalização, associados a outros fatores, como a história de vida do paciente, a maneira como ele assimila a doença, seu perfil de personalidade e seu contexto social, fazendo, assim, com que se ofereça um trabalho humanizado, efetivando, dessa forma, os princípios da Política Nacional de Humanização, todavia ressaltamos que essa busca não deve ser realizada somente pelo psicólogo, esse processo de humanização do atendimento deve ser realizado em um trabalho multidisciplinar, que envolva todos os profissionais que compõem a equipe.

\section{PRINCIPAIS REFERÊNCIAS}

ANGERAMI-CAMON, V. A. et al. Psicologia Hospitalar: teoria e prática. 2. ed. São Paulo: Pioneira, 1995.

BORGES, R. F.; WALDOW, V. R. Cuidar e humanizar: relações e significados. Acta Paulista de Enfermagem, v. 24, n. 3, p. 414-418, 2011.

BRASIL. Ministério da Saúde. Secretaria-Executiva. Núcleo Técnico da Política Nacional de Humanização. HumanizaSUS: Política Nacional de Humanização: a humanização como eixo norteador das práticas de atenção e gestão em todas as instâncias do SUS. Brasília: Ministério da Saúde, 2004.

CAMPOS, T. C. P. Psicologia Hospitalar: a atuação do psicólogo em hospitais. São Paulo: EPU, 1995.

CHIATTONE, H. B. de C. A Significação da Psicologia no Contexto Hospitalar. In: ANGERAMICAMON, V. A. (Org.). Psicologia da Saúde: um novo significado para a prática clínica. 2. ed. São Paulo: Cengage Learning Edições, 2011, p. 145-233.

LIMA, T. C. S. de; MIOTO, R. C. T. Procedimentos metodológicos na construção do conhecimento científico: a pesquisa bibliográfica. Revista Katálysis, Florianópolis, v. 10, n. esp., p. 37-45, 2007.

MARCONI, M. de A.; LAKATOS, E. M. Técnicas de Pesquisa: planejamento e execução de pesquisas, amostragens e técnicas de pesquisa, elaboração, análise e interpretação de dados. 7. ed. São Paulo: Atlas, 2008. 


\section{CONSTRUÇÃO DE UM INSTRUMENTO DE AVALIAÇÃO FISIOTERAPÊUTICA PRÉ E PÓS CIRÚRGICO NO AMBIENTE HOSPITALAR}

\section{Ana Carolina Alves de Oliveira ${ }^{1}$; Cláudia Patrícia da Silva Ribeiro Menezes²; Samila Sousa Vasconcelos $^{3}$}

${ }^{1}$ Residente em Urgência e Emergência, Centro Universitário INTA/Santa Casa de Misericórdia de Sobral (UNINTA/SCMS), Sobral, Ceará.

${ }^{2}$ Doutoranda em Saúde Coletiva, UECE

${ }^{3}$ Fisioterapeuta, Mestre em Saúde da Criança e do Adolescente pela Universidade Estadual do Ceará (UECE)

\section{RESUMO}

A atividade do fisioterapeuta no âmbito hospitalar consiste em preservar a funcionalidade do paciente por processo de cuidado e tratamento de alterações osteomioarticulares e de complicações respiratórias, trocas gasosas, cuidado com a via aérea, monitorização da mecânica respiratória, gerenciamento da ventilação invasiva e não invasiva, desmame e extubação. O estudo objetiva construir um instrumento avaliativo no ambiente de recuperação cirúrgica para apresentar sua efetividade no atendimento fisioterapêutico. Trata-se de um estudo de desenvolvimento metodológico, que se refere à elaboração e, posterior validação, de um instrumento de avaliação fisioterapêutica. A elaboração da ficha de avaliação fisioterapêutica se deu diante das evidências da escassez de instrumentos profissionais no ambiente pré e pós cirúrgico com um método focado na avaliação do paciente. Para a sistematização desse projeto, realizou-se uma revisão de literatura para a evidência da fundamentação científica, com base nos principais métodos de avaliação fisioterápica.

PALAVRAS-CHAVE: Serviço Hospitalar de Fisioterapia; Centro Cirúrgico Hospitalar; Questionário de Saúde do Paciente.

ÁREA TEMÁTICA: Clínico - Hospitalar.

\section{INTRODUÇÃO}

A atividade do fisioterapeuta no âmbito hospitalar consiste em preservar a funcionalidade do paciente por processo de cuidado e tratamento de alterações osteomioarticulares e de complicações respiratórias, trocas gasosas, cuidado com a via aérea, monitorização da mecânica respiratória, gerenciamento da ventilação invasiva e não invasiva, desmame e extubação. Além disso, visa também, 
integrar a equipe multidisciplinar para melhoria da assistência ao paciente (GAZOLA et al., 2017). A criação e validação de um instrumento abrange a eficácia de testes diante a avaliação com o intuito de solucionar alguns questionamentos específicos do processo de validação com o intuito do teste atingir o objetivo proposto. A execução da avaliação se entende pela utilização do instrumento válido, organizado e adaptado ao indivíduo específico (SILVA et al., 2013).

O estudo objetiva construir um instrumento avaliativo para uso no ambiente de recuperação cirúrgica para analisar sua efetividade no atendimento fisioterapêutico. Partiu-se do pressuposto de que, por meio de experiências práticas e da pesquisa na literatura, há uma falta de um instrumento de avaliação fisioterapêutica no âmbito da sala de recuperação pré e pós cirúrgica, sendo, portanto, necessária a sua construção e, posterior, validação. Visto que, a falta de um instrumento de avaliação com validação científica para aplicabilidade gera limitação da atuação fisioterapêutica e consequentemente sua escassez na área.

\section{METODOLOGIA}

Trata-se de um estudo de validação do tipo de pesquisa de desenvolvimento metodológico, que se refere à elaboração e validação de um instrumento de avaliação fisioterapêutica. A pesquisa metodológica permite a construção de instrumentos envolvendo procedimentos complexos e elaborados. Para a criação demanda análise de métodos de obtenção e formação de dados de pesquisas. Portanto, discorre sobre a preparação, validação e avaliação do mecanismo e métodos de pesquisa de Polit e Beck (2011), conforme demonstrado na figura 1.

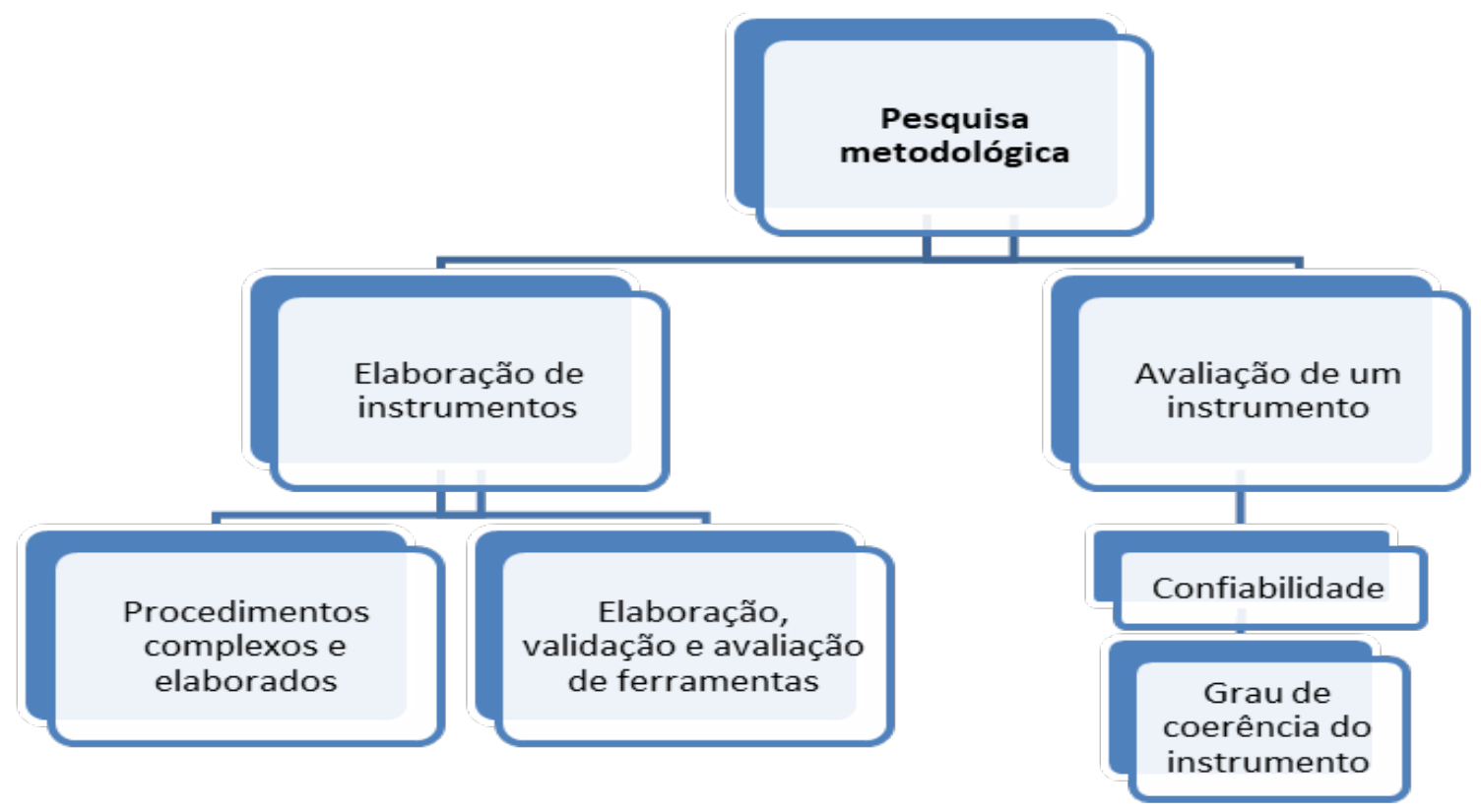

Fonte: Polit; Beck (2011) 
No desenvolvimento de avaliação de uma ferramenta deve-se levar em conta a confiança e a validade. A confiabilidade pode ser alcançada e entendida como coerência de como um instrumento que avalia a qualidade. Subsequente a validade é o grau de como a ferramenta imposta é conveniente. Isto é, a validação do projeto no qual a ferramenta foi criada (POLIT; BECK, 2011).

A validação é um método em que se pesquisa determinado instrumento ou resultado realizado mediante escores estabelecidos. É um procedimento contínuo de investigação e apuração do benefício de um instrumento de medida (RAYMUNDO, 2009). Nessa pesquisa, focou-se na construção do instrumento. Entretanto, enfatiza-se a necessidade do processo de validação.

\section{RESULTADOS E DISCUSSÃO}

A elaboração da ficha de avaliação fisioterapêutica correspondeu diante das evidências da escassez de profissionais no ambiente pré e pós cirúrgico com um método focado na avaliação do paciente. Esse argumento foi considerado significativo relacionado com o propósito da ficha. Para a sistematização desse projeto, realizou-se uma revisão de literatura para a evidência da fundamentação científica.

Logo após a triagem dos conteúdos, foi elaborada a ficha, com base nos principais métodos de avaliação fisioterápica, tendo como foco principal a fisioterapia respiratória e funcional, já que estas configuram o alvo pré e pós cirúrgico.

A primeira versão da ficha de avaliação, que será, posteriormente, submetida ao processo de validação contém os itens principais da avaliação em uma folha única, com dimensão de 297x210mm, impressas nas cores preto, branco e cinza, sobre papel A4. Para o texto, priorizaramse letras na cor preta, em contraste com o fundo branco. O título escolhido para o instrumento foi “Avaliação fisioterapêutica pré e pós operatório (afipo)".

Na parte superior da ficha, optou-se por colocar os dados referentes a identificação dos pacientes, como nome, diagnóstico, idade, data da avaliação pré e pós-cirúrgica. Os demais itens da ficha estão distribuídos em um quadro, com diferentes sessões, sendo elas: Histórico operatório, antecedentes pessoais, descrição da secreção traqueal, oxigenoterapia, nível de consciência, dados da ventilação invasiva ou não invasiva, mobilidade e sensibilidade, nível de força, gasometria, drenos, sinais vitais e lesão por pressão. A ficha contém 2 imagens, representativas do corpo humano (visão anterior e posterior) no item de lesão por pressão. O objetivo da imagem é facilitar a marcação do local da lesão.

A escolha pela ficha, com textos curtos e objetivos se deu com base na literatura, que enfatiza que o texto deve ser breve, objetivo, com linguagem simples e especialmente compreensível à clientela a que se destina. Frases longas tornam a leitura mais lenta e geram uma compreensão mais difícil. Palavras comuns devem ser usadas quase o tempo todo. Palavras técnicas e conceitos devem ser explicados através de exemplos (DOAK; DOAK; ROOT, 1996). Na cartilha 
em questão, o público a que se destina evolve profissionais da área da saúde de ensino superior, sendo, portanto, um grupo especializado, em que não há tanto a necessidade dos exemplos.

\section{CONSIDERAÇÕES FINAIS}

A experiência na construção de uma tecnologia leve, no qual esse trabalho faz parte, constituiu-se um importante meio de informar, transmitir conhecimentos e promover reflexão acerca da integralidade em saúde e do bem estar do paciente e da família. Nesse trabalho de forma específica, buscou-se favorecer e contribuir com a atuação do fisioterapeuta no ambiente hospitalar. Ressalta-se que para o material educativo possa ser de fato adequado e efetivo, é fundamental um planejamento eficaz da equipe, dinamicidade e propostas que garantam a participação e aplicação de aspectos significativos, do processo de saúde-doença.

\section{PRINCIPAIS REFERÊNCIAS}

DOAK, C. C; DOAK, L. G; ROOT, J. H. Teaching Patients with Low Literacy Skills. 2 ed. Philadelphia: JB Lippincott, 1996.

GAZOLA, Nayala Lirio Gomes. et al. Mapeamento e cruzamento das informações sobre avaliação clínica, diagnóstico e intervenções de fisioterapia. Contexto Enferm, São José - SC, v. 27, n. 4, pag. 1-8, dez. 2017.

POLIT, D. F; BECK C. T. Fundamentos de pesquisa em enfermagem: avaliação de evidências para as práticas da enfermagem. Porto Alegre (RS): Artmed, 7 ed, 2011. 669 p.

RAYMUNDO, V. P. Construção e validação de instrumentos: um desafio para a psicolingüística. Letras de Hoje, Porto Alegre, v. 44, n. 3, p. 86-93, jul./set. 2009.

SILVA, Larissa Paiva. et al. Confiabilidade intraclasse da Alberta Infant Motor Scale na versão brasileira. Rev Esc Enferm USP, v. 47, n. 5, pag. 1046-1051, 2013. 


\title{
OS DESAFIOS DA ASSISTÊNCIA HUMANIZADADA EVIDENCIADOS NO SERVIÇO HOSPITALAR POR ENFERMEIROS: REVISÃO INTEGRATIVA DA LITERATURA
}

\author{
Maíra de Lima Silva ${ }^{1}$ \\ ${ }^{1}$ Graduanda de bacharelado de Enfermagem, Universidade Federal de Pernambuco (UFPE), Vitória \\ De Santo Antão, Pernambuco.
}

\begin{abstract}
RESUMO
Introdução: O programa de residência em saúde tem um enfoque na implementação de um serviço de saúde embasado na humanização, que é conceituada como uma assistência da atenção à saúde que traz consigo prestação de cuidados holísticos, mas essa prática ainda apresenta desafios no cenário hospitalar. Objetivo: identificar os desafios da assistência humanizada por enfermeiros no lócus hospitalar. Metodologia: trata-se de uma revisão integrativa da literatura, realizada na base de dados LILACS e SCIELO, com descritores: Assistência de Enfermagem; Internato e Residência e Problematização, foram realizadas seleções resultando em 5 artigos compondo a amostra final. Resultados: Em 60\% dos artigos os desafios apresentados eram intervenções biomédicas desrespeitosas, em $20 \%$ situações de preconceito, racismo e segregações sociais-financeiras e em $20 \%$ mostrou que os desafios estavam mecanizados na instituição. Considerações finais: Portanto, a prática da humanização encontra-se com inúmeros problemas para que haja implementação de qualidade.
\end{abstract}

PALAVRAS-CHAVES: Assistência de Enfermagem; Enfermagem; Humanização da Assistência.

ÁREA TEMÁTICA: Atenção à Saúde

\section{INTRODUÇÃO}

O sistema público de saúde brasileiro conta com a atuação de residências multiprofissionais de saúde que auxiliam os profissionais que trabalham nas unidades públicas de saúde, essas residências são fundamentadas pela Política Nacional de Educação Permanente em Saúde, esse serviço de saúde é disponível para profissionais da área de Ciências da Saúde com curso superior, no qual através de um método seletivo público são classificados para se especializar em algumas áreas de saúde, como: cardiologia, pediatria, ginecologia, neurologia e outros. E assim realizam ações de práticas assistencialistas e de políticas públicas através de uma assistência humanística que conduz esses serviços com um eixo de profissionais-comunidade-ensino. A humanização do atendimento é propícia ao vínculo entre profissional e paciente, pois os pacientes possuem postura de respeito e de orientação às pessoas para formar confiança nas ações realizadas pelos profissionais e seus 
cuidadores, avaliando assim os serviços prestados e desenvolvidos. Desenvolveram ações próprias de saúde nas seguintes áreas: de forma qualificada, prestando bons serviços aos pacientes em tratamento e às pessoas que os atendem. Portanto, uma satisfação mútua é criada para pacientes e profissionais de saúde, logo são embasadas em um serviço como equipe multiprofissional e uniprofissional no qual são supervisionados com tutores e preceptores.

A residência traz inúmeros benefícios com experiências pessoais e profissionais para os selecionados, aumentando o seu conhecimento prático-teórico e técnicas abordados nos serviços de saúde, porém as práticas de residência possuem muitos desafios na designação dos seus serviços, um desses desafios é a prática da humanização no serviço hospitalar. Portanto, vê- se, a importância da assistência humanística e realização dessas por esses profissionais, uma vez que, posteriormente especializados tornam o serviço de saúde com o intuito mais humano e holístico na assistência.

Portanto, a assistência de enfermagem pode se valer de diversas formas de implementação da saúde humanizada nesses serviços, com objetivo de manter um bom relacionamento com o paciente e proporcionar uma aparência complexa com o eixo biopsicossocial e outros meios relacionados a esses vínculos. Assim, o objetivo deste estudo é identificar os desafios da assistência humanizada evidenciados no serviço hospitalar por enfermeiros.

\section{METODOLOGIA}

Trata-se de uma revisão integrativa da literatura, partindo da seguinte questão norteadora: quais os desafios relatados por enfermeiros para a prática de uma assistência humanizada no âmbito hospitalar?, a partir desse questionamento buscamos por produções científicas contidas na base de dados LILACS e na Biblioteca Virtual SCIELO referentes aos desafios encontrados nas práticas assistenciais evidenciadas por enfermeiros residentes, com os descritores disponíveis no DeCs: Assistência de Enfermagem; Internato e Residência e Problematização, no qual foram feitos cruzamentos deles para ampliar a captação dos artigos a serem avaliados, logo os pesquisadores foram: Assistência de Enfermagem and Internato e Residência, Internato e Residência and Problematização e Assistência de Enfermagem and. Após o levantamento bibliográfico, foram realizadas as seleções devidos aos critérios de inclusão: artigos disponíveis na íntegra, publicados nos últimos 5 anos (2016-2021), em idiomas: português, inglês e espanhol, e critérios de exclusão: artigos que não se enquadram no eixo temático da pesquisa e que não se enquadram com o tema. Logo, foram selecionados inicialmente 48 artigos e após a realização das leituras e adoção dos critérios de exclusão e inclusão, foram selecionados 5 artigos científicos para compor a amostra final. 


\section{FUNDAMENTAÇÃO TEÓRICA OU RESULTADOS E DISCUSSÃO}

Após a realização da leitura e seleção dos artigos conclui-se que, $60 \%$ dos artigos, equivalente a 3 artigos, dispõe sobre os desafios com conceito assistencialista biomédico. Com a presença de condutas inadequadas na assistência, falta de apoio e compreensão de sentimentos de vulnerabilidade, inferioridade, medo, angústia, abandono e momentos depressivos expressadas pelos usuários, logo os profissionais encontram-se indiferentes a esses sentimentos. Intervenções biomédicas desnecessárias que causam dores ao paciente ou até mesmo prejudicando na sua integridade física, atuações com comentários e falas pejorativas, sendo classificado uma violência verbal de desrespeito, casos de invasão de privacidade e quebra de sigilo, presença de violência física e psicológica, causando medo do serviço assistencial prestado e até mesmo do seu estado próprio estado de saúde. Logo esse modelo intervencionista apresenta-se com ausência da assistência humanista, uma vez que, o modelo biomédico apresenta cuidado centrado apenas na patologia, sem observar questões sociais, biológicas, psicológicas e espirituais apresentadas pelos usuários.

Em 20\% dos artigos, equivalente a 1 artigo, está relacionado a modelos práticos engessados na instituição, no qual os desmembramentos dessas ações causam comentários de mudança na assistência e muitas vezes prestados por profissionais de saúde desatualizados que não atuam de forma eficaz, e não estão cientes dobre o processo de aprendizagem-ensino de novas políticas/práticas de humanização.

Por fim, em 20\% dos artigos, sendo equivalente a 1 artigo, mostra que existe um processo de preconceito e racismo estrutural dentro dos sistemas de saúde, no qual os profissionais de saúde atuam de forma preconceituosa e racista com as pessoas com uma baixa condição financeira e condições sociais, no qual existe essa indiferença no atendimento em relação a características de gênero, sexualidade, questões socioeconômicas e de classe, logo, visualizamos também, que um dos desafios encontrados é o estresse profissional devido a altas cargas horárias de trabalho afetando a saúde mental do profissional de enfermagem em tentativas de conciliar sua vida social com a profissional.

\section{CONSIDERAÇÕES FINAIS OU CONCLUSÃO}

Portanto, a prática de humanização nos serviços de saúde vem com uma luta de sua implantação em alguns serviços, pois, muitos ainda são encontrados desafios que dificultam essa atuação de profissionais humanizados. Logo, é de suma importância atitudes profissionais dos residentes de enfermagem que tentem reduzir esses desafios presentes no centro hospitalar, como criação de debates em capacitações dos profissionais dos serviços, simpósios, rodas de conversas, debates de casos clínicos com implementações humanísticas e outros métodos que auxiliem em uma implementação mais alicerçada desse cuidado humano, além disso pode-se observar que é necessário que haja uma relação interpessoal presente entre os profissionais para que haja a disseminação dessas relações para com os usuários dos serviços. Assim, com essas atuações que tornem o serviço de saúde mais holístico, a assistência prestada traz consigo uma eficácia na qualidade da atenção à saúde, assim 
as implantações da humanização nesses serviços com a presença de desafios irão trazer inúmeros benefícios para o serviço de saúde.

\section{PRINCIPAIS REFERÊNCIAS}

GIANTAGLIA, F. N.; et al. Humanização do cuidado em um programa de residência enfermagem obstétrica: possibilidades e desafios. Enfermería (Montevideo) vol.9 no.2 Montevideo dic. 2020 Epub 20-Nov-2020.

MAROJA, M. C. S.; ALMEIDA, J. J. J.; NORONHA, C. A. Los desafíos de la formación problematizadora para profesionales de salud en un programa de residencia multiprofesional. Interface 2414 Nov 2019-2020.

SOUZA, S. V.; FERREIRA, B. J. Preceptoria: perspectivas e desafios na Residência Multiprofissional em Saúde / Preceptorship: perspectives and challenges in Multiprofessional Residency in Health. ABCS health sci; 44(1): 15-21, 2019.

PEREIRA, R. M.; et al. Novas práticas de atenção ao parto e os desafios para a humanização da assistência nas regiões sul e sudeste do Brasil. Ciênc. saúde coletiva vol.23 no.11 Rio de Janeiro Nov. 2018.

MENEZES, F. R.; et al. O olhar de residentes em Enfermagem Obstétrica para o contexto da violência obstétrica nas instituições. Interface 2423 Set 2019-2020. 


\title{
INTERVENÇÕES DE ENFERMAGEM PARA PACIENTES NA UTI COM INCONTINÊNCIA INTESTINAL: REVISÃO INTEGRATIVA
}

\author{
Michelle Venâncio Hong ${ }^{1}$ \\ ${ }^{1}$ Especialista em Sistematização da Assistência de Enfermagem, Hospital das Clínicas da Faculdade \\ de Medicina de Botucatu (HCFMB), Botucatu, São Paulo.
}

\begin{abstract}
RESUMO
Objetivos. Analisar a produção de evidências científicas, acerca das intervenções de enfermagem para pacientes internados em UTI com incontinência intestinal. Método. Tratou-se de revisão integrativa, com a pergunta norteadora: Como se configura a produção de conhecimento acerca das intervenções de enfermagem para pacientes internados na UTI com o diagnóstico de incontinência intestinal? A seleção da amostra deu-se por meio do acesso às bases de dados, a amostra final foram 22 artigos. Resultados. Os 22 artigos foram avaliados o nível de evidência, a produção científica foi exclusivamente internacional no continente americano, na língua inglesa. Considerações Finais. Os artigos encontrados nas bases de dados foram explorados e apresentaram informações sobre as possíveis intervenções assistenciais de enfermagem para pacientes criticamente enfermos internados com incontinência intestinal, com a utilização de protocolos padrões para o manejo da incontinência, dispositivos fecais, treinamentos para a equipe, aplicação de produtos para a pele e avaliação clínica do paciente.
\end{abstract}

PALAVRAS-CHAVE: Incontinência Intestinal; Atendimento de Enfermagem; Centro de Terapia Intensiva.

ÁREA TEMÁTICA: Clínico - Hospitalar.

\section{INTRODUÇÃO}

A incontinência intestinal se caracteriza pela perda involuntária de fezes, e sua prevalência é maior em pacientes internados em Unidades de Terapia Intensiva (UTI) (SAURUSAITIS et al., 2019). Os eventos adversos com mais preponderância no cotidiano da prática de enfermagem intensivista são as lesões por pressão (LP) e as dermatites associadas à incontinência (DAI), e sabese que a incontinência intestinal torna o paciente acamado mais vulnerável a infecções de pele e em tecidos moles, e no contexto dos cuidados intensivos diante ao problema da incontinência intestinal, ocorre o aumento dos custos, a demanda de trabalho para as equipes de enfermagem e os fatores de riscos para lesões de pele e infecções, e através destes conflitos há o aumento das intervenções 
e consequentemente o uso de insumos não programados e relativos para a troca de roupa de cama e procedimentos de higiene e demandando muitas vezes troca de curativos e que acabam interrompe os processos de trabalho da enfermagem (PITTMAN et al., 2012). Considerando a sobrecarga gerada pela incontinência intestinal ao paciente, equipe de enfermagem e às instituições de saúde, este estudo teve como objetivo de analisar a produção de evidências científicas, acerca das intervenções de enfermagem para pacientes internados em UTI com incontinência intestinal.

\section{MÉTODO}

Trata-se de revisão integrativa, com a pergunta norteadora: Como se configura a produção de conhecimento acerca das intervenções de enfermagem para pacientes internados na UTI com o diagnóstico de incontinência intestinal? A seleção da amostra deu-se por meio do acesso às bases de dados: Literatura Latino-Americana e do Caribe em Ciências da Saúde (LILACS), MEDLINE Complete - EBSCO, Scopus, Current Nursing and Allied Health Literature (CINAHL) e Web of Science (WoS), sem determinar um campo específico de busca (article title; abstract; keywords), mas optando por "all fields". Utilizaram-se como estratégia de busca os descritores controlados combinados com operadores booleanos, dispostos no Medical Subject Headings (MeSH). Na base de dados LILACS a equivalência em português dos descritores foi empregada. Adotou-se como critérios de inclusão: artigos completos com resumos e relacionados ao objeto de pesquisa, nos idiomas português, inglês e espanhol, originados de periódicos nacionais e internacionais, indexados nas bases de dados referidas, no período de 01/01/2011 a 31/12/2020. Foram selecionados seis artigos da base de dados CINAHL, dois artigos da MEDLINE Complete - EBSCO, 10 artigos da Web of Science e dois da Scopus, perfazendo a amostra final de 22 artigos.

\section{RESULTADOS E DISCUSSÕES}

Quanto à análise verificou que dos 22 artigos avaliados segundo o nível de evidência propostos por Melnyk e Fineout-Overholt, 2019 a maioria (11; 50\%) classifica no nível “4”, (4; 18,2\%) no “5”, $(3 ; 13,7 \%)$ no " 2 ", assim como dois no nível "6", um no nível "7” e um no nível "3". Trata-se de produção científica exclusivamente internacional, na língua inglesa, concentrada no continente americano, exclusivamente nos Estados Unidos (9; 41\%), seguidos por países da Europa (6; 27\%), Asiático $(5 ; 23 \%)$ e da Oceania $(2 ; 9 \%)$.

O gerenciamento da incontinência intestinal aguda em cuidados intensivos, é um problema substancial, entretanto, é subestimado nas UTIs, e está situação se associa uma série de consequências clínicas, incluindo lesões cutâneas e contaminações cruzadas, além de aumentar a carga de trabalho para a equipe de enfermagem e acabam elevando os custos intra-hospitalar (GARCÍA et al., 2012).

Das 22 publicações científicas que abordavam sobre as intervenções de enfermagem no cuidado ao paciente com incontinência intestinal, dentre os achados relevantes pode-se citar que há a 
necessidade de inserir protocolos e treinamentos para o manejo do paciente, utilização de dispositivos fecais indicados para melhorar o cuidado ao paciente, porém estes instrumentos são necessários mais estudos, e para evitar possíveis lesões diante a incontinência fecal, os estudos demonstraram a importância de introduzir nas unidades intensivas os cuidados diários diante a pele com aplicação de escalas de pontuação para avaliação e produtos para a pele e por último obteve-se recomendações para os enfermeiros que tem um papel fundamental para desempenhar diante aos pacientes gravemente enfermos a avaliação clínica diariamente referente a incontinência intestinal.

\section{CONSIDERAÇÕES FINAIS}

Encontrou-se 22 pesquisas publicadas nas bases de dados nos últimos 10 anos e que foram analisados e apresentaram informações sobre as possíveis intervenções assistenciais de enfermagem para pacientes criticamente enfermos internados com incontinência intestinal, com a utilização de protocolos padrões para o manejo na incontinência, dispositivos fecais, treinamentos para a equipe, cuidados diário diante a pele com aplicação de escalas de pontuação de avaliação e produtos para a pele e a avaliação clínica do paciente.

Entende-se que as iniciativas de enfermagem baseadas em evidências são importantes para a construção de protocolos para o manejo clínico dos pacientes críticos. Desta maneira, sugerem-se mais pesquisas com as possíveis intervenções a serem realizadas dentro das instituições.

Os dispositivos mencionados nos trabalhos foram eficazes para a contenção da incontinência, entretanto, faz-se necessário aprofundar o conhecimento, por meio de ensaios clínicos para avaliar os cuidados com esses materiais, em relação ao manuseio, ao período de permanência, às complicações referentes ao uso e quais são as exigências clínicas do paciente para utilizar esse método, sabendo que cada paciente requer cuidados individualizados.

\section{PRINCIPAIS REFERÊNCIAS}

SAURUSAITIS, A.D.; SANTIAGO, L.C.; PEREGRINO, A.A.F.; SILVA, R.C.L.; SCHUTZ, V. Diarreia: fator de risco para dermatite associada à incontinência e lesões por pressão. Rev. Enferm. UFPE online. 2019; 13: e241955;

PITTMAN, J.; BEESON, T.; TERRY, C.; KESSLER, W.; KIRK, L. Methods of bowel management in critical care: a randomized controlled trial. J Wound, Ostomy Cont Nurs. 2012;39(6):633-9;

MELNYK, B.M.; FINEOUT-OVERHOLT, E. Evidence-based practice in nursing and healthcare: a guide to best practice. Philadelphia: Wolters Klewer Health; 2019.

GARCÍA, C.B.; BINKS, R.; DE LUCA, E.; DIERKES, C.; FRANCI, A. GALLART, E. et al. Prevalence, management and clinical challenges associated with acute faecal incontinence in 
the ICU and critical care settings: The FIRST TM cross-sectional descriptive survey. Intensive Crit Care Nurs [Internet]. 2012 [cited 2020 Jul 10];28:242-50. 


\title{
ATUAÇÃO INTERPROFISSIONAL FRENTE À HIPERSENSIBILIDADE DENTINÁRIA CERVICAL
}

\author{
César Luis Porpino Santos da Silva Júnior ${ }^{1}$; Izabel Viviane de Oliveira Fagundes² \\ ${ }^{1}$ Graduado em Odontologia, Residente Multiprofissional em Atenção Básica, Escola Multicampi de \\ Ciências Médicas, Universidade Federal do Rio Grande do Norte (UFRN), Currais Novos, RN. \\ ${ }^{2}$ Graduada em Enfermagem, Residente Multiprofissional em Atenção Básica, Escola Multicampi de \\ Ciências Médicas, Universidade Federal do Rio Grande do Norte (UFRN), Currais Novos, RN.
}

\section{RESUMO}

Introdução: a hipersensibilidade dentinária cervical (HDC) é uma afecção bucal que se caracteriza por uma dor aguda e transitória, que ocorre diante de estímulos desencadeadores. Por sua etiologia multifatorial, demanda uma atuação interprofissional para desenvolver planos de tratamento concretos e eficazes. Metodologia: trata-se de uma revisão de literatura, de caráter descritivo convencional, que se baseia na coleta e na análise de informações relativas à temática proposta. Fundamentação teórica: a prevalência da HDC é descrita na literatura com resultados de 1,3\% a 92,1\%. Uma série de fatores locais e sistêmicos, assim como nutricionais e psicossociais, conferem à HDC uma etiologia multifatorial. Dessa forma, a atuação conjunta e colaborativa, no contexto da inteprofissionalidade, permite o desenvolvimento de intervenções clínicas condizentes com as particularidades de cada caso. Considerações finais: a atuação interprofissional frente à HDC é imprescindível para o manejo dos fatores etiológicos da doença.

PALAVRAS-CHAVE: Sensibilidade dentária; Clínica odontológica; Atenção à saúde.

ÁREA TEMÁTICA: Clínico-Hospitalar

\section{INTRODUÇÃO}

A hipersensibilidade dentinária cervical (HDC) é um processo patológico que acomete os tecidos dentários, na região cervical dos elementos, caracterizando-se por uma dor aguda e transitória, que ocorre frente a estímulos variados, como térmicos e táteis, estando geralmente associada a uma exposição dentinária. Trata-se de uma afecção bucal que compromete bastante a qualidade de vida dos pacientes acometidos, pois afeta a dimensão social, como o ato de falar e de se alimentar (SILVA et al., 2020). 
Com uma prevalência alta, por volta de 11,5\%, apresenta etiologia multifatorial, envolvendo uma série de fatores locais e sistêmicos, bem como sociais e psicológicos. Mas, nesse sentido, existem algumas condições clínicas, como lesões cervicais não-cariosas e recessão gengival, que são indicativos de uma predisposição ao adoecimento por HDC, pois ambas possuem uma etiologia contígua (ZEOLA; SOARES; CUNHA-CRUZ, 2019).

Por lidar com parâmetros subjetivos próprios da sintomatologia dolorosa, o diagnóstico da HDC acaba sendo difícil, de modo que é imprescindível o levantamento de todo histórico médicoodontológico pregresso do paciente e a realização de um exame intrabucal bastante criterioso. A partir disso, o clínico poderá lançar mão das inúmeras abordagens de tratamento que a literatura apresenta, sendo, o controle e/ou a remoção dos fatores etiológicos, o principal aspecto a ser considerado em qualquer projeto terapêutico individualizado (SOARES; GRIPPO, 2017).

Para que se tenha um prognóstico positivo a médio e a longo prazo, a atuação clínica do cirurgião-dentista de modo isolado não contempla toda a gama de pontos a serem considerados na elaboração de um plano de tratamento para HDC, principalmente no que diz respeito ao manejo dos fatores desencadeadores. Tendo em vista isso, a atuação interprofissional se apresenta como o método mais abrangente e com resultados mais duradouros, pois une os conhecimentos específicos da Odontologia com os saberes técnicos e científicos das demais áreas das ciências da saúde.

Com o intuito de discorrer justamente sobre a importância de uma equipe pautada no interprofissionalismo para o adequado tratamento da hipersensibilidade dentinária cervical, o presente trabalho objetiva revisar a literatura cientifica sobre essa temática.

\section{METODOLOGIA}

O presente trabalho se apresenta como uma revisão de literatura, de caráter descritivo convencional, que se baseia na coleta e na análise de informações relativas ao tema proposto. $\mathrm{O}$ levantamento primário dos estudos ocorreu por meio do acesso às bases de dados PubMed (Medline), Scielo (Scientific Eletronic Library Online) e Literatura Latino Americana e do Caribe em Ciências da Saúde (LILACS), utilizando diversos descritores relativos à hipersensibilidade dentinária cervical.

Fizeram parte do estudo artigos de relevância científica publicados nos últimos, com acesso livre, nos idiomas português e inglês e que abordaram a temática escolhida. Inicialmente, eles foram selecionados apenas pelo título e resumo. Em seguida, foi avaliada a qualidade desses trabalhos, fazendo-se a seleção das informações principais. Essas etapas foram realizadas de forma independente

pelos membros da equipe. 


\section{FUNDAMENTAÇÃO TEÓRICA}

A hipersensibilidade dentinária cervical é uma doença que ocorre no ambiente bucal e caracteriza-se por uma sintomatologia dolorosa aguda, de caráter transitório, que se estabelece diante de estímulos táteis, físicos, químicos, dentre outros. É uma afecção que compromete bastante a qualidade de vida dos pacientes, pois traz danos à sociabilidade e também ao aspecto fisiológico, por dificultar a ingestão de alimentos (LIU et al., 2020).

Inúmeras teorias foram propostas ao longo dos anos para explicar como a HDC ocorre. Atualmente a mais aceita é a Teoria Hidrodinâmica, segundo a qual o fluido, presente no interior de túbulos dentinários expostos, movimenta-se perante algum estímulo, o que acaba por sensibilizar ramificações nervosas, levando à dor (WEST, 2008).

Ao buscar dados relativos à sua prevalência, encontram-se resultados que vão desde $1.3 \%$ a 92,1\%. Com vias de melhor elucidar isso, autores, como Zeola, Soares e Cunha-Cruz (2019), por meio de uma revisão sistemática com metanálise, encontraram uma prevalência de 11,5\% para HDC, com uma média de prevalência de $33,5 \%$ entre os estudos analisados.

Sua etiologia é multifatorial, isto é, a HDC ocorre por uma conjunção de fatores, desde questões locais na boca a situações sistêmicas, que acabam por levar à sua ocorrência. O clínico, ao fazer a anamnese e o exame intrabucal, deve se atentar para entender quais são as causas particulares para o acometimento por HDC ocorrido em dado paciente (LIU et al., 2020).

A presença de lesões cervicais não cariosas (LCNC), como biocorrosão, abfração e abrasão, são achados clínicos muito importantes a serem observados. YOSHIZAKI et al. (2017) desenvolveram um estudo investigando HDC e LCNC. Perceberam que do total de dentes analisados que apresentavam HDC, 50\% tinham também LCNC, evidenciando uma associação positiva entre essas duas afecções.

A biocorrosão, por exemplo, é uma LCNC associada à degradação da estrutura dentária em decorrência, principalmente, da ação de ácidos (SOARES; GRIPPO, 2017). Quando os tecidos dentários superficiais são expostos de forma frequente e prolongada aos mais variados ácidos, ocorrem danos à estrutura do dente, e isso pode levar ao quadro de HDC. Esses ácidos podem ser oriundos de origens múltiplas, como associadas a: fatores intrínsecos, por problemas gastroesofágicos, bulimia, anorexia nervosa, diminuição do fluxo, acidez salivar; fatores extrínsecos, pela dieta, medicamentos ácidos, bebidas carbonatadas, drogas ilícitas; ou mesmo uma combinação entre eles (RAO et al., 2019).

Outra LCNC é a abfração, que ocorre quando o elemento dentário é submetido a forças oclusais fora do seu eixo axial, o que pode culminar em uma flexão da estrutura. Isso pode levar ao surgimento de trincas e de pequenas fraturas na região cervical, resultando, assim, na HDC. Tratase de uma lesão muito comum em pacientes com bruxismo ou hábitos parafuncionais (PEUMANS; POLITANO; VAN MEERBEEK, 2020; YOSHIZAKI et al., 2017). 
Já a abrasão decorre do desgaste mecânico da estrutura dentária, proveniente de fatores diversos, como movimentos escovatórios inadequados, aplicação de força excessiva durante a escovação, pelo uso de escovas com cerdas rígidas e pelo emprego de cremes dentais com agentes abrasivos (PEUMANS; POLITANO; VAN MEERBEEK, 2020).

A partir do diagnóstico, o cirurgião-dentista pode se valer das inúmeras abordagens de tratamento que a literatura apresenta. Desde a abordagem não invasiva, à microinsiva (com os agentes dessensibilizantes), às abordagens invasivas, como restaurações e cirurgias de recobrimento radicular. Mas, independentemente do plano de tratamento desenvolvido para o paciente, a abordagem não invasiva deve estar presente, pois ela consiste no controle e/ou remoção dos fatores etiológicos da HDC (CLARK; LEVIN, 2016).

Assim, deve-se, através do histórico médico-odontológico, do conhecimento sobre o estilo de vida do paciente e da identificação da etiologia, dar orientações ao paciente para buscar modificar os fatores causais desse processo patológico, como: controle dos fatores relacionados à tensão (ajuste da oclusão, uso de placas interoclusais e protetor bucal), controle dos fatores biocorrosivos (orientações relativas tanto sobre o consumo de alimentos ácidos, quanto sobre a higiene bucal após a ingestão desses alimentos) e controle dos fatores de fricção (técnica de escovação adequada, cremes dentais e tipos de escovas mais adequados).

Além dessas orientações realizadas no consultório odontológico, considerando a dimensão multifatorial da $\mathrm{HC}$, que perpassa por uma série de fatores nutricionais, gástricos, psicológicos e sociais, é preciso que o cirurgião-dentista esteja atento e atualizado para ter uma atuação conjunta aos demais profissionais da saúde. Portanto, o controle dos fatores etiológicos, caracterizado como a principal intervenção a ser realizada, necessita muitas vezes de uma atuação que vai além do consultório odontológico, havendo a necessidade do encaminhamento do paciente para complementar o tratamento com outros profissionais da saúde, e, assim, obter um melhor prognóstico do caso (SOARES; GRIPPO, 2017).

A atuação de um profissional da Nutrição, diante dos casos de biocorrosão, é importantíssimo, pois, como citado, será por meio também de reeducação alimentar ou outra estratégia lançada pelo nutricionista, que o fator causal da HDC pode ser solucionado de fato. O mesmo ocorre com a atuação do profissional da Psicologia para lidar também, por exemplo, com os paciente bulímicos, anoréxicos, com bruxismo, que acabam por desenvolver HDC. Aliar-se, em conjunto, com esses e demais profissionais da saúde pode fazer toda a diferença em qualquer tratamento proposto, permitindo um melhor prognóstico para cada caso (SOARES; GRIPPO, 2017).

\section{CONSIDERAÇÕES FINAIS}

Porserse tratardeumadoença comaltaprevalênciaeetiologiamultifatorial, ahipersensibilidade dentinária cervical é palco de diversos estudos lançados todos os anos atualizando os protocolos de atendimento e manejo clínico. E, sob esse viés, a importância da atuação interprofissional vem sendo 
posta cada vez mais à luz, pois a literatura elucida que é unindo os conhecimentos das mais diversas ciências da saúde que se pode atuar de modo eficaz no tratamento da HDC, em especial no controle dos fatores etiológicos.

\section{PRINCIPAIS REFERÊNCIAS.}

CLARK, Danielle; LEVIN, Liran. Non-surgical management of tooth hypersensitivity. International Dental Journal, [s. 1.], v. 66, n. 5, p. 249-256, out. 2016.

LIU, Xiu-Xin et al. Pathogenesis, diagnosis and management of dentin hypersensitivity: an evidencebased overview for dental practitioners. Bmc Oral Health, [s. 1.], v. 20, n. 1, p. 1-10, 14 ago. 2020.

RAO, K Arun et al. Prevalence of dentinal hypersensitivity and dental erosion among competitive swimmers, Kerala, India. Indian Journal Of Community Medicine, [s.1], v. 44, n. 4, p. 390-393, 2019.

SILVA, Lívia Luiza Carvalho da et al. Tratamento químico para hipersensibilidade dentinária cervicalParte 1. Research, Society And Development, [s. 1.], v. 9, n. 9, p. 1-13, 17 ago. 2020.

SOARES, Paulo Vinicius; GRIPPO, John O. Lesões cervicais não cariosas e hipersensibilidade dentinária cervical: etiologia, diagnóstico e tratamento. São Paulo: Santos Publicações, 2017.

WEST, Nicola X. Dentine hypersensitivity: preventive and therapeutic approaches to treatmente. Periodontology 2000, Copenhagen, v. 48, no. 1, p. 31-41, 2008.

YOSHIZAKI, Karina Tiemi et al. Clinical features and factors associated with non-carious cervical lesions and dentin hypersensitivity. Journal Of Oral Rehabilitation, [s. 1.], v. 44, n. 2, p. 112-118, 20 jan. 2017.

ZEOLA, Livia Favaro; SOARES, Paulo Vinícius; CUNHA-CRUZ, Joana. Prevalence of dentin hypersensitivity: systematic review and meta-analysis. Journal Of Dentistry, [s. 1.], v. 81, p. 1-6, fev. 2019. 


\title{
SÍNDROME DE FOURNIER: UM RELATO DE CASO
}

\section{Hemerson Garcia de Oliveira Silva ${ }^{1}$; Carolina Corrêa Lima ${ }^{2}$; Giselle Pena de Oliveira ${ }^{3}$; Henrique de Souza Rodrigues Fajardo ${ }^{4}$; Alex Loze Rocha ${ }^{5}$; Iago Gama Pimenta Murta ${ }^{6}$; Marcos Vinícius Mendes Barroso ${ }^{7}$;Robson da Silveira ${ }^{8}$}

${ }^{1}$ Medico, Mestre em Ciências Biológicas, Universidade Vale do Rio Doce (UNIVALE), Manhuaçu, MG.

${ }^{2}$ Discente de Medicina, Centro Universitário UNIFACIG (UNIFACIG), Manhuaçu, MG.

${ }^{3}$ Discente de Medicina, Centro Universitário UNIFACIG (UNIFACIG), Manhuaçu, MG.

${ }^{4}$ Médico Residente de Cirurgia Geral, Hospital César Leite (HCL), Manhuaçu, MG.

${ }^{5}$ Médico Residente de Cirurgia Geral, Hospital César Leite (HCL), Manhuaçu, MG.

${ }^{6}$ Médico Residente de Cirurgia Geral, Hospital César Leite (HCL), Manhuaçu, MG.

${ }^{7}$ Médico Residente de Cirurgia Geral, Hospital César Leite (HCL), Manhuaçu, MG

${ }^{8}$ Médico Cirurgião Geral e Urologista, Hospital César Leite (HCL), Manhuaçu, MG.

DOI: $10.47094 /$ ICONRES.2021/18

\begin{abstract}
RESUMO
Introdução: A Síndrome de Fournier é uma fasciíte necrosante que ocorre em região perineal, perianal e genital, gerada por processo infeccioso de microrganismos aeróbios e anaeróbios. Seu índice de mortalidade se mostra elevado, demonstrando a necessidade abordagem imediata. Objetivo: Descrever o caso de um paciente com síndrome de Fournier e os fatores que corroboraram com o estabelecimento do sucesso do tratamento. Metodologia: Trata-se de um relato de caso de um paciente com Grangrena de Fournier, feito na cidade de Manhuaçu, MG, sendo feita uma análise de prontuários. Resultados e Discussão: O paciente deu entrada ao hospital com quadro típico de Síndrome de Fournier. A antibioticoterapia inicial se mostrou ineficiente para conter o processo patológico. Os processos cirúrgicos de desbridamento, colostomia e reconstrução foram aplicados adequadamente para a efetiva terapêutica. Conclusão: A abordagem rápida e eficaz por uma equipe multidisciplinar foi importante para permitir satisfatória recuperação do paciente.
\end{abstract}

PALAVRAS-CHAVES: Gangrena; Antibioticoterapia; Síndrome de Fournier.

ÁREA TEMÁTICA: Clínico - Hospitalar 


\section{INTRODUÇÃO}

A Síndrome ou Gangrena de Fournier, é uma fasciíte necrosante considerada rara, que acomete a

região perineal, perianal e genital. É ocasionada por microrganismos aeróbicos e aneróbicos por meio de um processo infeccioso, o qual, dependendo de uma abordagem terapêutica ineficaz, pode irradiar para a parede do abdômen, membros inferiores, membros superiores e retroperitônio (AZEVEDO, 2016).

A síndrome tende a afetar predominantemente pacientes do sexo masculino, numa proporção aproximada de 10 casos do sexo masculino para 1 do sexo feminino (CARDOSO, FÉRES, 2007). A idade dos pacientes acometidos está em torno da $3^{\mathrm{a}}$ a $6^{\mathrm{a}}$ décadas de vida, tendo como fatores de risco o diabetes mellitus, hipertensão arterial, AIDS, sarampo, obesidade, alcoolismo, tabagismo, desnutrição, imunossupressão, infecções perianais e no trato urinário (DORNELAS, 2012)

O índice de mortalidade para a síndrome se mostra elevado, alcançando em certos estudos $30 \%$ a 50\% dos pacientes (HOFFMAN, 2009). Nesse sentido, a maioria dos casos de síndrome de Fournier é apresentada como emergência cirúrgica, necessitando de abordagem médica imediata, com a administração de antibióticos de amplo espectro e procedimento cirúrgico, a partir da remoção do tecido necrótico por meio do desbridamento e de curativos que permitam a reconstrução do tecido desvitalizado.

O presente trabalho tem como objetivo descrever um relato de caso de um paciente com a síndrome de Fournier, estabelecendo a importância de sua abordagem farmacêutica e cirúrgica rápida e eficaz, a fim de se estabelecer o sucesso do tratamento.

\section{METODOLOGIA}

Trata-se de um relato de caso de um paciente idoso internado em hospital no município de Manhuaçu, Minais Gerais em julho de 2019 com o quadro de síndrome de Fournier. O paciente assinou voluntariamente o Termo de Consentimento Livre e Esclarecido (TCLE) conforme padrão usado pelo COREME do Hospital César Leite, após esclarecimentos dos objetivos do estudo. Foi feita a sua análise de prontuários, baseando sua história clínica e conduta médica em literaturas recentes sobre a Síndrome de Fournier.

\section{RESULTADOS E DISCUSSÕES}

Paciente V.A., 67 anos, sexo masculino, sem comorbidades, deu entrada ao Hospital César Leite, no município de Manhuaçu, em Minais Gerais, no dia 04 de julho de 2019, com um possível abscesso em região glútea bilateral, relatando um quadro de febre, hiperemia e edema que evoluiu em 
cerca 20 dias. Foi iniciada como antibioticoterapia a Ceftriaxona e o Metronidazol. Na mesma data, foi realizado o primeiro procedimento cirúrgico de desbridamento profundo, com a coleta de material para cultura e antibiograma. Na data seguinte, iniciou o uso triplo dos antibióticos Clindamicina, Ampicilina e Amicacina sendo associado a curativo com colagenase.

Foi constatado em exame que as proteínas totais eram de 4,8g/dL (VR: 6,0 a 8,0g,dL), a albumina estava em 2,2g/dL(VR: 3,5 a 5,0g/dL) e a globulina em 2,6g/dL (VR: 2,0 a 4,0g/Dl). Por isso no dia 06 de julho, foi iniciada a dieta enteral hiperproteica, com acompanhamento de nutricionista.

Ao notar uma má resposta ao tratamento, a equipe médica fez novo desbridamento cirúrgico sendo identificada uma fístula retal o que levou a confecção da colostomia de proteção no dia 09 de julho. Após dois dias ao procedimento, foi feito novamente o desbridamento, associado à reconstrução de nádega em região perianal.

No dia 13 de julho, o curativo de colagenase foi trocado por creme de ureia, sendo associado a lavagem de ferida com Povidine tópico. Três dias depois com o resultado do exame de cultura denotou presença de bastonetes gram negativo (Escherichia coli) e coco gram positivo, não sendo possível isolar o gram positivo. E do antibiograma, o qual denotou resistência a determinados antibióticos, como Amoxicilina com Clavulanato, Ampicilina, Ceftriaxona e Ciprofloxacino, e demonstrou sensibilidade a outros, como Ceftazidima, Gentamicina, Meropenem e Carbapenem com Monobactam. Dessa forma, trocou-se o esquema de antibiótico triplo por Ceftazidima.

No dia 25 de julho, foi feito um avanço de retalho pela equipe de cirurgia plástica, seguindo por uma boa evolução e permitindo alta hospitalar do paciente no dia 02 de agosto de 2019. A colostomia foi mantida até o dia 30 de setembro de 2020, data essa em que também foi feita, sem intercorrências, a reconstrução de ferida do paciente.

O paciente do caso apresenta história típica de acometimento pela síndrome de Fournier, uma vez que se trata de um paciente do sexo masculino, com a idade dentro do que é mais amplamente constatado pela epidemiologia. Tendo em vista que o tempo de internação do paciente foi de 29 dias, esse dado entra de acordo, ainda que se mostre ligeiramente maior, com a taxa média de permanência de 26,1 dias dos pacientes acometidos pela gangrena (ABREU, 2014).

A causa dessa síndrome, na maioria das vezes, é uma infecção anorretal, que está frequentemente associada a abscessos perirretais (MELKONIAN,1999), mostrando-se concordante com o caso relatado. Entretanto, o que surpreendeu a equipe que o atendeu, foi que o paciente não havia comorbidades como fatores de risco, os quais são abordados extensamente na literatura e que corroboram com o desenvolvimento da doença.

Os microrganismos com maior prevalência na síndrome de Fournier são os aeróbios gram negativos, como a Escherichia coli e Klebsiella pneumoniae, os gram positivos Staphylococcus aureus, S. epidermidis, Streptococcus viridans e $S$. fecalis, os anaeróbios Bacteróides fragilis, $B$. melaninogenicus, cocos Gram positivos e Clostridium species. (AZEVEDO, 2016). Nesse sentido, o resultado do exame de cultura do paciente foi ao encontro do que se é comumente identificado. A 
antibioticoterapia empregada durante o período de tratamento do paciente parece ter tido influência direta na evolução da terapêutica do caso apresentado. A abordagem inicial com a Ceftriaxona e Metronidazol e, posteriormente, com o esquema triplo mostrou-se ineficiente para conter o processo patológico desencadeado pelos microrganismos que o originou. Após o resultado do antibiograma, foi possível estabelecer uma antibioticoterapia guiada pela sensibilidade apresentada, permitindo uma boa resposta e evolução do paciente, o que anteriormente não acontecia, demonstrando o quanto a morosidade do exame repercute negativamente na progressão da doença.

O tratamento cirúrgico da gangrena de Fournier, assim como foi feito no caso apresentado, consiste em desbridamento do tecido necrosado, a fim de se remover todo tecido lesado que possa impedir a ação do antibiótico (CARDOSO, 2007). Como ocorreu com o paciente, a colostomia também é indicada nas situações que facilitam a contaminação fecal. O cuidado com a ferida também foi feito adequadamente, uma vez que curativos a base de colagenase também são preconizados, bem como o uso de antimicrobiano tópico (CANDELARIA, 2009). Os métodos de reconstrução empregados pela equipe de cirurgia plástica ao paciente desse relato foram feitos visando minimizar as deformidades, nesse sentido, permitindo um bom resultado estético.

\section{CONCLUSÃO}

Apesar da demora na resposta para uma boa evolução do paciente apresentado, nota-se que a equipe de atendimento concluiu com efetividade a sua abordagem, demonstrando a importância do trabalho multidisciplinar direcionado às individualidades apontadas diante do seguimento do caso. As medidas adotadas pela equipe, tais como o desbridamento, a dieta nutricional hiperproteica, a antibioticoterapia ampla, a colostomia e a reconstrução foram satisfatórias para debelar a infecção e permitir a retomada da qualidade de vida do paciente.

\section{PRINCIPAIS REFERÊNCIAS}

ABREU, Rone Antônio Alves de et al. Síndrome de Fournier: estudo de 32 pacientes - do diagnóstico à reconstrução. Revista Ged: Gastroenterologia Endoscopia Digestiva, São Paulo, v. 33 , n. 2, p.45-51, 2014.

AZEVEDO, Cassius Clay S. F. Azevedo et al. Síndrome de Fournier: um artigo de revisão. Connection Line: Revista Eletrônica do UNIVAG, Várzea Grande, v. 15, n. 1, p.70-80, 2016.

CANDELARIA, Paulo de Azeredo Passos et al. Síndrome de Fournier: análise dos fatores de mortalidade. Rev bras. colo-proctol. Rio de Janeiro, v. 29, n. 2, p. 197-202, 2009.

CARDOSO, João B.; FÉRES, Omar. Gangrena de Fournier. Medicina (ribeirão Preto), Ribeirão Preto, v. 40, n. 4, p.493-499, out./dez. 2007. 
DORNELAS, Marilho Tadeu et al. Síndrome de Fournier: 10 anos de avaliação. Rev. Bras. Cir. Plás., v. 27, 2012.

HOFFMAN, Arthur Leopoldo et. al. Síndrome de Fournier: Relato de caso. Arquivos Catarinenses de Medicina, v. 38, suplemento 01, 2009.

MELKONIAN, E. T.; VILLAR, V.M.; CAMPAÑA, G.V. et al. Gangrena de Fournier. Revista Chilena Cirurgia, 1999. 


\title{
RELAÇÃO ENTRE ANEMIAS CARENCIAIS E LESÕES BUCAIS
}

\begin{abstract}
Lorena Rodrigues Souza ${ }^{1}$
${ }^{1}$ Graduanda em Odontologia, Universidade Estadual de Feira de Santana (UEFS), Feira de Santana, Bahia.
\end{abstract}

\section{RESUMO}

A deficiência de compostos hematínicos, como vitamina B 12, ferro e ácido fólico, pode acarretar vários tipos de aneminas carenciais. Essas carências podem ser resultado da má ingestão, má absorção ou dificuldade na alimentação por conta de lesões bucais, como glossite atrófica, líquen plano oral erosivo, estomatite aftosa recorrente, síndrome da ardência bucal e fibrose submucosa oral. Além disso, algumas dessas lesões podem se desenvolver em resultado às carências dos compostos hematínicos, pois ocorre uma menor oxigenação do tecido e dificuldade na renovação tecidual e na fisiologia celular, ocasionando a atrofia do tecido. Em adição, há o desenvolvimento de candidíase e sintomatologias, como ardência bucal, queimação, xerostomia e disgeusia. Por conta dessa interrelação, conhecer essas carências e sua associação com as patologias orais é importante para que os profissionais da saúde possam diagnosticar e tratar melhor os pacientes durante as rotinas clínicas.

PALAVRAS-CHAVE: Deficiência de Vitaminas; Índices de Eritrócitos; Patologia Bucal.

ÁREA TEMÁTICA: Clínico-Hospitalar

\section{INTRODUÇÃO}

Os exames de sangue são técnicas baratas que podem ser utilizadas para avaliar a saúde de um indivíduo, diagnosticar e acompanhar a progressão de várias patologias, como as anemias, que são situações ocasionadas pela diminuição na quantidade de hemoglobina. Para isso, é solicitado o hemograma completo, por onde é capaz de se avaliar as taxas de hemácias, hemoglobina (Hb), hematócrito, o volume celular médio dos eritrócitos (VCM) e suas distribuições (RDW), além da possibilidade de realizar uma análise microscópica das células para avaliar o formato e tamanho das hemácias. Juntamente com o hemograma completo, podem ser realizados os exames para avaliar a concentração de ferro sérico, vitamina B 12 e ácido fólico, pois a falta desses componentes pode causar as anemias carenciais, tanto por má alimentação como por má absorção (QUINN et al., 2016), sendo esta última normalmente é identificada por exames para avaliar a presença de anticorpos das células parietais gástricas (GPCA). Na clínica odontológica e médica é fundamental conhecer as patologias por deficiência hematínica e sua relação com as lesões orais, como a estomatite aftosa 
recorrente (EAR), glossite atrófica (GA), síndrome da ardência bucal (SAB), a fibrose submucosa oral (FSO), o líquen plano oral erosivo (LPOE) (WU et al., 2017) e a queilite angular. Com isso, o seguinte trabalho teve o objetivo de realizar uma revisão narrativa da literatura acerca da inter-relação entre as anemias carenciais e as lesões orais.

\section{METODOLOGIA}

A busca bibliográfica foi realizada no portal PubMed utilizando os descritores "Anemia" AND "Dentistry", "Erythrocyte Índices" AND "Dentistry" e "Cheilitis" AND "Anemia”. Foram incluídos na pesquisa artigos publicados entre 2016 e 2021, sem restrições de idiomas. Ao final da leitura, para a confecção da seguinte revisão de literatura foram selecionados nove artigos que abordavam a relação entre as anemias carenciais e as lesões orais.

\section{FUNDAMENTAÇÃO TEÓRICA}

A deficiência de ferro, vitamina B12 e ácido fólico pode causar vários sinais e sintomas bucais, sendo muitas vezes o primeiro indicativo de carências hematínicas. Exemplos dessas alterações podem ser: eritema na mucosa oral, queilite angular, impressão de queimação na boca e candidíase (RADOCHOVÁ; SLEZÁK; RADOCHA, 2020; LU, 2016). A deficiência de ferro pode causar palidez na mucosa oral (LU, 2016), e a falta de vitamina B 12 isolada pode causar pigmentação escurecida na pele e na língua (KAUR; GORAYA, 2018).

Essas anemias podem resultar em atrofia do epitélio oral (WU et al., 2016) por conta de problemas na fisiologia celular, principalmente pela falta de ferro, e problemas na síntese de DNA e divisão celular ocasionadas pela deficiência de vitamina B 12 e ácido fólico (QUINN et al., 2016). A baixa concentração de $\mathrm{Hb}$ nas hemácias ocasionadas pelas anemias dificultam o transporte do oxigênio para a mucosa oral, também influenciando no aparecimento de atrofia. Ainda, as anemias carenciais podem diminuir a barreira epitelial oral e facilitar a ocorrência de patologias atróficas no tecido, como a EAR. As lesões de EAR podem ocasionar sensação de queimação e dor na mucosa oral, dificultando a alimentação dos pacientes e levando à anemia carencial (WU et al., 2016), ou seja, há uma relação dupla entre a EAR e as deficiências hematínicas.

Outra patologia que pode ocasionar as anemias carenciais pela dificuldade na alimentação é a SAB, pois ela causa varicosidade lingual, boca seca, disgeusia, queimação e dormência da mucosa oral. Contudo, a falta de vitamina B 12 em pacientes com SAB também pode estar relacionada com a positividade sérica de GPCA, que dificulta a absorção da vitamina, resultando em carência da mesma (CHIANG et al., 2020).

$\mathrm{Na}$ GA, a sensação de queimação na língua, boca seca, dormência da mucosa oral e disfunção do paladar também podem dificultar a ingestão de alimentos e, consequentemente, ocasionar anemias carenciais (WU et al., 2016). Ainda, a EAR e a GA podem ocorrer simultaneamente, agravando ainda 
mais as deficiências hematínicas (WU et al., 2016).

A relação entre a GA, a $\mathrm{SAB}$ e as anemias carenciais funcionam como "via de mão dupla”, assim como a EAR, pois as deficiências hematínicas podem reduzir o número de papilas gustativas, dormência da mucosa oral, boca seca e perda do paladar, dificultando a alimentação e, consequentemente, piorando o quadro anêmico do paciente (CHIANG et al., 2020).

A dificuldade na mastigação, a ingestão alimentar difícil e a limitação da abertura bucal nos pacientes com FSO podem ocasionar deficiências de componentes e vitaminas no sangue por alimentação pobre nesses compostos (CHIANG et al., 2018). O mesmo pode acontecer com os pacientes com LPOE, pois suas lesões erosivas ou ulcerativas podem causar sensação de queimação e dor na mucosa oral, resultando na redução da ingestão de alimentos (CHANG et al., 2016).

Com isso, os hemogramas dos pacientes com EAR, GA (WU et al., 2016), SAB (CHIANG et al., 2020), FSO (CHIANG et al., 2018) e LPOE (CHANG et al., 2016) podem apresentar baixas taxas de $\mathrm{Hb}$, ferro, vitamina $\mathrm{B} 12$ e ácido fólico, além da presença de microcitose e macrocitose nas análises microscópicas, alterando os índices de VCM e RDW, podendo ser diagnosticadas as anemias perniciosa, macrocítica, microcítica, normocítica e anemia ferropriva.

Os tratamentos para as anemias carenciais são constituídos por acompanhamento profissional para conhecer a causa e, se for o caso, realizar a correta reposição dos componentes hematínicas. Nas lesões orais, o tratamento na maioria das vezes é para o alívio dos sintomas a partir do uso de anti-inflamatórios e antifúngicos para bochecho, no caso da candidíase (RADOCHOVÁ; SLEZÁK; RADOCHA, 2020; LU, 2016).

\section{CONSIDERAÇÕES FINAIS}

Patologias orais, como a EAR, GA, SAB, FSO e LPOE apresentam grande influência na causa de anemia e deficiências hematínicas, assim, os pacientes com essas lesões podem apresentar alterações nas taxas de ferro sérico, ácido fólico, vitamina B12,VCM, RDW e presença de macrocitose e microcitose. Além disso, a falta desses componentes no sangue pode potencializar essas lesões orais, ocasionar o aparecimento de queilite angular e candidíase, e gerar sinais e sintomas. Com isso, é necessário que os profissionais da saúde estejam cientes da via dupla entre as deficiências hematínicas e as lesões orais, proporcionando ao paciente melhores diagnósticos, tratamentos e qualidade de vida.

\section{REFERÊNCIAS}

CHANG, J.Y.F. et al. Anemia and hematinic deficiencies in gastric parietal cell antibody-positive and antibody-negative erosive oral lichen planus patients with thyroid antibody positivity. Journal of Formosan Medical Association, v. 115, n. 11, p. 1004-1011, 2016. 
CHIANG, C.P. et al. Anemia, hematinic deficiencies, hyperhomocysteinemia, and serum gastric parietal cell antibody positivity in 884 patients with burning mouth syndrome. Journal of Formosan Medical Association, v. 119, n. 4, p. 813-820, 2020.

CHIANG, C.P. et al. Hematinic deficiencies and anemia in gastric parietal cell antibody-positive and -negative oral submucous fibrosis patients. Journal of Dental Sciences, v. 13, n. 1, p.68-74, 2018.

QUINN, J.G. et al. Blood: tests used to assess the physiological and immunological properties of blood. Advances in Physiology Education, v. 40, 2016.

KAUR, S.; GORAYA, J.S. Dermatologic findings of vitamin $\mathrm{B}_{12}$ deficiency in infants. Pediatric Dermatology, v. 35, n. 6, p. 796-799, 2018.

LU, S.Y. Perception of iron deficiency from oral mucosa alterations that show a high prevalence of Candida infection, Journal of Formosan Medical Association,v. 115, n. 8, p. 619-627, 2016.

RADOCHOVÁ, V.; SLEZÁK, R.; RADOCHA, J. Oral Manifestations of Nutritional Deficiencies: Single Centre Analysis. Acta Medica (Hradec Kralove), v. 63, n. 3, p. 95-100, 2020.

WU, Y.H. et al. Anemia and hematinic deficiencies in oral mucosal disease patients with microcytosis. Journal of Formosan Medical Association, v. 116, n. 7, p. 505-511, 2017.

WU, Y.C. et al. Hematinic deficiencies and anemia statuses in recurrent aphthous stomatitis patients with or without atrophic glossitis. Journal of Formosan Medical Association, v. 115, v. 12, p. 10611068, 2016. 


\section{Educação em Saúde}




\title{
A FREQUÊNCIA DE ESTUDO DOS DISCENTES MÉDICOS DURANTE A PANDEMIA DO COVID-19 NO BRASIL
}

\author{
Welisson Conrado Carvalho'; Pedro Victor Freitas Medrado²; Karen Ruggeri Saad ${ }^{3}$ \\ ${ }_{1}$ Graduando, Fundação Universidade Federal do Vale do São Francisco (UNIVASF), Petrolina, \\ Pernambuco. \\ ${ }_{2}$ Graduando, Fundação Universidade Federal do Vale do São Francisco (UNIVASF), Petrolina, \\ Pernambuco. \\ 3 Doutora, Fundação Universidade Federal do Vale do São Francisco (UNIVASF), Petrolina, \\ Pernambuco. \\ welisson.carvalho@discente.univasf.edu.br.
}

\begin{abstract}
RESUMO
A pandemia ocasionada pelo novo coronavírus fez com que houvesse a necessidade de distanciamento social, o que ocasionou a suspensão das atividades acadêmicas presenciais de diversas faculdades médicas. Nesse sentido, o objetivo deste estudo observacional foi analisar o tempo diário de realização das atividades de estudo durante a pandemia do COVID-19 por parte dos estudantes de medicina de diversas faculdades médicas brasileiras. Para tanto, foram analisados, com softwares estatísticos, 395 questionários respondidos por estudantes de medicina de diversas universidades brasileiras que indicaram que 93,7\% (n=370) mantiveram frequência de estudo diário durante o isolamento social. Os dados mostraram uma diferença significativa, por meio do teste qui-quadrado, entre as diferentes regiões do país $(\mathrm{p}<0,05)$ na quantidade de horas estudadas. Isso pode estar associado a forma que as diferentes realidades sociais e culturais responderam à crise e a capacidade de adaptação ao ensino remoto e às Tecnologias da Informação e Comunicação.
\end{abstract}

PALAVRAS-CHAVE: Isolamento social; Graduação em saúde; Coronavírus.

ÁREA TEMÁTICA: Educação em Saúde

\section{INTRODUÇÃO}

Em dezembro de 2019 surgiu, na província de Wuhan, na China, o novo coronavírus (SarsCoV-2) que causa a doença COVID-19. O vírus é caracterizado por uma alta taxa de transmissão, o que possibilitou que ele rapidamente se espalhasse pelo mundo e, em 11 de março de 2020, 
a Organização Mundial da Saúde (OMS) declarou a COVID-19 como uma pandemia (DÍAZCASTRILLÓN; TORO-MONTOYA, 2020).

O vírus é transmitido através de gotículas respiratórias provenientes do contato direto, ou por intermédio de objetos e superfícies contaminadas. Sendo assim, o distanciamento social fora utilizado como a principal medida profilática para reduzir a transmissão do Sars-CoV-2 (DÍAZCASTRILLÓN; TORO-MONTOYA, 2020). No Brasil, atendendo as recomendações da OMS, foi determinado a suspensão de atividades acadêmicas presenciais das instituições de ensino superior desde 17 de março de 2020. (BRASIL, 2020).

O curso médico brasileiro possuí, além do conhecimento técnico e científico, uma grande dependência de interações humanas para a formação de seus discentes, pois isso possibilita que eles desenvolvam um cuidado integralizado e humanitário de seus futuros pacientes. Devido à necessidade de isolamento social em virtude da pandemia, os estudantes do curso de medicina tiveram sua rotina de estudos alterada e, para permanecerem realizando atividades de estudo acadêmico, utilizaram principalmente a internet (ROSE, 2020). No entanto, há dúvidas acerca de que forma esta população de estudantes se comportou em relação a manutenção dos estudos de forma remota. Desta forma esse estudo teve como objetivo analisar o tempo diário de realização das atividades de estudo durante a pandemia do COVID-19 por parte dos estudantes de medicina de diversas faculdades médicas brasileiras.

\section{METODOLOGIA}

Trata-se de um estudo observacional, transversal, realizado com 395 estudantes do curso de medicina do $1^{\mathrm{o}}$ ao $6^{\circ}$ ano, maiores de 18 anos, regularmente matriculados em Instituições de Ensino Superior (IES) devidamente regularizadas pelo Ministério da Educação (MEC) do Brasil.

O projeto foi aprovado pelo Comitê de Ética em Pesquisa com Seres Humanos do Instituto Federal de Educação, Ciência e Tecnologia do Sertão Pernambucano - IF SERTÃO-PE (38348020.4.0000.8052) e todos os participantes concordaram e assinaram o Termo de Consentimento Livre e Esclarecido para responderem aos questionários.

Os estudantes foram recrutados por intermédio das Tecnologias da Informação e Comunicação (TIC), respondendo a um formulário na plataforma Google Forms elaborado pelos pesquisadores com o intuito de coletar informações pertinentes para a realização desta pesquisa. O questionário foi composto por questões que visavam coletar dados acerca da situação sociodemográfica do pesquisado, bem como de sua frequência diária de estudo. Os dados coletados foram planilhados em arquivo Excel e, para a análise dos dados, foi utilizado teste de qui-quadrado de Pearson por meio do SOFTWARE IBM SPSS STATISTICS BASE 22 - DATA MINING AND STATISTICAL SOLUTIONS. 


\section{RESULTADOS E DISCUSSÕES}

Os formulários analisados mostraram que 93,7\% (n=370) manteve o estudo remoto de temas médicos como opção ao isolamento social. O panorama geral dos estudantes médicos brasileiros revela que $29,7 \%(n=110)$ estudam de duas a quatro horas por dia; $23,5 \%(n=87)$ mais do que seis horas por dia; $21,9 \%(n=81)$ entre uma a duas horas por dia; $18,6 \%(n=69)$ entre 4 e 6 horas diárias e $6,2 \%(n=23)$ dedicavam menos de uma hora diária.

Figura 1: Frequência absoluta do tempo diário de estudo, por faixas, agrupados por regiões geográfica

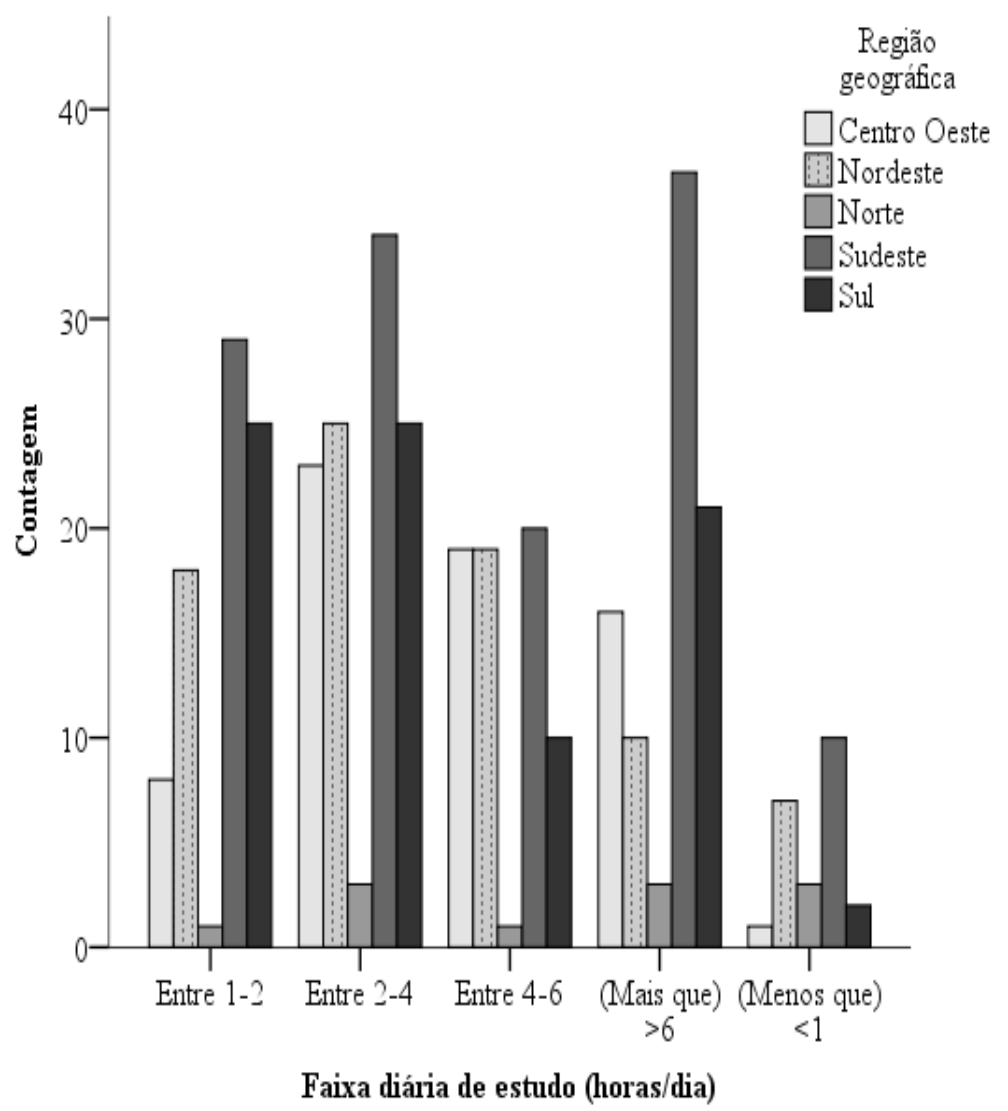

Fonte: autores, 2021.

A frequência do estudo diário variou conforme a região do país, com a região sudeste representando $34,6 \%$ dos estudantes com pelo menos 1 hora de estudo diário, enquanto a região norte com 2,3\% da mesma quantidade diária de estudo (Figura $1, \mathrm{X}_{(16,369)}^{2}=34,49, \mathrm{p}=0,005$ ). Além disso, o tempo diário de estudo variou, sem diferença significativa, entre os ciclos do curso $\left(\mathrm{X}_{(8,369)}^{2}=15,202\right.$, $\mathrm{p}=0,055)$, das faixas etárias $\left(\mathrm{X}_{(8,369)}^{2}=14,463 . \mathrm{p}=0,07\right)$, gêneros $\left(\mathrm{X}_{(8,369)}^{2}=10,945, \mathrm{p}=0,205\right)$ e etnias $\left(\mathrm{X}_{(12,369)}^{2}=7,281, \mathrm{p}=0,839\right)$. 
Constata-se entre as distintas regiões do país que haja uma diferença notável: Enquanto $36 \%$ dos pesquisados da região norte estudaram mais do que 4 horas por dia, $52 \%$ dos estudantes da região sul estudaram mais do que 4 horas por dia durante o período de isolamento social. Não obstante, a quantidade diária de tempo despendido não implica, necessariamente, em uma absorção de conteúdo que está associada, muitas vezes, ao planejamento e à gestão diária das 24 horas (PORTA; ANDERSON; STEELE, 2013; SPENCER-SMITH; KLINGBERG, 2015). Além do mais, essa diferença pelo país pode significar ao modo como cada instituição (DEWAR, 2020), e região, responderam a dicotômica relação entre a necessidade de continuidade do ensino e a suspensão das atividades devido ao isolamento social.

\section{CONCLUSÃO}

A pandemia de COVID-19 trouxe diversas mudanças na rotina dos estudantes de medicina de diversas universidades brasileiras por conta da necessidade de isolamento social e suspensão das atividades. Essa mudança na rotina acadêmica fez com que os estudantes se adaptassem ao meio remoto para continuidade de suas atividades de estudo, a destacar as TIC. A realidade da pesquisa demonstra que a maioria dos estudantes médicos brasileiros mantiveram uma frequência diária de estudo, variando conforme região do país $(\mathrm{p}<0,05)$. Isso representa não somente um dilema geográfico, mas sim associada às autoridades institucionais, sobretudo com políticas e incentivo para manutenção do estudo contínuo.

\section{PRINCIPAIS REFERÊNCIAS}

DÍAZ-CASTRILLÓN, Francisco Javier; TORO-MONTOYA, Ana Isabel. SARS-CoV-2/COVID-19: el virus, la enfermedad y la pandemia. Medicina y Laboratorio, vol. 24, no. 3, 2020.

https://doi.org/10.36384/01232576.268.

BRASIL. Diário oficial da União. PORTARIA No 544, DE 16 DE JUNHO DE 2020. 2020.

ROSE, S. Medical Student Education in the Time of COVID-19. JAMA - J Am Med Assoc 2020;323:2131-2. https://doi.org/10.1001/jama.2020.5227.

PORTA, C. Rees; ANDERSON, Michael R.; STEELE, Scott R. Effective time management: Surgery, research, service, travel, fitness, and family. Clinics in Colon and Rectal Surgery, 2013. https://doi.org/10.1055/s-0033-1356724.

SPENCER-SMITH, Megan; KLINGBERG, Torkel. Benefits of a working memory training program for inattention in daily life: A systematic review and meta-analysis. PLoS ONE, 2015. https://doi.org/10.1371/journal.pone.0119522. 
DEWAR, John. The role of universities in times of crisis: a vice-chancellor's perspective. Qualitative Research Journal, 2020. https://doi.org/10.1108/QRJ-06-2020-0072. 


\section{PROJETO DE EXTENSÃO NA ÁREA DE CIRURGIA E TRAUMATOLOGIA BUCO- MAXILO-FACIAL NO HOSPITAL DE URGÊNCIA DE TERESINA - RELATO DE EXPERIÊNCIA}

\section{Francisco Antonio de Jesus Costa SILVA'; Deloniê Eduardo Oliveira de LIMA²; Lara Fernanda Carlos LIMA²; Maria Cândida de Almeida LOPES ${ }^{3}$}

${ }^{1}$ Graduando de Odontologia, Universidade Federal do Piauí (UFPI), Teresina, Piauí.

${ }^{2}$ Graduandos de Odontologia, Universidade Federal do Piauí (UFPI), Teresina, Piauí.

${ }^{3}$ Professora Dra. do curso de Odontologia, Universidade Federal do Piauí (UFPI), Teresina, Piauí.

\section{RESUMO}

A Cirurgia e Traumatologia Buco-Maxilo-Facial (CTBMF) vem sendo necessitada cada vez mais ao passar dos tempos para tratamentos de pacientes vítimas de traumas, ocupando um espaço de destaque entre as especialidades odontológicas. O Projeto de Extensão na Área de Cirurgia e Traumatologia Buco-Maxilo-Facial é uma atividade que tem como objetivos proporcionar aos seus participantes um maior conhecimento teórico sobre os principais temas desta especialidade odontológica, além de estender aos mesmos, as condições de treinamento da prática cirúrgica e oferecer aos pacientes que são encaminhados para o Hospital de Urgência de Teresina (HUT) um atendimento especializado. Este Projeto de Extensão tem características peculiares, que desenvolvem em seus discentes um estrito senso de respeito, responsabilidade e hierarquia. As atividades possibilitam aos seus participantes adquirirem experiência na realização de cirurgias bucais e inúmeros conhecimentos acerca dos temas a que se dispõe.

PALAVRAS CHAVES: Facial Injuries; Dentistry; Acidents.

ÁREA TEMÁTICA: Educação em Saúde

\section{INTRODUÇÃO}

Tem-se a definição de trauma como um conjunto de alterações funcionais e anatômicas, gerais e/ou locais, podendo ser provocadas por organismos em meios violentos, queimaduras, agressões (espancamentos, ferimento por projétil de arma de fogo e arma branca) e/ou acidentes como quedas. A possibilidade do surgimento desta problemática é bastante observada na população, independentemente da idade, condição social ou cultural e representa um dos problemas mais frequentes em saúde pública. Os traumas, segundo dados da Organização Mundial de Saúde, estão 
entre as principais causas de morte e invalidez no mundo e estima-se que, a cada ano, 1,24 milhões de pessoas morrem em decorrência destes traumas. As lesões da cabeça e da face representam metade das mortes traumáticas, e centenas ou milhares sobrevivem a essas lesões, muitas vezes com sequelas limitadoras permanentes (AFFONSO et al, 2010).

Há diversos fatores sociais associados a epidemiologia de alguns destes traumas. A etiologia do trauma facial está diretamente ligada as características da população a ser estudada, contudo, em uma maior amplitude, observa-se que é tratado como um termo que possui heterogeneidade. O trauma da região facial frequentemente resulta em lesões aos tecidos moles, aos dentes e aos principais componentes do esqueleto da face, incluindo mandíbula, maxila, zigoma, ossos próprios do nariz (OPN), complexo naso-órbito-etmoidal (NOE) e estruturas supraorbitárias. Tais lesões, se não forem reparadas da maneira mais adequada, podem evoluir para importantes sequelas estéticas, emocionais e funcionais. Muitas dessas sequelas transformam-se em deformidades permanentes ao paciente, tornando tais lesões um dos mais significativos problemas do mundo no campo da saúde. (MACEDO et al, 2008)

O Hospital de Urgência de Teresina é uma unidade hospitalar do nordeste brasileiro, sendo referência em média e alta complexidade no estado do Piauí. Sua área de abrangência engloba além de Teresina, municípios em sua vizinhança. A epidemiologia dos traumas da face pode fornecer subsídios para o desenvolvimento de medidas preventivas, as quais auxiliarão na redução dessas lesões.

\section{OBJETIVO}

Tem-se como objetivo deste trabalho relatar a experiência de discentes estagiários acerca do serviço buco-maxilo-facial promovido pelo projeto de extensão denominado "Projeto de Extensão na Área de Cirurgia e Traumatologia Buco-Maxilo-Facial". Assim, esta ação permite o fornecimento de assuntos que não são tratados na graduação, além de incentivar a fomentação de pesquisas cientificas sobre a área eleita, seguindo a diretriz vigente da universidade - extensão, pesquisa e ensino. A atuação do projeto é realizada de modo integrado ao Serviço Buco-maxilo-facial do Hospital de Urgência de Teresina (HUT), Teresina-PI.

\section{METODOLOGIA}

O projeto de extensão foi idealizado a partir da constatação da ausência de voluntários no serviço de cirurgia e traumatologia buco-maxilo-facial entre a equipe do hospital de urgência de Teresina (HUT). As atividades de extensão se iniciaram pelo treinamento dos voluntários para o conhecimento e familiarização com o ambiente físico e rotina do hospital, sendo que o funcionamento se deu por meio de plantões semanais, dividindo-os em duplas. A cada semana, uma dupla acompanhou a equipe composta pelos preceptores e os residentes da especialidade, e posteriormente, houve a participação ativa dos graduandos nos atendimentos iniciais, internações, atividades de corrida de leito, evolução 
de pacientes, prescrições, altas hospitalares e análise de exames complementares.

O período semestral dividia-se em etapas mensais, onde o primeiro mês se fazia a seleção dos graduandos e após aprovação e vínculo passavam a acompanhar a rotina do hospital (etapa 1). A partir da evolução dos acadêmicos, a etapa 2 se configurava com a introdução direta dos alunos nas atividades. Juntamente com os preceptores do serviço. O plantão se iniciava com a corrida de leito, onde se realizava os exames de rotina de todos os pacientes internados pela especialidade no hospital. Cada paciente encontrava-se em uma enfermaria e a localização se dava pelo sistema interno no hospital, após exame físico constata-se a condição atual do paciente, faz-se a prescrição medicamentosa diária e em seguida a evolução do quadro dos pacientes que englobavam desde indivíduo com quadro pré ou pós-operatório, e a partir disso, a realização de possíveis altas hospitalares e seleção de cirurgias eletivas diárias. Ao fim do plantão fazia-se um relatório diário das atividades englobando os pacientes atendidos e que passaram pela especialidade durante os turnos. Todo registro era passado para o plantonista do dia seguinte para fins de controle.

\section{RESULTADOS E DISCUSSÃO}

A Lei de Diretrizes e Bases da Educação Nacional (LBD), criada em 1996, destacava a Universidade como um importante canal para a divulgação dos problemas sociais que assolavam o planeta. Com isso, cabia às universidades um papel formador ainda mais vital para o estudante, pondo-o em contato com as mazelas ao seu redor e promovendo uma relação estável deste com a comunidade, sobretudo através de prestação de serviço (ARANHA; FERREIRA; SOUZA, 2011).

Por outro lado, da parte da comunidade advinha também um rico material de troca. Se a universidade transportava para fora de seus muros o conhecimento e a assistência aos problemas da população, a comunidade por sua vez legava aos estudantes os conhecimentos populares - condensados em cultura, realidade, modos de vida, necessidades individuais e coletivas - que nascem através deste contato (CARNEIRO et al, 2015).

Sendo assim, a Extensão Universitária inicia um processo onde será idealizada como uma ferramenta que une a pesquisa e o ensino no seio da comunidade, sendo capaz, através desta integração, de pôr em prática os ensinamentos téoricos para além do ambiente da sala de aula (CARNEIRO et al, 2015).

Diante disso, inserir os graduandos de odontologia em um hospital da rede pública de saúde, fornece suporte às atividades curriculares e faz-se essencial ao reafirmar o compromisso social da odontologia com a população, ratificando pilares idealizados pelo sistema único de saúde englobando as esferas ensino-serviço-comunidade.

Além de proporcionar um maior conhecimento na área de Cirurgia e Traumatologia BucoMaxilo-Facial, o projeto de extensão permitia que os alunos participassem das cirurgias e do planejamento de acordo com a curva de aprendizado. O graduando tinha a possibilidade de estar em 
contato direto com o ambiente hospitalar e/ou ambulatorial, participar de planejamentos, participar de maneira supervisionada como instrumentador e evoluir para uma possivelmente participação como auxiliar nas cirurgias eletivas de pequeno porte, tudo baseado no crescimento da linha de aprendizado e observação de diversos casos.

\section{CONCLUSÃO}

Este Projeto de Extensão tem características peculiares, que desenvolvem em seus discentes um estrito senso de respeito, responsabilidade e hierarquia.Frente ao exposto, avistamos a importância da extensão no campo da cirurgia odontológica para acompanhamento de pacientes vítimas de fraturas maxilofaciais e atribuição de aprendizado aos discentes, fornecendo um conhecimento maior acerca do serviço buco-maxilo-facial e o manejo para tratamento dessa classe de pacientes.

Com isso, o vínculo ensino, extensão e pesquisa, quando bem articulados, permite-se haver mudanças significativas nos processos de ensino e aprendizagem, afetando consideravelmente na formação profissional dos alunos.

\section{REFERÊNCIAS}

ANDRADE, E.D. Terapêutica medicamentosa em odontologia. 3. ed. São Paulo: Artes Médicas, 2014.

ARNETT, GW; MCLAUGHLEN, RP. Planejamento facial e dentário para ortodondista e cirurgiões bucomaxilofaciais. Porto Alegre: ArTmed. 2004. 320p. Título original: Facial and dental planning for orthodontistand oral surgeons.

ARANHA, R. N.; FERREIRA, D. A. V.; SOUZA, M. H. F. O. Ligas acadêmicas: uma proposta discente para ensino, pesquisa e extensão. Interagir: pensando a extensão, Rio de Janeiro, n. 16, p. 47-51, 2011.

CARNEIRO, J. A. et al. Liga acadêmica: instrumento de ensino, pesquisa e extensão universitária. Revista Eletrônica Gestão e Saúde, Brasília, v. 6, n. 1, p. 667-79, 2015. Disponível em: http:// periodicos.unb.br/index.php/rgs/article/download/2596/2315/ Acesso em: 02 de janeiro de 2021.

FONSECA, R.J.; DAVIS, W.H. Reconstructive pre prosthetic oral and maxillofacialsurgery. W.B. Saunders Co., 1. ed., 1986. FONSECA, R.J.; WALKER, R.V. Trauma bucomaxilofacial.4 ed. Elsevier; 2015.

FREITAS, R. Tratado de cirurgia bucomaxilofacial. São Paulo: Santos, 2006.

HUPP, J.R.; ELLIS, E.; TUCKER, M.R. Cirurgia oral e maxilofacial contemporânea. 6. ed. Rio de Janeiro: Elsevier, 2015. PRADO, R.; SALIM, M. Cirurgia bucomaxilofacial - diagnóstico e 
tratamento. $2^{\circ}$ ed. Rio de Janeiro.

MACEDO JLS, CAMARGO LM, ALMEIDA PF and ROSA SC. Perfil epidemiológico do trauma de face dos pacientes atendidos no pronto socorro de um hospital público. Rev. Col. Bras. Cir. [online]. 2008, vol.35, n.1, pp.9-13. ISSN 1809-4546.

MALAMED, S.F. Manual de anestesia local. 3. ed. Rio de Janeiro: Guanabara Koogan, 2013.

MEDEIROS, P.J.; MEDEIROS, P.P. Cirurgia ortognática para o ortodontista. 2. ed. São Paulo: Santos, 2004.

MICHAEL MILORO, G. E.; GHALI, P. L.; WAITE, P.D. Princípios de cirurgia bucomaxilofacial de Peterson. 3. ed. São Paulo: Santos, 2016.

NEVILLE, B.W., et al. Patologia Oral \& Maxilofacial. 4ª ed. Rio de Janeiro: Elsevier; 2016. 


\section{ABORDAGEM DA FITOTERAPIA NOS CURSOS DE SAÚDE DOS MUNICÍPIOS DE PETROLINA (PE) E JUAZEIRO (BA)}

\section{Welisson Conrado Carvalho'; Drako de Amorim Souza²; Pedro Victor Freitas Medrado; Paulo Roberto Ramos ${ }^{4}$}

${ }^{1}$ Graduando, Fundação Universidade Federal do Vale do São Francisco (UNIVASF), Petrolina, Pernambuco.

${ }^{2}$ Graduando, Fundação Universidade Federal do Vale do São Francisco (UNIVASF), Petrolina, Pernambuco.

${ }^{3}$ Graduando, Fundação Universidade Federal do Vale do São Francisco (UNIVASF), Petrolina, Pernambuco.

${ }^{4}$ Doutor, Fundação Universidade Federal do Vale do São Francisco (UNIVASF), Petrolina, Pernambuco.

\section{RESUMO}

O estudo da fitoterapia é uma necessidade constante nas diversas regiões do Brasil. Nesse aspecto, foi conduzido uma pesquisa documental, de cunho exploratória, nas matrizes curriculares dos 36 cursos da área de saúde localizados nos municípios de Juazeiro, na Bahia, e Petrolina, em Pernambuco. A coleta de dados se deu por intermédio das tecnologias digitais e de comunicação, visto a atual situação pandêmica. Os resultados mostraram que 13,9\% $(n=5)$ apresentaram o currículo com tema da fitoterapia, e $11,1 \%(n=4)$ apresentaram detalhes da abordagem. A baixa cobertura da fitoterapia representa um problema à demanda popular e ao cuidado integral. As instituições que ofertam esse conteúdo o fazem de modo particularizado. Desse modo, é pontuado que, na atual região pesquisada, necessita-se uma maior abordagem com fins de fortalecimento das práticas integrativas e complementares e das equipes multiprofissionais em saúde.

PALAVRAS-CHAVE: Plantas medicinais; Educação; Práticas complementares.

ÁREA TEMÁTICA: Educação em Saúde 


\section{INTRODUÇÃO}

O uso de plantas medicinais, definidas como sendo aquelas utilizadas com objetivo terapêutico, está associado ao conhecimento popular transmitido por diversas gerações. Contrasta-se esta definição com a dada à fitoterapia, o estudo e desenvolvimento de medicamentos industrializados a partir de plantas medicinais (GADELHA et al., 2013). Notadamente, comunidades com baixo acesso ao sistema de saúde recorrem à utilização de plantas medicinais, em situações o único recurso terapêutico disponível. Também é sabido que comportamentos de desconfiança aos serviços médicos levam os pacientes a aderirem tratamentos ditos populares (BRASIL, 2012).

Forma-se, então, uma interface de conflito entre o formando da área de saúde e a população atendida, onde contrasta-se a necessidade de pesquisa e desenvolvimento sobre plantas medicinais em conjunto com a ampliação do Sistema Único de Saúde com a formação muitas vezes insuficiente desses profissionais (BARRETO et al., 2016). Vários estudos já demonstraram a necessidade do ensino na área e a importância de sua inserção (BARRETO \& SILVEIRA, 2014; FEITOSA et al., 2016; MOURA et al., 2016). Dessa forma, o presente estudo tem como objetivo verificar a inserção da fitoterapia na grade curricular dos cursos da área da saúde dos municípios de Petrolina (PE) e Juazeiro (BA).

\section{METODOLOGIA}

Trata-se de um recorte de um estudo de natureza quali e quantitativa, transversal e observacional realizado no segundo semestre de 2020. São apresentados aqui os principais resultados da pesquisa qualitativa/documental. O objeto de estudo foi a abordagem do tema fitoterapia em cursos da área de saúde nas cidades de Juazeiro - BA e Petrolina - PE (Biomedicina, Educação Física, Enfermagem, Farmácia, Fisioterapia, Medicina, Nutrição e Odontologia). Para investigá-lo, fez-se mapeamento das Instituições de Ensino Superior presentes nas duas cidades (tanto públicas como privadas) utilizando o canal e-MEC do Ministério da Educação e, contanto que possuíssem polos funcionantes nas cidades, fez-se busca em seus portais eletrônicos em busca das matrizes e projetos de curso para cada graduação.

Os documentos públicos coletados foram analisados quanto aos pontos: a fitoterapia é abordada nesses cursos? Se sim, de que forma? Somado a esse esforço, também foi feito contato com as secretarias e colegiados das instituições que não disponibilizaram documentos em seus portais, na tentativa de obter os documentos para análise.

\section{RESULTADOS E DISCUSSÕES}

Dentre os 36 cursos analisados nessas instituições, apenas 13,9\% (n=5) abordavam de maneira direta ou indireta a temática de "fitoterapia" em sua grade curricular (Tabela 1). 
Tabela 1: Oferta da disciplina de fitoterapia pelos cursos da saúde de Juazeiro (BA) e Petrolina (PE).

\begin{tabular}{ccc}
\hline Instituição & Curso & Disciplina com carga horária \\
\hline & Medicina & Fitoterapia -45 horas \\
Universidade Federal do Vale do São & Farmácia & Fitoterapia -60 horas \\
Francisco (UNIVASF) & & Nutrição Funcional e Fitoterapia - \\
Centro Universitário Maurício de & Nutrição & 60 horas \\
Nassau (UNINASSAU) & Fisioterapia & Fitoterapia -30 horas \\
Universidade de Pernambuco (UPE) & Farmácia & Fitoterapia -36 horas \\
Faculdade Soberana* & & \\
\hline
\end{tabular}

Fonte: Autores, 2021.

Nota: * Não foi possível obter acesso ao projeto pedagógico do curso.

Após a análise dos resultados encontrados, pode-se notar que a fitoterapia ainda é abordada de maneira insuficiente nos cursos da área da saúde dos municípios de Juazeiro (BA) e Petrolina (PE), haja vista que apenas 13,9\% dos cursos analisados abordaram essa temática de alguma maneira em sua grade curricular.

A forma como a fitoterapia e o conhecimento acerca de plantas medicinais é abordada sob a perspectiva de diferentes cursos também é passível de análise. É possível perceber que a abordagem da temática é feita de maneira peculiar em consonância com as particularidades de cada curso, onde cada IES prioriza aspectos que têm uma maior relevância para a área de atuação dos futuros profissionais da saúde.

No curso de medicina da UNIVASF, campus centro, a fitoterapia é abordada com ênfase em seus aspectos biopsicossociais, levando em consideração que o profissional médico deve ter conhecimento das principais plantas utilizadas como alternativas terapêuticas pelo conhecimento popular. Sendo assim, contribuir com uma orientação efetiva acerca dos benefícios e possíveis malefícios da utilização de fitoterápicos pelos seus futuros pacientes (BRASIL, 2016a).

Nos cursos de Farmácia, Nutrição e Fisioterapia, diferentemente do modo como é abordada no curso de medicina, a fitoterapia é tratada com um olhar mais técnico e direto, atendendo às principais necessidades de conhecimento dos futuros profissionais. Observa-se principalmente aspectos referentes a bioquímica dos fitoterápicos, suas aplicações clínicas, aspectos etnofarmacológicos e os principais efeitos gerados por essas substâncias no organismo humano, e possíveis futuras aplicações profissionais desse conhecimento (BRASIL, 2016b; BRASIL, 2020; PERNAMBUCO, 2017).

No atual contexto regional, enfatiza-se a necessidade de um conhecimento abrangente acerca de fitoterápicos e plantas medicinais, tanto por parte dos futuros profissionais de saúde, quanto das instituições, para que estes possam desfrutar de um conhecimento integralizado. O serviço ofertado precisa ser condizente com as especificidades regionais e individualidades de cada paciente. Desse 
modo, é essencial que o cuidado com o indivíduo seja feito por meio de uma prática integrativa de saúde realizada por intermédio de uma equipe multiprofissional constituída por profissionais que desfrutam de um conhecimento integralizado e complementar.

\section{CONCLUSÃO}

A fitoterapia necessita ter uma maior abordagem nos cursos da área de saúde da região analisada. A baixa carga horária e disciplinas de tal tópico no currículo dos futuros profissionais da saúde pode representar futuros problemas no atendimento e cuidado do paciente. Sobretudo, devido à fragilidade das práticas integrativas e complementares da saúde. Muito embora, a atual cobertura dos currículos das instituições regionais discorre de maneira eficaz e individualizada a cada realidade de formação desses profissionais. Isso representa respostas às políticas públicas de fortalecimento das equipes multiprofissionais e também uma demanda popular.

\section{PRINCIPAIS REFERÊNCIAS}

BARRETO, B. B.; SILVEIRA, D. Inclusion Courses Phytotherapy in undergraduate curriculum of health-related courses. Journal Of Medicinal PlantsResearch, vol. 8, no. 47, p. 1374-1386, 2014. https://doi.org/10.5897/JMPR2014.5546.

BARRETO, B. B. et al. Política e Programa Nacional de Plantas Medicinais e Fitoterápicos. $[S$. l.: s.n.], 2016.

BRASIL. Ministério da Educação. Fundação Universidade Federal do Vale do São Francisco. Relatório Perfil Curricular do Curso de Medicina, 15 de março de 2016a. Disponível em: https:// portais.univasf.edu.br/estudante/informacoes-ao-estudante/cursos/graduacao/arquivos/med_pet.pdf. Acesso em: 18 nov. 2020.

. Práticas integrativas e complementares: plantas medicinais e fitoterapia na Atenção Básica/ Ministério da Saúde. [S. l.: s. n.], 2012.

. Ministério da Educação. Fundação Universidade Federal do Vale do São Francisco. Relatório Perfil Curricular do Curso de Farmácia, 15 de março de 2016b. Disponível em: www.portais. univasf.edu.br/estudante/informacoes-ao-estudante/cursos/graduacao/arquivos/farm.pdf Acesso em: 18 nov. 2020.

Ministério da Educação. Centro Universitário Maurício de Nassau. Ementa Curricular da disciplina de Nutrição Funcional e Fitoterapia do curso de Nutrição. 2020. Disponível em: https://vestibular.uninassau.edu.br/Curso. aspx ?CursoId $=73 \&$ CursoUnidadeId $=4648 \&$ MenuId $=1 \&$ Cidade=Petrolina \&UF=PE. Acesso em: 18 nov. 2020. 
- Ministério da Educação. Universidade de Pernambuco. Projeto Pedagógico do Curso Bacharelado em Fisioterapia. Julho de 2017. Disponível em: www.upe.br/petrolina/wp-content/ uploads/2019/01/PPC-Fisioterapia.pdf. Acesso em 18 nov. 2020.

FEITOSA, M. H. A. et al. Inserção do Conteúdo Fitoterapia em Cursos da Área de Saúde. Revista Brasileira de Educação Médica, vol. 40, no. 2, p. 197-203, Jun. 2016. DOI 10.1590/1981-52712015v4 0n2e03092014. Accessed on: 17 Oct. 2020.

GADELHA, C. S. et al. Estudo bibliográfico sobre o uso das plantas medicinais e fitoterápicos no Brasil. Verde de Agroecologia e Desenvolvimento Sustentável, vol. 8, no. 5, p. 208-212, 2013.

MOURA, A. S. C. et al. Conhecimento sobre plantas medicinais e fitoterápicos: um estudo com acadêmicos de nutrição.R. Interd. v. 9, n. 3, p. 18-25, jul. ago. set. 2016. Disponível em:https:// dialnet.unirioja.es/servlet/articulo? codigo=6772015. Acesso em: 29 nov. 2020. 


\title{
CAPACITAÇÃO REMOTA DE PROFISSIONAIS DURANTE A PANDEMIA DO SARS- COV-2: UM RELATO DE EXPERIÊNCIA
}

\author{
Natalya Juliana da Silva ${ }^{1}$; Maria Eduarda de Araújo Nogueira ${ }^{\mathbf{1}}$; Maria Gabriela Leite ${ }^{\mathbf{1}}$; \\ Amanda Soares de Vasconcelos²; Amanda de Figueroa Silva²; José Reinaldo Madeiro Junior²; \\ Carolina Albuquerque da $\mathrm{Paz}^{2}$; Nara Miranda Portela ${ }^{2}$ \\ ${ }^{1}$ Acadêmica do curso de Medicina, Universidade Federal de Pernambuco (UFPE), Caruaru, \\ Pernambuco.
}

${ }^{2}$ Professor (a) do curso de Medicina, Universidade Federal de Pernambuco (UFPE), Caruaru, Pernambuco.

\section{RESUMO}

A telessaúde refere-se ao uso da tecnologia da informação para oferecer suporte clínico, educação e administração em saúde. Com a pandemia da COVID-19, esta tornou-se ferramenta na atualização de competências dos profissionais. Objetiva-se relatar a experiência de realização de cursos remotos voltados aos profissionais de saúde durante a pandemia da COVID-19, pela Universidade Federal de Pernambuco em parceria com a IV Gerência Regional de Saúde de Pernambuco, durante a pandemia. Como resultado, observou-se o engajamento de professores e estudantes na elaboração e execução dos cursos. Ademais, houve boa avaliação dos cursos por parte dos inscritos, sendo relatado impacto positivo em suas práticas profissionais. Conclui-se que, a impossibilidade de realização de cursos presenciais associada à necessidade massiva de atualização profissional fez com que a telessaúde se destacasse como uma importante ferramenta para aquisição de conhecimentos, bem como para aprimoramento dos existentes.

PALAVRAS-CHAVE: Telessaúde; Profissionais de saúde; COVID-19.

ÁREA TEMÁTICA: Educação em Saúde

\section{INTRODUÇÃO}

A manutenção de competências e habilidades é uma responsabilidade fundamental dos profissionais de saúde que visam oferecer uma melhor prestação de cuidados aos seus pacientes (WILBUR, 2016). Todavia, barreiras de ordem sociogeográfica, cultural e temporal podem prejudicar a manutenção destas competências e habilidades por parte dos profissionais presencialmente, fazendose necessária a utilização de estratégias, como a telessaúde. A telessaúde consiste no uso da tecnologia 
da informação para permitir a comunicação a distância entre profissionais da saúde (BERNARDES; COIMBRA; SERRA, 2018; WANDERLEI; MONTAGNA, 2018).

Em 2007, surgiu o Programa Nacional Telessaúde Brasil Redes com o objetivo de desenvolver atividades técnicas, científicas e administrativas para planejamento, execução, monitoramento e avaliação de ações de telessaúde (BRASIL, 2015). Uma das atividades desse programa é a teleeducação, ou e-learning, constituída por atividades educacionais, sob a forma de cursos, conferências ou aulas, que são ministradas à distância através de tecnologias da informação e comunicação (BRASIL, 2015; BAVARESCO et al, 2019).

Com a pandemia da COVID-19 e as medidas sanitárias implementadas, a tele-educação tornou-se indispensável na atualização das habilidades e competências dos profissionais de saúde, uma vez que tornou possível a colaboração entre profissionais de saúde do mundo inteiro no processo de aquisição de novos conhecimentos e aprimoramento dos já existentes (WIJESOORIYA et al, 2020).

Logo, este trabalho objetiva relatar a realização de cursos remotos voltados aos profissionais de saúde durante a pandemia da COVID-19.

\section{METODOLOGIA}

Trata-se de um relato de experiência sobre cursos componentes das atividades do projeto de extensão "Telessaúde como suporte para assistência de pacientes com COVID-19" e que foram ofertados a profissionais de saúde, incluindo residentes médicos e multiprofissionais, que fazem parte da IV Gerência Regional de Saúde de Pernambuco (IV GERES-PE). O projeto foi idealizado e executado pela Universidade Federal de Pernambuco (UFPE) em parceria com a IV GERES-PE.

O projeto de extensão tem, entre seus objetivos, a capacitação dos profissionais de saúde da rede municipal da IV GERES-PE para o atendimento de pacientes com COVID-19. Assim, são contemplados cursos de capacitação e a produção de protocolos e notas técnicas voltados para este fim. Foram envolvidos no projeto professores e estudantes do curso de medicina do Campus Acadêmico do Agreste da UFPE.

A partir das especialidades dos professores envolvidos e das competências necessárias para o enfrentamento da pandemia, foram ofertados dois cursos, de maneira remota, com os temas: "Paramentação e Desparamentação no contexto da COVID-19" ("Curso A") e "Cuidados Paliativos no contexto da COVID-19" (“Curso B"), que posteriormente puderam ser avaliados por seus participantes através de uma pesquisa de opinião utilizando formulário online, na plataforma Google Forms. 


\section{RESULTADOS E DISCUSSÕES}

Visando o respeito à recomendação do isolamento social, os cursos foram estruturados no formato remoto e ofertados através do Ambiente Virtual de Aprendizagem (AVA) da UFPE. As aulas foram realizadas de forma assíncrona e os materiais didáticos foram disponibilizados no AVA para que, cada inscrito, estabelecesse seu ritmo próprio de estudo. Como os cursos foram formatados para serem autoinstrucionais, não havia tutor disponível para os participantes.

$\mathrm{O}$ "Curso A" trouxe os principais protocolos envolvidos na paramentação dos profissionais de saúde, visando uma diminuição na chance de contaminação destes durante a execução de seu trabalho. Além disso, versou também sobre as principais técnicas para uma desparamentação segura, objetivando evitar esta contaminação também no momento de troca dos Equipamentos de Proteção Individual (EPIs). Já o "Curso B" tratou de temáticas como: as indicações dos cuidados paliativos para pacientes com COVID-19, a sensibilização do olhar para identificação de pacientes em processo ativo de morte e a condução destes casos e o tratamento adequado dos sintomas mais comuns dos pacientes com COVID-19 em cuidados paliativos.

Os professores do curso de medicina ficaram responsáveis pela elaboração do material didático e pela condução das aulas, enquanto os estudantes elaboraram os questionários de avaliação e acompanharam o preenchimento destes para tabulação dos dados.

Com relação à avaliação dos cursos, dos 109 profissionais inscritos no "Curso A", 92 participantes iniciaram as atividades propostas, 16 finalizaram o curso e 19 responderam ao formulário de avaliação. No "Curso B”, dos 89 inscritos, 73 iniciaram as atividades, 8 concluíram e 4 enviaram suas avaliações. A distribuição das profissões dos inscritos em cada curso está representada na Figura 1.

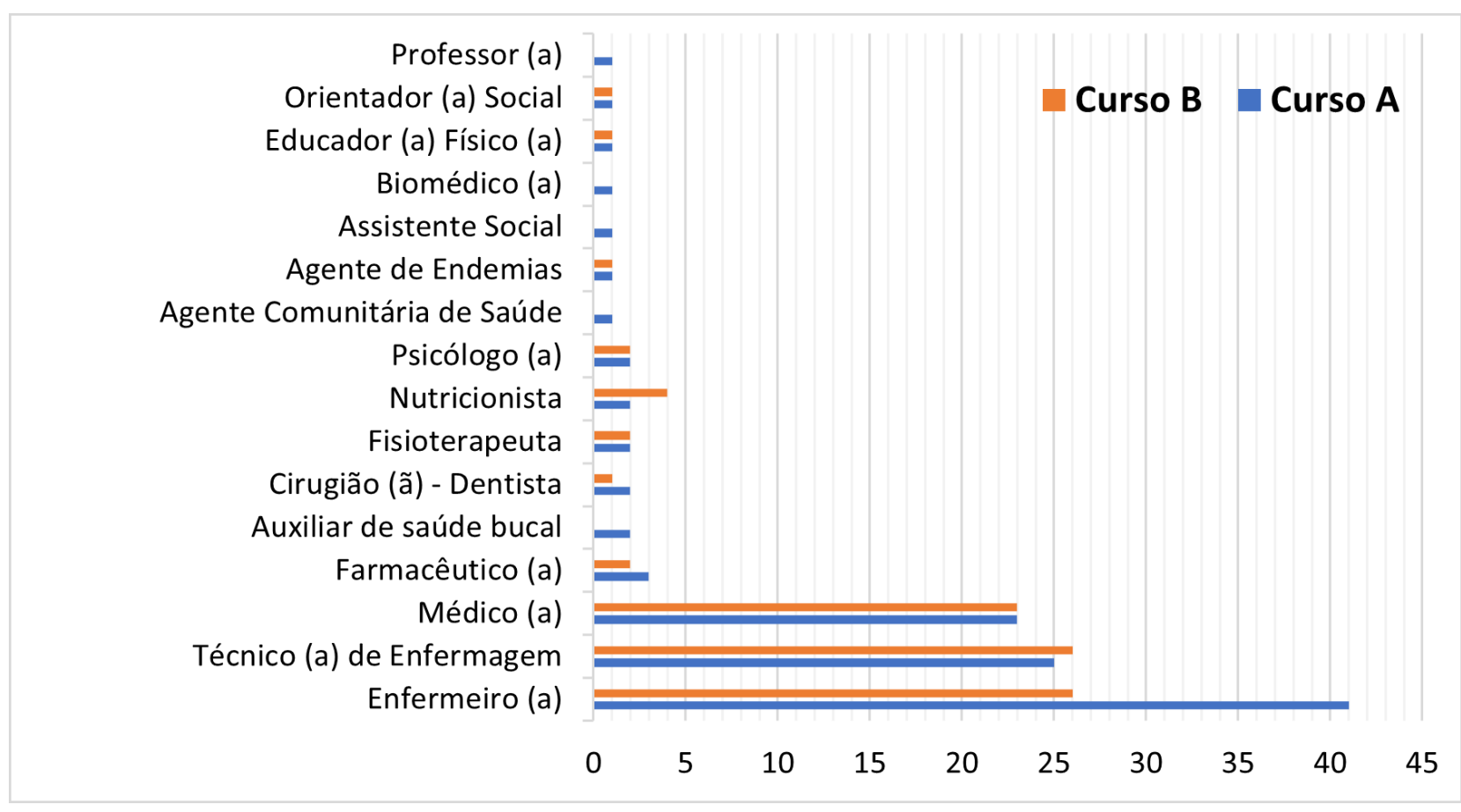


Fonte: Elaborado pelos próprios autores.

Quando questionados sobre a classificação do conhecimento prévio na temática do curso, 52,6\% dos participantes do "Curso A" classificaram como "ótimo" e 42,1\% como "regular", não havendo ninguém que classificasse como "ruim" ou "péssimo". Para o "Curso B", 75\% dos profissionais classificaram seu conhecimento prévio como "regular" e 25\% como "ótimo". Com relação à aquisição de novos conhecimentos, 94,7\% e 100\% dos participantes dos "Cursos A e B", respectivamente, afirmaram que obtiveram novos aprendizados. No que diz respeito ao impacto na prática profissional, $100 \%$ dos entrevistados de ambos os cursos confirmaram um impacto positivo destes. Além disso, a metodologia utilizada também foi avaliada pelos participantes, sendo considerada "ótima" por 94,7\% e $100 \%$ dos inscritos nos "Cursos A e B", respectivamente. Por fim, o AVA também teve uma boa aceitação dos profissionais, sendo considerado "ótimo" por 73,7\% dos profissionais que participaram do "Curso A" e por $100 \%$ dos que participaram do "Curso B'.

\section{CONCLUSÃO}

Observa-se que, no contexto pandêmico de impossibilidade de realização de cursos presenciais associado a uma necessidade massiva de atualização profissional na área da saúde, a tele-educação mostra-se uma importante ferramenta para aquisição de novos conhecimentos, bem como para o aprimoramento dos já existentes.

\section{PRINCIPAIS REFERÊNCIAS}

BAVARESCO, C. S. et al. Satisfaction of Primary Healthcare Dentists after the Completion of a Distance Learning Course in Pediatric Dentistry. Iranian Journal of Public Health, v. 48, n. 8, p. 1439-1444, 2019.

BERNARDES, A. C. F.; COIMBRA, L. C.; SERRA, H. O. Utilização do Programa Telessaúde no Maranhão como ferramenta para apoiar a Educação Permanente em Saúde. Revista Panamericana de Salud Pública, v. 42, p. 1-9, 2018.

BRASIL. NOTA TÉCNICA N 50/2015 - DEGES/SGTES/MS: Diretrizes para Oferta de Atividades do Programa Nacional Telessaúde Brasil Redes. Brasília: Ministério da Saúde, 2015.

WANDERLEI, P. N.; MONTAGNA, E. Formulation, implementation and evaluation of a distance course for accreditation in patient safety. Einstein (São Paulo), v. 16, n. 2, p. 1-8, 28 jun. 2018.

WIJESOORIYA, N. R. et al. COVID-19 and telehealth, education, and research adaptations. Paediatric Respiratory Reviews, v. 35, p. 38-42, set. 2020. 
WILBUR, K. Evaluating the online platform of a blended-learning pharmacist continuing education degree program. Medical Education Online, v. 21, n. 1, p. 31832-31836, jan. 2016. 


\title{
PALHAÇOTERAPIA COMO FERRAMENTA DE EDUCAÇÃO EM SAÚDE ACERCA DA HANSENÍASE: RELATO DE EXPERIÊNCIA
}

\section{Elivelton Sousa Montelo후 Amanda Azevedo Torres²; Alexia Jade Machado Sousa ${ }^{3}$; Andréia Ferreira dos Santos' ${ }^{4}$ Maria Samara Da Silva'; Amanda Célis Brandão Vieira ${ }^{6}$; Eneida Anjos Paiva $^{7}$}

${ }^{1}$ Acadêmico de Fisioterapia, Universidade Federal do Delta do Parnaíba (UFDPar), Parnaíba, Piauí. ${ }^{2}$ Acadêmica de Medicina, Universidade Federal do Delta do Parnaíba (UFDPar), Parnaíba, Piauí.

${ }^{3}$ Acadêmica de Psicologia, Universidade Federal do Delta do Parnaíba (UFDPar), Parnaíba, Piauí. ${ }^{4}$ Acadêmica de Medicina, Universidade Federal do Delta do Parnaíba (UFDPar), Parnaíba, Piauí. ${ }^{5}$ Pós Graduanda em Fisioterapia na Saúde da Mulher, Aprimore, Teresina, Piauí. ${ }^{6}$ Pós Graduanda em Fisioterapia na Saúde da Mulher, Inspirar, Teresina, Piauí. ${ }^{7}$ Prof ${ }^{a}$ do curso de Medicina, Universidade Federal do Delta do Parnaíba (UFDPar), Parnaíba, Piauí. DOI: $10.47094 /$ ICONRES.2021/4

\begin{abstract}
RESUMO
Introdução: Hanseníase é uma doença crônica que pode ser transmitida por fluidos orais. Diversos fatores atrasam o diagnóstico, como: busca tardia de atendimento e falta de informação sobre sintomatologia. A educação em saúde são práticas que buscam promoção e prevenção de saúde nos diversos níveis de complexidade. A palhaçoterapia busca melhorar a situação psicológica de populações vulneráveis, contribuindo para um cuidado multidisciplinar, tendo a alegria como instrumento e o palhaço como intérprete. Objetivo: Relatar a experiência de uma prática de educação em saúde sobre hanseníase, utilizando a palhaçoterapia. Método: relato de uma experiência realizada em Parnaíba-PI. A prática utilizou-se da palhaçoterapia para educar sobre hanseníase. Resultados e discussão: Os diálogos remetiam às dúvidas sobre fisiopatologia, transmissão, sintomatologia e histórico. Conclusão: A palhaçoterapia é uma potente ferramenta de educação em saúde, sobretudo, pelo impacto positivo do humor e da ludicidade em captar atenção dos ouvintes e pelo estado de bemestar provocado.
\end{abstract}


PALAVRAS-CHAVES: Doenças Negligenciadas; Humor; Humanização dos Serviços.

ÁREA TEMÁTICA: Educação em Saúde

\section{INTRODUÇÃO}

Define-se hanseníase como uma doença infectocontagiosa de evolução crônica, causada pela bactéria Mycobacterium leprae, de baixa patogenicidade e alta infectividade e que acomete os nervos periféricos e pele, podendo ser transmitida por meio de fluidos orais (NASCIMENTO C et al., 2019). Segundo a Organização Mundial da Saúde (OMS) o Brasil é o segundo país mais acometido pela patogenia, com $12,5 \%$ de casos registrados no mundo. A apesar da diminuição dos casos a cada ano, o país ainda não atingiu a meta de eliminação da doença, o que faz ainda desse cenário um problema de saúde pública (FREITAS BHBM et al., 2019).

Ademais, diversos fatores contribuem para o atraso no diagnóstico da doença, entre eles, pontua-se: a busca tardia de atendimento nos serviços de saúde, a falta de informação da população sobre sinais e sintomas, a dificuldade dos indivíduos em encontrar serviços especializados de saúde para detecção e tratamento da doença. Diante disso, apresenta-se como ferramenta para enfrentamento da hanseníase a Vigilância em Saúde, com execução de práticas de saúde adequadas, que garantam não só a detecção e o tratamento da doença, mas também a educação em saúde (COSTA AKAN, et al., 2018).

Entende-se como educação em saúde um campo de conhecimento e de práticas que buscam promoção e prevenção de saúde nos diversos níveis de complexidade do processo adoecimento em todo o ciclo de vida humana. Assim, é compreendida como o processo de aprendizagem teórico-prático que possui o objetivo de integrar diversos saberes, como o científico, o popular e o do senso comum, possibilitando que os indivíduos envolvidos desenvolvam uma visão crítica acerca da produção do cuidado e autocuidado em saúde (RAMOS CFV, et al., 2018)

A educação em saúde consiste em uma das ações mais importantes dos serviços de atenção primária a saúde (APS), podendo ser executada por todos os profissionais de saúde, independente do cargo exercido nestas instituições (RIBEIRO KG, et al. 2018). Diante dessa premissa multiprofissional, no âmbito da APS, são os agentes comunitários de saúde (ACS) que possuem a função de serem pontes de conhecimentos do universo cientifico para o popular, sendo assim importantes facilitadores do acesso da população aos cuidados de saúde, aumentando o alcance da educação em saúde como instrumento modificador de posturas e hábitos (MIALHE FL, et al., 2018).

Nessa perspectiva, a educação em saúde se fundamenta de acordo com a Política Nacional de Humanização (HumanizaSUS) que define humanização como estratégia de interferência no processo de produção de saúde, levando-se em conta que sujeitos sociais, quando mobilizados, são capazes de transformar realidades, transformando a si próprios nesse mesmo processo. Dessa forma, entende-se que as práticas de saúde devem propiciar aos pacientes ferramentas que vão além da prática clínica e 
do modelo biomédico (BRASIL, 2004).

Em linha com a HumanizaSUS, métodos como a palhaçoterapia têm por finalidade melhorar a situação psicológica de populações em risco, e atuar como promotores de saúde, contribuir para um cuidado inter e multidisciplinar, construir espaço onde os profissionais possam dar liberdade para expor a sua criatividade, estimular a manifestação da imaginação dos ouvintes e o desenvolvimento de sua autonomia, além de encurtar os espaços entre os diversos atores dos ambientes de saúde, tendo a alegria como instrumento e o palhaço como intérprete (MARINHO ADM, 2015). Com isso, o objetivo desse trabalho é relatar a experiência de uma prática de educação em saúde sobre hanseníase, utilizando a palhaçoterapia, organizada por ACS de Parnaíba - PI e por participantes do PET-Saúde/ Interprofissionalidade.

\section{METODOLOGIA}

Trata-se de um estudo descritivo do tipo relato de experiência. A atividade foi realizada em novembro de 2019 no Hospital Colônia do Carpina (HCC), no bairro Frei Higino em Parnaíba-PI. A prática de educação em saúde proposta foi executada pelo grupo Teatro dos Agentes Comunitários de Saúde (TACS), utilizando-se da figura do Clown em sua performance para repassar informações acerca da hanseníase. A plateia presente era composta por funcionários e moradores do HCC, equipes da APS de Parnaíba-PI, integrantes da Vigilância Epidemiológica (representando a gestão municipal), a população adscrita do território, os participantes do Movimento de Reintegração da Pessoa com Hanseníase (MORHAN), e, como organizadores do encontro, os integrantes do PETSaúde/Interprofissionalidade.

\section{RESULTADOS E DISCUSSÃO}

A ação de palhaçoterapia desenvolvida pelo grupo TACS foi o marco inicial de uma sequência de atividades que visava compreender a linha de cuidado e prevenção relacionada à hanseníase em Parnaíba-PI, além de promover uma articulação entre os atores institucionais e sociais ali presente. A apresentação iniciou às $9 \mathrm{~h}$ da manhã, ao ar livre, no ambiente externo do HCC, o grupo de palhaços entrou em cena, a caráter, portando instrumentos musicais e entoando canções autorais do grupo.

Logo após, deu início às cenas com diálogos entre os personagens que remetiam às dúvidas, estigmas e informações usualmente distorcidas sobre a hanseníase. Nesse momento, o grupo promoveu educação em saúde ao dinamizar o conhecimento científico sobre a fisiopatologia, cadeia de transmissão, sinais e sintomas, estigmas sobre a doença e um pouco sobre o HCC no contexto histórico do processo de isolamento compulsório dos atingidos pela hanseníase. O espetáculo prendeu a atenção do público enquanto promovia risadas dos presentes, utilizando-se de piadas bem colocadas, com um humor limpo e informações pertinentes, o tema hanseníase foi tratado com muita delicadeza e esclarecimento. 
Assim, a ação cumpriu com o que é preconizado na humanização no contexto da saúde, com a inserção de grupos que envolvam vários sujeitos e setores na modificação da cultura institucional do modelo biomédico, tornando-a mais humanizada (SILVA CPR, et al., 2017). Nesse cenário, pontuase que entre os sujeitos presentes, estavam os moradores do HCC e usuários do próprio território e territórios vizinhos, essa participação ressalta a importância de tais ações educativas e o protagonismo da comunidade nas práticas de educação em saúde, empoderando-a em relação ao autocuidado e a fim de quebrar paradigmas sobre a doença (ARAÚJO AP, 2017).

Como ferramenta para a educação em saúde, a palhaçoterapia visa fazer a ponte entre o cuidar eficiente a um cuidar mais humano, de acordo com a definição ampliada da saúde, que considera o ser humano como um todo em suas multiplicidades, para além do corpo físico. A centralidade deixa de ser a doença, o doente ou seus sintomas físicos e passa a ser a pessoa, sua nova realidade institucionalizada e os sentimentos consequentes dessas alterações (CATAPAN SC, 2017). Ademais, tendo em vista a participação e as boas risadas dos pacientes do HCC, ressalta-se a importância do humor ou terapia clown como uma alternativa lúdica para idosos institucionalizados, proporcionando alegria, descontração, ao mesmo tempo em que auxilia na manutenção da saúde e qualidade de vida (PIRES WGB, et al., 2015).

Segundo Silva e Paz (2010), para os profissionais da saúde, a educação em saúde é uma atividade primordial centrada na transmissão de informações, tanto aos portadores de hanseníase, como também à população como um todo. A participação dos usuários dos serviços durante atividades educativas é essencial, pois se tornam espaços de esclarecimento. A partir disso, quanto mais informação, melhor será o enfrentamento da doença.

Além disso, é necessário que os profissionais instruam os portadores da doença e a população em geral sobre o problema da hanseníase, sendo responsáveis por melhorar o conhecimento da população, não apenas dos que estão em tratamento, mas também daqueles que convivem com os portadores. Se inteirar e compreender as atividades educativas como fundamentais ao processo terapêutico no plano individual (SILVA MCD, PAZ EPA, 2010). Ainda é possível se observar grande carga de estigma e preconceito quanto à hanseníase, o que dificulta a execução de medidas de controle e também de profilaxia. Desse modo, a educação em saúde se mostra como um instrumento necessário para o esclarecimento de suas consequências e suas formas de prevenção (COROLIANO-MARINUS, 2012 citado em MOREIRA AJ et al., 2014).

\section{CONCLUSÃO}

Portanto, conclui-se que a palhaçoterapia é uma potente ferramenta quando usada em ações de educação em saúde, sobretudo, pelo impacto positivo do humor e da ludicidade em captar atenção dos ouvintes e pelo bem-estar provocado pelo riso. Nota-se também a importância de ações educativas, como essa, baseadas nas diretrizes do HumanizaSUS, sobre doenças negligenciadas como a hanseníase, afim de promover auto cuidado e autonomia de conhecimento quanto à prevenção e a 
quebra de paradigmas que envolve o histórico de estigmas sobre a doença.

\section{PRINCIPAIS REFERÊNCIAS}

DE SOUZA, Ronimara Gonçalves; LANZA, Fernanda Moura; SOUZA, Raissa Silva.

Sensibilização dos Agentes Comunitários de Saúde para a atuação nas ações prevenção e controle da hanseníase: relato de experiência. HU Revista, v. 44, n. 3, p. 411-415, 2018.

FREITAS, Bruna Hinnah Borges Martins de et al. Práticas educativas sobre laenfermedad de Hansen (Lepra) con adolescentes: revisión integrativa de la literatura. Revista Brasileira de Enfermagem, v. 72, n. 5, p. 1397-1404, 2019.

NASCIMENTO COSTA, Ana Karla Araújo et al. ASPECTOS CLÍNICOS E EPIDEMIOLÓGICOS DA HANSENÍASE. Journal of Nursing UFPE/Revista de Enfermagem UFPE, v. 13, n. 2, 2019.

SILVA, Maria Cristina Dias; PAZ, Elisabete Pimenta Araújo. Educação em saúde no programa de controle da hanseníase: a vivência da equipe multiprofissional. Esc. Anna Nery, Rio de Janeiro, v. 14, n. 2, p. 223-229, June 2010. 


\title{
USO DO 'SOCRATIVE' COMO FERRAMENTA DE ENSINO NA ÁREA DA SAÚDE: REVISÃO DE INTEGRATIVA
}

\section{Larissa Artimos Ribeiro', Amanda Curiel Trentin Corral' ${ }^{2}$, Gisella de Carvalho Queluci ${ }^{3}$}

${ }^{1}$ Graduanda em Enfermagem da Escola de Enfermagem Alfredo Pinto, Universidade Federal do Estado do Rio de Janeiro (UNIRIO), Rio de Janeiro, RJ.

${ }^{2}$ Graduanda em Enfermagem da Escola de Enfermagem Alfredo Pinto, Universidade Federal do Estado do Rio de Janeiro (UNIRIO), Rio de Janeiro, RJ.

${ }^{3}$ Doutora em Enfermagem, Professora Associada do Departamento de Enfermagem Fundamental da Escola de Enfermagem Alfredo Pinto, Universidade Federal do Estado do Rio de Janeiro (UNIRIO), Rio de Janeiro, RJ.

\begin{abstract}
RESUMO
Introdução: Há busca pelo aprimoramento do ensino e superação das dificuldades de atualização das metodologias ativas. Assim, a incorporação de plataformas em diferentes cenários da formação como complemento vem sendo utilizadas, como o aplicativo 'Socrative'. Objetivo: Revisar a literatura acerca do uso do 'Socrative' nos cursos da Saúde. Metodologia: Trata-se de uma revisão integrativa para responder à pergunta "Quais as contribuições do uso do Socrative na aprendizagem do estudante da área da Saúde?". Foram utilizadas as bases SciELO e Google acadêmico, com a palavrachave "Socrative' AND aprendizagem" em português e espanhol. Sendo selecionados 7 estudos. Fundamentação teórica: Os temas em destaque foram o aumento da motivação e o interesse dos discentes, a importância do 'software' na resolução de questões e dentre as desvantagens a limitação de alunos e a acessibilidade. Considerações finais: Há escassez de estudo nessa área sendo um campo em potencial para atuação e pesquisa.
\end{abstract}

PALAVRAS-CHAVES: Tecnologia Educacional; Aprendizagem; Metodologias Ativas.

ÁREA TEMÁTICA: Educação em saúde

\section{INTRODUÇÃO}

A forma de aprender já mudou e o uso da tecnologia está à frente desta transformação. Seja com o uso do celular, computador, smart tv ou tablet as pessoas se comunicam, interagem, trabalham, se divertem em uma velocidade diferente dos anos anteriores. Essa interação dinâmica, colaborativa e veloz também chegou ao ensino-aprendizagem. 
A incorporação de tecnologias no ensino vem ajudando a manter os alunos interessados e menos dispersos, além de tornar a aula mais dinâmica e menos em formato de palestra. Saindo dos modelos tradicionais de ensino e incorporando metodologias ativas. Contudo, tornar essas aulas mais dinâmicas não pode onerar os estudantes, por isso, o uso de aplicativos disponíveis gratuitos tanto em IOS quanto para Android é essencial.

Dessa forma é possível incorporar o uso dessas plataformas em diferentes cenários da formação em saúde como complemento das aulas presenciais, que são o princípio básico dos cursos, e não para substituição ou aprovação de um "possível” ensino à distância. Os cursos da área da saúde lidam diariamente com a busca pelo aprimoramento do ensino e superação das dificuldades de atualização das metodologias ativas.

Assim sendo, o "Socrative” é um 'software' de fácil aplicação e gratuito que pode ser usado na elaboração de questionários (testes, quizzes, entre outros) em sala de aula física ou em atividades remotas para receber feedback em tempo real da aprendizagem do aluno. Por isso, o estudo visa reunir e sintetizar achados do uso do "software' "Socrative" como ferramenta de ensino e aprendizagem na área da saúde.

\section{METODOLOGIA}

Trata-se de uma revisão integrativa da literatura, desenvolvida a partir das seguintes etapas: Definição do tema e elaboração da pergunta norteadora, busca na literatura, coleta de dados, análise crítica dos estudos incluídos, discussão dos resultados e apresentação da revisão. A questão norteadora para o estudo foi: "Quais as contribuições do uso do Socrative na aprendizagem do estudante da área da Saúde?"

A busca dos estudos ocorreu no período de setembro, outubro e novembro de 2020. Os critérios de inclusão foram: publicações em português e espanhol, que corresponda aos anos de 2015 a 2020, que contemplassem o uso do "software' "Socrative", que apresentasse no título, assunto ou no resumo as palavras chaves utilizadas na busca e indexados na base de dados SciELO e Google Acadêmico. Em relação aos critérios de exclusão apresentam-se: teses e dissertações, estudo cujo foco seja outros 'softwares' e aplicativos de ensino, artigos duplicados ou com fragilidades metodológicas e artigos que mencionam o "Socrative" sem ter utilizado o 'software' na prática ou que utilizaram fora do campo de ensino da área da saúde.

Para a realização da busca foram utilizadas as seguintes palavras-chave: "Socrative" AND aprendizagem" ou "Socrative" AND “aprendizaje". Nessa busca, foram identificados 6 artigos científicos na base de dados SciELO e 585 publicações no Google Acadêmico. Dessa forma, foram analisados 52 resumos e 7 publicações foram selecionadas como objeto de estudo, por apresentarem aspectos que respondiam à questão norteadora desta revisão, incluíam-se nos critérios de inclusão e não foram descartados pelos critérios de exclusão. 


\section{FUNDAMENTAÇÃO TEÓRICA}

Da análise do conteúdo das publicações emergiram 3 categorias temáticas: 1) Vantagens do uso do "Socrative" para o aprendizado dos discentes; 2) Contribuições do uso do "Socrative" na resolução de questões; 3) Desafios na implementação do "Socrative".

Em relação às vantagens do uso do "Socrative" para o aprendizado dos discentes, Costa et. al (2018), nos seus estudos, constatou que o "software" torna o estudo mais fácil, dinâmico e desperta um maior interesse nos alunos em aprender, devido ao uso do "Socrative" ser uma novidade para a maioria dos discentes do curso de medicina da Instituição. Oliveira et al. (2019) verificou que na formação médica as tecnologias de ensino, como o uso do "Socrative", buscam romper com o ensino tradicional e vem para inovar na educação, desenvolvendo habilidades e autonomia nos estudantes, além de, estimular a criatividade, o trabalho em equipe e ajudar na motivação dos discentes em adquirir novos conhecimentos. Já Frías et al. (2016) utilizou o "Socrative" com alunos dos cursos de odontologia, química e farmácia e constatou uma boa adesão e rápida adaptação dos alunos no uso do "software", além de, determinar que grande parte dos estudantes se sentiram mais motivados e consideraram que o "Socrative" ajudou no aprendizado e na revisão de conceitos.

No que se refere às contribuições do uso do "Socrative" na resolução de questões, Lagunas et al. (2017) constatou que devido ao 'software' ter a opção de realizar as questões sem ter que colocar o nome, há uma maior participação por parte dos alunos. Outro ponto abordado, foi o fato do feedback ser instantâneo e ser possível avaliar a quantidade de acertos da turma no geral e individualmente, o que permite relembrar conceitos ensinados, se necessário. Segundo Jesus, et al. (2017) a realização dos quizzes e os feedbacks instantâneos estimularam o debate sobre diversos assuntos e conteúdos, a opção do anonimato contribui para uma maior participação dos alunos e a modalidade preferida e mais dinâmica para os estudantes no "Socrative" é o Space Race, visto que é uma estratégia de gamificação, no qual equipes de discentes competem para responderem as questões, o que torna a ferramenta mais atrativa e motivadora.

Sobre os desafios na implementação do "Socrative", Gomes et al. (2020) constata que alguns alunos do curso de enfermagem não tinham acesso à internet ou a um smartphone, sendo necessário nesses casos a realização de atividades em grupo no "Socrative" para ter a participação de todos os discentes. Entretanto, o uso do 'software' foi considerado prazeroso e eficaz na construção do conhecimento. Já Vega et al. (2020) e Lagunas (2017) abordam o fato do "Socrative" possuir a limitação de só permitir o uso de 50 alunos simultaneamente na modalidade gratuita e 150 alunos na versão paga.

\section{CONSIDERAÇÕES FINAIS}

A utilização de dispositivos conectados a internet como método de ensino vem despontando como uma importante ferramenta de educação e traz muitos benefícios aos estudantes. Esse estudo permitiu analisar o uso do 'Socrative' nos cursos da área da saúde e revelou que a utilização dessa 
ferramenta motiva, atrai e aumenta a participação dos discentes, visto que, as aulas ficam cada vez mais interativas e motivadoras. Além disso, os questionários e feedbacks instantâneos tornam a resolução de questões mais práticas e dinâmicas, permitindo a revisão de conteúdos e o monitoramento da aprendizagem. As dificuldades na implantação estão associadas, principalmente, à acessibilidade e ao limite simultâneo de alunos na plataforma, por isso torna-se importante avaliar a turma e suas necessidades antes da aplicação do "Socrative" e se necessário pensar em alternativas como a de dividir a classe em grupos.

Identificou-se esse campo de atuação e pesquisa como um setor de grande potencial, porém ainda pouco explorado. Dessa forma, se faz necessário, maiores investigações e estudos mais detalhados para apurar sua eficácia e possíveis pontos de fragilidade, assim como necessidades de melhorias.

\section{PRINCIPAIS REFERÊNCIAS}

COSTA, Tales da; SOUZA, Joana Marques Maia; PASE, Camila Simonetti. Avaliação do uso do "Socrative" em atividades de monitoria de farmacologia para estudante de medicina. Anais do Salão Internacional de Ensino, Pesquisa e Extensão, v. 10, n. 1, 2018. Disponível em: https://periodicos.unipampa.edu.br/index.php/SIEPE/article/view/86406. Acesso em: 08 de out. 2020

FRÍAS, María Verónica; ARCE, Christian; MORALES, Patricio Flores. Uso de la plataforma “'Socrative”.com para alumnos de Química General. Rev. Educación Química, v.27, n.1, January, 2016, p. 59-66. Disponível em: https:/www.sciencedirect.com/science/article/pii/ S0187893X15000658. Acesso em: 18 de set. 2020.

GOMES, Flávia Carolina Ferreira et al. Uso do "Socrative" como ferramenta de ensino aprendizagem na graduação em enfermagem. Braz. J. of Develop., Curitiba, v. 6, n.11, p.91456 - 91465, nov. 2020. Disponível em: https://www.brazilianjournals.com/index.php/BRJD/article/ view/20407/16313. Acesso em: 30 de nov. 2020.

JESUS, Ângelo et al. A aprendizagem colaborativa com o 'Socrative". CNaPPES, 187 190, 2017. Disponível em: https://recipp.ipp.pt/handle/10400.22/14258. Acesso em: 15 de set. 2020.

LAGUNAS, María José Rodríguez et al. Amenizar las clases de Fisiología con la aplicación 'Socrative". FEM (Ed. impresa) vol.20, supl.1 Barcelona jul. 2017. Disponível em: http://scielo. isciii.es/scielo.php?script=sci_arttext\&pid=S201498322017000700010\&lng=es\&nrm=iso\&tlng=es. Acesso em: 10 de out. 2020.

OLIVEIRA, Alisson Martins et al. Aplicação combinada de Metodologia Ativa e tecnologia de informação e comunicação no ensino médico: um relato de experiência. Anais do Seminário de Atualização de Práticas Docentes, v.1, n.2, 2019. Disponível em: http://anais.unievangelica.edu.br/ index.php/praticasdocentes/issue/view/120/Edi\%C3\%A7\%C3\%A3o\%20Completa\%20-\%20PDF. Acesso em: 28 de nov. 2020. 
VEGA, Iván Fernández. Utilización de la aplicación "Socrative" en la asignatura de anatomía patológica del Grado en Medicina. FEM (Ed. impresa), v.23 n.3 Barcelona jun. 2020. Disponível em: http://scielo.isciii.es/scielo.php?script=sci_arttext\&pid=S201498322020000300004\&lng=es\&nrm=iso. Acesso em: 13 de nov. 2020. 


\title{
PERFIL DE AUTOMEDICAÇÃO EM UMA UNIDADE BÁSICA DE SAÚDE NO INTERIOR DO CEARÁ
}

\author{
Alice de Oliveira Silva ${ }^{1}$; Darcielle Bruna Dias Elias²; Naiane Nadylla Nobre Sombra ${ }^{3}$ \\ ${ }^{1}$ Farmacêutica especialista em análises clínicas, Faculdade Vale do Jaguaribe (FVJ), Aracati, Ceará. \\ ${ }^{2}$ Professora Dra. da Faculdade do Vale do Jaguaribe, Faculdade Vale do Jaguaribe (FVJ), Aracati, \\ Ceará. \\ ${ }^{3}$ Acadêmica do curso de farmácia, Centro Universitário Maurício de Nassau (UNINASSAU), \\ Fortaleza, Ceará.
}

\begin{abstract}
RESUMO
Introdução: A automedicação é a prática na qual o paciente decide fazer uso de medicamento sem prescrição médica, buscando alivio de algum sintoma ou tratar problemas de saúde menores. A presença do farmacêutico é importante para garantir eficácia, segurança e prescrição posológica adequada do medicamento. Objetivo: Identificar o perfil de pacientes que praticam automedicação atendidos numa unidade básica de saúde e seus fatores associados. Metodologia: Pesquisa de campo do tipo transversal, descritivo e quantitativa, relacionando variáveis e automedicação. Resultados e Discussão: Os resultados demonstraram que mulheres, indivíduos de baixa escolaridade e baixo poder aquisitivo são as que mais realizam essa prática. Conclusão: Percebe-se a necessidade do farmacêutico na automedicação responsável, conhecimentos, orientações sobre medicamentos a população, visando uso racional e conscientização dos efeitos adversos. Principais Referências: BRASIL. Ministério da Saúde. Secretaria de Políticas de Saúde. Automedicação. Biblioteca Virtual em Saúde. 2015. Disponível em: < http://bvsms.saude.gov.br/dicas-em-saude/698-automedicacao> Acesso em: 26 nov. 2019.
\end{abstract}

PALAVRAS-CHAVES: Educação em saúde; Medicamento; Saúde pública.

ÁREA TEMÁTICA: Educação em saúde

\section{INTRODUÇÃO}

De acordo com o Ministério da Saúde (2015) a automedicação é a prática na qual o paciente decide por conta própria fazer uso de algum medicamento sem a prescrição médica, buscando o alivio imediato de algum sintoma ou tratar problemas de saúde menores que ele mesmo reconhece, contudo essa pratica pode trazer graves consequências (PICON et al., 2014). 
A disponibilidade de informações seguras, confiáveis e atualizadas é de suma importância para garantir o uso racional de medicamento, tendo em vista que na maioria das vezes tais informações não chegam até o interessado, que muitas vezes é um usuário de medicamentos totalmente leigo e não reconhece a importância de informações sobre o medicamento do qual faz uso, levando, em alguns casos, ao uso desnecessário de medicamentos, ou o uso em condições contraindicadas, o que pode expor o paciente ao risco de Reações Adversas a Medicamentos (RAM) e em casos mais graves, até mesmo intoxicações (LIMA et al., 2008).

É fundamental que o farmacêutico esteja integrado na atenção básica a saúde, focando no paciente e não apenas no medicamento. Além disso, a ação do farmacêutico garantirá que o medicamento seja eficaz, seguro e prescrito na posologia adequada, tendo como resultado o efeito terapêutico desejado e diminuindo as reações adversas. (JOAQUIM, 2011; RIBEIRO; OKAMOTO, 2019).

Destaca-se ainda que o profissional farmacêutico dentro de suas habilitações é o único profissional da equipe de saúde que tem sua formação fundamentada na articulação de conhecimentos das áreas biológicas e exatas, sendo capaz de prestar orientação ao paciente quanto ao uso correto dos medicamentos, a disponibilização de informações técnicas sobre os medicamentos e dispensálos de forma controlada, constituindo essa uma das soluções para a diminuição da automedicação (FERREIRA; NOBREGA, 2012; DUARTE; MALTAJUNIOR, 2015). Frente ao exposto, esta pesquisa visa especificar as características do perfil de pacientes que praticam a automedicação atendidos em uma Unidade Básica de Saúde no interior do Ceará e os fatores associados a essa prática.

\section{METODOLOGIA}

O presente estudo constitui uma pesquisa de campo do tipo transversal, descritiva com abordagem quantitativa. Realizou-se uma entrevista com questionário semiestruturado com perguntas abertas e objetivas com variáveis de sexo, idade, escolaridade e automedicação aos pacientes os quais buscaram atendimento em uma Unidade Básica de Saúde (UBS) localizada na cidade de RussasCe, no período de outubro de 2019. Houve um total de 105 participantes, incluídos na pesquisa os pacientes com idade igual e superior a 18 anos, de ambos os sexos, excluídas crianças, gestantes e pacientes que não praticavam automedicação.

Analisou-se os dados coletados por meio de estatísticas simples, elaborados no programa Microsoft Office Excel. Foram apresentados aos participantes o Termo de Consentimento Livre e Esclarecido (TCLE) e seguidos aspectos éticos de acordo com o exigido pelo Ministério da Saúde, deste modo, sendo submetido ao comitê de Ética em pesquisa da Plataforma Brasil, aprovado sob o Parecer n 3.572.117, de acordo com as normas da Resolução Nº466/2012. 


\section{RESULTADOS E DISCUSSÕES}

Das 105 pessoas que estiveram presentes na UBS em outubro de 2019, 15 foram excluídos por não praticar automedicação. Dentre os indivíduos pesquisados, $86 \%$ admitiu praticar a automedicação. Em 2011, Mayolo e colaboradores investigou a prática da automedicação em uma drogaria de Arroio do Meio/RS e observou que a prevalência era de $80,4 \%$. Esses números podem ser justificados principalmente pela facilidade no acesso aos medicamentos, pois a venda livre nas farmácias e estabelecimentos não farmacêuticos favorece a utilização dos mesmos.

Neste trabalho, houve prevalência do sexo feminino (70\%) na prática de automedicação, também verificado em 2016 por Arrais et al em seu estudo sobre a prevalência da automedicação no Brasil, o que se deve, principalmente, pelo fato de as mulheres serem as que mais sofrem com dores de cabeça, enxaquecas, cólicas menstruais ou dismenorreia. Além disso, outra justificativa é a maior preocupação com a saúde e a busca mais frequente aos serviços de saúde (MAYOLO; FERNANDES, 2012).

A faixa etária mais envolvida na automedicação, a literatura demonstra diferentes resultados. Picon et al. (2014), concluiu que há predomínio na faixa etária de 41-50, destes, a maioria também pertencia ao sexo feminino. Coincidentemente neste estudo, a maioria dos indivíduos apresentamse com idade entre 31-50 anos (46\%) e menor frequência acima de 70 anos (3\%). Pode-se atribuir esse resultado ao tipo de problema de saúde, que envolve doenças agudas autolimitadas comuns a essa faixa etária, na qual o principal grupo terapêutico usado na prática da automedicação foram os analgésicos (ARRAIS et al.)

Em relação à escolaridade dos entrevistados, constatou-se que a maior parte relatou ter cursado o ensino fundamental incompleto (30\%), de igual modo com relação a renda familiar que apresentaram renda menor ou igual a um salário mínimo (55\%). A baixa escolaridade e o difícil acesso favorecem a pouca compreensão sobre os perigos causados pelos medicamentos e suas consequências a saúde (DUARTE; MALTA JUNIOR, 2015).

Segundo os dados da pesquisa, a principal causa para a automedicação é o fato de já terem consumido anteriormente (47\%), em que $56 \%$ dos casos de automedicação foi relatado que este se baseou em decisão própria (17\%) e em menor usam como critério a propaganda (4\%), justificado pelo difícil acesso ao sistema de saúde, a experiência prévia com o medicamento e o fácil acesso aos medicamentos na farmácia. (ARRAIS et al., 2016). Assim, a automedicação orientada pelo farmacêutico permite uma maior independência por parte da população nos cuidados com sua própria saúde e colabora com os governos na medida em que evita a superlotação nos consultórios médicos (SOUSA et al., 2008).

Nesse estudo, os analgésicos foram os medicamentos mais utilizados por conta própria, (68\%), enquanto a classe dos medicamentos menos utilizados foram os antibióticos (2\%). Dados similares a esses foram obtidos por Almeida et al. (2012) e Picon et al. (2014) em que 85\% dos idosos entrevistado e $41,3 \%$ se automedicavam com analgésicos (41,3\%), respectivamente. O baixo 
número de uso indevido de antibiótico, pode ser justificado pelo maior grau de dificuldade no acesso, dificultando assim a compra indiscriminada (ANVISA, 2013).

A dor de cabeça é a sintomatologia mais citada como causa para que pessoas recorram a automedicação. Estudos recentes reiteram que o hábito da automedicação está associado a presença de agravos menores, como dores de cabeça, gripe, febre e dores musculares (ARRAISI et al., 2016). Esse fato é coerente com a maior proporção de uso de analgésicos e anti-inflamatórios expresso na literatura (MARINHO et al., 2018). Assim, apesar de a dor de cabeça ser muitas vezes considerada um sintoma comum, precisa ser melhor investigada porque pode mascarar doenças mais graves e a automedicação pode levar o indivíduo a uma situação de ordem mais complexa (PROLUNGATTI et al., 2014).

As informações obtidas demonstram que a maioria dos entrevistados tem conhecimento dos riscos que estão envolvidos ao se automedicar (67\%). Assim observa-se claramente que essa é uma situação preocupante, pois mesmo tendo consciência dos riscos que a automedicação pode gerar se submetem a tal prática (BARBOSA; BOECHAT, 2012). A automedicação é uma prática permanente e difícil abolir, pela inviabilidade socioeconômica para o sistema de saúde público, assim torna-se claro a importância do profissional farmacêutico na automedicação responsável, sendo necessário oferecer mais conhecimentos e orientações relacionadas aos medicamentos, para que as pessoas que fazem uso de medicamento por conta própria procurem o profissional farmacêutico visando o uso racional de medicamentos (MARINHO et al., 2018).

\section{CONCLUSÃO}

O presente estudo demonstrou que as mulheres, pessoas com baixa escolaridade e com baixo poder aquisitivo são as principais praticantes da automedicação. Além disso, ainda segundo a pesquisa, a principal causa ou justificativa para a automedicação pelos indivíduos é a experiência prévia com o medicamento, em que a maioria é por decisão própria, sendo os analgésicos a classe de medicamentos mais escolhida.

Portanto, conclui-se que a automedicação é uma prática que envolve questões mais amplas como a escolaridade, renda, acesso a informações e questões culturais. Diante desse contexto, torna-se necessário que algumas medidas sejam tomadas para a redução dos riscos causados pela automedicação e consequentemente promover a conscientização à população quanto aos perigos dos efeitos adversos que certos medicamentos podem causar, sendo assim, possível minimizar os riscos, por meio da automedicação responsável, campanhas relacionadas ao uso racional de medicamentos são sempre bem-vindas e contribuem para o bem-estar da população de modo geral. 


\section{PRINCIPAIS REFERENCIAS}

BRASIL. Ministério da Saúde. Secretaria de Políticas de Saúde. Automedicação. Biblioteca Virtual em Saúde. 2015. Disponível em: < http://bvsms.saude.gov.br/dicas-em-saude/698-automedicacao> Acesso em: 26 nov. 2019.

DUARTE, D’Avilla Patrícia Souza; MALTA JUNIOR Alberto. Perfil da automedicação em uma farmácia de dispensação em Barbalha/Ce. Rev. e-ciência. v.3, n.2, p.66-73, 2015. Dispo- nível em: $<$ http://www.revistafjn.com.br/revista/index.php/eciencia/article/view/65> Acesso em: 06 jun. 2019. VITOR, Ricardo Sozo et al. Padrão de consumo de medicamentos sem prescrição médica na cidade de Porto Alegre/RS. Ciência \& Saúde Coletiva, v. 13 (Sup.), p. 737-743, 2008. Dispo- nível em: < http://www.scielo.br/pdf/csc/v13s0/a24v13s0.pdf> Acesso em: 19 nov. 2019. 


\title{
ESTÁGIO SUPERVISIONADO EM ENFERMAGEM NO CONTEXTO DA PANDEMIA DE COVID-19: EXPERIÊNCIA NA ATENÇÃO TERCIÁRIA
}

\author{
Kelly Rose Pinho Moraes ${ }^{1}$; Geovane Moura Viana²; Ana Paula Cunha Duarte²; Dheymi \\ Wilma Ramos Silva ${ }^{3}$ \\ ${ }^{1}$ Pós-graduanda em Enfermagem do Trabalho, (GB), São Luís, Maranhão. \\ ${ }^{2}$ Graduado em Enfermagem, (UEMA), Coroatá, Maranhão. \\ ${ }^{3}$ Mestre em Biodiversidade, Ambiente e Saúde, (UEMA), Caxias, Maranhão.
}

\begin{abstract}
RESUMO
O estágio curricular supervisionado deve seguir leis, como também as normas de cada instituição de ensino superior, pois na Enfermagem deve aprimorar os conhecimentos técnicos. O objetivo desse trabalho é relatar a experiência de discentes de enfermagem durante a execução do estágio supervisionado durante a pandemia. Trata-se de um relato de experiência, de cunho descritivo. O desenvolvimento das atividades acadêmicas na pandemia gerou sentimentos de medo e insegurança, como também cooperou para o aprendizado se tornando um ambiente rico em conhecimento colaborando para o desenvolvimento de competências. Desta forma, conclui-se que a realização das atividades contribuiu de forma positiva para o aprendizado e empoderamento dos acadêmicos.
\end{abstract}

PALAVRAS-CHAVES: Infecções por coronavírus; Educação em Enfermagem; Estudantes de enfermagem.

ÁREA TEMÁTICA: Educação em Saúde

\section{INTRODUÇÃO}

A Lei Federal nº 9.394, de 20 de dezembro de 1996, direciona que o Estágio Supervisionado deve ser executado, e que cada Instituição de Ensino Superior (IES) deve estruturar a grade de seu Estágio Curricular Supervisionado alinhando com as especificações da lei, pois oferecê-lo, no que se trata ao curso de Enfermagem possibilita oportunizar que o aluno entrelace seus conhecimentos de teoria com a prática (BRASIL, 2017). Contudo, embora os discentes recebam uma formação ampla sobre vários aspectos de saúde, o desenvolvimento de capacidades para atuar durante pandemias ainda é escasso na graduação.

No ano de 2020, o Brasil passou a registar altos número de casos da COVID-19, divulgados 
constantemente pelas mídias. Consequentemente, a atuação da enfermagem ficou em evidência para o mundo tanto pelo seu contato direto com os pacientes contaminados, como pelos números de profissionais da enfermagem que contraíram a patologia e pela exposição da precariedade das condições de trabalho. Com isso, abordar o contexto da pandemia durante a formação de novos enfermeiros faz-se necessário para reflexões sobre a adaptação do estágio curricular supervisionado nas unidades hospitalares.

Desta forma o objetivo deste trabalho é relatar as experiências de discentes de enfermagem durante o estágio curricular supervisionado na atenção terciária no contexto da pandemia da COVID-19.

\section{METODOLOGIA}

Trata-se de um relato de experiência, de cunho descritivo sobre as vivências de acadêmicos do curso de Bacharelado em Enfermagem de uma universidade pública do Estado do Maranhão.

O estágio foi realizado em um hospital de alta complexidade durante a pandemia da COVID-19 nos setores de Unidade de Terapia Intensiva (UTI) adulto, Centro Cirúrgico, Obstetrícia, UTI neonatal e Clínica Pediátrica. Em cada setor de estágio, os acadêmicos permaneciam por quinze dias úteis consecutivos, após isso havia troca de setores. Os discentes cursavam o $10^{\circ}$ semestre do curso, cumprindo seis horas diárias no turno da manhã, integralizando uma carga horária de 450 horas obrigatórias, realizadas no período de agosto a novembro de 2020, sob supervisão direta de enfermeiros executando cargos de professores preceptores.

O hospital de alta complexidade onde ocorreu o estágio, está localizado em um município no centro leste do Maranhão, onde atende a população de cerca de 85 municípios, contemplando-os com vários serviços de saúde, como Cirurgia Geral, Gastroenterologia, Ortopedia, Urologia, e entre outros, além de contar com uma ala COVID-19. O hospital em questão é referência para tratamento da COVID-19, recebendo pacientes críticos e semicríticos.

Esse relato desenvolve-se a partir das vivências de acadêmicos de enfermagem na execução das atividades do estágio curricular supervisionado no cenário do COVID-19.

\section{RESULTADOS E DISCUSSÕES}

Em março de 2020, houve a descontinuação das atividades do estágio devido ao estado de calamidade pública no estado do Maranhão (Tabela 1), em decorrência da SARS-CoV-2 como resultado disso, iniciou-se uma série de perguntas entre os alunos sobre a continuidade das atividades acadêmicas, tais como: quando concluiriam o curso, se a colação de grau ainda seria possível no mesmo ano, visto que ao mesmo tempo que almejavam pela retomada das atividades surgiam sentimentos de medos e anseio sobre a contaminação da COVID-19 pois se trata de um 
novo vírus.

Tabela 1: Dados da COVID-19 no Maranhão classificados por região (atualizados no dia $04 / 03 / 2021)$

\begin{tabular}{|c|c|c|c|c|c|}
\hline Sub-região & População & $\begin{array}{c}\text { Casos Novos } \\
\text { (últimos } 14 \text { dias) }\end{array}$ & $\begin{array}{c}\text { Casos } \\
\text { Acumulados }\end{array}$ & $\begin{array}{l}\text { Óbitos Novos } \\
\text { (últimos } 14 \\
\text { dias) }\end{array}$ & $\begin{array}{c}\text { Óbitos } \\
\text { Acumulados }\end{array}$ \\
\hline Interior & 5.442 .064 & 720 & 186.220 & 25 & 3.382 \\
\hline $\begin{array}{c}\text { Região } \\
\text { Metropolitana }\end{array}$ & 1.633 .117 & 132 & 35.664 & 10 & 1.780 \\
\hline TOTAIS & 7.075 .181 & 852 & 221.884 & 35 & 5.162 \\
\hline
\end{tabular}

Fonte: Ministério da Saúde (2021)

Como medidas de proteção para prevenção do contágio e de combate à propagação da transmissão do vírus, a Organização Mundial de Saúde (OMS) estabeleceu ações como o isolamento social, higienização frequente das mãos, uso constante de máscaras quando não houver a possibilidade de afastamento físico, e mudança de hábitos, como por exemplo não tocar olhos, nariz ou boca e quando espirrar e/ou tossir cobrir a boca e nariz, enquanto que no tocante a assistência dos serviços de saúde estabeleceu que haja uma boa oferta na qualidade de atendimento, como orientações de prevenção e diagnósticos, bem como organização nos serviços de saúde desde a atenção primária até a atenção terciária, além do preparo dos profissionais (LIMA, et al, 2021).

Dessa forma, em agosto de 2020 foi possível o retorno do estágio, recebendo as instruções e apoio da IES para segurança dos alunos e dos preceptores, bem como o fornecimento de Equipamento de Proteção Individual (EPI) em números suficientes para execução das atividades, assim como obedecendo as normas do hospital. O desenvolvimento das atividades acadêmicas permitiu que os discentes vivenciassem a rotina da enfermagem dentro da realidade do Sistema Único de Saúde (SUS), possibilitando que desenvolvam senso crítico diante de diversas situações, incluindo no contexto da pandemia, aprimorando suas habilidades técnicas, habilidades de coordenar e planejar ações no âmbito de um hospital de referência para tratamento da COVID-19. A unidade hospitalar conta com uma UTI COVID e Clínica médica COVID, nos quais eram proibidos a entrada de profissionais que não fossem do setor, assim como entrada de alunos também não era permitida. Portanto, os acadêmicos foram postos em segurança para a não contaminação e também para não disseminação do vírus na comunidade.

Os discentes em campo se tornam os promotores da inovação local reforçando a equipe que já estar a atuar, onde é possível aprender com as experiências da pandemia atual, formulando estratégias no combate desta pandemia e de outras que poderão surgir no futuro, assim reverberam de forma positiva nas ações e intervenções por eles executados, como também alimenta seu aprendizado 
em busca de ideias inovadoras e novas experiências (SOCCOL, SANTOS, MARCHIORI, 2021; VIEIGA, et al, 2020).

Nos diálogos entre alunos, era evidenciados sentimentos de insegurança em relação ao futuro e ao mercado de trabalho, devido as chances de colapso sanitário, a insegurança em lidar com cargas horárias de trabalho exaustivas e desvalorização da profissão, precariedade das condições de trabalho que já existiam antes da pandemia e se agravaram mais ainda nessas circunstâncias de pandemia, evidenciadas pelo aumento do número de denúncias realizadas no Conselho Regional de Enfermagem sobre a falta de EPI em muitas unidades. O medo de auto contaminação e possibilidades de levar a doença para dentro de seus lares, era discutido entre as conversas informais, assim como a importância da enfermagem no papel de protagonista na luta contra a COVID-19.

Os acadêmicos tiveram a oportunidade de vivenciar a adaptação de uma unidade a novos protocolos e fluxos assistências, que estavam em constante mudança. Foi possível compreender que a educação em saúde permeia em todos os níveis de atenção da saúde, em virtude que os discentes tiveram oportunidade de acolher e orientar puérperas e acompanhantes no Alojamento Conjunto quanto as boas práticas de cuidados com recém-nascido em tempos de pandemia, e também a orientação sobre a procura de assistência de saúde em casos de sintomas suspeitos do novo coronavírus. As principais dificuldades encontradas durante o estágio relacionaram-se uso dos EPI, tanto na adaptação ao uso constante de máscara, como também manuseio e cuidado com os EPI.

\section{CONCLUSÃO}

O estágio curricular supervisionado na atenção terciária desenvolvido no contexto da pandemia, colaborou de forma positiva no aprendizado dos alunos, fortalecendo a educação e desenvolvimento profissional e pessoal, com o enfrentamento dos sentimentos que surgiram ao decorrer da pandemia, incitando-os a desenvolver pensamento crítico, postura ética, além de ajudar a fortalecer a comunicação com os usuários do serviço, contribuindo para o transformar o social.

A possibilidade de desenvolver as atividades acadêmicas nesse cenário inédito, só reforça o protagonismo dos profissionais de enfermagem, assim como enfatiza a necessidade de formar profissionais capacitados e empoderados, tanto em teoria como em habilidades técnicas, para poder atuarem com competência em diversas situações. 


\section{REFERÊNCIAS}

BRASIL. Ministério da Educação. Coordenação de Edições Técnicas. Lei de diretrizes e bases da educação nacional. Brasília, DF: Senado Federal, 2017.

LIMA. L.S.; BESSA, M.M.; SILVA, S.W.S.; et al. Processo de enfermagem para pacientes com manifestações respiratórias da COVID-19. Rev enferm UFPE, Pernambuco, v. 14, n. e, p. 1-10, jan. 2021

SOCCOL, K.L.S.; SANTOS, N.O.; MARCHIORI, M.R.C.T. Estágio curricular supervisionado no contexto da covid-19 e o desenvolvimento profissional de estudantes de enfermagem. Rev Enfermagem em Foco, Brasilia, v. 22, n. 2 esp., p. 148-151, ago. 2020.

VEIGA, G.A.; ARAÚJO, M.C.; CAUDURO, F.L.F.; et al. Metodologia ativa no estágio supervisionado de enfermagem: inovação na Atenção Primária à Saúde. Rev baiana enferm., Bahia, v. 34, n. e, p. 1-9, abr. 2020. 


\title{
IMPORTÂNCIA DA EDUCAÇÃO EM SAÚDE NOS CASOS DE ACIDENTES
}

\section{PROVOCADOS POR ANIMAIS MARINHOS}

\author{
Ana Paula da Conceição Fernandes de Amorim'; Moana Ferreira dos Santos²; Ângelo Alves \\ de Moura ${ }^{3}$ Rafael Marques de Mesquita ${ }^{3}$ \\ ${ }^{1}$ Médica Veterinária. Universidade Federal do Rio de Janeiro (UFRJ). Rio de Janeiro, RJ. \\ ${ }^{2}$ Bióloga. Universidade Federal do Rio de Janeiro (UFRJ). Rio de Janeiro, RJ. \\ ${ }^{3}$ Médico. Universidade Federal do Rio de Janeiro (UFRJ). Rio de Janeiro, RJ.
}

DOI: $10.47094 /$ ICONRES.2021/20

\begin{abstract}
RESUMO
Esse trabalho refere-se à atividades de educação em saúde realizadas, em fevereiro de 2018, com pescadores tradicionais da localidade de Canto de Itaipu, região oceânica do município de Niterói, Rio de Janeiro, sobre acidentes com animais marinhos de importância médica. Realizou-se uma roda de conversa, que contou com a participação de 30 pescadores da região e 5 pesquisadores do Centro de Informação Toxicologica da Universidade Federal do Rio de Janeiro, que tiveram a oportunidade de colocar suas experiências em relação aos acidentes sofridos pela comunidade pesqueira e como eles encaminhavam e resolviam o agravo entre si. A participação da comunidade pesqueira foi muito efetiva, fortalecendo o saber local. Esse trabalho foi parte do projeto de extensão "Acidentes com animais marinhos - importância médica e socioambiental", realizado em parceria com o Programa de Pesquisa Ação na Cadeia Produtiva da Pesca Artesanal - PAPESCA- UFRJ, no âmbito da PROFAEx-2017.
\end{abstract}

PALAVRAS-CHAVES: Promoção da saúde; Educação em saúde; Populações tradicionais.

ÁREA TEMÁTICA: Educação em saúde

\section{INTRODUÇÃO}

A proximidade humana dos ambientes marinhos propicia diferentes situações de exposição aos riscos tratando-se de acidentes ocasionados por contato com animais marinhos. Estes acidentes podem estar associados a traumas com ou sem toxinas e ocorrem através do contato humano, que pode ser acidental ou ocupacional, com animais marinhos que oferecem riscos de acidentes de importância médica (Santoset al., 2021). Embora, acidentes causados por animais marinhos de graves 
consequências possam provocar morbidez importante em humanos, os envenenamentos e traumas são objeto de poucos estudos clínicos no Brasil (Holanda et al., 2019). E geralmente são passíveis de terapias, que nem sempre, estão baseadas em dados cientificamente comprovados (Haddad, 2003; Santos et al., 2017; Santos et al., 2021). Por esta razão, o principal objetivo deste estudo foi desenvolver atividade de educação em saúde, fortalecendo o empoderamento de populações tradicionais de pescadores artesanais, valorizando o saber popular, o que se refere aos acidentes provocados por animais marinhos.

\section{METODOLOGIA}

O Centro de Informação Toxicológica, do Hospital Universitário Clementino Fraga Filho, da Universidade Federal do Rio de Janeiro, realizou, em fevereiro de 2018, uma oficina participativa, através de uma roda de conversa, com pescadores artesanais, na localidade de Canto de Itaipu, região oceânica do município de Niterói, Rio de Janeiro. A atividade foi parte integrante do projeto "Acidentes com animais marinhos - importância médica e socioambiental", realizado em parceria com o Programa de Pesquisa Ação na Cadeia Produtiva da Pesca Artesanal - PAPESCAUFRJ, no âmbito da PROFAEx-2017.

A atividade foi realizada pela manhã no dia e horário escolhidos pelos pescadores, durante um café da manhã providenciado pela equipe de pesquisa, com a finalidade de integrar os participantes.

As etapas metodológicas da atividade foram as seguintes: primeiro realizar a mobilização com lideranças locais para apresentação da atividade; em seguida houve uma interação com os pescadores em seu ambiente de trabalho para enfim articular a melhor data para a realização do evento.

\section{RESULTADOS E DISCUSSÕES}

A oficina foi realizada em uma manhã de sábado de fevereiro de 2018, de 8 às $11 \mathrm{~h}$ horário e dia escolhido pelos pescadores, como sendo o ideal para a comunidade. Contou com a presença de 35 participantes, sendo 30 pescadores artesanais e 5 pesquisadores.

A equipe do projeto providenciou um café da manhã aberto à comunidade e os pescadores foram convidados a participar de uma roda de conversa que foi a oportunidade de integração para que eles colocassem suas experiências com os acidentes com animais marinhos sofridos por eles ou por colegas de trabalho e que procedimentos de primeiros socorros eles desenvolviam. Puderam expor suas experiências do dia a dia com acidentes sofridos ou auxiliando algum colega pescador durante as atividades.

Relataram que poucas vezes procuraram os serviços formais de atenção básica e nas vezes que fizeram o atendimento não foi muito eficiente, o que fortaleceu ações próprias da 
comunidade para encaminhamento e resolução do agravo.

A atividade foi muito produtiva, a participação foi efetiva tanto por parte dos pescadores quanto dos pesquisadores. Diversos líderes locais estiveram presentes, e pescadores de diversas idades, contribuíram com seu saber popular e sua experiência do dia a dia com os acidentes com animais marinhos, o que foi muito importante do ponto de vista da integração da comunidade.

\section{CONCLUSÃO}

A conclusão obtida dessa atividade é a de que oficinas de educação em saúde são excelentes oportunidades de troca de saberes, de mobilização social, de troca de informações sobre promoção de saúde, de prevenção de agravos e de integração entre o saber formal acadêmico e o saber informal de populações tradicionais.

Os acidentes com animais marinhos sejam acidentes traumáticos, sejam tóxicos, necessitam de um olhar mais focado das políticas públicas em saúde e pensar em uma forma de notificação ou descrição melhor desses agravos, oferecerá importantes dados epidemiológicos que hoje não dispomos.

\section{PRINCIPAIS REFERÊNCIAS}

HADDAD JUNIOR, V. Aquatic animals of medical importance in Brazil. Revista Sociedade Brasileira de Medicina Tropical. Vol. N5. Uberaba, SP. Sept/oct, 2003. 591-597p.

MONTENEGRO T. Inferno de verão. Revista Saúde 2000; 71-75.

SANTOS, M. F.; AMORIM, A. P. C. F.; MOURA, A. A. \& MESQUITA, R. M. Acidentes de interesse médico provenientes de animais marinhos: ocorrências em Itaipu, Niterói, RJ, Brasil. In ONE, G. M. C. (Org). Saúde: os desafios da pesquisa na atualidade - 3. Cap. 45. Ed. Instituto Medeiros de Educação Avançada - IMEA. João Pessoa. Paraíba. 2021. 915-937p.

SANTOS, M. F.; AMORIM, A. P. C. F.; MOURA, A. A.; MESQUITA, R. M. \& IGREJA, R. P. Acidentes com Animais Marinhos Importância Médica e Socioambiental. PROFAEXt 2017. Rio de Janeiro: UFRJ, Centro de Informação Toxicológica - CIT HUCFF; 2017. 


\title{
EDUCAÇÃO EM SAÚDE COMO ESTRATÉGIA DE PREVENÇÃO PARA O CÂNCER DE COLO DE ÚTERO
}

\author{
Stefany Augusto Pinto'; Maria Gizely Ferreira de Sena² \\ ${ }^{1}$ Graduanda em enfermagem, Centro Universitário de Patos (UNIFIP), Patos, Paraíba. \\ ${ }^{2}$ Graduanda em enfermagem, Centro Universitário de Patos (UNIFIP), Patos, Paraíba.
}

\begin{abstract}
RESUMO
O câncer de colo de útero (CCU) é causado através da infecção pelo papiloma vírus humana (HPV) e é uma das neoplasias que mais causa medo nas mulheres por apresentar alto risco de letalidade e morbidade. Foi relatado no manual técnico do Ministério da Saúde, lançado em 2002, que a prevenção do CCU se dá através da realização do exame cito patológico, também chamado de Papanicolau. Diante disso, esse resumo de caráter descritivo e que possui uma abordagem qualitativa, resulta na importância em educar as mulheres informando-as sobre a gravidade da doença e como a prevenção da mesma é uma positiva estratégia para a detecção precoce, onde o tratamento será realizado com antecedência, evitando assim, o agravamento e até mesmo os óbitos causados por ela.
\end{abstract}

PALAVRAS-CHAVE: Comunicação em Saúde; Neoplasias do Colo do Útero; Teste Papanicolau. ÁREA TEMÁTICA: Educação em saúde

\section{INTRODUÇÃO}

Segundo o INCA (2004) embora seja totalmente apto á prevenção e de ter um prognóstico positivo, quando se é tratado precocemente, o câncer de colo de útero é uma grandiosa problemática no meio da saúde pública por se tratar do terceiro tumor que acontece frequentemente entre as mulheres, ficando atrás somente do câncer de mama e colo retal, também está na quarta posição das causas de óbitos femininos por câncer no Brasil. Esta doença tem como principais fatores de risco o início precoce das atividades sexuais, tabagismo, múltiplos parceiros sexuais, baixa condições socioeconômicas, multiparidade, e também a infecção, transmitida sexualmente, por uma linhagem oncogênica do HPV (Papiloma Vírus Humano); O HPV está presente em aproximadamente cem por cento dos casos de câncer de útero e quase $20 \%$ dos indivíduos sadios, encontram-se infectados pelo vírus, onde a maioria desses possuem infecção assintomáticas e transmissoras, tornando-se inviável a detecção dentro do período entre um a dois anos, mas a infecção persistente pelo vírus torna o desenvolvimento de lesões pré-cancerosas favoráveis e, posteriormente, a neoplasia (Andrade 
MS, Almeida MMG, Araújo TM, Santos KOB, 2010-2014). Tendo conhecimento disso, a prevenção primária se dá diante do uso de preservativos durante as relações sexuais, bem como a vacinação contra o vírus do HPV juntamente com ações de promoção à saúde; A sua prevenção secundária, tem como objetivo a detecção precoce, através do exame Papanicolau que irá desenvolver o diagnóstico á tempo para, por fim, tratar a neoplasia caso ela esteja presente.

A prática em realizar o exame cito patológico de forma periódica é tida como a principal fonte de prevenção do CCU, onde realizada precocemente obtém resultados positivos através do tratamento desse câncer antes do seu agravamento e evitando muitos óbitos. O Ministério da Saúde aconselha á todas as mulheres com idade entre vinte e cinco e sessenta e quatro anos, com a vida sexual ativa, deve realizar o exame preventivo, inicialmente com periodicidade anual, e após ter se submetido a consecutivos dois exames que tiveram resultados negativos para neoplasia do colo do útero, este passa a ter periodicidade trianual. Após o resultado ter dado negativo, o risco de desenvolver a este câncer é muito reduzido, mantendo esta redução durante cinco anos subsequentes. (Ministério da Saúde, 2013).

Com esse contexto, o dito trabalho tem como objetivo a descrição da problemática em que se refere o câncer de colo de útero, seus fatores de risco, e sua prevenção, bem como salientar a importância de educar as mulheres levando conhecimento e as informando sobre como evitar obter este câncer com a realização da prevenção através do exame cito patológico, quando feito periodicamente e nas circunstâncias corretas, visto que, muitas dessas mulheres, principalmente as que se encontram no grupo de risco por estarem em situações socioeconômicas baixas, não apresentam conhecimento de como, quando e por que realizar o exame, tornando assim a educação em saúde um importante fator de estratégia para a luta contra o câncer cérvico-uterino.

\section{METODOLOGIA}

Trata-se de uma revisão bibliográfica, norteada de modo descritivo, onde é descrito problemáticas que acontecem dentro de uma população específica, tendo como método a revisão de literaturas de materiais como artigos científicos encontrados nos portais Scielo, INCA, Google Acadêmico e revistas como a Revista Científica da Faculdade de Educação e Meio Ambiente FAEMA, a Revista Brasileira em Promoção da Saúde e também a Revista Enfermagem Contemporânea sobre o tema abordado e que foram realizados nos últimos dez anos, utilizando descritores no idioma português, selecionados mediante a consulta nos Descritores em Ciências de Saúde (DeCS). Foram excluídos artigos de línguas estrangeiras, que ultrapassem o tempo de dez anos de publicação, além de monografias, dissertações e teses. Para fins de resultados foi utilizada a técnica de revisão sistemática, retirando informações de diferentes artigos. Este trabalho tem natureza qualitativa, onde busca entender o assunto tendo como fonte a coleta de dados e o pesquisador. 


\section{FUNDAMENTAÇÃO TEÓRICA}

Visto que o exame de Papanicolau é uma das maneiras mais eficientes de prevenção da neoplasia abordada nesse trabalho, surge o questionamento acerca do conhecimento das mulheres sobre o cito patológico, os motivos que as levam a não realizarem o exame, e como a educação em saúde pode ser favorável na estratégia de prevenção contra o câncer cérvico-uterino. Tendo isso, é possível descrever alguns motivos que afligem essas mulheres como o sentimento de vergonha, que acaba se tornando um dos motivos mais apresentados entre elas, sendo resultado de tabus á respeito da sexualidade feminina e do seu corpo, bem como a falta de informação, além disso, mulheres relatam desconforto diante da posição ginecológica para realizarem o exame; Outra expressão de sentimentos seria o medo e o nervosismo, em relação a realização do exame, muitas vezes não se é entendido o procedimento, a aflição perante os resultados; Pouca acessibilidade, seja por causa do marido que muitos dizem não aceitar certos períodos sem realizar atividade sexual, existe também a dificuldade de mãe em deixarem seus filhos pequenos para irem até a consulta.

Apesar dos empecilhos, fazendo uma análise de revisão sistemática no artigo sobre Câncer de colo Uterino: Conhecimento e Comportamento De Mulheres Para a Prevenção, publicado na revista Enfermagem Contemporânea em 2015, onde ao verificarem a respeito do conhecimento das mulheres sobre o exame, tiveram resultados positivos, onde as mulheres possuíam conhecimento da finalidade do mesmo, mas também foi concluído que não é um fator primordial e decisivo conhecer a finalidade deste, mas sim, ter convicção e disposição para eliminar bloqueios e inseguranças na hora do teste, para que assim se possa obter ir em direção da prevenção. Dessa forma, mesmo as mulheres, periodicamente, realizarem o exame, muitas delas não vão á consulta, por serem bloqueadas pelos sentimentos já citados neste presente trabalho, e uma grande estratégia para mudar isso, seria educalas e informa-las usando a Educação em saúde como meio de prevenção.

\section{CONCLUSÃO}

Diante do exposto, observou-se que o câncer de colo de útero, como uma neoplasia bastante presente e letal entre as mulheres, é de suma importância que haja prevenção para combater a doença, e uma das principais formas de fazer com que isso aconteça é realizando o exame preventivo cito patológico para obter uma detecção precoce e tratar o câncer quando positivado pelo teste, foi visto também, que existem fatores emocionais, bloqueios de insegurança a respeito da realização do exame, que muitas vezes são acarretados pela falta de informação que pode ser combatida através da educação em saúde, usando-a como estratégia de prevenção.

É afirmativa que a prática de educação em saúde é uma estratégia muito poderosa de promoção e prevenção á saúde; Como dito por Candeias NMF (1997) a Educação em Saúde é a um recurso onde o embasamento científico na área da saúde atinge a vida das pessoas, uma vez que as mesmas, quando educadas, adquirem hábitos saudáveis em seu dia-a-dia. É importante destacar também, 
que essa estratégia contribui para que a consciência crítica das pessoas seja formada a respeito das problemáticas de saúde presentes em sua realidade, e estimula a organização e a solução destes, individualmente e coletivamente. (Ministério da Saúde, 2008). Dessa forma, é preciso repensar sobre como promover saúde no sentido de expor orientações, é necessária que não seja somente de forma técnica, mas também adotar meios de compreensão para entender a cultura e o dia a dia das mulheres, seus sentimentos e empecilhos. Com medidas de educação em saúde sendo aplicadas, a contribuição para a mudança de hábitos comportamentais das mulheres, irá resultar na prevenção da doença de forma eficaz e consciente, e consequentemente a qualidade de vida que as mulheres merecem.

\section{PRINCIPAIS REFERÊNCIAS}

DE SOUZA A.F, COSTA L.H.R. Conhecimento de Mulheres sobre HPV e Câncer do Colo do Útero após Consulta de Enfermagem. Rev. Bras. Cancerol. [Internet], v. 61, n. 4, p. 121-220, 2015.

MARTINS M.L. et al, Rev Cient da Fac Educ e Meio Ambiente: Revista da Faculdade de Educação e Meio Ambiente - FAEMA, Ariquemes, v.10, n. Especial, 2020, p. 6-10. IV Semana da Enfermagem - Enfermagem Agora.

LOPES V.A.S.L, RIBEIRO J. M. Fatores limitadores e facilitadores para o controle do câncer de colo de útero: uma revisão de literatura. Ciênc. saúde coletiva, Rio de Janeiro, v. 24, n.9, p. 3431$3442,2019$.

RODRIGUES B.C. et al, Educação em saúde para a prevenção do câncer cérvico-uterino. Rev. bras. educ. med. Rio de Janeiro, v. 36, n. 1 supl.1, p. 20-36, 2012.

SANTOS A.M.R. et al. Câncer de colo uterino: conhecimento e comportamento de mulheres para prevenção. Revista Brasileira em Promoção da Saúde, Fortaleza, v. 28, n.2, p. 153-159, 2015.

SANTOS A.C.S. et al, Prevenção do Câncer de Colo Uterino: Motivos que influenciam a não realização do exame de papanicolaou. Revista Enfermagem Contemporânea, v. 4, n. 2, p. 179-188, 2015. 


\title{
BIOSSEGURANÇA E COVID-19: DESAFIOS DA ATENÇÃO PRIMÁRIA À SAÚDE
}

\author{
Raquel Soares Moreira ${ }^{\text {; }}$ Cláudia Zamberlan²; Maria Helena Gehlen ${ }^{3}$ \\ ${ }^{1}$ Biomédica Residente em Atenção Clínica Especializada com ênfase em Infectologia e Neurologia, \\ Universidade Franciscana, Santa Maria, Rio Grande do Sul. \\ ${ }^{2}$ Enfermeira, Doutora em Enfermagem. Docente e Coordenadora do Programa de Residência \\ em Atenção Clínica Especializada com ênfase em Infectologia e Neurologia, da Universidade \\ Franciscana, Santa Maria, Rio Grande do Sul. \\ ${ }^{3}$ Enfermeira. Doutora em gerontologia biomédica. Docente no curso de enfermagem da \\ Universidade Franciscana, Santa Maria, Rio Grande do Sul.
}

\section{RESUMO}

A Atenção Primária à Saúde é a principal porta de entrada do usuário no Sistema Único de Saúde. Mediante suas características, constitui um cenário importante no enfrentamento à pandemia de COVID-19. Objetiva-se descrever uma capacitação com ênfase na promoção da biossegurança para profissionais de saúde da atenção primária. Trata-se de um relato de experiência proveniente da vivência de forma virtual das autoras promovida por um município da Região Central do Rio Grande do Sul e uma universidade privada. Os encontros perfizeram um total de seis, com participação de um total de 95 profissionais. As discussões que emergiram foram oriundas dos questionamentos quanto à integração do conhecimento técnico com a efetividade da manutenção dos cuidados de biossegurança. As conversas evidenciaram a necessidade do fortalecimento das equipes mediante as capacitações, assim como, do protagonismo individual da população por meio de ações voltadas à educação em saúde

PALAVRAS-CHAVES: Pandemia; Assistência à Saúde; Educação em Saúde.

ÁREA TEMÁTICA: Educação em Saúde

\section{INTRODUÇÃO}

A Atenção Primária à Saúde (APS) é o mais alto nível de descentralização do Sistema Único de Saúde (SUS) e o serviço mais próximo dos usuários. É considerada a principal porta de entrada para o sistema, referenciando aqueles que necessitam de serviço de maior complexidade. Oferece serviços que visam a promoção, proteção, recuperação da saúde e possibilitam uma atenção integral ao usuário (BRASIL, 2012). 
A APS, devido às suas características, possui o papel fundamental no enfrentamento da atual pandemia causada pelo novo Coronavírus, atuando na identificação de casos, no encaminhamento para serviço de diagnóstico e nas campanhas de vacinação (MINISTÉRIO DA SAÚDE, 2020). Porém, a realidade pandêmica trouxe consigo a necessidade de adequar o serviço, a organização dos locais de trabalho e as próprias relações entre os colegas, assim como o vínculo profissional-usuário, gerando desafios diários.

Este trabalho tem como objetivo de descrever uma capacitação com ênfase na promoção da biossegurança para profissionais de saúde da atenção primária

\section{METODOLOGIA}

Trata-se de um relato de experiência baseado no desenvolvimento da capacitação e discussões sobre Biossegurança na Atenção Básica realizadas na roda de conversa promovida pelo Núcleo de Educação Permanente em Saúde (NEPeS) de um município do Rio Grande do Sul em parceria com uma universidade privada do mesmo município, com participação de docente do curso de Enfermagem e uma residente biomédica do programa de Atenção Clínica Especializada com ênfase em Infectologia e Neurologia. Os encontros ocorrem de forma virtual pela plataforma Google Meet ${ }^{\circledR}$ e devido a limitação de acesso desta, os profissionais foram convocados e separados de acordo com a sua formação ou atuação.

A roda de conversa foi dividida em dois momentos: um de explanação sobre questões teóricas e práticas relacionadas a biossegurança e outro mais aberto para discussão, embora, durante todo o período os questionamentos pudessem ser realizados.

\section{RESULTADOS E DISCUSSÕES}

Ao desenvolver a capacitação e a promoção da biossegurança para os profissionais de saúde atuantes na atenção primária obteve-se como público-alvo técnicos de enfermagem, enfermeiros, médicos, odontólogos, farmacêuticos, agentes comunitários de saúde, recepcionistas e funcionários do setor administrativo, totalizando 95 profissionais. À medida em que as capacitações foram promovidas, as discussões ocorreram de acordo com o cotidiano profissional e comunitário, os diálogos eram permeados por desafios, dúvidas e anseios principalmente no que se relaciona à segurança, proteção e promoção da saúde. De tal modo, elaborou-se um material interativo e dialogado, o qual socializou-se por meio da roda de conversa

Esta foi a primeira conversa sobre a biossegurança no enfrentamento à COVID-19 promovida pelo NEPeS no município e permitiu uma conversa ampla e sincera sobre os desafios, assim como troca de ideias sobre como superá-los. O espaço possibilitou que os profissionais fossem participantes do remodelamento da assistência, corroborando com a autonomia no seu próprio cuidado por meio da apropriação do conhecimento e do compartilhamento das dificuldades para que num momento tão 
ímpar na história do cuidado eles compreendessem que não estão sozinhos. Sendo a APS a base do SUS, é necessário que seja fortalecida para o enfrentamento da pandemia e não apenas os espaços de cuidado hospitalares e de urgência/emergência, como visto neste período. Medina et al. (2020) também reforçam a necessidade do fortalecimento e a valorização em do serviço e das unidades que a integram, principalmente no que se diz investimento financeiro e humano, dada o sucesso no enfrentamento de outras situações, esta também pode ser a chave para o sucesso contra o novo vírus.

As dificuldades percebidas se relacionavam tanto as práticas de biossegurança que devem ser aderidas pelas equipes quanto pela população, ficando em alguns momentos evidente a exaustão de ambas as partes devido à duração do período pandêmico e as restrições associadas ao mesmo e em contrapartida, também notada a tendência normalização desse estilo de vida sem os devidos cuidados, sendo sugeridas propostas de educação em saúde para superá-las e fortalecer o protagonismo no cuidado individual e no coletivo.

\section{CONCLUSÃO}

Os desafios enfrentados pela APS são relacionados a adequação das práticas de biossegurança ao seu cotidiano e na manutenção das mesmas tanto por parte da equipe quanto da população. As intervenções propostas foram o fortalecimento das ações em educação em saúde a fim de elucidar as questões técnicas e intensificar o protagonismo de profissionais e usuários no cuidado individual e coletivo.

\section{PRINCIPAIS REFERÊNCIAS}

BRASIL. Ministério da Saúde. Secretaria de Atenção à Saúde. Departamento de Atenção Básica. Política Nacional de Atenção Básica / Ministério da Saúde. Secretaria de Atenção à Saúde. Departamento de Atenção Básica. - Brasília : Ministério da Saúde, 2012.

MEDINA, Maria Guadalupe et al. Atenção primária à saúde em tempos de COVID-19: o que fazer?. Cadernos de Saúde Pública, [S.L.], v. 36, n. 8, p. 1-5, 2020. FapUNIFESP (SciELO).

MINISTÉRIO DA SAÚDE; (SAPS), Secretaria de Atenção Primária À Saúde. PROTOCOLO DE MANEJO CLÍNICO DO CORONAVÍRUS (COVID-19) NA ATENÇÃO PRIMÁRIA À SAÚDE. 7. ed. Brasília - DF, 2020. 38 p. 


\section{ENVELHECER BEM: PROMOVENDO O AUTOCUIDADO EM SAÚDE MENTAL NA TERCEIRA IDADE DURANTE A PANDEMIA}

\section{Nanielle Silva Barbosa ${ }^{1}$; Amanda de Oliveira Lima²; Maycon Guimarães Santos ${ }^{3}$; João Caio Silva Castro Ferreira ${ }^{4}$}

${ }^{1}$ Enfermeira. Pós-graduanda do Programa de Residência Multiprofissional em Saúde da Família e Comunidade, UESPI, Teresina, Piauí.

${ }^{2}$ Psicóloga. Pós-graduanda do Programa de Residência Multiprofissional em Saúde da Família e Comunidade, UESPI, Teresina, Piauí.

${ }^{3}$ Psicólogo. Pós-graduando do Programa de Residência Multiprofissional em Saúde da Família e Comunidade, UESPI, Teresina, Piauí.

${ }^{4}$ Enfermeiro. Pós-graduando do Programa de Residência Multiprofissional em Saúde da Família e Comunidade, UESPI, Teresina, Piauí.

\section{RESUMO}

O autocuidado vem sendo amplamente estudado em diversas áreas da saúde, sendo instrumento facilitador do envelhecimento ativo e autônomo. Portanto, este estudo traz como objetivo descrever a experiência de profissionais residentes no desenvolvimento de ações de autocuidado em saúde mental com o idoso durante a pandemia do novo coronavírus. Trata-se de um relato de experiência, onde se desenvolveu uma roda de conversa online, via ferramenta zoom, em Fevereiro de 2021. Adotaramse como recursos metodológicos: aula expositiva-dialogada, dinâmica participativa, musicoterapia e poesia. O encontro foi denominado "Envelhecer bem: trabalhando amor próprio e autoestima". A atividade de promoção à saúde mental realizada pelos profissionais residentes estabeleceu e fortaleceu vínculos, bem como educou em saúde, promovendo o empoderamento e a autonomia do idoso para o seu autocuidado, permitindo que este reconheça suas capacidades e importância na construção conjunta do cuidado a fim de promover bem-estar e melhor qualidade de vida.

PALAVRAS-CHAVES: Promoção da Saúde; Saúde do Idoso; Atenção Primária à Saúde.

ÁREA TEMÁTICA: Educação em Saúde 


\section{INTRODUÇÃO}

Ao longo das últimas décadas, observou-se o processo de envelhecimento populacional e o aumento da expectativa de vida. Porém, envelhecer se tornou algo desafiador à medida que a prevalência de agravos crônicos também sofreu aumento significativo. Logo, para se viver mais é preciso que haja qualidade de vida. Para tal, torna-se necessário investimentos em ações de prevenção e promoção da saúde.

O envelhecimento é um processo natural e inerente ao ser vivo, incluindo os seres humanos. Essa fase caracteriza-se por uma série de modificações biopsicossociais. Contudo, as pessoas devem procurar aprender a lidar positivamente com as limitações que podem surgir, mantendo-se ativas.

O idoso pode sofrem grandes cargas psicológicas comuns a essa faixa etária, como sofrimento mental, ansiedade, depressão, distúrbios do sono, demências e quadros psicóticos. A conduta adequada é procurar possibilidades para minimizar e/ou eliminar problemas que possam comprometer a saúde, incluindo a saúde mental.

No atual cenário de saúde pandêmico, a desinformação, notícias falsas, a necessidade de distanciamento, isolamento e perda de entes queridos vem impactando diretamente os idosos já que se encontram como grupo de risco para uma série de alterações e comprometimentos, necessitando de maior acolhimento e atenção em saúde.

Nessa perspectiva, se traz o autocuidado como um campo que vem sendo amplamente estudado em diversas áreas da saúde, sendo instrumento facilitador do envelhecimento ativo e autônomo. Por meio dessa estratégia o ser humano reflete sobre si mesmo, sobre o ambiente em que está inserido e passa a desenvolver e manter motivação para seu próprio cuidado. Ressalta-se que para o autocuidado deve-se considerar o apoio e inclusão das redes sociais do indivíduo.

Portanto, este estudo traz como objetivo descrever a experiência de profissionais residentes no desenvolvimento de ações de autocuidado em saúde mental com o idoso durante a pandemia do novo coronavírus.

\section{METODOLOGIA}

Trata-se de estudo descritivo, qualitativo do tipo relato de experiência, fundamentado na Teoria da Problematização do Arco de Maguerez, construído a partir de ações em saúde mental, com enfoque na promoção do autocuidado, promovidas por profissionais residentes do Programa de Residência Multiprofissional em Saúde da Família e Comunidade da Universidade Estadual do Piauí, sob orientação de suas tutoras de campo.

Desenvolveu-se roda de conversa online por meio da ferramenta zoom, com idosos, alunos da Universidade Aberta da Terceira Idade, vinculada à instituição de ensino superior pública, em Fevereiro de 2021, no município de Teresina, Piauí. Adotaram-se como recursos metodológicos: aula 
expositiva-dialogada, dinâmica participativa, musicoterapia e poesia.

\section{RESULTADOS E DISCUSSÕES}

Devido às necessidades de isolamento social decorrentes da pandemia, as aulas ministradas aos idosos passaram a ser via plataforma online zoom. Os residentes, à convite de professores da instituição de ensino, participaram de um contato inicial, contribuindo para a formação do vínculo entre os profissionais e o público-alvo, tornando-se possível identificar necessidades em saúde elencadas pelos próprios idosos, o que culminou no tema autocuidado, a ser trabalhado multi e interprofissionalmente entre as categorias de Enfermagem e Psicologia da residência.

Após a construção de um plano de ação, as propostas foram trabalhadas em encontro seguinte. Participaram do momento os idosos alunos, professores, demais categorias de residentes e tutoras. O encontro foi denominado 'Envelhecer bem: trabalhando amor próprio e autoestima".

O autocuidado é conceituado pelo conjunto de ações que o indivíduo desenvolve consciente e deliberadamente em seu benefício no sentido de manter a vida e o seu bem-estar e evolui até uma construção coletiva que aponta não só para a responsabilidade do indivíduo, mas também considera o apoio da família, dos amigos e das instituições de saúde como essenciais na contribuição para que os indivíduos tomem as melhores decisões para o seu bem-estar.

Assim sendo, iniciou-se a reunião com uma acolhida por meio de musicoterapia. Essa terapêutica alternativa contribui no processo curativo e preventivo, restaurando funções e potenciais do indivíduo, além de estimular a cognição e efeitos a nível do sistema nervoso. Em seguida, houve uma breve explanação, pelos enfermeiros residentes, sobre o processo de envelhecimento e importância do cuidado à saúde mental. Envelhecer de maneira saudável implica na possibilidade de manter as capacidades físicas e mentais de cada indivíduo, contribuindo para lidar com o estresse cotidiano, permitindo que o idoso identifique suas potencialidades e garanta melhor qualidade de vida. Os psicólogos residentes complementaram as informações trazendo conceitos relacionados e estímulo à prática diária do amor próprio e autoestima.

Uma dinâmica foi realizada, onde todos foram convidados a se sentir à vontade em participar e contribuir com o momento. Um objeto ou uma palavra deveria ser escolhida como forma de representação do autocuidado diário. Objetos pessoais e de uso cotidiano foram listados, como por exemplo, o cuidado às plantas, dança e a música também foi mencionada.

Exercitar o autocuidado através de formas saudáveis foi à perspectiva de educação em saúde proposta no encontro, pois fortalece as potencialidades de cada idoso e ajuda a construir uma autoestima, que nessa fase do desenvolvimento muitas vezes se encontra fragilizada, diante das mudanças de autoimagem corporal, do afastamento social pela aposentadoria, problemas familiares e doenças crônicas que os acometem nessa fase da vida.

Assim, momentos que possam ajudá-los a desenvolver e promover o amor-próprio diário são 
necessários para que esses possam fortalecer o conceito acerca de si próprio de maneira a valorizar sentimentos de autoconfiança. A soma de autoconfiança e amor-próprio formam uma autoestima amparada em um bem-estar emocional e psicológico. É esse o mecanismo que pode oferecer ao idoso uma maior percepção de si mesmo, reafirmando o valor pessoal, e fortalecendo o amor-próprio.

O momento final do encontro culminou na apresentação da poesia ''E se”, de Bráulio Bessa, trazendo a discussão das decisões que o ser humano deixa de tomar por medo do erro, seguida por agradecimentos e compartilhamentos de dúvidas, onde os idosos demonstraram-se participativos e interessados sobre a temática trabalhada.

\section{CONCLUSÃO}

A chegada da pandemia exigiu maior conscientização e cuidado da população em relação à saúde, sendo o isolamento social uma das principais medidas de enfrentamento em relação ao contágio pelo novo coronavírus. Em decorrência desse isolamento, os idosos, um dos principais grupos de risco para a doença, sofrem impactos negativos em suas atividades cotidianas o que pode levar a um maior sofrimento mental, exigindo amplas formas de intervenção em saúde e maiores cuidados a esse público.

A atividade de promoção à saúde mental realizada pelos profissionais residentes estabeleceu e fortaleceu vínculos, bem como educou em saúde, promovendo o empoderamento e a autonomia do idoso para o seu autocuidado, permitindo que este reconheça suas capacidades e importância na construção conjunta do cuidado a fim de promover bem-estar e melhor qualidade de vida.

\section{PRINCIPAIS REFERÊNCIAS}

ALMEIDA, L.; BASTOS, P. R. H. O. Autocuidado do Idoso: revisão sistemática da literatura. Espacios, v. 38, n. 28, 2017.

ANDRADE, F. B. et al. Promoção da saúde mental do idoso na atenção básica: as contribuições da terapia comunitária. Texto Contexto Enferm, Florianópolis, v. 19, n. 1, p. 129-36, 2010.

ANJOS, Alexandre Gonzaga dos et al. Musicoterapia como estratégia de intervenção psicológica com crianças: uma revisão da literatura. Rev. Interinst. Psicol., Belo Horizonte, v. 10, n. 2, p. 228238, dez., 2017.

CASEMIRO, N. V.; FERREIRA, H. G. Indicadores de saúde mental em idosos frequentadores de grupos de convivência. Rev. SPAGESP, Ribeirão Preto, v. 21, n. 2, p. 83-96, dez., 2020.

COUTINHO, L. S. B.; TOMASI, E. Déficit de autocuidado em idosos: características, fatores associados e recomendações às equipes de Estratégia Saúde da Família. Interface (Botucatu), v. 24, Supl. 1, e190578, 2020. 
VERAS, R. P.; OLIVEIRA, M. Envelhecer no Brasil: a construção de um modelo de cuidado. Ciência \& Saúde Coletiva, v. 23, n. 6, p. 1929-1936, 2018. 


\title{
PREVENÇÃO AO SUICÍDIO NA ATENÇÃO PRIMÁRIA DE SAÚDE NO MUNICÍPIO DE CASCAVEL - PR
}

\author{
Anderson Henrique Carboni ${ }^{1}$ \\ ${ }^{1}$ Assistente Social Residente em Saúde da Família, Escola de Saúde Pública Municipal ESPM- \\ SESAU, Cascavel, Paraná.
}

DOI: $10.47094 /$ ICONRES.2021/13

\begin{abstract}
RESUMO
Em escala global, o suicídio apresenta-se um grave problema de saúde pública. De acordo com dados divulgados pela Organização Mundial de Saúde (OMS, 2019), um óbito suicida ocorre a cada 40 segundos no mundo. Neste ranking, de acordo com o Ministério da Saúde (2018), o Brasil ocupa o $8^{\circ}$ lugar contabilizando 11 (onze) mil casos de óbitos suicidas. Mesmo diante de tal gravidade, o suicídio é percebido como um grande tabu dentro da sociedade, caracterizando-se, assim, um grande desafio para os profissionais de saúde, em especial para os atuantes na atenção primária, haja vista a proximidade das equipes com a população. Sendo assim, desenvolveu-se um projeto de orientação aos profissionais atuantes das equipes de saúde da família do Município de Cascavel - PR, que traz informações sobre o suicídio, objetivando orientar para o reconhecimento de pacientes em risco, cooperando assim, para prevenção dos casos.
\end{abstract}

PALAVRAS-CHAVES: Saúde Mental; População Adscrita; Educação Permanente.

ÁREA TEMÁTICA: Educação em Saúde

\section{INTRODUÇÃO}

Em linhas gerais, define-se o suicídio como o ato de óbito auto infligido, deliberado e executado pelo indivíduo, utilizando-se de método considerado fatal pelo mesmo, cujo objetivo é morrer. Este desejo é consciente e proposital, ainda que cercado de ambivalência. (CVV, 2014). Por ser um fenômeno complexo e cercado de tabus, muitas vezes é difícil detectar a ideação suicida, evitando assim que o manejo correto dos pacientes com esta intenção seja realizado, em especial nos estabelecimentos caracterizados como portas de entradas, sendo o projeto citado desenvolvido para as unidades de Atenção Primária de Saúde - APS. Este conjunto é composto principalmente pelas Unidades de Saúde da Família (USF) e Unidades de Básicas de Saúde (UBS), que contam com equipes multidisciplinares, sendo elas as instâncias mais próximas dos indivíduos, desempenhando, 
portanto, papel fundamental junto à população. Dessa forma, diversos pacientes buscam suas unidades de referência para pedir ajuda. Todavia, em razão dos estigmas entorno do suicídio, diversos dos profissionais atuantes não possuem instruções suficientes para abordar a temática de forma assertiva. Isto posto, buscando contribuir para o acolhimento humanizado dos pacientes em sofrimento psíquico, desenvolveu-se um projeto de orientação para os profissionais da atenção primária, que objetiva levar informações sobre a temática do suicídio, expondo suas complexidades - fatores de risco, mitos e verdades, posvenção do suicídio, etc. - e como abordar corretamente os pacientes com pensamentos de morte e ideação suicida, cooperando assim, para prevenção dos casos e na oferta de bem-estar para os pacientes atendidos pela equipe.

\section{METODOLOGIA}

Para desenvolvimento do projeto, utilizou-se da pesquisa bibliográfica nos materiais disponibilizados pelo Conselho Federal de Medicina (CFM), Ministério da Saúde e Centro de Valorização da Vida (CVV), pelos quais são grandes referências da temática. A pesquisa resultou no desenvolvimento de uma cartilha de orientação destina aos profissionais da Atenção Primária.

Em relação à aplicação do projeto, utilizou-se a dinâmica de grupos com os profissionais das unidades intervindas. Em decorrência do quadro pandêmico causado pelo SARS COV2 (COVID-19), ficou proibida a realização de reuniões com grandes aglomerações. Dessa forma, para viabilidade da intervenção, dividiu-se os profissionais em pequenos grupos, buscando abranger o máximo do público alvo, mas mantendo todas as medidas sanitárias e de saúde exigidas pelo momento. Por sua vez, a cartilha criada, serviu como guia para realização dos grupos, a mesma deu enfoque na atuação da atenção primária frente às situações envolvendo o suicídio e a importância do acolhimento humanizado para preservação da vida.

Nos grupos, desenvolveu-se uma linha do tempo com os pontos de essencial importância para sensibilização dos profissionais, sendo eles: definição de suicídio; saúde mental e os principais transtornos mentais relacionados ao suicídio; mitos e verdades, buscando desmistificar os mitos mais comuns acerca do tema; o papel da atenção primária de saúde na prevenção dos casos; questões norteadoras para escuta qualificada dos pacientes com adoecimento mental; posvenção do suicídio e os efeitos do luto no familiares; formas de ajudar alguém com pensamento de morte e ideação suicida.

Objetivando, também, atingir o maior número de profissionais com o conhecimento do tema, buscou-se adaptar as linguagens utilizadas dos materiais de referência para uma linguagem mais acessível dentro da cartilha criada para o projeto, de forma que a transmissão do conhecimento pudesse acontecer de modo abrangente. Sendo assim, as informações necessárias puderam ser compreendidas pelos profissionais de nível fundamental, médio, técnico e superior, sem distinção. Posteriormente, ao fim das intervenções, a cartilha foi disponibilizada aos profissionais para estudos e aprofundamento do tema. 
Até o presente momento, o projeto foi desenvolvido em 2 (duas) USFs, 1 (uma) UBS e realizado 1 (um) encontro com os assistentes sociais integrantes do Programa de Residência Multiprofissional em Saúde da Família do Município de Cascavel - PR. Ao todo, foram realizados 9 (nove) encontros entre os meses de agosto a dezembro de 2020.

\section{FUNDAMENTAÇÃO TEÓRICA}

A Política Nacional de Atenção Primária, estabelecida pela Portaria No 2.436/2017, é caracterizada como um conjunto de ações no âmbito coletivo e individual, que visam à promoção, divulgação, prevenção, redução de danos, além de cuidados paliativos e de recuperação da saúde, pelas quais possam abranger os diversos aspectos presentes no conceito de saúde, indo além do simples tratamento de enfermidades. Tudo isso se dará em conjunto com uma gestão qualificada, realizada por equipe multiprofissional, sendo as atividades direcionadas para população adscrita do local. (BRASIL, 2017).

Todas estas atividades precisam ser desenvolvidas com o maior grau de capilaridade, objetivando atender as diligências encontradas em cada área de abrangência. (BRASIL, 2017). Para que este objetivo seja atendido, a política é regida por princípios norteadores que desenham as intervenções, sendo eles os: "da universalidade, da acessibilidade, do vínculo, da continuidade do cuidado, da integralidade da atenção, da responsabilização, da humanização, da equidade e da participação social." (Brasil, 2017, p. 19). Sendo assim, a atenção primária se expressa como grande porta de entrada das demandas, além de ser a instância central de comunicação com a Rede de Atenção em Saúde - RAS, servindo de referência para pacientes e profissionais.

A ênfase na atenção primária em saúde, posta como campo central do projeto, busca reforçar os princípios norteadores da política e aproximar as equipes de saúde da família com a problemática do suicídio, que tem apresentado urgência em seu debate. De acordo com a OMS (2000), a atenção primária em saúde é capaz de ofertar cuidado continuado aos usuários, dispondo de acolhimento para pacientes e familiares dos pacientes, além de organizações e instituições voltadas para temática do suicídio, se tornando assim, campo rico para desenvolvimento de intervenções na temática.

O suicídio é considerado um comportamento caracterizado pelo desejo da própria morte, induzindo o indivíduo a autoaniquilação. Pode ser definido, ainda, como um fenômeno complexo, pois envolve uma série de violências autoinfligidas ao nível psicológico e físico, podendo haver um desfecho trágico. (UNASUS, 2020). Uma das formas mais eficazes de se evitar um desfecho trágico é a detecção precoce dos sinais de alerta emitidos pelo paciente e o correto manejo da situação, de forma que seja possível tratar as causas de cada indivíduo e oferecer bem-estar emocional, físico e social, afastando-o do risco. (ONU, 2015). A OMS (2000) também ressalta que a intervenção de profissionais junto às comunidades, realizando a conscientização de vizinhos, amigos e familiares do indivíduo com ideação suicida, é de grande eficácia para prevenção, uma vez que reforça a rede de apoio pessoal. 


\section{CONSIDERAÇÕES FINAIS}

$\mathrm{Na}$ realização dos grupos, os profissionais participaram e se envolveram bastante com a temática, de modo que a metodologia proposta foi alcançada com êxito, levando, assim, o conhecimento necessário proposto para equipe. Além disso, nos encontros, por vezes, os profissionais compartilharam experiências pessoais envolvendo situações de suicídio com pessoas próximas, ou então, o seu próprio adoecimento mental, enriquecendo os momentos de debate e sensibilizando os profissionais para os problemas da própria equipe.

Sensibilizar a equipe para temática do suicídio também apresentou resultados no cotidiano de trabalho das unidades. Os profissionais deram feedbacks, ou, então, trocaram informações entre si, quando perceberam pacientes com sinais de alerta, possibilitando realizar intervenções com os mesmos e aliviar o sofrimento psíquico destes.

Por fim, vale ressaltar que se pretende continuar realizando os grupos em outras unidades de saúde, auxiliando as equipes e contribuindo para prevenção do suicídio.

\section{PRINCIPAIS REFERÊNCIAS}

BRASIL. PORTARIA No 2.436, DE 21 DE SETEMBRO DE 2017. Política Nacional de Atenção Básica. 2017, Brasília, DF, Diário Oficial. Disponível em: < https://bvsms.saude.gov.br/bvs/saudelegis/ gm/2017/prt2436_22_09_2017.html>.Acesso em: 12/03/2021.

MINISTÉRIO DA SAÚDE. Novos dados reforçam a importância da prevenção do suicídio. 2018, Brasília, DF. Disponível em: < https://www.saude.gov.br/noticias/agencia-saude/44404-novosdados-reforcam-a-importancia-da-prevencao-do-suicidio >. Acesso em: 25/05/2020.

ORGANIZAÇÃO MUNDIAL DE SAÚDE. PREVENÇÃO DO SUICÍDIO: UM MANUAL PARA PROFISSIONAIS DA SAÚDE EM ATENÇÃO PRIMÁRIA. 2000, Genebra. Disponível em: < https://www.who.int/mental_health/prevention/suicide/en/suicideprev_phc_port.pdf $>$. Acesso em: $14 / 03 / 2021$.

Um suicídio ocorre a cada 40 segundos no mundo, diz

OMS. 2019. Disponível em: < https://nacoesunidas.org/um-suicidio-ocorre-a-cada-40-segundos-nomundo-diz-oms/ >. Acesso em: 14/03/2021.

UNIVERSIDAde ABERTA DO SUS. PREVENÇÃO AO SUICÍDIO. 2020, UFSC, Santa Catarina. Disponível em: $<$ https://unasus-quali.moodle.ufsc.br/course/view.php?id=56 > . Acesso em: $15 / 03 / 2021$. 


\title{
EDUCAÇÃO EM SAÚDE SOBRE INFECÇÕES SEXUALMENTE TRANSMISSÍVEIS COM PROFISSIONAIS DA SEGURANÇA PÚBLICA
}

\section{Jovelina Fernandes dos Santos ${ }^{1}$; Kelly Clennia Ribeiro Costa ${ }^{2}$; Joanne Days de Sousa Nóbrega $^{3}$; Fernanda Prudêncio da Silva ${ }^{4}$}

${ }^{1}$ Enfermeira. Universidade Federal de Campina Grande (UFCG). Catolé do Rocha. Paraíba.

${ }^{2}$ Nutricionista. Faculdade Internacional da Paraíba (FPB). Catolé do Rocha. Paraíba.

${ }^{3}$ Assistente Social. Centro Universitário de Patos (UNIFIP). Catolé do Rocha. Paraíba

${ }^{4}$ Psicóloga. Centro Universitário Maurício de Nassau (UNINASSAU). Catolé do Rocha. Paraíba.

\begin{abstract}
RESUMO
O enfrentamento às Infecções Sexualmente Transmissíveis (ISTs) constitui desafio à sociedade, no estabelecimento de medidas de controle das suscetibilidades ligadas aos aspectos individuais e coletivos. Este estudo teve por objetivo descrever a experiência vivenciada por residentes multiprofissionais em saúde coletiva em prática de educação em saúde acerca das ISTs com os profissionais da segurança pública. Trata-se de um estudo descritivo, do tipo relato de experiência. O público alvo foi constituído por profissionais da segurança atuantes em um presídio estadual, localizado no alto sertão paraibano. A partir do discurso dos participantes percebeu-se a existência do estigma relacionado à abordagem do tema no ambiente familiar, falta de espaços para diálogo com seus filhos e parceiros sexuais e receio em adquirir preservativos por medo de julgamento de terceiros. A experiência possibilitou promover educação em saúde para que os participantes sejam multiplicadores do saber dentro do ambiente de trabalho e familiar.
\end{abstract}

PALAVRAS-CHAVES: Educação em Saúde; Doenças Sexualmente Transmissíveis; Equipe de Assistência ao Paciente.

ÁREA TEMÁTICA: Educação em saúde

\section{INTRODUÇÃO}

$\mathrm{O}$ enfrentamento às Infecções Sexualmente Transmissíveis (ISTs) constitui desafio à sociedade, no estabelecimento de medidas de controle das suscetibilidades ligadas aos aspectos individuais e coletivos. No cenário brasileiro, as políticas públicas vêm ampliando os esforços para expandir o acesso universal e gratuito aos preservativos, testagem e tratamento gratuito para reduzir 
a incidência e melhorar a qualidade de vida dos indivíduos com ISTs (BRASIL, 2020).

Outra importante estratégia de prevenção para todas as IST é a divulgação sobre as formas de transmissão seus sinais e sintomas, com o objetivo de aumentar o conhecimento da população e orientar a busca precoce por assistência, apesar das informações serem amplamente divulgadas, ainda existe lacunas na adoção de medidas de proteção contra as IST na população (PINTO et al., 2014).

Este estudo teve por objetivo descrever a experiência vivenciada por residentes multiprofissionais em saúde coletiva em prática de educação em saúde acerca das IST com os profissionais da segurança pública.

\section{METODOLOGIA}

Trata-se de um estudo descritivo, do tipo relato de experiência. A idealização da construção do estudo partiu de uma atividade educativa realizada por residentes multiprofissionais em saúde coletiva. O público alvo foi constituído por profissionais da segurança pública atuantes em um presídio estadual, localizado no alto sertão paraibano, com o intuito de discutir sobre ISTs.

Para se efetivar esta atividade educativa utilizamos de uma metodologia de ensinoaprendizagem para tornar o sujeito ativo na construção do seu conhecimento, (re) construindo seus saberes, além de incentivar a participação, o respeito ao outro e o trabalho em grupo. Sendo assim, utilizou-se a metodologia de círculos de cultura, no qual Paulo Freire defende, uma vez que ele considera o homem sujeito da educação por meio da reflexão sobre sua realidade e compromisso com o objetivo de transformá-la (FREIRE, 2018).

\section{RESULTADOS E DISCUSSÕES}

O círculo de cultura ocorreu nas dependências do presídio, estiveram presentes nove profissionais da segurança, sendo quatro do sexo feminino e cinco do sexo masculino, além de residentes multiprofissionais em saúde coletiva e apoiadora regional da vigilância epidemiológica, essa ação ocorreu em alusão a semana de combate á sífilis.

Para conduzir o encontro, inicialmente, utilizou-se uma atividade de acolhimento com apresentação pessoal para facilitar a socialização entre os indivíduos envolvidos. Em seguida, para a discussão em grupo sobre a temática, foi apresentado pelos residentes casos clínicos fictícios, dentro de uma perspectiva que inclui o paciente, o sistema de saúde pública e a sociedade, no qual os participantes são confrontados com situações-problemas, referentes à prevenção, diagnóstico e tratamento da sífilis, herpes genital e labial, HIV e hepatites virais, entres outras ISTs, e a partir daí, são convidados para exporem seu modo de atuação para enfrentar a situação.

Durante o círculo de cultura os participantes se envolveram de forma ativa e dinâmica, 
exteriorizaram seus conhecimentos por meio de discussões de casos permitindo-se intervenções e questionamentos por parte das participantes antes da realização dos testes rápidos e esporam suas dificuldades e conhecimentos em relação ao tema abordado.

A educação em saúde contribui significativamente para o aumento do conhecimento dos participantes e da sua percepção de vulnerabilidade a respeito de ISTs. Entretanto, o conhecimento adquirido nem sempre produz mudança de atitude e comportamento, fazendo-se necessário que os profissionais da saúde reconheçam a importância das práticas educativas em seu cotidiano para a emancipação do indivíduo, favorecendo o desenvolvimento do sentido de responsabilidade por sua própria saúde (RUFINO et al., 2016).

A partir do discurso dos participantes percebeu-se a existência do estigma relacionado à abordagem do tema no ambiente familiar, falta de espaços para diálogo com seus filhos e parceiros sexuais e receio em adquirir preservativos por medo de julgamento de terceiros.

Após o circulo de cultura foram distribuídos insumos de prevenção (preservativos masculinos, gel lubrificante e folders informativos), foram realizados testes rápidos para o diagnóstico de sífilis, HIV e hepatites B e C, além de aconselhamento sobre saúde sexual de forma coletiva e individual.

Logo, essa discussão deve ocorrer de modo conjunto, com a inclusão da família e profissionais da saúde, para que em mescla possam compreender a realidade em que cada um está inserido, de modo a delimitar a responsabilidade e corresponsabilidade de cada um nesse processo de descobertas, sendo, esses atores protagonistas de sua saúde sexual, visto que a discussão sobre sexualidade deve ser considerada múltiplas dimensões dos sujeitos envolvidos (SANTOS, 2020).

Esses discursos evidenciam a necessidade de espaços de encontros coletivos e individuais no setor da segurança pública para abordar assuntos mais específicos sobre sexualidade e formas de prevenção, utilizando estratégias mais apropriadas para o envolvimento desses profissionais, criando espaços de diálogo, onde as duvidas seriam esclarecidas e as informações repassadas com mais segurança (ANDRADE et al., 2014).

\section{CONSIDERAÇÕES FINAIS}

A experiência possibilitou promover educação em saúde como ferramenta inovadora nas práticas de intervenção no contexto das ISTs. Foi utilizada a integração entre os setores da saúde e da segurança pública para alcançar a promoção da saúde. O círculo de cultura possibilitou compreender os questionamentos e desmistificar estigmas dos participantes referentes à temática agregando mais conhecimento, contribuindo para uma vida sexual saudável e para a diminuição da incidência de ISTs, além de culminar para que eles sejam multiplicadores do saber dentro do ambiente de trabalho e na dinâmica familiar. Ademais, essa ação enfatiza o protagonismo dos residentes multiprofissionais em saúde coletiva no compartilhamento do saberes e proporcionou maior autonomia como educadores em saúde, além de ampliar os espaços de atuação em saúde coletiva. 


\section{REFERÊNCIAS}

ANDRADE, Luciana Dantas Farias de et al. Promovendo Ações Educativas sobre Sífilis Entre Estudantes de uma Escola Pública: Relato de Experiência. Rev. bras. ciênc. saúde, p. 157-160, 2014.

BRASIL. Ministério da Saúde. Departamento de IST, Aids e Hepatites Virais. HIV / Aids. Bol Epidemiologico, 2020. Disponível em: http:/www.aids.gov.br/pt-br/pub/2020/boletimepidemiologico-hivaids-2020.

FREIRE, Paulo. Autonomia da Pedagogia: saberes necessários a prática educativa. $57^{\mathrm{a}}$ ed. Rio de Janeiro: Paz e Terra; 2018.

PINTO, Valdir Monteiro et al. Fatores associados às infecções sexualmente transmissíveis: inquérito populacional no município de São Paulo, Brasil. Ciência \& Saúde Coletiva, v. 23, p. 2423-2432, 2018.

RUFINO, Érika Cavalcanti et al . Conhecimento de mulheres sobre ist/aids: intervindo com educação em saúde. Ciência, Cuidado \& Saúde, v. 15, n. 2, p. 304-312, jun. 2016.

SANTOS, Silvana Cavalcanti et al. Oficinas de educação em saúde: sensibilização dos adolescentes sobre as infecções sexualmente transmissíveis. Revista Caravana, v. 5, n. 2, 2020. 


\title{
CAMPANHA OUTUBRO ROSA: EDUCAÇÃO EM SAÚDE COMO FERRAMENTA DE CONSCIENTIZAÇÃO PARA O CÂNCER DE MAMA
}

\author{
Maria da Conceição Lima Paiva ${ }^{1}$ \\ ${ }^{1}$ Graduada em Enfermagem, Centro Universitário (UNINTA), Sobral, Ceará
}

\begin{abstract}
RESUMO
A promoção da saúde é um processo que objetiva ampliar a participação dos indivíduos e comunidade nas ações que atuam sobre sua saúde. Tem como objetivo relatar a educação em saúde referente ao outubro rosa em um centro de saúde da família. Trata-se de um relato de experiência, transcorrido no mês de setembro de 2020, em Centro de Saúde da Família. A proposta de intervenção foi organizada juntamente com a enfermeira, gerente e os Agentes Comunitários de Saúde, enviando convites às mulheres para comparecerem a unidade. Esse modelo de ação abordou um assunto fundamental preconizado na atenção básica a promoção de saúde e a interação ensino-serviço-comunidade, contribuindo de forma significativa na vida das usuárias tendo em vista que a metodologia utilizada ofereceu voz ao usuário e facilitou os ensinamentos levados pelo grupo. Conclui-se que atividade educativa foi positiva, as mulheres demonstraram interesse em aprender mais sobre a temática estabelecendo um ambiente de ensino aprendizagem.
\end{abstract}

Palavra-chave: Promoção da Saúde; Atenção Básica; Enfermagem.

Área Temática: Educação em Saúde

\section{INTRODUÇÃO}

A promoção da saúde é entendida como um processo que objetiva ampliar a participação dos indivíduos e comunidade nas ações que atuam sobre os fatores que influenciam sua saúde (MALTA et al., 2020). Nesse contexto, a Organização Mundial da Saúde (OMS) considera a promoção da saúde eficaz, ao conduzir mudanças nos determinantes da saúde, que podem ser tanto os fatores que estão sob o controle do indivíduo, como estilos de vida e condutas, quanto os fatores externos, relativos às condições econômicas, sociais, ambientais e à prestação de serviços (BRASIL 2007).

Dados do Instituto Nacional do Câncer (INCA) assevera que no mundo e no Brasil o câncer de mama é mais comum nas mulheres. A mortalidade por essa neoplasia ainda é ascendente, em 2018 foi registrado 17. 572 óbitos por câncer de mama. Os Avanços terapêuticos nas últimas décadas vêm ampliando as possibilidades de enfrentamento da doença, porém a detecção precoce segue como 
desafio (INCA, 2019).

Nessa perspectiva a detecção precoce do câncer de mama visa identificar a doença em fase inicial, seja por meio do diagnóstico precoce, estratégia dirigida às mulheres com sinais e sintomas suspeitos da doença, ou do rastreamento mamográfico, exames de rotina em mulheres assintomáticas em faixa etária e periodicidades definidas (ASSIS; SANTOS; MIGOWSKI, 2020). Frente ao exposto, objetivou-se neste estudo relatar a educação em saúde referente ao outubro rosa em um centro de saúde da família.

\section{METODOLOGIA}

Trata-se de um estudo descritivo tipo relato de experiência vivenciado durante o internato em um Centro de Saúde da Família (CSF) na cidade de Sobral, transcorrido no mês de setembro de 2020. A proposta de intervenção foi organizada juntamente com a enfermeira, gerente e os Agentes Comunitários de Saúde (ACS), enviando convites às mulheres para comparecerem ao CSF. Houve decoração da sala com letras rosa e para melhor ilustração, foi utilizado cartazes sobre o tema, com informações retiradas do INCA.

Ao iniciar, a enfermeira juntamente com os internos dialogaram sobre o que representa a campanha, explicando-as sobre o que seria o câncer de mama, seus fatores de risco, sinais e sintomas, como prevenir, detecção precoce, e explicaram como fazer o autoexame das mamas e a importância do mesmo. No segundo momento houve a dinâmica do repolho, onde tocava uma música e ao parar as mulheres retirava uma pergunta e respondia. O terceiro momento ocorreu um diálogo para retirada de dúvidas com resultados satisfatórios Para finalizar foi ofertado um lanche.

\section{RESULTADOS E DISCUSSÃO}

Esse modelo de ação abordou um assunto fundamental preconizado na atenção básica a promoção de saúde e a interação ensino-serviço-comunidade, contribuindo de forma significativa na vida das usuárias, tendo em vista que a metodologia utilizada ofereceu voz ao usuário e facilitou os ensinamentos levados pelo grupo. Tal fato demonstra que a conexão estabelecida junto à comunidade favorece um melhor entendimento dos problemas de saúde a serem minimizados e solucionados por ações rotineiras e simples de serem aplicadas.

Nesta perspectiva Alves (2015), assevera que a educação em saúde são práticas orientadas para a promoção e prevenção de doenças. Trata-se de um recurso cientificamente produzido no campo da saúde, sendo intermediado pelos profissionais. No entanto traz-se a necessidade de discussões sobre os riscos e benefícios das intervenções em saúde. Nesse contexto, vale salientar que toda intervenção populacional devem ter sua segurança e efetividade comprovadas, cumprindo o que se propõe e causando o menor dano possível aos usuários (BRASIL, 2010). 
A ação educativa mostrou-se, portanto, enriquecedora para todos os envolvidos, sobretudo, porque pôde, por meio do estabelecimento de um ambiente que foge tanto à rotina do atendimento nas Unidades Básicas de Saúde como do ensino acadêmico tradicional, promover o autocuidado e , consequentemente, a prevenção do câncer de mama foco educativo da ação.

\section{CONCLUSÃO}

Conclui-se que atividade educativa foi de suma importância para o público alvo, pois as mulheres demonstraram interesse em aprender mais sobre a temática estabelecendo um ambiente de ensino aprendizagem, o que reafirmou a importância da realização da atividade de educação em saúde, contribuindo para prevenção de doenças e agravos. Para realizar a prevenção do câncer de mama e de outras doenças é necessária que a educação em saúde seja a ferramenta utilizada pelos profissionais de saúde, com o intuito de promover ações eficazes à promoção da saúde da população.

\section{REFERÊNCIAS}

BRASIL. Ministério da Saúde. Secretaria de Atenção à Saúde. Departamento de Atenção Básica. Política Nacional de Atenção Básica. Ministério da Saúde, Secretaria de Atenção à Saúde, Departamento de Atenção Básica. $4^{\mathrm{a}}$ ed. Brasília: Ministério da Saúde; 2007. 68 p. Disponível em:> https://www.inca.gov.br/sites/ufu.sti.inca.local/files//media/document/livro-abc-5-edicao_1.pdf. >. Acesso em 25 fev 2021.

Instituto Nacional do Câncer José Alencar Gomes da Silva - INCA. Câncer de colo do útero e mama. Rio de Janeiro: Ministério da Saúde, 2016. Disponível em: https:/www.inca.gov.br/sites/ufu. sti.inca.local/files//media/document/livro-abc-5-edicao_1.pdf. >. Acesso em 15 mar 2021.

MALTA, D. C. et al. Política Nacional de Promoção da Saúde: descrição da implementação do eixo atividade física e práticas corporais, 2006 a 2014. Revista Brasileira de Atividade Física e Saúde, Porto Alegre, v.19, n.3, p.286-299, 2020. 
Medicina Veterinária 


\section{SÍNDROME DE BURNOUT NA MEDICINA VETERINÁRIA}

\section{Gustavo Henrique Lima Pintoํㅗ Eduarda Rodrigues Teixeira Cassiano², Livia Fregnani de}

Almeida $^{3}$, Selene Daniela Babboni ${ }^{4}$

${ }^{1}$ Discente de Medicina Veterinária, Faculdade Anhanguera, São José dos Campos, SP.

${ }^{2}$ Discente de Medicina Veterinária, Universidade Paulista (UNIP), São José dos Campos, SP.

${ }^{3}$ Psicóloga autônoma, São José dos Campos, SP.

${ }^{4}$ Docente titular, Universidade Paulista (UNIP), São José dos Campos, SP.

DOI: $10.47094 /$ ICONRES.2021/11

\section{RESUMO}

A Síndrome de Burnout é uma condição alusiva ao fator ocupacional que interfere diretamente a saúde psicológica e física do indivíduo, gerando diversos sinais clínicos, onde a exaustão emocional é a dimensão precursora da síndrome, sendo seguida pela despersonalização, consequentemente a diminuição da realização do profissional em sua rotina de trabalho. Profissionais da área da saúde tem maior incidência nesta síndrome sendo médicos-veterinários os que representam a categoria com os índices de suicídio mais elevados, considerando a saúde mental desses profissionais acreditase que a rotina ocupacional desgastante, aliada com a predisposição do indivíduo, sejam os fatores predisponentes. A revisão de literatura teve o objetivo de descrever a Síndrome de Burnout destacando suas manifestações e inferências no que diz respeito ao médico-veterinário, profissional da saúde.

PALAVRAS-CHAVE: Profissional da saúde; estresse laboral; saúde mental.

ÁREA TEMÁTICA: Medicina Veterinária

\section{INTRODUÇÃO}

A Síndrome de Burnout é definida pela CID-11 como consequência do esgotamento mental crônico profissional (ICD-11, 2020). Em maio de 2018, a síndrome foi classificada pela Organização Mundial da Saúde como um fenômeno ocupacional, sendo incluída na Décima Primeira Revisão de Classificação Internacional de Doenças. Porém, salienta-se que a síndrome não foi categorizada como uma condição de saúde ou doença, mas especificada como um fator que influencia o estado de saúde (OPAS; OMS, 2019). 
Os profissionais da saúde estão prevalentemente relacionados à síndrome; dentre esses, os médicos-veterinários, e um dos fatores agravantes dessa profissão é a eutanásia, além das diversas responsabilidades cotidianas inerentes da prática veterinária (HANSEZ et al., 2008)

\section{METODOLOGIA}

O levantamento bibliográfico foi fundamentado a partir de buscas e análises de artigos científicos (língua portuguesa, inglesa e espanhola) obtidos nas bases de dados do Google acadêmico, PUBMED, Scientific Eletronic Library Online (SciELO). Buscou-se realizar uma revisão bibliográfica acerca da síndrome de Burnout nos profissionais de saúde enfatizando a classe da medicina veterinária, realizando um estudo descritivo.

\section{FUNDAMENTAÇÃO TEÓRICA}

O termo "Burnout", de origem inglesa, designa algo que deixou de funcionar por exaustão de energia (SILVEIRA et al, 2005). Burnout é definido por um tripé: exaustão emotiva, descaracterização e baixa realização profissional, sendo os três fatores negativos quanto a um elo saudável na profissão (CARLOTTO e PALAZZO, 2006).

O médico-veterinário se enquadra no grupo de profissionais de saúde com as manifestações clínicas da síndrome (MASLACH e LEITER, 1999), a exaustão emocional desse profissional é a primeira resposta a respeito do estresse laboral crônico, que traz consigo o desgaste físico e o esgotamento de recursos emocionais para lidar com a situação (CARLOTTO e PALAZZO, 2006). Podendo resultar em sinais físicos, como dores musculares e cefaleia, além do psíquico, como falta de paciência, ansiedade, manifestações de depressão, dificuldade no relacionamento interpessoal, perda de motivação profissional. Os médicos-veterinários estão entre os profissionais que mais sabotam a sua própria saúde mental e seu prazer de viver (MALAGRIS e FIORITO, 2006; CURY, 2016).

O DATASUS realizou uma pesquisa devido diversos relatos de suicídio e abandono de profissão por exaustão emocional, indicando que a taxa de suicídio de médicos-veterinários é de 10,6\% a frente da população geral, a frente de médicos $(5,8 \%)$ e enfermeiros $(3,6 \%)$, sendo a profissão prevalente na taxa de suicídio. Dos profissionais que desenvolvem a Síndrome as mulheres que trabalham com animais de pequenos portes são consideradas as mais predisponentes (ROLLIN, 2011; BARWALDT, 2020).

Os estudos publicados são baseados na rotina que este profissional exerce em sua rotina. Trabalham em torno de 44 a 54 horas semanais, sendo uma carga horária elevada, somando ao desequilíbrio entre a vida pessoal e profissional, sua autocrítica, são fatores que contribuem para o aumento do estresse emocional e desenvolvimento da Síndrome (MEEHAN e BRADLEY, 2007).

Outrossim, a responsabilidade do profissional, de comunicar os tutores de forma adequada 
sobre os tratamentos necessários para a cura e bem-estar do animal, e por vezes encontrando resistência do tutor, podem levar a um custo colateral da exaustão emocional (MCCULLOCH et al., 1992).

Sendo a única profissão da área da saúde que pode realizar o procedimento da eutanásia para seus pacientes, de acordo com normas éticas, o profissional tem uma sobrecarga emocional desgastante (MEEHAN e BRADLEY, 2007). A eutanásia podem envolver dilemas morais antecipatórios e futuros dilemas morais (se realizou a decisão correta, se houvesse algum procedimento que poderia ter tentado, insatisfação de ter que chegar nesse posicionamento e decisão e, explicar sobre a decisão ao tutor), o que torna um fator predisponente ao Burnout (NETT et al., 2015, FRANK, 2018).

\section{CONSIDERAÇÕES FINAIS}

A Síndrome de Burnout expõe a realidade da rotina do médico-veterinário como profissional da saúde, e as lacunas que a profissão revela quando a saúde psicológica e física é rejeitada pelo profissional e pela sociedade. As manifestações clínicas da síndrome expressam as reais condições que o médico-veterinário se enquadra, consequentemente a divergência de conectar-se consigo mesmo o que sensibiliza diretamente suas ações como profissional. Conhecer os enlaces da síndrome e suas manifestações motiva a classe veterinária a criar ações conjuntas para minimizar futuras intercorrências.

\section{PRINCIPAIS REFERÊNCIAS}

BARWALDT, E. T. et al. Reflexos da sociedade e a síndrome de Burnout na medicina veterinária: revisão de literatura. Braz. J. Hea. Rev., Curitiba, v. 3, n. 1, p. 2-14 jan./feb. 2020.

CARLOTTO, M.S.; PALAZZO, L.S. 2006. Síndrome de burnout e fatores associados: um estudo epidemiológico com professores. Cadernos de Saúde Pública, 22(5),1017-1026. Disponível em: https://www.scielosp.org/scielo.php?pid=S0102311X2006000500014\&script=sci_arttext\&tlng=en

CURY, A. 2016. Ansiedade 2- auto-controle: Como controlar o estresse e manter o equilíbrio. Benvirá, São Paulo (SP), BR.

FRANK, A. C. Síndrome de burnout na Medicina Veterinária. BOLETIM Apamvet, 2018.

HANSEZ, I.; SCHINS, F.; ROLLIN, F. Occupational stress, work-home interference and burnout among Belgian veterinary practitioners. Ir Vet J 61, 233 (2008). https://doi.org/10.1186/2046-048161-4-233

ICD-11 Implementation or Transition Guide, Geneva: World Health Organization; 2019; License: CC BY-NC-SA 3.0 IGO. Eleventh Revision, Version 09/2020.

MALAGRIS, L.E.N.; FIORITO, A. C. Avaliação do nível de stress de técnicos da área de saúde. 
Estudos de Psicologia, 23(4),391-398. 2006. Disponível em: www.scielo.br/pdf/estpsi/v23n4/ v23n4a07.pdf

MASLACH, C.; LEITER, M.P. 1999. Trabalho: fonte de prazer ou desgaste: guia para vencer o estresse na empresa. Papirus, Campinas, BR.

MCCULLOCH, M. J. et al. Ligação entre seres humanos e animais e a eutanásia - Um problema especial. In: ETTINGER, S. J. Tratado de Medicina Interna Veterinária. São Paulo: Manole, v.1, 1992, p.249-254.

MEEHAN, M.P.; BRADLEY, L. 2007. Identifying and evaluating job stress within the Australian small animal veterinary profession. Australian Veterinary Practitioner, 37(2),70-83. Disponível em:https://www.researchgate.net/profile/Michael_Meehan3/publication/43476786_Identifying_ and_evaluating_job_stress_within_the_Australian_small_animal_veterinary_profession/links/5 6e529e008ae68afa1112ae9.pdf

NETT, R. J. et al. Risk factors for suicide, attitudes toward mental illness, and practice-related stressors among US veterinarians. Journal of the American Veterinary Medical Association, 247(8), 945-955, 2015.

SAÚDE, Organização Pan Americana da; SAÚDE, Organização Mundial da. CID: Burnout é um fenômeno ocupacional. 2019. Disponível em: <https://www.paho.org/bra/index.php?option=com_co ntent\&view $=$ article\&id=5949: cidburnout-e-um-fenomeno-ocupacional\&Itemid=875>. Acesso em: 01 mar. 2021.

SILVEIRA, N.M. et al. Avaliação de burnout em uma amostra de policiais civis. Rev Psiquiatr RS. 2005; 27(2):159-63.

ROLLIN, B. E. Euthanasia, moral stress, and chronic illness in veterinary medicine. Veterinary Clinics: Small Animal Practice, 41, 651-659, 2011. 


\title{
LEPTOSPIROSE CANINA: RELATO DE CASO
}

\author{
Elizabetty de Melo Almeida Burity ${ }^{1}$ \\ ${ }^{1}$ Médica Veterinária Residente em Atenção Básica, UFRN/EMCM, Currais Novos, Rio grande do \\ Norte
}

\section{RESUMO}

A leptospirose é uma zoonose infectocontagiosa de distribuição mundial de grande significância para a saúde pública. Os cães são considerados importantes hospedeiros da doença, atuando também como reservatório. Relata-se a ocorrência da leptospirose em canino da raça Dachshund, atendido a domicilio no município de Carpina, interior do estado de Pernambuco. No exame físico observouse mucosas ictéricas, turgor da pele diminuído, aumento dos linfonodos poplíteos, dor abdominal, dispneia, taquipneia, taquicardia e pirexia. $\mathrm{Na}$ análise hematológica foi detectada anemia normocítica normocrômica, trombocitopenia, leucocitose por neutrofilia e alterações no bioquímico sérico. $\mathrm{O}$ resultado do teste sorológico constatou reagente para os sorovares icterohaemorrhagiae (1:100) e copenhageni(1:100). Como tratamento, instituiu-se fluidoterapia intensiva, terapia antibiótica associativa de doxiciclina e amoxicilina + clavulanato de potássio por 15 dias, Ranitidina, dipirona injetável e omeprazol. O animal não respondeu a terapia medicamentosa e foi a óbito 48 horas após início do tratamento.

PALAVRAS-CHAVES: Canino; Leptospira interrogans; Zoonose.

ÁREA TEMÁTICA: Medicina Veterinária

\section{INTRODUÇÃO}

A leptospirose é uma enfermidade infectocontagiosa de distribuição mundial, considerada de grande importância para a saúde pública devido a seu caráter zoonótico (HAGIWARA et al., 2015). É causada por bactérias da espécie Leptospira interrogans sendo considerado bastante resistente as condições ambientais, podendo sobreviver no meio ambiente por até 180 dias, contribuindo para a persistência de focos de leptospirose, além disso, possui diferentes sorovares, sendo descritos mais de 250, distribuídos em vários países do mundo, os quais acometem diversas espécies animais e apresenta como principal hospedeiro reservatório o rato (Rattus norvegicus), que, quando infectado não desenvolve a doença, ou seja, atua como portador assintomático, abrigando a Leptospira nos rins e, posteriormente, eliminando-a no meio ambiente, podendo contaminar o solo, fontes de água e alimento (HAGIWARA et al., 2015; NELSON \& COUTO, 2015; SCHULLER, 2017). Os cães 
também são considerados reservatórios da doença, favorecendo a transmissão da leptospirose para seres humanos em razão da sua estreita relação com o homem. Dentre os diversos sorovares, cita-se o L. icterohaemorrhagiae, L. pomona L. copenhageni, L. grippotyphosa, L. sejroe, L. australis e $L$. autumnalis como os mais identificados em cães (HAGIWARA et al., 2015; SCHULLER, 2017).

A transmissão ocorre principalmente após o contato do hospedeiro com água contaminada, podendo ocorrer pela pele integra ou lesada, mucosas conjuntivais, orais e nasais, além da ingestão de água ou alimentos contaminados (NELSON \& COUTO, 2015). Os sinais clínicos dependem de alguns fatores como resposta imunológica do hospedeiro frente à infecção, idade do mesmo e virulência do sorovar infectante (SANTIN et al., 2006). Observa-se na fase aguda, icterícia, apatia, anorexia, febre, vômitos, desidratação, dor abdominal, uveíte, dispneia, taquipneia, oligúria e anúria; a fase crônica geralmente não é aparente, notando apenas insuficiência renal crônica (SANTIN et al., 2006; NELSON \& COUTO, 2015; SCHULLER, 2017).

O diagnóstico ocorre através da associação dos sinais clínicos encontrados na anamnese e exames complementares sorológicos, microbiológicos e moleculares. Considera-se o teste de soroaglutinação microscópica (SAM) como o exame padrão ouro para a doença (NELSON \& COUTO, 2015). O tratamento é instituído por meio de antibioticoterapia, reposição de fluídos/metabolitos e terapia suporte de acordo com o sistema comprometido (SCHULLER, 2017).

O presente relato possui como objetivo, descrever o caso de um canino acometido pela Leptospirose, atendido a domicilio, destacando a importância do diagnóstico precoce e do tratamento para a espécie, que possui estreita relação com o homem.

\section{METODOLOGIA}

O artigo apresenta cunho descritivo, sendo um estudo de relato de caso. Foi atendido a domicilio, no município de Carpina, interior do estado de Pernambuco, um canino macho, inteiro, da raça Dachshund, quatro anos de idade, pesando $8 \mathrm{~kg}$. Relatou-se pelo tutor que o animal encontrava-se sem se alimentar direito a oito dias, apático, com quadro de vômito frequente, emagrecimento progressivo e diarreia sanguinolenta, mencionou-se que o início dos sinais clínicos ocorreu aproximadamente 15 dias após o proprietário encontrar em seu quintal um rato em estado de putrefação. No exame físico do paciente, observou-se mucosas ictéricas nas regiões oral, nasal e peniana (figura 1), turgor da pele diminuído, aumento dos linfonodos poplíteos, dor abdominal, dispneia, taquipneia (47 rpm), taquicardia (132 bpm) e temperatura retal de $41,5^{\circ} \mathrm{C}$, os demais parâmetros avaliados encontravamse dentro da normalidade. Diante do observado, suspeitou-se de leptospirose e posteriormente foi solicitado exames laboratoriais de hemograma, perfil bioquímico sérico (ureia, creatinina, AST, ALT e FA), proteínas totais e teste sorológico imunoenzimático (ELISA) para a doença. Na avaliação do hemograma, o animal apresentou anemia normocítica normocrômica, trombocitopenia, leucocitose por neutrofilia, no bioquímico sérico, observou-se aumento nos valores de uréia (275 mg/dL), creatinina $(17 \mathrm{mg} / \mathrm{dL}), \operatorname{AST}(260 \mathrm{U} / \mathrm{L})$, ALT (110 U/L) e FA (520 U/L). O resultado do teste sorológico constatou 
reagente para os sorovares icterohaemorrhagiae (1:100) e copenhageni (1:100). Como tratamento, instituiu-se fluidoterapia intensiva, terapia antibiótica associativa de doxiciclina $(20 \mathrm{mg} / \mathrm{mL}, \mathrm{IV}$, SID) e amoxicilina + clavulanato de potássio (20 mg/kg, SC, SID) durante 15 dias, ranitidina ( $2 \mathrm{mg} / \mathrm{kg}, \mathrm{SC}$, BID), dipirona injetável (25 mg/kg,IV, TID) e omeprazol (1 mg/kg, VO, SID) por 15 dias. O animal não respondeu a terapia medicamentosa e foi a óbito 48 horas após início do tratamento.

Figura 1: Mucosas ictéricas de um canino acometido por Leptospirose (A - mucosa conjuntival; $\mathbf{B}$ mucosa oral; $\mathbf{C}$ - mucosa peniana).

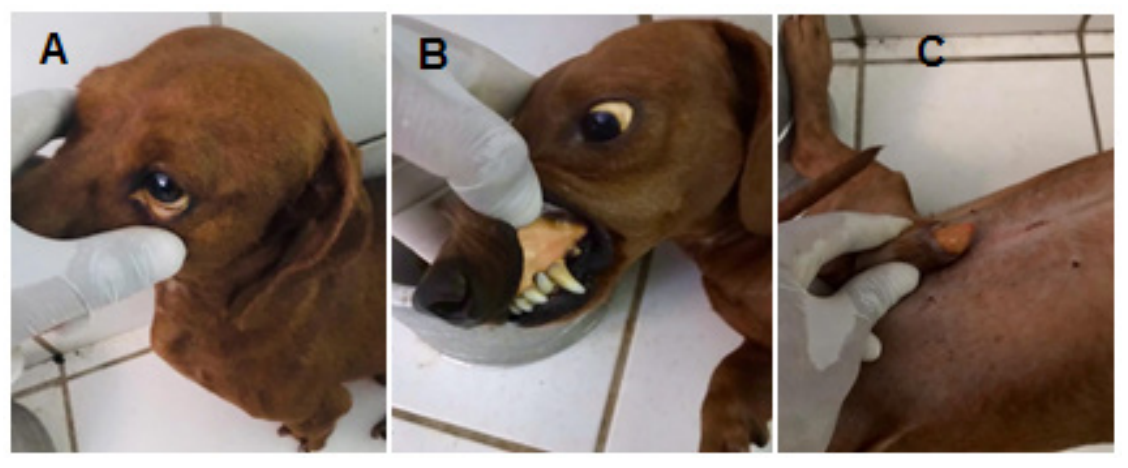

Fonte: Arquivo pessoal.

\section{RESULTADOS E DISCUSSÕES}

Os roedores sinantrópicos comensais são os hospedeiros mais frequentes do sorovares icterohaemorrhagiae e copenhageni, sendo os cães hospedeiros acidentais deste agente, coincidindo com o relato de caso, após provável contato do canino com o rato presente no quintal e detecção da infecção por Leptospira interrogans, sorovares icterohaemorrhagiae e copenhageni, na titulação de 1:100 pelo método ELISA (BHARTI et al., 2003).

A doença em cães ocorre com mais incidência em machos jovens, com idade entre 1-4 anos (HAGIWARA et al., 2015; SCHULLER, 2017), corroborando com o canino abordado, no qual, o paciente tratava-se de um cão macho de quatro anos de idade. Os sinais clínicos frequentemente observados nos cães infectados por leptospiras são icterícia, êmese, letargia, anorexia e dor abdominal (HAGIWARA et al., 2015), se assemelhando com os sinais clínicos apresentados pelo paciente relatado, que foram mucosas ictéricas, turgor da pele diminuído, aumento dos linfonodos poplíteos, dor abdominal, dispneia, taquipneia, taquicardia e pirexia. A ocorrência da icterícia em animais infectados pela L. interrogans justifica-se pela associação da lesão hepatocelular grave e colestase intra-hepática (HAGIWARA, 2015).

No hemograma apresentado pelo canino, notou-se presença de anemia normocítica normocrômica sendo considerada um achado hematológico importante, já a trombocitopenia é um resultado bastante comum em cães com leptospirose, ocorrendo devido à destruição imuno-mediada, 
sequestro esplênico ou ativação de plaquetas/endotélio pelo organismo (SCHULLER, 2017). Foi observado também leucocitose por neutrofilia, indo de acordo com os dados de Hagiwara et al. (2015) e Schuller (2017). O resultado da amostra bioquímica demostrou aumento considerável de ALT, AST, FA, creatinina e ureia, identificando significativa lesão hepática e renal, achados também identificados por Schuller (2017).

O tratamento da Leptospirose canina ocorre por antibioticoterapia, sendo a Doxiciclina o antibiótico de eleição, além de terapia suporte de acordo com os sistemas acometidos, citando como importante intervenção a reposição hidroeletrolítica, proteção hepática/gástrica e antiemético, semelhante a terapia medicamentosa abordada no relato (HAGIWARA et al. 2015).

O prognóstico do paciente depende do período de início do tratamento. Quando realizado de forma precoce as chances de sobrevida são favoráveis, além da virulência do sorovar infectante, resposta imunológica do hospedeiro frente à infecção e idade do mesmo, onde filhotes e cães idosos são considerados como grupo de risco devido a sua frágil imunidade (SANTIN et al., 2006; NELSON \& COUTO, 2015; SCHULLER, 2017). O animal do relato, estava bastante debilitado, com anorexia há oito dias, além de quadro acentuado de desidratação, decorrentes da êmese e diarreia, o que contribuiu para o óbito do mesmo.

\section{CONCLUSÃO}

A leptospirose canina é um problema de saúde animal e também de saúde pública devido a sua grave infecção, bem como pelo risco de contágio aos humanos. O prognostico da doença pode apresentar-se favorável quando se realiza um tratamento precoce e intensivo sendo estratégias de extrema importância para o restabelecimento do animal. Tratar o paciente após agravamento da sintomatologia, diminui significativamente as suas chances de sobrevida, além de retratar fonte de infecção para o homem e outros animais, com isso, ressalta-se a importância da vacinação dos cães e o controle de roedores sinantrópicos. 


\section{PRINCIPAIS REFERENCIAS}

BHARTI A.R, NALLY J.E, RICALDI J.N, MATTHIAS M.A, DIAZ M.M, LOVETT M.A, et al. Leptospirosis: a zoonotic disease of global importance. Lancet Infect Dis. Dez; 12:757-71, 2003.

HAGIWARA M.K., MIOTTO B.A., KOGIKA M.M. Leptospirose. In: Tratado de medicina interna de cães e gatos (eds. by Jericó M.M, Neto J.P.A, Kogika M.M), pp. 2678-708. Roca, Rio de Janeiro, Brasil, 2015.

NELSON R.W. \& COUTO C.G. Medicina interna de pequenos animais. Elsevier Editora, Amsterdan, 2015.

SANTIM K., SELLA A.B, CARDOSO M.R.I. Pesquisa de aglutininas anti-Leptospira em cães clinicamente sadios e em cães com suspeita clínica de leptospirose. Clin Vet. jan-fev; 60:48-52, 2006.

SCHULLER S. Leptospirosis. In: Textbook of veterinary internal medicine: diseases of the dog and the cat (eds. by Ettinger D \& Feldman E), pp. 2335-43. Elsevier, Missouri, USA, 2017. 


\title{
LEISHMANIOSE TEGUMENTAR EM CADELA: RELATO DE CASO
}

\author{
Elizabetty de Melo Almeida Burity ${ }^{1}$ \\ ${ }^{1}$ Médica Veterinária Residente em Atenção Básica, UFRN/EMCM, Currais Novos, Rio grande do \\ Norte.
}

\section{RESUMO}

As leishmanioses são zoonoses causadas por protozoários pertencentes ao gênero Leishmania, apresentando distribuição cosmopolita, sendo o cão, considerado o principal reservatório no ambiente urbano. A transmissão ocorre principalmente através de vetor, pela picada de insetos dípteros hematófagos pertencentes à subfamília Phlebotominae e, presenta duas prevalentes formas clínicas, a cutânea e a forma visceral. O objetivo deste trabalho foi relatar um caso de leishmaniose tegumentar em cadela da raça Pinscher, 6 anos de idade, atendida a domicilio, apresentando dermatite com alopecia nas regiões perioculares, perinasal e perilabial, além de onicogrifose e secreção ocular bilateral. O diagnóstico foi realizado através do exame parasitológico, executado por meio de escarificação da pele lesionada (raspado profundo), fixando o material obtido em lâminas, com metanol, corandoas pelo método de Giemsa, onde foi possível observar formas amastigotas da Leishmania spp. ao microscópio óptico. O tutor não desejou tratar o paciente, optando assim, pela eutanásia.

PALAVRAS-CHAVES: Leishmania spp.; Zoonose; Cães.

ÁREA TEMÁTICA: Medicina Veterinária

\section{INTRODUÇÃO}

As leishmanioses são enfermidades infecciosas, de caráter crônico e multissistêmico, causadas por protozoários pertencentes ao gênero Leishmania, apresentando diferentes formas de manifestações clínicas, envolvendo principalmente as formas tegumentar e visceral (ETTINGER \& FELDMAN, 2010; NELSON \& COUTO, 2015). Constituem um importante problema para a saúde pública, devido ao seu cunho zoonótico, que resulta em consideráveis taxas de morbidade e mortalidade (LONARDONI et al., 2006). No Brasil essa antropozoonose encontra-se em expansão, sendo considerada uma doença re-emergente. Com o crescimento exponencial humano e a devastação de áreas florestais, a leishmaniose não está mais reclusa apenas no meio rural e silvestre, mas também nos grandes centros urbanos (ETTINGER \& FELDMAN, 2010; LONARDONI et al., 2006). A Leishmania infecta diferentes hospedeiros, sejam eles domésticos ou silvestres, tendo como principal forma de transmissão a vetorial, ocorrendo por meio de insetos dípteros fêmeas, hematófagos, da 
família Psychodidae, sub família Phebotominae, gênero Lutzomya, conhecidos popularmente como "mosquito-palha", sendo os cães, considerados os principais reservatórios da doença em áreas urbanas (ETTINGER \& FELDMAN, 2010; NELSON \& COUTO, 2015).

A leishmaniose tegumentar (LT) é caracterizada por lesões na pele, mucosas e cartilagem, se manifestando por alopecia simétrica progressiva, dermatite esfoliativa, lesões mucocutâneas, pápulovesiculosas e úlceras de fundo granulomatoso, com bordas bastantes salientes que não cicatrizam, se iniciando na cabeça, principalmente nas regiões de orelhas, focinho e periocular (MEDLEAU \& HNILICA, 2009). Apesar de não existir um teste diagnóstico que demostre 100\% de especificidade e sensibilidade para a doença, a confirmação do diagnóstico baseia-se na associação dos achados clínicos com exames complementares de ordem parasitológica, sorológica ou moleculares, considerando como método de excelência o exame parasitológico, no qual, é possível visualizar o protozoário (LEONTIDES et al., 2002). Atualmente, recomenda-se pelo Ministério da Saúde técnicas sorológicas de imunofluorescência indireta (RIFI) e o método de imunoensaio enzimático (ELISA). O tratamento ainda é considerado questionável, devido a importante participação e comprometimento do tutor, além da leishmaniose canina ser bastante resistente ao tratamento, diferente da leishmaniose humana. Para que seja instituído o tratamento, se faz necessário avaliação clínica pelo médico veterinário, conjuntamente, o tutor terá a responsabilidade sobre as medidas de controle da doença. Para intervenção terapêutica medicamentosa, existem alguns fármacos como o antimoniato de n-metilglucamina, anfotericina $\mathrm{B}$, aminosidina, pentamidina, miltefosina. Com tudo, o tratamento de cães com antimoniato de n-metilglucamina e a anfotericina B não é permitido no Brasil. O trabalho apresenta como objetivo, relatar um caso de leishmaniose tegumentar em cadela, destacando a importância da prevenção da doença.

\section{METODOLOGIA}

A pesquisa apresenta cunho qualitativo (descritivo) na sua forma de abordagem, sendo um estudo de relato de caso, a fim de expor uma ocorrência leishmaniose tegumentar em cadela, comparando os resultados obtidos com a literatura. Foi atendida a domicilio na cidade de Carpina/ PE, uma cadela da raça Pinscher, 6 anos de idade, com peso corporal de 3,800 kg, protocolo vacinal atualizado e vermifugação em dias, apresentando queixa principal emagrecimento progressivo, intenso prurido e perca de pelos na região da face há aproximadamente 8 meses. O tutor relatou que o animal já havia passado por tratamento anteriormente para dermatofilose e escabiose, porém, sem regressão dos sinais clínicos apresentados, mencionou-se também que banha o animal semanalmente com shampoo a base de clorexidina e fornece uma dieta com ração industrial e complementação com comida caseira, além do uso semestral do Bravecto ${ }^{\mathrm{TM}}$ para controle de pulgas e carrapatos. A cadela não convive com outros animais, porém, viaja frequentemente para a região litorânea de Recife/PE e, segundo tutor, não tem acesso às ruas, sendo os passeios realizados apenas de forma guiada. O animal foi submetido ao exame clínico, iniciando-se pela avaliação externa dermatológica, avaliação das mucosas e palpação dos linfonodos, posteriormente ausculta cardíaca e pulmonar, e 
por fim, com auxílio de um termômetro para uso retal, aferiu-se sua temperatura. Foi solicitado como forma de complemento aos dados da anamnese e confirmação das hipóteses diagnósticas, exames complementares de perfil hematológico, bioquímico (albumina, ALT, creatinina e ureia), raspado profundo de pele (escarificando bordo das lesões) para pesquisa de ácaros e fungos, cultura fúngica pelo método Sabouraud/Mycosel e teste sorológico imunoenzimático (ELISA) para leishmaniose. Com tudo, não foi autorizado pelo tutor o teste sorológico ELISA, optando então pela busca direta da Leishmania spp., utilizando a técnica de pesquisa parasitológica de raspado da pele, de forma que a escarificação atingisse uma camada mais profunda, sendo realizada no bordo das lesões e, posteriormente fixando o material em lâminas com metanol, corando-as pelo método de Giemsa para análise das mesmas ao microscópio óptico (objetiva 100X e ocular de 10X).

\section{RESULTADOS E DISCUSSÕES}

No exame clínico, constatou-se dermatite com alopecia nas regiões perioculares, perinasal e perilabial, além de onicogrifose e secreção ocular bilateral (figura 1), a paciente encontrava-se apática, caquética, mucosas hipocoradas, linfonodos submandibulares e pré-escapulares reativos e temperatura retal de $40,9^{\circ} \mathrm{C}$, os demais parâmetros avaliados encontravam-se dentro da normalidade. Observou-se no hemograma anemia normocítica normocrômica $(\mathrm{VG}=25 \%$ ), trombocitopenia $(139.000 / \mu \mathrm{L})$ e leucopenia $\left(4.456 / \mathrm{mm}^{3}\right)$, as analises bioquímicas evidenciaram aumento de ureia (199,3 mg/dL) e creatinina $(3,86 \mathrm{mg} / \mathrm{dL})$, demais parâmetros dentro dos valores de referência. A cultura fúngica apresentou resultado negativo, assim como raspado de pele, não sendo identificado presença de fungos nem presença de ácaros, porém, foi possível observar formas amastigotas de Leshmania spp., fechando o diagnóstico de leishmaniose tegumentar. O tutor da paciente não desejou tratar o animal e optou pela eutanásia do mesmo, sendo realizado o procedimento com o uso do medicamento eutanásico T-61®, na dose única intravenosa de $0,3 \mathrm{~mL} / \mathrm{kg}$.

O presente relato ocorreu na região urbana da cidade de Carpina/PE, não coincidindo com a área de maior prevalência (zona rural), citada por autores, porém, o animal frequentemente viajava para zona litorânea de Recife/PE, sendo considerada uma área bastante endêmica para leishmaniose (LONARDONI et al., 2006). Os sintomas apresentados pela paciente estão de encontro aos citados na literatura, os quais citam-se emagrecimento progressivo, alopecia ao redor dos olhos, nariz e boca, unhas longas e/ou quebradiça, linfadenomegalia e pirexia (MEDLEAU \& HNILICA, 2009; NELSON \& COUTO, 2015). Os principais achados laboratoriais da leishmaniose tegumentar canina incluem anemia, geralmente normocítica normocrômica, trombocitopenia, leucocitose, eosinofilia, aumento de ureia, creatinina e proteína totais, concomitante com alguns achados do relato abordado (NELSON \& COUTO, 2015). O aumento de ureia e creatinina indicam insuficiência renal aguda, de acordo com Nelson \& Couto, 2015, decorrentes da deposição de imunocomplexos, podendo evoluir, caso não tratada, para uma glomerulonefrite. A forma diagnóstica do relato (exame parasitológico) é considerada como o teste ouro para o diagnóstico da leishmaniose, onde observa-se formas amastigotas do parasito (LEONTIDES et al., 2002). 
Figura 1: Imagem de uma cadela da raça Pinscher, de 6 anos de idade, acometida por Leishmaniose no Município de Carpina/PE. A) Alopecia periocular (seta amarela), alopecia perinasal (seta branca), alopecia perilabial (seta vermelha); B) Caquexia; C) Onicogrifose (crescimento excessivo das unhas).

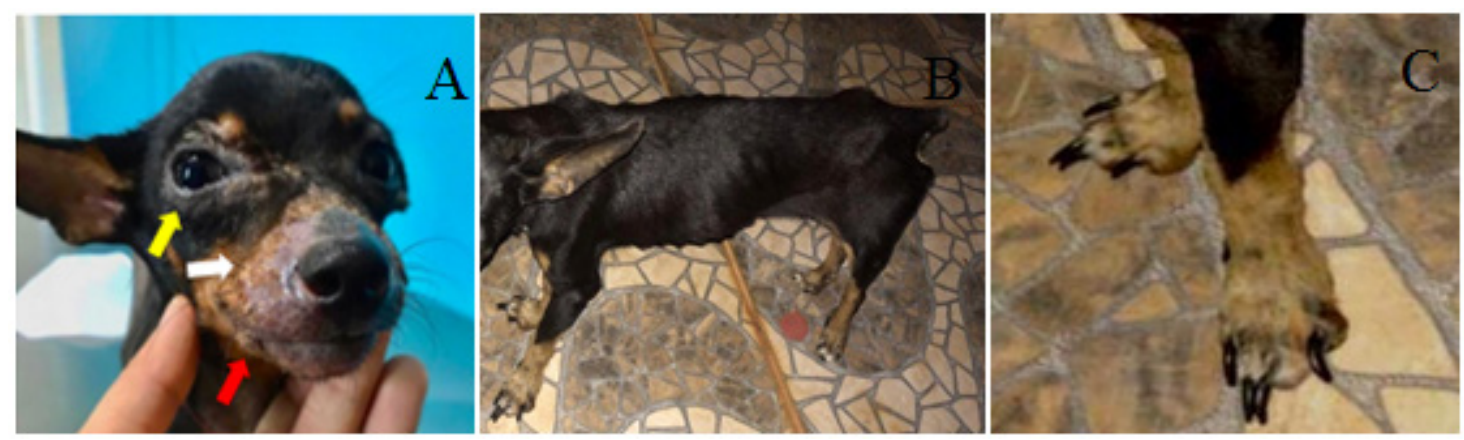

Fonte: Arquivo pessoal.

\section{CONCLUSÃO}

A leishmaniose é uma doença grave que acomete diversas espécies, inclusive o homem, tendo considerável impacto na saúde pública, no qual, o cão pode se manter assintomático e atuar como reservatório, perpetuando assim, a enfermidade. Os métodos de diagnóstico não são totalmente eficazes e o seu tratamento apresenta custo elevado, necessitando de constante monitoramento pelo médico veterinário, além de comprometimento do tutor, casos de recidivas dos sinais clínicos são bastante frequentes e muitos proprietários acabam por optar pela eutanásia do animal. Diante disso, faz-se necessário implementar medidas de prevenção, envolvendo o controle do inseto vetor, controle populacional de cães errantes e a vacinação preventiva de caninos domésticos, a fim de diminuindo o risco de infecção tanto para o homem quanto para o animal.

\section{PRINCIPAIS REFERÊNCIAS}

ETTINGER, S. J.; FELDMAN, E. C. Veterinary Internal Medicine. $7^{\mathrm{a}}$ ed. California: Saunders. Cap. 207. 2010.

MEDlEAU, L.; HNILICA, K. A. Dermatologia de pequenos animais. Atlas colorido e guia terapêutico. 2a Ed. São Paulo: Roca; Cap. 6, p. 154, 155, 2009.

LAPPIN, M. R. Doenças infecciosas In.: NELSON, R. W., COUTO, C. G. Medicina interna de pequenos animais. 5 ed. Rio de janeiro: Elsevier, cap. 96, p. 1367-1383, 2015.

LEONTIDES, L.S., et al., A cross-sectional study of Leishmania spp. infection in clinically healthy dogs with polymerase chain reaction and serology in Greece. Veterinary Parasitology 109, 19-27, 2002. 
LONARDONI, M.V.C., et al., Leishmaniose tegumentar americana humana e canina no Município de Mariluz, Estado do Paraná, Brasil. Cadernos de Saúde Pública 22, 2713-2716. 


\title{
ABORTO CANINO POR Toxoplasma gondii: RELATO DE CASO
}

\author{
Elizabetty de Melo Almeida Burity ${ }^{1}$ \\ ${ }^{1}$ Médica Veterinária Residente em Atenção Básica, UFRN/EMCM, Currais Novos, Rio grande do \\ Norte
}

\section{RESUMO}

A toxoplasmose é uma zoonose cosmopolita, causada por um protozoário coccídio Toxoplasma gondii, apresentando como hospedeiro definitivo os felinos domésticos e como intermediários, os vertebrados homeotérmicos. A ocorrência da toxoplasmose é de grande importância para a medicina veterinária por gerar muitos prejuízos reprodutivos em animais domésticos e de produção, além de ter suma importância na saúde pública, principalmente no público dos imunossuprimidos e gestantes, gerando natimortalidade e mal formação fetal. O objetivo desse trabalho foi relatar um caso de aborto canino provocado pelo $T$. gondii, onde o animal apresentou quadro epilético e tremores musculares, obtendo prognóstico favorável, reagindo ao tratamento sistêmico com antibiótico durante 15 dias consecutivos. Sugeriu-se ao tutor suspender o fornecimento de carne bovina crua, prevenindo a reinfecção do animal.

PALAVRAS-CHAVES: Toxoplasmose; Zoonose; Abortamento.

ÁREA TEMÁTICA: Medicina Veterinária

\section{INTRODUÇÃO}

A Toxoplasmose é uma enfermidade zoonótica de distribuição mundial, causada pelo protozoário coccídio Toxoplasma gondii, que pode infectar o homem e outros animais homeotérmicos (DUBEY \& BEATTIE, 1988; ETTINGER \& FELDMAN, 1997). Os felídeos apresentam um importante papel na disseminação da doença por atuarem tanto como hospedeiros intermediários como definitivos, ocorrendo a reprodução sexuada do parasito, gerando os oocistos que são eliminados com suas fezes, contaminando assim, o meio ambiente (GREENE et al., 1990; GARCIA et al.; 1999). A ocorrência da toxoplasmose expõe grande importância para a medicina veterinária por gerar muitos prejuízos reprodutivos em animais domésticos e de produção, além de ter suma importância na saúde pública, principalmente no público dos imunossuprimidos e gestantes, resultando natimortalidade e mal formação fetal (LAPPIN, 2004).

O T. gondii apresenta quatro formas principais, sendo elas os oocistos, que são eliminados 
pelas fezes do hospedeiro definitivo; taquizoítos, de reprodução rápida, encontrados nos tecidos dos hospedeiros intermediários; bradizoítos, organismos de multiplicação lenta também presentes nos tecidos; e cistos teciduais, estruturados com parede que abrigam os bradizoítos (GREENE, 1990). A transmissão ocorre pela ingestão acidental de oocitos presentes no ambiente, na água contaminada, legumes e/ou frutas ou através dos taquizoítos presentes na carne crua ou mal passada, leite não pasteurizado, transplantes de tecidos, transfusão de sangue e seus derivados (LAPPIN, 2004). Geralmente indivíduos imunocompetentes são assintomáticos quando se infectam com o T. gondii, poucos adoecem e raramente ocorreram óbitos, a preocupação está com os imunodeprimidos e fêmeas prenhes infectadas pela primeira vez (ETTINGER \& FELDMAN, 1997; LAPPIN, 2004). Os sinais clínicos quando presentes, dependem da resposta imune do animal, número de microorganismos ingeridos, presença de afecção concomitante como o caso de cinomose e parvovirose em cães. Observa-se principalmente sintomatologia neurológica (quadros convulsivos, tremores, ataxia, paresias e paralisias), problemas oftálmicos (uveíte, ceratoconjuntivite seca, retinite e coroidite), lesões musculares (marcha rígida, claudicação e problemas no miocárdio, resultando em arritmias e insuficiência cardíaca), afecções no sistema respiratório como necrose pulmonar e pneumonia, além de manifestações inespecíficas como febre, letargia, linfadenomegalia, anorexia e diarreia (LAPPIN, 2004).

O diagnóstico é baseado no histórico do paciente e confirmado através de exames sorológicos como RIFI, testes de aglutinação modificado, hemaglutinação e ELISA, além do teste molecular PCR, testes histopatológico e de imunohistoquímico por meio da biopsia de tecidos lesados (ETTINGER \& FELDMAN, 1997; LAPPIN, 2004). O tratamento consiste no controle dos sinais clínicos e na redução do desenvolvimento das formas proliferativas (taquizoítos) através do uso de antibióticos como clindamicina e sulfonamidas com ou sem associação com trimetoprim (GREENE et al., 1990). O objetivo desse trabalho foi relatar um caso de aborto canino provocado pelo $T$. gondii, onde o animal apresentou quadro epilético e tremores musculares.

\section{METODOLOGIA}

O trabalho apresenta caráter qualitativo, onde descreve um caso de abortamento canino causado pela toxoplasmose. No município de Carpina, interior de Pernambuco, durante uma madrugada de domingo, ocorreu atendimento de urgência à domicílio, cujo paciente era um canino fêmea da raça Shih-tzu, 2 anos de idade, pesando $4 \mathrm{~kg}$, apresentando tremores musculares e aborto gestacional (figura 1). Relatou-se pelo tutor que o animal encontrava-se com 59 dias de gestação, sem sintomatologia anterior, mas, naquela madrugada, apresentou crise de epilepsia com posterior aborto. O animal apresentava histórico vacinal desatualizado, assim como sua desverminação. A alimentação do paciente era a base de ração industrial com uso rotineiro de carne bovina crua como forma de petisco. Segundo proprietário, a cadela não convive com outros animais, nem tem acesso às ruas. $\mathrm{O}$ animal foi submetido ao exame clinico, iniciando pelo exame neurológico, observando a postura e estado mental do paciente através do seu comportamento, avaliou-se a propriocepção dos membros torácicos 
e pélvicos, além de estimulo de alguns nervos cranianos através da avaliação da resposta a ameaça, avaliação do reflexo palpebral, sensibilidade facial e do reflexo pupilar com o auxilio de uma lanterna oftálmica, por fim, palpou-se também toda coluna vertebral para observar alguma sensibilidade ou dor. Após exame neurológico, aferiu-se a temperatura retal do paciente, realizou-se ausculta cardíaca e pulmonar, analise das mucosas oculares e gengival, observando o tempo de preenchimento capilar (TPC), avaliação do turgor cutâneo, a fim de observar grau de desidratação, além da palpação aos linfonodos mandibulares, parotídeos, pré-escapulares, axilares, inguinais e poplíteos. Suspeitou-se de aborto infeccioso, com isso, foi solicitado exames complementares de hemograma completo, perfil bioquímico (albumina, ALT, creatinina e ureia), proteínas totais e, para fechar o diagnóstico, requisitou-se exame sorológico imunoensaio enzimático (ELISA) para toxoplasmose e neosporose, através da coleta de secreção vaginal pelo método de swab.

Figura 1: Aborto canino provocado por Toxoplasma gondii.

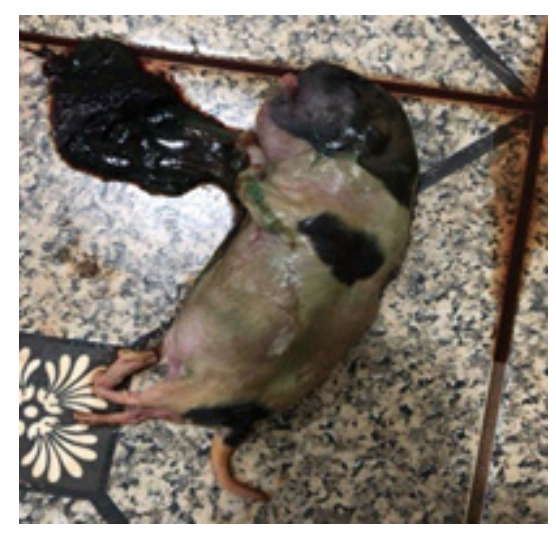

Fonte: Arquivo pessoal.

\section{RESULTADOS E DISCUSSÕES}

No exame clínico, o animal encontrava-se em alerta, deitado em decúbito lateral esquerdo. Com exceção dos tremores musculares, não foi observado nenhuma alteração no sistema nervoso, ou seja, ausência de alterações no exame neurológico. Observou-se considerável pirexia $\left(42,8^{\circ} \mathrm{C}\right)$, taquipneia $(45 \mathrm{rpm})$, taquicardia $(130 \mathrm{bpm})$, TPC inferior a 2 segundos, mucosas hipocoradas e aumento dos linfonodos pré-escapulares e poplíteos, sem mais alterações. O hemograma demostrou anemia normocítica normocrômica ( $\mathrm{VG}=23 \%$ ), e leucocitose com neutrofilia. Já o perfil bioquímico, foi observado elevação da ALT (95 UI/L), FA (101 UI/L) e hipoproteinemia (4,6 g/dL), demais parâmetros dentro dos valores de referência. O exame sorológico ELISA foi qualitativo, expondo não reagente para neosporose, porém reagente tanto para IgG quanto para IgM para toxoplasmose. Instituiu-se o tratamento com sulfametazol associado com trimetoprim, na dose de $30 \mathrm{mg} / \mathrm{kg}$, via oral a cada 12 horas, durante 15 dias, Omeprazol na dose de $0,5 \mathrm{mg} / \mathrm{kg}$, via oral, a cada 24 horas, durante 15 dias, $200 \mathrm{~mL}$ de água de coco diariamente para fornecer hidratação e reposição eletrolítica, 
dando a opção para o tutor fracionar essa quantidade ao decorrer do dia, suplementação alimentar com Hemolitan ${ }^{\circledR}$ Gold líquido na dose de $0,1 \mathrm{~mL} / \mathrm{kg}$, duas vezes ao dia durante 30 dias e, por fim, Contralac ${ }^{\circledR}, 0,1 \mathrm{mg} / \mathrm{kg}$, a cada 12 horas, por 8 dias para promover a interrupção do processo de lactação. Foi recomendado ao tutor, cozer bem a carne bovina antes de fornece-la ao animal, nunca fornecendo carnes cruas ou mal passadas. O tratamento instituído resultou em melhora do quadro clínico do paciente, onde não foram observados tremores musculares nem epilepsia, além de reversão do quadro anêmico e ganho de massa muscular $(0,9 \mathrm{~kg})$.

A infecção por T. gondii durante a gravidez e seus resultados desfavoráveis para o feto é observada em todo o mundo, o agente é transmitido ao feto de forma vertical, através da placenta da mãe (DUBEY \& BEATTIE, 1988). O contágio pode ocorrer através da ingestão de carne mal cozida, água ou alimentos contaminados com as formas infectantes, como foi observado no relato, no qual o tutor oferecia ao animal, carne bovina crua como forma de petisco (LAPPIN, 2004).

Na toxoplasmose aguda, em cães e gatos geralmente observa-se presença de anemia no perfil eritrocitário, e leucocitose com neutrofilia no perfil leucocitário, leucopenia ou linfocitose também podem estar presentes, sendo achados comuns, o bioquímico geralmente revela aumento das atividades enzimáticas séricas de alanina amino transferase (ALT), fosfatase alcalina (FA) e aumento nos níveis séricos de bilirrubina, além de hipoproteinemia e hipoglobulinemia, alguns parâmetros estando em similaridade com os encontrados no relato (ETTINGER \& FELDMAN, 1997; LAPPIN, 2004).

A maior parte dos casos de toxoplasmose clínica ocorre pelo déficit da imunidade do hospedeiro, o que foi observado no animal do referido relato, onde encontrava-se gestante, anêmico, com vacinação e desverminação desatualizada. Cães imunossuprimidos geralmente desenvolvem sinais clínicos nervosos, problemas respiratórios, oftálmicos e lesões ao tecido muscular/esquelético durante a infecção, porém, a cadela abordada apresentou apenas caso isolado de epilepsia e tremores musculares (LAPPIN, 2004).

\section{CONSIDERAÇÕES FINAIS OU CONCLUSÃO}

A toxoplasmose quando diagnostica e tratada precocemente, apresenta prognóstico favorável, com tudo, diante das variáveis espécies susceptíveis a doença e da sua importância para a saúde pública é necessário reforçar as medidas profiláticas a população, como não se alimentar nem fornecer aos animais carnes cruas ou mal passadas, consumir apenas leite pasteurizado, lavar bem frutas, verduras e legumes antes do consumo, conscientizar também sobre a necessidade de manter seus animais domésticos restritos ao ambiente domiciliar, além de realizar o controle populacional de cães e gatos errantes. 


\section{PRINCIPAIS REFERÊNCIAS}

DUBEY JP., BEATTIE C.P. Toxoplasmosis of Animals and Man. Boca Raton: CRC Press, 75, 1988.

ETINGER, S. J.; FEELDMAN, E. C.; Tratado De Medicina Interna Veterinária, $4^{a}$ ed. São Paulo: Manole, 1997.

GARCIA, J. L.; et al. Soroepidemiologia da toxoplasmose em gatos e cães de propriedades rurais do Município de Jaguapitã, Estado do Paraná, Brasil. Ciência Rural, Santa Maria, v.29, n.1, p.99104, 1999.

GREENE, C. E. Infectious diseases of the dog and cat. Philadelphia: W. B. Saunders. p.819-829, 1990.

LAPPIN, M. R. Segredo em medicina interna de felinos. Porto Alegre: Artmed, 2004. 


\title{
LEISHMANIOSE VISCERAL CANINA - RELATO DE CASO
}

\author{
Suélen Dalegrave1; João Pedro Grassi de Araujo²; Maurício Orlando Wilnsen³ \\ ${ }^{1}$ Residência em Clínica e Cirurgia de Pequenos Animais, Pontifícia Universidade Católica do Paraná \\ (PUCPR) Toledo, PR. \\ ${ }^{2}$ Residência em Clínica, Cirurgia e Reprodução de Animais de Produção, Pontifícia Universidade \\ Católica do Paraná (PUCPR) Toledo, PR. \\ ${ }^{3}$ Doutor, Professor do eixo de Medicina Veterinária Preventiva do Curso de Medicina Veterinária, \\ Pontifícia Universidade Católica do Paraná (PUCPR) Toledo, PR.
}

DOI: $10.47094 /$ ICONRES.2021/7

\section{RESUMO}

A Leishmaniose visceral canina é uma zoonose endêmica no Brasil e possui grande importância no que diz respeito à saúde pública. É causada pelo protozoário do gênero Leishmania spp. cujo período de incubação pode variar de três meses a vários anos, mesmo quando as manifestações clínicas variam conforme a resposta imunológica do hospedeiro. O diagnóstico clínico é realizado combinando testes patológicos, sorológicos e moleculares. Foi atendido um cão, 3 anos, raça buldogue francês com histórico recorrente de dificuldade respiratória, onicogrifose, alopecia, hiperqueratose, dermatite descamativa em diversos locais do corpo lesões em região membros pélvicos, torácicos e plano labial. O exame ELISA confirmou o diagnóstico de Leishmaniose Visceral Canina. Diante da gravidade das lesões e estado clinico, foi optado pela eutanásia do animal.

PALAVRAS-CHAVES: Diagnóstico; Doença infecciosa; Protozoário.

ÁREA TEMÁTICA: Medicina veterinária

\section{INTRODUÇÃO}

A leishmaniose é uma doença infeciosa transmitida por um protozoário do gênero Leishmania spp. No Brasil, os flebotomíneos causadores dessa enfermidade pertencem basicamente a duas espécies Lutzomyia longipalpis e Lutzomyia cruzi. Esses vetores são conhecidos popularmente como mosquito palha e se reproduzem em matéria orgânica em decomposição (LIMA \& GRISOTTIB, 2018). A doença é uma das principais zoonoses do país (SILVA et al., 2017). O diagnóstico ocorre pela realização de teste rápido, sorologia, imunohistoquimica, identificação do parasita em exame 
histopatológico, métodos de Reação em cadeia da polimerase (PCR) e observação direta da forma amastigota do protozoário pela análise de esfregaço uma vez que, o paciente apresenta sinais inespecíficos ou até mesmo assintomáticos (ROCHA et al., 2020). O tratamento pode ser considerado, contudo, irá depender do quadro clínico que o paciente se apresenta (BRASIL, 2012) O presente trabalho tem como objetivo, relatar um caso de leishmaniose visceral em um cão.

\section{METODOLOGIA}

Foi atendido na clínica veterinária da Pontifícia Universidade Católica do Paraná, campus Toledo-PR, um cão, macho, da raça Bulldog Francês, com três anos de idade, pesando 8,2 kg. A queixa principal do tutor se baseava nas lesões crostosas em pele há mais de 11 meses. As lesões apresentavam ainda, eritema e hiperqueratose, localizadas principalmente em região de face e membros. A pele apresentava aspecto descamativo principalmente em região axilar e de virilha, além de membros anteriores e posteriores, além de alopecia em região que circundava as lesões. O tutor relatou também dificuldade respiratória com produção de secreção purulenta pelas narinas.

O animal já havia sido consultado por profissionais, onde o diagnóstico suposto era de dermatofitose, com infecção bacteriana secundária e hemoparasitose. O cão foi submetido a dois meses atrás, a diferentes tipos de tratamentos medicamentosos a base de antibioticoterapia, antianêmicos, corticóide e imunossupressor, sem resultado satisfatório. O paciente estava com o protocolo de vacinas éticas e vermifugação em dia. A tutor relatou que o animal se alimentava com ração seca e comida caseira. $\mathrm{O}$ animal não tinha acesso à rua ou contactantes e tomava banho em casa. A cão apresentava normorexia, normodipsia, normoquesia e normúria.

No exame clínico geral, o animal estava alerta e apresentava dificuldade respiratória, ativo, mucosas normocoradas, desidratação de 5-6\%, TPC de 2 segundos, linfonodos submandibulares, préescapulares e poplíteo estavam reativos, frequência cardíaca de $92 \mathrm{bpm}$, frequência respiratória de 30 mpm e temperatura retal de $38,7^{\circ} \mathrm{C}$. Não foram identificadas alterações na palpação abdominal. Foi observado que o animal apresentava onicogrifose (Figura 1B), alopecia, hiperqueratose, dermatite descamativa em diversos locais do corpo, lesões crostosas e ulcerativas em região membros pélvicos, torácicos e plano labial (Figura 1A, C e D). Suspeitando-se de leishmaniose visceral canina e hemoparasitose. 
Figura 1: Cão, macho, da raça buldogue francês, três anos de idade. A- Lesões ulcerativas e crostosas em face; B- Onicogrifose com unhas já aparadas pela tutora e lesão crostosas ulcerativa em membro esquerdo; C e D- Alopecia e lesões descamativas generalizadas

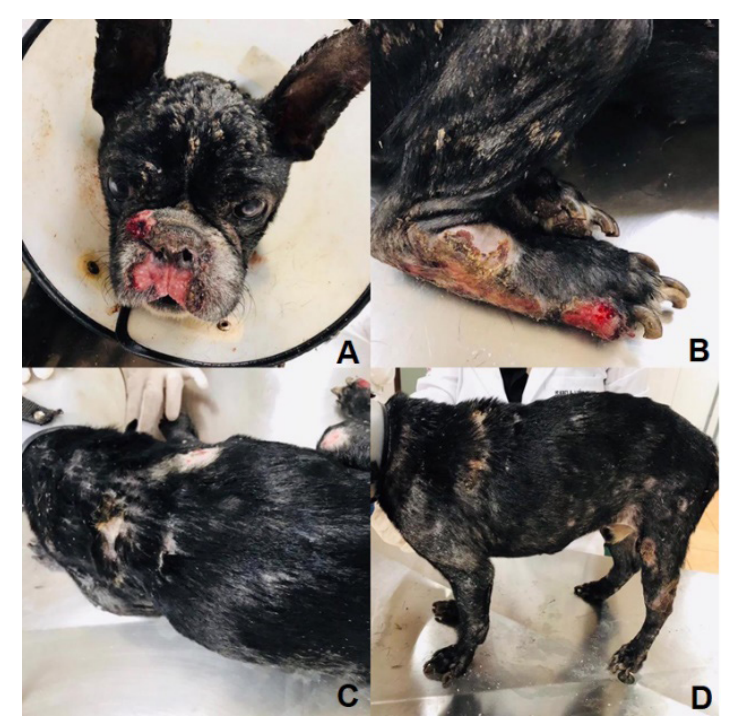

Fonte: Arquivo pessoal Suélen Dalegrave.

O resultado do hemograma, apontou anemia normocítica normocrômica, leucopenia com desvio à esquerda e trombocitopenia. Nos exames bioquímicos hipoalbuminemia e hiperproteinemia. Foram solicitados raspados de pele para pesquisa de ácaros, cultura fúngica, RIFI para Erhlichia canis e Babesia spp os quais evidenciaram resultados negativos. O exame imunocromatográfico, ELISA confirmou o diagnóstico de Leishmaniose Visceral Canina. Foi sugerido exame sorológico para leishmaniose, porém, tutora não aceitou. Após foi indicado, o tratamento com antimoniato de meglumina na dose de $2 \mathrm{mg} / \mathrm{kg} / \mathrm{dia}$, durante 45 dias, alopurinol $10 \mathrm{mg} / \mathrm{kg} / \mathrm{BID}$ durante 90 dias e coleira repelente. Diante da gravidade do quadro, a tutora optou pela eutanásia realizada com propofol e cloreto de potássio $19,1 \%$ dose ao efeito.

\section{RESULTADOS E DISCUSSÕES}

Os cães acometidos por leishmaniose muitas vezes podem ser assintomáticos. Alguns achados permitiram identificar alterações sistêmicas como hepatomegalia, esplenomegalia, epistaxe, secreção nasal e ocular, febre, emagrecimento progressivo, poliúria e polidipsia, diarreia, onicogrifose e lesões dermatológicas (FREIRE \& MORAES, 2019). O paciente em questão apresentou dificuldade respiratória, onicogrifose, alopecia, hiperqueratose, dermatite descamativa em diversos locais do corpo, lesões crostosas e ulcerativas em região membros pélvicos, torácicos e plano labial.

O perfil hematológico de anemia normocítica normocrômica, leucopenia ou leucocitose e trombocitopenia, são achados frequentes em pacientes com a doença, causados pela consequência 
do sequestro de hemácias do baço, eritropoiese diminuída devido a supressão da medula óssea, deficiência nutricional ou hemorragias (FONSECA JÚNIOR, et al. 2021). No avaliações bioquímicas a hiperproteinemia com hipoalbuminemia, observados no caso, podem ser normalmente encontrados pela fração reduzida de albumina/globulina, outras enzimas que podem estar aumentadas são aminotransferase (ALT), Fosfatase alcalina (FA) e Gama-glutamiltransferase (GGT) (GODOY et al., 2017).

O diagnóstico do animal foi realizado pelo método de imunocromatográfico ELISA. Contudo, pode ser realizado também pelos sinais clínicos quando presentes, teste rápido, sorologia, imunohistoquimica, identificação do parasita em exame histopatológico, métodos de Reação em cadeia da polimerase (PCR) e a análise do esfregaço pela observação direta da forma amastigota do protozoário (ROCHA et al., 2020).

O tratamento proposto para o caso em questão foi de antimoniato de meglumina na dose de $2 \mathrm{mg} / \mathrm{kg} /$ dia durante 45 dias que foi aceito em nota Técnica $\mathrm{n}^{\circ}$ 11/2016, assinada pelo Ministério da Agricultura Pecuária e Abastecimento (MAPA) vem sendo empregada (BRASIL, 2016), juntamente com outros medicamentos coadjuvantes como o alopurinol $10 \mathrm{mg} / \mathrm{kg} / \mathrm{BID}$ durante 90 dias (FONSECA JÚNIOR, et al. 2021). Os animais que não podem receber tratamento devem ser submetidos à eutanásia com base na Resolução n ${ }^{\circ} 1000$ do CFMV, utilizando anestesia e medicamentos adequados (BRASIL, 2012). A prevenção e profilaxia de ambientes ainda é considerada a melhor opção para controlar a zoonose. Atualmente, existem coleiras e inseticidas tópicos na forma de spray a base de permetrina usadas como repelentes, além da utilização de protocolos vacinais que auxiliam a prevenção da doença (MATIAS et al., 2020).

\section{CONCLUSÃO}

A leishmaniose visceral canina possui grande importância no âmbito da saúde pública e animal, por se tratar de uma zoonose. O conhecimento do agente etiológico, sinais clínicos, exames, afim de garantir eficácia no diagnóstico e consequentemente determinar uma conduta adequada para cada caso, sendo a melhor forma de se combater a doença é através de ações que propõem o controle do vetor.

\section{REFERÊNCIAS}

BRASIL. Conselho Federal de Medicina Veterinária. Resolução n 1000, de 11 de maio de 2012. Dispõe sobre procedimentos e métodos de eutanásia em animais e dá outras providências. Brasília: Diário Oficial da União de 17 de maio de 2012.

BRASIL. Ministério da Agricultura Pecuária e Abastecimento. Nota Técnica No 11/2016/CPV/DFIP/ SDA/GM/MAPA, 2016. 
FREIRE, C.G.V. \& MORAES, M.E. Cinomose canina: aspectos relacionados ao diagnóstico, tratamento e vacinação. Pubvet. v.13, n.2, a263, p.1-8, 2019.

FONSECA JÚNIOR, José Duarte da; MAZZINGHY, Cristiane Lopes; FRANÇA, Erycka Carolina; PINOW, Ana Clara Silva \& ALMEIDA, Katyane de Sousa. Leishmaniose visceral canina: revisão. Pubvet, v. 15, n. 3, p. 1-8, 2021.

GODOY, K.C.S., ANTUNES, T.R., BRAZ, P.H., ASSIS, A.R, OLIVEIRA, G.G., SILVEIRA, A.W., SILVA, M. P. \& SOUZA, A. I. Comportamento dos marcadores bioquímicos de injúria hepática nos cães com leishmaniose visceral. Pubvet, v. 11, n. 7, p. 670-675, 2017.

LIMA, C.C. \& GRISOTTIB, M. Relação humano-animal e leishmaniose: repercussões no cotidiano de indivíduos inseridos em região endêmica. Saúde Sociedade, v. 27, n. 4, p. 1261-1269, 2018.

MATIAS, Erica Pereira; SANTOS, Fernanda Fonseca; GUIMARÃES, Juliana Plácido \& CHUCRI, Thaís Martins. EFEITOS ADVERSOS DA VACINA LEISH-TEC® EM CÃES SORONEGATIVOS PARA LEISHMANIOSE VISCERAL. Brazilian Journal Of Development, [S.L.], v. 6, n. 7, p. 53019-53028, 2020.

ROCHA, S.T.F., SHIOSI, R.K. \& FREITAS, A.B.M. Leishmaniose visceral canina - Revisão de literatura. Revista científica de medicina veterinária, n.34, 2020. 


\title{
A TOXOPLASMOSE E SUA RELAÇÃO COM A SAÚdE PÚBLICA E A SAÚdE ANIMAL
}

\author{
Isadora Conceição de Souza'; Delcivan Lima dos Santos ${ }^{2}$ \\ ${ }^{1}$ Graduada em Medicina Veterinária, Universidade Federal do Recôncavo da Bahia (UFRB), Cruz \\ das Almas, BA.
}

${ }^{2}$ Mestre em Ciência Animal, Universidade Federal do Recôncavo da Bahia (UFRB), Cruz das Almas, BA.

\section{RESUMO}

O Toxoplasma gondii pode infectar todos os animais de sangue quente. A toxoplasmose é uma infecção causada pelo parasito e pode ser congênita ou adquirida. Ingestão de oocistos presentes no meio ambiente e o consumo de carne mal passada infectada com cistos teciduais são as duas formas principais de transmissão na infecção adquirida. A transmissão congênita ocorre após a infecção primária durante a gravidez. A toxoplasmose também é um problema sério na medicina veterinária porque o agente infecta uma ampla gama de animais de sangue quente, e é considerado uma das principais causas de perdas reprodutivas e econômicas principalmente em ovelhas, cabras, vacas e suínos. O risco de toxoplasmose em animais depende do tipo de gestão agrícola, da dieta animal e da região geográfica, bem como das condições sanitárias das fazendas. Os cistos teciduais contendo T. gondii são detectados com menos frequência em galinhas, coelhos e cavalos.

PALAVRAS CHAVE: Felinos; Infecção; Zoonose.

ÁREA TEMÁTICA: Medicina Veterinária

\section{INTRODUÇÃO}

O Toxoplasma gondii (filo Apicomplexa, família Sarcocystidae) é um coccídeo entérico intracelular obrigatório, que infecta gatos domésticos e outros felídeos. Este agente tem uma ampla distribuição geográfica e infecta vários animais de sangue quente, incluindo aves, mamíferos terrestres e aquáticos, e humanos. Portanto, a doença causada por esse patógeno, a toxoplasmose, é uma antropozoonose.

Os gatos são os hospedeiros definitivos de T. gondii, enquanto as outras espécies suscetíveis são hospedeiras intermediárias. A infecção geralmente ocorre pela ingestão de cistos ou pseudocistos teciduais presentes em diferentes tecidos animais ou pela ingestão de alimentos ou água contaminados com oocistos esporulados. O homem pode contrair o parasito através de alimentos contaminados 
ingeridos crus ou mal cozidos (carnes, embutidos, etc), hortaliças, leite não pasteurizado, ovos, além da contaminação por transplantes e transfusão sanguínea.

A Organização Mundial da Saúde (OMS) estima que um terço da população humana é infectado com T. gondii. Segundo os relatórios da OMS, mais de $60 \%$ da população foi infectada em algumas regiões do mundo. O objetivo deste estudo é avaliar as relações entre o parasito, os animais e os seres humanos.

\section{FUNDAMENTAÇÃO TEÓRICA}

O Toxoplasma gondii pode infectar todos os animais de sangue quente. A toxoplasmose é uma infecção causada pelo parasito, e pode ser congênita ou adquirida. A ingestão de oocistos presentes no ambiente e o consumo de carne mal cozida infectada com cistos teciduais são as duas principais formas de transmissão na infecção adquirida. A transmissão congênita ocorre após infecção primária durante a gravidez.

Os felinos são os hospedeiros definitivos de $T$. gondii, e os outros animais de sangue quente são os hospedeiros intermediários. O parasito realiza a reprodução sexuada em seus hospedeiros definitivos. Nos hospedeiros intermediários realiza apenas a reprodução assexuada. Sendo assim, na reprodução assexuada são originados os taquizoítos, presente em fluídos corporais e tecidos, e os bradizoítos em cistos teciduais, estando presente nas vísceras e na musculatura de hospedeiros infectados. A reprodução sexuada origina os oocistos que serão eliminados nas fezes dos hospedeiros definitivos.

A incidência de infecção depende da localização geográfica da região, dieta e saneamento. As pessoas são infectadas pelo parasito mais comumente pela via oral (mais de $80 \%$ dos casos), através do consumo de carne crua ou mal cozida contendo cistos nos tecidos, ou vegetais e frutas contaminadas com o solo contendo oocistos liberados nas fezes dos gatos.

Em homens e mulheres não grávidas a toxoplasmose é comumente assintomática ou apresenta sintomas similares ao estado de gripe. Quando a infecção ocorre antes da gravidez, há pouco risco para o feto, apesar de haver relatos indicando a transmissão congênita através de uma infecção crônica em humanos e ovinos. Há maior relevância em mulheres que se infectaram durante a gestação, pois, há elevado risco de transmissão congênita, que poderá comprometer, principalmente, o sistema neurológico e oftalmológico do feto.

Todas as gestantes devem ter sua primeira sorologia (IgM e IgG) para toxoplasmose solicitada na primeira consulta do pré-natal. Aquelas com IgG positiva e IgM negativa não precisarão realizar novas coletas, uma vez que, estará imune. Nos casos de sorologia IgM e IgG negativas, deverão seguir todo um protocolo preventivo com medidas em que o foco será na higiene das mãos, alimentos, cozimento adequado e cuidados redobrados ao manusear o recipiente em que os gatos fazem suas necessidades fisiológicas. 
Em indivíduos imunocomprometidos a infecção por $T$. gondii é crítica, pois, possui elevada taxa de mortalidade e resultam frequentemente da reativação de uma infecção crônica. $\mathrm{O}$ sistema nervoso central é o mais acometido, e a neurotoxoplasmose é a apresentação clínica mais comum em pessoas com Síndrome da Imunodeficiência Adquirida (AIDS).

Em pessoas com Aids, a toxoplasmose é a infecção oportunista mais comum do Sistema Nervoso Central. Acredita-se que a maioria apresenta encefalite devido à ativação de bradizoítos nos cistos teciduais após declínio das contagens do linfócito TCD4 ${ }^{+}$. Os sintomas mais frequentes da doença no gato e nos cães incluem a depressão, miosite, anorexia, febre seguida por hipotermia, efusão peritoneal, icterícia, dispneia, vômito, infecção respitatória, gastrointestinal ou neuromuscular.

A infecção por T. gondii em animais de produção provoca alterações clínicas como corrimento nasal, prostração, e hipertermia, porém, o principal problema que é observado é reprodutivo, causando abortamentos em fêmeas que adquiriram a infecção pela primeira vez no período gestacional.

A toxoplasmose também é considerada uma doença ocupacional para veterinários, fazendeiros, trabalhadores rurais, operários de abatedouro, cozinheiros e tratadores de zoológico que manuseiam material contaminado.

O tratamento da toxoplasmose em animais é a administração de clindamicina. Existem relatos de que o prognóstico é bom, se o diagnóstico e o tratamento forem feitos no início da doença. Gatos em que a doença não se manifesta no globo ocular, sistema nervoso central ou neuromuscular, respondem bem ao tratamento em 2 a 4 dias.

As drogas utilizadas no tratamento da toxoplasmose nos seres humanos é a sulfadiazina, sulfametoxazol, pirimetamina, espiramicina e clindamicina. O ácido folínico é utilizado junto aos medicamentos que contenham a pirimetamina, dada à sua mielotoxicidade.

$\mathrm{Na}$ toxoplasmose que afeta os gânglios, o tratamento é feito apenas quando a doença é muito sintomática, e não é feito nos casos leves. Nos casos em que é feito o tratamento, a sulfadiazina é utilizada associada a pirimetamina por quase dois meses. Na toxoplasmose ocular, o esquema é igual ao da ganglionar, associando-se a prednisona.

Em mulheres grávidas, em que haja a suspeita da doença na fase aguda, o tratamento é feito com espiramicina, e o diagnóstico de infecção fetal é confirmado pela reação em cadeia da polimerase, em que o líquido amniótico é coletado. Comprovando a infecção fetal, troca-se o tratamento para sulfadiazina com pirimetamina a partir da $21^{\text {a }}$ semana de gestação. O tratamento da toxoplasmose congênita é realizado durante um ano. 


\section{CONCLUSÃO}

Medidas simples podem ser tomadas para evitar a infecção por T. gondii. Um fator muito importante é que boa parte da população não tem conhecimento sobre a toxoplasmose, nesse caso, é necessário ter ações de conscientização na educação em saúde voltada á população.

O diagnóstico de toxoplasmose em animais de criação e implementações de protocolos de manejo, parece ser a chave para eliminar a principal fonte de transmissão do parasita para os seres humanos, que é o consumo de carne de animais infectados. É importante não permitir a presença de hospedeiros definitivos na propriedade para evitar a contaminação ambiental por oocistos.

A prevenção da infecção por T. gondii requer o conhecimento da epidemiologia do parasito, para poder estabelecer uma possível fonte de infecção. Para cães e gatos, é de suma importância a higienização das instalações e o cuidado com a alimentação (água, ração) e evitar fornecer carnes cruas. $\mathrm{O}$ comportamento de predação desses animais também deve ser evitado.

No Pré-natal, é imprescindível a participação de profissionais de saúde e de outras áreas do saber, com o objetivo de fortalecer e reforçar a prevenção durante o período gestacional.

Durante muito tempo, os felinos, principalmente o gato doméstico, foi considerado o vilão da toxoplasmose, e, ele não é. Uma vez que, a eliminação dos oocistos acontece por um curto período de tempo, quando são filhotes ou jovens. Após isso, criam imunidade, e só voltam a liberar os oocistos se o sistema imune estiver debilitado.

\section{PRINCIPAIS REFERÊNCIAS}

BOWMAN, D. D. G.: Parasitologia veterinária. Rio de Janeiro: Elsevier; 2010.

CÂMARA, J. T.; SILVA, M. G.; CASTRO, A. M. Prevalência de toxoplasmose em gestantes atendidas em dois centros de referência em uma cidade do Nordeste, Brasil. Revista Brasileira de Ginecologia e Obstetrícia, São Paulo, SP, BR, vol. 27, p. 64-70, 2015.

COSTA, R. C. B. 2013. Aspectos epidemiológicos e importância da toxoplasmose na sanidade animal e na saúde pública. 36f. (Dissertação). Programa de pós-graduação em Ciência Animal, Universidade Federal de Goiá, Goiás.

DUBEY, J. P.; LAGO, E. G.; GENNARI, S. M.; SU, C.; JONES, J. L. 2012. Toxoplasmosis in humans and animals in Brazil: high prevalence, high burden of disease, and epidemiology. Parasitol. 139, $1375-1424$.

ELMORE, S. A.; JONES, J. F.; CONRAD, P. A.; PATTON, S.; LINDSAY, D. S.; DUBEY, J. P. 2010. Toxoplasma gondii: epidemiology, feline clinical aspects, and prevention. Trends Parasitol; 26(4): 190-196. 
https://www.medicinanet.com.br/conteudos/revisoes/1270/toxoplasmose.htm\#: :text=O\%20 tratamento $\% 20 \mathrm{da} \% 20$ toxoplasmose $\% 20 \% \mathrm{C} 3 \%$ A 9 , baseado $\% 20 \mathrm{em} \% 20$ sulfadiazina $\% 20 \mathrm{e} \% 20$ pirimetamina.

HILL, D. E.; DUBEY, J. P. 2013. Toxoplasma gondii prevalence in farm animals in the United States. Int. J. Parasitol., 43, 107-113.

JONES, J. L.; DUBEY, J. P. 2012. Foodborne Toxoplasmosis. Clin. Infect. Dis., 55, 845-851.

MINISTÉRIO DA SAÚDE (BR). Define as terminologias adotadas em legislação nacional, conforme disposto no Regulamento Sanitário Internacional. Brasília. Ministério da Saúde; 2005. 


\title{
O PAPEL DO MÉDICO VETERINÁRIO NA SAÚDE PÚBLICA
}

\author{
Delcivan Lima dos Santos'; Isadora Conceição de Souza ${ }^{2}$ \\ ${ }^{1}$ Mestre em Ciência Animal, Universidade Federal do Recôncavo da Bahia (UFRB), Cruz das
} Almas, BA.

${ }^{2}$ Graduada em Medicina Veterinária, Universidade Federal do Recôncavo da Bahia (UFRB), Cruz das Almas, BA.

\begin{abstract}
RESUMO
A Medicina Veterinária surgiu é uma ciência que garante a saúde dos animais, com o objetivo de diminuir os danos e os prejuízos causados pelos diversos agentes patológicos que os afetavam. No decorrer do tempo e com a criação da medicina veterinária preventiva, intensificou-se a luta do homem contra as doenças que colocam em risco a saúde do homem e dos animais, devido ao contágio de doenças através do convívio entre eles. A saúde pública veterinária consiste na aplicação dos conhecimentos do profissional de Medicina Veterinária para a proteção e promoção da saúde humana. A partir do aumento da convivência entre as pessoas e os animais domésticos e silvestres, houve aumento na transmissão e uma mudança nos hospedeiros de diversos agentes patogênicos, bem como nos ambientes de sobrevivência deles. Com isso, ressaltou-se a importância da atuação do médico veterinário na Saúde Única.
\end{abstract}

PALAVRAS CHAVES: SUS; População; Zoonoses.

ÁREA TEMÁTICA: Medicina Veterinária

\section{INTRODUÇÃO}

A Medicina Veterinária é a primeira ciência do coletivo. De fato, o profissional incorporase facilmente ao grupo de profissionais da área de saúde por estar habilitado a proteger a população contra as enfermidades coletivas. A formação recebida por esse profissional está em harmonia com o conceito de saúde pública, que considera todos os fatores que determinam a saúde coletiva sem se limitar às necessidades do indivíduo.

No entanto, no Brasil, a Medicina Veterinária era relacionada pelo Ministério da Educação apenas como área de ciências agrárias. A inclusão normativa do médico veterinário na área da saúde data de 1991 e foi efetivada na Resolução do Conselho Nacional de Saúde (CNS) n ${ }^{\circ}$ 38, de 04 de fevereiro de 1993. Nessa época, era escasso o conhecimento da sociedade, das autoridades e dos 
profissionais de saúde sobre o papel desenvolvido pelo médico veterinário na Saúde Pública.

Com base no princípio da atuação multidisciplinar da área da saúde, a Resolução n ${ }^{\circ}$ 218, de 06 de março de 1997, republicada como Resolução n ${ }^{\circ} 287$ de 08 de outubro de 1998 no DOU n . 86 de 07 de maio de 1999, lista os profissionais de saúde de nível superior, confirmando a presença do médico veterinário. A inclusão do médico veterinário no modelo da atenção à saúde no campo de atuação do SUS verifica-se nas execuções das ações de Vigilância em Saúde, nela compreendida: vigilância sanitária, vigilância epidemiológica, vigilância ambiental e vigilância à saúde do trabalhador.

Ao analisar a inserção do médico veterinário no SUS, destaca que esse profissional, devido ao seu conhecimento na área biomédica, nas clínicas de diferentes espécies, e por estar habituado a lidar com coletivos (populações), aliado aos conhecimentos específicos em parasitologia, microbiologia, zoonoses, epidemiologia e, principalmente, por estar sempre voltado para a prevenção dos agravos, deveria ocupar um papel mais atuante no atual modelo de saúde proposto pelo SUS.

\section{FUNDAMENTAÇÃO TEÓRICA}

O interesse pelo conceito de "One Health" ocorreu como um resultado do aumento do surgimento de doenças infecciosas zoonóticas na década passada. Os impactos subsequentes dessas doenças em humanos, animais domésticos e silvestres, bem como os efeitos econômicos, deram à saúde internacional organizações e governos nacionais uma maior valorização da importância de esforços colaborativos na resolução de problemas de saúde. As escolas de veterinária estão reorganizando seu ensino a educação veterinária para melhorar os ensinamentos aos alunos, e aplicar os conceitos de Saúde Única. Os veterinários têm uma longa história de envolvimento com as atividades da One Health, e este envolvimento se ajustou e mudou com as necessidades de mudança de sociedade.

O médico veterinário possui diversas atribuições na Sociedade, e consequentemente, na Saúde Pública. De acordo com a World Health Organization, este profissional está diretamente ligado a investigação, diagnóstico, medidas de controle e prevenção em zoonoses, investigações comparativas de doenças não infecciosas em animais, que podem afetar os humanos, intercorrelação entre informações oriundas de pesquisa em parceria com a medicina humana, análise de compostos tóxicos e peçonha de animais, vigilância sanitária, inspeção de todos os alimentos de origem animal, monitoramento de indústrias alimentícias saneamento ambiental.

O conceito central de Saúde Única é a ideia de que a saúde humana, dos animais domésticos e selvagens, estão todos interligados no ecossistema. As interações entre os três elementos são multidirecionais, e podem ter interações diretas ou indiretas, ocasionando o surgimento de doenças As práticas de saúde dos animais domésticos têm o potencial de afetar a saúde humana.

O aumento da demanda global pela produção de proteína resultou em esforços para aumentar a eficiência da pecuária e outras formas de obtenção de proteína de origem animal. Isso levou a alta densidade nas instalações de produção animal e o aumento do uso de produtos farmacêuticos 
profiláticos para manter a saúde e aumentar as taxas de crescimento. A preocupação está em aumento exponencial, porquê esta prática está aumentando o potencial desenvolvimento de resistência a antibióticos e, portanto, diminuindo a eficácia dos antibióticos não apenas para animais de alimentação, mas também para humanos.

A Prevalência de multirresistência em isolados de Salmonella spp retirados de unidades de produção de suínos nos Estados Unidos, por exemplo, está acima de 50\%. Isso significa um maior risco de saúde para quem consome.

O número de zoonoses relacionado com cada espécie animal, e que podem infectar seres humanos, dependendo das circunstâncias favoráveis, que possam determinar os riscos de contágio direto, indireto, ou veiculados em seus produtos e subprodutos alimentares, foram descritas e mencionadas. Com isso, obtiveram-se os seguintes dados: 13 zoonoses em peixes; 42 em bovinos; 43 em caprinos; 58 em aves; 68 em ovinos; 68 em suínos; 80 em cães; e, pelo menos, 20 em gatos.

Pode-se destacar a importância do veterinário no controle de zoonoses, que são doenças transmissíveis entre animais e humanos, causadas por diversos tipos de agentes como bactérias, fungos, parasitas, fungos e vírus. Segundo a OMS, estima-se que $60 \%$ das doenças infecciosas humanas são zoonoses; 75\% das doenças infecciosas emergentes em humanos tem origem animal; e a cada cinco doenças que surgem em humanos, todos os anos, três possuem origem animal.

No Brasil, a Lista Nacional de Notificação Compulsória de 2016 contempla 48 doenças, agravos ou eventos de saúde pública, dos quais 25 têm o envolvimento de animais em sua cadeia de transmissão, acometem animais e/ou são zoonoses.

O médico veterinário é de suma importância para o SUS, uma vez que, as zoonoses representam a maior porcentagem das doenças de notificação obrigatória no Brasil. Um importante e recente cargo que vincula o médico veterinário à saúde pública, principalmente no controle e prevenção de zoonoses, é o médico veterinário do NASF. A seleção de profissionais da área da saúde a compor as equipes de Saúde da Família é definida pelos gestores municipais, seguindo critério de prioridade identificado por dados epidemiológicos e necessidades locais que serão apoiadas.

O médico veterinário passou a compor a gama de profissionais que podem fazer parte da equipe do NASF em 2011, a partir da Portaria do Ministério da Saúde no 2.488, de 21 de Outubro de 2011.

De acordo com o Conselho Nacional de Saúde Pública Veterinária (CNSPV) e com o Conselho Federal de Medicina Veterinária, são vastas as áreas em que o Médico Veterinário pode atuar no NASF. Dentre elas, destacam-se: ações socioeducativas por meio de palestras e cartilhas informativas à comunidade; educação em saúde na prevenção de doenças e agravos de natureza antropozoonótica; prevenção, controle e diagnóstico de doenças; visitas domiciliares; prevenção e auxílio em casos de acidentes com animais peçonhentos; pesquisa e realização de estudos na área da saúde; análise de resíduos sólidos; orientações sobre os riscos de contaminação de substâncias tóxicas, doenças e agravos transmitidos por alimentos; monitoramento das ações desenvolvidas pelo 
programa.

Os médicos veterinários que atuam no NASF devem ter conhecimento sobre seu território e problemas especiais da sua região, em termos ambientais e sanitários. Esses profissionais precisam demonstrar ao Conselho Municipal de Saúde a importância do seu papel na equipe com levantamento de dados epidemiológicos, planos estratégicos, cronogramas e estimativa de custos, desenvolvendo, assim, suas funções como uma das profissões mais importantes da saúde pública.

\section{CONCLUSÃO}

O Médico Veterinário é muito importante para a saúde pública, de um modo geral. Ele promove o bem estar da população. Com uma visão mais atual das diversas possibilidades da profissão, a OMS divulga de forma robusta á carência que diversos setores da sociedade têm desse profissional. As áreas de atuação não se resumem apenas á saúde e proteção animal, e ambiental, mas também na promoção da saúde humana em relação ao combate de doenças zoonóticas e a segurança sanitária de todos os produtos de origem animal.

Este profissional tem a incumbência de oferecer condições ambientais mais adequadas. Aliado a isso, tem papel fundamental na divulgação de informações, no direcionamento das informações e propenção ás pessoas de acordo com s Saúde Única, que veio para unificar os elos indissociáveis da saúde humana, animal e ambiental.

A participação do médico veterinário na saúde pública e em Programas de Atenção Básica, como o Núcleo de Saúde da Família, é muito importante para a consolidação da saúde e melhoria dos serviços públicos disponibilizados à população. A saúde envolve vários fatores, sendo necessário o olhar de diferentes profissionais para abordar todas as variáveis e condicionantes da saúde, sendo de responsabilidade do médico veterinário a observação e contribuição em aspectos relacionados à integração homem-animal.

\section{PRINCIPAIS REFERÊNCIAS}

ARÁMBULO, P. V. Veterinary public health: perspectives at the threshold of the 21 st century. Revue Scientific Technique, v.11, n.1, p.255-262, 1991.

BRASIL. Ministério da Saúde. Portaria no 104, de 25 de Janeiro de 2011. Define a relação de doenças, agravos e eventos em saúde pública de notificação compulsória. Diário Oficial da República Federativa do Brasil, Poder Legislativo, Brasília, DF, 25 Jan. 2011.

BRASIL. Ministério da Saúde. Portaria nº 154, de 24 de janeiro de 2008. Cria os Núcleos de Apoio à Saúde da Família - NASF. DOU, Brasília, DF, nº 43, 4 março de 2008. 
BRASIL. Ministério da Saúde. Portaria n 2.488, de 21 de outubro de 2011. Aprova a Política Nacional de Atenção Básica, estabelecendo a revisão de diretrizes e normas para a organização da Atenção Básica, para a Estratégia Saúde da Família (ESF) e o Programa de Agentes Comunitários de Saúde (PACS).

BARBOSA, D.S. A inserção do médico veterinário nos Núcleos de Apoio à Saúde da Família (NASF): novos caminhos de atuação na saúde pública. JMPHC. v.5, n.1, p.1-3, 2014.

OSBURN, B. I. Emerging diseases with a worldwide impact and the consequences for veterinary curricula. Veterinary Quarterly, v.18, n.3, p.124-126, 1996. 


\title{
LEPTOSPIROSE BOVINA: UMA ZOONOSE EMERGENTE
}

\author{
João Pedro Grassi de Araujo; ; Suélen Dalegrave²; Maurício Orlando Wilmsen³. \\ ${ }_{1}$ Residência em Clínica, Cirurgia e Reprodução de Animais de Produção, Pontifícia Universidade \\ Católica do Paraná - PUCPR campus Toledo, Paraná. \\ ${ }_{2}$ Residência em Clínica e Cirurgia de Pequenos Animais, Pontifícia Universidade Católica do \\ Paraná - PUCPR campus Toledo, Paraná. \\ ${ }_{3}$ Doutor, Professor do eixo de Medicina Veterinária Preventiva do Curso de Medicina Veterinária, \\ Pontifícia Universidade Católica do Paraná - PUCPR campus Toledo, Paraná.
}

DOI: $10.47094 /$ ICONRES.2021/8

\begin{abstract}
RESUMO
A leptospirose é uma zoonose emergente transmitida principalmente pela urina dos ratos e altamente prevalente em ambientes urbanos e rurais, com altos índices de prevalência em rebanhos bovinos do Brasil. A enfermidade causa diversos prejuízos de caráter clínico ao animal e/ou pessoas, além de comprometer seu eixo produtivo (carne, leite e derivados). Na disseminação estão envolvidas três espécies de roedores Rattus norvegicus, Rattus rattus e Mus musculus principalmente em áreas urbanas e em áreas rurais, o próprio bovino possui o papel de vetor. Levando em consideração que a Leptospirose é uma doença que se apresenta em diferentes formas, além da fase clínica, ao realizar testes sorológicos de manutenção no rebanho, os mesmos indicam a soroprevalência do agente, aumentando a incidência de abortos, fetos mumificados e nascimento de bezerros fracos. A imunoprofilaxia consiste na principal ferramenta de controle do rebanho, além do controle ao acesso de outros vetores em bebedouros e comedouros.
\end{abstract}

PALAVRAS-CHAVES: Doenças infectocontagiosas; Bovinocultura; Sorovar.

ÁREA TEMÁTICA: Medicina veterinária

\section{INTRODUÇÃO}

Há uma importância relevante em compreender que animais considerados reservatórios aumentam o risco de infecção e, além disso, diferentes espécies podem ser suscetíveis à diferentes cepas da bactéria, devido a alguma forma de coadaptação ao longo do tempo. Desta forma, é importante entender que os riscos em que o profissional da medicina veterinária está submetido é 
alto em decorrência de suas atividades serem executadas com diferentes espécies animais. Assim, a presença de diferentes sorovares contaminando diferentes espécies: cães (L. Canícola), bovinos ( $L$. Hardjo e L. Tarassovi) e suínos (L. Bratislava e L. Icterohaemorragiae) aumentam a incidência da doença nesses profissionais.

Muito embora os ratos sejam considerados os principais reservatórios, sobretudo, o Rattus norvegicus, por abrigar o serogrupos de Leptospira Icterohaemorrhagiae, considerado o mais patogênico para espécie humana, outras espécies podem servir de reservatório de outros sorovares. De acordo com dados do IBGE (2019), o Brasil conta com mais de 214 milhões de bovinos, destinados a produção de carne e leite, esses número disparam incertezas a respeito da veiculação da doenças de caráter zoonótico dentro da cadeia produtiva da bovinocultura. As leptospiroses constitui um grupo de destaque na veiculação e difusão desses patógenos em todo mundo. (LOUREIRO; LILENBAUM, 2019).

No Brasil, a distribuição dos sorovares em destaque para espécie bovina são restritos a Hardjo (genótipo hardjoprajitno), Pomona, Icterohaemorrhagiae, Wolffi, Goiano e Guaicurus. Contudo, as bactérias do gênero Leptospira, estão subdivididas em em três categorias com mais de 250 sorovares (PETRAKOVSKY et al., 2014). O objetivo desse trabalho foi monitorar a presença do agente em um rebanho bovino de um hospital escola da Clivet, fazenda escola da Puc-PR, localizada na cidade de Toledo, região Oeste do Paraná.

\section{METODOLOGIA}

Foi realizado através de um inquérito sorológico no rabanho bovino da PUCPR - campus Toledo, a presença de sorovares com caráter zoonótico relacionados as Bactérias do gênero Leptospira em 21 vacas de corte. Antes e depois dos animais serem imunizados A coleta de sangue foi realizada em dois momentos, pré (6 animais) e pós vacinação (15 animais), diretamente da veia caudal. O sangue foi armazenado em tubos sem anticoagulante previamente identificados. Após a obtenção das amostras, as mesmas foram enviadas ao laboratório clínico, onde foram centrifugas e alocadas em tubos ependorfe e sequencialmente congeladas a temperatura de $-20^{\circ} \mathrm{C}$ até o momento do processamento. $\mathrm{O}$ porcessamento das amostras foi realizado em laboratório particular, através do teste de aglutinação modificado ou ensaio de microaglutinação (MAT).

\section{RESULTADOS E DISCUSSÕES}

A partir dos resultados dos exames sorológicos foi possível entender a distribuição de diferentes soravares no rebanho de fêmeas bovinas. Do ponto de vista de veiculação de sorovares infecciosos que compartilham infecções entre humanos e animais, apenas um animal foi sorologicamente identificado com o sorovar L. Icterohaemorraghie (1:400), indicando inclusive infecção ativa pelo agente. O manejo determinado para esse animal envolve critérios de acompanhamento clínico, sorológico ou 
ainda qualquer impacto reprodutivo. A fêmea contaminada com este sorovar teve a prenhez confirmada sem abortamento ou mumificação, contudo, o bezerro nascido apresentou-se menor que o esperado.

Os resultados sorológicos dos animais no momento pré imunização, reveleram a presenca de L. Wolffi e L. Pomona com título de 1:100 em um animal e no segundo animal apenas L. Wolff 1:1800. De acordo com o manual de testes diagnósticos de animais terrestres da OIE de 2013, animais não vacinados, com titulação $\geq 100$, sugerem contato com o agente infeccioso e animais com titulação $\geq 400$ está relacionado com infecção ativa. De acordo com Petrakovsky et al., (2014), o teste de microaglutinação (MAT) de eleição para vários ensaios sorológicos para diagnosticar a leptospirose na América Latina, tendo como maior resultado de sorovares a L. Hardjo, Wolffi e Tarassovi. Segundo Zaratonelli et al., (2018), o MAT foi utilziado para detecção de rebanhos infectados no Uruguai, utilizando a titulação de $\geq 200$, sugerindo infecção ativa, para novas amostras e exames de PCR. No segundo momento, com os animais já vacinados, foi considerado titulação $\geq 400$ para confirmar a infecção ativa.

Dos 15 animais, 5 apresentaram titulação $\geq 400$ para L. Bratislava, Icterohaemorraghie, Pomona, Wolffi e Hardjo. Os animais com alguma titulação somaram 46,7\% de amostras positivas. Segundo Benschop et al., (2021), apontaram em um inquérito sorológico de um rebanho que esses sorovares apresentam alta prevalência em rebanhos bovinos. O teste de microaglutinação se mostra um excelente teste para avaliação de rebanhos, porém, quando a avaliação de animais com características crônicas da infecção e eliminação do agente pela urina, seria o emprego do teste de reação em cadeia pela polimerase (PCR), e a resposta para tal avaliação se dá pelo uso inadequado da técnica sugerindo resultados falsos negativos (LIBONATI et al., 2017); (LOUREIRO; LILENBAUM, 2019).

Após a confrimação do diagnóstico sorológico no rebanho, uma fêmea apresentou mumificação fetal sendo o título 1:1800 do sorovar L. Wolffi. Mumificações fetais podem ocorrer por diversos fatores, entre eles a Leptospirose (BRAGA et al., 2014). A leptospirose causa diversos distúrbios reprodutivos, como mumificação, infertilidade além de abortos no rebanho (MORI et al., 2017).

\section{CONCLUSÃO}

Este levantamento sorológico permitiu concluir que diferentes sorovares de Leptospiras spp são edêmicos no rebanho da instituição. Assim, através do monitoramento soroepiodemiológicos novas estratégias de para o controle o profilaxia do rebanho foram adotadas, principalmente quanto ao animal identificado com o sorovar L. Icterohaemorraghie, também reconhecido infectar seres humanos. A fêmea positiva não apresentou nenhum tipo de transtorno reprodutivo, e o controle da infecção foi realizado através do acompanhamento clínico e da imunização do animal.

\section{REFERÊNCIAS}

BENSCHOP, Jackie; NISA, Shahista; SPENCER, Simon E. F.. Still 'dairy farm fever'? A Bayesian 
model for leptospirosis notification data in New Zealand. Journal Of The Royal Society Interface, [S.L.], v. 18, n. 175, p. 20200964-20200964, fev. 2021.

BRAGA, P.O. e BARROSO, R.M. Aspectos fisiopatológicos da mumificação fetal. PUBVET, Londrina, V. 8, N. 15, Ed. 264, Art. 1752, Agosto, 2014.

IBGE- INSTITUTO BRASILEIRO DE GEOGRAFIA E ESTATÍSTICA. Efetivo de rebanho, por tipo (cabeças), Rio de Janeiro: IBGE, 2019. Disponível em: https://www.ibge.gov.br/estatisticas/ economicas/agricultura-e-pecuaria/9107-producao-da-pecuaria-municipal.html?=\&t=destaques. Acessado em: 12 de março de 2021.

LIBONATI, Hugo; PINTO, Priscila S.; LILENBAUM, Walter. Seronegativity of bovines face to their own recovered leptospiral isolates. Microbial Pathogenesis, [S.L.], v. 108, p. 101-103, jul. 2017.

LOUREIRO, Ana P.; LILENBAUM, Walter. Genital bovine leptospirosis: a new look for an old disease. Theriogenology, [S.L.], v. 141, p. 41-47, jan. 2020.

MORI, Marcella; BAKINAHE, Raïssa; VANNOORENBERGHE, Philippe; MARIS, Jo; JONG, Ellen de; TIGNON, Marylène; MARIN, Martine; DESQUEPER, Damien; FRETIN, David; BEHAEGHEL, Isabelle. Reproductive Disorders and Leptospirosis: a case study in a mixed-species farm (cattle and swine). Veterinary Sciences, [S.L.], v. 4, n. 4, p. 64, 1 dez. 2017.

OLIVEIRA, Stefan Vilges de; ARSKY, Maria de Lourdes Nobre Simões; CALDAS, Eduardo Pacheco de. RESERVATÓRIOS ANIMAIS DA LEPTOSPIROSE: uma revisão bibliográfica. Saúde (Santa Maria), [S.L.], v. 39, n. 1, p. 9-19, 1 mar. 2013.

PETRAKOVSKY, Jessica; BIANCHI, Alejandra; FISUN, Helen; NÁJERA-AGUILAR, Patricia; PEREIRA, Martha. Animal Leptospirosis in Latin America and the Caribbean Countries: reported outbreaks and literature review (2002-2014). International Journal Of Environmental Research And Public Health, [S.L.], v. 11, n. 10, p. 10770-10789, 16 out. 2014. 


\section{CERATITE PIGMENTAR: REVISÃO DE LITERATURA}

\section{Larissa Rodrigues Marchini ${ }^{1}$; Isabella Junqueira Rodrigues ${ }^{1}$, Francimery Aparecida Fachini²; Paola Castro Moraes ${ }^{3}$}

${ }^{1}$ Graduanda em Medicina Veterinária, Universidade Estadual Paulista Júlio de Mesquita Filho (FCAV/UNESP), Jaboticabal, São Paulo.

${ }^{2}$ Mestre em Cirurgia Veterinária, Universidade Estadual Paulista Júlio de Mesquita Filho (FCAV/ UNESP), Jaboticabal, São Paulo.

${ }^{3}$ Professora Doutora em Cirurgia Veterinária, Universidade Estadual Paulista Júlio de Mesquita Filho (FCAV/UNESP), Jaboticabal, São Paulo.

\section{RESUMO}

A ceratite pigmentar é comumente detectada nos cães, principalmente aqueles classificados como braquicefálicos, como é o caso dos cães da raça pug. A etiologia não é totalmente definida, porém se compreende que ocorre a pigmentação do epitélio e estroma corneano devido à migração e deposição de melanócitos nessas regiões, juntamente a inflamação crônica. É considerada um achado clínico que orienta o diagnóstico de distintas enfermidades, e as causas que predispõem o seu aparecimento são díspares, como quantidade e qualidade da lágrima, desordens ciliares e palpebrais, como entrópio, ectóprio, entre outros. O tratamento se dá pela retirada do fator que ocasiona a lesão e a irritação da córnea, conjuntamente a outras estratégias clínicas.

PALAVRAS-CHAVES: Braquicefálicos; Córnea; Oftalmologia Veterinária.

ÁREA TEMÁTICA: Medicina Veterinária

\section{INTRODUÇÃO}

O olho é tido como um órgão suscetível, em que reduzidas alterações são capazes de causarem desordens em sua homeostase, em virtude de distúrbios sistêmicos, locais ou devido a lesões diretas ${ }^{5}$. A ceratite pigmentar é caracterizada pelo desenvolvimento de pigmento na córnea, juntamente à inflamação crônica e, ocorre em consequência da migração de melanócitos do limbo e região perilimbal e consecutiva deposição, sendo esta mais superficial, ou seja, no epitélio da córnea ou mais profunda, no estroma anterior, podendo resultar em déficit visual ou completa perda de visão, nas ocorrências mais expressivas ${ }^{1,6,14}$. Inúmeras causas, como cílios ectópicos, distiquíase, formação lacrimal reduzida, anormalidades de conformação ou neurológicas palpebrais, pregas 
nasais exuberantes, resultam em lesões e inflamação crônica da córnea que procedem à migração do pigmento ${ }^{1,3,14}$. Para mais, a transparência da córnea é crucial para a visão, em que as células estaminais epiteliais do limbo desempenham papel essencial na manutenção do bom funcionamento corneano e consequentemente da visão ${ }^{11}$, no qual a inflamação da superfície da córnea é relacionada com a deficiência destas células ${ }^{12}$. Além do mais, é provável que a deficiência das células estaminais limbais estejam relacionadas com o desenvolvimento de algumas afecções, dentre elas da ceratite pigmentar $^{11}$. A pigmentação da córnea deve ser examinada e tida como sinal clínico que auxilia na identificação de diferentes enfermidades, sendo comumente encontrada nos cães da raça pug, em que sua etiologia ainda não é inteiramente definida ${ }^{6,9}$. O tratamento constitui na eliminação do agente causal $^{2,7}$. O objetivo desta revisão de literatura é discorrer sobre a ceratite pigmentar em cães e trazer informações pertinentes sobre esta temática.

\section{METODOLOGIA}

Para a produção deste resumo expandido foram realizadas pesquisas em bases de dados dissemelhantes como: Veterinary Ophthalmology, Portal PubVet, Scielo, Scopus e Google Acadêmico, por meio da pesquisa de termos como: "prevalência da ceratite pigmentar", "principais afecções oculares em cães"; entre outros, em que 14 artigos foram selecionados para o embasamento desta revisão de literatura.

\section{FUNDAMENTAÇÃO TEÓRICA}

Um estudo retrospectivo que objetivou estabelecer a frequência e os tipos dos achados oftalmológicos em cães da raça pug, revelou que dentre os 130 animais (258 olhos) com média de idade de 2,8 anos, 101 olhos exibiram pigmento na córnea. Ademais, demonstrou alto número de animais ( $n=61)$ que apresentaram pigmento na córnea sem a presença de ceratoconjuntivite seca, sugerindo a influência de outros aspectos envolvidos no aparecimento deste distúrbio ${ }^{4}$. Outro estudo, realizado com 210 pugs ( 420 olhos) com idade média de 2,5 anos, demonstrou que a ceratite pigmentar estava presente em 369 olhos, ou seja, em 87,8\% dos olhos. Neste estudo, o aumento da idade foi significativamente influente no aparecimento da ceratite pigmentar ${ }^{9}$. Em relação ao grau, 46,3\% dos casos foram discretos, enquanto $49,9 \%$ foram moderados ${ }^{9}$. Além disto, a pesquisa que analisou a ocorrência de diferentes enfermidades oculares se certificou que dentre 60 cães, a ocorrência da ceratite pigmentar, juntamente com úlcera de córnea, se destacou em 21,7\% dos animais afetados, em que a raça pug estava novamente em evidência ${ }^{5}$. Outro estudo que envolveu 57 cães, sendo 32 pugs e 25 cães braquicefálicos de outras raças, sendo estas, boston terrier $(n=10)$, shih-tzu $(n=7)$, pequinês $(n=5)$, lhasa apso $(n=3)$, mostrou que dentro do grupo pug, 23 animais possuíam a córnea pigmentada em pelo menos um olho ${ }^{13}$. Além disso, a crioterapia foi pesquisada em estudo com nove cães com pigmento corneano devido à ceratoconjuntivite seca e pannus oftálmico, em que os resultados foram favoráveis a curto prazo, porém após 90 dias houve recidiva nos $\operatorname{casos}^{1}$.Outrossim, apenas dois cães 
da raça pug, ou seja, uma quantidade não muito expressiva, apresentaram melhora significativa da pigmentação da córnea após desbridamento com diamond burr, por conta da formação de um novo epitélio corneano ${ }^{8}$ Para o tratamento, há relatos que a ceratectomia superficial. o uso de corticoides tópico, na ausência de úlcera e o uso de medicamentos que estimulem a produção lacrimal, podem auxiliar na terapêutica ${ }^{2,7}$.

\section{CONSIDERAÇÕES FINAIS}

A etiologia da ceratite pigmentar não é bem definida até o presente momento, em que a sua manifestação está associada à presença de outras enfermidades. Estudos futuros podem contribuir para o esclarecimento da sua origem, auxiliando em melhores condutas terapêuticas, assim como na sua prevenção, consequentemente contribuindo para o fornecimento de melhor qualidade visual para os indivíduos que são acometidos com este distúrbio.

\section{PRINCIPAIS REFERÊNCIAS}

1.AZOULAY, T. Adjunctive cryotherapy for pigmentary keratitis in dogs: a study of 16 corneas. Veterinary ophthalmology, v. 17, n. 4, p. 241-249, 2014.

2.GELATI, K. N. Comeal diseases in the dog. In: GLAZE, M. B. The compendium collection: ophthalmology in Smal1 animal practice. 2. ed. New Jersey: Veterinary Leaming Systems, 1996. p. 107-13

3.KASWAN, R. L.; MARTIN, C. L.; DAWE, D. L. Keratoconjunctivitis sicca: immunological evaluation of 62 canine cases. American Journal of Veterinary Research, v. 46, n. 2, p. 376-383, 1985.

4.KRECNY, M.; TICHY, A.; RUSHTON, J.; NELL, B. A retrospective survey of ocular abnormalities in pugs: 130 cases. Journal of Small Animal Practice, v. 56, n. 2, p. 96-102, 2015.

5.KUMAR, T.; PUNIA, M.; AGNIHOTRI, D.; SINDHU, N.; JAIN, V. K. Incidence of ophthalmic affections in dogs-A short study. International Journal of Current Microbioly and Applied Sciences, v. 7, n. 9, p. 1560-1565, 2018.

6.LABElle, A. L.; DRESSER, C. B.; HAMOR, R. E.; ALlENDER, M. C.; DiSNEY, J. L. Characteristics of, prevalence of, and risk factors for corneal pigmentation (pigmentary keratopathy) in Pugs. Journal of the American Veterinary Medical Association, v. 243, n. 5, p. 667-674, 2013.

7.LAUS, J. L.; ORIÁ, A. P. Doenças corneanas em pequenos animais. Revista de Educação Continuada em Medicina Veterinária e Zootecnia do CRMV-SP, v. 2, n. 1, p. 23-33, 1999.

8.LIMA, P.L.S.D. Ceratite Pigmentar ou ceratopatia pigmentar em pug? relato de caso. 2019. Trabalho 
de conclusão de curso (Bacharel em Medicina Veterinária) - Universidade Federal da Paraíba, Areia, 2019.

9.MAINI, S.; EVERSON, R.; DAWSON, C.; CHANG, Y. M.; HARTLEY, C.; SANCHEZ, R. F. Pigmentary keratitis in pugs in the United Kingdom: prevalence and associated features. BMC Veterinary Research, v. 15, n. 1, p. 1-11, 2019.

10.SANCHEZ, R.F. The Cornea. In: GOULD, D.; MCLELLAN, G. BSAVA Manual of Canine and Feline Ophthalmology. 3rd ed. Gloucester: British Small Animal Veterinary Association, 2014. p. 200 -31 .

11.SANCHEZ, R.F.; DANIELS, J.T. Mini-review: Limbal stem cells deficiency in companion animals: time to give something Back?. Current eye research, v. 41, n. 4, p. 425-432, 2016.

12.SCHLO“TZER-SCHREHARDT U.; KRUSE, F.E. Identification and characterization of limbal stem cells. Experimental eye research, v. 81, n. 3, p. 247-264, 2005.

13.VALLONE L.V.; ENDERS A.M.; MOHAMMED H.O.; LEDBETTER E.C. In vivo confocal microscopy of brachycephalic dogs with and without superficial corneal pigment. Veterinary ophthalmology, v. 20, n. 4, p. 294-303, 2017.

14.WESTERMEYER, H. D.; WARD, D. A.; ABRAMS, K. Breed predisposition to congenital alacrima in dogs. Veterinary ophthalmology, v. 12, n. 1, p. 1-5, 2009 


\title{
PROSPECÇÃO DE ESTUDOS SOBRE A TOXICIDADE DE OPIOIDES EM QUADROS DE DOR PÓS-OPERATÓRIA EM CANINOS
}

\author{
Paulo Ricardo Batista ${ }^{1}$ \\ ${ }^{1}$ Graduação em Ciências Biológicas, Universidade Regional do Cariri (URCA), Crato, Ceará.
}

\begin{abstract}
RESUMO
A dor pós-operatória é uma variável muito importante para a qualidade de vida e do resultado cirúrgico, sua contenção na prática veterinária com cães pode advir do uso de fármacos opioides. Não obstante, são considerados os efeitos adversos desses agentes. Desse modo esse estudo visou agrupar estudos da literatura científica que elucidem a toxicidade de agonistas opiodes no trato de algias pós-operatórias em cães. Trata-se de uma revisão integrativa realizada nos bancos de dados: MEDLINE, LILACS e SciELO sob os descritores: opioid, adverse effects, pain, postoperative e dogs. Os principais achados compilados indicam que agentes opioides nos últimos anos vêm sendo alvos de pesquisas clínicas quanto a sua eficácia e segurança, quer seja em sua administração isolada ou associada a drogas anti-inflamatórias não esteroidais. Atribuindo-se àqueles fármacos, efeitos colaterais como: vômito, hipotermia, hipersalivação, diarreia, anorexia e bradicardia. Espera-se que esta revisão fomente pesquisas veterinárias toxicológicas e farmacológicas.
\end{abstract}

PALAVRAS-CHAVE: Analgesia; Cães; Reações Adversas.

ÁREA TEMÁTICA: Medicina veterinária

\section{INTRODUÇÃO}

O controle da dor pós-operatória é relevante por interferir no tempo de recuperação, na qualidade de vida e no resultado cirúrgico. Nesse sentido, fármacos analgésicos opioides podem ser utilizados na rotina veterinária, em contrapartida, seus efeitos colaterais se distinguem de acordo com a espécie animal e são comuns quando há uso de doses excessivas, além disso, variam conforme o tipo de opioide empregado, momento e número de administrações (RIPPLINGER et al., 2018).

Sabe-se que drogas anti-inflamatórias não esteroidais e opioides são largamente utilizados para a promoção de analgesia pós-operatória em cães (LUNA et al., 2015). Com base nesse contexto, o presente trabalho tem por objetivo geral prospectar e agrupar estudos da literatura científica que elucidem a toxicidade de agonistas opiodes no trato de algias pós-operatórias em cães. 


\section{METODOLOGIA}

Trata-se de uma revisão integrativa de caráter descritivo e natureza quali-quantitativa. Para tanto foram seguidas as seguintes etapas: identificação da temática e definição da questão de pesquisa; estabelecimento de critérios de elegibilidade; identificação dos estudos pré-selecionados e selecionados com base na leitura dos títulos, resumos e palavras-chave; categorização dos estudos; análise e interpretação dos dados; e apresentação da revisão (BOTELHO; CUNHA; MACEDO, 2011).

A pergunta norteadora definida é: Qual a evolução do palco literário pertinente a toxicidade do uso de opioides na dor pós-operatória na espécie canina?

Os bancos de dados delimitados compreendem: MEDLINE e a Literatura Latino-Americana e do Caribe em Ciências da Saúde (LILACS), acessados através da Biblioteca Virtual em Saúde (BVS) e Scientific Electronic Library Online (SciELO). Os unitermos selecionados foram: opioid, adverse effects, pain, postoperative e dogs, aplicados com o operador booleano AND.

Os filtros de busca definidos foram: artigos completos e disponíveis, do tipo ensaios clínicos que relatem in vivo a toxicidade de agentes opioides em cães, sem recorte temporal a fim de contemplar o maior número de estudos devido à especificidade da temática, idioma Inglês com a finalidade de sintetizar o conhecimento publicado nesse idioma e torná-los acessíveis a leitores que possuem como idioma nativo o Português. Livros, resumos simples e expandidos de anais de eventos ou trabalhos de conclusão de curso de graduação ou pós-graduação foram excluídos.

O processo de amostragem se deu entre janeiro e março de 2021 e a análise dos resultados consistiu no estabelecimento da quantidade de artigos prospectados, faixa temporal de publicação e quadro-síntese contendo agentes opioides mencionados, intervenções para aplicação, tipo de estudo e reações adversas elencadas.

\section{FUNDAMENTAÇÃO TEÓRICA}

A amostra primária compreende 37 artigos, sendo 33 provenientes de MEDLINE, 3 de LILACS e 1 de $S c i E L O$, foram excluídas 3 duplicatas, e após a aplicação dos critérios de inclusão e exclusão restaram 12 estudos incluídos na amostra final que atenderam ao objetivo geral da pesquisa. A faixa temporal das publicações se expressa bem recente, correspondendo de 2008 a 2018. Prevaleceram os designs de estudo do tipo: ensaios clínicos, randomizados, prospectivos e controlados.

Entre os agentes opioides utilizados (isolados ou em combinações) nos estudos da amostra desta revisão incluem: Buprenorfina (Vetergesic ou Simbadol) (WATANABE et al. 2018), Metadona (BINI et al., 2018; GUTIÉRREZ-BAUTISTA et al., 2018), Oximorfona, Fentanil (MARTINEZ et al., 2013), Tramadol e Morfina (KONGARA; CHAMBERS; JOHNSON, 2012a). Souza et al. (2018) quando apresentam algumas abordagens terapêuticas analgésicas pós-operatórias em cães, listam a Morfina, a Oximorfona (derivado semi-sintético da Morfina), a Metadona (opioide sintético) e o 
Tramadol (agonista sintético de receptores opiáceos).

Para as principais intervenções nas quais foram verificados os efeitos de agonistas opioides no controle de dor pós-operatória, têm-se: ovariohisterectomia (WATANABE et al. 2018), cirurgias ortopédicas (GUTIÉRREZ-BAUTISTA et al., 2018), osteotomia não complicada de nivelamento do platô tibial (BINI et al., 2018) e castração (KONGARA et al., 2013b).

No que concernem os efeitos colaterais destacados nos estudos pode-se elencar: vômito, melena, hipotermia (WATANABE et al. 2018), hipersalivação, taquipneia transitória (GUTIÉRREZBAUTISTA et al., 2018), diarreia, anorexia (MARTINEZ et al., 2013), sedação, ataxia, bradicardia, conjuntivite e taquicardia (LINTON et al., 2012), corroborados pela literatura (VALADÃO; DUQUE; FARIAS, 2002; ALEIXO; TUDURY, 2005).

\section{CONSIDERAÇÕES FINAIS}

Em síntese, a indagação norteadora da pesquisa e o objetivo proposto foram alcançados, mostrando estudos recentes, porém relevantes para a prática veterinária e transcendendo de forma multidisciplinar para os campos da farmacologia e toxicologia. Tendo em vista os dados apresentados, espera-se que a leitura deste texto subsidie investigações que almejem o desenvolvimento e aplicação de alternativas analgésicas para a dor pós-operatória em cães mais promissoras, menos tóxicas, mais potentes e eficazes e de formas de administrações menos invasivas, posto essas limitações serem um desafio constante na prática clínica.

\section{PRINCIPAIS REFERÊNCIAS}

ALEIXO, G. A. S.; TUDURY, E. A. Utilização de opióides na analgesia de cães e gatos. Veterinária Notícias, v. 11, n. 2, p. 31-42, 2005.

BINI, G.; VETTORATO, E.; DE GENNARO, C.; CORLETTO, F. A retrospective comparison of two analgesic strategies after uncomplicated tibial plateau levelling osteotomy in dogs. Veterinary Anaesthesia and Analgesia, 2018.

BOTELHO, L. L. R.; CUNHA, C. C. A.; MACEDO, M. O método da revisão integrativa nos estudos organizacionais. Gestão e Sociedade, v. 5, n. 11, p. 121-136, 2011.

GUTIÉRREZ-BAUTISTA, A.; MORGAZ, J.; GRANADOS, M.; GÓMES-VILLAMANDOS, R.; DOMINGUEZ, J.; FERNANDEZ-SARMIENTO, J.; AGUILAR-GARCIA, D.; NAVARRETECALVO, R. Evaluation and comparison of postoperative analgesic effects of dexketoprofen and methadone in dogs. Veterinary Anaesthesia and Analgesia, 2018.

KONGARA, K.; CHAMBERS, J. P.; JOHNSON, C. B. Effects of tramadol, morphine or their combination in dogs undergoing ovariohysterectomy on peri-operative electroencephalographic 
responses and post-operative pain. New Zealand Veterinary Journal, v. 60, n. 2, p. 129-135, 2012 a. KONGARA, K.; CHAMBERS, J. P.; JOHNSON, C. B.; DUKKIPATI, V. S. R. Effects of tramadol or morphine in dogs undergoing castration on intra-operative electroencephalogram responses and postoperative pain. New Zealand Veterinary Journal, v. 61, n. 6, p. 349-353, 2013 b.

LINTON, D. D.; WILSON, M. G.; NEWBOUND, G. C.; FREISE, K. J.; CLARK, T. P. The effectiveness of a long-acting transdermal fentanyl solution compared to buprenorphine for the control of postoperative pain in dogs in a randomized, multicentered clinical study. Journal of Veterinary Pharmacology and Therapeutics, v. 35, p. 53-64, 2012.

LUNA, S. P. L.; MARTINO, I. D.; LORENA, S. E. R. S.; CAPUA, M. L. B.; LIMA, A. F. M.; SANTOS, B. P. C. R.; BRONDANI, J. T.; VESCE, G. Acupuncture and pharmacopuncture are as effective as morphine or carprofen for postoperative analgesia in bitches undergoing ovariohysterectomy. Acta Cirúrgica Brasileira, v. 30, n. 12, p. 831-837, 2015.

MARTINEZ, S. A.; WILSON, M. G.; LINTON, D. D.; NEWBOUND, G. C.; FREISE, K. J.; LIN, T. L.; CLARK, T. P. The safety and effectiveness of a long-acting transdermal fentanyl solution compared with oxymorphone for the control of postoperative pain in dogs: a randomized, multicentered clinical study. Journal of Veterinary Pharmacology and Therapeutics, v. 37, p. 394-405, 2013.

RIPPlingER, A.; AIEllo, G.; CHAVES, R. O.; ANDRADES, A. O.; BECKMANN, D. V.; POLIDORO, D.; SOARES, A. V.; MAZZANTI, A. Efeitos adversos da morfina, metadona e tramadol no pós-operatório de cães submetidos à cirurgia da coluna vertebral: 180 casos (2011-2016). Pesquisa Veterinária Brasileira, v. 38, n. 7, p. 1431-1437, 2018.

SOUZA, P. S.; MILIOZZI, G.; RODRIGUES, C. A.; FRANCO, M.; SABINO, F. A. Abordagem terapêutica no controle da dor em cães no pós-operatório. Ciência Veterinária UniFil, v. 1, n. 2, 2018.

VALADÃO, C. A. A.; DUQUE, J. C.; FARIAS, A. Administração epidural de opióides em cães. Ciência Rural, Santa Maria, v. 32, n. 2, p. 347-355, 2002.

WATANABE, R.; MONTEIRO, B. P.; EVAnGElistA, M. C.; CASTONGUAY, A.; EDGE, D.; STEAGALL, P. V. The analgesic effects of buprenorphine (Vetergesic or Simbadol) in combination with carprofen in dogs undergoing ovariohysterectomy: a randomized, blinded, clinical trial. BMC Veterinary Research, v. 14, p. 1-7, 2018. 


\section{USO DE SOLUÇÃO ALCOÓLICA E DE SAIS DE CURA NO PREPARO QUÍMICO \\ DE CADÁVERES DE PEQUENOS RUMINANTES, VISANDO AO TREINAMENTO CIRÚRGICO}

\section{Raphael Chiarelo Zero ${ }^{1}$; Marcela Rosalem²; Isabella Cristina da Silva Cavalini²; Lorraine Carlos Siqueira $^{3}$; Luiz Gustavo Oliveira Trindade ${ }^{3}$; Talita Cristina Adão ${ }^{3}$; Amanda Rodrigues Finotti $^{3}$}

${ }^{1}$ Me. Cirurgia Veterinária, Universidade Brasil, Fernandópolis, São Paulo.

${ }^{2}$ Aprimoramento em clínica e cirurgia veterinária, Universidade Brasil, Fernandópolis, São Paulo.

${ }^{3}$ Discente do curso de medicina veterinária, Universidade Brasil, Fernandópolis, São Paulo.

\section{RESUMO}

A demanda por modelos alternativos ao uso de animais vivos no ensino e treinamento cirúrgico é uma realidade cada vez mais presente nas universidades. No preparo de cadáveres, substâncias químicas são utilizadas. O formaldeído é o mais utilizados nos laboratórios de anatomia, apresar dos riscos à saúde e ao meio ambiente. Objetiva-se com o presente estudo, avaliar a eficácia da técnica anatômica, utilizando solução alcoólica e de sais de cura, no preparo de cadáveres de pequenos ruminantes, destinados ao ensino e treinamento cirúrgico. Via artéria carótida comum, injetou-se $150 \mathrm{~mL} / \mathrm{kg}$ de solução de álcool etílico puro com $5 \%$ de glicerina e $120 \mathrm{~mL} / \mathrm{kg}$ de solução contendo $20 \%$ de cloreto de sódio, $1 \%$ de nitrito de sódio e $1 \%$ de nitrato de sódio. Os cadáveres foram mantidos refrigerados até o momento dos treinamentos. Assim, conclui-se que a técnica anatômica utilizada é eficaz, mantendo as características morfológicas, sem indícios de putrefação e odores desagradáveis.

PALAVRAS-CHAVES: Bioética; Técnica cirúrgica; Ensino.

ÁREA TEMÁTICA: Medicina Veterinária

\section{INTRODUÇÃO}

Estabelecida em 2008, a Lei ${ }^{\circ} 11.794$, denominada Lei Arouca, regulamenta o uso de animais vivos em atividades de ensino e pesquisa, a partir das Comissões de Ética no Uso de Animais (CEUA), dando origem a crescente demanda por métodos alternativos ao uso de animais vivos. $\mathrm{O}$ uso de cadáveres é uma alternativa viável, entretanto, para que não ocorra deterioração dos tecidos, as peças são quimicamente preparadas. Soluções de formaldeído, apesar de alterar as características dos tecidos, ser prejudicial à saúde e ao meio ambiente, ainda é o agente químico mais utilizado nos laboratórios 
de anatomia. A falta de embasamento prático durante o curso de graduação, influencia negativamente na jornada profissional de médicos veterinários, em especial, os recém-formados. Objetiva-se com o presente estudo, avaliar a eficácia da técnica anatômica, utilizando solução alcoólica e de sais de cura, no preparo de cadáveres de pequenos ruminantes, destinados ao ensino e treinamento cirúrgico.

\section{METODOLOGIA}

Utilizaram-se três cadáveres de ovinos, com peso médio de $25 \mathrm{~kg}$, dois machos e uma fêmea, que vieram a óbito por causas distintas, na rotina do hospital veterinário. Foram preparados com 150 $\mathrm{mL} / \mathrm{kg}$ de álcool etílico puro com $5 \%$ de glicerina e $120 \mathrm{~mL} / \mathrm{kg}$ de solução contendo $20 \%$ de cloreto de sódio, $1 \%$ de nitrito e $1 \%$ de nitrato de sódio, via artéria carótida comum. Após a injeção das soluções, procedeu-se a tricotomia em todo o corpo dos cadáveres, dos quais foram acondicionados em sacos plásticos transparentes, conduzidos e conservados refrigerados em câmara fria $\left(2\right.$ a $\left.6{ }^{\circ} \mathrm{C}\right)$ durante 120 dias. Ao longo deste período, em datas aleatórias, procedeu-se o treinamento cirúrgico das técnicas de enucleação e amputação de dígito, lapatoromia pelo flanco esquerdo, laparotomia pelo flanco direito, laparotomia mediana ventral, seguidas de exploração da cavidade abdominal, rumenotomia, rumenostomia, abomasopexia, omentopexia, além de treinamento de miorrafia, redução de tecido subcutâneo e dermorrafia, conforme as técnicas descritas na literatura afim, por profissionais e discentes do curso de medicina veterinária.

\section{RESULTADOS E DISCUSSÕES}

A técnica anatômica de preparo, utilizando solução alcoólica, mostrou-se eficaz na fixação dos cadáveres de pequenos ruminantes, assim como já observado para cadáveres de cães e gatos (Cerqueira et al., 2017; Zero, 2020), e para cadáveres de humanos, por até um ano (Goyri-O’Neill et al., 2013) não havendo indícios de contaminação, putrefação e odores desagradáveis. A manutenção de características como textura, maleabilidade, consistência, coloração típica, e ausência de odores fétidos preservada ao se utilizar no preparo, a solução composta pelos sais de cura, assim como descrito na preservação de cadáveres por longos períodos Janczyk et al., 2010; Werdelmann e Gerics 2016).

O emprego da técnica anatômica no preparo de cadáveres de pequenos ruminantes destinados ao ensino e treinamento cirúrgico, mostrou-se eficaz, possibilitando a execução de diversas técnicas cirúrgicas, como enucleação, amputação de dígito, laparotomias, dentre outras. Resultados semelhantes já foram obtidos ao se utilizar cadáveres pequenos animais, quimicamente preparados, no ensino e treinamento cirúrgico (Zero, 2020; Rocha et al., 2019).

O modelo anatômico desenvolvido, simula condições reais, fornece condições para a realização de diversos procedimentos cirúrgico, além do estudo da técnica cirúrgica, anatomia, dentre outras, se enquadrando nos princípios bioéticos do ensino e pesquisa, assim como no proposto pela 
Lei Arouca (Brasil, 2008).

\section{CONCLUSÃO}

De acordo com o desenvolvimento da presente pesquisa, conclui-se que a técnica anatômica proposta para o preparo dos cadáveres de pequenos ruminantes destinados ao treinamento cirúrgico é eficaz, mantendo as características morfológicas, sem odores desagradáveis, putrefação, sem risco à saúde e ao meio ambiente, garantindo repetitividade e diversidade das técnicas e treinamentos cirúrgicos, além de respeitar os padrões bioéticos no ensino, assim como a vida animal.

\section{PRINCIPAIS REFERÊNCIAS}

BRASIL. Lei $n^{\circ} 11.794$, de 8 de outubro de 2008. Regulamenta o inciso VII do $\S 1^{\circ}$ do art. 225 da Constituição Federal, estabelecendo procedimentos para o uso científico de animais. Diário Oficial da União, 9 de outubro de 2008; (196): Seção 1; p. 1-4.

Cerqueira ESF, Pelógia MES, Silveira CPB, Fechis ADS, Rocha TASS, Laus JL, Oliveira FS (2017). Suture analysis and arterial traction test in dogs fixed on alcohol and preserved on saline solution aiming surgical practice. Global Advanced Research Journal of Medicine and Medical Sciences, v.6, n.11, p. 292-295.

Goyri-O’Neill J, Pais D, Freire de Andrade F, Ribeiro P, Belo A, O’Neill A, Ramos S, Neves MC (2013). Improvement of the embalming perfusion method: The innovation and the results by light and scanning electron microscopy. Acta Médica Portuguesa. n. 26, p. 188-194.

Janczyk P, Weigner J, Becker AL, Kaessmeyer S, Plendl J (2010). Nitrite pickling salt as an alternative to formaldehyde for embalming in veterinary anatomy - A study based on histo- and microbiological analyses. Annals of Anatomy - Anatomischer Anzeiger. v.193.p.71-75.

Rocha TASS, Santos CCC, Iozzi MT, Dias RS, Zero RC, Cardozom MV, Oliveira FS (2019). Chemically prepared dog cadavers in teaching of surgical technique - evaluation by students of a veterinary medicine course. Acta Scientiae Anatomica, v.1, n.2.

Werdelmann R, Gerics B (2016). Preservation of specimens for students - formaldehyde vs. Salt based fixative. XXXIth Congress of the European Association of Veterinary Anatomists. University of Veterinary Medicine Vienna, Vienna, Aústria.

Zero RC, Shimano AC, Cardozo MV, Santos CCC, Fechis ADS, Rocha TASS, Oliveira FS (2020). Cadáveres de gatos preparados químicamente para la enseñanza de técnicas quirúrgicas: análisis biomecánico de piel y yeyuno. Rev Inv Vet Perú v.31, n. 2. 


\title{
DOENÇA DA ARRANHADURA DO GATO: ZOONOSE SUBDIAGNOSTICADA
}

\author{
Eduarda Rodrigues Teixeira Cassianoㅜ; Joelma Moura Alvarez ${ }^{2}$ Selene Daniela Babboni² \\ ${ }^{1}$ Discente de Medicina Veterinária, Universidade Paulista (UNIP), São José dos Campos, SP. \\ ${ }^{2}$ Docente do curso de Medicina Veterinária, Universidade Paulista (UNIP), São José dos Campos, \\ SP.
}

\section{RESUMO}

A doença da arranhadura do gato é uma zoonose, ocorre através da arranhadura, mordedura ou lambedura, de gatos infectados, em locais expostos como feridas ou mucosas no humano. Apresenta alto índice de infecção em gatos filhotes, apesar de assintomática na espécie; a doença é reconhecida pela sigla DAG, sendo caracterizada pela presença de bactérias do gênero Bartonella. O contagio entre felinos se dá através de pulgas da espécie Ctenocephalides felis, tornando-se os reservatórios da bactéria. Cães, ratazanas e morcegos, além de outros mamíferos, são reservatórios para o agente etiológico, porém sem grande relevância na transmissão do mesmo para o homem. Nos humanos a patologia apresenta sintomas como febre, lesões do tipo papulosas e linfadenopatia, atingindo principalmente crianças, idosos e pessoas com imunossupressão, ou enfermidade primária debilitante. Todavia o grande entrave desta zoonose é o subdiagnóstico na medicina humana, o que revela uma falta de multiprofissionais nos sistemas públicos e privados.

PALAVRAS-CHAVES: Bartonella; Zoonose; Felinos.

ÁREA TEMÁTICA: Medicina Veterinária

\section{INTRODUÇÃO}

A primeira descrição desta injúria, foi em 1950, pelo médico pediatra Robert Debré, sendo que outros estudos foram feitos, onde se descobriu que a espécie Bartonella henselae é a principal causadora da enfermidade (CHOMEL e KASTEN, 2010). Essa bactéria gram-negativa, em formato de bacilo, infecta os felinos domésticos através da pulga, vetor onde a espécie Ctenocephalides felis é a responsável por essa transmissão. Os gatos por sua vez, transmitem para os humanos através de lesões cutâneas ocasionadas por mordidas e arranhões, já os cães, apesar de possíveis portadores, raramente foram indicados como transmissores da doença após mordedura ou arranhão (BREITSCHWERDT e KORDICK, 2000; SOUZA et al., 2010).

Os gatos domésticos e errantes, devido ao seu estilo de vida e hábitos, além do crescimento 
exponencial no número desses animais, propiciam que o Felis silvestres catus, seja a principal espécie associada à doença da arranhadura do gato (LOPES et al., 2020). Após contato com arranhões ou mordidas do gato, o agente etiológico penetra no tecido lesionado, tendo capacidade de aderência em células endoteliais e eritrócitos, instalando-se em suas hemácias; sendo o sinal clínico mais comum no homem, a linfadenomegalia benigna (BREITSCHWERDT e KORDICK, 2000).

\section{METODOLOGIA}

A pesquisa foi realizada com fundamentação teórica em base de dados online, Scientific Eletronic Library Online (SciELO), Google acadêmico, PUBMED; contando com informações de livros e artigos científicos (língua portuguesa e inglesa) afim de descrever a doença e correlacionar com a espécie Felis catus, o gato doméstico, ressaltando sua importância como zoonose e apresentando medidas profiláticas que podem ser adotadas.

\section{FUNDAMENTAÇÃO TEÓRICA}

Tendo como sinônimo linforreticulose benigna, a denominada doença da arranhadura do gato (VELHO, 2001), é uma importante doença infecciosa de caráter zoonótico, intimamente ligada à espécie felina, pois esta atua como principal reservatório do microrganismo causador da doença. Além disso, a DAG é subdiagnosticada na espécie humana, pois geralmente não é indicada como uma possibilidade de diagnóstico diferencial em muitos casos de linfadenomegalia por exemplo (SOUZA, 2011).

A zoonose, retrata a pulga como vetor do agente etiológico; a bactéria do gênero Bartonella, essa conta com mais de 30 espécies, porém apenas 15 relacionadas a doenças que atingem humanos, sendo a $B$. henselae, a espécie comumente associada à DAG, tendo a capacidade de aderir e invadir os eritrócitos. A infecção caracteriza-se por duas fases, a primeira é fase a aguda, onde, a bactéria entra na corrente sanguínea e invade células endoteliais, e a segunda fase, a crônica, ocorre a multiplicação do patógeno e sua hospedagem no citoplasma das hemácias (LOPES et al., 2020).

Um estudo realizado com 200 felinos na cidade de São Paulo, avaliou a existência de anticorpos IgG anti- $B$. henselae, através de imunofluorescência indireta, obtendo como resultado $16 \%$ soropositivos, sendo a maior parte desses, filhotes entre 7 à 12 meses. Tais resultados podem ser explicados pelo desenvolvimento dos anticorpos humorais, que tem o seu declínio conforme o animal avança em idade (LOUREIRO e HAGIWARA, 2007).

A doença tem alta incidência, com 24 mil casos anuais nos Estados Unidos, e cerca de 2 mil na Holanda, com 400 mil gatos portadores nesse país, sendo usado como critério de diagnostico o contato prévio com o animal. Com ocorrência notória no outono e inverno, devido à alta frequência das fêmeas felinas iniciarem a gestação na primavera ou início de outono e assim no final do verão seus filhotes já estão propícios a transmissão. Aliado a isso, no mesmo período corresponde ao ápice 
da procriação das pulgas, porém, essa variação sazonal é observada apenas em países com clima temperado, a mesma não ocorre em locais de clima tropical (BOYLER e CHERRY, 1992; VELHO, 2001).

O vetor tem substancial envolvimento na doença, tendo em vista estudos realizados por Chomel e colaboradores (1996) onde gatos filhotes ao conviver com gatos bacterêmicos, porém desparasitados, não contraiam a bactéria, mas ao retirar pulgas de gatos bacterêmicos e ao colocá-las nos filhotes, esses por sua vez apesar de não desenvolverem sinais clínicos, se tornavam bacterêmicos. Concluindo assim que a transmissão entre gatos se dá através do vetor, que amplia o número de reservatórios felinos e atua indiretamente na doença humana.

A incubação da doença se dá em poucos dias à algumas semanas, o aparecimento da lesão primária ocorre de 3 à 5 dias após o contato e mordedura ou arranhadura do gato, surgindo no local do trauma, uma pápula eritematosa sem presença de prurido, após 2 ou 3 dias evolui para uma vesícula com crostas, posteriormente involui para uma mácula que pode permanecer até 3 meses. É mais comum a ocorrência de lesões nos membros superiores, podendo também ter apresentação de pústula ou nódulo, e progredir para uma ulceração, entretanto a forma mais marcante da doença é a linfonodomegalia, muitas vezes, sendo unilateral (CARITHERS, 1985, NOSAL, 1997).

A bacteremia é notória entre uma a duas semanas após o contágio, e prossegue de 10 a 24 meses dependendo do caso. Concomitantemente, nas primeiras duas semanas, ocorre o aumento do título de anticorpos IgG anti- $B$. hanselae, atingindo seu ápice na terceira semana, após esse período, ocorre uma queda que se mantem até a sexta semana. A bacteremia diminui e os anticorpos aumentam, pois esses controlam a multiplicação bacteriana. Devido a isso, a dosagem de níveis de IgG é realizada afim de indicar infecção por $B$. hanselae, passada ou recorrente, pois esses de mantem após longo período da infecção. Além disso, o histórico do paciente, avaliando histórico de contato com gatos, exclusão de outras causas de adenopatias, são cruciais para o diagnóstico (LOUREIRO e HAGIWARA, 2007).

A profilaxia é indispensável para evitar a incidência dessa enfermidade, como medida primária, sendo a pulga um vetor importante da doença, é crucial manter o animal desparasitado, evitando seu contágio. Por segurança, um manejo calmo com os animais, bem como contenção dos mesmos de forma segura, em especial dos felinos, pode evitar a arranhadura ou mordedura nos seres humanos, que culminaria com uma lesão cutânea no indivíduo. Sendo ainda relevante destacar a importância de evitar o contato com animais errantes, dos quais não se tem conhecimento do histórico clínico e ainda não conhecendo o perfil destes, poderia ocorrer um ataque ao indivíduo que tente contê-lo (BREITSCHWERDT e KORDICK, 2000; LOPES et al., 2020).

\section{CONSIDERAÇÕES FINAIS}

A doença da arranhadura do gato sendo uma zoonose de grande relevância, muitas vezes subdiagnosticada na medicina humana, e esquecida na medicina veterinária, uma vez que no ser humano não tem sintoma clínico patognomônico e no gato é assintomática, ressalta-se então a 
importância da profilaxia, consistindo em hábitos e cuidados necessários, como manter o animal livre de ectoparasitas e ter cautela com o manejo do mesmo, afim de evitar mordidas e arranhões, auxiliando no controle dessa enfermidade infecciosa e contribuindo para manutenção da saúde pública.

\section{PRINCIPAIS REFERÊNCIAS}

BOYLER, K.M.; CHERRY, J.D. - Cat scratch disease. In FEIGIN, R.D.; CHERRY, J.D. Textbook of pediatric infectious diseases. 3 ed. Philadelphia, W.B. Saunders, v.1, 1084-9, 1992.

BREITSCHWERDT, E. B.; KORDICK, D. L. 2000. Bartonella Infection in Animals: Carriership, Reservoir Potential, Pathogenicity, and Zoonotic Potential for Human Infection. Clinical Microbiology Reviews, 13(3), 428-438. doi:10.1128/CMR.13.3.428-438.2000

CARITHERS, H.A. Cat-scratch disease. An overview based on a study of 1200 patients. Am. J. Dis. Child., 139:1124-33, 1985.

CHOMEL, B.; KASTEN, R.W. (2010). Bartonellosis, an increasingly recognized zoonosis. Journal of applied microbiology. 109. 743-50. 10.1111/j.1365-2672.2010.04679.x.

CHOMEL, B.B. et al. Experimental transmition of Bartonella henselae by the cat flea. J. Clin. Microbiol., 34: 1952-6, 1996.

LOPES, G. A.; DA SILVA, L. G. P.; RISCH, A. L. C. Doença da arranhadura do gato: importância das medidas profiláticas. 2020: ANAIS CONGREGA - 16ª MOSTRA DE INICIAÇÃO CIENTIFICA v.16 - 2020, ISBN: 978-65-86471-05-2

LOUREIRO, V. S.; HAGIWARA, M. Levantamento de anticorpos anti-bartonella henselae em felinos domiciliados na cidade de São Paulo, estado de São Paulo e sua importância em saúde pública. Revista Brasileira de Ciência Veteterinária, 2007; 14 (1): 39-42

NOSAL, J.M. - Bacillary angiomatosis, cat-scratch disease, and bartonellosis: what's the connection? Int. J. Dermatol., 36:405-11, 1997.

SOUZA, A. M. de et al. Bartonelose: análise molecular e sorológica em gatos do Rio de Janeiro. Revista Brasileira de Ciência Veterinária, v. 17, n. 1, p. 7-11, jan/abr. 2010.

SOUZA, G. F. de Doença da arranhadura do gato: relato de caso. Ver Med Minas Gerais, 2011; 21(1): p.75-78

VELHO, P. E. F. Estudo das bartoneloses humanas e Bartonella henselae: infecção experimental, microbiologia, microscopia de luz e eletronica de transmissão. 2001. 233 p. Tese (doutorado) Universidade Estadual de Campinas, Faculdade de Ciencias Medicas, Campinas, SP. 


\title{
ATUAÇÃO DE MÉDICOS VETERINÁRIOS RESIDENTES EM UMA UNIDADE DE TRIAGEM DE PACIENTES SUSPEITOS DE COVID-19 NO MUNICÍPIO DE JABOTICABAL/SP
}

\section{Rafael Bezerra Mamede $^{1}$; Talita Turmina ${ }^{1}$; Nívea Maria Gomes Misson Carneiro ${ }^{1}$; Maria Soban Martins Gaspar ${ }^{1}$; Thaynara Pavaneli Lira ${ }^{1}$; Pedro Wandscheer Zangrando ${ }^{2}$; Beatriz Estevez de Oliveira ${ }^{3}$; Karina Paes Bürger ${ }^{4}$}

${ }^{1}$ Residente em Medicina Veterinária, Faculdade de Ciências Agrárias e Veterinárias da Universidade Estadual Paulista Júlio de Mesquita Filho (FCAV-UNESP), Jaboticabal, São Paulo.

${ }^{2}$ Bacharel em Administração, Faculdade de Ciências Agrárias e Veterinárias da Universidade Estadual Paulista Júlio de Mesquita Filho (FCAV-UNESP), Jaboticabal, São Paulo.

${ }^{3}$ Mestranda em Medicina Veterinária, Faculdade de Ciências Agrárias e Veterinárias da Universidade Estadual Paulista Júlio de Mesquita Filho (FCAV-UNESP), Jaboticabal, São Paulo.

${ }^{4}$ Doutora em Medicina Veterinária, Universidade Estadual Paulista Júlio de Mesquita Filho (UNESP), Jaboticabal, São Paulo.

\begin{abstract}
RESUMO
Os profissionais residentes da área da saúde foram recrutados para atuar no enfrentamento da pandemia, como uma das estratégias para fortalecer o sistema de saúde nacional. O presente trabalho objetiva relatar a experiência dos médicos veterinários residentes do Programa de Residência em Área Profissional da Saúde - Medicina Veterinária e Saúde (PRAPS-MVS) da Faculdade de Ciências Agrárias e Veterinárias, UNESP Câmpus de Jaboticabal/SP, em uma unidade de triagem de pacientes suspeitos de COVID-19 no município de Jaboticabal/SP. Dentre as atividades desenvolvidas por esses profissionais destacam-se a elaboração e alimentação da planilha referente aos atendimentos na unidade de saúde, além de organização, sistematização e tabulação de todos seus dados; elaboração de relatórios semanais e estatística dos dados; telemonitoramento dos pacientes que buscaram o serviço; cooperação com o serviço de Vigilância Socioassistencial no georreferenciamento dos pacientes e a integração da unidade com a Atenção Básica, auxiliando no monitoramento de casos suspeitos nos territórios.
\end{abstract}

PALAVRAS-CHAVES: Saúde Única; Medicina Veterinária; COVID-19.

ÁREA TEMÁTICA: Medicina Veterinária 


\section{INTRODUÇÃO}

A pandemia do novo Coronavírus, SARS-CoV-2, agente causador da Coronavirus Disease 2019 (COVID-19), teve início nos primeiros meses de 2020 e exigiu que a comunidade global prestasse atenção ao termo saúde única (LIMONGI E OLIVEIRA, 2020). Este conceito defende que só é possível discutir saúde pensando na interligação entre saúde humana, saúde animal e suas interfaces com o meio ambiente. A dinâmica populacional de seres humanos e animais interfere na manutenção do ambiente. Um olhar tão amplo para a saúde exige que o assunto seja abordado de maneira multiprofissional e interdisciplinar (LIMONGI e OLIVEIRA, 2020).

No final do primeiro trimestre de 2020, o Ministério da Saúde anunciou a ação estratégica “O Brasil Conta Comigo - Residentes da Área da Saúde” (BRASIL, 2020), com o objetivo de que os residentes contribuíssem no enfrentamento da pandemia de COVID-19, atendendo a uma emergência sanitária, sem desconsiderar a formação destes profissionais. Diante desse quadro o Programa de Residência em Área Profissional da Saúde - Medicina Veterinária e Saúde (PRAPSMVS), da Faculdade de Ciências Agrárias e Veterinárias da Universidade Estadual Paulista, Câmpus de Jaboticabal (FCAV-UNESP/Jaboticabal), ampliou a parceria com o serviço de saúde do município e realocou os médicos veterinários residentes do programa no enfrentamento da pandemia na cidade.

A partir de abril, os profissionais atuaram em unidades básicas de saúde, na farmácia municipal, na divulgação de informações científicas por meio de mídias sociais, além de colaborarem com a equipe do Centro de Atendimento ao Coronavírus (CAC) do Município de Jaboticabal/SP.

Diante disso, este trabalho pretende apresentar as atividades desenvolvidas no CAC, pelos médicos veterinários residentes, que contribuíram para o enfrentamento da pandemia de COVID-19 no Município de Jaboticabal/SP.

\section{METODOLOGIA}

O presente trabalho é um relato de experiência das atividades desenvolvidas por médicos veterinários residentes do Programa de Residência em Área Profissional da Saúde - Medicina Veterinária e Saúde (PRAPS-MVS), da Faculdade de Ciências Agrárias e Veterinárias da Universidade Estadual Paulista, Câmpus de Jaboticabal (FCAV-UNESP/Jaboticabal), no centro de triagem de pacientes suspeitos de COVID-19 do Município de Jaboticabal, no Estado de São Paulo. As atividades foram desenvolvidas entre os meses de abril e novembro de 2020.

\section{RESULTADOS E DISCUSSÕES}

O Centro de Atendimento ao Coronavírus (CAC) foi inaugurado no Município de Jaboticabal/ SP no dia 27 de março de 2020, em decorrência da situação epidemiológica que a cidade vivia. Mesmo estando localizado há cerca de $350 \mathrm{~km}$ da capital do Estado de São Paulo, o município teve seu 
primeiro caso confirmado de COVID-19 no dia 22 de março de 2020. Tratava-se de um paciente que esteve em uma viagem pela costa brasileira, a bordo de uma embarcação em que foram identificados casos confirmados de COVID-19 dentre os passageiros e tripulantes. Cerca de 100 moradores de Jaboticabal estiveram no navio.

O CAC foi criado com o intuito de atender pacientes que apresentem sintomas de síndrome gripal, funcionando 24 horas e tendo a sua equipe composta por um médico, um enfermeiro, cinco técnicos de enfermagem a cada plantão de doze horas e também a presença de uma farmacêutica durante os plantões diurnos. O local oferece atendimento inicial aos pacientes e realiza exames de forma complementar para diagnóstico de COVID-19. São realizados exames de imunocromatografia para detecção de anticorpos para o vírus SARS-COV-2 e coleta de material nasofaringe para detecção de RNA viral por rt-PCR. Pacientes que necessitam de atendimento especializado são transferidos à unidade de pronto atendimento, ou à uma unidade hospitalar.

Ao assumir o desafio de colaborar com uma unidade de saúde como o CAC, os médicos veterinários residentes se colocaram à disposição para contribuir com a equipe da forma que lhe fosse mais necessária. Quando os residentes iniciaram suas atividades no CAC, a unidade já funcionava há seis dias e a equipe ainda não havia estabelecido uma organização para os prontuários dos pacientes, uma vez que o sistema de saúde do município, não foi integrado a unidade. Os residentes elaboraram uma planilha interativa no programa Microsoft Excel 2010, para que as informações descritas no prontuário de cada paciente pudessem ser tabuladas, além disso os médicos veterinários contribuíram com a alimentação da planilha e com a organização e sistematização de todos os dados que compõe a planilha.

A planilha contém informações como nome do paciente, data de nascimento, nome da mãe, endereço, telefone, sintomas que o paciente relata, qual a conduta médica, se houve realização de algum exame diagnóstico ou orientação para que o paciente ficasse em isolamento. Desde o primeiro dia de funcionamento da unidade, até o dia 30 de novembro de 2020, os residentes tabularam dados de mais de 9400 atendimentos. Essas informações permitiram que os profissionais elaborassem relatórios semanais a respeito do fluxo de atendimento da unidade, assim como pudessem criar estatística dos dados.

De acordo as orientações estabelecidas no início da pandemia todos os pacientes atendidos em unidade de triagem como o CAC, deveriam ser telemonitorados, recebendo ligações telefônicas das equipes de saúde a cada 48 horas, durante 14 dias para acompanhar a evolução do quadro clínico dos indivíduos. No caso de Jaboticabal, o CAC concentrou esse serviço e essa atividade foi desenvolvida pelos residentes que entravam em contato com os pacientes atendidos na unidade de saúde e faziam registros de todas as informações que lhes eram relatadas a respeito da evolução clínica de cada indivíduo, além de orientar a população sobre cuidados e prevenção durante o isolamento, e esclarecer dúvidas sobre a doença.

A partir dos dados tabulados foi possível estabelecer uma parceria com o serviço de Vigilância Socioassistencial do município e georreferenciar cada um dos pacientes atendidos pela unidade. Essa 
atividade permitiu às autoridades sanitárias da cidade visualizar os bairros que apresentavam maior número de atendimentos durante determinada semana epidemiológica e propor estratégias para enfrentar a situação. Além disso, os dados da planilha auxiliavam na interação entre os residentes que atuavam no CAC e os que estavam distribuídos nas unidades de saúde da atenção básica, complementando o monitoramento de casos suspeitos nos territórios.

Por conta dos dados do adquiridos com o trabalho de georreferenciamento, a Secretaria de Saúde buscou o PRAPS-MVS com a proposta de realizar um projeto de inquérito sorológico no município. Os residentes que atuaram no CAC foram parte de todo o processo de desenvolvimento deste projeto, da escrita até as atividades a campo, o que permitiu que colaborassem com diferentes profissionais de saúde do município.

\section{CONCLUSÃO}

Aárea da saúde é ampla em oportunidades de trabalho, sendo essencial a interdisciplinaridade e multiprofissionalismo. Os médicos veterinários residentes puderam contribuir com o serviço de saúde do Município de Jaboticabal/SP, além de extrapolarem a proposta de trabalho inicial e desenvolverem parcerias entre diferentes setores do serviço público.

\section{PRINCIPAIS REFERÊNCIAS}

BRASIL - Ministério da Saúde. Portaria n580/2020. Dispõe sobre a Ação Estratégica "O Brasil Conta Comigo - Residentes na área de Saúde", para o enfrentamento à pandemia do coronavírus (COVID-19). Brasília, MS, 2020. Disponível em: https://www.in.gov.br/en/web/dou/-/portaria-n580-de-27-de-marco-de-2020-250191376. Acesso em: 17 mar. 2021.

LIMONGI, J. E.; de OLIVEIRA, S. V. COVID-19 e a abordagem One Health (Saúde Única): uma revisão sistemática. Vigilan. Sanita. em Debate, Rio de Janeiro, 8(3), p. 139-149, Ago 2020. DOI: 10.22239/2317-269x.01610. Disponível em: https://doi.org/10.22239/2317-269x.01610. Acesso em: 17 mar. 2021. 


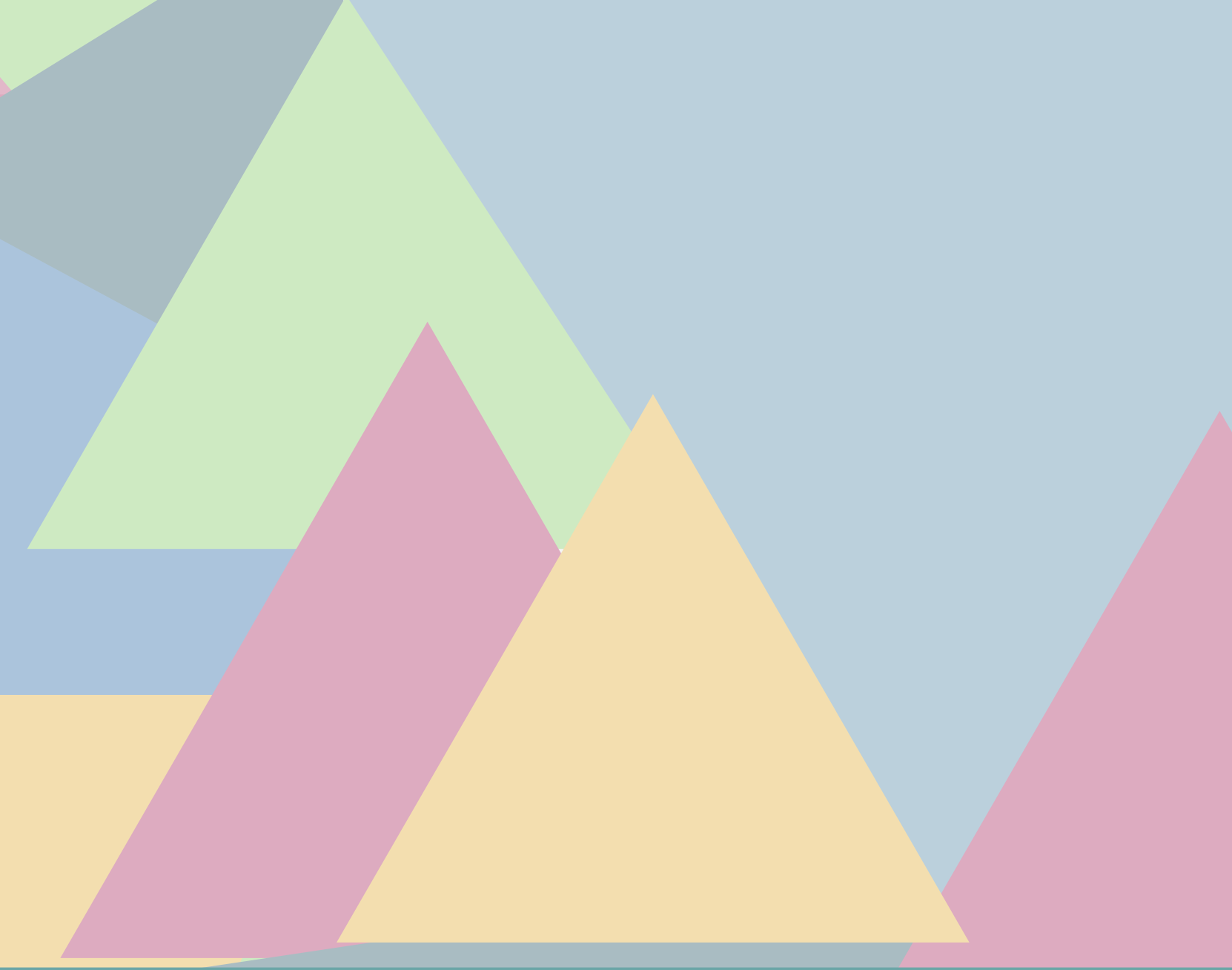

Saúde Coletiva 


\title{
EFEITO DA PANDEMIA DE COVID-19 SOBRE A INCIDÊNCIA DE TRAUMA DE TRÂNSITO NO ESTADO DO AMAZONAS
}

\author{
Luis Paulo Soares Pedrosa ${ }^{1}$ \\ ${ }^{1}$ Graduando em medicina, Universidade Nilton Lins (UNL), Manaus, Amazonas.
}

pedrosaengenharia2@gmail.com

\begin{abstract}
RESUMO
Trata-se de um estudo observacional realizado durante o período da pandemia de Covid-19 no estado do Amazonas no ano de 2020. Nele, aventam-se duas questões epidemiológicas de repercussão político e social: o traumatismo físico causado em pessoas por ocasião de acidentes de trânsito e as infecções causadas pelo novo coronavírus. A partir de informações coletadas em bases de dados públicos, foi possível constatar que durante a pandemia de Covid-19 houve uma redução significativa de internações causadas por traumas relacionados ao transporte. De acordo com a discussão deste trabalho, esses resultados são frutos de políticas de isolamento social no estado. Com base nisso, constatou-se dois efeitos positivos desse período: primeiro, houve redução na incidência de acidentes de trânsito; segundo reduziu-se a demanda de serviços médico-hospitalares para o setor do trauma fato que possibilitou o direcionamento da assistência a saúde para o setor da pandemia. Além disso, reflete-se sobre a importância da manutenção da segurança do trânsito no período da pós-pandemia.
\end{abstract}

PALAVRAS-CHAVE: Estatísticas; Epidemiologia; Isolamento social

ÁREA TEMÁTICA: Saúde Coletiva

\section{INTRODUÇÃO}

O trauma é caracterizado por um evento cinemático descontrolado que provoca lesões em estruturas do corpo humano. No contexto dos acidentes de trânsito, as frenagens, colisões e capotamentos constituem as principais causas desse tipo de incidente. Com relação a gravidade das lesões, o fator velocidade parece ser a variável mais importante nesse tipo de acometimento, de modo que quanto maior a velocidade maior será a conversão de energia cinética em mecânica e consequentemente pior será o prognóstico dos pacientes vítimas dessas colisões. (PHTLS, 20120).

Vale destacar que os hábitos culturais são um dos fatores que mais contribuem para a 
ocorrências de traumas no trânsito, visto que estão relacionados a condicionantes sociais enraizados em determinadas regiões. Prova disso, é a heterogeneidade epidemiológica dos dados de traumas de trânsito de acordo com as localidades. Há regiões em que os acidentes estão ligados ao maior consumo de bebidas alcoólicas. Fatores sazonais também influem nessas estatísticas, tais como em períodos de festividades e finais de semana. Essa dinâmica organizacional faz com que os traumas de trânsito sejam considerados atualmente como uma epidemia. (SILVA, SILVA e LIMA, 2015).

Em um outro ponto de vista, a incidências de doenças são responsáveis por provocar profundas mudanças estruturais nas sociedades. (MORRISON e BENNETT, 2016). A Peste Bulbônica na Europa medieval, a gripe espanhola no início do século XX e a contaminação por cólera no Brasil são exemplos de enfermidades que obrigaram a população a transformar hábitos outrora enraizados em seu contexto social.

Nesse contexto, observa-se que as doenças podem provocar mudanças no seio da sociedade, porque possibilitam que os indivíduos transforme os seus hábitos e costumes. Em suma, as atitudes que outrora eram socialmente aceitas passam a ser reprovadas pelo crivo comunitário. Essas mudanças de postura podem influir em outras áreas da saúde coletiva, tais como em indicadores epidemiológicos que apresentem relação de interdependência. (MORRISON e BENNETT, 2016)

No contexto atual, a infecção respiratória causada pelo vírus SARS CoV-2 foi fonte de profundas transformações sociais ainda mais porque estimulou do distanciamento de pessoas. Segundo a Fundação de Vigilância em Saúde do Amazonas (FVS/AM), no mês de março de 2020 a Covid-19 se tornou uma questão de saúde pública no estado do Amazonas. Com isso, muitas medidas de isolamento social foram tomadas visando reduzir os altos índices de infecção pela doença (OMS, 2020).

A partir desse contexto, objetivou-se relacionar a incidência de traumas oriundos de acidentes de trânsito no estado do Amazonas com o período crítico da pandemia, sobretudo nos meses de março e abril de 2020, período em que se acentuou a restrição de contato social.

\section{METODOLOGIA}

Foi realizado um estudo retrospectivo com coleta de informações na base de dados DATASUS do Ministério da Saúde, a partir da evolução das taxas de morbidade hospitalar de pacientes traumatizados vítimas de acidentes de trânsito. Foram catalogados as taxas de internações ao longo dos últimos dez anos. Esses dados permitiram que pudesse ser mensurado a taxa de ocorrência de acidentes de trânsito no período da pandemia de Covid-19, sobretudo durante o ápice de contágio nos meses de março e abril de 2020 no estado do amazonas. 


\section{RESULTADOS E DISCUSSÃO}

Com base nos dados da pesquisa, observa-se que há uma tendência de redução nas internações causadas por acidentes de trânsito no estado do Amazonas no período analisado. (Figura 1a).

Esse resultado pode estar relacionado com a implantação do programa Vida no Trânsito no estado do Amazonas em que as políticas de governo implementaram uma série de medidas visando a prevenção e redução desse tipo de ocorrência no estado.

Contudo, no ano de 2020 há uma redução abrupta das intercorrências de trânsito que resultaram em internações hospitalares no Amazonas. Em termos percentuais, entre os anos de 2018 e 2019 houve uma redução de $21,11 \%$ das taxas de internações hospitalares de pessoas traumatizadas no trânsito, ao passo que de 2019 para 2020 essa redução foi de aproximadamente 36\%.

Não obstante, segundo a Fundação de Vigilância Sanitária do Amazonas (FVS/AM) os meses de março e abril de 2020 constituíram o período de maior incidência do Covid-19 naquele estado. Nesse intervalo, o governo estadual decretou um conjunto de medidas de isolamento social visando reduzir a transmissão comunitária da doença. A partir desse cenário, buscou-se relacionar esse bimestre ao longo dos anos em estudo para que se pudesse ratificar a tendência de redução outrora verificada. (Figura 1b).

Figura 1a: Evolução anual na ocupação de leitos hospitalares em decorrência de trauma acorrido no trânsito no estado do Amazonas.

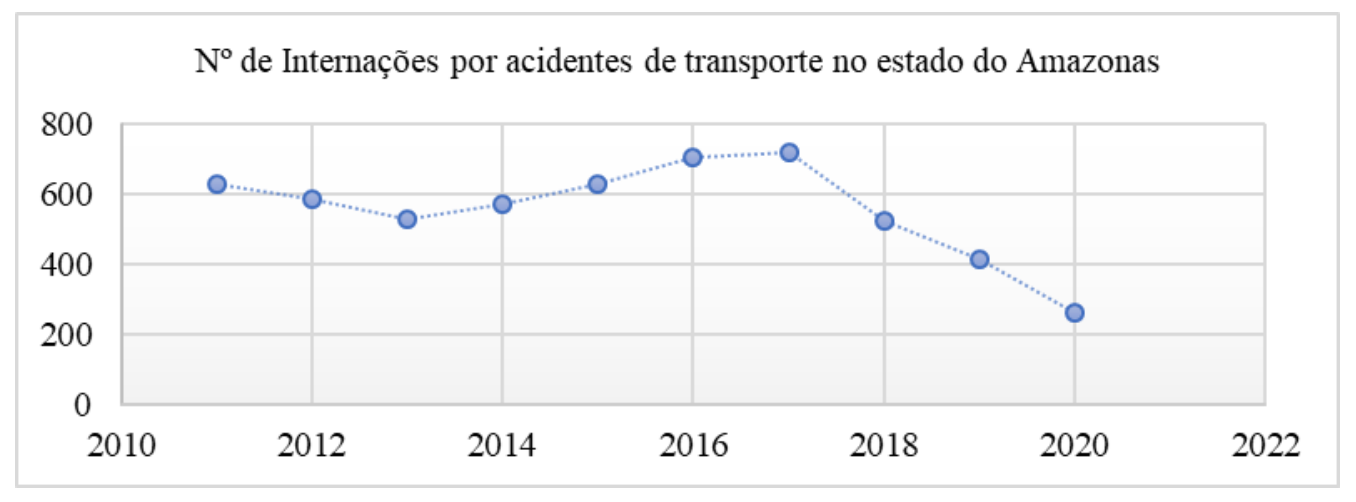

Fonte: DATASUS/2010-2020

Do ponto de vista analítico, houve uma redução significativa do bimestre analisado, porque de 2018 para 2019 o recuo foi de 26,93\% enquanto de 2019 para 2020 no mesmo bimestre analisado a redução foi de $36,84 \%$. Esses dados reiteram os dados demonstrados nos gráficos. 
Figura 1b: Evolução do número de acidentes de trânsito que resultaram em internações hospitalares nos meses de março e abril dos respectivos anos analisados durante o pico da pandemia de Covid-19 no estado do Amazonas.

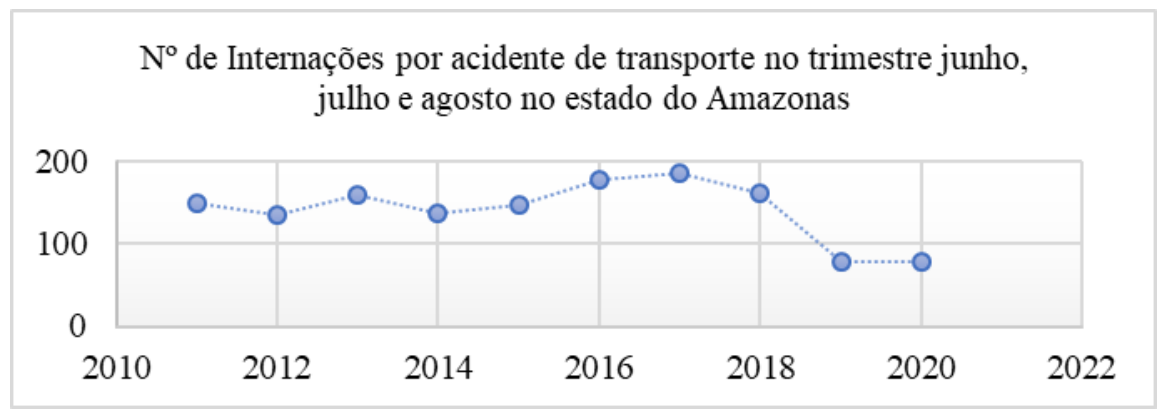

Fonte: DATASUS/2010-2020

Analisando-se os dez anos anteriores ora estudados, em nenhum biênio é verificado tal patamar de encolhimento das taxas. A hipótese para tal resultado é de que a mudança de hábitos sociais devido a pandemia de Covid-19 tenha contribuído para essas reduções percentuais, uma vez que as pessoas tiveram uma mudança significativa no estilo de vida durante o período analisado.

Esse efeito foi particularmente importante, pois constata-se que o isolamento social não só promoveu a redução da transmissão comunitária do vírus como também diminuiu a demanda pelo sistema de saúde na área do trauma, de modo a derivar a atenção de assistência à saúde aos infectados pelo novo coronavírus

\section{CONCLUSÃO}

A partir deste trabalho foi possível concluir que durante o pico da pandemia de Covid-19 houve uma redução significativa na taxa de internação de pessoas vítimas de acidentes de trânsito. Tal conclusão parece óbvia, uma vez que, com o isolamento social menos pessoas estão trafegando pelas vias públicas. Todavia, a importância deste trabalho reside na demonstração analítica de que é possível combater a epidemia do trauma no estado do Amazonas, não sendo admissível que a sociedade conviva com altos índices de insegurança no trânsito. É importante salientar também, que a pandemia acelerou o processo de mudança e modernização da sociedade, de modo que transformou inclusive as relações de trabalho, tal como visto no incremento do uso de aplicativos e no teletrabalho, ou seja, possibilitou que a sociedade experimentasse mudanças que jamais retrocederá ao período pré-pandemia. Dessa mesma forma, as autoridades públicas devem trabalhar para que os traumas oriundos de acidentes de trânsito não atinjam níveis outrora vigentes. 


\section{REFERÊNCIAS}

National Association of Emergency Medical Technicians. PHTLS - Prehospital trauma life support. Atendimento pré-hospitalar ao traumatizado: básico e avançado. Rio de Janeiro: Elsevier. 2012.

SILVA, Maria Gabriella Pacheco, SILVA, Vanessa de Lima. Craniofacial injuries resulting from motorcycle accidents: an integrative review. Rev. CEFAC. 17(5):1689-97. 2015.

MORRISON, Val, BENNETT, Paul. What is health. In An Introduction to Health Psychology. London, United Kingdom: Pearson Education Limited. 2016

MORRISON, Val, BENNETT, Paul. The impact and outcomes of illness: The patient perspective. In An Introduction to Health Psychology. London, United Kingdom: Pearson Education Limited. 2016.

OMS E GAL/SIVEP-GRIPE/e-SUS/ASTEC-SASS/FVS-AM. Dados atualizados em 04.07.2020, sujeito a revisão. Disponível em: http://www.fvs.am.gov.br/publicacoes. Data de acesso: 25/01/2021 


\title{
CAPACITAÇÃO EM BIOSSEGURANÇA PARA EQUIPE DE VIGILÂNCIA EM SAÚDE DO TRABALHADOR: RELATO DE EXPERIÊNCIA
}

\section{Karylane Rayssa de Oliveira Pessoa Araújo'; Fernanda de Medeiros Fernandes Dantas²; Daniella Mylena Paiva de Oliveira ${ }^{3}$; Kelly Katiucci Brito de Lima Maia ${ }^{4}$ \\ 1. Mestranda, CEREST/SESAP, Natal, Rio Grande do Norte.}

2. Mestre, CEREST/SESAP, Natal, Rio Grande do Norte.

3. Pós-graduação, CEREST/SESAP, Natal, Rio Grande do Norte.

4. Pós-graduação, CEREST/SESAP, Natal, Rio Grande do Norte.

\author{
karylane15@hotmail.com
}

\begin{abstract}
RESUMO
Introdução: Arealização de treinamentos em biossegurança é uma forma de desenvolver competências sobre a correta utilização de EPIs, inclusive para as equipes de Vigilância em Saúde do Trabalhador, que realizam inspeções nos ambientes de trabalho dos serviços essenciais, a fim de eliminar risco de acidentes e adoecimento relacionados ao trabalho. Objetivo: relatar a experiência da educação em serviço para uma equipe de inspeção de um CEREST estadual, frente à pandemia ocasionada pelo SARS CoV-2. Metodologia: Relato de experiência, a partir de capacitação sobre biossegurança direcionada aos trabalhadores(as) que compõem a equipe de VISAT do CEREST estadual do RN. Resultados e discussões: Evidenciou-se desconhecimento de informações básicas e relevantes sobre biossegurança, imprescindível em um contexto de pandemia. Conclusão: Qualificar a equipe de VISAT em biossegurança possibilitou o repasse de instruções para a proteção dos profissionais da equipe, e respectivamente contribuiu para a prevenção do adoecimento dos trabalhadores(as) dos ambientes inspecionados.
\end{abstract}

PALAVRAS-CHAVE: Educação continuada; Coronavírus; Saúde ocupacional.

ÁREA TEMÁTICA: Saúde coletiva 


\section{INTRODUÇÃO}

A Organização Mundial da Saúde (OMS) declarou a pandemia por COVID-19 em 11 de março de 2020, instituindo medidas não farmacológicas, tais como: adoção de etiqueta respiratória; higienização das mãos com água e sabão; uso de álcool em gel; evitar aglomerações; promover o distanciamento social e o uso individual de máscara (SANTOS et al., 2020).

No Brasil, além da prevenção, o controle e a minimização de contágio da COVID-19 entre os profissionais de saúde que atuam na linha de frente é um dos grandes desafios, devido às situações que os sistemas de saúde os impõem e os expõem: como desorganização das medidas de proteção nos estabelecimentos de saúde, sobrecarga de trabalho, precarização do vínculo trabalhista, salários atrasados, a escassez dos equipamentos de proteção individual (EPIs) e na presença deste, a falta de treinamento permanente para o uso correto (SANTOS et al., 2020).

Mediante todo o contexto que a pandemia impôs, é evidente a necessidade do conhecimento relacionado às medidas de biossegurança, especialmente por parte de profissionais que possam ser multiplicadores de informações relativas à prevenção e proteção à COVID-19.

A biossegurança é um conjunto de ações que visa prevenir, controlar, minimizar ou eliminar riscos inerentes às atividades que possam comprometer a saúde humana e, portanto, permitir que qualquer atividade seja realizada com segurança (MACHADO, 1997).

A realização de treinamentos em biossegurança, como atividade de educação/ensino, visa enfatizar a necessidade de cuidados, os quais devem ser ainda mais redobrados durante a pandemia. A realização de capacitações pode ser considerada uma forma de desenvolver competências sobre a correta utilização de EPIs para o desenvolvimento de atividades práticas com segurança e qualidade (CASIMIRO et al., 2020).

O cenário pandêmico demandou uma atuação constante das equipes de Vigilância em Saúde do Trabalhador (VISAT), principalmente nos ambientes de trabalho dos serviços essenciais, uma vez que as atividades dessas equipes são capazes de intervir nos processos de trabalho, com o objetivo de eliminar o risco de acidentes e adoecimento relacionados ao trabalho.

Dessa forma, o presente trabalho tem como objetivo relatar a experiência da educação em serviço para uma equipe de inspeção de um CEREST estadual, frente à pandemia ocasionada pelo SARS CoV-2. 


\section{METODOLOGIA}

Trata-se de um estudo do tipo relato de experiência, a partir de capacitação direcionada aos trabalhadores e trabalhadoras que compõem a equipe de VISAT do CEREST estadual do Rio Grande do Norte, durante a pandemia ocasionada pelo SARS CoV-2.

A capacitação foi organizada pela equipe de educação permanente do CEREST estadual e ocorreu em junho/2020, sendo ministrada palestra e aula prática de paramentação/desparamentação pela equipe técnica do CEREST Regional Natal. Inicialmente a equipe composta por 10 servidores foi dividida em dois pequenos grupos de 5 (cinco) pessoas, visando evitar aglomerações. Houve a participação de 7 (sete) servidores, que estavam em trabalho presencial. Os 3 (três) servidores não participantes se enquadram na categoria de teletrabalho.

Optou-se por adotar a aplicação de um questionário previamente estruturado, com perguntas fechadas, para percepção do conhecimento prévio dos participantes. Ao final da capacitação o mesmo questionário foi reaplicado, como instrumento para fixação da aprendizagem.

\section{RESULTADOS E DISCUSSÕES}

Para fins de fixação da aprendizagem, foi aplicado um questionário estruturado antes e após a capacitação. As perguntas contidas neste instrumento, bem como as respectivas respostas, estão inseridas no quadro 01 .

Quadro 1: Perguntas e respostas do questionário estruturado

\begin{tabular}{|c|c|c|c|c|}
\hline \multicolumn{5}{|l|}{ RESPOSTAS DOS PARTICIPANTES } \\
\hline \multicolumn{5}{|l|}{ Perguntas com alternativas "Sim/Não" } \\
\hline \multirow[t]{2}{*}{ PERGUNTAS } & \multicolumn{2}{|c|}{$\begin{array}{l}\text { Antes da } \\
\text { capacitação }\end{array}$} & \multicolumn{2}{|c|}{$\begin{array}{l}\text { Depois da } \\
\text { capacitação }\end{array}$} \\
\hline & Sim & Não & Sim & Não \\
\hline 1 - Você retira anéis, pulseiras ou relógio antes de realizar a lavagem das mãos? & $71 \%$ & $29 \%$ & $86 \%$ & $14 \%$ \\
\hline 2 - Você conhece os passos corretos para a técnica de lavagem das mãos? & $86 \%$ & $14 \%$ & $100 \%$ & $0 \%$ \\
\hline $\begin{array}{l}3 \text { - Você já recebeu instruções em algum momento sobre como utilizar Equipamentos de Proteção } \\
\text { Individual (EPI)? }\end{array}$ & $100 \%$ & $0 \%$ & $100 \%$ & $0 \%$ \\
\hline 4 - Você conhece a técnica correta para calçar as luvas? & $71 \%$ & $29 \%$ & $100 \%$ & $0 \%$ \\
\hline 5 - Você conhece a técnica correta para retirar as luvas? & $86 \%$ & $14 \%$ & $100 \%$ & $0 \%$ \\
\hline 6 - Você conhece a técnica correta para colocar a máscara? & $100 \%$ & $0 \%$ & $100 \%$ & $0 \%$ \\
\hline 7 - Você conhece a técnica correta para retirar a máscara? & $86 \%$ & $14 \%$ & $100 \%$ & $0 \%$ \\
\hline \multicolumn{5}{|l|}{ Perguntas com alternativas "a", "b", "c" e "d" } \\
\hline PERGUNTAS & A & $\mathrm{B}$ & $\mathrm{C}$ & $\mathrm{D}$ \\
\hline
\end{tabular}


8 - Em tempos de pandemia é necessário redobrar os cuidados e o conhecimento sobre os dispositivos de biossegurança. Assim, baseado em seus conhecimentos, para que servem as luvas de procedimento?

a) São dispositivos cirúrgicos que devem ser utilizados quando há risco de contato das mãos do profissional com sangue, fluidos corporais, secreções, excreções, mucosa ou pele não íntegra do paciente suspeito ou confirmado com COVID-19.

b) São dispositivos não cirúrgicos que devem ser utilizados quando há risco de contato das mãos do profissional com sangue, fluidos corporais, secreção, excreção, mucosa ou pele não íntegra do paciente suspeito ou confirmado com COVID-19. (alternativa correta)

c) São dispositivos não cirúrgicos que devem ser utilizados quando há risco de contato das mãos do profissional com sangue, fluidos corporais, secreção, excreção, mucosa ou pele não íntegra do paciente confirmado com COVID-19.

9 - Escolha a sequência correta para paramentação (colocação) com segurança dos seguintes EPIS: avental, gorro, luva, máscara e óculos de proteção.

a) Luva, máscara, avental, óculos de proteção e gorro.

b) Máscara, óculos de proteção, gorro, avental e luva.

c) Avental, máscara, óculos de proteção, gorro e luva (alternativa correta)

d) Não sei qual a sequência correta.

10 - Escolha a sequência correta para desparamentação (retirada) com segurança dos seguintes EPIS: avental, gorro, luva, máscara e óculos de proteção.

a) Luva, avental, gorro, óculos e máscara. (alternativa correta)

b) Luva, gorro, óculos, máscara, avental.

c) Gorro, avental, óculos, máscara e luva.

d) Não sei qual a sequência correta.

Antes da capacitação

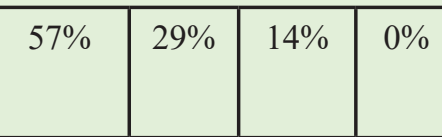

Depois da capacitação

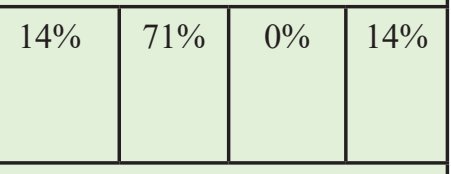

Antes da capacitação

\begin{tabular}{|l|l|l|l|}
\hline $14 \%$ & $71 \%$ & $0 \%$ & $14 \%$ \\
\hline
\end{tabular}

Depois da capacitação

\begin{tabular}{|l|l|l|l}
\hline $0 \%$ & $0 \%$ & $100 \%$ & $0 \%$
\end{tabular}

Antes da capacitação

\begin{tabular}{|l|l|l|l|}
\hline $57 \%$ & $14 \%$ & $29 \%$ & $0 \%$ \\
\hline
\end{tabular}

Depois da capacitação

\begin{tabular}{|c|c|c|c|}
\hline $100 \%$ & $0 \%$ & $0 \%$ & $0 \%$ \\
\hline
\end{tabular}

Fonte: autoras

A análise das respostas dos questionários evidenciou desconhecimento de informações básicas e relevantes sobre biossegurança, imprescindível em um contexto de pandemia. Apenas 71\% da equipe afirmou retirar adornos para a lavagem das mãos, e 14\% ainda referiu desconhecer a técnica correta de lavagem das mãos. Costa (2014) reforça que apesar de ser um procedimento simples e rotineiro, a lavagem das mãos requer atenção quanto a técnica correta, sendo necessário bom senso dos profissionais. Deixar de retirar adornos antes da lavagem das mãos, permite que haja continuidade da flora residente e dispersão de patógenos.

Todos os participantes relataram já ter recebido instruções de como utilizar Equipamentos de Proteção Individual (EPI), entretanto, apenas 71\% conheciam a técnica correta para colocação das luvas e $86 \%$ a forma correta de retirá-la. Em relação ao uso de máscara, todos sabiam a forma de colocá-la, porém 14\% não sabia como retirá-la com segurança. Ressalta-se que a temática de paramentação e desparamentação tem grande relevância para o público alvo da capacitação, uma vez que necessitam utilizar os EPIs durante as inspeções em ambientes de trabalho como forma de proteção individual, mas também podem orientar empresas e estabelecimentos quanto a importância da utilização correta de EPIs por parte de seus trabalhadores e trabalhadoras.

O conhecimento sobre paramentação e desparamentação é uma importante estratégia de promoção à saúde e prevenção de doenças, pois ao utilizar EPIs de forma correta há garantia da própria segurança (CASIMIRO et al., 2020). 


\section{CONCLUSÃO}

Qualificar a equipe de VISAT quanto a temática de biossegurança possibilitou o repasse de informações/instruções imprescindíveis para a proteção dos profissionais da equipe, e respectivamente contribuiu para a prevenção do adoecimento dos trabalhadores e trabalhadoras das empresas e instituições inspecionadas pela equipe do CEREST-RN durante a pandemia em curso.

\section{REFERÊNCIAS}

CASIMIRO, Cíntia Freitas; BARRETO, Tarcia Millene Almeida Costa; AMORIM, Raphael Florindo et al.. Narrativa do enfrentamento à COVID-19: resultados de uma ação de extensão a acadêmicos de enfermagem no extremo norte do Brasil. Rev Saude em Redes, v.6, n.2, p. 7-17, 2020. Disponível em: <http://revista.redeunida.org.br/ojs/index.php/rede-unida/article/view/3211/551>. Acesso em: 04 fev 2021.

COSTA, Gabriela de Almeida. Lavagem das mãos: uma revisão de literatura acerca dos fatores limitante a adesão à higienização das mãos pela equipe multiprofissional de saúde. Trabalho de Conclusão de Curso (Especialização) - Universidade Federal de Santa Catarina, Florianópolis, 2014. Disponível em: <https://repositorio.ufsc.br/handle/123456789/172675>. Acesso em: 03 fev. 2021. MACHADO, Jorge Mesquita Huet. Processo de vigilância em saúde do trabalhador. Cad. Saúde Pública, Rio de Janeiro, v. 13, supl. 2, p. S33-S45, 1997 . Disponível em: < http://dx.doi.org/10.1590/ S0102-311X1997000600004>. Acesso em: 02 fev. 2021.

SANTOS, Sonia Regina Belisario; SOUZA, Claudio Jose; SOARES, Hyago Henrique. Na linha de frente ao desconhecido: sistematizando as medidas de biossegurança frente ao Covid-19. Braz. J. Hea. Rev., Curitiba, v. 3, n. 5, p. 12206-12213 set./out. 2020. ISSN 2595-6825 


\title{
IMPACTOS DA PANDEMIA DA COVID-19 NA SAÚDE MENTAL DOS TRABALHADORES DA SAÚDE: REVISÃO INTEGRATIVA
}

\section{Fernanda de Medeiros Fernandes Dantas'; Karylane Rayssa de Oliveira Pessoa Araújo²; Sidney de Oliveira Bezerra ${ }^{3}$;}

5. Mestre, CEREST/SESAP, Natal, Rio Grande do Norte.

6. Mestranda, CEREST/SESAP, Natal, Rio Grande do Norte.

7. Pós-graduação, SMS PARNAMIRIM, Parnamirim, Rio Grande do Norte.

nandamfdantas@gmail.com

\begin{abstract}
RESUMO
Introdução: A COVID-19 é a maior pandemia da história, com grandes consequências à Saúde Mental, afetando principalmente os trabalhadores da saúde que estão na linha de frente. Além do risco da infecção, essa categoria enfrenta decisões difíceis. Objetivo: Discorrer sobre os impactos da pandemia da COVID-19 na saúde mental destes trabalhadores. Metodologia: Propõe-se nesse estudo discorrer sobre os impactos da pandemia na saúde mental destes trabalhadores através de uma revisão integrativa da literatura. Fundamentação teórica: Identificou-se a relação real do desenvolvimento de problemas psicológicos, como ansiedade, síndrome de Burnout, depressão e suicídio para os trabalhadores da saúde da linha de frente. Conclusão: Medidas simples do ponto de vista individual são fundamentais, como a busca do equilíbrio emocional e o reconhecimento da necessidade de procurar ajuda quando preciso, bem como do ponto de vista coletiva, pois os que antes cuidavam, agora precisarão ser cuidados.
\end{abstract}

PALAVRAS-CHAVE: Coronavírus; Saúde ocupacional; Profissionais da saúde.

ÁREA TEMÁTICA: Saúde Coletiva

\section{INTRODUÇÃO}

A COVID-19 é a maior pandemia da história, causada pelo vírus SARS-CoV-2. A agenda para o enfrentamento da pandemia engloba uma gama de áreas que devem ser cobertas, com atenção para as consequências da pandemia, que vão além das mortes e do colapso geral da saúde. Divide-se essas consequências em quatro ondas: a $1^{\mathrm{o}}$ refere-se à sobrecarga imediata sobre o sistema de saúde, que teve que se preparar rapidamente para cuidar dos pacientes graves infectados; a $2^{\circ}$ representa a 
diminuição de recursos para o cuidado com outras condições clínicas agudas, devido a transferências da verba para o enfretamento da pandemia; a $3^{\circ}$ tem relação com o impacto geral da interrupção nos cuidados de saúde de várias doenças crônicas; e por último, a $4^{\circ}$ onda, que inclui o aumento de transtornos mentais e traumas psicológicos provocados diretamente pela doença ou por seus desdobramentos (PFIZER, 2020).

É evidente que a pandemia não afeta a saúde mental da população da mesma forma, porém a exposição de grande parcela dela a condições ambientais extremamente desfavoráveis, pode desencadear transtornos mentais, mesmo em indivíduos com genética menos suscetível. Isso explica o potencial epidêmico para alterações de saúde mental pós-pandemia. E dentro da população mundial, existe um grupo exposto aos riscos de adoecer: os trabalhadores da saúde (PFIZER, 2020).

Além do risco da infecção, os trabalhadores da saúde enfrentam decisões dificeis, tais como: triagem de pacientes, escolhas terapêuticas, enfretamento do luto e receio de transmitir a doença para seus familiares. Mediante isso, acredita-se que todo esse contexto pandêmico pode ocasionar forte impacto na Saúde Mental desses trabalhadores. Algumas patologias podem ser mais frequentes, como síndrome de Burnout, ansiedade, depressão e suicídio.

Diante deste contexto, da forma como ele afeta a categoria de trabalhadores da saúde, bem como da sua relevância no atual cenário mundial, propõe-se nesse trabalho discorrer sobre os impactos da pandemia da COVID-19 na saúde mental destes trabalhadores.

\section{METODOLOGIA}

Trate-se de uma revisão integrativa da literatura pertinente à temática de pesquisa. Como parte do processo construtivo do estudo, foi realizada uma busca na Biblioteca Virtual em Saúde (BVS), e na base de dados Scielo com os descritores, "saúde mental", "pandemia COVID-19" e "profissionais da saúde". A pesquisa foi feita no mês de dezembro e incluiu todas as publicações do ano de 2020. A fim de atender melhor o objetivo da pesquisa, resolveu-se trabalhar apenas com artigos de publicação brasileira. Portanto, dentro dos critérios elencados, para realização deste trabalho, analisou-se 18 artigos.

Na BVS encontrou-se 636 artigos publicados, dos quais apenas 52 são artigos de publicação brasileira. Destes, apenas 14 artigos foram selecionados, por se adequarem melhor no delineamento da temática "saúde mental dos profissionais de saúde na pandemia de COVID-19".

Na base de dados Scielo, levantou-se 27 artigos, sendo 8 artigos publicações brasileiras. Porém destes 8 artigos eleitos, 4 já haviam sido selecionados na BVS, logo, na Scielo foram escolhidos apenas 4 artigos.

Além dos artigos pesquisados nas bases de dados, complementamos o trabalho com informações de manuais, guias e cartilhas elaboradas por órgãos especializados, como Fiocruz, e organizações internacionais, como a Organização Mundial de Saúde (OMS). 


\section{FUNDAMENTAÇÃO TEÓRICA}

Para tornar mais explicativo o resultado da leitura e análise dos autores à luz da literatura pertinente à temática de pesquisa, os resultados encontrados foram categorizados em dois grupos.

\section{GRUPO 1: IMPACTOS DA PANDEMIAA SAÚDE MENTAL DOS TRABALHADORES DA SAÚDE}

No cenário contemporâneo, muitos sofrimentos são causados pela adaptação ao trabalho. A intolerância e a exigência de permanecer no "bem-estar", fazem os trabalhadores "medicalizar" sua dor e inibir qualquer manifestação de adoecimento, ganhando contornos de patologia. É assim que se desenvolve o sofrimento mental, e posteriormente os transtornos (LEÃO; GOMEZ, 2014).

Diante deste fato, é esperado que as pessoas possam apresentar ansiedade, medo e perturbação comportamental. A frequência, a persistência e a intensidade desses sintomas podem requerer atenção especial quando afetam a qualidade de vida e/ou interferem negativamente na execução das tarefas diárias (FIOCRUZ, 2020).

Ainda existe desinformação/discriminação ao se falar sobre saúde mental, e o sofrimento psicológico é visto como uma fraqueza. Se o estresse crônico estiver afetando o bem-estar e prejudicando o trabalho, um serviço especializado de saúde mental pode ajudar no reequilíbrio emocional (FIOCRUZ,2020).

Dentre estes trabalhadores que estão expostos ao sofrimento mental, os profissionais de saúde, devido as condições de trabalho, que incluem jornada extensas e um ritmo intenso de trabalho, sofrem um maior desgaste físico e psíquico e, por isso, são mais susceptíveis a desenvolver algum tipo de sofrimento psicológico ao longo de sua carreira profissional (MIRANDA, 2020; LEÃO; GOMEZ, 2014).

Diante da ausência de tratamento comprovadamente eficaz para COVID-19, as equipes de assistência à saúde, da linha de frente, estão submetidas a enorme carga de estresse no atendimento aos pacientes, levando a afastamentos do trabalho e comprometendo a qualidade do atendimento prestado à população (TEIXEIRA et al, 2020).

Já foi evidenciada em experiências passadas, que há consequências significativas no pós-epidemia para a saúde mental dos trabalhadores de saúde, a exemplo do estresse psicológico agudo (MOREIRA; LUCCA, 2020).

As vivencias estressoras da COVID-19 como sobrecarga de trabalho, fadiga, exposição a mortes em larga escala, frustações relacionadas a qualidade da assistência, ameaças e agressões, o risco de infecção, emergem junto com o medo e a incerteza, que podem influenciar de forma negativa no comportamento e bem-estar geral desses profissionais, com interferência na qualidade dos cuidados em saúde. Destaca-se um aumento de síndrome de Burnout, fadiga, menor satisfação no trabalho, sofrimento moral e elevados níveis de estresse (RAMOS-TOESCHER et al, 2020; TEIXEIRA, 2020).

O sofrimento no trabalho pode levar a quadros como raiva, insegurança, frustração, medo, 
impotência e tantas outras reações. A falta de EPIs, bem como o desconforto e a limitação da mobilidade com uso deles; o medo de ser infectado; a falta de apoio; conflitos interpessoais; a preocupação com os familiares; sobrecarga de trabalho; exposição prolongada em ambientes crítico; a falta de acesso à informação e treinamentos permanentes; o receio de perder os meios de subsistência; a angústia de se separar de entes queridos; o sofrimento por reviver experiência anteriores; a gerência do sofrimento de pacientes e familiares; desmitificação de notícias falsas constantemente; e o estigma da população em relação aos profissionais que trabalham na linha de frente aos pacientes com COVID-19, repercutem negativamente à Saúde Mental. (MOREIRA; LUCCA, 2020; RAMOS-TOESCHER et al, 2020)

Os sentimentos mais declarados pelos profissionais de saúde frente à pandemia da COVID-19, são: medo, pesar, frustação, culpa, raiva, exaustão, incerteza, desesperança, sofrimento moral, síndrome de Burnout, estresse, ansiedade, ambivalência, sintomas depressivos, negação, impotência, sentimento de vulnerabilidade e irritabilidade; Além de alterações de apetite, distúrbio do sono e uso de drogas lícitas e ilícitas (RAMOS-TOESCHER et al, 2020; HUMEREZ, 2020).

\section{GRUPO 2: SUGESTÕES SOBRE COMO MINIMIZAR OS EFEITOS À SAÚDE MENTAL}

No tocante a saúde mental, é importante destacar que as sequelas de uma pandemia são grandiosas, porém é possível minimizá-las. Para isso, várias instituições, internacionais e nacionais, já lançaram cartilhas e manuais explicando como cuidar da saúde mental enquanto a pandemia perdurar. A seguir foi demonstrado algumas sugestões apontadas para minimizar os efeitos.

Dentro da organização dos locais de trabalho as mudanças envolvem: ampliação do número de leitos; distribuição de EPIs; relação adequada entre quantitativo de profissionais ajustado à demanda; adoção de medidas estratégicas a fim de garantir a segurança dos trabalhadores em todos os níveis da atenção à saúde; redução de estressores ocupacionais e da fadiga no trabalho. Além disso, oferecer apoio psicológico dentro da própria instituição, reduzir as jornadas de trabalho, criar mecanismos de valorização profissional, podem representar pontos de apoio social no trabalho, minimizando os fatores de sofrimento (HELIOTERIO et al, 2020).

A China para reduzir os danos psicológicos causados pela pandemia da COVID-19, publicou uma diretriz baseada nos seguintes níveis de atenção: o nível 1 incluiu pacientes hospitalizados com infecção confirmada ou condição grave da doença, profissionais de saúde da linha de frente e equipe administrativa; o nível 2 abrange pessoas em isolamento com proximidade de indivíduos confirmados para a doença ou que tiveram contato com pessoas suspeitas; nível 3, aqueles em contato próximo com os níveis 1 e 2; e nível 4, composto pela população em geral. O cuidado emergencial de atenção psicológica está voltado para o tratamento medicamentoso e apoio psicológico ao paciente, com avaliação oportuna para condutas auto lesivas e risco de suicídio. Sugere-se para os trabalhadores da linha de frente, antes de se iniciarem os trabalhos, treinamentos e entrevistas preventivas focadas na gestão do estresse, regulação das emoções e encorajamento para a busca de ajuda psicológica (FARO et al, 2020).

Para diminuir a presença das emoções negativas, a OMS divulgou um guia com cuidados para a saúde mental durante a pandemia. As orientações incluem: reduzir a leitura de notícias que 
possam causar ansiedade ou estresse, selecionando apenas fontes de informação confiáveis; fazer pausas no trabalho, inclusive em home office; manter alimentação saudável, sono regular e prática de exercícios físicos ou meditação; e manter contato com familiares através do ambiente virtual, respeitando a distância física (DUARTE et al, 2020).

\section{CONCLUSÃO}

A literatura pertinente a temática possibilitou aferir que as consequências da pandemia em curso extrapolam à infecção e demais doenças correlatas. Conclui-se que a ameaça à saúde mental dos trabalhadores da saúde é real, com reações variadas, legítimas e que podem ultrapassar a capacidade de enfrentamento dos trabalhadores da saúde.

Assim, para lidar com todas as experiências impostas pela pandemia, capazes de desencadear casos de transtornos de ansiedade, depressão, estresse pós-traumático e abuso de álcool e outras substâncias, além do luto e outras reações emocionais a esses trabalhadores, é necessário que os diversos atores sociais sejam corresponsáveis nesse processo. Nesse sentido, medidas simples do ponto de vista individual são fundamentais, como a busca do equilíbrio emocional da saúde mental e o reconhecimento da necessidade de procurar ajuda quando preciso, bem como do ponto de vista coletivo, pois os que antes cuidavam, agora precisarão ser cuidados.

\section{REFERÊNCIAS}

LEÃO, Luís Henrique da Costa; GOMEZ, Carlos Minayo. A questão da saúde mental na vigilância em saúde do trabalhador. Revista Ciência \& Saúde Coletiva, 19(12): 4649-4658, 2014. Disponível em: https://www.scielo.br/pdf/csc/v19n12/pt_1413-8123-csc-19-12-04649.pdf >. Acesso em: 12 Dez 2020.

MIRANDA, Fernanda Moura D’Almeida et al. Condições de trabalho e o impacto na saúde dos profissionais de enfermagem frente a Covid-19. Cogitare enferm. [Internet]. 2020. Disponível em: $<$ https://pesquisa.bvsalud.org/portal/resource/pt/biblio-1096018>. Aceso em: 17 Dez 2020.

MOREIRA, Amanda Sorce; LUCCA, Sergio Roberto de. Apoio psicossocial e saúde mental dos Profissionais de enfermagem no combate à Covid-19. Enfermagem em foco (Brasília); 11(1,n.esp): 155-161, ago. 2020. Disponível em: < https://pesquisa.bvsalud.org/portal/resource/pt/biblio-1116610>. Aceso em: 17 Dez 2020.

RAMOS-TOESCHER, Aline Marcelino et al. Saúde mental de profissionais de enfermagem durante a pandemia de COVID-19: recursos de apoio. Esc. Anna Nery, Rio de Janeiro, v.24, n. spe, e20200276, 2020. Disponível em: < https://www.scielo.br/scielo.php?script=sci_arttext\&pid=S141481452020000500503 >. Acesso em: 17 Dez 2020.

TEIXEIRA, Carmen Fontes de Souza et al. A saúde dos profissionais de saúde no 
enfrentamento da pandemia de Covid-19. Ciênc. Saúde coletiva, Rio de Janeiro, v.25, n.9, p. 3465-3474, set. 2020. Disponível em $<$ http:/www.scielo.br/scielo.php?script=sci_ arttext\&pid=S141381232020000903465\&lng=pt\&nrm=iso>. Acesso em: 17 Dez 2020. 


\title{
CARACTERÍSTICAS DOS ACIDENTES POR ESCORPIÃO EM SERRA TALHADA, SERTÃO DE PERNAMBUCO (2010-2019)
}

\author{
Carolline Xavier de Aguiar'; Darllington Weslley Souza Gomes'; Drako de Amorim Souza'; \\ Júlia Assucena Medrado de Castro ${ }^{1}$; Lucas Braga dos Santos ${ }^{1}$; Mateus Antunes de Carvalho \\ Santos'; Wanessa Nunes de Sousa루 César Augusto da Silva² \\ ${ }^{1}$ Discente, Universidade Federal do Vale do São Francisco (Univasf), Petrolina, Pernambuco. \\ ${ }^{2}$ Docente, Universidade Federal do Vale do São Francisco (Univasf), Petrolina, Pernambuco.
}

cesar.silva@univasf.edu.br

\section{RESUMO}

Este é um estudo observacional, retrospectivo e descritivo do perfil de acidentes com escorpiões registrados em Serra Talhada/PE, no período de 2010 a 2019. Foram registradas 949 notificações desses acidentes, com incidência mínima de 34,04, máxima de 222,68 e média de 112,30; crescimento linear $\left(\mathrm{R}^{2}=0,837\right)$ e coeficiente de $18,00 /$ ano. As maiores vítimas são de cor parda $(88,205)$, com 20 a 39 anos de idade $(35,41 \%)$ e ensino médio completo (17,81\%); na maioria, mulheres $(59,43 \%)$. O tempo decorrido para o atendimento foi, na maioria dos casos, de até 1 hora (62,08\%). Quanto à gravidade, $0,11 \%$ foram graves e 1,79\% moderados, sem registro de letalidade. Esses dados podem contribuir com o planejamento de estratégias para melhor condução destes eventos, com elaboração de medidas de controle e prevenção de acidentes e de amparo à população.

PALAVRAS-CHAVE: Epidemiologia; Animais peçonhentos; Doenças negligenciadas.

ÁREA TEMÁTICA: Saúde Coletiva

\section{INTRODUÇÃO}

Escorpiões são animais artrópodes comumente encontrados no Sertão brasileiro, sendo relacionados a acidentes por animais peçonhentos. As espécies recorrentes nesses ataques, no Brasil, são Tityus serrulatus, T. bahiensis e T. sigmurus. Devido aos graves problemas socioeconômicos e de infraestrutura em saúde que regiões como o nordeste brasileiro enfrentam para combater tais acidentes, a Organização Mundial da Saúde (OMS) incorporou o escorpionismo na lista de Doenças Tropicais Negligenciadas (DTN) em 2009 (BRASIL, 2019). 
Além disso, o desequilíbrio ecológico, o desmatamento causado pelo homem ao longo dos anos e o crescimento desordenado dos centros urbanos, têm sido alguns dos principais motivos da justaposição no uso do espaço entre o ser humano e esses animais, aumentando a probabilidade da ocorrência destes eventos. Diante disso, urge a necessidade de um sistema mais eficiente de notificações de acidentes. Nesse sentido, o Ministério da Saúde (MS), em 1998, por intermédio do Sistema de Informações de Agravos de Notificação (SINAN), regulamentou, por portaria, a obrigatoriedade de notificações de casos de escorpionismo (LAGUARDIA et al., 2004). Contudo, embora esse sistema tenha possibilitado maior facilidade em notificar os acidentes, a subnotificação ainda é presente, sobretudo, em virtude das dificuldades de preenchimento dos dados no sistema.

Dessa forma, este estudo tem por objetivo analisar dados epidemiológicos sobre acidentes envolvendo escorpiões registrados na cidade de Serra Talhada, Sertão de Pernambuco, no período de 2010 e 2019. Espera-se que os dados aqui apresentados possam contribuir com o planejamento de estratégias que melhorem a condução destes eventos e que possam aperfeiçoar estratégias de controle e prevenção que auxiliem na redução da sua incidência, com vistas à proteção e amparo da população.

\section{METODOLOGIA}

Trata-se de um estudo observacional, retrospectivo e descritivo dos casos confirmados e notificados de acidentes por escorpiões na cidade de Serra Talhada, Sertão de Pernambuco, no período de 2010 a 2019. Os dados foram obtidos do Departamento de Informática do Sistema Único de Saúde do Brasil (Datasus/MS), de acordo com o município de residência, no período estudado. Foram obtidas estimativas para número de residentes e casos de acidentes por escorpiões.

O coeficiente de incidência dos acidentes escorpiônicos foi calculado com base no número de novos casos identificados no município, por período, multiplicado por 100.000 e dividido pela população notificada no período considerado. Foram considerados ainda para cálculos os valores absolutos e relativos de notificações, de incidência, de gravidade e de evolução dos casos; além do número de notificações dos acidentes estratificados por grau de escolaridade, raça, idade e tempo de atendimento. Os dados do município foram confrontados com os registros das Macrorregiões de Saúde do Vale do São Francisco/Araripe e do Sertão de Pernambuco, possuindo, esta última, o município estudado como sede.

As informações foram obtidas através de um sistema de dados de domínio público, de alcance integral, que não atinge informação sigilosa ou individual, desobrigando, assim, a necessidade de análise do trabalho pelo Comitê de Ética em Pesquisa.

\section{RESULTADOS E DISCUSSÕES}

A cidade de Serra Talhada/PE, no período de 2010 a 2019, apresentou incidência anual média de acidentes por escorpião (112,30/100.000 habitantes) maior em todo o período de estudo quando 
comparada às Macrorregiões de Saúde do Vale do São Francisco/Araripe e Sertão de Pernambuco (49,81/100.000 habitantes). As Macrorregiões de Saúde do Vale do São Francisco/Araripe e Sertão de Pernambuco apresentaram crescimento linear $\left(\mathrm{R}^{2}=0,837\right.$ e 0,767 , respectivamente), porém, Serra Talhada cresceu com coeficiente de 18,00/ano, enquanto as macrorregiões cresceram em 9,98/ano. Respectivamente, a cidade e as macrorregiões apresentaram incidência mínima de 34,04 e 13,49, máxima de 222,68 e 116,85 e média de 112,30 e 95,0.

No período de 2017 a 2019, acidentes desse tipo aumentaram em média 126,88\% e 212,24\% na cidade e nas macrorregiões, respectivamente. Provavelmente, isso se deve ao crescimento urbano, à falta de saneamento básico e a fatores de desigualdade social, os quais proporcionam um ambiente propício ao seu crescimento (GONÇALVES et al., 2020).

No período estudado, foram notificados 949 casos de acidentes com escorpião em Serra Talhada, destes, a maioria $(59,43 \%)$ ocorreu em pessoas do sexo feminino; tendência também observada nas macrorregiões, onde as mulheres representaram a maioria $(56,48 \%)$ dos casos notificados ( $\mathrm{n}=9.069)$. A predominância de casos no sexo feminino se manteve em todos os anos de estudo, tanto em Serra Talhada, quanto nas macrorregiões. Essa frequência em relação ao sexo pode ser explicada pelo maior tempo de exposição das mulheres aos ambientes e atividades domésticas que na presença de entulhos, caixas de esgoto, frestas em paredes, podem se tornar abrigos para esse aracnídeo, tornando-as, assim, mais suscetíveis (OLIVEIRA et al., 2021).

A maioria dos acidentados do município, no período, declara ser de raça parda $(88,2 \%)$ e apenas 8,54\% declaram-se brancos. Em 2018, ano com maior número de notificações ( $\mathrm{n}=191)$ no município, 92,67\% dos sujeitos eram pardos. Fato que, provavelmente, se explica pela população brasileira ser, em sua maioria, parda (OLIVEIRA et al., 2021).

A faixa etária de 20 a 39 anos foi a mais acometida na cidade $(35,41 \%)$, corroborando com outros estudos realizados na região Nordeste (OLIVEIRA et al., 2021). A faixa etária de 0 a 4 anos, considerada mais vulnerável à letalidade e ao óbito devido, possivelmente, à quantidade de veneno inoculado em relação à superfície corpórea (OLIVEIRA et al., 2021), representou 8,22\% dos casos neste estudo.

Em relação ao grau de escolaridade, o município registrou 17,81\% de pacientes com ensino médio completo, $15,07 \%$ com ensino fundamental incompleto e 22,34\% de notificações onde esse dado foi ignorado. Nas macrorregiões, a maior parte das notificações (30,75\%) ignorou essa informação, enquanto que $13,11 \%$ dos pacientes possuíam ensino médio completo. Estudos apontam para menores graus de escolaridade entre os indivíduos acometidos por esses acidentes, vinculando tal fato à falta de informação e ao déficit de entendimento das medidas de prevenção (OLIVEIRA et al., 2021).

No período investigado, observa-se no município de Serra Talhada que a maior parte dos casos por escorpionismo $(62,08 \%)$ foi atendida em até 1 hora decorrente do tempo de picada; o tempo decorrido de 1 a 3 horas após o acidente compõe 16,5\% dos casos, enquanto que, após 3 horas 
decorrentes do evento representa 15,42\% das notificações; seguidos por 3 a 6 horas (5,69\%), 6 a 12 horas $(3,14 \%), 12$ a 24 horas $(3,73 \%)$ e após as 24 horas da ocorrência do evento $(2,84 \%)$.

Um estudo feito com crianças e adolescentes vítimas de escorpionismo demonstra aumento nas chances de gravidade quando o tempo para admissão hospitalar excede 3 horas (HORTA et al., 2007). Concomitante a isso, no município em análise, dos atendimentos hospitalares ocorridos anteriores a 3 horas da picada, em média, 1,3\% evoluiu para casos moderados, enquanto aqueles admitidos após 3 horas do acidente corresponderam a 5,33\%. No período, apenas um caso grave foi notificado, esse atendido no período de 1 a 3 horas da picada.

Ainda em relação à gravidade dos acidentes neste estudo, as macrorregiões juntas registraram $0,44 \%$ dos casos graves e 7,79\% moderados, enquanto que, em Serra Talhada há menor percentual de casos graves $(0,11 \%)$ e moderados $(1,79 \%)$. Quanto à evolução dos casos, se destaca a letalidade de 0,09\% nas macrorregiões e de 0,00\% em Serra Talhada. Esses baixos percentuais de letalidade podem se relacionar com o programa Mais Médicos, implementado em 2013, que permitiu maior acesso da população à saúde, principalmente no interior dos Estados, contribuindo com uma possível redução no número de óbitos nos anos subsequentes (PINTO et al., 2017).

\section{CONCLUSÃO}

A elevada incidência dos acidentes escorpiônicos na cidade de Serra Talhada, em comparação às macrorregiões, mostra que o município é área endêmica para tais eventos, podendo ser justificada por fatores como crescimento urbano desordenado e falta de saneamento básico. Além disso, a análise dos dados sugere que as mulheres, indivíduos na faixa etária de 20 a 39 anos, pardos e com níveis menores de escolaridade podem estar em maior risco. Por fim, é importante ressaltar que a maior parte das vítimas foram atendidas em até 1 hora após a picada e a gravidade é maior em crianças e adolescentes cuja admissão hospitalar ocorre 3 horas após o acidente.

\section{REFERÊNCIAS}

BRASIL. MINISTÉRIO DA SAÚDE. SECRETARIA DE VIGILÂNCIA EM SAÚDE. Acidentes de trabalho por animais peçonhentos entre trabalhadores do campo, floresta e águas, Brasil 2007 a 2017. Boletim Epidemiológico, v. 50, n. 11, 2019. Disponível em: https://portalarquivos2.saude.gov. br/images/pdf/2019/marco/29/2018-059.pdf. Acesso em: 2 fev. 2021.

GONÇALVES, J. E; MEDEIROS, S. M. F. R. S; CAVALCANTI, I. D. L. et al. Acidentes por animais peçonhentos: uma análise do perfil epidemiológico na região Nordeste do Brasil no período de 2010 a 2019. Research, Society and Development, v. 9, n. 10, 2020. Disponível em: http://dx.doi. org/10.33448/rsd-v9i10.8843. Acesso em: 2 fev. 2021.

HORTA, F. M. B; CALDEIRA, A. P; SARES, J. A. S. Escorpionismo em crianças e adolescentes: 
aspectos clínicos e epidemiológicos de pacientes hospitalizados. Rev. Soc. Bras. Med. Trop, Uberaba, v. 40, n. 3, p. 351-353, 2007. Disponível em: https://doi.org/10.1590/S0037-86822007000300022. Acesso em: 2 fev. 2021.

LAGUARDIA, J; DOMINGUES, C. M.; CARVALHO, C. et al. Sistema de informação de agravos de notificação em saúde (Sinan): desafios no desenvolvimento de um sistema de informação em saúde. Epidemiol. Serv. Saúde, Brasília, v. 13, n. 3, p. 135-146, 2004. Disponível em: http://scielo.iec. gov.br/scielo.php?script=sci_arttext\&pid=S1679-49742004000300002\&lng=pt\&nrm=iso. Acesso em: 2 fev. 2021.

OLIVEIRA, S. S; CRUZ, J. V. F; SILVA, M. A. Perfil epidemiológico de escorpionismo no Nordeste brasileiro (2009 a 2019). Brazilian Journal of Development, Curitiba, v. 7, n. 2, p. 11984-11996, 2021. Disponível em: https://www.brazilianjournals.com/index.php/BRJD/article/view/24123/19313. Acesso em: 2 fev. 2021.

PINTO H. A; OlIVEIRA, F. P; SANTANA, J. S. S. et al. Programa Mais Médicos: avaliando a implantação do eixo provimento de 2013 a 2015. Interface, Botucatu, v. 21, p. 1087-1101, 2017. Disponível em: http://dx.doi.org/10.1590/1807-57622016.0520. Acesso em: 2 fev. 2021. 


\title{
TESTAGEM RÁPIDA PARA COVID-19 EM TRABALHADORES DE UMA CENTRAL DE ABASTECIMENTO: EXPERIÊNCIA DE UM CEREST ESTADUAL
}

\author{
Fernanda de Medeiros Fernandes Dantas ${ }^{1}$; Karylane Rayssa de Oliveira Pessoa Araújo ${ }^{2}$; \\ Daniella Mylena Paiva de Oliveira ${ }^{3}$; Kelly Katiucci Brito de Lima Maia ${ }^{4}$, Ariluce Fernandes \\ Barbosa da Silva ${ }^{5}$; Edna Patricia Dias Alves ${ }^{6}$; Paula Francinete Silva de Araújo ${ }^{7}$; Mariana da \\ Costa Batista $^{8}$
}

1. Mestre, CEREST/SESAP, Natal, Rio Grande do Norte.

2. Mestranda, CEREST/SESAP, Natal, Rio Grande do Norte.

3. Pós-graduação, CEREST/SESAP, Natal, Rio Grande do Norte.

4. Pós-graduação, CEREST/SESAP, Natal, Rio Grande do Norte.

5. Pós-graduação, CEREST/SESAP, Natal, Rio Grande do Norte

6. Pós-graduação, CEREST/SESAP, Natal, Rio Grande do Norte

7. Pós-graduação, CEREST/SESAP, Natal, Rio Grande do Norte

8. Pós-graduação, CEREST/SESAP, Natal, Rio Grande do Norte

nandamfdantas@gmail.com

\begin{abstract}
RESUMO
Introdução: As estratégias de testagem associadas no enfrentamento à pandemia são relevantes, pois permite o monitoramento da doença. Objetivo: Relatar a experiência da equipe do CEREST-RN na realização da testagem rápida para COVID-19 em trabalhadores da CEASA-RN. Metodologia: Relato de experiência sobre a testagem rápida para COVID-19 em trabalhadores da CEASA/RN. A testagem foi realizada pela equipe do CEREST-RN, em outubro/2020. Resultados e discussões: Foram realizados 440 exames, onde 18 (dezoito) trabalhadores obtiveram resultado positivo para COVID-19. A ação possibilitou a elaboração de um boletim epidemiológico, em âmbito estadual. Conclusão: As orientações realizadas pela equipe do CEREST possibilitaram o encaminhamento precoce dos casos confirmados para a doença nos trabalhadores testados, além de orientação sobre medidas de isolamento, evitando a propagação do vírus no ambiente de trabalho inspecionado.
\end{abstract}


PALAVRAS-CHAVES: Coronavírus; Saúde ocupacional; Educação continuada.

ÁREA TEMÁTICA: Saúde coletiva

\section{INTRODUÇÃO}

A infecção pelo vírus SARS-CoV-2 ocorre por meio de transmissão por contato e gotículas, aerossóis e por superfícies contaminadas. Há uma probabilidade maior de infecção pela COVID-19 quando há um tempo prolongado de exposição e também quanto menor for o distanciamento entre pessoas suscetíveis e àquelas contaminadas. Assim, é imprescindível que as pessoas infectadas sejam identificadas rapidamente e que estas realizem o isolamento, bloqueando a cadeia de transmissão da doença, objetivando minimizar os casos da doença (MAGNO et al., 2020).

É fundamental que haja confirmação de casos de COVID-19 precocemente, sendo relevante a estratégia de testagem para a doença associada a outras medidas de enfrentamento à pandemia, pois o número de casos confirmados permite o monitoramento da progressão da doença, prevenindo o colapso da rede de atenção a saúde. Experiências na esfera internacional revelaram que, apesar de ainda não ser possível observar o efeito da estratégia de testagem em relação a incidência da doença, este pode ser considerado uma importante ferramenta no controle da pandemia (MAGNO et al., 2020).

Ainda no início da pandemia, a cidade de Wuhan, na China, apresentou casos de trabalhadores e clientes de um mercado de frutos do mar infectados pela COVID-19, sendo esse um provável foco inicial de contaminação pelo vírus SARS CoV-2. Em relação ao Brasil, houve o registro de óbito por COVID-19 de uma empregada doméstica, no exercício do trabalho, sendo esse o segundo registrado pela doença em contexto nacional. Esses fatos apontam para uma importante questão relacionada à Saúde do Trabalhador: o exercício das atividades de trabalho e as condições em que são desempenhadas essas atividades, são fontes consideráveis de risco de infecção. A adoção de estratégias de enfrentamento à pandemia, com adaptações dos processos e condições de trabalho, é de extrema importância ao cenário atual (JACKSON FILHO; ASSUNÇÃO; ALGRANTI et al., 2020).

A testagem dos trabalhadores é uma estratégia de detecção precoce, visando reforçar as medidas de isolamento e a redução da disseminação da infecção pelo SARS CoV-2 nos ambientes laborais. Cabe ao trabalhador entender o importante papel de seu trabalho diante de um contexto de pandemia e sua responsabilidade na adoção de medidas de biossegurança na execução das suas atividades.

Dessa forma, o presente trabalho tem como objetivo relatar a experiência da equipe do Centro de Referência estadual em Saúde do Trabalhador (CEREST-RN) na realização da testagem rápida para COVID-19 em trabalhadores da Central de Abastecimento do Rio Grande do Norte (CEASA). 


\section{METODOLOGIA}

Trata-se de um estudo do tipo relato de experiência, a partir da realização de testagem rápida para COVID-19 em trabalhadores da CEASA/RN. A testagem foi realizada pela equipe do CERESTRN, no mês de outubro/2020.

Foram disponibilizados kits do tipo Antibody Test da marca Wondfo para realização da testagem in loco dos trabalhadores e trabalhadoras da CEASA. Esses kits possuem sensibilidade para IgG e IgM, atestando que o paciente é portador do vírus, caso o resultado seja positivo para a presença de $\operatorname{IgM}$ a partir do $7^{\circ}$ dia de sintomas.

Em torno de 14 dias, se o IgG for positivo, significa que o paciente está convalescente, Após 28 dias do início dos sintomas, espera-se o $\operatorname{IgG}$ esteja positivo e o $\operatorname{IgM}$ não reagente

A ação foi realizada por uma equipe multiprofissional do CEREST-RN, tendo sido aplicado um questionário pré-coleta, seguida da coleta da testagem, com abordagem individual/orientações aos trabalhadores que testaram positivo. Por fim, a equipe do CEREST realizou a construção de um boletim epidemiológico para apresentar um panorama da testagem sorológica, contendo o quantitativo de exames realizados e a análise segundo alguns aspectos, tais como: ocupação, idade e vínculo empregatício.

\section{RESULTADOS E DISCUSSÕES}

A equipe de Vigilância em Saúde do Trabalhador (VISAT) realizou 4 visitas de inspeção na CEASA-RN, objetivando a correção de possíveis inconformidades existentes, mediante descrição em denúncias realizadas ao Ministério Público. Durantes as visitas as medidas preventivas à COVID-19 foram abordadas, objetivando a readequação dos processos e ambiente de trabalho.

Em geral, foram realizado um quantitativo de 440 exames nos trabalhadores da CEASA, onde $75 \%$ desse total correspondia a faixa-etária de 30 a 49 anos. Além disso, $40 \%$ das pessoas testadas estavam em serviços administrativos.

Foi obtido um resultado de 18 (dezoito) pessoas com resultado positivo para COVID-19, ou seja, 4\% do valor total de pessoas testadas. Do total de resultados positivos, 6 trabalhadores haviam sido diagnosticados em meses anteriores e relataram ter adotado as medidas de precaução no período de quarentena., 4 relataram que sentiram sintomas em dias anteriores a testagem e 8 referiram não ter apresentado sintoma nenhum. Ainda assim, houve encaminhamento para a Atenção Primária à Saúde, quando necessário, além de informação sobre o afastamento das atividades laborais e isolamento domiciliar na presença de sintomas suspeitos. 
Figura 1: Resultados positivos quanto a ocupação

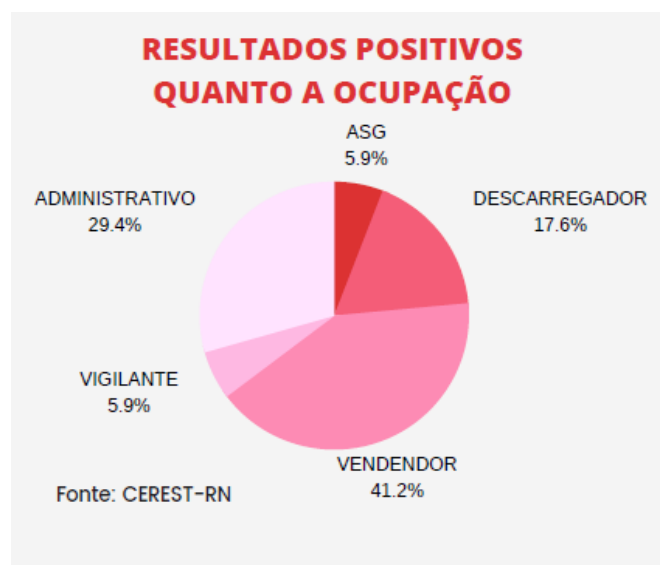

Fonte: CEREST-RN

Figura 2: Resultados positivos quanto ao vínculo empregatício

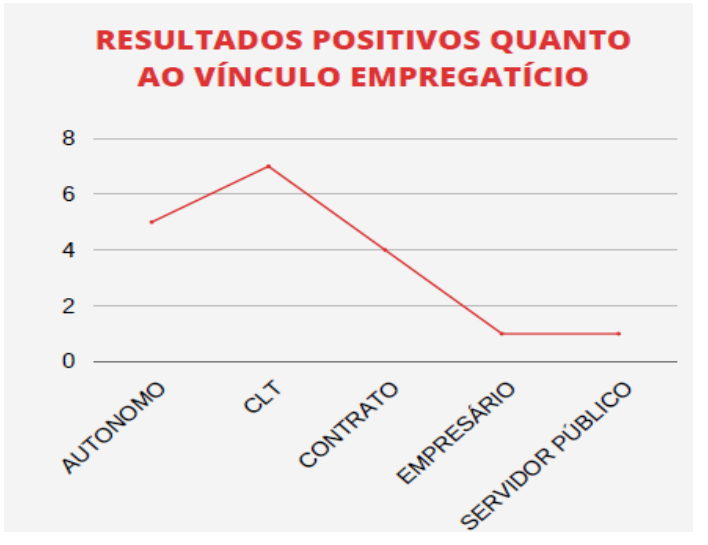

Fonte: CEREST-RN

Figura 3: Resultados positivos quanto a idade

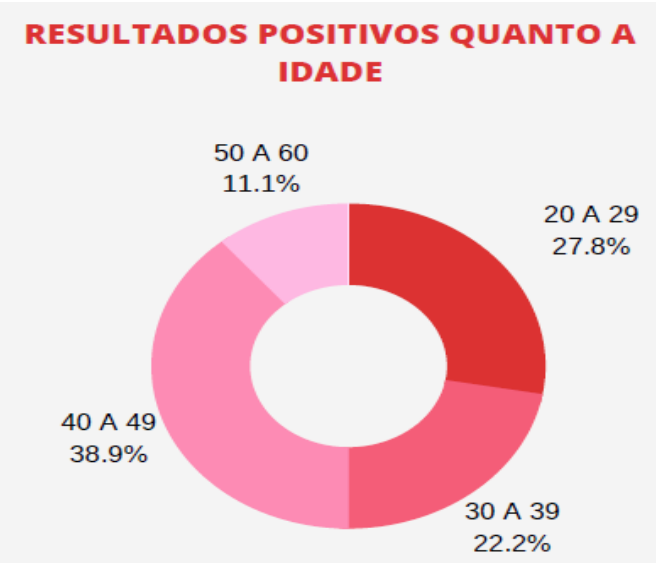

Fonte: CEREST-RN 


\section{CONCLUSÃO}

Durante as visitas realizadas pelos CEREST estadual à CEASA-RN foram realizadas diversas orientações no tocante às medidas preventivas, de caráter individual e coletivo, visando a minimização de casos de COVID-19. Portanto, essa ação possibilitou o encaminhamento precoce dos casos confirmados para a doença nos trabalhadores testados, além de orientação sobre medidas de isolamento, evitando a propagação do vírus no ambiente de trabalho inspecionado.

\section{REFERÊNCIAS}

BARROSO, Bárbara Iansã Lima; SOUZA, Marina Batista Chaves Azevedo; BREGALDA, Marília Meyer et al.. A saúde do trabalhador em tempos de COVID-19: reflexões sobre saúde, segurança e terapia ocupacional. Cad Bras Ter Ocup, v.28, n. 01, 2020. Disponível em: https:/www.scielo.br/ scielo.php?pid=S2526-89102020000301093\&script=sci_arttext\&tlng=pt. Acesso em 15 de fevereiro de 2021.

FILHO, José Marçal Jackson; ASSUNÇÃO, Ada Ávila; ALGRANTI, Eduardo et al.. A saúde do trabalhador e o enfrentamento da COVID-19. Rev Bras Saude Ocup, v.45, 2020. Disponível em: $<$ https://www.scielo.br/scielo.php?pid=S0303-76572020000100100\&script=sci_arttext\&tlng=pt $>$. Acesso em: 15 de fevereiro de 2021.

MAGNO, Laio; ROSSI, Thais Aranha; LIMA, Fernanda Whashington de Mendonça et al . Desafios e propostas para ampliação da testagem e diagnóstico para COVID-19 no Brasil. Ciênc. saúde coletiva, Rio de Janeiro, v. 25, n. 9, p. 3355-3364, Sept. 2020 . Available from $<$ http://www.scielo. br/scielo.php?script $=$ sci_arttext\&pid $=\mathrm{S} 1413-81232020000903355 \& \operatorname{lng}=\mathrm{en} \& \mathrm{nrm}=\mathrm{iso}>$. access on 15 Feb. 2021. Epub Aug 28, 2020. http://dx.doi.org/10.1590/1413-81232020259.17812020.

MEDVED, Isabely Vilanova et al. Atuação do Enfermeiro Residente na Testagem Rápida para COVID-19: um relato de experiência. Health Residencies Journal (HRJ). v. 1 n. 2 (2020): Pandemia COVID-19. Dipsonivel em: <https://escsresidencias.emnuvens.com.br/hrj/article/view/31/20>. Acesso em 15/02/2021 


\title{
RESIDÊNCIA MULTIPROFISSIONAL EM SAÚDE DA FAMÍLIA: A \\ TERRITORIALIZAÇÃO PARA ELABORAÇÃO DE ESTRATÉGIAS DE ATUAÇÃO
}

\author{
Morgana Gomes Izidório'; Breno Carvalho de Farias²; Pedro Ítalo Alves de Carvalho ${ }^{3}$; \\ Francisco Natanael Lopes Ribeiro ${ }^{4}$ : Maria Cassiana Rosa Carneiro Cunha ${ }^{5}$; Antonia Gescica \\ Arcanjo $^{6}$; Érika Aguiar Mouta ${ }^{7}$
}

1. Assistente Social. Residente em Saúde da Família, Escola de Saúde Pública Visconde de Saboia (ESPVS), Sobral, Ceará.

2. Profissional de Educação Física. Residente em Saúde da Família, Escola de Saúde Pública Visconde de Saboia (ESPVS), Sobral, Ceará.

3. Nutricionista. Residente em Saúde da Família, Escola de Saúde Pública Visconde de Saboia (ESPVS), Sobral, Ceará.

4. Assistente Social. Residente em Saúde da Família, Escola de Saúde Pública Visconde de Saboia (ESPVS), Sobral, Ceará.

5. Assistente Social. Centro Universitário INTA (UNINTA), Sobral, Ceará.

6. Graduanda em Serviço Social. Centro Universitário INTA (UNINTA), Sobral, Ceará.

7. Fisioterapeuta. Centro Universitário INTA (UNINTA), Sobral, Ceará.

morgana.izidorio@gmail.com

\section{RESUMO}

O conceito de território vem atravessando de forma mais pertinente o campo da saúde e vem sendo tecido para além de um lócus de atuação das equipes de saúde da família, sendo entendido como território vivo. Busca-se elucidar a importância da territorialização para a elaboração de estratégias de atuação no território. Trata-se de um relato de experiência sobre a territorialização, entre setembro a outubro de 2020, em dois territórios de Sobral - CE. Adentrar aos territórios possibilitou contemplar a inter-relação entre os diversos elementos de carácter social, econômico, cultural, ambiental, modos de produção e reprodução social, estruturais e demográficos, os quais exercem influência direta ou indireta na dinâmica do processo saúde/doença dos indivíduos e da coletividade. Conclui-se que o território é o reflexo de uma série de determinantes que condicionam a vida dos sujeitos que nele residem e que a produção de doenças no território também é resultado desse processo. 
PALAVRAS-CHAVES: Promoção da Saúde. Território. SUS.

ÁREA TEMÁTICA: Saúde Coletiva

\section{INTRODUÇÃO}

As Residências em Saúde é o resultado "da crença em uma nova pedagogia que tem como princípio a participação, a organicidade e a alegria dos processos educativos" (JÚNIOR et al., 2008). Ocasionada das necessidades pedagógicas de formar profissionais pautados no ideário da Reforma Sanitária (SUS, integralidade, trabalho em equipe). Considerando que a formação pedagógica das Residências em Saúde se faz dentro do trabalho vivo nos territórios, dialogando entre o teóricometodológico e a prática interventiva, o SUS se constitui aqui como o projeto ético-político dessa formação em serviço.

Desse modo, a territorialização deve ser entendida para além de uma prática essencialmente geográfica, mas como uma categoria de espaço singular, que se manifesta conforme a interação dos seus atores sociais e as condições econômicas, sociais, culturais, ambientais e políticas do espaço onde vivem (GONDIM, et al., 2008). O conceito de território vem atravessando de forma mais pertinente o campo da saúde e vem sendo tecido para além de um lócus de atuação das equipes de saúde da família, sendo entendido como território vivo.

Tendo em vista que o fazer da saúde deve se dar no território e que as políticas de saúde perante ao ideário do Sistema Único de Saúde - SUS, propõe um compromisso social para alcançar a atenção integral à saúde, é fundamental que a inserção da equipe de Residência Multiprofissional em Saúde da Família no território se dê para além do conhecimento da área de abrangência, população, dados epidemiológicos, equipamentos sociais, entre outros espaços objetivos. É preciso conhecer também os sentidos, significados e sentimentos dados pelas pessoas a esses espaços para compreensão dos sujeitos que ali vivem e suas relações.

\section{METODOLOGIA}

O trabalho em tela, trata-se de um relato de experiência, com o objetivo de elucidar a importância da territorialização para a equipe de Residência Multiprofissional em Saúde da Família para elaborar estratégias de atuação no território.

A vivência da equipe de Residência Multiprofissional em Saúde da Família, no processo de territorialização, ocorreu em dois territórios, situados no munícipio de Sobral, localizado na região noroeste do Ceará, a cerca de 230 quilômetros de Fortaleza, capital do estado. Conforme estimativa do Instituto Brasileiro de Geografia e Estatística - IBGE, de 2020, o munícipio é o quinto mais povoado do estado e o segundo maior do interior, com uma população de 210.711 habitantes. 
Tornou-se necessário caminhar por um percurso metodológico, guiado por uma observação participante com abertura para vivenciar, interagir, se relacionar, ouvir, dialogar, se comunicar, estabelecer vínculos, afetar e ser afetado no cotidiano dos territórios. Esta pesquisa ocorreu no período de 2 meses tendo início em setembro e conclusão em outubro do ano de 2020. Sendo realizadas visitas em equipamentos sociais, grupos não institucionalizados, espaços de cuidado, espaços religiosos, associações e ONGs. Para coleta de informações foi utilizado o instrumento questionário de territorialização, disponibilizado pela Secretaria Municipal de Saúde de Sobral - CE, no ano de 2020.

\section{RESULTADOS E DISCUSSÕES}

Adentrar aos territórios possibilitou à equipe contemplar a inter-relação entre os diversos elementos de carácter social, econômico, cultural, ambiental, modos de produção e reprodução social, estruturais e demográficos, os quais exercem influência direta ou indireta na dinâmica do processo saúde-doença dos indivíduos e da coletividade. A urgência desse novo olhar, ou melhor, novos olhares, no âmbito desse processo, se distanciando do modelo biomédico, privatista e curativista, proporcionou a compreensão das diferentes dimensões envolvidas no processo de saúde-doença dos territórios, potencializando e ampliando o espaço profissional no enfretamento das suas determinações.

Dessa maneira, possibilita-se realizar o planejamento, o diagnóstico, a identificação e a priorização dos problemas de saúde e programação, operacionalização e monitoramento das ações de saúde. No entanto, se faz necessário compreender que a territorialização é um processo constante e dinâmico de desvelamento das problemáticas, potencialidades e contradições dos territórios. Para além de um elemento desenvolvido para a obtenção de informações e formulação de diagnósticos sobre as reais condições de vida e da situação de saúde da população, essa ferramenta permite, sobretudo, conhecer a história dos sujeitos que ali sonham, sofrem, amam, trabalham, desejam e se expressam com conflitos contrastantes.

\section{CONCLUSÃO}

Conclui-se que o território é o reflexo de uma série de determinantes que condicionam a vida dos sujeitos que nele residem e, entende-se que a produção de doenças no território também é resultado desse processo. A partir da territorialização foi possível reconhecer as condições que promovem doenças no território e articular ações estratégicas de enfrentamento aos seus problemas e necessidades de saúde. Ademais, torna-se imprescindível a participação dos sujeitos individuais e coletivos do território nos processos de tomadas de decisão, estratégias e execução. A equipe multiprofissional, juntamente com a participação da comunidade, se torna uma importante ferramenta para a efetivação da promoção da saúde do território, dialogando com diversas áreas, de maneira transversal, integrada e intersetorial. 


\section{REFERÊNCIAS}

BRASIL. IBGE. Censo demográfico: 2000. Disponível em: www.ibge.gov.br. Acesso em: 21 de fevereiro de 2021.

GONDIM. G. M. de M. et al. O território da saúde: a organização do sistema de saúde e a territorialização. In: BARCELLOS, C. et al (org.). Território, ambiente e saúde. Rio de Janeiro: Editora Fiocruz, 2008, p. 237-255.

JUNIOR, T. M. et al. A Residência Multiprofissional em Saúde da Família em Sobral - Ceará. Sobral, v.7, n.2, p.23-30, jul./dez. 2008. 


\title{
A PARTICIPAÇÃO SOCIAL COMO LEGITIMAÇÃO DA DEMOCRACIA E A CONSOLIDAÇÃO DO SISTEMA ÚNICO DE SAÚDE
}

\section{Francisco Natanael Lopes Ribeiro'; Morgana Gomes Izidório²; Maria Cassiana Rosa Carneiro Cunha ${ }^{3}$; Antônia Gescica Arcanjo ${ }^{4}$}

1. Assistente Social. Residente em Saúde da Família, Escola de Saúde Pública Visconde de Saboia (ESPVS), Sobral, Ceará.

2. Assistente Social. Residente em Saúde da Família, Escola de Saúde Pública Visconde de Saboia (ESPVS), Sobral, Ceará.

3. Assistente Social. Centro Universitário INTA (UNINTA), Sobral, Ceará.

4. Graduanda em Serviço Social. Centro Universitário INTA (UNINTA), Sobral, Ceará.

\author{
fnlribeiro@gmail.com
}

\section{RESUMO}

Os processos de participação social no SUS surgem atrelados às reformas sanitárias e psiquiátricas e com o processo de tensionamento e mobilização para redemocratização da sociedade brasileira durante a ditadura civil-militar. Dessa forma, parte-se do seguinte questionamento: Como se configura a participação social no SUS? Objetivando compreender acerca da importância da participação social no Sistema Único de Saúde. Para tanto, desenvolveu-se uma pesquisa bibliográfica, de abordagem qualitativa. Foi possível compreender que a participação social é um determinante fundamental para a consolidação da democracia. À vista disso, pode-se dimensionar a importância da mobilização social e da efetivação dos conselhos de saúde para a concretização do controle social nas políticas públicas de saúde. Concluiu-se que o fomento para a concretização da participação social para além das instâncias institucionais é fulcral para a consolidação do SUS, para a construção de autonomia dos usuários dos serviços de saúde e para a consolidação da cidadania.

PALAVRAS-CHAVES: Atenção Primária a Saúde. Participação da Comunidade. Política de Saúde. ÁREA TEMÁTICA: Saúde Coletiva 


\section{INTRODUÇÃO}

Podemos compreender que os processos de participativos no SUS surgem atreladas às reformas sanitárias e psiquiátricas e com o processo de tensionamento e mobilização para redemocratização da sociedade brasileira perante a ditadura militar. Corroborando com tal afirmação Stoltz et al. (2013) elucida que desde a década de 1970, nos mais diversos setores da sociedade, principalmente a classe trabalhadora e os movimentos sociais têm lutado em busca de melhores condições de saúde para população, confrontando interesses econômicos e políticos direcionados ao interesse do capitalismo e da burguesia.

Desse modo, surge no ceio do processo de criação do Sistema Único de Saúde - SUS, o fomento da participação social. Tal fomento pode ser percebido principalmente durante a $8^{\circ}$ Conferência Nacional de Saúde que trouxe em seus debates três temas principais: 'A saúde como dever do Estado e direito do cidadão', 'A reformulação do Sistema Nacional de Saúde' e 'O financiamento setorial'. Como resultado da $8^{\circ}$ conferencia tem-se as bases para a formulação do Sistema de Saúde Pública e Universal através da Constituição Federal de 1988 e implementado pelas leis 8080 e 8142 . (COELHO, 2012).

\section{METODOLOGIA}

Dessa forma, o trabalho em tela parte do seguinte questionamento: Como se configura a participação social no SUS? Objetivando compreender acerca da importância da participação social no SUS - Sistema Único de Saúde. Para tanto, desenvolveu-se uma pesquisa bibliográfica, que segundo Gil (1999), é realizada com base em material já elaborado principalmente livros e artigos. A abordagem utilizada na pesquisa foi a qualitativa, pois, conforme Minayo (2006), trata-se de uma atividade da ciência que visa a construção da realidade em um nível que não pode ser quantificado.

\section{RESULTADOS E DISCUSSÕES}

A participação social está intrinsecamente ligada à influência de determinados indivíduos na sociedade através do desenvolvimento de ações que visem mudanças sociais em benefícios desses indivíduos. Compreende-se que a participação social é um determinante imprescindível para o fortalecimento da democracia. Desse modo, a realidade social da população pode e deve ser contemplada na solidificação de políticas públicas que vão de encontro às necessidades da população. À vista disso, podemos dimensionar a importância da mobilização social e da concretização dos conselhos de saúde com vistas a materialização do controle social nas políticas públicas de saúde.

Portanto, a reflexão sobre valores de uso coletivo, o papel do Estado e a relação Estado/ Sociedade são pressupostos para uma sociedade democrática. A agenda de lutas e mobilizações pelo direito à saúde torna-se uma amostra da formação de atores sociais, concomitante a construção e ampliação da cidadania. Pois, a construção do SUS, tal como o vemos hoje, se deu principalmente 
pela mobilização dos movimentos sociais. No entanto, é de fundamental importância compreender que a participação social não é um processo dado, e sim em permanente construção, e a depender das conjunturas sociais na qual as pessoas estão inseridas.

\section{CONCLUSÃO}

Salienta-se que o fomento para a concretização da participação social para além das instâncias institucionais é fulcral para a consolidação do SUS, para a construção de autonomia dos usuários dos serviços de saúde e para a consolidação da cidadania. Por fim, indica-se que para além dos usuários dos serviços de saúde, a participação social também é uma ferramenta imprescindível para os trabalhadores da saúde e para todo o SUS.

\section{REFERÊNCIAS}

COELHO, J. S. Construindo a participação social no SUS: um constante repensar em busca de equidade e transformação. Saúde e Sociedade, v. 21, p. 138-151, 2012.

GIL, A. C. Métodos e técnicas de pesquisa social. São Paulo: Atlas, 1999.

MINAYO, M. C. S. O Desafio do Conhecimento: Pesquisa qualitativa em saúde. $9^{a}$ edição revista e aprimorada. São Paulo: Hucitec; 2006. 406 p.

StOTZ, E. N.; LiMA, C. M. P.; SEVAlHO, G.; FlOORENTINO, M.; DOMINGUEZ, M. T. Movimentos Sociais e Saúde. 2013. Fundação Oswaldo Cruz. Caderno N ${ }^{\circ} 4$ de Monitoramento Epidemiológico e Ambiental. Outubro de 2013. 


\title{
ASPECTOS EPIDEMIOLÓGICOS DA FEBRE MACULOSA NO BRASIL NOS \\ ÚLTIMOS CINCO ANOS DE NOTIFICAÇÃO
}

\author{
Ana Paula da Conceição Fernandes de Amorim¹; Juliana Ferreira de Amorim² \\ 1. Médica Veterinária. Universidade Federal do Rio de Janeiro (UFRJ), Rio de Janeiro, RJ, Brasil. \\ 2. Graduanda. Universidade Federal do Estado do Rio de Janeiro (UNIRIO). Rio de Janeiro - RJ, \\ Brasil.
}

DOI: $10.47094 /$ ICONRES.2021/19

\begin{abstract}
RESUMO
A febre maculosa é uma zoonose emergente de notificação compulsória e importância em saúde pública, causada pela bactéria $R$. rickettsii e transmitida por carrapatos. A bactéria já foi isolada em cavalos, gambás, capivaras, muares, cães domésticos e humanos. Há relatos de casos em áreas rurais e urbanas. Esse estudo transversal apresenta dados epidemiológicos da doença, notificados no Brasil nos últimos cinco anos, de 2013 a 2017, em banco de dados do DATASUS/Ministério da Saúde, mostrando a dispersão da doença e a população afetada. O estudo mostrou 833 casos notificados nesse período cujos homens foram os que mais sofreram o agravo. A maioria dos afetados em idade produtiva evoluiu para a cura embora o número de óbitos também tenha sido expressivo. As notificações mostraram que a maioria dos casos ocorreu nas áreas urbanas da região sudeste e o estado de São Paulo foi o que apresentou maior numero de casos.
\end{abstract}

PALAVRAS-CHAVES: Doença do carrapato; Riquetsiose; Zoonose emergente.

ÁREA TEMÁTICA: Saúde Coletiva

\section{INTRODUÇÃO}

A febre maculosa (FM) é uma zoonose, de caráter endêmico emergente transmitida pela bactéria $R$. rickettsii, principalmente, com a participação de carrapatos vetores (Ueno et.al. 2020; Nunes et. al, 2020; Campos et.al. 2020; Martins, et.al., 2016). Foi identificada em 1896, no Vale do Rio Snake, Idaho, EUA, e atualmente é notificada em quase todos os estados norteamericanos. A partir de 1930, a doença foi identificada também em outros países como Canadá, México, Costa Rica, Panamá, Colômbia, Brasil e Argentina. No Brasil, a FM foi identificada em 1929 
(Martins, et.al., 2016). Hoje já se aceita a possibilidade de a FM ser transmitida por outros gêneros de Riquétsias infecciosas, conforme determinado a partir de diferenças de títulos de anticorpos contra diferentes antígenos de Rickettsia, como a R. parkeri ou R. bellii . (Uono, et.al.2020)

Os carrapatos, vetores envolvidos na transmissão da FM são ectoparasitas de distribuição mundial que afetam vertebrados e podem transmitir patógenos a diversos animais e humanos (Gonzalesz et.al.2017). Estudos demonstraram que embora o carrapato do gênero Amblyomma, como o A. aureolatum, presente em animais silvestres, e A. cajennense, carrapato estrela ou do cavalo, reconhecido como principal vetor (Martins, et.al., 2016). Estudo recentes correlacionaram outros gêneros envolvidos na transmissão da Rickettsia sp mostram que os carrapatos vetores mais encontrados em estudos a campo foram o Amblyomma sculptum, cujos os principais hospedeiros são os eqüinos, gambás, capivaras e antas (Ueno et.al. 2020); o Amblyomm dubitatum, cujos hospedeiros mais comuns são as capivaras (Nunes et.al. 2020) e Rhipicephalus sanguineus, muito frequente em cães domésticos, que tem um importante papel como sentinelas da doença (Campos, et, al, 2020).

É uma doença de notificação compulsória de grande importância em saúde pública, tanto no âmbito da medicina humana quanto na medicina veterinária e atualmente há relatos de casos em áreas rurais e urbanas (Ueno, et.al. 2020; Nunes, et.al, 2020; Campos, et.al. 2020).

O objetivo deste estudo é apresentar dados no Ministério da Saúde sobre a febre maculosa notificados entre os anos de 2013 a 2017, dados esses que foram atualizados em 2019.

\section{METODOLOGIA}

Esse trabalho é um estudo transversal, quantitativo e retrospectivo, em banco de dados do Ministério da Saúde/SVS - Sistema de Informação de Agravos de Notificação - SinanNet (DATASUSSINAN), sobre febre maculosa notificadas no Brasil no período de cinco anos entre 2013 e 2017. Os dados foram atualizados em 29/01/2019, totalizando 833 casos notificados nesse período. Os indicadores usados foram: unidades da federação, através da notificação compulsória do agravo; gênero; idade; evolução do caso e região de ocorrência. Para análise estatística descritiva simples foi utilizado o software Excel 2007.

A revisão bibliográfica levou em conta as palavras chave e o tema principal sobre febre maculosa, pesquisadas nas plataformas PubMed, Scielo e BVS. Na escolha dos artigos optou-se por artigos publicados nos últimos cinco anos e que tivessem como foco a multiplicidade de animais sujeitos à infecção e também o homem. 


\section{RESULTADOS E DISCUSSÕES}

O Brasil notificou entre os anos de 2013 a 2017 (dados atualizados em 17/01/2018), 833 casos de febre maculosa. O Sudeste foi a região que apresentou maior ocorrência com $72,15 \%$ dos casos sendo que apenas o estado de São Paulo teve 65,06\% do total da região Sudeste. As outras regiões tiveram respectivamente e em ordem de numérica de ocorrências: Sul (22,93\%), Nordeste (2,40\%); Centro-Oeste (1,92\%) e Norte ( $0,60 \%)$. Além de São Paulo os estados que mais notificaram a doença nesse período foram: Goiás (50,00\%), Santa Catarina $(83,77 \%)$, Ceará $(90,00 \%)$ e no Norte do país apenas o estado de Rondônia notificou (100\%) dos casos. Os anos de maior notificação foram 2015 e 2017 ambos igualmente com 21,10\% dos casos. O de menor ocorrência notificada foi 2013 com $15,58 \%$. A população afetada foi principalmente do sexo masculino com $72,51 \%$ das notificações e a idade mais afetada foi entre 20 e 59 anos perfazendo $63,03 \%$ do total dos casos. O que representa um importante impacto na faixa etária produtiva.

Quanto à evolução 38\% dos casos evoluiu com óbito do paciente e esse dado foi acompanhado pela região Sudeste e pelo estado de São Paulo que, além de ter o maior numero de notificações, teve também o maior numero de óbitos.

Já em relação à região de ocorrência registrada nas notificações, 72,75\% dos agravos ocorreram na área urbana. Todas as regiões brasileiras apresentaram a área urbana como a principal área de localização dos casos notificados.

\section{CONCLUSÃO}

A febre maculosa é uma doença emergente de importância em saúde pública e potencialmente patogênica para os seres humanos e vem ocorrendo mais frequentemente em regiões urbanas. Essa situação pode ser atribuída ao fato de que os patógenos de Rickettsia circulam em cães, que convivem muito bem com humanos e que inclusive podem servir como sentinelas de rickettsioses no ambiente urbano, e de diversos animais inclusive silvestres, antropizados, nas zonas urbanas. Outro fator é a presença constante de carrapatos em ambientes fechados, domiciliares ou peridomiciliares. Essa condição pode constituir um novo perfil de Riquetsioses distinto do rural, onde tradicionalmente ocorre a FM.

Evitar picadas de carrapatos é a única forma de prevenção disponível da doença. Uso de roupas de proteção e repelentes contra carrapatos, inspeção do corpo uma ou duas vezes ao dia e remoção de carrapatos antes de inocularem Rickettsia, reduzem o risco de infecção em ambientes rurais. Em ambientes urbanos, deve-se evitar aproximação e manipulação de animais silvestres, e controle rigoroso de ectoparasitos em cães e gatos domésticos, com visitas frequentes ao veterinário. Controle populacional de espécies como capivaras, por exemplo, em áreas com risco de transmissão de FM, é fundamental e pode diminuir a necessidade de eutanásia desses animais, principalmente nas situações em que eles possam freqüentar áreas urbanas ou periurbanas. 


\section{REFERÊNCIAS}

CAMPOS, S. D. E.; CUNHA, N. C. da; MACHADO, C. de S. C.; TELLERIA, E. Z.; CORDEIRO, M. D.; FONSECA, A. H. da; TOMA, H. K.; SANTOS, J. P. C. dos; ALMOSNY, N. R. P. Rickettsial pathogens circulating in urban districts of Rio de Janeiro, without report of human Brazilian Spotted Fever. Revista Brasileira de Parasitologia Veterinária, 29(4): e014220, 2020. 1-10P. Disponível em: https://www.scielo.br/pdf/rbpv/v29n4/1984-2961-rbpv-29-4-e014220.pdf. Acesso em 23/02/2021.

GONZALEZ, I. H. L; LABRUNA, M. B; CHAGAS, C. R. F.; SALGADO, P. A. B.; MONTICELLI, C.; MORAIS, L. H.; MORAES, A. A. de; ANTUNES, T. C.; RAMOS, P. L.; MARTINS, T. F. Ticks infesting captive and free-roaming wild animal species at the São Paulo Zoo, São Paulo, Brazil. Braz. J. Vet. Parasitol. Jaboticabal, v. 26, n. 4, p. 496-499, oct.-dec. 2017. Disponível em:https://www. scielo.br/pdf/rbpv/v26n4/1984-2961-rbpv-S1984-29612017036.pdf. Acesso em 24/02/2021.

NUNES, F.B. P.; NUNES, A. Z.; NUNES, M. P.; LABRUNA, M.B.; PIZZUTTO, C. S. Reproductive control of capybaras through sterilization in areas at risk of transmission of brazilian spotted fever. Ciência Rural. Santa Maria, v.50:9, e20200053, 2020. 1-9p. Disponível em: https:/www.scielo.br/ pdf/cr/v50n9/1678-4596-cr-50-09-e20200053.pdf. Acesso em 23/02/2021.

UENO, T. E. H.; CUTOlO, A. A.; MARTINS, T. F. ; MORAES-FILHO, J.; AZEVEDO, S. S. de; LABRUNA, M. B. Rickettsial infection in equids, opossums and ticks in the municipality of Monte Mor, state of São Paulo, Brazil. Revista Brasileira de Parasitologia Veterinária, vol.29, n.4, e015420. Epub Nov 23, 2020. 1-9p. Disponível em: https://www.scielo.br/pdf/rbpv/v29n4/19842961-rbpv-29-4-e015420.pdf. Acesso em 24/02/2021.

MARTINS, M.E.P.; BRITO, W.M.E. D.; LABRUNA, M.B; FILHO, J. M.; SOUSA-MARTINS, K. C.; RAFAEL PORTO VIEIRA, R. P. Epidemiological survey of supposed spottedfever outbreak. Ciência Animal Brasileira v.17, n.3, p. 459-471 jul./set. 2016. Disponível em: https://www.scielo. br/pdf/rbpv/v26n4/1984-2961-rbpv-S1984-29612017036.pdf. Acesso em 24/02/2021. 


\title{
SAÚDE DA POPULAÇÃO MASCULINA E SUAS PRINCIPAIS DEMANDAS NA UNIDADE BÁSICA: REVISÃO INTEGRATIVA
}

\section{Larissa Artimos Ribeiro; Pâmela Ramos Januário}

1 Acadêmica de Enfermagem da Universidade Federal do Estado do Rio de Janeiro (UNIRIO), Rio de Janeiro, RJ.

2. Acadêmica de Enfermagem da Universidade Federal do Estado do Rio de Janeiro (UNIRIO), Rio de Janeiro, RJ.

lari.artimos11@gmail.com

\begin{abstract}
RESUMO
Introdução: As demandas enfrentadas pela população masculina sofreram um grande histórico de negligência na saúde. Dito isso, fez-se necessário a criação de políticas sobre o território nacional para suprir tais carências. Objetivo: Assim, este estudo objetiva compreender o panorama das necessidades de saúde dos homens na atenção primária. Metodologia: A fim de saciar esse questionamento, foram utilizados os descritores "saúde do homem" e "atenção primária" nas bases de dados SciELO e LILACS, cujos resultados foram selecionados e analisados conforme frequência para a formação de uma revisão integrativa. Fundamentação teórica: Percebeu-se então a constante menção da diabetes e hipertensão, ambas demandas descritas como objetivos da Política Nacional De Atenção Integral À Saúde Do Homem (PNAISH), também foram encontradas resistências na criação de vínculos com assistência e nas unidades de saúde. Considerações finais: Portanto, embora esta política exista há mais de uma década, ainda se mantém longe do completo acesso e implementação.
\end{abstract}

PALAVRAS-CHAVES: Saúde do homem; Atenção Primária à Saúde; Acesso aos Serviços de Saúde.

ÁREA TEMÁTICA: Saúde coletiva. 


\section{INTRODUÇÃO}

As temáticas envolvendo saúde do homem estão gradativamente sendo implementadas nas Unidades Básicas de Saúde (UBS) com a criação da Política Nacional de Atenção Integral à Saúde do Homem (PNAISH) que visa atender às demandas masculinas e seus contextos socioculturais e econômicos. Implementada em 2009, essa política se embasa na necessidade de incluir o público masculino nos serviços de saúde através de medidas de prevenção de doenças e promoção à saúde, pois apesar de enfrentarem maiores taxas de mortalidade e diminuída expectativa de vida em comparação a mulheres, ainda atualmente podemos encontrar ampla resistência na procura por atendimentos em saúde (Storino, 2013).

Compreende-se que tais desafios estão intimamente relacionados ao fator cultural experimentado por estes brasileiros; ainda marcados por padrões de masculinidade associados à força, à invulnerabilidade e ao papel de provisão para suas famílias, ótica esta que, por consequência, aborda a saúde como um ponto de fraqueza. (Siqueira, 2014). Assim, com a finalidade de estar alinhado aos princípios do Sistema Único de Saúde (SUS), prover um cuidado integral diz respeito a buscar, em meio a produção de cuidados, um espaço que acomoda também o público masculino, de forma que ao se encontrar representado individual e coletivamente nos serviços ofertados, suas necessidades de saúde possam ser plenamente contempladas (Storino, 2013). Foi escolhido, portanto, o nível primário de atenção à saúde como "habitat" para esta política de inclusão pelo seu potencial de organização da rede de atenção em saúde (RAS), que por ser reconhecida como uma das portas de entrada do SUS, carrega como característica intrínseca a distribuição do fluxo de atendimento por todo o sistema de saúde conforme as demandas são identificadas em cada usuário.

A respeito da atenção primária em saúde (APS), podemos dizer também sobre o seu compromisso nas ações de promoção e proteção à saúde e prevenção de doenças e agravos, sendo assim um eixo indispensável na garantia da qualidade de vida e na melhora na sobrevida da população.

Dessa forma, se faz necessário compreender em primeiro lugar quais são de fato as demandas de saúde experimentadas pela população masculina na última década, a fim de que seja possível contemplar esse grupo de maneira mais intencional nas ações da atenção primária. Assim, o estudo visa identificar quais as principais demandas e necessidades da população masculina nas unidades básicas de saúde.

\section{METODOLOGIA}

Trata-se de uma revisão integrativa da literatura, que visa responder à questão: "Qual o panorama das condições de saúde da população masculina nas Unidades Básicas?”. Na busca, foram utilizadas as bases de dados SciELO e LILACS e as palavras-chaves "Saúde do homem" AND "Atenção Primária".

Dentre os critérios de inclusão estão artigos em português, correspondentes aos anos de 2010 
a 2020, que apresentassem no texto as palavras-chaves utilizadas na busca e indexados nas bases de dados usadas para pesquisa.

Os critérios de exclusão foram: teses e dissertações, artigos que não estivessem disponíveis em texto completo ou em português, artigos duplicados ou em anos anteriores ao usado para pesquisa e aqueles que não respondessem à pergunta norteadora. Assim, foram identificados 67 artigos científicos no SciELO e 96 no LILACS e destes 34 foram selecionados para integrar à revisão.

Com a finalidade de organizar e contabilizar os dados foi criada uma planilha no Excel contendo o título do artigo, ano de publicação, demandas e obstáculos apontados, de forma a analisar estatisticamente as respostas encontradas.

\section{FUNDAMENTAÇÃO TEÓRICA OU RESULTADOS E DISCUSSÕES}

O estudo foi dividido em dois eixos: 1) Principais demandas de saúde que levam os homens a procurar a UBS e; 2) Obstáculos da população masculina referentes ao atendimento.

Em relação às principais demandas de saúde, Jesus et al. (2014) constatou que os homens procuraram a Atenção Primária, principalmente, nos casos de problemas agudos ou para assistência de doenças crônicas já instaladas. Nessa perspectiva, verificou-se maior demanda dos homens para os casos de hipertensão e diabetes. Dos 34 estudos analisados, cerca de 67,6\% citaram a hipertensão arterial e aproximadamente $58,8 \%$ mencionaram a diabetes como doenças que levam a população masculina a buscar os serviços.

Outras demandas que aparecem com frequência na literatura, foram as questões referentes à saúde sexual, doenças cardiovasculares, sobrepeso e câncer de próstata. Além disso, foi possível perceber menor procura por questões relacionadas à promoção, prevenção e serviços odontológicos. Dos artigos analisados, apenas 2 citaram a imunização como serviços buscados pelos homens e outros 2 mencionaram as questões odontológicas.

No que se refere aos obstáculos da população masculina, Albuquerque, et al. (2014) e Xavier, et al. (2015) verificaram obstáculos referentes aos tamanhos das filas, aos padrões de masculinidade e aos horários de funcionamento da unidade, visto que, a maioria dos homens estão no trabalho nesse período.

$\mathrm{Na}$ análise dos 34 artigos, observa-se como principais problemas referentes ao atendimento a falta de ações voltadas para a população masculina, a falta de conhecimento sobre a PNAISH, a ausência de capacitação dos profissionais, a pouca aproximação dos homens com a unidade, a incompatibilidade de horários, os estereótipos de gênero, o medo e a vergonha de procurar os serviços.

Dos artigos analisados aproximadamente $38,2 \%$ demonstram como obstáculo a falta de tempo e/ou problemas de conciliar o trabalho com o horário de funcionamento das unidades. Em relação aos estereótipos de masculinidade, cerca de $41,1 \%$ dos estudos analisados consideraram este 
fato como um grande obstáculo para a busca do homem pelos serviços de saúde. Além disso, alguns autores, a exemplo de Daher, et al. (2017) e Siqueira, et al (2014), identificaram que os homens tendem a procurar mais por serviços de urgência e emergência ao invés da Atenção Primária. Albuquerque, et al. (2014) ainda identificou que a resistência de procurar os serviços de saúde são maiores e acontecem com mais frequência nas camadas populares mais baixas.

Nesse contexto, percebe-se a necessidade de estratégias voltadas para a saúde do homem, visando acolher, criar vínculos e diminuir a visão curativista que cerca esta população. Além disso, é essencial a capacitação dos profissionais, o aumento do quantitativo, a ampliação do horário de atendimento e a desconstrução desde a infância das questões relacionadas à masculinidade e fragilidade.

Ainda segundo Assis, et al. (2018) há a necessidade de investir na realização de pesquisas acerca da temática de saúde do homem e que as autoridades municipais realizem estudos visando entender a realidade local desta população, com intuito de investir em ações estratégicas e eficientes no atendimento desta população.

\section{CONSIDERAÇÕES FINAIS}

Assim, entende-se que embora as queixas principais apontadas nas Unidades básicas de Saúde nos últimos dez anos ainda se mantenham de acordo com as referenciadas inicialmente na PNAISH, persistem diversos empecilhos na sua implementação referente a falta de identificação da população com as atividades desenvolvidas dentro das Unidades.

Compreendemos então que a fim de entregar um serviço de fato integral se faz necessário investimentos em práticas voltadas para o envolvimento da população masculina. Dessa forma, reforçando os pontos de interesse masculino como a saúde no trabalho e afirmando a mentalidade de não culpabilização ou vitimização pelas suas condições de saúde (BATISTA, 2019), em associação com atividades de estímulo ao acompanhamento e não apenas à medicalização, podemos alcançar melhores resultados na inclusão masculina na saúde.

\section{REFERÊNCIAS}

ALBUQUERQUE, Grayce Alencar et al. O homem na atenção básica: percepções de enfermeiros sobre as implicações do gênero na saúde. Esc. Anna Nery, Rio de Janeiro, v. 18, n. 4. Dec. 2014.

ASSIS, Natália Oliveira de et al. Atuação dos enfermeiros frente à Política Nacional de Atenção Integral à Saúde do Homem: um estudo exploratório. Arq. Cienc. Saúde UNIPAR, Umuarama, v. 22, n. 3, p. 151-156. Set./dez. 2018.

BATISTA, Bruno Dias et al. Discursos de homens sobre o acesso à saúde na Atenção Básica. Rev 
Baiana Enferm. v. 33. 2019

DAHER, Donizete Vago et al. A construção do vínculo entre o homem e o serviço de atenção básica de saúde. Rev. Cubana de Enfermería, v. 33, n.1. 2017

JESUS, Maria Cristina Pinto de et al. Marcadores de saúde do homem em um município de pequeno porte. Esc. Anna Nery, Rio de Janeiro, v. 18, n. 4, p. 650-655. Dec. 2014.

SIQUEIRA, Bruna Paula de Jesus et al. Homens e cuidado à saúde nas representações sociais de profissionais de saúde. Esc. Anna Nery, Rio de Janeiro, v. 18, n. 4, p. 690-696, Dec. 2014.

STORINO, Luisa Pereira; SOUZA, Kleyde Ventura de; SILVA, Kênia Lara. Necessidades de saúde de homens na atenção básica: acolhimento e vínculo como potencializadores da integralidade. Esc. Anna Nery, Rio de Janeiro, v. 17, n. 4, p. 638-645, Dec. 2013

XAVIER, Sheila Quandt et. al. Grupos de educação em saúde: aproximação da população masculina à unidade básica de saúde. Rev. de Pesquisa Cuidado é Fundamental Online, Rio de Janeiro, v. 7, n. 2, p. 2372-2382. Jun. 2015. 


\title{
ACIDENTES PROVENIENTES DO CONTATO HUMANO COM ANIMAIS MARINHOS: UMA REVISAO DE LITERATURA
}

\section{Moana Ferreira dos Santos ${ }^{1}$; Ana Paula da Conceição Fernandes de Amorim²; Ângelo Alves de Moura $^{3}$; Rafael Marques de Mesquita ${ }^{4}$}

\author{
${ }_{1}$ Bióloga. Universidade Federal do Rio de Janeiro (UFRJ). Rio de Janeiro, RJ. \\ ${ }_{2}$ Médica Veterinária. Universidade Federal do Rio de Janeiro (UFRJ). Rio de Janeiro, RJ. \\ 3 Médico Residente em Clínica Médica. Hospital da Polícia Militar de Minas Gerais (HPM). Minas \\ Gerais, MG. \\ ${ }_{4}$ Médico. Exército Brasileiro (EB). Rio de Janeiro, RJ.
}

DOI: $10.47094 /$ ICONRES.2021/17

\begin{abstract}
RESUMO
A utilização humana dos ambientes marinhos favorece situações de exposição aos riscos de acidentes provocados via contato com animais marinhos. Estes acidentes geralmente ocorrem de forma acidental, e por via ocupacional, ou durante atividades de lazer desenvolvidas nestes ecossistemas. Os acidentes de importância médica podem provocar morbidez em humanos, por meio de envenenamentos e traumas. É de extrema importância que estudos sobre estes acidentes e suas ocorrências sejam desenvolvidos, visto a modesta disponibilidade bibliográfica encontrada sobre esse tema. Diante dessa perspectiva o principal objetivo deste artigo é apresentar informações sobre o cenário recente dos acidentes oriundos do contato entre humanos e animais marinhos que apresentem relevância médica.
\end{abstract}

PALAVRAS-CHAVES: Toxinas marinhas; Animais marinhos venenosos e traumatizantes; Risco à Saúde Humana.

ÁREA TEMÁTICA: Saúde Coletiva 


\section{INTRODUÇÃO}

Os ecossistemas marinhos são atraentes à presença humana para a realização de atividades de lazer, pesca de subsistência, dentre outros diversos usos. Esta proximidade torna esses ambientes propícios a diferentes situações de exposição aos riscos de acidentes envolvendo contato humano, por via acidental ou ocupacional, com animais marinhos de relevância médica (Haddad et al., 2018; Santos et al., 2021).

Embora, os acidentes causados por animais marinhos venenosos e traumatizantes possam resultar em casos de morbidez importante em humanos, estes são minimamente investigados no Brasil (Holanda et al., 2019; Santos et al., 2021).

Os acidentes de graves consequências são passíveis de terapias geralmente sem embasamento cientifico que muitas vezes são aplicadas fora e dentro de ambientes hospitalares (Santos et al., 2017).

Tendo em vista a importância dos agravos à saúde humana oriundos destes acidentes e a pouca disponibilidade bibliográfica sobre o tema, se faz presente a necessidade de revisões como esta.

Por esta razão, o principal objetivo deste artigo é apresentar informações sobre o cenário recente dos acidentes oriundos do contato entre humanos e animais marinhos.

\section{METODOLOGIA}

Utilizou-se uma pesquisa bibliográfica para realizar este estudo transversal retrospectivo. Foram analisados artigos e trabalhos publicados nos últimos seis anos (2015 a 2021) que referem acidentes ocorridos no litoral brasileiro, com ênfase no Estado do Rio de Janeiro, RJ. Foram utilizadas bases de dados como o Portal de periódicos da Capes, PubMed, MEDLINE, SciELO, livros e artigos completos publicados em eventos acadêmicos. Os descritores utilizados foram: animais marinhos peçonhentos, toxinas marinhas, riscos à saúde humana. Os idiomas utilizados como filtros de busca foram o português e inglês. Como resultado final encontrou-se dez artigos e um livro a serem utilizados nesta revisão

\section{FUNDAMENTAÇÃO TEÓRICA}

Os acidentes resultantes do contato com animais marinhos podem ocasionar traumas e/ou estar associados a toxinas (Brusca et al., 2016; Santos et al., 2017; Santos et al., 2021). As peçonhas e os venenos são constituídos por inúmeras toxinas e podem ser encontradas em distintos grupos de animais marinhos, tais como, crustáceos, poríferos (esponjas), equinodermos (ouriços-do-mar), cnidários (águas-vivas e caravelas), moluscos e peixes ósseos (Brusca et al., 2016; Santos et al., 2021).

O aumento da presença humana nos ambientes marinhos, associado ao desequilíbrio 
ecológico nestes ecossistemas e a outros fatores resulta no aumento da exposição humana aos riscos de acidentes (Haddad et al., 2018; Santos et al., 2021).

Um estudo de 2017 evidenciou um total de ocorrências significativo no que diz respeito a acidentes provocados por animais marinhos em pescadores artesanais em atividade (Santos et al., 2021). Segundo Santos (2017), os acidentes mais frequentes com pescadores e banhistas foram os por meio de perfuração. Nestes casos envolvendo ferrões, os mais citados são os ocorridos com peixe bagre e raia ou arraia. Nestas ocorrências relataram-se sintomas como dor local persistente, mal-estar, febre e vômitos (Santos et al., 2017; Santos et al., 2021).

O estudo dos acidentes causados por animais marinhos no litoral brasileiro vem sendo negligenciado no que diz respeito ao conhecimento, controle e prevenção das doenças que envolvem esses animais. Existe uma escassez de dados epidemiológicas das ocorrências desses acidentes, o que resulta em informações ínfimas com restrições referentes à coleção de dados secundários (Reckziegel et al., 2015; Santos et al., 2021).

Sobre o ictismo (acidentes causados por peixes), Holanda (2019) considera que os acidentes provocados por arraia representam um problema de saúde negligenciado no Brasil, salientado a necessidade imediata de tratamento após a ocorrência da ferroada em seres humanos. E isto se deve ao não conhecimento da profundidade das lesões provocadas pelo ferrão, bem como as proteínas venenosas que ele emite, podendo gerar infecções secundárias.

Os bagres marinhos (família Ariidae) são os peixes ósseos brasileiros que vêm provocando o maior número de acidentes no Sudeste do Brasil (Santos et al., 2017; Santos et al., 2021).

Em relação aos acidentes ocasionados por cnidários relata-se que os mais importantes são os envolvendo as caravelas (Physalia physalis), apresentado o maior número de acidentes com gravidade em algumas regiões do litoral brasileiro (Bastos et al., 2017; Santos et al., 2018; Santos et al., 2020). Os acidentes de maior gravidade são raros, mas todas as águas-vivas podem causar alergias, o que para alguns indivíduos pode ser muito grave. $\mathrm{O}$ acidentado que se envenenar com gravidade ou desenvolver essas reações alérgicas deve buscar atendimento hospitalar imediato (Haddad et al., 2017).

\section{CONSIDERAÇÕES FINAIS}

Percebe-se que a epidemiologia desses acidentes é escassa e as informações disponíveis na literatura são mínimas e limitadas. Há uma carência de dados que especifiquem, principalmente, os animais causadores dos acidentes, e as medidas terapêuticas e preventivas adequadas.

Há falta de registros oficiais das ocorrências de acidentes causados por animais marinhos no Estado do Rio de Janeiro e desta forma não se mensura seu legítimo impacto a saúde humana.

Recomendam-se estudos que abordem essa temática, objetivando desenvolver metodologias 
específicas para a notificação, a prevenção e o tratamento desses agravos.

\section{REFERÊNCIAS}

BASTOS, D.M.R.F.; HADDAD JR, V.; NUNES, J. L. S.. Human envenomations caused by Portuguese man-of-war (Physalia physalis) in urban beaches of São Luis City, Maranhão State, Northeast Coast of Brazil. Revista da Sociedade Brasileira de Medicina Tropical, Uberaba, v. 50, n. 1, p. 130-134, Feb. 2017.

BRUSCA, RC, Moore W, Shuster SM. Invertebrates. 3rd edition Oxford University Press; 3rd edition, 2016.

HADDAD JR, V.; MORANDINI, A. C.; RODRIGUES, L. E.. Jellyfish Blooms Causing Mass Envenomations in Aquatic Marathonists: Report of Cases in S and SE Brazil (SW Atlantic Ocean). Wilderness \& Environmental Medicine. New York: Elsevier Science Inc, v. 29, n. 1, p. 142145, 2018. Disponívelem http://hdl.handle.net/11449/160167 acesso em 10 set. 2020.

HADDAD JR, V.; SZPILMAN, D.; SZPILMAN, M.. Lesões por águas-vivas - Recomendação Sobrasa. Publicado em www.sobrasa.org, Fevereiro 2017. Disponível em <http://www.sobrasa.org/ new_sobrasa/arquivos/recomendacoes/LESOES\%20POR\%20AGUAS-VIVAS_Recomendacao_ SOBRASA.pdf>. acesso em 21 out. 2020.

HOLANDA, M. N. et al . Accident and vascular injury with stingray in the Alto Juruá, Acre, Brazil: a case report. Journal of Human Growth and Development, São Paulo , v. 29, n. 3, p. 427-432, dez. 2019. RECKZIEGEL, G. C. et al. Injuries caused by aquatic animals in Brazil: an analysis of the data present in the information system for notifiable diseases. Revista da Sociedade Brasileira de Medicina Tropical, Uberaba, v. 48, n. 4, p. 460-467,Aug. 2015.

SANTOS, Moana Ferreira dos; AMORIM, Ana Paula da Conceição Fernandes de; MOURA, Ângelo Alves de; MESQUITA, Rafael Marques de. Acidentes de Interesse Médico Provenientes de Animais Marinhos: Ocorrências em Itaipu, Niterói, RJ, Brasil. SAÚDE: os desafios da pesquisa na atualidade, vol. 3, cap 43. pp 915-937. ISBN: 978-65-89069-15-7. IMEA, João Pessoa-PB, 2021.

SANTOS, Moana Ferreira dos; AMORIM, Ana Paula da Conceição Fernandes de; MOURA, Ângelo Alves de; MESQUITA, Rafael Marques de; IGREJA, Ricardo Pereira. Acidentes com Animais Marinhos Importância Médica e Socioambiental. PROFAEXt 2017. Rio de Janeiro: UFRJ, Centro de Informação Toxicológica - CIT HUCFF; 2017.

SANTOS, Moana Ferreira dos; NOUER, Simone Aranha; IGREJA, Ricardo Pereira. Águas-vivas: Acidentes de Importância Médica. In: VI InfectoRio 2018; 2018; Rio de Janeiro.

SANTOS, Moana Ferreira dos; NOUÉR, Simone Aranha; IGREJA, Ricardo Pereira. Acidentes Provenientes do Contato Humano com Águas-Vivas e Caravelas: Uma Revisão de Literatura. In: 
III Encontro Nacional de Pós-Graduação em Doenças Tropicais e Infecciosas, Faculdade de Medicina - UNESP - Botucatu, 2020. Disponível em http://www.inscricoes.fmb.unesp.br/anais_completo.asp 


\title{
SAÚDE MENTAL NO BRASIL DIANTE DO CENÁRIO DA PANDEMIA DE COVID-19: DESAFIOS PARA A REDE DE ATENÇÃO PSICOSSOCIAL.
}

\begin{abstract}
José Wilson Felix da Silva ${ }^{1}$; Inácia Pereira Severo²; Suiane Nunes Pereira ${ }^{3}$
1 Psicólogo, Residente em Saúde Coletiva e Gestão de Redes de Saúde. Escola de Saúde Pública de Pernambuco (ESPPE), Ouricuri, Pernambuco.

2 Assistente Social, Residente em Saúde Coletiva e Gestão de Redes de Saúde. Escola de Saúde Pública de Pernambuco (ESPPE), Ouricuri, Pernambuco.

3 Nutricionista, Residente em Saúde Coletiva e Gestão de Redes de Saúde. Escola de Saúde Pública de Pernambuco (ESPPE), Ouricuri, Pernambuco.

wilson_psi@live.com

\section{RESUMO}

Pesquisas iniciais sobre a Covid-19 no Brasil vêm apontando para um aumento no surgimento de sintomas psicológicos na população em geral nesse período de pandemia, o que pode resultar na procura pelos serviços em saúde mental no Brasil. A restrição de mobilidade forçou boa parte da população a ficar em casa, com isso relatos do surgimento de sintomas ansiosos e depressivos tem se tornado comum nesse período. Outro fator a ser observado nesse momento difícil de pandemia é referente à proteção física e psíquica dos profissionais de saúde que atuam diretamente na linha de frente, alguns estudos relacionam essa alta carga de trabalho ao surgimento de síndrome de Burnout e outros sintomas psicológicos. Em todos os casos, fica evidente a necessidade de novos estudos que mensurem o impacto da pandemia do Covid-19 na saúde mental dos Brasileiros e a iminente necessidade de ampliar os serviços em saúde mental.
\end{abstract}

PALAVRAS-CHAVES: Infecção por Coronavirus; Isolamento Social; Sintomas Psíquicos. ÁREA TEMÁTICA: Saúde Coletiva. 


\section{INTRODUÇÃO}

Com o advento da pandemia da Covid-19 que o mundo vem enfrentando, e as medidas sanitárias implantadas em diversos países para conter a disseminação do vírus, em muitos casos, famílias inteiras foram colocadas em isolamento domiciliar. Diante desse cenário, rapidamente começaram a surgir questionamentos de como seria o impacto dessa crise sanitária na saúde mental dos indivíduos. Passados mais de 1 ano após o início da pandemia, ainda se fazem necessárias pesquisas com grandes contingentes populacionais, incluindo crianças e adultos, para averiguar melhor como as pessoas estão se sentindo do ponto de vista da saúde mental. Os estudos iniciais realizados por alguns pesquisadores brasileiros, já estão demonstrando que sintomas psicológicos como depressão e ansiedade estão surgindo na população em geral. Medo, insegurança e desesperança também fazem parte dos sentimentos encontrados nas pesquisas iniciais sobre o tema. Profissionais de saúde tendo que conviver com longas rotinas de trabalho também tem desenvolvido alguns transtornos físicos e mentais, como a síndrome de burnout. Nesse sentido o objetivo desse trabalho é analisar os estudos iniciais para melhor compreender o potencial risco dessa pandemia na saúde mental das pessoas.

\section{METODOLOGIA}

Para esse estudo foi realizada uma pesquisa bibliográfica, de modo que se possa reunir e sintetizar estudos anteriores sobre o tema, com artigos brasileiros publicados na base de dados da Biblioteca Virtual em Saúde - BVS, o recorte temporal serão os anos de 2020 e 2021. A seleção da produção científica aconteceu estipulando-se os seguintes descritores: "Saúde Mental"; "Covid-19" e "Brasil". Foram encontrados na base de dados 49 artigos científicos, Posteriormente foram selecionados 4 artigos, sendo 3 artigos originais, fruto de pesquisas aprovadas em comitês de ética, e que contam com a participação de mais de 45 mil voluntários e um artigo de reflexão sobre a temática da saúde mental em tempos de pandemia. Também foi utilizada nesse trabalho a resolução produzida pelo Conselho Federal de Psicologia sobre o atendimento psicológico via plataformas virtuais. Para sustentação da proposta de estudo, a revisão literária ocorreu a partir da leitura dos artigos escolhidos, onde se buscou identificar aqueles que apontavam para a relevância da pesquisa.

\section{FUNDAMENTAÇÃO TEÓRICA}

Após os primeiros casos da nova síndrome respiratória provocada pelo Coronavirus SARSCoV-2, sua disseminação pelo mundo aconteceu de forma rápida, em função das relações pessoas globalizadas e devido ao fluxo intenso de pessoas viajando entre os continentes. Desde então medidas restritivas de fechamento de fronteiras foram surgindo em diversos países para tentar frear a rápida disseminação do vírus. Após essas medidas iniciais, ainda foram colocadas em prática novas medidas para restringir a circulação de pessoas, mas dessa vez em seus próprios países, estados e cidades. Foi desde então que a maioria da população se deu conta que estava enfrentando uma nova pandemia e passaram a considerar a gravidade da situação. 
Porém com as medidas de isolamento domiciliar colocadas em prática, a pressão psicológica provocada pela possibilidade de se infectar e a interrupção brusca do convívio social, acabou desencadeando em muitas pessoas outra classe de sintomas, dessa vez sintomas psicológicos, como medo, ansiedade e depressão ${ }^{1,2}$. Foi então que o tema da saúde mental em tempos de pandemia passou a ser mais levado em consideração pelas autoridades de saúde e pela população em geral. Outra parcela da população que foi muito afetada pela pandemia foram os profissionais de saúde, em especial, os que atuam na linha de frente do cuidado, pois alem da pressão psicológica, foi adicionada a esses profissionais uma sobrecarga de trabalho ocasionando em alguns desses profissionais uma síndrome de Burnout ${ }^{1}$. Esses eventos estressores podem ser desencadeantes de uma ampla gama de sintomas físicos e psicológicos, como insônia, agitação, medo exagerado da morte e de se infectar além de depressão e transtornos de ansiedade.

Em estudo conduzido por Saidel et $\mathrm{al}^{1}$, com 490 profissionais de enfermagem que atuam na linha de frente de combate a pandemia no estado do Rio Grande do Norte, foi detectado que além dos sintomas da síndrome de Burnout relacionados à sobrecarga de trabalho, foram identificados a presença de outros sintomas, como depressão e ansiedade. Essa predisposição ao sofrimento mental também está diretamente relacionada com a adoção das medidas de isolamento social, pois entre os profissionais de saúde entrevistados, os que mantiveram o hábito de conversar com amigos e familiares apresentaram menor prevalência de sintomas psicológicos. Também foi observado que quanto maior a renda dos entrevistados menor foi a incidência de depressão e ansiedade, os profissionais com renda superior a 5 salários mínimos apresentaram taxas menores de prevalência de sintomas.

Barros et $\mathrm{al}^{2}$ desenvolveram um amplo estudo, que contou com uma amostra de mais de 45 mil pessoas de todas as macrorregiões do Brasil, e revelou que durante a pandemia e devido ao distanciamento social, $40 \%$ dos entrevistados relataram sentimentos de tristeza ou depressão. Alem disso, em 52,6\% referiu sensação de ansiedade ou nervosismo. Na pesquisa também foram relatadas agravamentos nas dificuldades para dormir. Em todos os casos, os sintomas psicológicos apresentados anteriormente se agravaram nas pessoas com história prévia de depressão, ansiedade e dificuldade para dormir. Ainda de acordo com os autores, pesquisas semelhantes têm sido conduzidas em outros países, e os resultados corroboram a tese de que a pandemia de Covid-19 tem acarretado considerável impacto psicológico na população estudada.

No Rio Grande do Sul, pesquisadores conduziram um questionário sócio-demográfico com 799 pessoas referente ao distanciamento social e sintomas psicológicos no período da pandemia. Os resultados indicaram que fatores como exposição ao risco de contaminação, baixa renda per capta e exposição exagerada as notícias relacionadas a mortos e infectados pelo Covid-19 também foram identificados como fatores preditivos para o adoecimento mental. Na pesquisa também foram identificados que pessoas mais jovens podem apresentar ate $6 \%$ maiores chances de desenvolver algum transtorno mental relacionado a vivencia do período de pandemia ${ }^{3}$.

Nesse cenário de incertezas de ate quando vai durar a pandemia da Covid-19, ainda falta do Ministério da Saúde ações efetivas na área da saúde mental para dar suporte aos profissionais de saúde 
e a população geral que desde já começam a buscar por serviços em saúde mental. Algumas ações pioneiras têm sido conduzidas por órgãos de classes como o Conselho Federal de Enfermagem e da Fundação Osvaldo $\mathrm{Cruz}^{4}$, no sentido de dar suporte psicológico aos profissionais de saúde, envolvidos na linha de frente de combate a pandemia, e do Conselho Federal de Psicologia ${ }^{5}$ na regulamentação dos atendimentos psicológicos via plataformas digitais, mas ainda são ações insuficientes para atingir a grande maioria da população. A própria Organização das Nações Unidas destacou a importância do cuidado da saúde mental publicando resoluções a respeito, resta ao Brasil fortalecer a rede de Atenção Psicossocial para atender essa demanda que pode emergir de suas residências a qualquer momento.

\section{CONCLUSÃO}

Desde o início da pandemia do Covid-19 o Ministério da Saúde vem lançando informativos sociais para orientar a população sobre as medidas protetívas que podem evitar o contágio. Mas além dos aspectos físicos da contaminação do Covid-19, existem outras preocupações que os pesquisadores vêm chamando a atenção, entre eles está à necessidade de se levar em consideração o surgimento de sintomas psicológicos na população, desde profissionais de saúde que estão atuando na linha de frente de combate ao Coronavirus como na população em geral, que perdeu boa parte dos seus vínculos sociais. Outros pesquisadores alertam ainda que a renda familiar afetada pelas medidas restritivas de circulação de pessoas pode afetar significativamente para o adoecimento mental. Depressão, ansiedade, medo, e agitação psicomotora como dificuldades para dormir e manter o sono, foram amplamente citados na literatura ate o momento como os principais sintomas surgidos na população em geral.

São vários os estudos relacionando o surgimento de transtornos mentais e a vivencia nesse período de pandemia que estamos passando. Mas ainda é necessário que novos estudos sejam conduzidos de modo que possam mensurar o impacto psicológico da pandemia em crianças e outras populações específicas. Uma vez que essa parcela da população foi diretamente afetada, seja pela impossibilidade de realizar atividades laborais ou mesmo pelo isolamento domiciliar compulsório como no caso das crianças.

\section{REFERÊNCIAS}

SAIDEL, Maria Giovana Borges et al. Intervenções em saúde mental para profissionais de saúde frente a pandemia de Coronavírus. Revista Enfermagem UERJ,v. 28, p. e49923, Maio 2020. ISSN 0104-3552. Disponível em: <https://www.e-publicacoes.uerj.br/index.php/enfermagemuerj/article/ view/49923 /33859 > . Acesso em: 16 Mar. 2021. doi:https://doi.org/10.12957/reuerj.2020.49923.

BARROS, Marilisa Berti de Azevedo et al . Relato de tristeza/depressão, nervosismo/ansiedade e problemas de sono na população adulta brasileira durante a pandemia de COVID-19. Epidemiol.

Serv. Saúde, Brasília, v. 29, n. 4, 2020. Disponível em: <http://www.scielo.br/scielo.php?script=sci_ 
arttext\&pid $=\mathrm{S} 2237-96222020000400311 \& \operatorname{lng}=\mathrm{en} \& \mathrm{nrm}=\mathrm{iso}>$. Acesso em: 16 Mar. 2021. https:// doi.org/10.1590/s1679 -49742020000400018.

DUARTE, Michael de Quadros et al . COVID-19 e os impactos na saúde mental: uma amostra do Rio Grande do Sul, Brasil. Ciênc. saúde coletiva, Rio de Janeiro, v. 25, n. 9, p. 3401-3411, Set. 2020. Disponível em: $<$ http://www.scielo.br/scielo.php?script=sci_ arttext\&pid=S141381232020000903401\&lng =en\&nrm=iso $>$. Acesso em:16 Mar. 2021. https://doi. org/10.1590/1413-81232020259.16472020.

NUNES RIBEIRO, Caique Jordan et al. Intervenções de restrição de mobilidade social durante a pandemia de covid-19 e suas repercussões psicossociais no Brasil. Enfermagem em Foco, [S.1.], v. 11, n. 1.ESP, Ago. 2020. ISSN 2357-707X. Disponível em: <http://revista.cofen.gov.br/index.php/ enfermagem/art icle/view/3412/823 > . Acesso em: 16 Mar. 2021. doi:https://doi.org/10.21675/2357707X.2020.v11.n1.ESP.3412.

CONSELHO FEDERAL DE PSICOLOGIA. Resolução $\mathbf{n}^{0}$ 04, de 26 de março de 2020. Dispõe sobre regulamentação de serviços psicológicos prestados por meio de Tecnologia da Informação e da Comunicação durante a pandemia do COVID-19. Brasília: 2020. Disponível em: < $\underline{\text { https:// }}$ atosoficiais.com.br/cfp/resolucao-do-exercicio-profissional-n-4-2020-dispoe-sobre-regulamentacaode-servicos-psicologicos-prestados-por-meio-de-tecnologia-da-informacao-e-da-comunicacaodurante-a-pandemia-do-covid-19?origin=instituicao\&q=04/2020>. Acesso em: 16 Mar. 2021. 


\title{
RELAÇÃO DA ESPOROTRICOSE COM A SAÚDE PÚBLICA
}

\section{Isadora Conceição de Souza ${ }^{1}$; Delcivan Lima dos Santos ${ }^{2}$}

\author{
${ }^{1}$ Graduada em Medicina Veterinária, Universidade Federal do Recôncavo da Bahia (UFRB), Cruz \\ das Almas, BA.
}

${ }^{2}$ Mestre em Ciência Animal, Universidade Federal do Recôncavo da Bahia (UFRB), Cruz das Almas, BA.

\section{isa.souza7@hotmail.com}

\begin{abstract}
RESUMO
Os agentes da micose de implantação, conhecida como esporotricose, são membros do gênero Sporothrix. Foram descritas cinco espécies. Sporothrix brasiliensis, S. schenckii, Sporothrix globosa, Sporothrix mexicana e Sporothrix luriei. Já houve grandes epidemias causadas por Sporothrix brasiliensis na América do Sul, quase sempre transmitido exclusivamente por gatos. Na maioria das esporotricoses, a detecção histopatológica do agente etiológico é difícil devido a uma baixa carga de fungos. $\mathrm{O}$ agente é encontrado em abundância nos tecidos apenas ocasionalmente. Um dos principais meios diagnósticos da esporotricose é o histológico. Quando é diagnosticada com vários elementos fúngicos, a patologia apresenta um resultado incomum. Geralmente está relacionado à diminuição da imunidade ou distúrbios subjacentes, como infecção pelo vírus da imunodeficiência humana (HIV), diabetes mellitus, alcoolismo ou uso de medicação prolongada, como a utilização terapêutica de corticosteroide.
\end{abstract}

PALAVRAS CHAVE: Ambiente; fungo; zoonose ÁREA TEMÁTICA: Saúde Coletiva

\section{INTRODUÇÃO}

O gênero Sporothrix spp é um grupo de fungos termicamente dimórficos, de caráter zoonótico, capaz de existir em sua forma saprófita no meio ambiente sob temperaturas entre 25$30^{\circ} \mathrm{C}$, e na forma de levedura à $37^{\circ}$, em temperatura corporal. Sporothrix schenckii é a principal espécie associada à doença e o principal patógeno responsável pela esporotricose, e seus esporos são 
geralmente encontrados no solo úmido ou em decomposição, madeira e algumas variedades de rosas, e, portanto, às vezes é chamada de doença de jardineiro.

O fungo é geralmente inoculado através da pele e frequentemente (95\%) envolve tecidos cutâneos e subcutâneos, e linfáticos em pacientes imunocompetentes. Em humanos, a doença pode acontecer na forma cutânea localizada ou disseminada, cutâneo-linfática e extracutânea ou sistêmica.

O objetivo desse estudo é analisar as relações do agente etiológico com os seres humanos e os animais, no âmbito da Saúde Pública.

\section{FUNDAMENTAÇÃO TEÓRICA}

A esporotricose é uma micose cutânea causada por fungos do gênero Sporothrix spp, que afeta tanto animais quanto o homem, sendo o gato doméstico uma importante fonte de infecção para os humanos. A doença é de ocorrência mundial e pode acometer várias espécies, já sendo observados relatos em equinos, cães, felinos, bovinos, suínos, camelos, primatas e no homem. Pode ser encontrado no ambiente, principalmente em locais onde há matéria orgânica ou vegetação em decomposição. Durante muito tempo foi considerada uma ergodermatose, por que afetava os profissionais que trabalhavam diretamente com o solo.

Aproximadamente $80 \%$ dos pacientes acometidos apresentam a forma linfocutânea. Porém, em pacientes com imunossupressão, podem ocorrer formas disseminadas. Na literatura existem diversos relatos de pacientes que apresentaram nódulos subcutâneos que desenvolveram inflamação, após drenagem de secreção seropurulenta e ulceração. Geralmente, o paciente tem histórico de comorbidades e contato prolongado ou não, com gatos de origem desconhecida. Vale ressaltar que gatos domiciliados também podem se infectar e transmitir o agente etiólógico. Ao exame físico, normalmente o paciente apresenta nódulos subcutâneos da cor da pele, eritematosos, e úlceras cobertas por crostas espessas e enegrecidas na face, tronco e membros. Devido à história epidemiológica compatível e ao padrão de evolução das lesões, um dos principais diagnósticos mais comumente adotados é a esporotricose.

As manifestações clínicas da doença no hospedeiro humano ou animal são dependentes de fatores de virulência da cepa em particular, e da termo-tolerabilidade. Os fungos que tem a capacidade de crescer a $37^{\circ} \mathrm{C}$ exibem lesões linfocutâneas em pacientes humanos. Aqueles que são capazes de crescer a $35^{\circ} \mathrm{C}$ causam lesões cutâneas fixas e mais superficiais.

No Brasil, desde os anos 1980, os casos de esporotricose em humanos relacionados a gatos vêm aumentando. A primeira epidemia registrada aconteceu no Rio de Janeiro, em 1998. Nesse estado, atualmente, a doença já é de notificação obrigatória. A esporotricose atinge principalmente pessoas de classes sociais menos privilegiadas, que vivem nas periferias, donas de casa, estudantes de medicina veterinária e médicos veterinários, grupos sujeitos a levar arranhadas ou mordidas de animais tanto pela proximidade estabelecida no exercício profissional, quanto pela falta de informação sobre o 
manejo e prevenção da doença. E importante ressaltar que a doença não e transmitida de humano para humano.

Nas regiões Sul e Sudeste do Brasil, S. brasiliensis é o principal (88\%) agente etiológico da esporotricose humana e animal. Existem relatos da doença causada por $S$. Schenckii e $S$. Globosa em outras regiões do País. As formas sistêmicas são raras e geralmente afetam indivíduos imunocomprometidos, principalmente aqueles com HIV .O abuso de álcool crônico resulta em linfopenia e ativação crônica do pool de células $\mathrm{T}$, o que pode alterar a capacidade das células $\mathrm{T}$ de se expandir e responderem á agentes patogênicos, induzindo a um estado de anergia e, alterando a resposta Th1 e Th2. A resposta Th1 é considerada como o principal fator de controle da infecção fúngica. Além da imunossupressão do paciente, deve-se enfatizar que S. brasiliensis é a espécie mais virulenta desse gênero, devido à sua capacidade de invadir tecidos e levar à morte.

O contato dos animais de estimação com seus tutores vem aumentando, e, dessa forma, cresce também o número de casos com possível envolvimento dermatozoonótico, que adquire importância ainda maior em indivíduos imunocomprometidos. Os profissionais relacionados à clínica de pequenos animais devem estar atentos à ocorrência da doença. $\mathrm{O}$ risco de contaminação pela mordedura e arranhadura de animais infectados é alto. Para minimizar e evitar esses acontecimentos, é importante o uso de luvas, desinfecção posterior das mãos, punhos e braços durante a manipulação de materiais contaminados, e, após o contato com esses pacientes.

A esporotricose tem sido diagnosticada com frequência nos gatos. Pode se manifestar na forma cutânea localizada, cutânea linfática e cutânea disseminada. Nos casos graves, foram observados manifestações sistêmicas da doença, com comprometimento de diversos órgãos como pulmões, linfonodos, fígado, baço e rim.

O diagnóstico baseia-se no isolamento e identificação do agente em cultura. Também pode ser diagnosticada através da correlação de dados clínicos, epidemiológicos e laboratoriais, incluindo o exame direto (citologia do exsudato das lesões) ou o exame histopatológico. As técnicas de imunohistoquímica e reação em cadeia da polimerase (PCR) também são úteis no diagnóstico, entretanto sua disponibilidade é reduzida.

A droga de eleição para tratamento tanto em humanos como em felinos é o itraconazol, fármaco efetivo e seguro quando comparado ao iodeto de sódio e o iodeto de potássio. Outras opções consistem no uso de fluconazol, terbinafina, termoterapia local, anfoterecina B, combinados com a ressecção cirúrgica das lesões.

Na saúde publica, atualmente, ainda falta muito investimento para tratamento de animais e criação de material educacional sobre a esporotricose para a população. É necessário que os donos de gatos também façam sua parte, e, sejam conscientes da posse responsável, castração dos animais, confinamento de felinos em casa, limpeza do ambiente e limite de gatos.

Os animais infectados que forem a óbito devem ser incinerados, ao invés de enterrados, evitando assim a disseminação no solo e a progressão do patógeno na natureza. 


\section{CONCLUSÃO}

A esporotricose é uma zoonose de grande ocorrência no Brasil, devido, entre outros fatores, às condições socioeconômicas do país. Sua transmissão ocorre, em grande parte das vezes por contato direto do homem com animais de estimação infectados.

Os profissionais de saúde humana e animal devem estar aptos não só a diagnosticar a doença, mas também a orientar a população sobre a ocorrência dessa enfermidade, a possibilidade de transmissão por contato com os animais de estimação, e conscientizando os proprietários sobre os riscos, contribuindo dessa forma com o controle e prevenção da doença.

O exame clínico do animal e a realização do exame citológico são fundamentais para o estabelecimento do diagnóstico definitivo da doença. Nos seres humanos, o histórico de mordedura e arranhadura por animal infectado, exames clínicos e laboratoriais, são importantes para o início e o correto tratamento.

\section{REFERÊNCIAS}

BARROS, M. B. L.; SCHUBACH, T. P.; COLL, J. O.; GREMIÃO, I. D.; WANKE, B.; SCHUBACH, A. 2010. Esporotricose: a evolução e os desafios de uma epidemia. Revta Panam. Salud Publica 27(6):455-460.

DE ALMEIDA, J. R.; KAIHAMI, G. H.; JANNUZZI, G. P.; DE ALMEIDA, S. R: 2015. Therapeutic vaccine using a monoclonal antibody against a $70-\mathrm{kDa}$ glycoprotein in mice infected with highly virulent Sporothrix schenckii and Sporothrix brasiliensis. Medical Mycology 53: 42-50.

FARIAS, M. R. 2000. Avaliação clínica, citopatológica e histopatológica seriada da esporotricose em gatos (Felis catus - Linnaeus, 1758) infectados experimentalmente. $97 \mathrm{f}$. Dissertacao (Mestrado em Medicina veterinaria) - Faculdade de Medicina Veterinaria e Zootecnia, Universidade Estadual Paulista, Botucatu.

FREITAS, D. F.; DO VAlle, A. C.; DA SILVA, M. B. T.; CAMPOS, D. P.; LYRA, M. R.; DE SOUZA, R. V. 2014. Sporotrichosis: Na Emerging Neglected Opportunistic Infection in HIV-Infected Patients in Rio de Janeiro, Brazil. PLoS Negl Trop Dis. 8(8):3110.

GONDIM, A. L. C. L.; LEITE, A. K .A. 2020. Aspectos gerais da esporotricose em pequenos animais e sua importância como zoonose. Revista Brasileira de Educação e Saúde. v.10, n.2, p.37-44.

GREMIÃO, I. D. F.; MENEZES, R. C.; SCHUBACH, T. M.; FIGUEIREDO, A. B.; CAVALCANTI, M. C.; PEREIRRA, S. A. 2018. Feline sporothricosis: epidemiological and clinical aspects. Medical Mycology, v. 53, n.1, p. 15-2.

HAN HS, KANO R, CHEN C, NOLI C: 2017. Comparison of two in vitro antifungal sensitivity tests and monitoring during therapy of Sporothrix schenckii sensu stricto in Malaysian cats. Veterinary 
Dermatology. 28: 156-e32.

LARSSON, C. E. 2011. Esporotricose. Brazilian Journal of Veterinary Research and Animal Science, Sao Paulo, v. 28, n. 3, p. 250-259. 


\title{
PREVENÇÃO DE INFECÇÃO DO ZIKA VÍRUS EM MULHERES GESTANTES INDÍGENAS
}

\section{Raquel Sampaio Amazonas dos Santos'; Jonathan Battanoli².}

\author{
${ }^{1}$ Acadêmica em enfermagem, Centro Universitário do Norte (UNINORTE), Manaus, Amazonas. \\ ${ }^{2}$ Acadêmico em enfermagem, Centro Universitário do Norte (UNINORTE), Manaus, Amazonas.
}

\section{raquelsampaioamazonas@gmail.com}

\begin{abstract}
RESUMO
Considerando o crescimento da população indígena e levando em conta sua estrutura social e condições habitacionais, foram observadas áreas de grande exposição e de grande influência climática ao Zika vírus na região amazônica. Suscitando a infecção em mulheres gestantes e a transmissão vertical, sendo causa da microcefalia e doenças neurológicas em bebês nascidos em zonas rurais indígenas. $\mathrm{O}$ trabalho propõe orientações de prevenção individuais e coletivas através da promoção de educação em saúde, para que exista controle da exposição de mulheres gestantes indígenas. Fora também imprescindível para a elaboração deste documento a revisão de literatura, onde buscou-se dados no IBGE referente aos índices populacionais indígenas no Brasil e, também na base de dados SciELO e Google Acadêmico.
\end{abstract}

PALAVRAS CHAVES: Educação; Saúde; Microcefalia.

ÁREA TEMÁTICA: Saúde Coletiva

\section{INTRODUÇÃO}

Tendo em vista a escassez de informação e intervenções preventivas de educação em saúde para a população de zona rural indígena, viemos por meio deste trabalho incentivar e produzir informação para a prevenção indígena, alertar a importância e a gravidade de uma das patologias que já fora considerada emergência de saúde pública. Diante da falta de acesso dessa população aos 3 níveis de saúde dispostos pelo SUS e também a carência de CASAI. Encontramos a falta de preparo científico profissional e a falta de profissionais atuantes nessas regiões mais isoladas, potencializando a incapacidade de suporte, inexistindo a possibilidade de uma boa qualidade de vida a essa população 
indígena e uma boa assistência de pré-natal a essas mulheres gestantes.

\section{PROBLEMA}

Segundo estudos realizados na cidade de Propriá, SE, foram entrevistadas 177 mulheres durante o período de novembro de 2016 á fevereiro de 2017 e observou-se que a relação das mulheres que se dispõem a utilização dos meios de prevenção são:

Tabela 1. Relação entre medidas preventivas e variáveis sociais e comportamentais.

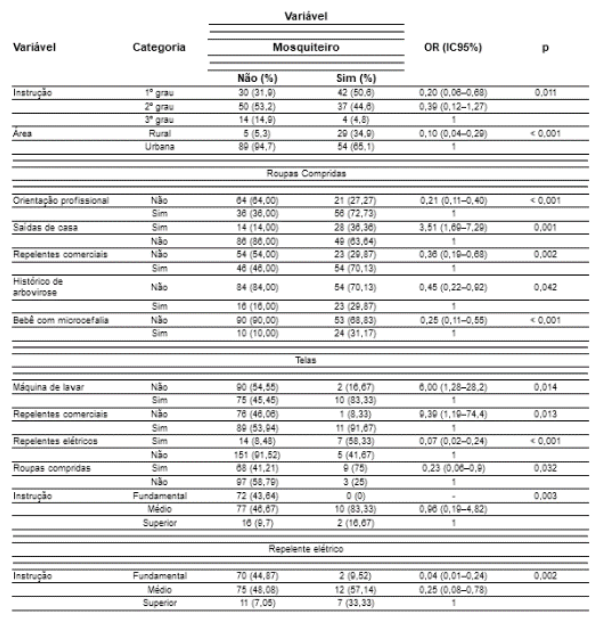

Revista de Saúde Pública: Medidas de proteção individual de gestantes contra a infecção pelo zika vírus

Tabela 2. Frequência relativa das medidas adotadas pelas gestantes do município de Propriá, SE, de acordo com critérios sociais.

\begin{tabular}{|c|c|c|c|c|c|c|c|c|c|c|}
\hline \multirow{3}{*}{ Variável } & \multicolumn{6}{|c|}{ Escolaridade } & \multicolumn{4}{|c|}{ Área } \\
\hline & \multicolumn{2}{|c|}{ Fundamental } & \multicolumn{2}{|c|}{ Médio } & \multicolumn{2}{|c|}{ Superior } & \multicolumn{2}{|c|}{ Rural } & \multicolumn{2}{|c|}{ Urbana } \\
\hline & $\mathrm{n}$ & $\%$ & $\mathrm{n}$ & $\%$ & $n$ & $\%$ & $\mathrm{n}$ & $\%$ & $n$ & $\%$ \\
\hline Repelentes & 26 & 36,0 & 59 & 68,0 & 15 & 83,0 & 16 & 47,0 & 84 & 59,0 \\
\hline Mosquiteiro & 42 & 58,0 & 37 & 43,0 & 4 & 22,0 & 29 & 85,0 & 54 & 37,0 \\
\hline Vestuário & 20 & 28,0 & 43 & 49,0 & 14 & 78,0 & 14 & 41,0 & 63 & 44,0 \\
\hline $\begin{array}{l}\text { Telas } \\
\end{array}$ & 0 & 0,0 & 10 & 11,0 & 2 & 11,0 & 3 & 6,0 & 9 & 8,0 \\
\hline Inseticidas & 21 & 21,0 & 42 & $\begin{array}{lll}44,0 \\
\end{array}$ & 10 & 56,0 & 10 & 29,0 & 33 & $\begin{array}{lll}44,0 \\
\end{array}$ \\
\hline Citronela & 6 & 8,0 & 18 & 20,0 & 6 & 33,0 & 5 & 14,0 & 25 & 17,0 \\
\hline $\begin{array}{l}\text { Produtos } \\
\text { caseiros }\end{array}$ & 18 & 25,0 & 19 & 22,0 & 2 & 11,0 & 5 & 14,0 & 34 & 24,0 \\
\hline $\begin{array}{l}\text { Repelentes } \\
\text { elétricos }\end{array}$ & 2 & 3,0 & 12 & 14,0 & 7 & 39,0 & 1 & 1,0 & 20 & 14,0 \\
\hline $\begin{array}{l}\text { Repelentes } \\
\text { em espiral }\end{array}$ & 17 & 24,0 & 16 & 18,0 & 3 & 17,0 & 3 & 9,0 & 33 & 23,0 \\
\hline Total & 72 & 100,0 & \begin{tabular}{l|l}
87 \\
\end{tabular} & 100.0 & 18 & 100,0 & 34 & 100,0 & 143 & 100,0 \\
\hline
\end{tabular}

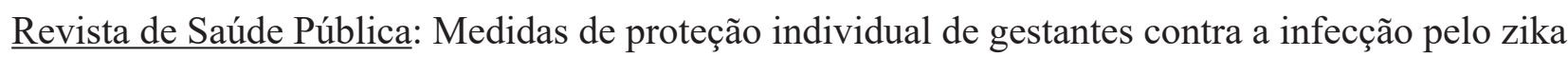
vírus 
Tabela 3. Mortalidade proporcional de crianças indígenas e não indígenas:

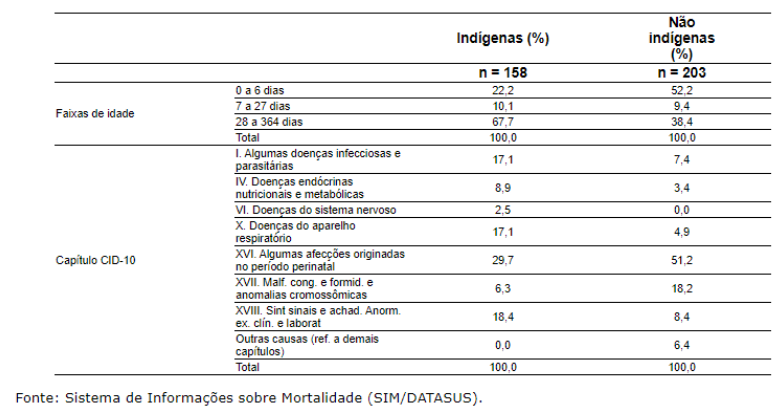

Fonte: Sistema de informações sobre mortalidade (SIM/DATASUS)

Analisando as variáveis e observando a porcentagem de mulheres que já adquiriram alguma arbovirose e possui filho com microcefalia, vemos a diferença da exposição de mulheres gestantes em zonas rurais, onde não foram inclusas mulheres indígenas que residem em uma região ainda mais isolada e com falta de informações para prevenções dessa patologia que tem sido não só um problema na saúde, mas social e econômico. A discrepância em números nos mostra a necessidade do trabalho de intervenção e prevenção a essa população.

\section{JUSTIFICATIVA}

A análise dos dados propostos pelo trabalho de instituições regulamentadas demonstra a sua importância e a falta de informação nesse setor de saúde. A falta de incentivo e taxas elevadas de afecções ou infecções originadas no período perinatal dessa população, é a maior preocupação proposta deste projeto, buscando uma assistência de saúde primária de qualidade, educação em saúde contínua, meios de prevenção através de orientação em zonas de maior exposição e o controle da infecção do Zika como prevenção de doenças neurológicas e má formação congênita em crianças indígenas.

\section{OBJETIVOS GERAIS E ESPECÍFICOS}

Demonstrar por meio da análise bibliográfica a necessidade de conscientização da população indígena pelos seus direitos de saúde preservando e continuando sua identidade coletiva. Alcançar a conscientização das mulheres gestantes indígenas para o problema de infecção do Zika, trazendo a compreensão da necessidade de medidas preventivas, ofertando a essa população uma grande mudança social. 


\section{METODOLOGIA}

Trata-se de uma revisão de literatura, onde buscou-se dados no IBGE. Priorizou-se os dados dos anos de 2010 a 2018, por não encontrar dados mais atualizados. Para tanto, buscou-se artigos e publicações referentes à temática na base de dados SCIELO, GOOGLEACADÊMICO, MINISTÉRIO DA SAÚDE e AMOSTRA DE ARTIGOS DA PUC DE GOIAIS. Não se excluíram amostragens de artigos que não condiziam com saúde indígena, pela escassa quantidade de informação sobre o conteúdo, foram relevados artigos sobre saúde de mulheres gestantes em zonas rurais. Após leitura dinâmica, os artigos foram salvos e lidos na íntegra para agrupamento de informações pertinentes aos objetivos deste estudo.

\section{RESULTADOS ESPERADOS}

Diante da dinâmica abordada através das intervenções propostas no trabalho, dispõe-se de técnicas utilizadas em saúde da família, técnicas holísticas para intervenções onde eles se sintam familiarizados (respeitando sua cultura e rituais) e técnicas em educação em saúde. Projetando assim o retorno de conscientização, mudanças de hábitos, saúde e prevenção de doenças a essa população com foco nas mulheres indígenas.

\section{CONSIDERAÇÕES FINAIS}

O estudo conduzido neste trabalho no traz dados de uma população que apresenta mais desvantagem em educação em saúde e acesso à saúde primária no espaço geográfico rural. Buscando de forma única à análise de dados com foco em saúde de mulheres gestantes indígenas, investigamos as recorrências em dados científicos a regiões rurais, demonstrando a atenção necessária à população indígena através de educação em saúde, estimulando a prevenção de infecção por Zika Vírus em mulheres gestantes indígenas, erradicando os impactos futuros negativos a essa população.

\section{REFERÊNCIAS}

MARINHO, Gerson; BORGES, Gabriel; SANTOS, Ricardo. Mortalidade infantil de indígenas e não indígenas nas microrregiões do Brasil. Mortalidade Infantil; População Indígena. Rio de Janeiro: [s. l.], DOI Scielo,20 abr. 2018. Acesso em: 17 mar. 2021.

MELO, Vladimir; SILVA, José; CORTE, Roseli. Gráficos e tabelas de indicies indígenas do IBGE. estudos especiais»O Brasil Indígena, [s. l.], 23 nov. 2018. DOI Scielo. Acesso em: 16 mar. 2021. 


\section{DESAFIOS NO ENFRENTAMENTO DA COVID-19: A MEDICINA VETERINÁRIA E SUA ÁREA DE ATUAÇÃO - REVISÃO}

\section{Maurício Orlando wilmsen; Suélen Dalegrave², João Pedro Grassi de Araújoº}

${ }^{1}$ Doutor, Professor do eixo de Medicina Veterinária Preventiva do Curso de Medicina Veterinária, Pontifícia Universidade Católica do Paraná - PUCPR campus Toledo, Paraná.

${ }^{2}$ Residência em Clínica e Cirurgia de Pequenos Animais, Pontifícia Universidade Católica do Paraná - PUCPR campus Toledo, Paraná.

${ }^{3}$ Residência em Clínica, Cirurgia e Reprodução de Animais de Produção, Pontifícia Universidade Católica do Paraná - PUCPR campus Toledo, Paraná.

DOI: $10.47094 /$ ICONRES.2021/3

\section{RESUMO}

O Sistema Único de Saúde (SUS), tem sido a principal linha de frente no enfrentamento da pandemia de Covid-19. A doença causa uma síndrome respiratória aguda pela infecção com o vírus Sars-cov-2 (Severe acute respiratory syndrome coronavirus 2), o qual possui alto potencial de disseminação entre a espécie humana. A medicina veterinária deixou de ser vista apenas como uma profissão com foco em saúde animal. A atuação do profissional na atualidade ocupa áreas da saúde, desenvolvendo importantes rotas de estudos em epidemiologia, controle de zoonoses e/ou higiene de alimentos, atividades laboratoriais de biologia além de estudos experimentais que contribuem na investigação de animais como possíveis reservatórios para COVID-19. Dessa forma, a atuação desses profissionais nas equipes de Saúde Pública é reconhecida pela OMS, que realça a importância dos conhecimentos adquiridos durante sua formação.

PALAVRA CHAVE: SUS. Sars-CoV-2. OneHealth .

ÁREA: Atenção básica.

\section{INTRODUÇÃO}

Amedicina veterinária possui experiência de longo prazo com odesenvolvimento de estratégias de controle e prevenção de coranaviroses (CoVs), em diferentes espécies animais. Biologicamente, os CoVs são reoconhecidos como vírus de RNA de fita simples, com alta plasticidade genética, capacidade 
de desenvolver mutações pontuais e eventos de recombinação. Esta variação genética é responsável pela emergência contínua de cepas virais com aumento da virulência e tropismos para diferentes tecidos (BUONAVOGLIA et al., 2007). Atualmente, os mesmos são classificados em quatro gêneros distintos: Alphacoronavirus, Betacoronavirus, Gammacoronavirus e Deltacoronavírus, que atuam em espécies domésticas e silvestres, sendo a última um possível indicador de reservatórios naturais. A infecção pelo gênero Alphacoronavírus ocorre em cães e gatos, desenvolvendo a doença entérica o cão (CCoV), com quadro de gastroenterite. Em felinos (FCoV), o acometimento ocorre em filhotes e/ ou adultos, com posterior desenvolvimento de peritonite infecciosa felina (PIF) (seca ou úmida), com evolução fatal na amioria dos animais infectados. O controle e profilaxia das doenças nessas espécies é realizado através de imunização, contudo, para FcoV, a eficácia da vacina é considerada uma insucesso. A nova variante do SARS-CoV-2, é capaz de infectar animais, entretanto, até o momento, o papel dos mesmos frente à disseminação da doença ainda segue sendo investigado. Em humanos, a doença viral é responsável por uma síndrome respiratória aguda com acometimento pulmonar severo, além do vírus comprometer fisiologicamente outros sistemas orgânicos. Tendo em vista o impacto da pandemia mundial de COVID-19 e atuação que saúde pública como um importante eixo de estudos dentro das dinâmicas estabelecidas pela trasmissão de doenças infecciosas de risco zoonótico ou ainda de segurança sanitária, vinculam ao médico veterinário, maior visibilidade a despeito de suas atribuições quanto a resolução de diretrizes relacionadas ao COVID-19 (DECARO et al., 2020). Portanto, o objetivo dessa revisão é apresentar a atuação do médico veterinário inserido na área da saúde e no enfrentamento da pandemia da COVID-19.

\section{MATERIAIS E MÉTODOS:}

Para o desenvolvimento desta revisão integrativa, foram selecionados três bases de dados (Google acadêmico, Periódicos Capes e PubMed), onde os critérios de seleção para a utilização de referências bibliográficas ocorreu através do uso de quatro palavras chaves, em dois diferentes idiomas (português e inglês): medicina veterinária, saúde pública, saúde única e COVID-19, foram utilizados materiais indexados a partir de 2017 até março de 2021.

\section{FUNDAMENTAÇÃO TEÓRICA}

\section{Saúde pública: a medicina veterinária como área da saúde}

Sistemas de saúde pública eficazes requerem uma abordagem interdisciplinar para vigilância, prevenção e controle de doenças de saúde pública. Para tanto, a avaliação da redução do impacto de emergências e desastres em saúde, reconhece a participação integralizada do profissional em planejar e avaliar medidas profiláticas e de controle, adotadas pelas equipes de saúde pública através de atividades estratégicas de vigilância, prevenção e controle de zoonoses (GOMES, 2017). A preoconização das Funções Essenciais de saúde Pública (FESP), são definidas através da Organização PanAmericana de Saúde, com reconhecimento da Organização Mundial da Saúde (OMS). 


\section{Saúde única, NASF e SUS: atuação do médico veterinário no enfrentamento da COVID-19}

A OMS, reconhece que o surto da síndrome respiratória aguda assume o posto de emergência em saúde pública de interesse internacional (GOMES, 2017). Para tanto, a compreensão do termo saúde única (One Health) engloba a atividade integrativa entre a saúde humana, animal, ambiental e a adoção de políticas públicas efetivas para prevenção e controle de enfermidades no âmbito de seu acontecimento.

No Brasil, a medicina veterinária foi implementada na atenção básica (AB), particularmente nos Núcleos de Apoio à Saúde da Família (NASF), através da Portaria nº 2.488, em 2011, que aprova a Política Nacional de AB para o Sistema Único de Saúde (SUS). A atuação do médico veterinário no SUS, como profissional de saúde tem corroborado com a necessidade de ações interdisciplinares, reconhecidas a partir da Resolução 218/1997 do Conselho Nacional de Saúde, como promotora de integralidade em atenção à saúde. Portanto, a atuação do veterinário está embasada na legislação que rege a profissão em vários artigos das competências privativas conforme cita Lei 5517/1968 e o Artigo $6^{\circ}$, que refere o estudo e a aplicação de medidas de saúde pública no tocante às doenças de

animais transmissíveis ao homem. A atuação e inserção no contexto de Saúde Única é citada pela OMS e Organização Mundial da Saúde Animal (OIE).

\section{Epidemiologia de SARS-CoV-2 em animais}

A atuação de médicos veterinários em comunidades científica revelam através de seus resultados de pesquisas a participação de diversos táxons de animais (domésticos e selvagens) como uma possível participação na cadeia epidemiológica da COVID-19. Os animais podem participar como reservatórios ou fontes de infecção/reinfecção a população humana e animal e essas possibilidades integram uma importante linha de pesquisa em diagnósticos laboratorial, estatística, epidemiologia e vacinologia.

As demandas da Covid-19 também se fazem necessária no acompanhamento de animais silvestres. Os estudos em epidemiologia apontam para o acompanhamento de rotas de infecção em animais de vida livre e mantidos em cativeiro, revelando a importância no monitoramento de fauna, frente as alterações clínicas e laboratoriais a nível de vigilância.

\section{CONCLUSÃO}

A atuação do médico veterinário em cenários emergenciais como a pandemia do COVID-19, permite deflagrar importantes áreas de atuação do profissional como as rotas de condução epidemiológica, visando entender a participação de animais como possíveis reservatórios do vírus, além de contribuir exponencialmente na integralidade da conservação da saúde humana e ambiental. A 
medicina veterinária possui uma formação integrativa com outras áreas profissionais, e o resultado de tal integração permite a construção de bases de conhecimentos sólidas e que assumem um importante papel na discussão e fundamentalização de políticas públicas capazes de auxiliar na contenção de futuros desastres biológicos.

\section{REFERÊNCIA}

DAVIS, A.; SHARP, J. Rethinking One Health: emergent human, animal and environmental assemblages.

Social Science \& Medicine, v.258, p.113093, 2020. doi:https://doi.org/10.1016/j. socscimed.2020.113093

DECARO, N.; MARTELlA, V.; SAIF, L. J.; BUONAVOGLIA, C.. COVID-19 from veterinary medicine and one health perspectives: what animal coronaviruses have taught us. Researchs in Veterinary Science, v.131, p.21-23, 2020. doi: https://doi.org/10.1016/j.rvsc.2020.04.009

GOMES, L. B.. Importância e atribuições do médico veterinário na saúde coletiva. Sinapse Múltipla, v.6, n.1,

p.70-75, 2017. 


\title{
CONTAMINAÇÃO DE AREIAS EM ÁREAS DE RECREÇÃO INFANTIL POR OVOS DE Toxocara E LARVAS DE Ancylostoma NO MUNICÍPIO DE SÃO JOSÉ DOS CAMPOS - SP
}

\author{
Letícia Amante Contiero Sena ${ }^{1}$; Catherine Armando ${ }^{1}$; Julia Perez Campos Moreira ${ }^{1}$; Anna \\ Gabriele Salles$^{1}$; Ellen Rayane Machado${ }^{1}$; Thiago Scharlau Xavier²; Joelma Moura Alvarez ${ }^{3}$.
}

${ }^{1}$ B.Sc. em Medicina Veterinária, UNIP, São José dos Campos, São Paulo.

${ }^{2}$ B.Sc. em Engenharia Eletrônica, ITA, São José dos Campos, São Paulo.

${ }^{3}$ Prof. Dra Médica Veterinária, UNIP, São José dos Campos, São Paulo.

\author{
leticiacontierosena@gmail.com
}

\begin{abstract}
RESUMO
Este estudo consistiu em verificar a presença de ovos de Toxocara spp. e larvas de Ancylostoma spp. em locais de recreação infantil do município de São José dos campos - SP no período de novembro de 2018 a maio de 2019, através de exame coproparasitológico, utilizando-se areia de parquinhos no Método de Flutuação em solução de açúcar (Método de Sheather) e exame microscópico para identificação de ovos e larvas. Nove parques de localizações geográficas diferentes da cidade de São José dos Campos foram pesquisados, verificando-se a presença de parasitos em 44\% (4 lugares positivos e 5 negativos) destes, podendo-se evidenciar que há um potencial risco de infecção da população exposta. Resultado este que ressalta a necessidade de adotar medidas que visem minimizar os riscos de infecção por geoparasitos em crianças frequentadoras desses ambientes.
\end{abstract}

PALAVRAS-CHAVE: Zoonose; Parasito; Geoparasito.

ÁREA TEMÁTICA: Saúde Coletiva

\section{INTRODUÇÃO}

Em áreas públicas de recreação infantil, frequentemente, pode-se encontrar fezes de cães e gatos, as quais muitas vezes podem contaminar o solo com parasitas transmissores de zoonoses. Dois exemplos de zoonoses parasitárias são a Larva Migrans Visceral e Cutânea, ocasionadas pelos agentes Toxocara spp. e Ancylostoma spp., nesta ordem. Devido a importância para a Saúde Pública 
da possível transmissão dessas zoonoses, esse estudo teve como objetivo verificar a presença de ovos e larvas desses parasitos em áreas de recreação infantil do município de São José dos Campos - SP.

\section{METODOLOGIA}

Foram escolhidas nove áreas de recreação infantil, presentes em praças públicas espalhadas pela cidade de São José dos Campos/SP. No período entre novembro de 2018 a maio de 2019, foi feita a coleta de cinco amostras do solo nas áreas de recreação infantil, com peso de aproximadamente $100 \mathrm{~g}$, sendo quatro amostras coletadas em cada um dos ângulos, considerando uma área retangular, e a quinta amostra coletadas ao centro desta área. A amostragem foi realizada a uma profundidade de $5,0 \mathrm{~cm}$, descartando as sujidades da superfície.

O material amostrado foi condicionado em sacos plásticos de primeiro uso e refrigerado até o processamento, o qual ocorreu no Laboratório Multidisciplinar da Universidade Paulista de São José dos Campos/SP, sendo submetidas ao exame coproparasitológico pelo Método de Sheather por Centrífugo Flutuação. Neste método, a amostra foi misturada com uma solução de sacarose, peneirada e centrifugada. Posteriormente, foi adicionada uma solução concentrada de sacarose, seguida da ressuspensão do sedimento seguida de homogeneização. Foram centrifugadas novamente por mais cinco minutos, e retirada uma amostra da camada mais superficial contendo os ovos, cistos e larvas. Logo após, foi transferida a amostra para uma lâmina de microscopia e coberta com lamínula.

Por fim, a lâmina foi examinada cuidadosamente ao microscópio com aumento de 100x. Começando a leitura de uma parte da lamínula, e indo de um canto ao outro para assim evitar omissões ou sobreposições de campo, foi realizada a avaliação morfológica dos organismos ali presentes e a identificação dos agentes em questão (Toxocara spp. e Ancylostoma spp.).

\section{RESULTADOS E DISCUSSÕES}

Foram analisadas amostras de solo coletadas de nove áreas públicas de recreação infantil da cidade de São José dos Campo/SP, escolhidas aleatoriamente. São elas a Praça Romão Gomes nomeada "Praça 1", Praça Humanismo nomeada "Praça 2", Praça Ulisses Guimarães nomeada "Praça 3", Parque Santos Dumont nomeado "Praça 4", Praça Nenê Cursino nomeada "Praça 5", Praça das Crianças nomeada "Praça 6", Praça Hermenegildo R. Caninhanha Filho nomeada "Praça 7", Praça Avenida Rio Doce nomeada "Praça 8" e Praça Hércules nomeada "Praça 9". Quatro praças dentre as nove apresentaram-se contaminadas.

Das 45 amostras submetidas ao exame coproparasitológico, 15,55\% (7/45) estavam contaminadas com larvas, e uma destas, correspondendo a 2,22\% (1/45), estava também contaminada com ovo, não sendo possível, no entanto, identificar a espécie das larvas e do ovo encontrados.

Embora não se possa afirmar que as larvas e o ovo encontrados em sete das quarenta e 
cinco amostras seja, de fato, de Ancylostoma spp. e Toxocara spp., podemos afirmar, com base nos resultados deste trabalho, que as praças em questão estão contaminadas por parasitos, estes podendo ou não ter potencial zoonótico.

Tabela 1. Resultado do Exame coproparasitológico através da técnica de Sheather em amostras de areia de parques infantis da cidade de São José dos Campos, SP.

\begin{tabular}{cccccccccc}
\hline Praça & $\mathbf{1}$ & $\mathbf{2}$ & $\mathbf{3}$ & $\mathbf{4}$ & $\mathbf{5}$ & $\mathbf{6}$ & $\mathbf{7}$ & $\mathbf{8}$ & $\mathbf{9}$ \\
\hline $\begin{array}{c}\text { Quantidade } \\
\text { de amostras } \\
\text { infectadas }\end{array}$ & 0 & 1 & 0 & 0 & 3 & 2 & 1 & 0 & 0 \\
\hline
\end{tabular}

Fonte: Autoria própria, 2019

Figura 1. Ovo larvado à esquerda (aumento de 100x) e larva de nematódeo à direita (aumento de
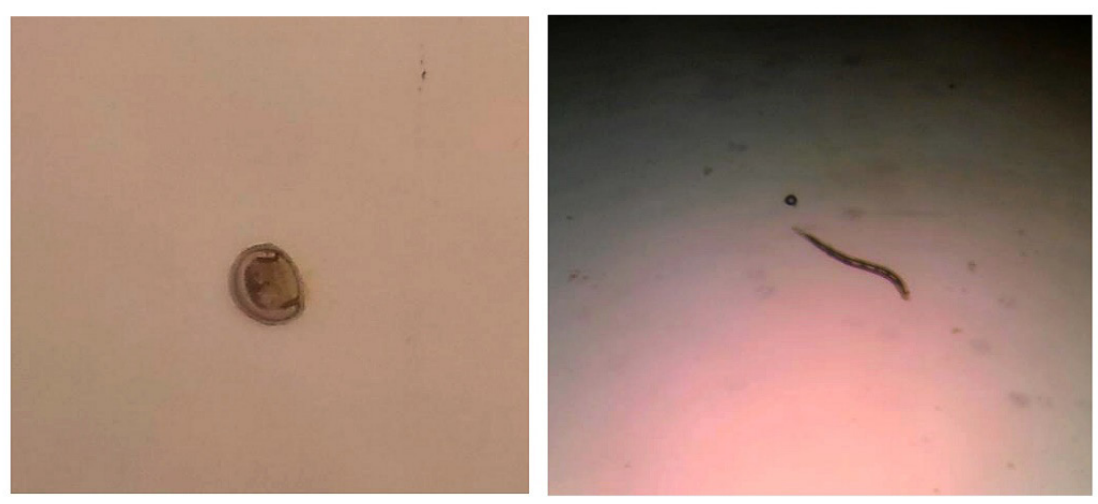

Fonte: Autoria própria, 2019

Para compreender melhor a precisão do teste em fornecer um resultado verdadeiro, calculouse a probabilidade de se encontrar pelo menos uma amostra contaminada para diferentes graus de contaminação. Considerando-se que uma em cada $\mathrm{N}$ amostras está contaminada e que são tomadas cinco amostras, a probabilidade citada é dada por $\mathrm{P}=1-(\mathrm{N}-1)^{5} / \mathrm{N}^{5} \mathrm{P}=1-(\mathrm{N}-1)^{5} / \mathrm{N}^{5}$. Em posse dessa equação, confeccionou-se o gráfico da Figura 2, cuja abscissa representa o $\mathrm{N}$ e cuja ordenada apresenta a probabilidade $\mathrm{P}$. 
Figura 2. Gráfico de $\mathrm{N} \times \mathrm{PN} \times \mathrm{P}$, sendo 1: N1: $\mathrm{N}$ o índice real de infecção da praça e PP a probabilidade de se obter no exame pelo menos uma amostra infectada das cinco.

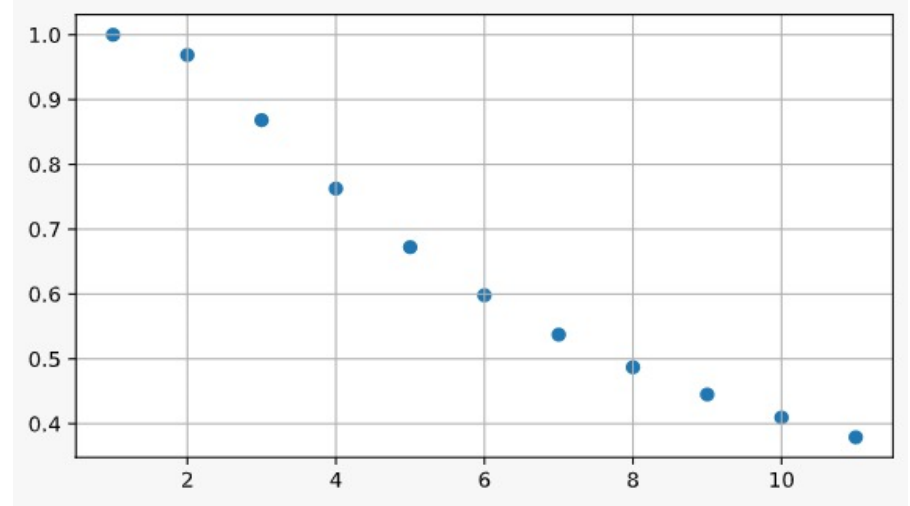

Fonte: Autoria própria, 2019

Ao se observar o $\mathrm{N} \geq 8$, a chance de que pelo menos uma das cinco amostras esteja contaminada é menor do que 50\%, conforme Figura 2, ou seja, na maioria das vezes o exame pode induzir a pensar que a praça não apresenta contaminação, quando na verdade pode apresentar em quantidades significativas. Entretanto, pode-se concluir que para praças significativamente infectadas, o exame proposto tende a fornecer o resultado correto, tendo em vista que para $\mathrm{N} \leq 7$ a probabilidade de que se encontre alguma amostra contaminada já é maior do que 50\%.

Vale ressaltar ainda que, durante o estudo, se verificou que o município já havia tomado medidas para controle em diversas praças que foram visitadas, e nestas não havia mais areia e sim piso emborrachado na área de recreação infantil.

\section{CONCLUSÃO}

Tendo em vista os resultados obtidos neste trabalho, conclui-se que há a possibilidade de infecção do ser humano que entre em contato com ambientes contaminados, pelas zoonoses investigadas (LMC e LMV), não descartando o risco nas outras áreas visto que as coletas foram feitas em apenas um período, reforçando-se a importância de se continuar adotando medidas preventivas de Saúde Pública.

\section{REFERÊNCIAS}

BOWMAN, Dwight. Georgis’ Parasitologia Veterinária. 9º Edição, Brasil: Editora Elsevier, 2010. CASTRO, João Manoel de. et al. Contaminação de canteiros da orla marítima do município de Praia Grande, São Paulo, por ovos de Ancylostoma e Toxocara em fezes de cães. São Paulo: 
Revista da Sociedade Brasileira de Medicina Tropical, 2005.

M NUNES, Cáris et al. Ocorrência de larva migrans na areia de áreas de lazer das escolas municipais de ensino infantil, Araçatuba: Journal of Public Health, 2000.

SANTARÉM, Vamilton Alvares. et al. Contaminação por ovos de Toxocara spp. Em praças públicas das regiões central e periurbana de Mirante do Paranapanema, São Paulo: Vet e Zootec, 2010. 


\title{
PERCEPÇÕES DA EQUIPE DE ENFERMAGEM ACERCA DA VIOLÊNCIA DOMÉSTICA CONTRA A MULHER
}

\author{
Ana Paula Cunha Duarte'; Kelly Rose Pinho Moraes²; Geovane Moura Viana ${ }^{3}$; Linielce \\ Portela Nina ${ }^{4}$; Joana Maria Machado Mendes5; Antônia Katia Lopes Araújo ${ }^{6}$; Dheymi Wilma \\ Ramos Silva ${ }^{7}$; Caroline Natielle Rocha da Silva ${ }^{8}$.
}

1,2,3,4,5,6 Graduados em Enfermagem Bacharelado, Universidade Estadual do Maranhão (UEMA), Coroatá, Maranhão. ${ }^{7}$ Mestre em Biodiversidade, Ambiente e Saúde, pela a Universidade Estadual do Maranhão (UEMA), Caxias, Maranhão. Graduada em Enfermagem Bacharelado, Universidade

Estadual do Maranhão (UEMA), Caxias, Maranhão; ${ }^{8}$ Especialização em Estratégia de Saúde da Família pela Sociedade de Ensino Superior Estácio de Ribeirão Preto LTDA (UNISEB), Ribeirão Preto, São Paulo. Graduação em Enfermagem pela Faculdade de Educação São Francisco (FAESF), Pedreiras, Maranhão.

DOI: $10.47094 /$ ICONRES.2021/23

\begin{abstract}
RESUMO
De acordo com a Organização mundial de saúde (OMS), o Brasil possui grandes índices de violência, se tornando um dos países mais violentos do globo. Só nas últimos décadas, cerca de 553 mil pessoas vieram a óbito devido à violência intencional. Sabe-se que muitas dessas agressões podem acontecer em âmbito doméstico. Este estudo objetivou conhecer a percepção da equipe de enfermagem acerca da violência doméstica contra a mulher. Sendo uma revisão da literatura brasileira, realizada entre os meses de dezembro de 2020 e janeiro de 2021, nas principais bases de dados da Biblioteca Virtual de Saúde. Constatou-se através da leitura aprofundada dos artigos selecionados, que os profissionais possuem uma visão limitada acerca da violência contra a mulher, considerando as capacitações e treinamentos como estratégias importantes para se qualificarem e prestarem um melhor atendimento.
\end{abstract}

PALAVRAS-CHAVES: Violência doméstica; Violência contra a mulher; Enfermagem.

ÁREA TEMÁTICA: Saúde Coletiva 


\section{INTRODUÇÃO}

O Brasil é um dos países mais violentos do mundo, possuindo índices alarmantes. Em relação a violência contra a mulher (VCM), não é diferente, só em 2018, de acordo com o Fórum Brasileiro de Segurança Pública (FBSP), foram registrados mais de 60 mil casos de violência sexual no Brasil. Já o Sistema de Informação de Agravos de Notificação (SINAN) no mesmo ano registrou 27.439 notificações de violência sexual ou estupro no âmbito do Sistema Único de Saúde (SUS) (BRASIL, 2020). Vale ressaltar que muitas dessas agressões físicas e abusos podem acontecem no ambiente doméstico, e que muitas vezes essas vítimas não são atendidas em unidades de saúde, pois não procuram por medo ou vergonha do ocorrido, o que prejudica os dados, gerando uma subnotificação (CERQUEIRA et al., 2018; BUENO et al., 2019). A equipe de enfermagem pode desempenhar um papel significativo na identificação, bem como na assistência e cuidado a mulheres vítimas de violência doméstica (MVVD), pois são profissionais que estão mais próximos aos pacientes, o que o leva a uma posição de destaque na promoção de ações e detecção precoce desses casos, bem como em seu acompanhamento, notificação, orientação e prevenção (ACOSTA et al., 2018; MINAYO et al., 2018). Neste interim, o presente trabalho objetivou conhecer a percepção da equipe de enfermagem, acerca da violência doméstica contra a mulher (VDCM).

\section{METODOLOGIA}

Trata-se de uma pesquisa de revisão integrativa da literatura brasileira, compreendendo uma busca nas bases de dados da Biblioteca Virtual de Saúde, nos bancos de dados Scielo, BDENF, e Portal de Periódicos da CAPES, no período de Dezembro de 2020 a Janeiro de 2021, com o auxílio dos descritores: Violência doméstica; Violência contra a mulher; Enfermagem e o operador booleano “AND”. Foram levantadas e analisados 20 publicações no período de 2016 a 2020, destas foram excluídas as que estavam fora do limite temporal exigido, e que não atendiam ao objetivo geral da pesquisa, assim, 11 artigos tiveram seus resultados sintetizados descritivamente e discutidos nos resultados do estudo.

\section{FUNDAMENTAÇÃO TEÓRICA}

A Violência contra a mulher (VCM) é conceituada pela a Organização dos Estados Americanos (OEA) desde 1994 como "qualquer ação ou conduta, baseada no gênero, que cause morte, dano ou sofrimento físico, sexual ou psicológico à mulher, tanto no âmbito público como privado" (OEA, 1995, p. 2). Já a Lei brasileira n 11.340 de 2006, considera a violência doméstica (VD) e familiar contra a mulher como "qualquer ação ou omissão baseada no gênero que lhe cause morte, lesão, sofrimento físico, sexual ou psicológico e dano moral ou patrimonial” (BRASIL, 2006, p. 5). A VDCM pode ocorrer de várias formas, sendo violência física, que pode ser qualquer conduta que possa ofender a integridade física da mulher; a violência psicológica, sendo considerada qualquer conduta que lhe cause prejuízos a saúde mental ou viole sua intimidade; Violência sexual, 
entendida como qualquer conduta que possa intimidar ou forçar a mulher a manter relações sexuais não consentidas; A violência patrimonial, que corresponde a qualquer conduta que retenha seus bens, como instrumentos de trabalho, documentos pessoais, ou recursos econômicos; e a violência moral, que engloba calúnias, difamação ou injúrias. A VDCM também pode ser dividida em três fases: a fase de tensão, que vai desde agressões verbais a agressões físicas leves e provocações; a segunda fase, que são as agressões físicas graves; e a última fase, em que o agressor se arrepende dos atos praticados, reiniciando o ciclo violento. Em todo o mundo a VD é um problema de saúde pública, no Brasil, não é diferente, e em decorrência disso foram instituídas algumas leis e portarias para o seu combate de forma efetiva e multidisciplinar, integrandos os órgãos de justiça, saúde, serviços sociais e segurança pública (NASCIMENTO et al., 2019; PIRES et al., 2019). Desta forma, vê-se que é importante que os profissionais de saúde, como os profissionais de enfermagem, que estão inseridos na equipe multiprofissional de estabelecimentos de saúde público ou privado, conheçam as bases legais de atendimento à mulher, incluindo as leis e portarias voltadas às mulheres vítimas de VD, para que consigam identificar, notificar e proporcionar um atendimento humanizado e integral, como por exemplo a lei de $n^{\circ} 12.845$ de 2013, conhecida como Lei do Minuto Seguinte, que dispõe sobre o atendimento integral a vítimas de violência sexual, na qual hospitais devem oferecer atendimento integral e emergencial através do tratamento profilático da gravidez e de Infecções Sexualmente Transmissíveis (IST) (BRASIL, 2013). Mulheres vítimas de violência doméstica, por vezes não relatam o ocorrido aos profissionais de saúde que lhes prestam assistência, chegando aos serviços de saúde e relatando outras queixas. Tal atitude além de dificultar a identificação e notificação de casos de violência, também interfere na implementação de ações para o enfrentamento e reflexões sobre o problema (MINAYO et al., 2020; PROCENTESE et al., 2019). Muitos profissionais, ainda entendem que a VCM é um problema que pode ser resolvido apenas por agentes judiciários, não sendo pertinente ao campo da saúde, esquecendo-se da responsabilidade do setor da saúde com os direitos humanos. Além disso, alguns profissionais veem dificuldades para lidar com esse problema, pois envolve muitas questões socioculturais, tornando difícil, inclusive, a identificação das vítimas (SILVA et al., 2020). É fato que a maior parte dos profissionais de enfermagem ainda não estão preparados para lidar com o problema da VD, principalmente por falta de informação ou treinamento. Isto reflete muitas vezes no julgamento das vítimas, que recebem tratamento apenas das feridas físicas da violência, e em seguida, são encaminhadas para outros serviços considerados mais adequados e não recebem atendimento voltado à sua saúde mental (XAVIER et al., 2017; MOTA et al., 2020). Estudo de Cortes et al (2016) relata que é comum que se faça somente o que está prescrito, o que caracteriza uma assistência unicamente clínica. O ideal, na verdade, é um cuidado clínico de enfermagem, acompanhado de escuta e diálogo que, além de um meio de enfrentamento, também tranquiliza a mulher.

\section{CONCLUSÃO}

Conclui-se que vários estudos mostram que a percepção da equipe de enfermagem acerca da VDCM ainda é limitada, o que impossibilita a identificação das vítimas. Muitas vezes esses profissionais associam a violência a agressões físicas e psicológicas, atribuindo como principais causas 
fatores socioculturais. Aliado a isso, também pode contribuir para a não identificação e subnotificação, questões relacionadas ao treinamento e falta de informação. Para isto, é extremamente necessário que os profissionais estejam preparados para notificar casos de VD assim que perceberem ou que tiverem conhecimento do ocorrido, e que estejam dispostos a serem coparticipantes no processo de apoio, combate à violência e reintegração da mulher. Salienta-se que a temática abordada neste estudo necessita de mais debates e investimentos, de forma a qualificar e informar os profissionais de saúde e de áreas afins, pois é um problema social e de saúde pública, que merece atenção especial e sensibilidade por parte dos profissionais que atendem ou que podem vir a atender uma mulher vítima de violência. Com isso, sugere-se que novos estudos sobre a temática, principalmente estudo qualitativos, que possam saber a sejam realizados, de forma a ampliar os conhecimentos e as evidências científicas acerca da violência doméstica contra a mulher.

\section{REFERÊNCIAS}

ACOSTA, D.F.; GOMES, V.L.O.; OLIVEIRA, D.C.; MARQUES, S.C.; FONSECA, A.D. Representações sociais de enfermeiras acerca da violência doméstica contra a mulher: estudo com abordagem estrutural. Revista Gaúcha de Enfermagem, Porto Alegre, v. 39, p. e61308, jul. 2018. Disponível em: https://www.scielo.br/pdf/rgenf/v39/1983-1447-rgenf-39-e61308.pdf. Acesso em: 23 dez. 2020.

BRASIL. Lei $\mathbf{n}^{\mathbf{0}} \mathbf{1 1 . 3 4 0}$, de 7 de agosto de 2006. Cria mecanismos para coibir a violência doméstica e familiar contra a mulher. Cria mecanismos para coibir a violência doméstica e familiar contra a mulher. Brasília (DF): 2006. Disponível em: http:/www.planalto.gov.br/ccivil_03/_ato20042006/2006/lei/111340.htm. Acesso em: 12 dez. 2020.

BUENO, S. Anuário Brasileiro de Segurança Pública 2019. Fórum Brasileiro de Segurança Pública, São Paulo, v. 13, p. 8-226, jun. 2019. Disponível em: https://forumseguranca.org.br/anuario-13/. Acesso em: 30 dez. 2020.

CERQUEIRA, D.; LIMA, R.S.D.; BUENO, S.; VALENCIA, L.I.; HANASHIRO, O.; MACHADO, P.H.G.; LIMA, A.D.S. Atlas da Violência. Mapeia os homicídios no Brasil. IPEA e FBSP, Rio de Janeiro, p. 27-51, 2018. Disponível em: https://www.ipea.gov.br/portal/images/stories/PDFs/ relatorio_institucional/180604_atlas_da_violencia_2018.pdf. Acesso em: 05 jan. 2021.

CORTES, L.F.; PADOIN, S.M.M; KINALSKI, D.D.F. Instrumentos para articulação da rede de atenção às mulheres em situação de violência: construção coletiva. Revista Gaúcha de Enfermagem, v. 37, n. esp., p. e2016-0056, jun. 2016. Disponível em: https://www.scielo.br/pdf/rgenf/v37nspe/01026933-rgenf-1983-14472016esp2016-0056.pdf. Acesso em: 28 dez. 2020.

Ministério da Saúde. Dados Epidemiológicos Sinan. 2020. Disponível em: http:// www.portalsinan.saude.gov.br/dados-epidemiologicos-sinan. Acesso em: 12 jan. 2021.

MINAYO, M.C.D.S.; SOUZA, E.R.D.; SILVA, M.M.A.D.; ASSIS, S.G.D. Institucionalização 
do tema da violência no SUS: avanços e desafios. Ciência \& Saúde Coletiva, Rio de Janeiro, v. 23, n. 6, p. 2007-16, jun. 2018. Disponível em: https://www.scielo.br/pdf/csc/v23n6/1413-8123csc-23-06-2007.pdf. Acesso em: 12 dez. 2020.

PIRES, V.M.M.M.; MORAIS, R.L.G.L.; SANTOS, L.S.; MACHADO, J.C.; GUEDES, C.A.; RODRIGUES, V.P. Violência por parceiro íntimo em abuso de álcool perpetrada contra mulheres no climatério. Revista de Enfermagem da UFSM, v. 9, e45, p. 1-20, 2019. Disponível em: https:// periodicos.ufsm.br/reufsm/article/view/34201/pdf. Acesso em: 07 dez, 2020.

ORGANIZAÇÃO DAS NAÇÕES UNIDAS (ONU). Transformando nosso mundo: a agenda 2030 para o desenvolvimento sustentável. 2015. Disponível em: http://svs.aids.gov.br/dantps/acesso-ainformacao/acoes-e-programas/ods/publicacoes/transformando-nosso-mundo-a-agenda-2030-parao-desenvolvimento-sustentavel.pdf. Acesso em: 01 dez. 2020.

PROCENTESE, F.; NAPOLI, L.D.; TUCCIllO, F.; CHIURAZZI, A.; ARCIDIACONO, C. Healthcare professionals' perceptions and concerns towards domestic violence during pregnancy in Southern Italy. International Journal of Environmental Research and Public Health, v. 16, n. 3087, p. 1-17, 2019. Disponível em: https://www.mdpi.com/1660-4601/16/17/3087/htm. Acesso em: 11 jan. 2021.

SILVA, AC.F.; LOSACCO, A.M.; MONTEIRO, I.A. ABRAHÃO, A.R. Violência sexual por parceiro íntimo identificada em Unidade Básica do PSF. Nursing (São Paulo), v. 23, n. 263, p. 3705-9, abr. 2020. Disponível em: http://www.revistanursing.com.br/revistas/263/pg48.pdf. Acesso em: 17 jan. 2021.

SILVA, V. G.; RIBEIRO, P. M. Violência Contra as Mulheres na Prática de Enfermeiras da Atenção Primária à Saúde. Escola Anna Nery, Rio de Janeiro, v. 24, n. 4, p. e20190371, jul. 2020. Disponível em: https://www.scielo.br/pdf/ean/v24n4/1414-8145-ean-24-4-e20190371.pdf. Acesso em: 22 jan. 2021.

XAVIER, A.A.P.; SILVA, E.G. Assistência de enfermagem no atendimento de mulheres em situação de violência na atenção básica. REICEN-Revista de Iniciação Científica e Extensão, v. 2, n. esp. 2, p. 293-300, 2019. Disponível em: https://revistasfacesa.senaaires.com.br/index.php/iniciacaocientifica/article/view/279/217. Acesso em: 20 out. 2020.

MELO, M.C.G.D; RODRIGUES, A.S. Políticas de atendimento às mulheres em situação de violência doméstica: os centros de referência de atendimento às mulheres e a abordagem interseccional. $\mathbf{O}$ Social em Questão, v. 38, p.153-70, maio./ago., 2017. Disponível em: http://osocialemquestao.ser. puc-rio.br/media/OSQ_38_art_8_Melo_Rodrigues.pdf. Acesso em: 19 jan. 2021.

NASCIMENTO, V.F.; ROSA, T.F.L.; TERÇAS, A.C.P.; HATTORI, T.Y.; NASCIMENTO. V.F. Desafios no atendimento à casos de violência doméstica contra a mulher em um município matogrossense. Arquivos de Ciências da Saúde da UNIPAR, Umuarama, v. 23, n. 1, p, 15-22, jan./ abr. 2019. Disponível em: https://www.revistas.unipar.br/index.php/saude/article/view/6625/3725. 
Acesso em: 21 dez. 2021.

Ministério da Saúde. Decreto $\mathbf{n}^{\mathbf{0}} \mathbf{7 . 9 5 8}$, de 13 de março de 2013. Estabelece diretrizes para o atendimento às vítimas de violência sexual pelos profissionais de segurança pública e da rede de atendimento do Sistema Único de Saúde. Brasília (DF): Ministério da Saúde, 2013. Disponível em: http://www.planalto.gov.br/ccivil_03/DECRETO/D7958.htm. Acesso em: 22 jul. 2019. 


\section{EXPOSIÇÃO À DISRUPTORES ENDÓCRINOS AMBIENTAIS E HIPOTIREOIDISMO: UMA BREVE REVISÃO NA PERSPECTIVA DA SAÚDE COLETIVA}

\section{Paulo Ricardo Batista ${ }^{1, *}$}

${ }^{1}$ Graduação em Ciências Biológicas, Universidade Regional do Cariri (URCA), Crato, Ceará.

\section{RESUMO}

Poluentes ambientais do grupo dos Disruptores Endócrinos (DE) podem acarretar hipotireoidismo, condição intricada a muitas complicações biológicas. Nesse contexto, esse estudo propõe sintetizar saberes publicados que interrelacionem os $\mathrm{DE}$ ao hipotireoidismo para aludir às consequências da exposição a esses contaminantes ambientais no âmbito da saúde coletiva. Para alcançar essa meta, uma revisão integrativa da literatura foi traçada nos bancos de dados PubMed, LILACS e SciELO, a partir das palavras-chaves: hypothyroidism e endocrine disruptors. A síntese do conhecimento possibilitou destacar: a importância fisiológica dos hormônios tireoidianos, a sensibilidade da glândula tireoide a sofrer disfunções por DE (a exemplo: Bifenilos Policlorados, Éteres Difenil Polibromados, Percloratos, Bisfenol A e Ftalatos) e as facetas sociais, econômicas, políticas e ambientais relacionadas à temática proposta, que por fim, merece atenção no campo da saúde coletiva para o direcionamento de estratégias em saúde.

PALAVRAS-CHAVE: Contaminantes emergentes; Saúde pública; Disfunção tireoidiana. ÁREA TEMÁTICA: Saúde coletiva.

\section{INTRODUÇÃO}

Disruptores Endócrinos (DE) são moléculas químicas exógenas (naturais ou sintéticas) que influenciam na biossíntese, liberação, transporte, ligação, atuação ou depleção de hormônios naturais - reguladores da manutenção, reprodução, desenvolvimento e/ou comportamento - pelo corpo. Podendo ser encontradas no meio ambiente e ser tóxicas à saúde humana e animal. Entre os efeitos deletérios vinculados as DE, têm-se o hipotireoidismo (BARROS et al., 2019). Este último, por sua vez, é caracterizado como um estado clínico decorrente de quantidade insuficiente ou ausência de hormônios circulantes produzidos pela glândula tireóide (T4 e T3) (OLIVEIRA; MALDONADO, 2014). 
Assim, dada a relevância desse quadro patológico para a saúde pública e das complicações advindas diretamente do hipotireoidismo ou associadas à comorbidades, esse estudo propõe sintetizar saberes publicados que interrelacionem os $\mathrm{DE}$ ao hipotireoidismo para aludir às consequências da exposição a esses contaminantes ambientais no âmbito da saúde coletiva.

\section{METODOLOGIA}

Esta pesquisa descritiva foi elaborada na forma de uma revisão integrativa abrangendo uma abordagem quali-quantitativa. As etapas básicas para sua construção foram concretizadas com base nas descrições de Botelho, Cunha e Macedo (2011), envolvendo desde o estabelecimento da temática e construção de uma pergunta de pesquisa até a apresentação da revisão.

Nesse sentido, a questão de pesquisa é: Há estudos que refletem a exposição à disruptores endócrinos e hipotireoidismo no âmbito da saúde coletiva?

Os sites de buscas definidos para a coleta dos estudos foram: PubMed, Literatura LatinoAmericana e do Caribe em Ciências da Saúde (LILACS) e Scientific Electronic Library Online (SciELO). As palavras-chaves aplicadas foram: hypothyroidism e endocrine disruptors, cruzadas com o operador booleano $A N D$.

Os critérios de elegibilidade delineados foram: artigos completos e disponíveis que retratem a temática, sem recorte temporal e idioma Inglês para assim favorecer uma revisão do conhecimento acessível no idioma Português. A coleta de dados procedeu entre fevereiro e março de 2021 e os dados foram extraídos e agrupados de acordo com similaridades e divergências, apresentando também resultados quantitativos.

\section{FUNDAMENTAÇÃO TEÓRICA}

A amostra inicial compôs-se de 17 artigos, sendo 14 retornados em PubMed, 1 em LILACS e 2 estudos em SciELO. A posteriori, foram desconsideradas 2 duplicatas, e aplicados os critérios de elegibilidade (inclusão e exclusão), resultando na amostra final de 9 artigos.

A síntese de conhecimento permitiu argumentar que alterações nas concentrações de hormônios tireoidianos causam efeitos deletérios no cérebro (PINSON; BOURGUIGNON; PARENT, 2016). Uma vez que os mesmos são imprescindíveis para o desenvolvimento cerebral normal, dessa forma, as consequências (prejuízos intelecto-comportamentais, por exemplo) podem reverberar na sociedade como um todo, apontando para o aumento nas despesas com saúde e redução na renda vitalícia (RAMHØJ et al., 2020). Além do neurodesenvolvimento fetal, os hormônios tireoidianos são importantes para a regulação metabólica e estão associados a doenças cardiovasculares e fertilidade (COPERCHINI et al., 2021). 
A glândula tireoide, por sua vez, é tida como sensível a atuação de DE que podem culminar em disfunção, e consequente, hipotireoidismo. Entre os produtos químicos industriais que influem no eixo hipotálamo-hipófise-tireioide, se têm: os Bifenilos Policlorados, Éteres Difenil Polibromados, Percloratos, Bisfenol A e Ftalatos (BARROS et al., 2019).

Esses DE onipresentes podem ser persistentes: (1) Bifenilos Policlorados, pertencentes a uma família de compostos industriais fabricados até os anos 70, e têm sido largamente empregados em capacitores e transformadores, além de descartados em altas concentrações no meio ambiente e (2) Éteres Difenílicos Polibromados, utilizados como retardadores de chama em móveis, eletrônicos, roupas, entre outros produtos, os níveis desses éteres no corpo humano aumentaram no final do século XX. Ou não persistentes, como o: Bisfenol A, ubíquo e fracamente estrogênico empregado na produção de plásticos de policarbonato e resinas epóxi (PINSON; BOURGUIGNON; PARENT, 2016).

O Di-(2-Etilhexil) Ftalato ou Éster de Ftalato é outro DE ambiental, de grande preocupação pública. Muito utilizado em produtos industriais como embalagens de alimentos e brinquedos, e que podem promover uma disfunção tireoidiana (WU; MA; NA, 2020).

A literatura também indica que a poeira doméstica é importante fonte de contaminantes originários, por exemplo, do uso e desgastes de produtos domésticos. Entre os quais, Fenóis, Ftalatos, Parabenos, Compostos Perfluoroalquil, Éteres Difenil Polibromados e Bifenilos Policlorados, ambos desreguladores do hormônio tireoidiano. Não obstante a ingestão de poeira doméstica ser a principal via de exposição para crianças (HAMERS et al., 2020).

Um estudo preliminar reportou uma relação significativa entre o aumento de chances de hipotireoidismo e DE com base nos níveis sanguíneos desses últimos, em voluntários com a doença (DUFOUR et al., 2019). Outro indicou as implicações para a saúde de pessoas que vivem em um estilo de vida de subsistência. Posto se ter identificado contaminação de peixes de água doce por Bifenilos Policlorados (HIPPEL et al., 2018).

Essas informações resgatadas são importantes no trato da saúde coletiva, uma vez que sua definição se volta para a compreensão da saúde e a explicação de seus determinantes sociais, assim como o cenário das práticas direcionadas para a sua promoção, prevenção e cuidado a agravos e doenças, tendo por objeto a própria coletividade (VIEIRA-DA-SILVA; PAIM; SCHRAIBER, 2014).

\section{CONSIDERAÇÕES FINAIS}

Destaca-se a incipiência de estudos prospectados pertinentes a temática, podendo também ter relação com o arranjo dos critérios de elegibilidade. Em adição, os DE merecem atenção no campo da saúde coletiva, visto que sua exposição (por ingestão, contato dérmico, inalação, e outros) pode trazer sérias consequências para a saúde humana - como o hipotireoidismo - e ambiental, sendo necessários direcionamentos, planejamentos e intervenções dos serviços (e estratégias) de saúde 
nessa perspectiva.

\section{REFERÊNCIAS}

BARROS, D. M.; MELO, M. A.; SANTOS, C. Y. B.; PEREIRA, A. S.; SOUSA, A. F.; ALVES, A. T. S.; COSTA, J. O.; FREITAS, T. S.; SANTOS, M. E. M.; CARVALHO, S. S.; JACOBINE, T. A.; SILVA, J. H. L.; AGUIAR, G. B.; PADILHA, A. C. B. S.; ROCHA, T. A.; FERREIRA, S. A. O.; MOURA, D. F. Disruptores endócrinos e sua influência na saúde humana. Brazilian Journal of Development, v. 5, n. 11, p. 24211-24225, 2019.

BOTELHO, L. L. R.; CUNHA, C. C. A.; MACEDO, M. O método da revisão integrativa nos estudos organizacionais. Gestão e Sociedade, v. 5, n. 11, p. 121-136, 2011.

COPERCHINI, F.; CROCE, L.; RICCI, G.; MAGRI, F.; ROTONDI, M.; IMBRIANI, M.; CHIOVATO, L. Thyroid disrupting effects of old and new generation PFAS. Frontiers in Endocrinology, v. 11, 2021.

DUFOUR, P.; PIRARD, C.; PETROSSIANS, P.; BECKERS, A.; CHARLIER, C. Association between mixture of persistent organic pollutants and thyroid pathologies in a Belgian population. Environmental Research, v. 181, 2019.

HAMERS, T.; KORTENKAMP, A.; SCHOLZE, M.; MOLENAAR, D.; CENIJN, P. H.; WEISS, J. M. Transthyretin-binding activity of complex mixtures representing the composition of thyroid-hormone disrupting contaminants in house dust and human serum. Environmental Health Perspectives, v. 128, n. 1, p. 017015-1-017015-15, 2020.

HIPPEL, F. A. V.; MILLER, P. K.; CARPENTER, D. O.; DILLON, D.; SMAYDA, L.; KATSIADAKI, I.; TITUS, T. A.; BATZEL, P; POSTLETHWAIT, J. H.; BUCK, C. L. Endocrine disruption and differential gene expression in sentinel fish on St. Lawrence Island, Alaska: health implications for indigenous residents. Environmental Pollution, v. 234, p. 279-287, 2018.

OLIVEIRA, V.; MALDONADO, R. R. Hipotireoidismo e hipertireoidismo - uma breve revisão sobre as disfunções tireoidianas. Interciência \& Sociedade, v. 3, n. 2, p. 36-44, 2014.

PINSON, A.; BOURGUIGNON, J. P.; PARENT, A. S. Exposure to endocrine disrupting chemicals and neurodevelopmental alterations. Andrology, v. 4, n. 4, p. 1-17, 2016.

RAMHØJ, L.; HASS, U.; GILBERT, M. E.; WOOD, C.; SVINGEN, T.; USAI, D.; VINGGAARD, A. M.; MANDRUP, K.; AXELSTAD, M. Evaluating thyroid hormone disruption: investigations of long-term neurodevelopmental effects in rats after perinatal exposure to perfluorohexane sulfonate (PFHxS). Scientific Reports, v. 10, 2020.

VIEIRA-DA-SILVA, L. M.; PAIM, J. S.; SCHRAIBER, L. B. O que é saúde coletiva? In: PAIM, J. S.; ALMEIDA-FILHO, N. (Org.). Saúde Coletiva: teoria e prática. Rio de Janeiro: MedBook, 
2014, p. 3-12.

WU, H.; MA, K.; NA, X. Rosmarinic acid alleviates di-2-ethylhexyl phthalate (DEHP)-induced thyroid dysfunction via multiple inflammasomes activation. The Journal of Toxicological Sciences, v. 45, n. 7, p. 373-390, 2020. 


\title{
HANSENÍASE EM UM MUNICÍPIO HIPERENDÊMICO: UM ESTUDO DESCRITIVO
}

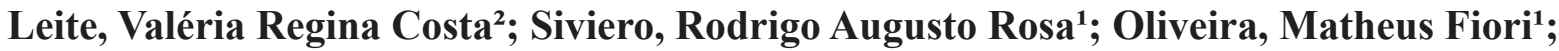 Carrati, Pietro Oliveira Ferrari'; ${ }^{\prime}$ Pereira, Ana Carolina Ribeiro ${ }^{3}$}

${ }^{1}$ Graduando de Medicina pela Universidade Federal de Mato Grosso-Campus Sinop (UFMT-Sinop), Instituto de Ciências da Saúde (ICS). Sinop, Mato Grosso.

${ }^{2}$ Médica Residente de Medicina de Família e Comunidade, Secretaria Municipal de Saúde de Sinop (SMS-Sinop). Sinop, Mato Grosso.

${ }^{3}$ Médica preceptora do Programa de Residência em Medicina de Família e Comunidade, Secretaria Municipal de Saúde de Sinop (SMS-Sinop). Sinop, Mato Grosso.

\begin{abstract}
RESUMO
Casos de Hanseníase estão cada vez mais sendo diagnosticados nas Unidades Básicas de Saúde (UBS) do município de Sinop. Essa é uma doença de notificação compulsória e de tratamento realizado pelo Sistema Único de Saúde (SUS) de acordo com a classificação de sua forma clínica, com a interrupção da transmissão ocorrendo poucos dias após o início do tratamento. Este estudo teve a intenção de realizar uma análise da situação epidemiológica no município de Sinop e compreender a importância do atendimento primário a saúde no diagnóstico da doença. Realizou-se um estudo documental a partir de dados de notificação compulsória do Ministério da Saúde (MS) entre 2012 e 2019. Sinop está classificada em situação hiperendêmica, sendo o município do estado de Mato Grosso com maior taxa de novos casos comunicados desde 2016 com um aumento significado em relação aos anos anteriores.
\end{abstract}

PALAVRAS-CHAVE: Infectoparasitária; Atenção Primária; Residência Médica ÁREA TEMÁTICA: Saúde Coletiva 


\section{INTRODUÇÃO}

A Hanseníase, antigamente chamada de Lepra, é uma doença infecciosa, transmissível e de caráter crônico, que ainda persiste como problema de saúde pública no Brasil (Boletim Epidemiológico de Hanseníase 2021). É causada pelo Mycobacterium leprae, um bacilo caracterizado por uma alta infectividade e uma baixa patogenicidade. É necessário um longo período de exposição à doença e uma baixa resposta imunológica contra o M. leprae. A patologia é adquirida por inalação, levando ao acometimento da pele e nervos periféricos, atingindo fibras sensitivas, motoras e autonômicas podendo causar graves consequências aos pacientes, em maior ou menor intensidade. A análise dessa doença é de grande importância tanto em relação a sua incidência quanto a suas sequelas devido ao seu poder gerador de incapacidade. O período de incubação é longo, de 3 a 7 anos (tendo como média 5 anos) e devido a isto é necessário a avaliação de contatos durante um período de 5 anos, a fim de diagnosticar novos casos. Sendo assim, quanto mais precoce for diagnosticada e tratada, menores são as chances de o paciente desenvolver prejuízos sensitivos e/ou motores e menores são as chances de transmissão. (NEVES, 2011)

O Brasil é o segundo país em número de casos no mundo, de acordo com a Organização Mundial de Saúde (OMS). Segundo o Sistema de Informação de Agravos de Notificação (SINAN), Mato Grosso é o $2^{\circ}$ Estado com maior número de casos no país, ficando atrás apenas do Estado do Pará. Já Sinop está classificada em situação hiperendêmica, sendo o município do Estado de Mato Grosso com maior taxa de novos casos comunicados desde 2016. Essa é uma doença de notificação compulsória e de tratamento realizado pelo Sistema Único de Saúde (SUS) de acordo com a classificação de sua forma clínica, com a interrupção da transmissão ocorrendo poucos dias após o início do tratamento.

\section{OBJETIVO:}

Realizar uma análise descritiva da situação epidemiológica de Hanseníase.

\section{METODOLOGIA:}

Este é um estudo epidemiológico descritivo documental por meio de dados obtidos pelo Sistema de Informação de Agravos de Notificação (SINAN) da Hanseníase no Município de SinopMT do ano 2012 à 2019. As variáveis analisadas foram número de casos, faixa etária, sexo e grau de incapacidade. 


\section{RESULTADOS E DISCUSSÃO:}

A partir da coleta de dados disponíveis no SINAN do Estado de Mato Grosso, foi possível realizar a comparação da evolução da Hanseníase em Sinop do ano de 2012 ao ano de 2019, totalizando 3.157 casos notificados. No município houve um notável aumento destas notificações a partir do ano de 2015.

Sinop ocupa a posição de município do Estado com maior número de casos notificados desde o ano de 2016, com um crescimento de casos diagnosticados em todas as faixas etárias. Esse dado mostra a necessidade de atenção local sobre essa doença, pois a presença de hanseníase em idades precoces indica uma alta endemicidade (FREITAS et al, 2017; PIRES et al, 2012). No município ocorreu um acréscimo de número de casos novos em relação a população de 1 a 14 anos de idade em 2017, sendo o período de 2012 a 2015 com um somatório de 20 (0,63\%) casos, enquanto de 2016 a 2019 ocorreram 78 (2,47\%) notificações. Em relação ao total de casos é possível observar uma alta, em que os casos notificados de 2012 a 2019 foram respectivamente 169 (5,35\%), 129 (4,08\%), 103 (3,26\%), 116 (3,67\%), 336 (10,64\%), 671 (21,25\%), 879 (27,84\%), 754 (23,88\%), ou seja, há uma forte ampliação de notificação a partir do ano de 2016, sendo um dos possíveis fatores o início do Programa de Residência Médica em Medicina de Família e Comunidade no município no ano de 2016.

A população feminina foi a mais acometida no somatório entre os anos de 2012 a 2019 , tendo como resultado 1.958 casos (62,02\%), enquanto a população masculina foi de 1.199 (37,97\%). Coincidentemente, antes do ano 2016 a maior parte dos casos notificados eram do sexo masculino e após passou a haver predomínio do sexo feminino.

Além disso, pôde-se observar uma melhora na qualidade de notificação a respeito da Hanseníase no município. Do ano de 2012 a 2015 ocorreram 88 (2,79\%) notificações sem avaliação do grau de incapacidade, além do não preenchimento desse campo em 8 (0,28\%) casos. Já em relação ao período 2016 a 2019 ocorreram apenas 9 (0,285\%) casos sem avaliação e 2 (0,063\%) sem preenchimento. Em relação à distribuição entre os Graus de Incapacidade, pôde-se notar que a maior parte se encontra no Grau 0, ou seja, sem incapacidade. Entretanto, o Grau 1 segue de perto os números deste último.

O Programa de Residência Médica de Família e Comunidade da Secretaria Municipal de Saúde do Município de Sinop-MT, criado em 2016, proporcionou capacitação em Hanseníase para os médicos residentes e toda a equipe da APS, assim como campanhas para exame de contatos e identificação de casos novos, o que poderia estar influenciando o comportamento da Hanseníase e justificar o aumento das notificações descritas anteriormente. 


\section{CONSIDERAÇÕES FINAIS:}

Há de se elencar como um dos possíveis fatores para aumento de diagnóstico e melhora da qualidade técnica de notificação a criação do Programa de Residência em Medicina de Família e Comunidade no município de Sinop-MT juntamente com seus treinamentos e campanhas realizadas com a presença dos residentes do programa. Sendo assim, a Atenção Primária é notavelmente essencial para a identificação da Hanseníase para que seja possível a quebra do ciclo de transmissão dessa doença e, assim, a melhora da qualidade de saúde da população. Esse estudo é descritivo e por isso não realiza correlações, sendo seu intuito a identificação de possibilidades para um estudo detalhado a posteriori.

\section{REFERÊNCIAS}

1. FREITAS, BHBM; CORTELA, DDCB; FERREIRA, SMB; Trend of leprosy in individuals under the age of 15 in Mato Grosso (Brazil), 2001-2013. Rev Saúde Pública. 2017 Apr 10;51:28. doi: 10.1590/S1518-8787.2017051006884. PMID: 28423139; PMCID: PMC5396506

2. NEVES, D.P. - Parasitologia humana. $12^{\mathrm{a}}$ ed. São Paulo, Atheneu, 2011

3. PIRES, Carla Andrea A. et al. Hanseníase em menores de 15 anos: a importância do exame de contato. Rev. paul. pediatr., São Paulo , v. 30, n. 2, p. 292-295, Jun 2012 . Disponível em: <http:// www.scielo.br/scielo.php?script=sci_arttext\&pid=S010305822012000200022\&ln g=en\&nrm=iso $>$. Accesso em 06 Fev. 2021. http://dx.doi.org/10.1590/S0103-05822012000200022.

4. SINAN. Hanseníase. Notificações Registradas: banco de dados. Disponível em: <http://tabnet. datasus.gov.br/cgi/tabcgi.exe?sinannet/cnv/hanswmt.def> . Acesso em 6 fev. 2021.

5. BRASIL. Ministério da Saúde. Boletim Epidemiológico de Hanseníase 2021. Número Especial. Jan 2021. Disponível em: <http://www.aids.gov.br/pt-br/pub/2021/boletim-epidemiologicohanseniase-2021>. Acesso em 02 mar. 2021. 


\section{ATENÇÃO À SAÚdE MENTAL: DOS MANICÔMIOS AOS PARÂMETROS ATUAIS}

\section{Izabel Viviane de Oliveira Fagundes'; César Luis Porpino Santos da Silva Júnior ${ }^{1}$}

${ }^{1}$ Graduada em Enfermagem, Residente Multiprofissional em Atenção Básica, Escola Multicampi de Ciências Médicas, Universidade Federal do Rio Grande do Norte (UFRN), Currais Novos, RN.

${ }^{2}$ Graduado em Odontologia, Residente Multiprofissional em Atenção Básica, Escola Multicampi de Ciências Médicas, Universidade Federal do Rio Grande do Norte (UFRN), Currais Novos, RN.

\section{RESUMO}

Introdução: com uma forte crítica ao modelo hospitalocêntrico, iniciaram-se, na década de 70, os movimentos que originaram a Reforma Psiquiátrica Brasileira, concomitante ao período de redemocratização, discutindo a garantia de direitos humanos às pessoas vítimas de violência psiquiátrica. O objetivo do estudo é discorrer sobre os principais modelos estratégicos de desinstitucionalização implementadas ao longo dos anos no Brasil. Metodologia: trata-se de uma revisão de literatura, descritiva convencional, baseada na coleta e análise de informações relativas à temática proposta. Fundamentação Teórica: ao longo dos anos, houve o notável aumento da criação de serviços substitutivos ao modelo hospitalar. Contudo, essas estratégias vêm sofrendo recuos que afetam diretamente o modelo iniciado pela Reforma Psiquiátrica. Considerações Finais: os avanços permitiram a construção de novos saberes capazes de enxergar o adoecimento mental pela subjetividade e autonomia do indivíduo. Entendendo essa importância, deve-se adotar estratégias de resistência aos retrocessos causados nos recentes anos.

PALAVRAS-CHAVES: Desinstitucionalização; Serviços de saúde mental; Reabilitação psiquiátrica ÁREA TEMÁTICA: Saúde Coletiva

\section{INTRODUÇÃO}

Os primeiros movimentos que desencadearam o início da Reforma Psiquiátrica Brasileira (RPB) iniciaram-se nos anos 70 com a denúncia das diversas violências nos serviços manicomiais, associado a uma forte crítica ao modelo médico-hospitalocêntrico. Esse cenário também estava atrelado ao período de redemocratização e de lutas contra a ditadura militar, além da própria luta pelos direitos humanos das pessoas vítimas de violência psiquiátrica (AMARANTE; NUNES, 2018). 
Foi só nos anos 2000, há 20 anos, que foi aprovada a chamada Reforma Psiquiátrica Brasileira através da Lei № 10.316/2001 que descreve sobre os direitos e proteção das pessoas com transtornos mentais além da mudança dos modelos e serviços em saúde mental. Ao longo desses anos, diversas estratégias foram criadas com vistas à substituição gradativa dos hospitais psiquiátricos para que dessem vez a um sistema integrado em redes voltado à atenção em saúde mental (BRASIL, 2005).

A implantação das Redes de Atenção à Saúde (RAS) também se configuraram como um marco essencial na estruturação do novo modelo de atenção à saúde mental no país. São definidas a partir de estratégias organizativas para o cuidado integralizado que se orienta pelas necessidades de saúde da população, caracterizando-se como arranjos definidos em rede centralizando a Atenção Primária à Saúde (APS) para a coordenação do cuidado e sendo a principal entrada para o Sistema Único de Saúde (SUS) (BRASIL, 2012).

Esses fatos proporcionaram condições para a instituição da Rede de Atenção Psicossocial no ano de 2011, tornando-se uma estratégia prioritária para as pessoas com sofrimento ou transtorno psíquico além das pessoas que apresentassem necessidades geradas pelo uso de álcool, crack e outras drogas, no âmbito do SUS (BRASIL, 2013)

Sabendo da importância do novo modelo de atenção à saúde metal proposto a partir da RPB, o trabalho tem por objetivo discorrer sobre os principais modelos estratégicos de desinstitucionalização da Rede de Atenção Psicossocial implementadas ao longo dos anos no Brasil.

\section{METODOLOGIA}

O trabalho trata-se de uma revisão de literatura, de caráter descritivo convencional, baseada na coleta e análise de informações relativas à temática proposta. Foi realizado o levantamento dos estudos primários através do acesso às bases de dados, Scielo (Scientific Eletronic Library Online), Literatura Latino Americana e do Caribe em Ciências da Saúde (LILACS) e PubMed (Medline), utilizando diversos descritores relativos à atenção à saúde mental, à reforma psiquiátrica e aos serviços de saúde mental.

Foram analisados os artigos com acesso livre, no idioma português que abordaram a temática do estudo, além dos documentos oficiais do Ministério da Saúde que apresentam relevância para à temática proposta. Inicialmente, os estudos foram selecionados apenas pelo título e resumo. Em seguida, avaliou-se a qualidade desses estudos, sendo feita a seleção das informações principais. Essas etapas foram realizadas de forma independente pelos membros do estudo. 


\section{FUNDAMENTAÇÃO TEÓRICA}

A construção da RPB foi adotada no sentido da amplitude desse processo, para não ser considerada apenas a mudança dos serviços e das tecnologias de cuidado em saúde, mas que houvesse o delineamento de um lugar social para loucura. No final dos anos 80 surge a perspectiva de criação para novos serviços que se mostrassem como práticas inovadoras ao modelo hospitalar que era predominante naquela época (AMARANTE; NUNES, 2018).

Junto com a proposta da mudança dos serviços de atenção à saúde mental surgem os Centros de Atenção Psicossocial (CAPS), que tiveram sua regulamentação nos anos 90 e atualização nos anos 2000 a partir da portaria instituída em 19 de fevereiro de 2002, n 336. Consistem-se como serviços estratégicos, substitutivos à lógica manicomial, caracterizados por porte e clientela nas seguintes divisões: CAPS I, CAPS II, CAPS III, CAPS i e CAPS ad. Esses serviços devem ser qualificados para atender os diversos tipos de transtornos mentais, de todos os graus, devendo funcionar de forma independente às estruturas hospitalares (GUEDES et al., 2010). Dessa forma, os CAPS trazem uma lógica de reinserção do paciente psiquiátrico em um ambiente comunitário e cultural que proporcione assistência à saúde mental, acolhimento e o exercício de sua autonomia. Segundo dados do Ministério da Saúde em 2014, a rede CAPS atingiu um total de 2.209 serviços, em detrimento de 1010 no ano de 2006 (BRASIL, 2015).

Os Serviços Residenciais Terapêuticos (SRT) foram instituídos pela portaria $n^{\circ} 106$, de 11 de fevereiro de 2000. Conceituadas como residências inseridas no meio comunitário, são destinadas ao cuidado do indivíduo com transtorno metal com longo histórico de internações psiquiátricas que não possuam apoio social ou laços familiares inviabilizando sua inserção social (BRASIL, 2000). Esses equipamentos contribuíram com a redução de leitos psiquiátricos ocupados por moradores com transtornos mentais que tinham perfil clínico para voltar à comunidade, porém, apresentavam comprometimento de seus laços (FRANÇA et al., 2017). Dados do Ministério da Saúde mostram que em dezembro de 2014 existiam 610 SRT espalhados por todo o país (BRASIL, 2015).

O Programa de Volta para Casa (PVC) foi regulamentado pela Lei $n^{\circ}$ 10.708/2003 (BRASIL, 2003). Constitui-se como um programa de pagamento beneficiário para pessoas com transtornos psíquicos em processo de desinstitucionalização e histórico de longas internações, favorecendo o indivíduo à inserção no meio produtivo, civilizatório e social a partir de um recurso financeiro (GUERRERO et al., 2019).

Em 2014, o programa atingiu um total de 4.349 beneficiários em detrimento de 206 no ano de 2003 (BRASIL, 2015).

A instituição da Lei Federal de Saúde Mental $n^{\circ}$ 10.216/01 preconizou a internação psiquiátrica apenas quando os recursos extra-hospitalares se mostrarem insuficientes. Nesses casos, as internações devem ser pautadas pela integralidade e oferta de todos os serviços essenciais para a recuperação da pessoa que dela necessita (BRASIL, 2005). Associado à RPB e aos serviços de desinstitucionalização, também ocorreu a diminuição gradativa de leitos em hospitais psiquiátricos 
pelo Brasil. Em 2002 esse número era de 51.393 e em 201425.988 (BRASIL, 2015). Todos esses dados se mostram em consonância com o processo de consolidação da reforma psiquiátrica.

Por fim, cabe aqui mencionar que apesar de todos esses avanços após a instituição da Lei da Reforma Psiquiátrica, atualmente, a Política Nacional de Saúde Mental (PNSM) vem sofrendo diversos recuos. Tendo sido os últimos anos atrelados à fragilização das políticas e dos serviços públicos. Entre 2016 a maio de 2019, houve edição de diversos documentos normativos, dentre portarias, decretos, resoluções e editais que culminou na nota técnica 11/2019-CGMAD/DAPES/SAS/MS chamada de "Nova Política Nacional de Saúde Mental", que incentiva as internações psiquiátricas, retornando ao modelo hospitalocêntrico (MOREIRA; GUERRERO; BESSONI, 2019; CRUZ; GONÇALVES; DELGADO, 2020).

\section{CONSIDERAÇÕES FINAIS}

A implementação dos serviços substitutivos ao modelo manicomial/hospitalocêntrico garantiu diversos avanços dentro da Rede de Atenção Psicossocial que foram ancorados pela Reforma Psiquiátrica ao longo dos anos. Tudo isso permitiu a construção de novos saberes que fossem capazes de enxergar o adoecimento mental a partir da subjetividade e autonomia do indivíduo além da valorização de sua dignidade pessoal e o livre exercício da cidadania. É entendendo a importância dos diversos avanços relacionados à atenção psicossocial brasileira que se deve adotar estratégias de resistência aos diversos retrocessos que políticas de governo atuais vêm promovendo.

\section{REFERÊNCIAS}

AMARANTE, Paulo; NUNES, Mônica de Oliveira. A reforma psiquiátrica no SUS e a luta por uma sociedade sem manicômios. Ciênc. saúde coletiva, Rio de Janeiro, v. 23, n. 6, p. 2067-2074, 2018. Disponível em: < https://doi.org/10.1590/1413-81232018236.07082018> $>$. Acesso em: 16 mar. 2021.

BRASIL. Ministério da Saúde. SAS/Dapes. Coordenação Geral de Saúde Mental, Álcool e Outras

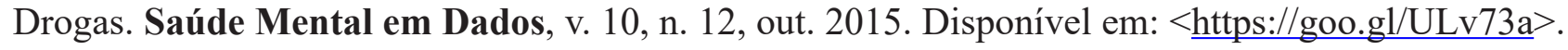
Acesso em: 17 mar 2021.

BRASIL. Ministério da Saúde. Secretaria de Atenção à Saúde. DAPE. Coordenação Geral de Saúde Mental. Reforma psiquiátrica e política de saúde mental no Brasil. Documento apresentado à Conferência Regional de Reforma dos Serviços de Saúde Mental: 15 anos depois de Caracas. OPAS. Brasília, Nov. 2005. Disponível em: $<$ https://bvsms.saude.gov.br/bvs/publicacoes/Relatorio15 anos_Caracas.pdf>. Acesso em: 16 mar. 2021.

CRUZ, Nelson Falcão de Oliveira; GONCALVES, Renata Weber; DELGADO, Pedro Gabriel Godinho. Retrocesso da reforma psiquiátrica: o desmonte da política nacional de saúde mental brasileira de 2016 a 2019. Trab. educ. saúde, Rio de Janeiro, v. 18, n. 3, 2020. Disponível em: 


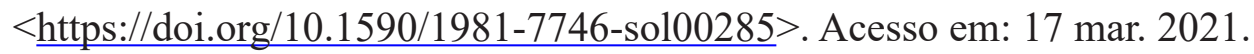

FRANÇA, Vanessa Vieira et al. Quem são os moradores de residências terapêuticas? Perfil de usuários portadores de transtornos mentais desinstitucionalizados. Saúde em Debate, v. 41, p. 872-884, 2017.

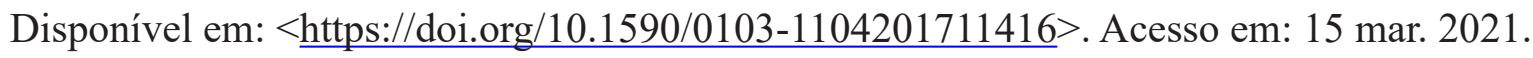

GUEDES, Ariane da Cruz et al. A mudança nas práticas em saúde mental e a desinstitucionalização: uma revisão integrativa. Revista Eletrônica de enfermagem, v. 12, n. 3, p. 547-53, 2010. Disponível em: < https://doi.org/10.5216/ree.v12i3.8198>. Acesso em: 15 mar. 2021.

MOREIRA, Maria Inês Badaró; GUERRERO, André Vinicius Pires; BESSONI, Enrique Araújo. Entre desafios e aberturas possíveis: vida em liberdade no contexto da desinstitucionalização brasileira. Saúde e Sociedade [online]. v. 28, n. 3. 2019. Disponível em: < $\underline{\text { https://doi.org/10.1590/ }}$ $\underline{\text { S0104-12902019000003 }>\text {. }}$

Acesso em: 16 mar. 2021. 


\title{
PERSPECTIVAS DE ATUAÇÃO DOS RESIDENTES EM SAÚDE DA FAMÍLIA DURANTE A PANDEMIA DE COVID-19
}

\section{Danieli Cristina Scalco'; Eli Fatima Monauer²; Luana Lunardi Alban³; Maria José Alves Boa Sorte Rodrigues ${ }^{4}$; Matheus Henrique Rossatto ${ }^{5}$}

\author{
${ }_{1}$ Preceptora em Enfermagem - Escola Municipal de Saúde Pública, Cascavel, Paraná. \\ ${ }_{2}$ Residente Multiprofissional em Saúde da Família - Serviço Social, Escola Municipal de Saúde \\ Pública, Cascavel, Paraná. \\ ${ }_{3}$ Residente Multiprofissional em Saúde da Família - Enfermagem, Escola Municipal de Saúde \\ Pública, Cascavel, Paraná. \\ 4Preceptora em Serviço Social - Escola Municipal de Saúde Pública - Cascavel, Paraná. \\ ${ }_{5}$ Residente Multiprofissional em Saúde da Família - Serviço Social, Escola Municipal de Saúde \\ Pública, Cascavel, Paraná.
}

\section{RESUMO}

Desde o início da pandemia, presenciamos um aumento exponencial dos casos, tivemos uma reorganização do sistema de saúde. Os profissionais de saúde vivenciam dias de incertezas e medos, precisando munir-se de coragem para enfrentar o que eles próprios desconhecem. Trata-se de um relato de experiência, dos residentes e preceptores do Programa de Residência Multiprofissional em Saúde da Família no Município de Cascavel, para apresentar as principais dificuldades e possibilidades da intervenção multiprofissional. $\mathrm{O}$ trabalho desses profissionais, tem destaque e grande importância, pois estes estão mais próximos da população do seu território adscrito e, priorizam ações de promoção, proteção e recuperação de saúde, de forma integral e continuada. Lidamos com uma "quebra" de expectativas do que iríamos encontrar no cenário de prática, mudando rotinas e buscando meios de desenvolver o atendimento de nossa população, mantendo o potencial resolutivo da APS, mesmo em meio às restrições.

PALAVRAS-CHAVE: Cuidados primários à Saúde; Equipe Multiprofissional; Estratégia de Saúde da Família

ÁREA TEMÁTICA: Saúde Coletiva 


\section{INTRODUÇÃO}

ACovid-19 é uma doença respiratória aguda, por vezes grave, causada pelo novo Coronavírus, o SARS-CoV-2, que apresenta uma taxa de transmissão extremamente alta. Diante disso, a Organização Mundial da Saúde (OMS) em 11 de março de 2020, decretou situação de pandemia (OMS, 2020). Desde o aparecimento do primeiro caso o Brasil têm apresentado um crescimento significativo da doença e, até o dia 17 de Março de 2021, foram registrados 11.603 .535 casos e 282.127 mortes em todo o território nacional. O Estado do Paraná registrou, nesse mesmo período, 769.609 casos e

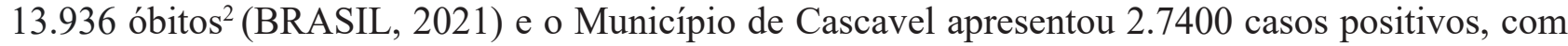
467 óbitos (CASCAVEL, 2021).

Com a pandemia, o mundo tem vivenciado dias de incertezas e medos e, em contrapartida, os profissionais de saúde, embora vivenciam os mesmos sentimentos, precisam munir-se de coragem e enfrentar o que eles próprios desconhecem. No Brasil, esse enfrentamento se dá através do Sistema Único de Saúde (SUS), assistido pela Lei 8.080 que reconhece a saúde como direito de todos e um dever do Estado e regulamenta as ações de serviço em saúde (BRASIL, 1990).

A Portaria $n^{\circ}$ 2.436, de 21 de setembro de 2017, aprova a Política Nacional de Atenção Básica que organiza e operacionaliza suas ações. No município de Cascavel, a Atenção Primária à Saúde (APS) está organizada em três distritos sanitários, conta atualmente com 29 Unidades de Saúde da Família (USF) e 14 Unidades Básicas de Saúde (UBS), responsáveis pelo acompanhamento das famílias do seu território de abrangência. Conta também com o Programa de Residência Multiprofissional em Saúde da Família, pela Escola Municipal de Saúde Pública, que tem por objetivo capacitar profissionais de saúde, por meio da educação em serviço, na modalidade de ensino em pósgraduação lato-sensu, para o desempenho de atividades no SUS.

Este relato de experiência tem por objetivo elencar as perspectivas de atuação dos residentes em saúde da família no contexto da pandemia de Covid-19, assim como expor a realidade no cenário de prática em uma USF.

\section{METODOLOGIA}

O presente estudo é um relato de experiência dos profissionais residentes e preceptores em Estratégia de Saúde da Família (ESF), a partir da metodologia descritiva e reflexiva, nos propomos a apresentar as principais dificuldades e possibilidades da intervenção multiprofissional em uma USF, durante o período da pandemia de Covid-19, de março de 2020 até o presente momento.

Realizamos também pesquisa documental e bibliográfica sobre as principais diretrizes da Atenção Primária em Saúde e Estratégia de Saúde da Família e protocolos de saúde que determinam e regulamentam o funcionamento dos serviços de saúde. 


\section{RESULTADOS E DISCUSSÕES}

A Atenção Primária em Saúde (APS) é uma estratégia de organização do SUS, a qual representa o primeiro nível de atenção em saúde, tendo como principais atributos: o primeiro contato, longitudinalidade, integralidade e coordenação. O trabalho dos profissionais de saúde na Estratégia de Saúde da Família, tem destaque e grande importância, pois estes estão mais próximos da população do seu território adscrito e priorizam ações de promoção, proteção e recuperação da saúde, de forma integral e continuada. Desta forma, busca-se fortalecer a vigilância epidemiológica e o planejamento de medidas de controle do território, por meio da descentralização de atendimentos, a busca ativa de novos casos e o monitoramento de casos suspeitos e confirmados (BRASIL, 2020).

Em março de 2021, considerando o agravamento da situação de saúde no município, com lotação máxima de enfermarias e leitos de Unidades de Terapia Intensiva (UTI's), houve o cancelamento/adiamento de todas as atividades eletivas nas Unidades Básicas de Saúde (UBS) e Unidades de Saúde da Família (USF) de Cascavel-PR. Na USF, onde atuamos enquanto residentes e preceptores, foram mantidas apenas atividades de vacinação de rotina, consultas de pré-natal e de pacientes com sintomas respiratórios, posteriormente notificados e teleconsultas para atendimento da demanda espontânea, assim como o monitoramento dos pacientes suspeitos e confirmados, vacinação de acamados e notificação de eventos adversos da vacina contra a Covid-19.

Estamos na linha de frente no combate para a contenção do vírus, adequando nosso atendimento, mudando rotinas e buscando meios de desenvolver de forma multiprofissional o atendimento de nossa população adstrita, mantendo o potencial resolutivo da APS, mesmo em meio às restrições. Destacase também os problemas relacionados ao isolamento social, como transtornos mentais, violência doméstica, alcoolismo e agudização de doenças crônicas. Cabe à APS desenvolver um trabalho de acolhimento desses casos, ao mesmo tempo em que enfrentamos as adversidades de prestar uma assistência humanizada, pois a maioria dos pacientes são acompanhados via teleatendimento. $\mathrm{O}$ desafio torna-se ainda maior devido à grande quantidade de casos em acompanhamento pela unidade e também à demanda espontânea, gerando um ambiente laboral de desgaste emocional e físico. 
Figura 1: Preceptores e residentes de enfermagem e serviço social, na USF Parque Verde.

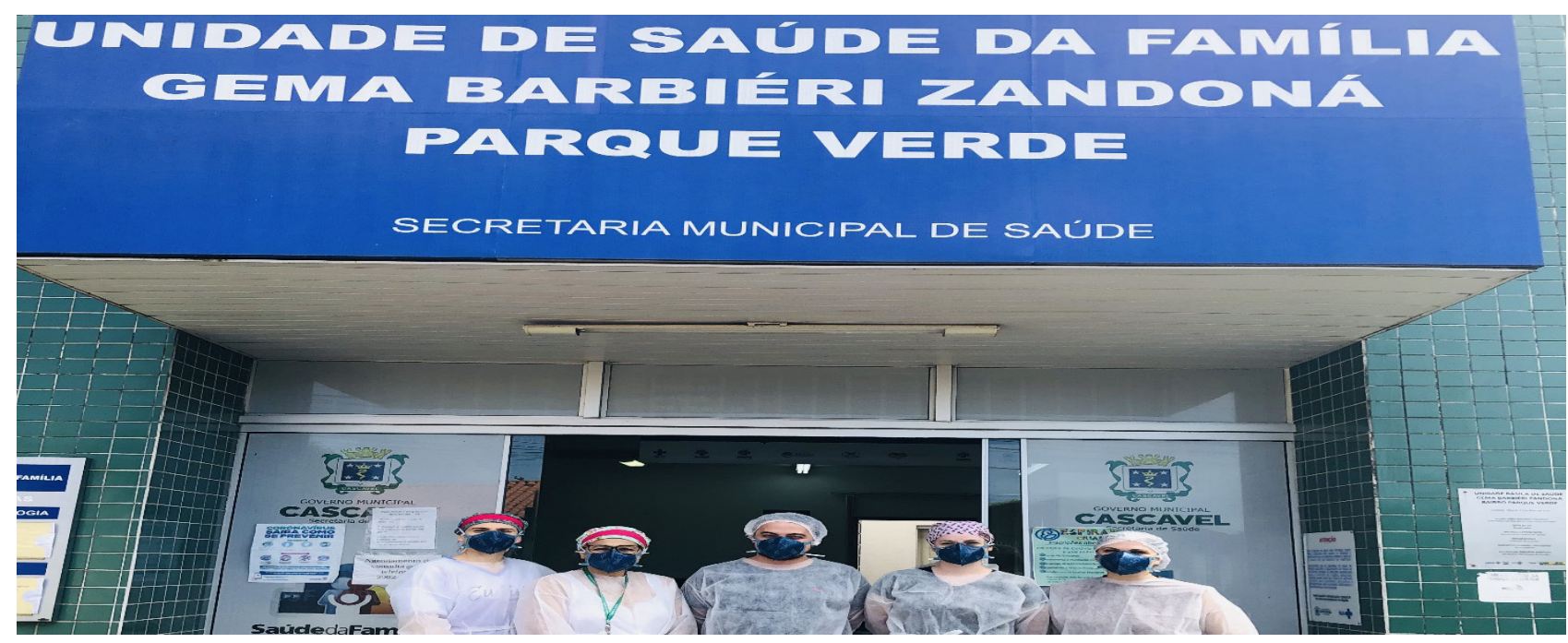

Fonte: autores.

\section{CONSIDERAÇÕES FINAIS OU CONCLUSÃO}

Concluindo, a mudança nas atividades de rotina, geram um desgaste psíquico e físico ainda maior, pois enquanto residentes e preceptores, lidamos com a "quebra" de expectativas relacionada as atividades programadas para o cenário de prática, adicionando o risco de contágio no atendimento às demandas da população, ainda assim, sabemos da nossa responsabilidade enquanto profissionais de saúde e da necessidade de dar continuidade ao nosso trabalho.

Com a pandemia o cronograma da residência foi alterado, as aulas deixaram de ser presenciais, nosso campo de prática se mostra incerto, porém sabemos da importância de nosso papel e o crescimento pessoal e profissional que esta residência está nos proporcionando. Mais do que nunca, o trabalho multiprofissional e os esforços de adaptação da equipe, se mostram essenciais para o atendimento. A possibilidade de troca de experiências e saberes entre as diversas profissões, tornam $\mathrm{o}$ atendimento integral e também mais humanizado.

\section{REFERÊNCIAS}

OMS. World Health Organization. Coronavirus disease 2019 (COVID-19): Situation Report 51[Internet]. Genebra: WHO; 2020. Disponível em: https:/www.who.int/emergencies/ diseases/ novel-coronavirus-2019/situation-reports/. Acesso em: 17 Março de 2021.

BRASIL. Ministério da Saúde. COVID-19 - Painel Coronavírus. 2021 Brasília, DF: MS; Disponível em: https:// covid.saude.gov.br/. Acesso em: 17 Março de 2021.

BRASIL. Ministério da Saúde. Orientações para manejo de pacientes com Covid-19 na APS. 2020, 
Brasília, DF: MS; Disponível em: Covid19-Orientac--o--esManejoPacientes.pdf (saude.gov.br). Acesso em: 17 Março de 2021. 


\title{
ATUAÇÃO DO PRAPS-MVS DA FCAV/UNESP/JABOTICABAL/SP NA VIGILÂNCIA DE EPIZOOTIAS DE PRIMATAS NÃO HUMANOS
}

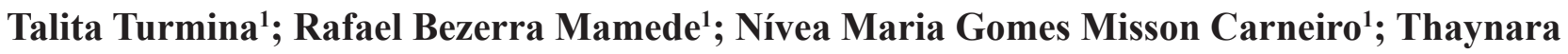 Pavaneli Lira'; Maria Soban Martins Gaspar'; Karina Paes Bürger²}

\begin{abstract}
Residente em Medicina Veterinária, Faculdade de Ciências Agrárias e Veterinárias da Universidade Estadual Paulista Júlio de Mesquita Filho (FCAV-UNESP), Jaboticabal, São Paulo

Doutora em Medicina Veterinária, Universidade Estadual Paulista Júlio de Mesquita Filho (UNESP), Jaboticabal, São Paulo
\end{abstract}

\begin{abstract}
RESUMO
A vigilância de epizootias de primatas não humanos (PNH) é uma ferramenta no monitoramento da Febre Amarela. O presente trabalho descreve umas das distintas atividades que englobam o trabalho do profissional veterinário residente na conjuntura da saúde única e que compõem o quadro de serviços do Programa de Residência em Área Profissional da Saúde - Medicina Veterinária e Saúde (PRAPS-MVS) da Faculdade de Ciências Agrárias e Veterinárias, Câmpus Jaboticabal, da Universidade Estadual Paulista Júlio de Mesquita Filho. Para tanto, foi descrito, de forma prática, o fluxograma de atividades para a adequada notificação e vigilância da enfermidade realizada pelos médicos veterinários residentes da área específica Medicina Veterinária Preventiva e Saúde Pública, demonstrando a notabilidade dessa notificação.
\end{abstract}

PALAVRAS-CHAVES: Medicina Veterinária; Saúde Pública; Prevenção.

ÁREA TEMÁTICA: Saúde Coletiva

\section{INTRODUÇÃO}

A febre amarela é uma doença infecciosa febril aguda, que possui como agente etiológico um arbovírus do gênero Flavivírus, protótipo da família Flaviviridae, denominado como vírus da febre amarela. Este vírus apresenta dois ciclos de transmissão distintos, o silvestre e o urbano, que se diferenciam unicamente pelo ambiente de ocorrência e espécie do mosquito, onde o Aedes aegypti é o vetor no ciclo urbano, que se caracteriza na transmissão mosquito humano, registrado pela última vez no Brasil em 1942. Já o ciclo silvestre é mais complexo e varia conforme localização global. Nas Américas, implica nos vetores dos gêneros Haemagogus e Sabethes, e no qual os PNH 
são os principais hospedeiros; o homem nesse ciclo apresenta-se como um hospedeiro acidental. A relevância epidemiológica decorre da elevada letalidade, da gravidade clínica e do potencial de impacto e disseminação, especialmente quanto à transmissão urbana (BRASIL, 2019). O ciclo natural de transmissão do vírus envolve mosquitos silvestres e PNH e, diante disso, o ciclo silvestre não é passível de eliminação. Portanto, o objetivo do trabalho é constatar a importância crucial da vigilância de epizootias de PNH como medida preventiva do aparecimento de novos surtos como também, apresentar as principais atividades desenvolvidas no Programa de Residência em Área Profissional da Saúde - Medicina Veterinária e Saúde (PRAPS-MVS), relatando os conceitos e a atuação profissional referente ao tema.

\section{METODOLOGIA}

O presente trabalho é um relato de experiência das atividades desenvolvidas por médicos veterinários residentes do Programa de Residência em Área Profissional da Saúde - Medicina Veterinária e Saúde (PRAPS-MVS), da Faculdade de Ciências Agrárias e Veterinárias da Universidade Estadual Paulista, Câmpus de Jaboticabal (FCAV-UNESP/Jaboticabal), Em parceria estabelecida entre o PRAPS-MVS e o Estado, foi definido que o Departamento de Patologia, Reprodução e Saúde Única seria responsável pela elaboração do fluxograma de ações, pelo armazenamento das amostras e parte burocrática de envio podendo atender, quando solicitado, a demanda dos 26 municípios que integram o XIII Departamento Regional de Saúde. As atividades foram desenvolvidas entre os meses de janeiro e março de 2020.

\section{RESULTADOS E DISCUSSÕES}

O programa de residência propicia acompanhar o fluxograma dessa relevante notificação, assim o presente trabalho apresentará um relato de caso de um PNH proveniente do Jardim Zoológico Mario Coras, do município de Olímpia. O cadáver foi enviado congelado ao Setor de Vetores e Zoonoses, junto da Ficha de Epizootia preenchida com o número do Sistema de Notificação de Agravos de Notificação (SINAN), e então encaminhado ao Departamento Patologia, Reprodução e Saúde Única. O animal foi encontrado morto no recinto e tratava-se de uma fêmea, do gênero Alouatta, popularmente conhecido como bugio, de sete anos de idade pesando cinco quilos. O primata possuía histórico clínico de cegueira, pois o olho foi mordido por um macho da mesma espécie, e vivia sozinha no recinto pois apresentava comportamento agressivo. O histórico clínico indicava que não se alimentava há três dias e havia presença de gás intestinal identificado através de exame radiográfico. No zoológico residiam outros gêneros de $\mathrm{PNH}$, como Sapajus e Callithrix, entretanto nenhum outro animal apresentava sintomatologia. Essa informação demonstra relevância devido a todas as espécies de PNH presentes na América no Sul serem susceptíveis ao vírus da febre amarela, embora, as proporções epizoóticas se verifiquem maiores no gênero Alouatta. 
Posteriormente, o cadáver foi direcionado ao Serviço de Patologia de Animais Selvagens (SEPAS) da área de Patologia Veterinária para exame de necropsia e coleta de amostras. Após procedimentos iniciais de identificação e exame externo, que foi observado estado corpóreo obeso, além de exame da pele e seus anexos que não possuíam alterações. Procedeu-se então para o exame interno, seguindo a técnica de necropsia baseada no Guia de Vigilância de Epizootias em Primatas Não Humanos e Entomologia aplicada à Vigilância da Febre Amarela, que consta com a inspeção do subcutâneo, cavidade torácica e abdominal, vísceras e sistema nervoso central. Os principais achados de necropsia na cavidade torácica foram presença de aproximadamente 7,0 mL de líquido livre na cavidade, de cor avermelhada (hemotórax); traqueia com presença de conteúdo espumoso (indicativo de edema pulmonar) e mucosa rósea; pulmões descritos como lobo direito com coloração vermelho escuro e lobo esquerdo com coloração vermelho claro e, quanto ao parênquima, ao corte fluía discreta de conteúdo espumoso e vermelho (edema pulmonar). No coração observou-se aspecto globoso, saco pericárdico espesso recoberto por gordura, além de flacidez de ventrículo direito. Identificou-se ainda uma massa amarelada pedunculada próxima ao diafragma em direção ao fígado, de aspecto gorduroso. Na cavidade abdominal, observou-se presença de líquido na cavidade com volume próximo a $6,0 \mathrm{~mL}$ e coloração avermelhada. Em estudo realizado no último grande surto de febre amarela no Brasil, identificou-se como padrão histopatológico em PNH do gênero Alouatta o frequente desenvolvimento de lesão hepática necrosante grave com lipidose. Os cuidados com a coleta, identificação, condicionamento e translado das amostras interferem de maneira direta nos resultados.

Assim sendo, atividades de responsabilidade exclusiva dos médicos veterinários residentes do Departamento de Patologia, Reprodução e Saúde Única realizadas com muita seriedade, diante das rigorosas exigências de recebimento dos institutos Pasteur e Adolfo Lutz, propiciando aos profissionais aprimoramento na coleta e envio de amostras. Dessa forma, foram coletadas amostras em duplicata de forma estéril, dos tecidos do fígado, baço, coração, pulmão, rins e cérebro, então condicionadas em 12 tubos criogênicos e imediatamente armazenados em nitrogênio líquido, identificados com o tipo de tecido e número do SINAN para análise de isolamento viral/ detecção de genoma viral/ sorologia. Ainda, um tubo coletor universal em temperatura ambiente, com todas as amostras juntas de solução de formaldeído a 10\%, foi utilizado para armazenar as amostras encaminhadas para análise de imuno-histoquímica e histopatológica, identificado com espécie do animal, município e número do SINAN. Finalmente, um tubo cônico (tipo Falcon) com amostra de cérebro, armazenado em freezer, identificado com tipo de tecido e número do SINAN era enviado ao Instituto Pasteur para diagnóstico de raiva (diferentemente do restante das amostras, que eram enviadas ao Instituto Adolfo Lutz para diagnóstico de febre amarela).

A necropsia e a coleta de amostras são procedimentos que se complementam e, assim sendo, reintegram o valor do trabalho em equipe e multidisciplinar. $\mathrm{O}$ transporte foi realizado por motorista capacitado funcionário da FCAV/UNESP. E o resultado dos exames foram encaminhados diretamente à Secretária Municipal de Saúde do município requisitante, ou seja, o município que gerou o registro no SINAN. Por conseguinte, foi possível observar que o Programa de Residência 
em Área Profissional de Saúde Medicina Veterinária e Saúde FCAV/UNESP auxilia de forma direta e responsável nas tarefas delegadas pelo Estado referentes ao assunto discutido. Isso ocorre através da vigilância passiva de forma completa e eficiente, com agilidade de transporte e realização criteriosa de necropsia e coleta de amostras.

\section{CONCLUSÃO}

A reurbanização do vírus é mais do que nunca uma preocupação verdadeira no cenário brasileiro, e nos desafia a promover a melhoria da vigilância e controle de vetores, além da maior proteção de PNH e melhoria da vigilância de epizootias. Em vista da notoriedade nacional da enfermidade, e não obstante sua relevância regional no Estado de São Paulo, o PRAPS-MVS possibilita acompanhar de forma ativa o exercício da Vigilância de Epizootias em PNH. Isto demonstra relevância regional pois recebe cadáveres de PNH oriundos de diferentes municípios do estado, além de fortalecer as políticas de vigilância e saúde auxiliando na investigação e controle vetorial e continuando a busca de casos e epizootias, sobretudo disseminando informação, educação e comunicação para detectar e controlar precocemente os surtos.

\section{REFERÊNCIAS}

BRASIL. Guia de Vigilância de Epizootias em Primatas Não Humanos e Entomologia aplicada à Vigilância da Febre Amarela. Ministério da Saúde, Secretaria de Vigilância em Saúde, Departamento de Vigilância das Doenças Transmissíveis. 2 ed. Brasília: Ministério da Saúde. 2017.

BRASIL. Guia de Vigilância em Saúde. Ministério da Saúde, Secretaria de Vigilância em Saúde, Coordenação Geral de Desenvolvimento da Epidemiologia em Serviços. 2 ed. Brasília: Ministério da Saúde. 2019. 


\section{RELAÇÃO ENTRE DIABETES MELLITUS E A SAÚDE PERIODONTAL}

\section{Lorena Rodrigues Souza ${ }^{1}$.}

${ }^{1}$ Graduanda em Odontologia, Universidade Estadual de Feira de Santana (UEFS), Feira de Santana, Bahia.

\section{RESUMO}

O acúmulo de biofilme nas superfícies dentais pode causar a periodontite, uma doença caracterizada pela inflamação do osso alveolar e que pode estar relacionada bidirecionalmente com o diabetes mellitus, uma patologia onde há a deficiência no cotrole glicêmico. Pela ligação entre as duas doenças, é importante que os profissionais da saúde saibam diagnosticar e proceder de maneira correta nesses casos. Com isso, esse trabalho buscou revisar na literatura a relação entre a inflamação periodontal e o diabetes mellitus. De acordo com a literatura, a inflamação do periodonto pode dificultar o controle da glicemia. Além disso, o diabetes mellitus pode dificultar a cicatrização do tecido periodontal. Para controlar as duas doenças é necessário o correto acompanhamento com profissionais especializados para o controle do biofilme dental e a hiperglicemia, assim como a realização de melhores hábitos de vida pelo paciente.

PALAVRAS-CHAVE: Complicações Diabéticas; Hiperglicemia; Periodontite.

ÁREA TEMÁTICA: Saúde coletiva.

\section{INTRODUÇÃO}

A periodontite é uma doença causada pelo acúmulo de biofilme bacteriano na superfície dentária, inflamando os tecidos de suporte dos dentes, como o ligamento periodontal e o osso alveolar. Os sinais clínicos da periodontite podem ser inflamação gengival, modificação no seu contorno, consistência e sangramento. A periodontite pode estar associada a condições sistêmicas, como o diabetes mellitus (CARRANZA et al., 2011), uma doença metabólica causada pelo defeito na secreção de insulina, na sua ação ou em ambos. O diabetes pode ser tipo 1 ou tipo 2 . O tipo 1 afeta cerca de $10 \%$ da população e ocorre quando ocorre o ataque das células beta pancreáticas pelo sistema imunológico, impedindo a produção da insulina e impossibilitando a coleta da glicose do sangue. O tipo 2 é causado pelo mau uso de insulina pelo corpo. Além disso, há o diabetes gestacional, que ocorre em mulheres durante a gravidez por alterações no metabolismo (SOCIEDADE BRASILEIRA 
DE DIABETES, 2019). Pela ligação entre as patologias, é de suma importância que os profissionais de saúde conheçam essas condições, a associação entre elas, como proceder e as medidas de saúde para o manejo dessas doenças (GENCO; GRAZIANI; HASTURK, 2020). Com isso, o seguinte trabalho teve o objetivo de revisar na literatura a relação entre o diabetes mellitus e a saúde periodontal.

\section{METODOLOGIA}

A busca bibliográfica dessa revisão narrativa foi realizada no portal PubMed utilizando os descritores “Diabetes Mellitus" AND “Periodontitis". Foram incluídos na pesquisa artigos publicados entre 2016 e 2021, sem restrição de idiomas. Ao final da leitura, foram selecionados nove artigos que abordavam a relação entre o diabetes mellitus e a saúde periodontal.

\section{FUNDAMENTAÇÃO TEÓRICA}

O diabetes mellitus (DM) e a periodontite apresentam uma dependência bidirecional, pois a periodontite pode influenciar no desenvolvimento do DM, e este é um fator predisponente da doença periodontal nos pacientes (WU et al., 2020; KHUMAEDI, et al., 2019; PRESHAW; BISSETT, 2019). Essa associação inclui tanto o diabetes tipo 1 quanto o tipo 2 e o gestacional, principalmente se não estiverem controlados (GENCO; BORGNAKKE, 2020), e podem estar relacionada à pequenas alterações vasculares, distúrbios no metabolismo, alteração na resposta imune do hospedeiro e fatores genéticos (KHUMAEDI, et al, 2019).

O controle glicêmico falho no diabetes está associado a condições periodontais precárias e deficientes (SANZ et al., 2018). A alta presença de bactérias no tecido gengival causa uma alta resposta inflamatória que pode afetar o controle glicêmico e contribui para aumentar a resistência à insulina por interferir na função do seu receptor, levando à hiperglicemia e aumento do risco de complicações (GENCO; GRAZIANI; HASTURK, 2020), incluindo mortalidade (SANZ et al., 2018). Em pacientes diabéticos mal controlados e com periodontite são encontradas concentrações elevadas de interleucina 1-beta, fator de necrose tumoral alfa, interleucina 6 e metabólitos de oxigênio, que dificultam o controle do diabetes (POLAK; SHAPIRA, 2018). Além disso, os níveis de hemoglobina glicolisada (HbA1c) e glicose no sangue em jejum nesses pacientes podem estar elevados em comparação com aqueles que não têm periodontite (PRESHAW; BISSETT, 2019).

Pacientes com periodontite grave possuem maior probabilidade de desenvolverem o diabetes mellitus tipo 2 quando comparado com os pacientes com periodontite leve por conta dos níveis mais elevados de HbA1c (WU et al., 2020; PRESHAW; BISSETT, 2019). Ainda, em pacientes com diabetes tipo 2 e doença periodontal pode ocorrer a redução da função das células beta pancreáticas, estresse oxidativo elevado e dislipidemia (SANZ et al., 2018).

Pacientes com DM, principalmente mal controlados, apresentam maior risco de periodontite em comparação com pacientes sem DM por conta da dificuldade na resposta imune e controle da 
quantidade de bactérias no tecido periodontal (GENCO; GRAZIANI; HASTURK, 2020; PRESHAW; BISSETT, 2019). Além disso, o DM apresenta outras alterações bucais, como o aumento da infecção fúngica oral, fissura da língua, alterações no paladar (GENCO; BORGNAKKE, 2020), sensação de boca seca, queimação e dificuldade na cicatrização das feridas (SANZ et al., 2018), afetando os atendimentos odontológicos, como a cirurgias e confecção de próteses removíveis. Os hábitos de vida do paciente também podem influenciar na incidência tanto do diabetes como da periodontite. Esses fatores são o tabagismo, consumo excessivo de álcool e açúcar, obesidade e sedentarismo (GENCO; BORGNAKKE, 2020).

Por conta dessas associações, o controle da doença periodontal, do diabetes, evitar os hábitos deletérios e praticar atividade física facilitam o manejo de ambas as doenças. Isso depende de uma abordagem multidisciplinar (GENCO; BORGNAKKE, 2020; PRESHAW; BISSETT, 2019; WU et al., 2020) incluindo dentistas, médicos, enfermeiros, nutricionistas e profissionais de educação física. Além do controle, é necessário rastrear os pacientes com periodontite e diabetes, informá-los acerca da associação entre as duas patologias e a importância do tratamento integrado entre os profissionais (PRESHAW; BISSETT, 2019; GENCO; GRAZIANI; HASTURK, 2020; WU et al., 2020), assim como o comprometimento do paciente em seguir as recomendações de higiene, dieta e cuidados físicos.

Nas consultas odontológicas é importante realizar uma anamnese completa e bem detalhada para investigar a condição sistêmica do paciente (SANZ et al., 2018). Deve-se realizar um bom exame bucal para detectar alterações indicativas de diabetes, e nos casos de diabetes, perguntar se o paciente está realizado algum tratamento para o controle glicêmico (PRESHAW; BISSETT, 2019, SANZ et al., 2018, WU et al., 2020). Nessas situações, o dentista desempenha um papel importante na detecção do diabetes nos pacientes (SANZ et al., 2018).

Caso o paciente tenha diabetes, um exame periodontal bem detalhado deve ser realizado, assim como consultas periódicas de controle (GENCO; GRAZIANI; HASTURK, 2020). Nos pacientes saudáveis devem ser realizadas medidas para prevenir a doença periodontal, e caso o paciente com diabetes tenha doença periodontal, deve-se realizar o tratamento, tanto para a periodontite com o dentista como para o diabetes com o médico especialista (GENCO; BORGNAKKE, 2020).

A terapia periodontal realizada pelo dentista com a remoção do biofilme pode influenciar no tratamento da hiperglicemia por conta da diminuição dos mediadores inflamatórios (GENCO; GRAZIANI; HASTURK, 2020; POLAK; SHAPIRA, 2018) e melhora os níveis séricos de HbA1C após a terapia com raspagem, alisamento radicular e educação em saúde bucal, mesmo em pacientes com diabetes mal controlado (SANZ et al., 2018; PRESHAW; BISSETT, 2019). A educação em saúde bucal deve ser realizada com todos os pacientes diabéticos, incluindo a instrução sobre fatores de risco, escovação dentária, uso do fio dental diário e a realização do controle químico com enxaguantes bucais, quando necessário. A cirurgia periodontal não é indicada em pacientes que não apresentam um controle aceitável do diabetes por conta da dificuldade de cicatrização e probabilidade de infecções aumentadas (SANZ et al., 2018). 
Assim como os dentistas, os médicos e enfermeiros devem estar cientes de que o diabetes pode ocasionar doença periodontal (SANZ et al., 2018; GENCO; GRAZIANI; HASTURK, 2020), devem buscar evidências para a presença de periodontite em pacientes com diabetes e perguntar sobre os sinais e sintomas (sangramento gengival, mobilidade dentária, halitose e dor). Em caso positivo, devem encaminhar o paciente para realizar um acompanhamento bucal com um especialista (GENCO; GRAZIANI; HASTURK, 2020).

Sobre o tratamento médico da diabetes, o tipo 1 envolve cuidado da dieta, atividade física, injeções de insulina e monitoramento dos níveis de glicose sanguínea. O tratamento do diabetes tipo 2 envolve perda de peso, exercícios, controle da dieta, monitoramento da glicose, cessação do tabagismo, medicamentos hipoglicemiantes orais e, em alguns casos, injeções de insulina, sendo a adesão é um fator importante para o sucesso do tratamento (PRESHAW; BISSETT, 2019; GENCO; BORGNAKKE, 2020).

\section{CONSIDERAÇÕES FINAIS}

Diante do exposto, é visível que a inter-relação entre a periodontite e o diabetes necessita de uma atenção especial, tanto para o diagnóstico das patologias como para os seus tratamentos, pois uma condição depende do curso da outra. Com isso, tanto dentistas quanto médicos e sua equipe precisam estar cientes da forte ligação entre a periodontite e o DM para propor melhores ações preventivas e curativas aos pacientes.

\section{REFERÊNCIAS}

CARRANZA, F.A. et al. Klokkevold. Carranza: periodontia clínica. Rio de Janeiro: Elsevier, 2011. $1328 p$.

GENCO, R.J.; BORGNAKKE, W.S. Diabetes as a potential risk for periodontitis: association studies. Periodontology 2000, v. 83, p. 40-45, 2020.

GENCO, R.J.; GRAZIANI, F.; HASTURK, H. Effects of periodontal disease on glycemic control, complications, and incidence of diabetes mellitus. Periodontology 2000, v. 83, n. 59, p.65, 2020.

KHUMAEDI, A.I. et al. The relationship of diabetes, periodontitis and cardiovascular disease. Diabetes \& Metabolic Syndrome: Clinical Research \& Reviews, v. 13, n. 2, p. 1675-1678, 2019.

POLAK, D.; SHAPIRA, L. An update on evidence for pathogenic mechanisms that may link periodontitis and diabetes. Journal of Clinical Periodontology, v. 45, n. 2, p. 150-166, 2018

PRESHAW, P.M.; BISSETT, S.M. Periodontitis and diabetes. British Dental Journal, v. 22, n. 7, p. 577-584, 2019. 
SANZ, M. et al. Scientific evidence on the links between periodontal diseases and diabetes: Consensus report and guidelines of the joint workshop on periodontal diseases and diabetes by International diabetes Federation and European Federation of Periodontology. Diabetes Research and Clinical Practice, v. 137, p. 231-241, 2018.

SOCIEDADE BRASILEIRA DE DIABETES (SBD). Tipos de diabetes. São Paulo, 2019. Disponível em: https://www.diabetes.org.br/publico/diabetes/tipos-de-diabetes. Acesso em: 06 mar. 2021.

WU, C.Z. et al. Epidemiologic relationship between periodontitis and type 2 diabetes mellitus. BMC Oral Health, v. 20, n. 1, 2020. 


\section{AÇÕES DO ENFERMEIRO PARA À PROMOÇÃO DA SAÚDE DA POPULAÇÃO LGBT}

\section{Hemerson Felipe Fernandes abreuㅜㄹ Linielce Portela Nina²; Antônia Katia Lopes Araújo³; Joana Maria Machado ${ }^{4}$; Caroline Natielle Rocha da Silva ${ }^{5}$}

1234 Graduados em Enfermagem Bacharelado, Universidade Estadual do Maranhão (UEMA), Coroatá, MA.

5 Graduação em Enfermagem pela Faculdade de Educação São Francisco, Pedreiras, Maranhão, Especialização em Saúde da Família pelo Centro Universitário Estácio Ribeirão Preto, Ribeirão Preto, São Paulo

\section{RESUMO}

Com a criação da Política Nacional de Saúde Integral à População LGBT (PNSIPLGBT) em 2011, se abriram várias portas para essa comunidade ter mais visibilidade dentro dos serviços de saúde A realização de ações de enfermagem voltadas para a população LGBT é uma forma de introduzir as pessoas dessa comunidade nos serviços que o SUS oferece. O trabalho tem como objetivo geral, compreender as ações do enfermeiro voltadas para à promoção da saúde da população LGBT. O estudo trata-se de uma revisão bibliográfica, realizada entre janeiro e fevereiro de 2021, com buscas nas principais bases de pesquisas da Biblioteca Virtual de Saúde. A partir desse ponto foi constatado através de uma leitura aprofundada dos artigos escolhidos, que constatou que são realizadas poucas ações por parte dos enfermeiros (as) que visam promover a saúde da população LGBT nos serviços básicos de saúde.

PALAVRAS-CHAVES: Pessoas LGBT; Enfermeiro; Atenção Primária à Saúde; Promoção da Saúde.

ÁREA TEMÁTICA: Saúde Coletiva 


\section{INTRODUÇÃO}

Após o surgimento da Política Nacional de Saúde Integral à População LGBT (PNSIPLGBT) em 2011, abriram-se várias portas para essa comunidade ter mais visibilidade dentro dos serviços de saúde. Com isso, a luta da classe LGBT está na desconstrução do caráter de anormalidade que suas escolhas configuram na atual sociedade (PRADO et al., 2017). A inserção desse grupo nos serviços de saúde, torna-se um desafio sendo importante entendê-los e botar em prática os princípios essenciais no que se tange ao SUS, sendo universal e integral quanto à forma de prestação de serviços de saúde (BRAGA, et al.,2016). A realização de ações de enfermagem voltadas para a população LGBT é uma forma de introduzir as pessoas dessa comunidade nos serviços que o SUS oferece, levando em conta todos os parâmetros possíveis na preocupação de proporcionar um serviço de qualidade (PRADO et al., 2017). O preconceito que se dar através dos trabalhadores na área da saúde em relação ao grupo LGBT está ligado ao pouco preparo destes profissionais para lidar com as diferentes demandas que advém desse público, isso ocorre desde o processo de formação associando-se ao fato de que não há abordagem de tal demanda social nos diversas esferas educacionais e profissionais (FERREIRA; PEREIRA; TAJRA et al., 2017). O estudo em questão tem como objetivo compreender as ações do enfermeiro voltadas para à promoção da saúde da população LGBT.

\section{METODOLOGIA}

Trata-se de uma pesquisa de revisão integrativa da literatura brasileira, compreendendo uma busca nas bases de dados da Biblioteca Virtual de Saúde, nos bancos de dados Scielo, BDENF, e portal de periódicos da CAPES, no período de janeiro de 2021 a fevereiro de 2021, com o auxílio dos descritores: Pessoas LGBT, Enfermeiro, Atenção Primária à Saúde, Promoção da Saúde e o operador booleano “AND”. Foram escolhidas e analisadas 20 publicações no período de 2016 a 2020, destas foram excluídas as que estavam fora do limite temporal exigido, e que não contemplava ao objetivo geral da pesquisa, assim 10 artigos tiveram seus resultados sintetizados descritivamente e discutidos nos resultados do estudo.

\section{FUNDAMENTAÇÃO TEÓRICA}

Os estudos mostram que a população LGBT encontra dificuldades em comunicar-se com os profissionais de saúde, com receio em revelar sua identidade de gênero ou orientação sexual, temendo a marginalização nos cuidados em saúde (FERREIRA; PEDROSA; NASCIMENTO, 2017).

Poucos enfermeiros tem conhecimento da política de saúde da população LGBT. Saber da existência da política corrobora com o aumento do conhecimento acerca da comunidade LGBT e suas necessidades, no que se diz respeito à saúde dos mesmos (TORRES et al 2020; NOGUEIRA et al., 2019). Apesar da existência da Política Nacional de Saúde Integral LGBT, a falta da implementação dessa política na narrativa saúde LGBT ainda é pouco difundida, a inclusão da mesma 
nas UBS gera a necessidade da efetivação de práticas de educação permanente para os profissionais de saúde (BORGES et al., 2020; BEZERRA et al., 2020). As ações que geram a promoção da saúde LGBT estão vinculadas aos interesses dos profissionais da saúde em fazê-las acontecerem. No que se diz respeito ao cenário internacional, indica que a população LGBT vivencia inúmeras disparidades no cuidado em saúde e tem menos acesso aos serviços e cuidados que lhes são de direito (PAULINO; RASERA et al., 2019). No âmbito da saúde, as ações de promoção dos cuidados são na maior partes das vezes enviesadas em função da orientação sexual não heterossexual do usuário, à medida que se restringiram aos aspectos sexuais com foco nas IST (SILVA, 2019; MIRANDA; LIMA., et al 2019). A pesquisa mostra a necessidade de políticas públicas a esta população que não seja só relacionadas às IST e, ainda sim apesar desse fator não diminui a sua importância no que tange a tal assunto, é preciso diminuir essa estereotipagem, e essa vinculação a este grupo (SANTOS, 2019). A enfermagem dentro do seu papel de cuidar precisa utilizar da educação em saúde como uma estratégia para melhoria do atendimento do usuário LGBT. Quando se trata do atendimento de pessoas LGBT, revela-se a necessidade de o profissional construir um vínculo com o usuário e, que tenha conhecimento da sexualidade desses pacientes. (TORRES; SOUZA et al., 2020; GONCALVES; LUSTOSA, 2020). É imprescindível o cuidado através da gestão dos profissionais inseridos nesse cenário, destacando-se o enfermeiro, tem que ser organizacionais e de planejamentos que se adaptam à esse público, visando supervisão e organização da equipe de saúde, desenvolvimento e implementação de atividades de educação em saúde e ações para resolução de problema, estratégias de cuidado, o atendimento ao indivíduo, família e comunidade buscando assim a efetivação das políticas públicas e a equidade ao acesso ao serviços de saúde (SILVA, 2017; SALUM, 2018). A abordagem de temas voltados para a promoção da saúde LGBT, minimiza as chances de trabalhadores de saúde reproduzir preconceito e discriminação em virtude da sexualidade de um indivíduo, dessa forma é de grande valia fazer com tal tema seja meio de debate (MATTA et al., 2020).

\section{CONCLUSÃO}

Os achados do estudo evidenciaram que ações por parte dos enfermeiros (as) que visam promover a saúde da população LGBT nos serviços básicos de saúde ainda são bem escassas. A falta dessas ações reflete nas vidas dessas pessoas que além de serem marginalizadas e terem menos oportunidades em outros campos dentro da sociedade, ainda tem menos acesso aos serviços de saúde. É importante também destacar, que a Política Nacional Integral da Saúde de Lésbicas, Gays, Bissexuais, Trans/Travestis passa despercebida entre os profissionais de enfermagem, o não conhecimento dessa política interfere diretamente na falta de ações que promovam a saúde da comunidade LGBT. Diante dessa problemática é importante que se tenha uma divulgação massiva dessa politica nas esferas educacionais, para que assim, tais profissionais de saúde tome consciência de que é necessário realizar ações que consequentemente melhore a vida dessa população. 


\section{REFERÊNCIAS}

BRAGA, L.S et al. Inovação da assistência à saúde prestada à população lésbica, bissexuais, gays, travestis e transexuais. Revista Brasileira de Ciências da Vida, [S.1.], v. 6, n. Especial, abr. 2018. ISSN 2525-359X. Disponível em: <http://jornal.faculdadecienciasdavida.com.br/index.php/RBCV/ article/view/765>. Acesso em: 30 janeiro 2021.

BEZERRA, Marcos Vinicius da Rocha et al. Política de saúde LGBT e sua invisibilidade nas publicações em saúde coletiva. Saúde em Debate, v. 43, p. 305-323, 2020. Disponivel em: https:// doi.org/10.1590/0103-11042019S822. Acesso em: 25 janeiro de 2021

BORGES, Marianne Raquel Bonfim et al. Avaliação da implementação do Plano Nacional de Saúde Integral LGBT: Revisão Integrativa. Research, Society and Development, v. 9, n. 11, 2020

FERREIRA,B. O.; PEREIRA, E.O.; TAJRA, F S. Caminhos e vivências de investigação acerca da saúde da população LGBT em uma capital do nordeste brasileiro, Tempus, actas de saúde colet, Brasília, 11(1), 41-49, mar, 2017, Disponível em: < http://dx.doi.org/10.18569/tempus.v11i1.1855> Acesso em: 04 de fevereiro de 2021.

FERREIRA, O. B; PEDROSA, S. I. J; NASCIMENTO, F. E. Diversidade de gênero e acesso ao sistema único de saúde, Revista brasileira promoção em saúde, Fortaleza, p.1-10. Jan/Mar. 2018

MIRANDA, D D S; DE LIMA, Karla M C et al., Acesso ao atendimento básico de saúde de lésbicas, gays, bissexuais, travestis e transexuais (lgbts): implicações para a enfermagem. Discursos, Saberes e Práticas da Enfermagem 2, p. 57-61, 2019. Disponível em: <https://www.atenaeditora.com.br/ post-artigo/27252>. Acesso em: 20 fev. 2021.

MATTA, Thenessi Freitas et al. Saúde LGBT e currículo de enfermagem: visão de futuras enfermeiras. Research, Society and Development, v. 9, n. 9, p. e722997855-e722997855, 2020

SILVA, B.S.W.J; FILHO, N.C et al. Politicas Publicas de Saúde Voltadas a População LGBT e atuação do Controle Social. Revista de saúde pública do Paraná, Londrina, PR, v.18, n.1, p.140-149, jul. 2017.

NOGUEIRA, F.J.S.; ARAGÃO, T.A.P. Política Nacional de Saúde Integral LGBT: O que Ocorre na Prática Sob o Prisma de Usuários (as) e Profissionais de Saúde. Saúde e Pesquisa, Maringá (PR). v. 12 , n. 3, p. 463-470, 2019

PAULINO D.B.; RASERA, E.F.; TEIXEIRA, F.B. Discursos sobre o cuidado em saúde de Lésbicas, Gays, Bissexuais, Travestis, Transexuais (LGBT) entre médicas(os) da Estratégia Saúde da Família. Interface (Botucatu). 2019.

PRADO, J.A.E.; SOUSA, F.M. Políticas Públicas e a Saúde LGBT: uma revisão integrativa. Tempus actas de saúde colet. Brasília, mar. 2017

SALUM, M, E, G et al. Gestão do cuidado à pessoa trans na atenção primária à saúde. 2018. 
SANTOS, Lauro Ricardo de Lima et al. Sexualidade, identidades de gênero, políticas públicas para a população LGBT e perfil socioeconômico de travestis profissionais do sexo. Repositório UFU, 2019. SILVA, Suellen Nedica Alves da. Desafios da enfermagem frente à Política Nacional de Saúde Integral de Lésbicas, Gays, Bissexuais, Travestis e Transexuais: uma revisão da literatura. 2019.

TORRES, Ruth Cristini et al. Conhecimento de discentes e enfermeiros acerca da política nacional dos direitos LGBT+. Brazilian Journal of Development, v. 6, n. 10, p. 75032-75043, 2020. 


\title{
ASSISTÊCIA DE ENFERMAGEM À POPULAÇÃO EM SITUAÇÃO DE RUA: REVISÃO INTEGRATIVA
}

\author{
Geovane Moura Viana'; Kelly Rose Pinho Moraes²; Ana Paula Cunha Duarte ${ }^{3}$; Linielce \\ Portela Nina ${ }^{4}$; Joana Maria Machado Mendes ${ }^{5}$; Hemerson Felipe Fernandes Abreu ${ }^{6}$; Dheymi \\ Wilma Ramos Silva ${ }^{7}$.
}

1,2,3,4,5,6 Graduados em Enfermagem Bacharelado, Universidade Estadual do Maranhão (UEMA), Coroatá, Maranhão.

${ }^{4}$ Mestre em Biodiversidade, Ambiente e Saúde, pela a Universidade Estadual do Maranhão (UEMA), Caxias, Maranhão. Especialista em Urgência e Emergência pré-hospitalar, pela Faculdade de Ensino Superior Dom Bosco (FESDB), Caxias, Maranhão. Graduada em Enfermagem Bacharelado, Universidade Estadual do Maranhão (UEMA), Caxias, Maranhão.

\begin{abstract}
RESUMO
Este estudo teve como objetivo levantar na produção cientifica brasileiro sobre a assistência de enfermagem a população em situação de rua. Trata-se de uma revisão integrativa da literatura realizada na Biblioteca Virtual em Saúde nos bancos de dados LILACS, SCIELO, em fevereiro de 2021, com auxílio dos descritores: Cuidados de Enfermagem, Pessoas em Situação de rua e Assistência à saúde. Foram levantadas 26 publicações nacionais no período entre 2015-2020, destas foram excluídos artigos duplicados e não relacionados diretamente com a temática pesquisada, assim 8 artigos foram selecionados e analisados para a construção do estudo. A literatura evidenciou que a assistência de enfermagem prestada a população em situação de rua é realizada através da educação em saúde como ferramenta principal de atuação, pois através dela o enfermeiro busca a promoção da conscientização dos indivíduos com objetivo de que eles desenvolvam o autoconhecimento, a autoconfiança e o autocuidado.
\end{abstract}

PALAVRAS-CHAVES: Cuidados de enfermagem; Pessoas em situação de rua; Assistência à saúde.

ÁREA TEMÁTICA: Atenção à Saúde 


\section{INTRODUÇÃO}

As pessoas que vivem em situação de rua possuem coisas em comum como a falta de uma moradia própria, vínculos familiares interrompidos ou fragilizados, vive em situação de pobreza extrema, ausência de trabalho e a sobreposição de vulnerabilidades sociais (BEZERRA et al., 2015). Existem vários fatores que contribui para que as pessoas que morram na rua aceitem está condição de vida, como os vínculos familiares fragilizados e interrompidos, violência familiar, desemprego, a perda da autoestima, incluindo a dependência às drogas tanto lícitas como as ilícitas, os transtornos mentais, a criminalidade, dificuldades de acesso à educação e profissionalização (SILVA et al., 2017). A Política Nacional de Atenção a População em Situação de rua tem princípios e diretrizes que visam estabelecer ações estratégicas para as necessidades dessa população, com o acesso universal e humanizado ao sistema único de saúde, diante disto houve a criação dos Consultórios de Rua (CnaR) que é extremamente importante para acolher os moradores de rua no seu ambiente e para atuar nas necessidades de saúde deste público sendo estes consultórios o ambiente de trabalho dos enfermeiros para prestar assistência de enfermagem para este público. O profissional enfermeiro é fundamental durante a prestação de cuidados aos moradores de rua, pois está habito para desenvolver atividades que tendem oferecer uma melhor qualidade de vida desses indivíduos e consequentemente prestará uma assistência de enfermagem resolutiva e efetiva, pois são profissionais que atua de forma direta na rede de atenção a saúde (PAIVA, 2016). Pela grande complexidade de oferecer uma assistência para este público, o profissional enfermeiro requer possuir conhecimentos eficazes para prestar uma assistência de enfermagem qualificada (SANTANA et al., 2019). É de sua importância o presente estudo, pois existem muitas pessoas que morram na rua, que estão um contexto de desamparo e é reduzido o acesso a saúde para este público. Diante disto é necessário que as políticas de atenção à saúde envolvam o maior número possível de pessoas que vive na rua, tendo o enfermeiro, como peça indispensável, e que o profissional enfermeiro seja abito para desenvolver uma assistência de enfermagem com qualidade e que seja capaz de empenhar uma promoção a saúde de forma integral e humanizada, para reduzir os danos sofridos pelas pessoas vivem nas ruas e restabelecer a saúde dos mesmos. A presente pesquisa tem como objetivo levantar na produção cientifica brasileiro sobre a assistência de enfermagem a população em situação de rua.

\section{METODOLOGIA}

Trata-se de uma revisão integrativa da literatura, desenvolvida por meio de buscas de artigos nas bases de dados da Biblioteca Virtual em Saúde (BVS), durante o mês fevereiro de 2021. Os cruzamentos foram realizados mediante a combinação dos descritores: Cuidados de Enfermagem [AND] Pessoas em Situação de Rua [AND] "Assistência à saúde”, resultando em 26 artigos, sem critérios de inclusão e exclusão. Os critérios de inclusão consistiram em estudos disponíveis na integra, nas bases de dados LILACS, SCIELO, de 2015 a 2020 em português e no formato de artigo. E os critérios de exclusão foram artigos duplicados e não relacionados diretamente com a temática pesquisada. A amostra final foi composta por oito artigos que foram lidos e analisados na integra. 


\section{FUNDAMENTAÇÃO TEÓRICA}

O acesso aos serviços de saúde pela população que vive na rua se dá, muitas vezes, através da atenção secundária e terciária da saúde, principalmente nos casos de necessidade extrema e risco iminente, pois a equipe da Estratégia de Saúde da Família encontra dificuldades para assistir estes pacientes, pelo fato de que muitos não têm locais fixos para viver e acabam ficando à margem e desassistidos (BEZERRA et al., 2015). Segundo Schervinski et al., (2017), o enfermeiro deve ter uma visão integral e holística do indivíduo e adotar estratégias para proporcionar uma assistência qualificada as pessoas que vivem nas ruas por meio da educação em saúde, mantendo sempre o paciente informado sobre suas condições de saúde, fazendo com que o paciente faça parte do seu processo de saúde e doença. Diante do exposto, vale a pena ressaltar que se devem levar em consideração as particularidades de cada indivíduo, o conhecimento, as especificidades, os desafios que está população apresentam, estando atenta às características inerentes e a individualidade de cada pessoa (SICARI; ZANETA, 2018). Para Hino, Santos e Rosa (2018), existem vários fatores e motivos que evitam ou atrasam a procura por serviços de saúde por parte das pessoas que convive em situação de rua, como a discriminação relacionada às condições de higiene, falta de banho, odor fétido, bem como a falta de documentação para a identificação e cadastro do usuário, além do preconceito, desse modo contesta-se que a saúde dessas pessoas está ainda mais comprometida porque são infringidos os princípios da universalidade, da equidade e da integralidade da assistência à saúde. Os profissionais de enfermagem devem desenvolver e promover uma assistência de boa qualidade, devem estar cientes das dificuldades e demandas que surgem por diferentes sujeitos que vive na rua, desempenhando um papel acolhedor e educador em saúde. O enfermeiro tem a educação em saúde como ferramenta principal de atuação e função primordial frente ao cuidado oferecido aos indivíduos que morram na rua, pois através disso, o enfermeiro deve buscar a promoção da conscientização dos indivíduos com objetivo de que eles desenvolvam o autoconhecimento, a autoconfiança e o autocuidado (DIAS et al., 2018). Os enfermeiros atuam diretamente com os moradores de rua desenvolvendo diversos cuidados, pois é o profissional que está mais perto desses moradores, com isto o enfermeiro pode envolver a equipe multiprofissional para prestar um cuidado mais amplo para estas pessoas. Isto decorre pelo fato de o enfermeiro ser um elo mediador entre a promoção de ações educativas, visto que apresenta um perfil criativo e sensível capaz de executar cuidados básicos as pessoas que morram na rua, e de promover discussão acerca dessa condição social junto a outros profissionais, articulando diferentes setores formando uma equipe interdisciplinar capaz de contribuir para integralização do acesso a saúde.

\section{CONSIDERAÇÕES FINAIS}

De acordo com os dados encontrados durante a realização da revisão da literatura, concluímos que os moradores de rua vivem em condições precárias de vida, em condição de miséria, com péssima qualidade de vida, sem emprego, sem moradia convencional, sem educação e excluídos da sociedade. Isto decorre pelo fato de que as pessoas que morram na rua possuem um acesso a saúde de forma 
restrita e está submetido as condições problemáticas de sobre vida nas ruas e são expostos as diferentes formas de violência que torna a sua saúde altamente vulnerável e consequentemente, à perda de autoestima e autoconfiança que interfere no autocuidado desses indivíduos. Dessa forma, para que os profissionais de enfermagem possam promover uma assistência de enfermagem de qualidade, devem estar bem preparados para acolher uma pessoa que vive em situação de rua, promover um acolhimento humanizado, sem preconceitos, possuindo uma visão holística para estes sujeitos, pois agindo desta forma, será possível adotar uma assistência de enfermagem de qualidade, efetiva e resolutiva. Com isto, será possível presta uma boa promoção de saúde, com um atendimento digno e de qualidade e que seja capaz de contribuir para a reinserção desses indivíduos na sociedade, reduzindo os fatores de risco que tornam vulnerável a saúde dos moradores de rua.

\section{REFERÊNCIAS}

BEZERRA, I.H.P.; FILHO, I.M; COSTA, R.J.L.M.; SOUSA, V.J.; CARVALHO, M.V.G. População em situação de rua: um olhar da enfermagem sobre o processo saúde/doença. Enfermagem Revista, v. 18, n. 1, p. 3-14, 2015. Disponível em: http://periodicos.pucminas.br/index.php/enfermagemrevista/ article/download/9365/10323. Acesso em: 05 de fev. 2021.

DIAS, L.J.L. F.; BRANDÃO, M.G.S.A.; AMARAL, V.F.; AGUIAR, M.I.L.; CAVALCANTE, A.S.P.; VASCONCELOS, M.I.O. O processo saúde-doença-cuidado à população em situação de rua: intervenções de acadêmicos de enfermagem. Expressa Extensão, v. 23, n. 2, p. 32-42, 2018. Disponível em: https://periodicos.ufpel.edu.br/ojs2/index.php/expressaextensao/article/view/13197 . Acesso em: 15 de fev. 2021.

HINO, P.; SANTOS, J.O.; ROSA, A.S. Pessoas que vivenciam situação de rua sob o olhar da saúde. Revista Brasileira de Enfermagem, v. 71, p. 684-692, 2018. Disponível em: https://www. scielo.br/scielo.php?pid=S0034-71672018000700684\&script=sci_arttext\&tlng=pt. Acesso em: 09 de fev. 2021.

PAIVA, I.K.S.; LIRA, C.D.G.; JUSTINO, J.M.R.; MIRANDA, M.G.O.; SARAIVA, A.K.M. Direito à saúde da população em situação de rua: reflexões sobre a problemática. Ciência \& Saúde Coletiva, v. 21, p. 2595-2606, 2016. Disponível em: https://www.scielosp.org/article/csc/2016.v21n8/25952606/pt/. Acesso em: 05 de fev. 2021.

SANTANA, C.S.; FREITAS, I.L.S.; MESQUITA, K.S.F.; ARAÚJO, B.R.O.; MELO, G.B.; ALMEIDA, A.V.A. Assistência de enfermagem à mulher em situação de rua no ciclo gravídicopuerperal: uma revisão de literatura. Caderno de Graduação-Ciências Biológicas e da Saúde, v. 5, n. 2, p. 71-82, 2019. Disponível em: https://periodicos.set.edu.br/fitsbiosaude/article/view/5912. Acesso em: 15 de fev. 2021.

SCHERVINSKI, A.C.; MERRY, C.N.; EVANGELISTA, I.C.; PACHEDO, V.C. Atenção à saúde da população em situação de rua. Revista Eletrônica de Extensão, v. 14, n. 26, p. 55-64, 2017. 
Disponível em: https://dialnet.unirioja.es/servlet/articulo?codigo=6176199. Acesso em: 10 de fev. 2021.

SICARI, A.A; ZANELLA, A.V. Pessoas em situação de rua no Brasil: revisão sistemática. Psicologia: Ciência e Profissão, v. 38, n. 4, p. 662-679, 2018. Disponível em: https://www.scielo.br/scielo. php?pid=S1414-98932018000500662\&script=sci_arttext\&tlng=pt. Acesso em: 25 de fev. 2021.

SILVA, R.P.; LEÃO, V.A.S.; SANTOS, E.S.V.; COSTA, G.N.; SANTOS, R.V.; CARVALHO, V.T.; MAIA, L.F.S.; ROSA, A. S. Assistência de enfermagem a pessoa em situação de rua. Revista Científica de Enfermagem, v. 7, n. 20, p. 31-39, 2017. Disponível em: https:/www.recien.com.br/ index.php/recien/article/view/222. Acesso em: 10 de fev. 2021. 


\title{
RELEVÂNCIA DA ATUAÇÃO DE MÉDICOS VETERINÁRIOS RESIDENTES EM CAMPANHAS DE VACINAÇÃO CONTRA RAIVA ANIMAL
}

\section{Nívea Maria Gomes Misson Carneiro ${ }^{1}$; Talita Turmina ${ }^{1}$; Rafael Bezerra Mamede ${ }^{1}$; Maria Soban Martins Gaspar'; Thaynara Pavaneli Lira' ${ }^{1}$; Karina Paes Bürger ${ }^{2}$}

\begin{abstract}
Residente em Medicina Veterinária, Faculdade de Ciências Agrárias e Veterinárias da Universidade Estadual Paulista Júlio de Mesquita Filho (FCAV-UNESP), Jaboticabal, São Paulo

Doutora em Medicina Veterinária, Universidade Estadual Paulista Júlio de Mesquita Filho (UNESP), Jaboticabal, São Paulo
\end{abstract}

\begin{abstract}
RESUMO
A raiva ainda é um sério problema de saúde pública para algumas áreas, portanto, ações de vigilância devem ser reforçadas e suportes de recursos, políticas, técnicas e educação devem ser continuados. Para a manutenção do controle epidemiológico da raiva urbana é necessário que sejam desenvolvidas anualmente campanhas de vacinação, sob responsabilidade dos municípios. O presente trabalho objetiva relatar o suporte técnico às campanhas de vacinação contra raiva animal como parte das atividades dos médicos veterinários residentes do Programa de Residência em área profissional da saúde - Medicina Veterinária e Saúde da FCAV/Unesp/ Jaboticabal/SP. Esta atividade faz parte da rotina dos residentes da área específica da medicina veterinária preventiva e conta com a colaboração dos alunos de graduação e pós-graduação da mesma instituição. Em 2018, a atividade foi desenvolvida em sete municípios da região de Jaboticabal/SP, mais de 32.000 animais foram vacinados, com a participação de mais de 100 graduandos e pós-graduandos. A iniciativa de unir a graduação e residência em medicina veterinária em diversos níveis de organização dessas campanhas é de grande valia para comunidade local e para formação sanitarista destes profissionais
\end{abstract}

PALAVRAS CHAVES: Extensão; Zoonose

ÁREA TEMÁTICA: Saúde Coletiva 


\section{INTRODUÇÃO}

A Raiva é uma zoonose viral, que se caracteriza por comprometer o Sistema Nervoso Central (SNC), causando uma encefalite progressiva aguda e letal. Todos os mamíferos são suscetíveis ao vírus da raiva e, portanto, podem transmiti-lo. Dessa forma, conhecendo o papel dos cães e gatos no ciclo urbano da doença, uma das principais medidas de controle da raiva é a vacinação destes animais, sendo esta ação responsável pela diminuição do número de casos de raiva animal, prevenindo consequentemente, a raiva humana (BÜRGER et al.,2016).

Considerada altamente temida em todo mundo devida à elevada letalidade e poucos índices de sucesso no tratamento da mesma, no Brasil a raiva animal se manifesta de maneira endêmica. Todavia, devido as campanhas anuais oferecidas pelos municípios os números de casos diagnosticados reduziram-se de modo significativo, reforçando a importância da adoção de tal política pública (SILVA, 2019).

Nesse sentido, o suporte técnico às campanhas de vacinação contra raiva animal realizado por médicos veterinários residentes do Programa de Residência em área profissional da saúde - Medicina Veterinária e Saúde da FCAV/Unesp/ Jaboticabal/SP é de suma importância para manutenção do status de controle epidemiológico da raiva urbana na região, além de estimular os alunos de graduação em Medicina Veterinária no tocante as habilidades e competências para o trabalho em Saúde Pública, a capacidade de entender e resolver problemas na prática, a responsabilidade social do profissional como agente de saúde e oferecer um serviço de qualidade para a sociedade.

\section{METODOLOGIA}

O presente trabalho é um relato de experiência das atividades desenvolvidas por meio de parcerias entre a FCAV, Câmpus Jaboticabal/SP e as Secretarias Municipais de Saúde de diversos municípios da região nordeste do Estado de São Paulo. Este suporte técnico é uma das atividades dos médicos veterinários residentes do Programa de Residência em área profissional da saúde- Medicina Veterinária e Saúde da FCAV/Unesp/Jaboticabal/SP, área específica Medicina Veterinária Preventiva, e supervisionada por tutores do Programa.

Nos meses de março e maio foi realizada avaliação de anticorpos antivírus da raiva dos estudantes como controle periódico do esquema pré-exposição e, se necessário, imunizados, conforme recomendado pelas Normas Técnicas de Profilaxia da Raiva Humana, os que não obtiveram resultados satisfatórios no exame receberam uma dose reforço no mês de setembro.

Nas semanas anteriores as campanhas os alunos foram informados sobre as mesmas e se voluntariavam como vacinadores. No dia das campanhas os alunos foram orientados sobre a importância e o correto armazenamento e manuseio das vacinas, dose e local de aplicação, além da manutenção da organização dos postos e postura perante os munícipes. E, posteriormente encaminhados para os postos de vacinação distribuídos pelo munícipio. 
Em cada posto de vacinação, havia pelo menos um aluno que já tinham participado de campanhas anteriores que era responsável pelo posto. As turmas foram divididas de forma que os alunos já formados em graduação ou cursando os últimos períodos pudessem auxiliar e instruir melhor os alunos dos primeiros anos da graduação e que nunca participaram de tais atividades. Durante a campanha os alunos tinham um contato mais próximo com a população, assim aproveitavam esse período para conscientizar os proprietários sobre diversos assuntos de saúde pública.

\section{RESULTADOS E DISCUSSÕES}

No ano de 2018, ao longo de 9 dias as campanhas contaram com mais de 100 alunos envolvidos que puderam vacinar mais de 32 mil animais nos municípios de Barrinha, Jaboticabal, Guariba, Matão, Pontal, Pradópolis e Viradouro.

Sabe-se que o anticorpo sérico dos animais cai anualmente, dessa forma é de suma importância a realização frequente das campanhas (SILVA,2019), prejudicadas no ano anterior em decorrência à situação pandêmica global, reforçando a necessidade de medidas de vigilância efetivas e premência na realização de novas campanhas de vacinação de cães e gatos contra raiva animal.

Assim sendo, a realização de campanhas de vacinação é de interesse da saúde pública, minimizando a circulação do vírus rábico no meio urbano. É valido destacar a importância do profissional médico veterinário nessas atividades, uma vez que esse apresenta ampla capacitação para atuar desde o planejamento, execução, armazenamento das vacinas, aplicação e orientação dos tutores e demais profissionais sobre assuntos de saúde (BOCCHI, 2017).

\section{CONCLUSÃO}

Desse modo é possível afirmar que os municípios contaram com um suporte técnico qualificado e que as iniciativas favoreceram a população animal e humana da região, além de permitir a capacitação dos alunos, minimizando um problema grave da dificuldade de atividades práticas na área de saúde pública durante o curso de graduação.

\section{REFERÊNCIAS}

BOCCHI, M. R. Campanha antirrábica canina e felina: a importância da equipe de trabalho: recursos utilizados e resultados obtidos pelos municípios no desenvolvimento da campanha antirrábica canina e felina na região de São José do Rio Preto/SP, Brasil, no período de 2009 a 2013 . Revista de Educação Continuada em Medicina Veterinária e Zootecnia do CRMV-SP, v. 15, n. 2, p. 8-16, 11 dez. 2017.

BÜRGER, K. P. et al. Campanha de vacinação contra raiva animal realizada por alunos na região de Descalvado/SP. Rev. Ciênc. Ext. v.12, n.2, p.116-124, 2016. 
SILVA, R. I. Avaliação soroepidemiológica de cães imunizados contra a raiva com vacina de cultivo celular em campanha anual de vacinação no município de Butucatu/SP. DissertaçãoFaculdade de Medicina Veterinária e Zootecnia, Universidade Estadual Júlio de Mesquita Filho. p.35. 2019. 


\title{
VARIÁVEIS ANTROPOMÉTRICAS EM ADULTOS E IDOSOS COM DIABETES MELLITUS
}

\section{Ednúbia Pereira Félix¹; Débora Cristina Couto Oliveira Costa² ${ }^{2}$ Lívia Lopes Custódio²; Debora Pena Batista e Silva²; Lucélia Rodrigues Afonso ${ }^{3}$; Ana Caroline Araújo da Silva ${ }^{4}$; Ilvana Lima Verde Gomes; ${ }^{5}$ Andrea Caprara ${ }^{5}$.}

\begin{abstract}
${ }^{1}$ Mestre em Saúde Coletiva, Universidade Estadual do Ceará (UECE), Fortaleza, Ceará. ${ }^{2}$ Doutoranda em Saúde Coletiva, Universidade Estadual do Ceará (UECE), Fortaleza, Ceará. ${ }^{3}$ Mestranda em Saúde Coletiva, Universidade Estadual do Ceará (UECE), Fortaleza, Ceará. ${ }^{4}$ Graduanda em Enfermagem, Universidade Estadual do Ceará (UECE), Fortaleza, Ceará. ${ }^{5}$ Docente do Programa de Pós-Graduação em Saúde Coletiva, Universidade Estadual do Ceará (UECE), Fortaleza, Ceará.
\end{abstract}

\begin{abstract}
RESUMO
Objetivo: identificar o índice de massa corporal e a circunferência abdominal em pessoas portadoras do Diabetes Mellitus tipo 2, atendidos no território de três unidades de saúde da atenção básica em Fortaleza no Ceará. Metodologia: Realizou-se um estudo transversal com 180 participantes, adultos e idosos em Fortaleza, Ceará. Foi utilizado um questionário semiestruturado para identificação de dados sociodemográficos, econômicos, dados clínicos e alimentares. Resultados: Observou-se predominância de sobrepeso (40,6\%), obesidade (40,6\%) e classificação muito alto para circunferência abdominal (81,7\%). A amostra relatou que os hábitos alimentares não auxiliam no controle da DM2 (64,4\%). Conclusão: O índice de massa corporal identificado no território, elevada circunferência abdominal e descrença na dieta foram observados na amostra. Os dados refletem a necessidade de uma intervenção por meio da educação em saúde, afim de melhorar a saúde de adultos e idosos investigados nos territórios.
\end{abstract}

PALAVRAS-CHAVE: Diabetes mellitus tipo 2. Empoderamento. Autocuidado.

ÁREA TEMÁTICA: Atenção à Saúde. 


\section{INTRODUÇÃO}

O diabetes mellitus (DM) é uma doença crônica, mais frequentes, considerada não transmissível e no que se refere ao aparecimento de novos casos, pode tomar proporções crescentes, tornando-se um problema de Saúde Pública com impactos crescentes nos sistemas de saúde mundial e brasileiro (DUNCAN et al., 2017).

O DM tipo 2 aparece como o mais predominante, se manifesta principalmente em adultos quando o organismo não consegue usar adequadamente a insulina que produz; ou não produz insulina suficiente para controla a taxa de glicemia. As principais causas deste tipo de DM estão relacionadas à obesidade e estilo de vida sedentário (SOCIEDADE BRASILEIRA DE DIABETES, 2016).

Com o aumento na expectativa de vida da população brasileira e consequentemente o envelhecimento da mesma, assim como mudança no perfil nutricional afetam a qualidade de vida dessas pessoas, estudos com base epidemiológica relacionam esses distúrbios com risco de morbidade e mortalidade entre o citado grupo. As medidas antropométricas são utilizadas na avalição nutricional e informações sobre variação física, entre elas faremos uso da Circunferência Abdominal (CA) e Índice de Massa Corpórea (IMC) como indicador antropométrico (CORTEZ 2012).

O IMC, segundo a organização mundial de saúde (OMS), é um parâmetro bastante utilizado para classificar o indivíduo de acordo com seu peso e altura, com índice identificado por meio de categorias: Baixo peso (IMC $<18,5 \mathrm{~kg} / \mathrm{m} 2$ ), peso Normal (IMC $\geq 18,5$ e $<25 \mathrm{~kg} / \mathrm{m} 2$ ), Sobrepeso (IMC $\geq 25$ e $<30 \mathrm{~kg} / \mathrm{m} 2$ ) e Obesidade (IMC $\geq 30 \mathrm{~kg} / \mathrm{m} 2$ ). Seu uso é disseminado a partir do nível de obesidade nos diferentes países, entre diversos profissionais.

Neste contexto, o presente trabalho teve como objetivo identificar o índice de massa corporal e a circunferência abdominal em pessoas portadoras do Diabetes Mellitus tipo 2, atendidos no território de três unidades de saúde da atenção básica em Fortaleza no Ceará.

\section{MÉTODO}

Realizou-se um estudo transversal, de abordagem quantitativo, realizado com adultos e idosos com diagnóstico de Diabetes Mellitus tipo 2, entre janeiro e setembro de 2016, em três Unidades de Atenção primaria à Saúde (UAPS), do Sistema Único de Saúde (SUS), na cidade de Fortaleza, Ceará, Brasil.

A amostra foi obtida por conveniência totalizando 180 participantes. Foram considerados critério de inclusão além da faixa etária, a condição clínica de DM2 e ter atendimento em uma das três UAPS. Excluíram se os pacientes recém-diagnosticados com DM2, aqueles sem cadastro no sistema municipal de prontuário eletrônico (FastMedic) e os que não faziam uso de tratamento medicamentoso.

O instrumento de coleta de dados ocorreu através de um questionário semiestruturado, 
contabilizando um tempo médio de 20 minutos para sua aplicação, contando com perguntas sobre as características sociodemográficas e econômicas: idade (anos), sexo (masculino ou feminino), endereço completo, escolaridade (ensino médio, fundamental, não estudou, outros), estado civil (solteiro, casado, viúvo, outros), ocupação e renda. Acresce-se ainda dados sobre índice de massa corporal, circunferência abdominal (centímetros) e questões sobre os hábitos alimentares, considerando dias normais e atípicos.

Os dados foram organizados em um banco de dados no Microsoft Excel. Utilizou-se o programa Statistical Package for the Social Sciences (SPSS), versão 17.0, para analisar os dados. A análise univariada foi utilizada para descrever as variáveis, o teste do qui-quadrado foi importante para determinar as associações na análise bivariada. Adotou-se índice de confiança de 95\% e p valor $<0,05$.

A pesquisa obedeceu aos parâmetros e itens que regem a Resolução 466 de 12 de dezembro de 2012 do Conselho Nacional de Saúde, a qual regulamenta pesquisa com seres humanos, sendo autorizada pelo Comitê de Ética sob parecer nº 461588/2014-5.

\section{RESULTADOS E DISCUSSÃO}

Participaram desse estudo 180 pacientes sendo, 73 adultos, com idade de 18 a 59 anos incompleto e, 107 idosos, com idade acima de 60 anos. A análise univariada das variáveis do estudo foram organizados em três blocos. Quanto as variáveis socioeconômicas e demográficas observaramse que a maioria da amostra apresentou média de idade de 61 anos, com predominância do sexo feminino $(71,1 \%)$, idosos $(59,4 \%)$, o estado civil revelou a presença de cônjuge $(55,9 \%)$, houve prevalência de escolaridade no ensino fundamental $(54,7 \%)$ e renda inferior a um salário mínimo $(83 \%)$.

Tendo em vista os dados sócios demográficos, o estudo apontou resultados semelhantes acerca da prevalência em portadores de DM tipo 2, dos quais 82,4\% eram mulheres, com média de idade do grupo total de 69,7 \pm 7 anos e houve predominância entre os idosos (BURGOS, AMORIM, CABRAL, 2017). Em outro estudo foi apresentado uma amostra final de 54 indivíduos, dos quais a maioria eram de homens (64\%), com idade $62 \pm 9$ anos, desses, 57\% eram casados, 48\% viviam com companheiro (a) e filhos e 59\% apresentavam baixa escolaridade, tendo o ensino fundamental incompleto (NOGUEIRA et al, 2019).

Sabe-se que o baixo grau de instrução entre as pessoas acometidas com algum adoecimento crônico é atitude desfavorável que pode limitar e/ou reduzir o acesso a cuidados de saúde relacionados à oportunidade de aprendizagem, principalmente quando são responsáveis pelo seu próprio cuidado, pois pode haver dificuldade para ter acesso à informação e entendimento para com as condutas terapêutica (PACE et al., 2006; GHANNADI et al., 2016; BRANDÃO et al, 2020).

Quanto as variáveis clínicas, observou-se que a maioria dos participantes teve IMC 
classificado com sobrepeso (40,6\%) e obeso $(40,6 \%)$ e a circunferência abdominal foi classificada como muito alta $(81,7 \%)$. Os dados antropométricos observados neste estudo são preocupantes. Visto que, refletem fator de risco importante para doenças cardiovasculares e podem ser potencializados na eminência de fatores comportamentais como o sedentarismo, tabagismo, etilismo, entre outros (FONTELA, WINKELMANN e VIECILI, 2017).

Acircunferência abdominaléummarcadorimportanterelacionadoàs doenças cardiovasculares e metabólicas. Um estudo de coorte retrospectiva realizado na Colômbia observou que o aumento da circunferência abdominal é um marcador para doenças cardiovasculares e metabólicas, o estudo inferiu prevalência alta e mais frequente em mulheres do que em homens (RUIZ et al, 2012).

Parte da amostra deste estudo inferiu que os hábitos alimentares não auxiliam no controle da DM2 (64,4\%), este dado é preocupante, uma vez que, manter uma dieta adequada, equilibrada e balanceada é importante no controle do DM, atuando como proteção para complicações, destaca-se que uma má alimentação pode estar relacionada ao aumento dos riscos de morbidades. A dieta deve ser prescrita observando o adequado fracionamento dos nutrientes, dessa forma, o acompanhamento nutricional é importante no processo de saúde dessas pessoas (BERTONHI; DIAS, 2018).

\section{CONSIDERAÇÕES FINAIS}

Este estudo identificou que nas UAPS investigadas a obesidade, sobrepeso e alta circunferência abdominal estão presentes na população dos territórios de forma predominante. O perfil dos pacientes com DM2 foi prioritariamente do sexo feminino, idosos com baixa renda, sedentários, com hábitos alimentares que necessitam de intervenção e de controle glicêmico. Os dados apresentados não retratam o perfil da população adulta e idosa brasileira com DM2. No entanto, os dados identificados são importantes para o planejamento de ações de promoção da saúde da pessoa com diabetes nos territórios investigados. Ações de empoderamento coletivo e individual dos pacientes e equipes de saúde, por meio da educação em saúde, podem ser direcionados aos grupos em seus territórios.

\section{REFERÊNCIAS}

BURGOS, Maria Goretti Pessoa de Araújo; AMORIM, Thaís Carvalho; CABRAL, Poliana Coelho. Perfil clínico e antropométrico de pacientes idosos com diabetes mellitus tipo 2 atendidos em ambulatório. Scientia Medica, v. 27, n. 3, p. ID26616-ID26616, 2017.

BERTONHI, L. G.; DIAS, J. C. R Diabetes mellitus tipo 2: aspectos clínicos, tratamento e conduta dietoterápica. Revista Ciências Nutricionais Online, v.2, n.2, p.1-10, 2018.

BRANDÃO, Barbara Maria Lopes da Silva et al. Relação da cognição e qualidade de vida entre idosos comunitários: estudo transversal. Revista Brasileira de Enfermagem, v. 73, 2020. DUNCAN, Bruce Bartholow et al. The burden of diabetes and hyperglycemia in Brazil and its states: findings 
from the Global Burden of Disease Study 2015.Rev. Bras. Epidemiol., São Paulo, v. 20, n. 1, p. 90$101,2017$.

FONTELA, P.C; WINKELMANN, E.R.; VIECILI, P.R.Z. Estudo do índice de conicidade, índice de massa corporal e circunferência abdominal como preditores de doença arterial coronariana. Revista Portuguesa de cardiologia, 357-64, 2017.

GHANNADI, Shima et al. Evaluating the Effect of Knowledge, Attitude, and Practice on SelfManagement in Type 2 Diabetic Patients on Dialysis. Journal of Diabetes Research, Egypt, v. 10, n. 1, p. 114-119, 2016 NOGUEIRA, Beatriz Cristina Murari et al . Aspectos emocionais e autocuidado de pacientes com Diabetes Mellitus Tipo 2 em Terapia Renal Substitutiva. Cad. Bras. Ter. Ocup., São Carlos , v. 27, n. 1, p. 127-134, Jan. 2019 . Available from <http://www.scielo.br/ scielo.php?script=sci_arttext\&pid=S2526-89102019000100127\&lng=en\&nrm=iso $>$. access on 18 Mar. 2021. https://doi.org/10.4322/2526- 8910.ctoao1575.

PACE, Ana Emilia et al. Conhecimento sobre diabetes mellitus no processo de autocuidado. Rev. Latino Am. Enfermagem, Ribeirão Preto, v. 14, n. 5, pág. 728-734, outubro de 2006.

\section{SOCIEDADE BRASILEIRA DE DIABETES. Diretrizes da Sociedade Brasileira de Diabetes} 2015-2016. São Paulo, Sociedade Brasileira de Diabetes, 2016. 348p.

RUIZ, A.J. et al.. Estudio IDEA(International Day for Evaluation of Abdominal Obesity ): prevalencia de obesidad abdominal y factores de riesgo asociados en atención primaria en Colombia. Biomédica. v.32, n. 4, 610-6, 2012 


\title{
NOTIFICAÇÃO DE ZOONOSES EM CÃES E GATOS EM VIÇOSA, MG: PRIMEIROS PASSOS
}

\section{Rodrigo Alves Barros ${ }^{1}$; Breno Filipe Reis de Oliveira ${ }^{2}$}

\author{
${ }^{1}$ Doutorando em Medicina Veterinária, Universidade Federal de Viçosa (UFV), Viçosa, MG \\ ${ }^{2}$ Graduando em Medicina Veterinária, Universidade Federal de Viçosa (UFV), Viçosa, MG
}

\begin{abstract}
RESUMO
Ainda é uma lacuna importante na prática veterinária a produção de histórico dos animais no controle de doenças. Além do mais, a notificação possui menor expressividade quando observada em animas de companhia (cães e gatos), que possuem um contato íntimo significativo com a população humana. O Ministério da Agricultura, Pecuária e Abastecimento possui sistema de notificação ainda limitado e voltado à animais de produção, enquanto o Ministério da Saúde mantém apenas o Sistema de Informação de Agravos de Notificação para agravos em humanos. Há um debate caloroso para a criação de uma instância específica voltada à pequenos animais, na garantia de uma saúde pública eficaz pela relação direta dos animais com a sociedade. É diante dessa problemática que vem sendo implantado em Viçosa, MG, um sistema de notificação de zoonoses em cães e gatos, que será relatado no presente resumo.
\end{abstract}

PALAVRAS-CHAVES: Vigilância; animais de companhia; saúde pública ÁREA TEMÁTICA: Saúde Coletiva

\section{INTRODUÇÃO}

A Organização Mundial da Saúde indica que as zoonoses são um grupo de doenças infecciosas que são naturalmente transmitidas de animais vertebrados a seres humanos. Ou seja, as zoonoses são todas as doenças de animais que podem ser transmitidas a humanos ou de humanos à animais, que circulam livremente entre essas populações (MEDRONHO, 2009). Dessa forma, são um grupo de agravos em que o controle eficaz permeia dois cenários diferentes e que devem ser levados em conta.

Para que as zoonoses tenham uma contenção adequada, baseada na prevenção e na avaliação dos indicadores de riscos, os animais deveriam ser observados com maior cautela. Estima-se que $60 \%$ de todas as doenças que acometem seres humanos são zoonóticas e grande parte destas ainda 
são pouco catalogadas e não há dados suficientes para a construção de indicadores e catalogação de padrões de desenvolvimento até chegarem à população humana. Algumas doenças zoonóticas são particularmente importantes para a população brasileira e possuem uma frequência relevante de casos, como a raiva, a leishmaniose e a esporotricose que, no entanto, não possuem um sistema de inserção de novos casos em animais, para acompanhamento e investigação (BRASIL, 2009).

Um sistema de notificação consiste em um canal de monitoração ativa da incidência de casos de doenças prioritárias para a saúde pública. Sua utilização efetiva permite a realização do diagnóstico dinâmico da ocorrência de um evento na população, podendo fornecer subsídios para explicações causais dos agravos de notificação compulsória, além de vir a indicar riscos aos quais as pessoas estão sujeitas, contribuindo assim, para a identificação da realidade epidemiológica de determinada área geográfica. O seu uso sistemático, de forma descentralizada, contribui para a democratização da informação, permitindo que todos os profissionais de saúde tenham acesso à informação e as tornem disponíveis para a comunidade. É, portanto, um instrumento relevante para auxiliar o planejamento da saúde, definir prioridades de intervenção, além de permitir que seja avaliado o impacto das intervenções (BRASIL, 2016).

O objetivo desse resumo é apresentar a fase inicial da implantação e os dados preliminares do sistema de notificação de zoonoses, em cães e gatos, no município de Viçosa, MG.

\section{METODOLOGIA}

O presente estudo é do tipo relato de experiência sobre a criação de um sistema de notificação, as estratégias para a sua implantação e os resultados preliminares dos primeiros dados coletados. A criação do sistema de notificação de zoonoses, em cães e gatos, no município de Viçosa, MG, é uma parceria entre o Setor de Vigilância Epidemiológica da Secretaria Municipal de Saúde, o Programa de Residência em Medicina Veterinária e o Grupo de Estudos em Saúde Única, da Universidade Federal de Viçosa. A coleta de dados se dá por meio de formulário impresso deixado nas clínicas e hospitais veterinários de Viçosa, MG. Na primeira visita, os veterinários foram sensibilizados a efetuarem as notificações e orientados sobre a forma de preenchimento do formulário. O processo de busca dos formulários ocorre mensalmente, em dia e horário pré-agendado com os veterinários. As primeiras visitas ocorrem em fevereiro de 2020. Os dados coletados são tabulados no programa Microsoft Excel. São respeitados os aspectos éticos conforme a Resolução 466/12, no entanto houve dispensa de autorização pelo CEP e CEUA-UFV, uma vez que os dados são de propriedade da Vigilância Epidemiológica.

\section{RESULTADOS E DISCUSSÕES}

Em Viçosa, MG, encontram-se em atividade 13 clínicas veterinárias e 02 hospitais veterinários. $\mathrm{Na}$ primeira visita foi entregue um folder (figura 1) o objetivo de disseminar a criação do sistema e 
realizar um trabalho educativo juntos aos profissionais para a importância da notificação de doenças na saúde pública. Todos os veterinários responsáveis pelas clínicas e hospitais se disponibilizaram a participar do projeto. Assim como relataram sentir a falta de uma forma de notificar os casos de zoonoses por eles atendidos. Inclusive, houve relatos de veterinários que, no passado, tentaram notificar casos de animais positivos para leishmaniose junto a Vigilância Epidemiológica, porém foram informados que esse tipo de notificação não era recebido pelo setor.

Figura 1: Folder para divulgação e orientação dos veterinários sobre o sistema de notificação de zoonoses.

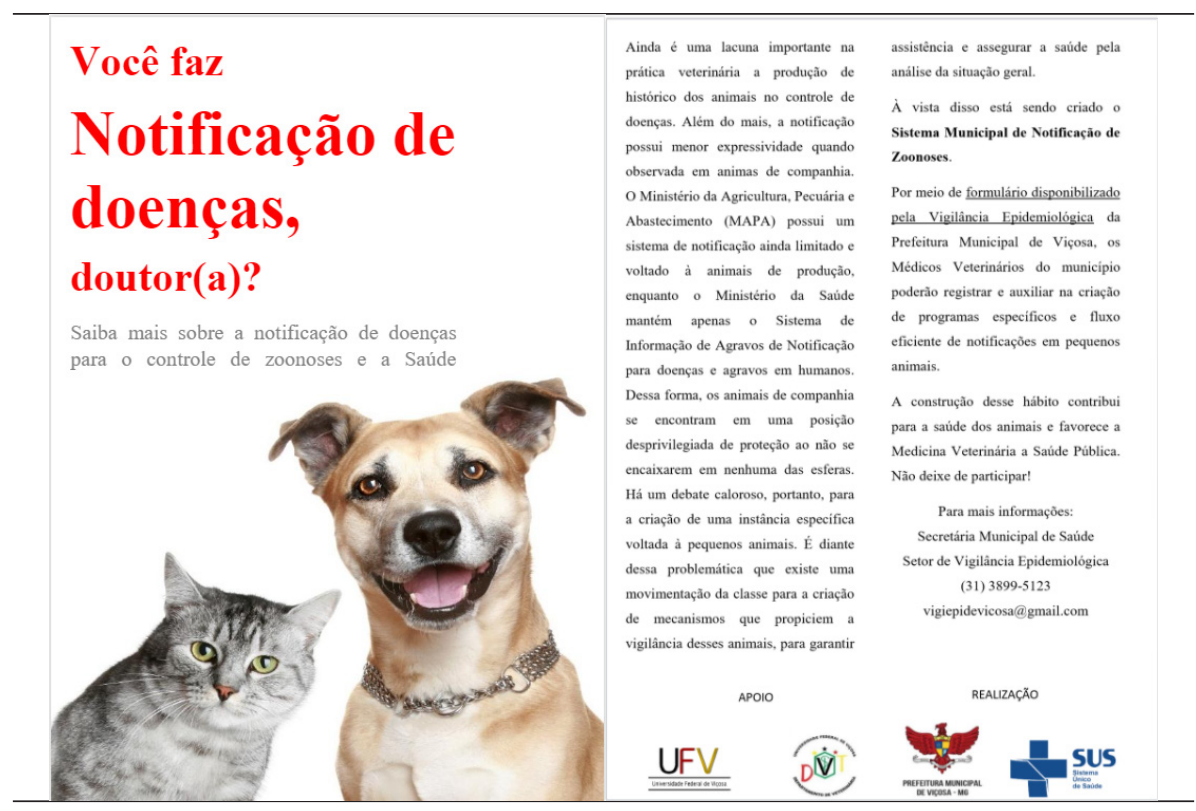

O caderno de notificação (figura 2) foi desenvolvido pela equipe do projeto, com o objetivo de coletar os dados básicos sobre o notificador, o responsável pelo animal e do animal. Optou-se pelo caderno impresso pela facilidade do preenchimento e o processo de busca ativa periódica das notificações, em cada clínica/hospital, permitiu a interação entre veterinários e equipe do projeto. Além de reforçar o compromisso de realizar a notificação. Quando a clínica/hospital não relatava o atendimento de nenhum caso suspeito ou confirmado de zoonose no período, era preenchida uma notificação negativa, atestando essa informação. Dessa forma os veterinários tornam-se corresponsáveis pela informação de "ausência" de notificação naquele período. A partir dos dados das notificações esperava-se realizar visitas aos domicílios para investigação epidemiológica dos casos, com a presença de Agente de Combate as Endemias ou de Agente Comunitária de Saúde, como forma de inserir a Vigilância Ambiental e Atenção Primária em Saúde no projeto. No entanto, a condição de pandemia de COVID-19 suspendeu as visitas domiciliares realizadas pelos agentes e dificultou a busca ativa das notificações. 
Figura 2: Caderno de notificação de zoonoses disponibilizada para as clínicas e hospitais veterinários, Viçosa, MG.

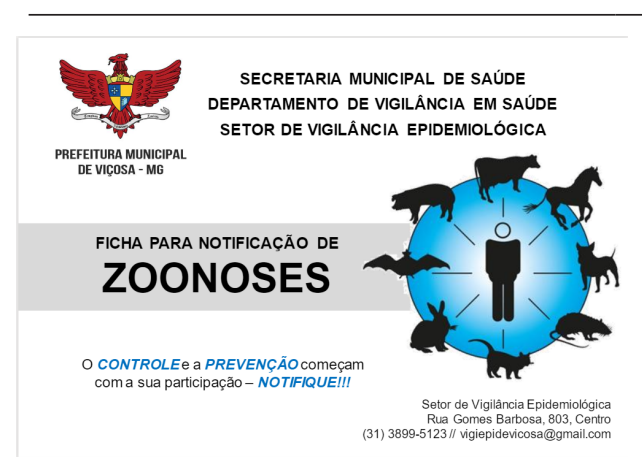

A - Capa do caderno de notificação

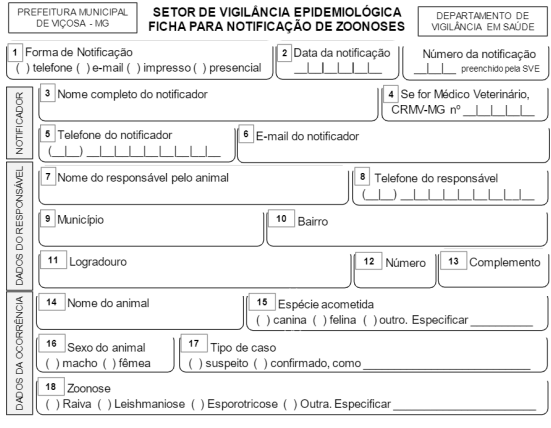

B - Ficha de notificação

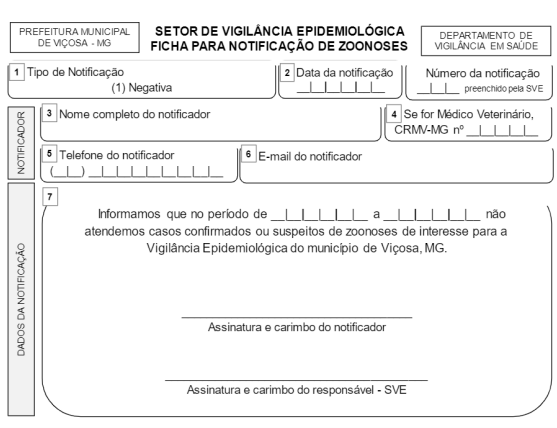

C - Ficha de notificação negativa

De fevereiro de 2020 a fevereiro de 2021 foram realizadas quatro visitas a cada clínica/ hospital. Foram notificados 07 casos confirmados de esporotricose em gatos e 18 casos confirmados de leishmaniose em cães. E, 45 notificações negativas. Viçosa, MG, não é região endêmica para esporotricose e leishmaniose, em humanos ou animais. Esses dados sugerem a introdução dessas zoonoses no município. A falta de notificação de casos suspeitos pode indicar que os veterinários estão aguardando a confirmação do caso para notificar.

\section{CONSIDERAÇÕES FINAIS}

A criação do sistema de notificação de zoonoses e a compreensão da epidemiologia dos casos visa a implantação de programa de prevenção e controle destes, focados nas características de ocorrência no município de Viçosa, MG. O benefício direto para a população é a diminuição da incidência desses casos, como consequência de programas mais efetivos de prevenção e controle. De forma indireta, pretende-se contribuir com a identificação de fatores de risco associados a aspectos sociais da distribuição dos casos zoonóticos. E, dessa forma, contribuir com redefinições de programas de controle e prevenção. Além disso, contribui para o fortalecimento da Medicina Veterinária e poderá servir de modelo para implantação em outros municípios, para um sistema de notificação animal eficaz e conectado ao SUS.

\section{REFERÊNCIAS}

BRASIL. Ministério da Saúde. Guia de Vigilância em Saúde. Brasília: Ministério da Saúde, 2016.

BRASIL. Ministério da Saúde. Vigilância em saúde: zoonoses. Brasília: Ministério da Saúde, 2009.

MEDRONHO RA, BLOCH KV, LUIZ RR, WERNECK GL, editores. Epidemiologia. 2.ed. Rio de Janeiro: Atheneu, 2009. 


\title{
PERFIL DE PACIENTES ATENDIDOS POR TENTATIVA DE SUICÍDIO EM UM SERVIÇO DE ATENDIMENTO MÓVEL DE URGÊNCIAS
}

\author{
Maria da Conceição Lima Paiva ${ }^{1}$ \\ ${ }^{1}$ Graduada em Enfermagem, Centro Universitário (UNINTA), Sobral, Ceará
}

\begin{abstract}
RESUMO
Trata-se de uma pesquisa documental, de caráter retrospectivo e abordagem quantitativa. A coleta de dados foi realizada através um instrumento com base nas fichas de atendimentos do serviço nos anos de 2018 a 2019. O estudo respeitou todos os preceitos éticos e legais da Resolução do Conselho Nacional de Saúde 466/12. É válido salientar que a pesquisa foi aprovada sob parecer nº 4.378.974. No período estudado, foram analisadas 203 fichas de intercorrências. Destas, 105 foram referentes ao ano de 2018 e 98 ao ano de 2019. No que concerne às características dos atendimentos, a maioria se referia a pacientes do sexo feminino $(55,2 \%)$ casos, e uma faixa etária média de 29 anos. A maior predominância os bairros periféricos $(74,4 \%)$, a maioria das vítimas estava na própria residência (94,1\%) durante o evento. O método utilizado pelas vítimas, observou-se a predominância intoxicação/ envenenamento $(68,5 \%)$, seguindo do enforcamento $(20,7 \%)$.
\end{abstract}

PALAVRA-CHAVE: Tentativa de suicídio; Atendimento móvel de urgências; Epidemiologia.

ÁREA TEMÁTICA: Saúde Coletiva.

\section{INTRODUÇÃO}

O comportamento suicida está associado aos atos em que um indivíduo causa lesão a si mesmo. Estão presentes desde pensamentos de ideação, gestos, ameaças, autodestruição, tentativas de suicídio até o suicídio consumado (BOTEGA, 2015).

Dados do Sistema de Informação de Agravos de Notificação (SINAM) apresentam que nos anos de 2011 a 2016 houve 1.173 .418 casos de violências interpessoais e autoprovocadas. Destas, $176.226(15,0 \%)$ foram relativas à prática de lesão autoprovocada, sendo $116.113(65,9 \%) \mathrm{em}$ mulheres e $60.098(34,1 \%)$ em homens. Identificou-se que $48.204(27,4 \%)$ estavam relacionadas às causas de tentativas de suicídio, sendo 33.269 (69,0\%) em mulheres e 14.931 (31,0\%) em homens (BRASIL, 2017). 
Frente ao exposto, o objetivo do estudo descrever o perfil dos pacientes atendidos por tentativa de suicídio pelo serviço de atendimento móvel de urgências.

\section{METODOLOGIA}

Trata-se de uma pesquisa documental, de caráter retrospectivo e abordagem quantitativa. Realizada no SAMU da cidade de Sobral, Ceará. A coleta de dados foi realizada através de um instrumento com base nas fichas de atendimentos do serviço. As variáveis exploradas foram: dados sociodemográfico e epidemiológico. Como critério de inclusão foram selecionados os prontuários de pacientes dentre os anos de 2018 a 2019, cujas informações estiveram devidamente preenchidas. Foram excluídos cinco prontuários cujos pacientes foram removidos por terceiros. Os dados coletados foram organizados por meio do software Excel 2013, e em seguida, processados com a utilização do programa estatístico software $R$, versão 3.4.1. O estudo respeitou todos os preceitos éticos e legais da Resolução do Conselho Nacional de Saúde 466/12. É válido salientar que a pesquisa foi submetida à apreciação do Comitê de Ética e Pesquisa do da Santa Casa de Misericórdia de Sobral (SCMS), com aprovação sob parecer $n^{\circ} 4.378 .974$.

\section{RESULTADOS E DISCUSSÃO}

No período estudado, foram analisadas 203 fichas de intercorrências por tentativas de suicídio atendidas pelo SAMU. Destas, 105 foram referentes ao ano de 2018 e 98 ao ano de 2019. No que concerne às características dos atendimentos, a maioria se referia a pacientes do sexo feminino com 112 (55,2\%) casos, e uma faixa etária média de 29 anos. Descrevendo a localização do atendimento, a maior predominância foi nos bairros periféricos $(151 / 74,4 \%)$, Na amostra supracitada, evidenciouse que a maioria das vítimas estava na própria residência $(191 / 94,1 \%)$ durante o evento quando o serviço de atendimento móvel chegou para prestar os devidos cuidados. No que tange ao método utilizado pelas vítimas, observou-se a predominância da intoxicação/envenenamento (139/68,5\%), seguindo do enforcamento (42/20,7\%) e outras causas (25/12,3\%), conforme a tabela I.

Tabela 1 - Características dos atendimentos relacionados à tentativa suicídio atendidas pelo SAMU. Sobral, Ceará, 2021.

\begin{tabular}{ccc}
\hline VARIÁVEIS & $\begin{array}{c}\mathbf{N}(\%) \\
\mathbf{N}=\mathbf{2 0 3}\end{array}$ & IC-95\% $^{\mathbf{1}}$ \\
\hline Sexo & $112(55,2)$ & \\
Feminino & $91(44,8)$ & $48,05-62,09$ \\
Masculino & & $37,90-51,94$ \\
Bairro & $151(74,4)$ & $67,70-80,12$ \\
Bairro Periférico & $52(25,6)$ & $19,87-32,29$
\end{tabular}




\begin{tabular}{|c|c|c|c|c|}
\hline \multicolumn{5}{|l|}{ Métodos utilizados ${ }^{2}$} \\
\hline Intoxicação/envenenamento & \multicolumn{2}{|c|}{$139(68,5)$} & \multicolumn{2}{|c|}{$61,53-74,69$} \\
\hline Enforcamento & \multicolumn{2}{|c|}{$42(20,7)$} & \multicolumn{2}{|c|}{$15,46-27,04$} \\
\hline \multirow{2}{*}{ Outras causas } & \multicolumn{2}{|c|}{$25(12,3)$} & \multicolumn{2}{|c|}{$8,27-17,82$} \\
\hline & Média & Mediana & $\mathbf{D P}^{2}$ & IIQ $^{3}$ \\
\hline Idade & 29,0 & 27,0 & 11,53 & 15,0 \\
\hline
\end{tabular}

Fonte: Elaborado pelos autore ; ${ }^{1} \mathrm{IC}$ - Intervalo de Confiança; ${ }^{2} \mathrm{DP}$ - Desvio Padrão; ${ }^{3} \mathrm{IIQ}$-Intervalo Interquartil

Dados do boletim epidemiológico da secretaria da vigilância em saúde do país, ao analisar as tentativas de suicídio registradas durante os anos de 2011 a 2016, detectou que 69\% dos casos estavam intimamente relacionadas às mulheres, e apenas $31 \%$ aos homens (BRASIL, 2017).

Refletindo sobre uma pesquisa internacional realizada em Cuba no ano 2017, descreveu que a tentativa de suicídio é mais predominante em mulheres de 15 a 30 anos de idade, sendo mais comuns em estudantes e donas de casa. Enquanto o método de escolha utilizado pelas vitimas, trazse a intoxicação exógena, como a ingesta de comprimidos (CARRAZANA; ARCIA; RODRÍGUEZ, 2020).

Em virtude dos aspectos citados, Freitas e Borges (2017), trazem em seu estudo que dos atendimentos realizados no acolhimento de um hospital do Sul do Brasil, as lesões autoprovocadas foram mais empregadas nas mulheres e o meio mais utilizado foi à intoxicação.

No que diz respeito à incidência de tentativas de suicídio por intoxicações exógenas/ envenenamento em domicilio, Ribeiro et al. (2018) citam que a escolha do local de exposição preferencial é a residência por está relacionado com a facilidade de acesso aos meios que facilitam esta prática e por estarem sozinhos durante o evento.

\section{CONCLUSÃO}

O presente estudo possibilitou a detecção das características epidemiológicas referente às tentativas de suicídio atendidas pelo SAMU. Desse modo, observou-se que a maior parte dos casos ocorreu em mulheres adultas que tentaram suicídio por intoxicação/envenenamento. Com isso, ressalta-se a preocupação quanto à prática de polifarmácia, estoque domiciliar de remédios e facilidade de acesso a esses agentes tóxicos. 


\section{REFERÊNCIAS}

BRASIL. Ministério da Saúde. Perfil epidemiológico das tentativas e óbitos por suicídio no Brasil e a rede de atenção à saúde. Brasília: Ministério da Saúde, 2017.Disponívelem<https://portalarquivos2. saude.gov.br/images/pdf/2017/setembro/21/2017-025-Perfil-epidemiologico-das-tentativas-e-obitospor-suicidio-no-Brasil-e-a-rede-de-atencao-a-saude.pdf>. Acesso em 02 de jan.2020.

CARRAZANA, A. L. A. A.; ARCIA,D.A.; RODRÍGUEZ, M. F. Comportamiento de la Conducta Suicida. Municipio Guisa. Año 2017. Rev. Médica Gramma. V. 24, n.1, p- 314-56. 


\title{
ESTRATÉGIA SAÚDE DA FAMÍLIA E O ENFRENTAMENTO DA RESISTÊNCIA BACTERIANA EM VIÇOSA, MG
}

\section{Rodrigo Alves Barros'; Leonardo Moises Sales Bueno²}

'Doutorando em Medicina Veterinária, Universidade Federal de Viçosa (UFV), Viçosa, MG.

²Graduando em Medicina Veterinária, Universidade Federal de Viçosa (UFV), Viçosa, MG.

\begin{abstract}
RESUMO
A resistência bacteriana aos antibióticos é uma discussão em voga, pois aflige tanto a saúde humana e quanto animal, e muitas vezes isso está associado à conduta dos profissionais de saúde e da população em geral. Objetivou-se a implantação de medidas de enfrentamento à resistência antimicrobiana junto aos profissionais e usuários de três Unidades Básicas de Saúde (UBS) de Viçosa por meio de coletas microbiológicas, aplicação de questionários e divulgação dos resultados, traçando o diagnóstico situacional de cada UBS e equipe de Saúde da Família (eSF). A compreensão acerca das especificidades das eSF serviu de base para a construção da relação perene entre as partes, refletindo principalmente na divulgação científica, de forma a atender a realidade local do público-alvo. $\mathrm{O}$ trabalho em consonância com as particularidades de cada eSF assegura o êxito na democratização do conhecimento, formação de multiplicadores do saber e consequente benefício à saúde pública.
\end{abstract}

PALAVRAS-CHAVE: Antibióticos; ESF; saúde pública.

ÁREA TEMÁTICA: Saúde Coletiva.

\section{INTRODUÇÃO}

Os principais órgãos da saúde mundiais como a Organização Mundial da Saúde (OMS) e a Organização Mundial da Saúde Animal (OIE) reconhecem a resistência aos antimicrobianos como um tema de discussão, conscientização e solução imediata. Porém, o uso desregrado de drogas antimicrobianas ainda é uma realidade ao redor do mundo, seja na medicina humana ou na veterinária, derivando-se em fatores como a desinformação ou desconhecimento de terapêuticas alternativas. Isso age como uma pressão seletiva de microrganismos, resultando em menor eficácia dos tratamentos, aumento da morbidade e desenvolvimento de superbactérias (PAIVA, 2013).

Por meio da implementação de um programa de enfrentamento à resistência antimicrobiana 
junto às equipes de Saúde da Família, da Atenção Primária à Saúde (APS), é possível compreender como essa temática se inseria nesses cenários. O diálogo junto aos profissionais da saúde e à comunidade é essencial para o êxito na implementação de estratégias, assegurando-se às diretrizes do Sistema Único de Saúde (SUS), uma vez que os a agentes de saúde são a chave fundamental da comunicação entre os usuários e a APS (COSTA NETO, 2000). Essas abordagens devem permitir levantar as demandas da população e mobilizar as pessoas para uma reflexão sobre as questões que os afetam, levando à conscientização sobre a totalidade dos assuntos e colaboração de todos os cidadãos. $\mathrm{O}$ objetivo do presente resumo é relatar a implantação de medidas de enfrentamento à resistência antimicrobiana junto aos profissionais e usuários de três Unidades Básicas de Saúde (UBS) de Viçosa, MG.

\section{METODOLOGIA}

O trabalho de extensão foi realizado junto a 05 equipes de Saúde da Família por meio de visitas a 03 Unidades Básicas de Saúde durantes os meses de março, abril, agosto e setembro de 2019 em Viçosa, MG. Durante as visitas, foram aplicados questionários a todos os profissionais de saúde presentes e a 18 usuários de cada UBS, com perguntas relacionadas a fatores sociodemográficos e de condutas de higienização das mãos. Também foi realizada coletas microbiológicas da mão dominante dos profissionais e usuários, do focinho de cães e do ambiente para posterior identificação morfológica, cromatográfica e antibiograma das bactérias. A devolução dos resultados bem como a discussão do tema foi feita por meio de metodologias participativas (DRP) e divulgação científica (infográficos e cartazes). O projeto foi aprovado pelo CEP UFV sob o parecer $\mathrm{n}^{\circ}$ 3.014.634. Os participantes só foram incluídos no projeto mediante assinatura prévia do Termo de Consentimento Livre e Esclarecido (TCLE). A tabulação dos dados foi feita no editor de planilhas Microsoft Excel e a análise dos dados no programa IBM SPSS Statistics 25.

\section{RESULTADOS E DISCUSSÕES}

Os profissionais de saúde entrevistados eram compostos por 23 homens (28\%) e 59 mulheres (72\%), sendo o ensino superior a escolaridade de $74 \%$ dos homens e de $47,5 \%$ das mulheres, sendo que todos os homens (100\%) e 60,7\% das mulheres tinham graduação na área da saúde. Os demais profissionais da saúde tinham como escolaridade o ensino médio completo. O grupo de Agentes Comunitárias de Saúde (ACS), principal elo entre a Atenção Primária à Saúde e a comunidade, era composto por 13 mulheres, entre 32 e 51 anos de idade e trabalhavam na ESF dentro de um período variando de 06 a 15 anos. Percebeu-se alta rotatividade nos médicos da família, com tempo de serviço na mesma equipe variando de um a doze meses, detalhe perceptível durante as visitas, já que muitas vezes os médicos das eSF eram outros entre uma visita e outra. A grande presença da mulher nas profissões de cuidado reforça a existência de viés de gênero na área da saúde. O princípio de longitudinalidade e vínculo foi percebido apenas na atuação das ACS. 
Dentre os usuários, foram entrevistadas 79 (69\%) mulheres e 33 (31\%) homens, sendo em maior prevalência a escolaridade até o ensino fundamental (73,7\%). As mulheres desempenhavam atividades domésticas, enquanto os homens trabalhavam na construção civil, funilaria, marcenaria, auxiliar de carga/descarga e na agricultura, estando expostos a diferentes riscos à saúde. Todos residiam próximos a UBS, cumprindo a adstrição proposta pelas diretrizes do SUS. No que se refere aos hábitos de higienização das mãos, apenas dois usuários (3,5\%) entrevistados declararam ter feito algum treinamento de higienização, ao passo que 19 (45,2\%) profissionais relataram o mesmo, todavia cinco profissionais $(11,9 \%)$ aplicam o treinamento na rotina. Era notável o desconhecimento de um procedimento padrão para higienização das mãos por parte da comunidade.

A apresentação e discussão dos resultados foi realizado junto as UBS por meio da confecção de cartazes (figura 1) e rodas de conversas (figura 2).

Figura 1: Cartaz para divulgação nas UBS contemplando os micro-organismos identificados no trabalho

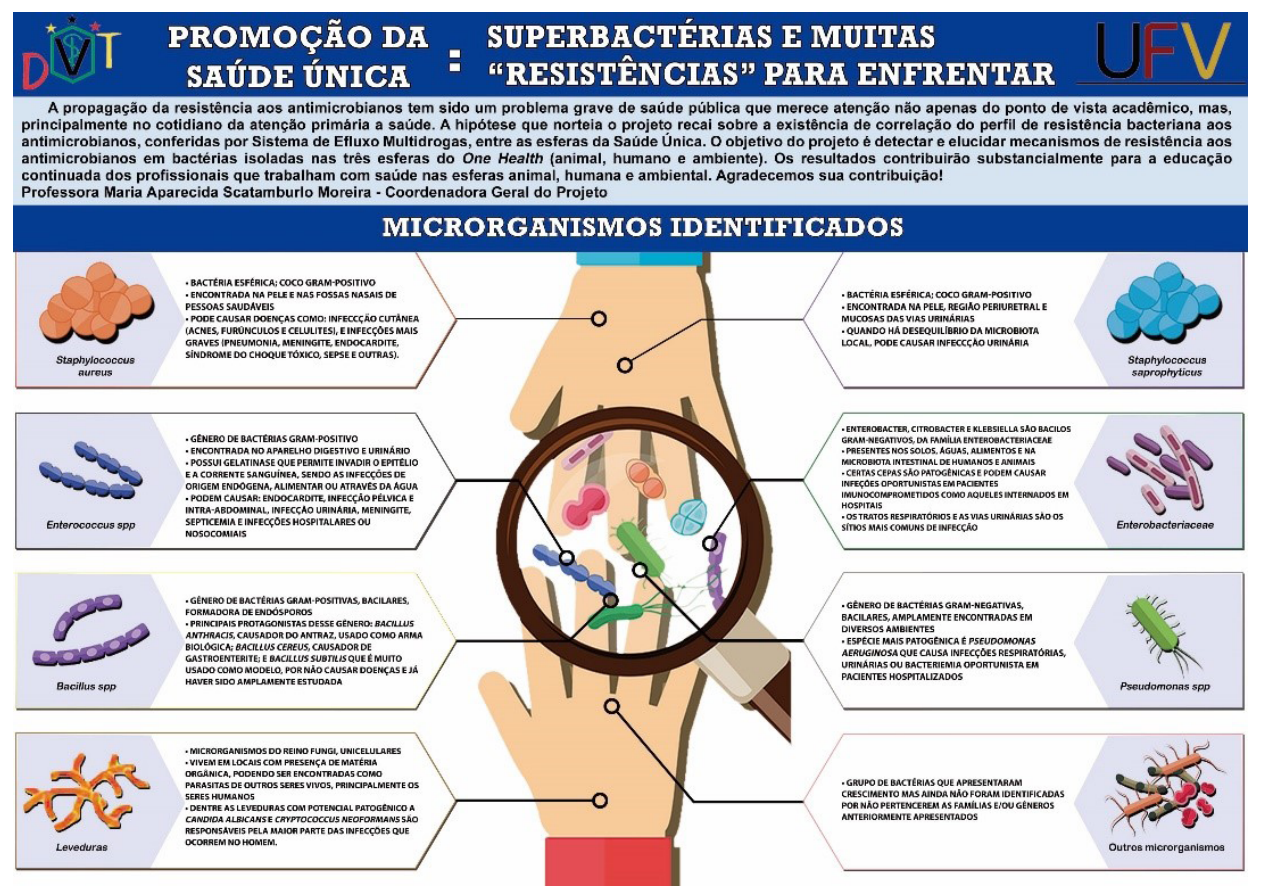


Figura 2: Grupo de discussão da temática com a eSF na UBS - Nova Viçosa

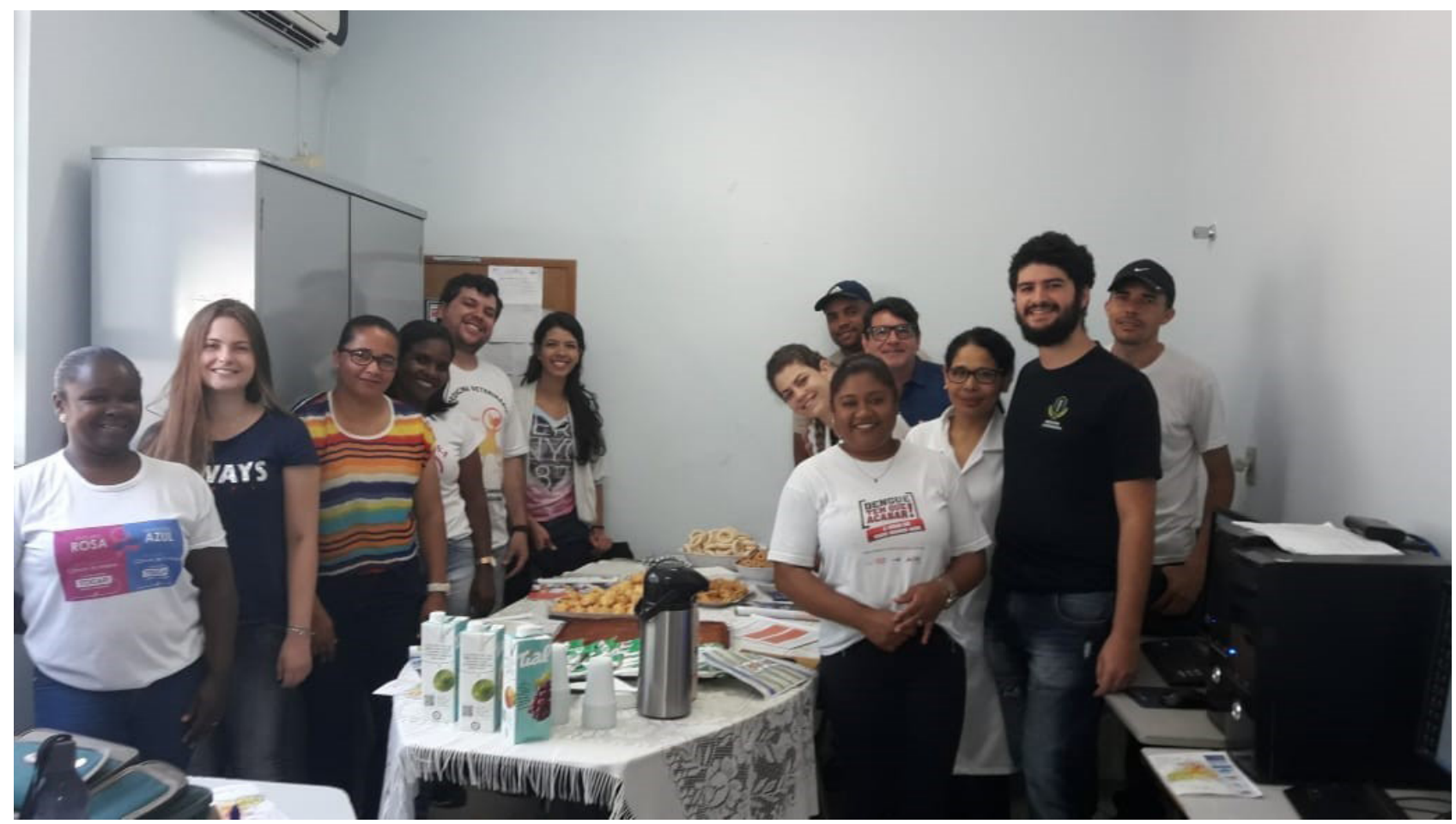

\section{CONSIDERAÇÕES FINAIS OU CONCLUSÃO}

O conhecimento das especificidades da ESF orientou as atividades dos demais projetos e serviu de base para a construção do diálogo entre universidade-eSF-comunidade, refletindo principalmente da devolução dos dados da pesquisa de forma a atender a realidade local dos profissionais e usuários. Trabalhar em consonância com as especificidades de cada eSF é a chave para o sucesso da prática na Saúde Pública.

\section{REFERÊNCIAS}

COSTA NETO, M.M. A implantação de unidade de saúde da família. Brasília: Ministério da Saúde, 2000.

OPAS - Organização Pan-Americana da Saúde. Folha informativa - Resistência aos antibióticos. Brasília, 2017. Disponível em: https://www.paho.org/bra/index.php?option=com_content\&view=arti cle\&id=5664:folha-informativa-resistencia-aos-antibioticos\&Itemid=812. Acesso em: 19 mar. 2021 .

PAIVA, C. L. Uso indiscriminado de antibióticos e superbactérias kpc: tema cts controverso no ensino de biologia. Espírito Santo: Revista Eletrônica Debates em Educação Científica e Tecnológica, 2013. 


\section{MEDICINA VETERINÁRA NO COMBATE A PANDEMIA DE COVID-19 EM VIÇOSA, MG}

\section{Rodrigo Alves Barros'; Melina Nascimento França²; Ana Paula Prueza de Almeida Luna Alves $^{3}$}

'Doutorando em Medicina Veterinária, Universidade Federal de Viçosa (UFV), Viçosa, MG.

${ }^{2}$ Residente em Medicina Veterinária, Universidade Federal Rural do Rio de Janeiro (UFRRJ), Seropédica, RJ.

${ }^{3}$ Residente em Medicina Veterinária, Universidade Federal de Viçosa (UFV), Viçosa, MG.

\section{RESUMO}

A Organização Mundial da Saúde declarou, em março de 2020, situação de pandemia de COVID-19 e diversas estratégias foram adotadas, a níveis municipal, estadual, nacional e mundial no combate à transmissão do vírus. Neste contexto, o presente trabalho visa relatar a atuação dos Médicos Veterinários discentes de Programas de Residência Multiprofissional em Saúde, integrados a ação estratégica dos Ministérios da Saúde e da Educação denominada "O Brasil Conta Comigo", junto à Secretaria Municipal de Saúde do município de Viçosa-MG no enfrentamento da pandemia da COVID-19. O relato de experiência foi construído por meio de uma abordagem etnográfica, com observação participante. A discussão e os resultados foram retratados de acordo com o local e atividade realizada. A participação nas atividades proporcionou a oportunidade de demonstrar e compreender a atuação do médico veterinário na saúde pública de forma intensiva, beneficiando o aprendizado dos residentes envolvidos e a atenção à comunidade.

PALAVRAS-CHAVE: Residência em Saúde; Vigilância em Saúde; Aprendizagem em Serviço. ÁREA TEMÁTICA: Saúde Coletiva. 


\section{INTRODUÇÃO}

Diante de um cenário pandêmico, em que questões sanitárias, sociais, políticas e ambientais tornam-se visíveis e urgentes, fez-se necessário uma compreensão ampla a partir de várias perspectivas e atuação efetiva de múltiplos atores. Dessa forma, os gestores municipais, por meio de parcerias entre a Secretaria Municipal de Saúde, Hospitais, Departamentos da Universidade Federal de Viçosa, implementaram um plano de contingência, adotando medidas coletivas e individuais (PREFEITURA MUNICIPAL DE VIÇOSA, 2020). Dentre essas ações de contingência foram suspensas as atividades acadêmicas em todo o município.

O Programa de Residência em Medicina Veterinária da Universidade Federal de Viçosa (UFV) é caracterizado como multiprofissional em saúde. Sendo assim, usualmente, os residentes desempenham atividades regulares junto à Secretaria Municipal de Saúde (SMS) do município de Viçosa, tais como intervenções de educação em saúde, iniciativas de posse animal responsável, projetos de castração, controle de escorpião, dentre outros. Com o isolamento social e consequente suspensão das atividades do Hospital Veterinário da UFV, os residentes perderam seu principal cenário de atuação, o que culminou na participação oportuna e intensiva dos mesmos na saúde pública, aderindo à iniciativa "O Brasil Conta Comigo -Residentes da Área da Saúde" e atuando junto à SMS em diversas atividades estratégicas no decorrer do ano de 2020.

O objetivo deste resumo é relatar a participação de médicas e médicos veterinários, discentes dos Programas de Residência em Medicina Veterinária da Universidade Federal de Viçosa e Universidade Federal do Rio de Janeiro no enfrentamento da pandemia de Covid-19, no município de Viçosa, MG.

\section{METODOLOGIA}

As atividades foram desenvolvidas nos setores de Vigilância Epidemiológica, Vigilância Sanitária e Central COVID-19 da Prefeitura Municipal de Viçosa e, o Núcleo de Vigilância em Saúde, Laboratório de Biotecnologia Animal e Telessaúde da Universidade Federal de Viçosa, durante o período de 17 de março de 2020 a 19 de março de 2021. Estiveram envolvidos nas atividades 32 residentes em Medicina Veterinária da Universidade Federal de Viçosa e 01 residente da Universidade Federal Rural do Rio de Janeiro.

O presente estudo é um relato de experiência de abordagem etnográfica. O relato de experiência é uma narrativa que legitima a experiência enquanto fenômeno científico, uma vez que traz as motivações ou metodologias para as ações, e as considerações e impressões de modo contextualizado, com objetividade e aporte teórico (DALTRO; FARIA, 2019). Considerou-se, como Ludke e André (1986), que abordagem etnográfica se baseia na descrição de um sistema de significados de determinado grupo e as experiências dos sujeitos envolvidos é o centro das atenções. Os autores foram os sujeitos que executaram, vivenciaram e relataram as experiências e, a observação participante o principal método de construção dos dados. 


\section{RESULTADOS E DISCUSSÕES}

Os residentes foram divididos em dois grupos: os que atuaram presencialmente e aqueles que participaram de forma remota, trabalhando em home office, seja por estarem no grupo de risco para COVID-19 ou por estarem em isolamento social, fora do município de Viçosa, MG. A distribuição dos residentes foi realizada de maneira dinâmica, com rodízio, atendendo à demanda de cada um dos setores, permitindo que os residentes vivenciassem diferentes experiências.

As atividades remotas foram: (i) Produção de Materiais para Veículos de Divulgação. As informações sobre a COVID-19, de fontes confiáveis, tais como, Conselho Federal de Medicina Veterinária, Organização Mundial de Saúde, Ministério da Saúde, Associação Americana de Medicina Veterinária, Associação Mundial de Medicina Veterinária de Pequenos Animais eram transformadas em postagens visualmente agradáveis e com linguagem acessível à população, para posteriormente serem divulgadas em redes sociais; (ii) Assessoria Técnica Remota, repasse de informações para a equipe, após a checagem dos fatos e fontes, com a produção e atualização periódica de um material intitulado: "Novo Coronavírus (COVID-19): Perguntas e Respostas"; (iii) Comunicação e Divulgação do material produzido pelas demais equipes. Além disso, dúvidas dos seguidores eram esclarecidas conforme demanda. Diariamente duas publicações eram postadas nas contas oficiais do programa de residência (Instagram: @residenciaufv e Facebook: Residência Veterinária UFV); (iv) Produção e Divulgação de Lives, apresentações online ao vivo, que se destacaram como a maneira mais eficiente e interativa de acessar a população durante a pandemia. A equipe fazia contato com especialistas, avaliava o roteiro e fornecia suporte e apoio técnico durante a transmissão. Após a apresentação sobre o assunto, o profissional convidado se colocava a disposição para esclarecer, em tempo real, as dúvidas dos espectadores; (v) Produção de Pitch, foram criados e divulgados nas redes sociais vídeos curtos sobre o tema "COVID-19 e a Medicina Veterinária"; (vi) Gerenciamento de Atividades, responsável pela verificação diária do andamento das atividades e atualização do restante da equipe sobre eventuais mudanças na rotina. Também realizavam a produção periódica de relatórios de atividades.

As principais atividades presenciais foram: (i) na Vigilância Epidemiológica, os residentes ficaram responsáveis pelo recebimento das notificações dos casos suspeitos e/ou confirmados via sistema de informação E-sus Notifica, sendo estas advindas dos estabelecimentos de saúde (Unidade Básicas de Saúde, hospitais, clínicas, farmácias e laboratórios) públicos e particulares. Posteriormente, ocorria o rastreamento, monitoramento e investigação epidemiológica dos casos positivos; (ii) na Vigilância Sanitária, os residentes atuaram no processo de fiscalização e autorização para o funcionamento dos estabelecimentos comerciais, conforme as novas normas de biossegurança necessárias ao combate ao COVID-19; (iii) na Central COVID-19, posto sentinela para atendimento médico e testes diagnósticos, os residentes atuavam na recepção dos pacientes, no envio dos resultados e na orientação e gestão de recursos humanos do setor; (iv) no Núcleo de Vigilância em Saúde da UFV, os residentes realizavam o monitoramento da situação epidemiológica da instituição, por meio de visitas aos locais de trabalho e testagem periódica dos servidores em atividades presenciais; (v) no Laboratório de Biotecnologia Animal do Departamento de Zootecnia (LABTEC), os residentes 
acompanhavam a rotina de realização dos testes de diagnóstico do SARS-Cov-2, por meio de PCR, das amostras oriundas de três Unidades Regionais de Saúde (Manhuaçu, Ponte Nova e Ubá) de Minas Gerais, compreendendo 95 municípios; (vi) no Telessaúde, os residentes participavam das atividades de teleatendimento e telemonitoramento de pacientes que entravam em contato com a equipe por meio telefônico. A equipe fornecia orientações e encaminhamentos de acordo com o fluxo da rede municipal de saúde, assim como, prestava auxílio na busca ativa dos contatos próximos/domiciliares de casos confirmados, em parceria com a Vigilância Epidemiológica, orientando adequadamente quanto à testagem e isolamento.

De forma geral, pode afirmar que os residentes em Medicina Veterinária estiveram envolvidos direta e indiretamente em todas as atividades de controle e prevenção do COVID-19, no município de Viçosa, MG. Dada formação profissional ampla e variada, o conhecimento do médico veterinário em áreas diversas, tais como, biologia geral e imunologia, permite que este agregue no entendimento de uma doença como um todo, desde sua epidemiologia, testes diagnósticos, medidas de prevenção e controle.

O médico veterinário é profissional de saúde reconhecido pelo Conselho Nacional de Saúde desde 1998 (BRASIL, 1968; CONSELHO NACIONAL DE SAÚDE, 1998) e, tal atuação reforça que o médico veterinário não está presente apenas na saúde animal e ambiental, mas também na promoção da saúde humana através do combate a doenças zoonóticas, segurança sanitária dos produtos de origem animal (FRIAS; MARIANO; PINHEIRO JUNIOR, 2009) e composição das equipes multiprofissionais em saúde, como a equipe do Núcleo de Apoio à Saúde da Família (BRASIL, 2011).

Da perspectiva da formação acadêmica dos residentes, considera-se, como Pimentel (2007), que aprender é um processo contínuo e ascendente, impulsionado pela experiência. Nesse contexto, a vivência dos residentes na saúde pública durante a pandemia contribuiu no entendimento das peculiaridades da saúde, a partir da percepção de residentes que escolheram, a princípio, a área clínica e cirúrgica. Esse entendimento passou pela ruptura de não ser o personagem principal, como acontece em um atendimento hospitalar, por exemplo, e ainda assim não pensar que, na saúde pública a atividade executada seja de menor relevância.

\section{CONSIDERAÇÕES FINAIS}

A participação dos residentes nessas atividades proporcionou, de forma intensiva, reflexões sobre o papel como educadores, profissionais de saúde e como cidadãos. Adequar-se aos trabalhos foi, no mínimo, desafiador, mas a experiência adquirida contribuiu, diretamente, na formação de profissionais com uma visão mais ampla de saúde. Além disso, poder contribuir com o município foi uma forma de retribuir à sociedade, cumprindo o papel de profissional da saúde em uma situação emergencial. 


\section{REFERÊNCIAS}

BRASIL. Portaria n⿳ 639, de 31 de março de 2020. Dispõe sobre a Ação Estratégica "O Brasil Conta Comigo - Profissionais da Saúde", voltada à capacitação e ao cadastramento de profissionais da área de saúde, para o enfrentamento à pandemia do coronavírus (COVID-19).

BRASIL. Portaria n $\mathbf{n}^{\mathbf{2}} \mathbf{2 . 4 8 8}$, de 21 de outubro de 2011. Aprova a Política Nacional de Atenção Básica, estabelecendo a revisão de diretrizes e normas para a organização da Atenção Básica, para a Estratégia Saúde da Família (ESF) e o Programa de Agentes Comunitários de Saúde (PACS).

CONSELHO NACIONAL DE SAÚDE. Resolução nº 287 de 08 de outubro de 1998.

DALTRO, M. R., FARIA, A. A. Relato de experiência: Uma narrativa científica na pós-modernidade. Psicologia Clínica e Psicanálise, v. 19, n.1, p. 223-237, Rio de Janeiro, 2019.

FRIAS, R. B., MARIANO, R. S. G., PINHEIRO JUNIOR, O. A. A importância do Médico Veterinário na Saúde Pública: Revisão Bibliográfica. Revista Científica Eletrônica de Medicina Veterinária, n. 12, Garça, 2009.

LUDKE, M.; ANDRE, M. E. D. A. Pesquisa em educação: abordagens qualitativas. São Paulo: EPU, 1986. 99 p.

PIMENTEL, A. A teoria da aprendizagem experiencial como alicerce de estudos sobre desenvolvimento profissional. Estudos de Psicologia. Sine loco, v. 12, n. 2, p. 159-168, 2007.

PREFEITURA MUNICIPAL DE VIÇOSA. Decreto $\mathbf{n}^{\circ} \mathbf{5 4 3 0 / 2 0 2 0}$. Estabelece providências complementares ao estado de "alerta" local, publicado na data de 14 de março de 2020, em razão Decreto de Situação de Emergência em Saúde Pública determinado pelo Estado de Minas Gerais e pelo Ministério da Saúde e dá outras providências. Viçosa, 2020. 


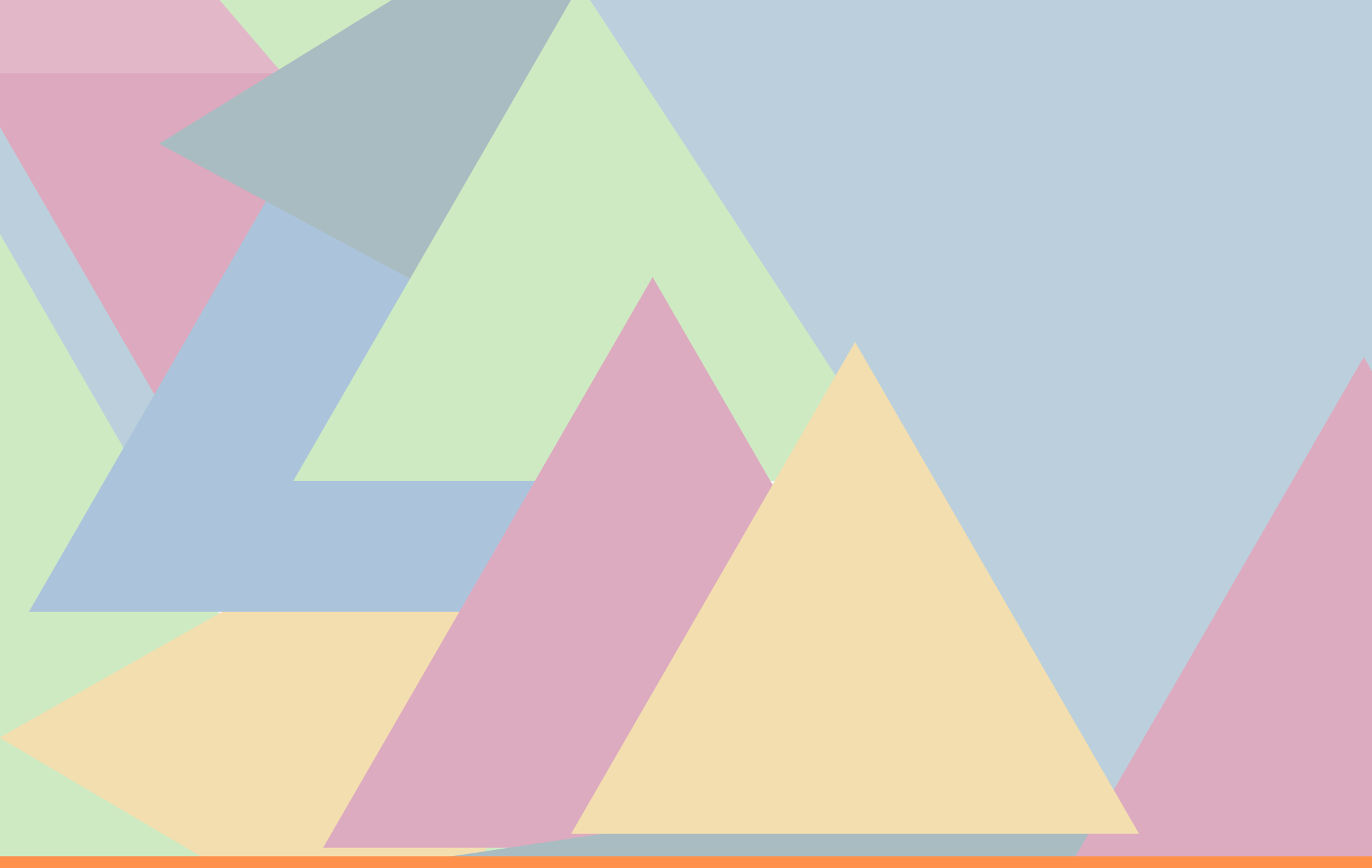

\section{Áreas afins}




\title{
MANIFESTAÇÕES ORAIS DECORRENTES DO TRATAMENTO QUIMIOTERÁPICO - REVISÃO DE LITERATURA
}

\author{
Francisco Antônio de Jesus Costa Silva'; \\ Silva Lima²; Maria Cândida de Almeida Lopes ${ }^{3}$ \\ ${ }^{1}$ Graduando de Odontologia. Universidade Federal do Piauí (UFPI). Teresina, Piauí. \\ ${ }^{2}$ Graduandos de Odontologia. Universidade Federal do Piauí (UFPI). Teresina, Piauí. \\ ${ }^{3}$ Professora Doutora do curso de Odontologia. Universidade Federal do Piauí (UFPI). Teresina, \\ Piauí.
}

\begin{abstract}
RESUMO
Em decorrência da quimioterapia, alterações na cavidade oral podem ser observadas e levar a complicações sistêmicas importantes, podendo aumentar o tempo de internação hospitalar, os custos do tratamento e afetar diretamente a qualidade de vida dos pacientes. Este trabalho teve como objetivo realizar uma revisão de principais manifestações encontradas nos trabalhos usados como referência textual foram: mucosite, xerostomia, candidíase, trismo e alteração do paladar. A partir disso, faz-se necessário a presença do cirurgião-dentista para o acompanhamento dos indivíduos submetidos a terapia quimioterápica, podendo promover o diagnóstico e prevenção dessas manifestações orais.
\end{abstract}

PALAVRAS-CHAVE: Oncologia; Câncer de Boca; Quimioterapia;

AREA TEMATICA: Educação em Saúde.

\section{INTRODUÇÃO}

O câncer consiste em um conjunto de mais de 100(cem) doenças que tem em comum o crescimento desordenado de células, com intensa multiplicação e invasão tecidual e de órgãos, espalhando-se por todo organismo. São neoplasias malignas cuja a capacidade de infiltrar tecidos normais é conhecida como metástase (Talmadge, 2010). Zanini et al. (2016) relatam que as manifestações bucais mais frequentes em pacientes que estão em tratamento oncológico são mucosite, xerostomia, infecções fúngicas e virais, osteorradionecrose, limitação do grau de abertura bucal (trismo), periodontite, diminuição da qualidade da função mastigatória, disgeusia e cárie de radiação.

Sendo assim, o objetivo geral deste estudo é analisar na literatura as principais manifestações orais decorrentes do tratamento quimioterápico. Tendo como objetivos específicos: verificar o papel 
do cirurgião-dentista no manejo do câncer de boca.

\section{METODOLOGIA}

Esta é uma pesquisa de caráter bibliográfico de natureza aplicada, com abordagem qualitativa e quantos aos objetivos é exploratório. Para a sua realização, foram selecionados artigos científicos, manuais, teses, dissertação, monografia relacionados ao assunto, publicados nos idiomas português e inglês, nos últimos 10 anos (2009 a 2019). No entanto, alguns artigos de suma importância para a compreensão do histórico ou das pesquisas acerca do tema, que datassem de um período anterior ao filtrado, foram incluídos com o intuito de enriquecer a discussão desse tema. As buscas ocorreram de forma online nas bases de dados Pubmed e Bireme, utilizando os Descritores em Ciência da Saúde (DeCS) cadastrados na Biblioteca Virtual em Saúde (BVS): Oncologia (Oncology); Câncer de Boca (Mouth Cancer); Quimioterapia (Chemotherapy). Como critérios de inclusão na realização da pesquisa foram utilizados artigos em inglês e português que discorreram sobre: câncer bucal, manifestações orais causadas pelo tratamento quimioterápico bem como as características e o tratamento dessas repercussões orais. Já como critérios de exclusão foram excluídos os artigos não publicados na íntegra e artigos sem resumo completo ou abstract. Os resultados foram organizados em forma descritiva, apontando os dados relevantes de cada obra.

\section{RESULTADO E DISCUSSÃO}

O câncer de boca é uma doença crônica multifatorial, resultante da interação dos fatores de risco que afetam os processos de controle da proliferação e crescimento celular. Essa patologia compreende um conjunto de neoplasias que acometem a cavidade oral em suas mais variadas etiologias e aspectos histopatológicos, afetando lábios, gengivas, mucosa jugal, palato duro, língua e assoalho (Martins et al., 2008).

Uma vez que o câncer está instalado, pode-se recorrer a várias terapias como :quimioterapia, radioterapia, cirurgia, terapia hormonal e imunoterapia, que dependendo da sua atividade farmacológica e sua farmacodinâmica pode ser feitos por combinações. Primeiramente, a quimioterapia é usada antes dos principais tratamentos visando reduzir o tamanho do tumor, a fim de facilitar o seu controle. O tratamento curativo, a fim de ser verdadeiramente alcançado em adultos. Dura em média cinco anos. Fala-se em tratamento adjuvante quando os quimioterápicos são administrados após a terapia principal para eliminar possíveis resíduos da doença e evitar a síntese de mais células oncogênicas, conhecidas como metástase (Mendes et al., 2013).

\section{Mucosite}

A mucosite bucal é definida como uma inflamação e ulceração da mucosa bucal com formação 
de pseudomembrana e fonte potencial de infecções com risco de morte. É um efeito debilitante de tratamentos do câncer como a radioterapia e a quimioterapia, bastante frequente (afeta mais de $40 \%$ dos pacientes) e doloroso (Biron et al., 2000).

\section{Xerostomia}

Considerada uma alteração frequente nos pacientes em tratamento oncológico, a xerostomia é definida como a secura da boca (Figura 3), produzida pela secreção insuficiente de saliva, denominada hipossalivação, quando essa manifestação é efeito da quimioterapia, torna-se uma alteração transitória no funcionamento das glândulas salivares, cessando logo após o término do tratamento (Kroetz, 2003).

\section{Candidíase}

A candidíase é uma doença oportunista causada pela proliferação de espécies de cândida, principalmente a $C$. albicans. Muitos casos de óbito em pacientes com câncer resultam da septicemia fúngica, sendo $60 \%$ dos casos associados a infecções preexistentes. A candidíase é uma das mais infecções fúngicas mais comuns. Seus os fatores contribuintes incluem mielossupressão, comprometimento do fluxo salivar, trauma na mucosa, inadequada higiene bucal, desnutrição, debilitante condição física (Morais et al., 2014).

\section{Trismo}

Pacientes com câncer de cabeça e pescoço podem vir, ao longo do tratamento, desenvolver manifestações bucais, e o trismo é uma dessas manifestações. Essa patologia afeta os músculos da mandíbula e faz com que o paciente tenha uma limitação da abertura bucal. Quando o paciente apresenta trismo tem a capacidade de mastigação afetada, assim como falar corretamente, higienização adequada dos dentes, principalmente nas faces palatinas (KENT et al., 2008).

\section{Alteração do Paladar}

O sabor ou gosto é uma sensação essencial que é importante para avaliar o teor nutritivo dos alimentos, contribui para uma ingestão oral adequada, além do que é fundamental para evitar a ingestão de alimentos tóxicos. Essa sensação é constituída pelo sabor, cheiro, textura e temperatura dos alimentos sentidos durante a mastigação (Smith, 2001). 


\section{CONCLUSÃO}

Após a análise feita com base na literatura, pode-se concluir que manifestações orais decorrentes do tratamento quimioterápico mais frequentes são caracterizadas como: mucosite, candidíase, trismo, xerostomia e alterações no paladar. O cirurgião-dentista tem papel fundamental no diagnóstico, prevenção e durante o acompanhamento dessas manifestações.

\section{REFERÊNCIAS}

BIRON, P. et al. Research controversies in management of oral mucositis. Supportive care in cancer, v. 8, n. 1, p. 68-71, 2000.

INCA, Estimativa. Incidência de câncer no Brasil. INCA, Rio de Janeiro, 2019.

KENT, M.L. et al. Radiation-induced trismus in head and neck cancer patients. Supportive care in cancer, v. 16, n. 3, p. 305-309, 2008.

KROETZ, F.M. \& CZLUSNIAK, G.D. Alterações bucais e condutas terapêuticas em pacientes infanto-juvenis submetidos a tratamentos anti-neoplásicos. Publ. UEPG Ci. Biol. Saúde, Ponta Grossa, v. 9, n. 2, p. 41-48, jun. 2003.

MARTINS, MAT et al. Avaliação do conhecimento sobre o câncer bucal entre universitários. Rev Bras Cir Cabeça Pescoço, v. 37, n. 4, p. 191-7, 2008.

MENDES, M. et al. Patients' perspectives on palliative chemotherapy of colorectal and noncolorectal cancer: a prospective study in a chemotherapy-experienced population. BMC câncer, v. 13, n. 1, p. 66, 2013.

MORAIS, EF et al. Oral manifestations resulting from chemotherapy in children with acute lymphoblastic leukemia. Brazilian journal of otorhinolaryngology, v. 80, n. 1, p. 78-85, 2014

SMITH, DV. MARGOLSKEE, RF. Making sense of taste. Scientific American, v. 284, n.3 , p. $32-$ $39,2001$.

TALMADGE J.; FIDLER IJ. \& AACR Centennial Series: The Biology of Cancer Metastasis: Historical Perspective. Cancer Res. 2010 Jul 15;70(14):5649-69. doi: 10.1158/0008-5472.CAN-101040. Epub 2010 Jul 7.

ZANINI, L et al. Conhecimento dos cirurgiões-dentistas do município de Capão da Canoa sobre o atendimento a pacientes oncológicos. Revista da Faculdade de Odontologia-UPF, v. 21. 


\title{
ASPECTOS FISIOLÓGICOS DA HIPERTROFIA CARDÍACA ESQUERDA EM ATLETAS: UMA REVISÃO DE LITERATURA
}

\author{
Welisson Conrado Carvalho'; Pedro Victor Freitas Medrado \\ ${ }^{1}$ Graduando, Fundação Universidade Federal do Vale do São Francisco (UNIVASF), Petrolina, \\ Pernambuco. \\ ${ }^{2}$ Graduando, Fundação Universidade Federal do Vale do São Francisco (UNIVASF), Petrolina, \\ Pernambuco.
}

\begin{abstract}
RESUMO
A hipertrofia cardíaca esquerda fisiológica é uma adaptação que ocorre, em sua maior parte, em atletas de alto rendimento, proporcionando uma maior adaptação cardiovascular à exercícios físicos intensos. Nesse sentido, esse estudo surge com o principal objetivo de reunir as informações dos últimos 20 anos e relevantes acerca dos aspectos fisiológicos da hipertrofia ventricular esquerda (HVE) em atletas. Para isso, foram analisados 14 artigos cuja temática se encaixava com a proposta desta revisão de literatura. Pode-se notar que essas alterações cardíacas induzidas pelo exercício, em sua maioria, traziam benefícios a seus praticantes e possuíam caráter reversível, dinâmico e possivelmente genético, podendo ser rastreadas por alguns exames cardiológicos. Além disso, também pode-se perceber uma diferença nos aspectos intrínsecos entre a HVE fisiológica e patológica.
\end{abstract}

PALAVRAS-CHAVE: Remodelação ventricular; Coração de atleta; Fisiologia.

ÁREA TEMÁTICA: Áreas afins

\section{INTRODUÇÃO}

Durante um treinamento físico intenso, e por tempo prolongado, as necessidades metabólicas dos músculos aumentam, demandando um alto débito cardíaco para suprir uma alta necessidade de oxigênio. Caso a prática desse exercício ocorra por um tempo prolongado, serão induzidas algumas alterações morfofuncionais no coração, gerando o conhecido "coração de atleta" (CABANELAS; FREITAS; GONCA̧LVES, 2013). Essas adaptações estão essencialmente relacionadas com a modalidade, tempo e intensidade do exercício físico praticado. Tais alterações são, em sua maioria, de natureza fisiológica, caracterizando-se por uma hipertrofia cardíaca adaptativa, descrita principalmente como a remodelação do ventrículo esquerdo (VE). Essa alteração cardíaca pode ser reversível caso haja uma interrupção da prática desportiva intensa (CABANELAS; FREITAS; GONCA̧LVES, 2013; GALANTI et al., 2016). 
A HVE é definida pelo aumento da espessura e massa cardíaca, bem como o aumento da cavidade, com funções sistólica e diastólica preservadas, ou até mesmo melhoradas. Ela pode ser tanto fisiológica, que ocorre no "coração de atleta"; quanto patológica, ocorrendo principalmente na hipertensão arterial sistêmica, diabetes e obesidade, por exemplo, e pode ter sua natureza distinguida por meio do estudo da função subendocárdica (ROBERTO PINTO FERREIRA FILHO, 2012).

Dessa maneira, esta revisão de literatura surge com o principal objetivo de reunir as informações dos últimos 20 anos e relevantes acerca dos aspectos fisiológicos da HVE em atletas.

\section{METODOLOGIA}

Para a construção desta revisão de literatura foram consultados artigos acadêmicos nas seguintes plataformas: Pubmed, Medline, Google Scholar e SciELO. Para a realização da busca de literatura, foram cruzados os descritores "left ventricular hypertrophy", "athlete heart", "lvh", "athlete" e "physiology". Foram utilizados artigos escritos em inglês e português publicados entre o período de 2000 - 2020. Inicialmente foi realizada uma triagem dos artigos, onde foram excluídos os artigos que não se encaixavam na temática desejada, não estavam escritos em português ou inglês ou que foram publicados foram do período de interesse dessa revisão. Após essa triagem, foram selecionados 14 artigos acadêmicos cuja leitura foi realizada integralmente para a construção desta revisão de literatura.

\section{FUNDAMENTAÇÃO TEÓRICA}

Em termos fisiológicos, a hipertrofia cardíaca está associada com a indução do aumento da expressão de subunidades de canais iônicos do miocárdio, proporcionalmente ao aumento global das expressões proteicas(YANG et al., 2010). O relaxamento ativo, na função diastólica final, a eficiência mecânica e o acoplamento ventrículo-arterial são mais eficientes na hipertrofia fisiológica, em comparação com a patológica(OLÁH et al., 2016). Um dos motivos do atraso de relaxamento, encontra-se no fato de que a hipertrofia por pressão, não fisiológica, tem uma densidade de corrente repolarizante, do potássio, diminuída, o que prolonga o intervalo QT e o potencial de ação. Em termos genéticos, o exercício físico em atletas de provas de resistência induz o crescimento do ventrículo esquerdo como resultado do genótipo DD, da enzima conversora da angiotensina I (ACE), independentemente de outros fatores biológicos conhecidos(HERNÁNDEZ et al., 2003). Além disso, em mutações dos sarcômeros, mas sem manifestações de características clínicas de cardiomiopatia, há uma correlação $(\mathrm{p}=0,03)(\mathrm{DEJGAARD}$ et al., 2018)entre exercícios e à massa ventricular esquerda.

O ventrículo esquerdo (VE), diante do exercício físico responde, inicialmente, com remodelação concêntrica, e não excêntrica, durante os primeiros 6-9 meses a depender da duração e intensidade(ARBAB-ZADEH et al., 2014). Vale ressaltar que as adaptações cardíacas fisiológicas na forma excêntrica ou concêntrica, podem ser consideradas específicas em decorrência do tipo do desenho 
do estudo(GALANTI et al., 2016). Essas adaptações hipertróficas do VE, em atletas, são reversíveis e dinâmicas, modificando-se consoante as exigências sazonais de atividades(CABANELAS; FREITAS; GONCA̧LVES, 2013), além de variar conforme indivíduo. As altas cargas de trabalho absolutas e hemodinâmicas diárias pressionam a pressão arterial (PA) sistólica para valores necessários à remodelação cardíaca. Por isso que atividades diárias de intensidade moderada, de baixa carga, reduzem, substancialmente, o estímulo para remodelação cardíaca, e induzem a regressão da massa do VE(LOVIC et al., 2017). Jovens atletas, por exemplo, podem apresentar uma maior espessura da parede do ventrículo esquerdo(SHARMA, Sanjay et al., 2002) em comparação com não atletas. As adaptações cardíacas em atletas podem não alterar, significativamente, os valores do diâmetro e espessura diastólica da parede posterior do VE, do septo interventricular ou da massa do VE, resultados não esperados pela hipótese de Morganroth(HAYKOWSKY, 2011). Alguns estudos (GHORAYEB et al., 2005)demonstram aumentos de tais valores, com bons valores da capacidade física cardiopulmonar, da força contrátil, da performance ventricular esquerda; além dos volumes finais, diastólicos e sistólicos, e a fração de ejeção dentro os limites de normalidade.

O uso de ferramentas, como o eletrocardiograma (ECG) de 12 derivações, são valiosos no rastreio de hipertrofia ventricular esquerda, sobretudo com o achado de Sokolow-Lyon positivo, não tão incomum em atletas(MACHADO; VAZ SILVA, 2015). Outras alterações, como inversão de ondas T profundas associadas à HVE em atletas são sugestivas de reavaliação, antes do diagnóstico de cardiomiopatia hipertrófica(BASAVARAJAIAH et al., 2006). Além disso, a ecocardiografia, com destaque a transtorácica, pode ser utilizada clinicamente na determinação da massa do VE e avaliação dos padrões geométricos(ROBERTO PINTO FERREIRA FILHO, 2012).

\section{CONCLUSÃO}

A HVE em atletas é uma resposta, em essência, dinâmica, adaptativa e reversível, cujos achados variam conforme subpopulações e desenhos de estudos. Além disso, destaca-se o papel de achados genéticos, e das novas tecnologias de rastreio, bem como reavaliação de conduta. Quando comparados, a hipertrofia ventricular fisiológica apresenta valores funcionais e performance melhor do que na hipertrofia de origem patológica, que em alguns estudos está associada com alterações arrítmicas no ECG de 12 derivações, e no potencial de ação da célula.

\section{PRINCIPAIS REFERÊNCIAS}

ARBAB-ZADEH, A. et al. Cardiac Remodeling in Response to 1 Year of Intensive Endurance Training. Circulation, dez. 2014. v. 130, n. 24, p. 2152-2161. Disponível em: <https://www. ahajournals.org/doi/10.1161/CIRCULATIONAHA.114.010775>.

BASAVARAJAIAH, S. et al. Physiological left ventricular hypertrophy or hypertrophic cardiomyopathy in an elite adolescent athlete: Role of detraining in resolving the clinical dilemma. 
British Journal of Sports Medicine, 2006. v. 40, n. 8, p. 727-729.

CABANELAS, N.; FREITAS, S.; GONCA̧LVES, L. Evolução das características morfofuncionais do coração do atleta durante uma época desportiva. Revista Portuguesa de Cardiologia, 1 abr. 2013. v. 32, n. 4, p. 291-296.

DEJGAARD, L. A. et al. Vigorous exercise in patients with hypertrophic cardiomyopathy. International Journal of Cardiology, 2018. v. 250, p. 157-163. Disponível em: <https://doi. org/10.1016/j.ijcard.2017.07.015>.

GALANTI, G. et al. Left ventricular remodeling and the athlete's heart, irrespective of quality load training. Cardiovascular Ultrasound, 2016. v. 14, n. 1, p. 1-9. Disponível em: <http://dx.doi. org/10.1186/s12947-016-0088-x>.

GHORAYEB, N. et al. Hipertrofia Ventricular Esquerda do Atleta. Resposta Adaptativa Fisiológica do Coração. Arquivos Brasileiros de Cardiologia. [S.1.]: [s.n.], 2005. Disponível em: <https://www. scielo.br/pdf/abc/v85n3/26003.pdf>. Acesso em: 26 jan. 2021.

HAYKOWSKY, M. J. Left ventricular remodelling and the athlete's heart: Time to revisit the Morganroth hypothesis. Journal of Physiology, 2011. v. 589, n. 24, p. 5915.

HERNÁNDEZ, D. et al. The ACE/DD genotype is associated with the extent of exercise-induced left ventricular growth in endurance athletes. Journal of the American College of Cardiology, 2003. v. 42 , n. 3, p. 527-532.

LOVIC, D. et al. Left ventricular hypertrophy in athletes and hypertensive patients. Journal of Clinical Hypertension, 2017. v. 19, n. 4, p. 413-417.

MACHADO, M.; VAZ SILVA, M. Benign and pathological electrocardiographic changes in athletes. Revista Portuguesa de Cardiologia. Sociedade Portuguesa de Cardiologia.

OLÁH, A. et al. Physiological and pathological left ventricular hypertrophy of comparable degree is associated with characteristic differences of in vivo hemodynamics. American Journal of Physiology - Heart and Circulatory Physiology, 2016. v. 310, n. 5, p. H587-H597.

ROBERTO PINTO FERREIRA FILHO, P. Padrões de Hipertrofia e Geometria do Ventrículo Esquerdo pela Ecocardiografia Transtorácica Patterns of Left Ventricular Hypertrophy and Geometry by Chest Echocardiography. 2012. v. 25, n. 2, p. 103-115. Disponível em: <http:// departamentos.cardiol.br/dic/publicacoes/revistadic/revista/2012/portugues/Revista02/06-padroes. pdf>. Acesso em: 27 jan. 2021.

SHARMA, Sanjay et al. Physiologic limits of left ventricular hypertrophy in elite junior athletes: Relevance to differential diagnosis of athlete's heart and hypertrophic cardiomyopathy. Journal of the American College of Cardiology.

YANG, K. C. et al. Homeostatic regulation of electrical excitability in physiological cardiac 
hypertrophy. Journal of Physiology, 2010. v. 588, n. 24, p. 5015-5032. 


\title{
TRATAMENTO COM ÁCIDO HIALURÔNICO PARA DISFUNÇÃO TEMPOROMANDIBULAR - REVISÃO DE LITERATURA
}

\author{
Francisco Antônio de Jesus Costa Silva ${ }^{1}$, Deloniê Eduardo Oliveira de Lima ${ }^{1}$, Luana Oliveira \\ Bandeira $^{1}$ Luis Paulo da Silva Dias², Maria Cândida de Almeida Lopes ${ }^{3}$ \\ ${ }^{1}$ Graduandos de Odontologia. Universidade Federal do Piauí. Piauí - Teresina. \\ ${ }^{2}$ Residente Buco-Maxilo-Facial. Universidade Federal do Piauí. Piauí - Teresina. \\ ${ }^{3}$ Profa. Dra. do curso de Odontologia. Universidade Federal do Piauí. Piauí - Teresina.
}

\begin{abstract}
RESUMO
Dores orofaciais muitas vezes são oriundas de desordens temporomandibulares (DTM), estando associadas a sintomatologia crônica a fatores psicológicos, sociais, culturais e fisiopatológicos. Este trabalho visa realizar uma revisão de literatura acerca dos benefícios da viscossuplementação como tratamento dos sintomas das desordens temporomandibulares, evidenciando sua eficácia. A disfunção temporomandibular (DTM) é considerada uma patologia pode ser tratada por diversos métodos como aconselhamento, farmacoterapia, fisioterapia e dispositivos interoclusais. Dito isso, observou-se que a injeção intra-articular de ácido hialurônico consiste em uma possibilidade terapêutica eficaz no tratamento e prognóstico das DTM, uma vez que foi comprovado a redução da sensação dolorosa, melhora na abertura bucal, nos parâmetros de qualidade de vida e efeito protetor na articulação. Em suma, conclui-se que a viscossuplementação é uma abordagem pouco invasiva, de baixo custo e com bons resultados em curto e médio prazo.
\end{abstract}

PALAVRA-CHAVE: Disfunção Temporomandibular; Tratamentos; Ácido Hialurônico;

ÁREA TEMÁTICA: Outros

\section{INTRODUÇÃO}

Tem-se denominado Dores Orofaciais como dores que permeiam a face, pescoço, cabeça, mandíbula ou boca. Logo, existe diversos fatores etiológicos que permitem o aparecimento deste problema, tendo como a mais visível as que são originadas de desordens temporomandibulares (DTM) e podem possuir sinais e sintomas que incluem dor persistente, progressiva, recorrente ou crônica na articulação temporomandibular (ATM), ouvidos e músculos da mastigação. Assim, há associação com possíveis limitações na abertura bucal, estalos ou crepitações, acarretando repercussões negativas no comportamento social e na qualidade de vida do paciente.

Dito isso, as disfunções temporomandibulares articulares possuem um colapso na 
normalidade da função do disco sobre o côndilo mandibular, ocasionado devido à ineficiência dos ligamentos colaterais do disco e lâmina retrodiscal inferior. Essas disfunções podem estar associadas a inflamações ou alterações degenerativas. Assim, tem-se como protocolo primário de controle das DTMs dá prioridade as medidas das mais simples, reversíveis e menos invasivas. Contudo, como as disfunções intracapsulares muitas vezes são o resultado de doenças das superfícies articulares, o tratamento conservador mostra-se algumas vezes ineficiente (OKESON, 2011).

\section{METODOLOGIA}

Este trabalho é uma revisão de literatura de caráter bibliográfico de natureza aplicada, com abordagem qualitativa. Para a sua realização, foram selecionados artigos científicos, manuais, teses, dissertação, monografia relacionados ao assunto, publicados nos idiomas português e inglês, nos últimos 10 anos (2009 a 2019). No entanto, alguns artigos de suma importância para a compreensão do histórico ou das pesquisas acerca do tema, que datassem de um período anterior ao filtrado, foram incluídos com o intuito de enriquecer a discussão desse tema. As buscas ocorreram de forma online nas bases de dados Pubmed e Bireme, utilizando os Descritores em Ciência da Saúde (DeCS) cadastrados na Biblioteca Virtual em Saúde (BVS): Disfunção Temporomandibular; Tratamentos; Ácido Hialurônico. Como critérios de inclusão na realização da pesquisa foram utilizados artigos em inglês e português. Já como critérios de exclusão foram excluídos os artigos não publicados na íntegra e artigos sem resumo completo ou abstract. Os resultados foram organizados em forma descritiva, apontando os dados relevantes de cada obra.

\section{RESULTADOS E DISCUSSÃO}

O ácido hialurônico possui algumas funcionalidades, como lubrificação das superfícies articulares, redução das aderências de exposição e atritos nas cavidades sinoviais lesionadas. Logo, percebe-se decréscimo nos níveis inflamatórios e nos sintomas dolorosos articulares. Mais também, AH possui uma atividade metabólica que contribui para a nutrição do disco, da cartilagem articular e de zonas avasculares (CARVALHO et al, 2017).

A viscossuplementação da ATM é uma técnica minimamente invasiva que consiste na injeção intra-articular de AH com vista à eliminação ou diminuição da dor e restabelecimento da atividade funcional da ATM, pelo melhoramento qualitativo e quantitativo do fluido sinovial. Devido às propriedades metabólicas e mecânicas do $\mathrm{AH}$, a técnica de viscossuplementação, isolada ou combinada com outras modalidades cirúrgicas como a artrocentese ou a artroscopia, pode ser uma opção terapêutica para condições inflamatórias ou alterações biomecânicas da ATM, sendo o tratamento conservador ideal, uma vez que é considerado minimamente invasivo e não apresenta efeitos deletérios até ao momento (LYRIO et al, 2010). 
A viscossuplementação com HS pode ser considerada uma medida terapêutica eficiente no restabelecimento funcional das ATM, a curto e médio prazo. Ensaios clínicos controlados com casuísticas significativas e com período de acompanhamento maior mostram-se necessários para avaliar a real eficácia da técnica de viscossuplementação e estabelecer um protocolo objetivo.

De acordo com Bonotto, Custódio e Cunali, em casos de alterações inflamatórias ou degenerativas o AH presente no líquido sinovial apresenta concentração e peso molecular diminuídos, fazendo-se necessário, como alternativa, a aplicação da técnica de viscossuplementação como tratamento das alterações da ATM. Em seu estudo, duas pacientes foram submetidas a infiltração semanal de AH por três semanas; foi observado a presença de prostaglandina E2 e leucotrieno B4, sugeridos como fatores causadores da dor. De forma conclusiva, a liberação das zonas de aderências entre o disco articular e a fossa mandibular permite melhor circulação do líquido sinovial, consequentemente leva ao aumento da movimentação mandibular. Sendo assim, ficou constatado que houve melhora no quadro de dor, além de melhorias na função mandibular (BONOTTO, CUSTODIO \& CUNALI, 2011).

\section{CONCLUSÃO}

Portanto, tem-se a utilização do ácido hialurônico já comprovado no ambiente cientifico como um dos métodos mais eficazes para disfunções temporomandibulares articulares. Afirma-se que com a infiltração do ácido associado a procedimentos cirúrgicos ou de modo isolado, sendo um tratamento simples, pouco invasivo, possui alta eficácia.

\section{REFERÊNCIAS}

BONOTTO D, CUSTÓDIO LG, CUNALI PA. Viscossuplementação como tratamento das alterações internas da articulação temporomandibular. Relato de casos. Rev Dor. São Paulo, 2011;12(3):274278.

CARVALHO AV, GROSSMANN E, FERREIRA FR, JANUZZI E, FONSECA RMDFB. The use ofdryneedling in thetreatmentof cervical andmasticatorymyofascialpain. Rev Dor. São Paulo, 2017; 18(3):255-60.

CAVALCANTI MOA, LIMA J, BATISTA A, OLIVEIRA LMC, LUCENA LBS. Grau de severidade da disfunção temporomandibular e hábitos parafuncionais em policiais militares. Rev Gaúcha Odontol. 2011;59(3):351-6

GUARDA-NARDINI L, OLIVO M, FERRONATO G, SALMASO L, BONNINI S, MANFREDINI D. Treatment effectiveness of arthrocentesis plus hyaluronic acid injections in different age groups of patients with temporomandibular joint osteoarthritis. J Oral MaxillofacSurg. 2012;70(9):2048-56.

LYRIO MCN, PEREIRA FILHO VA, SILVA LMC, MORAES M. Uso de Hialuronidato de sódio para 
tratamento de deslocamento anterior de disco articular com travamento bucal. Rev. Cir. Traumatol. Buco-Maxilo-fac., 2010; 10 (1):49-56.

MANFREDINI D, RANCITELLI D, FERRONATO G, GUARDA-NARDINI L. Arthrocentesis with or without additional drugs in temporomandibular joint inflammatory-degenerative disease: comparison of six treatment protocols. J Oral Rehabil. 2012;39(4):245-51.

OKESON JP, DE LEEUW R. Differential diagnosis of temporomandibular disorders and other orofacial pain disorders. DentClin North Am 2011;55(1):105-20. 
A TEMPESTADE DE CITOCINAS NO DESENVOLVIMENTO DA COVID-19.

\title{
Sheila Oliveira Falcão ${ }^{1}$; Aslanny Ferreira Siqueira Freitas ${ }^{1}$; Gustavo Henrique Dias da Silva ${ }^{1}$; Bianca Barbosa Martins ${ }^{1}$; Layene Ariely de Oliveira Barros ${ }^{1}$; Edson de Jesus Sá1; César Augusto da Silva ${ }^{2}$.
}

\author{
Discentes, Universidade Federal do Vale do São Francisco (UNIVASF), Petrolina, \\ Pernambuco. \\ Docente, Universidade Federal do Vale do São Francisco (UNIVASF), Petrolina, \\ Pernambuco.
}

DOI: $10.47094 /$ ICONRES.2021/1

\begin{abstract}
RESUMO
O mau-prognóstico da COVID-19 está relacionada ao desenvolvimento da tempestade de citocinas, por isso se observou a necessidade de investigar essa relação de causa e efeito que já causou tantas perdas e desgastes desde do início da pandemia. Assim, essa revisão sistemática tem como objetivo compreender esse problema e condensá-lo nesse trabalho. Para destacar esse fenômeno, foi realizado busca nas bases de dados PubMed, Science Direct e Frontiers in Immunology, usando os descritores específicos pelo DeCS, selecionando um total de 9 artigos. A análise desses artigos mostrou que o processo infeccioso na COVID-19 pode desregular a resposta imune ao contribuir para uma resposta hiper inflamatória sistêmica; além disso, observou-se o desenvolvimento de distúrbios no processo de coagulação do hospedeiro. Por fim, apesar dessa revisão condensar as principais referências sobre o desenvolvimento da tempestade de citocinas a partir da COVID-19, as pesquisas ainda são recentes, podendo variar algumas hipóteses futuramente.
\end{abstract}

PALAVRAS-CHAVES: Sars-cov-2; Hiperinflamação; Imunopatogenia.

ÁREA TEMÁTICA: Áreas afins .

\section{INTRODUÇÃO}

A rapidez com que o SARS-CoV-2 tomou proporções globais colocou em foco o manejo da principal causa das complicações apresentadas por uma parcela dos doentes, a tempestade de citocinas ${ }^{1}$. Apesar de não ser um fenômeno exclusivo da COVID-19, esse fator agravante se torna um desafio diário para os profissionais de saúde, devido às possíveis consequências trazidas ao indivíduo e à sua difícil administração ${ }^{2}$. Dito isso, este trabalho tem como objetivo abordar a reação do sistema 
imunológico do hospedeiro à invasão do vírus e a interação com suas proteínas estruturais; visa, ainda, elucidar o processo de amplificação da tempestade de citocinas, e, por fim, mostrar algumas consequências da sepse sistêmica, a exemplo da coagulopatia desencadeada pelo processo inflamatória exacerbado.

\section{METODOLOGIA}

Esta revisão de literatura foi desenvolvida a partir da busca de artigos científicos nas bases de dados PubMed, Science Direct e Frontiers in Immunology, utilizando-se os descritores: Cytokine Storm, SARS-CoV-2, COVID-19 e Comorbidities. Inicialmente foram selecionados 23 artigos relacionados aos descritores e lidos os seus resumos. Após a leitura integral de cada artigo, foram selecionados 9 artigos para serem base da fundamentação teórica.

\section{FUNDAMENTAÇÃO TEÓRICA}

A análise da estrutura e da composição do SARS-CoV-2 mostrou que as respostas imunes à infecção viral se iniciam a partir do reconhecimento de Padrões Moleculares Associados ao Patógeno (PAMPs), como as proteínas $\mathrm{N}$ e $\mathrm{S}$ que o compõem ${ }^{3,4}$. Os Receptores de Reconhecimento de Padrões (RPPs) presentes em células de defesa do organismo, ao reconhecerem esses PAMPs, ativam vias de sinalização que induzem a expressão inicial de citocinas ${ }^{3,4,5}$. Os danos celulares ocasionados pelo SARS-CoV-2, após a invasão da célula por meio da interação da proteína Spike (S) com o receptor Enzima Conversora da Angiotensina II (ECA-2), geram Padrões Moleculares Associados a Danos (DAMPs), que também podem ser reconhecidos pelos RRPs ${ }^{3}$.

Por intensificar a resposta imune, ampliar o recrutamento de células de defesa e ativar diferentes vias de sinalização de citocinas pró-inflamatórias, o processo de internalização do SARS-CoV-2 é considerado um dos precursores da tempestade de citocinas ${ }^{5,6}$. Isso porque leva a ativação e quimiotaxia de monócitos e macrófagos ao local inflamado e produzem citocinas pró-inflamatórias ${ }^{6}$. Apesar dos leucócitos exercerem papéis essenciais no combate à infecção viral, quando os mecanismos de controle às respostas imunes estão desequilibrados, essas células também podem estar envolvidas nos processos de lesão tecidual e, consequentemente, na persistência e disseminação do vírus pelo organismo ${ }^{4}$.

Normalmente, a expressão de citocinas pró-inflamatórias faz parte do curso normal da defesa imunológica em diferentes quadros infecciosos, porém, na COVID-19, alguns fatores são apontados como possíveis causas da desregulação da resposta imune já nos primeiros dias de infecção ${ }^{6}$. Dentre esses fatores, pode-se listar: 1) rápida replicação viral nos estágios iniciais da doença; 2) os mecanismos de evasão do SARS-CoV-2 às respostas imunes, que retardam a produção de IFNs e prejudicam a ação antiviral do sistema imune; e 3) atenuação da ação das células $\mathrm{T}$, que resulta em uma resposta inflamatória ainda mais descontrolada, podendo culminar na apoptose das células epiteliais ${ }^{3,6,7}$. 
Notou-se que o novo coronavírus humano $(\mathrm{HCoV})$ apresenta características intrínsecas que tornam sua patogenia bastante complexa ${ }^{3}$. As proteínas virais podem ativar a via de transcrição de citocinas, principalmente a da IL-6, por meio do aumento da expressão do gene Inibidor de NFKB alfa (NFKBIA), o qual regula a ativação da via NF-kB (fator nuclear kappa B) ${ }^{4,5}$. Essa maquinaria também é estimulada pela ativação do transdutor de sinal IL-6 e do fator de transcrição 3 (STAT3) ${ }^{5}$. Todas essas vias contribuem para o aumento dos níveis séricos da IL-6, criando um loop de feedback positivo, aumentando a concentração de proteínas da fase aguda da inflamação ${ }^{5,8}$. Por isso, tem-se que o processo de ativação simultânea do NF-kB e do eixo "Interleucina (IL)-6-STAT3" como um dos principais mecanismos de amplificação dessa resposta inflamatória excessiva ${ }^{5,6}$.

Como já observado, o SARS-CoV-2, ao invadir a célula do hospedeiro, induz a internalização da ECA2, enzima responsável por converter a Angiostensina II (ANGII) em Angiostensina (1-7) ${ }^{3}$. Esse processo promove o acúmulo de ANG II no organismo, a qual tem efeitos pró-inflamatórios e vasoconstritores quando interage com o Receptor da Angiotensina II tipo 1 (AT1R), sendo capazes de ativar a via Janus quinase (JAK) ${ }^{1}$. Em contrapartida, há uma redução dos níveis séricos de ANG (1-7), que tem papel anti-inflamatório e vasodilatador ${ }^{3}$. Assim, a desregulação da ação do Sistema Renina Angiotensina Aldosterona (SRAA) também é tida como um dos gatilhos para o começo da tempestade de citocinas ${ }^{5}$.

Diante do exposto, surge a hipótese de que os níveis séricos de ANG II e de IL-6 podem ser marcadores de um mau prognóstico da COVID-19 ${ }^{5,6,8}$. Desse modo, a tempestade de citocinas induzida pelo SARS-CoV-2 é caracterizada pela exacerbação na expressão de citocinas como IL-1 $\beta$, IL-6, IL-12, IL-18, TNF- $\alpha$ e IFN- $\gamma^{4,9}$. Quando esse fenômeno se estabelece, várias consequências sistêmicas são desencadeadas, visto que tais secreções circulam no sangue periférico, podendo causar danos ao corpo como um todo ${ }^{9}$. A IL-1 $\beta$, a IL-6 e o TNF- $\alpha$ aumentam a expressão de moléculas de adesão celular (CAMs) e fator de crescimento endotelial vascular (VEGF) no endotélio pulmonar após lesão do tecido, causando a destruição do glicocálice pulmonar e aumentando a permeabilidade do endotélio, permitindo que o vírus alcance outros órgãos ${ }^{6}$. É importante destacar que o vírus interage apenas com células que expressam receptores específicos, mas suas consequências serão sistêmicas ${ }^{2}$.

Durante a tempestade de citocinas pode haver uma hiper ativação das vias de coagulação ${ }^{2}$. Assim como a liberação de citocinas, essa ativação, quando equilibrada, faz parte do curso natural do combate ao patógeno ${ }^{7}$. No entanto, nos quadros de hiper inflamação, ocorre um desequilíbrio dos fatores pró coagulantes/anticoagulantes, já que os anticoagulantes fisiológicos relacionados ao controle dos níveis de trombina circulante têm sua produção prejudicada e um alto consumo ${ }^{2,7}$. Esse desbalanço favorece a formação de microtromboses sistêmicas que influenciam diretamente na perfusão dos tecidos, podendo levar a danos no fígado e no pâncreas, lesão renal aguda, danos neurológicos, lesão pulmonar grave, falência múltipla e sepse sistêmica ${ }^{2,6,9}$. 


\section{CONSIDERAÇÕES FINAIS}

Vários estudos disponíveis até o momento mostram que há uma tempestade de citocinas decorrente da infecção por SARS-CoV-2, sendo importante destacar a relevância de proteínas virais e a presença de receptores como fatores desencadeadores da resposta hiper inflamatória, que pode resultar no agravamento da doença e em danos a diversos órgãos e tecidos. Além disso, foi visto que o desequilíbrio no processo de coagulação sanguínea pode contribuir negativamente com o processo inflamatório na infecção. Vale salientar que novos estudos vêm sendo desenvolvidos mundialmente com o objetivo de esclarecer vários questionamentos e ampliar as informações acerca desse fenômeno inflamatório apresentado por alguns pacientes com COVID-19.

\section{PRINCIPAIS REFERÊNCIAS}

1. Mehta P, McAuley DF, Brown M, Sanchez E, Tattersall RS, Manson JJ. COVID-19: consider cytokine storm syndromes and immunosuppression, The Lancet, Volume 395, Issue 10229,2020,Pages 1033-1034,ISSN 0140-6736,https://doi.org/10.1016/S0140-6736(20)30628-0.

2. Ricardo J Jose, Ari Manuel,COVID-19 cytokine storm: the interplay between inflammation and coagulation, The Lancet Respiratory Medicine,Volume 8, Issue 6,2020,Pages e46-e47,ISSN 2213-2600,https://doi.org/10.1016/S2213-2600(20)30216-2.

3. Azkur, AK, Akdis, M, Azkur, D, et al. Immune response to SARS-CoV-2 and mechanisms of immunopathological changes in COVID-19. Allergy. 2020; 75: 1564- 1581. https://doi.org/10.1111/ all.14364.

4. KARWACIAK, I. et al. Nucleocapsid and Spike Proteins of the Coronavirus SARS-CoV-2 Induce IL6 in Monocytes and Macrophages-Potential Implications for Cytokine Storm Syndrome. Vaccines, vol. 9, nº 1, p. 54, 15 jan. 2021. DOI 10.3390/vaccines9010054. Disponível em: http:// dx.doi.org/10.3390/vaccines9010054.

5. HOJYO, S. et al. How COVID-19 induces cytokine storm with high mortality. Inflammation and Regeneration, vol. 40, $\mathrm{n}^{\mathrm{o}}$ 1, 1 out. 2020. DOI 10.1186/s41232-020-00146-3. Disponível em: http://dx.doi.org/10.1186/s41232-020-00146-3.

6. ZARRILLI, G. et al. The Immunopathological and Histological Landscape of COVID-19Mediated Lung Injury. International Journal of Molecular Sciences, vol. 22, nº 2, p. 974, 19 jan. 2021. DOI 10.3390/ijms22020974. Disponível em: http://dx.doi.org/10.3390/ijms22020974.

7. DE LA RICA, Roberto; BORGES, Marcio; GONZALEZ-FREIRE, Marta. COVID-19: In the Eye of the Cytokine Storm. Frontiers in Immunology, vol. 11, 24 set. 2020. DOI 10.3389/ fimmu.2020.558898. Disponível em: http://dx.doi.org/10.3389/fimmu.2020.558898.

8. ABDIN, S. M. et al. Tackling the cytokine storm in COVID-19, challenges and hopes. Life 
Sciences, vol. 257, p. 118054, set. 2020. DOI 10.1016/j.lfs.2020.118054. Disponível em: http:// dx.doi.org/10.1016/j.1fs.2020.118054.

9. ZHAO, Zhongyi; WEI, Yinhao; TAO, Chuanmin. An enlightening role for cytokine storm in coronavirus infection. Clinical Immunology, vol. 222, p. 108615, jan. 2021. DOI 10.1016/j. clim.2020.108615. Disponível em: http://dx.doi.org/10.1016/j.clim.2020.108615. 


\title{
UMA ANÁLISE HISTÓRICO-CULTURAL ACERCA DO ADOECIMENTO MENTAL DE PROFISSIONAIS DA ÁREA DA ENFERMAGEM
}

\author{
Fernanda Emanuely Oliveira Alves da Silva'; Hanna Helena Gadelha de Souza Othon² \\ ${ }^{1}$ Graduanda em Psicologia, Universidade Estadual do Ceará (UECE), Fortaleza, Ceará. \\ ${ }^{2}$ Graduanda em Psicologia, Universidade Estadual do Ceará (UECE), Fortaleza, Ceará.
}

\section{RESUMO}

A chegada da pandemia no Brasil gerou um aumento nos casos de ansiedade, causados principalmente pelo isolamento social forçado. No entanto, percebeu-se que os profissionais da saúde, os quais não tiveram a possibilidade de permanecerem em casa isolados, foram os que mais sofreram com o aumento dos índices de ansiedade. Dentro desse contexto, os enfermeiros e técnicos de enfermagem foram os profissionais mais atingidos, principalmente devido o maior tempo de contato deles com os pacientes. A partir disso, foi analisada, à luz da Histórico-Cultural, a possível influência do contexto e ambiente no surgimento/aumento dos sentimentos de ansiedade. Segundo a Histórico-Cultural, o sujeito realiza e constitui subprodutos do materialismo histórico e da influência do contexto em que está inserido, logo, os estressores presentes no dia a dia dos enfermeiros, contribuem diretamente nos seus psiquismos.

PALAVRAS-CHAVE: Saúde mental. COVID-19. Psicologia.

ÁREA TEMÁTICA: Áreas afins

\section{INTRODUÇÃO}

No final de fevereiro de 2020 foi confirmado no Brasil o primeiro caso de COVID-19. A partir de então, os índices de infecção aumentaram exponencialmente, culminando na necessidade dos governantes em instaurarem regras que limitassem a circulação e aglomeração de pessoas, no intuito de diminuir as taxas de transmissão do vírus. E assim iniciou-se o isolamento social no Brasil. A maior parte dos trabalhadores passou a realizar suas atividades em casa, o chamado home office. Além disso, a maioria das atividades de lazer se tornaram difíceis de serem praticadas, pois costumam ser realizadas em grupo ou em espaços públicos em que há muita circulação de pessoas, como na praia, em parques e shoppings.

Com isso, surgiram algumas consequências provocadas por esse isolamento forçado dos indivíduos. Uma das problemáticas que surgiu foi o aumento dos sintomas de ansiedade (TEIXEIRA 
et al., 2020). Isso porque a vida em sociedade é uma necessidade da natureza humana. Para além das necessidades básicas, o ser humano demanda se comunicar e receber afeto, atenção e respeito (DALLARI, 2014). A partir disso, um dado chama a atenção: os trabalhadores de serviços essenciais, os quais não tiveram suas atividades paralisadas, apresentaram probabilidade 55\% maior de terem ansiedade do que os profissionais em home office (BONI et al., 2020).

E dentro desse contexto, chama-se a atenção para a informação de que, dentre as 100 profissões mais perigosas para contágio pelo COVID-19, 99 delas são da área da saúde, tendo os enfermeiros na segunda posição, com 97,3\% de risco (CNN, 2020). Adicionado a isso, o risco de contaminação de profissionais da saúde que trabalham na linha de frente do combate ao coronavírus é três vezes maior (PEBMED, 2020). Além desses dados, o estudo de Bosco et al. (2020) indicou uma prevalência de 39,6\% em relação a sintomas de ansiedade moderada ou severa.

Assim surgiu o questionamento sobre a forma como as variáveis específicas presentes nessa área de trabalho influenciam nos processos psicológicos desses sujeitos.

É importante citar que a motivação para o delineamento dessa temática voltada para os profissionais da área da saúde, mais especificamente da enfermagem, se deu a partir das vivências das autoras do presente estudo. Ambas possuem, no seu convívio familiar, membros que trabalham nessa área, então, acompanharam de perto as consequências psicológicas para seus familiares que precisaram atuar na linha de frente no combate à pandemia, se expondo diretamente aos riscos de contaminação, e, muitas vezes, em situações de proteção precárias.

Sendo assim, o objetivo geral dessa pesquisa é discutir as principais variáveis que influenciaram na prevalência da ansiedade nos profissionais da enfermagem. E os objetivos específicos são: identificar quais foram os fatores preponderantes e de que forma eles atuaram no aumento da prevalência de ansiedade desses trabalhadores.

\section{METODOLOGIA}

O caráter desse artigo é explicativo, visto que buscamos os fatores que determinam ou contribuem para a ocorrência de fenômenos ansiosos (GERHARDT; SILVEIRA, 2009). Ademais, ele encontra-se na categoria de revisão bibliográfica, pois busca analisar os achados teóricos e práticos de estudos relacionados à temática em questão.

Para atingir os objetivos propostos, foi realizado um levantamento teórico em livros e periódicos retirados das plataformas Scielo, Google Books e Google Scholar. Assim, a metodologia utilizada é de cunho qualitativo, visto que busca compreender os fenômenos a partir da perspectiva do público da situação estudada, e partir daí gera suas interpretações.

\section{FUNDAMENTAÇÃO TEÓRICA}

A análise acerca da temática que envolve o adoecimento mental dos profissionais da saúde 
no contexto da pandemia à luz da abordagem histórico cultural irá partir do estudo da Patopsicologia Experimental, que aborda os transtornos do psiquismo como alterações da atividade mental, considerando seu caráter histórico e dependente das relações sociais (SILVA e TULESKI, 2015).

Tendo em vista esse apanhado histórico, é possível compreender que a abordagem não anula a influência orgânica no comportamento do sujeito, mas entende que as relações interpessoais são um fator essencial na sua saúde e vida como um todo dos sujeitos. Por isso, ao discutir sobre o adoecer dos profissionais da saúde em um contexto repleto de fatores negativos como é a pandemia, entende-se que o estigma, o isolamento, o estado de alerta e hipervigilância constante, a necessidade de adaptação a novas formas de trabalho, o medo de transmitir a doença a familiares, entre outros, estão entre as causas de maior ansiedade nesse grupo (COSTA, 2020).

Junto a isso, no que tange especificamente aos profissionais da enfermagem, além dessas problemáticas, o sofrimento psíquico está diretamente relacionado com a falta de reconhecimento profissional e ao maior tempo de cuidado direto com pacientes. Além disso, os enfermeiros e técnicos de enfermagem, no âmbito hospitalar, são os que possuem maiores chances de contágio (SILVA, 2021; SANTOS et al., 2021). A partir disso, considerando que, segundo a Histórico-Cultural, o sujeito realiza e constitui subprodutos do materialismo histórico e da influência do contexto em que está inserido, logo, os estressores presentes no dia a dia dos enfermeiros, contribuem diretamente nos seus psiquismos.

Pode-se afirmar que a abordagem histórico cultural compartilha da ideia de que a ansiedade está diretamente ligada às vivencias do sujeito em sociedade e ao que ele é submetido diariamente no seu cotidiano. Vigotski (2001), em seu livro Psicologia da Arte, fala sobre a necessidade de os psicólogos admitirem a ideia de que, no mais íntimo e pessoal do sujeito, o psiquismo é efetivamente social e também socialmente condicionado.

Além disso, é importante salientar a influência do modelo de sociedade capitalista no qual esses sujeitos estão inseridos, pois como afirma Marx (2008) e Leontiev (1978), o prazer e o trabalho estão divorciados. Logo, é possível perceber como a necessidade decorrente do sistema vigente, em detrimento do prazer pelo oficio, obriga o sujeito a submeter-se ao trabalho em situação precária e, ainda, sob o peso de um contexto de calamidade sanitária em que enfrentam, sobretudo, a escassez de equipamentos (ESTADÃO, 2020)

Portanto, o objetivo da abordagem de Vigotski não é eliminar o viés biologicista, mas não reduzir o sujeito a isso, e compreender que a subjetividade é um fator importante, pois a doença nunca será a mesma, visto que os sujeitos são diferentes. No entanto, o que acontece com os profissionais da saúde no atual contexto é uma sobrecarga, estando eles sob constante pressão, que se tornam fatores estressores e, por fim, adoecedores (COSTA, 2020). Além disso, o ambiente hospitalar é acometido, em grande parte, por uma filosofia muito mais biológica do que social, tornando o ambiente de trabalho menos acolhedor para esses profissionais.

Sendo assim, os enfermeiros, apesar de não vivenciarem o distanciamento social do mesmo 
modo que profissionais de áreas não essenciais ou até mesmo desempregados, o contato com familiares e pessoas queridas é encarado com um medo superior, pois eles têm ciência de que as chances de contaminarem alguém são muito superiores. Ademais, a carga horária desses profissionais também sofreu um aumento, o que também contribui para que haja menos chances de que o sujeito tenha tempo de se encontrar com outras pessoas fora do local de trabalho (SANTOS et al., 2021).

Assim, apesar dos enfermeiros entrarem em contato com outras pessoas com maior frequência do que diversos outros indivíduos, esse contato, na maior parte das vezes, não está permeado por afeto ou impactos positivos. Logo, levando em consideração que uma das bases do desenvolvimento humano são as relações sociais, isso é afetado por essa quebra nas experiências sociais positivamente significativas.

\section{CONCLUSÃO}

Com isso, conclui-se que o contexto social influencia consideravelmente na ocorrência de ansiedade, principalmente no que se refere aos profissionais da enfermagem, que, durante a pandemia, continuaram trabalhando em ambientes que podem ser considerados inóspitos, visto que corriam um risco altíssimo de se infetarem. Ou seja, pode-se dizer que o ambiente social favorece a instalação e manutenção da ansiedade.

No entanto, é preciso apontar que esse estudo possui limitações, e uma delas é que, apesar do público foco da pesquisa ser relevante, é preciso pensar que diversos outros contextos possivelmente se equiparam com os analisados, porém, dadas as suas disparidades. Por exemplo, indivíduos que ficaram desempregados e tiveram que trabalhar com delivery ou carro privado por aplicativo. Esses indivíduos passaram por situações bastante estressoras e também tiveram que transitar um meio não muito seguro devido às circunstâncias.

Mesmo assim, as presentes autoras desse trabalho se dão por satisfeitas pelos resultados iniciais encontrados e pretendem expandir esse estudo.

\section{PRINCIPAIS REFERÊNCIAS}

BONI, Balanzá-Martínez V et al. Depressão, ansiedade e estilo de vida entre trabalhadores essenciais: uma pesquisa na web do Brasil e da Espanha durante a pandemia do COVID-19. J Med Internet Res 2020; 22 (10): e22835. 2020.

Leontiev, A. N.. Actividad, conciencia e personalidad. Buenos Aires: Ciencias del Hombre, 1978.

MARX, K.. Manuscritos econômico-filosóficos. São Paulo: Boitempo, 2008.

SANTOS, Katarina Márcia Rodrigues dos et al. Depressão e ansiedade em profissionais 
de enfermagem durante a pandemia da covid-19. Esc. Anna Nery, Rio de Janeiro, v. 25, n. spe, e20200370, 2021.

SILVA, David Franciole Oliveira et al. Prevalência de ansiedade em profissionais da saúde em tempos de COVID-19: revisão sistemática com metanálise. Ciênc. saúde coletiva, Rio de Janeiro, v. 26, n. 2, p. 693-710, Feb. 2021.

TEIXEIRA, Carmen Fontes de Souza et al . A saúde dos profissionais de saúde no enfrentamento da pandemia de Covid-19. Ciênc. saúde coletiva, Rio de Janeiro, v. 25, n. 9, p. 3465-3474, Sept. 2020 Dalmo Dallari (2014). Viver em Sociedade. Frutal-MG: Prospectiva

VIGOTSKI, L. S. Psicologia da Arte. Tradução de Paulo Bezerra. São Paulo: Martins Fontes, 2001. 


\title{
DOSE CLÍNICA DE 5-FLUOROURACIL PROMOVE ALTERAÇÕES MORFOLÓGICAS E BIOQUÍMICAS NO FÍGADO DE RATOS
}

\author{
Mariana Conceição da Silva ${ }^{1}$ \\ Mestranda, Universidade Estadual de Maringá (UEM), Maringá, PR.
}

\begin{abstract}
RESUMO
O 5-FU é eficiente na eliminação das células neoplásicas, mas também afeta órgãos saudáveis. Pouco se sabe sobre os efeitos da dose padrão do 5-FU sobre o fígado. Para isso, este estudo busca enriquecer os conhecimentos a cerca dos efeitos do 5-FU sobre parâmetros morfométricos e bioquímicos do fígado de ratos saudáveis. Então, foram utilizados 14 ratos Wistar divididos em grupos controle e tratado. A administração do 5-FU foi realizada com dose clínica de $15 \mathrm{mg} / \mathrm{kg}$ por 4 dias seguidos, 6 $\mathrm{mg} / \mathrm{kg}$ por 4 dias alternados, $15 \mathrm{mg} / \mathrm{kg}$ no $14^{\circ}$ dia e eutanásia no $15^{\circ} \mathrm{dia}$. Assim, houve um aumento significativo no peso, nos níveis de AST e LOOH, no diâmetro dos capilares, núcleos e células do fígado dos animais tratados. Houve redução significativa dos níveis de GSH e na atividade de GST e CAT do grupo 5-FU. Portanto, o 5-FU promove alterações morfológicas e bioquímicas no fígado de ratos.
\end{abstract}

PALAVRAS-CHAVES: Hepatócitos; Enzimas; Quimioterápico.

ÁREA TEMÁTICA: Áreas afins

\section{INTRODUÇÃO}

Ao longo dos anos, o 5-Fluorouracil (5-FU) vem sendo inserido na lista dos medicamentos mais importantes e necessários em um sistema básico de saúde e esta popularidade se deve, principalmente, ao seu custo acessível e sua eficiência em uma amplitude de tratamentos neoplásicos, em especial o câncer colorretal (CCR) que apresenta uma das maiores taxas de incidência e mortalidade entre todos os cânceres (CHIONH et al., 2017; FREEMAN et al., 2015; WIGLE et al., 2019).

Assim como a maioria dos quimioterápicos, a ação do 5-FU não é direcionada as células tumorais. Portanto, tecidos saudáveis também são bastante atingidos pela toxicidade deste fármaco, ocasionando uma série de efeitos colaterais (ARIAS, 2008). O fígado é responsável por metabolizar a maior parte do 5-FU, logo está constantemente em contato com seus metabólitos (RANDO et al., 2019). No entanto, poucos estudos esclarecem como este órgão é afetado durante o tratamento com a dose padrão do 5-FU.

Neste sentido, esta pesquisa tem como objetivo avaliar os efeitos do tratamento clínico 
padrão com o 5-FU sobre os parâmetros morfométricos e bioquímicos do tecido hepático de ratos Wistar saudáveis.

\section{METODOLOGIA}

O protocolo animal neste estudo foi aprovado pelo Comitê de Conduta Ética no Uso de Animais em Experimentação da Universidade Estadual de Maringá (CEUA, nº 4422140918). Para tanto, foram utilizados 14 ratos Wistar machos, fornecidos pelo Biotério Central da Universidade Estadual de Maringá (UEM). O experimento foi delineado em dois grupos ( $n=7)$, sendo um controle e outro tratado. Os animais tratados, foram submetidos ao 5-FU por via intraperitoneal durante 4 dias consecutivos com a dose equivalente à de humanos $(15 \mathrm{mg} / \mathrm{kg})$, depois $6 \mathrm{mg} / \mathrm{kg}$ por 4 dias alternados, a última dose de $15 \mathrm{mg} / \mathrm{kg}$ no $14^{0}$ dia e eutanásia no $15^{\circ} \mathrm{dia}$. Os animais controles foram tratados com o mesmo volume de veículo (solução salina 0,9\%). A eutanásia dos animais ocorreu com dose letal de $120 \mathrm{mg} / \mathrm{kg}$ de Tiopental Sódico® por via intraperitoneal.

O fígado foi coletado, pesado e separado para as técnicas histológicas e de estresse oxidativo (EO). Os segmentos histológicos foram imediatamente fixados em Paraformaldeído 4\% (pH 7,4) durante 5 horas para a realização dos posteriores procedimentos de desidratação, diafanização, inclusão em parafina, corte e coloração. O fígado foi corado com Hematoxilina-Eosina (HE) onde foi feito a avaliação da densidade dos hepatócitos $(\mathrm{Na})$ determinado pela fórmula $\mathrm{Na}=\mathrm{N} / \mathrm{At}$, onde $\mathrm{N}$ é o número de hepatócitos na área de teste (At). Os cortes histológicos também foram corados com ácido periódico de Schiff (P.A.S.) para analisar o diâmetro dos capilares sinusóides, núcleo e células de duzentos hepatócitos por animal. As medidas morfométricas foram obtidas com o auxilio do software de analises Image-Pro Pus - Media Cybernetics.

Os segmentos do EO foram triturados e homogeneizados em Tampão Fosfato de Potássio (200 mM) pH 6,5 com volume de 10x o peso da amostra. Partes desses homogenatos foram separadas para a avaliação de grupos sulfídricos não proteicos (GSH) e o restante foi centrifugado a $9.000 \mathrm{rpm}$ durante 20 minutos, resultando em sobrenadante que foi aliquotado separadamente entre as técnicas de mensuração da catalase (CAT), superóxido dismutase (SOD), glutationa S-transferase (GST), especies reativas de oxigênio (ERO's) e lipoperoxidação (LOOH). Para os testes de função hepática (Aspartato Aminotransferase - AST e Alanina Aminotransferase - ALT), foi feito a punção cardíaca e centrifugação do sangue para a obtenção do plasma. As análises foram realizadas com o kit comercial Analisa ${ }^{\circledR}$ e cada leitura seguiram as recomendações do fabricante.

Os testes estatísticos foram realizadas com o programa GraphPad Prism 7 e os resultados expressos como média \pm erro padrão. Após teste de normalidade de Shapiro-Wilk. Para os dados paramétricos a comparação entre os grupos foi realizada com o Test $t$ de Student. Para os dados não paramétricos foi utilizado o teste de Mann Whitney. Foi considerado o valor de $p<0,05$ estatisticamente significativo. 


\section{RESULTADOS E DISCUSSÕES}

De acordo com os resultados obtidos, houve um aumento significativo no peso do fígado e no diâmetro dos capilares sinusóides, núcleos e células dos animais tratados com o 5-FU. No entanto, não houve diferença significativa na densidade dos hepatócitos do fígado tratado comparada ao controle (Tabela 1). A expansão da área e núcleo dos hepatócitos observada em consequência do tratamento com o 5-FU explica o aumento do peso do fígado e pode ser resultado de várias anormalidades hepáticas como, por exemplo, a inflamação do tecido e EO (GHIZONI et al., 2017). A dilatação sinusoidal pode ser resultado do inchaço dos hepatócitos que aumentam a pressão e a embolização das células endoteliais na parede dos vasos sinusóides, condição comum após tratamentos quimioterápicos (BRANCATELLI et al., 2018; RUBBIA-BRANDT et al., 2004).

Quanto aos marcadores de EO, houve redução significativa dos níveis de GSH e na atividade das enzimas GST e CAT do grupo 5-FU. Os níveis de LOOH aumentaram significativamente no grupo tratado. Não houve diferença significativa para SOD e ROS dos animais tratados quando comparados aos controles (Tabela 2). A redução dos antioxidantes endógenos gera um desequilíbrio redox que pode justificar a lipoperoxidação e consequente liberação de LOOH (DOUNOUSI et al., 2006). Apesar do aumento de ROS no fígado não ser significativo, houve redução da atividade dos antioxidantes endógenos e aumento nos níveis de $\mathrm{LOOH}$, o que indica um quadro de $\mathrm{EO}$ o qual promove lesão celular ocasionado pela quimioterapia (CONKLIN, 2004).

Os níveis de AST foram aumentados com significância no grupo 5-FU, mas os níveis de ALT não foram diferentes entre os grupos (Tabela 3). Segundo Ozer e colaboradores (2007), nem sempre as alterações de ALT são de utilidade para dados pré-clinicos de lesão no fígado. No entanto, apenas as alterações de AST podem estar relacionadas ao dano hepático.

Tabela 1: Análises histológicas do tecido hepático de ratos tratados com dose clínica de 5-FU.

\begin{tabular}{lll}
\hline & $\mathbf{C}$ & 5-FU \\
\hline Densidade hepatócitos $\left(\mathbf{N a} / \mathbf{m m}^{2}\right)$ & $1370 \pm 61,44$ & $1243 \pm 47,39$ \\
Capilares sinusóides $(\boldsymbol{\mu m})$ & $5,562 \pm 0,07339^{*}$ & $6,022 \pm 0,09753^{*}$ \\
Área célula $(\boldsymbol{\mu m})$ & $224,2 \pm 4,641^{*}$ & $261,4 \pm 3,727^{*}$ \\
Área núcleo $(\boldsymbol{\mu m})$ & $34,74 \pm 0,8656^{*}$ & $38,21 \pm 0,7748^{*}$ \\
Peso $(\mathbf{g})$ & $10,76863 \pm 0,39818^{*}$ & $13,28257 \pm 0,27732^{*}$ \\
\hline C - grupo controle; 5-FU - grupo tratado. Dados expressos em média \pm erro padrão, $\mathrm{n}=7$. $^{*} \mathrm{p}<0,05$
\end{tabular}


Tabela 2: Marcadores do estresse oxidativo no fígado de ratos tratados com dose clínica de 5-FU

\begin{tabular}{|c|c|c|}
\hline & $\mathbf{C}$ & 5-FU \\
\hline CAT $(\mu \mathrm{mol} / \mathrm{min} / \mathrm{mg}$ proteína $)$ & $0,05398 \pm 0,005877^{*}$ & $0,03009 \pm 0,002196^{*}$ \\
\hline SOD (U SOD/mg proteína) & $1,032 \pm 0,07241$ & $0,8616 \pm 0,04517$ \\
\hline GST ( $\mu \mathrm{mol} / \mathrm{min} / \mathrm{mg}$ proteína) & $0,05837 \pm 0,002593 *$ & $0,05009 \pm 0,002009 *$ \\
\hline GSH ( $\mu \mathrm{g}$ GSH/g tecido) & $738,8 \pm 646,5-956,4^{*}$ & $428,3 \pm 291-479,6^{*}$ \\
\hline $\begin{array}{l}\text { ROS (nmol DFD/mg } \\
\text { proteína) }\end{array}$ & $320,3 \pm 14,76$ & $375,8 \pm 30,88$ \\
\hline LOOH (mmol/mg tecido) & $29,77 \pm 27,23-31,7^{*}$ & $32,98 \pm 29,43-42,65 *$ \\
\hline
\end{tabular}

$\mathrm{C}$ - grupo controle; 5-FU - grupo tratado. Dados expressos em média \pm erro padrão (paramétricos) e mediana \pm limite inferior - limite superior (não paramétricos), $n=7{ }^{*} \mathrm{p}<0,05$

Tabela 3: Marcadores da função hepática de ratos tratados com dose clínica de 5-FU.

\begin{tabular}{lcc}
\hline & $\mathbf{C}$ & $\mathbf{5 - F U}$ \\
\hline AST (U/L) & $44,57 \pm 1,395^{*}$ & $52,86 \pm 2,075^{*}$ \\
ALT (U/L) & $14,57 \pm 1,232$ & $19,57 \pm 2,192$ \\
\hline
\end{tabular}

$\mathrm{C}$ - grupo controle; 5 -FU - grupo tratado. Dados expressos em média \pm erro padrão. ${ }^{*} \mathrm{p}<0,05$

\section{CONSIDERAÇÕES FINAIS OU CONCLUSÃO}

O 5-FU na dose clínica causa hepatotoxicidade em ratos saudáveis, caracterizada pelo aumento plasmático de AST, alteração de parâmetros morfológicos e de estresse oxidativo. Estes resultados poderão auxiliar na busca de substâncias adjuvantes que poderão amenizar estes efeitos colaterais do 5-FU.

\section{PRINCIPAIS REFERÊNCIAS}

ARIAS, J. L. Novel strategies to improve the anticancer action of 5-fluorouracil by using drug delivery systems. Molecules, v. 13, n. 10, p. 2340-2369, 2008.

BRANCATELli, G. et al. Hepatic sinusoidal dilatation. Abdominal Radiology, v. 43, n. 8, p. 20112022, 2018.

CHIONH, F. et al. Oral versus intravenous fluoropyrimidines for colorectal cancer. Cochrane Database of Systematic Reviews, n. 7, 2017.

CONKLIN, K. A. Chemotherapy-associated oxidative stress: Impact on chemotherapeutic effectiveness. Integrative Cancer Therapies, v. 3, n. 4, p. 294-300, 2004.

DOUNOUSI, E. et al. Oxidative Stress Is Progressively Enhanced With Advancing Stages of CKD. American Journal of Kidney Diseases, v. 48, n. 5, p. 752-760, 2006. 
FREEMAN, K. et al. Fluorouracil plasma monitoring: Systematic review and economic evaluation of the My5-FU assay for guiding dose adjustment in patients receiving fluorouracil chemotherapy by continuous infusion. Health Technology Assessment, v. 19, n. 91, 2015.

RANDO, A. et al. Chemotherapeutic agent 5-fluorouracil increases survival of SOD1 mouse model of ALS. PLoS ONE, v. 14, n. 1, p. 1-16, 2019.

RUBBIA-BRANDT, L. et al. Severe hepatic sinusoidal obstruction associated with oxaliplatin-based chemotherapy in patients with metastatic colorectal cancer. Annals of Oncology, v. 15, n. 3, p. 460466, 2004.

WIGLE, T. J. et al. DPYD and fluorouracil-based chemotherapy: Mini review and case report. Pharmaceutics, v. 11, n. 5, p. 1-17, 2019. 


\title{
EXERCÍCIO AERÓBICO NO TRATAMENTO DA FIBROMIALGIA E MELHORA DA QUALIDADE DE VIDA
}

\author{
Fernanda Evelyn Silva ${ }^{1}$ \\ ${ }^{1}$ Sanitarista, IMIP, Recife, Pernambuco.
}

\begin{abstract}
RESUMO
A fibromialgia (FM) causa dor musculoesquelética e outras alterações reduzindo a qualidade de vida. Aliado ao tratamento farmacológico, as terapias não-farmacológicas como a prática de exercícios aeróbicos, têm se mostrado eficazes. O objetivo do trabalho foi revisar a literatura acerca da relação do exercício aeróbico e a melhora na qualidade de vida de pacientes com fibromialgia. Trata- se de uma revisão bibliográfica realizada nas bases de dados PUBMED e SCIELO, com o uso dos descritores "Fibromyalgia" e "Quality of Life" unidos pelo operador booleano $A N D$, com a inclusão de publicações de 2016 a 2021. As referências bibliográficas evidenciam o efeito positivo do exercício aeróbico no grau de intensidade da dor musculoesquelética, na ansiedade, depressão, rigidez, fadiga, função física e qualidade de vida dos pacientes com FM. Deste modo, considerando o exposto, é possível observar a importância do exercício aeróbico como tratamento não-farmacológico da fibromialgia e melhora da qualidade de vida.
\end{abstract}

PALAVRAS-CHAVE: Síndrome; Dor musculoesquelética; Tratamento.

ÁREA TEMÁTICA: Áreas afins

\section{INTRODUÇÃO}

A fibromialgia (FM) é uma síndrome e afeta milhões de pessoas no mundo, especialmente mulheres a partir dos 50 anos de idade (ARAÚJO, 2019). A FM é idiopática, caracterizada por quadro crônico de dor musculoesquelética e sensibilidade generalizada, além de distúrbios do sono, rigidez no período da manhã, fadiga, parestesias de extremidades, sensação de edema, distúrbios cognitivos, podendo desencadear também ansiedade e depressão (PEREIRA, 2021).

A associação de comorbidades na síndrome é frequente, gerando um aumento do sofrimento e a piora da qualidade de vida destes indivíduos (MELO, 2020). A FM não tem cura definitiva e o tratamento se concentra principalmente no controle dos sintomas e na melhora da qualidade de vida (ARAÚJO, 2019). O objetivo do trabalho foi revisar a literatura existente acerca da relação do exercício aeróbico e melhora na qualidade de vida de pacientes com fibromialgia. 


\section{METODOLOGIA}

Trata-se de uma revisão bibliográfica, realizada em artigos científicos publicados em periódicos indexados nas bases de dados SCIELO e PUBMED, com o uso dos descritores "Fibromyalgia" e "Quality of Life" juntamente com o operador lógico de pesquisa “AND”. Incluiu-se artigos em inglês e em português com o recorte temporal de 2016 a 2021; foram excluídos artigos que não se adequaram ao objetivo proposto.

\section{FUNDAMENTAÇÃO TEÓRICA}

Uma revisão sistemática juntou evidências de 13 estudos que investigaram o efeito do exercício aeróbico, a terapia não farmacológica mais fortemente indicada, na intensidade da dor e qualidade de vida, rigidez, fadiga e capacidade física de pacientes com FM. Nessa revisão, foi possível concluir que o exercício aeróbico apresenta evidências moderadas em relação a uma melhor qualidade de vida (ARAÚJO, 2019).

Uma outra revisão analisou os efeitos da dança na diminuição da dor em pessoas com FM e observou que os programas com a prática da dança foram eficazes na redução do quadro doloroso. Portanto, acredita-se que a dança, como modalidade de exercício aeróbico, promova mudanças na ansiedade e depressão (BATISTA, 2020).

Além disso, todas as diretrizes recentes dão ênfase a importância das terapias não farmacológicas no tratamento da FM. Nas diretrizes atualizadas alemães, o exercício aeróbico recebeu forte recomendação e foi o único tratamento a receber forte recomendação da EULAR. (HÄUSER, 2018).

\section{CONSIDERAÇÕES FINAIS}

Deste modo, considerando o exposto, é possível observar a importância do exercício aeróbico como tratamento não-farmacológico da fibromialgia e melhora da qualidade de vida.

\section{PRINCIPAIS REFERÊNCIAS}

ARAÚJO, Fernanda; DeSantana, Josimari. Physical therapy modalities for treating fibromyalgia. Sergipe: F1000Research, 2019.

PEREIRA, Heloísa Salvador dos Santos et al. The effects of acupuncture in fibromyalgia: integrative review. São Paulo: BrJP, 2021.

MELO, Géssika; MADRUGA, Marcela; TORRO, Nelson. Análise das comorbidades associadas à fibromialgia: uma revisão bibliométrica. Lisboa: Psic., Saúde \& Doenças, 2020. 
BATISTA, Ana Sara Adriano et al. Depression, anxiety and kinesiophobia in women with fibromyalgia practitioners or not of dance. São Paulo: BrJP, 2020.

HÄUSER Winfried, Fitzcharles Mary-Ann. Facts and myths pertaining to fibromyalgia. Dialogues Clin Neurosci., 2018. 
Ilvana Lima Verde Gomes ${ }^{1}$; Débora Pena Batista e Silva ${ }^{2}$; Débora Silveira de Lima ${ }^{3}$; Ana Caroline Araújo da Silva ${ }^{4}$ : Lívia Lopes Custódio ${ }^{5}$; Débora Cristina Couto Oliveira Costa ${ }^{6}$; Lucélia Rodrigues Afonso $^{7}$; Cláudia Patrícia da Silva Ribeiro Menezes ${ }^{8}$

${ }^{1}$ Docente do Programa de Pós-Graduação em Saúde Coletiva, Universidade Estadual do Ceará (UECE), Fortaleza, Ceará,

${ }^{2,7}$ Mestranda em Saúde Coletiva pela Universidade Estadual do Ceará (UECE), Fortaleza, Ceará.

${ }^{3,4}$ Graduanda em Enfermagem, Universidade Estadual do Ceará (UECE), Fortaleza, Ceará.

5,6,8 Doutoranda em Saúde Coletiva pela Universidade Estadual do Ceará (UECE), Fortaleza, Ceará.

\section{RESUMO}

Objetivo: Compreender o significado da dor na doença falciforme através dos desenhos dos adultos. Metodologia: Pesquisa qualitativa, desenvolvida no Hemocentro inerente ao período de janeiro de 2018. Aplicou-se entrevista semiestruturada, onde o participante que realizou um desenho caracterizando a pergunta. Deste modo, participaram 22 pessoas de ambos os gêneros. Utilizou-se a Técnica de Análise de Conteúdos de Bardin. Resultados e Discussão: Através dos desenhos e das falas percebeu-se que a dor foi representada como algo intolerável e resultante do sofrimento expressado pelos participantes. Com isso, a dor está interligada com a perda da autonomia e com a sensação de impotência. Para tanto, os meios para a mudança na perspectiva da dor, é referida através do apoio familiar e a espiritualidade. Conclusão: Destarte é fundamental o aumento e o investimento no diagnóstico precoce, bem como, a intervenção da educação permanente, para que os profissionais de saúde que lidam com pessoas com DF, possam promover estratégias que favoreçam a implantação de políticas públicas.

PALAVRAS-CHAVE: Doença Falciforme; adulto; qualidade de vida.

ÁREA TEMÁTICA: Atenção à Saúde.

\section{INTRODUÇÃO}

A doença falciforme (DF) é classificada como crônica, hematológica, hereditária e recessiva, decorrente de uma alteração no gene responsável pela produção da hemoglobina A e hemoglobina $\mathrm{S}$ (ou $\mathrm{Hb} \mathrm{S}$ ). Para tanto, a variação genética, resulta na deformação das hemácias, assim, resultando na prevalência e variação do formato de foice (BRASIL, 2014; BRASIL, 2015). 
Essa forma alongada da hemácia promove a formação das hemoglobinopatias, com complicações de sinais e sintomas da doença mais frequentes decorrendo nos fenômenos vasoclusivos, fatores genéticos, de alimentação, de acesso ambiental e ao tratamento, com manifestações de crises álgicas de dor e infecções.

As crises dolorosas ocorrem nas extremidades, abdômen e nas costas, com forma recorrente de dor, intensidade e duração variável, manifestadas de forma diferente em cada indivíduo. Essas complicações de dor são causadas pelo dano tissular isquêmico secundário a obstrução do fluxo de sangue devido às hemácias falcizadas (BRASIL, 2013).

Ademais, no Brasil, a DF é considerada como, uma das doenças genéticas mais frequentes, chegando a uma população de 25 a 30 mil, sendo considerada hoje como um problema de saúde pública por tratar-se de um adoecimento crônico e pelas elevadas taxas de morbimortalidade. $\mathrm{Na}$ perspectiva mundial a anemia falciforme e a talassemia juntas são responsáveis por 3,4\% de todas as mortes de crianças menores de cinco anos (HANKINS,2010; RAMOS. et. al., 2015).

Uma das principais consequências da doença são as crises dolorosas, é comum constituírem a primeira manifestação da doença. Essas crises são incapacitantes e, muitas vezes, de difícil controle, ocorrem inesperadamente e impacta diretamente na qualidade de vida da pessoa. A dor não aliviada pode afetar sono, a alimentação e nas atividades da vida diária, assim como no desempenho na escola e no trabalho (BRASIL, 2014).

Nesse sentido o objetivo dessa pesquisa foi compreender o significado da dor na doença falciforme pelo olhar dos adultos através dos seus desenhos.

\section{METODOLOGIA}

Utilizou-se como método, a pesquisa qualitativa, tendo sido planejado o desvelar das situações observadas e presenciadas pelo integrante da investigação. O local do estudo foi o Hemocentro de Fortaleza (HEMOCE) onde ocorre às consultas com adultos de vários municípios do Ceará que tem doença falciforme.

Foram convidados a participar os usuários do ambulatório que tenham doença falciforme. $\mathrm{O}$ critério de inclusão foi: comparecer nos dias em que ocorreu a pesquisa. Critério de exclusão: baixo déficit cognitivo comprovado pelo médico. Cada participante foi abordado individualmente.

A coleta dos dados foi realizada em janeiro de 2018, no período da manhã, horário de funcionamento do ambulatório de hemoglobinopatias. Foram 22 participantes, as entrevistas

iniciaram somente após a aprovação do Comitê de Ética em Pesquisa. Foi preservada a autonomia do participante em querer ou não participar do estudo.

Utilizou-se uma entrevista semiestruturada contendo um item de identificação (sexo, idade, cor da pele (classificação do Instituto Brasileiro de Geografia e Estatística (IBGE), escolaridade, 
procedência, tipo de doença falciforme, tempo de diagnóstico) e o segundo item uma pergunta norteadora: Para você, o que significa a dor da doença falciforme. A cor da pele foi informada pelo participante.

Para coleta deste segundo item foi solicitado ao participante que fizesse um desenho livre representando essa pergunta, ou seja, atribuísse o seu significado e em seguida explicasse sobre o que produziu. As respostas foram gravadas e os desenhos numerados conforme o número da entrevista. Cada participante foi abordado individualmente, em separado, para que se sentisse à vontade e mantivesse preservado seu anonimato. Os materiais oferecidos foram: Folhas de papel ofício, lápis, borracha, apontador, lápis de cor, caneta pincel e caneta esferográfica.

Análise e interpretação dos dados foi utilizada a análise de conteúdo temática de Bardin (2011).

A pesquisa foi aprovada pelo Comitê de Ética em pesquisa da Universidade Estadual do Ceará - UECE (parecer n 2.385.689), Termo de Consentimento Livre e Esclarecido (TCLE) foi entregue ao participante para que ele lesse e tirasse suas dúvidas e em seguida assinasse (BRASIL, 2012).

\section{RESULTADOS E DISCUSSÃO}

\section{Caracterização dos participantes}

O tipo de Doença falciforme que mais prevaleceu foi a Anemia Falciforme (SS) com 81,8\% dos entrevistados, 13 eram do sexo feminino, a média de idade foi de 31,5 anos, variou entre 18 e 61 anos.

Houve predomínio da cor Parda com 59\%, reafirmando a origem africana e condizendo com a literatura. $13(59 \%)$ tinham ensino médio completo e apenas dois tinham ensino superior completo ainda condizente com o comparativo feito com Minas gerais onde $65 \%$ era a porcentagem da população de ensino médio completo (AMARAL, J. L.; et al, 2015).

Quanto a moradia, 14 morava em Fortaleza e sete moravam no interior do Ceará.

\section{Desenhando o (im)perceptível: a dor da DF}

Ao solicitar ao participante para desenhar sobre a dor na DF revelou que esta é ainda invisível e negligenciada, gerando um obstáculo para a melhoria da qualidade de vida desta população como é possível perceber após a explicação dos desenhos e pontuado pelas falas seguintes: 
O participante 07 descreveram assim sua dor:

É como se alguém pegasse um martelinho e batesse no seu osso, eu sinto assim, como se aqui fosse meu dedo, aqui fosse as junta e a unha, como se alguém pegasse um prego e batesse bem nas juntas, em cima da minha unha furando com um martelinho, é assim que eu sinto. (A7)

Figura 1: Desenho 07 - Dor insuportável.

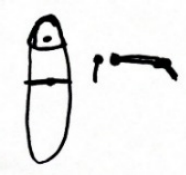

Fonte: Autor: A07

Já o participante 02 diz que a dor é tão insuportável que não consegue desenhar algo substancial, mas um emaranhado ou enlinhado confuso.

[...] representa a dor insuportável, não aguenta, você pede para morrer porque é horrivel. (A2)

Figura 2: Desenho 02 - Dor insuportável.

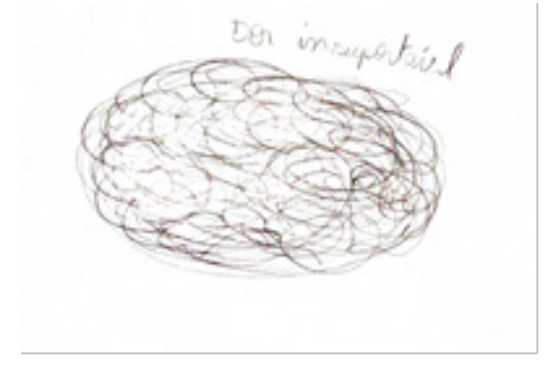

Fonte: Autor: A02

O grau de dor chega ao nível em que impede que se realize as atividades diárias e até mesmo compromete as necessidades humanas básicas. Em um estudo realizado em Minas Gerais com pacientes com DF trouxe como resultado que todos os participantes relataram apresentar crises álgicas e destes 75\% apresentaram dor incapacitante para a realização das Atividades de Vida Diária (AMARAL, J. L.; et al, 2015).

No desenho de A11 ele se retrata deitado numa cama sem conseguir fazer nada

Tem certas crises que é o tempo todo na cama, é muito dificil ir no banheiro fazer as necessidades (A11) 
Figura 3: Desenho 11 - Dor insuportável.

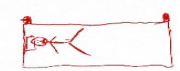

Fonte: Autor: A11

\section{CONSIDERAÇÕES FINAIS}

Destarte o sofrimento e as dificuldades vivenciadas por esta população, fazem-se relevante para o aumento do investimento no diagnóstico precoce e para a criação de estratégias que fortaleçam a implantação e a aplicação de políticas públicas, a fim de prevenir as crises correlacionadas a dor, tendo, como pilar melhorar a qualidade de vida deste público.

Nesta perspectiva, é de relevante o investimento na educação permanente dos profissionais de saúde, para que eles possam atender as pessoas com DF, ofertando um atendimento seguro e integral, principalmente nas crises álgicas.

\section{PRINCIPAIS REFERÊNCIAS}

AMARAL, J. L.; et al., Perfil sociodemográfico, econômico e de saúde de adultos com doença FalciForm. Rev Rene. v.16, n.3, p. 296-305, 2015.

BRASIL. Ministério da Saúde. Secretaria de Atenção à Saúde. Departamento de Atenção Hospitalar e de Urgência. Doença falciforme: o que se deve saber sobre herança genética / Ministério da Saúde, Secretaria de Atenção à Saúde, Departamento de Atenção Hospitalar e de Urgência - Brasília: Ministério da Saúde, 2014.

BRASIL. Ministério da Saúde. Secretaria de Atenção à Saúde. Doença falciforme: diretrizes básicas da linha de cuidado. Brasília: Ministério da Saúde, 2015.

HANKINS, J. Assistência médica de qualidade para a anemia falciforme: já chegamos lá? Jornal de Pediatria, v.86, n.4, p. 256-258, 2010.

RAMOS, J. T.; AMORIM, F.S.; PEDROSO, F. K. F.; et al. Mortalidade por doença falciforme em estado do nordeste brasileiro. R. Enferm. Cent. O. Min, v. 2, n. 5, p.1604-1612, mai/ago 2015. 


\title{
FATORES DE RISCOS PARA INCONTINÊNCIA URINÁRIA NO CICLO GRAVÍDICO PUERPERAL
}

\section{Maria Samara Da Silva ${ }^{1}$; Rayane Portela de Lima ${ }^{2}$; Elivelton Sousa Montelo; ${ }^{3}$ Amanda Célis Brandão Vieira ${ }^{4}$, Kayron Rodrigo Ferreira Cunha ${ }^{5}$, Jaiana Rocha Vaz Tanaka ${ }^{6}$}

Fisioterapeuta, Pós-graduanda em Saúde Da Mulher pela Instituição Cursos Aprimore, Teresina,PI.

$2 \quad$ Fisioterapeuta pela Universidade Estácio Sá de Teresina, Piauí.

Graduando em Fisioterapia pela Universidade Federal do Delta do Parnaíba (UFDPar), Parnaíba,PI.

${ }_{4} \quad$ Fisioterapeuta, Pós-Graduada em Saúde Da Mulher pela Inspirar, Teresina, Piauí.

Enfermeiro pela Universidade Estadual do Piauí (UESPI).

Fisioterapeuta, Mestre em Saúde da Família pelo Centro Universitário UNINOVAFAPI. São Luís, MA.

DOI: $10.47094 /$ ICONRES.2021/10

\begin{abstract}
RESUMO
INTRODUÇÃO: Existem diversos fatores de risco que podem influenciar na ocorrência de Incontinência Urinária durante o ciclo gravídico-puerperal, sendo a presença prévia de perdas urinárias à gestação como o mais relevante. METODOLOGIA: O estudo proposto refere-se a uma revisão da literatura, havendo como buscas as bases de dados: MEDLINE, PubMed e Sciencedirect, com estudos de 2016 a 2021, pelo qual 11 artigos foram elegíveis. FUNDAMENTAÇÃO TEÓRICA: Estudos evidenciaram que $20 \%$ das IUE após o parto estavam relacionados com a obesidade (o tecido adiposo aumenta a pressão sobre a bexiga). São apontados como fatores de risco a idade avançada, diabetes, histórico de IUE anterior à gestação, parto vaginal com procedimento cirúrgico como episiotomia ou parto instrumental. CONSIDERAÇÕES FINAIS: De acordo com os estudos foi apresentado que a obesidade, idade avançada, depressão pós-parto, IU antes da gestação e parto vaginal instrumental (vácuo, fórceps, episiotomia) foram os maiores fatores de risco para IU.
\end{abstract}

PALAVRAS-CHAVES: Micção involuntária; Gestação; Período pós-parto.

ÁREA TEMÁTICA: Outros 


\section{INTRODUÇÃO}

A incontinência urinária (IU) pode ser definida como déficit ou ineficiência de controlar a bexiga pela uretra. Pode ser representada por várias formas: incontinência por esforço (IUE) que é a perda involuntária da urina ao se realizar uma atividade que aumente a pressão abdominal; incontinência por urgência (IUU) quando a perda involuntária é motivada por episódios de urgência; incontinência mista (IUM) pode ser causada por um desequilíbrio sensitivo de hiperatividade do músculo detrusor associada também à perda por esforço (Choi \& Bae, 2016).

Fatores como idade, obesidade, gestações, cirurgias ginecológicas podem estar ligados a IU. No decorrer da gravidez e/ou puerpério, os fatores podem estar associados ao tipo de parto (cesárea ou vaginal), como também em mulheres que possuíam a disfunção antes da gestação. A IU pode ser tratada de maneira convencional ou por procedimento cirúrgico. $\mathrm{O}$ objetivo do presente estudo tem como base, ressaltar fatores de riscos na incontinência urinária em mulheres durante a gestação e puerpério (Bae et al., 2019).

\section{METODOLOGIA}

O estudo proposto refere-se a uma revisão da literatura com o propósito de buscar estudos clínicos já dispostos na literatura. As buscas foram elaboradas nas bases de dados Biblioteca Virtual em Saúde (BVS) / MEDLINE, PubMed, e outras fontes de busca como Sciencedirect utilizando a combinação "Booleano" "AND" com os descritores de forma associado ("Involuntary urination") AND ("Gestation")AND("Postpartum period"). em todos os idiomas. A fim de conduzir as evidências sobre fatores de riscos para incontinência urinária durante a gestação e puerpério, foram excluídos estudos que não delimitavam ao objetivo proposto, bem como, revisões de literatura, resumos, pesquisas de opinião, teses, estudos observacionais e artigos inferiores a cinco anos. Sendo assim, foram incluídos os estudos com embasamento clínico de 2016 a 2021 que respondiam ao objetivo proposto.

\section{FUNDAMENTAÇÃO TEÓRICA}

Para conclusão de tais achados foram obtidos 49, porém apenas 12 responderam aos critérios de elegibilidade. 
Quadro01: Dados das buscas de dados 2016 a 2021.

\begin{tabular}{|c|c|c|}
\hline $\begin{array}{c}\text { BASES DE } \\
\text { DADOS }\end{array}$ & ACHADOS NAS & $\begin{array}{c}\text { INCLUÍDOS APÓS LEITURA DE TITULO, } \\
\text { RESUMO E TEXTO COMPLETO. }\end{array}$ \\
\hline MEDLINE & $(\mathrm{n}=74)$ & $(\mathrm{n}=9)$ \\
\hline PubMed & $(\mathrm{n}=17)$ & $(\mathrm{n}=2)$ \\
\hline Sciencedirect & $(\mathrm{n}=12)$ & $(\mathrm{n}=1)$ \\
\hline TOTAL $=$ & $\mathbf{n}=\mathbf{4 9 / 2}$ duplicação & Total: $(\mathbf{n}=\mathbf{1 2})$ \\
\hline
\end{tabular}

Fonte: Elaborado pelos autores.

Rita Novo et al., 2018, mostraram que 20\% das IUE após o parto estavam relacionadas a obesidade (o tecido adiposo aumenta pressão sobre a bexiga), idade avançada, diabetes, histórico de IUE antes da gestação, parto vaginal com procedimento cirúrgico como episiotomia ou parto instrumental, sendo apontados como fator de risco para IU, corroborando com Johannessen et al., 2018, que realizou um estudo parecido apresentando os mesmos resultados de Lin et al., 2018 e Magnani el at., 2019 e Pizzoferrato et al., 2016. Confirmada tai fatos, Anne-Cécile et al., 2016 mostrou que a descida uretral na gravidez tardia e em mulheres com sobrepeso, como probabilidade de fatores de risco para IU um ano após o parto.

Nos achados de Hutton et al., 2018 mostraram que 17,8\% das IU estavam relacionadas a partos por via cesárea e $21,8 \%$ por parto vaginal e tal condição interferiu significativamente na qualidade de vida dessas mulheres. Tayrac et al., 2018, no seu estudo em 137 maternidades com 1.155 mulheres, com o intuito de identificar prevalência da IU no pós-parto em gestações gemelares sem histórico de IU antes da gestação, apresentou maior prevalência em IU no parto vaginal (38\%) em comparação com parto cesáreo (35\%).

Daly et al., 2018, realizaram um estudo randomizado com 860 mulheres, e revelaram que $34,8 \%$ das gestantes já sofriam de disfunção antes da gravidez, e que aumentou a prevalência de IU no decorrer da gestação. Fritel et al., 2016, expuseram que 37\% das IUE no pós-parto estavam relacionadas com a duração do trabalho de parto na segunda fase por mais 30 minutos e com bebês acima de 4 quilos. Corroborando com o estudo anterior, Swenson CW et al., 2017, correlacionaram a ocorrência de IU puerperal ao parto vaginal instrumental com a existência de laceração perineal, uso de fórceps e vácuo.

Li et al., 2019, apontaram maior prevalência de incontinência durante a gravidez no terceiro período de gestação. Estudos prospectivos nacionais relacionaram a presença de outros sintomas do trato urinário inferior (LUTS) neste peródo, como noctúria $(72,3 \%)$ e frequência aumentada $(43,9)$.

Tais estudos evidenciaram a carência de acompanhamento especializado para tal disfunção do assoalho pélvico no período pré-natal e de acesso à informação. Os achados mostram que o acompanhamento fisioterapêutico durante a gravidez e pós-parto reduzem os sintomas, no entanto não era o objetivo do estudo. Evidências de Dornowski et al., 2018, mostraram que o treino do 
assoalho pélvico reduz significativamente sintomas de IUE em mulheres grávidas, e nos achados de Sut et al., 2016, corroborando com estudo com anterior, mostraram que o treino desta musculatura resultada na melhora significativa da função miccional no ciclo gravídicopuerperal. Este exercício aumenta a força muscular do assoalho pélvico que por sua vez previne o aparecimento e o agravo da IU contribuindo, assim para a qualidade de vida destas mulheres.

Magnani et 1, 2019 e Lin et al, 2018, concordam que a obesidade e o sobrepeso tem correlação direta com o surgimento de IU em gestantes, sendo que, o risco se torna ainda maior nas mulheres que tiveram parto vaginal, sendo ele também um fator de risco. Johannessen et al, 2018, corroboram mostrando que o sobrepeso e o parto vaginal aumentam as chances do desenvolvimento de IU pósparto.

\section{CONSIDERAÇÕES FINAIS}

Os estudos expostos mostraram que os maiores fatores de risco associados à incontinência urinária na gestação e no pós-parto estão relacionados ao parto vaginal instrumental ou episiotomia, obesidade e principalmente à presença de perdas urinárias prévias a gestação. Tais achados foram relevantes para a compreensão de fatores de risco para a IU na gestação e pós-parto, no entanto ainda abre espaço para estudos futuros.

\section{REFERÊNCIAS}

CHOI, H. \& Bae, J. H. Overview of the Epidemiology of Lower Urinary Tract Dysfunction in South Korea. International Neurourology Journal, Jun-2016.

DALY, D; Clarke, M. \& Begley, C. Urinary incontinence in nulliparous women before and during pregnancy: prevalence, incidence, type, and risk factors. The International Urogynecological Association, 2018.

JOHANNESSEN, H. H. et al. Prevalence and predictors of double incontinence year after first delivery. The International Urogynecological Associatio, 2018.

Li, Z ; Xu, T; Zhang,L \& Zhu, L .Prevalence, potential risk factors, and symptomatic bother of lower urinary tract symptoms during and after pregnancy. Lower Urinary Tract Symptoms. 2019.

MAGNANI, P. S. et al., Urinary incontinence between 12 and 24 months postpartum: a cross-sectional study nested in a Brazilian cohort from two cities with different socioeconomic characteristics. International Urogynecology Journal, 2019.

RITA NOVA., et al. Prevalence and associated risk factors of urinary incontinence and dyspareunia during pregnancy and after deliver. Journal, Pre-proof, 2019. 


\section{QUALIDADE DE VIDA SEXUAL DE MULHERES NO CLIMATÉRIO}

\section{Maria Samara Da Silva ${ }^{1}$; Rayane Portela de Lima ${ }^{2}$; Elivelton Sousa Montelo; ${ }^{3}$ Amanda Célis Brandão Vieira ${ }^{4}$; Priscyla Maria Vieira Mendes ${ }^{5}$}

7 (1)

Fisioterapeuta, Pós-graduanda em Saúde Da Mulher pela Instituição Cursos Aprimore, Teresina,PI.

Fisioterapeuta pela Universidade Estácio Sá de Teresina, Piauí.

Graduando em Fisioterapia pela Universidade Federal do Delta do Parnaíba (UFDPar), Parnaíba,PI.

Fisioterapeuta, Pós-Graduada em Saúde Da Mulher pela Inspirar, Teresina, Piauí. Fisioterapeuta, Doutoranda em Farmacologia pela Universidade Federal do Piauí(UFPI), Teresina,PI.

DOI: $10.47094 /$ ICONRES.2021/9

\section{RESUMO}

INTRODUÇÃO: O período climatério pode refletir como um período desafiador, devido às alterações hormonais, podendo deixa-las vulneráveis as disfunções sexuais, possibilitando afetar significativamente em sua qualidade de vida sexual. Assim, objetivou-se identificar na literatura científica a qualidade de vida sexual de mulheres no período climatério. METODOLOGIA: O estudo trata-se de uma revisão da literatura, pelo qual, foram alocados nas bases de dados eletrônico 44 artigos e 6 estudos clínicos incluído entres 2016 a 2021. FUNDAMENTAÇÃO TEÓRICA: Foi identificado que os sintomas causados pelo climatério podem afetar significativamente na qualidade de sexual dessas mulheres. A redução da lubrificação vaginal pode impedir a excitação sexual e redução da libido foram os responsáveis pelos principais impactos na qualidade de vida sexual. CONCLUSÃO: Evidências apontam que os sintomas no climatério podem reduzir a qualidade de vida sexual, como ressecamento vaginal, redução da libido, fogacho. Dessa forma, desencadear disfunções sexuais consequentemente interferir no estado psicológico.

Palavras-chave: Climatério; Sexualidade; Qualidade de vida ÁREA TEMÁTICA: Outros 


\section{INTRODUÇÃO}

O climatério pode ser definido como marco não reprodutivo na vida das mulheres, podendo apresentar em media aos 40 anos e finalizar aos 65 anos, sendo capaz de se dividir em três fases: Período de transição da menopausa, menopausa e pós-menopausa. Devido às alterações hormonais, ocorrerá redução do colágeno e da elasticidade tecidual, resultando em alterações do tecido conjuntivo, diminuição do aporte sanguíneo e estrogênio, retração das paredes vaginais e, consequentemente, enfraquecimento dos músculos do assoalho pélvico. Dessa forma, a qualidade de vida sexual no período climatério também pode estar comprometida (Varella et al., 2017).

As alterações do climatério podem refletir na atividade sexual, podendo desenvolver transtornos sexuais e desencadear distúrbios do sono, irregularidade menstruais, sintomas vasomotores e distúrbios urogenitais como redução da lubrificação, dores na penetração vaginal (Camilo et al., 2019). Assim, objetivou-se identificar na literatura científica a qualidade de vida sexual de mulheres no período climatério.

\section{METODOLOGIA}

O presente estudo trata-se de uma revisão da literatura, como o intuito de ressaltar estudos com embasamento clínico publicados na integra. Para desenvolvimento da elegibilidade foram incluídos estudos publicados em todos os idiomas no período entre 2016 a 2021, sendo feita a busca nas bases de dados MEDLINE, LILASC, SciELO e Google Scholar com a combinação das seguintes palavras-chave: "Climacteric" AND "Sexuality" AND "Quality of life”. Foram excluídos artigos de revisão, duplicados, teses, resumos, estudos no qual trata-se de amamentação na adolescência. Foram localizados 44 estudos e selecionados apenas 6 artigos.

\section{FUNDAMENTAÇÃO TEÓRICA}

Para a construção do estudo foram localizados 44 trabalhos, no entanto, após a aplicação dos critérios de exclusão, apenas 6 artigos responderam aos critérios de elegibilidade, pelo qual continha embasamento do objetivo proposto (Quadro:01).

Quadro01: Dados dos achados

\begin{tabular}{|c|c|c|}
\hline Bases de dados & Achados nas bases de dados & $\begin{array}{c}\text { Inclú́dos após leitura de titulo, } \\
\text { resumo e texto completo. }\end{array}$ \\
\hline MEDLINE & $\mathrm{n}=5$ & $\mathrm{n}=1$ \\
\hline LILASC & $\mathrm{n}=8$ & $\mathrm{n}=2$ \\
\hline SciELO & $\mathrm{n}=8$ & $\mathrm{n}=1$ \\
\hline Google Scholar & $\mathrm{n}=23$ & $\mathrm{n}=2$ \\
\hline
\end{tabular}




\begin{tabular}{|l|l|l|}
\hline Total & 44 & 6 \\
\hline
\end{tabular}

Fonte: Elaborado pelo autor.

Um estudo realizado por Yanikkerem et al., 2018 com 572 mulheres identificou que 86,4\% a 54,9\% sofriam de transtornos depressivos no climatério, no qual foram avaliadas com Inventário de Depressão de Beck (BDI), Escala de Avaliação de Menopausa (MRS) e Índice de Função Sexual (FSFI). 19,2\% dessas mulheres apresentavam adversidades na qualidade de vida sexual com o esposo, apontou que os sintomas depressivos desencadearam disfunções sexuais, prejudicando a qualidade sexual. Corroborando com o estudo, Lara et al., 2018, identificou a ansiedade e depressão como principais alvos da decadência da qualidade de vida sexual em mulheres no período climatério (n=1716/ 5\%) levando ao distúrbio do sono, disfunção sexual, alteração no humor e depressão.

Nos achados de Castro et al., 2017, o fogacho teve maior probabilidade na perda da qualidade de vida sexual $(76,4 \%)$, ficando por trás das dores musculares e articular $(71,3 \%)$. Desse modo, outros sintomas poderem implicar de forma direta ou indireta na QV. Em media 48\% das mulheres relataram que com os sintomas do climatério reduziu significativamente à atividade sexual comparado a antes, 27,8 \% já não sentia satisfeita sexualmente, 14 \% não tinha a relação sexual como importante para sua qualidade de vida, 16 \% não se sentia feliz com a atividade sexual, 29,5\% estava sendo tratada de forma indiferente por seus parceiros e 13, 4\% sentia que era obrigação como esposa estar ativa na relação sexual consequentemente seu dever como esposa não estava sendo cumprido, mostrando assim, a falta de acesso a informação. Os dados mostraram que estado emocional implica para o desempenho sexual e que qualidade sexual pode interferir de forma direta ou indireta na vida conjugal.

Tais achados corroboram com estudo de Rocha et al., 2018, identificou que os sintomas causados pelo climatério podem afetar significativamente na qualidade de sexual. A redução da lubrificação vaginal pode impedir a excitação sexual (72,1\%), consequentemente, desencadear dor na penetração vaginal $(67,6 \%)$, resultando na redução da frequência sexual por até meses $(34,2 \%)$. Tais condições podem causar aversão por atividade sexual, divergência conjugal acerca de (n=120) 58,1\% apresentando conflitos entre seus parceiros e sintomas vasomotores pelo qual foi mais manifesto em ambientes quentes (Torres et a., 2018; Paez et al., 2017).

No desfecho de Torres et al., 2018, apontou que em consequência dos sintomas do climatério, a frequência do orgasmo reduziu (50\%) significativamente, podendo deixar a mulher aflita em estar em uma relação sem orgasmo. O estudo também apontou a redução da libido como predominante, em média $70 \%$ das mulheres alocadas teve como principal impacto na qualidade de vida sexual. 


\section{CONSIDERAÇÕES FINAIS}

Tais achados foram evidenciados que os sintomas do climatério podem reduzi significativamente na qualidade de vida sexual como: ressecamento vaginal, redução da libido, fogacho e acesso a informação. Tais alterações favorecem disfunções sexuais e conflito conjugais, refletindo também em variações no estado psicológico. Para os achados concludentes, foi possível identificar poucos estudos sobre atemáticas, dessa forma, mostrar a necessidade e relevância de estudos futuros sobre a temática.

\section{REFERÊNCIAS}

Castro, A .M; Méndez, L. C. D \& Madrid, M. S. Manifestaciones menopaúsicas y calidad de vida en afrocolombianas. Valoración con escala Cervantes. IATREIA Vol 30(4): 376-390 octubrediciembre 2017.

Lara, M. F. M; Castro, A. M \& Méndez, L. C. D. Evaluación de la calidad de vida en climatéricas con la Escala Cervantes. Influencia de la etni. Rev Peru Ginecol Obstet. 2018;64(1) 13.

Paez, T. B. H. et al., Factores socioculturales y laborales asociados a la sintomatología del síndrome climatérico. Revista Cubana de Obstetricia y Ginecología. 2017;43(2).

Rocha, A. S. G. \& Mitidiere, A. M. S. O Impacto Dos Sintomas Climatéricos Na Qualidade De Vida e Função Sexual. Revista Saúde UniToledo, Araçatuba, SP, v. 02, n. 01, p. 141-155, ago. 2018.

Torres, J. M; Bezerra, K. K. S \& Bezerra, A. M. F. Sexualidade No Climatério e Suas Implicações Na Qualidade De Vida De Mulheres Atendidas Na Atenção Primaria. Revista Enfermagem Atual. v. 86 n. 24 (2018): Edição:86| 24 Jul. Ago. Set. João Pessoa, p. 106-125, 2018.

Varela, L. M. D. V. et al., .Atividade física e função da musculatura do assoalho pélvico em mulheres climatéricas: um estudo transversal. ConScientiae Saúde, 2018;17(3):239-247.

Yanikkerem, E. et al., .Effects of physical and depressive symptoms on the sexual life of Turkish women in the climacteric period- NBR 6023/2018. 


\title{
JUVENTUDE E SAÚDE MENTAL
}

Caroline Louzada da Rosa ${ }^{1}$ - Escola de Saúde Pública (ESP),

Mara Rosange Acosta de Medeiros ${ }^{2}$

${ }^{1}$ Residente em saúde mental coletiva (ESP)

${ }^{2}$ Orientadora acadêmica

\begin{abstract}
RESUMO
Este trabalho buscou compreender as possíveis causas geradoras do adoecimento mental da população jovem na cidade de Pelotas. Para analisar o fator inicial que vem levando jovens a procurarem por serviços de saúde mental, é preciso compreender primeiramente quem são esses jovens que buscam atendimento em um Centro de Atenção Psicossocial (CAPS). E é isso que iremos contextualizar neste trabalho, assim como o contexto em que esses jovens vivem e quais suas expectativas frente ao tratamento.
\end{abstract}

PALAVRAS-CHAVES: Adoecimento mental; Adultos jovens; Atenção Psicossocial. ÁREA TEMÁTICA: Saúde Mental Coletiva.

\section{INTRODUÇÃO}

Pouco se tem de estudos que possam dar visibilidade ao processo de adoecimento mental de um jovem adulto, que possibilite compreender quais as demandas que perpassam a vida desses usuários.

Portanto, esse projeto visa analisar as questões de saúde mental de jovens adultos, a partir do olhar dos mesmos, partindo do pressuposto de como eles se veem neste processo de adoecimento e como lidam com a questão de estarem inseridos em um serviço de tratamento psicossocial e ao mesmo tempo os desafios das atividades rotineiras, como suas vidas pessoais, profissionais e escolares e/ou acadêmicas.

\section{METODOLOGIA}

Por se tratar de um projeto que visa construir coletivamente a pesquisa junto aos usuários jovens do centro de atenção psicossocial, a mesma será realizada de forma qualitativa, a fim de 
compreender individualmente quais suas demandas e expectativas, a partir do olhar dos próprios jovens.

Quanto a metodologia utilizada, como previsto no projeto de pesquisa, foi utilizada pesquisa bibliográfica - averiguando a baixa produtividade cientifica frente a esta temática, assim como pesquisa documental, através de prontuários e pesquisa de campo, feita através da observação e conversas informais com os adultos jovens do serviço, já que diante do grupo, de acompanhamentos, acolhimentos e atendimentos de jovens no serviço, foram aplicadas entrevistas aberta semiestruturada, através de conversas informais, e também questionários durante os grupos, perguntei sobre suas expectativas frente a vida e ao tratamento, suas demandas e frustrações

Para analisar o fator inicial que vem levando jovens a procurarem por centros de atenção psicossociais, é preciso compreender primeiramente quem são esses jovens, quais suas características e demandas.

Inicialmente os jovens que venho investigando, no CAPS, encontram-se na faixa etária de 18 a 28 anos, e em sua maioria costumam levar suas vidas de forma a conciliar o adoecimento mental com a vida cotidiana e de estudos. Em grande parte dos casos, noto que o emprego não é presente na vida desses jovens.

\section{RESULTADOS E DISCUSSÕES}

Levar uma vida como a de outros jovens, que não possuem transtorno mental, pode parecer difícil, pois a doença vem acompanhada de diversos sintomas, como apatia, desmotivação, tristeza, choro constante, dificuldades de lidar com outras pessoas, mudanças de humor, ansiedade, pensamentos de suicídio, temperamento alterado, e diversos outros sintomas, relacionadas aos diversos tipos de doenças mentais, e em praticamente todos os casos, a terapia medicamentosa é necessária, e com ela seus efeitos colaterais, como sonolência, dificuldade para acordar cedo, quedas da pressão arterial, tremores, náusea, dores de cabeça, tonturas, dentre tantos outros fatores que dificultam o andamento natural da vida jovem, mas que eles buscam superar quando procuram pelo tratamento.

Se tratando das possíveis causas que levam esse aumento significativo de números de adultos jovens no serviço, relaciono com a fase e as pressões sociais e familiares que jovens quando estão passando para a vida adulta sofrem, pois a cobrança de terminar o ensino médio, entrar para uma faculdade, conseguir um bom emprego, nesta conjuntura atual do Brasil, onde a retirada de direitos é evidente e desmotivadora, pode fazer com que os indivíduos sintam-se pressionados, e acarretar nesses possíveis adoecimentos mentais.

Muito embora, saibamos que na maioria dos casos, essas doenças não aparecem de uma hora para outra, e sim são acúmulos que vem da infância e juventude, por terem sofrido algum tipo de violência (sexuais e/ou psicológicas), podem estar ligados também a doenças mentais que fazem parte da vida de algum familiar. 
Os jovens vão em busca de tratamento, muitas vezes incentivados pelos pais ou familiares, por notarem que algo não está bem, que sua vida está desorganizada, seu humor ou personalidade estão mudando, ou em alguns casos, eles chegam por demanda da escola ou universidade, através de núcleos psicológicos, que acreditam ser necessário o acompanhamento de forma mais intensiva pelo CAPS, já em outros chegam por demanda própria, por perceberem que seus pensamentos desconectados e suas queixas necessitam serem tratadas.

Quanto as expectativas dos jovens, pôde-se perceber através de suas falas, que o que eles (jovens) mais buscam é uma maior qualidade de vida, poder aprender a conviver melhor com seus transtornos/doenças, sem que isso afete demais em suas vidas. Buscam aprender a lidar com suas crises, os sintomas, que para eles é a pior parte, pois prejudicam suas relações, suas vidas em geral.

\section{CONSIDERAÇÕES FINAIS}

É possível perceber os impactos no aumento da demanda jovem do serviço em decorrência da violência urbana, do desemprego, da ausência de perspectivas a curto e médio prazos, levando em conta a pressão da vida universitária, ou a de adentrar em um curso superior, ou mesmo terminar o ensino básico, se expressam na multiplicação de casos de depressão, transtornos de ansiedade, síndrome do pânico, suicídios e/ou tentativas.

O processo de adoecimento mental ocasiona na vida desses jovens adultos, como observado a partir de suas falas, a segregação da vida em sociedade, pois ainda há um estigma de que a pessoa com transtorno mental é perigosa e/ou incapazes. Muitas pessoas ainda acreditam na forma de cuidado hospitalocêntrica, e que os doentes mentais devem estar trancafiados em manicômios pois de certa forma ameaçam a população ou não são vistos como pessoas "normais" que devem conviver em sociedade como qualquer outra, uso aspas, pois o termo normal é muito relativo, e não é defino ao certo os parâmetros para normalidade, já que somos seres humanos e assim sendo, somos singulares e temos particularidades.

Estes estigmas dados às pessoas com transtornos mentais, em particular neste caso, aos adultos mais jovens, que têm como pressuposto da juventude a plena saúde e condição física e mental, geram as mais terríveis formas de preconceitos, de exclusão, tanto do mercado de trabalho, quanto do convívio familiar, escolar e da sociedade em si. 


\section{PRINCIPAIS REFERENCIAS}

Brasil. Saúde mental no SUS: os centros de atenção psicossocial / Ministério da Saúde, Secretaria de Atenção à Saúde, Departamento de Ações Programáticas Estratégicas. - Brasília: Ministério da Saúde, 2004

BRITO, Débora. Expectativa e insegurança sobre futuro levam jovem a problema mental. Disponível em: http://agenciabrasil.ebc.com.br/saude/noticia/2018-08/expectativae-insegura-quantoao-futuro-levam-jovem-problema-mental > Acesso em 18 de fevereiro de 2019.

PEREIRA, Flávia Pimentel. Expectativas de familiares de adultos jovens quanto ao tratamento proposto em um centro de atenção psicossocial. 2016. 51 f. Dissertação (Mestrado em Enfermagem) - Escola de Enfermagem, Universidade Federal do Rio Grande do Sul, Porto Alegre, 2016. 


\title{
RELATO DE EXPERIÊNCIA DE MESTRANDOS EM ENFERMAGEM NAS ATIVIDADES DESENVOLVIDAS EM TEMPO DE PANDEMIA
}

\author{
Amanda Maria Silva da Cunhaㄹ ; Ana Flávia Silva Lima ${ }^{2}$; Mário César Ferreira Lima Júnior ${ }^{3}$ \\ ${ }_{1}$ Mestranda, Enfermeira, Universidade Federal de Alagoas (UFAL), Maceió, Alagoas. \\ 2 Mestranda, Enfermeira, Universidade Federal de Alagoas (UFAL), Maceió, Alagoas. \\ ${ }_{3}$ Mestrando, Enfermeiro, Universidade Federal de Alagoas (UFAL), Maceió, Alagoas.
}

\begin{abstract}
RESUMO
Os impactos decorrentes das medidas adotadas no combate a propagação do Covid-19 repercutiu nos diferentes níveis de educação. Visando o avanço do calendário, programas de pós-graduação do país precisaram recorrer a medidas como a prática do ensino remoto e a distância para continuação das atividades. O objetivo deste trabalho é relatar a experiência vivenciada por mestrandos do Programa de Pós Graduação de Enfermagem da universidade federal de um estado brasileiro durante a pandemia, ocasião na qual adotou-se o espaço virtual como meio para o desenvolvimento das práticas educacionais. Apresentam-se os aspectos relacionados aos pensamentos iniciais dos envolvidos, recursos utilizados, benefícios e dificuldades encontradas. Passados os primeiros meses da experiência, a atual relação das mestrandos com a proposta demonstra-se harmoniosa e eficiente. Embora alguns docentes optem por não adotar o modelo virtual para a oferta da disciplina, a proposta apresenta considerável aceitação entre os membros do programa.
\end{abstract}

PALAVRAS-CHAVES: Educação de Pós-Graduação; Educação a Distância; Enfermagem.

ÁREA TEMÁTICA: Áreas afins

\section{INTRODUÇÃO}

Acompanhando as mudanças no cenário mundial, o ensino superior apresenta adequações relacionadas às inovações tecnológicas que, mesmo nos modelos educacionais tradicionais, trazem mudanças nas relações de ensino e aprendizado. A incrementação das tecnologias a educação permite a flexibilização do ensino e a expansão do alcance das instituições de ensino superior (IES) (FERREIRA; OLCINA-SEMPERE, 2020).

Os impactos na educação decorrentes da pandemia provocaram a necessidade de adaptação dos modelos educacionais vigentes com o fomento de recursos tecnológicos e digitais nas práticas 
pedagógicas. Dependendo das características presentes nessa relação, o cenário pode caracterizar-se por uma convivência harmoniosa ou de retrocesso. Nesse contexto fatores relacionados à infraestrutura e familiarização com os recursos interferem consideravelmente no desenvolvimento da proposta de ensino (RIBEIRO; CLÍMACO, 2020).

Com o cenário atual o foco de discussão sobre a utilização das tecnologias da informação e comunicação (TICs) no ensino mudou das discussões relacionadas a seus benefícios e a necessidade de sua inserção nas práticas pedagógicas para o desenvolvimento de estratégias que façam seu uso ser eficiente e proveitoso, considerando-se a elucidação de que o acesso à informação é expandido pelo seu emprego, o que reafirma a necessidade de uma qualidade dessa informação (LOBO; MAIA, 2015). Diante disto, o objetivo deste trabalho é relatar a experiência vivenciada por mestrandos do Programa de Pós Graduação de Enfermagem da universidade federal de um estado brasileiro durante a pandemia, ocasião na qual adotou-se o espaço virtual como meio para o desenvolvimento das práticas educacionais.

\section{METODOLOGIA}

Trata-se de um relato de experiência de mestrandos do Programa de Pós Graduação de Enfermagem (PPGENF) da universidade federal de um estado brasileiro acerca das atividades remotas e a distância desenvolvidas durante a pandemia decorrente do Covid-19. A proposta para o início das disciplinas obrigatórias na modalidade foi apresentada aos mestrandos em maio de 2020 em reunião com a coordenação do PPGENF através de plataforma virtual, sendo desenvolvida desde então.

\section{RESULTADOS E DISCUSSÕES}

Entre os mestrandos, a decisão pelo início das atividades por meio virtual gerou controvérsias. Enquanto alguns defendiam a estratégia, visto que possibilitaria o início das atividades em meio ao cenário de isolamento social e o consequente avanço no cronograma do PPGENF, outros preocupavam-se com a validade do aprendizado a ser construído nesses encontros. Salienta-se que cabia aos docentes das disciplinas a decisão pela oferta destas na modalidade proposta ou aguardo da autorização de retorno das atividades presenciais para a disponibilização.

Para o desenvolvimento das atividades individuais e coletivas na modalidade aceita pela maioria dos envolvidos, os docentes e estudantes utilizam a plataforma Google Meet para o andamento das aulas virtuais, reuniões de planejamento e estudo. Nesse recurso, a frequência de participação é realizada através de preenchimento de formulário no Google Forms ou registro realizado pelo recurso Meet Attendance. Questões administrativas, como matrículas em disciplinas, são realizadas no Sistema Integrado de Gestão de Atividades Acadêmicas da universidade; ademais, os mestrandos compõem um grupo de Whatsapp com a secretária do programa para uma comunicação direta de 
avisos, dúvidas e solicitações.

O compartilhamento de referências, ementa da disciplina, cronograma e demais materiais didáticos são realizados no ambiente virtual de aprendizagem (AVA) da universidade. A organização do espaço fica a cargo do docente, havendo a experiência de participação em ambientes divididos por semanas ou por atividades. A maneira de organização apresenta reflexos no envolvimento dos estudantes com a prática, notando-se uma diferença de participação entre o espaço organizado detalhadamente, indicando-se, inclusive uma sensação de acolhimento e conforto nas visitas ao ambiente.

Estimula-se a participação nos fóruns permanentes de discussão iniciados pelos docentes. Estes apresentam finalidades relacionadas a proposição de situações disparadoras, envio de referências complementares, síntese dos conteúdos e apresentação de dúvidas e esclarecimentos. $\mathrm{O}$ envio das atividades desenvolvidas pelos mestrandos também é realizado através do AVA, sendo possível a postagem para a visualização de todo grupo ou apenas dos docentes da disciplina, a depender da configuração aplicada. Outro recurso utilizado com a mesma finalidade do AVAé o Google Classroom, adotado em disciplina eletiva.

Destaca-se que para o desenvolvimento das atividades foram necessárias adequações propostas pelos docentes aos mestrandos. As aulas que em seu formato presencial apresentavam a duração de quatro horas por encontro tiveram a duração reduzida para duas ou três horas síncronas, a depender da proposta dos docentes, sendo as horas restantes destinadas para o estudo individual do mestrando a ser retornado para constatação do professor através do envio de resumos, sínteses críticas e portfólios nos ambientes virtuais, o que junto com a participação nas discussões realizadas nas aulas virtuais, constituem os métodos de avaliação adotados.

A disponibilidade de equipamentos com as configurações necessárias e acesso a internet de qualidade são as principais dificuldades enfrentadas pelos mestrandos no desenvolvimento da modalidade. Esses aspectos interferem no acompanhamento das exposições dos docentes, participação nas discussões coletivas e apresentações de seminários individuais ou em grupo.

Demonstra-se que a característica autônoma do aprendizado requer que o aluno comprometase com os estudos individuais, requerendo mudanças nos hábitos educacionais que influenciarão no seu processo de aprender a aprender. No ensino virtual, faz-se necessária a familiarização dos estudantes com os recursos utilizados o que, por não ser tarefa fácil considerando-se o avanço veloz dos recursos tecnológicos, pode gerar situações desanimadoras nos discentes que interferirão no processo de ensino-aprendizagem. Ademais, a indisponibilidade de equipamentos compatíveis e uma internet ágil interferem não apenas no acesso às ferramentas e materiais didáticos, mas no tempo destinado ao aprendizado (CAPELETTI, 2014).

Em situações como essas a interação com os docentes e a melhoria pedagógica e tecnológica ofertada pelos coordenadores dos cursos e desenvolvedores das tecnologias são capazes de estimular os estudantes para a continuidade do aprendizado. A superação das inseguranças associadas a plataforma 
virtual refletirá positivamente nas competências do estudante, devendo ser uma preocupação dos orientadores a oferta de recursos que atendam a realidade dos estudantes, seja relacionado a seus conhecimentos quanto ao acesso aos materiais e tecnologias ou a detenção das configurações e equipamentos necessários para essa conexão (ALVES; MENEZES; VASCONCELOS, 2014).

Por outro lado, a flexibilidade possibilitada pelo ensino remoto apresenta-se como a principal vantagem dessa modalidade. Devido ao isolamento social, os mestrandos residentes de outros estados e cidades do nordeste retornaram às suas residências, o que nessa modalidade não apresenta-se como um empecilho para a participação nas atividades. O mesmo é válido para aqueles que iniciaram a prestação de serviços de assistência nesse período e aqueles que já possuíam um vínculo empregatício, sendo comum a participação nas aulas nos ambientes de trabalho.

Outro benefício apresentado por essa flexibilização é a participação como aluno especial em disciplinas de diferentes programas de pós-graduação no país. A experiência possibilita a ampliação do histórico do estudante com a obtenção de créditos e aprendizados julgados necessários para o desenvolvimento da docência e do projeto de pesquisa, e a experiência de amplificar o círculo de contatos e experiências com pessoas de diferentes locais do país.

\section{CONSIDERAÇÕES FINAIS}

Mudanças requerem um período de adaptação, principalmente quando elas são apresentadas de surpresa, como foram as decorrentes a pandemia de Covid-19 no mundo e, em especial, na educação. Passado o período inicial da deflagração das medidas de isolamento social, as instituições de ensino buscaram estratégias para a continuação de suas atividades, sendo a adoção do ensino remoto a mais popular entre elas, inclusive nos programas de pós-graduação.

Os primeiros meses da experiência foram marcados por inseguranças e dificuldades relacionadas aos novos modelos adotados, associadas também a familiarização com os recursos e equipamentos necessários. Ademais, incertezas quanto à validade do processo de ensino-aprendizagem foram questões que estiveram presentes no imaginário dos envolvidos. Passado o período de adaptação, docentes e discentes demonstram-se receptivos a modalidade, reconhecendo os benefícios do modelo e utilizando os recursos disponíveis a seu favor. Ao desenvolverem uma relação eficiente e harmoniosa com o ensino remoto e as TICs, os sujeitos foram capazes de construir um aprendizado significativo e defendem a continuidade do cronograma seguindo-se o modelo virtual adotado.

\section{PRINCIPAIS REFERÊNCIAS (apresenta a possibilidade de utilizar apenas algumas referências para evitar a extrapolação do limite máximo de três páginas)}

ALVES, T.M.F.; MENEZES, A.H.N.; VASCONCELOS, F.M.B.P. Crescimento da educação a distância e seus desafios: uma revisão bibliográfica. REVASF, Petrolina, v.4, n. 6, 2014. 
CAPELETTI, A.M. Ensino a distância: desafios encontrados por alunos do ensino superior. Revista Eletrônica Saberes da Educação, v. 5, n. 1, 2014

FERREIRA, M.P.M.; OLCINA-SEMPERE, G. La pedagogia en la enseñanza superior: la mejora de las práticas académicas. Rev. Docência Ens. Sup., Belo Horizonte, v. 10, e015837, 2020.

LOBO, A.S.M; MAIA, L.C.G. O uso das TICs como ferramenta de ensino-aprendizagem no Ensino Superior. Caderno de Geografia, Belo Horizonte, v. 25, n. 44, 2015.

RIBEIRO, M.P.; CLÍMACO, F.C. Impactos da pandemia na educação infantil: a pandemia acelerou a necessidade de se problematizar a questão digital na educação infantil? Pedagogia em Ação, Belo Horizonte, v. 13, n. 1, 2020. 


\section{ESTRESSE OCUPACIONAL EM ENFERMEIROS NO AMBIENTE HOSPITALAR}

Lívia Lopes Custódio ${ }^{1}$; Cláudia Patrícia da Silva Ribeiro Menezes ${ }^{1}$; Débora Cristina Couto Oliveira Costa $^{1}$; Lucélia Rodrigues Afonso ${ }^{2}$; Ednúbia Pereira Félix ${ }^{2}$; Francisco Ariclene Oliveira ${ }^{3}$ Debora Silveira de Lima ${ }^{4}$; Ilvana Lima Verde Gomes ${ }^{5}$

${ }^{1}$ Doutoranda em Saúde Coletiva, Universidade Estadual do Ceará (UECE), Fortaleza, Ceara, Brasil.

${ }^{2}$ Mestranda em Saúde Coletiva, Universidade Estadual do Ceará (UECE), Fortaleza, Ceara, Brasil.

${ }^{3}$ Doutorando em Saúde Pública, Universidade Federal do Ceará (UFC), Fortaleza, Ceara, Brasil.

${ }^{4}$ Graduanda em Enfermagem, Universidade Estadual do Ceará (UECE), Fortaleza, Ceara, Brasil.

${ }^{5}$ Pós-doutorado em Saúde Coletiva e docente, Universidade Estadual do Ceará (UECE), Fortaleza, Ceara, Brasil.

\section{RESUMO}

O objetivo deste trabalho foi identificar a presença de estresse ocupacional de enfermeiros em uma unidade hospitalar da cidade de Fortaleza. Trata-se de um estudo transversal, descritivo, desenvolvido em uma unidade hospitalar publica de Fortaleza, Ceara, Brasil, de agosto a dezembro de 2019. A população foi constituída por 83 profissionais de enfermagem. Os dados foram coletados por meio de um questionário estruturado e a análise foi do tipo estatística descritiva. Os resultados revelam que a maioria dos profissionais eram do sexo feminino, em idade de 18 a 49 anos, atuavam como cooperados, com especialização, tendo de 1 a 10 anos pelo tempo de serviço na instituição. Foi identificado a presença de estresse ocupacional nos enfermeiros, apontando sintomas como tensão muscular, insônia, tensão muscular, desgaste físico e irritabilidade. Conclui-se que o estresse ocupacional é um problema real entre os profissionais de enfermagem. Portanto, é preciso adoção de medidas preventivas.

Palavras-chave: Sofrimento Emocional; Enfermagem; Unidade hospitalar.

\section{INTRODUÇÃO}

O profissional da enfermagem é essencial dentro do sistema de saúde, afinal são eles os responsáveis pela prestação de cuidados nos diversos níveis de intervenção, reforçando a importância da sua atuação e assistência prestada as pessoas adoecidas nos diferentes níveis de Atenção à Saúde.

Na tentativa de desempenhar tal função para a qualidade do atendimento prestado, o enfermeiro 
enfrenta grandes dificuldades encontradas em seu cotidiano e que ainda são pouco divulgadas (SILVA, INVENÇÃO, 2018). São vivencias diárias em condições de trabalho inadequadas, ambiente insalubre, com sobrecarga de trabalho e repetição de tarefas que motivam situações de exaustão física e emocional geradoras de estresse ocupacional (SANTOS et al, 2019).

O local de trabalho é um ambiente que faz parte da vida das pessoas e, inevitavelmente, podem corroborar para desencadear o estresse, definido pela International Labour Organization (ILO, 2016) como uma resposta física e emocional causada por um desequilíbrio entre as atividades laborais, tensões expositivas da labuta e habilidades do indivíduo para lidar com situações estressoras.

Tendo em vista a possibilidade dessas vivencias durante as atividades laborais que podem comprometem a saúde do enfermeiro é que este trabalho teve o objetivo de identificar a presença de estresse ocupacional de enfermeiros em uma unidade hospitalar da cidade de Fortaleza.

\section{MÉTODOS}

Para a realização do estudo adotamos a abordagem quantitativa, com delineamento do tipo transversal e descritivo. O estudo ocorreu no período de agosto a dezembro de 2019, em uma unidade hospitalar pública, da cidade de Fortaleza, Ceará, Brasil.

A população do estudo foi constituída por 83 profissionais de enfermagem, a amostra foi do tipo intencional e não probabilística. Os participantes elegíveis para a pesquisa foram recrutados por meio da técnica de amostragem por conveniência. Como critério de inclusão foi exigido estar atuando na assistência direta e ter no mínimo seis meses de atuação profissional na instituição. Os critérios de exclusão consistiram em: licença médica, licença maternidade e férias no período de coleta de dados.

O instrumento utilizado para coleta de dados foi um questionário autoaplicável e já validado, com questões fechadas de múltipla escolha relacionadas a informações relacionadas a profissão e aos fatores de estresse ocupacional que contemplou a temática da pesquisa. O questionário foi aplicado individualmente, no próprio local de trabalho dos participantes, teve uma duração de aproximadamente 15 minutos.

Os dados obtidos foram digitados e processados utilizando-se as planilhas eletrônicas do programa Microsoft ${ }^{\circledR}$ Office Excel ${ }^{\circledR}$ 2016. Após tabulados dos dados aplicou-se a análise estatística descritiva por meio do programa STATA, calculando-se as frequências absolutas e relativas.

A pesquisa seguiu as normas estabelecidas pela legislação vigente que rege sobre a realização de pesquisas envolvendo seres humanos e foi aprovada pelo Comitê de Ética em Pesquisa, sob parecer de $n^{\circ} .2 .903 .371$. 


\section{RESULTADOS}

A amostra foi constituída por 83 profissionais de enfermagem que atuavam diretamente na assistência à saúde de um hospital terciário, público, da cidade de Fortaleza, Ceará. Desse total, 74 $(93,9 \%)$ profissionais foram do sexo feminino, a maioria se encontrava em idade de 18 a 49 anos, contabilizando 66 (79,5\%). Esse resultado do sexo, corrobora com estudos que demonstram, a partir de amostras significativas, majoritariamente uma representação por profissionais da enfermagem que são do sexo feminino (SANTANA, FERREIRA, SANTANA, 2020; AZEVEDO, NERY, CARDOSO, 2017).

Em relação à escolaridade, verificou-se neste estudo que os enfermeiros, em sua maioria, são profissionais que atuam com especialização em seu total de 64 (77,1\%). Além de concluir o curso de graduação, muitos enfermeiros buscam se especializar, procurando como a principal modalidade de formação, a Pós-Graduação denominada de 'lato sensu', conforme apresentou a pesquisa de Machado et al (2016).

Quanto ao tempo de formação do curso de enfermagem, teve-se que $26(31,3 \%)$ enfermeiros já tinham de 1 a 5 anos de formados, seguido de 19 (22,8\%) enfermeiros com mais de 20 anos de formação da graduação. Referente ao tempo de serviço na instituição, abrangeu-se um total de 21 $(25,3 \%)$ enfermeiros para o tempo de recorte de 1 a 10 anos de tempo de trabalho na instituição. Analisando esse quesito do tempo de serviço na instituição, o estudo de Villela et al (2011) mostra que a atuação do profissional enfermeiro, a partir da sua graduação, aproxima-se de $50 \%$ no total da força de trabalho nos dez primeiros anos de seu exercício e $25 \%$ entre 11 a 20 anos.

Sobre o vínculo trabalhista dos enfermeiros com a instituição, observou-se que 48 (57,8\%) profissionais que prestam serviço com vínculo de trabalho na modalidade de cooperado. Esse dado tem relação com as consequências advindas do cenário de precarização do trabalho, apontam-se prejuízos para a saúde do trabalhador e para a organização devido à rotatividade de pessoal e à fuga de capital intelectual que interferem diretamente na qualidade da assistência (OLIVEIRA e TEIXEIRA, 2016).

Conforme os dados analisados, destacou-se que foi identificado sim a presença de estresse ocupacional nos enfermeiros da unidade hospitalar pesquisada, em sua maioria, foram expostos um total de $79(95,1 \%)$. Entre esses profissionais foi apontado características das variáveis relativas à manifestação de sintomas de estresse que acabam por impactar o dia a dia dos enfermeiros, causando danos físicos, psíquicos e sociais. Dentre os sintomas mais prevalentes, observaram-se a tensão muscular, insônia, tensão muscular, desgaste físico e irritabilidade.

A literatura aponta a presença de fatores de estresse entre os profissionais de enfermagem que atuam na assistência direta ao paciente clínico ou grave, apresentam percentuais de prevalência da presença de estresse, evidenciando a necessidade premente de ações que vise a redução/mitigação desses elementos estressores. Os profissionais de enfermagem de uma UTIN de um hospital público do Espírito revelaram que 56,7\% dos participantes apresentaram sinais de estresse (AZEVEDO et al., 2017; MELLO, REIS, RAMOS, 2018). 


\section{CONCLUSÃO}

Acredita-se que o objetivo proposto de identificar a presença de estresse ocupacional de enfermeiros em uma unidade hospitalar foi alcançado, tendo em vista que os resultados expressos, em sua maioria, foram positivos acerca de tal temática, conforme se verificou ao longo do estudo.

Os resultados apresentados evidenciam que o estresse ocupacional emerge como um problema real entre os profissionais de enfermagem que podem afetar e desencadear sintomas de doenças ocupacionais alterando a sua vida profissional. Portanto, é preciso adoção de medidas preventivas do estresse ocupacional no âmbito coletivo e organizacional, com vistas a proporcionar um ambiente de trabalho seguro e com recursos materiais indispensáveis a uma assistência de qualidade.

\section{REFERÊNCIAS}

AZEVEDO, Bruno Del Sarto; NERY, Adriana Alves; CARDOSO, Jefferson Paixão. Estresse ocupacional e insatisfação com a qualidade de vida no trabalho em enfermagem. Texto \& ContextoEnfermagem, v. 26, n. 1, 2017.

INTERNATIONAL LABOUR ORGANIZATION. WORKPLACE STRESS: A collective challenge. Turin: ILO, 2016.

MACHADO, Maria Helena et al. Aspectos gerais da formação da enfermagem: o perfil da formação dos enfermeiros, técnicos e auxiliares. Enfermagem in foco (Brasília), p. 15-34, 2016.

MELLO, Rita de Cassia Corrêa; REIS, Luciana Bicalho; RAMOS, Fabiana Pinheiro. Estresse em profissionais de enfermagem: importância da variável clima organizacional. Gerais: Revista Interinstitucional de Psicologia, v. 11, n. 2, p. 193-207, 2018.

OLIVEIRA, Alessandro Fábio; TEIXEIRA, Enéas Rangel. Concepções sobre o uso da automedicação pelos trabalhadores de enfermagem em terapia intensiva oncológica. Journal of Nursing UFPE/ Revista de Enfermagem UFPE, v. 10, n. 1, 2016.

SANTANA, LCarvalho; FERREIRA, Lúcia Aparecida; SANTANA, Lenniara Pereira Mendes. Estresse ocupacional em profissionais de enfermagem de um hospital universitário. Revista Brasileira Enfermagem, Brasília, v. 73, n. 2, e20180997, 2020 . Disponível em <http://www.scielo.br/scielo. php?script=sci_arttext\&pid=S0034-71672020000200179\&lng=pt\&nrm=iso $>$. acessos em 08 mar. 2021. Epub 17-Fev-2020. https://doi.org/10.1590/0034-7167-2018-0997.

SANTOS, Rosely Mota et al. Estresse ocupacional em profissionais de enfermagem. In: Congresso Nacional de Enfermagem-CONENF. 2019.

SILVA, Amanda Mendes Silva Mendes; INVENÇÃO, Andréa Santos. A atuação do enfermeiro no atendimento de urgência e emergência. UNILUS Ensino e Pesquisa, v. 15, n. 39, p. 5-13, 2018. 


\section{ATIVIDADE EDUCATIVA VIRTUAL SOBRE GRAVIDEZ NA ADOLESCÊNCIA: RELATO DE EXPERIÊNCIA}

\section{Rosely Leyliane dos Santos ${ }^{1}$}

1. Doutora em Enfermagem, Universidade Regional do Cariri, Crato, Ceará.

\section{RESUMO}

A gravidez na adolescência constitui-se problema de saúde pública em virtude das possíveis complicações obstétricas e maternas. Neste sentido, é importante que os profissionais da saúde adotem estratégias educativas que promovam a saúde do adolescente de modo eficaz. O objetivo do estudo foi relatar a experiência de atividade educativa virtual sobre gravidez na adolescência. Trata-se de um estudo do tipo relato de experiência sobre atividade educativa realizada por meio do plataforma digital. As facilitadoras definiram as principais causas relacionadas à gravidez nesta fase, as peculiaridades de atenção e cuidado bem como, estratégias importantes como parcerias intersetoriais que fomentem a promoção da saúde do adolescente em suas diversas singularidades e contextos. Apontaram que o letramento em saúde é importante neste cuidado e, deve permear às necessidade da população-alvo. Logo, reconhece-se que a atividade educativa virtual sobre gravidez na adolescência foi exitosa e contribuiu para a discussão abrangente da temática.

Palavras-chave: Promoção da Saúde; Gravidez; Adolescente.

Área Temática: Outras.

\section{INTRODUÇÃO}

A gravidez na adolescência constitui-se problema de saúde pública em virtude das possíveis complicações obstétricas e maternas. A presença dessa condição de vida em adolescentes foi justificada associada a fatores contextuais; motivacionais, emocionais e, fatores práticos que incluíam o desejo, da própria adolescente, em completar a família (WHITAKER et al., 2016). Adolescentes de baixa renda são mais propensas a se engajarem em comportamentos de riscos e, consequente, gravidez (BRINDIS; MOORE, 2014). No estudo canadense de Wong et al. (2020), cerca de 18\% das mães adolescentes moravam em bairros socioeconômicos desfavorecidos.

Por isso, além das vulnerabilidades a que estão expostos os adolescentes (BRINDIS; MOORE, 2014), é importante que os profissionais da saúde, sobretudo os enfermeiros atuantes na saúde pública e no cuidado às adolescentes grávidas, adotem estratégias que promovam a saúde do adolescente de 
modo eficaz.

Neste sentido, estudo estudo justifica-se pela necessidade de apontar a utilização de prática educativa para informações que impactam na atenção e cuidado à saúde do adolescente. Assim, o objetivo foi relatar a experiência de atividade educativa virtual sobre gravidez na adolescência.

\section{METODOLOGIA}

Trata-se de um estudo do tipo relato experiência. Em decorrência da prevenção da propagação e contingenciamento para a COVID-19, a atividade educativa ocorreu por meio remoto, em plataforma digital, de videoconferência. $\mathrm{O}$ público-alvo eram acadêmicos da área de saúde e profissionais. $\mathrm{O}$ período de realização da atividade educativa foi no mês de outubro de 2020 e, foi uma iniciativa de um projeto de extensão universitário vinculado a uma universidade pública brasileira.

No dia designado, a sala virtual estava disponível cerca de 20 minutos antes do horário previsto. Havia um cartaz com as principais informações e agradecendo a participação dos envolvidos. É válido destacar que a atividade foi organizada em momentos com a exposição dialogada, interação entre participantes, exposição dialogada da outra palestrante e interação com os presentes com espaço para sugestões, dúvidas ou discussão coletiva. Havia uma mediadora que conduzia o momento. Cerca de aproximadamente, 64 pessoas participaram do momento.

A primeira palestrante apresentou as definições sobre a adolescência, a importância da proteção e cuidado desta faixa-etária, aspectos relacionados ao letramento em saúde e sobre a gravidez, nesta fase. Durante o momento, havia a opção de interação entre os participantes, que poderia ser feito por meio da utilização do microfone e/ou vídeo do participante ou ainda; via chat, que podiam ser expostos comentários e sugestões de forma restrita ou coletiva. Algumas dúvidas e comentários foram realizados. Este momento proporcionou interação entre os presentes e sanou dúvidas que foram apresentadas. A mediadora conduzia o momento.

A seguir, a segunda palestrante abordou sobre a atuação do enfermeiro na atenção à gravidez na adolescência. Destacou a importância da atenção e cuidado interprofissional, neste momento, especialmente quando a gravidez não é programada. Reforçou aspectos relacionados à atenção no cuidado à adolescente e seu feto. Apontou aspectos importantes como a nutrição, peso, sono e repouso. Além disso, destacou a importância da escola e dos direitos da adolescente grávida. Houve ainda a apresentação de um vídeo educativo relacionado ao tema. Esta tecnologia foi importante porque proporcionou a percepção dos participantes sobre a temática.

Após o momento, a mediadora disponibilizou a oportunidade para que dúvidas e comentários fossem realizados. Este momento proporcionou interação e sanou dúvidas que foram apresentadas via chat, pelo formulário de dúvidas ou mesmo, o participante tinha opção de fazer o questionamento pelo seu microfone. 


\section{RESULTADOS E DISCUSSÃO}

A atividade educativa virtual proporcionou a discussão ampliada do tema e participação considerável de público-alvo. Quando se trata do público adolescente, há influência dos Determinantes Sociais da Saúde, que influenciam em vulnerabilidades para os adolescentes. As redes comunitárias e de apoio devem ser valorizadas bem como os fatores relacionados com as condições de vida e de trabalho dos indivíduos, suas condições econômicas, sociais e ambientais (GARBOIS; SODRÉ; DALBELLO-ARAUJO, 2017). A escola pode ser um importante espaço para promover e articular ações educativas.

De forma semelhante, a pesquisa de Lee et al. (2015) sugere que é importante considerar o período da primeira relação sexual e reforçar estratégias preventivas para a promoção da saúde do adolescente já que foram percebidas relação entre o início precoce das relações sexuais entre adolescentes e chances de desenvolverem Infecções Sexualmente Transmissíveis.

O letramento em saúde, conforme foi discutido na atividade educativa, é importante para a promoção da saúde do adolescente, especialmente quando na gravidez. O Letramento Funcional em Saúde (LFS) é uma condição funcional e envolve dimensões. É importante para avaliar o impacto do letramento no gerenciamento de alguma condição e na gestão da saúde e é, importante para a promoção da saúde. Ainda, permite compreender as necessidades das populações (SANTOS et al., 2015).

Como trata-se de uma experiência individual, apresentando-se unicamente a percepção de uma vivência, os resultados não podem ser generalizados; sendo esta a principal limitação do estudo. Contudo, o estudo contribuiu para a importância da utilização de plataformas digitais à promoção da saúde do adolescente, sobremaneira em período de pandemia à capacitação para profissionais e estudantes.

\section{CONSIDERAÇÕES FINAIS}

A atividade educativa virtual sobre gravidez na adolescência foi exitosa e contribuiu para a discussão abrangente da temática. Sugere-se que a discussão possa ser ampliada e que, novos estudos sejam realizados. Ademais, em decorrência da pandemia por COVID-19, a atividade educativa virtual foi importante à capacitação dos profissionais e estudantes.

\section{REFERÊNCIAS}

BRINDIS, C.D.; MOORE, K. Improving adolescent health policy: incorporating a framework for assessing state-level policies. Annu Rev Public Health., v.35, p.343-361, 2014. Doi: 10.1146/ annurev-publhealth-032013-182455 
GARBOIS, J.A.; SODRÉ, F.; DALBELLO-ARAUJO, M. Da noção de determinação social à de determinantes sociais da saúde. Saúde Debate. Rio de Janeiro, v. 41, n. 112, p. 63-76, 2017.

LEE, S.Y.; LEE, H.J.; KIM, T.K.; LEE, S.G.; PARK, EC. Sexually transmitted infections and first sexual intercourse age in adolescents: the nationwide retrospectivecross-sectional study. J Sex Med., v.12, n.12, p.2313-2323, 2015

SANTOS, M.I.P.O.; PORTELLA, M. R.; SCORTEGAGNA, H.M.; SANTOS, P.C.S dos. Letramento funcional em saúde na perspectiva da Enfermagem Gerontológica: revisão integrativa daliteratura. Rev. bras. geriatr. gerontol., v.18, n.3, p. 651-664, Set. 2015.

WHITAKER, R.; HENDRY, M.; ASLAM, R.; BOOTH, A.; CARTER, B.; CHARLES, J.M. et al. Intervention Now to Eliminate Repeat Unintended Pregnancy in Teenagers (INTERUPT): a systematic review of intervention effectiveness and cost-effectiveness, and qualitative and realist synthesis of implementation factors and user engagement. Health Technol Assess, n. 20, v. 16, p.1-214, 2016.

WONG, S.P.W.; TWYNSTRA, J.; GILLILAND, J.A.; COOK, J.L.; SEABROOK, J.A. Risk Factors and Birth Outcomes Associated with Teenage Pregnancy: A Canadian Sample. J Pediatr Adolesc Gynecol., v.33, n.2, p.153-159, 2020. Doi:10.1016/j.jpag.2019.10.006 


\title{
REVISÃO DE LITERATURA SOBRE SITEMATIZAÇÃO DA ASSISTÊNCIA EM ENFERMAGEM
}

\author{
Rosa Maria Guimarães Brito ${ }^{1}$ \\ ${ }^{1}$ Mestre em Ciências da Saúde, Universidade Federal do Amapá (UNIFAP), Macapá, Amapá.
}

\section{RESUMO}

A Sistematização da assistência de Enfermagem (SAE) é uma atividade exclusiva, que norteia as atividades do enfermeiro, tendo aplicação direta na assistência ao paciente, caracterizando a sua prática profissional de maneira organizada e humanizada e contribuindo na significação do seu papel. Trata-se de metodologia ideal para o enfermeiro empregar seus conhecimentos técnico-científicos na assistência ao paciente, favorecendo o cuidado e o aparelhamento das condições imprescindíveis para que ele seja realizado, estimulando a desburocratização do serviço e empoderando o profissional. Este trabalho objetivou a elaboração de revisão de literatura sobre a SAE de forma a embasar o conhecimento sobre a temática.

PALAVRAS-CHAVE: Assistência; Enfermagem; Sistematização

ÁREA TEMÁTICA: Áreas afins

\section{INTRODUÇÃO}

Em meados da década de 70, foi introduzido por Wanda Horta no Brasil o processo de enfermagem (PE) como um modelo conceitual para esclarecer a natureza desta ciência, determinar seu campo de ação e seu método de trabalho. Em 1973 nos EUA aconteceu a $1^{\text {a }}$ Conferência Internacional sobre diagnóstico de Enfermagem que teve como objetivos identificar e denominar as situações ou fenômenos clínicos nos quais os enfermeiros poderiam intervir, culminando na $1^{\text {a }}$ Classificação de diagnósticos de Enfermagem.

Desde então, a utilização da SAE tem trazido importantes benefícios para a prática profissional do Enfermeiro em muitos países do mundo, assim como para a equipe multiprofissional; para as instituições de saúde e para o indivíduo, família e comunidade. Além disso, este instrumento favorece ao uso dos conhecimentos técnico-científicos e humanos na prática da enfermagem, na administração do tempo na realização de tarefas com qualidade, assegurando o exercício profissional pautado na assistência ao paciente. 
A SAE também estimula a desburocratização do trabalho do enfermeiro, que é sobrecarregado cotidianamente com atividades administrativas e gerenciais, atrapalhando a realização dos cuidados

cabíveis e direcionados ao paciente. Conforme Sperandio e Évora (2000) "os enfermeiros ao longo da sua prática profissional, têm sido historicamente sobrecarregados com atividades burocráticas, utilizando grande parte de seu tempo na busca de documentação e de informações”. Este instrumento também possibilita ao profissional o desenvolvimento do processo de cuidar com autonomia, responsabilidade e ética, promovendo um cuidar humanizado, contínuo e com qualidade ao paciente, estabelecendo seu diagnóstico de enfermagem, planejando sua assistência e prescrevendo cuidados pertinentes ao indivíduo doente.

Esta pesquisa objetivou a elaboração de uma revisão bibliográfica em textos, artigos e documentos sobre a SAE, como forma de embasamento para a elaboração de um instrumento para ser utilizado futuramente por profissionais em unidades de saúde locais.

\section{METODOLOGIA}

Realizou-se uma pesquisa do tipo bibliográfica, de cunho qualitativo, utilizando subsídios de fontes primárias sobre a "SAE", por meio da leitura, seleção, arquivamento e fichamento das informações, de acordo com as predefinições de tópicos do estudo. A análise aconteceu no período de abril a maio de 2019 .

A seleção de artigos e textos foi realizada na base eletrônica de dados da Biblioteca Virtual em Saúde (BVS) indexados na Scientific Electronic Library (SCIELO), Literatura Latino-Americana e do Caribe em Ciências da Saúde (LILACS) e Base de Dados em Enfermagem (BDENF) utilizando os seguintes descritores ou palavras-chave: assistência, enfermagem e sistematização.

Os critérios de inclusão considerados na busca foram os seguintes: artigos com idioma em português, de qualquer modalidade de estudo, disponíveis na íntegra e gratuitamente e que contemplem em seus conteúdos, títulos e/ou resumos e/ou descritores ou palavras-chave. Como critérios de exclusão: artigos em inglês e espanhol, artigos incompletos e as duplicidades.

\section{FUNDAMENTAÇÃO TEÓRICA}

O presente estudo traz uma contextualização histórica da profissão e a relação da enfermagem com a ciência, além de uma abordagem das teorias de enfermagem; processo de enfermagem e suas etapas; definições; propósitos e implicações

Quanto ao histórico da enfermagem, observamos que desde os primórdios da humanidade o cuidar se faz necessário, pois, a partir do momento em que começou a haver vida existe cuidado e este é indispensável para que a vida possa continuar. Para Souza e colaboradores (2006) a enfermagem se sobressaiu por cuidar bem e organizadamente de seus clientes, com disciplina e conhecimento 
científico. Se caracterizando por ser uma prática realizada sobretudo por mulheres em seus primórdios, cujo conhecimento era transmitido de geração a geração.

A formação de enfermeiros no Brasil teve início em 1923, com a criação por Carlos Chagas da escola de enfermeiras do Departamento Nacional de Saúde Pública, Escola Anna Nery. Em 1860 na Inglaterra Vitoriana, teve início a Enfermagem Moderna, onde Florence Nightingale iniciou sua caminhada para adoção de uma prática baseada em conhecimentos científicos, abandonando gradativamente a postura de atividade caritativa, eminentemente intuitiva e empírica. Até por volta de 1940, o foco das tarefas era abalizado no modelo biomédico, centrado nas tarefas e procedimentos, sem levar em consideração a construção intelectual. Em 1950, inicia-se a busca por princípios científicos, notando-se as primeiras menções ao processo de enfermagem (PE) que tem sido visto como a aplicação do método científico na prática desta profissão. Surgindo a ênfase no cuidado de enfermagem como um processo interpessoal, centrando a assistência na pessoa e na promoção de sua integridade. (TANNURE E GONÇALVES, 2008). A partir de 1960, são desenvolvidas as primeiras teorias por enfermeiras norte-americanas e disseminadas para outros países, visando embasar a prática profissional. Em 70, a teórica brasileira Wanda Horta, cria a primeira teoria de enfermagem brasileira, designada Teoria das Necessidades Humanas Básicas.

A enfermagem enquanto ciência, é uma apresentação da realidade pela inteligência, constituída por um corpo de conhecimentos empíricos, que foram acumulados de maneira crescente historicamente através da atividade humana. Para Horta (1979) a enfermagem é a ciência e a arte de assistir ao ser humano no atendimento de suas necessidades básicas, de torná-lo independente desta assistência, quando possível, pelo ensino do autocuidado, de recuperar, manter e promover a saúde em colaboração com outros profissionais.

Assim, a enfermagem deve ser considerada como uma ciência pelos seguintes fatores: 1) Os fenômenos estudados são reais e passíveis de experimento. 2) As teorias mostram nexos claros entre os eventos e as ações. 3) Suas conclusões estão dentro da confiança probabilística.

De tal modo, essas teorias contribuem para determinar a profissão como uma área científica por si própria, funcionando como um embasamento estrutural para a implementação da SAE. A primeira teórica foi Florence Nightingale, que considerava que a finalidade da enfermagem era colocar a pessoa na melhor condição para que a natureza restaurasse e preservasse a sua saúde. Entre os teóricos mais recentes estão: Levine - A enfermagem apóia a adequação da pessoa às alterações que provém de estímulos ambientais interiores e exteriores; Orem - Enfermeiros auxiliam o indivíduo a achar as condições básicas, do desenvolvimento e do autocuidado nas necessidades de saúde; Roy - Profissionais da enfermagem manejam os estímulos para facilitar a adaptação em quatro domínios - fisiológico, auto conceitual, função dos papéis e analogias de interdependência; Neuman - A enfermagem age nas respostas aos estressores das áreas fisiológica, psicológica, sociocultural e de desenvolvimento do ser humano; King - Os enfermeiros compartilham informações com clientes, que são sistemas abertos, para alcançar objetivos reciprocamente postos; Rogers - Os profissionais (enfermeiros) provocam a influência mútua entre o indivíduo e o ambiente, para elevar ao máximo a 
saúde.

Quanto ao processo de enfermagem (PE) e suas etapas: O processo de enfermagem se trata de um método sistemático de planejamento e implementação, para organização e prestação da assistência, que é composta por etapas que fornecem estrutura organizacional para a concretização da finalidade do processo.

Enfim, através dele o enfermeiro coleta dados, define problemas ou necessidades, estabelece resultados e ações que ajudarão a atingir os objetivos globais, coloca o plano em ação e determina as respostas do paciente aos cuidados providos. Para Nettina (2002) o PE é um procedimento para resolução de problemas, satisfazendo as necessidades de cuidados de saúde e de enfermagem junto aos pacientes.

A American Nurses Association em 1998 estabeleceu a seguinte sequência de etapas: avaliação, diagnóstico, identificação de resultado, planejamento, implementação e avaliação. No entanto, para efeito deste trabalho, assim como diversos autores, não consideraremos a etapa de identificação de resultado.

Portanto, as etapas estão definidas em: Investigação/Histórico/Avaliação, que é a observação cuidadosa e a apreciação do estado de saúde de um paciente, cujos dados iniciais servem para a comparação de sinais e sintomas futuros e representam uma referência para se determinar se a saúde do paciente está melhorando. Esta é uma atividade recorrente da enfermagem que continua enquanto houver necessidade de assistência à saúde, onde o enfermeiro coleta e registra os dados para estabelecer funções anormais e fatores de risco que colaboram para os problemas de saúde, assim como as forças do paciente.

A segunda etapa, dos diagnósticos de enfermagem, é onde os dados coletados previamente são analisados e interpretados, baseando-se em problemas reais ou potenciais, notando que elaborar um diagnóstico de enfermagem demanda crítica, síntese e acurácia ao interpretar as informações clínicas, admitindo ao profissional definir quanto às intervenções necessárias e resultados esperados para o paciente.

$\mathrm{Na}$ fase do Planejamento elaboram-se estratégias para prevenir, minimizar ou corrigir os diagnósticos de enfermagem identificados, consistindo em: estabelecer prioridades para os problemas diagnosticados, fixar resultados, registrar diagnósticos de enfermagem, dos resultados esperados e de intervenções de forma organizada.

A Implementação da Assistência de Enfermagem, constitui a quarta etapa do processo e é nela que são colocadas em prática as ações prescritas e necessárias ao prognóstico esperado, colocando o plano em ação, refletindo sobre o que está sendo feito, investigando a situação do paciente antes de agir, realizando as intervenções e reinvestigando para produzir as respostas do cliente, comunicando e registrando as respostas.

O último passo é a Avaliação ou Evolução de Enfermagem, onde é identificado o quanto 
as metas de cuidados foram alcançadas e é avaliado o progresso do paciente referente aos objetivos constituídos inicialmente, podendo ser realizadas alterações, se necessário, no plano de cuidados.

A SAE é a expressão na prática da utilização do PE, sendo a metodologia de assistência utilizada pelo enfermeiro para identificar problemas de saúde reais ou potenciais do paciente/ família ou comunidade, visando estabelecer o diagnóstico e a intervenção de enfermagem em busca de respostas; esta metodologia tem como propósitos, proporcionar um marco referencial com o objetivo de satisfazer essas necessidades dos assistidos; diagnosticar, intervir e avaliar problemas de saúde reais e potenciais do ser humano visando o alcance dos objetivos considerados no âmbito da enfermagem, numa determinada realidade; possibilitar a avaliação da eficácia dos cuidados prestados e conseqüentes mudanças das respostas humanas do paciente.

\section{CONSIDERAÇÕES FINAIS}

A SAE é um processo que visa qualificar a assistência prestada ao paciente e familiares, cujas implicações são determinantes para o profissional enfermeiro, no sentido da autonomia e valorização, exigência de educação permanente, visibilidade, linguagem padronizada, definição dos domínios da profissão, desenvolver competência e autoridade do enfermeiro; para o indivíduo/ família e comunidade, pela humanização do atendimento, individualidade, acurácia dos diagnósticos e intervenções de enfermagem, segurança, acolhimento, entre outros; para a equipe multidisciplinar, pelo trabalho organizado e em conjunto e para a instituição de saúde, diminuído o tempo de internação e os custos.

Apesar de todos os benefícios demonstrados as dificuldades ainda são muitas, requerendo estímulo, conhecimento e empoderamento dos profissionais para implementá-la.

\section{PRINCIPAIS REFERÊNCIAS}

HORTA, W. Processo de Enfermagem. São Paulo: EPU, 1979.

SOUZA, A. C. C; FILHA, M. J. M. M; SILVA, L. C; MONTEIRO, A. R. M; FIALHO, A. V. M. Formação do Enfermeiro para o cuidado: Reflexões da Prática Profissional. Revista Brasileira de Enfermagem, v. 59, n. 6, p. 805-807, nov-dez, 2006. 

